\title{
Guía de Práctica Clínica sobre lactancia materna
}

DOCUMENTO METODOLÓGICO

GUÍAS DE PRÁCTICA CLÍNICA EN EL SNS

MINISTERIO DE SANIDAD Y POLITICA SOCIAL
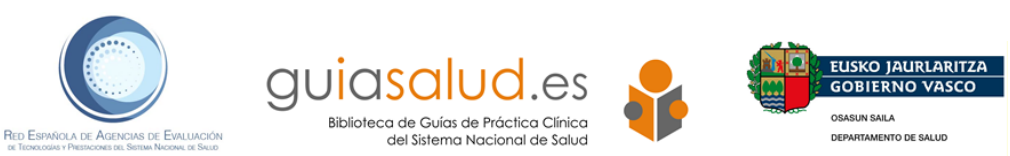
Descripción de la metodología de elaboración empleada en la Guía de Práctica Clínica sobre lactancia materna. Ministerio de Sanidad, Servicios Sociales e Igualdad; 2017. Guías de Práctica Clínica en el SNS. Osteba. 
Índice

1.- INTRODUCCIÓN

2.- METODOLOGÍA DE ELABORACIÓN DE LA GUÍA

3.- FICHAS DE RESPUESTA PARA CADA PREGUNTA CLÍNICA

4.- BIBLIOGRAFÍA

ANEXOS

Anexo I. Listado de preguntas clínicas que se abordan en la GPC sobre lactancia materna

Anexo II. Estrategia general de búsqueda de GPC

Anexo III. Resultados de la valoración de la calidad de las GPC identificadas

Anexo IV. Fichas de elaboración de cada pregunta clínica

Anexo V. Recogida y respuesta a los comentarios recibidos sobre la estructura y las preguntas clínicas a abordar en la GPC sobre lactancia materna.

Anexo VI. Recogida y respuesta a los comentarios de los revisores externos por parte de los autores de la GPC. 


\section{1.- INTRODUCCIÓN}

En este documento se hace una descripción metodológica de las etapas y los procedimientos utilizados para elaborar la Guía de Práctica clínica (GPC) sobre lactancia materna. Para ello se han utilizado los principios metodológicos del Programa de elaboración de Guías de Práctica Clínica (GPC) basadas en la evidencia del Sistema Nacional de Salud, que se encuentran recogidos en el Manual Metodológico de elaboración de GPC de GuiaSalud (1).

En el caso de esta guía se ha optado por utilizar el sistema GRADE (Grading of Recommendations Assessment, Development and Evaluation) para sintetizar y evaluar la evidencia disponible para cada pregunta clínica, así como para formular las recomendaciones, tal y como se indica en la actualización del manual metodológico de Guíasalud de 2016 (2).

El material donde se presenta de forma detallada la información sobre la estrategia de búsqueda utilizada para responder a cada pregunta clínica, así como las tablas de perfil de evidencia GRADE o el proceso para pasar de la evidencia a la recomendación (EtR), se encuentra en el Anexo IV de este documento metodológico. 


\section{2.- METODOLOGÍA}

Para la elaboración de la Guía de Práctica Clínica (GPC) sobre lactancia materna se ha seguido el Manual Metodológico «Elaboración de Guías de Práctica Clínica en el Sistema Nacional de Salud» (1), que puede ser consultado en la página Web de la Biblioteca de GPC del SNS, GuíaSalud.

\subsection{Constitución del grupo elaborador de la Guía}

El grupo elaborador de la guía (GEG) está integrado por un equipo multidisciplinar que cuenta con expertos en lactancia materna con acreditación reconocida tanto del ámbito hospitalario como extrahospitalario (dos pediatras, una enfermera, una matrona, una ginecóloga y una madre monitora de un grupo de apoyo). El grupo lo completan tres expertas en metodología (una durante todo el proceso y dos en colaboración parcial), una documentalista y una gestora de proyecto del Servicio de Evaluación de Tecnologías Sanitarias del País Vasco (Osteba).

Todas las personas que forman parte del GEG declararon por escrito los conflictos de interés antes de iniciar la elaboración la guía.

\subsection{Selección de preguntas clínicas a responder}

Para definir la estructura y las preguntas que se iban a formular en la guía se utilizó como punto de partida el listado de preguntas que se plantean en el apartado sobre la alimentación del lactante de la guía de Cuidado Postnatal de la National Institute for Clinical Excellence (NICE) (3). A este borrador se añadieron algunas preguntas que el grupo elaborador consideró de interés.

La propuesta fue enviada al grupo seleccionado de colaboradores expertos en lactancia materna, que valoraron tanto los apartados que se proponían como la estructura de la GPC y las preguntas a abordar en cada uno de ellos. Las propuestas y comentarios recibidos por parte de los colaboradores fueron estudiados por el GEG. La respuesta a todos los comentarios recibidos, así como la aceptación o no de las propuestas, se recogieron en un documento que fue remitido a los colaboradores que habían participado en el proceso. Este documento se ha recogido en el Anexo V.

De todas las preguntas que se propusieron se seleccionaron 36 , que son las preguntas que han sido finalmente abordadas en esta guía.

\subsection{Estrategia metodológica utilizada para responder a las preguntas clínicas}

Los pasos que se han seguido para poder responder a las preguntas clínicas planteadas se detallan a continuación.

\subsubsection{Formulación de las preguntas en formato PICO}

Las preguntas se han formulado siguiendo el formato PICO: P (pacientes), I (intervenciones), $\mathrm{C}$ (comparaciones) y $\mathrm{O}$ (outcomes o resultados)

\subsubsection{Definición y valoración de los desenlaces críticos}

Siguiendo la metodología del Grading of Recommendations Assessment, Development and Evaluation working group (GRADE), el GEG ha definido los desenlaces que 
consideraba de interés para cada pregunta y ha valorado su importancia en una escala del 1 al 9 (de menos a más importante) (4-5).

\subsubsection{Revisión y evaluación de la literatura}

\section{Búsqueda de guías, revisiones sistemáticas y estudios individuales}

Para la búsqueda y revisión de la literatura, se ha utilizado una estrategia mixta escalonada que consta de las siguientes fases:

a. Búsqueda de GPC sobre lactancia materna, a nivel nacional e internacional, para utilizarlas como revisiones sistemáticas.

b. Búsqueda de revisiones sistemáticas (RS) actuales y/o informes de evaluación que respondan de forma consistente a las preguntas planteadas y desde la publicación de las guías seleccionadas, si es necesario.

c. Búsqueda de estudios originales específicos para cada pregunta cuando no se hayan encontrado estudios secundarios o cuando se debe analizar si se han publicado nuevos estudios desde la fecha de publicación de los estudios secundarios identificados.

El abordaje de cada pregunta clínica ha dependido de si las guías identificadas incluían la pregunta o de la existencia de revisiones sistemáticas que respondieran a la misma.

\begin{tabular}{|l|l|}
\hline Tipo de abordaje & Situación \\
\hline Adoptar GPC/ Revisión sistemática & $\begin{array}{l}\text { Abordado en guías, sin necesidad de actualización, } \\
\text { coherencia, recomendación fuerte o Revisión } \\
\text { Cochrane actualizada }\end{array}$ \\
\hline $\begin{array}{l}\text { Elaboración parcial: } \\
\text { Actualización } \\
\text { abreviada y evaluación crítica }\end{array}$ & $\begin{array}{l}\text { La evidencia científica no está suficientemente } \\
\text { actualizada (la inclusión de nuevas evidencias } \\
\text { puede modificar el contenido o la fuerza de las } \\
\text { recomendaciones) } \\
\text { Abordado parcialmente (aspectos concretos de la } \\
\text { preguntas que no están abordados en las guías) }\end{array}$ \\
\hline Elaborar de novo & $\begin{array}{l}\text { Incongruencias entre guías o entre la evidencia } \\
\text { científica y las recomendaciones }\end{array}$ \\
\hline $\begin{array}{l}\text { No abordado en guías } \\
\text { Cuestiones novedosas con publicaciones muy } \\
\text { recientes } \\
\text { Abordado pero sólo de forma narrativa o como } \\
\text { consenso (frecuente en cuestiones de diagnóstico, } \\
\text { historia natural o pronóstico) }\end{array}$ \\
\hline
\end{tabular}

* Adaptación de la propuesta para decidir la estrategia a seguir con cada pregunta

La búsqueda de GPC se ha realizado en las bases de datos de la National Guideline Clearinghouse (NGC), Guideline International Network (GIN), Tripdatabase, NICE y GuiaSalud.

En relación a los informes de evaluación, revisiones, y estudios originales, se han consultado las bases de la Cochrane Library, Centre for Reviews and Disseminations (CRD) y las bases de datos de Medline y Embase, Cinahl y PsyINFO. Además de las bases consultadas, también se ha consultado la página de la IHAN y de la OMS en relación a la lactancia materna. También se han realizado búsquedas con texto libre y se 
han recogido las aportaciones bibliográficas realizadas por el grupo de trabajo, así como las aportaciones de los colaboradores expertos.

Las palabras clave y las estrategias de búsqueda utilizadas se encuentran disponibles en el documento metodológico disponible en la sección del Programa de Guias de Pactica Clínica del SNS del Portal GuiaSalud.

\section{Evaluación de la calidad de la literatura}

La evaluación de la calidad de las GPC encontradas se ha realizado por pares y mediante el instrumento AGREE II (http://www.agreetrust.org/resource-centre/agree-ii/). Tras la evaluación, se seleccionaron las guías de mayor calidad y se analizó si éstas respondían a alguna de las preguntas clínicas planteadas por el GEG.

La evaluación de la calidad de las RS encontradas se ha realizado utilizando el "Assessment of Multiple Systematic Reviews" (AMSTAR) (http://www.biomedcentral.com/14712288/7/10/table/T2). En cuanto a los estudios individuales, el riesgo de sesgo en el diseño y ejecución de los estudios se ha valorado con diferentes herramientas, dependiendo del diseño de los estudios a evaluar. Para los ensayos clínicos controlados (ECA) se ha utilizado el "Risk of bias" propuesto por la colaboración Cochrane; para las preguntas de tipo diagnóstico, el instrumento QUADAS II, y para estudios de cohortes o casos controles, la escala Newcastle-Ottawa Quality Assessment Scale.

\subsubsection{Evaluación y síntesis de la evidencia}

La evaluación de la calidad y síntesis de la evidencia para cada pregunta se ha realizado siguiendo la metodología del Grupo GRADE (4-20).

La evidencia científica encontrada para cada pregunta se ha sintetizado por desenlace de interés. Para ello, el grupo elaborador de la guía ha definido y valorado de forma previa cuáles serían los desenlaces que son de interés para las madres lactantes.

Cuando se trata de preguntas de tipo intervención, el grupo GRADE considera que los ECA proporcionan evidencia de "calidad alta" y los estudios observacionales de "calidad baja". No obstante, también se sugieren una serie de criterios que pueden disminuir la calidad de la evidencia proporcionada por los ECA, así como aumentar la calidad de la evidencia proporcionada por los estudios observacionales.

Los criterios que pueden disminuir la calidad de la evidencia de los ECA son los siguientes:

- Limitaciones en el diseño o ejecución del ECA: la ausencia de ocultamiento de la secuencia de aleatorización, un enmascaramiento inadecuado, la existencia de pérdidas importantes o la ausencia de análisis por intención de tratar, entre otros, pueden hacer disminuir la confianza que tenemos en los resultados presentados en los ECA.

- Resultados inconsistentes: si los estudios presentan estimaciones del efecto de un tratamiento muy dispares (heterogeneidad o variabilidad entre los estudios), esas diferencias pueden deberse a que los estudios incluyen poblaciones diferentes o que existan diferencias en la intervención, los desenlaces de interés o la calidad de los estudios. Por ello, cuando existe heterogeneidad entre los estudios y ésta no puede explicarse de manera razonable, la confianza que se tiene en la estimación global del efecto disminuye.

- Ausencia de evidencia científica directa: en caso de ausencia de comparaciones directas entre dos tratamientos (existen estudios que comparan cada tratamiento frente a placebo, pero no estudios que comparen ambos 
tratamientos entre sí) o la extrapolación de los resultados de un estudio, por ejemplo con un determinado fármaco al resto de fármacos de su misma familia cuando no está demostrado un efecto de clase, también se considera evidencia científica indirecta. Asimismo, es frecuente que existan grandes diferencias entre la población en la que se van a aplicar las recomendaciones y la incluida en los estudios evaluados. Por último, deben ser también valorados los aspectos de la potencial aplicabilidad en nuestro entorno o la validez externa de la evidencia científica disponible. Todos estos aspectos pueden hacer bajar la confianza en la estimación del efecto por ausencia de evidencia directa.

- Imprecisión: cuando los estudios disponibles incluyen relativamente pocos eventos y pocas mujeres y, por tanto, presentan intervalos de confianza amplios, la confianza que tenemos en la estimación del efecto puede disminuir.

- Sesgo de notificación: en este caso la calidad o la confianza que se tiene en la estimación global del efecto puede disminuir si existe una duda razonable sobre la inclusión por parte de los autores de todos los estudios que existen (por ejemplo, el sesgo de publicación en el contexto de una RS) o si han incluido o no los resultados de todos los desenlaces relevantes (outcome reporting bias).

Por otro lado, los criterios que pueden aumentar la confianza en los resultados de los estudios observacionales son los siguientes:

- Efecto importante: cuando se observa una asociación fuerte $(R R>20<0,5)$ o muy fuerte $(R R>50<0,2)$ y consistente (obtenida de estudios que no tienen factores de confusión), la confianza que se tiene en la estimación del efecto puede aumentar de baja a moderada, o incluso a alta.

- La presencia de un gradiente dosis-respuesta puede llevar a aumentar la confianza en la estimación global del efecto.

- Situaciones en las que todos los posibles factores de confusión podrían haber reducido la asociación observada: por ejemplo, cuando las mujeres que reciben la intervención de interés presentan un peor pronóstico y, aun así, presentan mejores resultados que el grupo control, es probable que el efecto observado real sea mayor, por lo que se podría aumentar la calidad de la evidencia.

En base a la valoración de todos esos criterios, la calidad o la confianza en la evidencia encontrada para cada desenlace de interés se clasifica como muy baja, baja, moderada o alta.

En el texto de la guía, la calidad de la evidencia encontrada para cada desenlace de interés se va presentando en el margen derecho del texto.

La calidad global de la evidencia en la que se fundamenta cada pregunta clínica depende de la calidad individual obtenida por los desenlaces considerados críticos para esa pregunta. Así, la calidad global vendrá definida por del desenlace crítico para el cual se obtenga el nivel de evidencia más bajo.

\subsubsection{Formulación de las recomendaciones}

Para la elaboración de las recomendaciones se ha seguido el marco estructurado de GRADE denominado EtR- de la Evidencia a la Recomendación, en el que se tienen en cuenta los siguientes factores:

- Balance entre beneficios y riesgos: Para realizar una adecuada valoración del balance entre los beneficios y los riesgos es necesario tener en cuenta el riesgo basal de la pobla 
- ción a la que va dirigida la recomendación y el efecto tanto en términos relativos como absolutos.

- Calidad de la evidencia científica: antes de llevar a cabo una recomendación es necesario conocer la confianza en la estimación del efecto observado. Si la calidad de la evidencia científica no es alta, la confianza en los resultados disminuye y también por ello disminuiría la fuerza con la que se lleve a cabo una recomendación.

- Utilización de recursos: a diferencia de otros desenlaces de interés, los costes son variables en el tiempo, lugar y otros condicionantes. Un coste elevado disminuirá probablemente la fuerza de una recomendación, por lo que el contexto es crítico en la valoración final.

- Equidad, aceptabilidad y factibilidad: la incertidumbre sobre los valores y las preferencias de la población diana a la cual va dirigida la GPC será otro de los factores a tener en cuenta. El personal sanitario, el colectivo de mujeres o la sociedad en general deben ver reflejados sus valores y sus preferencias, lo que influirá en la graduación de las recomendaciones.

Así, las recomendaciones que se formulan pueden ser fuertes o débiles, dependiendo principalmente de la confianza que tiene el GEG en la evidencia identificada. En ambos casos, las recomendaciones pueden ser a favor o en contra de lo considerado en la pregunta clínica.

Para las intervenciones de las que no se dispone de evidencia y el grupo elaborador quiere resaltar un determinado aspecto, se formulan recomendaciones basadas en la experiencia clínica y el consenso del grupo elaborador, que se han identificado con el símbolo $\mathrm{V}$.

\subsubsection{Actualización de las búsquedas realizadas para cada pregunta clínica}

Se han monitorizado las búsquedas realizadas para responder a las preguntas de la guía hasta el 31 de octubre de 2016. En caso de haber identificado artículos de interés, éstos se han descrito en el texto, señalando si los resultados de estos modifican o no los resultados anteriores descritos en la evidencia.

\subsubsection{Diseño de los indicadores para valorar la implementación de la GPC}

Para el diseño de los indicadores que podrían ser útiles para evaluar el posible impacto de la implementación de las recomendaciones de la guía, se realizó una búsqueda no sistemática de documentos que incluyeran posibles indicadores para medir resultados en lactancia materna. También se preguntó a los profesionales sanitarios, tanto a los miembros del GEG como a los revisores externos de la guía, por los posibles indicadores que se podrían utilizar para medir la implementación de las recomendaciones de la guía. De las referencias identificadas y relacionadas, fueron seleccionadas tres (21-23). Se seleccionaron aquellos indicadores directamente relacionados con las recomendaciones de la GPC y se discutió con el grupo elaborador de la guía cuáles incluir y si había que realizar modificaciones a las definiciones de los mismos. Los indicadores finales fueron incluidos en la versión completa de la GPC sobre lactancia materna.

\subsection{Revisión externa del contenido de la GPC}


La revisión externa del contenido de la GPC sobre lactancia materna ha sido realizada por expertos de diferentes especialidades y Sociedades Científicas relacionadas con la lactancia materna.

Los cambios de formato, correcciones ortográficas etc señalados por los revisores externos han sido incorporados tanto en las fichas metodológicas de las preguntas como en la GPC completa.

En cuanto a los comentarios que implican cambios mayores, como los relacionados con la redacción de las recomendaciones, éstos han sido discutidos por el grupo elaborador de la guía, y la aceptación o no de dichos cambios, así como la respuesta del grupo, han sido recogidos en un documento, que se incluye en el Anexo VI.

\subsection{Actualización de la GPC}

Está prevista una actualización de la guía un plazo de entre tres a cinco años como máximo, o en plazos inferiores si se dispone de nueva evidencia científica que pueda modificar algunas de las recomendaciones que contiene. Las actualizaciones se realizarán sobre la versión electrónica de la guía, disponible en la siguiente URL: $<$ http://www.guiasalud.es>.

\section{3.- FICHAS DE ELABORACIÓN PARA CADA PREGUNTA CLÍNICA}

Como se ha comentado anteriormente, para cada una de las preguntas clínicas abordadas en esta guía se ha elaborado una ficha en la que se describe todo el proceso que se ha llevado a cabo desde la definición de la pregunta PICO hasta la formulación de las recomendaciones.

La estructura general de cada una de estas fichas se describe a continuación:

1. Pregunta clínica en formato PICO

Para facilitar la organización de la búsqueda, se define cada componente de la pregunta en formato PICO.

\section{Introducción}

En este punto se indica la justificación por la que se plantea la pregunta clínica.

3. Estrategia de elaboración seguida

Aquí se describe si las guías base seleccionadas responden a la pregunta clínica concreta, si existen revisiones sistemáticas al respecto y en su caso, si es necesario realizar búsqueda de estudios individuales.

4. Resumen de la evidencia

En este apartado se presenta, por un lado, el perfil de evidencia GRADE elaborado para responder a la pregunta y por otro lado, se realiza una descripción de los estudios identificados y utilizados para responder a la pregunta, así como los resultados o la estimación del efecto identificada para cada desenlace de interés, indicando en cada caso y de forma adyacente su calidad.

5. Paso de la evidencia a la recomendación

En este apartado se detallan los juicios realizados sobre cada uno de los factores que hay que tener en cuenta a la hora de formular las recomendaciones, así como la redacción de la recomendación y su justificación. 


\section{Anexos}

En cada ficha se incluyen como anexos la estrategia de búsqueda específica, los forest plot de los desenlaces de interés seleccionados, así como las tablas descriptivas de los estudios individuales e información de costes, cuando procede. En último lugar se incluyen las referencias que se han incluido o tenido en cuenta para responder a la pregunta.

El contenido completo de estas fichas se encuentra disponible en el Anexo IV de este documento. 


\section{BIBLIOGRAFÍA}

(1) Grupo de trabajo sobre GPC. Elaboración de Guías de Práctica Clínica en el Sistema Nacional de Salud. Manual Metodológico. Madrid: Plan Nacional para el SNS del MSC. Instituto Aragonés de Ciencias de la Salud-I+CS; 2007. Guías de Práctica Clínica en el SNS: I+CS N²006/0I.

(2) Elaboración de Guías de Práctica Clínica en el Sistema Nacional de Salud. Actualización del Manual Metodológico. Julio de 2016. Disponible en: http://portal.guiasalud.es/emanuales/elaboracion 2/Capitulos/completo.pdf

(3) NICE. Postnatal care up to 8 weeks after birth. Julio 2006 (actualizado en Febrero de 2015). Disponible en: http://guidance.nice.org.uk/CG37.

(4) Guyatt GH, Oxman AD, Schunemann HJ, Tugwell P, Knottnerus A. GRADE guidelines: a new series of articles in the Journal of Clinical Epidemiology. J Clin Epidemiol. 2011 Apr;64(4):380-2.

(5) Guyatt GH, Oxman AD, Schunemann HJ. GRADE guidelines-an introduction to the 10th-13th articles in the series. J Clin Epidemiol. 2013 Feb;66(2):121-3.

(6) Guyatt G, Oxman AD, Akl EA, Kunz R, Vist G, Brozek J, et al. GRADE guidelines: 1. Introduction-GRADE evidence profiles and summary of findings tables. J Clin Epidemiol. 2011 Apr;64(4):383-94.

(7) Guyatt GH, Oxman AD, Kunz R, Atkins D, Brozek J, Vist G, et al. GRADE guidelines: 2. Framing the question and deciding on important outcomes. J Clin Epidemiol. 2011 Apr;64(4):395-400.

(8) Balshem $H$, Helfand M, Schunemann HJ, Oxman AD, Kunz R, Brozek J, et al. GRADE guidelines: 3. Rating the quality of evidence. J Clin Epidemiol. 2011 Apr;64(4):401-6.

(9) Guyatt GH, Oxman AD, Vist G, Kunz R, Brozek J, Alonso-Coello P, et al. GRADE guidelines: 4. Rating the quality of evidence--study limitations (risk of bias). J Clin Epidemiol. 2011 Apr;64(4):407-15.

(10) Guyatt GH, Oxman AD, Montori V, Vist G, Kunz R, Brozek J, et al. GRADE guidelines: 5. Rating the quality of evidence--publication bias. J Clin Epidemiol. 2011 Dec;64(12):1277-82.

(11) Guyatt GH, Oxman AD, Kunz R, Brozek J, Alonso-Coello P, Rind D, et al. GRADE guidelines 6 . Rating the quality of evidence--imprecision. J Clin Epidemiol. 2011 Dec;64(12):1283-93.

(12) Guyatt GH, Oxman AD, Kunz R, Woodcock J, Brozek J, Helfand M, et al. GRADE guidelines: 7 . Rating the quality of evidence--inconsistency. J Clin Epidemiol. 2011 Dec;64(12):1294-302.

(13) Guyatt GH, Oxman AD, Kunz R, Woodcock J, Brozek J, Helfand M, et al. GRADE guidelines: 8. Rating the quality of evidence--indirectness. J Clin Epidemiol. 2011 Dec;64(12):1303-10.

(14) Guyatt GH, Oxman AD, Sultan S, Glasziou P, Akl EA, Alonso-Coello P, et al. GRADE guidelines: 9. Rating up the quality of evidence. J Clin Epidemiol. 2011 Dec;64(12):1311-6.

(15) Brunetti M, Shemilt I, Pregno S, Vale L, Oxman AD, Lord J, et al. GRADE guidelines: 10. Considering resource use and rating the quality of economic evidence. J Clin Epidemiol. 2013 Feb;66(2):140-50.

(16) Guyatt G, Oxman AD, Sultan S, Brozek J, Glasziou P, Alonso-Coello P, et al. GRADE guidelines: 11. Making an overall rating of confidence in effect estimates for a single outcome and for all outcomes. J Clin Epidemiol. 2013 Feb;66(2):1517. 
(17) Guyatt GH, Oxman AD, Santesso N, Helfand M, Vist G, Kunz R, et al. GRADE guidelines: 12. Preparing summary of findings tables-binary outcomes. J Clin Epidemiol. 2013 Feb;66(2):158-72.

(18) Guyatt GH, Thorlund K, Oxman AD, Walter SD, Patrick D, Furukawa TA, et al. GRADE guidelines: 13. Preparing summary of findings tables and evidence profiles-continuous outcomes. J Clin Epidemiol. 2013 Feb;66(2):173-83.

(19) Andrews J, Guyatt G, Oxman AD, Alderson P, Dahm P, Falck-Ytter Y, et al. GRADE guidelines: 14. Going from evidence to recommendations: the significance and presentation of recommendations. J Clin Epidemiol. 2013 Jul;66(7):719-25.

(20) Andrews JC, Schunemann HJ, Oxman AD, Pottie K, Meerpohl JJ, Coello PA, et al. GRADE guidelines: 15. Going from evidence to recommendationdeterminants of a recommendation's direction and strength. J Clin Epidemiol. $2013 \mathrm{Jul} ; 66(7): 726-35$.

(21) Cómo obtener estadísticas de lactancia en la Maternidad. UNICEF/OMS. IHAN España. 2016.

(22) Estrategia centros de salud IHAN. Manual para la acreditación. UNICEF/OMS. IHAN España”. www.ihan.es. 2014.

(23) Informe sobre la Atención al Parto y Nacimiento en el Sistema Nacional de Salud. Diciembre 2012. Disponible en:

http://www.msssi.gob.es/organizacion/sns/planCalidadSNS/pdf/Informe-

FinalEAPN_revision8marzo2015.pdf. 
ANEXOS 


\section{ANEXO I.}

\section{LISTADO DE PREGUNTAS CLÍNICAS QUE SE ABORDAN EN LA GPC SOBRE LACTANCIA MATERNA}

\section{Atención postparto inmediata}

1. ¿Es eficaz y seguro el contacto piel con piel inmediato e ininterrumpido postparto para el buen inicio de la lactancia materna?

2. ¿Cómo debería ser la primera toma del recién nacido?

3. ¿Cuánto tiempo se puede esperar a que el recién nacido haga la primera toma?

\section{Prácticas que influyen en la lactancia materna}

4. ¿Cómo pueden colocarse la madre y el recién nacido para facilitar el amamantamiento?

5. ¿Es eficaz y seguro el colecho en las madres que amamantan para facilitar el buen inicio y el mantenimiento de la lactancia materna?

6. ¿Cómo afecta la restricción de las tomas de pecho nocturnas en la instauración y duración de la lactancia materna?

7. ¿Se debería evitar el uso del chupete en las primeras semanas para favorecer la instauración de la lactancia materna?

\section{Valoración de la lactancia materna}

8. ¿Qué criterios indican un buen inicio y una adecuada instauración de la lactancia materna?

9. ¿Qué datos se deberían recoger en la historia clínica para valorar adecuadamente la lactancia materna? ¿Cómo se deberían recoger esos datos?

10. ¿Se debe realizar la observación y valoración de la toma con una herramienta estandarizada durante la estancia en la maternidad?

\section{Extracción del calostro}

11. ¿Se debe recomendar la extracción del calostro en la maternidad cuando el recién nacido no realiza tomas efectivas?

12. ¿Cuál es la forma más eficaz de extraer el calostro?

\section{Suplementos y lactancia materna}

13. ¿Se debe evitar la administración rutinaria de suplementos al recién nacido amamantado?

14. ¿Cuándo está indicada la administración de suplementos en recién nacidos sanos?

15. ¿Cuál es el suplemento más adecuado en recién nacidos sanos?

16. ¿Cómo deben administrarse los suplementos?

\section{Protección y apoyo a la lactancia en instituciones sanitarias}

17. ¿Cuáles son las mejores estrategias estructuradas para el apoyo y protección de la lactancia materna durante la estancia en el hospital? 
18. ¿Cuáles son las mejores estrategias estructuradas para el apoyo y protección de la lactancia materna en los centros de salud?

\section{Seguimiento del lactante amamantado}

19. ¿Cómo interpretar la pérdida de peso del recién nacido sano amamantado en los primeros días?

20. ¿Qué curvas de crecimiento reflejan mejor el crecimiento normal de un niño sano? ¿Cuáles son los parámetros que se deben monitorizar?

\section{Manejo de los problemas con la lactancia materna}

21. ¿Qué hacer ante un recién nacido adormilado que no demanda o que no hace tomas efectivas?

22. ¿Qué hacer ante un lactante amamantado que presenta una pérdida excesiva de peso en los tres primeros días?

23. Es necesario realizar una frenotomía al lactante amamantado que presenta anquiloglosia?

24. ¿Qué métodos son más eficaces para aumentar la producción de leche?

25. ¿Son eficaces los galactogogos para estimular la producción de leche? ¿Cuál es el galactogogo más eficaz?

26. ¿Qué hacer cuando una madre sufre ingurgitación mamaria?

27. ¿Qué hacer si hay dificultades en el agarre por las características anatómicas del pezón?

28. ¿Cómo abordar el dolor en los pezones y en las mamas durante el amamantamiento?

29. ¿Cuál sería el tratamiento más adecuado para tratar el dolor y las grietas en el pezón que pueden aparecer durante la lactancia materna?

30. ¿Qué síntomas y signos deben hacer sospechar una infección en la mama?

31. Ante sospecha de infección, ¿cuándo está indicada la realización del cultivo de la leche?

32. En madres que amamantan y presentan mastitis aguda, ¿se debería empezar de forma inmediata con tratamiento antibiótico o con vaciamiento efectivo de la mama, tratamiento antiinflamatorio y reposo?

33. En madres que amamantan y presentan mastitis aguda, ¿es más eficaz el tratamiento con probióticos que el tratamiento con antibióticos?

34. Ante un proceso doloroso de la mama, ¿es más útil el paracetamol o el ibuprofeno?

35. ¿Cuál sería el antibiótico de elección en el tratamiento empírico de las mastitis agudas?

36. ¿Se puede utilizar el drenaje por aspiración con aguja bajo control ecográfico como alternativa al drenaje quirúrgico tradicional en el tratamiento del absceso mamario? 


\title{
ANEXO II.
}

\section{ESTRATEGIA GENERAL DE BÚSQUEDAS DE GPC}

\author{
Búsqueda de GPC sobre lactancia materna existentes a nivel nacional e \\ internacional
}

Se llevó a cabo una búsqueda en el metabuscador TripDatabase con la intención de identificar aquellas guías de práctica clínica sobre la lactancia materna. Posteriormente se realizó una búsqueda más exhaustiva en las principales bases de datos que recogen GPCs: National Guidelines Clearinghouse (NGC), NICE, Scottish Intercollegiate Guidelines Network (SIGN), Canadian Medical Association (CMA) Infobase, Guiasalud y New Zealand Guidelines Group (NZGG).

La estrategia de búsqueda empleada constaba de los siguientes términos: breastfeeding OR "breast feeding"

La búsqueda no se limitó temporalmente, si bien se tuvieron en cuenta los parámetros que establece el manual metodológico sobre la obsolescencia de las GPC.

La búsqueda se realizó en julio de 2013.

También se preguntó al grupo elaborador por si conocían otras posibles guías de práctica clínica sobre lactancia materna que no hubieran sido identificadas en la búsqueda.

\section{Evaluación de la validez de las guías identificadas:}

Dos investigadores revisaron los resultados de las búsquedas para seleccionar aquellas guías cuya calidad iba a ser evaluada por pares mediante la herramienta AGREE II. 


\section{ANEXO III.}

\section{RESULTADOS DE LA VALORACIÓN DE LA CALIDAD DE LAS GPC IDENTIFICADAS (julio de 2013)}

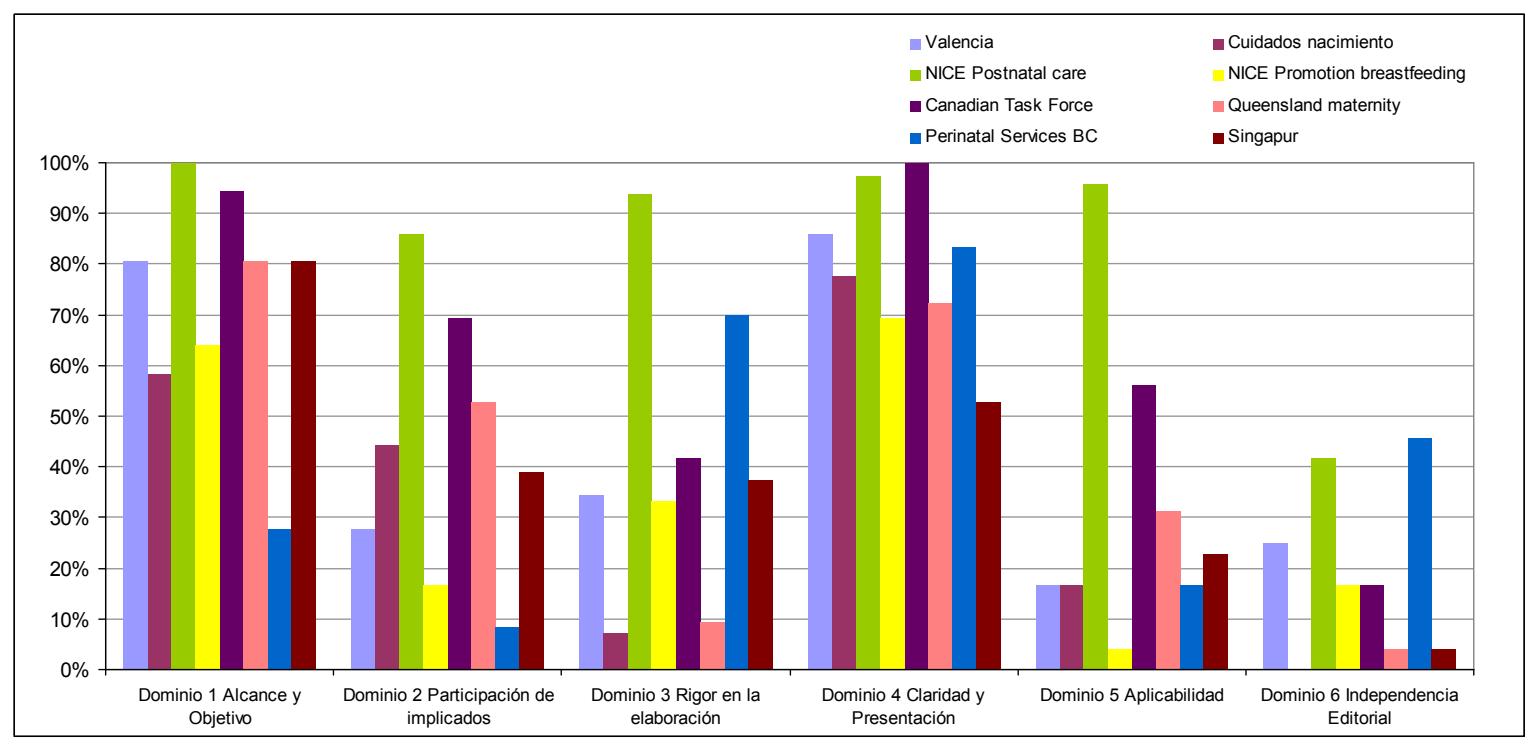

\begin{tabular}{|c|c|}
\hline "Valencia" & $\begin{array}{l}\text { Manejo de la lactancia materna desde el embarazo hasta el segundo año. } \\
\text { http://www.aeped.es/sites/default/files/1-guia Im peset.pdf }\end{array}$ \\
\hline "Cuidados & $\begin{array}{l}\text { Cuidados desde el nacimiento } \\
\text { http://www.msps.es/organizacion/sns/planCalidadSNS/pdf/equidad/cuidadosDesdeN } \\
\text { acimiento.pdf }\end{array}$ \\
\hline $\begin{array}{l}\text { "NICE Postnatal } \\
\text { care" }\end{array}$ & $\begin{array}{l}\text { Routine postnatal care of women and their babies } \\
\text { http://www.nice.org.uk/nicemedia/live/10988/30144/30144.pdf }\end{array}$ \\
\hline "NICE Promotion" & $\begin{array}{l}\text { Promotion of breastfeeding initiation and duration } \\
\text { http://www.nice.org.uk/niceMedia/pdf/EAB Breastfeeding final version.pdf }\end{array}$ \\
\hline $\begin{array}{l}\text { "Perinatal } \\
\text { Services BC" }\end{array}$ & $\begin{array}{l}\text { Perinatal services BC } \\
\text { Breastfeeding the Healthy Term Infant: } \\
\text { http://www.perinatalservicesbc.ca/NR/rdonlyres/B34C2802-3478-4CBE-BDAE- } \\
\text { 19D1A960814F/0/BFGuidelinesBreastfeedingHealthyTermInfants06Feb2013.pdf) }\end{array}$ \\
\hline $\begin{array}{l}\text { "Queensland } \\
\text { maternity" }\end{array}$ & $\begin{array}{l}\text { Queensland maternity and neonatal clinical guidelines program } \\
\text { http://www.health.qld.gov.au/qcg/documents/g bf5-0.pdf }\end{array}$ \\
\hline $\begin{array}{l}\text { "Canadian Task } \\
\text { Force" }\end{array}$ & $\begin{array}{l}\text { Intervention to Promote Breastfeeding: Updated Recommendations from the } \\
\text { Canadian Task Force on Preventive Health Care } \\
\text { http://canadiantaskforce.ca/wp- } \\
\text { content/uploads/2012/09/CTF BreastFeed TR final.pdf?9d7bd4 }\end{array}$ \\
\hline "Singapur" & $\begin{array}{l}\text { Management of breastfeeding for healthy full-term infants } \\
\text { http://www.moh.gov.sg/content/dam/moh web/HPP/Nurses/cpg nursing/2002/manag } \\
\text { ement of breastfeeding for fullterm infants.pdf }\end{array}$ \\
\hline
\end{tabular}


ANEXO IV.

FICHAS DE ELABORACIÓN DE CADA PREGUNTA CLÍNICA 
PREGUNTA CLÍNICA: N 1

\section{¿Es eficaz y seguro el contacto piel con piel inmediato e ininterrumpido postparto para el buen inicio de la lactancia materna?}

\section{1- Pregunta clínica en formato PICO}

Tabla 1. Componentes de la pregunta clínica en formato PICO

\begin{tabular}{|c|c|}
\hline Pacientes & $\begin{array}{l}\text { RN sanos y a término } \\
\text { Subgrupos: } \\
\text { - } \text { Parto vaginal } \\
\text { - } \text { Parto por cesárea }\end{array}$ \\
\hline Intervención & Contacto piel con piel temprano e ininterrumpido postparto \\
\hline Comparación & Cuidados habituales \\
\hline Resultados & $\begin{array}{ll}\text { - } & \text { Primera toma correcta (crítica) } \\
\text { - } & \text { Tasa de LME al alta (crítica) } \\
\text { - } & \text { Duración de la lactancia materna (crítica) } \\
\text { - } & \text { Peso del bebé (48-72h.) (crítica) } \\
\text { - } & \text { Complicaciones de las mamas (crítica) } \\
\text { - } & \text { Satisfacción materna (con los cuidados recibidos) (crítica) } \\
\text { - } & \text { Seguridad (importante) } \\
\text { - } & \text { Tasa de LM a los } 4 \text { meses (importante) } \\
\text { - } & \text { Tasa de LME a los } 4 \text { meses (importante) }\end{array}$ \\
\hline Tipo de estudio & GPC, RS, ECAs y estudios observacionales \\
\hline
\end{tabular}

\section{2- Introducción}

El contacto piel con piel (CPP) de la madre con su recién nacido, inmediato e ininterrumpido tras el parto tiene beneficios importantes. Se ha demostrado que favorece la vinculación materno-filial y la aparición de conductas instintivas que facilitan el comienzo de la lactancia materna. Sin embargo y a pesar de las recomendaciones de la Estrategia del Parto Normal del Ministerio de Sanidad, Servicios Sociales e Igualdad (MSSSI), todavía hay muchos hospitales españoles en los que ésta no es una práctica habitual.

Por otra parte, en los últimos años, se han descrito episodios aparentemente letales en recién nacidos en las dos primeras horas tras el nacimiento, mientras permanecían en CPP en posición prono sobre sus madres.

Por todo ello, es necesario preguntarse sobre la importancia de esta práctica, la necesidad de su implantación y la existencia de limitaciones para su aplicación. 


\section{3- ESTRATEGIA DE ELABORACIÓN DE LA PREGUNTA}

\subsection{GPC}

Tabla 2. GPC de base

\begin{tabular}{|c|c|c|c|c|}
\hline & $\begin{array}{l}\text { Resumen sobre la evidencia } \\
\text { (Calidad de la evidencia) }\end{array}$ & $\begin{array}{l}\text { Recomendaciones } \\
\text { (Grado) }\end{array}$ & $\begin{array}{l}\text { Referencias bibliográficas } \\
\text { (Tipo de publicación) }\end{array}$ & Comentarios \\
\hline NICE 2006 & $\begin{array}{l}\text { La mayoría de los bebés sanos a término } \\
\text { mostrarán comportamientos pre- } \\
\text { alimentarios dentro de la primera hora de } \\
\text { vida. [Nivel 1++] (Anderson 2003, Jansson } \\
\text { 1995, Righard and Alade 1990) } \\
\text { La iniciativa "the Baby Friendly Initiative" } \\
\text { en el paso } 4 \text { recomienda que se ofrezca un } \\
\text { primer amamantamiento tan pronto como } \\
\text { sea posible después del nacimiento. [Nivel } \\
\text { 4] (UNICEF 2006) } \\
\text { La separación temprana de la madre y el } \\
\text { bebé puede alterar los comportamientos } \\
\text { pre-alimentarios. [Nivel 3+] (,Jansson } \\
\text { 1995) } \\
\text { El CPP temprano parece tener beneficios } \\
\text { en relación con los resultados de la LM y } \\
\text { no muestra efectos negativos aparentes a } \\
\text { corto o largo plazo [Nivel 1++] (Anderson } \\
2003, \text { Mikiel 2002) } \\
\text { El CPP con agarre/succión se asocia con } \\
\text { una mayor duración de la LM. [Nivel 1+] } \\
\text { (Taylor 1985) }\end{array}$ & $\begin{array}{l}\text { Para un inicio exitoso de la lactancia se debe } \\
\text { evitar la separación de la madre y del bebé en la } \\
\text { primera hora para realizar procedimientos } \\
\text { rutinarios como pesar, medir o bañar a menos que } \\
\text { la madre lo solicite o esos cuidados sean } \\
\text { necesarios para el cuidado del bebé. [C] } \\
\text { Se debe animar a las mujeres a tener CPP con su } \\
\text { bebé tan pronto como sea posible después del } \\
\text { nacimiento. [A] } \\
\text { RN en parto por cesárea } \\
\text { Se debe ofrecer apoyo adicional para colocar } \\
\text { al RN y para el agarre para comenzar la } \\
\text { lactancia en aquellas mujeres que han tenido } \\
\text { un parto por cesárea, en especial para } \\
\text { proteger la cicatriz abdominal (D GPP). }\end{array}$ & $\begin{array}{l}\text { Anderson, G. C., Moore, E., Hepworth, J., } \\
\& \text { Bergman, N. 2003, "Early skin-to skin } \\
\text { contact for mothers and their healthy } \\
\text { newborn infants," in Cochrane Database of } \\
\text { Systematic Reviews } 2003 \text { Issue 2, } \\
\text { Chichester, John Wiley \& Sons Ltd. (RS } \\
\text { Cochrane) } \\
\text { Carfoot, S., Williamson, P., \& Dickson, R. } \\
\text { 2005, "A randomised controlled trial in the } \\
\text { north of England examining the effects of } \\
\text { skin-to-skin care on breast feeding", } \\
\text { Midwifery, vol. 21, no. 1, pp. 71-79 (ECA) } \\
\text { Jansson, U. M., Mustafa, T., Khan, M. A., } \\
\text { Lindblad, B. S., \& Widström, A. M. 1995, } \\
\text { "The effects of medically-orientated labour } \\
\text { ward routines on prefeeding behaviour and } \\
\text { body temperature in newborn infants", } \\
\text { Journal of Tropical Pediatrics, vol. 41, no. } \\
\text { 6, pp. 360-363. (estudio de cohortes) } \\
\text { Mikiel, K. K., Mazur, J., \& Boltruszko, I. } \\
\text { 2002, "Effect of early skin-to-skin contact } \\
\text { after delivery on duration of breastfeeding: } \\
\text { a prospective cohort study", Acta } \\
\text { Paediatrica, vol. 91, no. 12, pp. 1301- } \\
\text { 1306. (estudio de cohortes) } \\
\text { Righard, L. \& Alade, M. O. 1990, "Effect of } \\
\text { delivery room routines on success of first } \\
\text { breast-feed", Lancet, vol. 336, no. 8723, } \\
\text { pp. } 1105-1107 \text {. (estudio de cohortes) }\end{array}$ & $\begin{array}{l}\text { Un estudio no } \\
\text { encuentra } \\
\text { diferencias en } \\
\text { tasa de LM al } \\
\text { mes (Carfoot } \\
\text { 2005) } \\
\text { - NICE } \\
\text { guidelines. The } \\
\text { evidence levels } \\
\text { and } \\
\text { recommendation } \\
\text { are based on the } \\
\text { Institute's } \\
\text { technical manual } \\
\text { http://www.nice.o } \\
\text { rg.uk/page.aspx? } \\
\text { o=guidelinestech } \\
\text { nicalmanual). } \\
\text { The grading of } \\
\text { recommendation } \\
\text { s was carried out } \\
\text { in accordance } \\
\text { with the NICE } \\
\text { Technical Manual } \\
\text { in use at the } \\
\text { outset of the } \\
\text { guideline }\end{array}$ \\
\hline
\end{tabular}




\begin{tabular}{|c|c|c|c|c|}
\hline & & & $\begin{array}{l}\text { Taylor, P. M., Maloni, J. A., Taylor, F. H., \& } \\
\text { Campbell, S. B. 1985, “Extra early mother- } \\
\text { infant contact and duration of breast- } \\
\text { feeding", Acta Paediatrica Scandinavica, } \\
\text { vol. 316, no. Supp, pp. 15-22. (ECA) } \\
\text { UNICEF. Ten steps to successful } \\
\text { breastfeeding. 2006 Available from: } \\
\text { www.unicef.org/newsline/tenstps.htm } \\
\text { (informe) }\end{array}$ & $\begin{array}{l}\text { development } \\
\text { process. } \\
\text { However, during } \\
\text { the development } \\
\text { of the Postnatal } \\
\text { Care guidance } \\
\text { NICE protocols } \\
\text { were revised ano } \\
\text { grading of } \\
\text { recommendation } \\
\text { s was abolished. } \\
\text { Therefore, the } \\
\text { recommendation } \\
\text { s for postnatal } \\
\text { care are not } \\
\text { graded in the } \\
\text { NICE version of } \\
\text { the guideline. }\end{array}$ \\
\hline $\begin{array}{l}\text { NICE - } \\
\text { UPDATE } \\
2011\end{array}$ & $\begin{array}{l}\text { Una revisión Cochrane (Moore 2007, SR) } \\
\text { evaluó los efectos del contacto temprano } \\
\text { piel con piel sobre la lactancia materna, } \\
\text { el comportamiento y la adaptación } \\
\text { fisiológica en las díadas madre - RN. Se } \\
\text { concluye que la intervención puede } \\
\text { beneficiar la lactancia materna, el apego } \\
\text { temprano entre madre y bebé, el llanto } \\
\text { infantil y la estabilidad cardiorrespiratoria, y } \\
\text { no tiene efectos negativos a corto o largo } \\
\text { plazo. } \\
\text { Un ECA (Moore 2007, ECA) evaluó los } \\
\text { efectos del CPP madre-hijo durante las } \\
\text { primeras } 2 \text { horas después del nacimiento } \\
\text { en comparación con la atención estándar } \\
\text { (el niño envuelto en mantas) sobre la LM al } \\
\text { mes. Los autores concluyeron que el CPP } \\
\text { temprano contribuye al éxito de la lactancia } \\
\text { durante el puerperio temprano pero que no } \\
\text { se hay diferencias significativas al mes. }\end{array}$ & $\begin{array}{l}\text { No se ha encontrado evidencia nueva que invalide } \\
\text { las recomendaciones existentes. }\end{array}$ & $\begin{array}{l}\text { Moore ER and Anderson GC. (2007) } \\
\text { Randomized controlled trial of very early } \\
\text { mother-infant skinto-skin contact and } \\
\text { breastfeeeding status. Journal of Midwifery } \\
\text { \& Women's Health 52:116-125. (ECA) } \\
\text { Moore ER, Anderson GC, and Bergman N. } \\
\text { (2007) Early skin-to-skin contact for } \\
\text { mothers and their healthy newborn infants. } \\
\text { [Review] [111 refs][Update of Cochrane } \\
\text { Database Syst Rev. 2003;(2):CDO03519; } \\
\text { PMID: 12804473]. Cochrane Database of } \\
\text { Systematic Reviews CD003519. (RS } \\
\text { Cochrane) }\end{array}$ & \\
\hline
\end{tabular}




\begin{tabular}{|c|c|c|c|}
\hline BC 2013 & $\begin{array}{l}\text { Tras el parto, realizar CPP colocando al } \\
\text { bebé sobre la madre para que tenga } \\
\text { acceso completo al pecho y pezones de la } \\
\text { madre. El CPP en el nacimiento se asocia } \\
\text { con mejores resultados de la LM (Moore } \\
2007 \text { SR, Bramson 2010) } \\
\text { Facilitar el inicio a la LM para madre-hijo; } \\
\text { mantenerlos juntos en CPP para permitir al } \\
\text { bebé lamer, succionar y tocar el pezón con } \\
\text { su mano (Matthiesen 2001). En la primera } \\
\text { hora tras el nacimiento el reflejo de succión } \\
\text { del bebé es generalmente intenso, los } \\
\text { bebés están alerta y despiertos, y las } \\
\text { madres experimentan una oleada de } \\
\text { oxitocina que se asocia con la producción } \\
\text { de leche, el aumento de las contracciones } \\
\text { uterinas y la mejora del vínculo madre-hijo } \\
\text { (Riordan 2010, Matthiesen 2001). } \\
\text { Asistir a la madre con la lactancia lo más } \\
\text { pronto posible o dentro de } 1 \text { a } 2 \text { horas. } \\
\text { Si debe transportarse a una unidad de } \\
\text { posparto, mantener el CPP. }\end{array}$ & $\begin{array}{l}\text { Tras el parto colocar al bebé CPP con la madre } \\
\text { para que el bebé tenga acceso directo al pecho } \\
\text { de la madre, manteniendo este contacto piel con } \\
\text { piel hasta la finalización de la primera toma (A) } \\
\text { Se recomienda fomentar y facilitar la lactancia } \\
\text { materna exclusiva en el período posparto } \\
\text { temprano. (A) } \\
\text { a. Apoyar el amamantamiento temprano y } \\
\text { frecuente. } \\
\text { b. Fomentar el CPP. } \\
\text { c. Mantener junto a las madres con los bebés. } \\
\text { d. Los padres deben mostrar cómo reconocer } \\
\text { cuales son las señales precoces de hambre del } \\
\text { bebé. } \\
\text { e. Los padres deben aprender a reconocer los } \\
\text { signos de la ingesta de leche materna adecuada. }\end{array}$ & $\begin{array}{l}\text { Bramson I, Lee JW, Moore E et al (2010. } \\
\text { Effect of early skin-to-skin mother-infant } \\
\text { contact during the first } 3 \text { hours following } \\
\text { birth on exclusive breastfeeding during the } \\
\text { maternity hospital stay. Journal of Human } \\
\text { Lactation 26,130-137. http:///hl. } \\
\text { sagepub.com//content/26/2/130. (estudio } \\
\text { de cohortes prospectivo) } \\
\text { Matthiesen A-S, Ransjö-Arvidson A-B, } \\
\text { Nissen E \& Uvnäs-Moberg K. (2001). } \\
\text { Postpartum maternal oxytocin release by } \\
\text { newborns: Effects of infant hand massage } \\
\text { and sucking. Birth 28(1), 13-19. (estudio } \\
\text { observacional) } \\
\text { Moore ER, Anderson, G, Bergman, N. } \\
\text { (2007). Early skin-to-skin contact for } \\
\text { mothers and their healthy newborn infants. } \\
\text { Cochrane Database of Systematic } \\
\text { Reviews Issue 2. Art. No. } \\
\text { DC003519.DOI:10.1002/14651858.CD003 } \\
\text { 519.pub2. (RS Cochrane) } \\
\text { Riordan J \& Wambach, K. (2010). } \\
\text { Breastfeeding and human lactation (4th } \\
\text { Ed.). Boston: Jones and Bartlett } \\
\text { Publishers (libro) }\end{array}$ \\
\hline
\end{tabular}

Tabla 2. Resumen de GPC del SNS

\begin{tabular}{|c|c|c|c|c|}
\hline $\begin{array}{l}\text { GPC SNS } \\
\text { parto normal }\end{array}$ & $\begin{array}{l}\text { Hay evidencia procedente de una GPC } \\
\text { (National Collaborating Centre for Women's } \\
\text { and Children's Health. 2007) y ECAs de } \\
\text { buena calidad (Mercer 2007, Moore } 2008 \\
\text { RS) que encuentra que el CPP es } \\
\text { beneficioso a corto plazo para mantener la } \\
\text { temperatura y disminuir el llanto del niño, y } \\
\text { a largo plazo para aumentar la duración de } \\
\text { lactancia materna. }(1+)\end{array}$ & $\begin{array}{l}\text { Se recomienda que las mujeres mantengan el } \\
\text { CPP con sus bebés inmediatamente después del } \\
\text { nacimiento. }(A) \\
\text { Para mantener caliente al bebé, se recomienda } \\
\text { cubrirlo y secarlo con una manta o toalla, } \\
\text { previamente calentadas, al tiempo que se } \\
\text { mantiene el CPP con la madre. }(\sqrt{ }) \\
\text { Se recomienda evitar la separación de la madre y }\end{array}$ & $\begin{array}{l}\text { Mercer JS, Erickson-Owens DA, Graves } \\
\text { B, Haley MM. Evidence-based practices } \\
\text { for the fetal to newborn transition. J } \\
\text { Midwifery Womens Health 2007; } \\
52(3): 262-72 \text {. (revisión narrativa) } \\
\text { Moore ER, Anderson GC, Bergman N. } \\
\text { Contacto piel-a-piel temprano para las } \\
\text { madres y sus recién nacidos sanos } \\
\text { (Revisisón Cochrane traducida). En: La } \\
\text { Biblioteca Cochrane Plus, 2008. Número } 1 \\
\text { Oxford: Update Software Ltd Disponible }\end{array}$ & $\begin{array}{l}\text { Esta GPC se ha } \\
\text { realizado con } \\
\text { SIGN. }\end{array}$ \\
\hline
\end{tabular}




\begin{tabular}{|c|c|c|c|}
\hline & & $\begin{array}{l}\text { el bebé dentro de la primera hora de vida y hasta } \\
\text { que haya finalizado la primera toma. Durante este } \\
\text { periodo se recomienda que la matrona mantenga } \\
\text { una vigilancia con observación periódica que } \\
\text { interfiera lo menos posible en la relación entre la } \\
\text { madre y el RN con registro de signos vitales de } \\
\text { los RN (color, movimientos respiratorios, tono y, si } \\
\text { es preciso la frecuencia cardiaca) alertando al } \\
\text { especialista de cualquier cambio } \\
\text { cardiorrespiratorio. }(\downarrow)\end{array}$ & $\begin{array}{l}\text { en: http://www update-software com } \\
\text { (Traducida de The Cochrane Library, } 2008 \\
\text { Issue } 1 \text { Chichester, UK: John Wiley \& } \\
\text { Sons, Ltd) 2008. (RS Cochrane) } \\
\text { National Collaborating Centre for } \\
\text { Women's and Children's Health. } \\
\text { Intrapartum care: care of healthy women } \\
\text { and their babies during childbirth. Clinical } \\
\text { Guideline 2007. (guideline) }\end{array}$ \\
\hline
\end{tabular}

Tabla 3. Otros documentos

\begin{tabular}{|c|c|c|}
\hline IHAN 32009 & $\begin{array}{l}\text { El Paso } 4 \text { de los Diez Pasos para una lactancia exitosa } \\
\text { establece: Ayudar a las madres a iniciar la lactancia } \\
\text { durante la media hora después del parto. } \\
\text { Este paso se interpreta ahora como: Colocar a los } \\
\text { bebés en CPP con sus madres inmediatamente } \\
\text { después del parto por lo menos durante una hora y } \\
\text { alentar a las madres a reconocer cuando sus bebés } \\
\text { están listos para amamantar, ofreciendo su ayuda si } \\
\text { fuera necesario. } \\
\text { Asegure el CPP precoz, ininterrumpido, sin prisas, } \\
\text { entre la madre y su bebé sano sin envolver, empiece } \\
\text { inmediatamente, aún antes de pinzar el cordón, o tan } \\
\text { pronto como sea posible en algunos minutos después } \\
\text { del nacimiento. Arregle que el CPP continúe por lo } \\
\text { menos por una hora después del nacimiento. Se } \\
\text { recomienda un período más prolongado de CPP si el } \\
\text { bebé no ha succionado en la primera hora después del } \\
\text { nacimiento. } \\
\text { RN nacidos por cesárea } \\
\text { Se puede ofrecer contacto temprano de modo } \\
\text { rutinario a las mujeres que han tenido un parto } \\
\text { por cesárea. }\end{array}$ & $\begin{array}{l}\text { Existe cierta } \\
\text { confusión entre } \\
\text { el CPP temprano } \\
\text { y el inicio de la } \\
\text { LM. }\end{array}$ \\
\hline
\end{tabular}




\subsection{Revisiones sistemáticas}

En la tabla 4 se presenta un resumen de las dos revisiones seleccionadas $(1 ; 2)$.

Tabla 4. Resumen de RS

\begin{tabular}{|c|c|c|c|c|c|c|}
\hline $\begin{array}{l}\text { Referencia } \\
\text { (Cita } \\
\text { Abreviada) }\end{array}$ & $\begin{array}{l}\text { Estudio } \\
\text { (Diseño y } \\
\text { objetivo) }\end{array}$ & $\begin{array}{l}\text { Población } \\
\left(n^{\circ} y\right. \\
\text { características })\end{array}$ & $\begin{array}{l}\text { Intervención/ } \\
\text { Comparación. } \\
\text { exposiciones o } \\
\text { pruebas a estudio }\end{array}$ & $\begin{array}{l}\text { Resultados } \\
\text { (Estimadores de resultados-Magnitud } \\
\text { del efecto) }\end{array}$ & $\begin{array}{l}\text { Conclusiones } \\
\text { (Conclusiones) }\end{array}$ & $\begin{array}{l}\text { Comentarios } \\
\text { (Calidad de la evidencia, } \\
\text { financiación comentarios) }\end{array}$ \\
\hline $\begin{array}{l}\text { Moore } 2012 \\
\text { RS Cochrane }\end{array}$ & $\begin{array}{l}\text { Diseño } \\
\text { RS de ECAs } \\
\text { Objetivo } \\
\text { Evaluar los } \\
\text { efectos del CPP } \\
\text { temprano en la } \\
\text { lactancia } \\
\text { materna. }\end{array}$ & $\begin{array}{l}\mathbf{N} \\
2.177 \text { díadas } \\
\text { madre-RN; } 34 \\
\text { estudios } \\
\text { Características } \\
\text { Bebés a término } \\
\text { o prematuros } \\
\text { tardíos (34-37 } \\
\text { semanas) con } \\
\text { los que se } \\
\text { realiza CPP } \\
\text { antes de } 24 \mathrm{~h} .\end{array}$ & $\begin{array}{l}\text { Intervención } \\
\text { 1. "CPP al nacer" } \\
\text { (in birth SSC) - } \\
\text { CPP que se inicia } \\
\text { el 1er minuto tras } \\
\text { el parto } \\
\text { 2. "CPP muy } \\
\text { temprano" (very } \\
\text { early SSC) - CCP } \\
\text { que se inicia desde } \\
\text { 30/ 40" tras el } \\
\text { parto } \\
\text { 3. "CPP temprano" } \\
\text { (early SSC) - CCP } \\
\text { que se inicia entre } \\
60 \text { " y } 24 \mathrm{~h} . \text { tras el } \\
\text { parto } \\
\text { Comparación } \\
\text { Cuidados } \\
\text { habituales, } \\
\text { incluyendo bebés } \\
\text { arropados con } \\
\text { mantas o vestidos } \\
\text { en los brazos de la } \\
\text { madre, en cunas o }\end{array}$ & 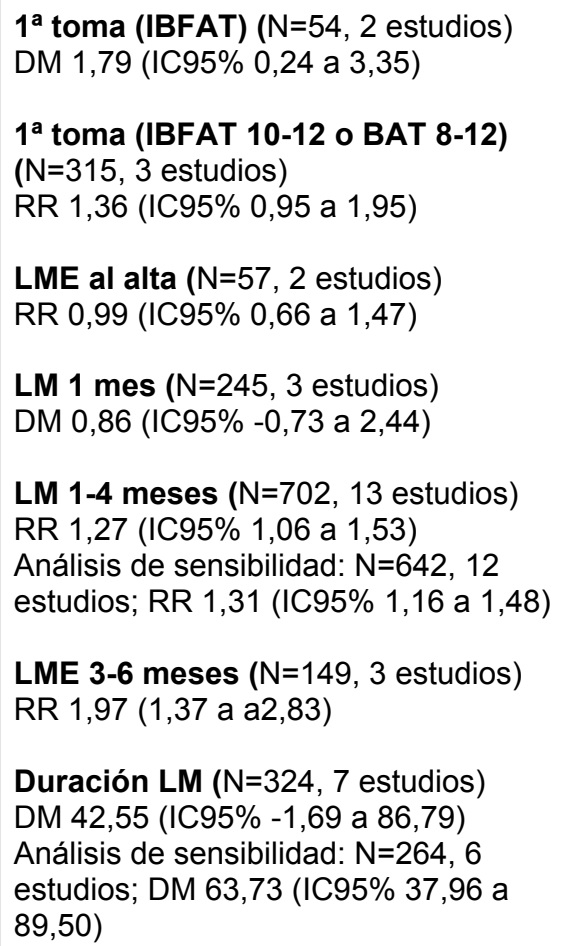 & $\begin{array}{l}\text { - Los resultados apoyan } \\
\text { las prácticas } \\
\text { recomendadas por } \\
\text { UNICEF y la Iniciativa } \\
\text { Hospitales Amigos de los } \\
\text { Niños, que promueven el } \\
\text { CPP la } 1^{a} \text { hora después } \\
\text { del nacimiento. } \\
\text { - Sin embargo, la } \\
\text { evidencia es insuficiente } \\
\text { respecto al momento de } \\
\text { iniciación, duración del } \\
\text { CPP y la técnica. } \\
\text { - Destacar que una } \\
\text { intervención practicada } \\
\text { por un corto tiempo tras el } \\
\text { nacimiento tiene efectos } \\
\text { medibles en la lactancia } 1 \\
\text { a } 4 \text { meses después del } \\
\text { nacimiento. } \\
\text { - No parece conllevar } \\
\text { consecuencias negativas } \\
\text { a corto o largo plazo. }\end{array}$ & $\begin{array}{l}\text { Comentarios } \\
\text { (-) Los autores de la RS } \\
\text { indican que no hay datos } \\
\text { suficientes para llevar a } \\
\text { cabo sub-análisis por } \\
\text { grupos } \\
\text { (-) Limitaciones del diseño } \\
\text { de los estudios primarios, } \\
\text { aunque son ECAs } \\
\text { muchos de baja calidad. } \\
\text { (-) Variabilidad en los } \\
\text { desenlaces, que dificulta } \\
\text { MA. } \\
\text { (-) Algunos estudios } \\
\text { incluyen RN pretérmino o } \\
\text { con parto con cesárea } \\
\text { Conflicto de interés } \\
\text { Three of the review } \\
\text { authors have been active } \\
\text { trialists in this area and } \\
\text { have personal contact } \\
\text { with many groups in this } \\
\text { field, including the } \\
\text { International Network for } \\
\text { KMC based in Trieste, }\end{array}$ \\
\hline
\end{tabular}




\begin{tabular}{|c|c|c|c|c|c|c|}
\hline $\begin{array}{l}\text { Referencia } \\
\text { (Cita } \\
\text { Abreviada) }\end{array}$ & $\begin{array}{l}\text { Estudio } \\
\text { (Diseño y } \\
\text { objetivo) }\end{array}$ & $\begin{array}{l}\text { Población } \\
\left(n^{\circ} y\right. \\
\text { características })\end{array}$ & $\begin{array}{l}\text { Intervención/ } \\
\text { Comparación. } \\
\text { exposiciones o } \\
\text { pruebas a estudio }\end{array}$ & $\begin{array}{l}\text { Resultados } \\
\text { (Estimadores de resultados-Magnitud } \\
\text { del efecto) }\end{array}$ & $\begin{array}{l}\text { Conclusiones } \\
\text { (Conclusiones) }\end{array}$ & $\begin{array}{l}\text { Comentarios } \\
\text { (Calidad de la evidencia, } \\
\text { financiación comentarios) }\end{array}$ \\
\hline & & & $\begin{array}{l}\text { en calentadores } \\
\text { radiantes }\end{array}$ & $\begin{array}{l}\text { Problemas >3 días ( } \mathrm{N}=131,2 \text { estudios) } \\
\text { DME }-0,41 \text { (IC95\% }-0,76 \text { a }-0,06) \\
\text { Peso RN (g.) día } 14 \text { ( } \mathrm{N}=43,2 \text { estudios) } \\
\text { DM -8,00 (IC95\% }-175,60 \text { a 159,61) } \\
\text { Preferencia materna ( } \mathrm{N}=199,1 \\
\text { estudio) } \\
\text { RR 2,82 (IC95\% 2,08 a 3,82) }\end{array}$ & & $\begin{array}{l}\text { Italy; Bogota, Colombia; } \\
\text { and Cleveland, Ohio. Dr } \\
\text { Bergman has received } \\
\text { reimbursement for } \\
\text { lectures that he has } \\
\text { conducted on KMC he } \\
\text { sale of KMC related } \\
\text { products. } \\
\text { Financiación } \\
\text { Financiación externa de } \\
\text { NIHR NHS Cochrane } \\
\text { Collaboration Programme } \\
\text { (CPGS 10/4001/02, UK) } \\
\text { Calidad } \\
\text { Ver AMSTAR }\end{array}$ \\
\hline $\begin{array}{l}\text { Herlenius } \\
2013\end{array}$ & $\begin{array}{l}\text { Diseño } \\
\text { RS de estudios } \\
\text { de series de } \\
\text { casos } \\
\text { Objetivo } \\
\text { Revisar la } \\
\text { evidencia } \\
\text { disponible de } \\
\text { estudios de } \\
\text { casos sobre los } \\
\text { episodios de } \\
\text { colapso neonatal } \\
\text { durante los } \\
\text { primeros días de } \\
\text { vida. }\end{array}$ & $\begin{array}{l}\text { N } \\
398 \text { casos en la } \\
\text { primera se mana } \\
\text { de vida } \\
\text { Características } \\
\text { RN de hasta } 1 \\
\text { semana; } \\
\text { aparentemente } \\
\text { sanos, >35 } \\
\text { semanas; Apgar } \\
>710 \text { " }\end{array}$ & $\begin{array}{l}\text { Casos de EALs y } \\
\text { muerte súbita }\end{array}$ & $\begin{array}{l}\text { Resultados } \\
\text { - } 233 \text { casos de muerte súbita neonatal } \\
\text { (153 sin etiología aparente) } \\
\text { - } 1 / 3 \text { ocurre en las primeras dos horas; } \\
1 / 3 \text { entre las } 2-24 \mathrm{~h} \text {. y } 1 / 3 \text { entre días } 1-7 \\
\text { - incidencia estimada: } 2,6 \text { a } 133 \text { por } \\
\text { cada } 100.000 \text { nacimientos }\end{array}$ & $\begin{array}{l}\text { Conclusiones } \\
\text { Aunque los episodios de } \\
\text { colapso neonatal son } \\
\text { poco frecuentes, se } \\
\text { recomienda una } \\
\text { adecuada supervisión de } \\
\text { los bebes durante este } \\
\text { periodo. } \\
\text { La mayoría de los casos } \\
\text { ocurren cuando los RN } \\
\text { están en posición prono } \\
\text { en CPP con la madre } \\
\text { (aunque no todos los } \\
\text { estudios tienen datos a } \\
\text { este respecto) }\end{array}$ & $\begin{array}{l}\text { Comentarios } \\
\text { (-) No en todos los } \\
\text { estudios se describe la } \\
\text { posición del RN en el } \\
\text { momento del colapso. } \\
\text { (-) Se incluyen estudios } \\
\text { hasta la primera semana } \\
\text { de vida } \\
\text { (-) No en todos los } \\
\text { estudios hay datos de la } \\
\text { autopsia del RN o } \\
\text { examen de las causas del } \\
\text { colapso } \\
\text { (-) Revisión de series de } \\
\text { casos o informes de } \\
\text { casos, baja calidad de los } \\
\text { estudios primarios }\end{array}$ \\
\hline
\end{tabular}




\begin{tabular}{|l|l|l|l|l|l|}
\hline $\begin{array}{l}\text { Referencia } \\
\text { (Cita } \\
\text { Abreviada) }\end{array}$ & $\begin{array}{l}\text { Estudio } \\
\text { (Diseño } y \\
\text { objetivo) }\end{array}$ & $\begin{array}{l}\text { Población } \\
\left(\mathrm{n}^{\circ} \mathrm{y}\right. \\
\text { características) }\end{array}$ & $\begin{array}{l}\text { Intervención/ } \\
\text { Comparación. } \\
\text { exposiciones o } \\
\text { pruebas a estudio }\end{array}$ & $\begin{array}{l}\text { Resultados } \\
\text { (Estimadores de resultados-Magnitud } \\
\text { del efecto) }\end{array}$ & $\begin{array}{l}\text { Conclusiones } \\
\text { (Conclusiones) }\end{array}$ \\
\hline & & & $\begin{array}{l}\text { Comentarios } \\
\text { (Calidad de la evidencia, } \\
\text { financiación comentarios) }\end{array}$ & $\begin{array}{l}\text { Conflicto de interés } \\
\text { No hay conflicto de } \\
\text { interés } \\
\text { Financiación } \\
\text { Sweedish Research } \\
\text { Council and Karolinksa } \\
\text { Institutet } \\
\text { Calidad } \\
\text { Ver AMSTAR }\end{array}$ & \\
\hline
\end{tabular}

BAT: Breastfeding Assessment Tool; CPP: contacto piel con piel; EAL: episodios aparentemente letales; IBFAT: Infant Breastfeeding Assessment Tool; LM: lactancia materna; LME: lactancia materna exclusiva; RN: recién nacido 


\subsection{Resumen de GPC base y RS disponibles}

La GPC del NICE (3) recoge la evidencia de la "Iniciativa del Hospital Amigo de los Niños" (4), de una revisión Cochrane (5) y de un ECA (6) que muestran que el CPP tras el parto tiene beneficios sobre la lactancia materna, y recomienda que las mujeres hagan CPP con su recién nacido tan pronto como sea posible tras el parto, evitando la separación de la madre y el recién nacido durante la primera hora de vida para realizar procedimientos rutinarios. La actualización de la guía del NICE (7) incluye nueva evidencia de una revisión Cochrane (8), que es una actualización de una revisión previa (5) ya incluida en la GPC del NICE , y un ECA (9), aunque se mantiene la misma recomendación.

La guía de la Perinatal Services British Columbia (PSBC) (10) también recoge la misma revisión Cochrane (8) y la evidencia de dos estudios observacionales $(11 ; 12)$ que muestran que durante la primera hora tras el parto los recién nacidos están alerta y que su reflejo de succión es intenso, por lo que recomienda colocar al recién nacido en CPP con la madre tras el nacimiento para que tenga acceso directo al pecho, manteniendo el CPP hasta la finalización de la primera toma.

La GPC del parto normal del SNS (13) recoge la evidencia de una GPC (14), la misma revisión Cochrane (8) y un ECA de buena calidad (15), y también recomienda que las mujeres mantengan al recién nacido en CPP inmediatamente después del nacimiento, evitando la separación de madre y recién nacido dentro de la primera hora de vida y hasta que haya finalizado la primera toma. En relación a la seguridad durante la realización del CPP recomienda que la matrona mantenga una vigilancia con observación periódica que interfiera lo menos posible en la relación entre la madre y el recién nacido con registro de signos vitales del recién nacido (color, movimientos respiratorios, tono y, si es preciso, la frecuencia cardiaca) y alertando al pediatra de cualquier cambio cardiorrespiratorio.

El cuarto paso de "Los diez pasos hacia una lactancia feliz" de la IHAN (4) establece que hay que ayudar a las madres a iniciar la lactancia durante la media hora después del parto. Se debe asegurar el CPP inmediato, ininterrumpido, sin prisas, entre la madre y su recién nacido sano sin envolver, inmediatamente después del nacimiento, aún antes de pinzar el cordón. El CPP debe de continuar por lo menos durante una hora, aunque se recomienda un período más prolongado si el recién nacido no ha succionado en la primera hora después del nacimiento.

Se han realizado búsquedas para localizar revisiones sistemáticas que evaluasen el efecto del CPP sobre la lactancia materna, así como los posibles riesgos que conlleva esta práctica. Por un lado, se han identificado dos revisiones que responden a la pregunta sobre la importancia de realizar CPP precoz $(1 ; 16)$. En el primer caso, se trata de una revisión Cochrane reciente (1), que corresponde a la actualización de dos revisiones previas $(5 ; 8)$ ya incluidas en las GPC evaluadas. La segunda (16) es una revisión descriptiva de baja calidad que no incluye nuevos estudios. Para presentar los resultados asociados a esta pregunta, y tras la valoración metodológica de las dos revisiones, se ha seleccionado la revisión Cochrane. Esta revisión concluye que el CPP precoz es beneficioso para la lactancia materna, aunque la evidencia es insuficiente en relación a la iniciación, duración y técnica más adecuada.

Por otro lado, se ha localizado una revisión en base a estudios de series de casos (2) que evalúa el riesgo de colapso neonatal durante la realización del CPP precoz. Esta revisión concluye que aunque estos episodios se dan con baja frecuencia, una 
vigilancia adecuada durante los primeros días de vida (y especialmente durante las primeras horas tras el nacimiento) puede evitar problemas graves y salvar muchas vidas. Recientemente se ha publicado una revisión en la que también se señala la existencia de este riesgo y en la que se insite en las condiciones que deben darse en los hospitales para poder llevar a cabo el contacto piel con piel y para el sueño seguro del recién nacido (17).

En cuanto al recién nacido en parto por cesárea, el paso 4 de la IHAN (4) recomienda la práctica rutinaria del contacto precoz tras el parto por cesárea. Por su parte, la GPC del NICE (3) sugiere ofrecer apoyo con la colocación del recién nacidos para proteger la cicatriz abdominal. De la revisión de Moore (1) se han seleccionado únicamente los estudios en los que se incluyen partos por cesárea para su valoración individual. Además se he localizado una RS reciente en la que se incluyen únicamente partos por cesárea (18). Se han seleccionado los ECA incluidos para su valoración

\subsection{Conclusión}

\begin{tabular}{|l|l|}
\hline & Adopción GPC/Revisión sistemática \\
\hline$X$ & Elaboración parcial \\
\hline & Elaboración de novo \\
\hline
\end{tabular}

\subsection{Diseño de la estrategia de búsqueda de estudios individuales}

\begin{tabular}{|l|l|}
\hline Criterios de selección de & $\begin{array}{l}\text { - ECAs } \\
\text { estudios }\end{array}$ \\
\begin{tabular}{|l} 
Estudios de casos controles o series de casos (para evaluar la \\
seguridad)
\end{tabular} \\
\hline Período de búsqueda & $\begin{array}{l}\text { - Enero 2011 - noviembre 2013, para el efecto del CPP } \\
\text { temprano en la LM se toma como base la revisión Cochrane de } \\
\text { Moore, cuya búsqueda llega hasta } 30 \text { noviembre } 2011 \\
-2012-\text { noviembre 2013, para la actualización de la revisión de } \\
\text { seguridad }\end{array}$ \\
\hline Bases de datos & $\begin{array}{l}\text { Cochrane Library } \\
\text { Medline via Pubmed } \\
\text { Embase via OVID } \\
\text { Cinahl via EBSCO } \\
\text { PsylNFO via OVID }\end{array}$ \\
\hline
\end{tabular}

Ver estrategias de búsqueda de estudios originales en el anexo I. 


\section{4- Evidencia}

Ver tablas de estudios individuales y valoración de calidad las revisiones y de los estudios en los anexo II y III.

\subsection{GRADE Evidence Profile}

\section{Comparación 1. Contacto piel con piel temprano vs. cuidados habituales}

Bibliografía: Aghdas K, et al, 2013; Girish M, 2013; Herlenius E, 2013; Mahmooed I, 2011; Nahidi F, 2010; Moore ER; 2012; Thukrai A, 2012

\begin{tabular}{|c|c|c|c|c|c|c|c|c|c|c|c|c|}
\hline \multicolumn{7}{|c|}{ Evaluación de la calidad } & \multicolumn{2}{|c|}{$\mathrm{N}^{\mathrm{a}}$ de pacientes } & \multicolumn{2}{|c|}{ Magnitud del efecto } & \multirow{2}{*}{ Calidad } & \multirow{2}{*}{ Importancia } \\
\hline $\begin{array}{c}N^{\circ} \text { de } \\
\text { estudios }\end{array}$ & Diseño & $\begin{array}{c}\text { Riesgo de } \\
\text { sesgo }\end{array}$ & Inconsistencia & $\begin{array}{c}\text { Evidencia } \\
\text { indirecta }\end{array}$ & Imprecisión & $\begin{array}{c}\text { Otras } \\
\text { consideraciones }\end{array}$ & $\begin{array}{c}\text { CPP } \\
\text { temprano }\end{array}$ & $\begin{array}{l}\text { Cuidados } \\
\text { habituales }\end{array}$ & $\begin{array}{l}\text { Relativa } \\
\text { (IC95\%) }\end{array}$ & Absoluta & & \\
\hline \multicolumn{13}{|c|}{ Primera toma correcta (IBFAT 10-12 o BAT 8-12) } \\
\hline \multirow[t]{2}{*}{71} & \multirow[t]{2}{*}{ ECAs } & \multirow[t]{2}{*}{ No serio } & \multirow[t]{2}{*}{ Serio ${ }^{2}$} & \multirow[t]{2}{*}{ No serio } & \multirow[t]{2}{*}{ Serio $^{3}$} & \multirow[t]{2}{*}{ Poco probable } & $\begin{array}{l}257 / 345 \\
(74,5 \%)\end{array}$ & $\begin{array}{l}196 / 342 \\
(57,3 \%)\end{array}$ & \multirow[t]{2}{*}{$\begin{array}{l}\text { RR } 1,30(1,18 \\
\text { a } 1,44)\end{array}$} & $\begin{array}{l}172 \text { más por } 1000 \text { (de } \\
103 \text { a } 252 \text { más) }\end{array}$ & \multirow[t]{2}{*}{$\begin{array}{c}\oplus \oplus \oplus \mathrm{O} \\
\text { MODERADA }\end{array}$} & \multirow[t]{2}{*}{ CRITICA } \\
\hline & & & & & & & & $35,6 \%$ & & $\begin{array}{l}107 \text { más por } 1000 \text { (de } \\
64 \text { a } 160 \text { más) }\end{array}$ & & \\
\hline \multicolumn{13}{|c|}{\begin{tabular}{|l|} 
Lactancia materna exclusiva al alta \\
\end{tabular}} \\
\hline \multirow[t]{2}{*}{$2^{4}$} & \multirow[t]{2}{*}{ ECAs } & \multirow[t]{2}{*}{ No serio } & \multirow[t]{2}{*}{ No serio } & \multirow[t]{2}{*}{ Serio 5} & \multirow[t]{2}{*}{ Serio ${ }^{6}$} & \multirow[t]{2}{*}{ Poco probable } & \begin{tabular}{|l|}
$28 / 37$ \\
$(75,7 \%)$
\end{tabular} & $\begin{array}{l}17 / 38 \\
(44,7 \%)\end{array}$ & \multirow[t]{2}{*}{$\begin{array}{l}\text { RR } 1,69(1,13 \\
\text { a } 2,54)\end{array}$} & $\begin{array}{l}309 \text { más por } 1000 \text { (de } \\
58 \text { a } 689 \text { más) }\end{array}$ & \multirow[t]{2}{*}{$\begin{array}{c}\oplus \oplus \oplus \mathrm{O} \\
\mathrm{BAJA}\end{array}$} & \multirow[t]{2}{*}{ CRITICA } \\
\hline & & & & & & & & $52,9 \%$ & & $\begin{array}{l}365 \text { más por } 1000 \text { (de } \\
69 \text { a } 815 \text { más) }\end{array}$ & & \\
\hline \multicolumn{13}{|c|}{ Duración de la lactancia materna (días) } \\
\hline $6^{7}$ & ECAs & No serio & No serio & No serio & No serio & Poco probable & 134 & 130 & & $\begin{array}{l}\text { MD 63,73 más (37,96 a } \\
89,5 \text { más) }\end{array}$ & $\begin{array}{l}\oplus \oplus \oplus \oplus \\
\text { ALTA }\end{array}$ & CRITICA \\
\hline \multicolumn{13}{|c|}{ Lactancia materna a los 4 meses } \\
\hline \multirow[t]{2}{*}{$13^{8}$} & \multirow[t]{2}{*}{ ECAs } & \multirow[t]{2}{*}{ Serio ${ }^{9}$} & \multirow[t]{2}{*}{ Serio ${ }^{10}$} & \multirow[t]{2}{*}{ Serio ${ }^{11}$} & \multirow[t]{2}{*}{ No serio } & Poco probable & $\begin{array}{l}282 / 412 \\
(68,4 \%)\end{array}$ & $\begin{array}{l}226 / 408 \\
(55,4 \%)\end{array}$ & $\begin{array}{l}\text { RR 1,26 }(1,05 \\
\text { a } 1,52)\end{array}$ & $\begin{array}{l}144 \text { más por } 1000 \text { (de } \\
28 \text { a } 288 \text { más) }\end{array}$ & $\begin{array}{l}\oplus \oplus \mathrm{OO} \\
\text { BAJA }\end{array}$ & IMPORTANTE \\
\hline & & & & & & & & $42,3 \%$ & & $\begin{array}{l}110 \text { más por } 1000 \text { (de } \\
21 \text { a } 220 \text { más) }\end{array}$ & & \\
\hline Lactancia & materna es & clusiva a lo & s 4 meses & & & & & & & & & \\
\hline $3^{12}$ & ECAs & Serio ${ }^{13}$ & No serio & Serio ${ }^{14}$ & No serio & Poco probable & $\begin{array}{l}100 / 141 \\
(70,9 \%)\end{array}$ & $\begin{array}{l}67 / 145 \\
(46,2 \%)\end{array}$ & $\begin{array}{l}\text { RR 1,58 (1,14 } \\
\text { a 2,2) }\end{array}$ & $\begin{array}{l}268 \text { más por } 1000 \text { (de } \\
65 \text { a } 554 \text { más) }\end{array}$ & $\begin{array}{l}\oplus \oplus \mathrm{OO} \\
\mathrm{BAJA}\end{array}$ & IMPORTANTE \\
\hline
\end{tabular}




\begin{tabular}{|c|c|c|c|c|c|c|c|c|c|c|c|c|}
\hline & & & & & & & & $33,5 \%$ & & $\begin{array}{l}194 \text { más por } 1000 \text { (de } \\
47 \text { a } 402 \text { más) }\end{array}$ & & \\
\hline \multicolumn{13}{|c|}{ Molestias en las mamas al 3er día (mejor valores bajos) } \\
\hline 115 & ECAs & Serio ${ }^{16}$ & No serio & No serio & No serio & Poco probable & 28 & 28 & - & $\begin{array}{l}\text { DM 0,8 menos ( } 1,46 \text { a } \\
0,14 \text { menos) }\end{array}$ & $\begin{array}{c}\oplus \oplus \oplus \oplus \mathrm{O} \\
\text { MODERADA }\end{array}$ & CRITICA \\
\hline \multicolumn{13}{|c|}{ Molestias en las mamas ( $\%$ de madres) días $0-3$ (mejor valores bajos) } \\
\hline \multirow[t]{2}{*}{$11^{17}$} & ECA & No serio & No serio & No serio & No serio & Probable $^{18}$ & $\begin{array}{l}11 / 50 \\
(22 \%) \\
\end{array}$ & $\begin{array}{l}22 / 50 \\
(44 \%)\end{array}$ & \begin{tabular}{|l} 
RR $0,50(0,27$ \\
a 0,92$)$
\end{tabular} & $\begin{array}{l}220 \text { menos por } 1000 \\
\text { (de } 35 \text { a } 321 \text { menos) }\end{array}$ & $\begin{array}{c}\oplus \oplus \mathrm{OO} \\
\text { MODERADA }\end{array}$ & CRITICA \\
\hline & & & & & & & & $44 \%$ & & $\begin{array}{l}220 \text { menos por mil } \\
\text { (de } 35 \text { a } 321 \text { menos) }\end{array}$ & & \\
\hline \multicolumn{13}{|c|}{ Variación del peso (gr.) del bebé $48 \mathrm{~h}$. (mejor valores bajos) } \\
\hline 119 & ECA & No serio & No serio & No serio & No serio & Probable 20 & 20 & 21 & - & $\begin{array}{l}\text { DM } 54 \text { menos (de } \\
266,32 \text { menos a } 158,32 \\
\text { más) }\end{array}$ & $\mid \begin{array}{c}\oplus \oplus \oplus \mathrm{O} \\
\text { MODERADA }\end{array}$ & CRITICA \\
\hline \multicolumn{13}{|c|}{ Satisfacción materna con el cuidado recibido } \\
\hline \multirow[t]{2}{*}{121} & \multirow[t]{2}{*}{ ECA } & \multirow[t]{2}{*}{ Serio 22} & \multirow[t]{2}{*}{ No serio } & \multirow[t]{2}{*}{ No serio } & \multirow[t]{2}{*}{ No serio } & \multirow[t]{2}{*}{ Poco probable } & $\begin{array}{l}105 / 120 \\
(87,5 \%) \\
\end{array}$ & $\begin{array}{l}41 / 120 \\
(34,2 \%)\end{array}$ & \multirow[t]{2}{*}{$\begin{array}{l}\text { RR } 2,54(1,96 \\
\text { a } 3,28)\end{array}$} & $\begin{array}{l}526 \text { más por } 1000 \text { (de } \\
328 \text { a } 779 \text { más) }\end{array}$ & \multirow[t]{2}{*}{$\begin{array}{c}\oplus \oplus \oplus \mathrm{O} \\
\text { MODERADA }\end{array}$} & \multirow[t]{2}{*}{ CRITICA } \\
\hline & & & & & & & & $33,1 \%$ & & $\begin{array}{l}510 \text { más por } 1000 \text { (de } \\
318 \text { a } 755 \text { más) }\end{array}$ & & \\
\hline \multicolumn{13}{|c|}{ Preferencia materna en el futuro por el mismo cuidado recibido } \\
\hline \multirow[t]{2}{*}{223} & \multirow[t]{2}{*}{ ECAs } & \multirow[t]{2}{*}{ Serio 24} & \multirow[t]{2}{*}{ No serio } & \multirow[t]{2}{*}{ No serio } & \multirow[t]{2}{*}{ No serio } & \multirow[t]{2}{*}{ Poco probable } & $\begin{array}{l}151 / 177 \\
(85,3 \%) \\
\end{array}$ & $\begin{array}{l}49 / 182 \\
(26,9 \%) \\
\end{array}$ & \multirow{2}{*}{$\begin{array}{l}\text { RR } 3,15(2,37 \\
\text { a 4,17) }\end{array}$} & $\begin{array}{l}579 \text { más por } 1000 \text { (de } \\
369 \text { a } 853 \text { más) }\end{array}$ & \multirow[t]{2}{*}{$\begin{array}{c}\oplus \oplus \oplus \mathrm{O} \\
\text { MODERADA }\end{array}$} & \multirow[t]{2}{*}{ CRITICA } \\
\hline & & & & & & & & $26,5 \%$ & & $\begin{array}{l}570 \text { más por } 1000 \text { (de } \\
363 \text { a } 840 \text { más) }\end{array}$ & & \\
\hline \multicolumn{13}{|c|}{ Seguridad (todos los EALs (primeras 24 horas de vida) } \\
\hline \multirow[t]{2}{*}{625} & \multirow[t]{2}{*}{$\begin{array}{l}\text { Series de } \\
\text { casos }\end{array}$} & \multirow[t]{2}{*}{ Serio 26} & \multirow[t]{2}{*}{ Serio 27} & \multirow[t]{2}{*}{ Serio } & \multirow[t]{2}{*}{ Serio } & Serio 28 & $\begin{array}{l}60 / 103 \\
(58,3 \%) \\
\end{array}$ & $\begin{array}{l}43 / 103 \\
(41,7 \%) \\
\end{array}$ & $\begin{array}{l}\text { OR } 1,82 \\
(1,08 \text { a } 3,06)\end{array}$ & $\begin{array}{l}149 \text { más por } 1000 \text { (de } \\
19 \text { a } 269 \text { más) }\end{array}$ & $\begin{array}{c}\oplus \mathrm{OOO} \\
\text { MUY BAJA }\end{array}$ & IMPORTANTE \\
\hline & & & & & & & & $35,9 \%$ & & $\begin{array}{l}146 \text { más por } 1000 \text { (de } \\
18 \text { a } 273 \text { más) }\end{array}$ & & \\
\hline Seg & (todos los & EALs (pri & eras 2 hol & da) & & & & & & & & \\
\hline $2^{29}$ & $\begin{array}{l}\text { Series de } \\
\text { casos }\end{array}$ & Serio $^{30}$ & Serio & Serio & Serio & Serio $^{31}$ & $\begin{array}{l}10 / 10 \\
(100 \%) \\
\end{array}$ & $\begin{array}{l}0 / 10 \\
(0 \%)\end{array}$ & $\begin{array}{l}\text { OR } 91(5,2 \text { a } \\
1592,26)\end{array}$ & - & $\begin{array}{c}\oplus \mathrm{OOO} \\
\text { MUY BAJA }\end{array}$ & IMPORTANTE \\
\hline & & & & & & & & $0 \%$ & & - & & \\
\hline
\end{tabular}

${ }^{1}$ Carfoot 2004, Carfoot 2005, Moore 2007, Khadivzadeh 2008, Mahmood 2011, Aghdas 2013, Girish 2013; ${ }^{2}$ Resultados en diferente dirección, alta heterogeneidad ( ${ }^{2}=87 \%$ ); ${ }^{3}$ Puede haber efecto mixtos a favor y en contra; 7 Sosa 1976b, Sosa 1976c, De Chateau 1977, Syfrett 1996, Shiau 1997, Mizuno 2004; ${ }^{8}$ Sosa 1976b, Sosa 1976c, De Chateau 1977, Carlsson 1978, Syfrett 1996, Shiau 1997, Thompson 1979, Carfoot 2004, Carfoot 2005, Vaidya 2005, Nolan 2009, Mahmood 2011, Thukral 2012; ${ }^{2}$ Estudios con alto riesgo de sesgo, ver risk of bias; ${ }^{10}$ Resultados mixtos que muestran diferencias a favor y no diferencias, N muy pequeña en la mayoría de los estudios: ${ }^{11} \mathrm{Los}$ datos provienen de estudios que miden duración de la lactancia entre 1 y 4 meses; ${ }^{12}$ Vaidya 2005, Gouchon 2010, Mahmood 2011; ${ }^{13} \mathrm{El}$ estudio que tiene mayor peso en el MA es de baja calidad; ${ }^{14}$ Resultados provienen de seguimientos cortos; ${ }^{15} \mathrm{Shiau} 1997 ;{ }^{16} \mathrm{Estudio}$ de calidad moderada, con posible 
sesgo de publicación de resultados; ${ }^{17}$ Girish 2013; ${ }^{18} \mathrm{No}$ explican cómo miden el "nivel de dolor"; ${ }^{19}$ Thukral 2012; ${ }^{20}$ Diferencias significativas entre los grupos pre-intervención; ${ }^{21}$ Mahmood 2011 , Nahidi 2010; ${ }^{22}$ Metodología obtención datos; ${ }^{23}$ Carfoot 2005, Mahmood 2011; ${ }^{24}$ Metodología obtención datos; ${ }^{25}$ Dageville 2008, Peters 2009, Poets 2011, Rodríguez-Alarcón 2011, Becher 2012, Pejovic 2013; ${ }^{26}$ Limitaciones propias del diseño, series de casos; ${ }^{27}$ Alta heterogeneidad entre estudios I2=84,8\%; ${ }^{28}$ En el estudio de Rodríguez-Alarcón 2011 el $75 \%$ de los casos ocurren durante la noche; ${ }^{29}$ Dageville 2008, Rodríguez-Alarcon 2011; ${ }^{30}$ Limitaciones propias del diseño, series de casos, N muy pequeña; ${ }^{31}$ En el estudio de Rodríguez-Alarcón 2011 el $75 \%$ de los casos ocurren durante la noche

\section{Subgrupo parto por cesarea (20/01/2015)}

Comparación: CPP temprano vs. cuidados habituales tras parto por cesárea

Bibliografía: Gouchon S 2010; Nolan A, 2009; Beiranvand S, 2014.

\begin{tabular}{|c|c|c|c|c|c|c|c|c|c|c|c|c|}
\hline \multicolumn{7}{|c|}{ Calidad de la evidencia } & \multicolumn{2}{|c|}{ No of patients } & \multicolumn{2}{|r|}{ Efecto } & \multirow{2}{*}{ Calidad } & \multirow{2}{*}{ Importancia } \\
\hline $\begin{array}{c}\mathrm{N}^{\circ} \text { de } \\
\text { estudios }\end{array}$ & Diseño & $\begin{array}{c}\text { Riesgo de } \\
\text { sesgo }\end{array}$ & Inconsistencia & $\begin{array}{l}\text { Evidencia } \\
\text { indirecta }\end{array}$ & Imprecisión & \begin{tabular}{|c|} 
Otras \\
consideraciones
\end{tabular} & $\begin{array}{c}\text { CPP } \\
\text { temprano }\end{array}$ & $\begin{array}{l}\text { Cuidados } \\
\text { habituales }\end{array}$ & $\begin{array}{l}\text { Relativo } \\
\text { (IC 95\%) }\end{array}$ & Absoluto & & \\
\hline \multicolumn{13}{|c|}{ Primera toma correcta (IBAT) } \\
\hline $2^{1,2}$ & ECA & No serio & No serio & No serio & Serio $^{3}$ & Ninguna & 65 & 65 & - & $\begin{array}{l}\text { DM 1,37 más (de 0,15 } \\
\text { menos a 2,59 más) }\end{array}$ & $\begin{array}{c}\oplus \oplus \oplus \oplus \mathrm{O} \\
\text { MODERADA }\end{array}$ & Crítica \\
\hline \multicolumn{13}{|c|}{ LME al alta } \\
\hline \multirow[t]{2}{*}{11} & \multirow[t]{2}{*}{ ECA } & \multirow[t]{2}{*}{ No serio } & \multirow[t]{2}{*}{ No serio } & \multirow[t]{2}{*}{ No serio } & \multirow[t]{2}{*}{ Serio $^{4}$} & \multirow[t]{2}{*}{ Ninguna } & $\begin{array}{l}9 / 17 \\
(52,9 \%) \\
\end{array}$ & $\begin{array}{l}9 / 17 \\
(52,9 \%) \\
\end{array}$ & \multirow[t]{2}{*}{$\begin{array}{l}\text { RR 1 } 1(0,53 \text { a } \\
1,88)\end{array}$} & $\begin{array}{l}0 \text { menos por } 1000 \text { (de } 249 \\
\text { menos a } 466 \text { más) }\end{array}$ & \multirow[t]{2}{*}{$\begin{array}{c}\oplus \oplus \oplus \mathrm{O} \\
\text { MODERADA }\end{array}$} & \multirow[t]{2}{*}{ Crítica } \\
\hline & & & & & & & & $52,9 \%$ & & $\begin{array}{l}0 \text { menos por } 1000 \text { (de } 249 \\
\text { menos a } 466 \text { más) }\end{array}$ & & \\
\hline \multicolumn{13}{|l|}{ LM al alta } \\
\hline \multirow[t]{2}{*}{15} & \multirow[t]{2}{*}{ ECA } & \multirow[t]{2}{*}{ No serio } & \multirow[t]{2}{*}{ No serio } & \multirow[t]{2}{*}{ No serio } & \multirow[t]{2}{*}{ Serio $^{6}$} & \multirow[t]{2}{*}{ Ninguna } & $\begin{array}{l}19 / 25 \\
(76 \%) \\
\end{array}$ & $\begin{array}{l}13 / 25 \\
(52 \%)\end{array}$ & \multirow{2}{*}{$\begin{array}{l}\text { RR 1,46 }(0,94 \\
\text { a 2,26) }\end{array}$} & $\begin{array}{l}239 \text { más per } 1000 \text { (de } 31 \\
\text { menos a } 655 \text { más) }\end{array}$ & \multirow[t]{2}{*}{$\begin{array}{c}\oplus \oplus \oplus \mathrm{O} \\
\text { MODERADA }\end{array}$} & \multirow[t]{2}{*}{ Importante } \\
\hline & & & & & & & & $52 \%$ & & $\begin{array}{l}239 \text { más per } 1000 \text { (de } 31 \\
\text { menos a } 655 \text { más) }\end{array}$ & & \\
\hline \multicolumn{13}{|c|}{ LME a los 3 meses } \\
\hline \multirow[t]{2}{*}{11} & \multirow[t]{2}{*}{ ECA } & \multirow[t]{2}{*}{ No serio } & \multirow[t]{2}{*}{ No serio } & \multirow[t]{2}{*}{ No serio } & \multirow[t]{2}{*}{ Serio $^{7}$} & Ninguna & $\begin{array}{l}8 / 17 \\
(47,1 \%)\end{array}$ & $\begin{array}{l}5 / 17 \\
(29,4 \%)\end{array}$ & \begin{tabular}{|l|}
$\operatorname{RR} 1,6(0,66 a$ \\
$3,91)$
\end{tabular} & $\begin{array}{l}176 \text { más por } 1000 \text { (de } 100 \\
\text { menos a } 856 \text { más) }\end{array}$ & $\begin{array}{c}\oplus \oplus \oplus \mathrm{O} \\
\text { MODERADA }\end{array}$ & Importante \\
\hline & & & & & & & & $29,4 \%$ & & $\begin{array}{l}176 \text { más por } 1000 \text { (de } 100 \\
\text { menos a } 856 \text { más) }\end{array}$ & & \\
\hline LM 1-3 me & ses & & & & & & & & & & & \\
\hline $2^{1,5}$ & ECA & No serio & No serio & No serio & No serio & Ninguna & \begin{tabular}{|l|}
$27 / 42$ \\
$(64,3 \%)$ \\
\end{tabular} & \begin{tabular}{|l}
$16 / 42$ \\
$(38,1 \%)$ \\
\end{tabular} & \begin{tabular}{|l|} 
RR 1,64 (1,05 \\
a 2,56)
\end{tabular} & $\begin{array}{l}244 \text { más por } 1000 \text { (de } 19 \\
\text { más a } 594 \text { más) }\end{array}$ & $\begin{array}{l}\oplus \oplus \oplus \oplus \\
\text { ALTA }\end{array}$ & Importante \\
\hline & & & & & & & & $39,5 \%$ & & $\begin{array}{l}253 \text { más por } 1000 \text { (de } 20 \\
\text { más a } 616 \text { más) }\end{array}$ & & \\
\hline
\end{tabular}




\begin{tabular}{|c|c|c|c|c|c|c|c|c|c|c|c|}
\hline$\sqrt{11}$ & ECA & No serio & No serio & No serio & No serio & Ninguna & 17 & 17 & $\begin{array}{l}\text { DM } 15 \text { más (de } 9,81 \text { a } \\
39,81)\end{array}$ & $\begin{array}{c}\oplus \oplus \oplus \oplus \\
\text { ALTA }\end{array}$ & Crítica \\
\hline \multicolumn{12}{|c|}{ Satisfacción materna } \\
\hline$\sqrt{12}$ & ECA & No serio & No serio & No serio & $\begin{array}{l}\text { No } \\
\text { calculable }\end{array}$ & Otros $^{8}$ & & & Ver resumen de evidencia & $\begin{array}{c}\oplus \oplus \mathrm{OO} \\
\text { BAJA }\end{array}$ & Critica \\
\hline
\end{tabular}

${ }^{1}$ Gouchon 2010; ${ }^{2}$ Beiranvand $2014 ;{ }^{3}$ IC cruza la linea de no efecto; ${ }^{4}$ IC cruza la linea de no efecto; ${ }^{5}$ Nolan $2009 ;{ }^{6}$ IC cruza la linea de no efecto; ${ }^{7}$ IC cruza la linea de no efecto; ${ }^{8}$ Se ofrecen unicamente resultados narrativos 


\subsection{Resumen de la evidencia}

\begin{abstract}
Recién nacidos por parto vaginal
En la revisión Cochrane de Moore (1) se incluyen 19 ECA sobre el efecto del contacto piel con piel tras el parto. Los dos estudios llevado a cabo en cesáreas electivas $(19 ; 20)$ se han eliminado del primer análisis para estudiarlos por separado, ya que es sabido que, en general, los índices de lactancia materna de los recién nacidos por cesárea son inferiores a los de los nacidos por parto vaginal. Un tercer estudio (21) también ha sido excluido por contribuir a una alta heterogeneidad en los resultados. Además, en la búsqueda de estudios individuales se han identificado cinco ECA posteriores a la revisión (22-26)) y cuyos resultados se han incluido en el análisis.
\end{abstract}

En relación a la realización de una primera toma correcta (puntuación The infant breastfeeding assessment tool (IBFAT) de 10-12 o del Breastfeeding Assessment Tool (BAT) de 8-12), los resultados de 7 estudios $(n=687) \quad(9 ; 23 ; 25-29) \quad$ muestran que hay diferencias significativas entre los recién nacidos que realizaron CPP tras el parto frente a los que recibieron cuidados habituales [RR 1,3 (IC95\%1,18 a $1,44)]$. Al mismo tiempo la tasa de lactancia materna exclusiva al alta (2 estudios, $N=75)(19 ; 24)$ fue significativamente más alta entre las madres que realizaron CPP [RR 1,69 (IC95\% 1,13 a 2,54)]. Sin embargo, no se encontraron diferencias significativas en el peso del recién nacido a las 48 horas (1 estudio, $N=41)(24)(D M-54$; IC95\% de $-266,32$ a 158,32$)$.

Los resultados de seis estudios ( $\mathrm{N}=264)(21 ; 30-33)$ muestran que la realización de CPP inmediato tras el parto también es beneficiosa para la duración de la lactancia materna, encontrándose diferencias significativas entre las madres que realizaron CPP precoz y las que no lo hicieron (DM 63,73; IC95\% de 37,96 a 89,90).

La tasa de lactancia materna a los cuatro meses (13 estudios, $N=820$ ) $(20 ; 21 ; 23 ; 24 ; 27 ; 28 ; 30-32 ; 34-36)$ fue significativamente mayor en el grupo que realizó CPP (RR 1,22; IC95\% de 1,04 a 1,42) y, en particular, la proporción de lactantes con lactancia materna exclusiva a los cuatro meses (3 estudios, $N=286) \quad(19 ; 23 ; 36)$ también fue significativamente más alta en el grupo que realizó CPP $(R R$ 1,56; IC95\% de 1,19 a 2,04).

Las madres del grupo que realizó CPP refirieron significativamente menos molestias en las mamas a las 48-72 horas. En un estudio $(\mathrm{N}=56)$ (32) las mujeres que realizaron CPP obtuvieron una menor puntuación en la percepción de tensión o dureza en sus pechos que las que recibieron cuidados habituales [DM -0,8 (IC95\% -1,46 a -0,14)]. Así mismo, en otro estudio ( $N=100)(26)$ un menor porcentaje de madres en el grupo CPP manifestaron molestias en las mamas [RR 0,5 (IC95\% 0,27 a 0,92)]. Además estas mujeres manifestaron mayor satisfacción materna en relación a la atención posparto recibida ( 2 estudios, $\mathrm{N}=240$ ) $(22 ; 23)$ (RR 2,54; IC95\% de 1,96 a 3,28), así como su preferencia por el mismo tipo de atención en un futuro parto (2 estudios, $N=359)(23 ; 28)$
Calidad moderada

\section{Calidad baja}

Calidad moderada

\section{Calidad alta \\ Calidad baja \\ Calidad baja}

\section{Calidad moderada}

Calidad moderada 
(RR 3,15; IC95\% de 2,37 a 4,17

Por otro lado, se realizó una búsqueda específica para clarificar la posible relación entre la aparición de episodios aparentemente letales (EALs) y muerte súbita durante la realización del CPP. Se localizó una revisión (2) sobre la ocurrencia de EAL en los primeros días de vida del recién nacido y los factores de riesgo. Esta revisión se ha utilizado para identificar los estudios que evalúan la ocurrencia de EALs durante las primeras 24 horas de vida y su relación con el CPP (37-41). Además se ha localizado otro estudio de series de casos (42) publicado posteriormente. Los resultados muestran que la incidencia de este tipo de episodios es baja, de 0,061 casos por 1.000 nacimientos durante las primeras 24 horas tras el nacimiento, si bien los autores coinciden en señalar que es probable que haya casos menos graves que no son registrados si los recién nacidos se recuperaron sin secuelas. El análisis combinado de los estudios indica que el CPP parece ser un factor de riesgo para este este tipo de eventos [OR 1,82 (IC95\% 1,08 a 3,06)], aunque la alta heterogeneidad de los estudios y la naturaleza de los mismos (series de casos) no permite establecer conclusiones firmes. Todos los autores concluyeron que teniendo en cuenta los beneficios claros del CPP para la madre y el recién nacido y que la incidencia de estos eventos es muy baja debe mantenerse la recomendación, pero es necesario supervisar al recién nacido durante el tiempo que dura el CPP en el periodo postnatal inmediato, bien sea por un profesional, por la madre o por un acompañante. Para ello es importante que éstos sepan reconocer los signos de alerta: tono, coloración de la piel, respiración.

\section{Recién nacidos por cesárea}

De la RS de Moore (1) se han seleccionado los dos ECA que fueron llevados a cabo en cesáreas electivas $(19 ; 20)$. Estos dos estudios se incluyen también en la revisión más reciente (18), de la cual no se ha seleccionado ningún estudio adicional ya que no se trataban de ensayos clínicos. Posteriormente a esta revisión se ha localizado un estudio adicional (43). En los tres casos el contacto piel con piel se realizó en el postoperatorio. De hecho, los resultados pueden estar influidos por el tiempo transcurrido y las acciones realizadas entre el nacimiento y el inicio del contacto piel con piel, sobre todo en el estudio de Gouchon en el que antes del CPP se bañó incluso a los niños .(44)

Los resultados de dos ECA $(19 ; 43)$ con 130 recién nacidos sanos a término nacidos por cesárea muestran que aquellos que reciben CPP realizan una mejor primera toma que los que reciben cuidados habituales [(MD 1,37 en puntuación IBAT (IC95\% 0,15 a 2,59)]. No obstante en un estudio (19) $(n=34)$ no se encontraron diferencias significativas en relación a la tasa de lactancia materna exclusiva al alta entre los recién nacidos que realizaron CPP y los que no [RR 1 (IC95\% 0,53 a 1,88)]. De modo similar, en otro ensayo $(20)(n=50)$ tampoco se encontraron diferencias en relación a la tasa de lactancia materna al alta (cualquier tipo) entre los recién nacidos que recibieron CPP precoz y los que recibieron cuidados habituales (RR 1,46; IC95\%

Calidad moderada

\section{Calidad alta}

Calidad moderada de 0,94 a 2,26). 
Según los datos de un ECA (19) $(n=34)$ la tasa de lactancia materna exclusiva a los 3 meses fue más alta en el grupo de recién nacidos que recibió CPP, aunque las diferencias no fueron significativas ( $R R$ 1,6 ; IC95\% de 0,66 a 3,91). Por el contrario, la tasa de lactancia materna al primer-tercer mes (cualquier tipo) $(19 ; 20)$ (2 estudios, $n=84$ ) fue significativamente mayor en el grupo de recién nacidos que realizó CPP frente al que recibió cuidados habituales [RR 1,64 (IC95\% 1,05 a 2,56)]. En conjunto, la duración de la lactancia materna (cualquier tipo) (19) (1 estudio, $n=34$ ) resultó ser significativamente más larga entre los recién nacidos que realizaron CPP (DM 15 días; IC95\% de 9,81 a 39,81).

Por otro lado, (43) $(n=96)$ la mayoría de las madres mostraron satisfacción con el contacto piel con piel (no hay datos).

Calidad
moderada
$\begin{gathered}\text { Calidad } \\ \text { alta }\end{gathered}$
$\begin{gathered}\text { Calidad } \\ \text { alta }\end{gathered}$
$\begin{gathered}\text { Calidad } \\ \text { baja }\end{gathered}$

ACTUALIZADO A FECHA DE: 31 de Octubre de 2016 


\section{5- De la evidencia a la recomendación (Tabla de EtR)}

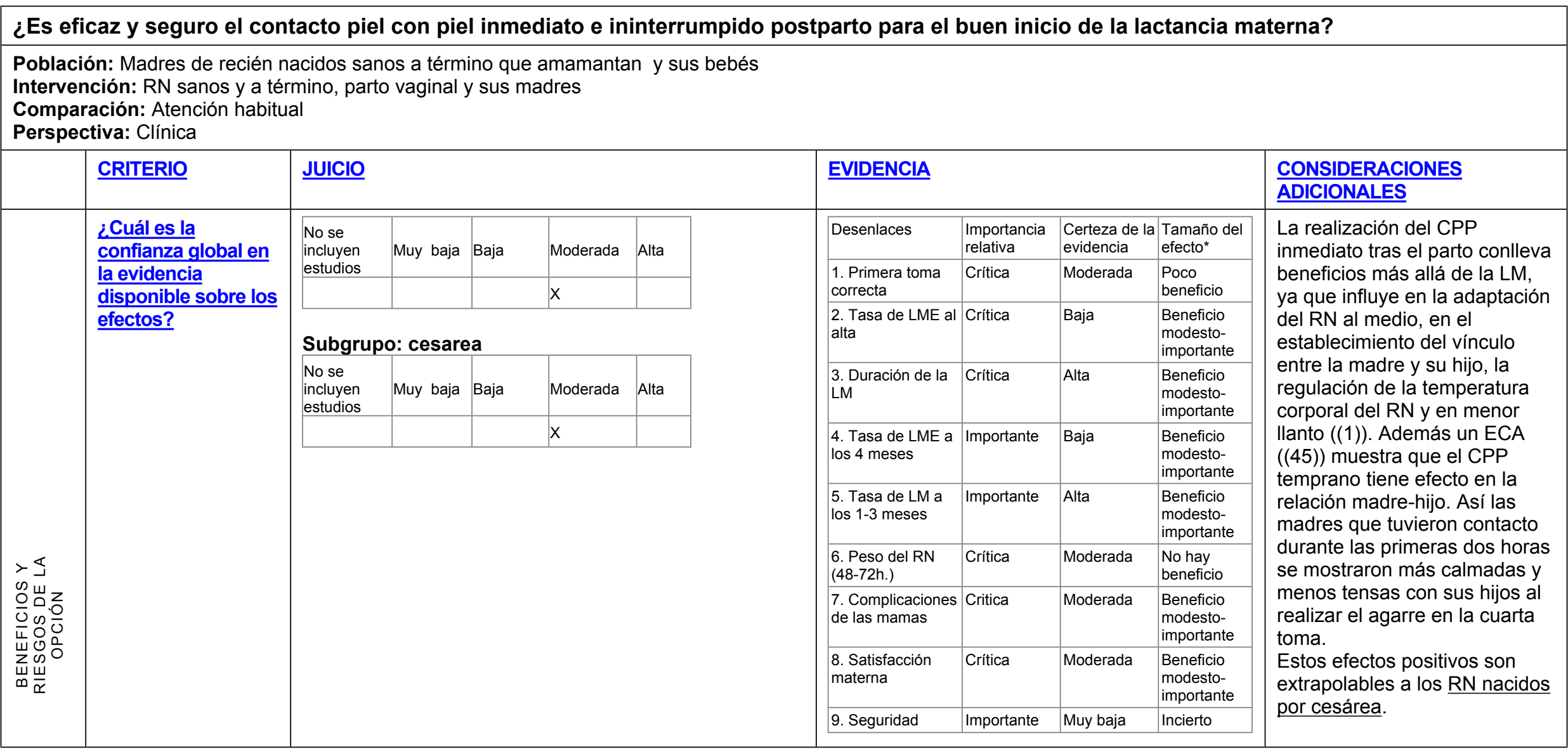




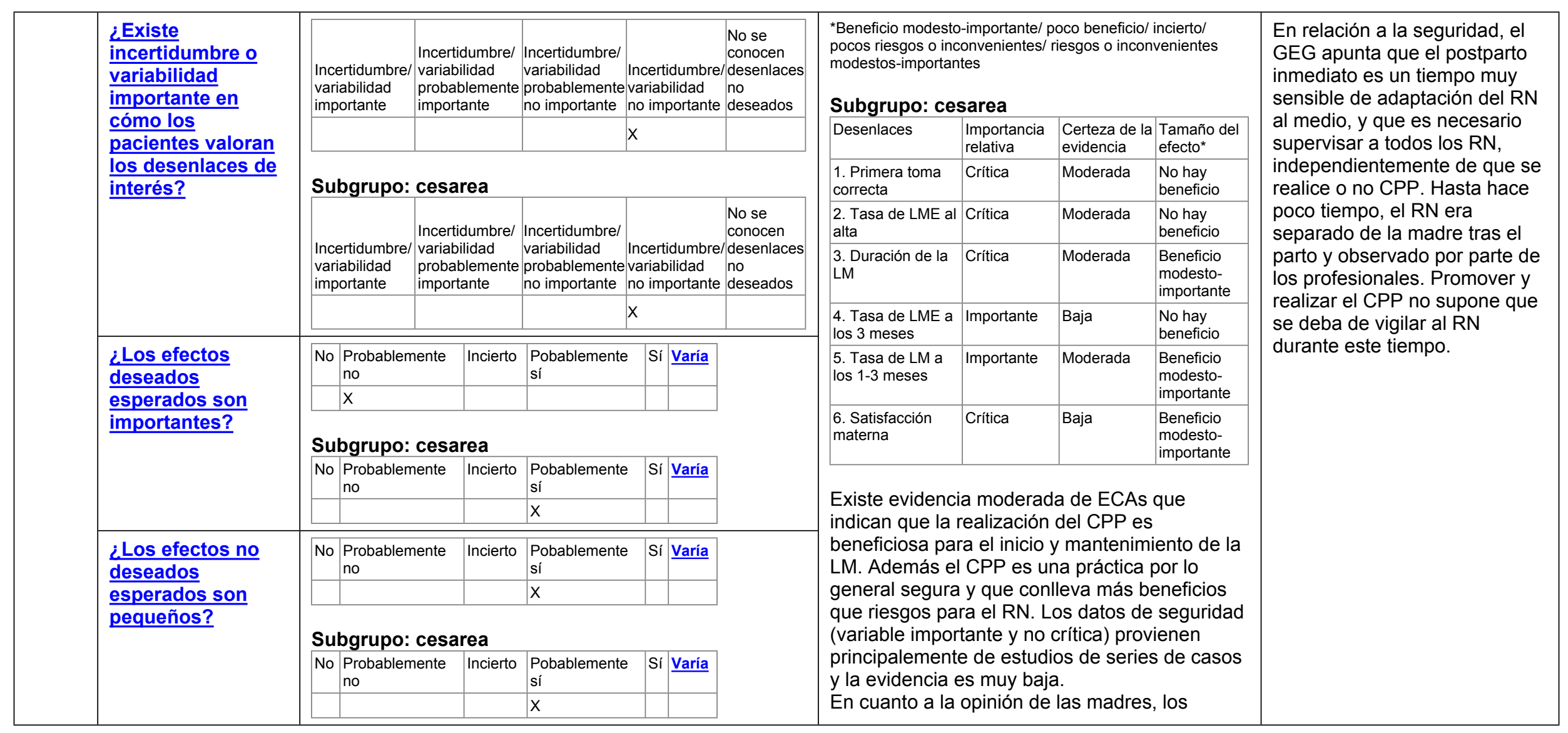




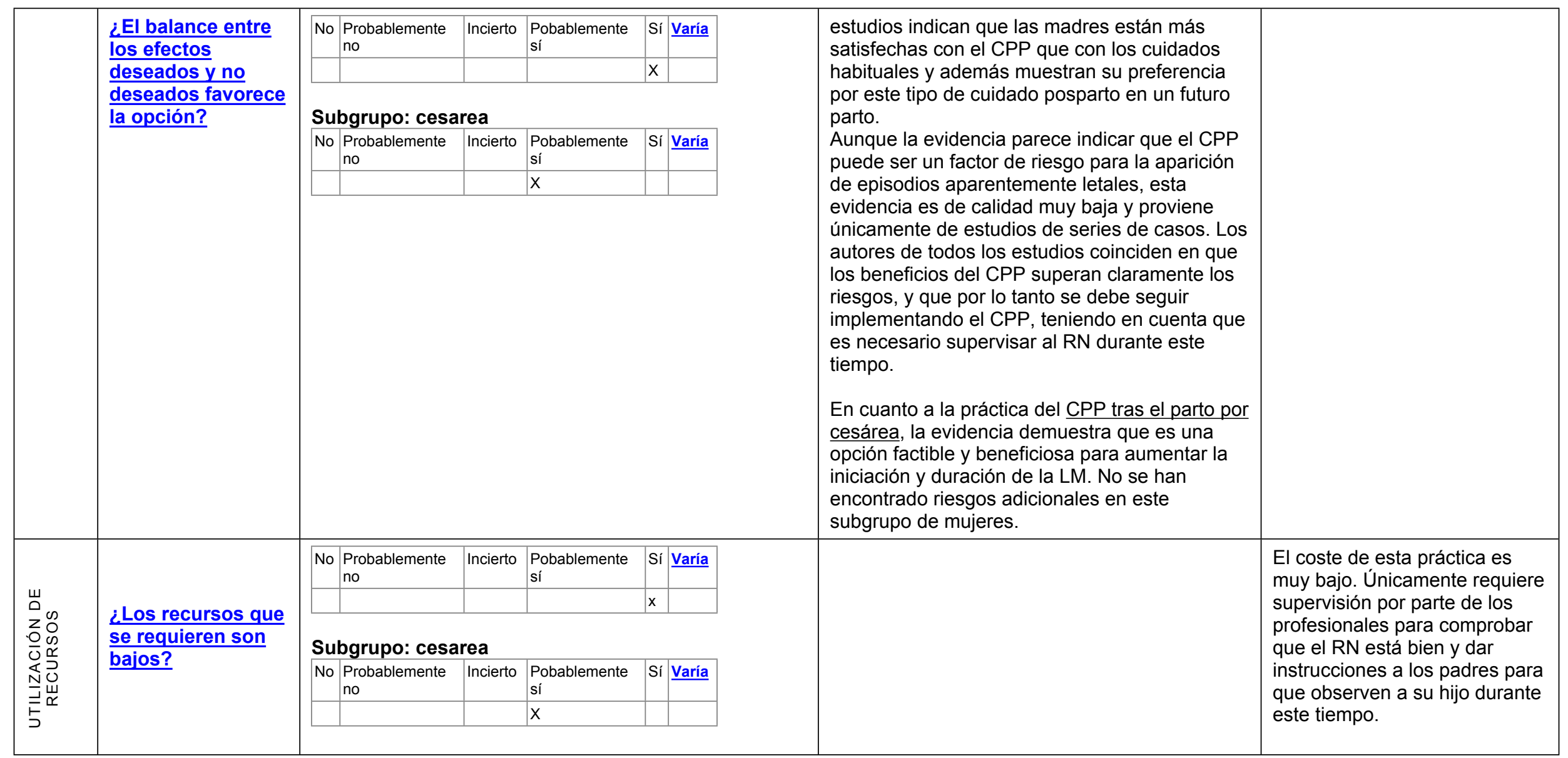




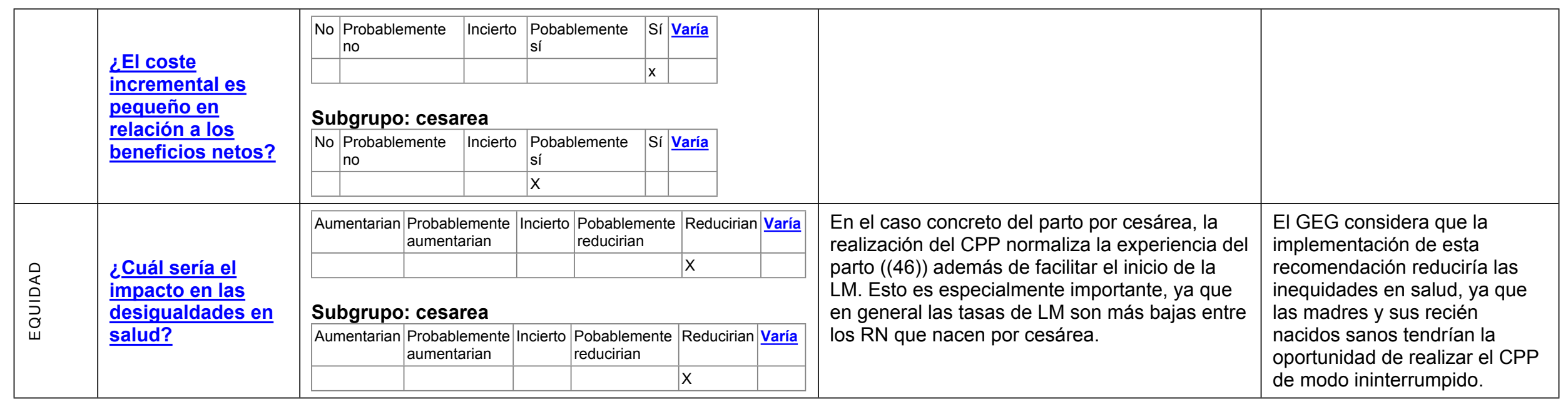




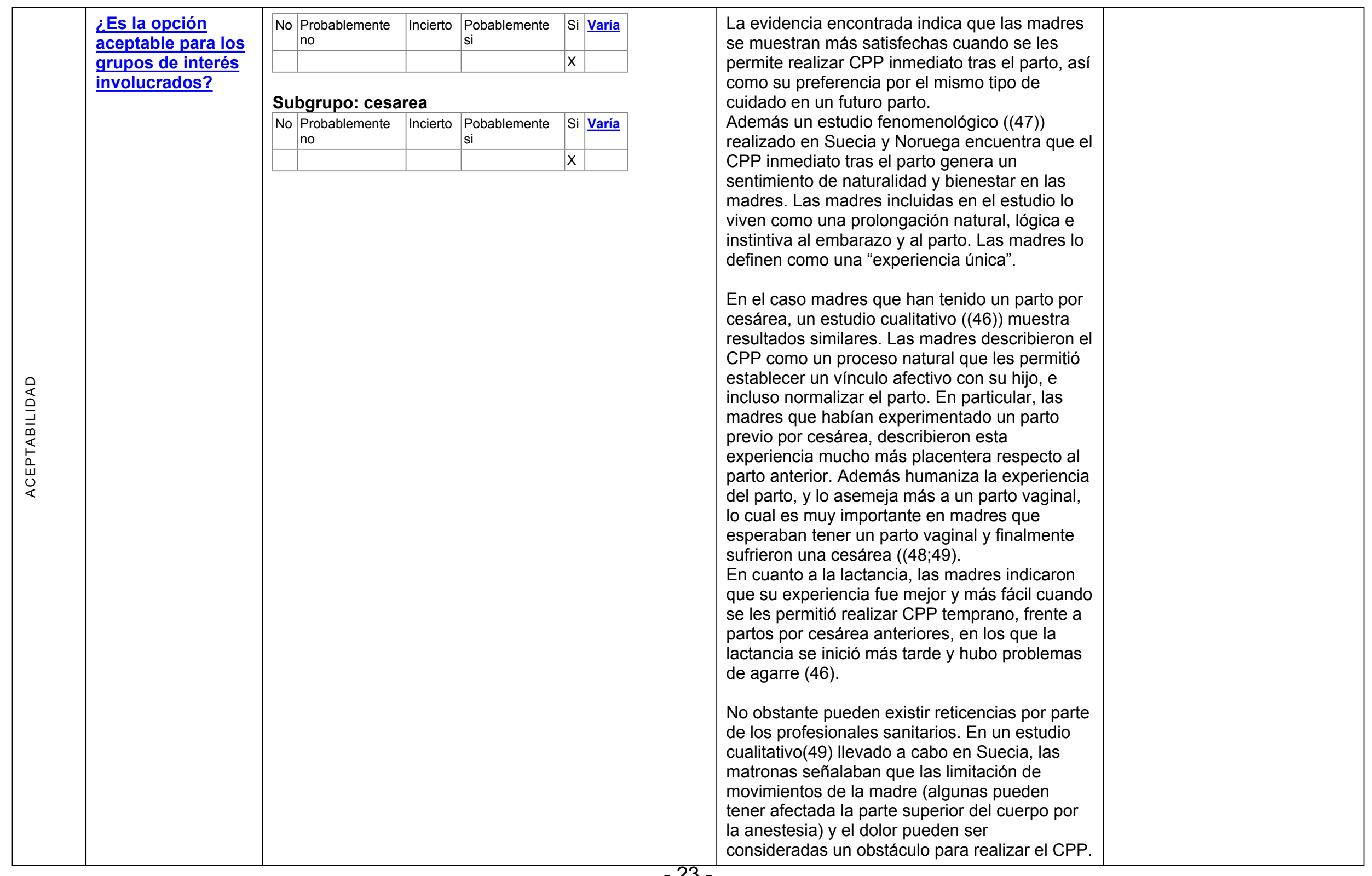




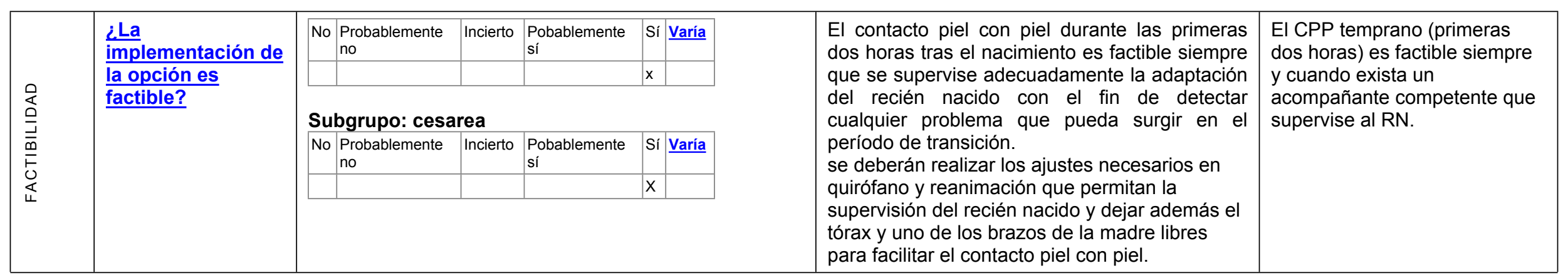

\begin{tabular}{|c|c|c|c|c|c|c|c|c|}
\hline $\begin{array}{l}\text { Balance de las } \\
\text { consecuencias }\end{array}$ & $\begin{array}{l}\text { Las consecuencias no } \\
\text { deseadas superan } \\
\text { claramente las } \\
\text { consecuencias } \\
\text { deseadas en la mayoría } \\
\text { de los escenarios }\end{array}$ & \multicolumn{2}{|c|}{$\begin{array}{l}\text { Las consecuencias no } \\
\text { deseadas } \\
\text { probablemente superan } \\
\text { las consecuencias } \\
\text { deseadas en la mayoría } \\
\text { de los escenarios }\end{array}$} & \multicolumn{2}{|c|}{$\begin{array}{l}\text { El balance entre las } \\
\text { consecuencias } \\
\text { deseadas y no } \\
\text { deseadas está muy } \\
\text { equilibrado o es incierto }\end{array}$} & \multicolumn{2}{|c|}{$\begin{array}{l}\text { Las consecuencias } \\
\text { deseadas } \\
\text { probablemente superan } \\
\text { las consecuencias no } \\
\text { deseadas en la } \\
\text { mayoría de los } \\
\text { escenarios }\end{array}$} & $\begin{array}{l}\text { Las consecuencias } \\
\text { deseadas claramente } \\
\text { superan las } \\
\text { consecuencias no } \\
\text { deseadas en la } \\
\text { mayoría de los } \\
\text { escenarios }\end{array}$ \\
\hline CPP parto vaginal & & & & & & & & $x$ \\
\hline CPP cesarea & & & & & & $x$ & & \\
\hline $\begin{array}{l}\text { Tipo de } \\
\text { recomendación }\end{array}$ & \multicolumn{2}{|c|}{$\begin{array}{l}\text { Se recomienda no ofrecer la } \\
\text { opción }\end{array}$} & \multicolumn{2}{|c|}{ Se sugiere no ofrecer la opción } & \multicolumn{2}{|c|}{ Se sugiere ofrecer la opción } & \multicolumn{2}{|c|}{$\begin{array}{l}\text { Se recomienda ofrecer la } \\
\text { opción }\end{array}$} \\
\hline CPP parto vaginal & & & & & & & \multicolumn{2}{|l|}{$X$} \\
\hline CPP cesarea & & & & & & & \multicolumn{2}{|l|}{$X$} \\
\hline
\end{tabular}




\begin{tabular}{|l|l|}
\hline$\frac{\text { Recomendación }}{\text { (Texto) }}$ & $\begin{array}{l}\text { Fuerte } \\
\text { Se recomienda realizar el contacto piel con piel inmediato e ininterrumpido tras el parto, colocando al recién nacido en decúbito } \\
\text { prono, desnudo, con la cabeza ladeada sobre el abdomen y pecho desnudo de la madre durante los primeros 120 minutos tras el } \\
\text { nacimiento. Se recomienda secar suavemente la cabeza y espalda del recién nacido, pero no sus manos. Para evitar la pérdida de } \\
\text { calor se recomienda cubrirle con una manta precalentada y ponerle un gorro. El estado de la madre y del recién nacido deben ser } \\
\text { supervisados durante ese tiempo por un acompañante correctamente informado o por un profesional sanitario. } \\
\text { Fuerte } \\
\text { En recién nacidos por cesárea, se recomienda realizar el contacto piel con piel inmediato tras el parto siempre que la situación del } \\
\text { recién nacido y la madre lo permita. Los cuidados que sean necesarios se pueden realizar con el recién nacido sobre el pecho de } \\
\text { la madre. }\end{array}$ \\
\hline Justificación & $\begin{array}{l}\text { Dados los beneficios que se observan en la lactancia a corto y a largo plazo, y al hecho de que en general es una práctica segura } \\
\text { se recomienda el contacto piel con piel inmediato tras el parto. Es necesario observar al recién nacido durante la adaptación a la } \\
\text { vida extrauterina, para detectar los problemas que puedan en el periodo de transición. }\end{array}$ \\
\hline
\end{tabular}




\begin{tabular}{|c|c|}
\hline $\begin{array}{l}\text { Consideraciones de } \\
\text { subgrupos }\end{array}$ & 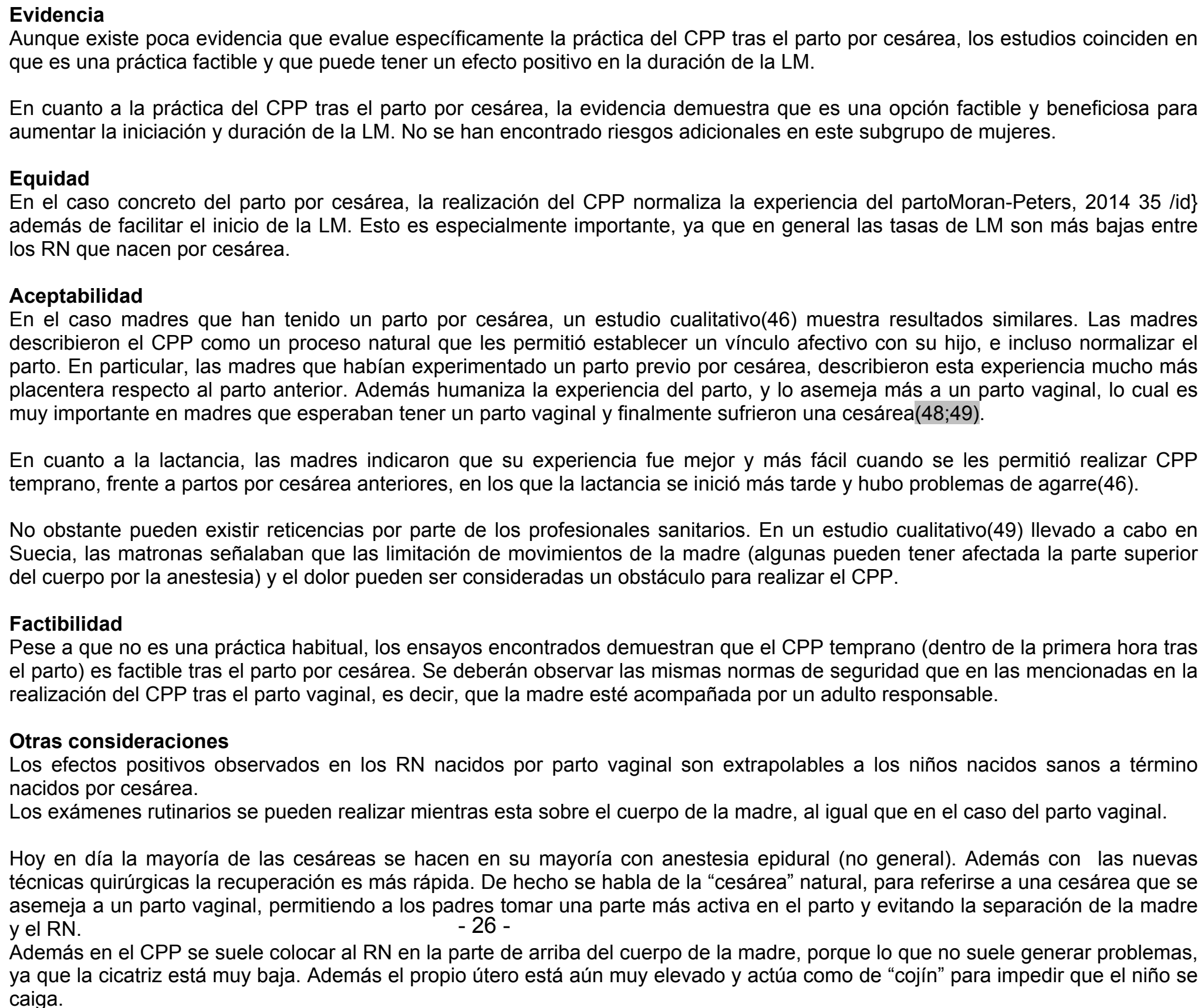 \\
\hline
\end{tabular}




\begin{tabular}{|c|c|}
\hline $\begin{array}{l}\text { Consideraciones para } \\
\text { la implementación }\end{array}$ & 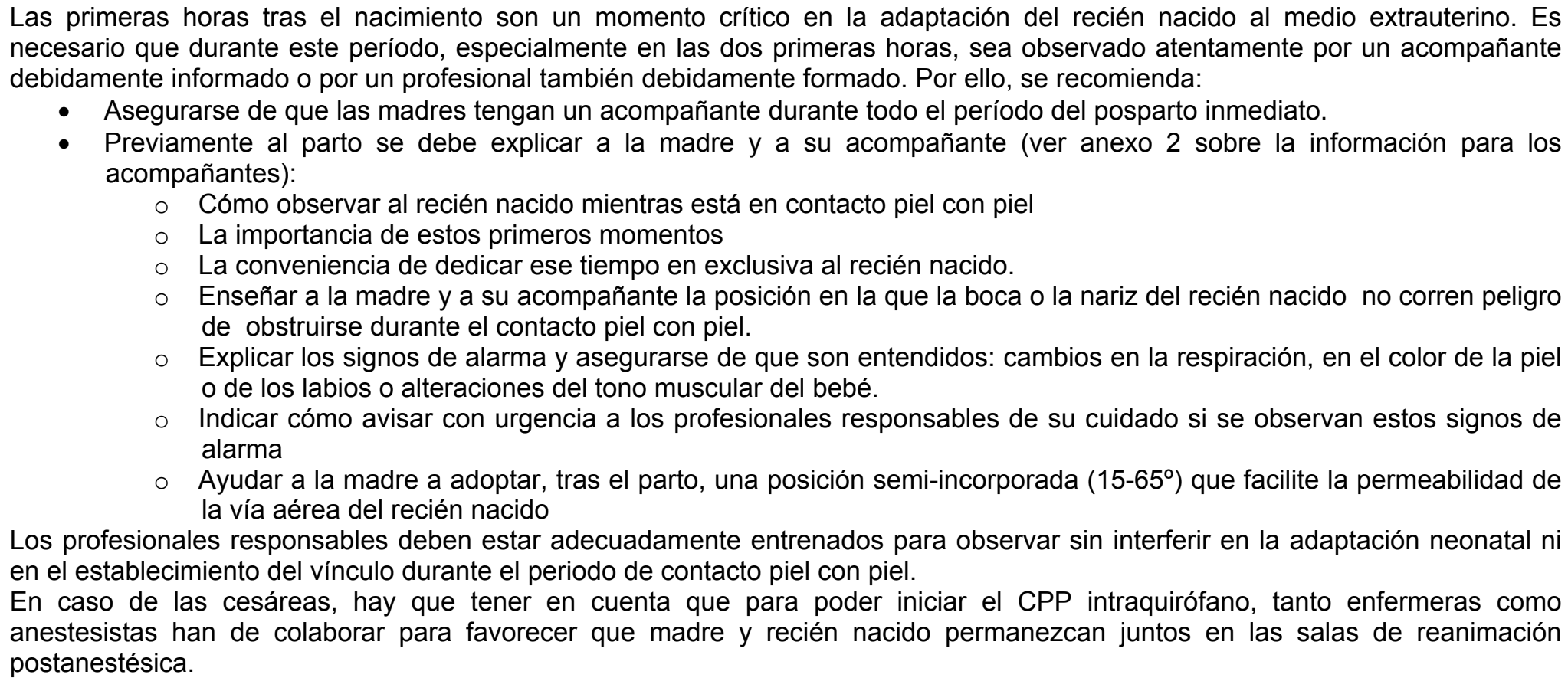 \\
\hline$\frac{\text { Prioridades para la }}{\text { investigación }}$ & - \\
\hline
\end{tabular}


GPC Lactancia Materna - pregunta 1. Contacto piel con piel

\section{ANEXOS}

Anexo I. Estrategias de búsqueda

Anexo II. Valoración de la calidad de los estudios

Anexo III. Tablas de estudios individuales

Anexo IV. Forest plots 


\section{ANEXO I. ESTRATEGIAS DE BÚSQUEDA}

\section{Cochrane Library}

Searched 14/10/2013

\section{Updated search 14/10/2013 a xx/xx/xxxx}

\#1 MeSH descriptor: [Kangaroo-Mother Care Method] explode all trees 16

\#2 "kangaroo-mother" and care and method 48

\#3 "kangaroo mother care method"

\#4 kangaroo and mother and care and method 63

\#5 "kangaroo mother care"

91

\#6 kangaroo and mother and care

\#7 "kangaroo care" 113

\#8 kangaroo and care 191

\#9 "kangaroo method" 10

\#10 Kangaroo and method 80

\#11 kangaroo and position 25

\#12 \#1 or \#2 or \#3 or \#4 or \#5 or \#6 or \#7 or \#8 or \#9 or \#10 or \#11 197

\#13 "skin-to-skin" 232

\#14 "skin to skin" 232

\#15 "skin skin" 183

\#16 "skin-skin" 183

\#17 \#13 or \#14 or $15 \# 16 \quad 272$

\#18 contact or touch 17925

\#19 MeSH descriptor: [Touch] explode all trees 564

\#20 \#18 or \#19 17925

\#21 \#17 and \#20 195

\#22 \#12 or \#21 101

CPP + Seguridad

\#1 MeSH descriptor: [Kangaroo-Mother Care Method] explode all trees 16

\#2 MeSH descriptor: [Sudden Infant Death] explode all trees 7

\#3 MeSH descriptor: [Death, Sudden] explode all trees 751

\#4 ("sudden infant death" or "sudden infant deaths") or (sudden and infant and (death or deaths)) 216

\#5 ("infant death" or "infant deaths") or (infant and (death or deaths)) 3148

\#6 MeSH descriptor: [Infantile Apparent Life-Threatening Event] explode all trees 1

\#7 "life-threatening event" or "life-threatening events" or "life threatening event" or "life threatening events" 156

\#8 "life-threatening episode" or "life-threatening episodes" or "life threatening episode" or "life threatening episodes" 8

\#9 (life and threatening) and (event or events or episode or episodes) 2105

\#10 ("neonatal sudden death" or "neonatal sudden deaths") or (neonatal and sudden and (deaths or death)) 121

$\# 11 \quad \# 2$ or \#3 or \#4 or \#5 or \#6 or \#7 or \#8 or \#9 or \#10

5745 


\begin{tabular}{|c|c|c|c|c|}
\hline \#12 & 5745 & & & \\
\hline $\begin{array}{l}\# 13 \text { and mother) } \\
\text { and }\end{array}$ & \multicolumn{4}{|c|}{$\begin{array}{l}\text { kangaroo or "kangaroo mother" or "kangaroo-mother" or (kangaroo } \\
205\end{array}$} \\
\hline \#14 & \multicolumn{2}{|c|}{ care or (method or methods) or position* } & \multirow[t]{3}{*}{473482} & \\
\hline \#15 & \#13 and \#14 & 198 & & \\
\hline \#16 & \#1 or \#15 & 198 & & \\
\hline \#17 & \multicolumn{3}{|c|}{ "skin to skin" or "skin-to-skin" or "skin skin" or "skin-skin" } & 415 \\
\hline \#18 & contact & 16305 & & \\
\hline \#19 & \#17 and \#18 & 194 & & \\
\hline \#20 & \#16 or \#19 & 332 & & \\
\hline \#21 & $\# 20$ and \#11 & 36 & & \\
\hline
\end{tabular}

\section{MEDLINE, via Pubmed}

\section{Searched 14/10/2013}

\section{Updated search 14/10/2013 a xx/xx/xxxx}

(("Kangaroo-Mother Care Method"[Mesh]) OR ("kangaroo-mother"[All fields] AND "care"[All fields] AND "method"[All fields]) OR ("kangaroo-mother care method"[All fields]) OR ("kangaroo"[All fields] AND "mother"[All fields] AND "care"[All fields] AND "method"[All fields]) OR ("kangaroo mother care"[All fields]) OR ("kangaroo care"[All fields]) OR ("kangaroo"[All fields] AND "care"[All fields]) OR ("kangaroo"[All fields] AND ("method"[All fields] OR "methods"[All fields] OR "methods"[MeSH Terms])) OR ("kangaroo"[All fields] AND "position"[All fields])) OR (("skin-to-skin"[All fields] OR "skin to skin"[All fields] OR "skin-skin"[All fields] OR "skin skin"[All fields]) AND ("contact"[All fields] OR "touch"[All fields] OR "touch"[MeSH Terms]))

\section{AND systematic[sb]}

AND (((random OR randomized OR randomised) AND (control OR controlled OR clinical) AND (trial OR trials)) OR ("randomized controlled trial"[Publication Type] OR "randomized controlled trials as topic"[MeSH Terms]))

CPP + Seguridad

((("Kangaroo-Mother Care Method"[Mesh]) OR ("kangaroo-mother"[All fields] AND "care"[All fields] AND "method"[All fields]) OR ("kangaroo-mother care method"[All fields]) OR ("kangaroo"[All fields] AND "mother"[All fields] AND "care"[All fields] AND "method"[All fields]) OR ("kangaroo mother care"[All fields]) OR ("kangaroo care"[All fields]) OR ("kangaroo"[All fields] AND "care"[All fields]) OR ("kangaroo"[All fields] AND ("method"[All fields] OR "methods"[All fields] OR "methods"[MeSH Terms])) OR ("kangaroo"[All fields] AND "position"[All fields])) OR (("skin-to-skin"[All fields] OR "skin to skin"[All fields] OR "skin-skin"[All fields] OR "skin skin"[All fields]) AND ("contact"[All fields] OR "touch"[All fields] OR "touch"[MeSH Terms]))) AND (("sudden infant death"[MeSH Terms] OR ("sudden"[All Fields] AND "infant"[All Fields] AND ("death"[All Fields] OR "deaths"[All Fields])) OR "sudden infant death"[All Fields] OR "sudden infant deaths"[All Fields]) OR ("infantile apparent life-threatening event"[MeSH Terms] OR "infantile"[All Fields] AND "apparent"[All Fields] AND "life-threatening"[All Fields] AND ("event"[All Fields] OR "events"[All Fields]) OR "infantile apparent lifethreatening event"[All Fields] OR "infantile apparent life-threatening events"[All Fields] OR ("infantile"[All Fields] AND "apparent"[All Fields] AND "life"[All Fields] AND "threatening"[All Fields] AND ("event"[All Fields] OR "events"[All Fields])) OR 
"infantile apparent life threatening event"[All Fields] OR "infantile apparent life threatening events"[All Fields] OR "life threatening event"[All Fields] OR "life threatening events"[All Fields]) OR ("life threatening episode"[All Fields] OR "life threatening episodes"[All Fields] OR "life-threatening episode"[All Fields] OR "lifethreatening episodes"[All Fields] OR "life-threatening"[All Fields] AND ("episode"[All Fields] OR "episodes"[All Fields]) OR "life" AND "threatening"[All Fields] AND ("episode"[All Fields] OR "episodes"[All Fields])) OR (neonatal[All Fields] AND ("death, sudden"[MeSH Terms] OR (("death"[All Fields] OR "deaths"[All Fields]) AND "sudden"[All Fields]) OR "sudden death"[All Fields] OR "sudden deaths"[All Fields] OR ("sudden"[All Fields] AND ("death"[All Fields] OR "deaths"[All Fields]))) OR "neonatal sudden death"[All Fields] OR "neonatal sudden deaths"[All Fields]) OR (death AND (infant[MeSH])))

\section{EMBASE, via Ovid}

\section{Searched 14/10/2013}

\section{Updated search 14/10/2013 a xx/xx/xxxx}

\section{1 kangaroo care/}

2 (kangaroo or kangaroo-mother or "kangaroo mother").mp. [mp=title, abstract, heading word, drug trade name, original title, device manufacturer, drug manufacturer, device trade name, keyword]

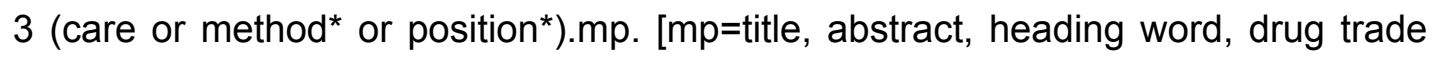
name, original title, device manufacturer, drug manufacturer, device trade name, keyword]

\section{2 and 3}

\section{1 or 4}

6 ("skin to skin" or "skin skin" or skin-to-skin or skin-skin).mp. [mp=title, abstract, heading word, drug trade name, original title, device manufacturer, drug manufacturer, device trade name, keyword]

7 (contact or touch*).mp. [mp=title, abstract, heading word, drug trade name, original title, device manufacturer, drug manufacturer, device trade name, keyword]

86 and 7

95 or 8

10 limit 9 to "systematic review"

11 controlled clinical trial/ or randomized controlled trial/

12 ((random or randomized or randomised) and (control or controlled or clinical) and (trial or trials)).mp. [mp=title, abstract, heading word, drug trade name, original title, device manufacturer, drug manufacturer, device trade name, keyword]

1311 or 12

149 and 13

\section{CPP + Seguridad}

1 kangaroo care.ti,ab,kw. 278

2 kangaroo mother care.ti, ab,kw.

3 "kangaroo mother method".ti,ab,kw. 21

4 "kangaroo mother care method*".ti,ab,kw. 15

5 kangaroo position.ti,ab,kw. 24

61 or 2 or 3 or 4 or $5 \quad 534$ 
7 (skin-to-skin or "skin to skin" or skin-skin or "skin skin").ti,ab,kw.

8 (contact or touch).ti,ab,kw. 302041

97 and 8795

106 or 91215

11 sudden infant death.ti,ab,kw. 6578

12 life threatening event.ti,ab,kw. $\quad 1164$

13 "life threatening episode*".ti,ab,kw. 298

14 sudden death.ti,ab,kw. 27332

15 limit 14 to infant <to one year> 317

16 neonatal sudden death.ti,ab,kw. 10

17 death.ti,ab,kw. $\quad 700442$

18 limit 17 to infant <to one year> $\quad 7789$

1911 or 12 or 13 or 15 or 16 or 1814604

2010 and $19 \quad 18$

CINAHL, via EBSCOhost databases

Searched 14/10/2013

Updated search 14/10/2013 a xx/xx/xxxx

S1 (MH "Kangaroo Care")

S2 kangaroo OR "kangaroo mother" OR "kangaroo-mother" OR ( kangaroo AND mother )

S3 care OR ( method OR methods ) OR position*

S4 S2 AND S3

S5 S1 OR S4

S6 "skin to skin" OR "skin-to-skin" OR "skin skin" OR "skin-skin"

S7 contact

S8 S6 AND S7

S9 S5 OR S8

S10 (MH "Randomized Controlled Trials")

S11 ( random OR randomized OR randomised ) AND ( control OR controlled OR clinical ) AND ( trial OR trials OR study OR studies )

S12 S10 OR S11

S13 S9 AND S12

S14 S9 AND S12 Limitadores - Fecha de publicación: 2011010120131231

CPP + Seguridad

S1 (MH "Kangaroo Care")

S2 kangaroo OR "kangaroo mother" OR "kangaroo-mother" OR ( kangaroo AND mother )

S3 care OR ( method OR methods ) OR position*

S4 S2 AND S3

S5 S1 OR S4

S6 "skin to skin" OR "skin-to-skin" OR "skin skin" OR "skin-skin"

S7 contact 
S8 S6 AND S7

S9 S5 OR S8

S10 (MH "Sudden Infant Death") OR (MH "Infant Death") OR (MH "Death, Sudden")

S11 ( "sudden infant death" OR "sudden infant deaths" ) OR ( sudden AND infant AND (death OR deaths))

S12 ( "infant death" OR "infant deaths" ) OR ( infant AND (death OR deaths) )

S13 (death OR deaths ) AND AG infant

S14 "life-threatening event" OR "life-threatening events" OR "life threatening event" OR "life threatening events"

S15 "life-threatening episode" OR "life-threatening episodes" OR "life threatening episode" OR "life threatening episodes"

S16 (life AND threatening ) AND ( event OR events OR episode OR episodes )

S17 ( "neonatal sudden death" OR "neonatal sudden deaths" ) OR ( neonatal AND sudden AND (deaths OR death))

S18 S10 OR S11 OR S12 OR S13 OR S14 OR S15 OR S16 OR S17

S19 S9 AND S18 


\section{ANEXO II. EVALUACIÓN DE LA CALIDAD DE LOS ESTUDIOS}

\section{Revisiones sistemáticas - AMSTAR}

\begin{tabular}{|c|c|c|c|}
\hline AMSTAR & $\begin{array}{l}\text { Moore } \\
2012\end{array}$ & $\begin{array}{l}\text { Lucchini- } \\
\text { Raies } 2012\end{array}$ & $\begin{array}{l}\text { Herlenius } \\
2013\end{array}$ \\
\hline $\begin{array}{l}\text { 1. ¿Se brindó un diseño "a priori”? } \\
\text { La pregunta de la investigación y los criterios de inclusión deberían establecerse antes de llevar a cabo la revisión }\end{array}$ & $\mathrm{Si}$ & No & $\mathrm{Si}$ \\
\hline $\begin{array}{l}\text { 2. ¿Hubo duplicación en la selección de estudios y extracción de datos? } \\
\text { Debería haber al menos dos personas independientes a cargo de la extracción de datos, y debería existir un procedimiento } \\
\text { consensuado para los desacuerdos }\end{array}$ & $\mathrm{Si}$ & $\begin{array}{l}\text { No } \\
\text { responde }\end{array}$ & $\begin{array}{l}\text { No } \\
\text { responde }\end{array}$ \\
\hline $\begin{array}{l}\text { 3. ¿Se realizó una búsqueda exhaustiva de literatura? } \\
\text { Deberían consultarse al menos dos fuentes electrónicas. El informe debe incluir los años y las bases de datos utilizadas (por ej. } \\
\text { Central, EMBASE y MEDLINE). Deben especificarse las palabras clave y/o los términos MESH y, de ser posible, debe proveerse la } \\
\text { estrategia de búsqueda. Todas las búsquedas deberían ser complementadas con consultas a contenidos actuales, revisiones, libros de } \\
\text { textos, registros especializados, o expertos en el campo particular de estudio, y mediante la revisión de las referencias en los estudios } \\
\text { encontrados }\end{array}$ & $\mathrm{Si}$ & No & $\mathrm{Si}$ \\
\hline $\begin{array}{l}\text { 4. ¿Se utilizó el estado de publicación (es decir, literatura gris) como criterio de inclusión? } \\
\text { Los autores deberían especificar que buscaron informes sin tener en cuenta el tipo de publicación. Los autores deberían especificar si } \\
\text { excluyeron o no algún informe (de la revisión sistemática), en función del estado de publicación, idioma, etc. }\end{array}$ & $\mathrm{Si}$ & $\begin{array}{l}\text { No } \\
\text { responde }\end{array}$ & $\begin{array}{l}\text { No } \\
\text { responde }\end{array}$ \\
\hline $\begin{array}{l}\text { 5. ¿Se brindó una lista de estudios (incluidos y excluidos)? } \\
\text { Debería proveerse una lista de estudios incluidos y excluidos }\end{array}$ & $\mathrm{Si}$ & No & No \\
\hline $\begin{array}{l}\text { 6. ¿Se brindaron las características de los estudios incluidos? } \\
\text { De manera adjunta tal como una tabla, deberían proveerse los datos de los estudios originales sobre los participantes, las } \\
\text { intervenciones y los resultados. Deberían informarse los rangos de las características en todos los estudios analizados, por ej, la edad, } \\
\text { la raza, el sexo, los datos socioeconómicos relevantes, el estado de enfermedad, la duración, la severidad, o cualquier otra } \\
\text { enfermedad }\end{array}$ & $\mathrm{Si}$ & No & $\mathrm{Si}$ \\
\hline $\begin{array}{l}\text { 7. ¿Se evaluó y documentó la calidad científica de los estudios incluidos? } \\
\text { Deberían proveerse métodos "a priori" (por ej, para estudios de efectividad si el autor o los autores eligen incluir sólo estudios } \\
\text { aleatorizados, de doble ciego, controlados con placebo, u ocultamiento de las asignaciones como criterios de inclusión). Para otros } \\
\text { tipos de estudios, serán relevantes los ítems alternativos }\end{array}$ & $\mathrm{Si}$ & No & No \\
\hline $\begin{array}{l}\text { 8. ¿Se utilizó de manera adecuada la calidad científica de los estudios incluidos al formular las conclusiones? } \\
\text { El rigor metodológico y la calidad científica de los estudios deberían considerarse en el análisis y las conclusiones de la revisión, y } \\
\text { plantearse explícitamente al formular las recomendaciones }\end{array}$ & $\mathrm{Si}$ & $\begin{array}{l}\text { No } \\
\text { responde }\end{array}$ & No \\
\hline 9. ¿Fueron adecuados los métodos utilizados para combinar los hallazgos de los estudios? & $\mathrm{Si}$ & No & No \\
\hline
\end{tabular}




\begin{tabular}{|c|c|c|c|}
\hline $\begin{array}{l}\text { Para los resultados conjuntos, debería hacerse una prueba para garantizar que los estudios pudieron combinarse y para evaluar sus } \\
\left.\text { homogeneidad (es decir, la prueba chi-cuadrado para la homogeneidad, } I^{2}\right) \text {. Si existe heterogeneidad debería utilizarse un modelo de } \\
\text { efectos aleatorios y/o debería considerarse lo adecuado de la combinación (es decir, ¿fue adecuado combinar los resultados?) }\end{array}$ & & aplicable & aplicable \\
\hline $\begin{array}{l}\text { 10. ¿Se valoró la probabilidad de sesgo de publicación? } \\
\text { Una evaluación de sesgo de publicación debería incluir una combinación de ayudas gráficas (por ej. un gráfico en embudo - funnel plot } \\
-, \text { otras pruebas disponibles) y/o pruebas estadísticas (por ej. prueba de regresión de Egger) }\end{array}$ & $\begin{array}{l}\text { No } \\
\text { aplicable }\end{array}$ & No & No \\
\hline $\begin{array}{l}\text { 11. ¿Se planteó el conflicto de intereses? } \\
\text { Deberían reconocerse claramente las fuentes posibles de apoyo tanto en la revisión sistemática como en los estudios incluidos }\end{array}$ & $\mathrm{Si}$ & No & $\mathrm{Si}$ \\
\hline
\end{tabular}

\section{ECAs - Risk of bias - Cochrane}

\section{Riesgo de sesgo de los estudios incluidos en la Revisión Cochrane de Moore}

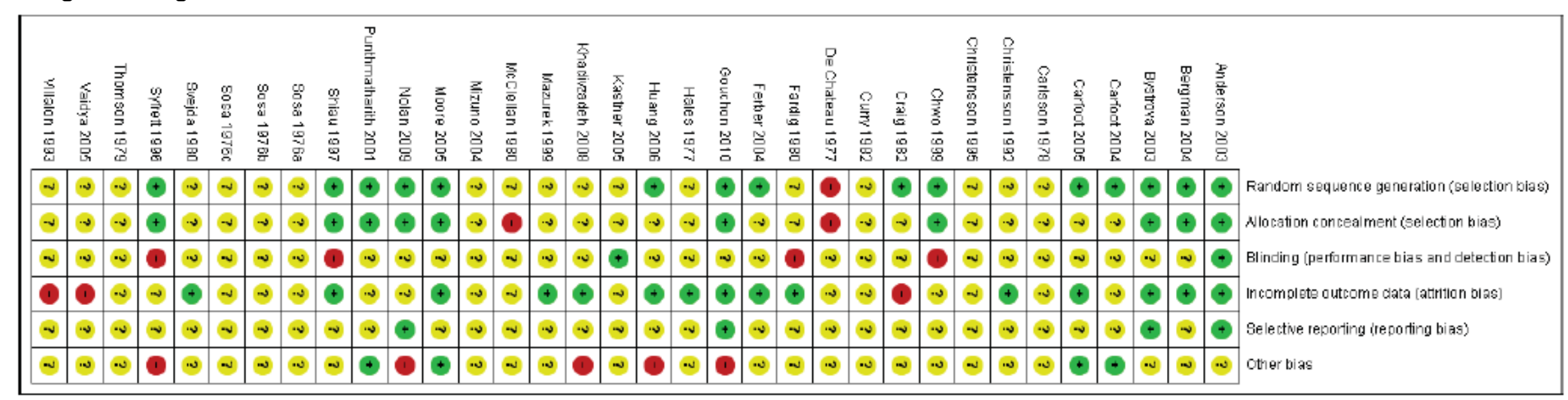

Risk of bias summary: review authors' judgements about each risk of bias item for each included study. (Moore 2012)

\section{Riesgo de sesgo de los ECAs incluidos en la actualización}




\begin{tabular}{|c|c|c|c|c|c|c|}
\hline $\begin{array}{l}\text { Referencia } \\
\text { (Cita Abreviada) }\end{array}$ & $\begin{array}{l}\text { Random sequence } \\
\text { generation (selection } \\
\text { bias) }\end{array}$ & $\begin{array}{l}\text { Allocation } \\
\text { conceallement } \\
\text { (selection bias) }\end{array}$ & $\begin{array}{l}\text { Blinding (performance } \\
\text { bias and detection bias) } \\
\text { All outcomes }\end{array}$ & $\begin{array}{l}\text { Incomplete outcome } \\
\text { data (attrition bias) } \\
\text { All outcomes }\end{array}$ & $\begin{array}{l}\text { Selective reporting } \\
\text { (reporting bias) }\end{array}$ & Other bias \\
\hline $\begin{array}{l}\text { Aghdas } 2013 \\
\text { (Irán) }\end{array}$ & $\begin{array}{l}\text { Bajo riesgo } \\
\text { "The randomisation } \\
\text { sequence was generated } \\
\text { by the statistical adviser } \\
\text { of the research } \\
\text { programme using } \\
\text { computerised research } \\
\text { randomiser..." }\end{array}$ & $\begin{array}{l}\text { Bajo riesgo } \\
\text { "The sequence was } \\
\text { concealed from the } \\
\text { research assistants in } \\
\text { sequentially numbered } \\
\text { sealed opaque envelop. } \\
\text { The envelops were } \\
\text { opened after the mothers } \\
\text { signed the consent } \\
\text { forms." }\end{array}$ & $\begin{array}{l}\text { Bajo riesgo/ riesgo } \\
\text { poco claro } \\
\text { Los evaluadores son } \\
\text { ciegos a la valoración de } \\
\text { los resultados, pero por la } \\
\text { propia naturaleza de la } \\
\text { intervención no es } \\
\text { posible el cegado. }\end{array}$ & $\begin{array}{l}\text { Riesgo poco claro } \\
\text { "114 eligible mothers } \\
\text { according to inclusion } \\
\text { and exclusion criteria } \\
\text { were enrolled in this } \\
\text { research programme. At } \\
\text { the end of the study } 92 \\
\text { mother-infant dyads were } \\
\text { assessed" tasa del } \\
80,70 \%\end{array}$ & $\begin{array}{l}\text { Riesgo poco claro/Bajo } \\
\text { riesgo } \\
\text { Si se incluyen todas las } \\
\text { vv de interés pero los } \\
\text { resultados no se } \\
\text { presentan tabulados, por } \\
\text { lo que no es posible } \\
\text { reanalizarlos. }\end{array}$ & Poco riesgo \\
\hline $\begin{array}{l}\text { Girish } 2012 \\
\text { (India) }\end{array}$ & $\begin{array}{l}\text { Bajo riesgo } \\
\text { "Allocation to one of two } \\
\text { groups, control group and } \\
\text { intervention groups was } \\
\text { made by simple } \\
\text { randomization." }\end{array}$ & $\begin{array}{l}\text { Riesgo poco claro } \\
\text { No hay información }\end{array}$ & $\begin{array}{l}\text { Bajo riesgo/ riesgo } \\
\text { poco claro } \\
\text { "outcome data were } \\
\text { collected by a research } \\
\text { assistant who was } \\
\text { masked to group } \\
\text { assignments". No se } \\
\text { habla de blinding the } \\
\text { personal y participantes, } \\
\text { pero obviamente no es } \\
\text { possible. } \\
\text { No obstante ambos } \\
\text { grupos reciben apoyo } \\
\text { para la lactancia. }\end{array}$ & $\begin{array}{l}\text { Riesgo poco claro } \\
\text { - Se incluyen } 100 \\
\text { mujeres, } 50 \text { en cada } \\
\text { grupo. No se indica si hay } \\
\text { pérdidas al seguimiento. } \\
\text { - La pérdida de peso es } \\
\text { mayor en el grupo control } \\
\text { pero no hay datos. } \\
\text { - No todos los resultados } \\
\text { se presentan tabulados., } \\
\text { ni en \%. Error entre datos } \\
\text { en texto y tablas. }\end{array}$ & $\begin{array}{l}\text { Riesgo poco claro } \\
\text { Parece que se incluyen } \\
\text { todos los outcomes pero } \\
\text { hay resultados no } \\
\text { tabulados. }\end{array}$ & $\begin{array}{l}\text { Riesgo poco claro } \\
\text { - No sabemos el } \mathrm{n}^{\circ} \text { de } \\
\text { mujeres que rechazan } \\
\text { participar en el estudio; } \\
\text { - Existen algunas } \\
\text { diferencias entre ambos } \\
\text { grupos, aunque no } \\
\text { sabemos si son o no } \\
\text { siginificativas }\end{array}$ \\
\hline $\begin{array}{l}\text { Mahmood } 2011 \\
\text { (Pakistan) }\end{array}$ & $\begin{array}{l}\text { Riesgo poco claro } \\
\text { No se indica }\end{array}$ & $\begin{array}{l}\text { Bajo riesgo } \\
\text { "During the second stage } \\
\text { of labor, pre-mixed } \\
\text { sealed envelopes with } \\
\text { allocation cards were } \\
\text { opened sequentially and } \\
\text { mothers and research } \\
\text { assistants were informed } \\
\text { accordingly." }\end{array}$ & $\begin{array}{l}\text { Riesgo poco claro } \\
\text { No se indica }\end{array}$ & $\begin{array}{l}\text { Alto riesgo } \\
11 \text { y } 12 \text { mujeres del gr } \\
\text { CPP y control } \\
\text { respectivamente son } \\
\text { excluidas } \\
\text { posaleatorizacion por } \\
\text { distintos motivos } \\
\text { (justificados). } \\
\text { Además hay } 13 \text { y } 12 \\
\text { pérdidas al seguimiento } \\
\text { respectivamente (se } \\
\text { desconoce por qué) }\end{array}$ & $\begin{array}{l}\text { Bajo riesgo } \\
\text { All outcomes were listed } \\
\text { under the aims of the } \\
\text { study and numerical } \\
\text { results are reported for all } \\
\text { of them. } \\
\text { Lo unico que no se } \\
\text { especifica quien mide los } \\
\text { outcomes y hay que tener } \\
\text { en cuenta que no } \\
\text { sabemos si es ciego o no } \\
\text { a las condiciones del } \\
\text { estudio. }\end{array}$ & $\begin{array}{l}\text { Riesgo poco claro } \\
\text { - Tamaño muestral inicial } \\
\text { adecuado ( } 91 \text { y 92), se } \\
\text { calcula que se necesitan } \\
72 \text { en cada grupo. } \\
\text { - no hay diferencias } \\
\text { basales entre grupos } \\
\text { excepto en experiencia } \\
\text { previa de LM en mujeres } \\
\text { multiparas }\end{array}$ \\
\hline
\end{tabular}




\begin{tabular}{|c|c|c|c|c|c|c|}
\hline \multirow{2}{*}{$\begin{array}{l}\text { Nahidi } \\
\text { Thukral } 2012\end{array}$} & \multicolumn{6}{|l|}{ No evaluable, abstract only. } \\
\hline & $\begin{array}{l}\text { Bajo riesgo } \\
\text { "We randomly allocated } \\
\text { the enrolled infants to } \\
\text { either the early-SSC } \\
\text { group or to the } \\
\text { conventional-care group } \\
\text { (control group) at birth } \\
\text { using computer- } \\
\text { generated random } \\
\text { sequence numbers". }\end{array}$ & $\begin{array}{l}\text { Bajo riesgo } \\
\text { "Serially numbered, } \\
\text { sealed and opaque } \\
\text { envelopes were used to } \\
\text { ensure allocation } \\
\text { concealment." }\end{array}$ & $\begin{array}{l}\text { Bajo riesgo/ riesgo } \\
\text { poco claro } \\
\text { "Given the nature of the } \\
\text { intervention, neither the } \\
\text { investigators nor the } \\
\text { treating team could be } \\
\text { blinded to the study } \\
\text { groups. The outcome } \\
\text { assessment team } \\
\text { responsible for measuring } \\
\text { BF behavior was, } \\
\text { however, blinded to the } \\
\text { group allocation." } \\
\text { No obstante ambos } \\
\text { grupos reciben apoyo } \\
\text { para la lactancia. }\end{array}$ & $\begin{array}{l}\text { Riesgo poco claro } \\
\text { " } 41 \text { infants were randomly } \\
\text { allocated into early SSC } \\
\text { and control groups }(n= \\
20 \text { and } 21, \text { respectively)... } \\
\text { Four mothers who gave } \\
\text { consent to participate in } \\
\text { the study withdrew } \\
\text { consent at the time of } \\
\text { video recording.... Videos } \\
\text { of } 2 \text { infants were of poor } \\
\text { quality and were not } \\
\text { included in the final } \\
\text { análisis }(n=17 \text { and } 18, \\
\text { respectively)." }\end{array}$ & $\begin{array}{l}\text { All outcomes were listed } \\
\text { under the aims of the } \\
\text { study and numerical } \\
\text { results are reported for all } \\
\text { of them. } \\
\text { Riesgo según variables: } \\
\text { Bajo riesgo } \\
\text { Resto de variables, ya } \\
\text { que se utilizan } \\
\text { cuestionarios o medidas } \\
\text { validadas. } \\
\text { Riesgo poco claro } \\
\text { Percepción materna, } \\
\text { autoreported, non- } \\
\text { validated questionnaire } \\
\text { although previously used } \\
\text { in other study. }\end{array}$ & $\begin{array}{l}\text { Riesgo poco claro } \\
\text { - Tamaño muestral } \\
\text { pequeño; } \\
\text { - } 45 \text { de } 128 \text { mujeres } \\
\text { rechazan participar; } \\
\text { - no hay diferencias } \\
\text { basales entre grupos; } \\
\text { - el hecho de grabar en } \\
\text { video puede conllevar } \\
\text { una alteración del } \\
\text { comportamiento de la } \\
\text { madre }\end{array}$ \\
\hline Srivastava 2014 & $\begin{array}{l}\text { Bajo riesgo } \\
\text { "Randomization was } \\
\text { carried out using the } \\
\text { block randomization } \\
\text { method..." }\end{array}$ & $\begin{array}{l}\text { Bajo riesgo } \\
\text { "A sealed envelope } \\
\text { technique was used for } \\
\text { randomization" }\end{array}$ & Riesgo poco claro & $\begin{array}{l}\text { Riesgo poco claro } \\
\text { Pérdida al seguimiento } \\
\text { de } 15 \text { y } 11 \text { díadas en los } \\
\text { grupos intervención y } \\
\text { control respectivamente. } \\
\text { No se indican las causas. }\end{array}$ & $\begin{array}{l}\text { Bajo riesgo de sesgo } \\
\text { Se utiliza el IBFAT para } \\
\text { valorar la primera toma. } \\
\text { Para la satisfacción una } \\
\text { escala lickert. }\end{array}$ & Poco riesgo \\
\hline
\end{tabular}

\section{Series de casos}

No se ha valorado la calidad individual de estos estudios. Se considera que dada su naturaleza todos ellos son de calidad muy baja. 


\section{ANEXO III. Tabla de estudios para la pregunta 1}

\section{Tabla de ECAs}

\begin{tabular}{|c|c|c|c|c|c|c|}
\hline Referencia & Estudio & Población & $\begin{array}{l}\text { Descripción de las } \\
\text { intervenciones } \\
\text { comparaciones, exposiciones o } \\
\text { pruebas a estudio }\end{array}$ & Resultados & Conclusiones & Comentarios \\
\hline $\begin{array}{l}\text { Agdas } \\
2013 \text { (Irán) }\end{array}$ & $\begin{array}{l}\text { Diseño } \\
\text { ECA } \\
\text { Objetivo } \\
\text { Evaluar el efecto } \\
\text { del CPP } \\
\text { temprano en la } \\
\text { LM }\end{array}$ & $\begin{array}{l}\text { N } \\
92 \text { ( } 80.70 \%) ; n \text { ccp } 47 ; \\
\text { n control } 45 \\
\text { Características } \\
\text { Mujeres primíparas, } \\
\text { entre } 18-35 \text { años, parto } \\
\text { vaginal y con intención } \\
\text { de amamantar }\end{array}$ & $\begin{array}{l}\text { Intervención } \\
\text { Los RN fueron colocados } \\
\text { desnudos sobre el abdomen de la } \\
\text { madre en posición prono, con un } \\
\text { gorro en la cabeza y una manta } \\
\text { precalentada durante al menos } 2 \mathrm{~h} \text {. } \\
\text { Comparación } \\
\text { Los RN recibieron cuidados } \\
\text { habituales (inyección vitamina } \mathrm{K} \text {, } \\
\text { peso, talla..) y posteriormente } \\
\text { entregados a sus madres } \\
\text { envueltos en una manta } \\
\text { precalentada. }\end{array}$ & $\begin{array}{l}\text { Éxito en la primera toma (IBFAT } \geq 10) \\
56,6 \% \text { vs. } 35,6 \% ; p=0,02 \\
\text { Tiempo hasta primera toma } \\
21,98 \pm 9,10 \text { vs. } 66,55 \pm 20,76 ; p<0,0001\end{array}$ & $\begin{array}{l}\text { El CPP temprano tiene } \\
\text { un efecto positive en el } \\
\text { éxito en la primera toma } \\
\text { del bebé. }\end{array}$ & $\begin{array}{l}\text { (+) Cegamiento } \\
\text { investigadores } \\
(-) \text { importante } \\
\text { pérdida al } \\
\text { seguimiento } \\
\text { Financiación } \\
\text { No se indica. } \\
\text { Conflicto de interés } \\
\text { No se indica. } \\
\text { Calidad } \\
\text { Moderada }\end{array}$ \\
\hline $\begin{array}{l}\text { Girish } 2013 \\
\text { (India) }\end{array}$ & $\begin{array}{l}\text { Diseño } \\
\text { ECA simple ciego } \\
\text { Objetivo } \\
\text { Determinar el } \\
\text { impacto del } \\
\text { agarre } \\
\text { espontáneo en } \\
\text { relación al inicio } \\
\text { de la LM }\end{array}$ & $\begin{array}{l}\mathbf{N} \\
100 \text { (50 intervención, } 50 \\
\text { control) } \\
\text { Características } \\
\text { Parto vaginal, sin } \\
\text { complicaciones } \\
\text { posparto que impidan } \\
\text { CPP, RN } 37 \text { semanas, }\end{array}$ & $\begin{array}{l}\text { Intervención } \\
\text { El RN es colocado sobre vientre de } \\
\text { la madre en CPP durante } 1 \mathrm{~h} \\
\text { inmediatamente tras el parto } \\
\text { Comparación } \\
\text { El RN recibe los cuidados según } \\
\text { protocolo hospital: examen de } \\
\text { rutina, inyección vitamina K y } \\
\text { entregados a la madre } 30 \text { " a } 1 \mathrm{~h} \text {. } \\
\text { después }\end{array}$ & $\begin{array}{l}\text { Comportamiento del lactante } \\
\quad 183 \text { IBFAT }>10 \text { en día } 0: 48 \text { vs. } 46 \\
\text { (n.s.) } \\
\text { Problemas en las mamas } \\
22 \% \text { vs. } 44 \% ; p=0,0327 \\
\text { Pérdida de peso día } 72 \mathrm{~h} \text {. } \\
\text { Significativamente menor en grupo } \\
\text { intervención (no hay cifras) ( } p=0,032) \\
\text { Utilización de suplementos } \\
26 \% \text { vs. } 4 \% ; p=0,003\end{array}$ & $\begin{array}{l}\text { El arrastre al pecho } \\
\text { conlleva un beneficio } \\
\text { positivo significativo en el } \\
\text { inicio de la lactancia y la } \\
\text { pérdida de peso del RN. }\end{array}$ & $\begin{array}{l}(+) \text { aleatorización } \\
\text { simple } \\
(-) \text { mayoría } \\
\text { resultados no } \\
\text { tabulados } \\
\text { Conflicto de interés } \\
\text { No hay. } \\
\text { Financiación } \\
\text { No se indica. } \\
\text { Calidad } \\
\text { CALIDAD MEDIA }\end{array}$ \\
\hline $\begin{array}{l}\text { Mahmood } \\
2011 \\
\text { (Pakistán) }\end{array}$ & $\begin{array}{l}\text { Diseño } \\
\text { ECA } \\
\text { Objetivo } \\
\text { Evaluar el efecto } \\
\text { del CPP }\end{array}$ & $\begin{array}{l}\text { N } \\
183(90,1 \%) ; n \text { CPP } 91, \\
\text { n control } 92 \\
\text { Características } \\
\text { Criterios inclusión }\end{array}$ & $\begin{array}{l}\text { Intervención } \\
\text { CPP: los RN se colocan desnudos } \\
\text { sobre el abdomen de la madre } \\
\text { después de ser secados, con un } \\
\text { gorro y cubiertos con una manta } \\
\text { precalentada. Contacto }\end{array}$ & $\begin{array}{l}\text { Éxito de la primera toma (IBFAT >10) } \\
58,8 \% \text { vs. } 32,5 \% ; X^{2} 11,10(p=0,001) \\
\text { Tiempo (min.) hasta } 1^{\text {a }} \text { toma (media) } \\
40,62 \pm 10,56 \text { vs. } 101,88 \pm 67,94 ; p<0,001\end{array}$ & $\begin{array}{l}\text { El CPP tiene un efecto } \\
\text { positivo y significativo en } \\
\text { el éxito de la primera } \\
\text { toma ( } 26 \% \text { más en el gr. } \\
\text { CPP), y además el } \\
\text { agarre se hace de modo }\end{array}$ & $\begin{array}{l}\text { Ambos grupos } \\
\text { reciben asistencia } \\
\text { con la LM } \\
(+) \text { calculo tamaño } \\
\text { muestral } \\
(-) \text { Alto } \mathrm{n}^{\circ} \text { de }\end{array}$ \\
\hline
\end{tabular}




\begin{tabular}{|c|c|c|c|c|c|c|}
\hline & $\begin{array}{l}\text { temprano en la } \\
\text { LM }\end{array}$ & Mujeres & $\begin{array}{l}\text { ininterrumpido hasta la primera } \\
\text { toma y } 45 \text { minutos. Se finaliza CPP } \\
\text { a los } 120 \text { minutos si no se realiza } \\
\text { la primera toma. } \\
\text { Comparación } \\
\text { Cuidados habituales: Ios RN son } \\
\text { trasladados a una cuna térmica } \\
\text { con calentador radiante tras cortar } \\
\text { el cordón, se limpian y se } \\
\text { envuelven con mantas } \\
\text { precalentadas y se trasladaban a } \\
\text { la sala de postparto con las } \\
\text { madres para su primera toma. }\end{array}$ & $\begin{array}{l}\text { Satisfacción materna } \\
\text { Muy satisfecha: } 56 \% \text { vs. } 6,2 \% \\
\text { Satisfecha: } 30,0 \% \text { vs. } 30,0 \% \\
\text { Algo satisfecha: } 11,2 \% \text { vs. } 48,8 \% \\
\text { Insatisfecha: } 2,5 \% \text { vs. } 15,0 \% \\
\text { Muy insatisfecha: } 0 \% \text { vs. } 0 \% \\
X^{2} 57,89 ; p<0,001 \\
\text { Preferencia materna } \\
\text { Muy segura: } 53,8 \% \text { vs. } 5,0 \% ; p<0,001 \\
\text { Segura: } 31,2 \% \text { vs. } 17,5 \% ; p<0,001 \\
\text { Algo segura: } 7,5 \% \text { vs. } 31,2 \% ; p<0,001 \\
\text { Casi seguro no: } 7,5 \% \text { vs. } 36,2 \% ; \\
\text { p<0,001 } \\
\text { Seguro que no: } 0 \% \text { vs. } 10 \% ; p<0,001 \\
\text { LME al mes (IBS) } \\
\text { Exclusiva: } 85,3 \% \text { vs. } 65,7 \% ; p<0,025 \\
\text { Parcial: } 14,7 \% \text { vs. } 32,8 \% ; p<0,025 \\
\text { Comfort: } 0 \% \text { vs. } 1,5 \% ; p<0,025\end{array}$ & $\begin{array}{l}\text { más temprano. } \\
\text { Las mujeres del gr CPP } \\
\text { muestran mayor } \\
\text { satisfacción materna. } \\
\text { La duración de la LM es } \\
\text { más prolongada: LME al } \\
\text { mes del } 85,3 \% \text { en } \\
\text { comparación con el } \\
65,7 \% \text { en el gr. Control. }\end{array}$ & $\begin{array}{l}\text { pérdidas al } \\
\text { seguimiento ( } 13 \text { gr. } \\
\text { CPP y } 12 \text { en control) } \\
\text { (-) En mujeres } \\
\text { multíparas dif. } \\
\text { Significativas entre } \\
\text { las que tienen } \\
\text { experiencia con LM } \\
\text { previa y las que no } \\
(p=0,04) \text {. } \\
\text { Conflicto de interés } \\
\text { No se indica. } \\
\text { Financiación } \\
\text { No se indica. } \\
\text { Calidad } \\
\text { CALIDAD MEDIA }\end{array}$ \\
\hline $\begin{array}{l}\text { Srivastava } \\
2014\end{array}$ & $\begin{array}{l}\text { Diseño } \\
\text { ECA } \\
\text { Objetivo } \\
\text { Comparar el } \\
\text { efecto del CPP } \\
\text { frente a la no } \\
\text { intervención en la } \\
\text { LM y en la } \\
\text { satisfacción } \\
\text { materna }\end{array}$ & $\begin{array}{l}\text { N } \\
298 \text { díadas madre-RN } \\
\text { Características } \\
\text { RN sanos a término, } \\
\text { embarazos únicos }\end{array}$ & & & & \\
\hline $\begin{array}{l}\text { Nahidi } \\
2011 \\
\text { (Irán) }\end{array}$ & $\begin{array}{l}\text { Diseño } \\
\text { ECA } \\
\text { Objetivo } \\
\text { Evaluar la } \\
\text { satisfacción } \\
\text { materna con el } \\
\text { CPP temprano }\end{array}$ & $\begin{array}{l}\mathbf{N} \\
80 \text { díadas } \\
\text { Características } \\
\text { ¿?? }\end{array}$ & $\begin{array}{l}\text { Intervención } \\
\text { CPP temprano } \\
\text { Comparación } \\
\text { Cuidados habituales }\end{array}$ & $\begin{array}{l}\text { Satisfacción materna } \\
\text {-CPP muy satisfechas: } 70 \% \\
\text {-CPP satisfechas: } 20 \\
\text {-Control muy insatisfechas: } 35 \% \\
\text { - Insatisfechas: } 35 \% \\
\text {-Significativamente más mujeres del } \\
\text { grupo CPP muestran su preferencia por } \\
\text { el mismo trato en futuro parto }\end{array}$ & $\begin{array}{l}\text { Las mujeres del grupo } \\
\text { CPP están más } \\
\text { satisfechas y muestran } \\
\text { su preferencia por el } \\
\text { mismo trato en el futuro. }\end{array}$ & $\begin{array}{l}\text { (-) Solo disponemos } \\
\text { del abstract, articulo } \\
\text { en persa } \\
\text { Conflicto de interés } \\
\text { ¿?? } \\
\text { Financiación } \\
\text { ¿?? } \\
\text { Calidad } \\
\text { NO EVALUABLE }\end{array}$ \\
\hline
\end{tabular}




\begin{tabular}{|c|c|c|c|c|c|c|}
\hline $\begin{array}{l}\text { Thukral } \\
2012 \\
\text { (India) }\end{array}$ & $\begin{array}{l}\text { Diseño } \\
\text { ECA } \\
\text { Objetivo } \\
\text { Evaluar si el CPP } \\
\text { temprano mejora } \\
\text { la LM y la LME }\end{array}$ & $\begin{array}{l}\mathbf{N} \\
41 \text { (20 intervención, } 21 \\
\text { control) } \\
\text { Características } \\
\text { RN apropiados para su } \\
\text { edad gestacional. } \\
\text { Se excluyen RN con } \\
\text { malformaciones } \\
\text { congénitas, de madres } \\
\text { diabéticas o que } \\
\text { requieran resucitación o } \\
\text { admisión en UCIN. (42 } \\
\text { excluidas) }\end{array}$ & $\begin{array}{l}\text { Intervención } \\
\text { CPP temprano: el RN es colocado } \\
\text { sobre el pecho de la madre tras el } \\
\text { parto durante } 2 \mathrm{~h} \text {. } \\
\text { Comparación } \\
\text { Cuidados convencionales: el RN } \\
\text { es colocado al lado de la madre } \\
\text { pero sin CPP }\end{array}$ & $\begin{array}{l}\text { Comportamiento del lactante, 36-48h. } \\
\text { (alta hospitalaria) (BAT modificado) } \\
50 \% \text { vs. } 52,4 \% \text {; RR 0,9 (IC95\% 0,6 a } \\
\text { 1,7); } p=0,89 \\
\text { LME 48h. } \\
95 \% \text { vs. } 38,1 \% \text {; RR 2,5 (IC95\% 1,4 a } \\
\text { 4,3); p=0,001 } \\
\text { LME } 6 \text { semanas } \\
90 \% \text { vs. } 28,6 \% \text {; RR } 3,2 \text { (IC95\% } 1,61 \\
6,3) ; p=0,001 \\
\text { Peso RN, 48h. } \\
2,714 \pm 220 \text { vs. 2,574 } \pm 275 ; \text { dif. Medias } \\
139 \text { (IC95\% -18 a 298); p=0,11 }\end{array}$ & $\begin{array}{l}\text { - El CPP temprano } \\
\text { mejora las tasas de LME } \\
\text { al alta hospitalaria, } \\
\text { aunque no hay } \\
\text { diferencias en el } \\
\text { comportamiento del } \\
\text { lactante (puntuación BAT } \\
\text { modificado). } \\
\text { - Los bebés del grupo } \\
\text { CPP tienen mejores } \\
\text { tasas a las } 6 \text { semanas. } \\
\text { - Las mujeres del grupo } \\
\text { CPP tienen mejor } \\
\text { percepción de la LM } \\
\text { (asociado a la } \\
\text { satisfacción con la LM). }\end{array}$ & $\begin{array}{l}\text { Todas las madres } \\
\text { reciben apoyo y se } \\
\text { fomenta el inicio de la } \\
\text { LM } \\
\text { (+) Utilizan } \\
\text { grabaciones de video } \\
\text { (+) Adecuada } \\
\text { aleatorización } \\
\text { (+) Cegamiento del } \\
\text { equipo evaluador } \\
\text { (-) Potencia limitada } \\
\text { Conflicto de interés } \\
\text { No hay. } \\
\text { Financiación } \\
\text { Indian Council of } \\
\text { Medical Research } \\
\text { Calidad } \\
\text { CALIDAD MEDIA }\end{array}$ \\
\hline $\begin{array}{l}\text { Gouchon } \\
2010\end{array}$ & $\begin{array}{l}\text { Diseño } \\
\text { RCT }\end{array}$ & $\begin{array}{l}\mathbf{N} \\
34 \text { díadas madre-RN } \\
\text { (17 en cada grupo) } \\
\text { Características }\end{array}$ & $\begin{array}{l}\text { Intervención } \\
\text { CPP temprano que comienza } \\
\text { durante la primera hora de vida, si } \\
\text { no hay contraindicación médica } \\
\text { Comparación }\end{array}$ & $\begin{array}{l}\text { Tiempo hasta la primera toma } \\
\text { (minutos) } \\
22 \pm 8 \text { vs. } 43 \pm 67 \\
\text { Primera toma correcta (IBAT) } \\
9,2 \pm 3,8 \text { vs. } 8,2 \pm 3,2 ; \text { ns } \\
\text { LME alta } \\
52,94 \% \text { vs. } 52,94 \% \\
\text { LME } 3 \text { meses } \\
47,06 \% \text { vs. } 29,41 \% \\
\text { LM } 3 \text { meses } \\
64,70 \% \text { vs. } 47,06 \% \\
\text { Duración LM (días) } \\
63 \pm 38,8 \text { vs. } 48 \pm 34,9 \\
\text { Satisfacción materna }\end{array}$ & $\begin{array}{l}\text { EI CPP temprano } \\
\text { (primera hora tras el } \\
\text { parto) es factible en RN } \\
\text { nacidos por cesárea. } \\
\text { Favorece el inicio } \\
\text { temprano de la LM y su } \\
\text { duración. }\end{array}$ & $\begin{array}{l}\text { (+) análisis por } \\
\text { intención de tratar } \\
\text { (-) pérdidas al } \\
\text { seguimiento, muestra } \\
\text { pequeña, no } \\
\text { sabemos si se ha } \\
\text { hecho cegamiento o } \\
\text { no } \\
\text { Conflicto de interés } \\
\text { No hay } \\
\text { Financiación } \\
\text { University of Western } \\
\text { Sydney } \\
\text { Calidad } \\
\text { Ver risk of bias }\end{array}$ \\
\hline Nolan 2009 & Diseño & $\mathbf{N}$ & Intervención & Tiempo hasta la primera toma & El CPP tras un parto por & $(+)$ \\
\hline
\end{tabular}




\begin{tabular}{|c|c|c|c|c|c|c|}
\hline & RCT & $\begin{array}{l}50 \text { díadas madre-RN } \\
\text { ( } 25 \text { en cada grupo) } \\
\text { Características }\end{array}$ & $\begin{array}{l}\text { CPP temprano tras el parto (no se } \\
\text { indica exactamente cuándo } \\
\text { empieza), duración media 113(sd } \\
\text { 16) minutos } \\
\text { Control } \\
\text { Cuidados habituales, normalmente } \\
\text { separación de la madre y del RN }\end{array}$ & $\begin{array}{l}\text { (minutos) } \\
49 \pm 12 \text { vs. } 90 \pm 72 ; p=0,03 \\
\text { LM al alta } \\
76 \% \text { vs. } 52 \% \\
\text { LM al mes } \\
64 \% \text { vs. } 32 \% \\
\text { Satisfacción materna } \\
t(40)=-1,28 ; p>0,05\end{array}$ & $\begin{array}{l}\text { cesárea es factible y } \\
\text { conlleva consecuencias } \\
\text { positivas en la LM al alta } \\
\text { y al mes. }\end{array}$ & $\begin{array}{l}\text { (-) Muestra pequeña, } \\
\text { estudio piloto } \\
\text { Conflicto de interés } \\
\text { No indicado } \\
\text { Financiación } \\
\text { No indicado } \\
\text { Calidad } \\
\text { Ver risk of bias }\end{array}$ \\
\hline $\begin{array}{l}\text { Beiranvand } \\
2014\end{array}$ & $\begin{array}{l}\text { Diseño } \\
\text { ECA } \\
\text { Objetivo } \\
\text { Determinar el } \\
\text { efecto del CPP en } \\
\text { la LM en RN } \\
\text { sanos a término } \\
\text { nacidos por } \\
\text { cesárea }\end{array}$ & $\begin{array}{l}\mathbf{N} \\
96 \text { díadas madre-RN } \\
\text { Características } \\
\text { Madres } 16-40 \text { años, } \\
\text { cesárea electiva, RN } \\
\text { sano a término, EG 38- } \\
42 \text { semanas }\end{array}$ & $\begin{array}{l}\text { Intervención } \\
\text { Los RN son colocados solo con el } \\
\text { pañal sobre el pecho de la madre } \\
\text { en posición prono al salir del } \\
\text { quirófano } \\
\text { Control } \\
\text { Los RN son vestidos y entregados } \\
\text { a la madre a la vuelta a la salida } \\
\text { del quirófano } \\
\text { *En ambos grupos los RN son } \\
\text { envueltos en una manta } \\
\text { precalentada al nacer y son } \\
\text { llevados a la sala materno-infantil } \\
\text { hasta la salida de la madre del } \\
\text { quirófano }\end{array}$ & $\begin{array}{l}\text { Primera toma correcta (IBAT) } \\
8,76 \pm 3,63 \text { vs. } 7,25 \pm 3,5 ; p=0,048 \\
\text { Satisfacción materna } \\
\text { La mayoría de las madres del grupo } \\
\text { CPP se mostraron satisfechas con el } \\
\text { cuidado recibido. No hay datos } \\
\text { tabulados. }\end{array}$ & $\begin{array}{l}\text { La realización del CPP es } \\
\text { posible tras el parto por } \\
\text { cesárea, y puede tener } \\
\text { un efecto positivo sobre } \\
\text { la LM }\end{array}$ & $\begin{array}{l}(+) \\
(-) \\
\text { Conflicto de interés } \\
\text { No hay } \\
\text { Financiación } \\
\text { No indicado } \\
\text { Calidad } \\
\text { Ver risk of bias }\end{array}$ \\
\hline
\end{tabular}

BAT: Breastfeeding Assessment Tool; CPP: contacto piel con piel; IBS: Index of Breastfeeding Status; IBTAT: Infant Breastfeeding Assessment Tool; LM: lactancia materna; LME: Iactancia materna exclusiva; RN: recién nacido; UCIN: Unidad de Cuidados Intensivos Neonatal

\section{Tabla de series de casos}

\begin{tabular}{|c|c|c|c|c|c|c|c|c|c|c|c|}
\hline Estudio & $\begin{array}{l}\text { Tipo de } \\
\text { estudio }\end{array}$ & $\mathbf{N}^{\circ}$ de casos/ & $\begin{array}{l}N^{\circ} \text { de } \\
\text { nacimientos }\end{array}$ & $\begin{array}{l}\text { Edad } \\
\text { gestacional }\end{array}$ & $\begin{array}{l}\text { Periodo de } \\
\text { estudio }\end{array}$ & $\begin{array}{l}\text { Desenlace } \\
\text { - se recupera }\end{array}$ & $\begin{array}{l}\text { Desenlace } \\
\text { - con } \\
\text { secuelas }\end{array}$ & $\begin{array}{l}\text { Desenlace } \\
\text { - muerte }\end{array}$ & $\begin{array}{l}\text { Causa } \\
\text { subyacente? }\end{array}$ & $\begin{array}{l}\text { CPP posición } \\
\text { prono? }\end{array}$ & $\begin{array}{l}\text { Madre a } \\
\text { solas? }\end{array}$ \\
\hline Pejovic 2013 & $\begin{array}{l}\text { Serie de } \\
\text { casos }\end{array}$ & $\begin{array}{l}26 \\
(0,037 \% \circ)\end{array}$ & 69.364 & $>35$ & $<24 \mathrm{~h}$ & $16 / 19$ & $3 / 19$ & - & $3 / 26$ & $15 / 26$ & $13 / 26$ \\
\hline
\end{tabular}




\begin{tabular}{|c|c|c|c|c|c|c|c|c|c|c|c|}
\hline Becher 2012 & $\begin{array}{l}\text { Serie de } \\
\text { casos }\end{array}$ & $\begin{array}{l}45 \\
(0,052 \%)\end{array}$ & 858.466 & $\geq 37$ & $<12 \mathrm{~h}$. & $25 / 45$ & $8 / 45$ & $12 / 45$ & $15 / 45$ & $21 / 45$ & $17 / 45$ \\
\hline Leow 2011 *+ & $\begin{array}{l}\text { Serie de } \\
\text { casos }\end{array}$ & \begin{tabular}{|l}
30 \\
$(0,036 \% \circ)$
\end{tabular} & 828.648 & $\geq 35$ & $<7$ días & - & - & $30 / 30$ & $5 / 28$ & $8 / 30$ & nd \\
\hline $\begin{array}{l}\text { Rodríguez- } \\
\text { Alarcón } 2011\end{array}$ & $\begin{array}{l}\text { Serie de } \\
\text { casos }\end{array}$ & $\begin{array}{l}8 \\
(0,74 \% 0)\end{array}$ & 10.804 & $\geq 36$ & $<2 \mathrm{~h}$. & $5 / 8$ & $2 / 8$ & $1 / 8$ & $0 / 8$ & $8 / 8$ & $8 / 8$ \\
\hline Poets 2011 & $\begin{array}{l}\text { Serie de } \\
\text { casos }\end{array}$ & $\begin{array}{l}17 \\
(0,026 \% 0)\end{array}$ & 665.126 & $\geq 37$ & $<24 \mathrm{~h}$. & $4 / 17$ & $6 / 17$ & $7 / 17$ & nd & $12 / 17$ & nd \\
\hline Peters 2009* & $\begin{array}{l}\text { Serie de } \\
\text { casos }\end{array}$ & $\begin{array}{l}5 \\
(0,040 \%)\end{array}$ & 12.362 & $\geq 36$ & $<12 \mathrm{~h}$ & $0 / 5$ & $1 / 5$ & $4 / 5$ & $0 / 5$ & $2 / 5$ & nd \\
\hline Dageville 2008 & $\begin{array}{l}\text { Serie de } \\
\text { casos }\end{array}$ & $\begin{array}{l}2 \\
(0,032 \%)\end{array}$ & 62.968 & $\geq 36$ & $<2 \mathrm{~h}$ & $1 / 2$ & $1 / 2$ & $0 / 2$ & $0 / 2$ & $2 / 2$ & $2 / 2$ \\
\hline TOTAL ${ }^{2}$ & & $103(0,061 \%)$ & 1.679 .090 & $>35$ & $<24 h$. & $51 / 96$ & $21 / 96$ & $24 / 77$ & $18 / 86$ & $60 / 103$ & $40 / 81$ \\
\hline
\end{tabular}

(1) se incluyen datos no incluidos previamente en Poets 2011; (2) se he eliminado datos de Leow 2011 debido a periodo de seguimiento de 7 días; (*) datos obtenidos de la revisión de Herlenius;

$(+)$ Solo se incluyen las muertes postnatales; (nd) no hay datos 


\section{ANEXO IV. FOREST PLOTS}

Comparación: CPP temprano vs. cuidados habituales Desenlace: Éxito en la primera toma (puntuación IBFAT 10-12 o BAT 8-12)

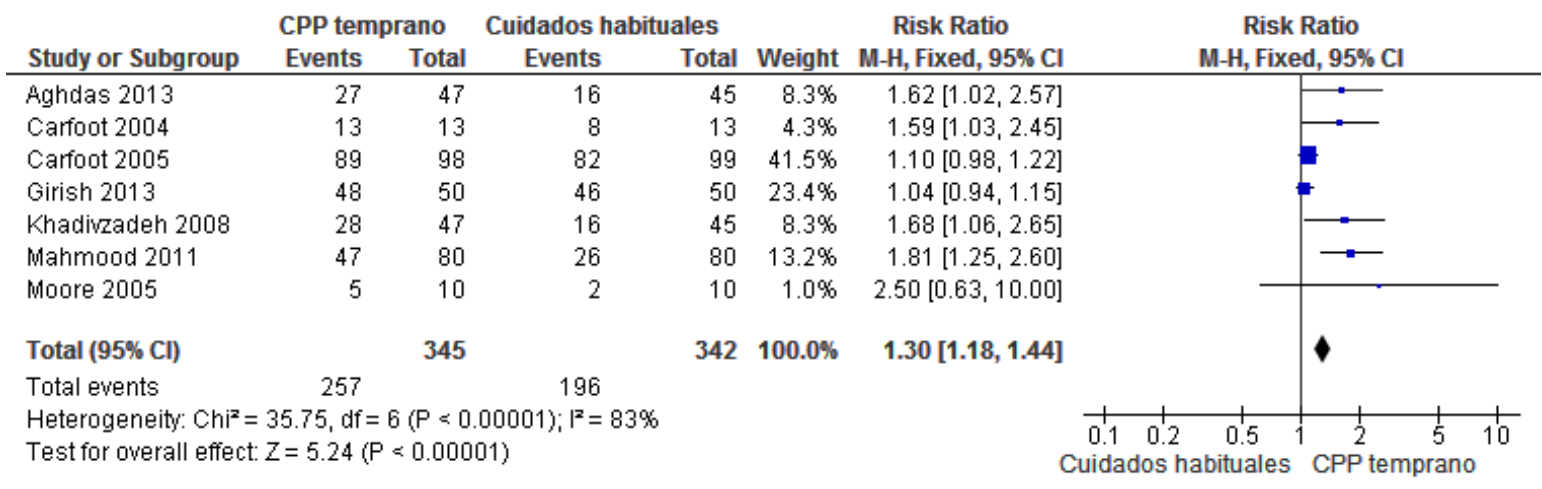

Comparación: CPP temprano vs. cuidados habituales Desenlace: LME al alta

\begin{tabular}{|c|c|c|c|c|c|c|c|}
\hline \multirow[b]{2}{*}{ Study or Subgroup } & \multicolumn{2}{|c|}{ CPP temprano } & \multicolumn{2}{|c|}{ Cuidados habituales } & \multirow[b]{2}{*}{ Weight } & \multirow{2}{*}{$\begin{array}{c}\text { Risk Ratio } \\
\text { M-H, Fixed, } 95 \% \mathrm{Cl}\end{array}$} & \multirow{2}{*}{$\begin{array}{c}\text { Risk Ratio } \\
\text { M-H, Fixed, } 95 \% \mathrm{Cl}\end{array}$} \\
\hline & Events & Total & Events & Total & & & \\
\hline Gouchon 2010 & 9 & 17 & 9 & 17 & $53.6 \%$ & $1.00[0.53,1.88]$ & \\
\hline Thukral 2012 & 19 & 20 & 8 & 21 & $46.4 \%$ & $2.49[1.43,4.34]$ & $\rightarrow-$ \\
\hline Total $(95 \% \mathrm{Cl})$ & & 37 & & 38 & $100.0 \%$ & $1.69[1.13,2.54]$ & \\
\hline Total events & 28 & & 17 & & & & \\
\hline \multicolumn{7}{|c|}{$\begin{array}{l}\text { Heterogeneity: } \text { Chi }^{2}=4.53, d f=1(P=0.03) ;\left.\right|^{2}=78 \% \\
\text { Test for overall effect: } Z=2.54(P=0.01)\end{array}$} & $\begin{array}{cccc}0.02 & 0.1 & 1 & 10 \\
\text { Cuidados habituales } & \text { CPP temprano }\end{array}$ \\
\hline
\end{tabular}

Comparación: CPP temprano vs. cuidados habituales Desenlace: Duración de la LM

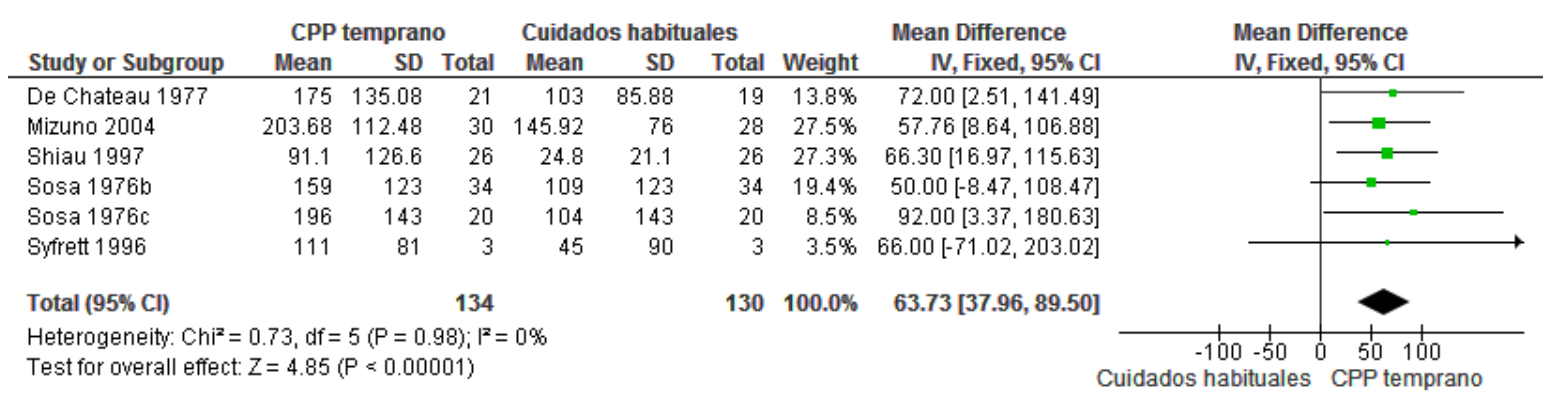


Comparación: CPP temprano vs. cuidados habituales Desenlace: LM 3 meses

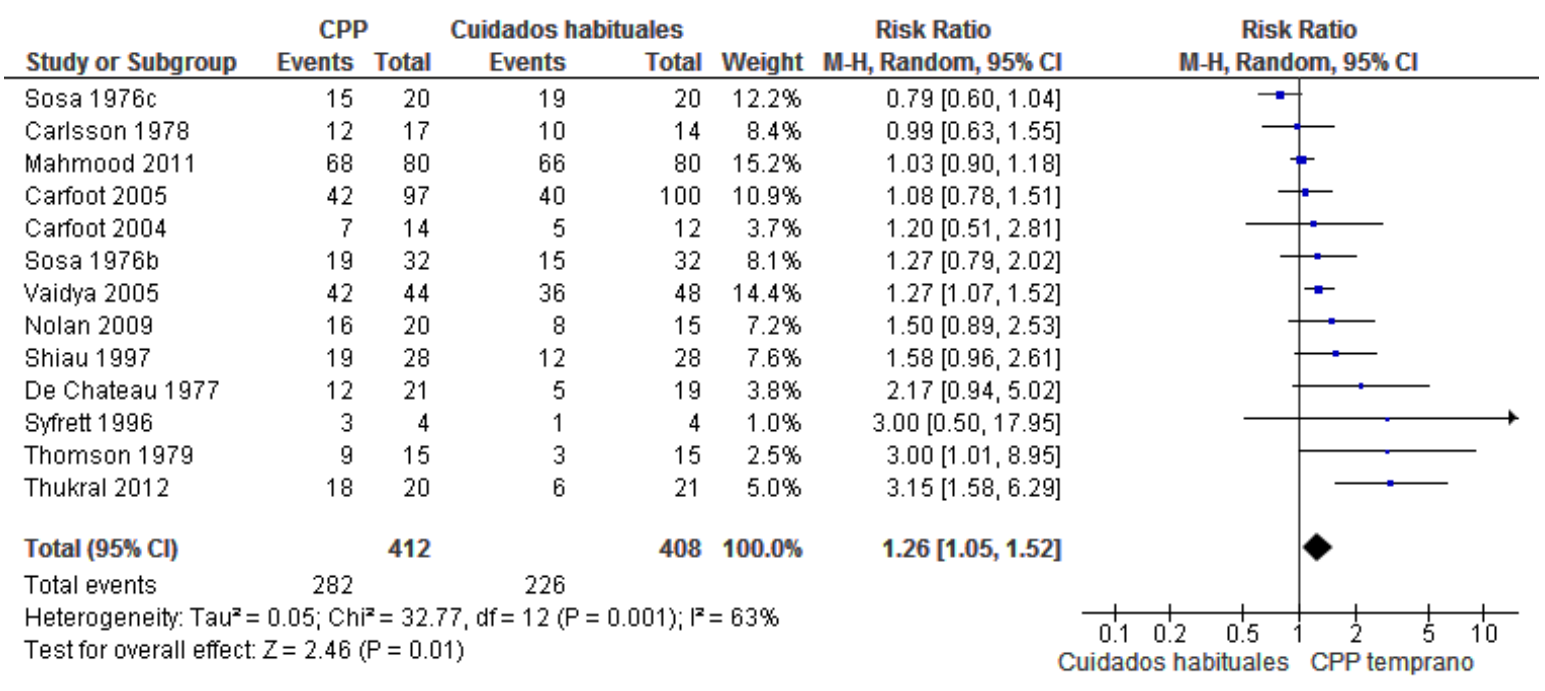

Comparación: CPP temprano vs. cuidados habituales Desenlace: LME 3 meses

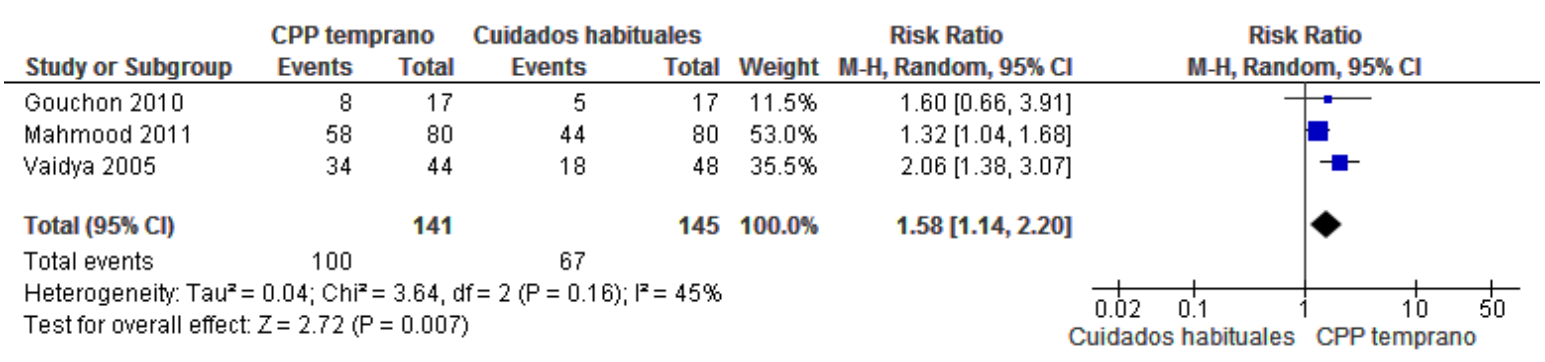

Comparación: CPP temprano vs. cuidados habituales Desenlace: Problemas en las mamas (puntuación)

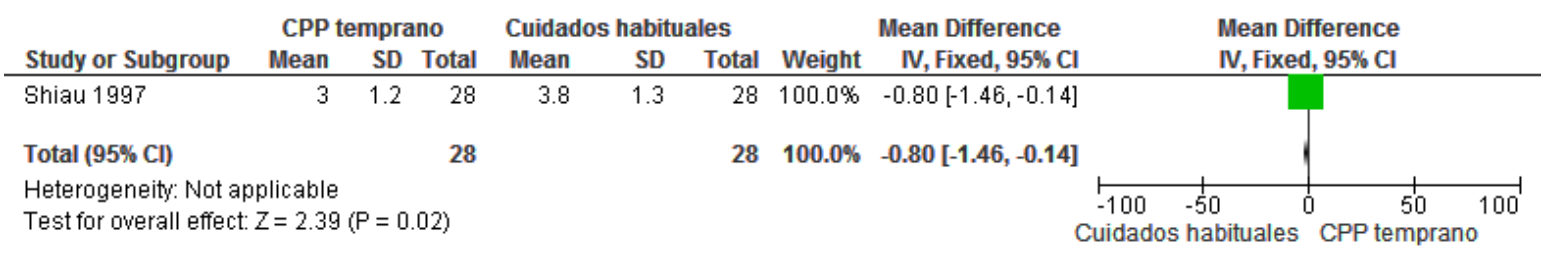

Comparación: CPP temprano vs. cuidados habituales Desenlace: Problemas en las mamas (\% de mujeres)

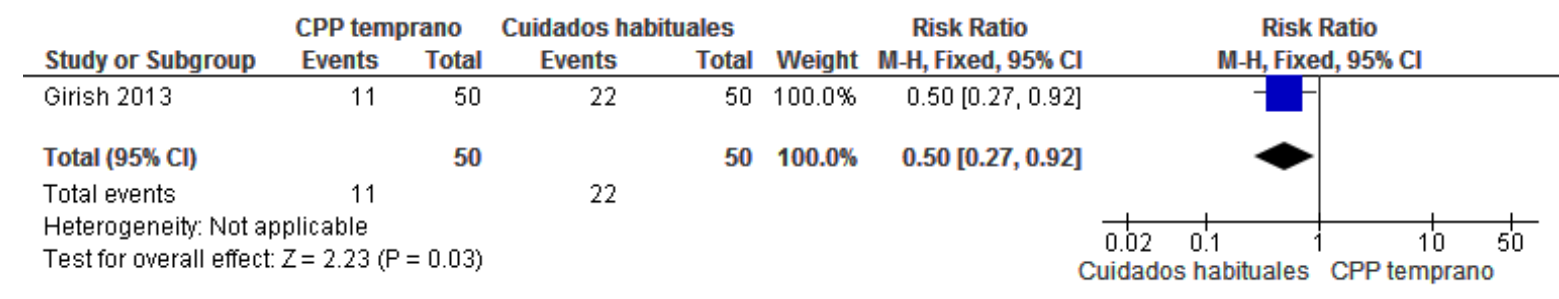


Comparación: CPP temprano vs. cuidados habituales Desenlace: Peso del RN (48-72h) (variación peso respecto nacimiento)

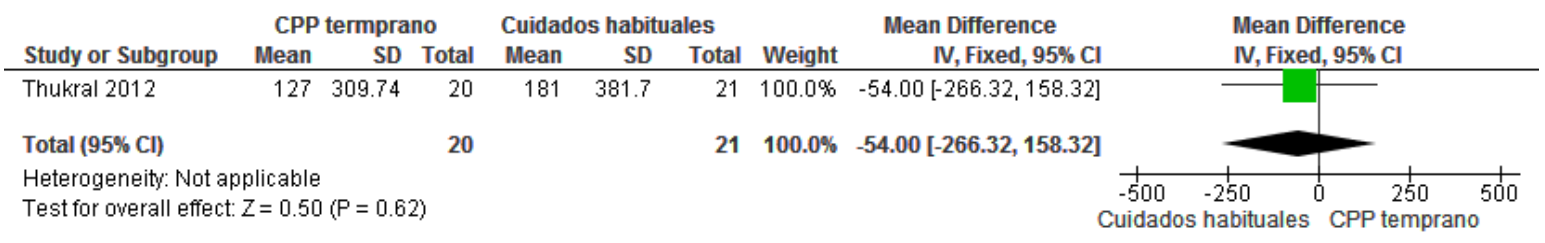

Comparación: CPP temprano vs. cuidados habituales

Desenlace: Satisfacción materna con el cuidado recibido

\begin{tabular}{|c|c|c|c|c|c|c|c|c|}
\hline \multirow[b]{2}{*}{ Study or Subgroup } & \multicolumn{2}{|c|}{ CPP temprano } & \multicolumn{2}{|c|}{ Cuidados habituales } & \multirow[b]{2}{*}{ Weight } & \multirow{2}{*}{$\begin{array}{c}\text { Risk Ratio } \\
\text { M-H, Random, } 95 \% \mathrm{Cl} \\
\end{array}$} & \multirow{2}{*}{\multicolumn{2}{|c|}{$\begin{array}{c}\text { Risk Ratio } \\
\text { M-H, Random, } 95 \% \mathrm{Cl}\end{array}$}} \\
\hline & Events & Total & Events & Total & & & & \\
\hline Mahmood 2011 & 69 & 80 & 29 & 80 & $71.8 \%$ & $2.38[1.76,3.22]$ & & \\
\hline Nahidi 2011 & 36 & 40 & 12 & 40 & $28.2 \%$ & $3.00[1.85,4.87]$ & & $\rightarrow-$ \\
\hline Total $(95 \% \mathrm{Cl})$ & & 120 & & 120 & $100.0 \%$ & $2.54[1.96,3.28]$ & & \\
\hline Total events & 105 & & 41 & & & & & \\
\hline $\begin{array}{l}\text { Heterogeneity: Tau } \\
\text { Test for overall effec }\end{array}$ & $\begin{array}{l}0.00 ; \mathrm{Chi}^{2} \\
\mathrm{Z}=7.10(\mathrm{~F}\end{array}$ & $\begin{aligned} & 0.64, d \\
= & 0.000\end{aligned}$ & $\begin{array}{l}f f=1(P=0.4 \\
01)\end{array}$ & $=0 \%$ & & & $\begin{array}{cc}0.02 & 0.1 \\
\text { Cuidados habituales }\end{array}$ & ${ }_{\text {CPP temprano }}^{10} 50$ \\
\hline
\end{tabular}

Comparación: CPP temprano vs. cuidados habituales Desenlace: Preferencia mismo tratamiento en el futuro

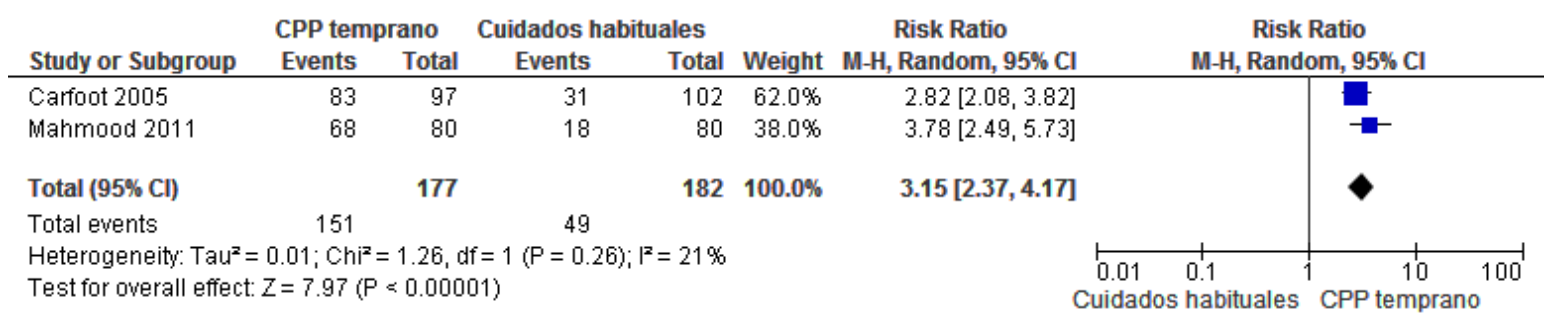


Comparación: CPP temprano vs. cuidados habituales Desenlace: Seguridad

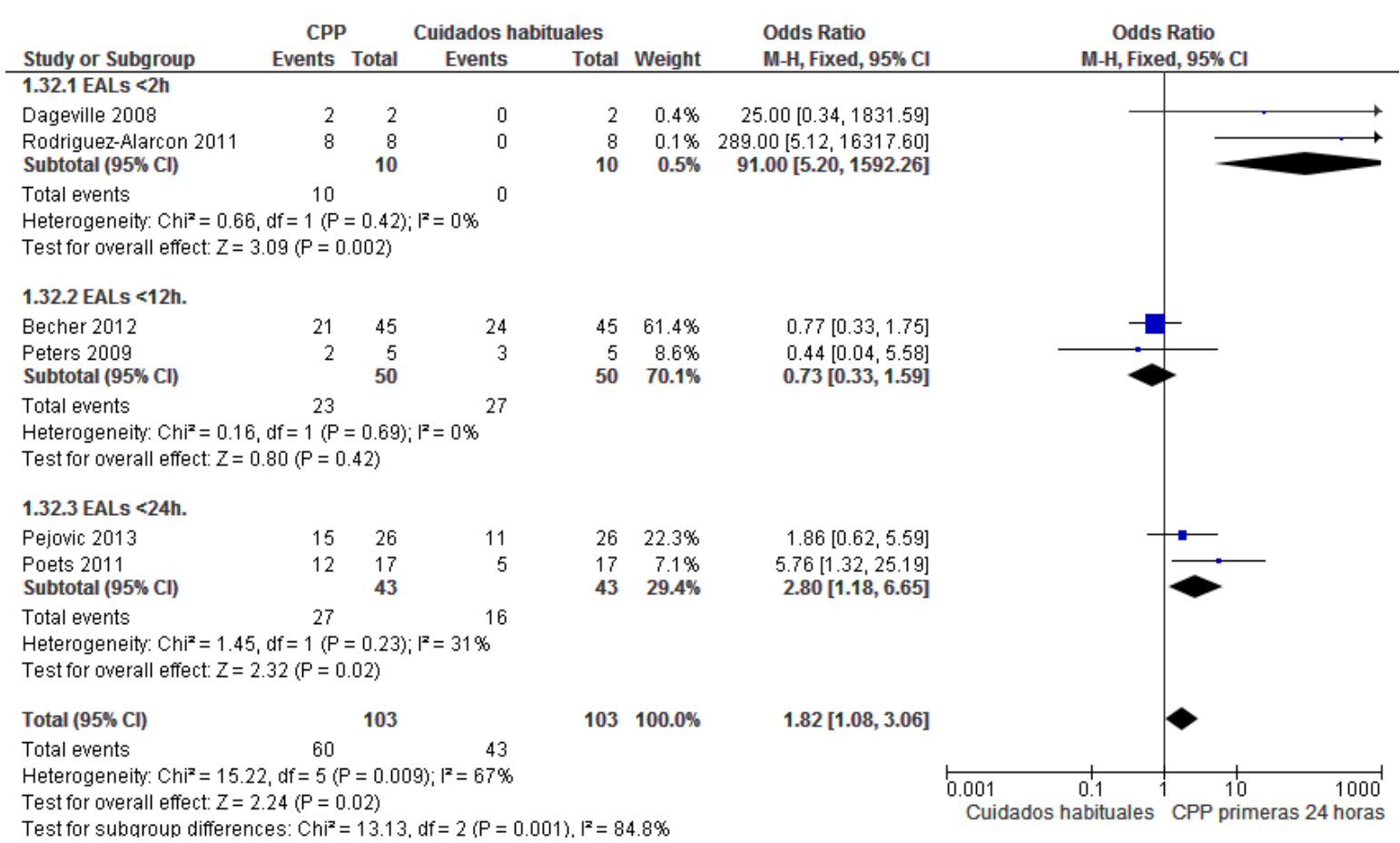

\section{Subgrupo cesarea}

Comparación: CPP temprano tras parto por cesárea vs. cuidados habituales Desenlace: primera toma correcta (puntuación IBAT)

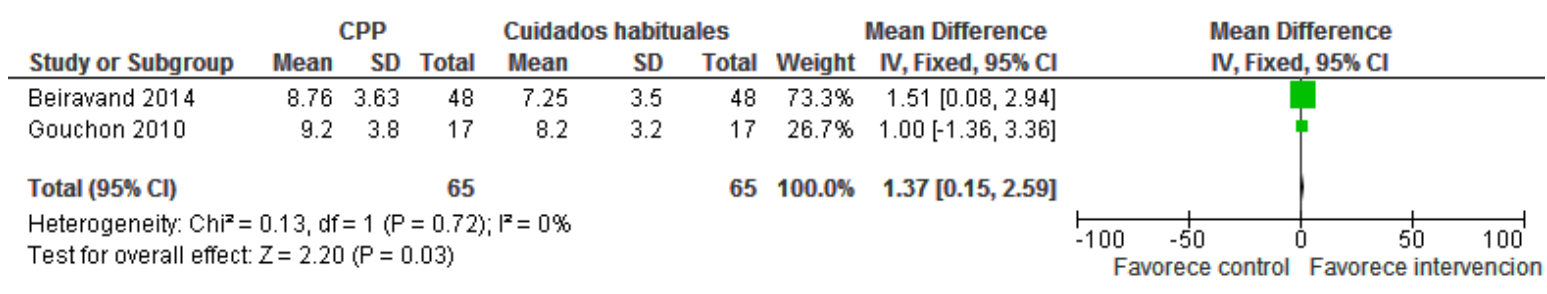

Comparación: CPP temprano tras parto por cesárea vs. cuidados habituales Desenlace: LME al alta

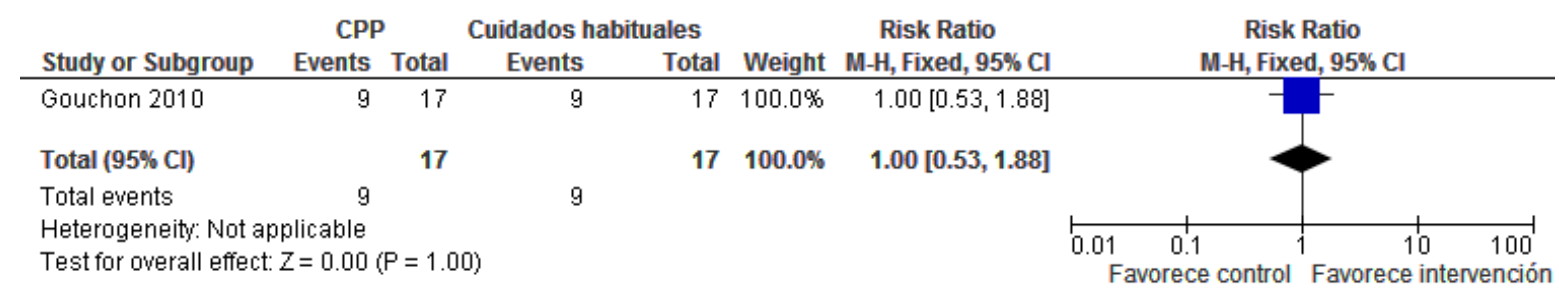


Comparación: CPP temprano tras parto por cesárea vs. cuidados habituales Desenlace: LM al alta

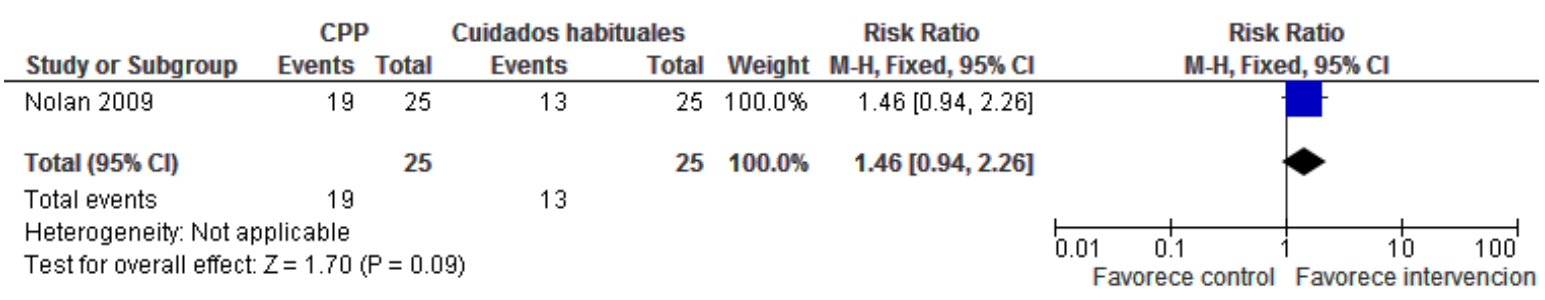

Comparación: CPP temprano tras parto por cesárea vs. cuidados habituales Desenlace: LME a los 3 meses

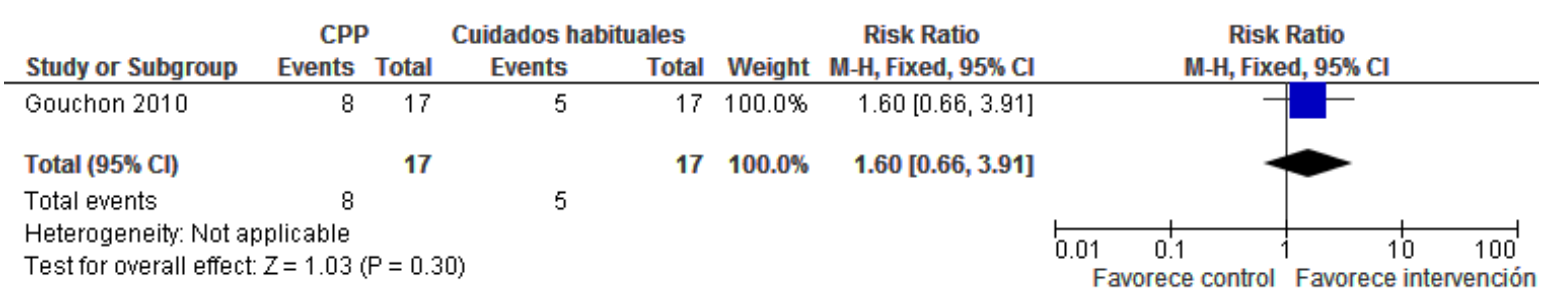

Comparación: CPP temprano tras parto por cesárea vs. cuidados habituales Desenlace: LM a los 1-3 meses

\begin{tabular}{|c|c|c|c|c|c|c|c|c|}
\hline \multirow[b]{2}{*}{ Study or Subgroup } & \multicolumn{2}{|c|}{ CPP } & \multicolumn{2}{|c|}{ Cuidados habituales } & \multirow[b]{2}{*}{ Weight } & \multirow{2}{*}{$\begin{array}{c}\text { Risk Ratio } \\
\text { M-H, Random, } 95 \% \mathrm{Cl}\end{array}$} & \multirow{2}{*}{$\begin{array}{c}\text { Risk Ratio } \\
\text { M-H, Random, } 95 \% \mathrm{Cl}\end{array}$} & \\
\hline & Events & Total & Events & Total & & & & \\
\hline Gouchon 2010 & 11 & 17 & 8 & 17 & $52.2 \%$ & $1.38[0.74,2.54]$ & & \\
\hline Nolan 2009 & 16 & 25 & 8 & 25 & $47.8 \%$ & $2.00[1.05,3.80]$ & & \\
\hline Total $(95 \% \mathrm{Cl})$ & & 42 & & 42 & $100.0 \%$ & $1.64[1.05,2.56]$ & & \\
\hline Total events & 27 & & 16 & & & & & \\
\hline \multicolumn{7}{|c|}{$\begin{array}{l}\text { Heterogeneity: } \operatorname{Tau}^{2}=0.00 ; \mathrm{Chi}^{2}=0.70, \mathrm{df}=1(P=0.40) ;\left.\right|^{2}=0 \% \\
\text { Test for overall effect: } Z=2.20(P=0.03)\end{array}$} & $\begin{array}{lll}0.01 & 0.1 & 1\end{array}$ & $\begin{array}{c}100 \\
\text { venciór }\end{array}$ \\
\hline
\end{tabular}

Comparación: CPP temprano tras parto por cesárea vs. cuidados habituales Desenlace: duración de la LM (total días)

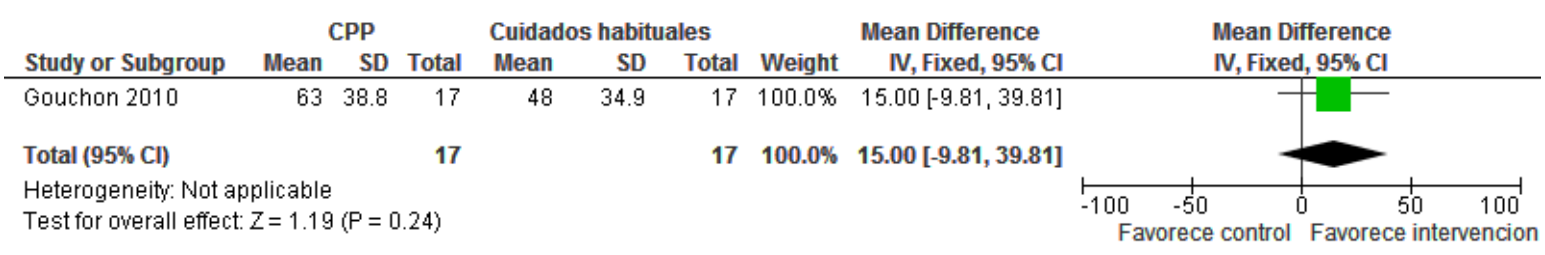




\section{BIBLIOGRAFÍA}

(1) Moore ER, Anderson GC, Bergman N, Dowswell T. Early skin-to-skin contact for mothers and their healthy newborn infants. Cochrane Database Syst Rev 2012;5:CD003519.

(2) Herlenius E, Kuhn P. Sudden unexpected postnatal collapse of newborn infants: a review of cases, definitions, risks, and preventive measures. Transl Stroke Res 2013 Apr;4(2):236-47.

(3) NICE. Postnatal care up to 8 weeks after birth. Julio 2006 (actualizado en Febrero de 2015). Disponible en: http://guidance.nice.org.uk/CG37.

(4) IHAN. Hospitales IHAN. Guía detallada para la aplicación paso por paso. Disponible en: https://www.ihan.es/docs/documentacionacreditacion/hospitales/generales/00.Guia detallada hospital.pdf.

(5) Anderson GC, Moore E, Hepworth J, Bergman N. Early skin-to-skin contact for mothers and their healthy newborn infants. Cochrane Database Syst Rev 2003;(2):CD003519.

(6) Mikiel-Kostyra K, Mazur J, Boltruszko I. Effect of early skin-to-skin contact after delivery on duration of breastfeeding: a prospective cohort study. Acta Paediatr 2002;91(12):1301-6.

(7) National Institute for Clinical Excellence (NICE). Recommendation for Guidance Executive Review of Clinical Guideline (CG37) - Postnatal care. 2012. Disponible en: http://www.nice.org.uk/guidance/cg37/resources/cg37-postnatalcare-review-decision-march-20122.

(8) Moore ER, Anderson GC, Bergman N. Early skin-to-skin contact for mothers and their healthy newborn infants. Cochrane Database Syst Rev 2007;(3):CD003519.

(9) Moore ER, Anderson GC. Randomized controlled trial of very early motherinfant skin-to-skin contact and breastfeeding status. Journal of Midwifery \& Women's Health 2007 Apr 1;52(2):116-25.

(10) Perinatal Services BC. Health Promotion Guideline. Breastfeeding Healthy Term Infants. 2013 Feb.

(11) Matthiesen AS, Ransjo-Arvidson AB, Nissen E, Uvnas-Moberg K. Postpartum maternal oxytocin release by newborns: effects of infant hand massage and sucking. Birth 2001 Mar;28(1):13-9.

(12) Bramson L, Lee JW, Moore E, Montgomery S, Neish C, Bahjri K, et al. Effect of early skin-to-skin mother--infant contact during the first 3 hours following birth on exclusive breastfeeding during the maternity hospital stay. J Hum Lact 2010 May;26(2):130-7.

(13) Grupo de trabajo de la Guía de Práctica Clínica sobre atención al parto normal. Guía de Práctica Clínica sobre la atención al parto normal. Plan de Calidad para el Sistema Nacional de Salud del Ministerio de Sanidad y Política Social. Agencia de Evaluación de Tecnologías Sanitarias del País Vasco (OSTEBA). Agencia de Evaluación de Tecnologías Sanitarias de Galicia (Avalia-t). 2010. Guías de Práctica Clínica en el SNS: OSTEBA No 2009/01 National Collaborating Centre for Women's and Children's Health. Intrapartum care: care of healthy women and their babies during childbirth. Clinical Guideline 2007. 2007.

(14) National Collaborating Centre for Women's and Children's Health. Intrapartum care: care of healthy women and their babies during childbirth. Clinical Guideline 2007. 2007. 
(15) Mercer JS, Erickson-Owens DA, Graves B, Haley MM. Evidence-based practices for the fetal to newborn transition. J Midwifery Womens Health 2007 May;52(3):262-72.

(16) Lucchini Raies C, Márquez Doren F, Uribe Torres C. Efectos del contacto piel con piel del recién nacido con su madre. Index de Enfermería 21, 209-213. 2012.

(17) Feldman-Winter L, Goldsmith JP. Safe Sleep and Skin-to-Skin Care in the Neonatal Period for Healthy Term Newborns. Pediatrics 2016 Sep;138(3).

(18) Stevens J, Schmied V, urns E, ahlen H. Immediate or early skin-to-skin contact after a Caesarean section: a review of the literature. Maternal \& child nutrition 2014.

(19) Gouchon S, Gregori D, Picotto A, Patrucco G, Nangeroni M, Di Giulio P. Skinto-skin contact after cesarean delivery: an experimental study. Nursing research 2010;59(2):78-84.

(20) Nolan A, Lawrence C. A pilot study of a nursing intervention protocol to minimize maternal-infant separation after cesarean birth. Journal of Obstetric, Gynecologic, \& Neonatal Nursing 2009;38(4):430-42.

(21) Sosa R, Kennell JH, Klaus M, Urrutia JJ. The effect of early mother-infant contact on breast feeding, infection and growth. Ciba Found Symp 1976;45:179-93.

(22) Nahidi F, Ravari M, Akbarzade A. Effect of early skin- to- skin contact of mother and newborn on mother's satisfaction. Journal of Nursing and Midwifery 2010;20(71).

(23) Mahmood I, Jamal M, Khan N. Effect of mother-infant early skin-to-skin contact on breastfeeding status: a randomized controlled trial. J Coll Physicians Surg Pak 2011 Oct;21(10):601-5.

(24) Thukral A, Sankar MJ, Agarwal R, Gupta N, Deorari AK, Paul VK. Early skin-toskin contact and breast-feeding behavior in term neonates: a randomized controlled trial. Neonatology 2012;102(2):114-9.

(25) Aghdas K, Talat K, Sepideh B. Effect of immediate and continuous motherinfant skin-to-skin contact on breastfeeding self-efficacy of primiparous women: a randomised control trial. Women Birth 2014 Mar;27(1):37-40.

(26) Girish M, Mujawar N, Gotmare P, Paul N, Punia S, Pandey P. Impact and feasibility of breast crawl in a tertiary care hospital. J Perinatol 2013 Apr;33(4):288-91.

(27) Carfoot S, Williamson PR, Dickson R. The value of a pilot study in breastfeeding research. Midwifery 2004 Jun;20(2):188-93.

(28) Carfoot S, Williamson P, Dickson R. A randomised controlled trial in the north of England examining the effects of skin-to-skin care on breast feeding. Midwifery 2005 Mar;21(1):71-9.

(29) Khadivzadeh $T$, arimi $A$. The effects of post-birth mother-infant skin-to-skin contact on first breastfeeding. International Journal of Nurse Midwifery Research 2009;14(3):111-6.

(30) De Chateau P., Wiberg B. Long-term effect on mother-infant behaviour of extra contact during the first hour post partum. I. First observations at 36 hours. Acta Paediatr Scand 1977 Mar;66(2):137-43.

(31) Syfrett EB, Anderson GC. Very early kangaroo care beginning at birth for healthy preterm infants and mothers who choose to breastfeed: effect on outcome. A workshop on the Kangaroo-mother method for low birthweight infants. World Health Organisation; 1996 October; Trieste, Italy. 1996. 1996. 
(32) Shiau S-HH. Randomized controlled trial of kangaroo care with full term infants: effects on breastmilk maturation, breast engorgement, and breastfeeding status. International Breastfeeding Conference, Australia's Breastfeeding Association; 1997 October; Sydney, Australia. 1997. 1997.

(33) Mizuno K, Mizuno NF, Shinohara TF, Noda M. Mother-infant skin-to-skin contact after delivery results in early recognition of own mother's milk odour. Acta Paediatr 2004 Dec 1;93(12):1640-5.

(34) Carlsson SG, Fagerberg H, Horneman G, Hwang CP, Larsson K, Rodholm M, et al. Effects of amount of contact between mother and child on the mother's nursing behavior. Dev Psychobiol 1978 Mar;11(2):143-50.

(35) Thomson ME, Hartsock TG, Larson C. The importance of immediate postnatal contact: its effect on breastfeeding. Can Fam Physician 1979 Nov;25:1374-8.

(36) Vaidya K, Sharma A, Dhungel S. Effect of early mother-baby close contact over the duration of exclusive breastfeeding. Nepal Med Coll J 2005 Dec;7(2):13840.

(37) Dageville C, Pignol J, De SS. Very early neonatal apparent life-threatening events and sudden unexpected deaths: incidence and risk factors. Acta Paediatr 2008 Jul;97(7):866-9.

(38) Peters C, Becher JC, Lyon AJ, Midgley PC. Who is blaming the baby? Arch Dis Child Fetal Neonatal Ed 2009 Sep;94(5):F377-F378.

(39) Poets A, Urschitz MS, Steinfeldt R, Poets CF. Risk factors for early sudden deaths and severe apparent life-threatening events. Arch Dis Child Fetal Neonatal Ed 2012 Nov;97(6):F395-F397.

(40) Rodriguez-Alarcon J, Melchor JC, Linares A, Aranguren G, Quintanilla M, Fernandez-Llebrez L, et al. Early neonatal sudden death or near death syndrome. An epidemiological study of 29 cases. Acta Paediatr 1994 Jul;83(7):704-8.

(41) Becher JC, Bhushan SS, Lyon AJ. Unexpected collapse in apparently healthy newborns--a prospective national study of a missing cohort of neonatal deaths and near-death events. Arch Dis Child Fetal Neonatal Ed 2012 Jan;97(1):F30F34.

(42) Pejovic NJ, Herlenius E. Unexpected collapse of healthy newborn infants: risk factors, supervision and hypothermia treatment. Acta Paediatr 2013 Jul;102(7):680-8.

(43) Beiranvand S, Valizadeh F, Hosseinabadi R, Pournia Y. The Effects of Skin-toSkin Contact on Temperature and Breastfeeding Successfulness in Full-Term Newborns after Cesarean Delivery. Int J Pediatr 2014 Dec 25;2014:846486.

(44) Burke-Aaronson AC. Skin-to-skin care and breastfeeding in the perioperative suite. MCN Am J Matern Child Nurs 2015 Mar;40(2):105-9.

(45) Dumas L, Lepage M, Bystrova K, Matthiesen AS, Welles-Nyström B, Widström AM. Influence of Skin-to-Skin Contact and Rooming-In on Early Motherâ€“Infant Interaction: A Randomized Controlled Trial. Clinical Nursing Research 2013 Aug 1;22(3):310-36.

(46) Moran-Peters JA, Zauderer CR, Goldman S, Baierlein J, Smith AE. A Quality Improvement Project Focused on Women's Perceptions of Skin-to-Skin Contact After Cesarean Birth. Nursing for women's health 2014;18(4):294-303.

(47) Dalbye R, Calais E, Berg M. Mothers' experiences of skin-to-skin care of healthy full-term newborns--a phenomenology study. Sexual \& Reproductive Healthcare 2011;2(3):107-11.

(48) Barbero P, Madamangalam AS, Shields A. Skin to Skin after cesarean birth. Journal of Human Lactation 2013;29(4):446-8. 
GPC Lactancia Materna - pregunta 1. Contacto piel con piel

(49) Zwedberg S, Blomquist J, Sigerstad E. Midwives' experiences with motherinfant skin-to-skin contact after a caesarean section: "Fighting an uphill battle". Midwifery 2015;31(1):215-20. 
PREGUNTAS CLÍNICAS N² y N³

¿Cómo debería ser la primera toma del recién nacido?

\section{Pregunta clínica en formato PICO}

Comparación 1 (Pregunta 2): Inicio temprano (primera hora) vs. inicio tardío (después de la primera hora)

Tabla 1. Componentes de la pregunta clínica en formato PICO

\begin{tabular}{|c|c|}
\hline Pacientes & RN sanos a término \\
\hline Exposición & Primera toma en la primera hora (inicio temprano) \\
\hline Comparación & Primera toma después de la primera hora (inicio tardío) \\
\hline Desenlaces & $\begin{array}{l}\text {-Primera toma correcta (crítica) } \\
\text {-Tasa de LME al alta (crítica) } \\
\text {-Inicio de la lactogénesis II (importante) } \\
\text {-Duración de la lactancia materna (crítica) } \\
\text {-Peso del bebé (48-72h.) (crítica) } \\
\text {-Complicaciones de las mamas (crítica) } \\
\text {-Uso de suplementos (crítica) } \\
\text {-Satisfacción materna (con los cuidados recibidos) (crítica) } \\
\text {-Tasa de LM a los } 4 \text { meses (importante) } \\
\text {-Tasa de LME a los } 4 \text { meses (importante) }\end{array}$ \\
\hline Tipo de estudio & GPC, RS, ECA y estudios observacionales \\
\hline
\end{tabular}

Comparación 2 (Pregunta 3): Agarre espontáneo vs. Agarre dirigido del RN al pecho

Tabla 2. Componentes de la pregunta clínica en formato PICO

\begin{tabular}{|c|c|}
\hline Pacientes & RN sanos a término \\
\hline Exposición & Agarre espontáneo \\
\hline Comparación & Agarre dirigido del $\mathrm{RN}$ al pecho \\
\hline Desenlaces & $\begin{array}{l}\text {-Primera toma correcta (crítica) } \\
\text {-Tasa de LME al alta (crítica) } \\
\text {-Inicio de la lactogénesis II (importante) } \\
\text {-Duración de la lactancia materna (crítica) } \\
\text {-Peso del bebé (48-72h.) (crítica) } \\
\text {-Complicaciones de las mamas (crítica) } \\
\text {-Uso de suplementos (crítica) } \\
\text {-Satisfacción materna (con los cuidados recibidos) (crítica) } \\
\text {-Tasa de LM a los } 4 \text { meses (importante) } \\
\text {-Tasa de LME a los } 4 \text { meses (importante) }\end{array}$ \\
\hline Tipo de estudio & GPC, RS, ECA y estudios observacionales \\
\hline
\end{tabular}




\section{Introducción}

La preocupación por conseguir que la lactancia se inicie en la primera hora de vida, al considerarse una condición importante para su éxito hace que, en ocasiones, los profesionales coloquen al recién nacido directamente sobre el pezón y fuercen un agarre que debería ser espontáneo.

Sin embargo, aunque sí es conveniente que los recién nacidos succionen y estimulen el pecho cuanto antes, estudios recientes sugieren que el agarre espontáneo favorece un mejor acoplamiento de la boca al pecho.

Por todo ello, se pretende determinar la evidencia existente y cuál de las dos posturas, intervención activa frente a actitud expectante, es más recomendable. 


\section{Estrategia de elaboración de la pregunta}

\subsection{GPC}

Tabla 3. GPC de base (seleccionadas con el AGREE)

\begin{tabular}{|c|c|c|c|c|}
\hline Guía & Evidencia & Recomendación & Referencias & Comentarios \\
\hline NICE 2006 & 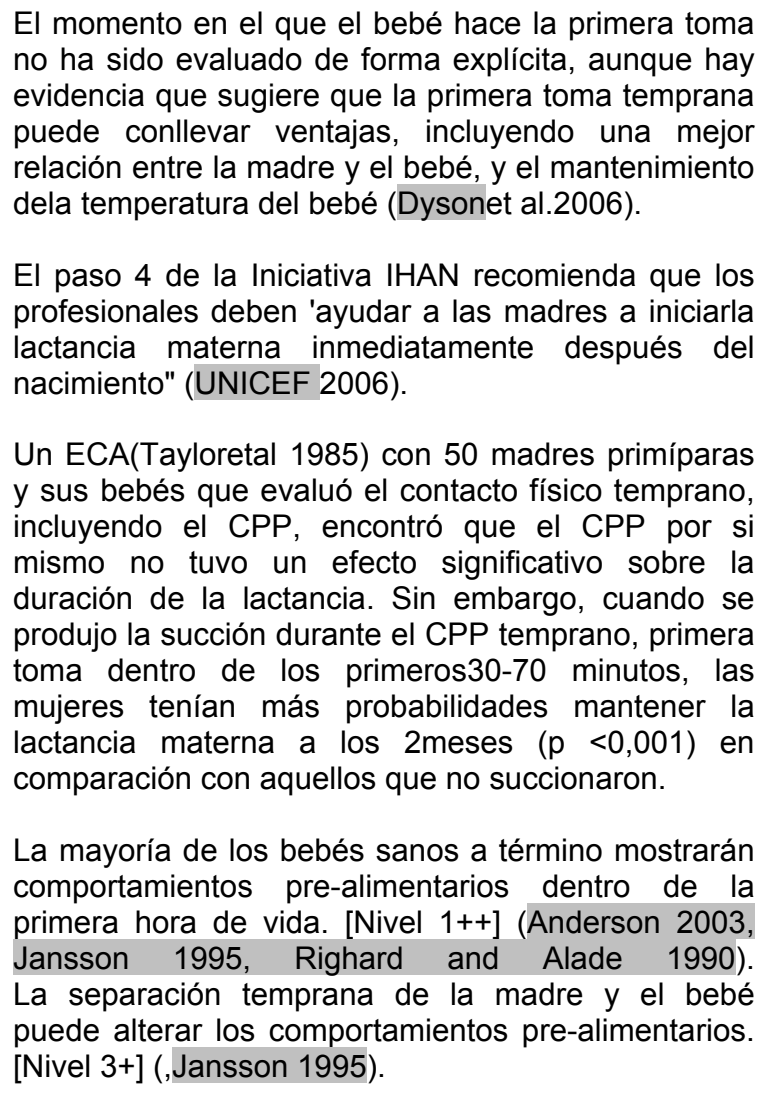 & $\begin{array}{l}\text { El inicio dela lactancia materna debería } \\
\text { hacerse tan pronto como sea posible } \\
\text { después del nacimiento, idealmente } \\
\text { dentro de1 hora. } \\
\text { Como parte de la atención postnatal en } \\
\text { el hospital se debe facilitar un entorno } \\
\text { adecuado para la LM. Esto incluye } \\
\text { hacer las disposiciones necesarias para } \\
\text { un alojamiento conjunto las } 24 \text { horas y } \\
\text { CPP continuo cuando sea posible [A] } \\
\text { Para un inicio exitoso de la lactancia se } \\
\text { debe evitar la separación de la madre y } \\
\text { del bebé en la primera hora para } \\
\text { realizar procedimientos rutinarios como } \\
\text { pesar, medir o bañar a menos que la } \\
\text { madre lo solicite o esos cuidados sean } \\
\text { necesarios para el cuidado del bebé. [C] }\end{array}$ & $\begin{array}{l}\text { Anderson, G. C., Moore, E., } \\
\text { Hepworth, J., \& Bergman, } \\
\text { N. 2003, "Early skin-to skin } \\
\text { contact for mothers and } \\
\text { their healthy newborn } \\
\text { infants," in Cochrane } \\
\text { Database of Systematic } \\
\text { Reviews 2003 Issue 2, } \\
\text { Chichester, John Wiley \& } \\
\text { Sons Ltd. (RS Cochrane) } \\
\text { Dyson, Renfrew, } \\
\text { McFadden, McCormick, } \\
\text { Herbert and Thomas } \\
\text { 2006,Effectiveness of } \\
\text { public health interventions } \\
\text { to promote the duration of } \\
\text { breastfeeding: systematic } \\
\text { review. London: National } \\
\text { Institute for Health and } \\
\text { Clinical Excellence. } \\
\text { Jansson, U. M., Mustafa, } \\
\text { T., Khan, M. A., Lindblad, } \\
\text { B. S., \&Widström, A. M. } \\
\text { 1995, "The effects of } \\
\text { medically-orientated labour } \\
\text { ward routines on prefeeding } \\
\text { behaviour and body } \\
\text { temperature in newborn } \\
\text { infants", Journal of Tropical }\end{array}$ & \\
\hline
\end{tabular}




\begin{tabular}{|c|c|c|c|}
\hline & & $\begin{array}{l}\text { Pediatrics, vol. 41, no. } 6 \text {, } \\
\text { pp. 360-363. (estudio de } \\
\text { cohortes) } \\
\text { Righard, L. \&Alade, M. O. } \\
\text { 1990, "Effect of delivery } \\
\text { room routines on success } \\
\text { of first breast-feed", Lancet, } \\
\text { vol. 336, no. 8723, pp. } \\
\text { 1105-1107. (estudio de } \\
\text { cohortes) } \\
\text { Taylor, P. M., Maloni, J. A., } \\
\text { Taylor, F. H., \& Campbell, } \\
\text { S. B. 1985, "Extra } \\
\text { earlymother-infant contact } \\
\text { and duration of breast- } \\
\text { feeding", } \\
\text { ActaPaediatricaScandinavic } \\
\text { a, vol. 316, no. Supp, pp. } \\
\text { 15-22. } \\
\text { UNICEF. Ten steps to } \\
\text { successul breastfeeding. } \\
\text { 2006 Available from } \\
\text { URL:www.unicef.org/newsli } \\
\text { ne/tenstps.htm }\end{array}$ & \\
\hline NICE UPDATE & NO & & \\
\hline $\begin{array}{lc}\text { BC } & 2013 \\
\text { BREASTFEEDING } \\
\text { HEALTH } & \text { TERM } \\
\text { INFANTS } & \end{array}$ & $\begin{array}{l}\text { Facilitar el inicio a la LM para madre-hijo; } \\
\text { mantenerlos juntos en CPP para permitir al bebé } \\
\text { lamer, succionar y tocar el pezón con su mano } \\
\text { (Matthiesen 2001). En la primera hora tras el } \\
\text { nacimiento el reflejo de succión del bebé es } \\
\text { generalmente intenso, los bebés están alerta y } \\
\text { despiertos, y las madres experimentan una oleada } \\
\text { de oxitocina que se asocia con la producción de } \\
\text { leche, el aumento de las contracciones uterinas y la } \\
\text { mejora del vínculo madre-hijo (Riordan 2010, }\end{array}$ & $\begin{array}{l}\text { Matthiesen A-S, Ransjö- } \\
\text { Arvidson A-B, Nissen E } \\
\text { \&Uvnäs-Moberg K. (2001). } \\
\text { Postpartum maternal } \\
\text { oxytocin release by } \\
\text { newborns: Effects of infant } \\
\text { hand massage and } \\
\text { sucking. Birth 28(1), 13-19. } \\
\text { (estudioobservacional) } \\
\text { Riordan J \& Wambach, K. }\end{array}$ & \\
\hline
\end{tabular}




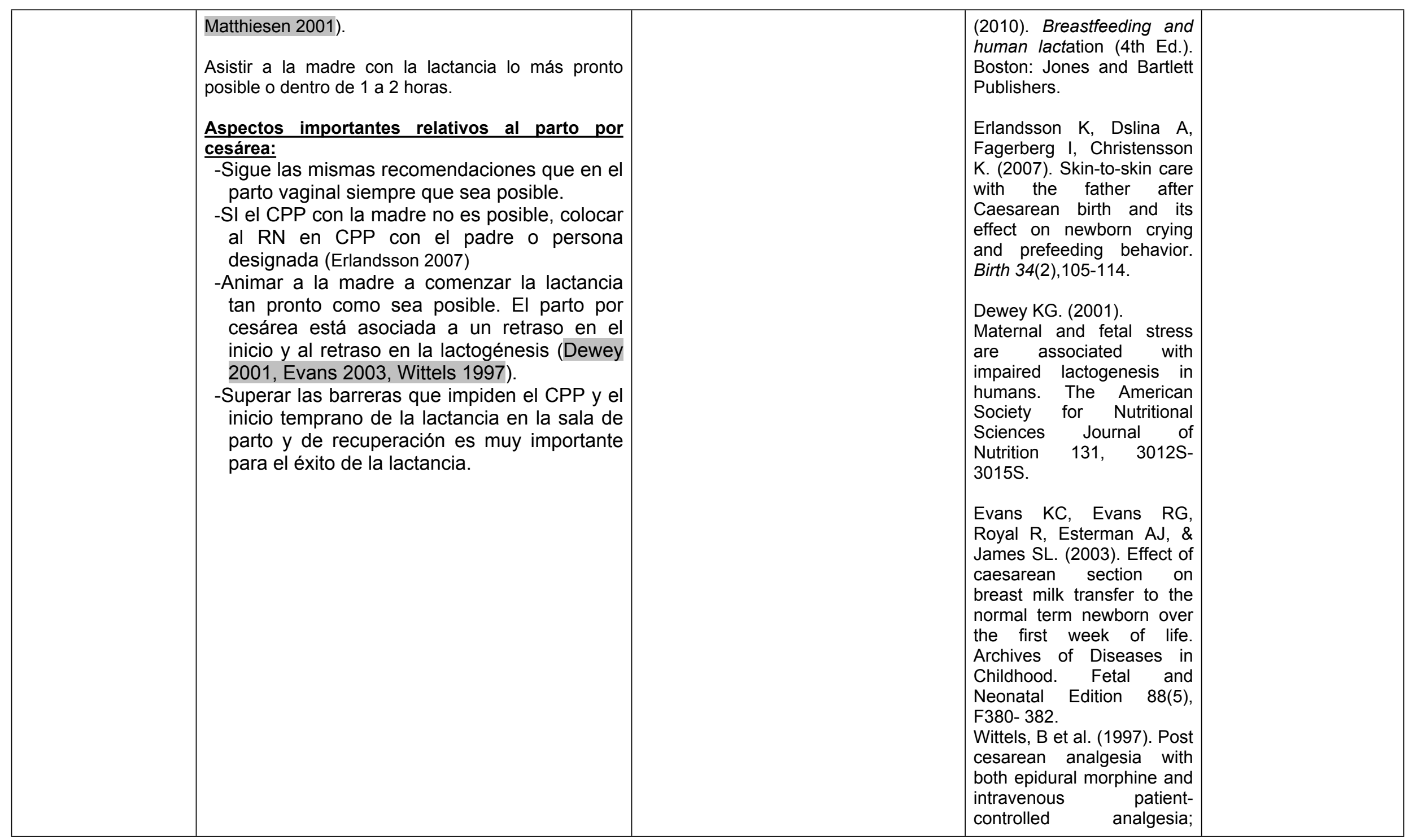




\begin{tabular}{|l|l|l|l|}
\hline & & & Neurobehavioral outcomes \\
among nursing neonates. \\
Anesthesia Analgesia \\
$85(3), 600-6006$.
\end{tabular}

Tabla 4. Resumen de GPC del SNS

\begin{tabular}{|c|c|c|c|c|}
\hline Guía & Evidencia & Recomendación & Referencias & Comentarios \\
\hline GPC parto & NO & & & \\
\hline GPC embarazo & NO & & & \\
\hline
\end{tabular}

Tabla 5. Resúmenes otras guías/ docs de referencia

\begin{tabular}{|c|c|c|c|c|}
\hline Guía & Evidencia & Recomendación & Referencias & Comentarios \\
\hline IHAN/ OMS 3 ES & $\begin{array}{l}\text { No existe evidencia en la investigación referida a la } \\
\text { alimentación de un bebé de término sano que no } \\
\text { amamanta. La mayoría de bebés que no amamantan no } \\
\text { necesitan recibir alimento en la primera hora o dos } \\
\text { después del parto. } \\
\text { El Paso } 4 \text { de los Diez Pasos para una lactancia exitosa } \\
\text { establece: Ayudar a las madres a iniciar la lactancia } \\
\text { durante la media hora después del parto. Este paso se } \\
\text { interpreta ahora como: Colocar a los bebés en CPP con } \\
\text { sus madres inmediatamente después del parto por lo } \\
\text { menos durante una hora y alentar a las madres a } \\
\text { reconocer cuando sus bebés están listos para } \\
\text { amamantar, ofreciendo su ayuda si fuera necesario. }\end{array}$ & $\begin{array}{l}\text { Asegure el CPP precoz, } \\
\text { ininterrumpido, sin prisas, entre la } \\
\text { madre y su bebé sano sin } \\
\text { envolver, } \\
\text { inmediatamente, aún antes de } \\
\text { pinzar el cordón, o tan pronto } \\
\text { como sea posible después del } \\
\text { nacimiento. El CPP debe continuar } \\
\text { por lo menos una hora después } \\
\text { del nacimiento. Se recomienda un } \\
\text { período más prolongado si el bebé } \\
\text { no ha succionado en la primera } \\
\text { hora después del nacimiento. }\end{array}$ & & $\begin{array}{l}\text { Existe cierta confusión } \\
\text { entre el CPP temprano } \\
\text { y el inicio de la LM. }\end{array}$ \\
\hline
\end{tabular}

\subsection{Revisiones sistemáticas}

Se han encontrado dos revisiones sistemáticas en relación a la pregunta $(1 ; 2)$. 


\subsection{Resumen de GPC base y RS disponibles}

\section{Comparación 1. \\ Inicio en la primera hora frente a inicio tardío (después de la primera hora)}

La guía NICE (3) concluye que aunque el momento en que el recién nacidos recibe la primera toma no ha sido evaluado de modo explícito, sí parece existir evidencia que sugiere que el inicio temprano de la lactancia materna conlleva beneficios positivos en su duración. En línea con la recomendación de la IHAN del año 2006, NICE recomienda que lo más adecuado es que se inicie la lactancia en la primera hora de vida.

En concreto el paso cuatro de los Diez Pasos para una lactancia exitosa que se recoge en el documento de la IHAN (4) establece que hay que "ayudar a las madres a iniciar la lactancia durante la media hora después del parto". Este paso se interpreta ahora como: "colocar a los recién nacidos en CPP con sus madres inmediatamente después del parto por lo menos durante una hora de modo ininterrumpido y alentar a las madres a reconocer cuando sus recién nacidos están listos para amamantar, ofreciendo su ayuda si fuera necesario". EI CPP debe de continuar por lo menos una hora después del nacimiento, aunque se recomienda un período más prolongado si el recién nacido no ha succionado en la primera hora tras el nacimiento.

Por otro lado, la guia del PSBC (5) recomienda facilitar el inicio de la lactancia materna manteniendo juntos a la madre y al recién nacido, y recoge evidencia de dos estudios $(6 ; 7)$ que concluyen que el reflejo de succión del recién nacido es generalmente intenso en la primera hora tras el parto. Recomienda además ayudar a la madre con la lactancia lo más pronto posible o dentro las primeras dos horas tras el parto.

En cuanto a los recién nacidos por cesárea, sugiere seguir las mismas recomendaciones que en el parto vaginal siempre que sea posible, e incluye un estudio (8) que sugiere que en caso de que el CPP con la madre no sea posible, se coloque al recién nacidos en CPP con el padre o persona designada. Recomienda además animar a la madre a comenzar la lactancia tan pronto como sea posible, ya que el parto por cesárea está asociado con un retraso en el inicio de la lactancia materna y al retraso en la lactogénesis (9-11). Por lo tanto superar las barreras que impiden el CPP y el inicio temprano de la lactancia en la sala de parto y de recuperación es muy importante para el éxito de la lactancia.

Se han encontrado dos RS en relación al inicio de la primera toma que finalmente no se han incluido en la revisión. Por un lado la revisión de Debes (1) define inicio temprano a la realización de la primera toma en las primeras 24 horas tras el nacimiento. Además, no ofrece resultados en las variables de interés. Por otro, la revisión de Khan (2) si incluye dos estudios que evalúan el inicio de la lactancia materna en la primera hora de vida $(12 ; 13)$, pero solo evalúan el desenlace de mortalidad.

Comparación 2. Agarre espontáneo vs. agarre dirigido al pecho en la primera toma

La GPC NICE (3) recoge la evidencia de un ECA (14) que concluye que el CPP con agarre/ succión se asocia a una mayor duración de la lactancia materna.

Aunque la revisión Cochrane de Moore (15) destaca la importancia del agarre espontáneo no lo evalúa de modo explícito, por lo que no se ha incluido en la revisión. 


\subsection{Conclusión}

Comparación 1. Inicio temprano (primera hora) vs. inicio tardío (después de la primera hora)

En base a la evidencia encontrada se decide hacer una actualización de la GPC de NICE (3).

\begin{tabular}{|c|l|}
\hline & Adopción GPC/Revisión sistemática \\
\hline $\mathrm{X}$ & Elaboración parcial \\
\hline & Elaboración de novo \\
\hline
\end{tabular}

Comparación 2. Agarre espontáneo vs. agarre dirigido al pecho en la primera toma

\begin{tabular}{|l|l|}
\hline & Adopción GPC/Revisión sistemática \\
\hline & Elaboración parcial \\
\hline & Elaboración de novo \\
\hline
\end{tabular}

\subsection{Diseño de la estrategia de búsqueda de estudios individuales}

Comparación 1. Inicio temprano (primera hora) vs. inicio tardío (después de la primera hora)

Criterios de selección de ECAs o estudios observacionales en caso de no haber ECAs estudios

\begin{tabular}{|l|l|}
\hline Período de búsqueda & 2005- enero 2015 \\
\hline Bases de datos & $\begin{array}{l}\text { Cochrane Library, Medline (Pubmed), Embase(OVID), Cinalh } \\
\text { (EBSCO) }\end{array}$
\end{tabular}

Comparación 2. Agarre espontáneo vs. agarre dirigido al pecho en la primera toma

\begin{tabular}{|l|l|}
\hline $\begin{array}{l}\text { Criterios de selección de } \\
\text { estudios }\end{array}$ & $\begin{array}{l}\text { ECAs y estudios de cohortes o estudios observacionales en caso } \\
\text { de no encontrar }\end{array}$ \\
\hline Período de búsqueda & Hasta enero 2015 \\
\hline Bases de datos & $\begin{array}{l}\text { Cochrane Library, Medline via Pubmed, Embase via OVID, } \\
\text { Cinahlvia EBSCO }\end{array}$ \\
\hline
\end{tabular}

Ver estrategias de búsqueda de estudios originales en el ANEXO I. 


\section{4- Resumen de la evidencia (Tablas de estudios individuales y valoración de calidad en el ANEXO X)}

\subsection{GRADE Evidence Profile}

Comparación 1. Inicio temprano vs. Inicio tardío

1- Inicio temprano (Primeros 30 minutos) vs. Inicio tardío (Más de 30 minutos).

\begin{tabular}{|c|c|c|c|c|c|c|c|c|c|c|c|c|}
\hline & & & & & & & \multicolumn{4}{|c|}{ Resumen de los resultados } & \multirow{3}{*}{ Calidad } & \multirow{3}{*}{ Importancia } \\
\hline \multicolumn{7}{|c|}{ Evaluación de la calidad } & \multicolumn{2}{|c|}{$\mathrm{N}^{\circ}$ de pacientes } & \multicolumn{2}{|r|}{ Magnitud del efecto } & & \\
\hline $\begin{array}{l}\mathrm{N}^{\circ} \text { de } \\
\text { estudi } \\
\text { os }\end{array}$ & Diseño & $\begin{array}{l}\text { Riesgo } \\
\text { de } \\
\text { sesgo }\end{array}$ & Inconsistencia & \begin{tabular}{|l|} 
Evidencia \\
indirecta
\end{tabular} & Imprecisión & $\begin{array}{c}\text { Otras } \\
\text { consideraciones }\end{array}$ & $\begin{array}{l}\text { Primeros } \\
30 \mathrm{~min}\end{array}$ & $\begin{array}{l}\text { Más de } \\
30 \mathrm{~min}\end{array}$ & $\begin{array}{l}\text { Relativa } \\
(95 \% \mathrm{CI})\end{array}$ & Absoluta por 1000 & & \\
\hline \multicolumn{13}{|c|}{ LME 1 mes } \\
\hline \multirow[t]{2}{*}{11} & \multirow[t]{2}{*}{ ECA } & \multirow[t]{2}{*}{ Serio ${ }^{2}$} & \multirow[t]{2}{*}{ No serio } & \multirow[t]{2}{*}{ No serio } & \multirow[t]{2}{*}{ Serio $^{3}$} & \multirow[t]{2}{*}{ No } & $\begin{array}{l}26 / 26 \\
(100 \%) \\
\end{array}$ & $\begin{array}{l}20 / 20 \\
(100 \%)\end{array}$ & \multirow[t]{2}{*}{\begin{tabular}{|c|} 
RR $1(0,92 \mathrm{a}$ \\
$1,09)$
\end{tabular}} & $\begin{array}{c}0 \text { menos por } 1000 \text { (de } 80 \\
\text { menos a } 90 \text { más) }\end{array}$ & \multirow[t]{2}{*}{ MODERADA } & \multirow[t]{2}{*}{ CRITICA } \\
\hline & & & & & & & & $100 \%$ & & $\begin{array}{c}0 \text { menos por } 1000 \text { (de } 80 \\
\text { menos a } 90 \text { más) }\end{array}$ & & \\
\hline \multicolumn{13}{|c|}{ LME 4 meses } \\
\hline \multirow[t]{2}{*}{$1^{11}$} & \multirow[t]{2}{*}{ ECA } & \multirow[t]{2}{*}{ Serio $^{2}$} & \multirow[t]{2}{*}{ No serio } & \multirow[t]{2}{*}{ No serio } & \multirow[t]{2}{*}{ Serio $^{3}$} & \multirow[t]{2}{*}{ No } & $\begin{array}{c}9 / 26 \\
(34.6 \%) \\
\end{array}$ & $\begin{array}{c}3 / 20 \\
(15 \%)\end{array}$ & \multirow[t]{2}{*}{\begin{tabular}{|c|} 
RR 2,31 \\
$(0,72$ a 7,43$)$
\end{tabular}} & $\begin{array}{c}197 \text { more per } 1000 \text { (de } 42 \\
\text { menos a } 965 \text { más) }\end{array}$ & \multirow[t]{2}{*}{ MODERADA } & \multirow[t]{2}{*}{ IMPORTANTE } \\
\hline & & & & & & & & $15 \%$ & & $\begin{array}{c}197 \text { más por } 1000 \text { (de } 42 \\
\text { menos a } 965 \text { más) }\end{array}$ & & \\
\hline \multicolumn{13}{|c|}{ LM 1 mes } \\
\hline $1^{4}$ & observacional & Serio $^{5}$ & No serio & No serio & No serio & Otras $^{6}$ & - & - & $\begin{array}{c}\text { OR } 1,47 \\
(1,13 \text { a } 1,90) \\
\end{array}$ & No calculable & MUY BAJA & IMPORTANTE \\
\hline \multicolumn{13}{|c|}{ LM 3 meses } \\
\hline \multirow[t]{2}{*}{14} & \multirow[t]{2}{*}{ Observacional } & \multirow[t]{2}{*}{ Serio $^{5}$} & \multirow[t]{2}{*}{ No serio } & \multirow[t]{2}{*}{ No serio } & No serio & Otras $^{6}$ & - & - & OR 1,47 & No calculable & MUY BAJA & IMPORTANTE \\
\hline & & & & & & & & $0 \%$ & $(1,13$ a 1,90$)$ & No calculable & & \\
\hline Duració & LM & & & & & & & & & & & \\
\hline 11 & ECA & Serio $^{2}$ & No serio & No serio & Serio $^{3}$ & No & 26 & 20 & - & $\begin{array}{c}\text { DM 0,75 más (de } 0,27 \text { menos } \\
\text { a } 1,77 \text { más) }\end{array}$ & MODERADA & CRITICA \\
\hline
\end{tabular}

1 Limrattaron 2013; 2 No queda claro como se ha llevado a cabo el proceso de aleatorizacion y cegamiento; 3 Cruza la linea de no efecto, y puede haber tanto beneficio negativo como positivo; 4

Chien 2007; 5 estudio retrospectivo mediante encuesta; 6 No describe porque unos RN empiezan antes o después, no ajustan resultados por otroas factores/ practcicas. Además encuesta

autoreporte con baja tasa se respuesta (53\%). Muy pocas mujeres empiezan LM en los primeros 30 minutos; 7 Cruza la linea de no efecto, y puede haber tanto efecto negativo como positivo 


\section{2- Inicio temprano (Primeros 60 minutos) vs Inicio tardío (Más de 60 minutos)}

\begin{tabular}{|c|c|c|c|c|c|c|c|c|c|c|c|c|}
\hline & & & & & & & \multicolumn{4}{|c|}{$\begin{array}{c}\text { Resumen de los resultados } \\
\end{array}$} & \multirow[b]{3}{*}{ Calidad } & \multirow[b]{3}{*}{ Importancia } \\
\hline \multicolumn{7}{|c|}{ Evaluación de la calidad } & \multicolumn{2}{|c|}{$\mathrm{N}^{\circ}$ de pacientes } & \multicolumn{2}{|c|}{ Magnitud del efecto } & & \\
\hline $\begin{array}{l}N^{\circ} \text { de } \\
\text { estudi } \\
\text { os }\end{array}$ & Diseño & $\begin{array}{l}\text { Riesgo } \\
\text { de } \\
\text { sesgo }\end{array}$ & $\begin{array}{c}\text { Inconsistenc } \\
\text { ia }\end{array}$ & \begin{tabular}{|c} 
Evidenc \\
ia \\
indirect \\
a
\end{tabular} & $\begin{array}{l}\text { Imprecisi } \\
\text { ón }\end{array}$ & $\begin{array}{c}\text { Otras } \\
\text { consideracion } \\
\text { es }\end{array}$ & $\begin{array}{l}\text { Primero } \\
\text { s } 60 \\
\text { min }\end{array}$ & $\begin{array}{l}\text { Más de } 60 \\
\min \end{array}$ & $\begin{array}{l}\text { Relativa } \\
(95 \% \mathrm{Cl})\end{array}$ & Absoluta por 1000 & & \\
\hline \multicolumn{13}{|c|}{ LME al alta } \\
\hline \multirow[t]{2}{*}{$1^{1}$} & \multirow[t]{2}{*}{ observacional } & \multirow[t]{2}{*}{ Serio $^{2}$} & \multirow[t]{2}{*}{ No seria } & \multirow[t]{2}{*}{ Seria $^{3}$} & \multirow[t]{2}{*}{ No seria } & \multirow[t]{2}{*}{ Otras $^{4}$} & $\begin{array}{l}34 / 63 \\
(54 \%)\end{array}$ & $\begin{array}{l}217 / 630 \\
(34,4 \%) \\
\end{array}$ & \multirow{2}{*}{$\begin{array}{c}\mathrm{RR} 1,57 \\
(1,22 \text { a } 2,02)\end{array}$} & $\begin{array}{c}196 \text { más por } 1000 \text { (de } 76 \\
\text { más a } 351 \text { más) }\end{array}$ & \multirow[t]{2}{*}{ MUY BAJA } & \multirow[t]{2}{*}{ CRITICA } \\
\hline & & & & & & & & $34,4 \%$ & & $\begin{array}{c}196 \text { más por } 1000 \text { (de } 76 \\
\text { más a } 351 \text { más) }\end{array}$ & & \\
\hline \multicolumn{13}{|c|}{ LME 1 mes } \\
\hline \multirow[t]{2}{*}{$2^{5}$} & \multirow[t]{2}{*}{ observacional } & \multirow[t]{2}{*}{ Serio $^{2}$} & \multirow[t]{2}{*}{ Seria $^{6}$} & \multirow[t]{2}{*}{ Serio $^{7}$} & \multirow[t]{2}{*}{ Seria ${ }^{8}$} & \multirow[t]{2}{*}{ Otras $^{9}$} & $\begin{array}{l}407 / 677 \\
(60,1 \%) \\
\end{array}$ & $\begin{array}{l}428 / 728 \\
(58,8 \%) \\
\end{array}$ & \multirow[t]{2}{*}{$\begin{array}{c}\mathrm{RR} 1,02 \\
(0,94 \text { a } 1,12)\end{array}$} & $\begin{array}{c}12 \text { más por } 1000 \text { (de } 35 \\
\text { menos a } 71 \text { más) }\end{array}$ & \multirow[t]{2}{*}{ MUY BAJA } & \multirow[t]{2}{*}{ CRITICA } \\
\hline & & & & & & & & $51,2 \%$ & & $\begin{array}{c}10 \text { más por } 1000 \text { (de } 31 \\
\text { menos a } 61 \text { más) }\end{array}$ & & \\
\hline \multicolumn{13}{|c|}{ LM 6 semanas } \\
\hline \multirow[t]{2}{*}{$1^{10}$} & \multirow[t]{2}{*}{ observacional } & \multirow[t]{2}{*}{ Serio $^{2}$} & \multirow[t]{2}{*}{ No seria } & \multirow[t]{2}{*}{ No seria } & No seria & Otras $^{11}$ & $\begin{array}{c}1013 / 1137 \\
(89,1 \%) \\
\end{array}$ & $\begin{array}{l}620 / 770 \\
(80,5 \%) \\
\end{array}$ & \begin{tabular}{|c|}
$\mathrm{RR} 1.11$ \\
$(1,06$ to 1,15$)$
\end{tabular} & $\begin{array}{c}89 \text { más por } 1000 \text { (de } 48 \\
\text { más a } 121 \text { más) } \\
\end{array}$ & MUY BAJA & IMPORTANTE \\
\hline & & & & & & & & $80,5 \%$ & & $\begin{array}{c}89 \text { más por } 1000 \text { (de } 48 \\
\text { más a } 121 \text { más) }\end{array}$ & & \\
\hline LME $2 \mathrm{~m}$ & neses & & & & & & & & & & & \\
\hline $11^{12}$ & observacional & Serio $^{2}$ & No seria & No seria & No seria & Otras $^{13}$ & $\begin{array}{c}1181 / 1534 \\
(77 \%) \\
\end{array}$ & $\begin{array}{c}370 / 561 \\
(66 \%) \\
\end{array}$ & $\begin{array}{c}\text { RR } 1,17 \\
(1,09 \text { a } 1,25)\end{array}$ & $\begin{array}{c}112 \text { más por } 1000 \text { (de } 59 \\
\text { más a } 165 \text { más) }\end{array}$ & MUY BAJA & IMPORTANTE \\
\hline & & & & & & & & $66 \%$ & & $\begin{array}{c}112 \text { más por } 1000 \text { (de } 59 \\
\text { más a } 165 \text { más) }\end{array}$ & & \\
\hline Duración & n LME & & & & & & & & & & & \\
\hline $1^{14}$ & observacional & $\begin{array}{l}\text { No } \\
\text { evaluable }\end{array}$ & No evaluable & $\begin{array}{l}\text { No } \\
\text { evaluable }\end{array}$ & $\begin{array}{l}\text { No } \\
\text { evaluable }\end{array}$ & No evaluable & 734 & 1014 & - & $\begin{array}{l}\text { DM 0,17 más }(0,18 \\
\text { menos a } 0,52 \text { más) }\end{array}$ & $\begin{array}{c}\text { NO } \\
\text { EVALUABLE }^{15}\end{array}$ & CRITICA \\
\hline
\end{tabular}

${ }^{1}$ Tang 2013; ${ }^{2}$ Limitaciones inherentes al diseño del estudio; ${ }^{3}$ definición de RN sano no equivalente a la de nuestra guía; ${ }^{4}$ no se ajustan los resultados por otros factores, el inicio temprano de la LM es muy bajo (menos del 10\%) y un elevado \% de RN recibe suplementos. No se describe por qué unos RN empiezan antes la LM; ${ }^{5}$ Di Frisco 2011 , Vieira $2007 ;{ }^{6}$ el estudio más pequeño muestra resultados significativos, mientras que el estudio con más participantes no encuentra diferencias; ${ }^{7}$ La evidencia de un estudio es indirecta, ya que los datos son para tasas de LM a las $2-4$ semanas; ${ }^{8}$ cruza la línea de no efecto; 9 No describe por qué unos niños hacen la $1^{2 a}$ toma antes y si hay otras variables a tener en cuenta, no hace regresión paso a paso; 10 DiGirolamo $2008 ; 11$ No se explica porque a unas madres se les aplicó el paso 4 y a otras no, y si hay diferencias entre ambos grupos, es una encuesta, autoreporte; 12 Murray $2007 ; 13$ No queda claro porque unos niños empiezan durante la $1^{\text {a }}$ hora y otros más tarde, no hace regresión paso a paso, encuesta auto-reporte; ${ }^{14}$ Zahed $2012 ;{ }^{15}$ No se puede evaluar la calidad del estudio ya que solamente se dispone del abstract. 


\section{3- Inicio temprano (primeros 120 minutos) vs inicio tardío (>120 minutos)}

\begin{tabular}{|c|c|c|c|c|c|c|c|c|c|c|c|c|}
\hline & & & & & & & \multicolumn{4}{|c|}{ Resumen de los resultados } & \multirow[b]{3}{*}{ Calidad } & \multirow[b]{3}{*}{ Importancia } \\
\hline \multicolumn{7}{|c|}{ Evaluación de la calidad } & \multicolumn{2}{|c|}{$\mathrm{N}^{\circ}$ de pacientes } & \multicolumn{2}{|c|}{\begin{tabular}{|c|} 
Magnitud del efecto \\
\end{tabular}} & & \\
\hline $\begin{array}{l}N^{\circ} \text { de } \\
\text { estudi } \\
\text { os }\end{array}$ & Diseño & $\begin{array}{c}\text { Riesgo } \\
\text { de sesgo }\end{array}$ & $\begin{array}{c}\text { Inconsistenc } \\
\text { ia }\end{array}$ & \begin{tabular}{|c}
$\begin{array}{c}\text { Evidenc } \\
\text { ia } \\
\text { indirect } \\
\text { a }\end{array}$ \\
\end{tabular} & $\begin{array}{l}\text { Imprecisi } \\
\text { ón }\end{array}$ & $\begin{array}{c}\text { Otras } \\
\text { consideracione } \\
\mathbf{s}\end{array}$ & $\begin{array}{l}\text { Primero } \\
\text { s } 60 \text { min }\end{array}$ & $\begin{array}{l}\text { Más de } \\
60 \mathrm{~min}\end{array}$ & $\begin{array}{l}\text { Relativa } \\
(95 \% \mathrm{Cl})\end{array}$ & Absoluta por 1000 & & \\
\hline \multicolumn{13}{|c|}{ LME al alta } \\
\hline \multirow[t]{2}{*}{11} & \multirow[t]{2}{*}{ observacional } & \multirow[t]{2}{*}{ Muy serio ${ }^{2}$} & \multirow[t]{2}{*}{ No seria } & \multirow[t]{2}{*}{ No seria } & \multirow[t]{2}{*}{ Seria $^{3}$} & \multirow[t]{2}{*}{ Otras $^{4}$} & $\begin{array}{l}148 / 334 \\
(44,3 \%) \\
\end{array}$ & $\begin{array}{c}41 / 94 \\
(43,6 \%) \\
\end{array}$ & \multirow[t]{2}{*}{$\begin{array}{c}\text { RR } 1,02 \\
(0,78 \text { a } 1,32)\end{array}$} & $\begin{array}{c}9 \text { más por } 1000 \text { (de } 96 \\
\text { menos a } 140 \text { más) }\end{array}$ & \multirow[t]{2}{*}{ MUY BAJA } & \multirow[t]{2}{*}{ CRITICA } \\
\hline & & & & & & & & $43,6 \%$ & & $\begin{array}{c}9 \text { más por } 1000 \text { (de } 96 \\
\text { menos a } 140 \text { más) }\end{array}$ & & \\
\hline
\end{tabular}

${ }^{1}$ Noomsen-Rivers 2011; ${ }^{2}$ estudio transversal mediante encuesta; 3 Cruza la linea de no efecto, y puede haber tanto efecto negativo como positivo; ${ }^{4}$ El objetivo no es evaluar específicamente si hacer la primera toma antes o después de las dos primeras horas influye, es un factor más. No se ajustan resultados por otros factores.

Comparación 2. Agarre espontáneo vs. Agarre dirigido del bebé al pecho en la primera toma

\begin{tabular}{|c|c|c|c|c|c|c|c|c|c|c|c|c|}
\hline \multicolumn{7}{|c|}{ Evaluación de la calidad } & \multicolumn{2}{|c|}{$\mathbf{N}^{\circ}$ de pacientes } & \multicolumn{2}{|c|}{ Magnitud del efecto } & \multirow[b]{2}{*}{ Calidad } & \multirow[b]{2}{*}{ Importancia } \\
\hline $\begin{array}{c}N^{\circ} \text { de } \\
\text { estudios }\end{array}$ & Diseño & $\begin{array}{c}\text { Riesgo de } \\
\text { sesgo }\end{array}$ & Inconsistencia & $\begin{array}{l}\text { Evidencia } \\
\text { indirecta }\end{array}$ & Imprecisión & \begin{tabular}{|c|} 
Otras \\
consideraciones
\end{tabular} & $\begin{array}{c}\text { Grupo } \\
\text { intervención }\end{array}$ & $\begin{array}{l}\text { Grupo } \\
\text { control }\end{array}$ & $\begin{array}{l}\text { Relativa } \\
\text { (IC95\%) }\end{array}$ & Absoluta por 1000 & & \\
\hline \multicolumn{13}{|c|}{\begin{tabular}{|l} 
\\
Primera toma correcta $($ IBTAT $>10)$ \\
\end{tabular}} \\
\hline \multirow[t]{2}{*}{$2^{1}$} & \multirow[t]{2}{*}{ ECAs } & \multirow[t]{2}{*}{ Serio $^{2}$} & \multirow[t]{2}{*}{ Serio $^{3}$} & \multirow[t]{2}{*}{ No serio } & \multirow[t]{2}{*}{ No serio } & \multirow[t]{2}{*}{ Poco probable } & $\begin{array}{l}95 / 130 \\
(73,1 \%)\end{array}$ & \begin{tabular}{|c|}
$72 / 130$ \\
$(55,4 \%)$
\end{tabular} & \multirow[t]{2}{*}{$\begin{array}{c}\text { RR } 1,32 \\
(1,12 \text { a } 1,56)\end{array}$} & $\begin{array}{c}177 \text { más por } 1000 \text { (de } 66 \text { a } \\
310 \text { más) }\end{array}$ & \multirow[t]{2}{*}{$\begin{array}{c}\oplus \oplus \mathrm{OO} \\
\text { BAJA }\end{array}$} & \multirow[t]{2}{*}{ CRITICA } \\
\hline & & & & & & & & $62,3 \%$ & & $\begin{array}{c}199 \text { más por } 1000 \text { (de } 75 \text { a } \\
349 \text { más) }\end{array}$ & & \\
\hline \multicolumn{13}{|c|}{\begin{tabular}{|l|} 
Primera toma correcta (agarre correcto) \\
\end{tabular}} \\
\hline \multirow[t]{2}{*}{\begin{tabular}{|l|l}
14 & \\
\end{tabular}} & \multirow[t]{2}{*}{ Observacional } & \multirow[t]{2}{*}{ Muy serio 5} & \multirow[t]{2}{*}{ No serio } & \multirow[t]{2}{*}{ No serio } & \multirow[t]{2}{*}{ Serio 6} & \multirow[t]{2}{*}{ Poco probable } & $\begin{array}{c}24 / 38 \\
(63,2 \%)\end{array}$ & \begin{tabular}{|c|}
$7 / 34$ \\
$(20,6 \%)$ \\
\end{tabular} & \multirow{2}{*}{$\begin{array}{c}\mathrm{RR} 3,07 \\
(1,52 \text { a } 6,2)\end{array}$} & $\begin{array}{c}426 \text { más por } 1000 \text { (de } 107 \text { a } \\
1000 \text { más) }\end{array}$ & \multirow[t]{2}{*}{$\begin{array}{c}\oplus \oplus \mathrm{OO} \\
\text { MUY BAJA }\end{array}$} & \multirow[t]{2}{*}{ CRITICA } \\
\hline & & & & & & & & $20,6 \%$ & & \begin{tabular}{|c|}
426 más por 1000 (de 107 a \\
1000 más)
\end{tabular} & & \\
\hline
\end{tabular}

${ }^{1}$ Mahmood 2011, Girish 2013;

2ECAs de calidad moderada y baja, importantes riesgos de selección

${ }^{3}$ Diferentes resultados según estudios. Inconsistencia e imprecisión, pero se baja la calidad solo por uno de ellos.

${ }^{4}$ Righard\&Alade 1990

${ }^{5}$ Limitaciones propias del diseño

${ }^{6}$ Ver IC 


\begin{tabular}{|c|c|c|c|c|c|c|c|c|c|c|c|c|}
\hline \multicolumn{13}{|c|}{ Lactancia materna al mes } \\
\hline \multirow[t]{2}{*}{$11^{7}$} & \multirow[t]{2}{*}{ ECA } & \multirow[t]{2}{*}{ Serio } & \multirow[t]{2}{*}{ No serio } & \multirow[t]{2}{*}{ No serio } & \multirow[t]{2}{*}{ No serio } & \multirow[t]{2}{*}{ Poco probable } & $\begin{array}{l}68 / 80 \\
(85 \%)\end{array}$ & $\begin{array}{c}66 / 80 \\
(82,5 \%)\end{array}$ & \multirow[t]{2}{*}{$\begin{array}{c}\mathrm{RR} 1,03 \\
(0,90 \text { a } 1,18)\end{array}$} & $\begin{array}{c}25 \text { más por mil (de } 83 \text { menos } \\
\text { a } 148 \text { más) }\end{array}$ & \multirow[t]{2}{*}{$\begin{array}{c}\oplus \oplus \mathrm{OO} \\
\text { MODERADA }\end{array}$} & \multirow[t]{2}{*}{ IMPORTANTE } \\
\hline & & & & & & & & $82,5 \%$ & & $\begin{array}{c}25 \text { más por mil (de } 83 \text { menos } \\
\text { a } 148 \text { más) }\end{array}$ & & \\
\hline \multicolumn{13}{|c|}{ Lactancia materna exclusiva al mes } \\
\hline \multirow[t]{2}{*}{$1^{18}$} & \multirow[t]{2}{*}{ ECA } & \multirow[t]{2}{*}{ Serio } & \multirow[t]{2}{*}{ No serio } & \multirow[t]{2}{*}{ No serio } & \multirow[t]{2}{*}{ No serio } & \multirow[t]{2}{*}{ Poco probable } & $\begin{array}{l}58 / 80 \\
(72,5 \%)\end{array}$ & $\begin{array}{l}44 / 80 \\
(55 \%)\end{array}$ & \multirow[t]{2}{*}{\begin{tabular}{|c|} 
RR 1,32 \\
$(1,04$ a 1,68$)$ \\
\end{tabular}} & \begin{tabular}{|c|}
176 más por 1000 (de 22 a \\
374 más)
\end{tabular} & \multirow[t]{2}{*}{$\begin{array}{c}\oplus \oplus \mathrm{OO} \\
\text { MODERADA }\end{array}$} & \multirow[t]{2}{*}{ CRITICA } \\
\hline & & & & & & & & $55 \%$ & & \begin{tabular}{|c|}
176 más por 1000 (de 22 a \\
374 más)
\end{tabular} & & \\
\hline \multicolumn{13}{|c|}{ Problemas en las mamas (\% de mujeres) } \\
\hline \multirow[t]{2}{*}{$1^{9}$} & \multirow[t]{2}{*}{ ECA } & \multirow[t]{2}{*}{ Serio ${ }^{10}$} & \multirow[t]{2}{*}{ No serio } & \multirow[t]{2}{*}{ No serio } & \multirow[t]{2}{*}{ No serio } & \multirow[t]{2}{*}{$\begin{array}{l}\text { Se desconoce cómo } \\
\text { se mide la variable }\end{array}$} & $\begin{array}{l}11 / 50 \\
(22 \%)\end{array}$ & $\begin{array}{l}22 / 50 \\
(44 \%)\end{array}$ & \multirow[t]{2}{*}{\begin{tabular}{|l|}
$\operatorname{RR} 0,5(0,27$ \\
$\quad$ a 0,92$)$
\end{tabular}} & $\begin{array}{l}220 \text { menos por } 1000 \\
\text { (de } 35 \text { a } 321 \text { menos) }\end{array}$ & \multirow[t]{2}{*}{$\begin{array}{l}\oplus \oplus \mathrm{OO} \\
\text { BAJA }\end{array}$} & \multirow[t]{2}{*}{ CRITICA } \\
\hline & & & & & & & & $44 \%$ & & $\begin{array}{c}220 \text { menos por } 1000 \text { (de } 35 \\
\text { a } 321 \text { menos) }\end{array}$ & & \\
\hline \multicolumn{13}{|c|}{ Satisfacción materna (con el cuidado recibido) } \\
\hline \multirow[t]{2}{*}{111} & ECA & No serio & No serio & No serio & No serio & Poco probable & $\begin{array}{c}699 / 80 \\
(86.3 \%) \\
\end{array}$ & $\begin{array}{c}29 / 80 \\
(36.3 \%) \\
\end{array}$ & \begin{tabular}{|c|}
$\mathrm{RR} 2,38$ \\
$(1,76$ a 3,22$)$ \\
\end{tabular} & $\begin{array}{c}500 \text { más por } 1000 \text { (de } 275 \text { a } \\
805 \text { más) }\end{array}$ & $\begin{array}{c}\oplus \oplus \oplus \mathrm{O} \\
\text { MODERADA }\end{array}$ & CRITICA \\
\hline & & & & & & & & $36.3 \%$ & & $\begin{array}{c}501 \text { más por } 1000 \text { (de } 276 \text { a } \\
806 \text { más) }\end{array}$ & & \\
\hline Pre & cia po & 10 cuidads & en futuro & & & & & & & & & \\
\hline 112 & ECA & No serio & No serio & No serio & No serio & Poco probable & $\begin{array}{l}68 / 80 \\
(85 \%) \\
\end{array}$ & $\begin{array}{c}18 / 80 \\
(22.5 \%) \\
\end{array}$ & \begin{tabular}{|c|} 
RR 3,78 \\
$(2,49$ a 5,73$)$
\end{tabular} & \begin{tabular}{|c|}
625 más por 1000 (de 325 a \\
1000 más) \\
\end{tabular} & $\begin{array}{c}\oplus \oplus \oplus \mathrm{O} \\
\text { MODERADA }\end{array}$ & CRITICA \\
\hline & & & & & & & & $22.5 \%$ & & $\begin{array}{c}625 \text { más por } 1000 \text { (de } 325 \text { a } \\
1000 \text { más) }\end{array}$ & & \\
\hline
\end{tabular}

${ }^{7}$ Mahmood 2011

${ }^{8}$ Mahmood 2011

${ }^{9}$ Girish 2013

${ }^{10}$ Calidad ECA baja, ver risk of bias

${ }^{11}$ Mahmood 2011

${ }^{12}$ Mahmood 2011 


\subsection{Resumen de la evidencia}

\section{Comparación 1. Inicio temprano versus inicio tardío de la primera} toma

Un ECA (16) y un estudio observacional (17)) comparan los resultados en lactancia entre los RN que inician la LM en la primera media hora tras el parto y los que no. Los resultados del ECA (16) $(n=50)$ muestran que no existen diferencias significativas en las tasas de LME al mes [RR 1 (IC95\% 0,92 a 1,09)], en las tasas de LME a los 4 meses [RR 2,31 (IC95\% 0,72 a 7,43)] ni en la duración de la LM global [DM 0,75 (IC95\% -0,27 a 1,77)] entre ambos grupos.

Por el contrario, los resultados del estudio observacional (17)) $(n=2.064)$ si encuentran diferencias en las tasas de LM al mes [OR 1,47 (IC95\% 1,13 a 1,90)], y en las tasas de LM a los 3 meses [OR 1,57 (IC95\% 01,21 a 2,05)].

Siete estudios observacionales (18-24) comparaban los resultados en lactancia entre los RN que iniciaron la primera toma en la primera hora tras el parto y los que no.

Los resultados de un estudio (23) $(n=581)$ apuntan que la incidencia de problemas de agarre o succión en la primera toma es menor en los $\mathrm{RN}$ que hicieron la primera toma en la primera hora frente a los que la hicieron a las 1-2 horas tras el parto [razón de tasas 2,39 (IC95\% 1,54 a $3,70)$ ]; a las 2-4 horas tras el parto [razón de tasas 3,75 (IC95\% 2,38 a $5,92)$ y a los que la realizaron transcurridas más de 4 horas tras el parto [razón de tasas 5,59 (IC95\% 3,27 a 9,72)].

En relación a la tasa de LME al alta, 1 estudio (24) $(n=695)$ encontró que el inicio temprano de la LM, durante la primera hora de vida, estaba asociado con mayores tasas de LME al alta [RR 1,57 (IC95\% 1,22 a $2,02)$ ]. Igualmente otro estudio (20) $(n=1.907)$ también encontró diferencias en la tasa de lactancia materna a las seis semanas entre los que hacen la primera toma en la primera hora y las que no (paso 4 de la IHAN) [RR 1,1 (IC95\% 1,06 a 1,15)]. Las diferencias son significativas incluso cuando se ajusta por otros factores o la aplicación de otros pasos de la estrategia IHAN (aOR 0,71 (IC95\% 0,53 a 0,95). Además otro estudio (18) $(n=4.544)$ también encontró que el inicio de la LM en la primera hora de vida estaba asociado con mayores tasas de LME a los 2 meses [RR 1,17 (IC95\% 1,09 a 1,25)].

Por el contrario, dos estudios $(19 ; 21) \quad(n=1.422)$ no encontraron diferencias en cuanto a la tasa de LME al mes [RR 1,02 (IC95\% 0,94 a $1,12)$. De modo similar otro estudio (22) $(n=1.689)$ tampoco encontró diferencias en relación a la duración de la LM global [DM 0,17 (IC95\% $-0,18$ a 0,52$)]$.

Un estudio observacional (25) $(n=428)$ evaluaba el retraso en el inicio de la lactogénesis II entre los RN que iniciaban la lactancia en las primeras dos tras el parto y lo que no, y no encontró diferencias significativas entre ambos grupos [RR 1,02 (IC95\% 0,78 a 1,32)].

Comparación 2. Agarre espontáneo versus agarre dirigido al pecho en la primera toma

\section{Calidad \\ moderada \\ para los tres \\ Calidad \\ muy baja \\ para los \\ dos}

Calidad

muy baja

\section{Calidad \\ muy baja para los dos}

Calidad muy baja

Calidad muy baja para los dos

Calidad muy baja 
En la búsqueda de estudios individuales se identificaron dos ECA $(26 ; 27)$ y dos estudios observacionales $(28 ; 29))$ que evaluaban de modo específico el posible beneficio del agarre espontáneo durante el CPP precoz en la lactancia materna.

En un estudio observacional (28) los recién nacidos que permanecieron en CPP precoz con la madre durante al menos una hora, o hasta que se finalizó la primera toma, mostraron una mejor técnica de agarre que aquellos que solo estuvieron en CPP durante los primeros 15 a 20 minutos y que posteriormente fueron separados para realizar cuidados rutinarios (24 de 38 en el grupo CPP y 7 de 34 en el grupo que recibe cuidados rutinarios). Para el estudio se definió como agarre correcto si el bebé tenía la boca abierta, la lengua debajo de la areola y extraía la leche del pecho con succiones efectivas.

En un ECA (27) $(n=100)$ la pérdida de peso a las 72 horas tras el nacimiento fue significativamente menor en el grupo intervención $(p=0,032)$ (datos insuficientes para incluirlo en la tabla GRADE).

En cuanto a la duración de la lactancia materna, los datos de un ECA (26) $(n=160)$ no muestran diferencias significativas en la tasa de lactancia materna al mes [RR 1,03 (IC95\% 0,90 a 1,18)], aunque los datos de ese mismo estudio (26) si encuentra diferencias en la tasa de lactancia materna exclusiva al mes (RR 1,32; IC95\% de 1,04 a 1,68).

En relación a la ocurrencia de problemas en las mamas, los datos de un ECA (27) $(n=100)$ mostraron que el número de mujeres que manifestó tener problemas fue un 50\% menor en el grupo en el que las madres realizaron CPP con agarre espontáneo [RR 0,50 (IC95\% 0,27 a $0,92)$ ]. Además las madres que realizaron CPP con arrastre al pecho mostraron mayor satisfacción materna $(1 \mathrm{ECA}, \mathrm{n}=160)(26)$ que las del grupo control [RR 2,38 (IC95\% 1,76 a 3,22], así como su preferencia por el mismo tipo de cuidados en un futuro parto [RR 3,78 (IC95\% 2,49 a 5,73)]. Igualmente, en un estudio observacional $(29)(n=651)$ el $87,2 \%$ de las madres que realizaron cuidados canguro con sus recién

Calidad muy baja

\section{Calidad baja}

Calidad
muy baja
Calidad
moderada
$\begin{gathered}\text { Calidad } \\ \text { baja }\end{gathered}$
Calidad
moderada
para los
dos

ACTUALIZADO A FECHA DE: 31 de Octubre de 2016 


\section{De la evidencia a la recomendación (Tabla de EtR)}

¿Cómo debería ser la primera toma del recién nacido?

Población: Madres de recién nacidos sanos a término que amamantan y sus recién nacidos

Perspectiva: Clínica

C1. Inicio temprano vs. inicio tardío de la primera toma

C2. Agarre espontáneo vs. agarre dirigido del RN al pecho en la primera toma

COMPARACION 1. INICIO TEMPRANO VS INICIO TARDIO DE LA PRIMERA TOMA

\begin{tabular}{|c|c|c|c|c|c|c|c|c|c|c|c|}
\hline & CRITERIO & JUICIO & & & & & \multicolumn{4}{|l|}{ EVIDENCIA } & $\begin{array}{l}\text { CONSIDERACIONE } \\
\text { SADICIONALES }\end{array}$ \\
\hline & \multirow{11}{*}{$\begin{array}{l}\text { ¿Cuál es la confianza global en } \\
\text { la evidencia disponible sobre los } \\
\text { efectos? }\end{array}$} & \multirow{2}{*}{$\begin{array}{l}\text { No se } \\
\text { incluyen } \\
\text { estudios }\end{array}$} & \multirow{2}{*}{$\begin{array}{c}\text { Muy baja } \\
x\end{array}$} & \multirow[t]{2}{*}{ Baja } & \multirow[t]{2}{*}{ Moderada } & \multirow[t]{2}{*}{ Alta } & \multicolumn{4}{|c|}{$\begin{array}{l}\text { Resumen de los resultados cuantitativos } \\
\text { C1. Inicio temprano vs. inicio tardío }\end{array}$} & \multirow{11}{*}{$\begin{array}{l}\text { La OMS recomienda el } \\
\text { inicio temprano de la LM } \\
\text { (durante la primera hora } \\
\text { de vida) para todos los } \\
\text { lactantes. }\end{array}$} \\
\hline & & & & & & & Desenlaces & $\begin{array}{l}\text { Importancia } \\
\text { relativa }\end{array}$ & $\begin{array}{c}\text { Certeza de la } \\
\text { evidencia }^{* *}\end{array}$ & Tamaño del efecto & \\
\hline & & & & & & & $\begin{array}{l}\text { Primer agarre } \\
\text { correcto }\end{array}$ & Crítica & Muy baja & $\begin{array}{c}\text { Beneficio moderado- } \\
\text { alto }\end{array}$ & \\
\hline & & & & & & & \begin{tabular}{|l|} 
Inicio de la \\
lactogénesis II
\end{tabular} & Critica & Baja & No hay beneficio & \\
\hline & & & & & & & $\begin{array}{l}\text { Tasa de LME al } \\
\text { alta }\end{array}$ & Critica & Muy baja & $\begin{array}{c}\text { Beneficio moderado/ } \\
\text { alto }\end{array}$ & \\
\hline & & & & & & & $\begin{array}{l}\text { Duración de la } \\
\text { LM }\end{array}$ & Crítica & Moderada & No hay beneficio & \\
\hline & & & & & & & $\begin{array}{l}\begin{array}{l}\text { Tasa de LME al } \\
\text { mes }\end{array} \\
\end{array}$ & Critica & Moderada & No hay beneficio & \\
\hline & & & & & & & $\begin{array}{l}\text { Tasa de LME a } \\
\text { los } 2 \text { meses } \\
\end{array}$ & Importante & Muy baja & Poco beneficio & \\
\hline & & & & & & & $\begin{array}{l}\text { Tasa de LME a } \\
\text { los } 4 \text { meses }\end{array}$ & Importante & Baja & No hay diferencias & \\
\hline & & & & & & & $\begin{array}{l}\text { Tasa de LM al } \\
\text { mes }\end{array}$ & Importante & Muy baja & Poco beneficio & \\
\hline$\infty u$ & & & & & & & $\begin{array}{l}\text { *Alta/ moderada/ } \\
{ }^{* *} \text { Beneficio mode } \\
\text { inconvenientes/ ri } \\
\text { Los resultad } \\
\text { importancia } \\
\text { primeras dos } \\
\text { evidencia de }\end{array}$ & $\begin{array}{l}\text { muy baja } \\
\text { mportante/ poc } \\
\text { s o inconvenie } \\
\text { no son co } \\
\text { inicio temp } \\
\text { oras de vi } \\
\text { n ECA qu }\end{array}$ & $\begin{array}{l}\text { beneficio/ incie } \\
\text { es modestos-im/ } \\
\text { cluyentes e } \\
\text { ano de la L } \\
\text { a). Solo se } \\
\text { no encue }\end{array}$ & $\begin{array}{l}\text { erto/ pocos riesgos o } \\
\text { iportantes } \\
\text { LM relación a la } \\
\text { ha encontrado } \\
\text { htra diferencias }\end{array}$ & \\
\hline
\end{tabular}




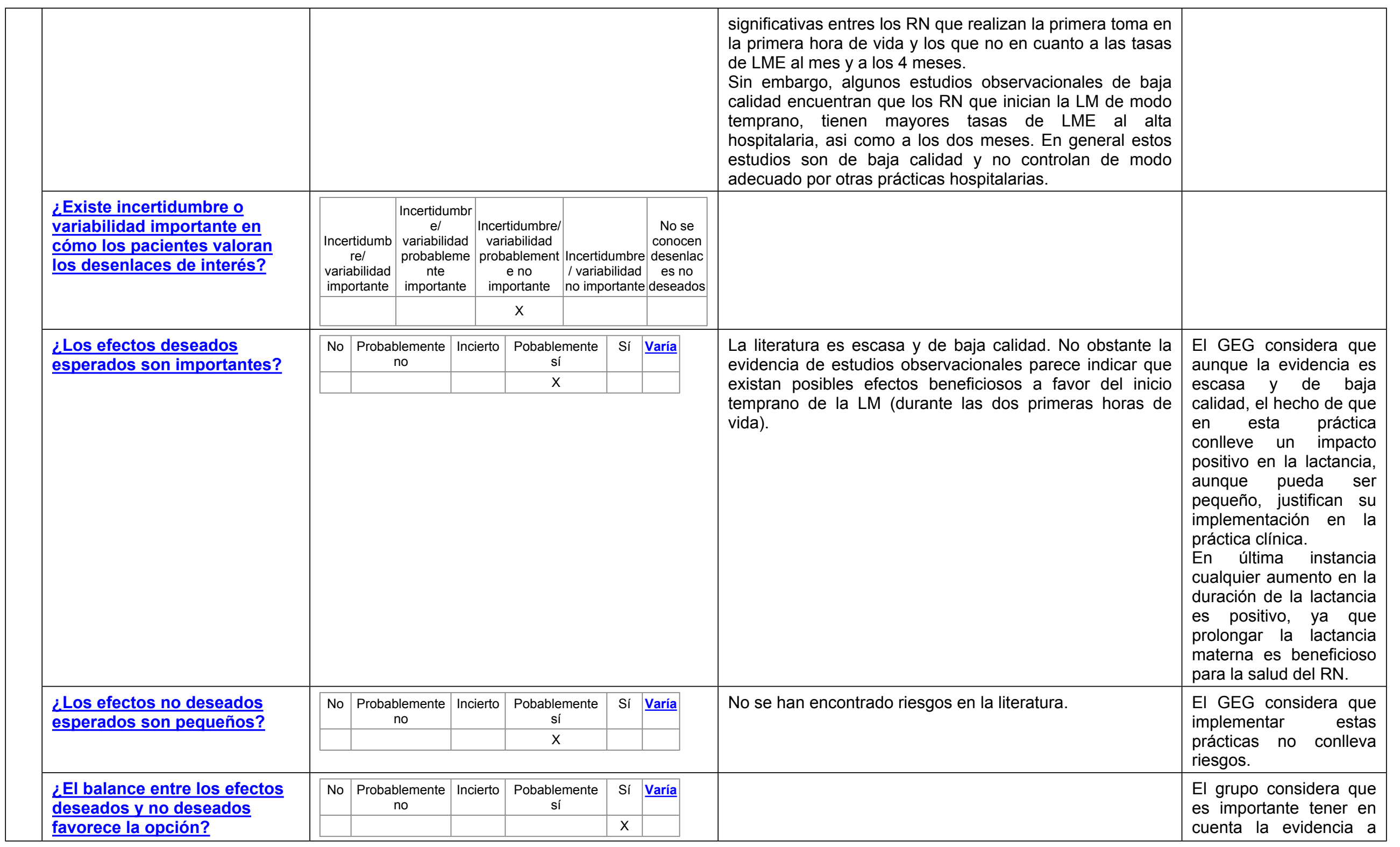




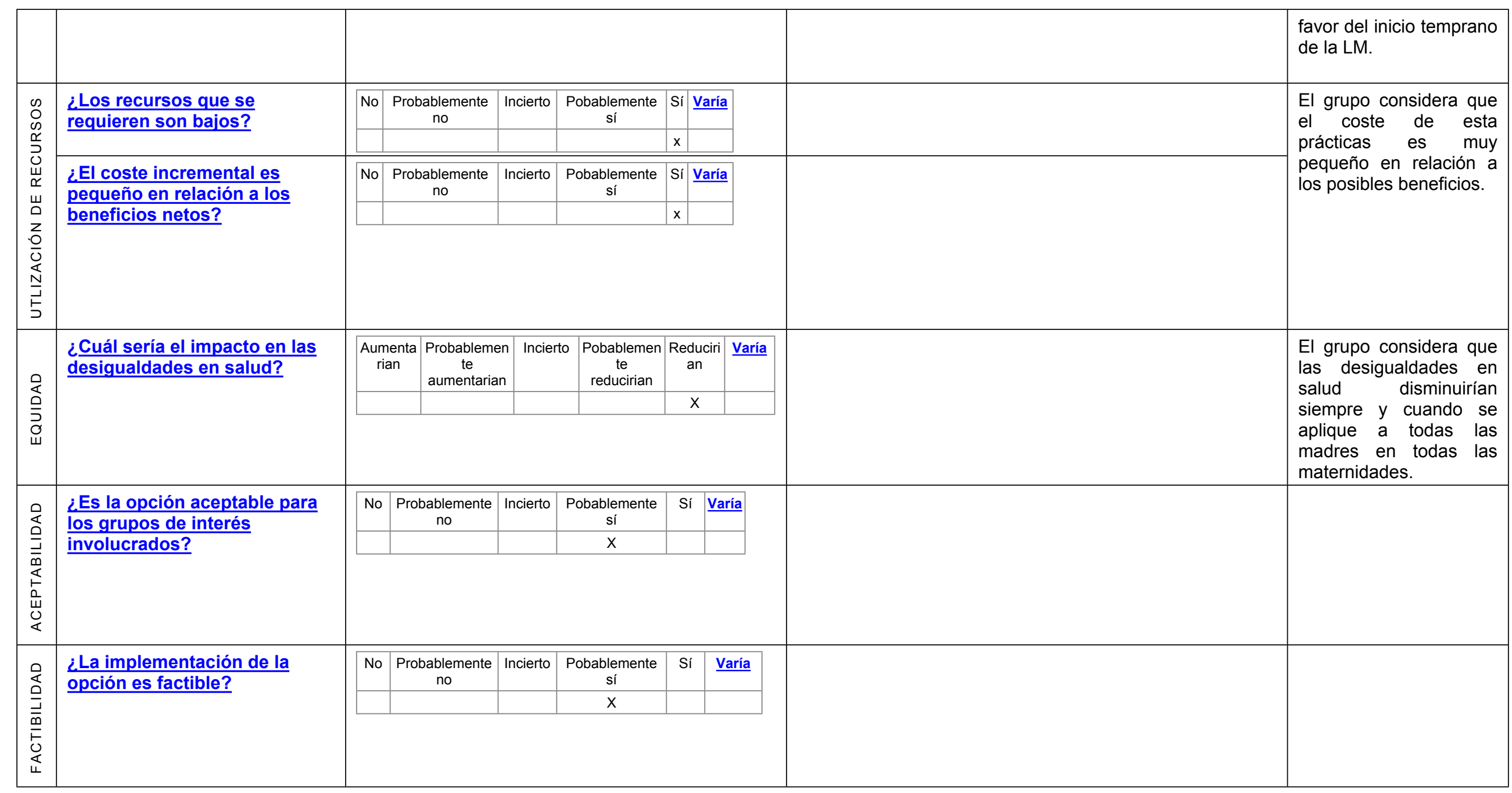




\begin{tabular}{|c|c|c|c|c|c|c|c|c|}
\hline \multirow[t]{2}{*}{$\begin{array}{l}\frac{\text { Balance de las }}{\text { consecuencias }} \\
\\
\text { C1 } 1\end{array}$} & \multirow{2}{*}{\multicolumn{2}{|c|}{$\begin{array}{l}\text { Las consecuencias no } \\
\text { deseadas superan } \\
\text { claramente las } \\
\text { consecuencias } \\
\text { deseadas en la mayoría } \\
\text { de los escenarios }\end{array}$}} & \multirow{2}{*}{\multicolumn{2}{|c|}{$\begin{array}{c}\text { Las consecuencias no } \\
\text { deseadas } \\
\text { probablemente superan } \\
\text { las consecuencias } \\
\text { deseadas en la mayoría } \\
\text { de los escenarios }\end{array}$}} & \multirow{2}{*}{\multicolumn{2}{|c|}{$\begin{array}{l}\text { El balance entre las } \\
\text { consecuencias } \\
\text { deseadas y no } \\
\text { deseadas está muy } \\
\text { equilibrado o es } \\
\text { incierto }\end{array}$}} & \multirow[t]{2}{*}{$\begin{array}{l}\text { Las consecuencias } \\
\text { deseadas } \\
\text { probablemente } \\
\text { superan las } \\
\text { consecuencias no } \\
\text { deseadas en la } \\
\text { mayoría de los } \\
\text { escenarios } \\
\mathrm{X}\end{array}$} & \multirow[t]{2}{*}{$\begin{array}{l}\text { Las consecuencias } \\
\text { deseadas claramente } \\
\text { superan las } \\
\text { consecuencias no } \\
\text { deseadas en la mayoría } \\
\text { de los escenarios }\end{array}$} \\
\hline & & & & & & & & \\
\hline \multirow[t]{2}{*}{ Tipo de recomendación } & \multirow[b]{2}{*}{ C1 } & \multicolumn{2}{|c|}{$\begin{array}{c}\text { Se recomienda no ofrecer la } \\
\text { opción }\end{array}$} & \multicolumn{2}{|c|}{$\begin{array}{l}\text { Se sugiere no ofrecer la } \\
\text { opción }\end{array}$} & \multicolumn{2}{|c|}{ Se sugiere ofrecer la opción } & $\begin{array}{l}\text { Se recomienda ofrecer la } \\
\text { opción }\end{array}$ \\
\hline & & & & & & & & $x$ \\
\hline \multicolumn{2}{|l|}{ Recomendación (Texto) } & \multicolumn{7}{|c|}{$\begin{array}{l}\text { Recomendación de buena práctica } \\
\checkmark \text { Dejar que el recién nacido se agarre espontáneamente al pecho durante el período de contacto piel con piel. En caso } \\
\text { de que el recién nacido no encuentre el pezón espontáneamente se recomienda, antes de que finalice la primera hora, } \\
\text { un profesional entrenado debería ofrecer apoyo y ayuda práctica, procurando interferir lo menos posible en la } \\
\text { vinculación del recién nacido con la madre. } \\
\sqrt{ } \text { En el caso en el que el recién nacido no muestre signos de búsqueda, se sugiere ofrecer ayuda adicional a la madre } \\
\text { con el agarre. }\end{array}$} \\
\hline Justificación & & \multicolumn{7}{|c|}{$\begin{array}{l}\text { Por un lado la evidencia sugiere que es mejor el inicio temprano de la lactancia materna, en las dos primeras horas de } \\
\text { vida del recién nacido. Por otro, la evidencia sugiere que el arrastre al pecho con agarre espontáneo por parte del recién } \\
\text { nacido es la forma más óptima de iniciar la lactancia, y conlleva beneficios. Aunque varios estudio apuntan que la } \\
\text { mayoría de los recién nacidos alcanzarán el pecho espontáneamente entre los primeros } 20 \text { a } 90 \text { minutos de vida, } \\
\text { también se sabe que debido al efecto de la anestesia, hay recién nacidos que no consiguen agarrarse al pecho por s } \\
\text { mismos durante esas dos primeras horas de vida. Por lo tanto, teniendo la importancia de que el recién nacido se agarre } \\
\text { por sí solo, pero también la importancia de que se haga una primera toma en el postparto inmediato, el grupo llega al } \\
\text { consenso de recomendar permitir que el recién nacido haga el arrastre al pecho en la primera hora durante el CPP y, } \\
\text { pasado ese tiempo, ayudarle para que asegurarse que el primer agarre se hace en las dos primeras horas de vida. }\end{array}$} \\
\hline Consideraciones de subgrup & & \multicolumn{7}{|c|}{$\begin{array}{l}\text { El arrastre al pecho durante el CPP es una práctica aceptable para la mayoría de las madres, aunque es importante } \\
\text { tener en cuenta los deseos y preocupaciones individuales de cada madre. También es posible que las madres } \\
\text { primíparas tengan más dudas y un menor sentimiento de auto-eficacia sobre su capacidad de amamantar correctamente } \\
\text { a su hijo. }\end{array}$} \\
\hline
\end{tabular}




\section{Consideraciones para la} implementación

Es posible que el personal sanitario tenga dudas acerca de la factibilidad de implementar el arrastre al pecho durante el CPP prolongado tras el parto, especialmente en aquellos centros donde aún no se haya adoptado esta práctica de modo rutinario.

También hay que tener en cuenta que no todos los RN consiguen engancharse espontáneamente al pecho durante el CPP precoz, fundamentalmente debido a que están afectados por la anestesia de la madre, y que precisarán ayuda.

\section{Monitorización y evaluación} $--$

Prioridades para la investigación

\begin{tabular}{|c|c|c|c|c|c|c|c|c|c|c|c|}
\hline \multicolumn{12}{|c|}{ COMPARACION 2. AGARRE ESPONTÁNEO VS AGARRE DIRIGIDO AL PECHO (EN LA PRIMERA TOMA) } \\
\hline & CRITERIO & \multicolumn{5}{|l|}{$\underline{\text { JUICIO }}$} & \multicolumn{4}{|l|}{ EVIDENCIA } & $\begin{array}{l}\text { CONSIDERACIONES } \\
\text { ADICIONALES } \\
\end{array}$ \\
\hline \multirow{11}{*}{ 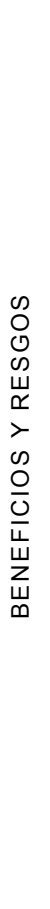 } & \multirow{10}{*}{$\begin{array}{l}\text { ¿Cuál es la confianza global } \\
\text { en la evidencia disponible } \\
\text { sobre los efectos? }\end{array}$} & & & & & & \multicolumn{4}{|c|}{ Resumen de los resultados cuantitativos } & \\
\hline & & $\begin{array}{l}\text { incluyen } \\
\text { estudios }\end{array}$ & Muy baja & Baja & Moderada & Alta & Desenlaces & $\begin{array}{c}\begin{array}{l}\text { Importancia } \\
\text { relativa }\end{array} \\
\text {. }\end{array}$ & \begin{tabular}{|c|} 
Certeza de \\
la
\end{tabular} & Tamaño del efecto & \\
\hline & & & & $x$ & & & & & & & \\
\hline & & & & & & & \begin{tabular}{|l|}
$\begin{array}{l}\text { Primer agarre } \\
\text { correcto }\end{array}$ \\
\end{tabular} & Crítica & Moderada & $\begin{array}{c}\text { Beneficio modesto- } \\
\text { importante }\end{array}$ & \\
\hline & & & & & & & \begin{tabular}{|l|}
$\begin{array}{l}\text { Tasa de LME al } \\
\text { mes }\end{array}$ \\
\end{tabular} & Importante & Moderada & $\begin{array}{c}\begin{array}{c}\text { Beneficio modesto- } \\
\text { importante }\end{array} \\
\end{array}$ & \\
\hline & & & & & & & $\begin{array}{l}\text { Tasa de LM al } \\
\text { mes }\end{array}$ & Importante & Moderada & No hay beneficio & \\
\hline & & & & & & & Peso RN 72h. & Importante & Muy baja & Poco beneficio & \\
\hline & & & & & & & $\begin{array}{l}\text { Complicaciones } \\
\text { de las mamas }\end{array}$ & Crítica & Baja & $\begin{array}{c}\text { Beneficio modesto- } \\
\text { importante }\end{array}$ & \\
\hline & & & & & & & \begin{tabular}{|l|}
$\begin{array}{l}\text { Satisfacción } \\
\text { materna }\end{array}$ \\
\end{tabular} & Crítica & Moderada & $\begin{array}{c}\text { Beneficio modesto- } \\
\text { importante }\end{array}$ & \\
\hline & & & & & & & \multicolumn{4}{|c|}{$\begin{array}{l}{ }^{*} \text { Alta/ moderada/ baja/ muy baja } \\
\text { *BBeneficio modesto-importante/ poco beneficio/ incierto/ pocos riesgos o } \\
\text { inconvenientes/ riesgos o inconvenientes modestos-importantes } \\
\text { Evidencia de calidad moderada de ECA muestra un } \\
\text { beneficio moderado del agarre espontáneo en la primera } \\
\text { toma en relación a la realización de una primera toma } \\
\text { correcta y en la tasa de LME al mes. }\end{array}$} & \\
\hline & $\begin{array}{l}\text { ¿Existe incertidumbre o } \\
\text { variabilidad importante en } \\
\text { cómo los pacientes valoran }\end{array}$ & \begin{tabular}{|c|} 
Incertidum \\
bre/ \\
variabilida
\end{tabular} & $\begin{array}{l}\text { Incertidumb } \\
\text { re/ } \\
\text { variabilidad }\end{array}$ & $\begin{array}{l}\text { Incertidu } \\
\text { / variabil } \\
\text { probable }\end{array}$ & \begin{tabular}{l|l} 
bre & Incertidur \\
dad & e/ \\
hent & variabilid
\end{tabular} & \begin{tabular}{l|c|}
$\mathrm{nbr}$ & No se \\
conocen \\
ad & desenlac \\
\end{tabular} & & & & & \\
\hline
\end{tabular}




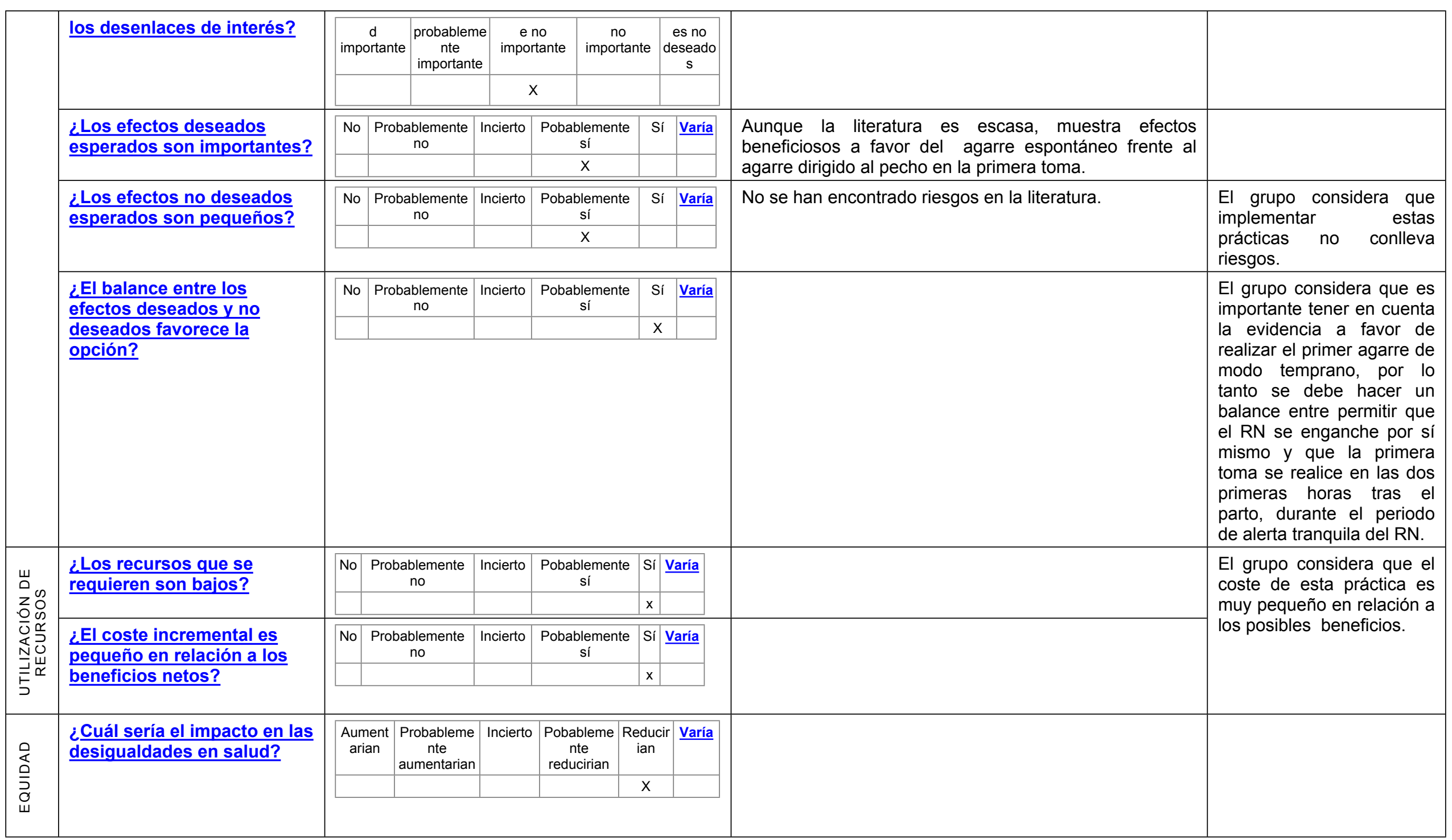




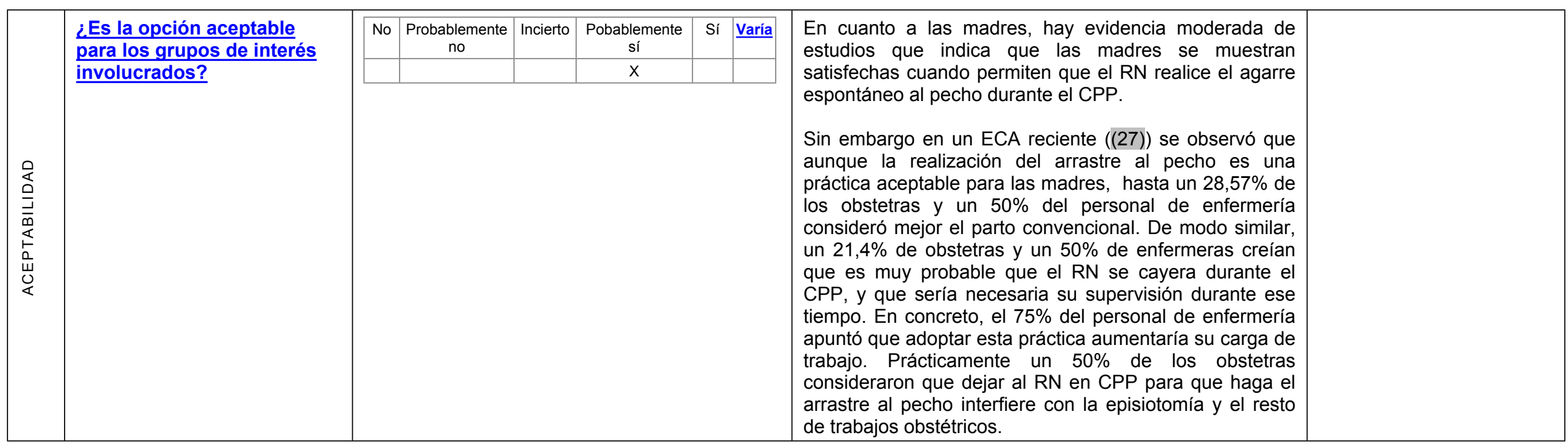




\begin{tabular}{|c|c|c|c|c|c|c|c|c|c|}
\hline 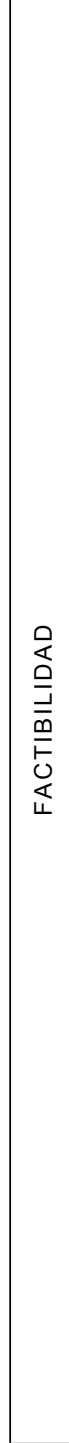 & $\begin{array}{l}\text { ¿La implementación de la } \\
\text { opción es factible? }\end{array}$ & No & $\begin{array}{c}\text { Probablemente } \\
\text { no }\end{array}$ & Incierto & \begin{tabular}{|c|}
$\begin{array}{c}\text { Pobablemente } \\
\text { sí }\end{array}$ \\
$\mathrm{X}$ \\
\end{tabular} & Sí & Varía & 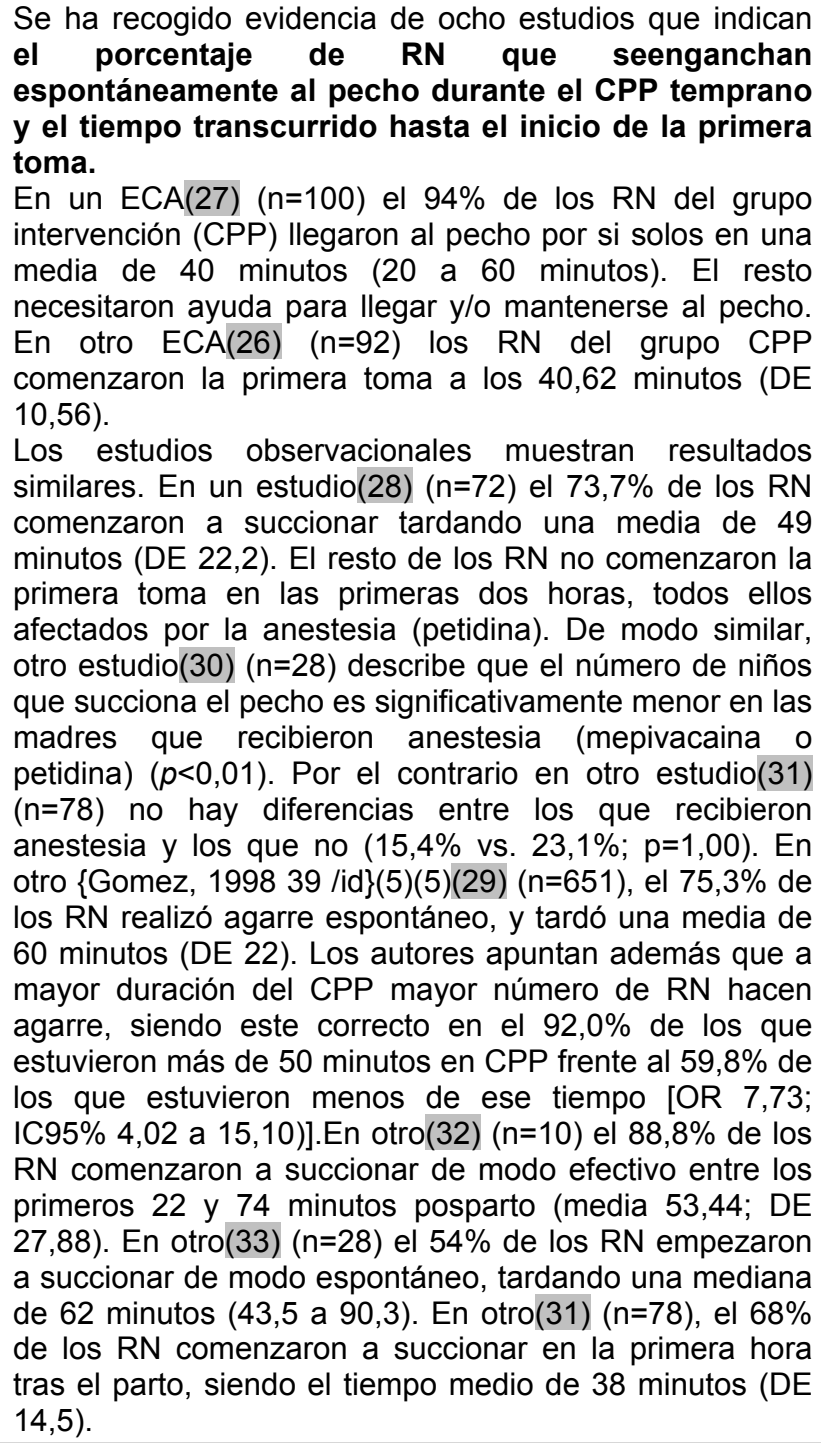 & $\begin{array}{l}\text { Al grupo le parece } \\
\text { importante señalar que, tal } \\
\text { y como se resalta en la } \\
\text { evidencia, muchos RN } \\
\text { estarán afectados por la } \\
\text { anestesia, y que por lo } \\
\text { tanto será necesario } \\
\text { ofrecer ayuda ya que no } \\
\text { conseguirán engancharse } \\
\text { al pecho por sí mismos. }\end{array}$ \\
\hline
\end{tabular}




\begin{tabular}{|c|c|c|c|c|c|c|c|c|}
\hline \multirow[t]{2}{*}{$\begin{array}{l}\text { Balance de las } \\
\text { consecuencias } \\
\end{array}$} & \multirow{2}{*}{\multicolumn{2}{|c|}{$\begin{array}{l}\text { Las consecuencias no } \\
\text { deseadas superan } \\
\text { claramente las } \\
\text { consecuencias } \\
\text { deseadas en la mayoría } \\
\text { de los escenarios }\end{array}$}} & \multirow{2}{*}{\multicolumn{2}{|c|}{$\begin{array}{c}\text { Las consecuencias no } \\
\text { deseadas } \\
\text { probablemente superan } \\
\text { las consecuencias } \\
\text { deseadas en la mayoría } \\
\text { de los escenarios }\end{array}$}} & \multirow{2}{*}{\multicolumn{2}{|c|}{$\begin{array}{l}\text { El balance entre las } \\
\text { consecuencias } \\
\text { deseadas y no } \\
\text { deseadas está muy } \\
\text { equilibrado o es } \\
\text { incierto }\end{array}$}} & $\begin{array}{l}\text { Las consecuencias } \\
\text { deseadas } \\
\text { probablemente } \\
\text { superan las } \\
\text { consecuencias no } \\
\text { deseadas en la } \\
\text { mayoría de los } \\
\text { escenarios }\end{array}$ & $\begin{array}{c}\text { Las consecuencias } \\
\text { deseadas claramente } \\
\text { superan las } \\
\text { consecuencias no } \\
\text { deseadas en la mayoría } \\
\text { de los escenarios }\end{array}$ \\
\hline & & & & & & & $x$ & \\
\hline \multirow[t]{2}{*}{ Tipo de recomendación } & & \multicolumn{2}{|c|}{$\begin{array}{l}\text { Se recomienda no ofrecer la } \\
\text { opción }\end{array}$} & \multicolumn{2}{|c|}{$\begin{array}{l}\text { Se sugiere no ofrecer la } \\
\text { opción }\end{array}$} & \multicolumn{2}{|c|}{ Se sugiere ofrecer la opción } & $\begin{array}{l}\text { Se recomienda ofrecer la } \\
\text { opción }\end{array}$ \\
\hline & C2 & & & & & & & $x$ \\
\hline \multicolumn{2}{|l|}{ Recomendación (Texto) } & \multicolumn{7}{|c|}{$\begin{array}{l}\text { Recomendación de buena práctica } \\
\checkmark \text { No se conoce cuál es el tiempo máximo que se puede esperar hasta que el recién nacido se agarre al pecho. Por ello, } \\
\text { en recién nacidos sanos, asintomáticos y sin riesgo de hipoglucemia, se puede observar y esperar a que se agarren al } \\
\text { pecho, y si tras la primera hora no lo ha conseguido, ofrecer ayuda práctica. } \\
\sqrt{ } \mathrm{Si} \text { a pesar de la ayuda prestada no se consigue una primera toma, se debería informar a la madre sobre los signos } \\
\text { precoces de hambre (ver Anexo } 6 \text { ), cómo estimular al recién nacido mediante el contacto piel con piel y cómo identificar } \\
\text { los signos y síntomas de alarma. } \\
\sqrt{ } \text { No realizar controles de glucemia ni administrar suplementos de forma rutinaria a los recién nacidos sanos, salvo que } \\
\text { presenten clínica sugestiva de hipoglucemia. }\end{array}$} \\
\hline Justificación & & \multicolumn{7}{|c|}{$\begin{array}{l}\text { Por un lado la evidencia sugiere que es mejor el inicio temprano de la lactancia materna, en las dos primeras horas de } \\
\text { vida del recién nacido. Por otro, la evidencia sugiere que el arrastre al pecho con agarre espontáneo por parte del recién } \\
\text { nacido es la forma más óptima de iniciar la lactancia, y conlleva beneficios. Aunque varios estudio apuntan que la } \\
\text { mayoría de los recién nacidos alcanzarán el pecho espontáneamente entre los primeros } 20 \text { a } 90 \text { minutos de vida, } \\
\text { también puede que haya recién nacidos que no consiguen agarrarse al pecho por sí mismos durante esas dos primeras } \\
\text { horas de vida. Por lo tanto, teniendo la importancia de que el recién nacido se agarre por sí solo, pero también la } \\
\text { importancia de que se haga una primera toma en el postparto inmediato, el grupo llega al consenso de recomendar } \\
\text { permitir que el recién nacido haga el arrastre al pecho en la primera hora durante el CPP y, pasado ese tiempo, ayudarle } \\
\text { para que asegurarse que el primer agarre se hace en las dos primeras horas de vida. }\end{array}$} \\
\hline
\end{tabular}




\section{Consideraciones de subgrupos}

\section{Consideraciones para la}

implementación
El arrastre al pecho durante el CPP es una práctica aceptable para la mayoría de las madres, aunque es importante tener en cuenta los deseos y preocupaciones individuales de cada madre. También es posible que las madres primíparas tengan más dudas y un menor sentimiento de auto-eficacia sobre su capacidad de amamantar correctamente a su hijo.

Es posible que el personal sanitario tenga dudas acerca de la factibilidad de implementar el arrastre al pecho durante el

CPP prolongado tras el parto, especialmente en aquellos centros donde aún no se haya adoptado esta práctica de modo

rutinario.

También hay que tener en cuenta que no todos los recién nacidos consiguen engancharse espontáneamente al pecho

durante el CPP inmediato, fundamentalmente debido a que puede estar afectados por la anestesia general de la madre y que precisarán ayuda. 
GPC Lactancia Materna - Preguntas 2 y 3. Primera toma del recién nacido

\section{ANEXOS}

Anexo I. Estrategias de búsqueda

Anexo II. Valoración de la calidad de los estudios

Anexo III. Tablas de estudios individuales

Anexo IV. Forestplots 


\section{ANEXO I. ESTRATEGIAS DE BÚSQUEDA}

Para esta pregunta se han hecho dos búsquedas independientes:

Búsqueda 1: ¿Cuándo debe de comenzar la primar toma?

\section{Cochrane Library \\ Searched 09/12/2014}

Updated search09/12/2014 a xx/xx/xxxx

\#1hour or hours or "time to" or "time before" or timely or delayed:ti,ab,kw and breastfeeding or "breast feeding" or lactation or breastfeed or "breast feed":ti,ab,kw and initiation:ti,ab,kw (Word variations have been searched)36

\#2"first hour":ti,ab,kw and breastfeeding or "breast feeding" or lactation or breastfeed or "breast feed" or lactating:ti,ab,kw (Word variations have been searched)31

\#3"first breastfeeding" or "first breast feeding" or "first breastfeed" or "first breast feed":ti,ab,kw (Word variations have been searched)23

\#4\#1 or \#2 or \#3 86

\section{MEDLINE, via Pubmed}

\section{Searched 09/12/2014}

\section{Updated search 09/12/2014 a xx/xx/xxxx}

\#1 (((hour[Title/Abstract] OR hours[Title/Abstract] OR "time to"[Title/Abstract] OR "time before"[Title/Abstract] OR timely[Title/Abstract] OR delayed[Title/Abstract])) AND (breastfeeding[Title/Abstract] OR "breast feeding"[Title/Abstract] OR lactation[Title/Abstract] OR breastfeed[Title/Abstract] OR "breast feed"[Title/Abstract])) AND initiation[Title/Abstract]339

\#2 ("first breastfeeding"[Title/Abstract] OR "first breast feeding"[Title/Abstract] OR "first breastfeed"[Title/Abstract] OR "first breast feed"[Title/Abstract])89

\#3 ("first hour"[Title/Abstract]) AND (breastfeeding[Title/Abstract] OR "breast feeding"[Title/Abstract] OR lactating[Title/Abstract] OR breastfeed[Title/Abstract] OR "breast feed"[Title/Abstract])108

\#4 ("first feed"[Title/Abstract] OR "first feeding"[Title/Abstract])477

\#5 \#1 OR \#2 OR \#3 OR \#4947

\#6 "baby friendly"[Title/Abstract]562

\#7 \#5 AND \#6 35

\section{EMBASE, via Ovid}

\section{Searched 09/12/2014}

\section{Updated search 09/12/2014 a xx/xx/xxxx}

\#1 (hour or hours or "time to" or "time before" or timely or delayed).ti,ab,kw.3255595

\#2 (breastfeeding or "breast feeding" or lactation or breastfeed or "breast feed").ti,ab,kw.56795

\#3 initiation.ti,ab,kw.200322

\#4 1 and 2 and 3701

\#5 "first hour".ti,ab,kw.6538

\#6 (breastfeeding or "breast feeding" or lactation or breastfeed or "breast feed" or lactating).ti,ab,kw.67979

\#7 5 and 6124

\#8 ("first breastfeeding" or "first breast feeding" or "first breastfeed" or "first breast feed").ti, ab,kw.111

\#9 4 or 7 or 8879

\#10 "baby friendly".ti,ab,kw.620 
\#11 9 and 1050

\#12 "first feed".ti,ab,kw.143

\#13 9 or 121008

\#14 10 and 1351

\section{CINAHL,via EBSCOhost databases}

\section{Searched 09/12/2014}

\section{Updated search 09/12/2014 a xx/xx/xxxx}

\#1 (hour or hours or "time to" or "time before" or timely or delayed) AND (breastfeeding or "breast feeding" or lactation or breastfeed or "breast feed") AND initiation

\#2 "first hour" AND (breastfeeding or "breast feeding" or lactation or breastfeed or "breast feed" or lactating)

\#3 "first breastfeeding" or "first breast feeding" or "first breastfeed" or "first breast feed" \#4 1 OR 2 OR 3

\#5 "baby friendly"

\#6 4 AND 5

\#7 "first feed" OR "first feeding"

\#8 4 OR 7

\#9 5 AND 844

Cinahl11

Búsqueda 2: ¿cómo debe realizarse la primera succión al pecho?

\section{Cochrane Library}

Searched 22/10/2013

Updated search 22/10/2013 a xx/xx/xxxx

\#1 MeSH descriptor: [Sucking Behavior] explode all trees

\#2 "sucking behaviour" or "sucking behavior"

\#3 sucking and (behaviour or behavior)

\#4 \#1 or \#2 or \#3

\#5 "biological nurturing" or (biological and nurturing)

\#6 MeSH descriptor: [Breast] explode all trees

\#7 breast or chest

\#8 \#6 or \#7

\#9 crawl or crawling

\#10 \#8 and \#9

\#11 MeSH descriptor: [Reflex] explode all trees

$\# 12$ reflex or reflexes

\#13 \#11 or \#12

\#14 primitive and neonatal and \#13

\#15 MeSH descriptor: [Infant] explode all trees

\#16 MeSH descriptor: [Infant, Newborn] explode all trees

\#17 primitive or neonatal or infant or \#15 or infantile or newborn or \#16

\#18 \#17 and \#13

\#19 (suck or sucking) or (suckle or suckling) or (root or rooting)

\#20 \#19 and \#13

\#21 MeSH descriptor: [Nipples] explode all trees

\#22 nipple or nipples

\#23 \#21 or \#22

\#24 \#23 or \#8

\#25 (suck or sucking) or (suckle or suckling) or (lick or licking)

\#26 \#24 and \#25

\#27 latch-on or latching-on 


\section{MEDLINE, via Pubmed}

Searched 22/10/2013

Updated search 22/10/2013 a xx/xx/xxxx

(sucking behaviour) OR (("biological"[All Fields] AND nurturing[All Fields]) OR "biological nurturing"[All Fields]) OR (breast AND (crawl OR crawling)) OR (primitive[All Fields] AND neonatal[All Fields] AND ("reflex"[MeSH Terms] OR "reflex"[All Fields] OR "reflexes"[All Fields])) OR (latch-on OR latching-on) OR ((feed OR feeding OR suck OR sucking OR suckle OR suckling OR grasp OR grasping) AND ("reflex"[MeSH Terms] OR "reflex"[All Fields] OR "reflexes"[All Fields])) OR ((suck OR sucking OR suckle OR suckling OR lick OR licking OR grab OR grabbing OR latch OR latching OR grip OR gripping OR grasp OR grasping) AND (nipple OR breast OR chest OR bust)) Filters: Infant: birth-23 months

\section{EMBASE, via Ovid}

Searched 22/10/2013

\section{Updated search 22/10/2013 a xx/xx/xxxx}

1 sucking/ 3371

2 ("sucking behaviour" or (sucking and behaviour)).mp. [mp=title, abstract, heading word, drug trade name, original title, device manufacturer, drug manufacturer, device trade name, keyword] $\quad 303$

3 "biological nurturing".mp. 7

4 ((breast or chest) and (crawl or crawling)).mp. [mp=title, abstract, heading word, drug trade name, original title, device manufacturer, drug manufacturer, device trade name, keyword] 62

5 (primitive and neonatal and (reflex or reflexes)).mp. [mp=title, abstract, heading word, drug trade name, original title, device manufacturer, drug manufacturer, device trade name, keyword]

6 ((primitive or infant or infantile or neonatal or newborn) and (reflex or reflexes)).mp. [ $\mathrm{mp}=$ title, abstract, heading word, drug trade name, original title, device manufacturer, drug manufacturer, device trade name, keyword] 8868

7 (latch-on or latching-on).mp. [mp=title, abstract, heading word, drug trade name, original title, device manufacturer, drug manufacturer, device trade name, keyword] 73 8 ((suck or sucking or suckle or suckling or (root or rooting)) and (reflex or reflexes)).mp. [mp=title, abstract, heading word, drug trade name, original title, device manufacturer, drug manufacturer, device trade name, keyword] 4744

9 ((suck or sucking or suckle or suckling or (lick or licking)) and (nipple or nipples or breast or chest)).mp. [mp=title, abstract, heading word, drug trade name, original title, device manufacturer, drug manufacturer, device trade name, keyword] 2966

101 or 2 or 3 or 4 or 5 or 6 or 7 or 8 or 918163

11 limit 30 to infant <to one year $>1264$

12 randomized controlled trial/ or "randomized controlled trial (topic)"/ 445446

13 ((random or randomized or randomised) and (control or controlled or clinical) and (trial or trials)).mp. [mp=title, abstract, heading word, drug trade name, original title, device manufacturer, drug manufacturer, device trade name, keyword] 607606

1312 or 13

1510 and $13 \quad 303$

CINAHL, via EBSCOhost databases

Searched 22/10/2013

Updated search 22/10/2013 a xx/xx/xxxx

S1 (MH "Breast Feeding") 
S2 "breast feeding" OR breastfeeding OR "breast feed" OR breastfeed OR "breast fed" OR breastfed

S3 S1 OR S2

S4 "biological nurturing"

S5 ( "breast crawl" OR "breast crawling" ) OR ( "chest crawl" OR "chest crawling" )

S6 (MH "Sucking Behavior") OR "sucking behaviour" OR "sucking behavior"

S7 ( neonatal OR infant OR infantile OR primitive ) AND ( reflex OR reflexes )

S8 ( (MH "Latching, Breastfeeding") OR latch OR latching OR attach OR attaching )

AND ( breast OR nipple )

S9 (MH "Sucking Behavior") OR (MH "Attachment Behavior")

S10 MH behavior OR ( behaviour OR behavior )

S11 S3 AND S10

S12 (MH "Eating Behavior")

S13 S12 Limitadores - Grupos de edad: Infant, Newborn: birth-1 month

S14 MH lactation OR lactation

S15 S10 AND S14

S16 "pre-feeding behavior" OR "pre-feeding behaviour"

S17 ( "suck reflex" OR "suck reflexes" or "sucking reflex" OR "sucking reflexes" ) OR ( "suckle reflex" OR "suckle reflexes" or "suckling reflex" OR "suckling reflexes" ) OR ( "root reflex" OR "root reflexes" OR "rooting reflex" OR "rooting reflexes" )

S18 "feeding reflex" OR "feeding reflexes"

S19 "spontaneous breast feeding" OR "spontaneous breast-feeding" OR "spontaneous breast feed" OR "spontaneous breast-feed" OR "spontaneous breast fed" OR "spontaneous breast-fed"

S20 S4 OR S5 OR S6 OR S7 OR S8 OR S9 OR S11 OR S13 OR S15 OR S16 OR S17 OR S18 OR S19

S21 S3 AND S20

S22 (MH "Systematic Review") OR PT systematic reviews OR ( "systematic review" OR "systematic reviews" )

S23 S21 AND S22

S24 (MH "Randomized Controlled Trials") OR (MH "Clinical Trials")

S25 PT clinical trials OR ( "clinical trial" OR "clinical trials" )

S26 (random OR randomized) AND (control OR controlled OR clinical ) AND (trial OR trials OR study OR studies)

S27 S24 OR S25 OR S26

S28 S21 AND S27 


\section{ANEXO II. EVALUACIÓN DE LA CALIDAD DE LOS ESTUDIOS}

\section{Revisiones sistemáticas - AMSTAR}

No se han incluido RS.

\section{ECAs - Risk of bias - Cochrane}

\begin{tabular}{|c|c|c|c|c|c|c|}
\hline $\begin{array}{l}\text { Referencia } \\
\text { (Cita Abreviada) }\end{array}$ & $\begin{array}{l}\text { Random sequence } \\
\text { generation (selection } \\
\text { bias) }\end{array}$ & $\begin{array}{l}\text { Allocation } \\
\text { conceallement } \\
\text { (selection bias) }\end{array}$ & $\begin{array}{l}\text { Blinding } \\
\text { (performance bias } \\
\text { and detection bias) } \\
\text { All outcomes }\end{array}$ & $\begin{array}{l}\text { Incomplete outcome } \\
\text { data (attrition bias) } \\
\text { All outcomes }\end{array}$ & $\begin{array}{l}\text { Selective reporting } \\
\text { (reporting bias) }\end{array}$ & Other bias \\
\hline Limrattamorn 2013 & $\begin{array}{l}\text { Riesgo poco claro } \\
\text { No indicado }\end{array}$ & $\begin{array}{l}\text { Riesgo poco claro } \\
\text { No indicado }\end{array}$ & $\begin{array}{l}\text { Riesgo poco claro } \\
\text { No indicado }\end{array}$ & Bajo riesgo de sesgo & Bajo riesgo de sesgo & Bajo riesgo \\
\hline Girish 2013 & $\begin{array}{l}\text { YA ESTA EN } \\
\text { PREGUNTA } 1 \text { CPP }\end{array}$ & & & & & \\
\hline Mahmood 2011 & $\begin{array}{l}\text { YA ESTA EN } \\
\text { PREGUNTA } 1 \text { CPP }\end{array}$ & & & & & \\
\hline
\end{tabular}




\section{ANEXO III. Tabla de estudios para la pregunta 2}

\section{Tabla de ECAs}

\begin{tabular}{|c|c|c|c|c|c|c|}
\hline $\begin{array}{l}\text { Referencia } \\
\text { (Cita } \\
\text { Abreviada) }\end{array}$ & $\begin{array}{l}\text { Estudio (Diseño y } \\
\text { objetivo) }\end{array}$ & $\begin{array}{l}\text { Población } \\
\left(n^{\circ} y\right. \\
\text { características })\end{array}$ & $\begin{array}{l}\text { Descripción de las } \\
\text { intervenciones } \\
\text { comparaciones, } \\
\text { exposiciones o pruebas } \\
\text { a estudio }\end{array}$ & $\begin{array}{l}\text { Resultados } \\
\text { (Estimadores de resultados- } \\
\text { Magnitud del efecto) }\end{array}$ & $\begin{array}{l}\text { Conclusiones } \\
\text { (conclusiones) }\end{array}$ & $\begin{array}{l}\text { Comentarios } \\
\text { Calidad de la evidencia Financiación } \\
\text { comentarios) }\end{array}$ \\
\hline $\begin{array}{l}\text { Limrattamorn } \\
2013\end{array}$ & $\begin{array}{l}\text { Diseño } \\
\text { ECA } \\
\text { Objetivo } \\
\text { Comparar la } \\
\text { duración de la } \\
\text { LME en madres } \\
\text { que amamantan } \\
\text { en los primeros } 30 " \\
\text { (temprano) vs. las } \\
\text { que lo hacen } \\
\text { después }\end{array}$ & $\begin{array}{l}\mathrm{N} \\
50 \\
\text { Características } \\
\text { RN a término sano }\end{array}$ & $\begin{array}{l}\text { Intervención } \\
\text { Contacto e inicio primera } \\
\text { toma primeros } 30 " \\
\text { (temprano) } \\
\text { Comparación } \\
\text { Contacto e inicio primera } \\
\text { toma después de los } \\
\text { primeros } 30 " \text { (tardio) }\end{array}$ & $\begin{array}{l}\text { Tasa de LME } 1 \text { mes } \\
100 \% \text { vs. } 100 \% \\
\text { Tasa de LME } 4 \text { meses } \\
34,6 \% \text { vs. } 15 \% ; p=0,300 \\
\text { Duración de la LM } \\
\text { Media (SD): } 3,15 \pm 1,91 \text { vs. } \\
2,40 \pm 1,63 ; p=0,166\end{array}$ & $\begin{array}{l}\text { No hay diferencias } \\
\text { significativas en la tasa } \\
\text { de LME entre los RN que } \\
\text { realizan la primera toma } \\
\text { en los primeros 30" y los } \\
\text { que la realizan después. }\end{array}$ & $\begin{array}{l}\text { (+) analiza expresamente antes/ } \\
\text { después } 30 " \\
(-) 4 \text { perdidas al seguimiento, no se } \\
\text { puede contactar a las madres, } \\
\text { muestra pequeña } \\
\text { Conflicto de interés } \\
\text { No declarado } \\
\text { Financiación } \\
\text { No declarado } \\
\text { CALIDAD } \\
\text { Calidad moderada (ver RoB) }\end{array}$ \\
\hline Girish 2013 & $\begin{array}{l}\text { YA ESTA EN } \\
\text { PREGUNTA } 1 \\
\text { CPP }\end{array}$ & & & & & \\
\hline $\begin{array}{l}\text { Mahmood } \\
2011\end{array}$ & $\begin{array}{l}\text { YA ESTA EN } \\
\text { PREGUNTA } 1 \\
\text { CPP }\end{array}$ & & & & & \\
\hline
\end{tabular}


Tabla de estudios observacionales

\begin{tabular}{|c|c|c|c|c|c|c|}
\hline $\begin{array}{l}\text { Referencia } \\
\text { (Cita } \\
\text { Abreviada) }\end{array}$ & $\begin{array}{l}\text { Estudio (Diseño y } \\
\text { objetivo) }\end{array}$ & $\begin{array}{l}\text { Población } \\
\left(n^{\circ} y\right. \\
\text { características })\end{array}$ & $\begin{array}{l}\text { Descripción de las } \\
\text { intervenciones } \\
\text { comparaciones, } \\
\text { exposiciones o pruebas } \\
\text { a estudio }\end{array}$ & $\begin{array}{l}\text { Resultados } \\
\text { (Estimadores de resultados- } \\
\text { Magnitud del efecto) }\end{array}$ & $\begin{array}{l}\text { Conclusiones } \\
\text { (conclusiones) }\end{array}$ & $\begin{array}{l}\text { Comentarios } \\
\text { Calidad de la evidencia Financiación } \\
\text { comentarios) }\end{array}$ \\
\hline Carberry 2013 & $\begin{array}{l}\text { Diseño } \\
\text { Estudio transversal } \\
\text { Objetivo } \\
\text { Evaluar el impacto } \\
\text { de las prácticas } \\
\text { "amigas de los } \\
\text { niños" en la } \\
\text { duración de la LM }\end{array}$ & $\begin{array}{l}\mathbf{N} \\
581 \\
\text { Características } \\
\text { RN a término sano }\end{array}$ & $\begin{array}{l}\text { Exposición } \\
\text { Paso } 4 \text { de la IHAN: Inicio } \\
\text { de la lactancia en la } \\
\text { primera hora de vida }\end{array}$ & $\begin{array}{l}\text { Toma no efectiva } \\
\text { - } 1 \mathrm{~h} \text {. vs. } 1-2 \mathrm{~h} \text { : razón de tasas } 2,39 \\
\text { (IC95\% } 1,54 \text { a } 3,70 \text { ) } \\
\text { - } 1 \mathrm{~h} \text {. vs } 2-4 \mathrm{~h} \text { : razón de tasas } 3,75 \\
\text { (IC95\%2,38 a } 5,92 \text { ) } \\
\text { - } 1 \mathrm{~h} \text {. vs. >4h: razón de tasas } 5,59 \\
\text { (IC95\% } 3,27 \text { a 9,72) }\end{array}$ & $\begin{array}{l}\text { Por cada hora que } \\
\text { transcurre desde el inicio } \\
\text { de la lactancia hay } \\
\text { mayor riesgo de que } \\
\text { existan complicaciones } \\
\text { (frecuencia tomas, } \\
\text { agarre, uso de } \\
\text { suplementos) }\end{array}$ & $\begin{array}{l}\text { (-) No queda claro porque unos } \\
\text { niños empiezan durante la } 1^{\text {a }} \text { hora y } \\
\text { otros más tarde, no distingue por } \\
\text { problemas de LM, imprecisión de los } \\
\text { resultados, no hay datos tabulados, } \\
\text { no ajusta por otras prácticas o } \\
\text { factores } \\
\text { Conflicto de interés } \\
\text { No declarado } \\
\text { Financiación } \\
\text { No declarado } \\
\text { CALIDAD } \\
\text { Muy baja }\end{array}$ \\
\hline Di Frisco 2011 & $\begin{array}{l}\text { Diseño } \\
\text { Encuesta } \\
\text { Objetivo } \\
\text { Evaluar el impacto } \\
\text { de las prácticas } \\
\text { "amigas de los } \\
\text { niños" en la } \\
\text { duración de la LM }\end{array}$ & $\begin{array}{l}\mathbf{N} \\
113 \text { mujeres que } \\
\text { dieron a luz } 2-4 \\
\text { semanas antes }\end{array}$ & $\begin{array}{l}\text { Exposición } \\
\text { Inicio de la LM en la } \\
\text { primera hora de vida } \\
\text { (paso } 4 \text { IHAN) }\end{array}$ & $\begin{array}{l}\text { LME 2-4 semanas } \\
72,1 \% \text { vs. } 42,9 \% ; p=0,05\end{array}$ & $\begin{array}{l}\text { Las madres que iniciaron } \\
\text { la lactancia en la primera } \\
\text { hora de vida tenían más } \\
\text { probabilidades de seguir } \\
\text { con LME a las } 2-4 \\
\text { semanas tras el parto }\end{array}$ & $\begin{array}{l}\text { (-) No se explica bien porque a unas } \\
\text { madres unas madres tardan más y } \\
\text { otras no, aunque si muestra } \\
\text { diferencias significativas entre las } \\
\text { que tiene parto vaginal y cesárea. } \\
\text { Es una encuesta, autoreporte. } \\
\text { Sesgo en la presentación de datos, } \\
\text { ya que recoge intervalos para hora } \\
\text { inicio LM pero no presenta los } \\
\text { resultados } \\
\text { Conflicto de interés } \\
\text { No declarado } \\
\text { Financiación } \\
\text { No declarado } \\
\text { CALIDAD } \\
\text { Muy baja }\end{array}$ \\
\hline
\end{tabular}




\begin{tabular}{|c|c|c|c|c|c|c|}
\hline $\begin{array}{l}\text { Referencia } \\
\text { (Cita } \\
\text { Abreviada) }\end{array}$ & $\begin{array}{l}\text { Estudio (Diseño y } \\
\text { objetivo) }\end{array}$ & $\begin{array}{l}\text { Población } \\
\left(n^{\circ} y\right. \\
\text { características) }\end{array}$ & $\begin{array}{l}\text { Descripción de las } \\
\text { intervenciones } \\
\text { comparaciones, } \\
\text { exposiciones o pruebas } \\
\text { a estudio }\end{array}$ & $\begin{array}{l}\text { Resultados } \\
\text { (Estimadores de resultados- } \\
\text { Magnitud del efecto) }\end{array}$ & $\begin{array}{l}\text { Conclusiones } \\
\text { (conclusiones) }\end{array}$ & $\begin{array}{l}\text { Comentarios } \\
\text { Calidad de la evidencia Financiación } \\
\text { comentarios) }\end{array}$ \\
\hline $\begin{array}{l}\text { Noomson- } \\
\text { Rivers } 2010\end{array}$ & $\begin{array}{l}\text { Diseño } \\
\text { Encuesta } \\
\text { longitudinal } \\
\text { Objetivo } \\
\text { Examinar las } \\
\text { varibles } \\
\text { relacionadas con } \\
\text { el retraso en la } \\
\text { lactogénsesis }\end{array}$ & $\begin{array}{l}\mathbf{N} \\
431 \\
\text { Características } \\
\text { Madres primerizas, } \\
\text { parto a término que } \\
\text { inician LM }\end{array}$ & $\begin{array}{l}\text { Exposición } \\
\text { Inicio de la LM antes o } \\
\text { después de las primeras } \\
\text { dos horas }\end{array}$ & $\begin{array}{l}\text { Retraso lactogenesis } \\
44,3 \%(39,0 \text { a } 49,7) \text { vs. } 43,6 \% \\
(33,4 \text { a } 53,8) ; p=0,905\end{array}$ & $\begin{array}{l}\text { Los factores de riesgo } \\
\text { para el retraso en la } \\
\text { lactogénesis son } \\
\text { múltiples. En este } \\
\text { estudio el inicio } \\
\text { temprano o tardío ( } 2 \\
\text { primeras horas) no } \\
\text { influye significativamente }\end{array}$ & $\begin{array}{l}(+) \\
(-) \text { El objetivo no es evaluar } \\
\text { específicamente si hacer la primera } \\
\text { toma antes o después de las dos } \\
\text { primeras horas influye, es un factor } \\
\text { más. El retraso en la lactogénesis } \\
\text { es una variable surrogada } \\
\text { Conflicto de interés } \\
\text { No hay } \\
\text { Financiación } \\
\text { No se indica, pero parece que } \\
\text { nohay } \\
\text { CALIDAD } \\
\text { Muy baja }\end{array}$ \\
\hline $\begin{array}{l}\text { DiGirolamo } \\
2008\end{array}$ & $\begin{array}{l}\text { Diseño } \\
\text { Encuesta } \\
\text { longitudinal (IFPS } \\
\text { II study) } \\
\text { Objetivo } \\
\text { Evaluar el impacto } \\
\text { de las prácticas } \\
\text { "amigas de los } \\
\text { niños" en la } \\
\text { duración de la LM }\end{array}$ & $\begin{array}{l}\mathbf{N} \\
1.907 \text { mujeres que } \\
\text { tienen intención de } \\
\text { dar LM más de } 6 \\
\text { semanas } \\
\text { Características } \\
\text { Madres que inician } \\
\text { la LM y que tienen } \\
\text { intención de dar de } \\
\text { mamar al menos } 2 \\
\text { meses }\end{array}$ & $\begin{array}{l}\text { Exposición } \\
\text { Paso } 4 \text { de la IHAN: Inicio } \\
\text { de la lactancia en la } \\
\text { primera hora de vida }\end{array}$ & $\begin{array}{l}\text { LM }<6 \text { semanas } \\
10,9 \% \text { vs. } 19,5 \% ; \text { aOR } 071 \\
\text { (IC95\% 0,53 a 0,95) } \\
\\
\text { 2ajustado por otras prácticas } \\
\text { hospitalarias; variables socio- } \\
\text { demográficas y actitud e intención de la } \\
\text { madre. }\end{array}$ & $\begin{array}{l}\text { El inicio de la lactancia } \\
\text { en la primera hora de } \\
\text { vida está asociado con } \\
\text { una mayor duración de } \\
\text { la LM. }\end{array}$ & $\begin{array}{l}(+) \\
(-) \text { No se explica porque a unas } \\
\text { madres se les aplicó el paso } 4 \text { y a } \\
\text { otras no, hay diferencias entre } \\
\text { ambos grupos?, es una encuesta, } \\
\text { autoreporte, no sabemos si se han } \\
\text { aplicado otras estrategias } \\
\text { Conflicto de interés } \\
\text { No declarado } \\
\text { Financiación } \\
\text { FDA, NIH, centre for disease control } \\
\text { and prevention, office for Women's } \\
\text { health, } \\
\text { CALIDAD } \\
\text { Muy baja }\end{array}$ \\
\hline Chien 2007 & $\begin{array}{l}\text { Diseño } \\
\text { Obervacional }\end{array}$ & $\begin{array}{l}\mathbf{N} \\
2.064\end{array}$ & $\begin{array}{l}\text { Exposición } \\
\text { Inicio de la LM: }\end{array}$ & $\frac{\text { Inicio antes-después } 30 "}{\text { LM } 1 \text { mes }}$ & $\begin{array}{l}\text { El inicio de la } L M \text { antes } \\
\text { de los primeros } 30\end{array}$ & $\begin{array}{l}\text { (-) No describe bien, porque unos } \\
\text { RN empiezan antes o después no }\end{array}$ \\
\hline
\end{tabular}




\begin{tabular}{|c|c|c|c|c|c|c|}
\hline $\begin{array}{l}\text { Referencia } \\
\text { (Cita } \\
\text { Abreviada) }\end{array}$ & $\begin{array}{l}\text { Estudio (Diseño y } \\
\text { objetivo) }\end{array}$ & $\begin{array}{l}\text { Población } \\
\left(n^{\circ} y\right. \\
\text { características })\end{array}$ & $\begin{array}{l}\text { Descripción de las } \\
\text { intervenciones } \\
\text { comparaciones, } \\
\text { exposiciones o pruebas } \\
\text { a estudio }\end{array}$ & $\begin{array}{l}\text { Resultados } \\
\text { (Estimadores de resultados- } \\
\text { Magnitud del efecto) }\end{array}$ & $\begin{array}{l}\text { Conclusiones } \\
\text { (conclusiones) }\end{array}$ & $\begin{array}{l}\text { Comentarios } \\
\text { Calidad de la evidencia Financiación } \\
\text { comentarios) }\end{array}$ \\
\hline & $\begin{array}{l}\text { retrospectivo } \\
\text { mediante encuesta } \\
\text { Objetivo } \\
\text { Evaluar el efecto } \\
\text { del tipo de parto y } \\
\text { del tiempo hasta la } \\
\text { primera toma en la } \\
\text { duración de la LM }\end{array}$ & $\begin{array}{l}\text { Características } \\
\text { Datos de mujeres } \\
\text { que dan a luz niños } \\
\text { sin anormalidades } \\
\text { congénitas hasta } \\
\text { octubre } 2003 \text { en } \\
\text { Taiwan }\end{array}$ & $\begin{array}{l}<30 \text { " }(15 \%) \text {; } \\
\text { durante la estancia en el } \\
\text { hospital }(49,6 \%) \text {; } \\
\text { entre alta hospitalaria y } \\
\text { primer mes }(18,9 \%)\end{array}$ & $\begin{array}{l}\text { OR 1,47 (IC95\% 1,13 a 1,90) } \\
\text { LM } 3 \text { meses } \\
\text { OR 1,57 (IC95\% 1,21 a } 2,05)\end{array}$ & $\begin{array}{l}\text { minutos está asociado } \\
\text { con tasas más altas de } \\
\text { LM al mes y a los } 3 \\
\text { meses. }\end{array}$ & $\begin{array}{l}\text { hace regresión paso a paso, no } \\
\text { obstante el parto por cesárea está } \\
\text { significativamente asociado a un } \\
\text { inicio tardío de la LM, encuesta } \\
\text { autoreporte con baja tasa se } \\
\text { respuesta ( } 53 \% \text { ). Muy pocas } \\
\text { mujeres empiezan en los primeros } \\
30 \text { minutos } \\
\text { Conflicto de interés } \\
\text { No declarado } \\
\text { Financiación } \\
\text { No declarado } \\
\text { CALIDAD } \\
\text { Muy baja }\end{array}$ \\
\hline Murray 2007 & $\begin{array}{l}\text { Diseño } \\
\text { Encuesta } \\
\text { longitudinal } \\
\text { Objetivo } \\
\text { Evaluar el impacto } \\
\text { de las prácticas } \\
\text { "amigas de los } \\
\text { niños" en la } \\
\text { duración de la LM, } \\
\text { incluyendo el inicio } \\
\text { de la LM en la } \\
\text { primera hora }\end{array}$ & $\begin{array}{l}\mathbf{N} \\
4.544 \\
\text { Características } \\
\text { Datos de partos } \\
\text { años } 2002 \text { y } 2003\end{array}$ & $\begin{array}{l}\text { Exposición } \\
\text { Paso } 4 \text { de la IHAN: Inicio } \\
\text { de la lactancia en la } \\
\text { primera hora de vida }\end{array}$ & $\begin{array}{l}1^{\text {a }} \text { toma en la primera hora de } \\
\text { vida } \\
1.534 \text { vs. } 561 \\
\text { Tasa de LME a las } 8 \text { semanas } \\
77 \%(\text { IC } 95 \% 74 \text { a } 79) \text { vs. } 66 \% \\
\text { (IC95\% } 61 \text { a } 70)\end{array}$ & $\begin{array}{l}\text { El inicio de la LM en la } \\
\text { primera hora de vida es } \\
\text { una de las } 5 \text { prácticas } \\
\text { que contribuyen a que la } \\
\text { duración de la LM sea } \\
\text { mayor }\end{array}$ & $\begin{array}{l}\text { (-) No queda claro porque unos } \\
\text { niños empiezan durante la } 1^{a} \text { hora y } \\
\text { otros más tarde, no hace regresión } \\
\text { paso a paso, encuesta autoreporte } \\
\text { Conflicto de interés } \\
\text { No declarado } \\
\text { Financiación } \\
\text { No declarado } \\
\text { CALIDAD } \\
\text { Muy baja }\end{array}$ \\
\hline Tang 2013 & $\begin{array}{l}\text { Diseño } \\
\text { Cohortes } \\
\text { prospectivo } \\
\text { Objetivo } \\
\text { Ver la prevalencia } \\
\text { del inicio temprano }\end{array}$ & $\begin{array}{l}\text { N } \\
695 \\
\text { Características } \\
\text { Madres y sus RN } \\
\text { sanos a término (< } \\
4 \text { dias en UCIN) }\end{array}$ & & $\begin{array}{l}\text { Tasa de LME al alta } \\
54 \% \text { vs. } 46 \% ; \text { OR } 2,23(1,32 \text { a } \\
3,76) ; p=0,003\end{array}$ & $\begin{array}{l}\text { El inicio temprano de la } \\
\text { LM, durante la primera } \\
\text { hora de vida, está } \\
\text { asociado con mayores } \\
\text { tasas de LM E al alta. }\end{array}$ & $\begin{array}{l}(+) \\
(-) \text { definicion de RN sano no } \\
\text { equivalente a la de nuestra guia, no } \\
\text { se ajustan los resultados por otros } \\
\text { factores, el inicio temprano de la LM } \\
\text { es muy bajo (menos del 10\%) y un } \\
\text { elevado \% de RN recibe }\end{array}$ \\
\hline
\end{tabular}




\begin{tabular}{|c|c|c|c|c|c|c|}
\hline $\begin{array}{l}\text { Referencia } \\
\text { (Cita } \\
\text { Abreviada) }\end{array}$ & $\begin{array}{l}\text { Estudio (Diseño y } \\
\text { objetivo) }\end{array}$ & $\begin{array}{l}\text { Población } \\
\text { ( } n^{\circ} y \\
\text { características) }\end{array}$ & $\begin{array}{l}\text { Descripción de las } \\
\text { intervenciones } \\
\text { comparaciones, } \\
\text { exposiciones o pruebas } \\
\text { a estudio }\end{array}$ & $\begin{array}{l}\text { Resultados } \\
\text { (Estimadores de resultados- } \\
\text { Magnitud del efecto) }\end{array}$ & $\begin{array}{l}\text { Conclusiones } \\
\text { (conclusiones) }\end{array}$ & $\begin{array}{l}\text { Comentarios } \\
\text { Calidad de la evidencia Financiación } \\
\text { comentarios) }\end{array}$ \\
\hline & $\begin{array}{l}\text { de la LM y su } \\
\text { influencia en la } \\
\text { tasa de LME al alta }\end{array}$ & $\begin{array}{l}\text { nacidos en } 4 \\
\text { hospitales chinos }\end{array}$ & & & & $\begin{array}{l}\text { suplementos. No se describe por } \\
\text { qué unos RN empiezan antes la LM. } \\
\text { Conflicto de interés } \\
\text { No declarado } \\
\text { Financiación } \\
\text { No declarado } \\
\text { CALIDAD } \\
\text { Muy baja }\end{array}$ \\
\hline $\begin{array}{l}\text { Vieira } 2010 \\
\text { Brazil }\end{array}$ & $\begin{array}{l}\text { Diseño } \\
\text { Estudio de } \\
\text { cohortes } \\
\text { Objetivo } \\
\text { Determinar los } \\
\text { factores asociados } \\
\text { con la duración de } \\
\text { la LME al mes, } \\
\text { incluyendo el inicio } \\
\text { temprano/ tardío } \\
\text { de la LM }\end{array}$ & $\begin{array}{l}\mathbf{N} \\
1.309 \\
\text { Características } \\
\text { Diadas madre-RN, } \\
\text { no sabemos tipo } \\
\text { de parto, EG,... }\end{array}$ & $\begin{array}{l}\text { Comparaciones } \\
\text { Temprano }\left(1^{a} \text { hora) vs. }\right. \\
\text { tardío (después de la } 1^{a} \\
\text { hora) }\end{array}$ & $\begin{array}{l}\text { LME } 1 \text { mes } \\
58,6 \% \text { vs. } 41,1 \% ; p=0,806\end{array}$ & $\begin{array}{l}\text { El inicio temprano de la } \\
\text { LM ( } 1^{a} \text { hora de vida) no } \\
\text { influye en el } \\
\text { mantenimiento de la } \\
\text { LME al mes }\end{array}$ & $\begin{array}{l}(+) N \text { grande } \\
(-) \text { No describe por qué unos niños } \\
\text { hacen la } 1^{a} \text { toma antes y si hay otra } \\
\text { variables a tener en cuenta, no hace } \\
\text { regresión paso a paso } \\
\text { Conflicto de interés } \\
\text { No hay conflicto de interés } \\
\text { Financiación } \\
\text { Fundación PASESB } \\
\text { CALIDAD } \\
\text { Muy baja }\end{array}$ \\
\hline $\begin{array}{l}\text { Zahed } 2012 \\
\text { (Iran) }\end{array}$ & $\begin{array}{l}\text { Diseño } \\
\text { Estudio de } \\
\text { cohortes } \\
\text { Objetivo } \\
\text { Determinar la } \\
\text { influencia del } \\
\text { tiempo hasta la } \\
\text { primera toma en la } \\
\text { duración de la } \\
\text { LME }\end{array}$ & $\begin{array}{l}\mathbf{N} \\
1.869 \\
\text { Características } \\
\text { No disponemos de } \\
\text { la información, solo } \\
\text { abstract }\end{array}$ & $\begin{array}{l}\text { Comparaciones } \\
\text { Gr1. } 1^{\mathrm{a}} \text { toma }<60 "(39,2 \%) \\
\mathrm{Gr} 2.1^{\mathrm{a}} \text { toma } 60 "-24 \mathrm{~h} . \\
(54,2 \%) \\
\text { Gr3. } 1^{\mathrm{a}} \text { toma }>24 \mathrm{~h} .(6,6 \%)\end{array}$ & $\begin{array}{l}\text { Duración de la LME (media) } \\
\text { Gr1. 5,5 meses (IC95\% } 5,40 \text { a } \\
5,63 \text { ) } 5,43 \text { meses (IC95\% } 5,33 \text { a } \\
\text { Gr2. 5,43) } \\
\text { 5,53) } \\
\text { Gr3. } 2,69 \text { meses (IC95\% } 2,17 \text { a } \\
\text { 3,2) }\end{array}$ & $\begin{array}{l}\text { El inicio de la LM en los } \\
\text { primeros } 60 " \text { tras el parto } \\
\text { conlleva efectos } \\
\text { positivos en la duración } \\
\text { de la LME, por lo que se } \\
\text { recomienda que todas la } \\
\text { maternidades hagan un } \\
\text { programa para el inicio } \\
\text { de la LM en la primera } \\
\text { hora de vida. }\end{array}$ & $\begin{array}{l}(+) N \text { grande } \\
(-) \text { No se evalúa de modo lineal } \\
\text { (pasa de >60" a 24h.). No podemos } \\
\text { determinar por qué unos niños } \\
\text { hacen la } 1^{a} \text { toma antes y si hay } \\
\text { otras variables a tener en cuenta } \\
\text { Conflicto de interés } \\
\text { No disponemos de la información, } \\
\text { solo abstract }\end{array}$ \\
\hline
\end{tabular}




\begin{tabular}{|c|c|c|c|c|c|c|}
\hline $\begin{array}{l}\text { Referencia } \\
\text { (Cita } \\
\text { Abreviada) }\end{array}$ & $\begin{array}{l}\text { Estudio (Diseño y } \\
\text { objetivo) }\end{array}$ & $\begin{array}{l}\text { Población } \\
\left(n^{\circ} y\right. \\
\text { características) }\end{array}$ & $\begin{array}{l}\text { Descripción de las } \\
\text { intervenciones } \\
\text { comparaciones, } \\
\text { exposiciones o pruebas } \\
\text { a estudio }\end{array}$ & $\begin{array}{l}\text { Resultados } \\
\text { (Estimadores de resultados- } \\
\text { Magnitud del efecto) }\end{array}$ & $\begin{array}{l}\text { Conclusiones } \\
\text { (conclusiones) }\end{array}$ & $\begin{array}{l}\text { Comentarios } \\
\text { Calidad de la evidencia Financiación } \\
\text { comentarios) }\end{array}$ \\
\hline & & & & & & $\begin{array}{l}\text { Financiación } \\
\text { No disponemos de la información, } \\
\text { solo abstract } \\
\text { CALIDAD } \\
\text { No se puede valorar la calidad ya } \\
\text { que solo se dispone del abstract. }\end{array}$ \\
\hline Righard 1990 & $\begin{array}{l}\text { Diseño } \\
\text { E. observacional } \\
\text { Objetivo } \\
\text { Evaluar el efecto } \\
\text { de las rutinas de } \\
\text { cuidados que se } \\
\text { Ilevan a cabo en la } \\
\text { sala de partos }\end{array}$ & $\begin{array}{l}\mathbf{N} \\
72 \text { díadas } \\
\text { CPP } n=38 \\
\text { Separación } n=34 \\
\text { Características } \\
\text { RN sanos a } \\
\text { término, parto } \\
\text { vaginal excluyendo } \\
\text { aquellos en los que } \\
\text { la situación } \\
\text { materna lo } \\
\text { desaconseja o RN } \\
\text { admitidos en UCIN. }\end{array}$ & $\begin{array}{l}\text { Intervención } \\
\text { Los bebés se mantienen } \\
\text { en CPP con la madre al } \\
\text { menos } 1 \mathrm{~h} \text {. o hasta la } \\
\text { primera toma } \\
\text { Comparación } \\
\text { Los bebés se mantienen } \\
\text { en CPP con la madre } \\
\text { durante15- 20" y después } \\
\text { son separados para } \\
\text { cuidados rutinarios. La } \\
\text { madre generalmente } \\
\text { manipula el pezón para } \\
\text { ayudar al bebé en el inicio } \\
\text { de la toma }\end{array}$ & $\begin{array}{l}\text { El } 56 \% \text { de las madres habían sido } \\
\text { sedadas con petidina y los niños no } \\
\text { succionaron } \\
\text { Agarre correcto } \\
\text { - } 24 / 38 \text { gr. CPP vs. } 7 / 34 \text { gr. Control } \\
\text { Amamanta durante las } 2 \\
\text { primeras horas? } \\
\text { - NO: } 10 \text { gr. CPP (10 petidina) vs. } \\
16 \text { gr. Control (15 petidina) }\end{array}$ & $\begin{array}{l}\text { El recién nacido debe } \\
\text { permanecer en CPP con } \\
\text { la madre hasta que se } \\
\text { ha completado la } \\
\text { primera toma. }\end{array}$ & $\begin{array}{l}(+) \\
(-) \text { Definición de toma correcta no } \\
\text { estandarizada. } \\
\text { Conflicto de interés } \\
\text { No se indica } \\
\text { Financiación } \\
\text { No se indica } \\
\text { Calidad }\end{array}$ \\
\hline $\begin{array}{l}\text { Gómez-Papí } \\
1998\end{array}$ & $\begin{array}{l}\text { Diseño } \\
\text { Estudio de } \\
\text { cohortes } \\
\text { prospectivo } \\
\text { Objetivo } \\
\text { Conocer la } \\
\text { tolerancia y } \\
\text { aceptación del } \\
\text { método canguro } \\
\text { en la sala de } \\
\text { partos }\end{array}$ & $\begin{array}{l}\text { N } \\
533 \text { de } 651 \mathrm{RN} \\
\text { sanos a término } \\
(82 \%)(188 \\
\text { desaconsejado por } \\
\text { razones médicas y } \\
35 \text { por admisión en } \\
\text { la UCIN) } \\
\text { Características } \\
\text { RN sanos a } \\
\text { término, parto } \\
\text { vaginal excluyendo }\end{array}$ & $\begin{array}{l}\text { Intervención } \\
\text { Los RN fueron secados, } \\
\text { identificados, con pañal y } \\
\text { gorro y colocados sobre el } \\
\text { pecho de la madre } \\
\text { cubiertos con una manta } \\
\text { a } 36^{\circ} \text { hasta máximo } 2 \mathrm{~h} \text {. }\end{array}$ & 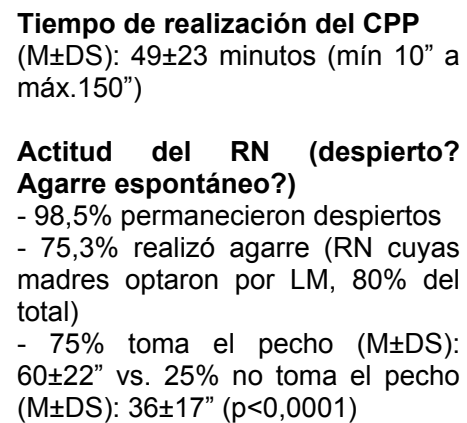 & $\begin{array}{l}\text { El contacto madre } \\
\text { canguro en la sala de } \\
\text { partos en RN a término } \\
\text { permite una succión } \\
\text { correcta por parte del } \\
\text { bebé cuando se deja el } \\
\text { tiempo suficiente. } \\
\text { Los bebés que hicieron } \\
\text { una toma correcta } \\
\text { permanecieron } \\
\text { significativamente más } \\
\text { tiempo en CPP }\end{array}$ & $\begin{array}{l}\text { Calidad } \\
(-) \text { No indica la razón por la que } \\
\text { algunos RN están menos tiempo en } \\
\text { CPP } \\
\text { Conflicto de interés } \\
\text { No se indica } \\
\text { Financiación } \\
\text { No se indica } \\
\text { Calidad } \\
\text { baja }\end{array}$ \\
\hline
\end{tabular}




\begin{tabular}{|c|c|c|c|c|c|c|}
\hline $\begin{array}{l}\text { Referencia } \\
\text { (Cita } \\
\text { Abreviada) }\end{array}$ & $\begin{array}{l}\text { Estudio (Diseño y } \\
\text { objetivo) }\end{array}$ & $\begin{array}{l}\text { Población } \\
\left(n^{\circ} y\right. \\
\text { características })\end{array}$ & $\begin{array}{l}\text { Descripción de las } \\
\text { intervenciones } \\
\text { comparaciones, } \\
\text { exposiciones o pruebas } \\
\text { a estudio }\end{array}$ & $\begin{array}{l}\text { Resultados } \\
\text { (Estimadores de resultados- } \\
\text { Magnitud del efecto) }\end{array}$ & $\begin{array}{l}\text { Conclusiones } \\
\text { (conclusiones) }\end{array}$ & $\begin{array}{l}\text { Comentarios } \\
\text { Calidad de la evidencia Financiación } \\
\text { comentarios) }\end{array}$ \\
\hline & & $\begin{array}{l}\text { aquellos en los que } \\
\text { la situación } \\
\text { materna lo } \\
\text { desaconseja o RN } \\
\text { admitidos en UCIN. }\end{array}$ & & $\begin{array}{l}\text { - A > duración CPP mejor agarre: si } \\
\text { CPP } 50+" 92,0 \% \text { vs. } 59,8 \%[\mathrm{OR} \\
7,73 ; \text { IC } 95 \% \text { 4,02 a 15,10)] } \\
\text { Actitud de la madre } \\
\text { - } 87,2 \% \text { contentas } \\
\text { - } 21 \% \text { manifiesta cansancio }\end{array}$ & $\begin{array}{l}\text { Si el RN estuvo } 50+\text { " en } \\
\text { CPP era } 8 \text { veces más } \\
\text { probable que cogiera el } \\
\text { pecho. } \\
\text { La madres se mostraron } \\
\text { contentas pese al lógico } \\
\text { cansancio posparto }\end{array}$ & \\
\hline $\begin{array}{l}\text { Ransjo- } \\
\text { Arvidson }\end{array}$ & $\begin{array}{l}\text { Diseño } \\
\text { E. descriptivo } \\
\text { (grabaciones } \\
\text { video) } \\
\text { Objetivo } \\
\text { Evaluar el } \\
\text { compartamiento } \\
\text { innato neonatal del } \\
\text { RN sobre el pecho } \\
\text { de la madre } \\
\text { durante las } \\
\text { primeras horas de } \\
\text { vida y determinar } \\
\text { el posible impacto } \\
\text { de la anestesia } \\
\text { sobre este } \\
\text { comportamiento } \\
\text { espontáneo }\end{array}$ & $\begin{array}{l}\mathbf{N} \\
28 \\
\text { Caracteristicas } \\
\text { RN y sus madres }\end{array}$ & $\begin{array}{l}\text { Intervención } \\
\text { Gr. } 1(n=4) \text { las madres no } \\
\text { habian recibido anestesia } \\
\text { durante el parto } \\
\text { Gr. } 2(n=6) \text { las madres } \\
\text { habian recibido } \\
\text { mepivacaine } \\
\text { Gr. } 3(n=12) \text { las madres } \\
\text { habian recibido petidine o } \\
\text { bupivacaine }\end{array}$ & $\begin{array}{l}\text { Todos los RN realizaron } \\
\text { movimientos mano-boca } \\
\text { Los RN cuyas madres habian } \\
\text { recibido analgesis realizaron } \\
\text { menos movimientos. } \\
\text { Un número significativamente } \\
\text { menor de RN en el grupo } 3 \text { realizo } \\
\text { movimientos mano-boca ( } p<0,001) \\
\text { Un número significativamente } \\
\text { menor de RN en los grupos } 2 \text { y } 3 \\
\text { tocaron el pezón con la mano antes } \\
\text { de la succión, lamieron o } \\
\text { succionarion el pezón ( } p<0,01) \text {. } \\
\text { Casi la mitad de los RN en los } \\
\text { grupo } 2 \text { y } 3 \text { no succionaron el } \\
\text { pecho en las primeras } 2,5 \text { horas de } \\
\text { vida. }\end{array}$ & $\begin{array}{l}\text { Este estudio demuestra } \\
\text { que el uso de la } \\
\text { analgesia durante el } \\
\text { parto puede tener un } \\
\text { efecto negativo en el } \\
\text { comportamiento innato } \\
\text { del RN y retrasar el inicio } \\
\text { de la LM. }\end{array}$ & $\begin{array}{l}\text { (+) las evaluaciones de los videos } \\
\text { se hicieron ciegas a las condiciones } \\
\text { de intervención } \\
\text { Conflicto de interés } \\
\text { No indicado } \\
\text { Financiación } \\
\text { No indicado } \\
\text { Calidad } \\
\text { Muy baja }\end{array}$ \\
\hline
\end{tabular}




\section{ANEXO IV. FOREST PLOTS}

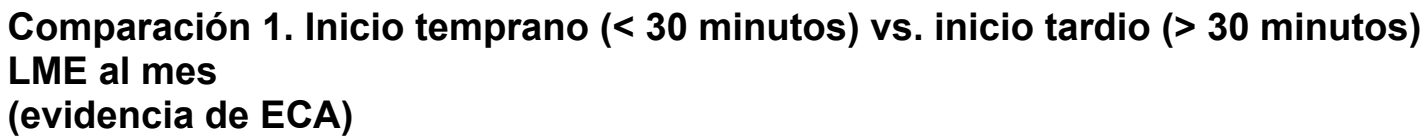

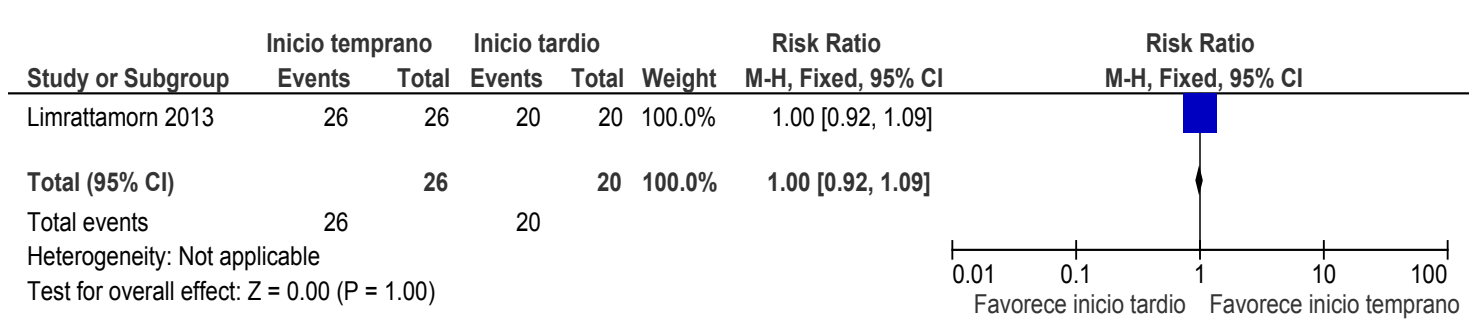

Comparación 1. Inicio temprano ( $<30$ minutos) vs. inicio tardio ( $>30$ minutos) LME a los 4 meses (evidencia de ECA)

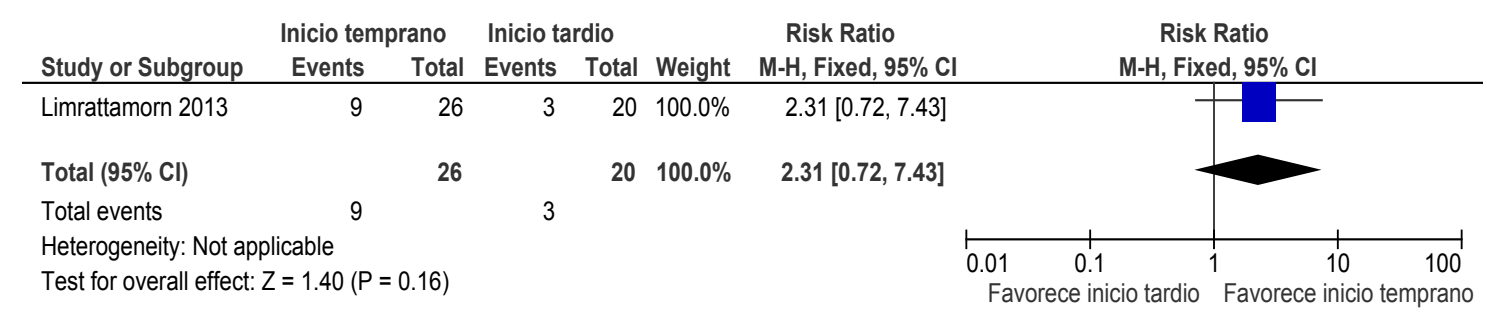

Comparación 1. Inicio temprano ( $<30$ minutos) vs. inicio tardio ( $>30$ minutos) Duración LM

(evidencia de ECA)

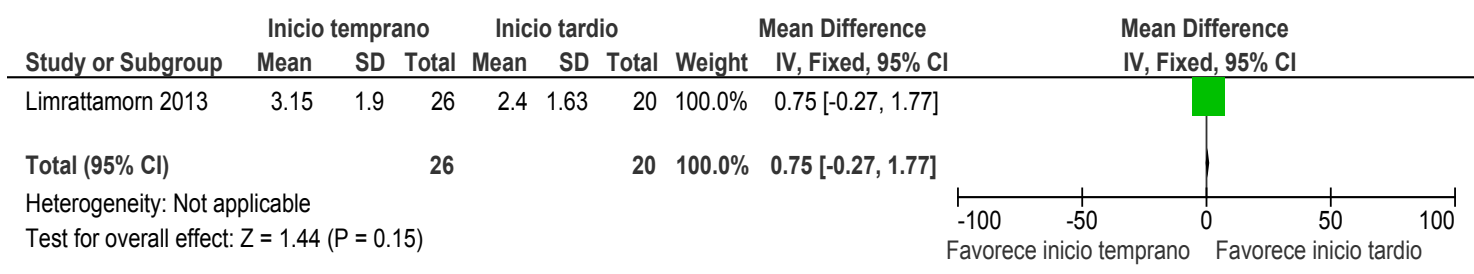

Comparación 1. Inicio temprano (< 60 minutos) vs. inicio tardio ( $>60$ minutos) Tasa de LME al alta (evidencia de estudios observacionales)

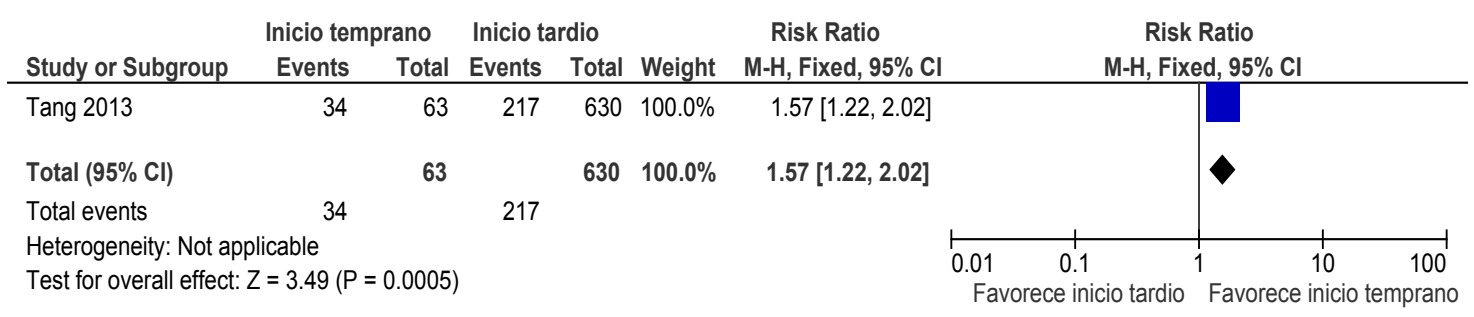


Comparación 1. Inicio temprano (< 60 minutos) vs. inicio tardio (60 minutos a 24 horas)

Tasa de LME al mes

(evidencia de estudios observacionales)

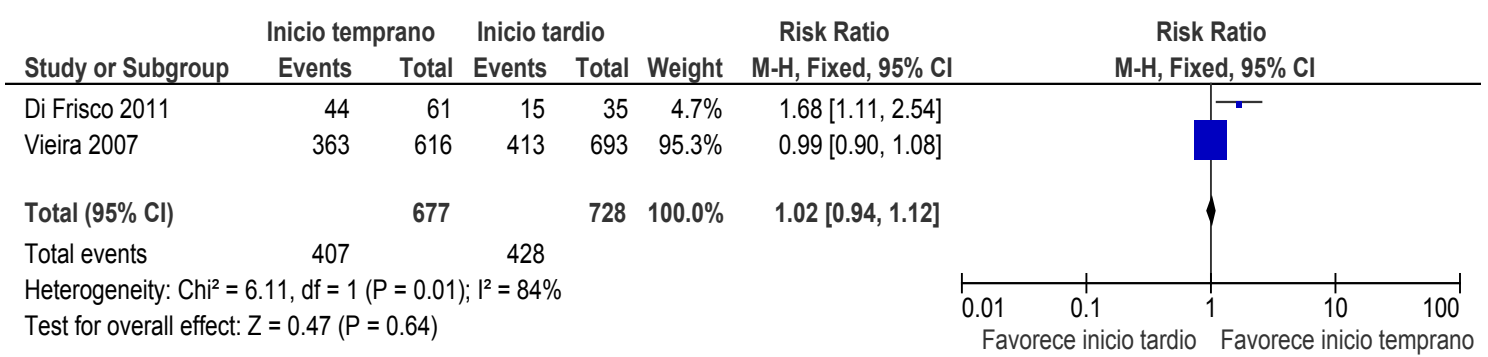

Comparación 1. Inicio temprano (< 60 minutos) vs. inicio tardio (60 minutos a 24 horas)

Tasa de LME a los dos meses

(evidencia de estudios observacionales)

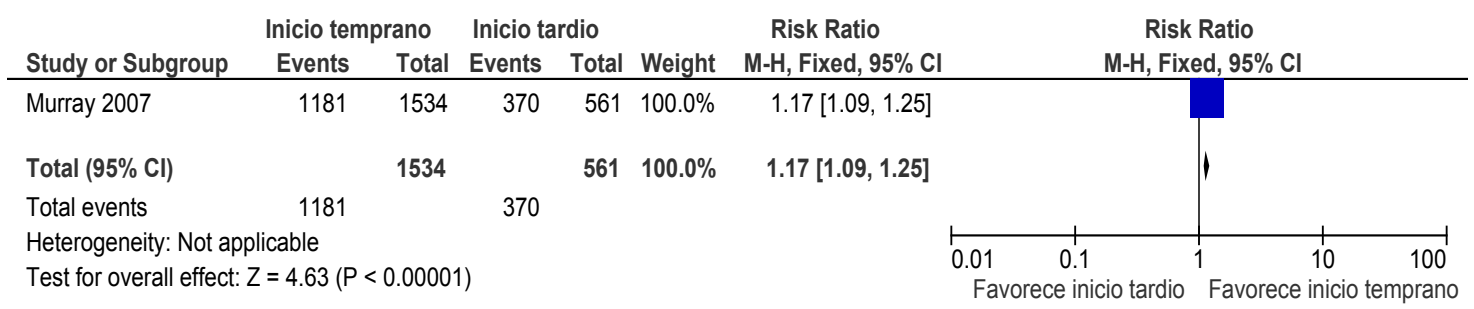

Comparación 1. Inicio temprano (< 60 minutos) vs. inicio tardio (60 minutos a 24 horas)

Duración LME

(evidencia de estudios observacionales)

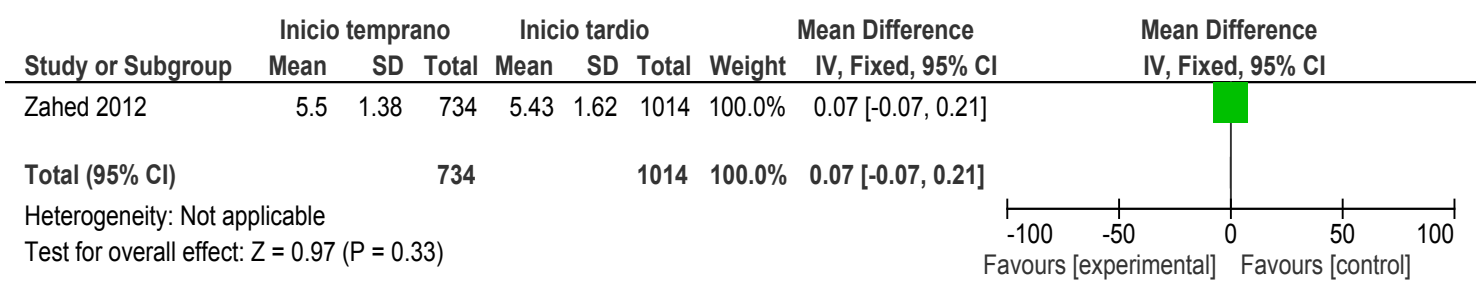

Comparación 1. Inicio temprano (< 120 minutos) vs. inicio tardio (120 minutos a 24 horas)

Retraso en el inicio de la lactogénesis II (evidencia de estudios observacionales)

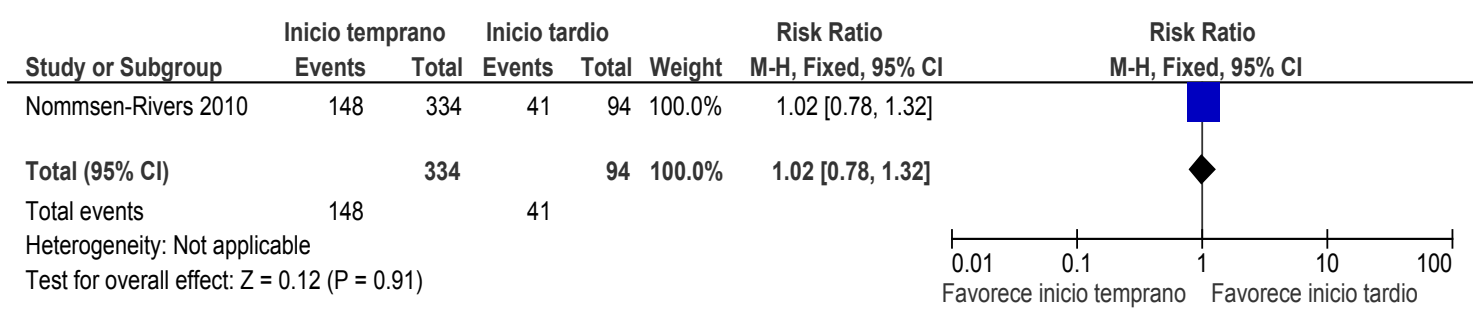




\section{Bibliografía}

(1) Debes AK, Kohli A, Walker N, Edmond K, Mullany LC. Time to initiation of breastfeeding and neonatal mortality and morbidity: a systematic review. BMC Public Health 2013;13(Suppl 3):S19.

(2) Khan J, Vesel L, Bahl R, Martines JC. Timing of Breastfeeding Initiation and Exclusivity of Breastfeeding During the First Month of Life: Effects on Neonatal Mortality and Morbidity. A Systematic Review and Meta-analysis. Maternal and child health journal 2014;1-12.

(3) NICE. Postnatal care up to 8 weeks after birth. Julio 2006 (actualizado en Febrero de 2015). Disponible en: http://guidance.nice.org.uk/CG37.

(4) IHAN. Hospitales IHAN. Guía detallada para la aplicación paso por paso. Disponible en: https://www.ihan.es/docs/documentacionacreditacion/hospitales/generales/00.Guia_detallada hospital.pdf.

(5) Perinatal Services BC Health Promotion Guideline. Breastfeeding Healthy Term Infants. March 2015. Disponible en: http://www.perinatalservicesbc.ca/Documents/GuidelinesStandards/HealthPromotion/BreastfeedingHealthyTermInfantGuideline.pdf.

(6) Matthiesen AS, Ransjo-Arvidson AB, Nissen E, Uvnas-Moberg K. Postpartum maternal oxytocin release by newborns: effects of infant hand massage and sucking. Birth 2001 Mar;28(1):13-9.

(7) Riordan J, Wambach K. Breastfeeding and human lactation. Jones \& Bartlett Learning; 2010.

(8) Erlandsson K, Dsilna A, Fagerberg I, Christensson K. Skin-to-skin care with the father after cesarean birth and its effect on newborn crying and prefeeding behavior. Birth 2007 Jun;34(2):105-14.

(9) Dewey KG. Maternal and fetal stress are associated with impaired lactogenesis in humans. J Nutr $2001 \mathrm{Nov} ; 131(11): 3012 S-5 S$.

(10) Evans KC, Evans RG, Royal R, Esterman AJ, James SL. Effect of caesarean section on breast milk transfer to the normal term newborn over the first week of life. Arch Dis Child Fetal Neonatal Ed 2003 Sep;88(5):F380-F382.

(11) Wittels B, Glosten B, Faure EA, Moawad AH, Ismail M, Hibbard J, et al. Postcesarean analgesia with both epidural morphine and intravenous patientcontrolled analgesia: neurobehavioral outcomes among nursing neonates. Anesth Analg 1997 Sep;85(3):600-6.

(12) Edmond KM, Kirkwood BR, Amenga-Etego S, Owusu-Agyei S, Hurt LS. Effect of early infant feeding practices on infection-specific neonatal mortality: an investigation of the causal links with observational data from rural Ghana. The American journal of clinical nutrition 2007;86(4):1126-31.

(13) Mullany LC, Katz J, i YM, hatry SK, eClerq SC, armstadt GL, et al. Breastfeeding patterns, time to initiation, and mortality risk among newborns in southern Nepal. The Journal of nutrition 2008;138(3):599-603.

(14) Taylor PM, Maloni JA, Taylor FH, Campbell SB. Extra Early Mother-Infant Contact and Duration of Breastfeeding. Acta paediatrica 1985;74(s316):15-22.

(15) Moore ER, Anderson GC, Bergman N, Dowswell T. Early skin-to-skin contact for mothers and their healthy newborn infants. Cochrane Database Syst Rev 2012;5:CD003519. 
(16) Limrattamorn P, Kaewkiattikun K. The Effect of Early Mother-Infant Skin to Skin Contact and Suckling on Duration of Exclusive Breastfeeding: A Randomized Controlled Trial. Thai Journal of Obstetrics and Gynaecology 2013;21:101-9.

(17) Chien LY, Tai CJ. Effect of delivery method and timing of breastfeeding initiation on breastfeeding outcomes in Taiwan. Birth 2007;34(2):123-30.

(18) Murray EK, Ricketts S, Dellaport J. Hospital practices that increase breastfeeding duration: Results from a population-based study. Birth 2007;34(3):202-11.

(19) Vieira GO, Martins C, Vieira T, Oliveira NF, Silva LR. Factors predicting early discontinuation of exclusive breastfeeding in the first month of life. Jornal de pediatria 2010;86(5):441-4.

(20) DiGirolamo AM, Grummer-Strawn LM, Fein SB. Effect of maternity-care practices on breastfeeding. Pediatrics 2008;122(Supplement 2):S43-S49.

(21) DiFrisco E, Goodman KE, Budin WC, Lilienthal MW, Kleinman A, Holmes B. Factors associated with exclusive breastfeeding 2 to 4 weeks following discharge from a large, urban, academic medical center striving for babyfriendly designation. The Journal of perinatal education 2011;20(1):28.

(22) ZAHED PE, ZENOOZI F, BALEGHI M, BIJANI A, ZAHED PY. Association of breastfeeding in the first hours of life with duration of lactation (solo abstract). $J$ Babol Univ Med Sci 2012 Nov 1;14(6).

(23) Carberry AE, Raynes-Greenow CH, Turner RM, Jeffery HE. Breastfeeding within the first hour compared to more than one hour reduces risk of early-onset feeding problems in term neonates: A cross-sectional study. Breastfeeding Medicine 2013;8(6):513-4.

(24) Tang L, Binns CW, Lee AH, Pan X, Chen S, Yu C. Low prevalence of breastfeeding initiation within the first hour of life in a rural area of Sichuan Province, China. Birth 2013;40(2):134-42.

(25) Nommsen-Rivers LA, Chantry CJ, Peerson JM, Cohen RJ, Dewey KG. Delayed onset of lactogenesis among first-time mothers is related to maternal obesity and factors associated with ineffective breastfeeding. The American journal of clinical nutrition 2010;92(3):574-84.

(26) Mahmood I, Jamal M, Khan N. Effect of mother-infant early skin-to-skin contact on breastfeeding status: a randomized controlled trial. J Coll Physicians Surg Pak 2011 Oct;21(10):601-5.

(27) Girish M, Mujawar N, Gotmare P, Paul N, Punia S, Pandey P. Impact and feasibility of breast crawl in a tertiary care hospital. J Perinatol 2013 Apr;33(4):288-91.

(28) Righard L, Alade MO. Effect of delivery room routines on success of first breastfeed. Lancet 1990 Nov 3;336(8723):1105-7.

(29) Gómez PA, Baiges Nogues MT, Batiste Fernandez MT, Marca Gutiérrez MM, Nieto JA, Closa MR. Método canguro en sala de partos en recién nacidos a término. An Esp Pediatr 1998 Jun;48(6):631-3.

(30) Maternal analgesia during labor disturbs newborn behavior: effects on breastfeeding, temperature, and crying Wiley Online Library; 2001.

(31) Cantrill RM, Creedy DK, Cooke M, Dykes F. Effective suckling in relation to naked maternal-infant body contact in the first hour of life: an observation study. BMC Pregnancy Childbirth 2014;14:20.

(32) Walters MW, Boggs KM, Ludington-Hoe S, Price KM, Morrison B. Kangaroo care at birth for full term infants: a pilot study. MCN Am J Matern Child Nurs 2007 Nov;32(6):375-81. 
(33) Widstrom AM, Lilja G, Aaltomaa-Michalias P, Dahllof A, Lintula M, Nissen E. Newborn behaviour to locate the breast when skin-to-skin: a possible method for enabling early self-regulation. Acta Paediatr 2011 Jan;100(1):79-85. 
PREGUNTA CLÍNICA: № 4

\section{¿Cómo pueden colocarse la madre y el recién nacido para facilitar el amamantamiento?}

\section{Pregunta clínica en formato PICO}

Tabla 1. Componentes de la pregunta clínica en formato PICO

\begin{tabular}{|l|l|}
\hline Pacientes & Madres parto vaginal y RN sanos a término \\
\hline Intervención & $\begin{array}{l}\text { C1. Posición madre-bebé correcta vs. posición incorrecta } \\
\text { C2.1.Postura de afianzamiento espontáneo vs. posturas clásicas de } \\
\text { amamantamiento } \\
\text { C2.2. Posturas clásicas de amamantamiento entre sí. }\end{array}$ \\
\hline Comparación & \\
\hline Desenlaces & $\begin{array}{l}\text { - Tasa de LME al alta (crítica) } \\
\text { - Peso del bebé (48-72h.) (crítica) } \\
\text { - Complicaciones de las mamas (grietas, ingurgitaciones) (crítica) } \\
\text { - Satisfacción materna (crítica) } \\
\text { - Enganche adecuado (crítica) } \\
\text { - Tasa de LM a los 4 meses (importante) } \\
\text { - Tasa de LME a los 4 meses (importante) }\end{array}$ \\
\hline Tipo de estudio & GPC, RS, ECAs, estudios observacionales y estudios descriptivos \\
\hline
\end{tabular}

\section{Introducción}

La postura de la madre y la colocación del lactante al pecho han sido objeto de todo tipo de recomendaciones, algunas contradictorias entre sí. Aunque es bien sabido que lo realmente importante es la relación entre la boca del lactante, el pezón y la areola maternas, identificar las posturas que pueden favorecer que el lactante se agarre adecuadamente al pecho de su madre permitirá a los profesionales ofrecer una ayuda más eficaz. 


\section{Estrategia de elaboración de la pregunta}

\subsection{GPC}

Tabla 2. GPC de base (seleccionadas con el AGREE)

\begin{tabular}{|c|c|c|c|c|}
\hline Guía & Evidencia & Recomendación & Referencias & Comentarios \\
\hline NICE 2006 & $\begin{array}{l}\text { ¿Cómo debe colocarse al bebé para un correcto } \\
\text { enganche al pecho? } \\
\text { La mayoría de los problemas de lactancia podrían } \\
\text { evitarse si el bebé se amamantara de modo efectivo y } \\
\text { eficiente desde el principio. Con el fin de evitar dolor en } \\
\text { los pezones y un amamantamiento ineficaz es } \\
\text { importante que la madre reciba apoyo para aprender a } \\
\text { colocar y enganchar a su bebé al pecho. La madre } \\
\text { puede utilizar una variedad de posiciones. El consejo } \\
\text { común es que la madre mantenga al bebé a la altura del } \\
\text { pecho, con el cuerpo hacia ella y con la cabeza y cuello } \\
\text { alineados (ILCA 1999). } \\
\text { ¿Cómo puede la madre enganchar correctamente al } \\
\text { bebé al pecho? } \\
\text { No se identificaron estudios que evaluasen el enganche } \\
\text { del bebé al pecho para el inicio de la LM. La publicación } \\
\text { "frombirthtofive" (DoH 2005) recomienda una posición } \\
\text { adecuada de madre y bebé e indica que la toma debe } \\
\text { de ser cómoda y que debe de sentirse una deglución } \\
\text { audible. Ambos deben de estar relajados. En caso } \\
\text { contrario se recomienda romper la succión (la madre } \\
\text { puede deslizar un dedo en la boca del bebé) e intentarlo } \\
\text { de nuevo. } \\
\text { ¿Cómo se debe colocar la madre para facilitar una } \\
\text { LM eficaz? } \\
\text { Se identificó escasa evidencia acerca de la posición } \\
\text { óptima de la madre durante la lactancia. } \\
\text { Un estudio de cohortes (Ingram 2002) utilizó la técnica } \\
\text { de la lactancia "manos fuera" para mejorar las tasas de }\end{array}$ & $\begin{array}{l}\text { Se debe ofrecer a las madres apoyo } \\
\text { profesional sobre la lactancia desde la } \\
\text { primera toma para conseguir una } \\
\text { posición cómoda tanto de la madre } \\
\text { como del bebé y para asegurar un buen } \\
\text { agarre que permita el establecimiento } \\
\text { de una lactancia efectiva y prevenir } \\
\text { problemas como el dolor en el pezón [D } \\
\text { (GPP)] } \\
\text { Se debe ofrecer apoyo adicional a las } \\
\text { madres que: } \\
\text { Han recibido anestesia o analgesia } \\
\text { durante el parto, ya que inicialmente el } \\
\text { bebé puede no mostrar signos de } \\
\text { hambre [C] } \\
\text { Han tenido parto por cesárea, ya que } \\
\text { pueden necesitar ayuda con la } \\
\text { colocación del RN para proteger la } \\
\text { cicatriz [D (GPP)] } \\
\text { No han realizado contacto temprano [D } \\
\text { (GPP)] } \\
\text { Las madres deben saber que en } \\
\text { general los bebés dejan de mamar } \\
\text { cuando están satisfechos, lo que puede } \\
\text { suceder tras hacer la toma en un solo } \\
\text { pecho. Se les debe ofrecer el segundo } \\
\text { pecho sí parecen no estar satisfechos } \\
\text { [D (GPP)] }\end{array}$ & $\begin{array}{l}\text { International Lactation Consultant } \\
\text { Association. 1999, Evidence-based } \\
\text { guidelinesfor breastfeeding } \\
\text { management during the first fourteen } \\
\text { days. Raleigh (NC):International } \\
\text { Lactation Consultant Association. } \\
\text { Department of Health. 2005, Birth to } \\
\text { Five. London: Department of Health. } \\
\text { Ingram J, Johnson D, \& Greenwood R. } \\
\text { Breastfeeding in Bristol: teaching good } \\
\text { positioning, and support from fathers } \\
\text { and families. Midwifery 2002; 18(2):87- } \\
\text { 101. } \\
\text { Shaw, F. A. 2002, "Management of } \\
\text { common breastfeeding problems", } \\
\text { Community Practitioner, vol. } 75 \text {, no. 11, } \\
\text { pp. 432-435. } \\
\text { Renfrew, M. J. 1989, "Positioning the } \\
\text { baby at the breast: more than a visual } \\
\text { skill", Journal of Human Lactation, vol. } \\
5 \text {, no. 1, pp. 13-15. }\end{array}$ & \\
\hline
\end{tabular}




\begin{tabular}{|c|c|c|c|}
\hline & $\begin{array}{l}\text { LM. Un componente de la técnica incluía dar consejos a } \\
\text { la madre para ponerse cómoda apoyando la espalda } \\
\text { utilizando cojines y apoyando los pies en el suelo o } \\
\text { sobre una banqueta o similar. } \\
\text { Una revisión narrativa recomendaba que la madre se } \\
\text { sentase erguida, con la espalda bien apoyada y los pies } \\
\text { apoyados en el suelo o en un reposapiés (Shaw 2002). } \\
\text { Otra revisión narrativa señaló que la importancia de la } \\
\text { posición de la madre durante la lactancia se aborda } \\
\text { inadecuadamente en la literatura. La toma puede no } \\
\text { funcionar correctamente si el pecho de la madre y el } \\
\text { cuerpo del bebé están en un ángulo inadecuado. La } \\
\text { madre debe encontrar una posición cómoda, en la que } \\
\text { su cuerpo esté bien apoyado y llevar al bebé a la mama } \\
\text { (Renfrew 1989). }\end{array}$ & $\begin{array}{l}\text { Se debe explicar a las mujeres que si el } \\
\text { bebé no está bien enganchado al pecho } \\
\text { se le puede estimular a que abra la } \\
\text { boca tocándole los labios con el pezón } \\
\text { [D (GPP)] }\end{array}$ & \\
\hline $\begin{array}{l}\text { BC } 2013 \\
\text { BREASTFEEDI } \\
\text { NG HEALTH } \\
\text { TERM } \\
\text { INFANTS }\end{array}$ & $\begin{array}{l}\text { Posturas para amamantar (Baby'sBest Chance) } \\
\text { - Fomentar el uso de ropa no restrictiva que permita un } \\
\text { fácil acceso al pecho. } \\
\text { - Destacar la importancia de adoptar una posición } \\
\text { cómoda y un adecuado soporte del cuerpo durante la } \\
\text { toma. } \\
\text { - Destapar al bebé y asegurarse que está despierto y } \\
\text { alerta. } \\
\text { - Promover el CPP durante la toma. } \\
\text { - Mantener al bebé cerca, "barriga con barriga". } \\
\text { - Sujetar la cabeza y los hombros del bebé y } \\
\text { mantenerlos al nivel del pecho, con la nariz a la altura } \\
\text { del pezón de la madre. La cabeza puede inclinarse } \\
\text { ligeramente hacia atrás, sin estar hiper-extendida, } \\
\text { evitando presión sobre la parte posterior de la cabeza. } \\
\text { - La madre puede sostener su pecho por debajo con la } \\
\text { mano, sobre todo si la mama es grande. La mano o los } \\
\text { dedos deben estar detrás de la areola y no interferir con } \\
\text { el enganche del bebé al pecho. } \\
\text { Sentada: cuna, cuna cruzada o fúttbol. } \\
\text {-La madre se sienta erguida con la espalda apoyada, y } \\
\text { acerca al bebé al pecho (en lugar de inclinarse hacia el } \\
\text { bebé). Se pueden usar almohadas o reposapiés para } \\
\text { mayor comodidad y para elevar al niño al nivel del }\end{array}$ & & $\begin{array}{l}\text { Health Canada. (2000, reviewed 2010). } \\
\text { Family-centred maternity and newborn } \\
\text { care: National guidelines, 4th Ed. } \\
\text { Minister of Public Works and } \\
\text { Government Services: Ottawa. } \\
\text { http://www.phac-aspc.gc.ca/dca- } \\
\text { dea/publications/fcm-smp/index- } \\
\text { eng.php. } \\
\text { Province of British Columbia, Ministry of } \\
\text { Health. (2510). Baby's best chance, 6th } \\
\text { Edition. Second Revision. Crown } \\
\text { Publication \& Queen's Printer of British } \\
\text { Columbia: Victoria, BC. }\end{array}$ \\
\hline
\end{tabular}




\begin{tabular}{|l|l|l|l|}
\hline & $\begin{array}{l}\text { pecho dela madre. } \\
\text { - La madre sujeta los hombros y la espalda del bebé } \\
\text { con el brazo y la mano, sosteniendo el cuello (Health } \\
\text { Canada National Guidelines 2000/2010). }\end{array}$ & \\
$\begin{array}{l}\text { Tumbada } \\
\text { - Madre y bebé tumbados en la cama uno frente al otro. } \\
\text { La madre puede utilizar una almohada para la cabeza, } \\
\text { detrás de la espalda o entre las piernas. } \\
\text {-Mantener al bebé cerca, con la posición de cuello y } \\
\text { cabeza descrita anteriormente. }\end{array}$ & & \\
\hline
\end{tabular}

Tabla 3. Resumen de GPC del SNS

\begin{tabular}{|l|l|l|l|l|}
\hline Guía & Evidencia & Recomendación & Referencias & Comentarios \\
\hline GPC parto & NO & & & \\
\hline GPC embarazo & NO & & & \\
\hline
\end{tabular}

Tabla 4. Resúmenes de otras guías/ docs de referencia

\begin{tabular}{|l|l|l|l|l|}
\hline Guía & Evidencia & Recomendación & Referencias & Comentarios \\
\hline WHO 2006 & & 1. La cabeza y el cuerpo del bebé están alineados & & \\
& & 2. El bebé está en contacto con el cuerpo dela madre & \\
& 3. El bebé está sujeto por la cabeza y el cuello & & \\
& 4. El bebé se acerca al pecho, estando la nariz a la altura del pezón & & \\
\hline
\end{tabular}

\subsection{Revisiones sistemáticas}

No se ha localizado ninguna RS. 


\subsection{Resumen de GPCs base y RSs disponibles}

\section{¿Cómo deben de colocarse madre y bebé para facilitar el agarre?}

La GPC de NICE (1) recoge entre otros, la evidencia de la Internacional Lactation Consultant Association (ILCA) (2), un estudio de cohortes (3) y dos revisiones narrativas $(4 ; 5)$. Describe que la madre debe apoyar la espalda de modo adecuado y apoyar los pies en el suelo (se pueden usar almohadas o reposapiés para mayor comodidad) y llevar al lactante al pecho. Debe mantener al lactante pegado a su cuerpo y sujetarle la espalda y la cabeza. Es importante que la cabeza esté alineada con el cuello, que la nariz esté a la altura del pezón y que la boca esté bien abierta, tanto para el agarre como durante la toma (barbilla hacia el pecho). Si es necesario la madre puede sostener su pecho por debajo con la mano, teniendo en cuenta que la mano o los dedos deben estar detrás de la areola y no interferir con el agarre del lactante al pecho. La toma debe de ser cómoda y ha de sentirse una deglución audible. Ambos deben de estar relajados. En caso contrario se recomienda interrumpir la succión (la madre puede deslizar un dedo en la boca del lactante) e intentarlo de nuevo.

La GPC de la PSBC (6), recoge las recomendaciones del documento Baby'sBest Chance (7) y destaca la importancia de adoptar una posición cómoda y un adecuado soporte del cuerpo durante la toma, promover el CPP durante la misma y mantener al recién nacido cerca "barriga con barriga", sujetándole la cabeza y los hombros para mantenerlos al nivel del pecho, con la nariz a la altura del pezón de la madre. La cabeza puede inclinarse ligeramente hacia atrás, sin estar hiper-extendida, evitando presión sobre la parte posterior de la cabeza. La madre puede sostener su pecho por debajo con la mano, sobre todo si la mama es grande, teniendo en cuenta que la mano o los dedos deben estar detrás de la areola y no interferir con el agarre del lactante al pecho.

Por su parte la OMS (8) concluye que lo importante es que la cabeza y el cuerpo del lactante están alineados; que el lactante esté en contacto con el cuerpo de la madre y sujeto por la cabeza y el cuello y que se acerca al pecho, estando la nariz a la altura del pezón

No se ha localizado ninguna RS al respecto.

\section{¿Cuál es la postura más eficaz para amamantar?}

La GPC de NICE (1) no encuentra estudios que evalúen una postura específica.

La GPC del Perinatal Services (6) resume las posturas clásicas para amamantar, aunque no hace recomendaciones a favor de una postura determinada:

- Posición sentada: cuna, cuna cruzada o fútbol

- La madre se sienta erguida con la espalda apoyada, y acerca al bebé al pecho (en lugar de inclinarse hacia el bebé). Se pueden usar almohadas o reposapiés para mayor comodidad y para elevar al niño al nivel del pecho de la madre.

- La madre sujeta los hombros y la espalda del bebé con el brazo y la mano, sosteniendo el cuello.

- Posición tumbada

- La madre y el bebé están tumbados en la cama uno frente al otro. La madre puede colocar una almohada para la cabeza, detrás de la espalda o entre las piernas.

- Mantener al bebé cerca, con la posición de cuello y cabeza descrita anteriormente.

En cuanto a las cesáreas, la guía NICE recomienda ofrecer apoyo adicional a las madres 
que han tenido parto por cesárea, ya que pueden necesitar ayuda con la colocación del RN para proteger la cicatriz (Recomendación de grado D).

No se ha localizado ninguna revisión sistemática.

\subsection{Conclusión}

Comparación 1. ¿Cómo deben de colocarse madre y bebé para facilitar el agarre? Posición correcta vs. Posición incorrecta

Se decide tomar como base la GPC de NICE ((1)).

\begin{tabular}{|c|l|}
\hline & Adopción GPC/Revisión sistemática \\
\hline $\mathrm{X}$ & Elaboración parcial \\
\hline & Elaboración de novo \\
\hline
\end{tabular}

Comparación 2. ¿Cuál es la postura más eficaz para amamantar?

2.1- Postura de afianzamiento espontáneo vs. posturas tradicionales

2.2- Posturas tradicionales entre sí

Se realizará una búsqueda de novo, para incluir la postura de afianzamiento espontáneo

\begin{tabular}{|l|l|}
\hline & Adopción GPC/Revisión sistemática \\
\hline & Elaboración parcial \\
\hline $\mathrm{x}$ & Elaboración de novo \\
\hline
\end{tabular}

\subsection{Diseño de la estrategia de búsqueda de estudios individuales}

\begin{tabular}{|l|l|}
\hline Criterios de selección de estudios & ECAs, estudios de cohortes o estudios observacionales \\
\hline Período de búsqueda & $\begin{array}{l}\text { C1: } 2006 \text { - abril } 2014 \\
\text { C2: búsqueda de novo, sin restricción de fechas }\end{array}$ \\
\hline Bases de datos & $\begin{array}{l}\text { Cochrane Library } \\
\text { Medline via Pubmed } \\
\text { Embase via OVID } \\
\text { Cinahlvia EBSCO } \\
\text { PsylNFOvia OVID }\end{array}$ \\
\hline
\end{tabular}

Ver estrategias de búsqueda de estudios originales en el ANEXO I. 


\section{4- Resumen de la evidencia (Tablas de estudios individuales y valoración de calidad en el ANEXO X)}

\subsection{GRADE Evidence Profile}

No se ha elaborado.

\subsection{Resumen de la evidencia}

\author{
¿Cómo deben de colocarse madre y bebé para un agarre correcto al \\ pecho?
}

Se han encontrado 5 estudios $(9 ; 10)(11-13)$ que describen cuál debe ser la posición del cuerpo del lactante en relación a la de la madre para realizar un agarre correcto y su impacto en el inicio y mantenimiento de la lactancia materna. Los estudios no han podido incluirse en la tabla GRADE, por lo que los resultados se describen de modo descriptivo.

En cuanto a la duración de la lactancia materna, un estudio descriptivo (12) $(n=570)$ concluye que una mala posición y un mal agarre se asociaban con una menor duración de la lactancia materna. Sin embargo estos resultados no son significativos cuando se ajusta por la presencia de otros problemas (daño en los pezones, conductos bloqueados y mastitis) (HRa 1,03; IC95\% de 0,86 a $1,25)$. De modo similar, en otro estudio (9) $(n=220)$ se observó que una posición incorrecta a los 30 días posparto (según los criterios de la OMS) se asociaba con una menor tasa de lactancia materna a los 6 meses, pero estas diferencias no son significativas cuando se ajusta por el resto de variables (HRa 1,01; IC95\% de 0,86 a 1,18). Por el contrario en un estudio transversal (10) $(n=77)$, se observa que la tasa de lactancia materna exclusiva a los 4 meses es significativamente más baja en las díadas que tienen una posición incorrecta $(p=0,06)$ (según los criterios de la OMS).

Una posición incorrecta también parece influir en la aparición de complicaciones en las mamas. En un estudio transversal (13) $(n=192)$ se observó que los problemas en las mamas, tales como grietas en los pezones y mastitis estaban asociados a una mala posición (según los criterios de la OMS) $(57,1 \%, p=0,0002)$ y un mal agarre $(71,4 \% ; p=0,0006)$. Asimismo, un estudio prospectivo (12) $(n=570)$ encontró que una posición inadecuada ("¿está el lactante colocado barriga con barriga con la madre?; ¿están el cuello y la cabeza del lactante alineados?") contribuía a la aparición temprana de problemas relacionados con la lactancia, incluyendo mal agarre, daño en los pezones, conductos bloqueados y mastitis $(p<0,001)$.

Un estudio transversal (11) $(n=99)$ con lactantes de hasta seis meses de edad, evaluó cómo influía mantener un posición inadecuada en los problemas con la lactancia materna. En este estudio se definió la "posición inadecuada" con los siguientes criterios: cuello del lactante torcido o inclinado hacia delante, con su cuerpo mirando hacia el techo sin estar "barriga con barriga" y sujeto únicamente por cabeza u hombros. Se observó que la mitad de los lactantes tenían algún tipo de problema relacionado con la lactancia (menos de ocho tomas en $24 \mathrm{~h}$, uso de suplementos o bajo peso para su edad). De estos lactantes con problemas, el $31,4 \%$ tenían el cuello torcido, el $27,4 \%$ estaban
Calidad

baja

\section{Calidad \\ baja}

Calidad

muy baja

\section{Calidad \\ baja}

\section{Calidad}

muy baja 
sujetos únicamente por la cabeza o los hombros, el 25,5\% tenían el cuerpo girado y en el $5,9 \%$ el cuerpo de madre y lactante estaban separados.

\section{¿Cuál es la postura más eficaz para amamantar?}

Además de las posturas clásicas descritas en la guía de la PSBC, algunos autores hacen referencia a la postura de "afianzamiento espontáneo" (ver anexo 3).

Chistina Smillie acuña el término "amamantamiento dirigido por el lactante" ("baby-led breastfeeding"), partiendo de la idea de que los lactantes están programados para encontrar el pecho por sí mismos. Kittie Frantz, basándose en la experiencia de Smillie, lo denomina "afianzamiento espontáneo" y Suzanne Colson (14-19) establece el concepto de "amamantamiento en posición de crianza biológica ${ }^{\circledR}$ " ("biological nurturing®") para describir la secuencia en la que tiene lugar el amamantamiento cuando se permite al lactante acceder al pecho para amamantarse de modo activo. En todos los casos es el lactante el que dirige la búsqueda y el agarre al pecho, mientras la madre con su posición semi-reclinada favorece los movimientos del lactante.

En la búsqueda de estudios individuales se han identificado un ECA (20), tres estudios descriptivos $(17 ; 21 ; 22)$ y un informe de casos (23) en relación a la postura de afianzamiento espontáneo. No se ha encontrado ningún estudio que comparase las diferentes posturas tradicionales. Los estudios no han podido incluirse en la tabla GRADE, por lo que los resultados se describen de modo descriptivo.

En relación al agarre correcto son clásicos los trabajos de Smillie, Frantz y Colson, aunque se trata únicamente de estudios descriptivos que no evalúan los posibles beneficios que puede tener en la lactancia a corto o largo plazo.

Smillie (21) y Frantz (22) realizan observaciones a través de grabaciones en video con lactantes de edades entre 6 días y 3 meses, algunos de ellos prematuros y otros a los que solo se había alimentado con biberón, con y sin problemas con la lactancia. Según ambas, situando a la madre desnuda de cintura para arriba y reclinada en un lugar cómodo, colocando al lactante en CPP en decúbito prono y en vertical sobre el tórax de la madre a la altura de los pechos, cuando el lactante desea mamar y está preparado (lo cual puede ocurrir inmediatamente o al cabo de un rato) se moverá hacia el pecho. El roce de la mejilla con el pecho desencadena el reflejo de búsqueda (comenzará a mover la cabeza a ambos lados) hasta que su nariz se encuentre a la altura del pezón de la madre. Una vez situado con la barbilla tocando el pecho, echará su cabeza hacia atrás, abrirá la boca y se agarrará correctamente al pecho. A la madre, se la anima a acariciar y sujetar al lactante de modo que se encuentre seguro, evitando forzar la colocación del pecho en la boca del lactante.

De modo similar, en otro estudio llevado a cabo por Colson (17) con 40 díadas de madres con recién nacidos a término sanos, se realizaron grabaciones en video de las tomas, tanto en el hospital como en casa, durante el primer mes posparto. Se observó un mayor desencadenamiento de reflejos primitivos neonatales cuando los lactantes estaban en posición de crianza biológica ${ }^{\circledR}$ (la madre reclinada en un ángulo de unos $45^{\circ}$ ) que cuando la madre estaba sentada (ángulo mayor de $65^{\circ}$ ) o tumbada en decúbito lateral (ángulo entre $0^{\circ}$ $\left.15^{\circ}\right)(p=0,0005)$. Estos reflejos primitivos desencadenados fueron efectivos para encontrar el pecho.

De modo similar, un informe de casos (23) describe la experiencia de tres 
diadas madre-lactante con problemas de agarre. Estas madres colocan a sus recién nacidos a término desnudos en CPP sobre su abdomen durante una hora, y se observa cómo en los tres casos los lactantes consiguen engancharse por sí mismos al pecho de modo eficaz.

En un ECA reciente (20) se evaluó el efecto del CPP en lactantes de entre 1 y 16 semanas con problemas de agarre severos. Las madres del grupo intervención se colocaron en posición semi-reclinada con el recién nacido desnudo en CPP, permitiendo que éste se dirigiera al pecho por sí mismo, mientras que en el grupo control madre y lactante se encontraban vestidos y en la posición habitual de amamantamiento. No se encontraron diferencias significativas entre ambos grupos en relación al número de lactantes que consiguieron realizar el agarre correcto de modo regular $(75 \%$ vs. $85 \%$, $p=0,217$ ), aunque los lactantes del grupo que realizó CPP con agarre espontáneo lo consiguió significativamente antes ( 2 vs. 4 semanas $p=0,020$ ).

Los autores tampoco encontraron diferencias significativas en la tasa de lactancia materna exclusiva tras la intervención entre los lactantes que comenzaron a engancharse y succionar $(63 \%$ vs. $58 \% ; p=0,685)$ ni tampoco en la tasa de lactancia materna a los cuatro meses de la intervención ( $73 \%$ vs. $63 \% ; p=0,284)$.

En cuanto a la satisfacción materna, las madres del grupo intervención obtuvieron una puntuación media significativamente más alta en la "Breasfeeding Emotional Scale" (69,2 (DE 1,68) vs. 62,4 (DE 2,44); $p=0,022$ ). Además estas madres manifestaron significativamente menos molestias en las mamas (dolor), que las madres del grupo control [mediana: 1,0 (IQ 1,0 a $1,0)$ vs. 1,0 (IQ 1,0 a 2,0$), p=0,044]$

Calidad

moderada

Calidad

moderada

Calidad

baja

Calidad

baja

Calidad

moderada

ACTUALIZADO A FECHA DE: Octubre de 2016 


\section{De la evidencia a la recomendación (Tabla de EtR)}

\begin{tabular}{|c|c|c|c|c|c|c|c|c|c|c|c|}
\hline \multicolumn{12}{|c|}{ ¿Cómo pueden colocarse la madre y el recién nacido para facilit } \\
\hline \multicolumn{12}{|c|}{$\begin{array}{l}\text { Población: Madres de recién nacidos sanos a término que amamantan y sus bebés } \\
\text { Intervención: } \\
\text { Comparación: } \\
\text { Perspectiva: clínica } \\
\text { C1.: Posición correcta vs. posición incorrecta } \\
\text { C2.: Postura afianzamiento espontáneo vs. posturas tradicionales } \\
\text { C3.: Posturas tradicionales vs. posturas tradicionales }\end{array}$} \\
\hline CRITERIO & $\underline{\mathrm{JUI}}$ & & & & & & \multicolumn{4}{|l|}{ EVIDENCIA } & $\begin{array}{l}\text { CONSIDERACIONES } \\
\text { ADICIONALES }\end{array}$ \\
\hline \multirow{15}{*}{$\begin{array}{l}\frac{\text { ¿Cuál es la confianza }}{\text { global en la evidencia }} \\
\text { disponible sobre los } \\
\text { efectos? }\end{array}$} & & $\begin{array}{l}\text { No se } \\
\text { incluyen } \\
\text { estudios }\end{array}$ & Muy baja & Baja & Moderada & Alta & \multicolumn{4}{|c|}{$\begin{array}{l}\text { Resumen de los resultados cuantitativos } \\
\text { C1. Posición correcta vs. posición incorrecta }\end{array}$} & \multirow{15}{*}{$\begin{array}{l}\text { González-Rodríguez (1996)(24) describe } \\
\text { que cuando el bebé no mama en } \\
\text { posición correcta, no puede extraer la } \\
\text { leche del final, y se producen lo que } \\
\text { denomina "síndrome de la posición } \\
\text { inadecuada". La madre experimenta } \\
\text { dolor en los pezones y grietas, debido a } \\
\text { que el bebé ejerce presión mantenida } \\
\text { sobre una pequeña superficie, y también } \\
\text { pueden darse ingurgitación, inflamación } \\
\text { o incluso mastitis, dado que el pecho no } \\
\text { se vacía. Además nota fuertes y } \\
\text { repetidos reflejos de eyección (apoyos), } \\
\text { debido a que la secreción de oxitocina } \\
\text { aumenta para expulsar la leche que el } \\
\text { bebé no puede tomar activamente. El } \\
\text { bebé hace tomas largas (>30 minutos) y } \\
\text { no suelta el pecho espontáneamente, ya } \\
\text { que no consigue extraer la leche final. } \\
\text { Pide el pecho con gran frecuencia } \\
\text { (raramente "aguanta" >2 h.) y se } \\
\text { muestra nervioso, intranquilo y llorón, e } \\
\text { incluso "se pelea con el pecho", dado } \\
\text { que está hambriento y frustrado al no } \\
\text { obtener la leche que espera. Es } \\
\text { frecuente que regurgite o vomite debido }\end{array}$} \\
\hline & C1 & & & & $x$ & & Desenlaces & $\begin{array}{c}\text { Importancia } \\
\text { relativa }\end{array}$ & \begin{tabular}{|c|}
$\begin{array}{c}\text { Certeza de } \\
\text { la evidencia* }\end{array}$ \\
\end{tabular} & $\begin{array}{c}\text { Tamaño del } \\
\text { efecto** }^{* *}\end{array}$ & \\
\hline & 62 & & $\mathrm{x}$ & & & & Agarre correcto & Crítica & Baja & & \\
\hline & C3. & $\mathrm{x}$ & & & & & \begin{tabular}{|l|} 
LME al alta* \\
\end{tabular} & Critica & Muy baja & & \\
\hline & & & & & & & \begin{tabular}{|l|}
$\begin{array}{l}\text { Peso del RN 48- } \\
82 \text { horas }^{*}\end{array}$ \\
\end{tabular} & Crítica & Muy baja & & \\
\hline & & & & & & & \begin{tabular}{|l|} 
Complicacione \\
$\mathbf{s}$ de las mamas
\end{tabular} & Critica & Baja & & \\
\hline & & & & & & & \begin{tabular}{|l|}
$\begin{array}{l}\text { Satisfacción } \\
\text { materna }\end{array}$ \\
\end{tabular} & Critica & No hay estudio ₹ & & \\
\hline & & & & & & & \begin{tabular}{|l|} 
LME a los 4 \\
meses \\
\end{tabular} & Importante & No hay estudio \& & & \\
\hline & & & & & & & \begin{tabular}{|l|} 
LM a los 4 \\
meses
\end{tabular} & Importante & No hay estudiof & & \\
\hline & & & & & & & $\begin{array}{l}\text { C2.Postura af } \\
\text { tradicionales }\end{array}$ & anzamiento & espontáneo & vs. posturas & \\
\hline & & & & & & & Desenlaces & $\begin{array}{c}\text { Importancia } \\
\text { relativa }\end{array}$ & \begin{tabular}{|c|} 
Certeza de \\
la evidencia*
\end{tabular} & $\begin{array}{c}\text { Tamaño del } \\
\text { efecto }^{* *}\end{array}$ & \\
\hline & & & & & & & Agarre correcto & Crítica & Muy baja & & \\
\hline & & & & & & & \begin{tabular}{|l|} 
LME al alta* \\
\end{tabular} & Critica & No hay estudio\& & & \\
\hline & & & & & & & \begin{tabular}{|l|}
$\begin{array}{l}\text { Peso del RN 48- } \\
82 \text { horas* }^{*}\end{array}$ \\
\end{tabular} & Crítica & No hay estudio & & \\
\hline & \multicolumn{6}{|c|}{ } & Complicacione & Critica & Moderada & & \\
\hline
\end{tabular}




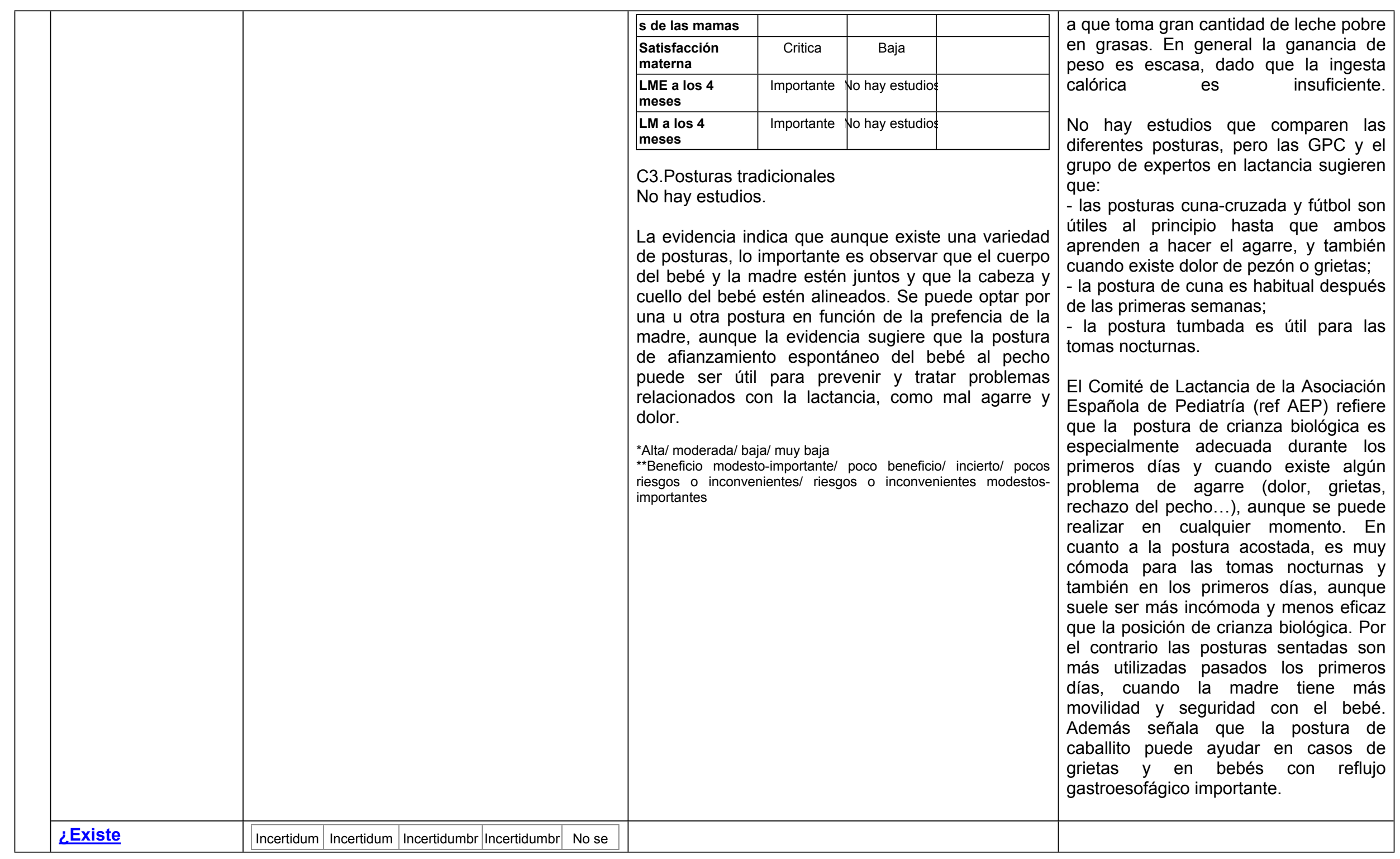




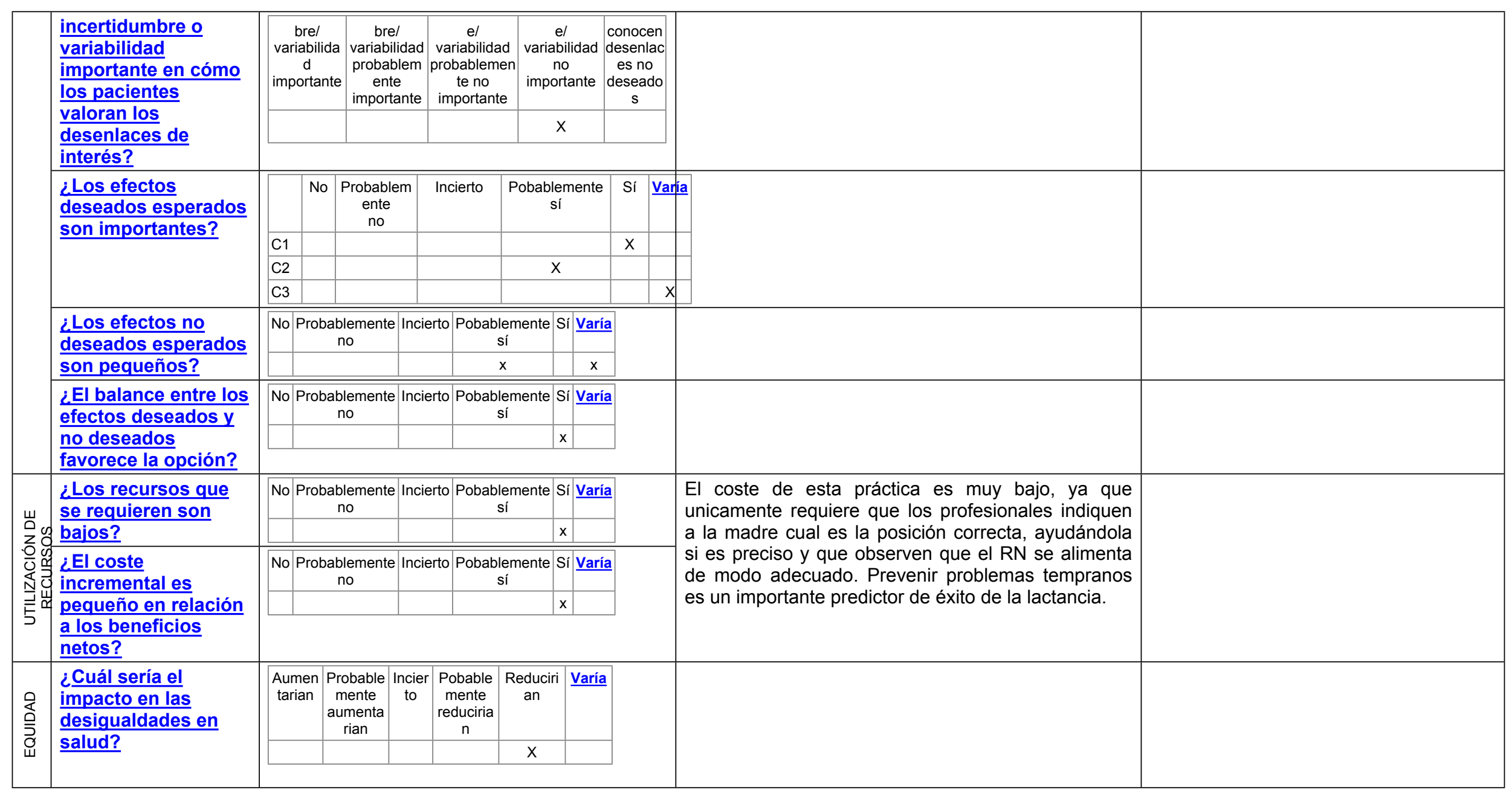




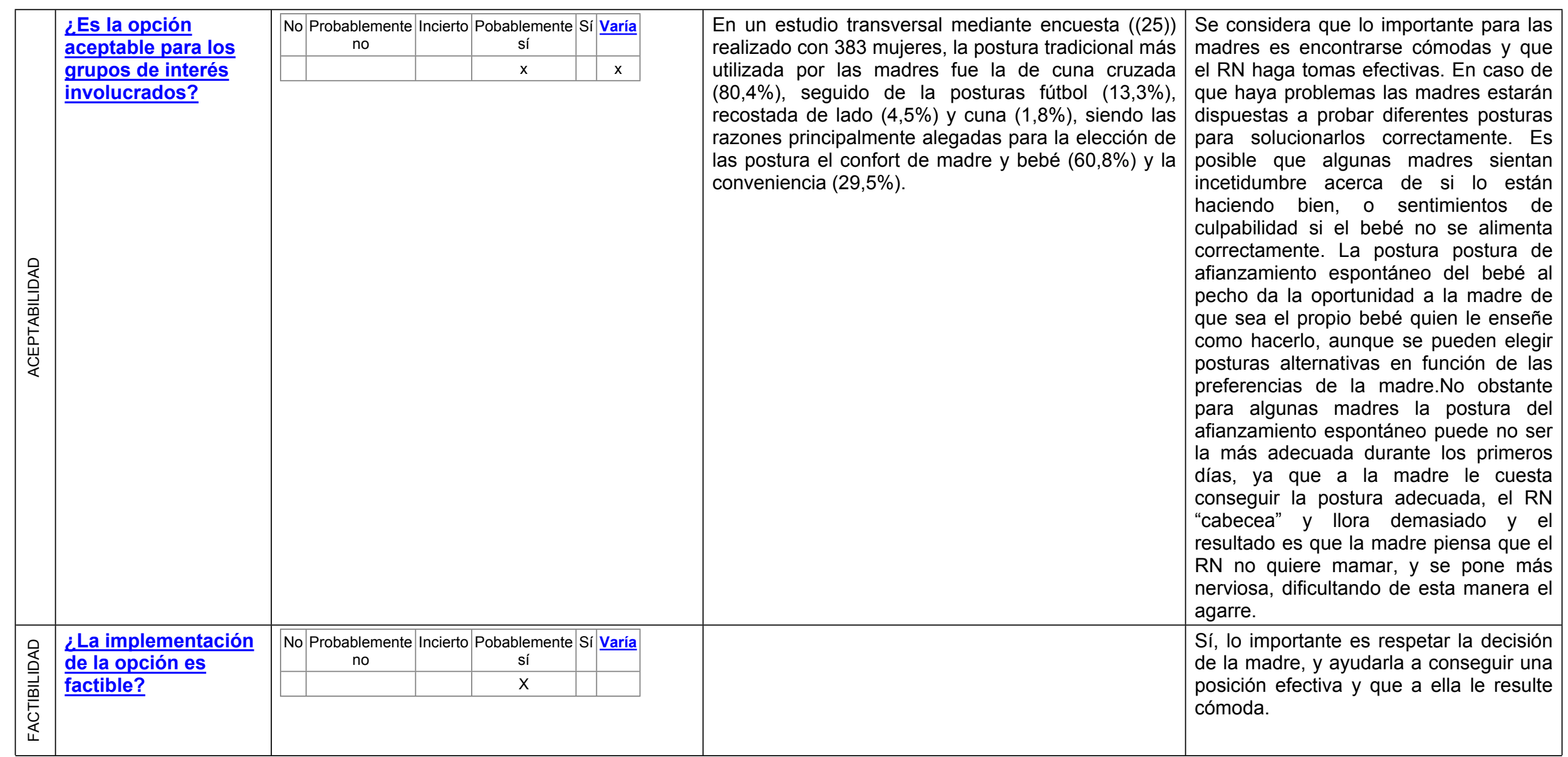

\begin{tabular}{|c|c|c|c|c|c|}
\hline $\begin{array}{l}\text { Balance de las } \\
\text { consecuencias }\end{array}$ & $\begin{array}{l}\text { Las consecuencias } \\
\text { no deseadas } \\
\text { superan claramente } \\
\text { las consecuencias } \\
\text { deseadas en la } \\
\text { mayoría de los }\end{array}$ & $\begin{array}{l}\text { Las consecuencias } \\
\text { no deseadas } \\
\text { probablemente } \\
\text { superan las } \\
\text { consecuencias } \\
\text { deseadas en la }\end{array}$ & $\begin{array}{l}\text { El balance entre las } \\
\text { consecuencias } \\
\text { deseadas y no } \\
\text { deseadas está muy } \\
\text { equilibrado o es } \\
\text { incierto }\end{array}$ & $\begin{array}{c}\text { Las consecuencias } \\
\text { deseadas } \\
\text { probablemente } \\
\text { superan las } \\
\text { consecuencias no } \\
\text { deseadas en la }\end{array}$ & $\begin{array}{l}\text { Las consecuencias } \\
\text { deseadas } \\
\text { claramente superan } \\
\text { las consecuencias } \\
\text { no deseadas en la } \\
\text { mayoría de los }\end{array}$ \\
\hline
\end{tabular}




\begin{tabular}{|c|c|c|c|c|c|}
\hline & escenarios & $\begin{array}{l}\text { mayoría de los } \\
\text { escenarios }\end{array}$ & & $\begin{array}{l}\text { mayoría de los } \\
\text { escenarios }\end{array}$ & escenarios \\
\hline $\mathrm{C} 2$ & & & & $x$ & \\
\hline
\end{tabular}

\begin{tabular}{|c|c|c|c|c|c|}
\hline \multirow[t]{3}{*}{$\begin{array}{l}\text { Tipo de } \\
\text { recomendación }\end{array}$} & \multirow[b]{2}{*}{ C1 } & $\begin{array}{l}\text { Se recomienda no } \\
\text { ofrecer la opción }\end{array}$ & $\begin{array}{l}\text { Se sugiere no ofrecer la } \\
\text { opción }\end{array}$ & $\begin{array}{l}\text { Se sugiere ofrecer la } \\
\text { opción }\end{array}$ & $\begin{array}{l}\text { Se recomienda ofrecer } \\
\text { la opción }\end{array}$ \\
\hline & & & & & $\mathrm{x}$ \\
\hline & $\mathrm{C} 2$ & & & $\mathrm{x}$ & \\
\hline$\frac{\text { Recomendación }}{\text { (Texto) }}$ & $\begin{array}{l}\text { Recomendación de buene } \\
\sqrt{ } \text { Los profesionales debe } \\
\text { problemas con el amamar } \\
\text { Recomendación débil a fa } \\
\text { Se sugiere utilizar la pos } \\
\text { reclinada, recién nacido } \\
\text { madre y el recién nacido } \\
\text { presentan dificultades con } \\
\text { Recomendación de buene } \\
\sqrt{V} \text { Independientemente de } \\
\text { del recién nacido bien alir } \\
\text { flexionado durante la toma } \\
\text { Recomendación de buena } \\
\sqrt{ } \text { Ofrecer ayuda con la cc } \\
\text { postura cómoda. }\end{array}$ & $\begin{array}{l}\text { áctica } \\
\text { ayudar a las madr } \\
\text { miento. } \\
\text { a de afianzamiento } \\
\text { ocado en prono sob } \\
\text { favorece el agarre } \\
\text { lactancia. } \\
\text { áctica } \\
\text { postura elegida, ma } \\
\text { dos, con la nariz a } \\
\text { áctica } \\
\text { cación a las madres }\end{array}$ & $\begin{array}{l}\text { encontrar la postura en } \\
\text { ontáneo, también denom } \\
\text { u cuerpo) que facilita qu } \\
\text { ontáneo al pecho materr } \\
\text { y recién nacido deberían } \\
\text { Itura del pezón, evitando } \\
\text { tras un parto por cesár }\end{array}$ & $\begin{array}{l}\text { que se encuentren más } \\
\text { da "postura de crianze } \\
\text { se pongan en marcha } \\
\text { especialmente durante } \\
\text { ar en estrecho contactc } \\
\text { sturas que obliguen a } \\
\text { puedan tener más dific }\end{array}$ & $\begin{array}{l}\text { ómodas y tengan menos } \\
\text { iológica"® (madre semi- } \\
\text { nductas instintivas en la } \\
\text { s primeros días y si se } \\
\text { on la cabeza y el cuerpo } \\
\text { intener el cuello girado o } \\
\text { ades para encontrar una }\end{array}$ \\
\hline
\end{tabular}




\begin{tabular}{|c|c|}
\hline Justificación & $\begin{array}{l}\text { Hay escasa evidencia que indique que postura es la más adecuada, aunque parece que la postura de afianzamiento espontáneo } \\
\text { ayuda a prevenir el dolor. Igualmente la experiencia clínica indica que la postura rugby es útil cuando existen problemas. Por el } \\
\text { contrario sí que existe evidencia que indica que lo importante es que el agarre se haga de modo adecuado. Es importante que los } \\
\text { profesionales expliquen a la madre los signos de un buen agarre y la ayuden con la postura del RN si es preciso. }\end{array}$ \\
\hline $\begin{array}{l}\text { Consideraciones de } \\
\text { subgrupos }\end{array}$ & $\begin{array}{l}\text { No se ha encontrado evidencia para sugerir recomendaciones en función de la edad del bebé. } \\
\text { En cuanto a las cesáreas, la guía NICE recomienda ofrecer apoyo adicional a las madres que han tenido parto por cesárea, ya que } \\
\text { pueden necesitar ayuda con la colocación del RN para proteger la cicatriz [D (GPP)]. }\end{array}$ \\
\hline $\begin{array}{l}\text { Consideraciones para } \\
\text { la implementación }\end{array}$ & $\begin{array}{l}\text { Los profesionales deben ser capaces de identificar si el agarre del lactante al pecho es adecuado o no y ayudar a las madres que } \\
\text { lo necesiten a mejorar la postura de amamantamiento para conseguir un buen agarre y una succión eficaz, lo que requiere una } \\
\text { formación continuada en consejería y técnica de lactancia. }\end{array}$ \\
\hline $\begin{array}{l}\text { Monitorización y } \\
\text { evaluación } \\
\end{array}$ & - \\
\hline $\begin{array}{l}\text { Prioridades para la } \\
\text { investigación }\end{array}$ & Se necesitan estudios comparativos entre las diferentes posturas. \\
\hline
\end{tabular}




\section{ANEXOS}

Anexo I. Estrategias de búsqueda

Anexo II. Valoración de la calidad de los estudios

Anexo III. Tablas de estudios individuales

Anexo IV. Forestplots

\section{Anexo I. Estrategias de búsqueda}

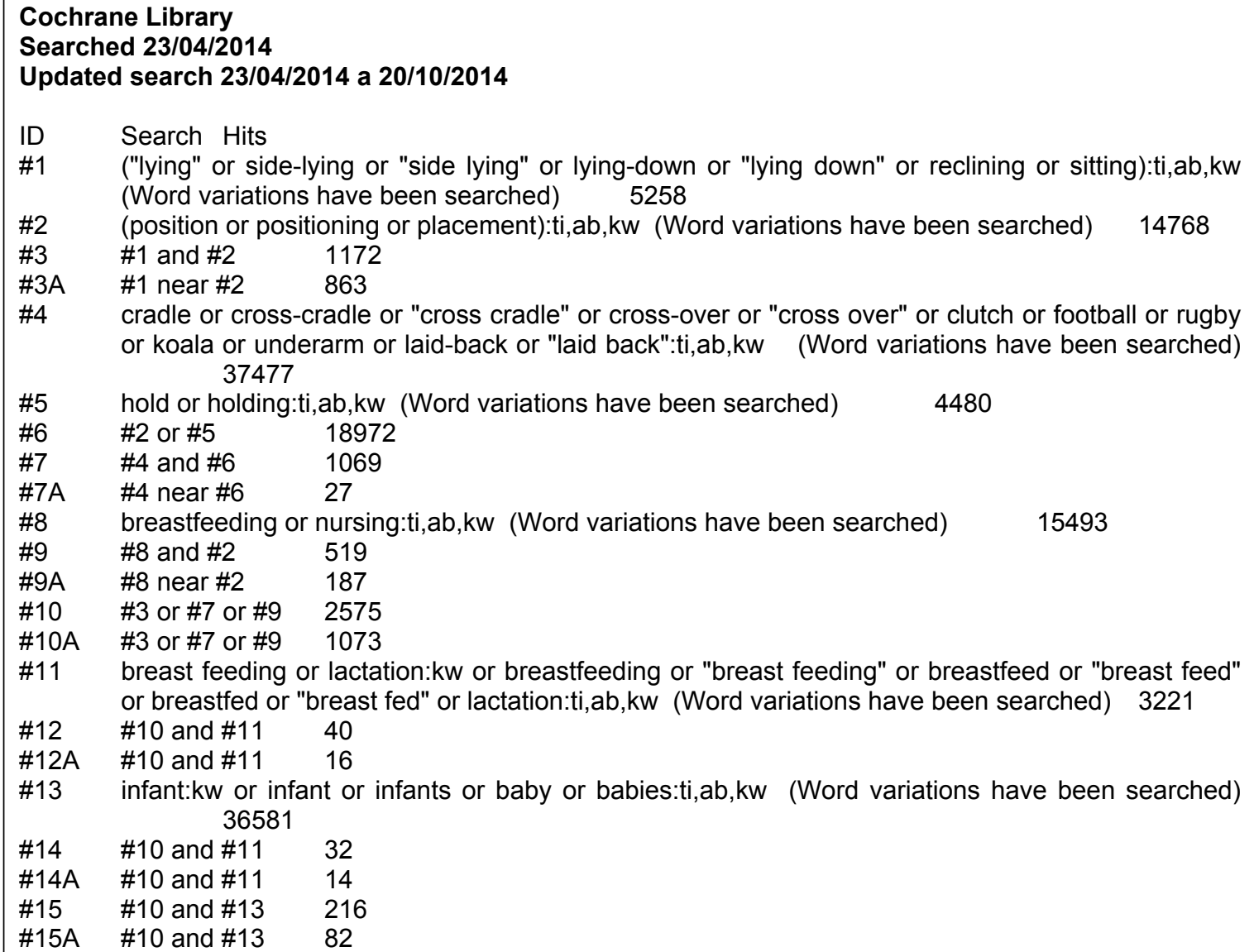

Medline, víaPubmed

Searched 23/04/2014

Updated search 23/04/2014 a 20/10/2014

\#1 Search ((((lying[Title/Abstract]) OR side-lying[Title/Abstract]) OR "side lying"[Title/Abstract]) OR lying-down[Title/Abstract]) OR "lying down"[Title/Abstract]) OR reclining[Title/Abstract] 17868

\#2 Search ((position[Title/Abstract]) OR positioning[Title/Abstract]) OR placement[Title/Abstract] 392989

\#3 $\quad$ Search \#1 AND \#2 2335

\#4 Search $(((()((()(($ cradle[Title/Abstract] $) \quad$ OR $\quad$ cross-cradle[Title/Abstract]) $\quad$ OR $\quad$ cross cradle"[Title/Abstract]) OR cross-over[Title/Abstract]) OR "cross over"[Title/Abstract]) OR clutch[Title/Abstract]) OR football[Title/Abstract]) OR rugby[Title/Abstract]) OR underarm[Title/Abstract]) OR koala[Title/Abstract]) OR laid-back[Title/Abstract]) OR "laid back"[Title/Abstract] 26457

\#5 Search (hold[Title/Abstract]) OR holding[Title/Abstract]

\#6 $\quad$ Search \#2 OR \#5442841

Search \#4 AND \#6 1158

Search (nursing[Title/Abstract]) OR breastfeeding[Title/Abstract] $\quad 206525$

\#9 Search \#8 AND \#2 5375 


\begin{tabular}{|c|c|}
\hline$\# 10$ & Search \#3 OR \#7 OR \#9 $\quad \underline{8808}$ \\
\hline \#11 & Search \#3 OR \#7 OR \#9 Filters: Infant: birth-23 months 523 \\
\hline$\# 12$ & $\begin{array}{l}\text { Search }(((((\text { breast feeding[MeSH Terms] }) \text { OR breastfeeding[Title/Abstract] }) \text { OR "breast } \\
\text { feeding"[Title/Abstract] }) \text { OR breastfeed[Title/Abstract]]) OR "breast feed"[Title/Abstract]) OR }\end{array}$ \\
\hline$\# 13$ & Search \#11 AND \#12 204 \\
\hline \multicolumn{2}{|c|}{$\begin{array}{l}\text { CINAHL,via EBSCOhost databases } \\
\text { Searched } 23 / 04 / 2014 \\
\text { Updated search } 23 / 04 / 2014 \text { a } 20 / 10 / 2014\end{array}$} \\
\hline S1 & $\begin{array}{l}\text { lying OR side-lying OR "side lying" OR lying-down OR "lying down" OR reclining OR sitting } \\
4,448\end{array}$ \\
\hline S2 & position OR positioning OR placement $\quad 46,015$ \\
\hline S3 & S1 AND S2 $\quad 1,351$ \\
\hline S4 & $\begin{array}{l}\text { cradle OR cross-cradle OR "cross cradle" OR cross-over OR "cross over" OR clutch OR football } \\
\text { OR rugby OR underarm OR koala OR laid-back OR "laid back" } 5,290\end{array}$ \\
\hline S5 & hold OR holding 7,582 \\
\hline S6 & S2 OR S5 $\quad 53,181$ \\
\hline S7 & S4 AND S6 349 \\
\hline S8 & nursing OR breastfeeding OR "breast feeding" \\
\hline s9 & S2 AND S8 10,322 \\
\hline S10 & S3 OR S7 OR S9 $\quad 11,873$ \\
\hline S11 & $\begin{array}{l}\text { MH breast feeding OR ( breastfeeding OR "breast feeding" OR breastfeed OR "breast feed" OR } \\
\text { breastfed OR "breast fed" ) OR MH lactation OR lactation } 15,451\end{array}$ \\
\hline S12 & S10 AND S11 $\quad 306$ \\
\hline $\mathrm{S} 13$ & Limitadores - Grupos de edad: Infant, Newborn: birth-1 month, Infant: 1-23 months 114,161 \\
\hline S14 & S12 AND S13 182 \\
\hline \multicolumn{2}{|c|}{$\begin{array}{l}\text { EMBASE, via Ovid } \\
\text { Searched } 23 / 04 / 2014 \\
\text { Updated search } 23 / 04 / 2014 \text { a 20/10/2014 }\end{array}$} \\
\hline 1 & $\begin{array}{l}\text { (lying or side-lying or "side lying" or lying-down or "lying down" or reclining or sitting).ti,ab,kw. } \\
35175\end{array}$ \\
\hline 2 & (position or positioning or placement).ti,ab,kw. $\quad 458080$ \\
\hline 3 & 1 and $2 \quad 9041$ \\
\hline 4 & $\begin{array}{l}\text { (cradle or cross-cradle or "cross cradle" or cross-over or "cross over" or clutch or football or rugby } \\
\text { or underarm or koala or laid-back or "laid back").ti,ab,kw. } 32730\end{array}$ \\
\hline 5 & (hold or holding).ti,ab,kw. 62194 \\
\hline 6 & 2 or $5 \quad 516599$ \\
\hline 7 & 4 and 61408 \\
\hline 8 & (nursing or breastfeeding or "breast feeding").ti,ab,kw. \\
\hline 9 & 2 and 86703 \\
\hline 10 & 3 or 7 or $9 \quad 16948$ \\
\hline 11 & ("breast feeding" or lactation).kw. 5236 \\
\hline 12 & $\begin{array}{l}\text { (breastfeeding or "breast feeding" or breastfeed or "breast feed" or breastfed or "breast fed" or } \\
\text { lactation).ti,ab,kw. } \quad 59076\end{array}$ \\
\hline 13 & 11 or $12 \quad 59076$ \\
\hline 14 & 10 and $13 \quad 579$ \\
\hline 15 & limit 14 to infant <to one year> \\
\hline
\end{tabular}




\section{Anexo II. Evaluación de la calidad de los estudios}

1. Riesgo de sesgo de los ECAs incluidos en la actualización

\begin{tabular}{|c|c|c|c|c|c|c|}
\hline $\begin{array}{l}\text { Referencia } \\
\text { (Cita Abreviada) }\end{array}$ & $\begin{array}{l}\text { Random sequence } \\
\text { generation (selection } \\
\text { bias) }\end{array}$ & $\begin{array}{l}\text { Allocation } \\
\text { conceallement } \\
\text { (selection bias) }\end{array}$ & $\begin{array}{l}\text { Blinding } \\
\text { (performance bias } \\
\text { and detection bias) } \\
\text { All outcomes }\end{array}$ & $\begin{array}{l}\text { Incomplete outcome } \\
\text { data (attrition bias) } \\
\text { All outcomes }\end{array}$ & $\begin{array}{l}\text { Selective reporting } \\
\text { (reporting bias) }\end{array}$ & Other bias \\
\hline Svensson 2013 & $\begin{array}{l}\text { Bajo riesgo } \\
\text { "randomized block } \\
\text { design" }\end{array}$ & $\begin{array}{l}\text { Riesgo poco claro } \\
\text { Información no } \\
\text { disponible }\end{array}$ & $\begin{array}{l}\text { Riesgo poco claro } \\
\text { "not conducted as a } \\
\text { blind Study" }\end{array}$ & Alto riesgo & Bajo riesgo & Poco riesgo \\
\hline
\end{tabular}

\section{Calidad de los estudios observacionales}

No hay.

\section{Calidad de los estudios descriptivos}

Los estudios descriptivos se consideran de calidad muy baja. No se ha evaluado su calidad de modo individual. 


\section{Anexo III. Tabla de estudios para la pregunta 1}

\section{Tabla de ECA}

\begin{tabular}{|c|c|c|c|c|c|c|}
\hline Referencia & Estudio & Población & $\begin{array}{l}\text { Descripción de las intervenciones } \\
\text { comparaciones, exposiciones o } \\
\text { pruebas a estudio }\end{array}$ & Resultados & Conclusiones & Comentarios \\
\hline $\begin{array}{l}\text { Svensson } \\
2013\end{array}$ & $\begin{array}{l}\text { Diseño } \\
\text { ECA } \\
\text { Objetivo } \\
\text { Evaluar si el } \\
\text { CPP es útil para } \\
\text { resolver } \\
\text { problemas de } \\
\text { agarre en bebés } \\
\text { mayore }\end{array}$ & $\begin{array}{l}\mathbf{N} \\
103 \\
\text { Características } \\
\text {-Diadas madre- } \\
\text { bebe con } \\
\text { importantes } \\
\text { problemas de } \\
\text { agarre } \\
\text {-Lactantes entre } \\
1-16 \text { semanas } \\
\text { de edad }\end{array}$ & $\begin{array}{l}\text { Intervención } \\
\text { Agarre no dirigido con CPP } \\
\text { Comparación } \\
\text { Agarre dirigido (intervención } \\
\text { habitual) }\end{array}$ & $\begin{array}{l}\text { Agarre correcto } \\
75 \% \text { vs. } 85 \% ; p=0,217 \\
\text { LME tras la intervención } \\
63 \% \text { vs. } 58 \% ; p=0,685 \\
\text { LM a los } 4 \text { meses de la intervención } \\
73 \% \text { vs. } 63 \% ; p=0,284 \\
\text { Satisfacción materna } \\
\text { Media (DE): } 69,2(1,68) \text { vs. } 63,4(2,44) ; \\
p=0,022 \\
\text { Molestias en las mamas } \\
\text { Mediana: } 1,0(1,0 \text { a } 1,0) \text { vs. } 1,0(1,0 \text { a } 2,0) \\
p=0,044\end{array}$ & $\begin{array}{l}\text { No existen diferencias entre } \\
\text { el CPP con agarre } \\
\text { espontáneo y las } \\
\text { intervenciones habituales } \\
\text { para resolver problemas de } \\
\text { agarre, aunque los bebés } \\
\text { que reciben CPP lo } \\
\text { consiguen antes. Además } \\
\text { las madres se sienten más } \\
\text { satisfechas con esta } \\
\text { intervención. }\end{array}$ & $\begin{array}{l}(+) \text { el unico ECA que } \\
\text { evalua especifimante el } \\
\text { uso del CPP con agarre } \\
\text { espontáneo para } \\
\text { resolver problemas de } \\
\text { agarre } \\
(-) \\
\text { Financiación } \\
\text { Financial support from } \\
\text { Vårdalstiftelsen, } \\
\text { Stiftelsen Frimurare } \\
\text { Barnhuset i Stockholm, } \\
\text { Karolinska Institutet, } \\
\text { Sällskapet barnavård, } \\
\text { Solstickan and ALF } \\
\text { Foundation } \\
\text { Conflicto de interés } \\
\text { No hay } \\
\text { Calidad } \\
\text { Moderada - ver RoB }\end{array}$ \\
\hline
\end{tabular}




\section{Bibliografía}

(1) NICE. Postnatal care up to 8 weeks after birth. Julio 2006 (actualizado en Febrero de 2015). Disponible en: http://guidance.nice.org.uk/CG37.

(2) International Lactation Consultant Association. Clinical Guidelines for the Establishment of Exclusive Breastfeeding. June 2005. Disponible en: http://www.breastcrawl.org/pdf/ilca-clinical-guidelines-2005.pdf. $\mathrm{h}$.

(3) Ingram J, Johnson D, Greenwood R. Breastfeeding in Bristol: teaching good positioning, and support from fathers and families. Midwifery 2002 Jun;18(2):87-101.

(4) Renfrew MJ. Positioning the baby at the breast: more than a visual skill. J Hum Lact 1989 Mar;5(1):13-5.

(5) Shaw-Flach A. Management of common breastfeeding problems. Community Practitioner 2002;75:432-5.

(6) Perinatal Services BC Health Promotion Guideline. Breastfeeding Healthy Term Infants. $\quad 2015.2$ Darch en: http://www.perinatalservicesbc.ca/Documents/GuidelinesStandards/HealthPromotion/BreastfeedingHealthyTermInfantGuideline.pdf.

(7) Province of British Columbia MoH. Baby's best chance, 6th Edition. Second Revision. Crown Publication \& Queen's Printer of British Columbia: Victoria, BC 2012.

(8) Infant and young child feeding: standard recommendations for the European Union. European Commission. Karolinska Institutet. Institute for Child Health IRCCS Burlo Garofolo. WHO. 2006 Disponible en: http://www.ihan.es/cd/documentos/Rec UE_en.pdf.

(9) Santo LC, de Oliveira LD, Giugliani ER. Factors associated with low incidence of exclusive breastfeeding for the first 6 months. Birth 2007 Sep;34(3):212-9.

(10) Kishore MS, Kumar P, Aggarwal AK. Breastfeeding knowledge and practices amongst mothers in a rural population of North India: a community-based study. J Trop Pediatr 2009 Jun;55(3):183-8.

(11) Dongre AR, Deshmukh PR, Rawool AP, Garg BS. Where and how breastfeeding promotion initiatives should focus its attention? A study from rural wardha. Indian $\mathrm{J}$ Community Med 2010 Apr;35(2):226-9.

(12) Kronborg $\mathrm{H}$, Vaeth $\mathrm{M}$. How are effective breastfeeding technique and pacifier use related to breastfeeding problems and breastfeeding duration? Birth 2009 Mar;36(1):34-42.

(13) Goyal RC, Banginwar AS, Ziyo F, Toweir AA. Breastfeeding practices: Positioning, attachment (latch-on) and effective suckling - A hospital-based study in Libya. J Family Community Med 2011 May;18(2):74-9.

(14) Colson S. Cuddles, biological nurturing, exclusive breastfeeding and public health. The journal of the Royal Society for the Promotion of Health 2003;123(2):76-7.

(15) Colson S. Biological nurturing (1). A non-prescriptive recipe for breastfeeding. The practising midwife 2007;10(9):42-4.

(16) Colson S. Biological nurturing (2). The physiology of lactation revisited. The practising midwife 2007;10(10):14.

(17) Colson SD, Meek JH, Hawdon JM. Optimal positions for the release of primitive neonatal reflexes stimulating breastfeeding. Early human development 2008;84(7):441-9.

(18) Colson S. What happens to breastfeeding when mothers lie back? Clinical applications of Biological Nurturing. Clinical Lactation 2010;1(1):11-4. 
(19) Colson S. Biological nurturing: The laid-back breastfeeding revolution. Midwifery today [verkkojulkaisu] Spring 2012.

(20) Svensson KE, Velandia MI, Matthiesen AS, Welles-Nyström BL, Widström AM. Effects of mother-infant skin-to-skin contact on severe latch-on problems in older infants: a randomized trial. International breastfeeding journal 2013;8(1):1.

(21) Abbott KL. Video Review: Baby-Led Breastfeeding: The Mother-Baby Dance by Smillie CD. Leaven 2008; 44, (1): 7. Disponible en La Leche League International, http://www.llli.org/llleaderweb/lv/lviss1-2008p7.html. 2008.

(22) Frantz K. The baby knows how. Disponible en: http://pregnant.livejournal.com/8404800.html . 2006.

(23) Meyer K, Anderson GC. Using kangaroo care in a clinical setting with fullterm infants having breastfeeding difficulties. MCN: The American Journal of Maternal/Child Nursing 1999;24(4):190-2.

(24) Gonzalez Rodriguez CJ. Sindrome de la posicion inadecuada al mamar. Anales españoles de pediatria 1996;45(5):527-9.

(25) Mbada CE, Olowookere AE, Faronbi JO, Oyinlola-Aromolaran FC, Faremi FA, Ogundele $\mathrm{AO}$, et al. Knowledge, attitude and techniques of breastfeeding among Nigerian mothers from a semi-urban community. BMC research notes 2013;6(1):552. 
PREGUNTA CLÍNICA No 5

\section{¿Es eficaz y seguro el colecho en las madres que amamantan para facilitar el buen inicio y el mantenimiento de la lactancia materna?}

\section{1- PREGUNTA CLÍNICA EN FORMATO PICO}

En esta pregunta se distinguen dos subpreguntas:

Pregunta 5.1: colecho durante la estancia en la maternidad

Tabla 1- Componentes de la pregunta clínica en formato PICO

\begin{tabular}{|l|l|}
\hline Pacientes & $\begin{array}{l}\text { Madres de recién nacidos sanos a término que amamantan y } \\
\text { sus hijos }\end{array}$ \\
\hline Intervención & $\begin{array}{l}\text { Colecho (recién nacido tanto en la misma cama de la madre } \\
\text { como en cuna sidecar) }\end{array}$ \\
\hline Comparación & $\begin{array}{l}\text { Recién nacido en cuna individual pero en la misma habitación } \\
\text { que la madre }\end{array}$ \\
\hline Resultados & $\begin{array}{l}\text { Tasa de lactancia materna exclusiva al alta } \\
\text { Tasa de lactancia materna a las 4-6 meses } \\
\text { Tasa de lactancia materna exclusiva a los 4-6 meses } \\
\text { Satisfacción materna ("iharías otra vez colecho en el } \\
\text { hospital?") } \\
\text { Complicaciones de las mamas (grietas, ingurgitaciones) } \\
\text { Peso del recién nacido (48-72h.) }\end{array}$ \\
$\begin{array}{l}\text { Frecuencia de tomas } \\
\text { Episodios potencialmente letales }\end{array}$ \\
\hline Tipo de estudio & $\begin{array}{l}\text { RS de ECA, ECA, RS de estudios observacionales o estudios } \\
\text { observacionales }\end{array}$ \\
\hline
\end{tabular}

Pregunta 5.2: colecho en el hogar

Tabla 2- Componentes de la pregunta clínica en formato PICO

\begin{tabular}{|l|l|}
\hline Pacientes & $\begin{array}{l}\text { Madres de recién nacidos a término que amamantan y sus } \\
\text { hijos }\end{array}$ \\
\hline Intervención & $\begin{array}{l}\text { Colecho (tanto en la misma cama de la madre como en cuna } \\
\text { sidecar) }\end{array}$ \\
\hline Comparación & $\begin{array}{l}\text { Lactante en cuna individual pero en la misma habitación que } \\
\text { la madre }\end{array}$ \\
\hline Resultados & Tasa de lactancia materna a los 4-6 meses \\
\hline
\end{tabular}




\begin{tabular}{|l|l|}
\hline & $\begin{array}{l}\text { Tasa de lactancia materna exclusiva a los 4-6 meses } \\
\text { Satisfacción materna } \\
\text { Complicaciones de las mamas } \\
\text { Frecuencia de tomas } \\
\text { Muerte súbita del lactante }\end{array}$ \\
\hline Tipo de estudio & $\begin{array}{l}\text { RS de ECA, ECA, RS de estudios observacionales o estudios } \\
\text { observacionales }\end{array}$ \\
\hline
\end{tabular}

\section{2- INTRODUCCIÓN}

La separación de los recién nacidos de sus madres y el alojamiento en nidos en las maternidades han sido identificadas como prácticas inadecuadas porque suponen un obstáculo para el inicio y el éxito de la lactancia materna. Actualmente, en la mayoría de los hospitales los recién nacidos no son separados y permanecen durante su estancia hospitalaria en una cuna junto a la cama de la madre, lo que ha supuesto un avance muy importante. Pero, como más recientemente se está sugiriendo que el colecho favorece la lactancia materna, interesa conocer si su práctica puede ayudar a la instauración de la lactancia y a su mantenimiento y si es segura, tanto en el medio hospitalario como en el hogar. 


\section{ESTRATEGIA DE ELABORACIÓN DE LA PREGUNTA}

3.1. GPC Base

Tabla 2- Resumen de GPC Base

\begin{tabular}{|c|c|c|c|c|}
\hline $\begin{array}{c}\text { Guía } \\
\text { (Enfoque) }\end{array}$ & $\begin{array}{l}\text { Resumen sobre la evidencia } \\
\text { (Calidad de la evidencia) }\end{array}$ & $\begin{array}{l}\text { Recomendaciones } \\
\text { (Grado) }\end{array}$ & $\begin{array}{l}\text { Referencias bibliográficas } \\
\text { (Tipo de publicación) }\end{array}$ & Comentarios \\
\hline $\begin{array}{l}\text { NICE_2006 } \\
\text { (Actualiz. } \\
\text { 2011) }\end{array}$ & $\begin{array}{l}\text { Los factores de riesgo más consistentes relacionados con el } \\
\text { síndrome de muerte súbita del lactante son posición } \\
\text { decúbito prono, cubrir la cabeza del niño y que la madre sea } \\
\text { fumadora [Nivel 2++] } \\
\text { El Co-sleeping es un factor de riesgo para SMSL si los } \\
\text { niños tienen menos de } 11 \text { semanas de vida [Nivel 2++] } \\
\text { (Estudios descritos en punto 7.8.2. de la versión completa } \\
\text { de la guía) } \\
\text { Prácticas que fomentan la lactancia materna } \\
\text { En un ECA (74) se investigó si la proximidad de la madre y } \\
\text { el niño a la hora de dormir afectaba al inicio de la lactancia y } \\
\text { la seguridad del niño, para lo que asignaron los niños a tres } \\
\text { estados: 1) en la cama de la madre con barreras de } \\
\text { seguridad; } 2 \text { ) en una cuna colecho pegada a la cama de la } \\
\text { madre o 3) en una cuna cerca de la cama de la madre. La } \\
\text { frecuencia de las tomas era mayor en los dos primeros } \\
\text { grupos en comparación con los niños que dormían en una } \\
\text { cuna cerca de la cama de la madre y aunque no había } \\
\text { efectos adversos en los niños, se consideró que los niños } \\
\text { que dormían en la cama se encontraron en situaciones } \\
\text { potencialmente adversas con mayor frecuencia. } \\
\text { Los autores concluyen que las cunas colecho son eficaces } \\
\text { para potenciar el inicio de la lactancia materna y que } \\
\text { preservan la seguridad del niño en la maternidad. } \\
\text { Un ECA (75) compara las cunas colecho con cunas } \\
\text { adyacentes a la cama. Los resultados demuestran que el } \\
\text { uso de las cunas colecho no aumentó la duración de la } \\
\text { lactancia o la frecuencia del colecho en casa. } \\
\text { Un estudio (76) investigó si la tasa de lactancia materna era }\end{array}$ & $\begin{array}{l}\text { Se debería dar información a los padres sobre la } \\
\text { muerte súbita y "co-sleeping" ("Reduce the risk of } \\
\text { cot death, November 2005), documento en el que } \\
\text { se indica que el lugar más seguro para que el } \\
\text { lactante duerma durante los primeros } 6 \text { meses de } \\
\text { vida es en una cuna individual en la habitación de } \\
\text { sus padres. } \\
\text { Se sugiere que existe riesgo de aplastar o asfixiar } \\
\text { al lactante, o de que éste se quede atrapado entre } \\
\text { la pared y la cama, o que se caiga de la cama y se } \\
\text { haga daño [B]. } \\
\text { Se debería aconsejar a los padres que nunca } \\
\text { duerman en un sofá con sus hijos [B]. } \\
\text { Si los padres escogen compartir la cama con su } \\
\text { hijo, se les debería advertir del aumento del riesgo } \\
\text { de muerte súbita, sobre todo si el niño tiene } \\
\text { menos de } 11 \text { semanas de vida, o si alguno de los } \\
\text { padres: [B] } \\
\text { - es fumador } \\
\text { - ha bebido alcohol } \\
\text { - ha tomado medicación para dormir } \\
\text { está muy cansado }\end{array}$ & $\begin{array}{l}\text { 74. Ball HL, Ward-Platt MP, } \\
\text { Heslop E et al. (2006) } \\
\text { Randomised trial of infant } \\
\text { sleep location on the postnatal } \\
\text { ward. Archives of Disease in } \\
\text { Childhood 91:1005-1010. } \\
\text { 75. Ball HL, Ward-Platt MP, } \\
\text { Howel D et al. (2011) } \\
\text { Randomised trial of sidecar } \\
\text { crib use on breastfeeding } \\
\text { duration (NECOT). Archives of } \\
\text { Disease in Childhood 96:630- } \\
\text { 634. } \\
\text { 76. Bartington S, Griffiths LJ, } \\
\text { Tate AR et al. (2006) Are } \\
\text { breastfeeding rates higher } \\
\text { among mothers delivering in } \\
\text { Baby Friendly accredited } \\
\text { maternity units in the UK? } \\
\text { International Journal of } \\
\text { Epidemiology } 35: 1178-1186 \text {. } \\
\text { 77. Blair PS, Heron J, and } \\
\text { Fleming PJ. (2010) } \\
\text { Relationship between bed } \\
\text { sharing and breastfeeding: } \\
\text { longitudinal, population-based } \\
\text { analysis. Pediatrics } \\
\text { 126:e1119-e1126. }\end{array}$ & $\begin{array}{l}\text { UNICEF señala que la } \\
\text { guía NICE no contempla } \\
\text { la relación que existe } \\
\text { entre la lactancia materna } \\
\text { y el colecho } \\
\text { (http://www.unicef.org.uk/ } \\
\text { BabyFriendly/News-and- } \\
\text { Research/News/UNICEF- } \\
\text { UK-statement-on-draft- } \\
\text { NICE-guidelines-on-co- } \\
\text { sleeping-and-SIDS/ ). }\end{array}$ \\
\hline
\end{tabular}




\begin{tabular}{|c|c|c|c|c|}
\hline $\begin{array}{c}\text { Guía } \\
\text { (Enfoque) }\end{array}$ & $\begin{array}{l}\text { Resumen sobre la evidencia } \\
\text { (Calidad de la evidencia) }\end{array}$ & $\begin{array}{l}\text { Recomendaciones } \\
\text { (Grado) }\end{array}$ & $\begin{array}{l}\text { Referencias bibliográficas } \\
\text { (Tipo de publicación) }\end{array}$ & Comentarios \\
\hline & $\begin{array}{l}\text { mayor entre las madres que daban a luz en las } \\
\text { maternidades del Reino Unido con acreditación de la "Baby } \\
\text { Friendly Initiative". } \\
\text { Los autores concluyen que es probable que se aumente el } \\
\text { inicio pero no la duración de la lactancia. Se necesitan otras } \\
\text { estrategias para ayudar a las madres a dar el pecho durante } \\
\text { el tiempo recomendado. } \\
\\
\text { Una cohorte prospectiva (77) investigó los patrones del } \\
\text { colecho, las características asociadas a esos patrones y la } \\
\text { relación con la lactancia, concluyendo que antes de } \\
\text { desaconsejar el colecho se necesita tener en cuenta su } \\
\text { importante relación con la lactancia materna. }\end{array}$ & & & \\
\hline $\begin{array}{l}\text { Perinatal } \\
\text { Services BC } \\
2011\end{array}$ & $\begin{array}{l}\text { La Sociedad pediátrica canadiense (CPS) recomienda que } \\
\text { el lactante duerma en su propia cuna en la misma } \\
\text { habitación los primeros seis meses de vida. Estar cerca de } \\
\text { su madre le permite un acceso más fácil para dar el pecho } \\
\text { al niño (38) } \\
\text { La Academia Americana de Pediatría recomienda que la } \\
\text { madre y el niño duerman en cercanía estrecha para facilitar } \\
\text { la lactancia materna (39) } \\
\text { Blair ha demostrado que el riesgo de muerte súbita de los } \\
\text { niños que duermen cerca del adulto es la mitad en } \\
\text { comparación a los niños que duermen en una habitación } \\
\text { aparte o incluso en una habitación con otros niños. Esta } \\
\text { cercanía puede darse tanto en una cuna pegada a la cama } \\
\text { o en compartir la cama con la madre ( } 41 \text { ) } \\
\text { En un estudio longitudinal poblacional en el Reino Unido, } \\
\text { Blair et al examinaron los hábitos de colecho y lactancia } \\
\text { materna durante } 5 \text { períodos en los primeros cuatro años de } \\
\text { vida de los niños (de } 0 \text { a } 2 \text { meses, de } 6 \text { a } 8 \text { meses, de } 17 \text { a } \\
30 \text { meses etc). Demostraron que las madres que } \\
\text { compartían la cama con sus recién nacidos tenían mayor } \\
\text { nivel de estudios y estatus socioeconómico, y que en los } \\
\text { casos en los que el lactante compartía la cama los primeros } \\
15 \text { meses de vida reportaban una mayor incidencia de } \\
\text { lactancia materna. Los autores concluyeron que "debido a } \\
\text { los probables beneficios de compartir la cama sobre la tasa } \\
\text { y duración de la lactancia materna, los mensajes para }\end{array}$ & $\begin{array}{l}\text { Niños y padres/cuidadores deberían dormir cerca } \\
\text { en la misma habitación (en una superficie } \\
\text { separada segura) durante los primeros } 6 \text { meses). } \\
\text { Se ha encontrado que tener el niño cerca } \\
\text { (cercanía estrecha) reduce la muerte súbita del } \\
\text { lactante (B) (38,39, 41, 48, 111, 113, 114-118, } \\
\text { 119, 121, 122-124) } \\
\text { Se debe evitar abrigar en exceso (overheating) al } \\
\text { niño (A) } \\
\text { La superficie en la que duerme el niño debe ser } \\
\text { firme y libre de riesgos (A) (112, 121) } \\
\text { Las cunas y moisés deben cumplir los estándares } \\
\text { de la normativa (A) (76,77) } \\
\text { Informar a los padres/cuidadores de que reducir el } \\
\text { riesgo a la hora de compartir superficie al dormir } \\
\text { incluye: colocar al niño sobre su espalda para } \\
\text { dormir, no fumar, colchón firme y plano, } \\
\text { asegurarse de que el lactante no se caerá de la } \\
\text { cama o que quedará atrapado entre el colchón y la } \\
\text { pared, la estructura de la cama; mantener el área } \\
\text { para dormir del niño libre de almohadas, sábanas } \\
\text { pesadas y lleno de peluches; no cubrir la cabeza } \\
\text { del niño, no abrigarle en exceso ni sobrecalentar } \\
\text { demasiado la habitación; que los adultos que } \\
\text { duermen en la cama sepan que el niño está en la }\end{array}$ & $\begin{array}{l}\text { 38. Community Pediatric } \\
\text { Committe, } 2009 \text {. } \\
\text { Recomendations for safe } \\
\text { sleeping environments for } \\
\text { infants and children. } \\
\text { Paediatrics \& Child Health. } \\
\text { CPS 9(9),659-663. } \\
\text { 39. Buswell S. Parent-Infant } \\
\text { Co-sleeping and its } \\
\text { relationship to breastfeeding. } \\
\text { Journal of Pediatric Health } \\
\text { Care, 2007; Vol 21,n¹. P22- } \\
\text { 28. } \\
41 . \text { Blair Ps, Fleming PJ, } \\
\text { Smith IJ et al (1999). Babies } \\
\text { sleeping with parents: case- } \\
\text { control study of factors } \\
\text { influencing the risk of the } \\
\text { sudden infant death } \\
\text { syndrome. CESDI SUDI } \\
\text { research group. British } \\
\text { Medical Journal. 319:1457- } \\
\text { 1462. } \\
48 . \text { Blair PS, Heron J and } \\
\text { Fleming PJ (2010). } \\
\text { Relationship Between bed } \\
\text { sharing and breastfeeding: } \\
\text { longitudinal, population based }\end{array}$ & \\
\hline
\end{tabular}




\begin{tabular}{|c|c|c|c|c|}
\hline $\begin{array}{c}\text { Guía } \\
\text { (Enfoque) }\end{array}$ & $\begin{array}{l}\text { Resumen sobre la evidencia } \\
\text { (Calidad de la evidencia) }\end{array}$ & $\begin{array}{l}\text { Recomendaciones } \\
\text { (Grado) }\end{array}$ & $\begin{array}{l}\text { Referencias bibliográficas } \\
\text { (Tipo de publicación) }\end{array}$ & Comentarios \\
\hline & $\begin{array}{l}\text { reducir el riesgo de muerte súbita se deberían centrar en } \\
\text { evitar prácticas no seguras, como dormirse en el sofá, } \\
\text { compartir la cama tras consumir alcohol o drogas o si los } \\
\text { padres fuman (48) } \\
\text { El gobierno de Canadá ha publicado recientemente cambios } \\
\text { a la regulación de cunas, para que los estándares también } \\
\text { sean aplicados a los moisés (76,77) } \\
\text { Compartir la cama o dormir en proximidad representa un } \\
\text { comportamiento normal y saludable. El amamantamiento } \\
\text { nocturno representa una adaptación común a toda la } \\
\text { especie, que es una constante y proporciona un entorno } \\
\text { biológicamente y emocionalmente enriquecedor para la } \\
\text { madre y el niño (111). } \\
\text { La publicación de Mckenna Sleeping with Your Baby A } \\
\text { Parent's Guide to Cosleeping (ie. bedsharing) describe la } \\
\text { forma correcta como "cada persona que comparte la cama } \\
\text { debería acordar que se responsabiliza del niño de forma } \\
\text { igualitaria y que conoce que el niño está presente". Los } \\
\text { padres no fuman, están sobrios, han decidido compartir la } \\
\text { cama y están dando el pecho. El colchón se coloca en el } \\
\text { suelo, lejos de paredes y muebles, se usa una sábana ligera } \\
\text { y no hay almohadas cerca del niño. No debe haber otros } \\
\text { niños, animales o muñecos en la cama con el niño (112) } \\
\text { La biología que subyace al comportamiento de lactancia se } \\
\text { potencia por la proximidad de la madre y niño a la noche, } \\
\text { mientras se duerme en la misa cama o en una superficie } \\
\text { diferente dentro del alcance de los brazos de la madre } \\
\text { (113). } \\
\text { Un mayor contacto sensorial y la proximidad entre madre e } \\
\text { hijo induce un beneficio potencial en los cambios fisiológicos } \\
\text { y en el comportamiento en el niño, reportado por las madres } \\
\text { como menos lloros, mayor descanso de la madre y el niño } \\
\text { y una mayor producción de leche debido a la mayor } \\
\text { frecuencia de tomas nocturnas que facilita el contacto } \\
\text { íntimo. ( } 114,115,116,117,118 \text { ). } \\
\text { Ball reportó los potenciales beneficios en el comportamiento }\end{array}$ & $\begin{array}{l}\text { cama y que los padres no deberían consumir } \\
\text { alcohol o drogas. No se debería tener a otros } \\
\text { niños o mascotas en la cama y no se debe dejar a } \\
\text { los niño solos en la cama del adulto (A). } \\
\text { Cuando existen factores de riesgo, se debe } \\
\text { advertir a los padres/cuidadores que el compartir } \\
\text { la superficie para dormir no es seguro. }\end{array}$ & $\begin{array}{l}\text { analysis. Pediatrics. } \\
0126(5) \text { :E1118-1127. } \\
\text { Published online October 18, } \\
2010 . \\
\text { 76. Health Canada, April 11, } \\
\text { 2009 http://gazette.gc.ca/rp- } \\
\text { pr/p1/2009/2009-04-- } \\
\text { 11/html/reg4-eng.html } \\
\text { 77. http://gazette.gc.ca/rp- } \\
\text { pr/p1/2009/2009-04- } \\
\text { 11/html/reg3-eng.html } \\
\text { 111. McKenna, J. (2007). } \\
\text { Sleeping with your Baby: a } \\
\text { parent's guide to cosleeping. } \\
\text { Platypus Media, LLC. } \\
\text { Washington, DC. } \\
\text { 112. Ibid } \\
\text { 113. McKenna, JJ, Mosko S, } \\
\text { Richard E, et al. (1994). } \\
\text { Mutual behavioral and } \\
\text { physiological influences } \\
\text { among solitary and co- } \\
\text { sleeping mother-infant pairs: } \\
\text { Implications for SIDS. Early } \\
\text { Human Development. 38:182- } \\
\text { 201. } \\
\text { 114. Ball H, Hooker E, Kelly P. } \\
\text { (1999). Where will the baby } \\
\text { sleep? Attitudes and practices } \\
\text { of new and experienced } \\
\text { parents regarding cosleeping } \\
\text { with their new-born infants. } \\
\text { American Anthropologist. } \\
\text { 101(1):143-151. } \\
\text { 115. McCoy RC, Hung CL, } \\
\text { Leska SM, et al. (2004). } \\
\text { Frequency of bed sharing and } \\
\text { its relationship to } \\
\text { breastfeeding. Developmental } \\
\text { and Behavioural Pediatrics. }\end{array}$ & \\
\hline
\end{tabular}




\begin{tabular}{|c|c|c|c|c|}
\hline $\begin{array}{c}\text { Guía } \\
\text { (Enfoque) }\end{array}$ & $\begin{array}{l}\text { Resumen sobre la evidencia } \\
\text { (Calidad de la evidencia) }\end{array}$ & $\begin{array}{c}\text { Recomendaciones } \\
\text { (Grado) }\end{array}$ & $\begin{array}{l}\text { Referencias bibliográficas } \\
\text { (Tipo de publicación) }\end{array}$ & Comentarios \\
\hline & 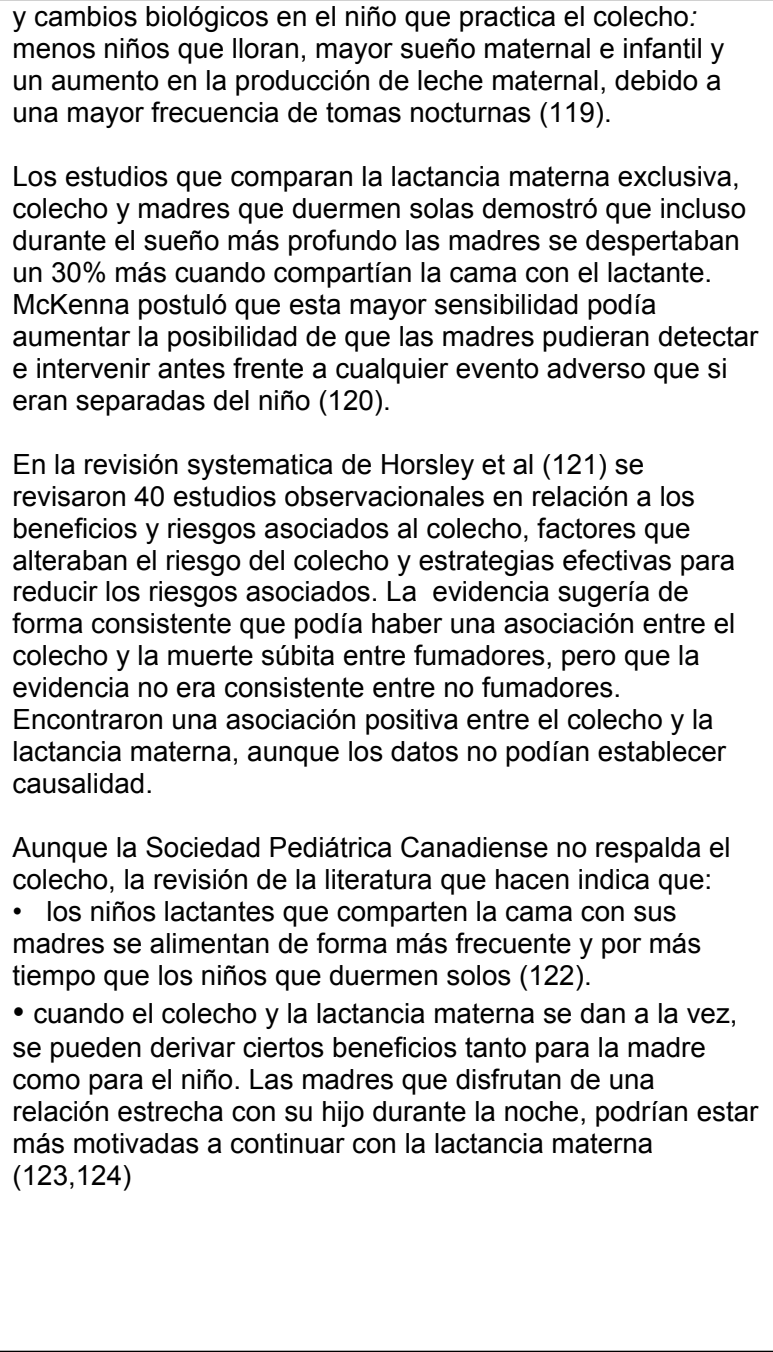 & & $\begin{array}{l}\text { 25:141-149. } \\
\text { 116. Rigda RS, McMillen IC, } \\
\text { Buchley P (2000). Bed sharing } \\
\text { patterns in a cohort of } \\
\text { Australian infants during the } \\
\text { first six months after birth. } \\
\text { Journal of Pediatrics and Child } \\
\text { Health. 36:117-121. } \\
\text { 117. Ball HL (2002). Reasons } \\
\text { to bedshare: why parents } \\
\text { sleep with their infants. Journal } \\
\text { of Reproductive and Infant } \\
\text { Psycholgy. 20:207-222. } \\
\text { 118. McKenna JJ, Mosko SS, } \\
\text { Richard CA (1997). Bed } \\
\text { sharing promotes } \\
\text { breastfeeding. Pediatrics. } \\
\text { 100:214-219. } \\
\text { 19. Ball H, Hooker E, Kelly P } \\
\text { (1999). } \\
\text { 120. McKenna JJ, Mosko SS, } \\
\text { Richard CA (1997). } \\
\text { 121. Horsley T, Clifford T, } \\
\text { Barrowman N ,et al. 2007. } \\
\text { Benefits and Harms } \\
\text { Associated with the Practice of } \\
\text { Bed Sharing. Arch Pediatr } \\
\text { Adolesc Med. 161 (3);237-245. } \\
\text { 122. McKenna JJ, Moskeo SS, } \\
\text { Richard CA (1997). } \\
\text { 123. Stein MT, Colarusco C, } \\
\text { McKenna JJ, Powers NG } \\
\text { (2001). Cosleeping } \\
\text { (bedsharing) among infants } \\
\text { and toodlers. Pediatrics. } \\
\text { 107:873-877. } \\
\text { 124. Richard C, Mosko S, } \\
\text { Mckenna J, Drummond S } \\
\text { (1996). Sleeping position, }\end{array}$ & \\
\hline
\end{tabular}




\begin{tabular}{|c|c|c|c|}
\hline $\begin{array}{c}\text { Guía } \\
\text { (Enfoque) }\end{array}$ & $\begin{array}{c}\text { Resumen sobre la evidencia } \\
\text { (Calidad de la evidencia) }\end{array}$ & $\begin{array}{c}\text { Recomendaciones } \\
\text { (Grado) }\end{array}$ & $\begin{array}{c}\text { Referencias bibliográficas } \\
\text { (Tipo de publicación) }\end{array}$ \\
\hline & & & $\begin{array}{l}\text { Orientation and proximity in } \\
\text { bed-sharing infants and } \\
\text { mothers. Sleep. 19:685-690. }\end{array}$ \\
\hline
\end{tabular}

\section{Tabla 3. Resumen de GPC del SNS}

\begin{tabular}{|c|c|c|c|c|}
\hline $\begin{array}{l}\text { Guía } \\
\text { (Enfoque) }\end{array}$ & $\begin{array}{l}\text { Resumen sobre la evidencia } \\
\text { (Calidad de la evidencia) }\end{array}$ & $\begin{array}{l}\text { Recomendaciones } \\
\text { (Grado) }\end{array}$ & $\begin{array}{l}\text { Referencias bibliográficas } \\
\text { (Tipo de publicación) }\end{array}$ & Comentarios \\
\hline $\begin{array}{l}\text { Cuidados } \\
\text { desde el } \\
\text { nacimiento } \\
\text { Recomendaci } \\
\text { ones basadas } \\
\text { en pruebas y } \\
\text { buenas } \\
\text { prácticas } \\
\text { MSPSI_2010 }\end{array}$ & $\begin{array}{l}\text { Sólo se ha encontrado un ensayo clínico que aborda este } \\
\text { tema [1] y que compara tres ubicaciones del recién nacido: } \\
\text { en la misma habitación de la madre pero en cuna, en cuna } \\
\text { adosada a la cama de la madre (cuna sidecar) y en la cama } \\
\text { de la madre. La medida del resultado principal fue la } \\
\text { frecuencia de las tomas y la seguridad del recién nacido. } \\
\text { Filmaron } 4 \text { horas durante la noche a madre e hijo. EI RN que } \\
\text { dormía en la cama o en la cuna sidecar mamaba más veces } \\
\text { que el que dormía en su cuna (diferencia de las medias } \\
\text { [intervalo de confianza del } 95 \% \text { ] cama vs cuna } 2,56 \text { [IC } 95 \% \\
0,72-4,41] \text {; cuna sidecar vs cuna } 2,52 \text { [IC } 95 \% \text { 0,87-4,17]; } \\
\text { cama vs cuna sidecar } 0,04 \text { [-2,10 a +2,18]). } \\
\text { En este mismo ensayo clínico no se observaron efectos } \\
\text { adversos, pero sí situaciones potencialmente peligrosas en } \\
\text { aquellos que dormían en la cama de la madre, no así en la } \\
\text { llamada cuna sidecar. } \\
\text { La ABM (Academy of Breastfeeding Medicine) expone sus } \\
\text { recomendaciones para un colecho seguro [2]: posición } \\
\text { supina del niño, superficie plana y firme, no cubrir la cabeza } \\
\text { del niño, no con madre fumadora ni que ingiera } \\
\text { medicamentos que alteren el nivel de conciencia o alcohol, } \\
\text { etc. En este protocolo, la ABM nombra como alternativa a } \\
\text { compartir el lecho el uso de la cuna sidecar, ya que provee } \\
\text { proximidad y acceso al lactante, pero en una superficie } \\
\text { independiente. } \\
\text { UNICEF y la OMS, con su iniciativa "amigo de los niños" y la } \\
\text { FSID (Foundation for the Study of Infant Deaths) han } \\
\text { elaborado una guía titulada "Compartiendo la cama con tu } \\
\text { bebé" que también recoge estos consejos sobre colecho } \\
\text { seguro [3] }\end{array}$ & $\begin{array}{l}\text { Recomendaciones para un colecho seguro: } \\
\text { posición supina del niño, superficie plana y firme, } \\
\text { no cubrir la cabeza del niño, no con madre } \\
\text { fumadora ni que ingiera medicamentos que alteren } \\
\text { el nivel de conciencia o alcohol. }\end{array}$ & $\begin{array}{l}\text { 1. Ball HL, Ward-Platt MP, } \\
\text { Heslop E, Leech SJ, Brown KA. } \\
\text { Randomised trial of infant sleep } \\
\text { location on the postnatal ward. } \\
\text { Arch Dis Child. 2006;91:1005- } \\
\text { 1010. } \\
\text { 2. ABM clinical protocol \#6: } \\
\text { guideline on co-sleeping and } \\
\text { breastfeeding. Revision, March } \\
\text { 2008. Breastfeed Med. } \\
\text { 2008;3:38-43. } \\
\text { 3. UNICEF, OMS, FSID. } \\
\text { Compartiendo la cama con tu } \\
\text { bebé. Consultado el } 20 \text { de abril } \\
\text { de 2009. Disponible en: } \\
\text { http://www.babyfriendly.org.uk/p } \\
\text { dfs/spanish/sharingbed_spanish. } \\
\text { pdf }\end{array}$ & \\
\hline
\end{tabular}




\subsection{Revisiones sistemáticas}

Se ha identificado una revisión sistemática Cochrane que aborda el efecto de cohabitar con el niño (rooming-in) sobre la duración de la lactancia materna (1). Esta revisión incluye un único estudio (2), en el que se indica que el ratio de lactancia materna exclusiva en el cuarto día postparto es significativamente menor en el grupo de mujeres y niños que duermen en habitaciones separadas (45\%) frente al grupo que comparte habitación (86\%), siendo el RR de 0,58 (IC95\% de 0,42 a 0,81), aunque a los 4 meses las diferencias no son significativas.

En cuanto a la relación del colecho con la muerte súbita del lactante se han identificado tres revisiones recientes de estudios de casoscontroles (3-5) que abordan este tema. La revisión de Carpenter (4) incluye 5 de los estudios de casos controles más importantes. Sin embargo, el metanálisis de Venemaan (3) detalla mejor cuál ha sido la metodología utilizada para identificar y seleccionar los estudios a incluir en el análisis, indicando además que no pudieron analizar si había interacción entre lactancia materna y colecho en relación a la muerte súbita del lactante en los estudios identificados, porque éstos no incluían los datos necesarios para ello. En la última revisión identificada (5) los autores también encuentran que el colecho se asocia con un aumento del riesgo de SMSL $(23,3 \%$ vs. $11,2 \%$; OR 2,36 (IC95\% de 1,97 a 2,83 ), aunque en este caso también señalan que colechar con el niño se asocia con mayores tasas de lactancia materna a las 4 semanas de vida (75,5\% vs. $50 \%$; OR 3,09 (IC95\% de 2,67 a 3,58$)$ ).

Asimismo, se ha identificado un metanálisis reciente en el que se demuestra la asociación que existe entre la lactancia materna y la disminución del riesgo de muerte súbita del lactante (6). Se trata de un metaanálisis de estudios casos-controles donde los autores analizan la asociación entre lactancia materna y SMLS distinguiendo los casos en los que se trata de cualquier tipo de lactancia materna (mixta o exclusiva) de cualquier duración o de una duración de dos o más meses, o de lactancia materna exclusiva de cualquier duración. 
Tabla 3- Resumen de RS actuales

\begin{tabular}{|c|c|c|c|c|c|c|}
\hline $\begin{array}{l}\text { Referencia } \\
\text { (Cita } \\
\text { Abreviada) }\end{array}$ & $\begin{array}{l}\text { Estudio (Diseño y } \\
\text { objetivo) }\end{array}$ & $\begin{array}{l}\text { Población } \\
\left.\text { ( } \mathrm{n}^{\circ} \text { y características }\right)\end{array}$ & $\begin{array}{l}\text { Descripción de las intervenciones } \\
\text { comparaciones, exposiciones o } \\
\text { pruebas a estudio }\end{array}$ & $\begin{array}{l}\text { Resultados } \\
\text { (Estimadores de resultados-Magnitud del } \\
\text { efecto) }\end{array}$ & $\begin{array}{l}\text { Conclusiones } \\
\text { (conclusiones) }\end{array}$ & $\begin{array}{l}\text { Comentarios } \\
\text { Calidad de la } \\
\text { evidencia } \\
\text { Financiación } \\
\text { comentarios) }\end{array}$ \\
\hline $\begin{array}{l}\text { Vennemann MM } \\
2012\end{array}$ & $\begin{array}{l}\text { Diseño } \\
\text { Metanálisis de } \\
\text { estudios de casos } \\
\text { controles } \\
\text { Objetivo } \\
\text { Realizar un } \\
\text { metanálisis sobre la } \\
\text { relación entre el } \\
\text { colecho y el } \\
\text { síndrome de muerte } \\
\text { súbita del lactante } \\
\text { (SMSL). }\end{array}$ & $\begin{array}{l}11 \text { estudios } \\
2464 \text { casos } \\
6495 \text { controles }\end{array}$ & $\begin{array}{l}\text { Se extraen los OR sin ajustar y } \\
\text { ajustados de cada estudio y se } \\
\text { metanalizan con el modelo de efectos } \\
\text { fijos de Mantel-Haenzel. } \\
\text { Se estratifican los estudios según el } \\
\text { hábito fumador de los padres, la edad } \\
\text { del niño la última noche } \\
\text { independientemente del tabaco y si el } \\
\text { colecho era habitual o no. }\end{array}$ & $\begin{array}{l}\text { Colecho vs no colecho (TOTAL): } \\
\text { OR 2,89 (IC95\% 1,99;4,18) } \\
\text { Hábito fumador materno: } \\
\text { Madres fumadoras: OR 6,27 (IC95\% } \\
3,94 ; 9,99) \\
\text { Madres no fumadoras: OR 1,66 (IC95\%: } \\
0,91 ; 3,01) \\
\text { Edad del niño: } \\
\text { Menores de } 12 \text { semanas: OR 10,37 } \\
\text { (IC95\%: 4,44; } 24,21) \\
\text { Mayores de } 12 \text { semanas: OR } 1,02 \\
\text { (IC95\%:0,49;2,12) } \\
\text { Colecho habitual o no: } \\
\text { Habitual: OR } 1,42 \text { (IC95\% 0,85;2,38) (2 } \\
\text { estudios) } \\
\text { No habitual y sí la última noche: } \\
\text { OR 2,18 (IC95\%: } 1,45 ; 3,28)(4 \text { estudios) }\end{array}$ & $\begin{array}{l}\text { El colecho } \\
\text { aumenta el riesgo } \\
\text { del SMSL, en } \\
\text { especial los padres } \\
\text { fuman y los niños } \\
\text { tienen menos de } \\
12 \text { semanas de } \\
\text { vida. }\end{array}$ & \\
\hline Hauck FR 2011 & $\begin{array}{l}\text { Diseño } \\
\text { Metanálisis de } \\
\text { estudios de casos } \\
\text { controles } \\
\text { Objetivo } \\
\text { Realizar un } \\
\text { metanálisis para } \\
\text { medir la asociación } \\
\text { entre la lactancia } \\
\text { materna y SMSL. }\end{array}$ & $\begin{array}{l}18 \text { estudios } \\
\text { Estudios de casos- } \\
\text { controles }\end{array}$ & $\begin{array}{l}\text { Se extraen los OR sin ajustar y } \\
\text { ajustados de cada estudio y se meta- } \\
\text { analizan por medio delmétodo } \\
\text { ponderado por la inversa de la } \\
\text { varianza, de efectos fijos y aleatorios. } \\
\text { de varianza inversa de efectos fijos y } \\
\text { aleatorios. } \\
\text { Se tiene en cuenta si la lactancia } \\
\text { materna era de cualquier tipo y } \\
\text { duración, si se trataba de una lactancia } \\
\text { de una duración de } 2 \text { meses o más o } \\
\text { de si se trataba de lactancia materna } \\
\text { exclusiva, independientemente de la } \\
\text { duración. }\end{array}$ & $\begin{array}{l}\text { SOR (Summary Odds Ratio) de SMSL } \\
\text { Cualquier tipo de lactancia ( } n=18 \\
\text { estudios; multi sólo } 7): \\
\text { Uni: SOR } 0,40 \text { (IC } 95 \%: 0,35 ; 0,44) \\
\text { Multi: SOR } 0,55 \text { (IC } 95 \%: 0,44 ; 0,69) \\
\text { Cualquier lactancia a los } 2 \text { meses o } \\
\text { más de edad ( } n=3 \text { estudios (multi solo } 2 \text { ): } \\
\text { Uni: SOR } 0,38 \text { (IC 95\%: } 0,24 ; 0,54) \\
\text { (I'=78\%) } \\
\text { Multi: No hay información } \\
\text { Lactancia exclusiva: ( } n=8 \text { estudios) } \\
\text { Uni: SOR } 0,27(0,24 ; 0,31)(I 2=87 \%) \\
\text { Multi: No hay información }\end{array}$ & $\begin{array}{l}\text { La lactancia } \\
\text { materna protege } \\
\text { frente el SMLS. } \\
\text { Este efecto } \\
\text { protector es mayor } \\
\text { cuando la lactancia } \\
\text { materna es } \\
\text { exclusiva. Dentro } \\
\text { de las } \\
\text { recomendaciones } \\
\text { que se hacen para } \\
\text { evitar el SMSL se } \\
\text { debería incluir la } \\
\text { lactancia materna. }\end{array}$ & \\
\hline Das RR, 2014 & $\begin{array}{l}\text { Diseño } \\
\text { Metanálisis de }\end{array}$ & $\begin{array}{l}21 \text { estudios. } \\
8 \text { estudios: asociación }\end{array}$ & $\begin{array}{l}\text { La intervención es el colecho de forma } \\
\text { habitual. }\end{array}$ & $\begin{array}{l}\text { Asociación entre colecho y lactancia } \\
\text { materna a las } 3-4 \text { semanas de vida: }\end{array}$ & $\begin{array}{l}\text { El \% de SIDS en el } \\
\text { grupo control fue }\end{array}$ & $\begin{array}{l}\text { Financiado por } \\
\text { la OMS. Señala }\end{array}$ \\
\hline
\end{tabular}




\begin{tabular}{|c|c|c|c|c|c|c|}
\hline $\begin{array}{l}\text { Referencia } \\
\text { (Cita } \\
\text { Abreviada) }\end{array}$ & $\begin{array}{l}\text { Estudio (Diseño y } \\
\text { objetivo) }\end{array}$ & $\begin{array}{l}\text { Población } \\
\text { (nº y características) }\end{array}$ & $\begin{array}{l}\text { Descripción de las intervenciones } \\
\text { comparaciones, exposiciones o } \\
\text { pruebas a estudio }\end{array}$ & $\begin{array}{l}\text { Resultados } \\
\text { (Estimadores de resultados-Magnitud del } \\
\text { efecto) }\end{array}$ & $\begin{array}{l}\text { Conclusiones } \\
\text { (conclusiones) }\end{array}$ & $\begin{array}{l}\text { Comentarios } \\
\text { Calidad de la } \\
\text { evidencia } \\
\text { Financiación } \\
\text { comentarios) }\end{array}$ \\
\hline & $\begin{array}{l}\text { estudios } \\
\text { observacionales } \\
\text { Objetivo: } \\
\text { Medir la eficacia y } \\
\text { seguridad del } \\
\text { colecho durante la } \\
\text { infancia para dar } \\
\text { evidencia } \\
\text { actualizada a la } \\
\text { OMS (en relación a } \\
\text { su asociación con la } \\
\text { lactancia materna y } \\
\text { a SMSL). }\end{array}$ & $\begin{array}{l}\text { entre lactancia } \\
\text { materna y colecho } \\
13 \text { estudios } \\
\text { asociación entre SIDS } \\
\text { y colecho } \\
\text { Sólo } 1 \text { estudio } \\
\text { determina ambas } \\
\text { asociaciones. }\end{array}$ & $\begin{array}{l}\text { Los resultados que se miden son: } \\
\text { 1. \% de niños lactantes (de cualquier } \\
\text { tipo o exclusiva) a las } 4-6 \text { semanas, } \\
3-4 \text { meses y } 6 \text { meses de vida } \\
\text { 2. \% de niños que mueren por SMSL } \\
\text { en el primer año de vida. } \\
\text { Se define SMSL como: la muerte } \\
\text { inexplicable sin aviso previo de un niño } \\
\text { aparentemente sano y mientras } \\
\text { duerme. } \\
\text { Se considera como colecho sólo si el } \\
\text { niño comparte la misma cama que la } \\
\text { madre. }\end{array}$ & $\begin{array}{l}\text { OR: 3,09 (IC95\%:2,67;3,58) } \\
\text { Asociación entre colecho y SMSL: } \\
\text { OR: 2,36 (IC95\%: 1,97;2,83) } \\
\text { *Análisis de subgrupo: } \\
\text { Colecho habitual vs. no habitual y } \\
\text { SMSL: } \\
\text {-Habitual: } 2,22(1,71 ; 2,87)(6 \text { estudios) } \\
\text {-Última noche: } 2,51(1,95 ; 3,23) \text { (7 } \\
\text { estudios) }\end{array}$ & $\begin{array}{l}\text { de } 11,3 \% \text { (mucho } \\
\text { mayor que el \% } \\
\text { real de casos) } \\
\text { Los estudios } \\
\text { acerca de la } \\
\text { asociación entre } \\
\text { LM y colecho son } \\
\text { en su mayoría } \\
\text { transversales, y en } \\
\text { el caso del estudio } \\
\text { entre la asociación } \\
\text { de LM y SMSL, } \\
\text { estudios casos } \\
\text { control. }\end{array}$ & $\begin{array}{l}\text { que el } \\
\text { financiador no } \\
\text { tuvo ningún } \\
\text { papel en el } \\
\text { diseño del } \\
\text { estudio, } \\
\text { recogida y } \\
\text { análisis de los } \\
\text { datos, en la } \\
\text { decisión de } \\
\text { publicar o en la } \\
\text { preparación del } \\
\text { artículo. }\end{array}$ \\
\hline
\end{tabular}




\subsection{Resumen de GPCs base y RSs disponibles}

La guía de NICE (7) recomienda aconsejar a los padres que nunca se duerman en un sofá con sus hijos y que se les debería advertir del aumento del riesgo de muerte súbita si éstos deciden compartir la cama con su hijo, sobre todo si éste tiene menos de 11 semanas de vida o si alguno de los padres es fumador, ha bebido alcohol, ha tomado medicación para el sueño o está extenuado.

La guía del Perinatal Care services (8) recomienda que niños y padres/cuidadores deberían dormir cerca en la misma habitación (en una superficie separada segura) durante los primeros 6 meses, y en el caso en que los padres decidan compartir la misma superficie para dormir, se debería proporcionar una serie de consejos de seguridad a los padres, como colocar al niño sobre su espalda para dormir, no fumar o tener un colchón firme y plano entre otros, para reducir los riesgos para el niño.

En el documento sobre Cuidados en el Nacimiento (9) se hacen una serie de recomendaciones para practicar un colecho seguro, que son: posición supina del niño, superficie plana y firme, no cubrir la cabeza del niño, no con madre fumadora ni que ingiera medicamentos que alteren el nivel de conciencia o alcohol.

Las RS identificadas indican que el colecho se asocia con mayores tasas de lactancia materna a las 4 semanas (5) y que aumenta el riesgo de SMSL (3-5), aunque la lactancia materna también se asocia con la disminución del riesgo de SMSL (6).

\subsection{Conclusión (marcar con una $\mathrm{X}$ ):}

\begin{tabular}{|l|l|}
\hline & Adopción GPC/Revisión sistemática \\
\hline$X$ & Elaboración parcial \\
\hline & Elaboración de novo \\
\hline
\end{tabular}

\subsection{Diseño de la estrategia de búsqueda de estudios individuales}

\begin{tabular}{|l|l|}
\hline Criterios de selección de estudios & $\begin{array}{l}\text { ECAs o estudios observacionales, en el caso de no } \\
\text { haber ECAs }\end{array}$ \\
\hline Período de búsqueda & $2011-24$ Octubre 2013 \\
\hline Bases de datos & Cochrane Library \\
& MEDLINE, via Pubmed \\
& EMBASE, via Ovid \\
& Cinahl, via EBSCOhost databases \\
& PsylNFO, via OVID
\end{tabular}

Ver estrategias de búsqueda de estudios originales en el ANEXO I. 


\section{4- RESUMEN DE LA EVIDENCIA (Tablas de estudios individuales y valoración de calidad en el ANEXO X)}

\section{1- GRADE Evidence Profile}

\section{Pregunta 5.1. Colecho durante la estancia en la maternidad}

Comparación 1: Colecho en cama de la madre vs. Misma habitación pero en cuna individual Bibliografía: Ball HL, 2006

\begin{tabular}{|c|c|c|c|c|c|c|c|c|c|c|c|c|}
\hline \multirow{2}{*}{\multicolumn{7}{|c|}{ Evaluación de la calidad }} & \multicolumn{4}{|c|}{ Resumen de los Resultados } & \multirow{3}{*}{ Calidad } & \multirow{3}{*}{ Importancia } \\
\hline & & & & & & & \multicolumn{2}{|c|}{$\mathrm{N}^{\circ}$ de pacientes } & \multicolumn{2}{|c|}{ Magnitud del efecto } & & \\
\hline $\begin{array}{c}N^{\circ} \text { de } \\
\text { estudios }\end{array}$ & Diseño & \begin{tabular}{|l} 
Riesgo de \\
sesgo
\end{tabular} & Inconsistencia & \begin{tabular}{|l} 
Evidencia \\
indirecta
\end{tabular} & Imprecisión & \begin{tabular}{|c|} 
Otras \\
consideraciones
\end{tabular} & $\begin{array}{c}\text { Grupo cama de } \\
\text { la madre }\end{array}$ & $\begin{array}{c}\text { Grupo cuna } \\
\text { individual }\end{array}$ & $\begin{array}{l}\text { Relativa } \\
(95 \% \mathrm{Cl})\end{array}$ & Absoluta por 1000 & & \\
\hline \multicolumn{13}{|c|}{ Número de tomas (intentos y tomas buenas) por hora durante la estancia en el hospital } \\
\hline \begin{tabular}{|l|l}
11 \\
\end{tabular} & ECA & No serio & No seria & No seria & Seria ${ }^{2}$ & Poco probable & 18 & 20 & _- & DM 2,56 (de 0,72 a 4,41) & MODERADA & CRITICA \\
\hline \multicolumn{13}{|c|}{ Puntuación obtenida para la satisfacción materna al alta hospitalaria (no se especifica el cuestionario utilizado ni la puntuación máxima que se puede obtener) } \\
\hline \begin{tabular}{|l|l}
11 \\
\end{tabular} & ECA & No serio & No seria & No seria & Seria ${ }^{2}$ & Poco probable & 18 & 20 & - & DM 0,39 (de -0,2 a 1,0) & MODERADA & CRITICA \\
\hline \multicolumn{13}{|c|}{ Proporción de tiempo expuesto a situaciones potencialmente peligrosas durante la noche en la estancia hospitalaria } \\
\hline 11 & ECA & No serio & No seria & No seria & Seria $^{2}$ & Poco probable & 18 & 20 & . & DM 1,03 (de -0,07 a 2,12) & MODERADA & IMPORTANTE \\
\hline
\end{tabular}

${ }^{1}$ Ball 2006; ${ }^{2}$ Un único estudio y pocos pacientes en cada grupo, e intervalos de confianza muy amplios

Comparación 2: Colecho en cuna sidecar vs. Misma habitación pero en cuna individual

Bibliografía: Ball HL, 2006; Ball HL, 2011.

\begin{tabular}{|c|c|c|c|c|c|c|c|c|c|c|c|c|}
\hline \multirow{2}{*}{\multicolumn{7}{|c|}{ Evaluación de la calidad }} & \multicolumn{4}{|c|}{ Resumen de los Resultados } & \multirow{3}{*}{ Calidad } & \multirow{3}{*}{ Importancia } \\
\hline & & & & & & & \multicolumn{2}{|c|}{$\mathrm{N}^{\circ}$ de pacientes } & \multicolumn{2}{|c|}{\begin{tabular}{|l|} 
Magnitud del efecto \\
\end{tabular}} & & \\
\hline $\begin{array}{c}N^{\circ} \text { de } \\
\text { estudios }\end{array}$ & Diseño & $\begin{array}{c}\text { Riesgo de } \\
\text { sesgo }\end{array}$ & Inconsistencia & $\begin{array}{c}\text { Evidencia } \\
\text { indirecta }\end{array}$ & Imprecisión & $\begin{array}{c}\text { Otras } \\
\text { consideraciones } \\
\end{array}$ & Grupo Sidecar & \begin{tabular}{|c|}
$\begin{array}{c}\text { Grupo cuna } \\
\text { individual }\end{array}$ \\
\end{tabular} & $\begin{array}{l}\text { Relativa } \\
(95 \% \mathrm{CI})\end{array}$ & Absoluta por 1000 & & \\
\hline \multicolumn{13}{|c|}{ Duración de cualquier tipo de lactancia materna (4 meses de seguimiento) } \\
\hline 11 & $\mathrm{ECA}$ & Serio $^{2}$ & No seria & No seria & No seria & Poco probable & 601 & 603 & \begin{tabular}{|l|} 
HR 0,96 (de \\
0,79 a 1,18 )
\end{tabular} & - & MODERADA & IMPORTANTE \\
\hline \multicolumn{13}{|c|}{ Duración de lactancia materna exclusiva (4 meses de seguimiento) } \\
\hline \begin{tabular}{|l|l}
11 \\
\end{tabular} & ECA & Serio $^{2}$ & No seria & No seria & No seria & Poco probable & 601 & 603 & \begin{tabular}{|l|} 
HR 0,99 (de \\
$0,85$ a 1,16$)$
\end{tabular} & - & MODERADA & IMPORTANTE \\
\hline
\end{tabular}




\begin{tabular}{|c|c|c|c|c|c|c|c|c|c|c|c|c|}
\hline $1^{3}$ & ECA & No serio & No seria & No seria & Seria ${ }^{4}$ & Poco probable & 23 & 20 & - & DM 2,52 (de 0,87 a 4,17 ) & MODERADA & CRITICA \\
\hline \multicolumn{13}{|c|}{ Puntuación obtenida para la satisfacción materna al alta hospitalaria (no se especifica el cuestionario utilizado ni la puntuación máxima que se puede obtener) } \\
\hline $1^{3}$ & ECA & No serio & No seria & No seria & Seria ${ }^{4}$ & Poco probable & 23 & 20 & & DM 0,46 (de $-0,9$ a 1,0$)$ & MODERADA & CRITICA \\
\hline \multicolumn{13}{|c|}{ Proporción de tiempo expuesto a situaciones potencialmente peligrosas durante la noche en la estancia hospitalaria } \\
\hline $1^{3}$ & ECA & No serio & No seria & No seria & Seria ${ }^{4}$ & Poco probable & 23 & 20 & - & DM - 0,05 (de $-0,40$ a 0,30$)$ & MODERADA & IMPORTANTE \\
\hline
\end{tabular}
amplios.

Comparación 3: Colecho en cama de la madre vs. Colecho en cuna sidecar Bibliografía: Ball HL, 2006

\begin{tabular}{|c|c|c|c|c|c|c|c|c|c|c|c|c|}
\hline \multirow{2}{*}{\multicolumn{7}{|c|}{ Evaluación de la calidad }} & \multicolumn{4}{|c|}{ Resumen de los Resultados } & \multirow{3}{*}{ Calidad } & \multirow{3}{*}{ Importancia } \\
\hline & & & & & & & \multicolumn{2}{|c|}{$\mathrm{N}^{\circ}$ de pacientes } & \multicolumn{2}{|c|}{ Magnitud del efecto } & & \\
\hline $\begin{array}{c}\mathrm{N}^{0} \text { de } \\
\text { estudios }\end{array}$ & Diseño & \begin{tabular}{|c|}
$\begin{array}{c}\text { Riesgo de } \\
\text { sesgo }\end{array}$ \\
\end{tabular} & Inconsistencia & \begin{tabular}{|l|}
$\begin{array}{l}\text { Evidencia } \\
\text { indirecta }\end{array}$ \\
\end{tabular} & Imprecisión & \begin{tabular}{|c|} 
Otras \\
consideraciones \\
\end{tabular} & \begin{tabular}{|c|}
$\begin{array}{c}\text { Grupo cama de } \\
\text { la madre }\end{array}$ \\
\end{tabular} & $\begin{array}{c}\text { Grupo } \\
\text { sidecar }\end{array}$ & $\begin{array}{l}\text { Relativa } \\
(95 \% \mathrm{Cl}) \\
\end{array}$ & Absoluta por 1000 & & \\
\hline \multicolumn{13}{|c|}{ Número de tomas (intentos y tomas buenas) por hora durante la estancia en el hospital } \\
\hline 11 & ECA & No serio & No seria & No seria & Seria ${ }^{2}$ & Poco probable & 18 & 20 & - & DM 0,04 (de -2,10 a 2,18) & MODERADA & CRITICA \\
\hline \multicolumn{13}{|c|}{ Puntuación obtenida para la satisfacción materna al alta hospitalaria (no se especifica el cuestionario utilizado ni la puntuación máxima que se puede obtener) } \\
\hline 11 & ECA & No serio & No seria & No seria & Seria ${ }^{2}$ & Poco probable & 18 & 20 & & DM $-0,08$ (de $-0,7$ a 0,6$)$ & MODERADA & CRITICA \\
\hline \multicolumn{13}{|c|}{ Proporción de tiempo expuesto a situaciones potencialmente peligrosas durante la noche en la estancia hospitalaria } \\
\hline 11 & ECA & No serio & No seria & No seria & Seria ${ }^{4}$ & Poco probable & \begin{tabular}{|l|l|}
18 & \\
\end{tabular} & 20 & & DM 1,08 (de 0,06 a 2,10) & MODERADA & IMPORTANTE \\
\hline
\end{tabular}

${ }^{1}$ Ball 2006; ${ }^{2}$ Un único estudio y pocos pacientes en cada grupo, e intervalos de confianza muy amplios. 


\section{Pregunta 5.2. Colecho en el hogar}

Bibliografía: Blair PS, 2010; Huang Y, 2013; Vennemann MM, 2012; McKenna JJ, 1997; Santos IS, 2009.

\begin{tabular}{|c|c|c|c|c|c|c|c|c|c|c|c|c|c|}
\hline \multirow{2}{*}{\multicolumn{7}{|c|}{ Evaluación de la calidad }} & \multicolumn{5}{|c|}{ Resumen de los Resultados } & \multirow{3}{*}{ Calidad } & \multirow{3}{*}{ Importancia } \\
\hline & & & & & & & \multicolumn{2}{|c|}{$N^{\circ}$ de pacientes } & \multicolumn{3}{|c|}{ Magnitud del efecto } & & \\
\hline $\begin{array}{c}N^{\circ} \text { de } \\
\text { estudios }\end{array}$ & Diseño & $\begin{array}{c}\text { Riesgo de } \\
\text { sesgo }\end{array}$ & Inconsistencia & $\begin{array}{l}\text { Evidencia } \\
\text { indirecta }\end{array}$ & Imprecisión & \begin{tabular}{|c|} 
Otras \\
consideraciones
\end{tabular} & $\begin{array}{l}\text { Grupo que } \\
\text { colecha }\end{array}$ & $\begin{array}{l}\text { Grupo que } \\
\text { no colecha }\end{array}$ & $\begin{array}{l}\text { Relativa } \\
(95 \% \mathrm{Cl})\end{array}$ & \multicolumn{2}{|c|}{ Absoluta por 1000} & & \\
\hline \multicolumn{14}{|c|}{ Tasa de lactancia materna a los 12 meses } \\
\hline 11 & \begin{tabular}{|l} 
Estudio \\
observacional
\end{tabular} & Serio $^{2}$ & No serio & No serio & No seria & Poco probable & \multicolumn{2}{|c|}{$\begin{array}{l}\text { *Son cuatro grupos (clases } \\
\text { latentes): } \mathrm{N} \text { total=7447 } \\
\text { - Colecho temprano: } 13,2 \% \\
\text { - Colecho tardío: } 15,2 \% \\
\text { - Colecho constante: } 6,1 \% \\
\text { - Colecho excepcional: } 65,5 \% \\
\end{array}$} & \multicolumn{3}{|c|}{$\begin{array}{l}\text { OR (comparación: colecho excepcional): } \\
\text { - Colecho tardío: 1,72 (IC95\%:1,36;2,18) } \\
\text { - Colecho temprano: 2,36 (IC95\%:1,87;2,97) } \\
\text { - Colecho constante:5,29 (IC95\%:4,05;6,91) } \\
\end{array}$} & MUY BAJA & IMPORTANTE \\
\hline \multicolumn{14}{|c|}{ Cese de la lactancia materna exclusiva en los primeros 6 meses } \\
\hline $1^{3}$ & $\begin{array}{l}\text { Estudio } \\
\text { observacional }\end{array}$ & Serio ${ }^{4}$ & No seria & No seria & No seria & Poco probable & \multicolumn{2}{|c|}{$\mathrm{N}$ total $=1800$} & \begin{tabular}{|l|} 
HR $0,96(\mathrm{de}$ \\
$0,89$ a 1,04$)$
\end{tabular} & \multicolumn{2}{|c|}{-} & MUY BAJA & IMPORTANTE \\
\hline \multicolumn{14}{|c|}{ Cese de cualquier tipo de lactancia materna en los primeros 12 meses } \\
\hline $2^{5}$ & $\begin{array}{l}\text { Estudio } \\
\text { observacional }\end{array}$ & Serio ${ }^{6}$ & No seria & No seria & No seria & Poco probable & \multicolumn{2}{|c|}{$\mathrm{N}$ total: 4.712} & \begin{tabular}{|l} 
HR 0,85 (de \\
$0,79$ a 0,90$)$ \\
PR 0,75 (de \\
0,69 a 0,81 ) \\
\end{tabular} & & & MUY BAJA & IMPORTANTE \\
\hline \multicolumn{14}{|c|}{ Frecuencia de tomas (media del número de tomas por noche) } \\
\hline $1^{7}$ & ECA cruzado & Serio $^{8}$ & No seria & No seria & Seria $^{9}$ & Poco probable & 20 & 15 & $\begin{array}{l}\begin{array}{l}\text { Grupo } \\
\text { colecho }\end{array} \\
\text { Habitual } \\
\text { Sin colecho } \\
\end{array}$ & \begin{tabular}{|c|}
$\begin{array}{c}\text { Noche en } \\
\text { colecho }\end{array}$ \\
$4,7 \pm 0,6$ \\
$3,8 \pm 0,7$ \\
\end{tabular} & $\begin{array}{c}\begin{array}{l}\text { Noche } \\
\text { separados }\end{array} \\
3,3 \pm 0,4 \\
2,3 \pm 0,3 \\
\end{array}$ & BAJA & CRITICA \\
\hline \multicolumn{14}{|c|}{ Duración total de las tomas (Minutos totales por noche) } \\
\hline $1^{7}$ & ECA cruzado & Serio $^{8}$ & No seria & No seria & Seria ${ }^{9}$ & Poco probable & 20 & 15 & $\begin{array}{l}\begin{array}{l}\text { Grupo } \\
\text { colecho }\end{array} \\
\text { Habitual } \\
\text { Sin colecho } \\
\end{array}$ & \begin{tabular}{|c|}
$\begin{array}{l}\text { Noche en } \\
\text { colecho }\end{array}$ \\
$55,9 \pm 7,7$ \\
$35,3 \pm 7,1$ \\
\end{tabular} & $\begin{array}{l}\begin{array}{l}\text { Noche } \\
\text { separados }\end{array} \\
26,4 \pm 2,6 \\
19,8 \pm 2,6 \\
\end{array}$ & BAJA & CRITICA \\
\hline \multicolumn{14}{|c|}{ Riesgo de SMSL durante el primer año de vida (12 meses de seguimiento) } \\
\hline $11^{10}$ & \begin{tabular}{|l|} 
Estudios \\
observacionales
\end{tabular} & Serio $^{11}$ & No seria & No seria & No seria & $\begin{array}{l}\text { Posible sesgo de } \\
\text { publicación }{ }^{12}\end{array}$ & $710 / 1573^{13}$ & $1754 / 7386^{14}$ & \begin{tabular}{|l|} 
OR 2,89 (de \\
$1,99$ a 4,18$)$
\end{tabular} & 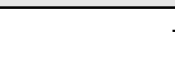 & & MUY BAJA & IMPORTANTE \\
\hline
\end{tabular}

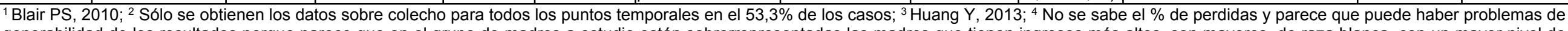

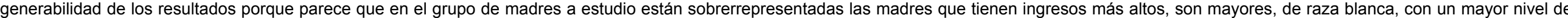

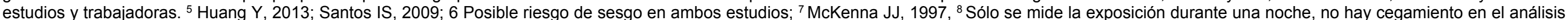




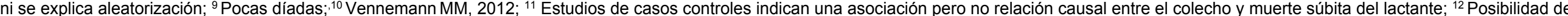

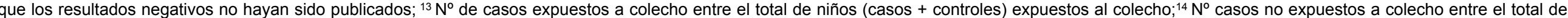
niños (casos+ controles) no expuestos a colecho. 


\section{2- Resumen de la Evidencia}

\section{Colecho en la maternidad}

Ninguna de las revisiones identificadas habla del colecho en la maternidad y su efecto sobre el inicio de la lactancia materna, por lo que para responder a esta pregunta se han utilizado los datos de dos ECA individuales $(10 ; 11)$, que ya han sido incluidos en la actualización de la guía NICE (7).

En el primer ECA (12), los autores determinan si la proximidad de la madre y el niño a la hora de dormir afecta al inicio de la lactancia materna y la seguridad del niño. Para ello, los autores incluyen 64 diadas madrehijo y los asignan de forma aleatoria a tres grupos según el lugar en el que iban a dormir los niños: 1) en la cama de la madre con barreras protectoras, 2) en cunas sidecar pegadas a la cama de la madre o 3) en cunas individuales cerca de la cama de la madre.

Tras dos noches de grabación nocturna durante períodos de observación estandarizados de 4 horas, los autores observan que en los grupos en los que los niños duermen en cama o cuna sidecar se da una mayor frecuencia de tomas por hora (tanto intentos como tomas buenas) que en el grupo de lactantes que duermen en cunas individuales $(2,56$ tomas más en cama que en cuna individual (IC95\% de 0,72 a 4,41 ) y 2,52 tomas más en cuna sidecar que en cuna individual (IC95\% de 0,82 a 4,17)), y que no hay diferencia en la frecuencia de tomas entre los que duermen en cama o cuna sidecar. Asimismo, la proporción de tiempo que los niños se exponían a situaciones potencialmente peligrosas era mayor para los niños que dormían en la cama con la madre que los que dormían en cunas sidecar (DM 1,08 (IC95\% de 0,06 a 2,10). En cambio, no hubo diferencias entre los que dormían en cuna sidecar 0 en cunas individuales.

No se observaron diferencias significativas en la duración del sueño de la madre o el niño, así como en la puntuación materna de satisfacción postnatal, aunque la diferencia era casi de medio punto entre las que tuvieron cunas sidecar frente al grupo en el que los recién nacidos dormían en cunas individuales.

El segundo estudio (11) evaluaba el uso de cunas sidecar en las maternidades y su efecto en la duración de la lactancia materna. Se aleatorizaron 1.204 mujeres embarazadas con intención de amamantar en dos grupos según el lugar en el que iban a dormir los niños (cunas sidecar $(n=601)$ o cunas individuales $(n=603)$ ). Mediante llamada telefónica a las 26 semanas tras dar a luz, se preguntó a las madres por la duración de cualquier tipo de lactancia materna y de lactancia materna exclusiva. Se obtuvieron los datos de 870 de las 1204 madres que fueron incluidas inicialmente (433 del grupo intervención y 437 del grupo control), y tras ajustar por edad de la madre, nivel de educación, si había amamantado anteriormente y el tipo de parto no se encontró diferencia en la duración de la lactancia materna. Además se encontró que el colecho en el hogar no era más frecuente en las madres que utilizaron la cuna sidecar en el hospital (67\% vs $64 \%)$. Por lo tanto, se concluye que mientras que el uso de cunas sidecar puede facilitar el inicio de la lactancia materna, no parece que influya sobre la duración de la misma o

Calidad moderada

Calidad moderada

Calidad moderada

Calidad moderada 
sobre la práctica del colecho en el hogar.

\section{Colecho en el hogar}

Las revisiones sistemáticas que se han identificado describen la asociación entre el colecho y el aumento del riesgo del SMSL (3-5), la asociación entre la lactancia materna y la disminución del SMSL (6), así como la asociación entre el colecho y el aumento de la tasa de lactancia materna a las cuatro semanas de vida (5). De las tres revisiones sobre la asociación entre el colecho y el SMSL se han utilizado los datos de las revisiones de Vennemann (3) y Daas (5). Para el efecto del colecho sobre la lactancia materna, no se ha utilizado el metanálisis de Daas (5) pero sí los resultados de un estudio longitudinal incluido en dicho metanálisis (13) y otro estudio longitudinal posterior (14) que estudia la asociación entre colecho y duración de la lactancia materna.

En relación a la asociación entre el colecho y la duración de la lactancia materna aunque los dos estudios incluidos $(13 ; 14)$ señalan que existe una asociación entre ambos, no está claro si es la práctica del colecho la que se asocia con una mayor duración de la lactancia materna o si son las madres que amamantan a sus hijos las que deciden posteriormente compartir la cama con el niño.

El estudio de Blair (13), en el que se definió por colecho que el niño pasara de forma habitual parte del sueño nocturno en la misma cama que el adulto, encontró que tanto el colecho tardío (a partir de los 12 meses), como el colecho temprano y el colecho continuo se asociaban con mayores tasas de lactancia materna a los 12 meses OR 1,72 (IC95\% de 1,36 a 2,18); OR 2,36 (IC95\% de 1,87 a 2,97); OR 5,29 (IC95\% de 4,05 a 6,91) respectivamente).

En un estudio posterior (14) se definía por colecho que la madre estuviera tumbada y durmiera con el niño en la misma cama o en otra superficie (excluyendo cunas sidecar) durante el sueño nocturno o durante el período de sueño principal. Para definir el grado de colecho, los autores contabilizaron el número de veces que la madre señalaba haber compartido la cama en los 7 puntos temporales en los que se medía la exposición, lo que permitió definir cuatro grupos de exposición al colecho: no colecho (0 puntos), colecho excepcional (1 0 o 2 puntos), colecho moderado (de 3 a 4 puntos) y colecho frecuente (de 5 a 7 puntos).

En este estudio se observó que el aumento de un nivel en la puntuación acumulada de colecho entre las madres que inician el colecho en la misma edad del niño, el riesgo de cese de cualquier tipo de lactancia materna a los 12 meses se reducía en un 15,5\% (HR 0,85 (IC95\% de $0,79$ s 0,90$)$ ), aunque el riesgo no disminuía de forma significativa para el cese de la lactancia exclusiva a los 6 meses. En otro estudio observacional (15) se observó que aquellos niños que a los tres meses estaban con lactancia materna y compartían la cama con la madre, la Razón de Prevalencia (RP) de seguir con lactancia materna a los 12 meses era de 0,75 (IC $95 \%$ de 0,69 a 0,81 ).

En cuanto a la relación entre el colecho y el número y duración de las tomas nocturnas, estudios como el de Mckenna (16) demuestran que los niños que comparten la cama con la madre de forma habitual con sus madres son amamantados con mayor frecuencia y que la duración total

Calidad muy baja

Calidad muy baja Calidad muy baja

Calidad 
de los episodios de lactancia también es mayor. El hallazgo más importante señala que para los niños que comparten la cama con la madre de forma habitual en el hogar, el tiempo que son amamantados durante la noche del estudio en colecho con sus madres es tres veces mayor que el de los niños que duermen solos de forma habitual y en la noche del estudio que duermen solos.

En cuanto a la muerte súbita del lactante, según el metaanálisis de Vennemann (3) cuando hubo colecho la noche en la que el lactante murió el OR para el SMSL era de 2,89 (IC95\% de 1,99 a 4,18). Asimismo, en un análisis de subgrupos, los autores encontraron que cuando el colecho era una práctica habitual no se asociaba de forma significativa con la muerte súbita del lactante (OR de 1,42; IC $95 \%$ de 0,85 a 2,38), aunque este resultado no se confirma en el metaanálisis posterior de Das RR (5). En cuanto a la edad del niño, este metaanálisis señala que el OR de muerte súbita en niños menores de 12 semanas que compartían la cama con la madre era de 10,37 (IC95\% de 4,44 a 24,21) frente al OR de 1,02 (IC95\% de 0,49 a 2,12) en niños mayores de 12 semanas (3). Sin embargo, en un artículo publicado en 2013 (4) en el que se combinan los datos individuales de dos estudios casos control realizados en Inglaterra, se encuentra que cuando no existían factores de riesgo (colecho en cama, sin consumo de alcohol ni tabaco) el riesgo de muerte súbita no es significativo, no encontrando además mayor riesgo de muerte súbita en niños que tenían menos de 3 meses de edad (OR de de 1,6 (IC95\% de 0,96 a 2,7)).

Por otro lado, el metanálisis de Hauck (6) describe que la lactancia materna se asocia con un menor riesgo de síndrome de muerte súbita del lactante, siendo este OR de 0,27 (IC95\% de 0,24 a 0,31) cuando se trata de lactancia materna exclusiva, lo que señala la necesidad de saber si en realidad existe interacción entre la lactancia materna y el colecho y cómo afecta esto al riesgo del SMSL.

De hecho, se ha descrito en la literatura (12) que el comportamiento de las madres que amamantan cuando comparten la cama con sus hijos es diferente al comportamiento de aquellas que no amamantan. En un estudio en el que participaron 20 familias se filmó durante tres días el comportamiento de las madres y los niños cuando compartían la cama en sus casas. Las madres que amamantaban a sus hijos colocaban al niño en posición lateral y con la cabeza más cerca del pecho de la madre, mientras que las madres que no amamantaban lo colocaban en posición supina y con la cabeza más cerca de la almohada y de la cabeza de los padres. La frecuencia de la alimentación y su duración también era diferente, al igual que los despertares sincronizados, más frecuentes en las diadas de madres y niños amamantados. Por ello, los autores indican que los estudios casos-control que evalúan el riesgo del lactante cuando comparte la cama con su madre deberían tener en cuenta estas diferencias en el comportamiento.

\section{ACTUALIZADO A FECHA DE: 31 de Octubre de 2016}




\section{5- DE LA EVIDENCIA A LA RECOMENDACIÓN (Tabla de EtR)}

\section{¿Es eficaz y seguro el colecho en las madres que amamantan para facilitar el buen inicio y el mantenimiento de la lactancia materna?}

\section{COLECHO EN LA MATERNIDAD}

Población: Madres de recién nacidos sanos a término que amamantan y sus hijos

Intervención: Colecho (en cama o cuna sidecar)

Comparación: Habitación separada o cuna individual en la misma habitación

Perspectiva: Clínica

1: Cama vs. cuna individual; C2: Cuna sidecar vs. cuna individual; C3: Cama vs. cuna sidecar

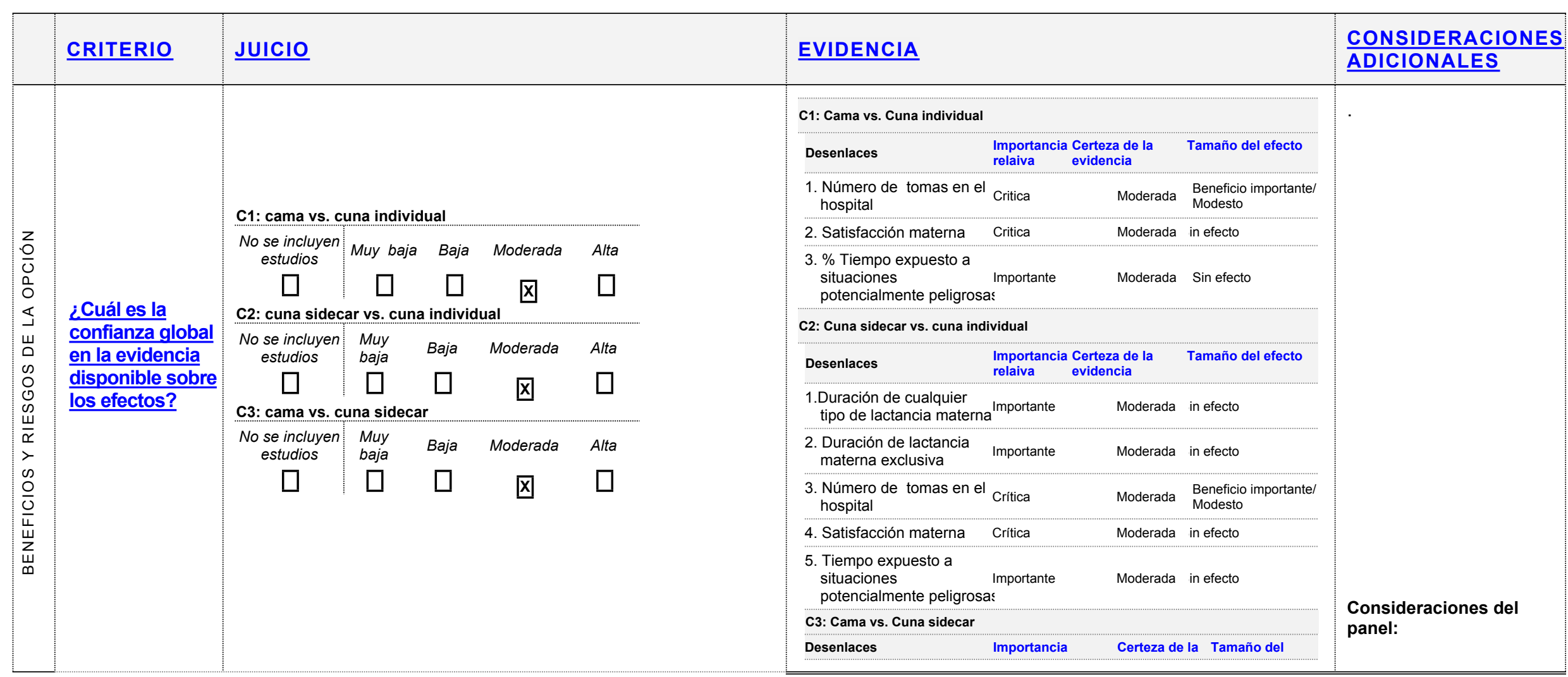




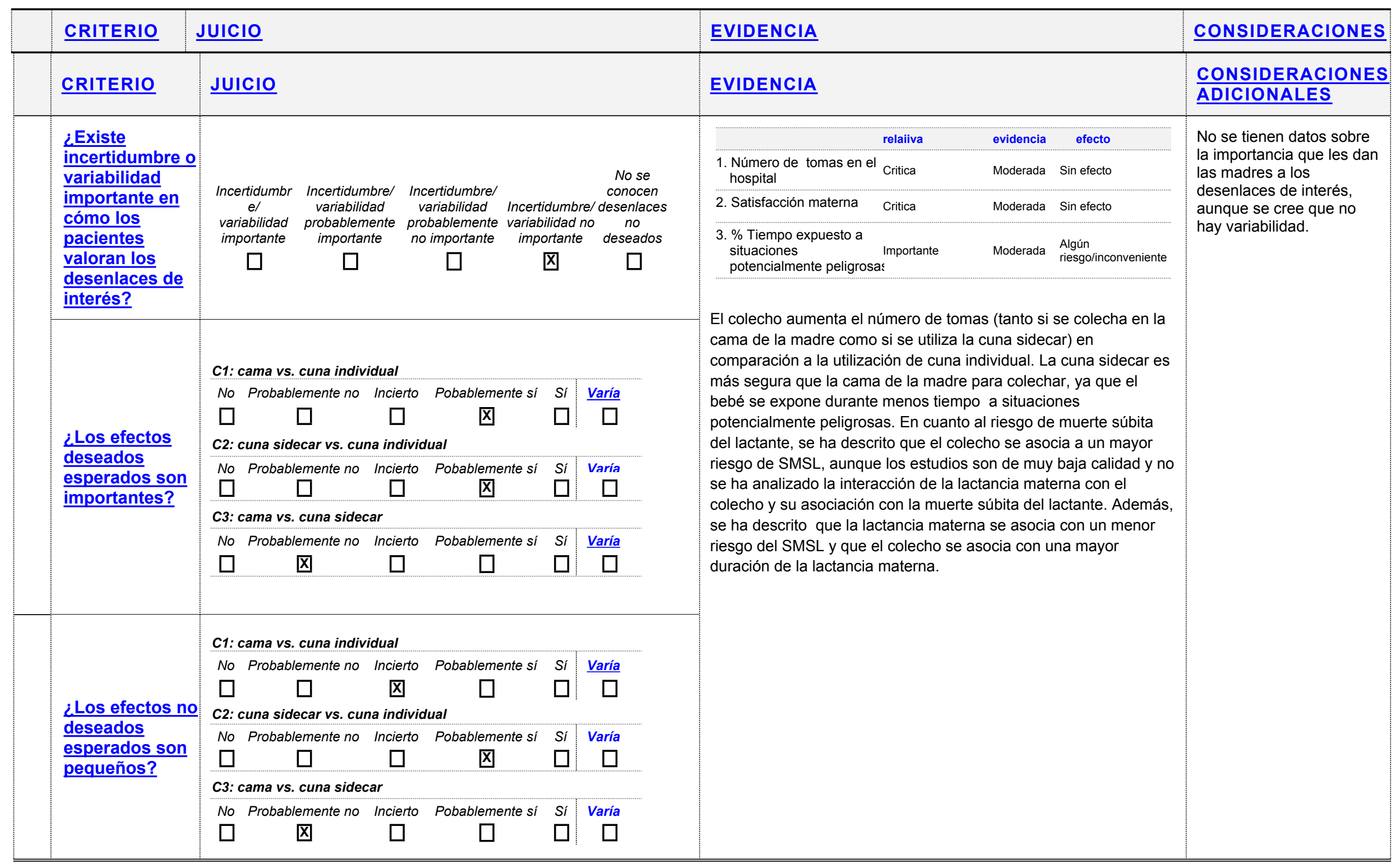




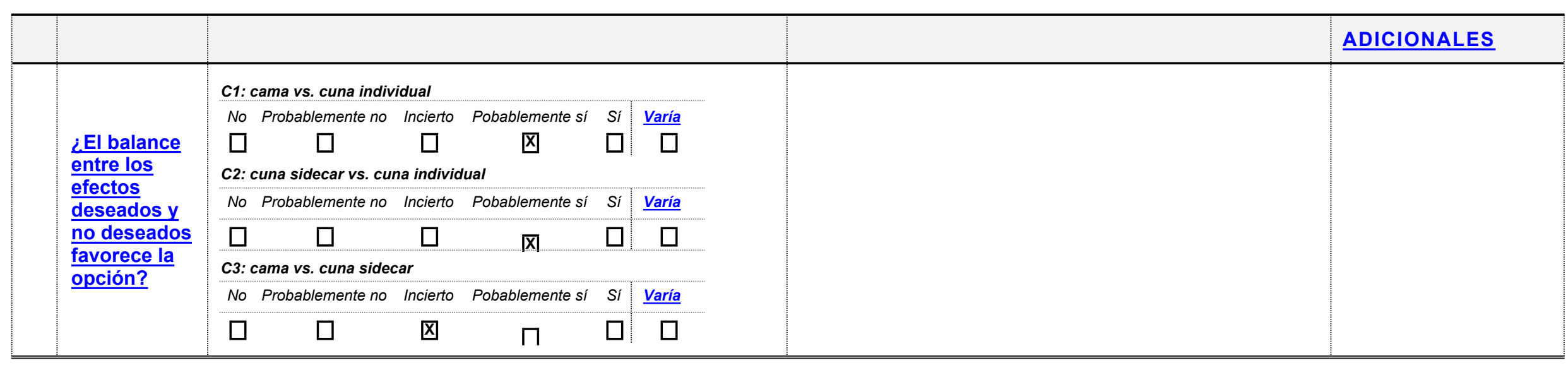




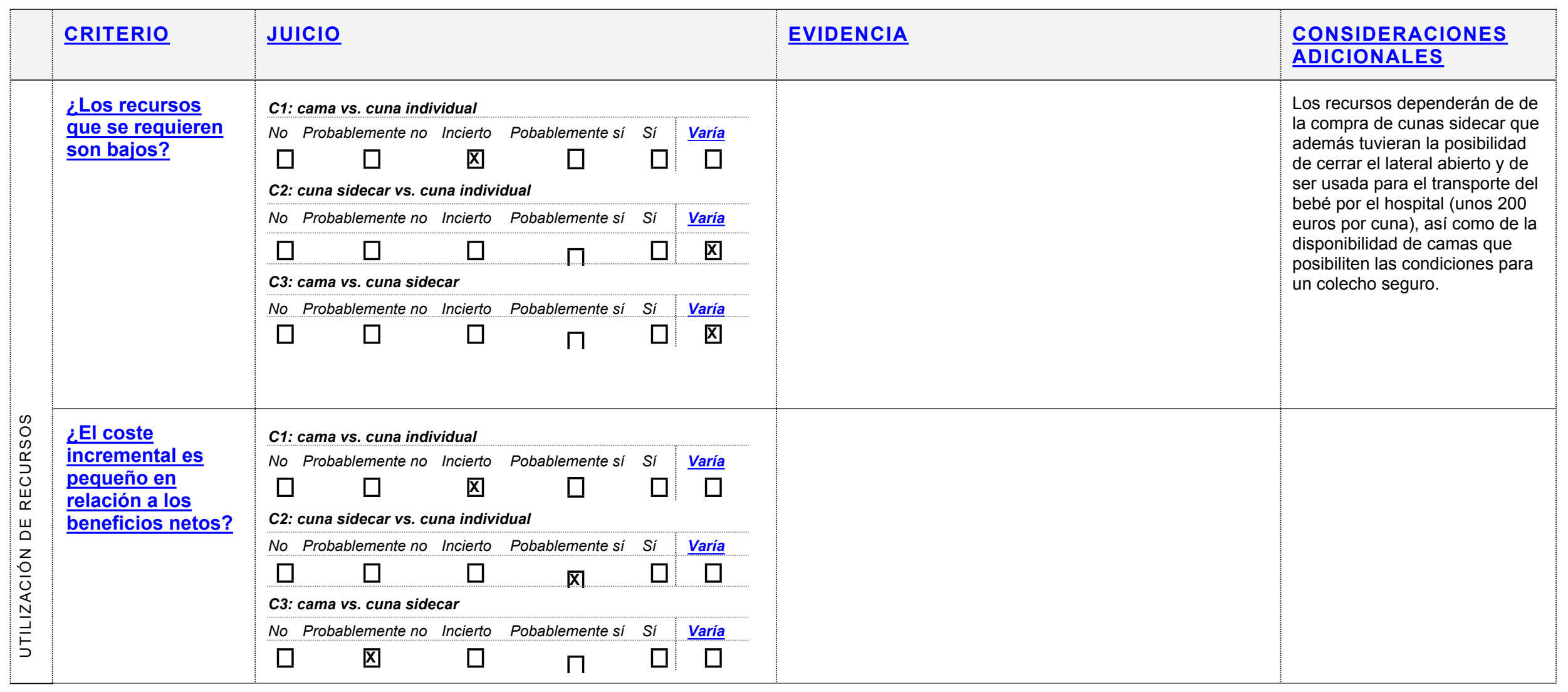




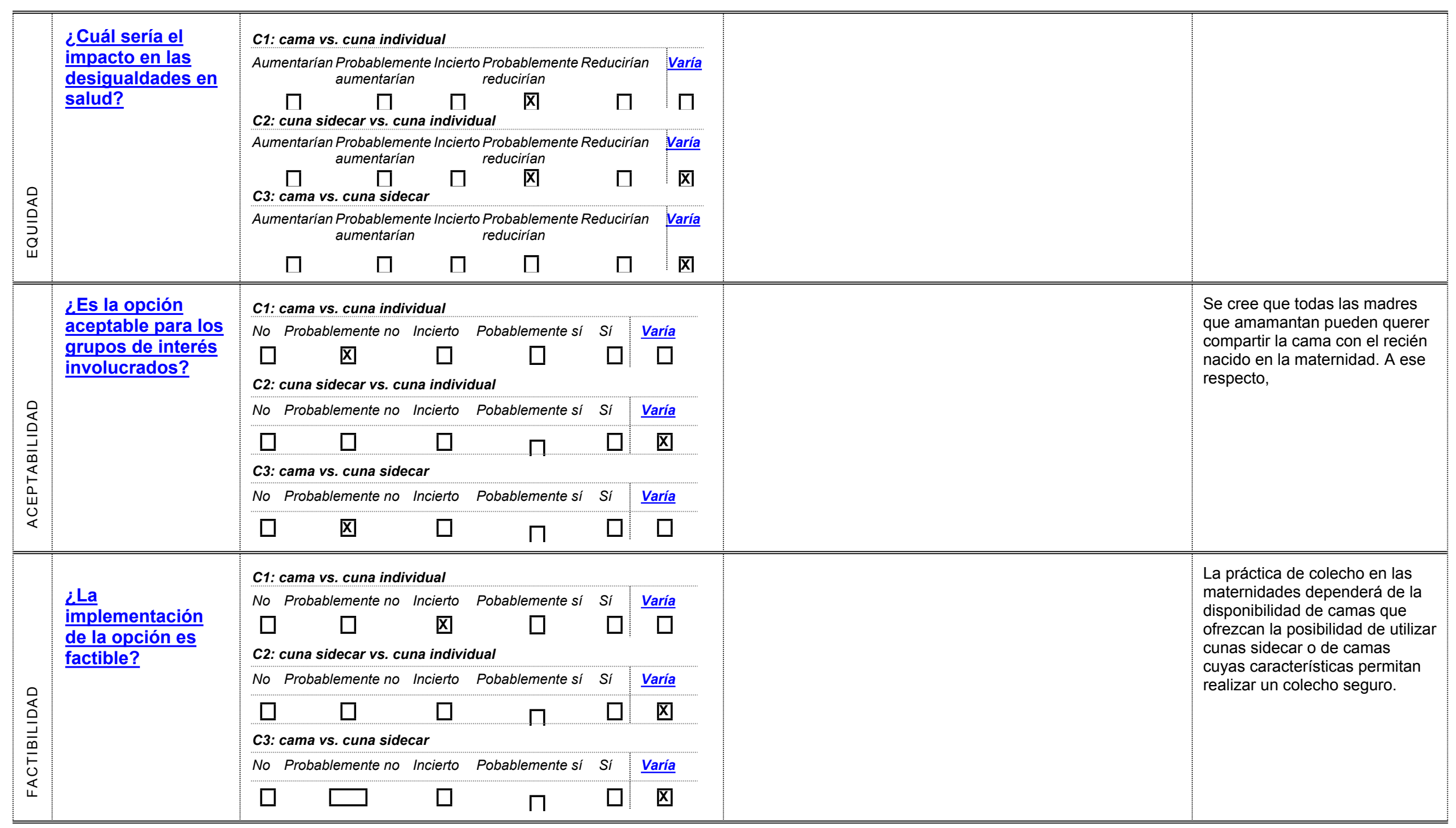




\begin{tabular}{|c|c|c|c|c|c|}
\hline $\begin{array}{l}\text { Balance de las } \\
\text { consecuencias }\end{array}$ & $\begin{array}{l}\text { Las consecuencias no } \\
\text { deseadas superan } \\
\text { claramente las } \\
\text { consecuencias deseadas } \\
\text { en la mayoría de los } \\
\text { escenarios }\end{array}$ & $\begin{array}{c}\text { Las consecuencias no } \\
\text { deseadas probablemente } \\
\text { superan las consecuencias d } \\
\text { deseadas en la mayoría de } \\
\text { los escenarios }\end{array}$ & $\begin{array}{c}\text { El balance entre las } \\
\text { consecuencias } \\
\text { deseadas y no deseadas } \\
\text { está muy equilibrado o } \\
\text { es incierto }\end{array}$ & $\begin{array}{c}\text { Las consecuencias } \\
\text { deseadas probablemente } \\
\text { superan las consecuencias } \\
\text { no deseadas en la mayoría } \\
\text { de los escenarios }\end{array}$ & $\begin{array}{c}\text { Las consecuencias } \\
\text { deseadas claramente } \\
\text { superan las consecuencias } \\
\text { no deseadas en la mayoría } \\
\text { de los escenarios }\end{array}$ \\
\hline
\end{tabular}

\begin{tabular}{|c|c|c|c|c|}
\hline C1 & $\square$ & $\square$ & 凶 & $\Gamma$ \\
\hline C2 & $\square$ & $\square$ & $\square$ & [ \\
\hline C3 & $\square$ & 凶 & $\square$ & [ \\
\hline
\end{tabular}

\begin{tabular}{lcccc}
\hline \hline $\begin{array}{l}\text { Tipo de } \\
\text { recomendación }\end{array}$ & Se recomienda no ofrecer la opción & Se sugiere no ofrecer la opción & $\begin{array}{c}\text { Se sugiere ofrecer la opción } \\
\text { C1 }\end{array}$ & $\begin{array}{c}\text { Se recomienda ofrecer } \\
\text { la opción }\end{array}$ \\
C2 & $\square$ & $\square$ & $\square$ & $\square$ \\
C3 & $\square$ & $\square$ & $\square$ & $\square$ \\
\hline \hline
\end{tabular}

\begin{tabular}{ll}
\hline \hline$\frac{\text { Recomendación }}{\text { (Texto) }}$ & Recomendación débil a favor \\
& $\begin{array}{l}\text { Se sugiere el colecho en la maternidad como una práctica que favorece el buen inicio de la lactancia materna, siempre y cuando se mantengan las } \\
\text { condiciones que favorecen un colecho seguro. }\end{array}$
\end{tabular}

\section{Recomendación de buena práctica}

Ofrecer a todo los padres información de manera sistemática sobre las condiciones que favorecen un colecho seguro (Ver Anexo 4). Las maternidades deberían considerar la utilización de camas en las que pueda practicarse un colecho seguro. 
Justificación

Se considera que la práctica del colecho puede facilitar el inicio de la lactancia materna. Por ello se recomienda, aunque de forma débil, el colecho como práctica que puede favorecer el inicio e instauración de la lactancia materna.

Sin embargo, debido al posible riesgo que supone para el lactante dormir en la misma cama que la madre, y teniendo en cuenta además que las camas que se encuentran en las maternidades pueden ser estrechas, se recomienda informar siempre sobre las condiciones que deben darse para favorecer un colecho seguro. Las cunas sidecar podrían ser una alternativa más segura. Sin embargo, aunque su precio sería asumible por los hospitales, existe un problema de seguridad cuando la maternidad cuenta sólo con camas articuladas, puesto que si por cualquier motivo se activara el mecanismo de la cama cuando la cuna sidecar está adosada a la misma, podría ocasionar la caída de la cuna y del lactante. Este problema no ha sido solucionado todavía por el fabricante, por lo que para que una maternidad pueda utilizar este tipo de cunas debe contar con camas no articuladas que permitan un acoplamiento seguro de la cuna a la cama.

\section{Consideraciones de}

\section{subgrupos}

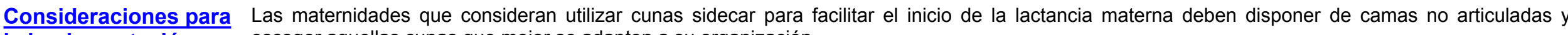
la implementación escoger aquellas cunas que mejor se adapten a su organización.

\section{Monitorización y}

evaluación

\section{Prioridades para la}

\section{investigación}




\section{¿Es eficaz y seguro el colecho en las madres que amamantan para facilitar el buen inicio y el mantenimiento de la lactancia materna?}

\section{COLECHO EN EI HOGAR}

Población: Madres de recién nacidos sanos a término que amamantan y sus hijos

Intervención: Colecho (en cama o cuna sidecar)

Comparación: Cuna individual en la misma habitación

Perspectiva: Clínica

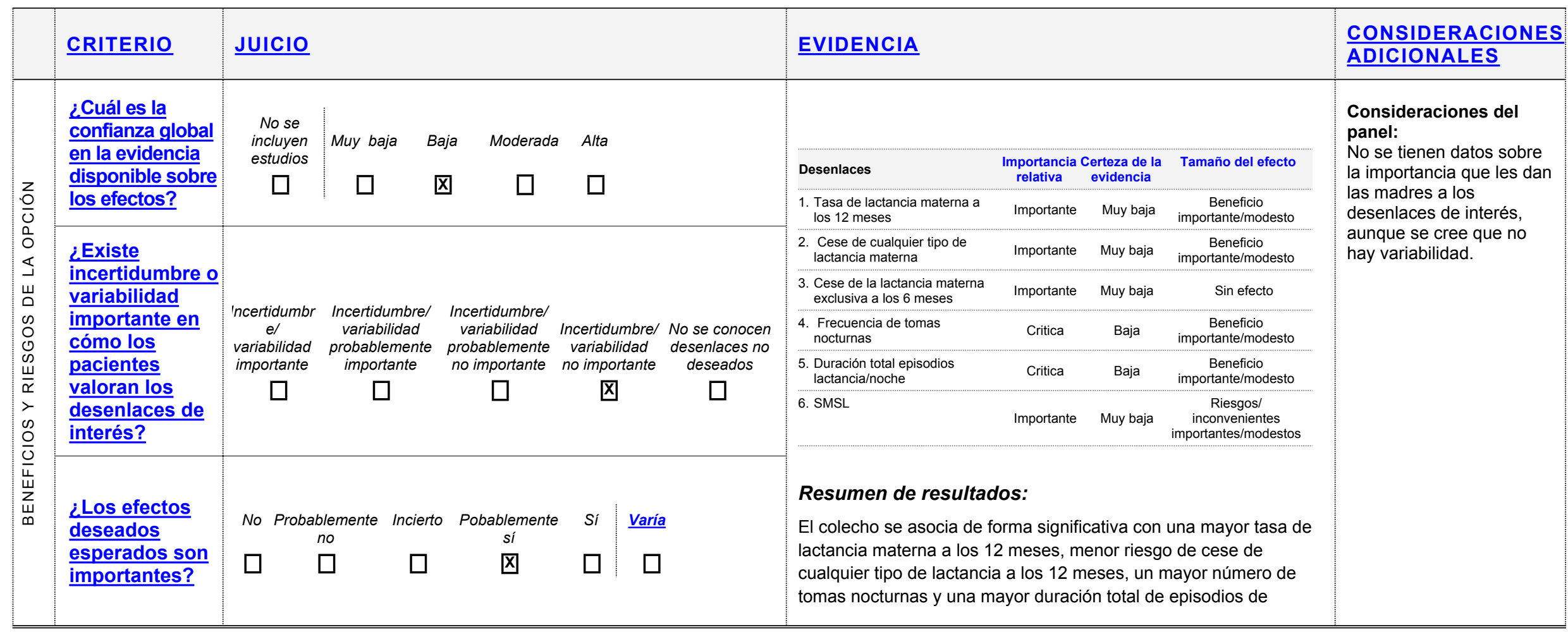




\begin{tabular}{|c|c|c|c|c|c|c|c|}
\hline CRITERIO & $\underline{\text { JUICIO }}$ & & & & & EVIDENCIA & $\begin{array}{l}\text { CONSIDERACIONES } \\
\text { ADICIONALES }\end{array}$ \\
\hline $\begin{array}{l}\text { LLos efectos } \\
\text { no deseados } \\
\text { esperados } \\
\text { son } \\
\text { pequeños? }\end{array}$ & $\begin{array}{l}\text { No Probablemente } \\
\text { no } \\
\square \quad \square\end{array}$ & $\begin{array}{c}\text { Incierto } \\
\square\end{array}$ & $\begin{array}{c}\text { Pobablemente } \\
\text { si } \\
\text { 冈 }\end{array}$ & $\square$ & $\frac{\text { Varía }}{\square}$ & $\begin{array}{l}\text { lactancia materna nocturnos. Sin embargo, también parece haber } \\
\text { una asociación con el riesgo de SMSL, aunque queda por } \\
\text { determinar cuál es la interacción entre la lactancia materna y el } \\
\text { colecho y su efecto sobre el SMSL. } \\
\text { Ver la tabla GRADE de perfil de evidencia. }\end{array}$ & \\
\hline
\end{tabular}




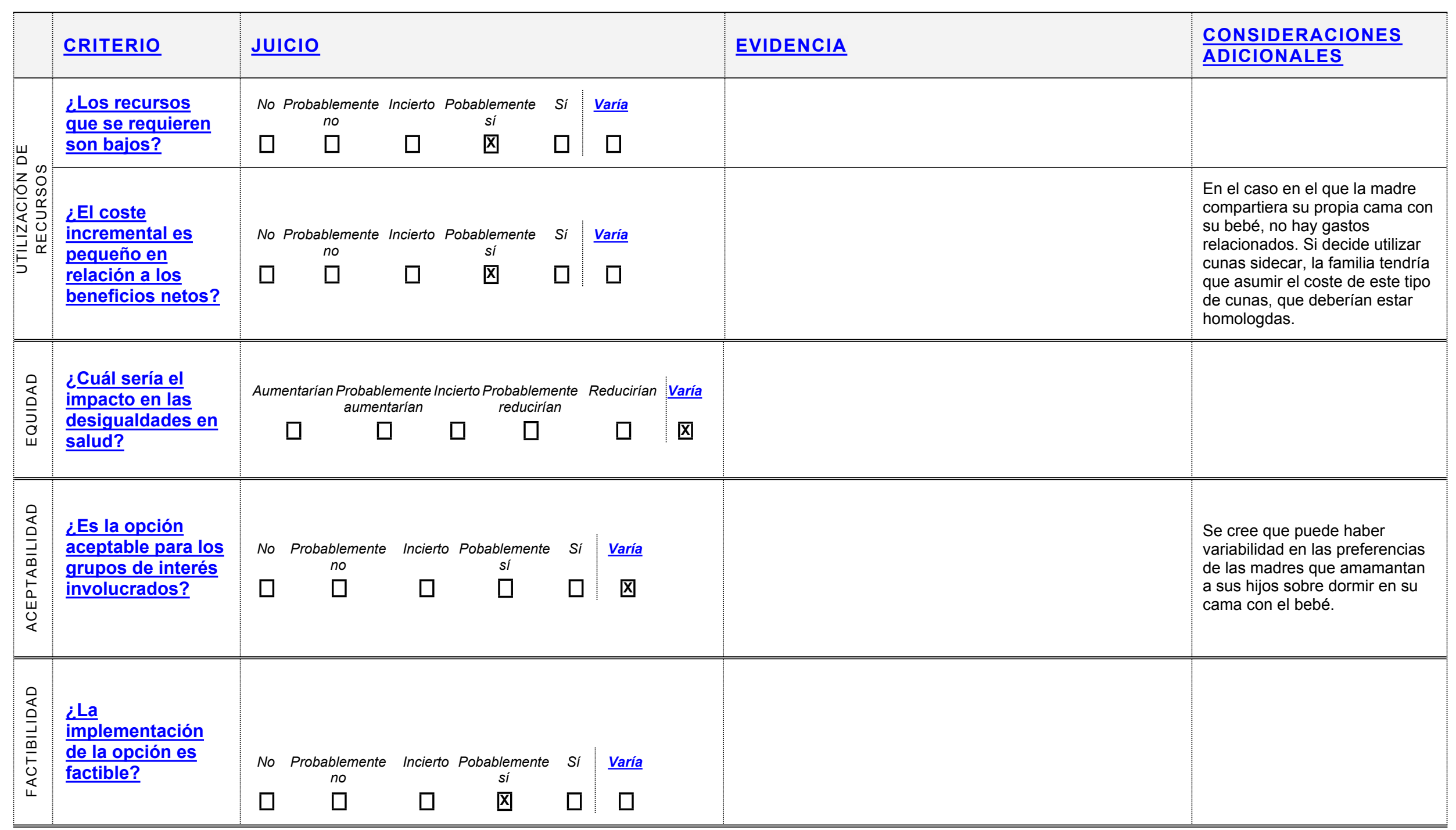




\begin{tabular}{|c|c|c|c|c|c|}
\hline \multirow[t]{2}{*}{$\begin{array}{l}\text { Balance de las } \\
\text { consecuencias }\end{array}$} & $\begin{array}{l}\text { Las consecuencias no } \\
\text { deseadas superan } \\
\text { claramente las } \\
\text { consecuencias deseadas } \\
\text { en la mayoría de los } \\
\text { escenarios }\end{array}$ & $\begin{array}{l}\text { Las consecuencias no } \\
\text { deseadas probablemente } \\
\text { superan las } \\
\text { consecuencias deseadas } \\
\text { en la mayoría de los } \\
\text { escenarios }\end{array}$ & $\begin{array}{c}\text { El balance entre las } \\
\text { consecuencias deseadas y } \\
\text { no deseadas está muy } \\
\text { equilibrado o es incierto }\end{array}$ & $\begin{array}{l}\text { Las consecuencias } \\
\text { deseadas } \\
\text { probablemente superan } \\
\text { las consecuencias no } \\
\text { deseadas en la mayoría } \\
\text { de los escenarios }\end{array}$ & $\begin{array}{c}\text { Las consecuencias } \\
\text { deseadas claramente } \\
\text { superan las } \\
\text { consecuencias no } \\
\text { deseadas en la mayoría } \\
\text { de los escenarios }\end{array}$ \\
\hline & $\square$ & $\square$ & $\square$ & 凶 & $\square$ \\
\hline
\end{tabular}

Recomendación (Texto)

\section{Recomendación débil a favor}

Se sugiere el colecho en el hogar (en cama o en cuna sidecar) como una opción que puede ayudar a la madre a mantener la lactancia materna.

\section{Recomendación de buena práctica}

Dado que la mayoría de las madres, aunque no haya planificado compartir la cama con su hijo lo hace en algún momento, se debería ofrecer información de manera sistemática sobre las condiciones que favorecen un colecho seguro.

Informar a las madres y padres sobre la existencia de cunas sidecar homologadas que además de facilitar la lactancia materna favorecen un colecho seguro.

\section{Recomendación fuerte a favor}

Se recomienda informar a las madres y a las familias del peligro que supone para la seguridad del lactante:

1. Quedarse dormido con el lactante en brazos, en un sofá o en una silla, por el riesgo de sofocación o caídas durante el sueño del adulto.

2. Que duerman en la misma cama que el lactante otros hermanos personas que no son su madre o su padre y animales domésticos.

3. Que el lactante permanezca sólo en la cama de un adulto, en un sofá o en un sillón. 
Justificación La práctica del colecho facilita el mantenimiento de la lactancia materna, aunque existe controversia en cuanto a los riesgos que esta práctica supone para el niño. Aunque el cumplimiento de los consejos sobre la realización de un colecho seguro reduce esos riesgos, para minimizarlos al máximo se podría informar a las madres sobre la posibilidad de utilizar cunas sidecar homologadas que cumplen con la misión de facilitar la proximidad a la hora de dormir de la madre y el niño, a la vez que disminuyen el riesgo para el niño.

\section{Consideraciones de} subgrupos

\section{Consideraciones para El colecho es seguro si se cumple lo siguiente:}

\section{la implementación}

1) El lactante nació a término y sin problemas graves de salud.

2) El lactante es amamantado en exclusiva y a demanda (la lactancia artificial aumenta el riesgo de muerte súbita del lactante)

3) Ninguno de los adultos que va a compartir cama con el lactante fuma (aunque no lo haga en presencia del mismo)

4) Ninguno de los progenitores que va a compartir cama con el lactante ha consumido alguna bebida alcohólica, drogas o medicamentos que provoquen un sueño más profundo del habitual

5) Ninguno de los progenitores que va a compartir la cama con el lactante sufre obesidad mórbida

6) Todos los adultos que duermen en la cama saben que el lactante comparte la cama con ellos

7) El lactante duerme siempre acostado en decúbito supino (boca arriba). Dormir en decúbito prono o lateral aumenta el riesgo de muerte súbita del lactante.

8) El lactante duerme con ropa ligera y la temperatura de la habitación no es superior a $20^{\circ} \mathrm{C}$.

9) La cabeza del lactante no está tapada

10) La superficie para dormir es firme y no hay en ella:

- Edredones pesados tipo patchwork, mantas eléctricas, almohadones, peluches, cordones y otros elementos que puedan impedir respirar al lactante en algún momento durante la noche.

- Espacios por donde el lactante pueda caer o quedar atrapado.

Se deben tener en cuenta los valores y preferencias de las madres que amamantan, sus dudas y preocupaciones cuando se aborda el tema del colecho en el hogar.

\section{Monitorización y}

\section{evaluación}

Prioridades para la investigación
En el diseño de futuros estudios de casos controles sobre SIDS se deberían recoger datos en relación a los hábitos de sueño del niño en general y durante la última noche (dónde dormía, cuáles eran las condiciones en las que dormía), si estaba siendo amamantado o no, si estaba enfermo la última noche, la posición en la que se encontró al niño, si el niño estaba expuesto al humo de tabaco, cuáles fueron las condiciones de la última noche o porqué estaba el niño durmiendo con los padres. 


\title{
6. ANEXOS
}

\section{ANEXO I, ESTRATEGIAS DE BÚSQUEDA}

\author{
Cochrane Library \\ Searched 24/10/2013 \\ Updated search 24/10/2013 a 31/12/2013
}

\#1 "bed sharing" or bedsharing or bed-sharing:ti,ab,kw or "bed share" or bedshare or bed-share:ti,ab,kw (Word variations have been searched)

\#2 "co sleeping" or cosleeping or co-sleeping:ti,ab,kw or "co sleep" or cosleep or co-sleep:ti,ab,kw (Word variations have been searched)

\#3 side or sidecar or side-car or "side car" or bedside or bed-side or "bed side":ti,ab,kw and cot or cots or crib or cribs:ti,ab,kw (Word variations have been searched)

\#4 \#1 or \#2 or \#3

\author{
MEDLINE, via Pubmed \\ Searched 24/10/2013 \\ Updated search 24/10//2013 a 31/12/2013
}

("bed sharing"[All Fields] OR bedsharing[All Fields] OR bed-sharing[All Fields] OR "bed share"[All Fields] OR bedshare[All Fields] OR bed-share[All Fields]) OR ("co sleeping"[All Fields] OR cosleeping[All Fields] OR co-sleeping[All Fields] OR "co sleep"[All Fields] OR cosleep[All Fields] OR co-sleep[All Fields]) OR ((side OR sidecar OR side-car OR "side car" OR bedside OR bed-side OR "bed side") AND (cot OR cots OR crib OR cribs)) Filters: Publication date from 2011/01/01 to 2013/12/31

\section{EMBASE, via Ovid \\ Searched 24/10/2013 \\ Updated search 24/10/2013 a 31/12/2013}

\#1 bed sharing/

\#2 ("bed sharing" or bedsharing or bed-sharing).mp. [mp=title, abstract, subject headings, heading word, drug trade name, original title, device manufacturer, drug manufacturer, device trade name, keyword] \#3 ("bed share" or bedshare or bed-share).mp. [mp=title, abstract, subject headings, heading word, drug trade name, original title, device manufacturer, drug manufacturer, device trade name, keyword]

\#4 1 or 2 or 3

\# 5("co sleeping" or cosleeping or co-sleeping).mp. [mp=title, abstract, subject headings, heading word, drug trade name, original title, device manufacturer, drug manufacturer, device trade name, keyword] \#6 ("co sleep" or cosleep or co-sleep).mp. [mp=title, abstract, subject headings, heading word, drug trade name, original title, device manufacturer, drug manufacturer, device trade name, keyword]

\#7 5 or 6

\#8 (side or sidecar or side-car or "side car" or bedside or bed-side or "bed side").mp. [mp=title, abstract, subject headings, heading word, drug trade name, original title, device manufacturer, drug manufacturer, device trade name, keyword] \#9 (cot or cots or crib or cribs).mp. [mp=title, abstract, subject headings, heading word, drug trade name, original title, device manufacturer, drug manufacturer, device trade name, keyword] 
\#10 8 and 9

\#11 4 or 7 or 10

\#12 limit 11 to $y r=" 2011$-Current"

Cinahl, via EBSCOhost databases

Searched 24/10/2013

Updated search 24/10/2013 a 31/12/2013

S1 (MH "Bed Sharing")

S2 "bed sharing" OR bedsharing OR bed-sharing

S3 "bed share" OR bedshare OR bed-share

S4 S1 OR S2 OR S3

S5 "co sleeping" OR co-sleeping OR cosleeping

S6 "co sleep" OR co-sleep OR cosleep

S7 S5 OR S6

S8 side OR sidecar OR side-car OR "side car" OR bedside OR bed-side OR "bed side" S9 (MH "Cribs") OR ( crib OR cribs) OR ( cot OR cots )

S10 S8 AND S9

S11 S4 OR S7 OR S10

S12 S4 OR S7 OR S10 Limitadores - Fecha en que se publicó desde:20110101-

20131231

\section{PsyINFO, via OVID}

Searched: $24 / 10 / 2013$

Updated search 24/10/2013 a 31/12/2013

\#1 ("bed sharing" or bedsharing or bed-sharing).mp. [mp=title, abstract, heading word, table of contents, key concepts, original title, tests \& measures]

\#2 ("bed share" or bedshare or bed-share).mp. [mp=title, abstract, heading word, table of contents, key concepts, original title, tests \& measures]

\#3 1 or 2

\#4 ("co sleeping" or cosleeping or co-sleeping).mp. [mp=title, abstract, heading word, table of contents, key concepts, original title, tests \& measures]

\#5 ("co sleep" or cosleep or co-sleep).mp. [mp=title, abstract, heading word, table of contents, key concepts, original title, tests \& measures]

\#6 4 or 5

\#7 (cot or cots or crib or cribs).mp. [mp=title, abstract, heading word, table of contents, key concepts, original title, tests $\&$ measures]

\#8 (side or sidecar or side-car or "side car" or bedside or bed-side or "bed side").mp. [mp=title, abstract, heading word, table of contents, key concepts, original title, tests \& measures]

$\# 97$ and 8

\#10 3 or 6 or 9

\#11 limit 10 to yr="2011 -Current" 


\section{ANEXO II, Tabla de estudios individuales para la pregunta}

\section{Pregunta 5.1. Colecho en la maternidad}

\begin{tabular}{|c|c|c|c|c|c|c|}
\hline $\begin{array}{l}\text { Referencia } \\
\text { (Cita Abreviada) }\end{array}$ & $\begin{array}{l}\text { Estudio (Diseño y } \\
\text { objetivo) }\end{array}$ & $\begin{array}{l}\text { Población } \\
\text { (nº y características) }\end{array}$ & $\begin{array}{l}\text { Descripción de las intervenciones } \\
\text { comparaciones, exposiciones o } \\
\text { pruebas a estudio }\end{array}$ & $\begin{array}{l}\text { Resultados } \\
\text { (Estimadores de resultados-Magnitud del } \\
\text { efecto) }\end{array}$ & $\begin{array}{l}\text { Conclusiones } \\
\text { (conclusiones) }\end{array}$ & $\begin{array}{l}\text { Comentarios } \\
\text { Calidad de la } \\
\text { evidencia } \\
\text { Financiación } \\
\text { comentarios) }\end{array}$ \\
\hline Ball H, 2006 & $\begin{array}{l}\text { Diseño: ECA } \\
\text { Objetivo: } \\
\text { Determinar si la } \\
\text { proximidad madre hijo } \\
\text { afecta al inicio de la } \\
\text { lactancia materna y a la } \\
\text { seguridad del niño. }\end{array}$ & $\begin{array}{l}64 \text { diadas madre-hijo } \\
\text { con intención prenatal } \\
\text { de amamantar, parto } \\
\text { vaginal sin analgésicos } \\
\text { opiáceos en las } 24 \\
\text { horas anteriores). }\end{array}$ & $\begin{array}{l}\text { Aleatorización en tres grupos: } \\
\text { 1. Niño en cuna individual cerca de la } \\
\text { cama de la madre } \\
\text { 2. Cuna sidecar } \\
\text { 3. Cama }\end{array}$ & $\begin{array}{l}\text { 1. Frecuencia de tomas } \\
\text { - Cama vs. cuna individual: DM } 2,56 \\
(0,72 \text { a } 4,4) \\
\text { - Cuna sidecar vs. cuna individual: DM } \\
2,52(0,87 \text { a } 4,17) \\
\text { - Cama vs. cuna sidecar: DM } 0,04(-2,10 \\
\text { a } 2,18) \\
\text { 2. Proporción de tiempo expuesto a } \\
\text { situaciones potencialmente peligrosas. } \\
\text { - Cama vs. cuna individual: ns } \\
\text { - Cuna sidecar vs. cuna individual: ns } \\
\text { - Cama vs. cuna sidecar: } 1,08 \text { ( } 0,06 \text { a } \\
\text { 2,10) } \\
\text { Diferencias no significativas en } \\
\text { satisfacción materna. }\end{array}$ & $\begin{array}{l}\text { Las cunas sidecar } \\
\text { son efectivas en } \\
\text { potenciar el inicio } \\
\text { de la lactancia } \\
\text { materna y } \\
\text { preservar la } \\
\text { seguridad de los } \\
\text { niños en las } \\
\text { maternidades. }\end{array}$ & $\begin{array}{l}\text { Estos resultados } \\
\text { sólo pueden } \\
\text { generalizarse en } \\
\text { madres con } \\
\text { parto vaginal y } \\
\text { sin analgesia } \\
\text { opiácea en las } \\
24 \text { horas } \\
\text { previas. } \\
\text { Financiado por } \\
\text { NHS trust. }\end{array}$ \\
\hline Ball H, 2011 & $\begin{array}{l}\text { Diseño: ECA (no cegado) } \\
\text { Objetivo: evaluar si el uso } \\
\text { de cunas sidecar en la } \\
\text { maternidad afecta a la } \\
\text { duración de la lactancia } \\
\text { materna. }\end{array}$ & $\begin{array}{l}1204 \text { mujeres } \\
\text { embarazadas que } \\
\text { quieren dar el pecho } \\
\text { son reclutadas a las } \\
20 \text { semanas de } \\
\text { gestación y } \\
\text { aleatorizadas a las } \\
34 \text { semanas de } \\
\text { gestación. }\end{array}$ & $\begin{array}{l}\text { - Grupo sidecar: } 601 \text { (al final 433) } \\
\text { - Grupo en cuna individual en la misma } \\
\text { habitación: } 603 \text { (al final } 437 \text { ) } \\
\text { Análisis por regresión de Cox }\end{array}$ & $\begin{array}{l}\text { Duración de lactancia exclusiva y de } \\
\text { cualquier tipo hasta las } 26 \text { semanas } \\
\\
\text { Duración lactancia materna exclusiva: HR } \\
0,96(0,79 \text { a } 1,18) \\
\text { Duración cualquier tipo de lactancia } \\
\text { materna: HR } 0,99(0,85 \text { a } 1,16) \text {. } \\
\text { El colecho no era más común en madres } \\
\text { que utilizaron cunas sidecar ( } 67 \% \text { vs. } \\
64 \%) \text {. }\end{array}$ & $\begin{array}{l}\text { El uso de cuna } \\
\text { sidecar no mejoró } \\
\text { la duración de la } \\
\text { lactancia materna } \\
\text { exclusiva o de } \\
\text { cualquier tipo ni } \\
\text { aumentó la } \\
\text { frecuencia de } \\
\text { colecho en el } \\
\text { hogar. }\end{array}$ & $\begin{array}{l}\text { National Institute } \\
\text { for Health } \\
\text { Research. } \\
\text { Newcastele and } \\
\text { north Tyneside } \\
\text { Acute Hospital } \\
\text { Trust eran el } \\
\text { sponsor para } \\
\text { esta } \\
\text { investigación. }\end{array}$ \\
\hline
\end{tabular}




\section{Pregunta 5.2. Colecho en el hogar}

\begin{tabular}{|c|c|c|c|c|c|c|c|c|}
\hline $\begin{array}{l}\text { Referencia } \\
\text { (Cita Abreviada) }\end{array}$ & $\begin{array}{l}\text { Estudio (Diseño y } \\
\text { objetivo) }\end{array}$ & $\begin{array}{l}\text { Población } \\
\text { (nº y características) }\end{array}$ & $\begin{array}{l}\text { Descripción de las intervenciones } \\
\text { comparaciones, exposiciones o } \\
\text { pruebas a estudio }\end{array}$ & \multicolumn{3}{|c|}{$\begin{array}{l}\text { Resultados } \\
\text { (Estimadores de resultados-Magnitud del } \\
\text { efecto) }\end{array}$} & $\begin{array}{l}\text { Conclusiones } \\
\text { (conclusiones) }\end{array}$ & $\begin{array}{l}\text { Comentarios } \\
\text { Calidad de la } \\
\text { evidencia } \\
\text { Financiación } \\
\text { comentarios) }\end{array}$ \\
\hline \multirow[t]{7}{*}{ Mckenna JJ, 1997} & \multirow{7}{*}{$\begin{array}{l}\text { Diseño: ECA cruzado } \\
\text { Objetivo: estudiar el } \\
\text { efecto del colecho en el } \\
\text { comportamiento nocturno } \\
\text { de la lactancia materna. }\end{array}$} & \multirow{7}{*}{$\begin{array}{l}20 \text { díadas que } \\
\text { colechan de forma } \\
\text { rutinaria } \\
15 \text { díadas que duermen } \\
\text { separados de forma } \\
\text { rutinaria. } \\
\text { Todas las madres son } \\
\text { latinas, y los niños } \\
\text { tienen de } 3 \text { a } 4 \text { meses } \\
\text { de edad. }\end{array}$} & \multirow{7}{*}{$\begin{array}{l}\text { Se graba el comportamiento nocturno } \\
\text { durante tres noches. La primera es de } \\
\text { adaptación, y luego } 1 \text { noche se hace } \\
\text { colecho en una cama de matrimonio y la } \\
\text { otra noche el niño duerme en cuna en } \\
\text { habitación adyacente. } \\
\text { Se mide: } \\
\text { - No de episodios de lactancia materna } \\
\text { - Duración total de los episodios (min) } \\
\text { - Duración media de cada episodio } \\
\text { (min) }\end{array}$} & $\mathrm{N}^{\circ}$ de episodi & s de lactancia & materna & \multirow{7}{*}{$\begin{array}{l}\text { Se sugiere que al } \\
\text { aumentar la } \\
\text { lactancia materna } \\
\text { el colecho puede } \\
\text { proteger frente a } \\
\text { SMSL al menos en } \\
\text { algunos contextos. }\end{array}$} & \multirow{7}{*}{$\begin{array}{l}\text { Es el primer } \\
\text { estudio en medir } \\
\text { el } \\
\text { comportamiento } \\
\text { nocturno de } \\
\text { lactancia } \\
\text { materna en un } \\
\text { grupo cultural. }\end{array}$} \\
\hline & & & & $\begin{array}{l}\begin{array}{l}\text { Grupo } \\
\text { colecho }\end{array} \\
\end{array}$ & $\begin{array}{l}\text { Noche en } \\
\text { colecho }\end{array}$ & $\begin{array}{l}\text { Noche } \\
\text { separados }\end{array}$ & & \\
\hline & & & & Habitual & $4,7 \pm 0,6$ & $3,3 \pm 0,4$ & & \\
\hline & & & & Sin colecho & $3,8 \pm 0,7$ & $2,3 \pm 0,3$ & & \\
\hline & & & & \multicolumn{3}{|c|}{ Duración total de las tomas: } & & \\
\hline & & & & $\begin{array}{l}\text { Grupo } \\
\text { colecho }\end{array}$ & $\begin{array}{l}\begin{array}{l}\text { Noche en } \\
\text { colecho }\end{array} \\
559+77\end{array}$ & \begin{tabular}{l|} 
Noche \\
separados
\end{tabular} & & \\
\hline & & & & $\begin{array}{l}\text { Sin } \\
\text { colecho }\end{array}$ & $35,3 \pm 7,1$ & $19,8 \pm 2,6$ & & \\
\hline Blair PS, 2010 & $\begin{array}{l}\text { Diseño: cohorte } \\
\text { prospectiva } \\
\text { Objetivo: investigar el } \\
\text { patrón longitudinal del } \\
\text { colecho, las características } \\
\text { asociadas a ese patrón y } \\
\text { su relación con la lactancia } \\
\text { materna. }\end{array}$ & $\begin{array}{l}14.062 \text { nacimientos, } \\
7.447(53 \%) \text { tienen } \\
\text { datos para todos los } \\
\text { puntos temporales. }\end{array}$ & $\begin{array}{l}\text { Se investiga el colecho en } 5 \text { puntos en } \\
\text { el tiempo desde el nacimiento a los } 4 \\
\text { años de edad. } \\
\text { Se identifican cuatro grupos: } \\
\text { 1. No comparten cama ( } 66 \%) \\
\text { 2. Colechan sólo al principio (13\%) } \\
\text { 3. Colecho tardío (tras el primer año) } \\
\text { (15\%) } \\
\text { 4. Colecho constante (durante los } 4 \\
\text { años) }(6 \%) \text {. }\end{array}$ & \multicolumn{3}{|c|}{$\begin{array}{l}\text { Asociación con lactancia materna a los } 12 \\
\text { meses: } \\
\text { 1. No comparten cama: } \\
\text { 2. Colecho al principio: } 2,36(1,87 \text { a } 2,97) \\
\text { 3. Colecho tardío: } 1,72(1,36 \text { a } 2,18) \\
\text { 4. Colecho constante: } 5,29(4,05 \text { a } 6,91)\end{array}$} & $\begin{array}{l}\text { Antes de dar } \\
\text { consejo sobre no } \\
\text { colechar con el } \\
\text { bebé, se debería } \\
\text { tener en cuenta la } \\
\text { importante relación } \\
\text { entre la lactancia } \\
\text { materna y el } \\
\text { colecho. }\end{array}$ & $\begin{array}{l}\text { Modelo ajustado } \\
\text { por educación } \\
\text { materna, más de } \\
\text { tres niños, edad } \\
\text { madre, } \\
\text { nacimiento } \\
\text { múltiple, raza, } \\
\text { bajo peso al } \\
\text { nacer, edad } \\
\text { gestacional, } \\
\text { sexo del niño y } \\
\text { no tener pareja. } \\
\text { Financiación por } \\
\text { Fundación para } \\
\text { el estudio de } \\
\text { muertes } \\
\text { infantiles. }\end{array}$ \\
\hline
\end{tabular}




\begin{tabular}{|c|c|c|c|c|c|c|}
\hline $\begin{array}{l}\text { Referencia } \\
\text { (Cita Abreviada) }\end{array}$ & $\begin{array}{l}\text { Estudio (Diseño y } \\
\text { objetivo) }\end{array}$ & $\begin{array}{l}\text { Población } \\
\text { (nº y características) }\end{array}$ & $\begin{array}{l}\text { Descripción de las intervenciones } \\
\text { comparaciones, exposiciones o } \\
\text { pruebas a estudio }\end{array}$ & $\begin{array}{l}\text { Resultados } \\
\text { (Estimadores de resultados-Magnitud del } \\
\text { efecto) }\end{array}$ & $\begin{array}{l}\text { Conclusiones } \\
\text { (conclusiones) }\end{array}$ & $\begin{array}{l}\text { Comentarios } \\
\text { Calidad de la } \\
\text { evidencia } \\
\text { Financiación } \\
\text { comentarios) }\end{array}$ \\
\hline Huang Y, 2013 & $\begin{array}{l}\text { Diseño: estudio de } \\
\text { cohortes } \\
\text { Objetivo: cuantificar la } \\
\text { influencia del colecho en la } \\
\text { duración de la lactancia } \\
\text { materna }\end{array}$ & $\begin{array}{l}\text { Datos longitudinales } \\
\text { del Infant Feeding } \\
\text { Practices Study II. } \\
\text { Hacen cuatro } \\
\text { categorías: } \\
\text { 1. No colecho (0 } \\
\text { puntos) } \\
\text { 2. Colecho raro (de } 1 \text { a } \\
\text { 2 puntos) } \\
\text { 3. Colecho moderado } \\
\text { (de } 3 \text { a } 4 \text { puntos) } \\
4 . \text { Colecho frecuente } \\
\text { (de } 5 \text { a } 7 \text { puntos) }\end{array}$ & $\begin{array}{l}\text { Definen colecho como dormir tumbado } \\
\text { con el niño en la misma cama u otra } \\
\text { superficie para dormir a la noche o } \\
\text { durante el período de sueño más } \\
\text { importante. } \\
\text { Se envían cuestionarios a la edad de } 1 \text { a } \\
7,9,10 \text { y } 12 \text { meses. } \\
1846 \text { madres responden al menos una } \\
\text { pregunta en relación al colecho y si } \\
\text { estaban con lactancia materna a la edad } \\
\text { de } 2 \text { semanas. }\end{array}$ & $\begin{array}{l}\text { Estudio de supervivencia sobre el efecto } \\
\text { de colecho en cama en la duración de la } \\
\text { lactancia materna de cualquier tipo y } \\
\text { exclusiva. } \\
\text { Cese de la lactancia materna exclusiva en } \\
\text { los primeros } 6 \text { meses: HR } 0,96 \text { (de } 0,89 \text { a } \\
1,04 \text { ). } \\
\text { Cese de cualquier tipo de la lactancia } \\
\text { materna en el primer año: HR } 0,85 \text { (de } \\
0,79 \text { a } 0,90 \text { ) }\end{array}$ & $\begin{array}{l}\text { Muchos factores } \\
\text { se asocian con } \\
\text { lactancia materna, } \\
\text { incluyendo el } \\
\text { colecho. Debido al } \\
\text { riesgo de SMSL } \\
\text { relacionada con el } \\
\text { colecho, se } \\
\text { deberían diseñar y } \\
\text { testar estrategias } \\
\text { para promocionar } \\
\text { la lactancia } \\
\text { materna. }\end{array}$ & \\
\hline Santos IS, 2009 & $\begin{array}{l}\text { Diseño: estudio de } \\
\text { cohortes } \\
\text { Objetivo: investigar la } \\
\text { asociación entre el colecho } \\
\text { a los } 3 \text { meses de vida y la } \\
\text { lactancia a los } 12 \text { meses. }\end{array}$ & $\begin{array}{l}4231 \text { niños de los } \\
\text { cuales } 2889 \text { estaban } \\
\text { con lactancia materna } \\
\text { a los } 3 \text { meses. } \\
\text { Se hace una entrevista } \\
\text { perinatal y se vuelve a } \\
\text { entrevistar a las } \\
\text { madres en visitas en su } \\
\text { casa a los } 3 \text { y } 12 \\
\text { meses tras el parto. }\end{array}$ & $\begin{array}{l}\text { Prevalencia de lactancia maaterna a los } \\
12 \text { meses de } 59,2 \% \text { en niños que } \\
\text { colechaban a los } 3 \text { meses y } 44 \% \text { que } \\
\text { no lo hacían. } \\
\text { Colechar: se define como compartir la } \\
\text { cama de forma habitual entre la madre y } \\
\text { el niño por toda la noche o parte de la } \\
\text { noche. El análisis se limitó a embarazos } \\
\text { únicos y niños amamantados a los } 3 \\
\text { meses. } \\
\text { Se utiliza el Prevalence Ratio (PR). }\end{array}$ & $\begin{array}{l}\text { Niños con cualquier lactancia materna a } \\
\text { los tres meses: PR } 0,75(0,69 \text { a } 0,81) \\
\text { Niños con lactancia materna exclusiva a } \\
\text { los tres meses: PR } 0,63(0,53 \text { a } 0,75)\end{array}$ & $\begin{array}{l}\text { Colechar a los tres } \\
\text { meses protegía } \\
\text { frente al cese de la } \\
\text { lactancia materna } \\
\text { a los } 12 \text { meses. }\end{array}$ & $\begin{array}{l}\text { Lactancia } \\
\text { materna } \\
\text { exclusiva } \\
\text { ajustado por: } \\
\text { nivel } \\
\text { socioeconómico, } \\
\text { color de piel } \\
\text { madre, tipo de } \\
\text { parto, sexo del } \\
\text { niño. } \\
\text { Cualquier tipo: } \\
\text { edad madre } \\
\text { ajustado } \\
\text { también por: } \\
\text { madre trabaja } \\
\text { fuera de casa a } \\
\text { los } 3 \text { meses, y } \\
\text { bajo peso al } \\
\text { nacer. }\end{array}$ \\
\hline
\end{tabular}




\section{7- BIBLIOGRAFÍA}

(1) Jaafar SH, Lee KS, Ho JJ. Separate care for new mother and infant versus rooming-in for increasing the duration of breastfeeding. Cochrane Database Syst Rev 2012;9:CD006641.

(2) Bystrova K. Skin to skin contact and suckling in early postpartum: effects on temperature, breastfeeding and mother-Infant interaction. A study in St. Petersburg, Russia. Karolinska Institute. 2008.

(3) Vennemann MM, Hense HW, Bajanowski T, Blair PS, Complojer C, Moon RY, et al. Bed sharing and the risk of sudden infant death syndrome: can we resolve the debate? J Pediatr 2012 Jan;160(1):44-8.

(4) Carpenter R, McGarvey C, Mitchell EA, Tappin DM, Vennemann MM, Smuk M, et al. Bed sharing when parents do not smoke: is there a risk of SIDS? An individual level analysis of five major case-control studies. BMJ Open 2013;3(5).

(5) Das RR, Sankar MJ, Agarwal R, Paul VK. Is "Bed Sharing" Beneficial and Safe during Infancy? A Systematic Review. Int J Pediatr 2014;2014:468538.

(6) Hauck FR, Thompson JM, Tanabe KO, Moon RY, Vennemann MM. Breastfeeding and reduced risk of sudden infant death syndrome: a metaanalysis. Pediatrics $2011 \mathrm{Jul} ; 128(1): 103-10$.

(7) NICE. Postnatal care up to 8 weeks after birth. Julio 2006 (actualizado en Febrero de 2015). Disponible en: http://guidance.nice.org.uk/CG37.

(8) Perinatal Services BC. Health Promotion Guideline 1. Safe Sleep Environment Guideline For Infants 0 to 12 months of age. February 2011. Disponible en: http://www.perinatalservicesbc.ca/NR/rdonlyres/D799441C-3E00-49EE-BDF72A3196B971F0/0/HPGuidelinesSafeSleep1.pdf.

(9) Cuidados desde el nacimiento. Recomendaciones basadas en pruebas y buenas prácticas. Ministerio de Sanidad y Política Social. 2010. http://msssi.gob.es/organizacion/sns/planCalidadSNS/pdf/equidad/cuidadosDes deNacimiento.pdf.

(10) Ball HL, Ward-Platt MP, Heslop E, Leech SJ, Brown KA. Randomised trial of infant sleep location on the postnatal ward. Arch Dis Child 2006 Dec;91(12):1005-10.

(11) Ball HL, Ward-Platt MP, Howel D, Russell C. Randomised trial of sidecar crib use on breastfeeding duration (NECOT). Arch Dis Child 2011 Jul;96(7):630-4.

(12) Ball HL. Parent-infant bed-sharing behavior: efects of feeding type, and presence of father. Human nature : an interdisciplinary bioso cial $p$ ersp ective., 17 (3). pp. 301-318. Human nature: an interdisciplinary biosocial perspective 2006;17(3):301-18.

(13) Blair PS, Heron J, Fleming PJ. Relationship between bed sharing and breastfeeding: longitudinal, population-based analysis. Pediatrics 2010 Nov;126(5):e1119-e1126.

(14) Huang Y, Hauck FR, Signore C, Yu A, Raju TN, Huang TT, et al. Influence of Bedsharing Activity on Breastfeeding Duration Among US Mothers. JAMA Pediatr 2013 Sep 23.

(15) Santos IS, Mota DM, Matijasevich A, Barros AJ, Barros FC. Bed-sharing at 3 months and breast-feeding at 1 year in southern Brazil. J Pediatr 2009 Oct;155(4):505-9.

(16) McKenna JJ, Mosko SS, Richard CA. Bedsharing promotes breastfeeding. Pediatrics 1997 Aug;100(2 Pt 1):214-9. 
PREGUNTA CLÍNICA Nº 6.

¿Cómo afecta la restricción de las tomas de pecho nocturnas en la instauración y duración de la lactancia materna?

\section{1- PREGUNTA CLÍNICA EN FORMATO PICO}

Tabla 1- Componentes de la pregunta clínica en formato PICO

\begin{tabular}{|l|l|}
\hline Población & $\begin{array}{l}\text { Madres de recién nacidos sanos a término que amamantan y } \\
\text { sus hijos }\end{array}$ \\
\hline Intervención & Tomas de pecho nocturnas a demanda \\
\hline Comparación & Restricción de tomas de pecho nocturnas \\
\hline Resultados & $\begin{array}{l}\text { Tasa de lactancia materna exclusiva al alta/a la semana } \\
\text { Tasa de lactancia materna a los 4-6 meses } \\
\text { Tasa de lactancia materna exclusiva a los 4-6 meses } \\
\text { Satisfacción materna } \\
\text { Complicaciones de las mamas (grietas, ingurgitaciones) } \\
\text { Peso del bebé (48-72h.) } \\
\text { Tiempo total de sueño nocturno de los niños y de las madres } \\
\text { (al mes, a los tres meses, antes de los 6 meses y después de } \\
\text { los } 6 \text { meses). }\end{array}$ \\
\hline Tipo de estudio & RS de estudios observacionales o estudios observacionales \\
\hline
\end{tabular}

\section{2- INTRODUCCIÓN}

Suele insistirse en la importancia de las tomas nocturnas debido a que, al producir una liberación más importante de prolactina que las tomas diurnas, pueden favorecer una mayor producción de leche. Dado que muchas mujeres encuentran agotador amamantar varias veces por la noche y que la fatiga y el desánimo materno son perjudiciales para el éxito de la lactancia, interesa conocer hasta que punto esta recomendación está justificada. 


\section{ESTRATEGIA DE ELABORACIÓN DE LA PREGUNTA}

3.1. GPC Base

Tabla 2- Resumen de GPC Base

\begin{tabular}{|c|c|c|c|c|}
\hline $\begin{array}{l}\text { Guía } \\
\text { (Enfoque) }\end{array}$ & $\begin{array}{l}\text { Resumen sobre la evidencia } \\
\text { (Calidad de la evidencia) }\end{array}$ & $\begin{array}{l}\text { Recomendaciones } \\
\text { (Grado) }\end{array}$ & $\begin{array}{l}\text { Referencias bibliográficas } \\
\text { (Tipo de publicación) }\end{array}$ & Comentarios \\
\hline $\begin{array}{l}\text { NICE_2006 } \\
\text { (Actualiz. } \\
\text { 2011) }\end{array}$ & $\begin{array}{l}\text { Birth to Five (Department of Health. 2005) recomienda que } \\
\text { las mujeres alimenten a sus hijos con la frecuencia y el } \\
\text { tiempo que el niño quiera. Las tomas frecuentes, incluyendo } \\
\text { las tomas nocturnas, estimulan la producción de leche. }\end{array}$ & & - & \\
\hline $\begin{array}{l}\text { Perinatal } \\
\text { Services BC } \\
2011\end{array}$ & $\begin{array}{l}\text { De } 2 \text { a } 24 \text { horas: } \\
\text { Alimentar al niño de forma frecuente, mínimo unas } 5 \text { veces } \\
\text { durante las primeras } 24 \text { horas (38), para prevenir la } \\
\text { hipoglucemia en el niño, acelerar la producción de leche } \\
\text { materna, asegurar el drenaje de la leche, prevenir la } \\
\text { distensión e ingurgitación mamaria (61) y estimular la } \\
\text { evacuación y el peristaltismo digestivo del niño (38). } \\
\text { Recomendar las tomas nocturnas. } \\
\text { De } 72 \text { horas a } 7 \text { días y más: } \\
\text { Valorar el conocimiento y revisar o informar según las } \\
\text { necesidades sobre: los patrones de lactancia una vez que } \\
\text { ya se ha establecida la lactancia; tomas agrupadas (cluster } \\
\text { feeding); irritabilidad del niño (infant fussiness); la necesidad } \\
\text { de amamantar durante la noche; hidratación; los recursos } \\
\text { de la comunidad y los retos de la lactancia. }\end{array}$ & & $\begin{array}{l}\text { 38. Riordan J \& Wambarch, K. } \\
\text { (2010). Breastfeeding and } \\
\text { human lactation (4th Ed.). } \\
\text { Boston: Jones and Bartlett } \\
\text { Publishers. } \\
\text { 61. de Carvalho M, Robertson } \\
\text { S, Merkatz R, Klaus M.. } \\
\text { (1982). Milk intake and } \\
\text { frequency of feeding in } \\
\text { breastfed infantis. Early } \\
\text { Human Development } 7 \text { (2), } \\
\text { 155-163. }\end{array}$ & \\
\hline
\end{tabular}




\subsection{Otros documentos}

\begin{tabular}{|c|c|c|c|c|}
\hline $\begin{array}{c}\text { Guía } \\
\text { (Enfoque) }\end{array}$ & $\begin{array}{l}\text { Resumen sobre la evidencia } \\
\text { (Calidad de la evidencia) }\end{array}$ & $\begin{array}{l}\text { Recomendaciones } \\
\text { (Grado) }\end{array}$ & $\begin{array}{l}\text { Referencias bibliográficas } \\
\text { (Tipo de publicación) }\end{array}$ & Comentarios \\
\hline $\begin{array}{l}\text { Iniciativa IHAN } \\
\text { (De las guías } \\
\text { detalladas } \\
\text { para los } \\
\text { hospitales y } \\
\text { para los } \\
\text { centros de } \\
\text { salud). }\end{array}$ & $\begin{array}{l}\text { Todas las madres deben poder discutir y recibir información } \\
\text { individualizada sobre el manejo de las tomas nocturnas y } \\
\text { sobre que el hecho de administrar suplementos no favorece } \\
\text { el sueño del bebé. } \\
\text { Las tomas nocturnas y el descanso de la madre y el bebé } \\
\text { son un motivo frecuente de preocupación. Muchas madres y } \\
\text { familias piensan que ofreciendo biberones al bebé por la } \\
\text { noche el descanso nocturno se hace más fácil, a pesar de } \\
\text { que hay estudios que demuestran mayor número de horas } \\
\text { de sueño en los padres (madre y padre) de lactantes } \\
\text { amamantados durante el primer año. } \\
\text { Es importante que los profesionales ofrezcan a la madre } \\
\text { información y apoyo para el manejo de las tomas nocturnas } \\
\text { sin ofrecer sucedáneos, ya que esta práctica conlleva el } \\
\text { riesgo de dificultades con la lactancia durante el día y } \\
\text { aumenta el riesgo de enfermedades infantiles. } \\
\text { Esto debe incluir información sobre la importancia del } \\
\text { amamantamiento nocturno y sobre cómo amamantar al } \\
\text { bebé, tumbada en la cama. } \\
\text { Para el manejo de las tomas nocturnas: } \\
\text { - Es preferible que duerma en la misma habitación que } \\
\text { los padres al menos durante el primer año } \\
\text { - El colecho favorece la lactancia materna y el descanso } \\
\text { nocturno de los padres, siempre que se sigan las } \\
\text { normas de seguridad para practicarlo y las situaciones } \\
\text { en las que está contraindicado. } \\
\text { Dado que es común que la madre sienta sueño durante } \\
\text { estos momentos, debe hacerse hincapié en cómo hacer un } \\
\text { colecho seguro. El colecho consiste en dormir con el bebé } \\
\text { en la misma cama. Es una práctica que favorece y hace } \\
\text { más fácil el amamantamiento nocturno, y que ha sido } \\
\text { practicado por la mayoría de las madres y padres en algún } \\
\text { momento. Pero el colecho puede no ser una práctica segura } \\
\text { si está contraindicado o si se practica en un entorno no } \\
\text { seguro. Es especialmente útil hacerlo durante la educación } \\
\text { prenatal y al menos una vez, después de nacido el bebé. }\end{array}$ & & & \\
\hline
\end{tabular}




\begin{tabular}{|c|c|c|c|c|}
\hline $\begin{array}{l}\text { Guía } \\
\text { (Enfoque) }\end{array}$ & $\begin{array}{l}\text { Resumen sobre la evidencia } \\
\text { (Calidad de la evidencia) }\end{array}$ & $\begin{array}{l}\text { Recomendaciones } \\
\text { (Grado) }\end{array}$ & $\begin{array}{l}\text { Referencias bibliográficas } \\
\text { (Tipo de publicación) }\end{array}$ & Comentarios \\
\hline & $\begin{array}{l}\text { Es importante que los profesionales hablen con la familia } \\
\text { sobre las contraindicaciones y las precauciones a tomar } \\
\text { durante la práctica del colecho. Puede ser útil utilizar para } \\
\text { ello el documento de OMS/UNICEF. Se debe resaltar que } \\
\text { no se debe dormir con el bebé en un sofá o en un sillón o } \\
\text { rodeados de almohadas y hablar con las familias sobre la } \\
\text { utilidad de las cunas que se pueden adosar al lecho y que } \\
\text { permiten realizar un colecho seguro. }\end{array}$ & & & \\
\hline
\end{tabular}

\subsection{Revisiones sistemáticas}

No se han encontrado revisiones sistemáticas sobre el hecho de no amamantar por la noche y el fracaso de la lactancia materna. Las únicas revisiones que se han encontrado se relacionan con intervenciones en el comportamiento para mejorar el sueño nocturno de niños y padres, pero que no estudian su efecto en el éxito o duración de la lactancia materna exclusiva, como la revisión de Douglas PS et al, 2013(1). 


\subsection{Resumen de GPC base y RS disponibles}

En general, las guías señalan que la lactancia materna debe ser a demanda, y que no hay que olvidarse de la importancia de las tomas nocturnas (2-5).

La estrategia IHAN además hace hincapié en que no se deben ofrecer biberones al niño por la noche para mejorar el descanso nocturno, puesto que además de tener un efecto negativo sobre la lactancia materna, existen estudios que demuestran que los padres de niños amamantados durante el primer año de vida tienen un mayor número de horas de sueño $(4 ; 5)$.

\subsection{Conclusión (marcar con una $\mathrm{X}$ ):}

\begin{tabular}{|l|l|}
\hline & Adopción GPC/Revisión sistemática \\
\hline & Elaboración parcial \\
\hline$X$ & Elaboración de novo \\
\hline
\end{tabular}

\subsection{Diseño de la estrategia de búsqueda de estudios individuales}

\begin{tabular}{|l|l|}
\hline Criterios de selección de estudios & ECA o Estudios observacionales \\
\hline Período de búsqueda & Sin límite- hasta diciembre de 2014 \\
\hline Bases de datos & Cochrane Library \\
& CINAHL, via EBSCOhost databases \\
& EMBASE, via Ovid \\
& MEDLINE, via Pubmed
\end{tabular}

Ver estrategias de búsqueda de estudios originales en el ANEXO I. 


\section{4- Resumen de la evidencia}

\section{Asociación entre frecuencia de tomas nocturnas y duración de la lactancia materna}

El único estudio identificado que describe la asociación entre la frecuencia de tomas nocturnas y la duración de la lactancia materna es el estudio retrospectivo de Radwan $\mathrm{H}, 2013$ (6). En este estudio, con una muestra de conveniencia de 593 madres de niños menores de 2 años, se observó que la cohabitación $(\mathrm{OR}=4,48)$, la lactancia materna a demanda $(O R=2,29)$ y una mayor frecuencia de tomas nocturnas $(p<0,001)$ se asociaban de forma significativa con la duración de lactancia materna (exclusiva o predominante) (6). Se encontró que la realización de entre 4 y 6 tomas nocturnas se asociaba con una duración de la lactancia de 11,7 meses de media, mientras que la no realización de tomas nocturnas se asociaba con una duración media de 6,1 meses. En un estudio reciente (7) se encontró que uno de los factores que se asociaba con el cese de la lactancia materna era la limitación del número de tomas nocturnas por parte de la madre (HR 1,58; IC95\% de 1,11 a 2,23).

En otro estudio (8) se observó que la duración de la lactancia materna exclusiva, o de la lactancia materna en general, se asociaba con una mayor frecuencia de tomas, una mayor duración de la lactancia previa a ésta y un mayor nivel de estudios, aunque no se describe si ésta también se asociaba con una mayor frecuencia de tomas nocturnas.

\section{Patrones de alimentación en lactantes amamantados de forma exclusiva}

Se han encontrado varios estudios que señalan la existencia de dos patrones diferentes de alimentación en lactantes amamantados de forma exclusiva.

En el estudio de Kent et al, 2006, que incluyó 71 diadas con lactancia materna exclusiva a demanda, se observó que los niños de 1 a 6 meses de edad realizaban una media de $11 \pm 3$ tomas en 24 horas (RIC de 6 a 18), y que cada toma suponía una ingesta media de $76 \pm 12,6 \mathrm{~g}$ (RIC de 0 a 240). Los autores observaron que el $64 \%$ de los niños realizaba entre 1 y 3 tomas nocturnas (de $22.00 \mathrm{~h}$ a $04.00 \mathrm{~h}$ ). El número de tomas no difería entre los niños de 4 y 26 semanas de vida y no se encontraron diferencias significativas en la producción de leche durante 24 horas entre los niños que eran amamantados por la noche y los que no. El número de tomas nocturnas era menor que el número de tomas realizado durante cualquier otro intervalo del día (mediana de 1; RIC de 1 a 2), y en aquellos que no hacían tomas nocturnas, las tomas eran más largas durante la mañana que durante el resto del día (9). Resultados similares se describen en el estudio de Butte et al 1985, en el que se incluyen 45 niños amamantados de forma exclusiva y a demanda durante los cuatro primeros meses de vida. En este estudio se describen dos patrones principales de alimentación: uno en el que las tomas se distribuyen a lo largo de las $24 \mathrm{~h}$ del día y otro en el que el niño no realiza tomas entre las $00.00 \mathrm{~h}$ y las 06.00h. En este último grupo, el porcentaje de ingesta de leche durante las $06.00 \mathrm{~h}$ y las $12.00 \mathrm{~h}$ es del $41 \%$ del total, en comparación al $26 \%$ 
registrado en el grupo que sí realiza tomas nocturnas. En ningún caso se encontraron diferencias significativas en la ingesta total de leche $(\mathrm{g} / 24 \mathrm{~h})$ durante los primeros cuatro meses o entre ambos patrones de alimentación.

Por otro lado, en un estudio realizado en Suecia con 506 madres con experiencia previa en lactancia materna, se observó que sólo un $2 \%$ de los niños no hacían tomas nocturnas(8). El número de tomas era muy variable, y la mediana de tomas nocturnas disminuía con el tiempo, siendo ésta de 2,2 tomas (RIC 1 a 5,1 ) a las 2 semanas y de 1,8 tomas (RIC de 0 a 4) a las 20 semanas de vida. El porcentaje de niños que hacía de media entre 1 y 2,9 tomas nocturnas era del $85 \%$ a las 2 semanas, del $81 \%$ a las 4 y del $73 \%$ a las 12 y 20 semanas de vida.

En otro estudio longitudinal posterior (10), en el que se incluyeron 52 mujeres caucásicas que amamantaban de forma exclusiva, los autores observaron que la frecuencia de las tomas disminuía entre los meses 1 y 3 , así como el volumen ingerido en cada toma. Estos parámetros se mantenían constantes entre el $3^{\text {er }}$ y $6^{\circ}$ mes de vida, y aunque la duración de cada toma disminuía constantemente entre el primer y sexto mes, la ingesta total de 24 horas permanecía constante (10).

3. Influencia del uso de fórmula durante la noche en niños amamantados y sobre el sueño nocturno

En un estudio reciente (11), en el que se realizaron encuestas a 94 madres de niños de 2 a $\mathbf{4}$ meses de edad, se encontró que los lactantes amamantados de forma exclusiva tenían una incidencia más baja de cólicos $(p=0,04)$, menor severidad de los episodios de irritabilidad $(p=0,03)$ y una tendencia a dormir más tiempo por la noche $(p=0,06)$ que los no amamantados de forma exclusiva.

El estudio de Montgomery-Downs HE et al, 2010 (12) no encuentra ninguna diferencia objetiva 0 subjetiva, 0 diferencias en la somnolencia/fatiga entre mujeres que utilizaban diferentes métodos de alimentación en las primeras 12 semanas de vida del lactante.

En el estudio longitudinal más reciente (13), en el que se incluyen 120 madres primerizas de bajos ingresos y de diversas etnias se observa que las madres que amamantaban de forma exclusiva al mes dormían $30 \mathrm{~min}$ más de media por la noche que las que utilizaban algo de fórmula durante la noche $(386 \pm 66 \mathrm{~min}$ de sueño nocturno y $356 \pm 67 \mathrm{~min}$, respectivamente), aunque en un estudio anterior(14) se encontró que el tipo de alimentación no se relacionaba con un mayor tiempo de sueño nocturno o diurno de la madre al mes postparto, aunque el porcentaje de tiempo que la madres estaba despierta frente al tiempo en la cama tras dormirse era mayor en las que amamantaban de forma exclusiva.

En el estudio transversal de Dorheim (15) se encontró que a las 8 semanas postparto la calidad global del sueño de las madres que amamantaban era mayor que la de las que proporcionaban lactancia mixta, pero no mayor que la de las madres que no amamantaban.

En otro estudio de 2007 (16), en el que se comparaban los patrones de sueño y alimentación a los tres meses postparto de 133 madres y 
padres primerizos, se encontró que las madres que amamantaban de forma exclusiva a sus hijos durante las 48 horas del período de monitorización dormían 40 min más de media $(7,2 \mathrm{~h} \pm 1,3$ horas) que las madres que utilizaban suplementos $(6,4 \pm 1,3 \mathrm{~h})$, sin encontrar diferencias significativas para los padres. Asimismo, las madres que amamantaban a sus hijos durante la noche (de 00.00h a 06.00h) dormían 47 min más que las mujeres que les daban algo de fórmula por la noche, algo que también ocurría con los padres, que dormían 38 min más.

En el estudio retrospectivo de Galbally $M$ et al 2013 (17), con 4507 madres de niños amamantados hasta los 6 meses de vida, se señala que cuando el niño es amamantado de forma exclusiva es un $66 \%$ más probable que éste despierte durante la noche y un $72 \%$ más probable que tenga dificultades para dormir solo. Sin embargo, también se describe que la lactancia materna tuvo un fuerte efecto protector sobre la presencia de sibilancias, tos, ronquidos y problemas respiratorios en los niños y que ésta no se asociaba con un sueño no reparador o problemas del niño para dormirse.

Otro estudio longitudinal en el que se incluyeron 1200 lactantes encontró resultados similares. Los autores encontraron dos patrones de sueño diferentes: los Durmientes o Sleepers (66\% de los niños) y los Durmientes transitorios o Transient sleepers (34\% de los niños), que eran aquellos que presentaban despertares nocturnos 7 noches por semana a los 6 meses, 2 noches a los 15 meses y 1 noche a los 24 meses de vida. Los durmientes transitorios tenían mayor probabilidad de tener un temperamento difícil a los 6 meses, de ser amamantados a los 6 y 15 meses y de que las madres estuvieran más deprimidas a los 6 meses de vida (18).

En el estudio de Demirci (19), que incluía madres de niños de entre 6 y 11 meses de edad, encontró que la duración del sueño del niño, tanto el diurno como el nocturno y el total, era similar entre niños amamantados y no amamantados, y en cuanto a la duración del sueño de las madres, la mayoría reportaban no dormir todo lo que necesitaban. El $40 \%$ reportaba dormir menos o 6 horas por la noche y había diferencias significativas en el tiempo de sueño nocturno entre las que amamantaban y las que no $(6,76 \pm 1,31 \mathrm{~h}$ vs $6,42 \pm 1,18 \mathrm{~h} ; \mathrm{p}=0,224)$, aunque éstas sí se despertaban más veces por la noche $(1,13 \pm 0,17$ vs. $0,90 \pm 0,15$; $p=0,024)$.

4) Intervenciones para mejorar el sueño nocturno de madres y niños amamantados de forma exclusiva

En una revisión reciente de estudios publicados entre 1993 y 2013 que evalúan el efecto de intervenciones conductuales para mejorar los problemas de sueño en los primeros 6 meses de vida, se señala que los estudios no han demostrado que dichas intervenciones disminuyan el llanto, prevengan problemas de conducta y de sueño en el niño y la depresión postnatal. La revisión no describe si los estudios incluían niños alimentados con lactancia materna, con fórmula o ambos. Asimismo, los autores señalan que estas intervenciones pueden producir resultados no intencionados, como mayores problemas de sueño, el cese prematuro de la lactancia y mayor ansiedad para la madre (1).

En un estudio anterior aleatorizado no incluido en dicha revisión (20), en 
el que se evalúa el efecto de una intervención en lactantes amamantados de forma exclusiva, sí se encuentra un efecto. La intervención en estudio consistía en una serie de pautas que los padres debían seguir para ayudar a sus hijos a dormir desde la medianoche hasta las 5 de la mañana, junto con una toma de leche materna o "focal feed" entre las $22 \mathrm{~h}$ y la medianoche. El estudio incluyó 33 díadas, y se observó que tras la $4^{a}$ semana de vida el efecto de la intervención fue significativo, independientemente de haber realizado o no el "focal feed" $(p<0,05)$. Se observó que una proporción importante de los padres del grupo intervención no siguieron las instrucciones del focal feed, y en el grupo control hubo díadas en las que ésta se ofreció de forma espontánea. Así, al analizar el efecto de hacer o no un "focal feed", se observó que no era suficiente para modificar el estatus de sueño del niño.

A las 8 semanas de vida, el $100 \%$ de los niños del grupo de la intervención dormía durante toda la noche (desde la medianoche hasta las 5 de la mañana) en comparación al $23 \%$ del grupo control. Asimismo, aunque los niños del grupo tratamiento eran alimentados de forma menos frecuente durante la noche, estos lo compensaban con un mayor consumo de leche durante la mañana temprano, por lo que el volumen de leche consumido durante 24 horas no difería entre los dos grupos. Lo que el estudio no describe es si la intervención afecta a la duración de la lactancia materna.

ACTUALIZADO A FECHA DE: 31 de Octubre de 2016 


\section{5- De la evidencia a la recomendación (Tabla de EtR)}

\section{¿Cómo afecta la restricción de las tomas de pecho nocturnas en la instauración y duración de la lactancia materna?}

Población: Madres de recién nacidos sanos a término que amamantan y sus hijos

Intervención: Realizar tomas nocturnas

Comparación: No realizar tomas nocturnas

Perspectiva: Clínica

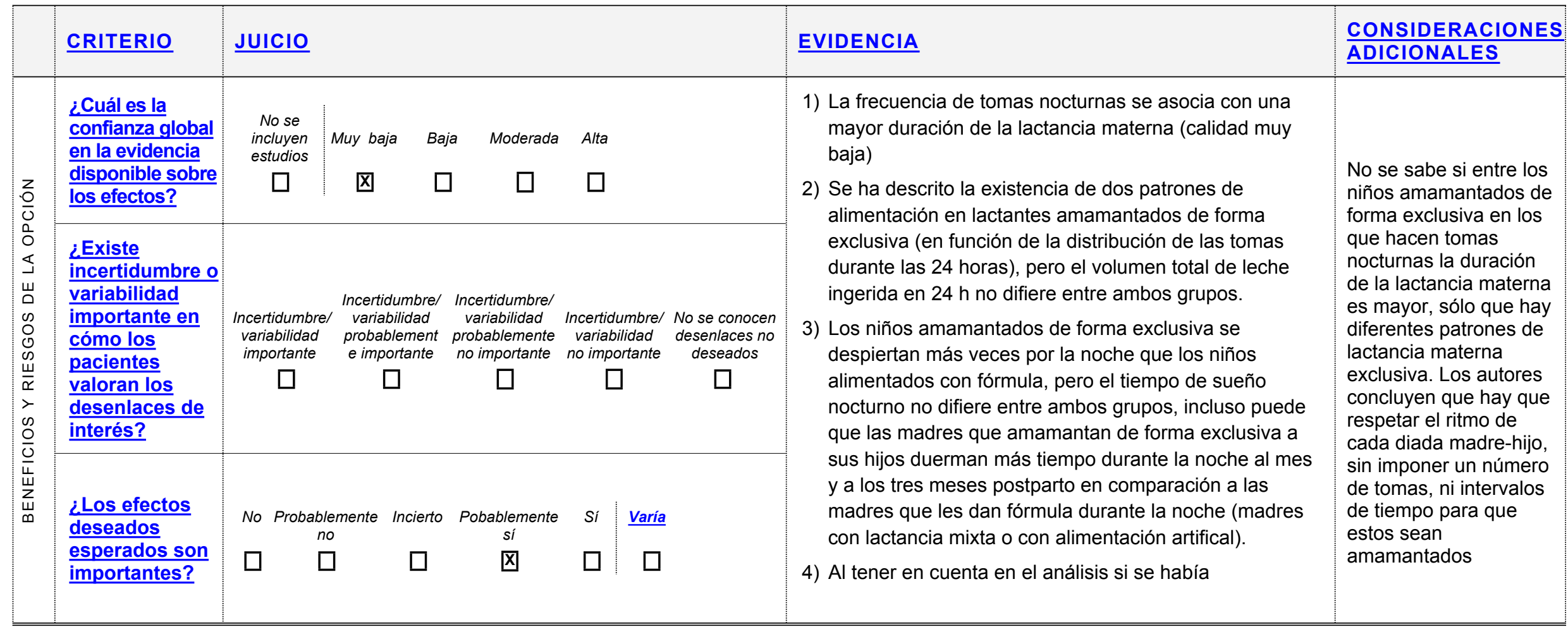




\begin{tabular}{|c|c|c|c|c|c|c|c|}
\hline CRITERIO & JUICIO & & & & & EVIDENCIA & $\begin{array}{l}\text { CONSIDERACIONES } \\
\text { ADICIONALES }\end{array}$ \\
\hline $\begin{array}{l}\text { LLos efectos } \\
\text { no deseados } \\
\text { esperados } \\
\text { son } \\
\text { pequeños? }\end{array}$ & $\begin{array}{l}\text { No Probablemente } \\
\text { no } \\
\square \quad \square\end{array}$ & $\begin{array}{c}\text { Incierto } \\
\square\end{array}$ & $\begin{array}{c}\text { Pobablemente } \\
\text { si } \\
\text { 冈 }\end{array}$ & $\square$ & $\frac{\text { Varía }}{\square}$ & $\begin{array}{l}\text { amamantado al niño hasta quedarse dormido, la } \\
\text { diferencia en el número de despertares nocturnos entre } \\
\text { los amamantados y los alimentados con fórmula dejaba } \\
\text { de ser significativa. }\end{array}$ & \\
\hline
\end{tabular}




\section{¿Cómo afecta la restricción de las tomas de pecho nocturnas en la instauración y duración de la lactancia materna?}

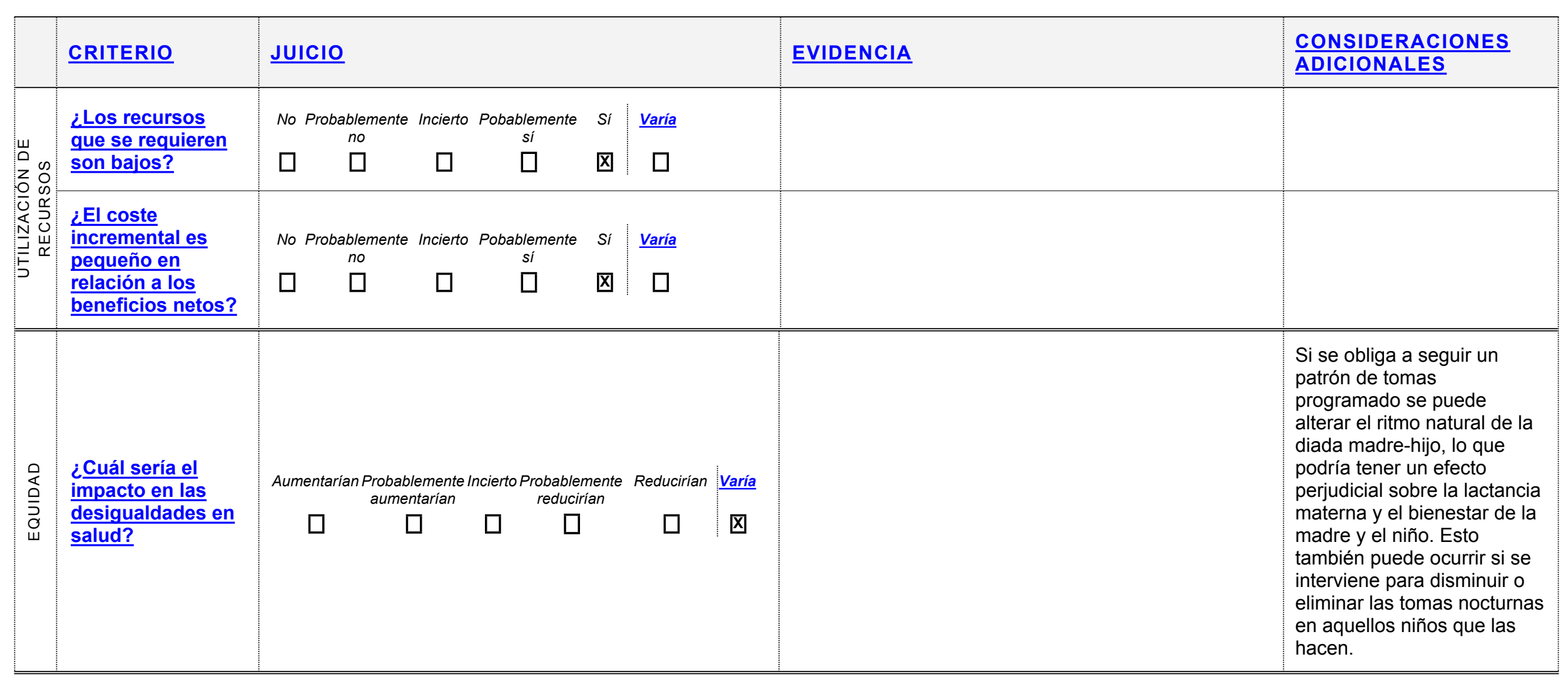




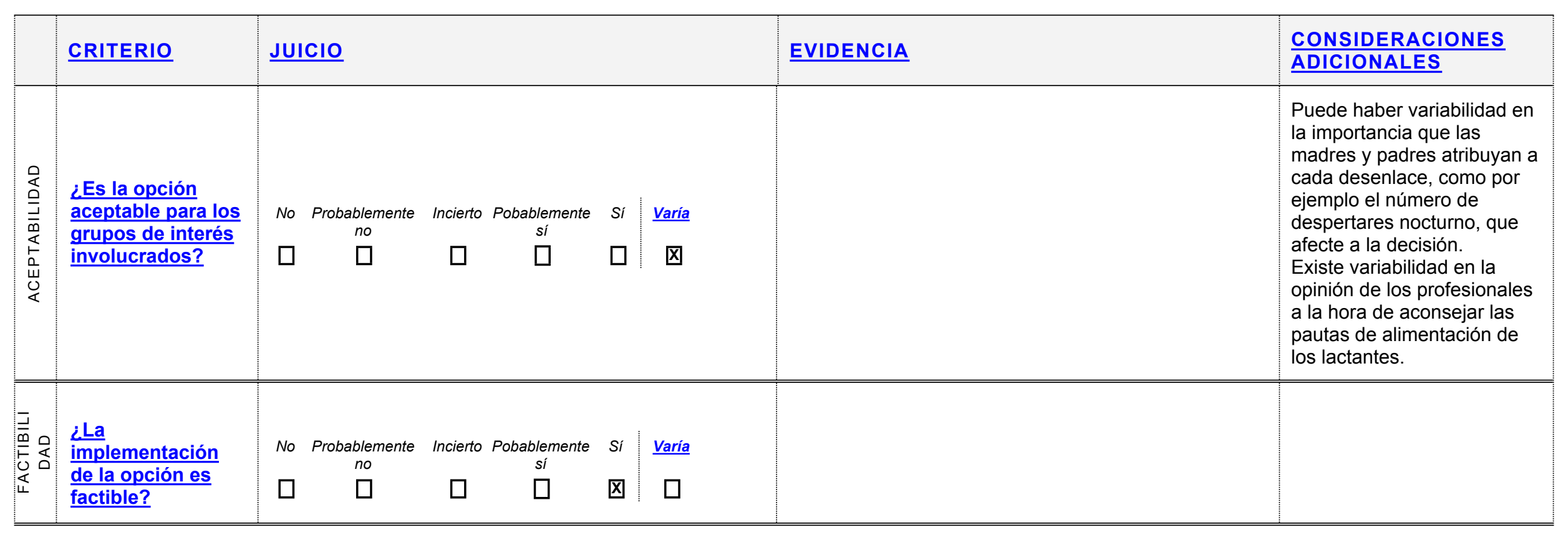

\begin{tabular}{|c|c|c|c|c|c|}
\hline $\begin{array}{l}\text { Balance de las } \\
\text { consecuencias } \\
\end{array}$ & $\begin{array}{l}\text { Las consecuencias no } \\
\text { deseadas superan } \\
\text { claramente las } \\
\text { consecuencias deseadas } \\
\text { en la mayoría de los } \\
\text { escenarios }\end{array}$ & $\begin{array}{l}\text { Las consecuencias no } \\
\text { deseadas probablemente } \\
\text { superan las } \\
\text { consecuencias deseadas } \\
\text { en la mayoría de los } \\
\text { escenarios }\end{array}$ & $\begin{array}{l}\text { El balance entre las } \\
\text { consecuencias deseadas y } \\
\text { no deseadas está muy } \\
\text { equilibrado o es incierto }\end{array}$ & $\begin{array}{l}\text { Las consecuencias } \\
\text { deseadas } \\
\text { probablemente superan } \\
\text { las consecuencias no } \\
\text { deseadas en la mayoría } \\
\text { de los escenarios }\end{array}$ & $\begin{array}{c}\text { Las consecuencias } \\
\text { deseadas claramente } \\
\text { superan las } \\
\text { consecuencias no } \\
\text { deseadas en la mayoría } \\
\text { de los escenarios }\end{array}$ \\
\hline & $\square$ & 囚 & $\square$ & $\square$ & $\square$ \\
\hline
\end{tabular}


Recomendación (Texto)

Justificación

$\checkmark$ La lactancia materna debería ser a demanda para todos los lactantes sanos, respetando el ritmo nocturno del bebé.

Los estudios señalan que existe asociación entre la duración de la lactancia materna y la frecuencia de tomas nocturnas, auque también se ha descrito que no todos los niños amamantados de forma exclusiva realizan tomas nocturnas, sin que esto suponga que existan diferencias en el volumen de leche ingerido entre los niños que hacen tomas nocturnas y los que no. En relación al sueño, se ha descrito que las madres que amamantan de forma exclusiva a sus hijos, tanto al mes como a los tres meses de edad, duermen incluso más tiempo que las que utilizan algo de fórmula por la noche o alimentan a su hijo de forma artificial, aunque también se ha visto que entre los niños alimentados con fórmula y los amamantados de forma exclusiva, la asimetría día-noche se observa por primera vez a las 6 semanas de vida. Por lo tanto, la conclusión a la que se llega es que mientras el niño esté sano y su evolución sea normal, se debería seguir el ritmo de alimentación que cada niño demanda.

Consideraciones de subgrupos

Se han descrito diferentes patrones de alimentación en niños sanos amamantados de forma exclusiva. No todos los niños sanos amamantados requieren realizar tomas nocturnas. Por eso, tampoco se debería "despertar" al niño durante la noche para que las realice, sino seguir su ritmo y realizar las tomas a demanda. Consideraciones para Para facilitar a los padres el manejo de las tomas nocturnas se debería recomendar la cohabitación y dar información sobre el la implementación colecho seguro.

\section{Monitorización y}

evaluación

\section{Prioridades para la} investigación
Se necesitan estudios prospectivos que describan si la duración de la lactancia materna exclusiva es mayor en los niños sanos amamantados que hacen tomas nocturnas que en los niños que no las hacen. 


\section{ANEXO I, ESTRATEGIAS DE BÚSQUEDA}

\section{Cochrane Library}

Searched 09/12/2014

Updated search 09/12/2014 a xx/xx/xxxx

\#1 breastfeeding or "breast feeding" or lactation:ti,ab,kw and night or "night feeding" or "night feedings" or "night feeds" or "night feed":ti,ab,kw (Word variations have been searched) $\mathbf{3 0}$

\section{MEDLINE, via Pubmed}

\section{Searched 09/12/2014}

Updated search 09/12/2014 a xx/xx/xxxx

\#1 (breastfeeding[Title/Abstract] OR "breast feeding"[Title/Abstract] OR

lactation[Title/Abstract]) 49587

\#2 (night[Title/Abstract] OR "night feeding"[Title/Abstract] OR "night feedings"OR "night feed"[Title/Abstract] OR "night feeds"[Title/Abstract]) 47004

\#3 \#1 and \#2 318

\section{EMBASE, via Ovid}

\section{Searched 09/12/2014}

Updated search 09/12/2014 a xx/xx/xxxx

\#1 (breastfeeding or "breast feeding" or lactation).ti,ab,kw. 56175

\#2 (night or "night feeding" or "night feedings" or "night feed" or "night feeds").ti,ab,kw. 63603

\#3 \#1 AND \#2 345

\section{CINAHL, via EBSCOhost databases}

Searched 09/12/2014

Updated search 09/12/2014 a xx/xx/xxxx

S1 ( breastfeeding or breast feeding or breast-feeding) OR lactation 92734

S2 night OR "night feeding" OR "night feedings" OR "night feeds" OR "night feed

S3 S1 AND S2 504

Cinahl 78 


\section{1- BIBLIOGRAFÍA}

(1) Douglas PS, Hill PS. Behavioral sleep interventions in the first six months of life do not improve outcomes for mothers or infants: a systematic review. J Dev Behav Pediatr 2013 Sep;34(7):497-507.

(2) NICE. Postnatal care up to 8 weeks after birth. Julio 2006 (actualizado en Febrero de 2015). Disponible en: http://guidance.nice.org.uk/CG37.

(3) Perinatal Services BC. Health Promotion Guideline 1. Safe Sleep Environment Guideline For Infants 0 to 12 months of age. 2011.

(4) IHAN. Hospitales IHAN. Guía detallada para la aplicación paso por paso. Disponible en: https://www.ihan.es/docs/documentacionacreditacion/hospitales/generales/00.Guia_detallada_hospital.pdf.

(5) IHAN. Guía detallada para la aplicación paso por paso. Centros de Salud IHAN. Disponible en: https://www.ihan.es/docs/documentacionacreditacion/centros salud/Manual para la acreditacion IHAN en AP 2015. pdf.

(6) Radwan $\mathrm{H}$. Patterns and determinants of breastfeeding and complementary feeding practices of Emirati Mothers in the United Arab Emirates. BMC Public Health 2013;13:171.

(7) Vieira TO, Vieira GO, de Oliveira NF, Mendes CM, Giugliani ER, Silva LR. Duration of exclusive breastfeeding in a Brazilian population: new determinants in a cohort study. BMC Pregnancy Childbirth 2014;14:175.

(8) Hornell A, Aarts C, Kylberg E, Hofvander Y, Gebre-Medhin M. Breastfeeding patterns in exclusively breastfed infants: a longitudinal prospective study in Uppsala, Sweden. Acta Paediatr 1999 Feb;88(2):203-11.

(9) Kent JC, Mitoulas LR, Cregan MD, Ramsay DT, Doherty DA, Hartmann PE. Volume and frequency of breastfeedings and fat content of breast milk throughout the day. Pediatrics 2006 Mar;117(3):e387-e395.

(10) Kent JC, Hepworth AR, Sherriff JL, Cox DB, Mitoulas LR, Hartmann PE. Longitudinal changes in breastfeeding patterns from 1 to 6 months of lactation. Breastfeed Med 2013 Aug;8(4):401-7.

(11) Cohen EA, Hadash A, Shehadeh N, Pillar G. Breastfeeding may improve nocturnal sleep and reduce infantile colic: potential role of breast milk melatonin. Eur J Pediatr 2012 Apr;171(4):729-32.

(12) Montgomery-Downs HE, Clawges HM, Santy EE. Infant feeding methods and maternal sleep and daytime functioning. Pediatrics 2010 Dec;126(6):e1562e1568.

(13) Doan T, Gay CL, Kennedy HP, Newman J, Lee KA. Nighttime breastfeeding behavior is associated with more nocturnal sleep among first-time mothers at one month postpartum. J Clin Sleep Med 2014 Mar 15;10(3):313-9.

(14) Gay CL, Lee KA, Lee SY. Sleep patterns and fatigue in new mothers and fathers. Biol Res Nurs 2004 Apr;5(4):311-8.

(15) Dorheim SK, Bondevik GT, Eberhard-Gran M, Bjorvatn B. Sleep and depression in postpartum women: a population-based study. Sleep 2009 Jul;32(7):847-55. 
(16) Doan T, Gardiner A, Gay CL, Lee KA. Breast-feeding increases sleep duration of new parents. J Perinat Neonatal Nurs 2007 Jul;21(3):200-6.

(17) Galbally M, Lewis AJ, McEgan K, Scalzo K, Islam FA. Breastfeeding and infant sleep patterns: an Australian population study. J Paediatr Child Health 2013 Feb;49(2):E147-E152.

(18) Weinraub M, Bender RH, Friedman SL, Susman EJ, Knoke B, Bradley R, et al. Patterns of developmental change in infants' nighttime sleep awakenings from 6 through 36 months of age. Dev Psychol 2012 Nov;48(6):1511-28.

(19) Demirci JR, Braxter BJ, Chasens ER. Breastfeeding and short sleep duration in mothers and 6-11-month-old infants. Infant Behav Dev 2012 Dec;35(4):884-6.

(20) Pinilla T, Birch LL. Help me make it through the night: behavioral entrainment of breast-fed infants' sleep patterns. Pediatrics 1993 Feb;91(2):436-44. 


\section{PREGUNTA CLÍNICA No 7}

¿Se debería evitar el uso de chupete en las primeras semanas para favorecer la instauración de la lactancia materna?

1- Pregunta clínica en formato PICO

Tabla 1- Componentes de la pregunta clínica en formato PICO

\begin{tabular}{|l|l|}
\hline Pacientes & $\begin{array}{l}\text { Recién nacido lactante desde el nacimiento hasta las } \\
\text { primeras semanas }\end{array}$ \\
\hline Intervención & $\begin{array}{l}\text { Utilización de chupete en la maternidad /tras el alta } \\
\text { hospitalaria }\end{array}$ \\
\hline Comparación & $\begin{array}{l}\text { No utilización del chupete en la maternidad/ tras el alta } \\
\text { hospitalaria }\end{array}$ \\
\hline Resultados & $\begin{array}{l}\text { Tasa de lactancia materna exclusiva al alta } \\
\text { Tasa de lactancia materna exclusiva al mes } \\
\text { Tasa de lactancia materna a los 4 meses } \\
\text { Tasa de lactancia materna exclusiva a los 4 meses } \\
\text { Satisfacción materna } \\
\text { Complicaciones de las mamas (grietas, ingurgitaciones) } \\
\text { Pérdida ponderal del bebé (48-72h.) } \\
\text { Hipoglucemias } \\
\text { Frecuencia de tomas } \\
\text { Riesgo de muerte súbita (SIDS) }\end{array}$ \\
\hline Tipo de estudio & $\begin{array}{l}\text { RS de ECA, ECA, RS de estudios observacionales o } \\
\text { estudios observacionales }\end{array}$ \\
\hline
\end{tabular}

\section{2- Introducción}

Para iniciar y mantener la lactancia materna, la OMS y UNICEF, en el paso 9 de la IHAN, recomiendan no dar a los niños alimentados al pecho chupetes ni tetinas artificiales, ya que pueden interferir con la lactancia materna al producir confusión en la succión y hacer que el niño mame menos veces. Por otra parte, algunos estudios han observado un posible efecto protector del uso del chupete frente al riesgo de síndrome de muerte súbita del lactante.

Dado que en nuestra sociedad el uso del chupete está muy arraigado y que las recomendaciones publicadas son contradictorias, se hace necesario conocer si su uso durante las primeras semanas influye en la instauración de la lactancia materna. 


\section{ESTRATEGIA DE ELABORACIÓN DE LA PREGUNTA}

\subsection{GPC Base}

Tabla 2- Resumen de GPC Base

\begin{tabular}{|c|c|c|c|c|}
\hline $\begin{array}{c}\text { Guía } \\
\text { (Enfoque) }\end{array}$ & $\begin{array}{l}\text { Resumen sobre la evidencia } \\
\text { (Calidad de la evidencia) }\end{array}$ & $\begin{array}{l}\text { Recomendaciones } \\
\text { (Grado) }\end{array}$ & $\begin{array}{l}\text { Referencias bibliográficas } \\
\text { (Tipo de publicación) }\end{array}$ & Comentarios \\
\hline $\begin{array}{l}\text { NICE_2006 } \\
\text { (1) }\end{array}$ & $\begin{array}{l}\text { Eficacia: } \\
\text { Una revisión sistemática del } 2011 \text {, evalúa el efecto del } \\
\text { uso del chupete frente a su restricción en la duración de } \\
\text { la lactancia y otros resultados. No se observaron } \\
\text { diferencias en la prevalencia o duración de la lactancia } \\
\text { exclusiva o parcial. [1++]. } \\
\text { La evidencia existente puntualiza el no efecto del uso del } \\
\text { chupete en la duración de la lactancia materna [1++]. } \\
\text { Aunque su uso durante el período neonatal fue en } \\
\text { detrimento de la lactancia materna exclusiva y general, } \\
\text { OR } 1,5 \text { (IC 1,0-2,0). (Howard, CR, 2003) } \\
\text { Seguridad: Reducción del riesgo de Síndrome de muerte } \\
\text { súbita del lactante. (SMSL) } \\
\text { La conclusión de una RS (119) sobre intervenciones } \\
\text { para reducir el riesgo de SMSL fue la de evitar dormir } \\
\text { boca abajo, la exposición al tabaco sin humo, superficies } \\
\text { blandas para dormir, sobrecalentamiento o envolver y } \\
\text { compartir la cama, y para fomentar la lactancia materna, } \\
\text { el promover el uso chupete y promover compartir la } \\
\text { habitación (sin compartir la cama) } \\
\text { En el análisis multivariante de un estudio casos-control } \\
\text { se observó una relación inversa entre el uso de chupete } \\
\text { OR 0,38 (0,21-0,.70) y la muerte súbita (Fleming P.J } \\
\text { 1996) } \\
\text { Un cambio en el comportamiento del uso habitual de } \\
\text { chupete podría ser un factor de riesgo de SMSL [2+] } \\
\text { (Fleming P.J 1999) } \\
\text { El estudio SUDI (Fleming P.J). La proporción de } \\
\text { lactantes que utilizaron alguna vez chupete para dormir }\end{array}$ & $\begin{array}{l}\text { - BFHI: paso 9: No dar a los niños alimentados } \\
\text { al pecho tetinas o chupetes artificiales. } \\
\text { Seguridad } \\
\text { Debería advertirse a las madres que si un bebé } \\
\text { está acostumbrado a usar el chupete mientras } \\
\text { duerme, no se debe suspender repentinamente } \\
\text { durante las primeras } 26 \text { semanas. [B] } \\
\text { Las recomendaciones para promover el uso } \\
\text { chupete para reducir el riesgo de SMSL son } \\
\text { relativamente nuevas, y se limitan a unos pocos } \\
\text { países (Estados Unidos, los Países Bajos y } \\
\text { Alemania). [26] [51] [54]. Ningún estudio ha } \\
\text { evaluado el resultado de estas campañas, o } \\
\text { cualquier evidencia de daños del uso de } \\
\text { chupete trá las campañas. } \\
\text { Se necesitan más pruebas y estudios en esta } \\
\text { área. }\end{array}$ & $\begin{array}{l}\text { Eficacia : } \\
\text { 71. Jaafar SH, Jahanfar S, Angolkar M } \\
\text { et al. (2011) Pacifier use versus no } \\
\text { pacifier use in breastfeeding term } \\
\text { infants for increasing duration of } \\
\text { breastfeeding. [Review]. Cochrane } \\
\text { Database of Systematic Reviews } \\
\text { 3:CD007202. } \\
\text { Howard, CR, Howard, FM, Lanphear, } \\
\text { Bet al. (2003). Randomized clinical } \\
\text { trial of pacifier use and bottle-feeding } \\
\text { or cup feeding and their effect on } \\
\text { breastfeeding. Pediatrics 111(3), 511- } \\
\text { 518. } \\
\\
\text { Seguridad: } \\
\text { 119. Hauck FR and Tanabe KO. (5-6- } \\
\text { 2009) Sids. Clinical Evidence 2009. } \\
\text { 26. Hauck FR, Omojokun OO, Siadaty } \\
\text { MS. Do pacifiers reduce the risk of } \\
\text { sudden infant death syndrome? A } \\
\text { meta-analysis. Pediatrics } \\
\text { 2005;116:e716-e723. } \\
\text { 51. American Academy of Pediatrics } \\
\text { Task Force on Sudden Infant Death } \\
\text { Syndrome. The changing concept of } \\
\text { sudden infant death syndrome: } \\
\text { diagnostic coding shifts, controversies } \\
\text { regarding the sleeping environment, } \\
\text { and new variables to consider in } \\
\text { reducing risk. Pediatrics } \\
\text { 2005;116:1245-1255. }\end{array}$ & \\
\hline
\end{tabular}




\begin{tabular}{|c|c|c|c|c|}
\hline $\begin{array}{c}\text { Guía } \\
\text { (Enfoque) }\end{array}$ & $\begin{array}{l}\text { Resumen sobre la evidencia } \\
\text { (Calidad de la evidencia) }\end{array}$ & $\begin{array}{l}\text { Recomendaciones } \\
\text { (Grado) }\end{array}$ & $\begin{array}{l}\text { Referencias bibliográficas } \\
\text { (Tipo de publicación) }\end{array}$ & Comentarios \\
\hline & $\begin{array}{l}\text { de día o de noche fue exactamente el mismo ( } 66 \%, \text { ) pero } \\
\text { significativamente menos lactantes con SMSL utilizaron } \\
\text { el chupete en el último sueño OR } 0.41(0,22-0,77) \text {, } \\
\text { ofreciendo un aparente efecto protector al SMSL. } \\
\\
\text { En el análisis multivariante la utilización de posición } \\
\text { prono (OR } 11,47 ; 1,24-106,06) \text {, el colecho (OR 16,47; } \\
3,73-72,75) \text { y la ausencia de uso rutinario de chupete } \\
\text { (OR } 5, .86 ; 2,37-14,36 \text { ) se relacionaron estadísticamente } \\
\text { con los casos de SMSL.( McGarvey, C, 2003) }\end{array}$ & & $\begin{array}{l}\text { 54. L'Hoir MP, Engelberts AC, van } \\
\text { Well GT, et al. Dummy use, thumb } \\
\text { sucking, mouth breathing and cot } \\
\text { death. Eur J Pediatr 1999;158:896- } \\
\text { 901. } \\
\text { Fleming, P. J., Blair, P. S., Bacon, C., } \\
\text { et al. 1996, "Environment of infants } \\
\text { during sleep and risk of the sudden } \\
\text { infant death syndrome: results of } \\
\text { 1993-5 case-control study for } \\
\text { confidential inquiry into stillbirths and } \\
\text { deaths in infancy. Confidential Enquiry } \\
\text { into Stilllibiths and Deaths Regional } \\
\text { Coordinators and Researchers.", BMJ, } \\
\text { vol. 313, } \\
\text { no. 7051, pp. 191-195. } \\
\text { Fleming, P. J., Blair, P. S., Pollard, K., } \\
\text { et al. 1999, "Pacifier use and sudden } \\
\text { infant death syndrome: results from } \\
\text { the CESDI/SUDI case control study.", } \\
\text { Archives of Disease in Childhood, vol. } \\
\text { 81, no. 2, pp. 112-116. } \\
\text { McGarvey, C., McDonnell, M., Chong, } \\
\text { A., et al. 2003, "Factors relating to the } \\
\text { infant's last sleep environment in } \\
\text { sudden infant death syndrome in the } \\
\text { Republic of Ireland", Archives of } \\
\text { Disease in childhood, vol. 88,no. 12, } \\
\text { pp. 1058-1064. }\end{array}$ & \\
\hline $\begin{array}{l}\text { Perinatal } \\
\text { Services (2) }\end{array}$ & $\begin{array}{l}\text { OMS: No dar tetinas o chupetes artificiales (llamados } \\
\text { tetinas o chupetes) a bebés lactant (2) } \\
\text { una RS muestra que la duración de la lactancia no se ve } \\
\text { afectada por el uso de chupete en los primeros } 4 \text { meses } \\
\text { entre las madres motivadas a amamantar a sus bebés } \\
\text { (77) } \\
\text { mientras que otros estudios revelan: } \\
\text { El uso del chupete en las primeras } 4 \text { semanas se asocia }\end{array}$ & $\begin{array}{l}\text { Evitar el uso de pezones artificiales, chupetes, } \\
\text { pezoneras y extractores de leche a menos que } \\
\text { esté clínicamente indicado o hasta que se } \\
\text { establezca la lactancia materna. } \\
\text { Apoyar a las madres a alimentar y cuidar a sus } \\
\text { bebés con lactancia materna sin el uso de } \\
\text { tetinas o chupetes artificiales (chupetes o } \\
\text { tetinas) (1). }\end{array}$ & $\begin{array}{l}\text { 2. World Health Organization/United } \\
\text { Nations Children's Fund (1989). } \\
\text { Protecting, promoting and supporting } \\
\text { breastfeeding: The special role of } \\
\text { maternity services. Geneva, } \\
\text { Switzerland: World Health } \\
\text { Organization. } \\
\text { 1. Breastfeeding Committee for } \\
\text { Canada. (2010). Summary: Integrated } \\
10 \text { steps practice outcome indicators } \\
\text { for hospitals and community health } \\
\text { services. }\end{array}$ & \\
\hline
\end{tabular}




\begin{tabular}{|c|c|c|c|c|}
\hline $\begin{array}{c}\text { Guía } \\
\text { (Enfoque) }\end{array}$ & $\begin{array}{l}\text { Resumen sobre la evidencia } \\
\text { (Calidad de la evidencia) }\end{array}$ & $\begin{array}{l}\text { Recomendaciones } \\
\text { (Grado) }\end{array}$ & $\begin{array}{l}\text { Referencias bibliográficas } \\
\text { (Tipo de publicación) }\end{array}$ & Comentarios \\
\hline & $\begin{array}{l}\text { con una menor tasa de lactancia materna exclusiva en el } \\
\text { primer mes y disminuyó la duración de la lactancia entre } \\
\text { los niños seguidos durante } 1 \text { año (78) } \\
\text { El uso podría indicar un problema de lactancia que puede } \\
\text { necesitar de una intervención (79), por ejemplo, el } \\
\text { aplazamiento o una menor alimentación por } 24 \text { horas; } \\
\text { problemas dentales y de ortodoncia, accidentes y } \\
\text { lesiones (asfixia); candidiasis; desarrollo del habla; apego } \\
\text { infantil, (38) y la otitis aguda media (80) }\end{array}$ & & 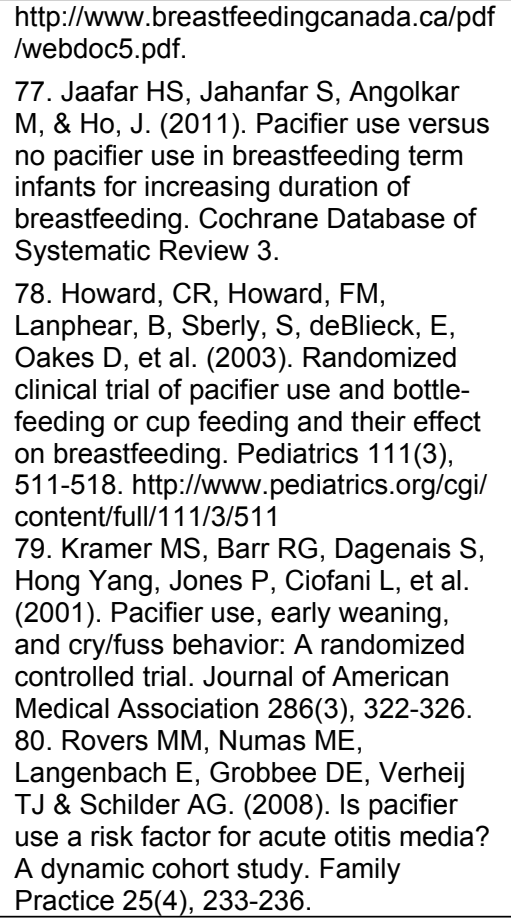 & \\
\hline
\end{tabular}


Tabla 3. Resumen de GPC del SNS

\begin{tabular}{|c|c|c|c|c|}
\hline $\begin{array}{l}\text { Guía } \\
\text { (Enfoque) }\end{array}$ & $\begin{array}{l}\text { Resumen sobre la evidencia } \\
\text { (Calidad de la evidencia) }\end{array}$ & $\begin{array}{l}\text { Recomendaciones } \\
\text { (Grado) }\end{array}$ & $\begin{array}{l}\text { Referencias bibliográficas } \\
\text { (Tipo de publicación) }\end{array}$ & Comentarios \\
\hline $\begin{array}{l}\text { IHAN Calidad } \\
\text { en la } \\
\text { asistencia } \\
\text { profesional al } \\
\text { nacimiento y } \\
\text { la lactancia } \\
\text { (3) }\end{array}$ & $\begin{array}{l}\text { En las primeras semanas de vida los lactantes } \\
\text { expuestos a tetinas o chupetes son más propensos a } \\
\text { presentar las manifestaciones del síndrome de } \\
\text { confusión de pezón con dificultad para el agarre, daño } \\
\text { del pezón, grietas, disminución del flujo de leche y cese } \\
\text { de la lactancia (5). } \\
\text { En relación al uso del chupete y la lactancia materna, } \\
\text { estudios observacionales han señalado una fuerte } \\
\text { asociación entre uso de chupetes y abandono precoz de } \\
\text { la lactancia pero no han permitido determinar si esta } \\
\text { asociación es casual (5,6, } 9-15) \text {. Algunos autores } \\
\text { observan una relación dosis-respuesta en el sentido de } \\
\text { que a mayor utilización del chupete menor duración de } \\
\text { la lactancia materna (13,14). } \\
\text { Una revisión sistemática de } 29 \text { estudios realizados entre } \\
1950 \text { y 2006, publicado en abril de } 2009, \text { señala que el } \\
\text { más alto nivel de evidencia no ha podido demostrar una } \\
\text { relación entre la utilización del chupete y la duración o } \\
\text { exclusividad de la lactancia materna (41). } \\
\text { Efecto protector del uso del chupete durante el sueño } \\
\text { pare prevenir el síndrome de muerte súbita del lactante, } \\
\text { en los lactantes amamantados debe recomendarse su } \\
\text { uso a partir del primer mes (32, 36). En todos los } \\
\text { lactantes, el chupete debe ser retirado antes del año de } \\
\text { edad (32). }\end{array}$ & $\begin{array}{l}\text { Paso } 9 \text {. No dar a los niños alimentados al } \\
\text { pecho biberones, tetinas o chupetes durante } \\
\text { la estancia en la Maternidad. } \\
\text { En un servicio de maternidad los chupetes } \\
\text { no deberían ser nunca necesarios (24). } \\
\text { En los recién nacidos amamantados es } \\
\text { mejor evitar el chupete durante los primeros } \\
\text { días de vida y usarlo solo cuando la } \\
\text { lactancia materna está bien establecida (32, } \\
36) \\
\text { El uso del chupete en los lactantes } \\
\text { amamantados debe recomendarse a partir } \\
\text { del primer mes (32, } 36 \text { ). } \\
\text { En todos los lactantes, el chupete debe ser } \\
\text { retirado antes del año de edad (32). } \\
\text { El uso de chupetes en bebés amamantados } \\
\text { debe recomendarse a partir del mes de vida, } \\
\text { fecha en que la lactancia materna está } \\
\text { establecida y edad en la que comienza el } \\
\text { riesgo del síndrome de muerte súbita del } \\
\text { lactante. }\end{array}$ & \multicolumn{2}{|c|}{$\begin{array}{l}\text { (5) Lang S, Lawrence C J \& Orme R. Cup feeding: an alternative method of } \\
\text { infant feeding. Arch Dis Child 1994; 71: 365-369. } \\
\text { (6) Howard CR, Howard FM, Lanphear B, Eberly S, de Blieck EA et al. } \\
\text { Randomized clinical trial of pacifier use and bottle-feeding or cup feeding } \\
\text { and their effect on breastfeeding. Pediatrics 2003; } 111 \text { : } 511-518 \\
\text { (9) Victora C G, Tomasi E, Olinto MT, Barros FC. Use of pacifiers and } \\
\text { breastfeeding duration. Lancet 1993; 341: 404-406. } \\
\text { (10) Barros F C, Victora CG, Semer TC, Tonioli Filho S, Tomasi E, } \\
\text { Weirderpass E. Use of pacifiers is associated with decreased breast- } \\
\text { feeding duration. Pediatrics 1995; 95: 497-499 } \\
\text { (11) Victora C G, Behage DP, Barros FC, Olinto MT, Weirderpass E. } \\
\text { Pacifier use and short breastfeeding duration: cause, consequence or } \\
\text { coincidence? Pediatrics 1997; 99:445-453. } \\
\text { (12) Kramer MS, Barr RG, Dagenais S, Yang H, Jones P, Ciofani L, Jané F } \\
\text { Pacifier use, early weaning, and cry/fuss behavior: a randomized controlled } \\
\text { trial. JAMA. 2001; } \\
\text { 286: } 322-6 \text {. } \\
\text { (13) Aarts C, Hornell A, Kylberg E, Hofvander Y, Gebre-MedhinM. } \\
\text { Breastfeeding patterns in relation to thumb sucking and pacifier use. } \\
\text { Pediatrics 1999;104:e50 } \\
\text { (14) Vogel AM, Hutchison BL; Mitchell EA. The impact of pacifier use in } \\
\text { breastfeeding: a prospective cohort study. J Paediatr Chile Health 2001; } \\
\text { 37:58-63. } \\
\text { (15) Howard CR, Howard FM, Lanphear B, deBlieck EA, Eberly S, } \\
\text { Lawrence A. The effects of early pacifier use on breastfeeding duration. } \\
\text { Pediatrics 1999: 103:e33 } \\
\text { c } \\
\text { (41) O'Connor NR, Tanabe KO, Siadaty MS, Hauck FR. Pacifiers and } \\
\text { breastfeeding. A systematic Review. Arch Pediatr Adolesc Med } \\
\text { 2009;163:378-382 }\end{array}$} \\
\hline
\end{tabular}




\subsection{Revisiones sistemáticas}

Tabla 4- Resumen de RSs actuales

\begin{tabular}{|c|c|c|c|c|c|c|}
\hline $\begin{array}{l}\text { Referencia } \\
\text { (Cita } \\
\text { Abreviada) }\end{array}$ & $\begin{array}{l}\text { Estudio (Diseño y } \\
\text { objetivo) }\end{array}$ & $\begin{array}{l}\text { ción } \\
\text { aracterísticas) }\end{array}$ & $\begin{array}{l}\text { Descripción de las intervenciones } \\
\text { comparaciones, exposiciones o } \\
\text { pruebas a estudio }\end{array}$ & $\begin{array}{l}\text { Resultados } \\
\text { (Estimadores de resultados-Magnitud } \\
\text { del efecto) }\end{array}$ & $\begin{array}{l}\text { Conclusiones } \\
\text { (conclusiones) }\end{array}$ & $\begin{array}{l}\text { Comentarios } \\
\text { Calidad de la } \\
\text { evidencia } \\
\text { Financiación } \\
\text { comentarios) }\end{array}$ \\
\hline \multicolumn{7}{|c|}{ Efecto sobre la lactancia } \\
\hline Jaafar $2012(4)$ & $\begin{array}{l}\text { Diseño } \\
\text { Metaanálisis de ECA } \\
\text { Objetivo } \\
\text { Realizar un metanálisis } \\
\text { sobre el efecto de la } \\
\text { restricción del uso del } \\
\text { chupete en la lactancia } \\
\text { materna }\end{array}$ & $\begin{array}{l}3 \text { estudios (2 } \\
\text { estudios } \\
\text { utilizados en } \\
\text { el análisis de } \\
\text { datos) } \\
\mathrm{N}=1302 \text { en } \\
\text { dos estudios } \\
\text { que incluían } \\
\text { niños sanos a } \\
\text { término }\end{array}$ & $\begin{array}{l}\text { Utilización de chupete sin restricciones } \\
\text { o activamente alentada comparado } \\
\text { con consejo en contra de su } \\
\text { utilización. }\end{array}$ & $\begin{array}{l}\text { Proporción de lactancia exclusiva a } \\
\text { los } 3 \text { meses: (2ECAs con } 1228 \\
\text { pacientes) } \\
\text { RR 0,99 (IC del } 95 \% 0,93 \text { a } 1,05) \\
\text { Proporción de lactancia exclusiva a } \\
\text { los } 4 \text { meses: (1ECA con } 970 \text { pacientes) } \\
\text { RR } 0,99 \text { (IC del } 95 \% 0,92 \text { a } 1,06 \text { ) } \\
\text { Proporción de lactancia parcial a los } \\
3 \text { meses: (2ECAs con } 1228 \text { pacientes) } \\
\text { RR } 1,00 \text { (IC del } 95 \% 0,98-1,13 \text { ) } \\
\text { Proporción de lactancia parcial a los } \\
\mathbf{4} \text { meses: (1ECA con } 970 \text { pacientes) } \\
\text { RR } 1,01 \text { (IC del } 95 \% 0,98 \text { a } 1,03 \text { ) }\end{array}$ & $\begin{array}{l}\text { El uso de chupetes } \\
\text { en niños sanos a } \\
\text { término, desde el } \\
\text { nacimiento o una } \\
\text { vez establecido la } \\
\text { lactancia, no afecta } \\
\text { significativamente la } \\
\text { prevalencia o } \\
\text { duración de la } \\
\text { lactancia exclusiva o } \\
\text { parcial hasta el } \\
\text { cuarto mes. Sin } \\
\text { embargo, existe falta } \\
\text { de evidencia en } \\
\text { relación a las } \\
\text { dificultades a corto } \\
\text { plazo para la } \\
\text { lactancia y sobre el } \\
\text { efecto a largo plazo } \\
\text { de la utilización del } \\
\text { chupete. }\end{array}$ & \\
\hline \multicolumn{7}{|c|}{ Efecto sobre la muerte súbita del lactante } \\
\hline Mitchell 2006 (5) & $\begin{array}{l}\text { Diseño } \\
\text { Metanálisis de E. casos } \\
\text { control } \\
\text { Objetivo } \\
\text { Revisar la evidencia sobra } \\
\text { la reducción de riesgo de } \\
\text { SMSL y el uso de chupete, } \\
\text { discutir los posibles } \\
\text { mecanismos y revisar otros } \\
\text { posibles efectos del uso del } \\
\text { chupete }\end{array}$ & $\begin{array}{l}7 \text { estudios } \\
\text { casos-control } \\
\text { y un } \mathrm{E} \text {. } \\
\text { cohorte (de } \\
\text { datos no } \\
\text { publicados) } \\
\mathrm{N}=7,970 \\
\text { controles y } \mathrm{N}= \\
2042 \text { casos } \\
\text { en total. }\end{array}$ & & $\begin{array}{l}\text { - Riesgo de muerte súbita del lactante } \\
\text { asociado a la utilización habitual del } \\
\text { chupete durante el sueño: OR } 0,83 \text { (de } \\
0,75 \text { a } 0,93 \text { ) } \\
\text { - Riesgo de muerte súbita del lactante } \\
\text { asociado a la utilización del chupete } \\
\text { en el último sueño: OR } 0,48 \text { ( de } 0,43 \\
\text { a } 0,54 \text { ) }\end{array}$ & $\begin{array}{l}\text { Sigue habiendo un } \\
\text { debate abierto en } \\
\text { relación a si } \\
\text { recomendar o no el } \\
\text { uso de chupete }\end{array}$ & \\
\hline
\end{tabular}




\subsection{Resumen de GPC base y RS disponibles}

La guía de NICE (1) recomienda seguir los pasos de la iniciativa del hospital amigo de los niños y con ella el paso número 9, donde se recomienda no dar tetinas artificiales o chupetes a niños que están siendo amamantados. En base a estudios observacionales que evalúan el riesgo de utilización de chupetes y su relación con el síndrome de muerte súbita del lactante (SMSL) $(6 ; 7)$, en la guía se recomienda que si el lactante se ha acostumbrado a utilizar el chupete mientras duerme su uso no debería interrumpirse repentinamente en las primeras 26 semanas. En la actualización de la de la evidencia de la guía publicada en el 2012, se incluyen 2 nuevas RS (8;9). La primera (8) pretende evaluar la eficacia del uso del chupete en ECA y no encuentra ninguna diferencia sobre la prevalencia y duración de la lactancia materna frente a políticas de restricción del uso de chupete. En esta revisión no se incluye un ECA que sí ha sido tenido en cuenta en la guía NICE (10), que muestra que el uso del chupete en el período neonatal fue en detrimento de la lactancia materna exclusiva a las 4 semanas y lactancia global medida a un año, y que es precisamente el estudio que apoya la recomendación.

La segunda revisión (9) sobre intervenciones para reducir el riesgo de SMSL en relación al uso del chupete concluye que la promoción de su uso disminuye el riesgo de SMSL y fomenta la lactancia materna. La inclusión de esta nueva evidencia no provoca una modificación de las recomendaciones de la guía, por lo que la recomendación se mantiene.

La guía del Perinatal Care services (2) recoge la misma RS publicada en 2011 (8) en la que se observa que la duración de la lactancia materna no se ve afectada por el uso del chupete en los primeros cuatro meses de vida entre las madres que quieren amamantar.

También recoge el ECA (10), excluido del análisis de la RS de 2011, que muestra que el uso del chupete en el período neonatal fue en detrimento de la lactancia materna exclusiva y global. Estos resultados respaldan las recomendaciones para evitar la exposición de los lactantes alimentados con leche materna a pezones artificiales en el período neonatal, a menos que esté clínicamente indicado, durante el periodo postparto y hasta que se establezca la lactancia materna. Y por ello, se debe apoyar a las madres a alimentar al recién nacido con lactancia materna, sin el uso de chupete.

En el documento de la IHAN (3) sobre "Cuidados en el Nacimiento" en el noveno paso de los diez de la iniciativa hospital amigo de los niños, se recomienda no dar a los niños amamantados biberones, tetinas o chupetes durante la estancia en la maternidad. El documento recoge estudios observacionales en los que se ha observado una fuerte asociación entre el uso de chupetes y el abandono precoz de la lactancia (11-18), aunque estos estudios no han demostrado una relación de causalidad. De hecho, la RS publicada en 2009 (19) y recogida en el documento de la IHAN, señala que los ECA no han podido mostrar una relación entre el uso de chupete y la duración y exclusividad de la lactancia materna. Se ha observado que los lactantes expuestos a tetinas en los primeros días de vida son más propensos a presentar las manifestaciones del síndrome de confusión del pezón con dificultad para el agarre y cese de lactancia entre otros desenlaces no deseados (16). Además, las recomendaciones de este documento también consideran la evidencia que sugiere un efecto protector del uso del chupete para prevenir el síndrome de muerte súbita durante el sueño $(20 ; 21)$. Por ello, se recomienda que el uso de chupetes en lactantes amamantados a partir del mes de vida, fecha en la que la lactancia materna está ya 
establecida y al tratarse de la edad en la que comienza el riesgo de muerte súbita del lactante.

Se han identificado cuatro revisiones $(4 ; 9 ; 19 ; 21 ; 22)$. Una de ellas fue eliminada por ser narrativa y no aportar estudios que las demás no incluían (4). De las otras tres revisiones sistemáticas, la del 2012 (4) era una corrección y actualización de la del 2011 (8), por lo que esta última fue excluida. La revisión publicada en 2009 (19) incluía 4 estudios también identificados en las RS del 2012 y 2011, por lo que finalmente se consideró seleccionar la RS más actual, que pretende evaluar el efecto de la restricción del uso del chupete sobre las tasas de lactancia materna exclusiva.

También se realizó una búsqueda específica sobre el SMSL, con el objetivo de clarificar el posible efecto protector descrito de la utilización del chupete sobre este desenlace. Se identificó una revisión narrativa (23) y tres RS $(5 ; 9 ; 24)$, dos de las cuales, metaanalizaban los datos $(5 ; 24)$. Estas dos últimas revisiones incluían los mismos estudios observacionales, en su mayoría de tipo casos control, aunque finalmente se seleccionó de entre las dos aquella que era más exhaustiva en la presentación del método y los resultados (5).

\subsection{Conclusión (marcar con una X):}

\begin{tabular}{|l|l|}
\hline & Adopción GPC/Revisión sistemática \\
\hline$X$ & Elaboración parcial \\
\hline & Elaboración de novo \\
\hline
\end{tabular}

\subsection{Diseño de la estrategia de búsqueda de estudios individuales}

\section{Criterios de selección de estudios \\ Período de búsqueda}

Bases de datos

ECAs, estudios de cohortes
2010-Marzo 2014
$2006-2012$
Cochrane Library
MEDLINE, via Pubmed
EMBASE, via Ovid
Cinahl, via EBSCOhost databases
PsyINFO, via OVID

Ver estrategias de búsqueda de estudios originales en el ANEXO I. 


\section{4- Resumen de la evidencia (Tablas de estudios individuales y valoración de calidad en los Anexos)}

\section{1- GRADE Evidence Profile}

Comparación 1: : uso de chupete vs. Restricción uso de chupete Bibliografía: (4) (10) (5)

\begin{tabular}{|c|c|c|c|c|c|c|c|c|c|c|c|c|}
\hline \multirow{2}{*}{\multicolumn{7}{|c|}{ Evaluación de la calidad }} & \multicolumn{4}{|c|}{ Resumen de los Resultados } & \multirow{3}{*}{ Calidad } & \multirow{3}{*}{ Importancia } \\
\hline & & & & & & & \multicolumn{2}{|c|}{$\mathrm{N}^{\circ}$ de pacientes } & \multicolumn{2}{|c|}{ Magnitud del efecto } & & \\
\hline $\begin{array}{c}N^{0} \text { de } \\
\text { estudios }\end{array}$ & Diseño & $\begin{array}{c}\text { Riesgo de } \\
\text { sesgo }\end{array}$ & Inconsistencia & $\begin{array}{l}\text { Evidencia } \\
\text { indirecta }\end{array}$ & Imprecisión & \begin{tabular}{|c|} 
Otras \\
consideraciones
\end{tabular} & $\begin{array}{l}\text { Restricción de } \\
\text { uso chupete }\end{array}$ & \begin{tabular}{|c|}
$\begin{array}{l}\text { Uso } \\
\text { chupete }\end{array}$ \\
\end{tabular} & $\begin{array}{l}\text { Relativa } \\
(95 \% \mathrm{Cl})\end{array}$ & Absoluta por 1000 & & \\
\hline \multicolumn{13}{|c|}{ Proporción de niños amamantados exclusivamente con leche materna a las 4 semanas } \\
\hline 11 & ECA & No serio & No seria & No seria & Seria ${ }^{2}$ & Poco probable & $-/ 354^{3}$ & $-1346^{3}$ & $\begin{array}{c}\text { OR } 1,5 \\
\text { (de } 1,0 \text { a } 2,0 \text { ) }\end{array}$ & $\mathrm{N} / \mathrm{A}^{3}$ & MODERADA & CRITICA \\
\hline \multicolumn{13}{|c|}{ Proporción de niños amamantados exclusivamente con leche materna a los 3 meses } \\
\hline $2^{4}$ & ECA & No serio & No seria & Seria ${ }^{5}$ & No seria & Probable $^{6}$ & $452 / 598(75.6) \%$ & $\begin{array}{l}472 / 63) \\
(74.9 \%\end{array}$ & $\begin{array}{c}\text { RR 1,01 } \\
\text { (de 0,96 a } \\
1,07)\end{array}$ & $\begin{array}{c}8 \text { más de } 1000 \text { (de } \\
30 \text { menos a } 53 \text { más) }\end{array}$ & BAJA & IMPORTANTE \\
\hline \multicolumn{13}{|c|}{ Proporción de niños amamantados exclusivamente con leche materna a los 4 meses } \\
\hline $1^{7}$ & ECA & No serio & \begin{tabular}{|l|} 
No seria \\
\end{tabular} & Seria $^{8}$ & \begin{tabular}{|l|} 
No seria \\
\end{tabular} & Probable $^{6}$ & $354 / 471(75.2) \%$ & $\begin{array}{l}371 / 499 \\
(74.3) \%\end{array}$ & $\begin{array}{c}\text { RR 1,01 } \\
\text { (de 0,94 a } \\
1,09)\end{array}$ & \begin{tabular}{|c|}
7 más de 1000 (de \\
45 menos a 67 más)
\end{tabular} & BAJA & IMPORTANTE \\
\hline \multicolumn{13}{|c|}{ Duración de lactancia exclusiva } \\
\hline 11 & ECA & No serio & No seria & No seria & Seria ${ }^{8}$ & Poco probable & $346^{9}$ & $354^{10}$ & $\begin{array}{c}\text { HR 1,09 } \\
\text { (de 0,94 a } \\
1,27)^{11}\end{array}$ & $\mathrm{~N} / \mathrm{A}$ & MODERADA & CRITICA \\
\hline \multicolumn{13}{|c|}{ Duración de la lactancia materna } \\
\hline 11 & ECA & No serio & No seria & No seria & No seria & Poco probable & $346^{12}$ & $354^{13}$ & $\begin{array}{c}\text { HR 1,22 } \\
\text { (de 1,03 a } \\
1,44)^{11} \\
\end{array}$ & $\mathrm{~N} / \mathrm{A}$ & ALTA & CRITICA \\
\hline \multicolumn{13}{|c|}{ Síndrome de Muerte súbita del lactante (tanto uso habitual como no habitual de chupete durante el sueño) } \\
\hline $44^{14}$ & $\begin{array}{l}\text { E. } \\
\text { observacionales }\end{array}$ & No serio & Seria ${ }^{15}$ & Seria ${ }^{16}$ & No seria & Poco probable & $\mathrm{N} / \mathrm{A}^{17}$ & $\mathrm{~N} / \mathrm{A}^{18}$ & $\begin{array}{l}\text { OR 0,71 (de } \\
0,59 \text { a } 0,85)^{19}\end{array}$ & $\mathrm{~N} / \mathrm{A}$ & MUY BAJA & IMPORTANTE \\
\hline \multicolumn{13}{|c|}{ Síndrome de Muerte súbita del lactante (tanto uso habitual como no habitual en el último sueño) } \\
\hline $8^{20}$ & $\begin{array}{l}\text { E. } \\
\text { observacionales }\end{array}$ & No serio & Seria ${ }^{15}$ & Seria ${ }^{16}$ & No seria & Poco probable & $\mathrm{N} / \mathrm{A}^{21}$ & $\mathrm{~N} / \mathrm{A}^{22}$ & $\begin{array}{l}\text { OR } 0,36 \text { (de } \\
0,29 \text { a } 0,45)^{23}\end{array}$ & $\mathrm{~N} / \mathrm{A}$ & MUY BAJA & IMPORTANTE \\
\hline
\end{tabular}

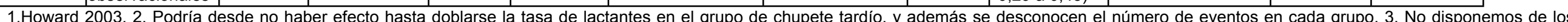

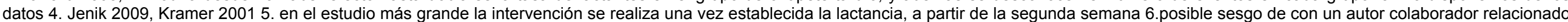

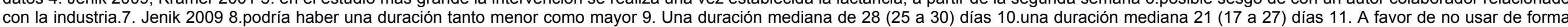

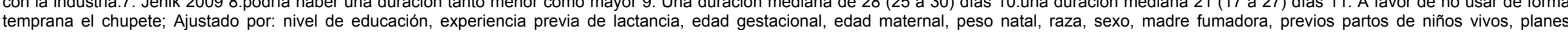

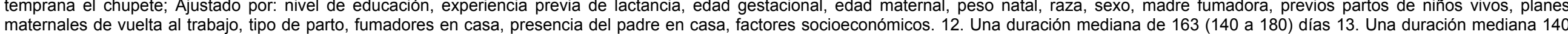

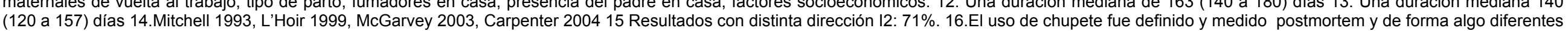
$-6-$ 


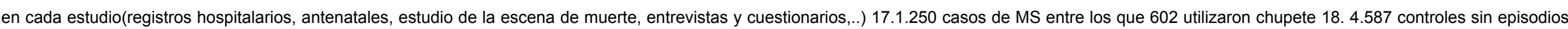

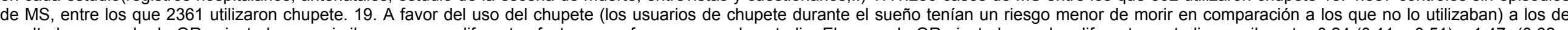

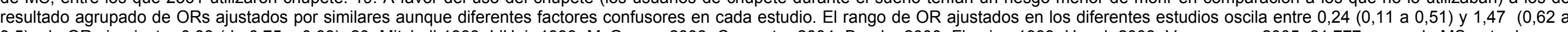

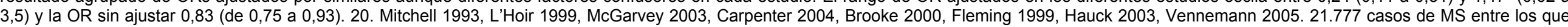

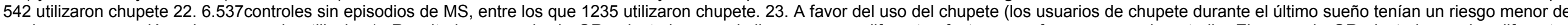

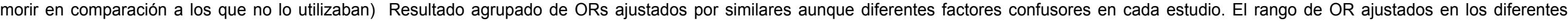
estudios oscila entre $0,10(0,03$ a 0,31$)$ y $0,44(0,29$ a 0,60$)$ y la OR sin ajustar 0,48 (de 0,43 a 0,54). 


\section{2- Resumen de la Evidencia}

En la búsqueda de estudios individuales se identificó un ECA (25) que fue finalmente excluido por no cumplir con los criterios de selección definidos. También se identificaron dos estudios observacionales, uno de ellos que estudiaba de forma prospectiva los factores asociados a la duración de la lactancia, donde se incluía la utilización del chupete como uno de los factores independientes (26), y otro estudio transversal retrospectivo que analizó la asociación entre la implementación de una política de restricción del uso de chupete en una maternidad hospitalaria y las tasas de lactancia materna exclusiva (27). Estos dos últimos estudios fueron finalmente excluidos de la agregación de datos, porque el objetivo del primero no era comprobar el efecto del uso del chupete en la lactancia, sino de varios de los factores y el segundo porque pretendía valorar el impacto de diferentes políticas relacionadas con el uso de chupete en resultados de rendimiento en una institución y no en los pacientes individuales.

En la RS de 2012 (4) seleccionada se incluyeron tres ECA de los cuales dos contribuyeron al análisis de la proporción de lactantes alimentados con leche materna de forma parcial o exclusiva a los tres y cuatro meses de edad $(n=1.302$ lactantes sanos a término) $(14 ; 28)$. El tercer estudio (29) fue eliminado del análisis por presentar hasta un $40 \%$ de pérdidas en el seguimiento en el grupo intervención. En esta revisión se excluye un ECA (10) que sí ha sido tenido en cuenta en este caso, puesto que se cree que es un estudio que cumple con los criterios de inclusión.

Los resultados sobre la comparación entre el uso restringido de chupete o uso tardío (intervención) y el uso del chupete o uso temprano (control) reveló una tasa de lactancia exclusiva a las cuatro semanas que tendía a ser mayor en los que no usaron chupete de forma temprana (1 estudio, $\mathrm{n}=700$ ), siendo el OR de 1,5 (IC95\% de 1,0 a 2,0). Sin embargo, no hubo diferencias significativas en la proporción de lactantes amamantados de forma exclusiva a los tres meses ( 2 estudios, $n=$ 1.228 niños), siendo el RR de 1,01 (IC95\% de 0,96 a 1,07 ), ni a los cuatro meses de edad ( 1 estudio, $n=970$ niños; RR 1,01 (IC del $95 \%$ de 0,94 a 1,09)]. Tampoco se observaron diferencias significativas en la duración de la lactancia materna exclusiva entre los que utilizaban el chupete de forma tardía y de forma temprana ( 1 estudio, $n=700$ ), siendo el HR de 1,09 (IC95\% de 0,94 a 1,27), aunque la duración de la lactancia global fue significativamente mayor en el grupo que utilizó el chupete de forma tardía frente al que lo utilizó de forma temprana, con una duración de aproximadamente $\mathbf{2 0}$ días más de lactancia materna, siendo el HR de 1,22 (IC95\% de 1,03 a 1,44).

La RS que estudió la asociación entre el uso de chupete y la muerte súbita incluía estudios de tipo casos control, con controles emparejados de la población. La mayoría de los estudios ajustaron sus resultados realizando un análisis multivariante controlado por un amplio número de factores confusores (similares aunque diferentes en cada estudio), entre los que se incluían factores relacionados con la muerte súbita, como la posición de dormir, el estado fumador de los padres, y el estado socioeconómico, entre otros.

La utilización habitual de chupete durante las horas de sueño mostró una

Calidad moderada

\section{Calidad baja Calidad baja Calidad moderada}

\section{Calidad alta}


disminución del riesgo de SMSL en casi todos los estudios que aportaban resultados ajustados (ORa de 0,71; IC95\% de 0,59 a 0,85). Se observó heterogeneidad en las estimaciones y se consideró la existencia de riesgo de sesgos por apoyarse en una evidencia que puede considerarse indirecta, debido a que la definición de uso habitual de chupete y su medición no fue igual en todos los estudios. No obstante, los resultados muestran una tendencia de riesgo disminuido entre los lactantes que utilizan chupete tanto de forma habitual como durante el último sueño, siendo el OR de 0.36 (IC95\% de 0,29 a 0,45). Cabe destacar, no obstante, que en tan solo dos de los estudios incluidos se ajustaron los resultados teniendo en cuenta la lactancia (lactancia exclusiva o fórmula) como factor confusor, cuando existe evidencia de una posible relación de protección de la lactancia materna sobre el riesgo de SMSL recogido en dos metaanálisis $(30 ; 31)$. Estos meta-análisis evalúan la relación de la lactancia con el riesgo de SMSL, incluyendo siete estudios de casos y controles, en países desarrollados en el primer meta-análisis (30) y dieciocho de cualquier país en el segundo (31). Estos metaanálisis encuentran una asociación significativa entre la lactancia materna y un menor riesgo de SMSL, con un rango de OR ajustado entre 0,55 y 0,64 .

Por lo tanto, la restricción temprana del uso de chupete en los recién nacidos a término mostró una mayor tasa de lactancia exclusiva a las cuatro semanas y una mayor duración de la lactancia global a los cuatro meses. Sin embargo, la prevalencia y duración de la lactancia exclusiva o casi exclusiva a lo largo de un año no fue diferente entre lactantes de hasta cuatro meses que utilizaron chupete antes o después del establecimiento de la lactancia. Existe evidencia sobre la asociación entre el uso de chupete durante las horas de sueño y un menor riesgo de SMSL, así como evidencia que asocia la lactancia materna con un menor riesgo de SMSL, lo que denota la necesidad de saber si en realidad existe interacción entre la lactancia materna y el uso de chupete y cómo afecta esto al riesgo del SMSL.

\section{Resultados de la actualización de la revisión a octubre de 2016}

En la actualización de la búsqueda se ha identificado la actualización de la revisión Cochrane utilizada (8) para responder a esta pregunta. Los autores de la revisión no identifican estudios nuevos que se puedan incluir, por lo que no cambian sus conclusiones (32).

\section{ACTUALIZADO A FECHA DE: 31 de Octubre de 2016}




\section{5- De la evidencia a la recomendación (Tabla de EtR)}

\section{¿Se debería evitar el uso de chupete en las primeras semanas para favorecer la instauración de la lactancia materna?}

Población: Recién nacido lactante desde el nacimiento hasta las primeras semanas

Intervención: No utilización / restricción del chupete

Comparación: Utilización de chupete en maternidad /tras la alta hospitalaria

Perspectiva: Clínica

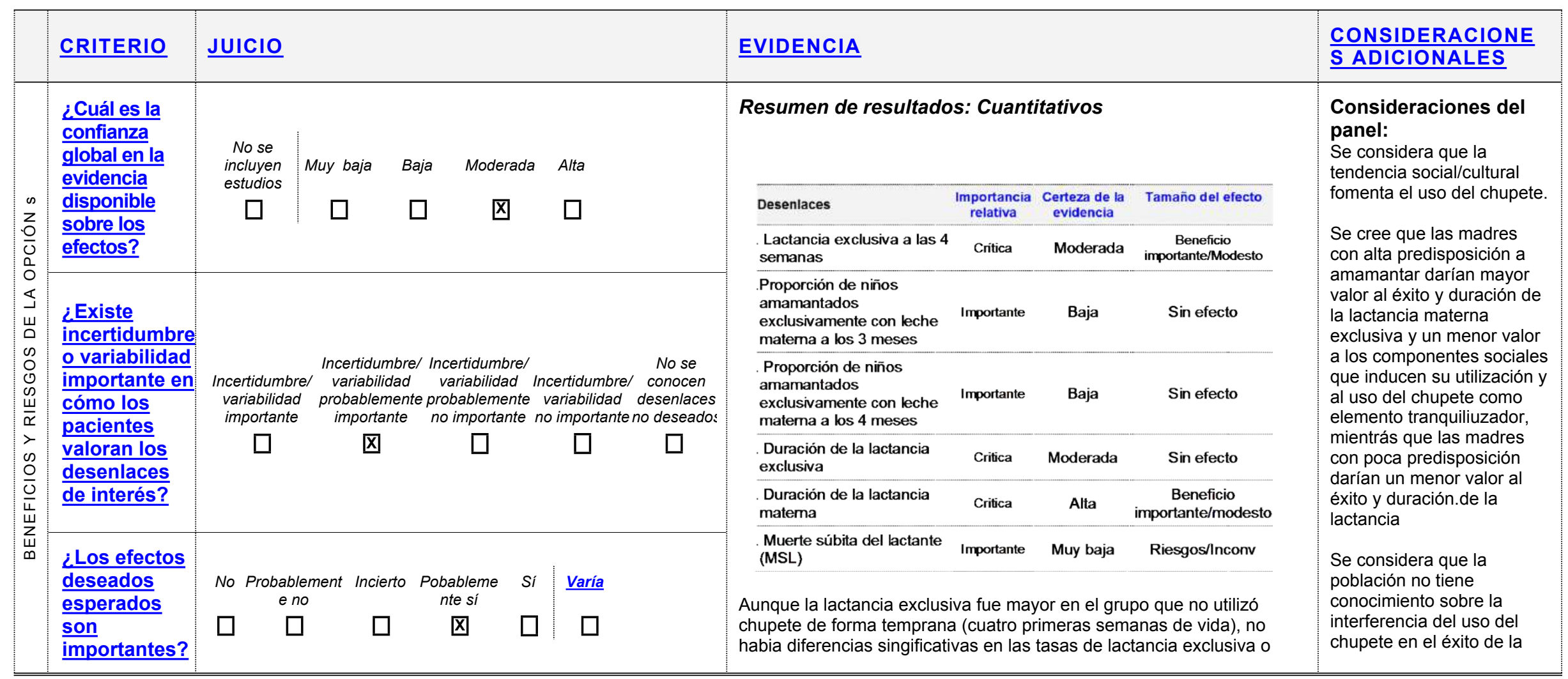




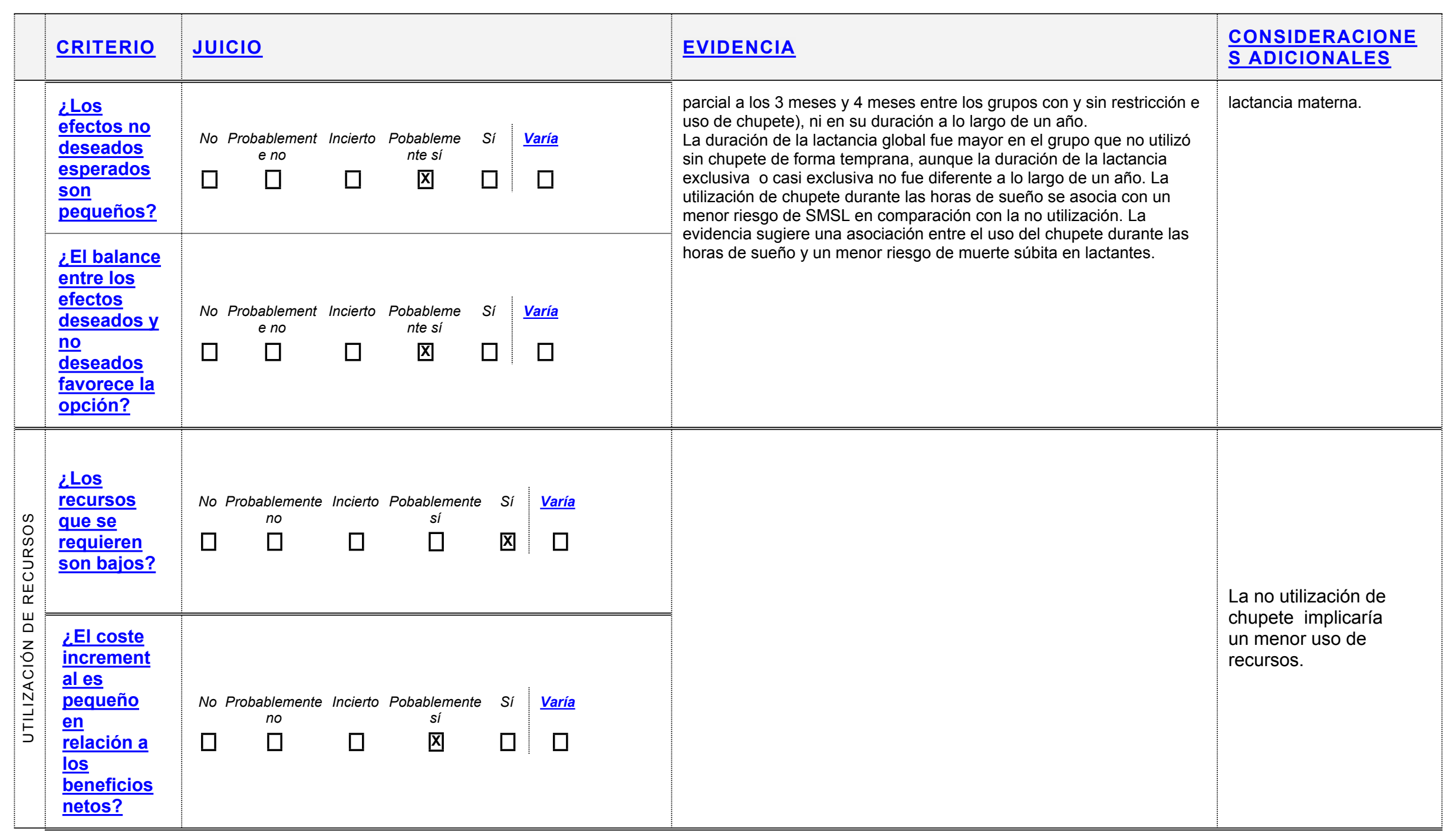




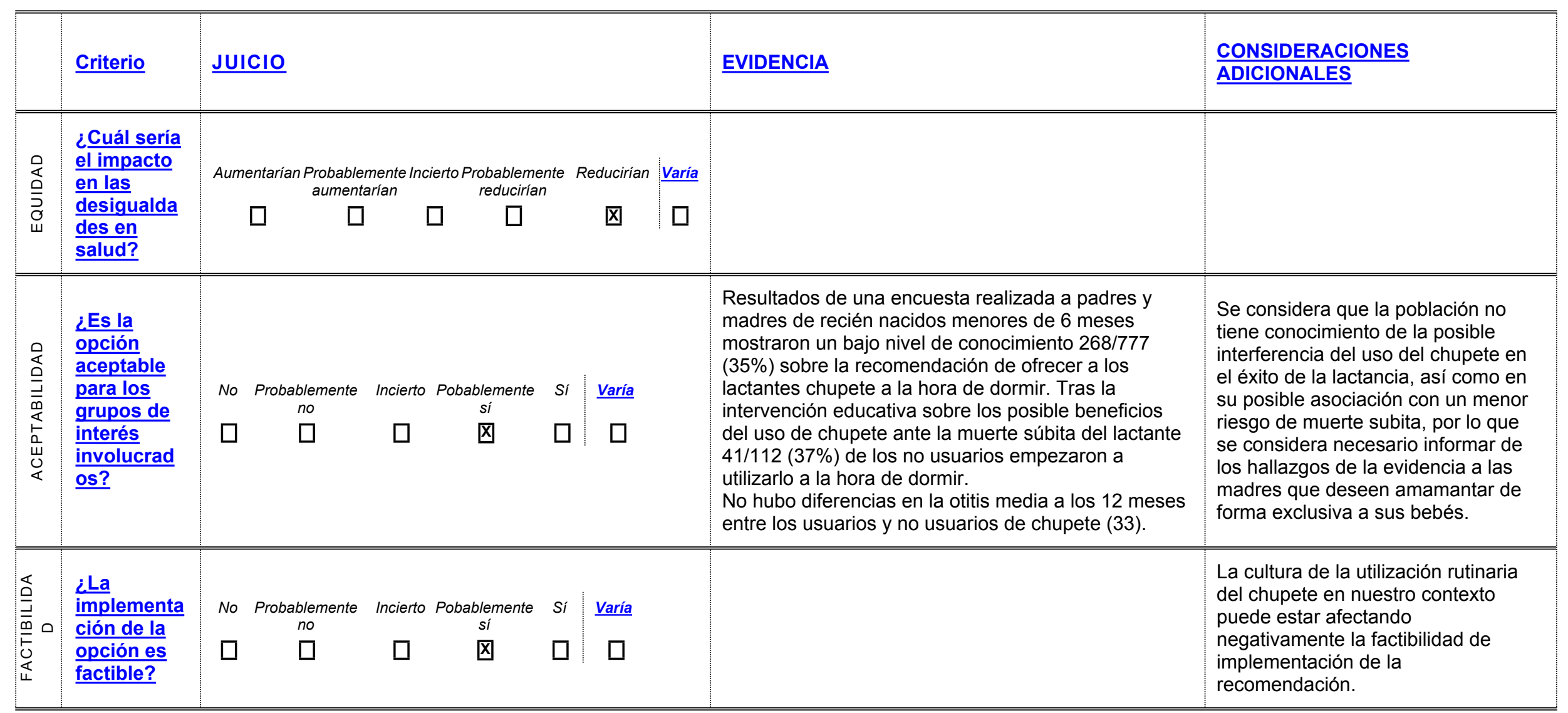




\begin{tabular}{|c|c|c|c|c|c|}
\hline$\frac{\text { Balance de las }}{\text { consecuencias }}$ & $\begin{array}{c}\text { Las consecuencias no } \\
\text { deseadas superan } \\
\text { claramente las } \\
\text { consecuencias deseadas en } \\
\text { la mayoría de los escenarios }\end{array}$ & $\begin{array}{l}\text { Las consecuencias no } \\
\text { deseadas probablemente } \\
\text { superan las } \\
\text { consecuencias deseadas } \\
\text { en la mayoría de los } \\
\text { escenarios }\end{array}$ & $\begin{array}{c}\text { El balance entre las } \\
\text { consecuencias deseadas y } \\
\text { no deseadas está muy } \\
\text { equilibrado o es incierto }\end{array}$ & $\begin{array}{l}\text { Las consecuencias } \\
\text { deseadas } \\
\text { probablemente superan } \\
\text { las consecuencias no } \\
\text { deseadas en la mayoría } \\
\text { de los escenarios }\end{array}$ & $\begin{array}{c}\text { Las consecuencias } \\
\text { deseadas claramente } \\
\text { superan las } \\
\text { consecuencias no } \\
\text { deseadas en la mayoría } \\
\text { de los escenarios }\end{array}$ \\
\hline
\end{tabular}

$\square$

Tipo de

recomendación

Se recomienda no ofrecer la opción

$\square$ $\square$

凶

$\square$

Se recomienda ofrecer la opción

$\square$

$\square$

$\square$

\section{Recomendación} (Texto)

\section{Recomendación débil en contra}

Se sugiere evitar siempre que sea posible el uso del chupete durante el primer mes para facilitar el buen inicio de la lactancia materna.

\section{Recomendación de buena práctica}

No existe evidencia suficiente para asegurar que el uso del chupete sea beneficioso para la prevención de muerte súbita en el lactante amamantado, por lo que mientras siga tomando el pecho, no se debería ofrecer de forma rutinaria.

Sin embargo, en aquellos lactantes que ya están acostumbrados a utilizarlo sería mejor no interrumpir su uso durante las horas de sueño en los primeros seis meses de vida. 
La evidencia muestra que evitar tempranamente la utilización de chupete mejora la instauración de la lactancia, con mejores tasas de lactancia materna exclusiva a las 4 semanas. Además también se ha observado una mayor tasa de lactancia global a los 4 meses, aunque sin diferencias en la tasa de lactancia materna exclusiva a los 4 meses. Por otro lado, cabe destacar que la utilización de chupete durante las horas de sueño se asocia con un menor riesgo de SMSL, aunque también se sugiere que dicho efecto podría ser diferente en recién nacidos amantados o no amamantados, debido a que la lactancia también se asocia con la disminución del riesgo de SMSL. Se considera que puede haber variabilidad en la población en la que se pretende aplicar la recomendación, con preferencias tanto por la utilización por razones de disminución de estrés del recién nacido y/o de la madre, así como mujeres que dan un mayor valor a la instauración adecuada de la lactancia y menor valor al llanto de recién nacido. La no utilización de chupete durante la estancia hospitalaria implicaría un menor uso de recursos. Se cree que la recomendación afectaría positivamente a aspectos de inequidad, con una aceptación probablemente variable por parte de los niños y madres que habría que considerar para una adecuada implementación de la recomendación.

\section{Consideraciones de subgrupos}

Consideraciones

para la

implementación

Existe cierta evidencia de los perjuicios del uso del chupete sobre la instauración de la lactancia y por tanto, los profesionales sanitarios deben evitar su entrega y/o uso rutinario en las maternidades, debiendo estar restringido su uso a casos de indicación médica

Las madres y familias reciben sobre este tema gran cantidad de mensajes contradictorios: la importancia de evitar su uso para asegurar el buen funcionamiento de la lactancia, frente a la costumbre y la publicidad que impulsa el uso generalizado del chupete o los mensajes sobre la conveniencia de su uso para evitar el síndrome de muerte súbita del lactante. Por esto es necesario ofrecer información objetiva que no fuerce a su uso ni que lo estigmatice, dado que en la actualidad, no existe evidencia científica poderosa en un sentido ni en otro.

\section{Monitorización y}

evaluación

Prioridades para la investigación

- Son necesarios estudios que evalúen la relación entre la restricción del chupete durante la estancia hospitalaria y la iniciación y duración de la lactancia materna, y que ofrezcan resultados individuales de los lactantes-madres.

- Son necesarios estudios observacionales y RS que evalúen los factores que afectan a desenlaces de SMSL y que tengan en cuenta como posible factor confusor la lactancia materna exclusiva, y su posible influencia en resultados que evalúan el efecto del uso del chupete en la SMSL. 


\section{ANEXO I, ESTRATEGIAS DE BÚSQUEDA}

\section{BUSQUEDA DE EFECTIVIDAD}

\section{Cochrane Library}

Searched 10/03/2014

Updated search 10/03/2014 a 20/10/2014

\#1 breastfeeding or "breast feeding" or breastfeed or "breast feed" or breastfed or "breast fed" or lactation:ti,ab,kw (Word variations have been searched)

\#2 pacifier or pacifiers or dummy or dummies or teat or teats:ti,ab,kw (Word variations have been searched)

\#3 \#1 AND \#2

\section{MEDLINE, via Pubmed}

Searched 10/03/2014

Updated search 10/03/2014 a 20/10/2014

\#1 "breast feeding"[MeSH Terms] OR "breast feeding"[All Fields] OR

"breastfeeding"[All Fields] OR "breast feeding"[All Fields] OR "breastfeed"[All Fields])

OR "breast feed"[All Fields] OR "breastfed" [All Fields] OR "breast fed"[All Fields]

\#2 "lactation"[MeSH Terms] OR "lactation"[All Fields]

\#3 \#1 OR \#2

\#4 "pacifiers"[MeSH Terms] OR "pacifiers"[All Fields] OR "pacifier"[All Fields]

\#5 "dummy" OR "dummies"

\#6 "teat" OR "teats"

\#7 \#5 OR \#6 OR \#7

\#8 \#3 AND \#7

\section{EMBASE, via Ovid}

Searched 10/03/2014

Updated search 10/03/2014 a 20/10/2014

\#1 (breastfeeding or "breast feeding" or breastfeed or "breast feed" or breastfed or "breast fed").ti,sh,hw,ab,kw.

\#2 lactation.ti,sh,hw,ab,kw.

\#3 \#1 or \#2

\#4 (pacifier or pacifiers).ti,sh,hw,ab,kw.

\#5 (dummy or dummies).ti,sh,hw,ab,kw.

\#6 (teats or teat).ti,sh,hw, ab,kw.

\#7 \#4 or \#5 or \#6

\#8 \#3 and \#7

\#9 limit 8 to $y r=" 2012$ - 2014"

\section{Cinahl, via EBSCOhost databases}

Searched 10/03/2014

Updated search 10/03/2014 a a 20/10/2014

\#1 (MH "Breast Feeding") 


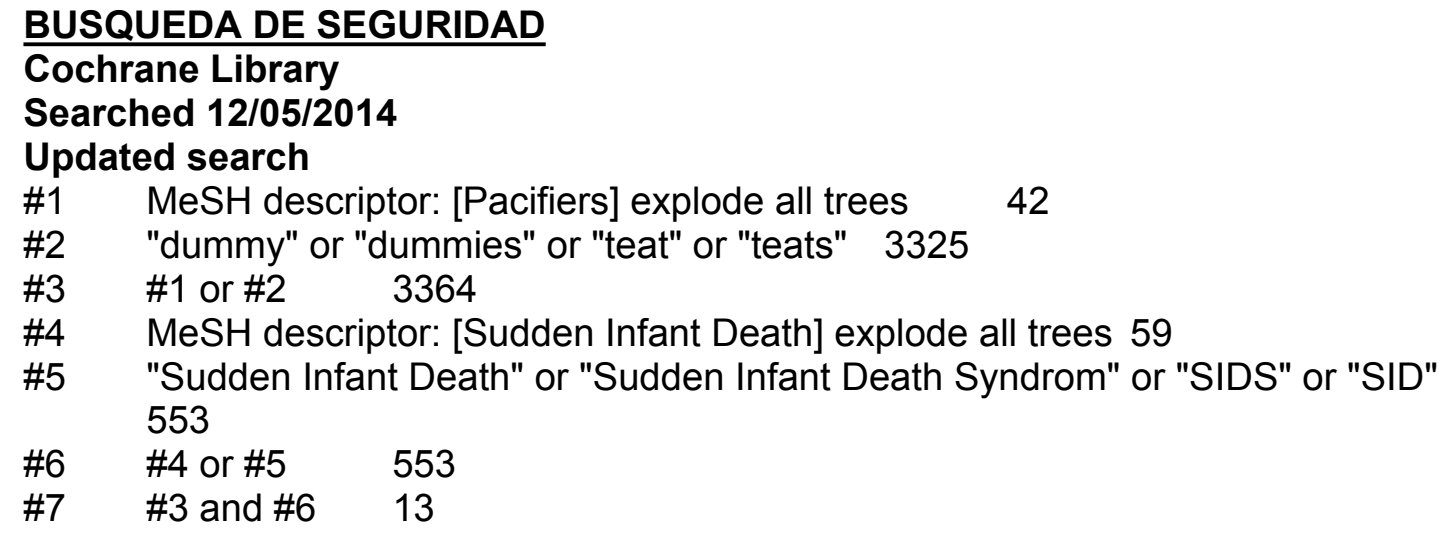

\title{
MEDLINE, via Pubmed \\ Searched 12/05/2014 \\ Updated search
}

\author{
\#1 Search "Pacifiers"[Mesh] \\ \#2 Search ("dummy" OR "dummies" OR "teat" OR "teats") \\ \#3 (\#1 OR \#2) Search ("Pacifiers"[Mesh]) OR (("dummy" OR "dummies" OR \\ "teat" OR "teats")) \\ \#4 Search "Sudden Infant Death"[Mesh] \\ \#5 Search ("Sudden Infant Death" OR "Sudden Infant Death syndrom" OR "SIDS" \\ OR "SID") \\ \#6 (\#4 OR \#5) Search ((("Sudden Infant Death" OR "Sudden Infant Death syndrom" OR \\ "SIDS" OR "SID"))) OR "Sudden Infant Death"[Mesh] \\ \#7 (\#4 and \#10) Search ((("Pacifiers"[Mesh]) OR (("dummy" OR "dummies" OR \\ "teat" OR "teats")))) AND (((("Sudden Infant Death" OR "Sudden Infant Death syndrom" \\ OR "SIDS" OR "SID"))) OR "Sudden Infant Death"[Mesh])
}

\section{EMBASE, via Ovid \\ Searched 12/05/2014 \\ Updated search}

\#1 (pacifier or pacifiers).mp. [mp=title, abstract, subject headings, heading word, drug trade name, original title, device manufacturer, drug manufacturer, device trade name, keyword] (1001)

\#2 (dummy or dummies).mp. [mp=title, abstract, subject headings, heading word, drug trade name, original title, device manufacturer, drug manufacturer, device trade name, keyword] (4938)

\#3 (teats or teat).mp. [mp=title, abstract, subject headings, heading word, drug trade name, original title, device manufacturer, drug manufacturer, device trade name, keyword] (1811)

\#4 1 or 2 or $3(7681)$

\#5 sudden infant death syndrome/ (8866)

\#6 ("sudden infant death syndrome" or " sudden infant death " or "SIDS" or "SID").mp. [mp=title, abstract, subject headings, heading word, drug trade name, original title, device manufacturer, drug manufacturer, device trade name, keyword] (11345)

\#7 5 or $6(11345)$

\#8 4 and 7 (176) 


\section{ANEXO II, Tabla de estudios individuales para la pregunta}

\section{Estudios sobre efectos en la lactancia}

\begin{tabular}{|c|c|c|c|c|c|c|}
\hline $\begin{array}{l}\text { Referencia } \\
\text { (Cita Abreviada) }\end{array}$ & $\begin{array}{l}\text { Estudio (Diseño y } \\
\text { objetivo) }\end{array}$ & $\begin{array}{l}\text { Población } \\
\left(n^{\circ} \text { y características }\right)\end{array}$ & $\begin{array}{l}\text { Descripción de las } \\
\text { intervenciones } \\
\text { comparaciones, exposiciones o } \\
\text { pruebas a estudio }\end{array}$ & $\begin{array}{l}\text { Resultados } \\
\text { (Estimadores de resultados-Magnitud del } \\
\text { efecto) }\end{array}$ & $\begin{array}{l}\text { Conclusiones } \\
\text { (conclusiones) }\end{array}$ & $\begin{array}{l}\text { Comentarios } \\
\text { Calidad de la } \\
\text { evidencia } \\
\text { Financiación } \\
\text { comentarios) }\end{array}$ \\
\hline $\begin{array}{l}\text { Howard CR, } 2003 \\
\text { (10) }\end{array}$ & $\begin{array}{l}\text { Diseño: ECA } \\
\text { Objetivo: evaluar los } \\
\text { efectos de la introducción } \\
\text { de chupete temprano vs. } \\
\text { tardío y de dos tipos de } \\
\text { exposición a pezones } \\
\text { artificiales (vaso vs. } \\
\text { biberón para la provisión } \\
\text { de suplementos en el } \\
\text { hospital) sobre la } \\
\text { duración de la lactancia } \\
\text { materna }\end{array}$ & $\begin{array}{l}700 \text { recién nacidos } \\
\text { ( } 36-42 \text { semanas, } \\
\text { peso al nacer } \geq 2200 \\
\text { g) } \\
\text { Madres con intención } \\
\text { de amamantar. }\end{array}$ & $\begin{array}{l}\text { Asignación aleatoria a dos } \\
\text { intervenciones } \\
\text { 1.- Uso de biberón Vs. Baso } \\
\text { 2.- uso de chupete: } \\
\text { I: uso de chupete temprano ( } 2 \text { a } 5 \\
\text { días) } \\
\text { C: uso tardío del chupete (>4 } \\
\text { semanas) } \\
\text { a) biberón/chupete temprano } \\
\text { ( } n=169 \text { ), b)Biberón/introducción } \\
\text { tardía chupete ( } n=167) ; \\
\text { c)vaso/uso temprano chupete } \\
\text { ( } n=185) \text { ) d)vaso/uso tardío de } \\
\text { chupete ( } n=179 \text { ). } \\
\text { e)chupete temprano sin } \\
\text { suplementos( } n=104 \text { ) y f)chupete } \\
\text { tardío sin suplementos ( } n=112 \text { ) } \\
\\
\text { Los datos se recogen a las } 2,5, \\
\text { 10, } 16,24,38 \text { y } 52 \text { semanas. } \\
\text { Los efectos de la intervención en } \\
\text { la duración de la lactancia fueron } \\
\text { evaluados con regresión logística } \\
\text { y análisis de supervivencia. El } \\
\text { análisis fue controlado por los } \\
\text { siguientes factores confusores: } \\
\text { historia obstétrica materna, edad, } \\
\text { raza, educación, estado de } \\
\text { suplementación postnatal. }\end{array}$ & 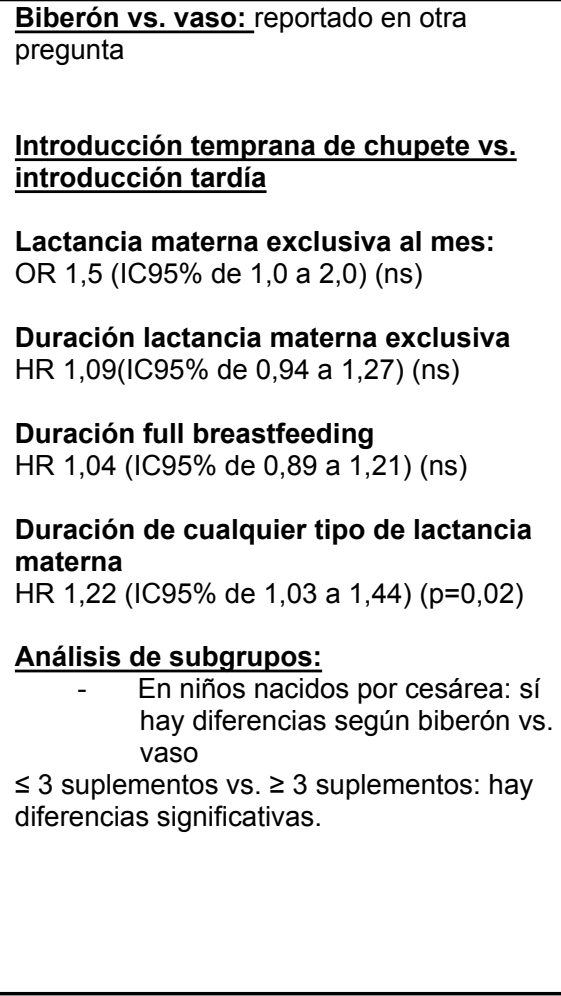 & $\begin{array}{l}\text { El uso de chupete en el } \\
\text { período neonatal era } \\
\text { perjudicial para la } \\
\text { lactancia materna } \\
\text { exclusiva y la duración } \\
\text { de cualquier tipo de } \\
\text { lactancia materna de. } \\
\text { Conclusiones sobre la } \\
\text { forma de administrar } \\
\text { los suplementos } \\
\text { resumido en otra } \\
\text { pregunta. resultados } \\
\text { Estos las } \\
\text { apoyan randaciones de } \\
\text { recomendación a } \\
\text { evitar la exposición a } \\
\text { pezones artificiales en } \\
\text { los amamantados en el } \\
\text { período neonatal }\end{array}$ & \\
\hline
\end{tabular}

\begin{tabular}{|c|c|}
\hline Study & Reason for exclusion \\
\hline Collins 2004 & $\begin{array}{l}\text { This RCT aimed to deternine the effect of artificial teats and cup on breasteeding in preserm infants and not term } \\
\text { infants, our prespecifeed indusion criteria }\end{array}$ \\
\hline Howand 2003 & 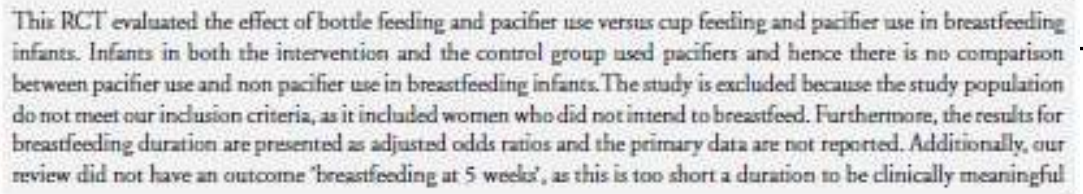 \\
\hline
\end{tabular}


Jerik 2009

\begin{tabular}{|c|c|}
\hline Methods & 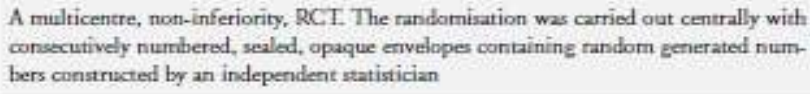 \\
\hline Participants & 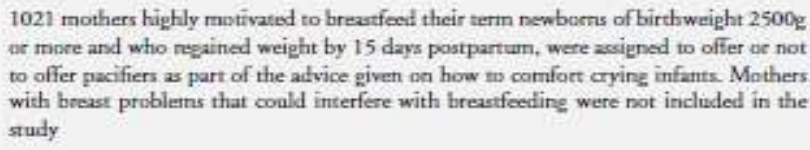 \\
\hline Interventions & 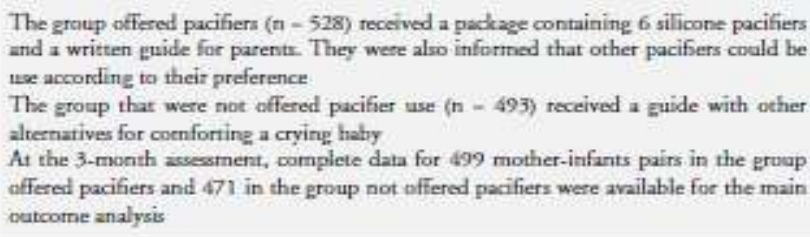 \\
\hline Outcotnes & 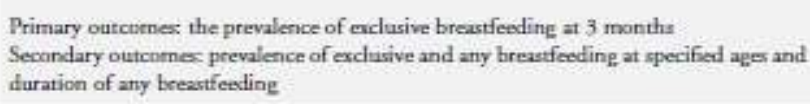 \\
\hline Notes & 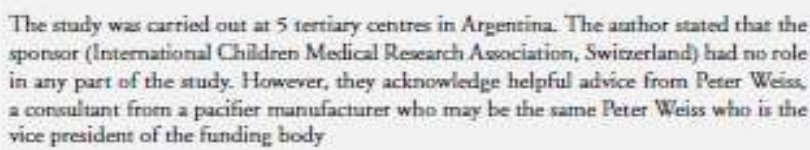 \\
\hline
\end{tabular}

\section{Kramer 2001}

\begin{tabular}{|c|c|}
\hline Methods & Double-blinded RCT. \\
\hline Participants & A total of 281 healthy breatfeeding wornen and their healthy term sinpleton infants \\
\hline Interventions & 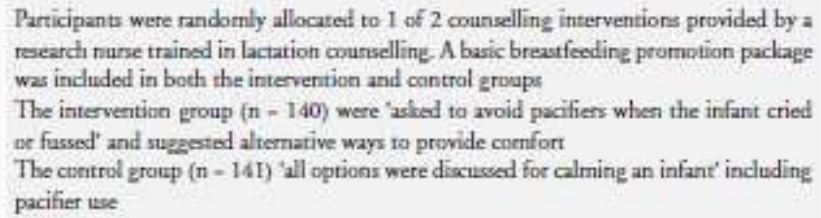 \\
\hline
\end{tabular}

Machers was ashed to complete $\mathrm{a}$ validated behaviour diary on 3 consecurive dayx, at 4 . 6 and 9 weeks of age. Study mothers were intervieved at 3 muath

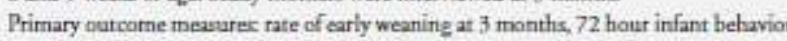
loger detailine frequency and duration of crying and fuscing and pacifier use at 4,6, weels

The trial was carried out frutr ] anuary 1998 to August 1999 on wamen giving birth at the Royal Victuria Hospital, a McCill Universiry-affiliatted materciry bogoital in Mantreal Quebe:

\section{Risk of biars}

Bias

Randons sequence peneration (selection Low risk

biast

Allocation cancealment (selection bias) Lew risk

Support for judgenent

\begin{tabular}{|c|c|c|}
\hline & & 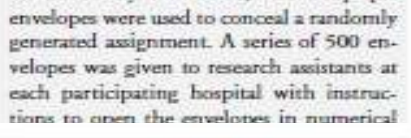 \\
\hline & & $\begin{array}{l}\text { sequence and ev assign the dyads to the cor- } \\
\text { responding eroup }\end{array}$ \\
\hline $\begin{array}{l}\text { Blinding (perfinemance bias and decection } \\
\text { bias) } \\
\text { All Outcomes }\end{array}$ & Low risk: & 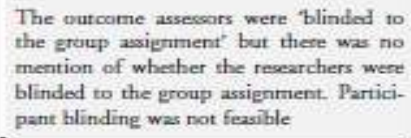 \\
\hline $\begin{array}{l}\text { Incomplete outcome data (attrition bias) } \\
\text { All uatcornes }\end{array}$ & Low risk & 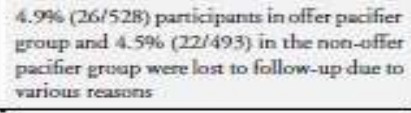 \\
\hline Selective reporting (reporting bizs) & Low risk: & None detected. \\
\hline Other bias & Undear risk & $\begin{array}{l}\text { Unsure of confilic of interest between the } \\
\text { funding body and the rsearcher }\end{array}$ \\
\hline
\end{tabular}

\begin{tabular}{|c|c|c|}
\hline $\begin{array}{l}\text { Random sequence generation (selection } \\
\text { bias) }\end{array}$ & Low risk & 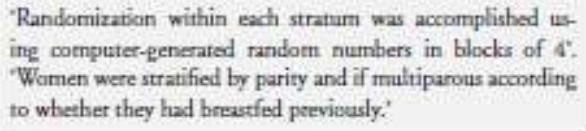 \\
\hline Allocation conceslment (selection bias) & Low risk & $\begin{array}{l}\text { The assigned allocation was cotuzined in an upraque envelope } \\
\text { opened by a research nume affer the convent was obtained' }\end{array}$ \\
\hline $\begin{array}{l}\text { Blinding (perfuctuance bias and decection } \\
\text { biast) } \\
\text { All Outcomes }\end{array}$ & Low risk & $\begin{array}{l}\text { "Study mothers were interviewer at } 3 \text { months by a nsearch avis- } \\
\text { tant who was blainded to the intervention ssatus of the mother. }\end{array}$ \\
\hline $\begin{array}{l}\text { Incomplete outcome data (attrition bias) } \\
\text { All outcomes }\end{array}$ & Low risk & $\begin{array}{l}8.2 \% \text { (23/281) participans, i.e. } 13 / 1 \text { to frompocifies avoidance } \\
\text { group, } 10 / 141 \text { from pacifier advived group last to follow-up } \\
\text { and did not cornglete the trial }\end{array}$ \\
\hline Selective reporting (reporting bias) & Low risk & None detected. \\
\hline Other bies & Low risk & None detected. \\
\hline
\end{tabular}

It is reported that the randomilastion was carried our centrally with random genera. on condacted by an independent statisti.

Consecutively numbered, sealed of eque 政 ech participating bospital with instrucequence and exp assign the dyats to the corrThe outcorne assessens were blinded to mention of whether the researchers ween pant blinding was not feasible

9.96 (26/528) participants in offer pecificer lost to follow-up due to funding body and the researcher

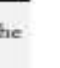

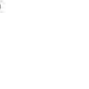




\section{Schubiger 1997}

\begin{tabular}{|c|c|}
\hline Methods & Multicentre prospertive randumised trial (from 10 centres)- \\
\hline Participants & 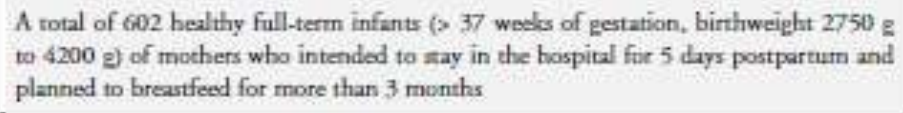 \\
\hline Interventions & 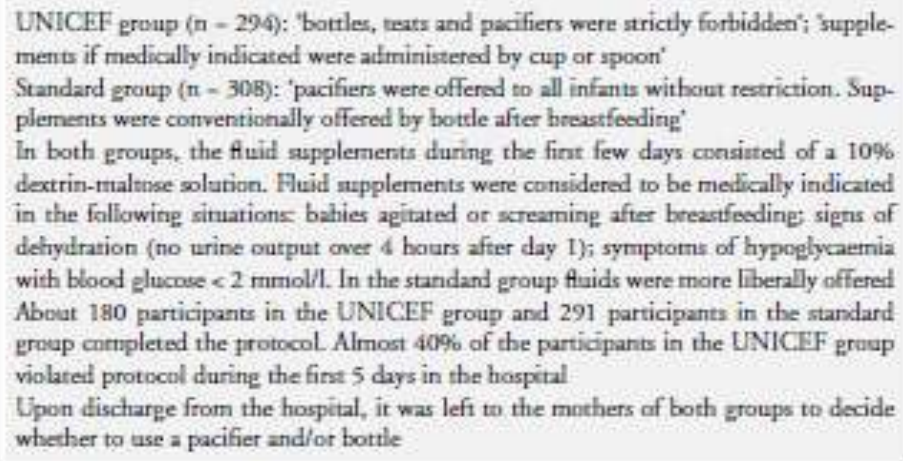 \\
\hline Outrotnes & 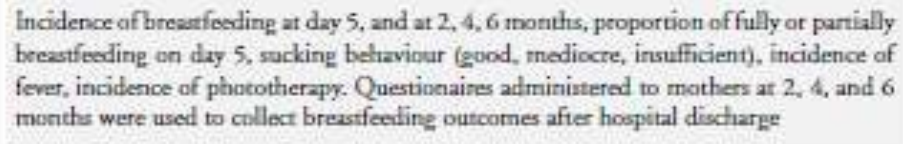 \\
\hline Notes & 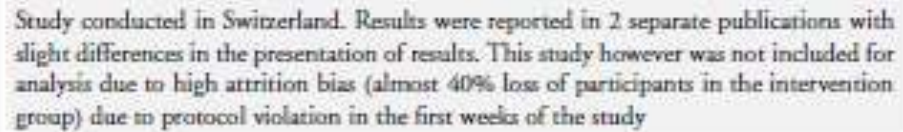 \\
\hline
\end{tabular}

\begin{tabular}{|c|c|c|}
\hline \multicolumn{3}{|l|}{ Risk of biats } \\
\hline Biss & Authors' judgemeat & Support for judgemeat \\
\hline $\begin{array}{l}\text { Random equence generation (selection } \\
\text { bias). }\end{array}$ & Low risk & $\begin{array}{l}\text { Centrally randormised, method of sequence } \\
\text { generation not reparted }\end{array}$ \\
\hline Allocation concealnent (seloction bias) & Undear risk & $\begin{array}{l}\text { Seled protocol forms distributed to cach } \\
\text { centre turt it is not reported whether they } \\
\text { were conseavtively numbered or nthether } \\
\text { opaque envelopos were wed }\end{array}$ \\
\hline $\begin{array}{l}\text { Blinding (performance bias and detection } \\
\text { bixs) } \\
\text { Al Outoomes }\end{array}$ & Undear risk & $\begin{array}{l}\text { There is no mention of blinding of re } \\
\text { searchers or outcones assecsors. Wlinding } \\
\text { of participants would not be feasible }\end{array}$ \\
\hline $\begin{array}{l}\text { Incomplete outcome data (atrition bias) } \\
\text { All outcomes }\end{array}$ & High risk & 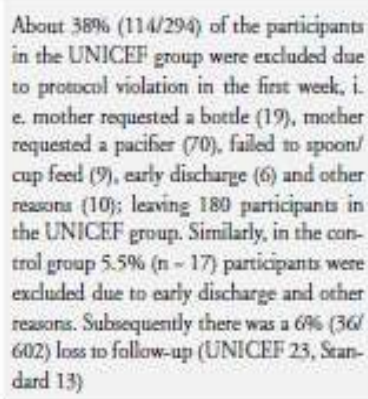 \\
\hline Selective reporting (reporting bias) & Low risk & None detected: \\
\hline Other bia: & Low risk & None detected. \\
\hline
\end{tabular}




\section{Estudios sobre efectos en la Muerte súbita del lactante}

TABLE 1. Characteristics of Studies Reviewed for Meta-analysis

\begin{tabular}{|c|c|c|c|c|c|c|c|}
\hline \multicolumn{3}{|c|}{ Study } & \multicolumn{2}{|c|}{ No. of Infants } & \multirow[t]{2}{*}{ Controls Matched On } & \multirow{2}{*}{$\begin{array}{l}\text { Time From Infant's Death or } \\
\text { Identification of Controls to } \\
\text { Interview With Parents }\end{array}$} & \multirow[t]{2}{*}{ Failed Criteria* } \\
\hline Authors & Location & Years & SIDS & Controls & & & \\
\hline Carpenter et al ${ }^{7}$ & Europe & $1992-1996$ & 745 & 2411 & Age, region & $\begin{array}{l}\text { Median: } 15 \mathrm{~d} \text { (cases) and } 18 \mathrm{~d} \\
\text { (controls) }\end{array}$ & None \\
\hline Fleming et $\mathrm{al}^{10}$ & United Kingdom & 1993-1996 & 318 & 1299 & Age & Two interviews, both within 2 wk & None \\
\hline Hauck et al ${ }^{11}$ & United States & 1993-1996 & 260 & 260 & Race/ethnicity, age, birth weight & 2 wk & None \\
\hline McGarvey et al ${ }^{12}$ & Ireland & $1994-1998$ & 203 & 622 & Age, region & $<6$ wk & None \\
\hline Mitchell et al ${ }^{13}$ & New Zealand & $1987-1990$ & 485 & 1800 & Not matched & $81 \%<7 \mathrm{wk}$ & None \\
\hline Tappin et al ${ }^{14}$ & Scotland & $1996-2000$ & 131 & 278 & Age, season, maternity unit & $<28 \mathrm{~d}$ & $\begin{array}{l}\text { None ( } 1 \text { was not stated } \\
\text { explicitly but was } \\
\text { implied) }\end{array}$ \\
\hline L'Hoir et al ${ }^{4}$ & Netherlands & $1995-1996$ & 73 & 146 & Age & $\begin{array}{l}\text { Median: } 34 \mathrm{~d} \text { (cases) and } 77 \mathrm{~d} \\
\text { (controls) }\end{array}$ & 2 \\
\hline
\end{tabular}

- AAP Criteria: 1, appropriate definition of SIDS; 2, autopsies performed in >98\% of cases; 3 , adequate description of SIDS ascertainment in the study population; 4 , matched control subjects; 5 , adequate description of process of control selection; and 6 , inclusion of sufficient data to calculate ORs and $95 \%$ CIs or the actual ORs and CIs. 15

\begin{tabular}{|c|c|c|c|c|c|}
\hline Study/setting & Deskgn & Exposute/outcone & Confounders controtled & Anatyses & 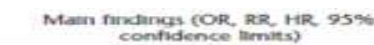 \\
\hline 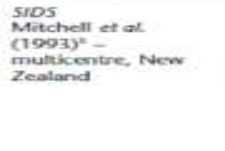 & 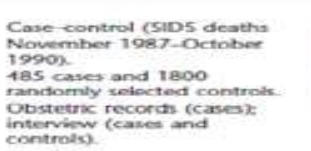 & 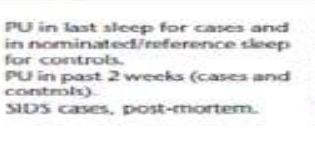 & 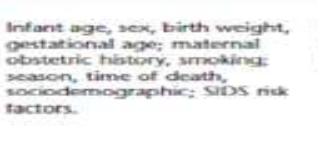 & 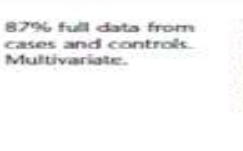 & 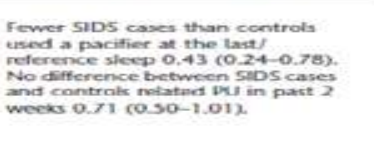 \\
\hline 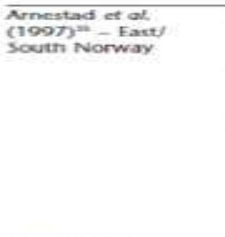 & 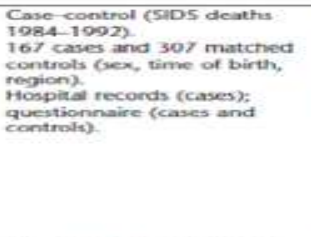 & 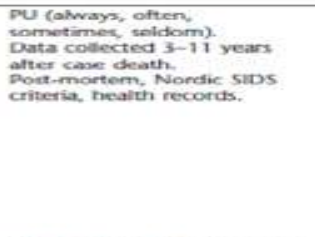 & & 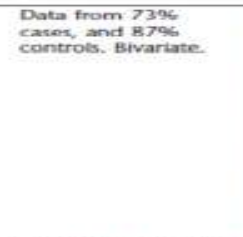 & 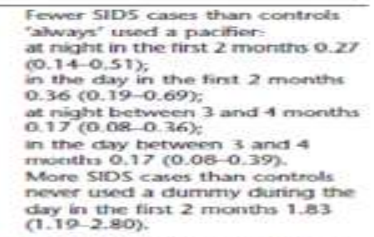 \\
\hline 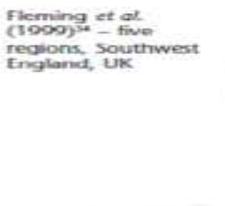 & 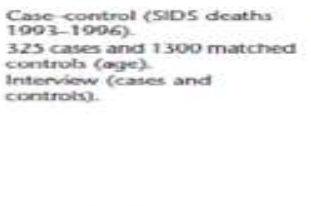 & 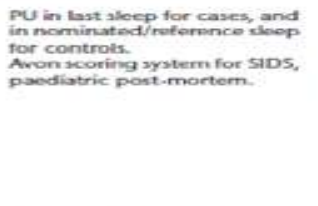 & 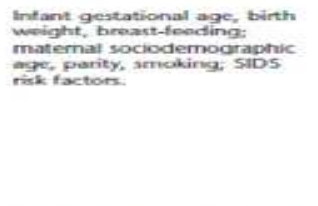 & 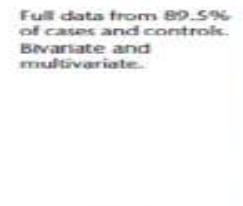 & 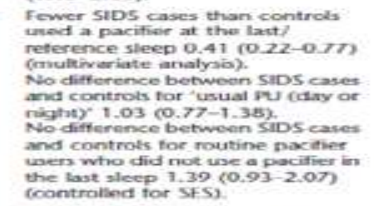 \\
\hline 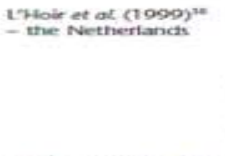 & 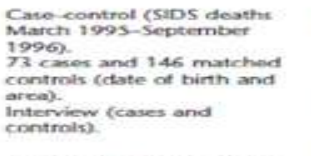 & 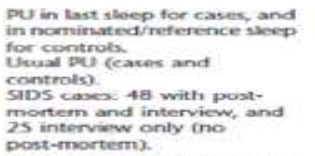 & 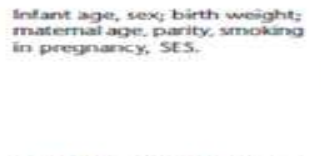 & 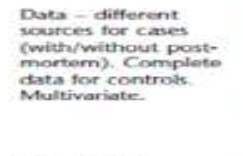 & 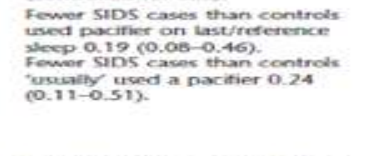 \\
\hline 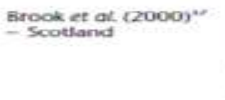 & 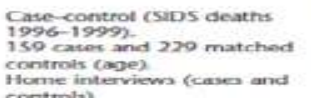 & 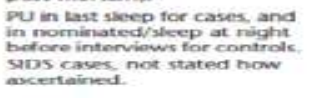 & 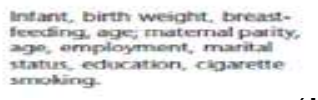 & $\begin{array}{l}\text { Not stated it } \\
\text { courpliter dota. } \\
\text { Mentivariato. }\end{array}$ & 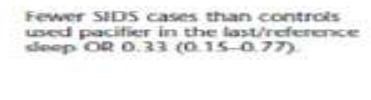 \\
\hline
\end{tabular}




\begin{tabular}{|c|c|c|c|c|c|c|}
\hline $\begin{array}{l}\text { Referencia } \\
\text { (Cita Abreviada) }\end{array}$ & $\begin{array}{l}\text { Estudio (Diseño y } \\
\text { objetivo) }\end{array}$ & $\begin{array}{l}\text { Población } \\
\left(n^{\circ} \text { y características }\right)\end{array}$ & $\begin{array}{l}\text { Descripción de las } \\
\text { intervenciones } \\
\text { comparaciones, exposiciones o } \\
\text { pruebas a estudio }\end{array}$ & $\begin{array}{l}\text { Resultados } \\
\text { (Estimadores de resultados-Magnitud del } \\
\text { efecto) }\end{array}$ & $\begin{array}{l}\text { Conclusiones } \\
\text { (conclusiones) }\end{array}$ & $\begin{array}{l}\text { Comentarios } \\
\text { Calidad de la } \\
\text { evidencia } \\
\text { Financiación } \\
\text { comentarios) }\end{array}$ \\
\hline $\begin{array}{l}\text { Walsh et al, } 2014 \\
\text { (33) }\end{array}$ & $\begin{array}{l}\text { Diseño: } \\
\text { Estudio de cohorte } \\
\text { longitudinal } \\
\text { Objetivo: probar la } \\
\text { hipótesis (1) que los } \\
\text { cuidadores estaban } \\
\text { menos familiarizados con } \\
\text { el papel de chupetes en la } \\
\text { prevención del síndrome } \\
\text { de muerte súbita del } \\
\text { lactante (SMSL) que otras } \\
\text { recomendaciones, y (2) } \\
\text { que la intervención } \\
\text { educativa incrementaría } \\
\text { el uso del chupete en } \\
\text { bebés menores de seis } \\
\text { meses, y (3) que la otitis } \\
\text { no ocurriría con mayor } \\
\text { frecuencia en los usuarios } \\
\text { de chupetes. }\end{array}$ & $\begin{array}{l}\text { Recién nacidos } \\
\text { menores de } 12 \\
\text { meses y sus } \\
\text { cuidadores } \\
\text { principales }\end{array}$ & $\begin{array}{l}\text { Encuesta a cuidadores sanitarios } \\
\text { principales e intervención } \\
\text { educativa con los padres de } \\
\text { recién nacidos con un } \\
\text { seguimiento de } 12 \text { meses, en un } \\
\text { hospital docente }\end{array}$ & $\begin{array}{l}\text { Se analizaron los datos de } 780 \text { niños. Los } \\
\text { padres sabían sobre el asesoramiento contra } \\
\text { del colecho en } 469 / 780(60 \%) \text { de los casos, } \\
\text { de hábitos de fumar en } 660 / 776(85 \%) \text {, y el } \\
\text { dormir boca abajo en } 613 / 780(79 \%) \text {. } \\
\text { Sólo } 268 / 777 \text { ( } 35 \% \text { ) conocían la } \\
\text { recomendación de ofrecer el chupete a la } \\
\text { hora de acostarse. Al inicio del estudio } \\
449 / 780(58 \%) \text { no utilizaron un chupete. De } \\
210 / 338 \text { lactantes de menos de } 6 \text { meses } \\
\text { seguidos durante el estudios } 41 / 112(37 \%) \\
\text { no usuarios habían empezado a utilizar el } \\
\text { chupete a la hora de dormir (NNT 3). Durante } \\
\text { el mismo período, } 37 / 98 \text { (38\%) usuarios } \\
\text { habían suspendido su chupete. } \\
\text { La otitis media no difirió entre los usuarios y } \\
\text { los no usuarios a los } 12 \text { meses }\end{array}$ & & \\
\hline
\end{tabular}




\section{ANEXO III. Forest-Plot}

1. Proporción de niños amamantados exclusivamente con leche materna a los 3 meses

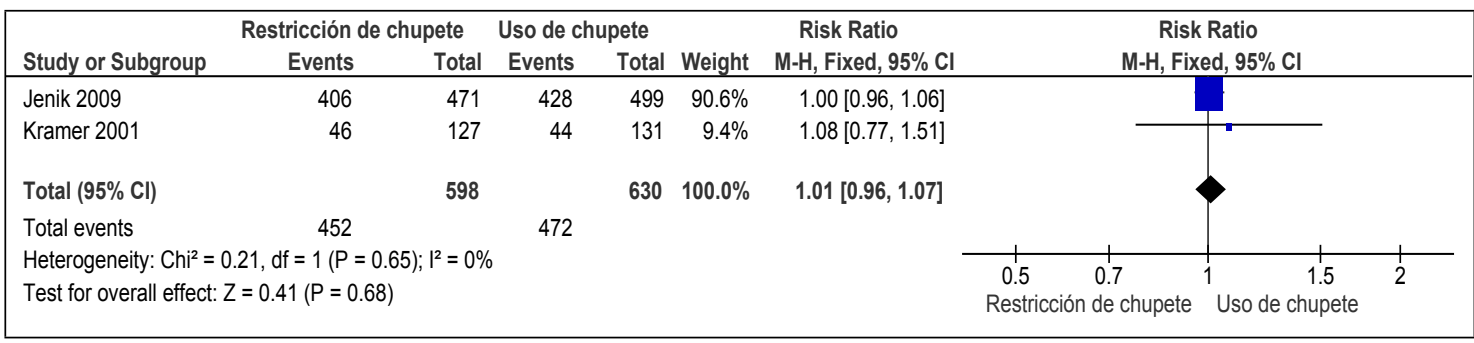

2. Proporción de niños amamantados exclusivamente con leche materna a los 4 meses

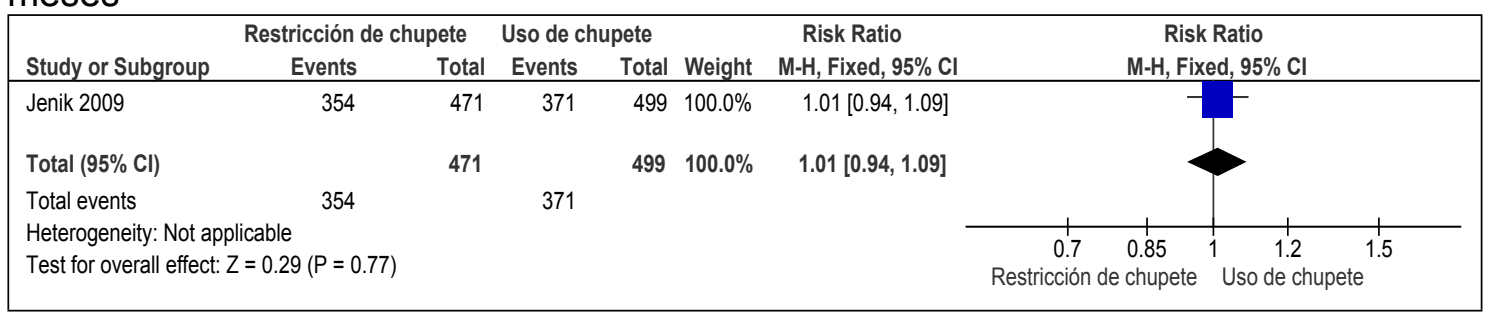

3. Proporción de niños amamantados parcialmente con leche materna a los 3 meses

\begin{tabular}{|c|c|c|c|c|c|c|c|}
\hline \multirow[b]{2}{*}{ Study or Subgroup } & \multicolumn{2}{|c|}{ Pacifier use } & \multicolumn{2}{|c|}{ Pacifier restriction } & \multirow[b]{2}{*}{ Weight } & \multirow{2}{*}{$\begin{array}{c}\text { Risk Ratio } \\
\text { M-H, Fixed, } 95 \% \mathrm{Cl} \\
\end{array}$} & \multirow{2}{*}{$\begin{array}{c}\text { Risk Ratio } \\
\text { M-H, Fixed, } 95 \% \mathrm{Cl}\end{array}$} \\
\hline & Events & Total & Events & Total & & & \\
\hline Jenik 2009 & 494 & 499 & 468 & 471 & $82.2 \%$ & $1.00[0.99,1.01]$ & \\
\hline Kramer 2001 & 107 & 131 & 103 & 127 & $17.8 \%$ & $1.01[0.90,1.13]$ & \\
\hline Total $(95 \% \mathrm{Cl})$ & & 630 & & 598 & $100.0 \%$ & $1.00[0.98,1.02]$ & 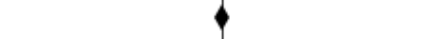 \\
\hline Total events & 601 & & 571 & & & & \\
\hline \multicolumn{7}{|c|}{$\begin{array}{l}\text { Heterogeneity: } \mathrm{Chi}^{2}=0.13, \mathrm{df}=1(\mathrm{P}=0.72) ; \mathrm{I}^{2}=0 \% \\
\text { Test for overall effect: } Z=0.15(P=0.88)\end{array}$} & 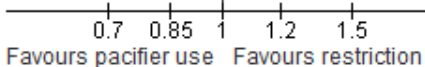 \\
\hline
\end{tabular}

4. Proporción de niños amamantados parcialmente con leche materna a los 4 meses

\begin{tabular}{|c|c|c|c|c|c|c|c|}
\hline \multirow[b]{2}{*}{ Study or Subgroup } & \multicolumn{2}{|c|}{ Pacifier use } & \multicolumn{2}{|c|}{ Pacifier restriction } & \multirow[b]{2}{*}{ Weight } & \multirow{2}{*}{$\begin{array}{c}\text { Risk Ratio } \\
\text { M-H, Fixed, } 95 \% \mathrm{Cl}\end{array}$} & \multirow{2}{*}{$\begin{array}{c}\text { Risk Ratio } \\
\text { M-H, Fixed, } 95 \% \mathrm{Cl}\end{array}$} \\
\hline & Events & Total & Events & Total & & & \\
\hline Jenik 2009 & 482 & 499 & 452 & 471 & $100.0 \%$ & $1.01[0.98,1.03]$ & \\
\hline Total $(95 \% \mathrm{Cl})$ & & 499 & & 471 & $100.0 \%$ & $1.01[0.98,1.03]$ & \\
\hline Total events & 482 & & 452 & & & & \\
\hline \multicolumn{3}{|c|}{$\begin{array}{l}\text { Heterogeneity: Not applicable } \\
\text { Test for overall effect: } Z=0.52(P=0.61)\end{array}$} & & & & & 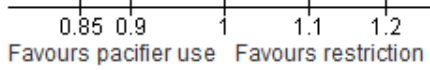 \\
\hline
\end{tabular}


4. Casos de síndrome de muerte súbita del lactante en uso rutinario vs. no uso rutinario de chupete durante las horas de sueño.

OR (ajustado por factores confusores) de muerte súbita del lactante con utilización habitual de chupete o no en las horas sueño

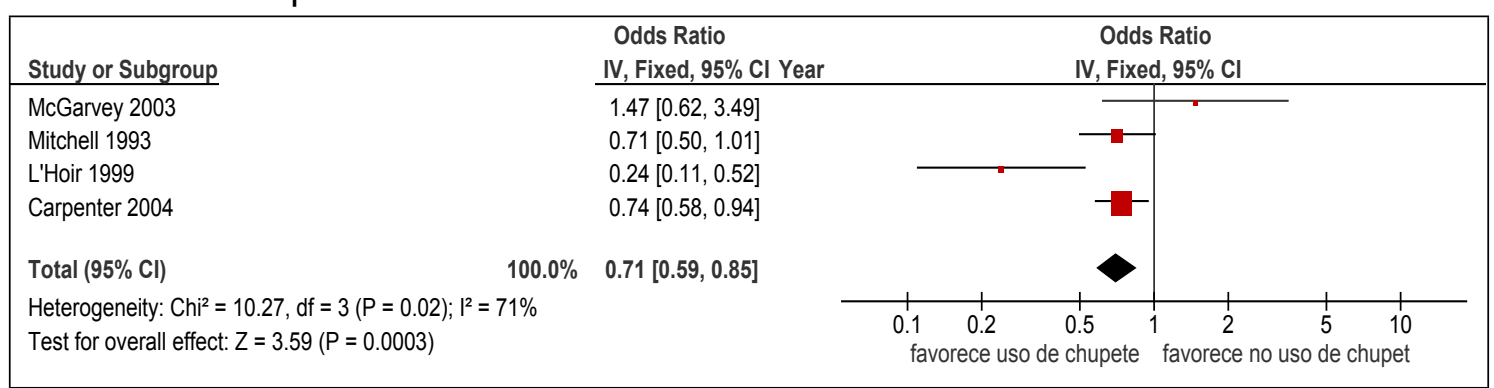

(resultados sin ajustar por factores confusores)

\begin{tabular}{|c|c|c|c|c|c|c|c|c|c|}
\hline \multirow[b]{2}{*}{ Study or Subgroup } & \multicolumn{2}{|c|}{ uso chupete } & \multicolumn{2}{|c|}{ no uso de chupete } & \multicolumn{3}{|c|}{ Odds Ratio } & \multirow{2}{*}{\multicolumn{2}{|c|}{$\begin{array}{c}\text { Odds Ratio } \\
\text { M-H, Fixed, } 95 \% \mathrm{Cl}\end{array}$}} \\
\hline & Events & Total & Events & Total & Weight & M-H, Fixed, $95 \% \mathrm{Cl}$ & Year & & \\
\hline Mitchell 1993 & 74 & 446 & 318 & 1537 & $16.5 \%$ & $0.76[0.58,1.01]$ & 1993 & $\rightarrow$ & \\
\hline Michell (a) 1993 & 5 & 100 & 116 & 938 & $2.9 \%$ & $0.37[0.15,0.94]$ & 1993 & & \\
\hline Arnestad 1997 & 63 & 256 & 58 & 172 & $7.2 \%$ & $0.64[0.42,0.98]$ & 1997 & & \\
\hline Fleming 1999 & 194 & 980 & 124 & 637 & $16.7 \%$ & $1.02[0.79,1.31]$ & 1999 & 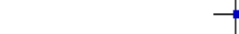 & \\
\hline L'Hoir 1999 & 15 & 101 & 58 & 118 & $6.3 \%$ & $0.18[0.09,0.35]$ & 1999 & & \\
\hline Alm 2002 & 162 & 771 & 70 & 307 & $10.9 \%$ & $0.90[0.66,1.24]$ & 2002 & & \\
\hline McGarvey 2003 & 119 & 530 & 36 & 245 & $5.3 \%$ & $1.68[1.12,2.53]$ & 2003 & & \\
\hline Carpenter 2004 & 394 & 1886 & 236 & 974 & $34.1 \%$ & $0.83[0.69,0.99]$ & 2004 & $\rightarrow$ & \\
\hline Total $(95 \% \mathrm{Cl})$ & & 5070 & & 4928 & $100.0 \%$ & $0.83[0.75,0.93]$ & & 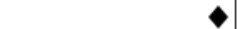 & \\
\hline Total events & 1026 & & 1016 & & & & & & \\
\hline $\begin{array}{l}\text { Heterogeneity: } \mathrm{Chi}^{2}= \\
\text { Test for overall effect }\end{array}$ & $\begin{array}{l}39.73, d f \\
Z=3.31\end{array}$ & $\begin{array}{l}7(P \& \\
=0.00\end{array}$ & $\begin{array}{l}0.00001) ; 1^{2} \\
\text { 109) }\end{array}$ & & & & & $\begin{array}{lll}0.1 & 0.2 & 0.5 \\
\text { Favours uso de chupete }\end{array}$ & $\begin{array}{ccc}2 & 5 & 10 \\
\text { Favours no uso chupete }\end{array}$ \\
\hline
\end{tabular}

OR (ajustado por factores confusores) de muerte súbita del lactante con utilización de chupete chupete o no en el último sueño

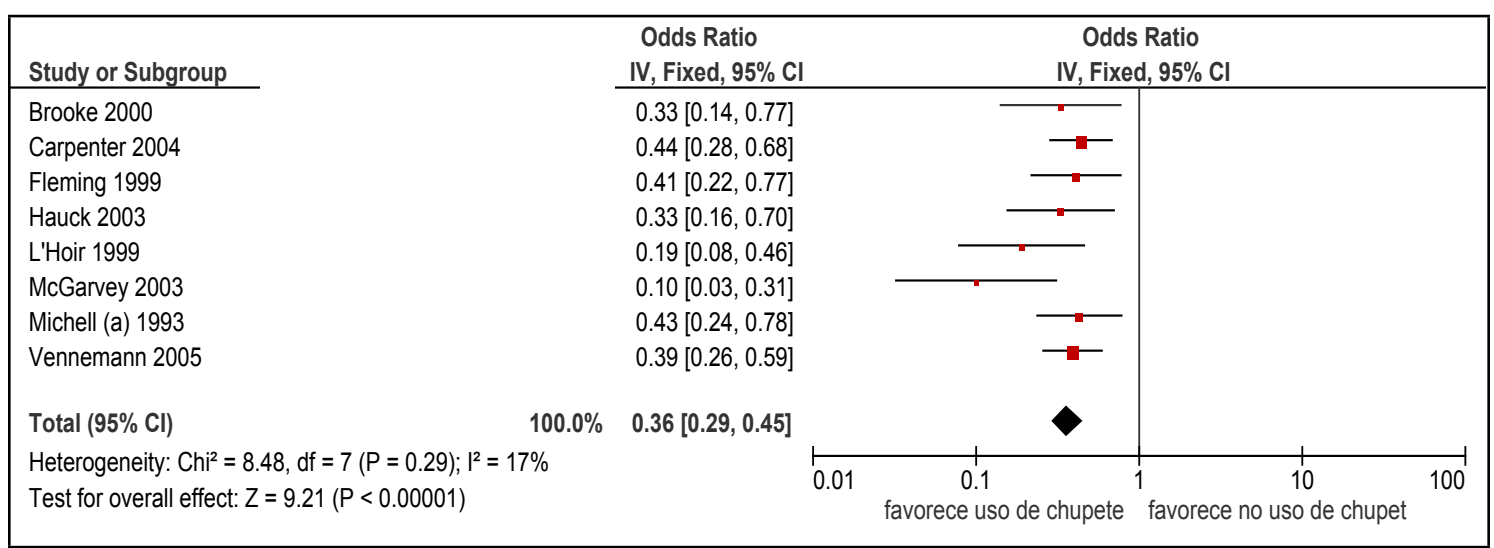


OR (no ajustado) de muerte súbita del lactante con utilización de chupete o no en el último sueño

\begin{tabular}{|c|c|c|c|c|c|c|c|c|c|c|}
\hline \multirow[b]{2}{*}{ Study or Subgroup } & \multicolumn{2}{|c|}{ Experimental } & \multicolumn{2}{|c|}{ Control } & \multirow[b]{2}{*}{ Weight } & \multirow{2}{*}{$\begin{array}{c}\text { Odds Ratio } \\
\text { M-H, Fixed, } 95 \% \mathrm{Cl}\end{array}$} & \multirow{2}{*}{\multicolumn{4}{|c|}{$\begin{array}{c}\text { Odds Ratio } \\
\text { M-H, Fixed, 95\% Cl }\end{array}$}} \\
\hline & Events & Total & Events & Total & & & & & & \\
\hline Brooke 2000 & 42 & 160 & 66 & 177 & $5.6 \%$ & $0.60[0.38,0.95]$ & & $\longrightarrow$ & & \\
\hline Carpenter 2004 & 130 & 783 & 229 & 761 & $23.5 \%$ & $0.46[0.36,0.59]$ & & - & & \\
\hline Fleming 1999 & 124 & 788 & 189 & 821 & $18.9 \%$ & $0.62[0.49,0.80]$ & & $\rightarrow$ & & \\
\hline Hauck 2003 & 39 & 122 & 221 & 398 & $8.6 \%$ & $0.38[0.25,0.58]$ & & 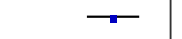 & & \\
\hline L'Hoir 1999 & 8 & 77 & 65 & 142 & $5.0 \%$ & $0.14[0.06,0.31]$ & & & & \\
\hline McGarvey 2003 & 45 & 400 & 106 & 386 & $11.6 \%$ & $0.33[0.23,0.49]$ & & 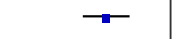 & & \\
\hline Michell (a) 1993 & 19 & 391 & 165 & 1586 & $7.5 \%$ & $0.44[0.27,0.72]$ & & $\longrightarrow$ & & \\
\hline Vennemann 2005 & 135 & 678 & 194 & 644 & $19.3 \%$ & $0.58[0.45,0.74]$ & & $\rightarrow$ & & \\
\hline Total $(95 \% \mathrm{Cl})$ & & 3399 & & 4915 & $100.0 \%$ & $0.48[0.43,0.54]$ & & $\theta$ & & \\
\hline Total events & 542 & & 1235 & & & & & & & \\
\hline \multicolumn{7}{|c|}{ Heterogeneity: $\mathrm{Chi}^{2}=21.23, \mathrm{df}=7(\mathrm{P}=0.003) ; \mathrm{I}^{2}=67 \%$} & & 01 & 10 & 100 \\
\hline \multicolumn{7}{|c|}{ Test for overall effect: $Z=12.10(P<0.00001)$} & $\mathrm{Fa}$ & $\begin{array}{l}0.1 \\
\text { s [experimental] }\end{array}$ & Favours [control] & 100 \\
\hline
\end{tabular}

Asociación entre lactancia materna y SMSL (31)

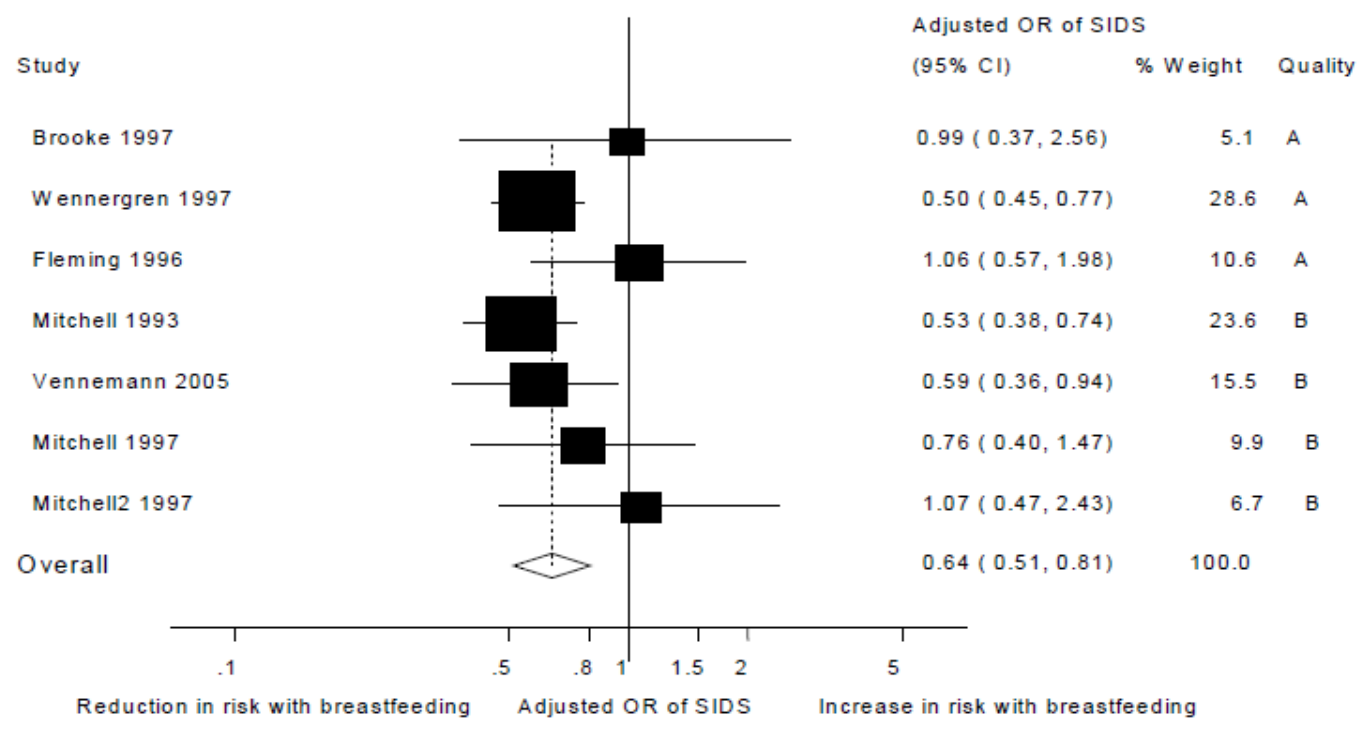


Asociación entre lactancia materna y SMSL (32)

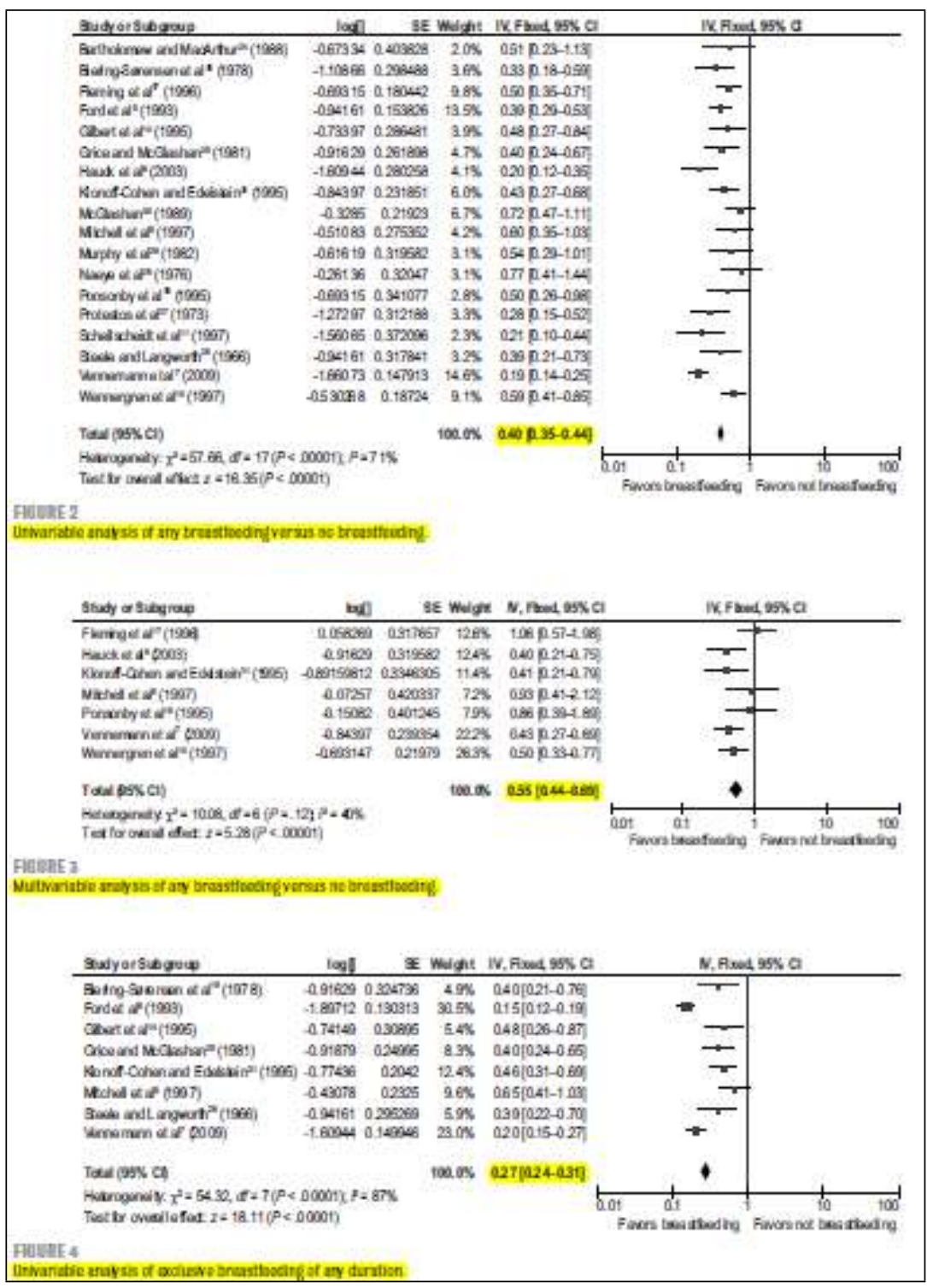




\section{ANEXO IV. Evaluación de la calidad}

\section{AMSTAR Herramienta de medición para evaluar revisiones sistemáticas}

\begin{tabular}{|c|c|c|c|}
\hline AMSTAR & $\begin{array}{l}\text { Jaafar, } \\
2012 \text { (4) }\end{array}$ & $\begin{array}{l}\text { Callhagan } \\
2005 \text { (25) }\end{array}$ & $\begin{array}{l}\text { Mitchell } \\
2006(5)\end{array}$ \\
\hline $\begin{array}{l}\text { 1. ¿Se brindó un diseño "a priori”? } \\
\text { La pregunta de la investigación y los criterios de } \\
\text { inclusión deberían establecerse antes de llevar a } \\
\text { cabo la revisión }\end{array}$ & Sí & $\mathrm{Si}$ & $\begin{array}{l}\text { No } \\
\text { responde }\end{array}$ \\
\hline $\begin{array}{l}\text { 2. ¿Hubo duplicación en la selección de estudios } \\
\text { y extracción de datos? Debería haber al menos dos } \\
\text { personas independientes a cargo de la extracción de } \\
\text { datos, y debería existir un procedimiento } \\
\text { consensuado para los desacuerdos }\end{array}$ & Sí & $\mathrm{Si}$ & $\begin{array}{l}\text { No } \\
\text { responde }\end{array}$ \\
\hline $\begin{array}{l}\text { 3. ¿Se realizó una búsqueda exhaustiva de } \\
\text { literatura? } \\
\text { Deberían consultarse al menos dos fuentes } \\
\text { electrónicas. El informe debe incluir los años y las } \\
\text { bases de datos utilizadas (por ej. Central, EMBASE y } \\
\text { MEDLINE). Deben especificarse las palabras clave } \\
\text { y/o los términos MESH y, de ser posible, debe } \\
\text { proveerse la estrategia de búsqueda. Todas las } \\
\text { búsquedas deberían ser complementadas con } \\
\text { consultas a contenidos actuales, revisiones, libros de } \\
\text { textos, registros especializados, o expertos en el } \\
\text { campo particular de estudio, y mediante la revisión } \\
\text { de las referencias en los estudios encontrados }\end{array}$ & Sí & $\mathrm{Si}$ & $\begin{array}{l}\text { No } \\
\text { responde }\end{array}$ \\
\hline $\begin{array}{l}\text { 4. ¿Se utilizó el estado de publicación (es decir, } \\
\text { literatura gris) como criterio de inclusión? } \\
\text { Los autores deberían especificar que buscaron } \\
\text { informes sin tener en cuenta el tipo de publicación. } \\
\text { Los autores deberían especificar si excluyeron o no } \\
\text { algún informe (de la revisión sistemática), en función } \\
\text { del estado de publicación, idioma, etc. }\end{array}$ & $\begin{array}{l}\text { No } \\
\text { responde }\end{array}$ & $\mathrm{Si}$ & Sí \\
\hline $\begin{array}{l}\text { 5. ¿Se brindó una lista de estudios (incluidos y } \\
\text { excluidos)? } \\
\text { Debería proveerse una lista de estudios incluidos y } \\
\text { excluidos }\end{array}$ & Sí & $\mathrm{Si}$ & $\begin{array}{l}\text { Si (solo } \\
\text { de } \\
\text { estudios } \\
\text { incluidos) }\end{array}$ \\
\hline $\begin{array}{l}\text { 6. ¿Se brindaron las características de los } \\
\text { estudios incluidos? De manera adjunta tal como } \\
\text { una tabla, deberían proveerse los datos de los } \\
\text { estudios originales sobre los participantes, las } \\
\text { intervenciones y los resultados. Deberían informarse } \\
\text { los rangos de las características en todos los } \\
\text { estudios analizados, por ej, la edad, la raza, el sexo, } \\
\text { los datos socioeconómicos relevantes, el estado de } \\
\text { enfermedad, la duración, la severidad, o cualquier } \\
\text { otra enfermedad }\end{array}$ & Sí & $\mathrm{Si}$ & No \\
\hline $\begin{array}{l}\text { 7. ¿Se evaluó y documentó la calidad científica } \\
\text { de los estudios incluidos? Deberían proveerse } \\
\text { métodos "a priori" (por ej, para estudios de } \\
\text { efectividad si el autor o los autores eligen incluir sólo } \\
\text { estudios aleatorizados, de doble ciego, controlados } \\
\text { con placebo, u ocultamiento de las asignaciones } \\
\text { como criterios de inclusión). Para otros tipos de } \\
\text { estudios, serán relevantes los ítems alternativos }\end{array}$ & Sí & $\mathrm{Si}$ & No \\
\hline
\end{tabular}




\begin{tabular}{|c|c|c|c|}
\hline $\begin{array}{l}\text { 8. ¿Se utilizó de manera adecuada la calidad } \\
\text { científica de los estudios incluidos al formular las } \\
\text { conclusiones? El rigor metodológico y la calidad } \\
\text { científica de los estudios deberían considerarse en el } \\
\begin{array}{l}\text { análisis y las conclusiones de la revisión, y } \\
\text { plantearse explícitamente al formular las } \\
\text { recomendaciones }\end{array}\end{array}$ & Sí & $\mathrm{Si}$ & $\mathrm{Si}$ \\
\hline $\begin{array}{l}\text { 9. ¿Fueron adecuados los métodos utilizados } \\
\text { para combinar los hallazgos de los estudios? } \\
\text { Para los resultados conjuntos, debería hacerse una } \\
\text { prueba para garantizar que los estudios pudieron } \\
\text { combinarse y para evaluar sus homogeneidad (es } \\
\text { decir, la prueba chi-cuadrado para la homogeneidad, } \\
\mathrm{I}^{2} \text { ). Si existe heterogeneidad debería utilizarse un } \\
\text { modelo de efectos aleatorios y/o debería } \\
\text { considerarse lo adecuado de la combinación (es } \\
\text { decir, ¿fue adecuado combinar los resultados?) }\end{array}$ & Sí & \begin{tabular}{|lr} 
No aplicable \\
(no r se \\
combinaron)
\end{tabular} & $\begin{array}{l}\text { No } \\
\text { aplicable } \\
\text { (no se } \\
\text { combinar } \\
\text { on) }\end{array}$ \\
\hline $\begin{array}{l}\text { 10. ¿Se valoró la probabilidad de sesgo de } \\
\text { publicación? } \\
\text { Una evaluación de sesgo de publicación debería } \\
\text { incluir una combinación de ayudas gráficas (por ej. } \\
\text { un gráfico en embudo - funnel plot -, otras pruebas } \\
\text { disponibles) y/o pruebas estadísticas (por ej. prueba } \\
\text { de regresión de Egger) }\end{array}$ & Sí & No responde & $\begin{array}{l}\text { No } \\
\text { responde, } \\
\text { aunque } \\
\text { utiliza } \\
\text { datos no } \\
\text { publicado } \\
\text { S }\end{array}$ \\
\hline $\begin{array}{l}\text { 11. ¿Se planteó el conflicto de intereses? } \\
\text { Deberían reconocerse claramente las fuentes } \\
\text { posibles de apoyo tanto en la revisión sistemática } \\
\text { como en los estudios incluidos }\end{array}$ & Sí & $\mathrm{Si}$ & No \\
\hline
\end{tabular}




\section{0- BIBLIOGRAFÍA}

(1) NICE. Postnatal care up to 8 weeks after birth. Julio 2006 (actualizado en Febrero de 2015). Disponible en: http://guidance.nice.org.uk/CG37.

(2) Perinatal Services BC. Health Promotion Guideline 1. Safe Sleep Environment Guideline For Infants 0 to 12 months of age. February 2011. Disponible en: http://www.perinatalservicesbc.ca/NR/rdonlyres/D799441C-3E00-49EE-BDF72A3196B971F0/0/HPGuidelinesSafeSleep1.pdf.

(3) Aguayo Maldonado J, Arana Cañedo Argüelles C, Arena Ansótegui J, Canduela Martínez V, Flores Antón B, Gómez Papí A, Hernández Aguilar MT, Lasarte Velillas JJ, Lozano de la Torre MJ, Martín Calama J, Navas Lucena V. IHAN Calidad en la asistencia profesional al nacimiento y la lactancia. Ministerio de Sanidad, Política Social e Igualdad. Informes, estudios e investigación. 2011.

(4) Jaafar SH, Jahanfar S, Angolkar M, Ho JJ. Effect of restricted pacifier use in breastfeeding term infants for increasing duration of breastfeeding. Cochrane Database Syst Rev 2012;7:CD007202.

(5) Mitchell EA, Blair PS, L'Hoir MP. Should pacifiers be recommended to prevent sudden infant death syndrome? Pediatrics 2006 May;117(5):1755-8.

(6) Fleming PJ, Blair PS, Bacon C, Bensley D, Smith I, Taylor E, et al. Environment of infants during sleep and risk of the sudden infant death syndrome: results of 1993-5 case-control study for confidential inquiry into stillbirths and deaths in infancy. Confidential Enquiry into Stillbirths and Deaths Regional Coordinators and Researchers. BMJ 1996 Jul 27;313(7051):191-5.

(7) Fleming PJ, Blair PS, Pollard K, Platt MW, Leach C, Smith I, et al. Pacifier use and sudden infant death syndrome: results from the CESDI/SUDI case control study. CESDI SUDI Research Team. Arch Dis Child 1999 Aug;81(2):112-6.

(8) Jaafar SH, Jahanfar S, Angolkar M, Ho JJ. Pacifier use versus no pacifier use in breastfeeding term infants for increasing duration of breastfeeding. Cochrane Database Syst Rev 2011;(3):CD007202.

(9) Hauck FR, Tanabe KO. SIDS. Clin Evid (Online ) 2009;2009.

(10) Howard CR, Howard FM, Lanphear B, Eberly S, deBlieck EA, Oakes D, et al. Randomized clinical trial of pacifier use and bottle-feeding or cupfeeding and their effect on breastfeeding. Pediatrics 2003 Mar;111(3):511-8.

(11) Aarts C, Hornell A, Kylberg E, Hofvander Y, Gebre-Medhin M. Breastfeeding patterns in relation to thumb sucking and pacifier use. Pediatrics 1999 Oct;104(4):e50.

(12) Barros FC, Victora CG, Semer TC, Tonioli FS, Tomasi E, Weiderpass E. Use of pacifiers is associated with decreased breast-feeding duration. Pediatrics 1995 Apr;95(4):497-9.

(13) Howard CR, Howard FM, Lanphear B, deBlieck EA, Eberly S, Lawrence RA. The effects of early pacifier use on breastfeeding duration. Pediatrics 1999 Mar;103(3):E33.

(14) Kramer MS, Barr RG, Dagenais S, Yang H, Jones P, Ciofani L, et al. Pacifier use, early weaning, and cry/fuss behavior: a randomized controlled trial. JAMA 2001 Jul 18;286(3):322-6.

(15) Lang S, Lawrence CJ, Orme RL. Cup feeding: an alternative method of infant feeding. Arch Dis Child 1994 Oct;71(4):365-9.

(16) Victora CG, Tomasi E, Olinto MT, Barros FC. Use of pacifiers and breastfeeding duration. Lancet 1993 Feb 13;341(8842):404-6. 
(17) Victora CG, Behague DP, Barros FC, Olinto MT, Weiderpass E. Pacifier use and short breastfeeding duration: cause, consequence, or coincidence? Pediatrics 1997 Mar;99(3):445-53.

(18) Vogel AM, Hutchison BL, Mitchell EA. The impact of pacifier use on breastfeeding: a prospective cohort study. J Paediatr Child Health 2001 Feb;37(1):58-63.

(19) O'Connor NR, Tanabe KO, Siadaty MS, Hauck FR. Pacifiers and breastfeeding: a systematic review. Arch Pediatr Adolesc Med 2009 Apr;163(4):378-82.

(20) AMERICAN ACADEMY OF PEDIATRICS. Breastfeeding and the Use of Human Milk. Pediatrics 2005 Feb 1;115(2):496-506.

(21) Hauck FR, Omojokun OO, Siadaty MS. Do pacifiers reduce the risk of sudden infant death syndrome? A meta-analysis. Pediatrics 2005 Nov;116(5):e716e723.

(22) Nelson AM. A comprehensive review of evidence and current recommendations related to pacifier usage. J Pediatr Nurs 2012 Dec;27(6):690-9.

(23) Horne RS, Hauck FR, Moon RY, L'Hoir MP, Blair PS. Dummy (pacifier) use and sudden infant death syndrome: potential advantages and disadvantages. J Paediatr Child Health 2014 Mar;50(3):170-4.

(24) Callaghan A, Kendall G, Lock C, Mahony A, Payne J, Verrier L. Association between pacifier use and breast-feeding, sudden infant death syndrome, infection and dental malocclusion. Int J Evid Based Healthc 2005 Jul;3(6):14767.

(25) Feldens CA, Ardenghi TM, Cruz LN, Scalco GP, Vitolo MR. Advising mothers about breastfeeding and weaning reduced pacifier use in the first year of life: a randomized trial. Community Dent Oral Epidemiol 2013 Aug;41(4):317-26.

(26) Leviniene G, Tamuleviciene E, Kudzyte J, Petrauskiene A, Zaborskis A, Azeliene I, et al. Factors associated with breastfeeding duration. Medicina (Kaunas ) 2013;49(9):415-21.

(27) Kair LR, Kenron D, Etheredge K, Jaffe AC, Phillipi CA. Pacifier restriction and exclusive breastfeeding. Pediatrics 2013 Apr;131(4):e1101-e1107.

(28) Jenik AG, Vain NE, Gorestein AN, Jacobi NE. Does the recommendation to use a pacifier influence the prevalence of breastfeeding? J Pediatr 2009 Sep;155(3):350-4.

(29) Kind C, Schubiger G, Schwarz U, Tonz O. Provision of supplementary fluids to breast fed infants and later breast feeding success. Adv Exp Med Biol 2000;478:347-54.

(30) Ip S, Chung M, Raman G, Chew P, Magula N, DeVine D, et al. Breastfeeding and maternal and infant health outcomes in developed countries. Evid Rep Technol Assess (Full Rep) 2007 Apr;(153):1-186.

(31) Hauck FR, Thompson JM, Tanabe KO, Moon RY, Vennemann MM. Breastfeeding and reduced risk of sudden infant death syndrome: a metaanalysis. Pediatrics $2011 \mathrm{Jul} ; 128(1): 103-10$.

(32) Jaafar $\mathrm{SH}$, Ho JJ, Jahanfar S, Angolkar M. Effect of restricted pacifier use in breastfeeding term infants for increasing duration of breastfeeding. Cochrane Database Syst Rev 2016 Aug 30;(8):CD007202.

(33) Walsh P, Vieth T, Rodriguez C, Lona N, Molina R, Habebo E, et al. Using a pacifier to decrease sudden infant death syndrome: an emergency department educational intervention. Peer J 2014 Mar 13;2:e309. 
PREGUNTA CLÍNICA: Nº 8

¿Qué criterios indican un buen inicio y una adecuada instauración de la lactancia materna?

\section{1- Pregunta clínica en formato PICO}

Tabla 1. Componentes de la pregunta en formato PICO

\begin{tabular}{|l|l|}
\hline Pacientes & RN sanos a término parto vaginal \\
\hline Exposición & $\begin{array}{l}\text { C1. Buen inicio LM } \\
\text { C2. Buena instauración de la LM }\end{array}$ \\
\hline Comparación & $\begin{array}{l}\text { C1. Mal inicio de la LM } \\
\text { C2. Mala instauración de la LM }\end{array}$ \\
\hline Desenlaces & $\begin{array}{l}\text { - Primera toma correcta (crítica) } \\
\text { - Tasa de LME al alta (crítica) } \\
\text { - Inicio de la lactogénesis II (importante) } \\
\text { - Duración de la lactancia materna (crítica) } \\
\text { - Peso del bebé (48-72h.) (crítica) } \\
\text { - Complicaciones de las mamas (crítica) } \\
\text { - Uso de suplementos (crítica) } \\
\text { - Tasa de LM a los 4 meses (importante) } \\
\text { - Tasa de LME a los 4 meses (importante) }\end{array}$ \\
\hline Tipo de estudio & GPC, RS, ECA y estudios observacionales \\
\hline
\end{tabular}

\section{2- Introducción}

Conocer si el lactante se alimenta adecuadamente es prioritario tanto para la madre como para los profesionales. Por ello, es necesario disponer de criterios objetivos que nos indiquen un buen inicio y una adecuada instauración de la lactancia y nos permitan detectar cualquier alteración o situación de riesgo. 


\section{3- Estrategia de elaboración de la pregunta}

\subsection{GPC}

Tabla 1. Resumen de GPC base

\begin{tabular}{|c|c|c|c|c|}
\hline Guía & Definición & Parámetros & Referencias bibliográficas & Comentarios \\
\hline $\begin{array}{l}\text { NICE } 2006 \\
\text { (guía de } \\
\text { implementac } \\
\text { ión de NICE) }\end{array}$ & $\begin{array}{l}\text { Inicio } \\
\text { Se define como inicio de la LM si } \\
\text { durante las primeras } 48 \text { horas tras el } \\
\text { nacimiento el bebé es puesto en el } \\
\text { pecho de la madre o recibe leche } \\
\text { materna (Department of Health 2005) } \\
\\
\text { Otro estudio incluido en esta guia } \\
\text { define la iniciación de la lactancia } \\
\text { materna como la proporción de } \\
\text { madres que ponen su bebé al pecho, } \\
\text { aunque sea solo por una sola vez } \\
\text { (Bartington 2005) } \\
\text { Instauración } \\
\text { No hay una definición. }\end{array}$ & $\begin{array}{l}\text { Inicio } \\
\text { - } \\
\text { Instauración } \\
\text { Se debe de informar a las madres que los indicadores de } \\
\text { un buen agarre, colocación y alimentación exitosa son: } \\
\text { Indicadores de buen agarre y posicionamiento } \\
\text { - boca abierta } \\
\text { - menos areola visible por debajo de la barbilla que por } \\
\text { encima del pezón } \\
\text { - la barbilla del bebé toca el pecho, el labio inferior está } \\
\text { enrollado hacia abajo, y la nariz libre } \\
\text { - no hay dolor } \\
\text { Indicadores de alimentación correcta en los bebés } \\
\text { - deglución audible y visible } \\
\text { - succión rítmica sostenida } \\
\text { - brazos y manos relajados } \\
\text { - pañales empapados regularmente } \\
\text { Indicadores de LM adecuada en mujeres } \\
\text { - ablandamiento de mama } \\
\text { - la mujer se siente relajada y soñolienta }\end{array}$ & $\begin{array}{l}\text { Bartington SE, Foster LJ, } \\
\text { Dezateaux C. (2005) 'Evaluation } \\
\text { of the UNICEF UK baby friendly } \\
\text { initiative for the promotion of } \\
\text { breastfeeding: findings from the } \\
\text { millennium cohort study'. } \\
\text { London: Institute of Child Health. } \\
\text { Archives of Disease in } \\
\text { Childhood } 200590 \text { (Suppl } \\
\text { II):A73-76. (estudio de cohortes) } \\
\text { Department of Health (2005) } \\
\text { Clarification of breastfeeding } \\
\text { initiation data collection [online]. } \\
\text { Available from: } \\
\text { www.dh.gov.uk/assetRoot/04/07 } \\
\text { /16/96/04071696.pdf (web } \\
\text { institucional) }\end{array}$ & $\begin{array}{l}\text { Los criterios que da } \\
\text { el NICE son } \\
\text { "assessing } \\
\text { successful } \\
\text { breastfeeding" y no } \\
\text { específicos del } \\
\text { establemiento. }\end{array}$ \\
\hline $\begin{array}{l}\text { BC - } \\
\text { Breatfeeding }\end{array}$ & Inicio & $\begin{array}{l}\text { Inicio } \\
\text { Instauración }\end{array}$ & $\begin{array}{l}\text { American Academy of Pediatrics } \\
\text { (2005). Policy Statement: }\end{array}$ & \\
\hline
\end{tabular}




\begin{tabular}{|c|c|c|c|}
\hline $\begin{array}{l}\text { Healthy } \\
\text { Term Infants }\end{array}$ & Instauración & $\begin{array}{l}\text { La evaluación es compleja, ya que incluye madre, niño, y } \\
\text { cómo "encajan" en conjunto para permitir que el proceso } \\
\text { de la LM sea adecudada. Esta información se obtiene a } \\
\text { través de la observación de la toma. } \\
\text { Proceso de lactancia materna } \\
\text { - La madre coloca al bebé de forma que favorezca un } \\
\text { agarre óptimo y su comodidad durante la toma } \\
\text { - La succión del bebé indica deglución audible y } \\
\text { transferencia de leche (Riordan 2010,Riordan 2002) } \\
\text { - La toma incluye ambos pechos hasta que la lactancia } \\
\text { está bien instaurada } \\
\text { - El bebé muestra signos de saciedad } \\
\text { - La madre y el bebé interactúan positivamente durante y } \\
\text { después de la lactancia } \\
\text { Evaluación de la madre } \\
\text { - La transición de la madre de lactogénesis I a } \\
\text { lactogénesis II, indicada por la plenitud de mama, por lo } \\
\text { general se produce dentro de las } 72 h \text {, pero puede tardar } \\
\text { más si la madre es primípara, no ha amamantado } \\
\text { previamente, ha sido separada del bebé o ha tenido un } \\
\text { parto por cesárea (Riordan } 2010, \text { Dewey } 2003, \\
\text { Mangarano } 2001 \text { ) } \\
\text { - Congestión de las mamas } \\
\text { - Dolor en los pezones y otros problemas que puedan } \\
\text { interferir con la lactancia y/o transferencia de la leche del } \\
\text { pezón. Cuando el bebé se resbala del pecho por lo } \\
\text { general indica un mal agarre. } \\
\text { - Sentimientos y preocupaciones de la madre: confianza } \\
\text { en sí misma, percepción de la producción de leche, del } \\
\text { proceso de la lactancia materna, del bebé y del aproyo } \\
\text { prestado por familiares y amigos } \\
\text { - Conocimiento de las señales de alimentación infantil, la } \\
\text { frecuencia de las tomas, duración, variaciones y signos } \\
\text { de una hidratación adecuada } \\
\text { Evaluación del bebé } \\
\text { - Se despierta espontáneamente cada } 21 / 2 \text { a } 3 \text { horas, las } \\
\text { alas al día, para comer }\end{array}$ & $\begin{array}{l}\text { Breastfeeding and the Use of } \\
\text { Human Milk. Pediatrics, } 115(2) \text {, } \\
\text { 496- } 506 \text {. (Policy Statement } \\
\text { American Academy of } \\
\text { Pediatrics) } \\
\text { Dewey KG, Nommsen-Rivers } \\
\text { LA, Heinig MJ, Cohen RJ. } \\
\text { (2003). Risk factors for } \\
\text { suboptimal infant breastfeeding } \\
\text { behavior, delayed onset of } \\
\text { lactation, and excess neonatal } \\
\text { weight loss. Pediatrics } 11(3) \text {, } \\
\text { 607-609. (serie de casos) } \\
\text { International Lactation } \\
\text { Consultants Association. (2005). } \\
\text { Clinical guidelines for the } \\
\text { establishment of exclusive } \\
\text { breastfeeding. Raleigh (NC): } \\
\text { Author. (guideline) } \\
\text { Lawrence RA \& Lawrence RM. } \\
\text { (2005). Breastfeeding: A guide } \\
\text { for the medical profession (6th } \\
\text { Ed.). Philadelphia: Mosby Inc. } \\
\text { Disponible en: } \\
\text { http://books.google.es/books?id } \\
\text { =jhQ2zHnKEKwC\&printsec=fron } \\
\text { tcover\&source=gbs_ge_summar } \\
\text { y_r\&cad=0\#v=onepage\&q\&f=fal } \\
\text { se (guideline) } \\
\text { Manganaro R, Mami C, Marrone } \\
\text { T, Marseglia L \& Gemelli M. } \\
\text { (2001). Incidence of dehydration } \\
\text { and hypernatremia in exclusively } \\
\text { breast-fed infants. Journal of } \\
\text { Pediatrics 139(5), 673-675. } \\
\text { (serie de casos) }\end{array}$ \\
\hline
\end{tabular}




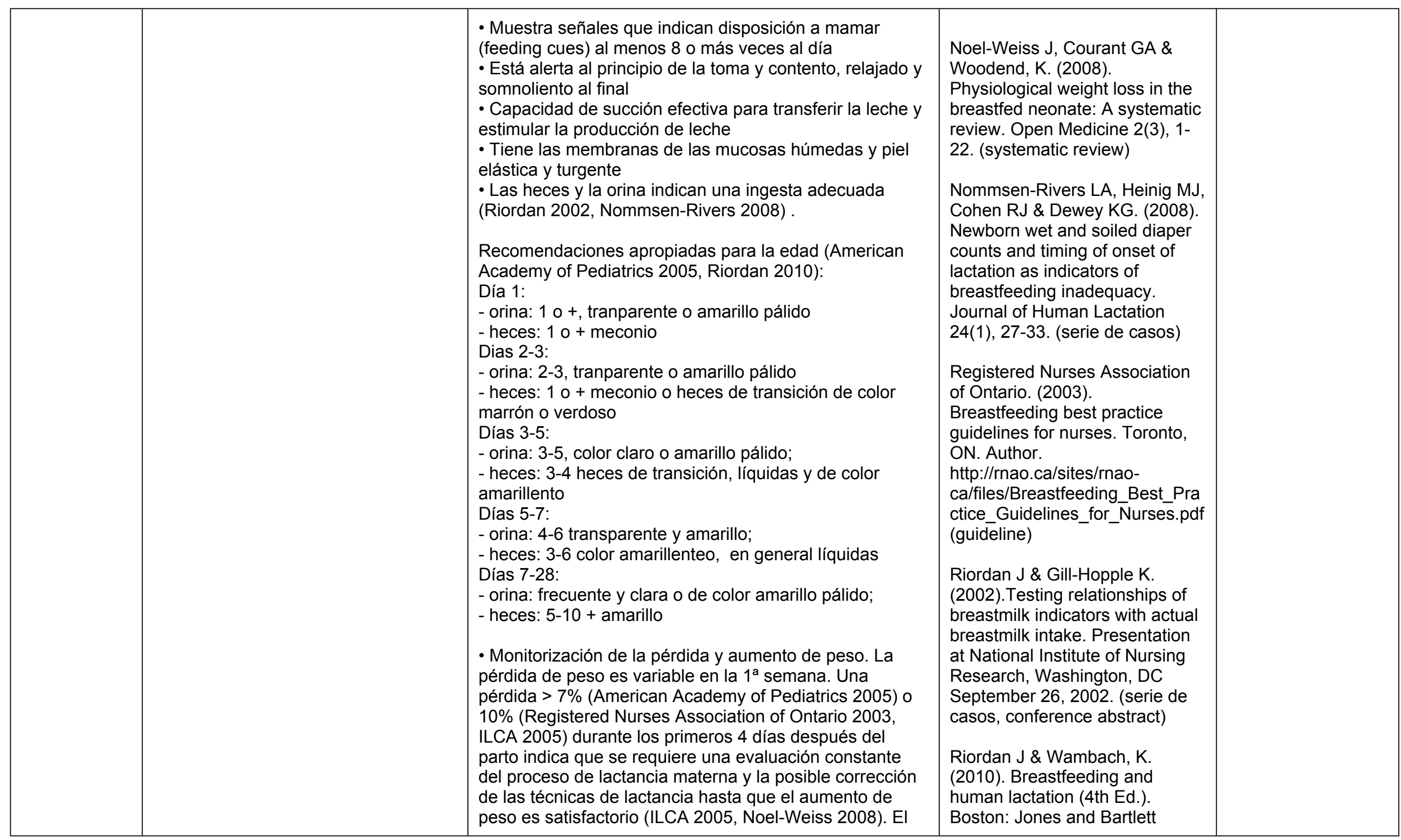




\begin{tabular}{|l|l|l|l|}
\hline & $\begin{array}{l}\text { consenso general es que el peso al nacer debe ser } \\
\text { recuperado en aproximadamente 2 semanas (Riordan } \\
\text { 2010, Lawrence 2005, Noel-Weiss 2008) }\end{array}$ & Publishers. (libro) \\
\hline
\end{tabular}

Tabla 2. Otras guías

\begin{tabular}{|c|c|c|c|c|}
\hline Guía & Definición & Parámetros & Referencias bibliográficas & Comentarios \\
\hline $\begin{array}{l}\text { ILCA } \\
\text { guideline }\end{array}$ & $\begin{array}{l}\text { Inicio } \\
- \\
\text { Instauración } \\
-\end{array}$ & $\begin{array}{l}\text { Inicio } \\
\text { - } \\
\text { Instauración } \\
\text { Los signos de una lactancia efectiva en el niño son: } \\
\text { - Pérdida de peso durante los primeros } 3 \text { días menor del } \\
7 \% \text { (Avoa 1990, Macdonald 2003, Marchini 1998, } \\
\text { Rodriguez 2000, Shrago 1996, Yaseen 2004) } \\
\text { - No hay pérdida de peso después del tercer día. La } \\
\text { pérdida de peso después del tercer día } 3 \text { está } \\
\text { fuertemente correlacionada con el destete prematuro } \\
\text { (Macdonald 2003, Merlob 1994) } \\
\text { - Los recién nacidos sanos a término ganan } \\
\text { aproximadamente } 20 \text { a } 35 \text { gramos o } 2 / 3 \text { a } 1 \text { oz cada día } \\
\text { al quinto día (Dewey } 1993, \text { Kramer } 2002 \text { ) } \\
\text { - Los recién nacidos sanos a término recuperan el peso } \\
\text { al nacer al décimo día (Macdonald 2003, Shrago 1996) } \\
\text { - Al menos } 3 \text { deposiciones cada } 24 \text { horas después del } \\
\text { primer día. La falta de deposiciones en el bebé } \\
\text { alimentado con leche materna es un indicador clave de } \\
\text { ingesta calórica insuficiente (Metaj } 2003, \text { Nyhan } 1952, \\
\text { Shrago } 1996, \text { Yaseen } 2004 \text { ) } \\
\text { - Deposiciones amarillas al quinto día } \\
\text { - Al menos } 6 \text { micciones diarias al } 4^{\circ} \text { día, siendo la orina } \\
\text { clara o o de color amarillo pálido } \\
\text { - El bebé se muestra satisfecho y contento tras las } \\
\text { comidas } \\
\text { - Deglución audible }\end{array}$ & $\begin{array}{l}\text { Avoa A, Fischer PR. The influence } \\
\text { of perinatal education about } \\
\text { breast-feeding on neonatal weight } \\
\text { loss. Pediatrics 1990;86(11):313- } \\
\text { 5. (tipo de estudio: ??) } \\
\text { Dewey KG, Heinig MJ, Nommsen } \\
\text { LA, Peerson JM, Lonnerdal B. } \\
\text { Breast-fed infants are leaner than } \\
\text { formula-fed infants at } 1 \text { y of age: } \\
\text { the DARLING study. Am J Clin } \\
\text { Nutr 1993;57(2):140-5. (estudio } \\
\text { de cohortes) } \\
\text { Kramer MS, Guo T, Platt RW, } \\
\text { Shapiro S, Collet JP, Chalmers B, } \\
\text { et al. Breastfeeding and infant } \\
\text { growth: biology or bias? Pediatrics } \\
\text { 2002;110(2 Pt 1):343-7. (ECA) } \\
\text { Macdonald PD, Ross SR, Grant L, } \\
\text { Young D. Neonatal weight loss in } \\
\text { breast and formula fed infants. } \\
\text { Arch Dis Child Fetal Neonatal Ed } \\
\text { 2003;88(6):F472-6. (estudio de } \\
\text { cohortes prospectivo) } \\
\text { Marchini G, Fried G, Ostlund E, } \\
\text { Hagenas L. Plasma leptin in }\end{array}$ & \\
\hline
\end{tabular}




\begin{tabular}{|c|c|c|c|}
\hline & & $\begin{array}{l}\text { Los signos de la lactancia materna eficaz son: } \\
\text { - Incremento notable en la firmeza, peso y tamaño de los } \\
\text { senos y aumento notable en el volumen de leche y la } \\
\text { composición al día } 5 \\
\text { - No hay daño en los pezones } \\
\text { - La plenitud de los senos se alivia tras la lactancia }\end{array}$ & $\begin{array}{l}\text { infants: relations to birth weight } \\
\text { and weight loss. Pediatrics } \\
1998 ; 101 \text { (3 Pt 1):429-32. (estudio } \\
\text { de casos y controles) } \\
\text { Merlob P, Aloni R, Prager H, Jelin } \\
\mathrm{N} \text {, Idel M, Kotona J. Continued } \\
\text { weight loss in the newborn during } \\
\text { the third day of life as an indicator } \\
\text { of early weaning. Isr J Med Sci. } \\
1994 \text { Aug;30(8):646-8. (estudio } \\
\text { de cohortes) } \\
\text { Metaj M, Laroia N, Lawrence RA, } \\
\text { Ryan RM. Comparison of breast- } \\
\text { and formula-fed normal newborns } \\
\text { in time to first stool and urine. J } \\
\text { Perinatol 2003;23(8):624-8. } \\
\text { (estudio de cohortes) } \\
\text { Neifert MR. The optimization of } \\
\text { breast-feeding in the perinatal } \\
\text { period. Clin Perinatol 1998;25(2): } \\
\text { 303-26. (revision no sistematica) } \\
\text { Nyhan WL. Stool frequency of } \\
\text { normal infants in the first week of } \\
\text { life. Pediatrics 1952;10(4):414-25. } \\
\text { (estudio de cohortes) } \\
\text { Rodriguez G, Ventura P, Samper } \\
\text { MP, Moreno L, Sarria A, Perez- } \\
\text { Gonzalez JM. Changes in body } \\
\text { composition during the initial } \\
\text { hours of life in breast-fed healthy } \\
\text { term newborns. Biol Neonate } \\
\text { 2000;77(1): 12-6. (series de } \\
\text { casos) } \\
\text { Shrago L. The relationship }\end{array}$ \\
\hline
\end{tabular}




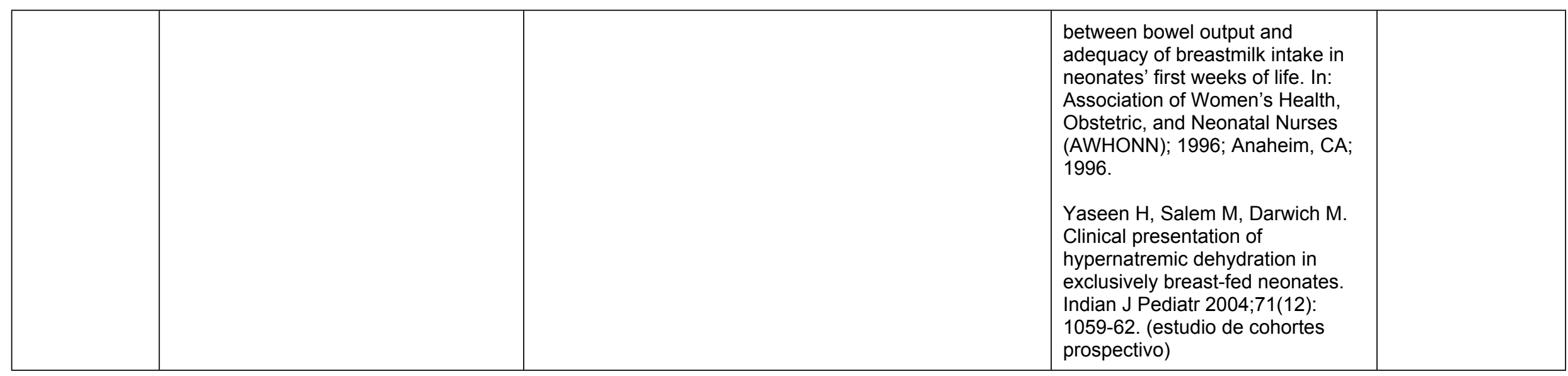

\subsection{Revisiones sistemáticas}

No se ha llevado a cabo una búsqueda de RS dado que se adopta la evidencia de las GPC disponibles. 


\subsection{Resumen de las GPC base}

La guía de NICE (1) adopta la definición del Department of Health (2), que define como inicio de la lactancia materna si durante las primenta 48 horas tras el nacimiento el recién nacido es puesto en el pecho de la madre o recibe leche materna. En el resto de guías analizadas no hay una definición consensuada de qué es inicio e instauración de la lactancia.

En relación a los criterios que indican una buena instauración de la LM, la guía NICE (1) estableces los siguientes criterios:

- Indicadores de buen agarre y posicionamiento:

$\checkmark$ boca abierta

$\checkmark$ menos areola visible por debajo de la barbilla que por encima del pezón

$\checkmark$ la barbilla del lactante toca el pecho, el labio inferior está enrollado hacia abajo, y la nariz libre

$\checkmark$ no hay dolor

- Indicadores de alimentación correcta en los lactantes

$\checkmark$ deglución audible y visible

$\checkmark$ succión rítmica sostenida

$\checkmark$ brazos y manos relajados

$\checkmark$ boca húmeda

$\checkmark$ pañales empapados regularmente

- Indicadores de LM adecuada en mujeres

$\checkmark$ ablandamiento de mama

$\checkmark$ sin compresión en el pezón al final de la toma

$\checkmark$ la mujer se siente relajada y soñolienta

La guía Perinatal Services BC recoge la evidencia de la American Academy of Pediatric) (3), de la asociación de Registered Nurses of Ontario(4) y de la International Lactation Consultant Association (5) asi como de varios estudios (6-12) y establece que hay que valorar como madre y bebé "encajan" en conjunto, y esta observación se obtiene a través de la observación de la toma.

- Proceso de lactancia materna

$\checkmark$ La madre coloca al lactante de forma que favorezca un agarre óptimo y su comodidad durante la toma

$\checkmark$ La succión del bebé indica deglución audible y transferencia de leche

$\checkmark$ La toma incluye ambos pechos hasta que la lactancia está bien instaurada

$\checkmark$ El lactante muestra signos de saciedad

$\checkmark$ La madre y el bebé interactúan positivamente durante y después de la lactancia

- Evaluación de la madre

$\checkmark$ La transición de la madre de lactogénesis I a lactogénesis II, indicada por la plenitud de mama, por lo general se produce dentro de las $72 \mathrm{~h}$, pero puede tardar más si la madre es primípara, no ha amamantado previamente, ha sido separada del lactante o ha tenido un parto por cesárea

$\checkmark$ Congestión de las mamas

$\checkmark$ Dolor en los pezones y otros problemas que puedan interferir con la lactancia y/o transferencia de la leche del pezón. Cuando el bebé se resbala del pecho por lo general indica un mal agarre.

$\checkmark$ Sentimientos y preocupaciones de la madre: confianza en sí misma , percepción de la producción de leche, del proceso de la lactancia 
materna, del lactante y del aproyo prestado por familiares y amigos

$\checkmark$ Conocimiento de las señales de alimentación infantil, la frecuencia de las tomas, duración, variaciones y signos de una hidratación adecuada

- Evaluación del lactante

$\checkmark$ Se despierta espontáneamente cada $2 \frac{1}{2}$ a 3 horas, las 24 horas al día, para comer

$\checkmark$ Muestra señales que indican disposición a mamar (feeding cues) al menos ocho o más veces al día

$\checkmark$ Está alerta al principio de la toma y contento, relajado y somnoliento al final

$\checkmark$ Capacidad de succión efectiva para transferir la leche y estimular la producción de leche

$\checkmark$ Tiene las membranas de las mucosas húmedas y piel elástica y turgente

$\checkmark$ Las deposiciones y micciones indican una ingesta adecuada. Recomendaciones apropiadas para la edad:

- Día 1:

- Dias 2-3:

- micciones: $10+$, tranparente o amarillo pálido

o heces: $10+$ meconio

- micciones: 2-3, tranparente o amarillo pálido

o deposiciones: $10+$ meconio o heces de transición de color marrón o verdoso

- Días 3-5:

- micciones: 3-5, color claro o amarillo pálido;

- deposiciones: 3-4 heces de transición, líquidas y de color amarillento

- Días 5-7:

o micciones: 4-6 transparente y amarillo;

- deposiciones: 3-6 color amarillenteo, en general líquidas

- Días 7-28:

- micciones: frecuente y clara o de color amarillo pálido;

o deposiciones: 5-10 + amarillo

Monitorización de la pérdida y aumento de peso. La pérdida de peso es variable en la primera semana. Una pérdida $>7 \%$ o $10 \%$ durante los primeros cuatro días después del parto indica que se requiere una evaluación constante del proceso de LM y la posible corrección de las técnicas de lactancia hasta que el aumento de peso es satisfactorio. El consenso general es que el peso al nacer debe ser recuperado en aproximadamente dos semanas

En el documento de la International Lactation Consultant Association (5) se establecen los siguientes criterios en base a la evidencia de estudios observacionales (13-22)):

- Signos de LM efectiva en el niño:

$\checkmark$ Pérdida de peso durante los primeros 3 días menor del $7 \%$

$\checkmark$ No hay pérdida de peso después del tercer día. La pérdida de peso después del tercer día 3 está fuertemente correlacionada con el destete prematuro

$\checkmark$ A partir del quinto día, los recién nacidos sanos a término ganan aproximadamente 20 a 35 gramos al día

$\checkmark$ Los RN sanos a término recuperan el peso al nacer al décimo día

$\checkmark$ Al menos 3 deposiciones cada 24 horas después del primer día. La falta de deposiciones en el recién nacido alimentado con leche materna es un indicador clave de ingesta calórica insuficiente 
$\checkmark$ Deposiciones amarillas al quinto día

$\checkmark$ Al menos 6 micciones diarias al cuarto día, siendo la orina clara o o de color amarillo pálido

$\checkmark$ El lactante se muestra satisfecho y contento tras las comidas

$\checkmark$ Deglución audible

- Los signos de la lactancia materna eficaz son:

$\checkmark$ Incremento notable en la firmeza, peso y tamaño de los senos y aumento notable en el volumen de leche y la composición al quinto día

$\checkmark$ No hay daño en los pezones

$\checkmark$ La plenitud de los senos se alivia tras la lactancia

\subsection{Conclusión}

En base a la evidencia encontrada se decide adoptar las recomendaciones propuestas por NICE y BC.

\begin{tabular}{|l|l}
\hline Adopción GPC/Revisión sistemática \\
Elaboración parcial \\
\hline Elaboración de novo
\end{tabular}

ACTUALIZADO A FECHA DE: 31 de Octubre de 2016 


\section{4- De la evidencia a la recomendación (Tabla de EtR)}

\section{¿Qué criterios indican un buen inicio y una adecuada instauración de la lactancia materna?}

Población: Madres de recién nacidos sanos a término que amamantan y y sus $R N$

Intervención: Buen inicio y adecuada instauración de la $L M$

Comparación: Mal inicio e instauración de la LM

Perspectiva: Clínica

C1. Buen inicio de la LM vs. mal inicio de la LM

C2. Buena instauración de la LM vs. mala instauración de la LM

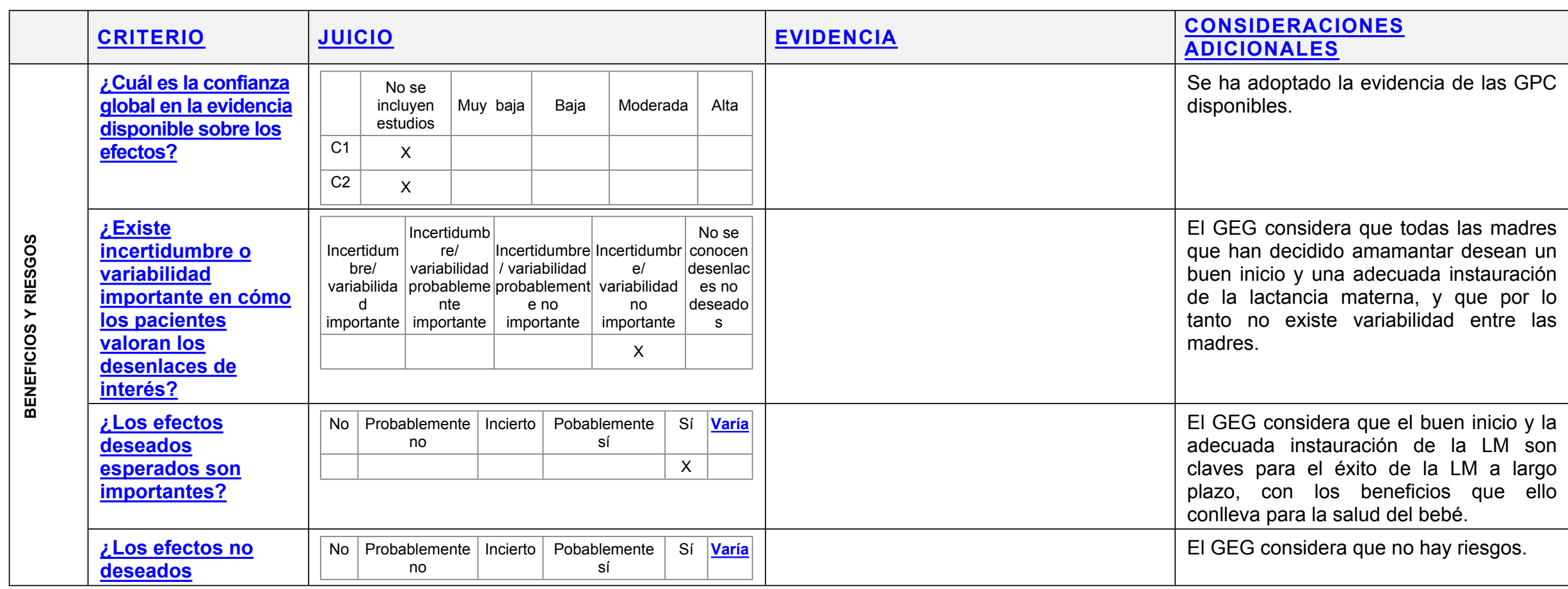




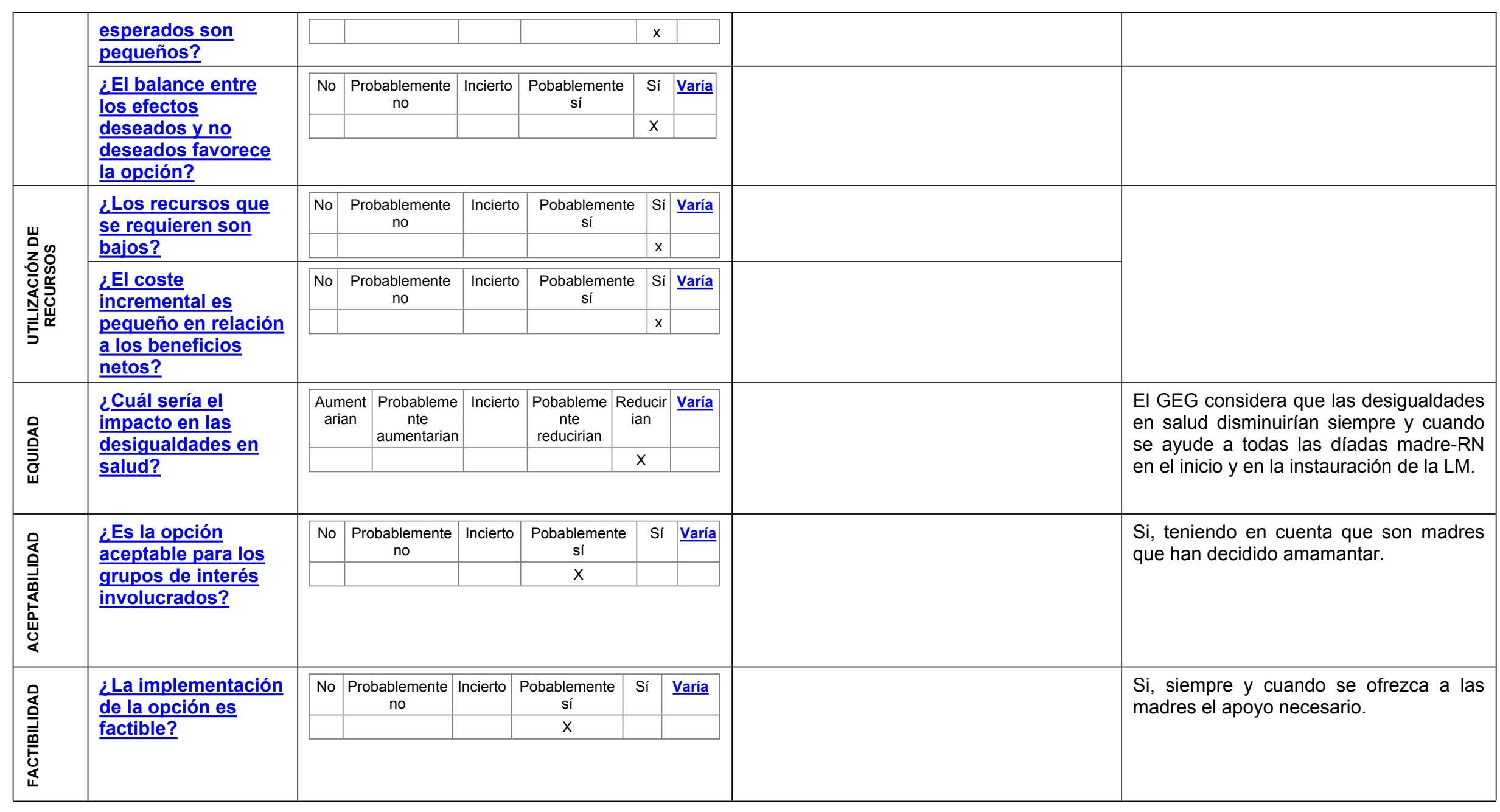

\begin{tabular}{l|c|c|c|c|c|}
\hline \hline Balance de las & Las consecuencias no & Las consecuencias no & El balance entre las & Las consecuencias & Las consecuencias \\
\cline { 2 - 6 }
\end{tabular}




\begin{tabular}{l|c|c|c|c|c}
\hline \hline consecuencias & $\begin{array}{c}\text { deseadas superan } \\
\text { claramente las } \\
\text { consecuencias } \\
\text { deseadas en la } \\
\text { mayoría de los } \\
\text { escenarios }\end{array}$ & $\begin{array}{c}\text { deseadas } \\
\text { probablemente superan } \\
\text { las consecuencias } \\
\text { deseadas en la mayoría } \\
\text { de los escenarios }\end{array}$ & $\begin{array}{c}\text { consecuencias } \\
\text { deseadas y no } \\
\text { deseadas está muy } \\
\text { equilibrado o es incierto }\end{array}$ & $\begin{array}{c}\text { deseadas probablemente } \\
\text { superan las } \\
\text { consecuencias no } \\
\text { deseadas en la mayoría } \\
\text { de los escenarios }\end{array}$ & $\begin{array}{c}\text { deseadas claramente } \\
\text { superan las } \\
\text { consecuencias no } \\
\text { deseadas en la } \\
\text { mayoría de los } \\
\text { escenarios }\end{array}$ \\
\cline { 2 - 6 } & & & \\
\hline
\end{tabular}

\begin{tabular}{|c|c|c|c|c|}
\hline \multirow[t]{2}{*}{ Tipo de recomendación } & $\begin{array}{c}\text { Se recomienda no ofrecer la } \\
\text { opción }\end{array}$ & $\begin{array}{l}\text { Se sugiere no ofrecer la } \\
\text { opción }\end{array}$ & Se sugiere ofrecer la opción & $\begin{array}{c}\text { Se recomienda ofrecer la } \\
\text { opción }\end{array}$ \\
\hline & & & & $X$ \\
\hline Recomendación (Texto) & \multicolumn{4}{|c|}{$\begin{array}{l}\text { Recomendación de buena práctica } \\
\text { Para identificar los critieros de buen inicio e instauración de la lactancia materna se debería realizar una valoración de } \\
\text { la madre, del recién nacido y la técnica de la lactancia: postura, agarre y signos de transferencia eficaz de leche. }\end{array}$} \\
\hline
\end{tabular}

\section{Parámetros que indican un buen inicio de la lactancia}

a) Valoración del amamantamiento mediante la observación de la toma:

\section{a.1) Buena postura}

- La madre es capaz de colocar al lactantede forma que favorece un agarre óptimo

- Madre y lactante están cómodos e interactúan positivamente durante y después de la toma

\section{a.2) Buen agarre}

- Antes del agarre, la cabeza del lactante está enfrente del pecho con el pezón a la altura de la nariz

- El cuello permanece ligeramente deflexionado y no está girado, la barbilla toca el pecho y la nariz está libre

- La boca está bien abierta con el labio inferior evertido y ambos labios forman un ángulo de unos $120^{\circ}$

- Hay menos areola visible por debajo de la barbilla que por encima del pezón

- La madre no siente dolor en el pecho

- El pezón no se le escapa al lactante de la boca ni hay sonidos de chupeteo.

- El pezón al finalizar la toma no está deformado ni presenta signos de compresión 


\section{a.3.) Transferencia adecuada de leche}

- El lactante realiza succiones profundas, mantenidas y con pausas no muy largas

- La deglución ees visible y/o audible

- Se ofrecen ambos pechos en cada toma, comenzando por el que se vación menos en la anterior. Se espera a que suelte espontáneamente el pezón antes de ofrecerle el segundo pecho.

- La madre experimenta los efectos de la liberación de oxitocina (contracciones uterinas, aumento de loquios, goteo de leche durante la toma, sed, relajación o sueño)

- El lactante muestra signos de saciedad tras la toma: suelta el pezón espontáneamente y queda relajado y satisfecho.

\section{b) Valoración de la madre}

- La madre presenta signos de lactogénesis II ("subida" de la leche) a partir de las 48-72 horas. En general las madres notan un incremento de la firmeza, peso y tamaño de los senos. Puede producirse algo más tarde en madres primíparas sanas, si no amamantan con frecuencia los primeros días, si han sido separadas de sus hijos o si han tenido un parto por cesárea.

- Hay un aumento notable del volumen de leche antes del quinto día

- La madre sabe reconocer las señales que indican disposición para mamar en el RN, se muestra receptiva y le ofrece el pecho cuando las detecta.

- La madre sabe despertar al RN para alimentarlo, si fuera necesario, hasta que se establece un patrón de aumento de peso adecuado

- Se siente segura y confía en su capacidad para amamantar y producir leche.

- La madre tiene apoyo de su pareja, familiares, amigas o grupos de apoyo.

- No hay presencia de dolor o molestias importantes en las mamas durante o entre las tomas (descartar la presencia de grietas o lesiones en los pezones).

- Tras la subida de la leche los pechos se ablandan después de la toma

- No hay signos de ingurgitación mamaria.

\section{c) Valoración del recién nacido}

- Realiza al menos 8 tomas en 24 horas sin ayuno de más de seis horas (algunos recién nacidos realizan tomas cada 2 o 3 horas día y noche; otros realizan tomas seguidas durante 4-6 horas y luego descansan otras 4-6 horas).

- Da señales de disposición para mamar al menos 8 veces al día: bostezos, movimientos oculares, chupeteo o búsqueda, chuparse el puño (ver anexo 6). 
- Está alerta al principio de la toma y cuando está saciado suelta el pecho espontáneamente y se muestra satisfecho y relajado (manos y brazos relajados).

- Muestra un buen agarre realizando succiones efectivas y se le oye tragar.

- Muestra signos de buena hidratación (mucosas húmedas, conjuntivas brillantes, piel elástica y turgente)

- Muestra coloración normal de piel y mucosas y no está excesivamente ictérico

- Un patrón adecuado de deposiciones y micciones indican una ingesta adecuada según el día de vida: Día 1

- Micciones: 1 o más, transparente o amarillo pálido

- Deposiciones: 1 o más, meconio

Días 2-3

- Micciones: de 2 a 3, transparentes o amarillo pálido

- Deposiciones: 1 o más, meconio o deposiciones de transición de color marrón verdoso

Días $3-5$ :

- Micciones: de 3 a 5 , color claro o amarillo pálido

- Deposiciones: 3-4 heces de transición, líquidas y de color amarillento

Días 5-7:

- Micciones: de 4 a 6 , transparentes y de color amarillo

- Deposiciones de 3 a 6 , de color amarillento, en general líquidas

Días 7-28:

- Micciones: frecuentes (seis o más al día) y claras o de color amarillo pálido

- Deposiciones de 5 a 10 o más, y de color amarillo

- La falta de deposiciones en el recién nacido alimentado con leche materna puede indicar una ingesta calórica insuficiente.

- Las micciones escasas o rojizas, o de color amarillo intenso después del tercer día de vida pueden indicar una ingesta insuficiente y riesgo de deshidratación

- Monitorización del peso:

- La pérdida de peso es variable en la primera semana. Una pérdida > al $7 \%$ durante los primeros cuatro días después del parto indica que se requiere una evaluación constante de la lactancia materna y la corrección de los problemas que se detecten hasta que el aumento de peso sea satisfactorio (no es adecuado suplementar con fórmula de forma sistemática a todos los RN que pierden más de un $7 \%$ de peso, pero sí es necesario realizar una evaluación y ofrecer apoyo y ayuda práctica).

- El consenso general es que el peso al nacer debe ser recuperado en aproximadamente dos semanas.

- Una curva ponderal ascendente, con una ganancia media de 20-35 gr/día a partir del cuarto día asegura una ingesta adecuada.

\section{Parámetros que indican que una lactancia está bien establecida}




\begin{tabular}{|c|c|}
\hline & $\begin{array}{l}\text { Pasados los primeros días, los siguientes signos son de ayuda para valorar si una lactancia está bien establecida. } \\
\text { a) En el lactante } \\
\text { - Mama tranquilo y se muestra satisfecho y relajado tras la toma. } \\
\text { - La frecuencia y la duración de las tomas disminuye progresivamente a medida que el RN crece, aunque pueden } \\
\text { producirse picos de aumento de la frecuencia durante los brotes de crecimiento, enfermedades del RN o } \\
\text { - Pambios bruscos en el entorno. } \\
\text { - Presenta un patrón de micciones y deposiciones adecuado a su edad. } \\
\text { b) En la madre } \\
\text { - Se siente segura y satisfecha. } \\
\text { - Tiene sensación de suficiente producción de leche. } \\
\text { - Responde a las señales de hambre de su RN y lo amamanta a demanda. } \\
\text { - No precisa utilizar suplementos de leche de formula. }\end{array}$ \\
\hline Justificación & $\begin{array}{l}\text { El funcionamiento complejo, ya que requiere una buena interacción entra la madre y el RN. Por lo tanto es importante } \\
\text { conocer los criterios que indican que el RN se está alimentando adecuadamente desde el principio, y así poder detectar } \\
\text { posibles problemas que puedan presentarse tanto durante el inicio como durante la instauración de la lactancia. }\end{array}$ \\
\hline $\begin{array}{l}\text { Consideraciones de } \\
\text { subgrupos }\end{array}$ & - \\
\hline $\begin{array}{l}\text { Consideraciones para la } \\
\text { implementación }\end{array}$ & $\begin{array}{l}\text { Todos los signos hay que valorarlos dentro de un contexto, ya que un signo aislado no tiene porque sgnificar que haya } \\
\text { un problema. Por ejemplo, las contracciones uterinas, el goteo y la sed te indican que la madre ha liberado oxitocina y } \\
\text { por lo tanto se ha producido eyeccion de leche y es tranquilizador, pero el hecho de que no aparezcan como signo } \\
\text { aislado no quiere decir que las cosas vayan mal. Tambien hay muchas madres que no gotean por el otro pecho. }\end{array}$ \\
\hline Monitorización y evaluación & - \\
\hline$\frac{\text { Prioridades para la }}{\text { investigación }}$ & - \\
\hline
\end{tabular}




\section{5.- BIBLIOGRAFÍA}

(1) NICE. Postnatal care up to 8 weeks after birth. Julio 2006 (actualizado en Febrero de 2015). Disponible en: http://guidance.nice.org.uk/CG37.

(2) Department of Health. Clarification of breastfeeding initiation data collection [online]. Available from: www.dh.gov.uk/assetRoot/04/07/16/96/04071696.pdf . 2005.

(3) AMERICAN ACADEMY OF PEDIATRICS. Breastfeeding and the Use of Human Milk. Pediatrics 2005 Feb 1;115(2):496-506.

(4) Registered Nurses of Ontario. Breastfeeding best practice guidelines for nurses. Toronto, ON. 2003.

(5) International Lactation Consultant Association. Clinical Guidelines for the Establishment of Exclusive Breastfeeding. June 2005. Disponible en: http://www.breastcrawl.org/pdf/ilca-clinical-guidelines-2005.pdf. $\mathrm{h}$.

(6) Manganaro R, Mami C, Marrone T, Marseglia L, Gemelli M. Incidence of dehydration and hypernatremia in exclusively breast-fed infants. J Pediatr 2001 Nov;139(5):673-5.

(7) Riordan J , Gill-Hopple K. Testing relationships of breastmilk indicators with actual breastmilk intake. Presentation at National Institute of Nursing Research, Washington, DC September 26, 2002. 2002.

(8) Dewey KG, Nommsen-Rivers LA, Heinig MJ, Cohen RJ. Risk factors for suboptimal infant breastfeeding behavior, delayed onset of lactation, and excess neonatal weight loss. Pediatrics 2003 Sep;112(3 Pt 1):607-19.

(9) Lawrence RA, Lawrence RM. Breastfeeding: A guide for the medical profession (6th Ed.). Philadelphia: Mosby Inc.Disponible en: http://books.google.es/books?id=jhQ2zHnKEKwC\&printsec=frontcover\&source=gbs ge summary $r \& c a d=0 \# v=$ onepage\&q\&f=false .2005.

(10) Nommsen-Rivers LA, Heinig MJ, Cohen RJ, Dewey KG. Newborn wet and soiled diaper counts and timing of onset of lactation as indicators of breastfeeding inadequacy. J Hum Lact 2008 Feb;24(1):27-33.

(11) Noel-Weiss J, Courant G, Woodend AK. Physiological weight loss in the breastfed neonate: a systematic review. Open Med 2008;2(4):e99-e110.

(12) Riordan J, Wambach K. Breastfeeding and human lactation (4th Ed.). Boston: Jones and Bartlett Publishers . 2010.

(13) NYHAN WL. Stool frequency of normal infants in the first week of life. Pediatrics 1952 Oct;10(4):414-25.

(14) Avoa A, Fischer PR. The influence of perinatal instruction about breast-feeding on neonatal weight loss. Pediatrics 1990 Aug;86(2):313-5.

(15) Dewey KG, Heinig MJ, Nommsen LA, Peerson JM, Lonnerdal B. Breast-fed infants are leaner than formula-fed infants at $1 \mathrm{y}$ of age: the DARLING study. Am J Clin Nutr 1993 Feb;57(2):140-5.

(16) Merlob P, Aloni R, Prager H, Jelin N, Idel M, Kotona J. Continued weight loss in the newborn during the third day of life as an indicator of early weaning. Isr J Med Sci 1994 Aug;30(8):646-8.

(17) Shrago L. The relationship between bowel output and adequacy of breastmilk intake in neonates' first weeks of life. In: Association of Women's Health, Obstetric, and Neonatal Nurses (AWHONN); Anaheim, CA . 1996.

(18) Marchini G, Fried G, Ostlund E, Hagenas L. Plasma leptin in infants: relations to birth weight and weight loss. Pediatrics 1998 Mar;101(3 Pt 1):429-32. 
(19) Rodriguez G, Ventura P, Samper MP, Moreno L, Sarria A, Perez-Gonzalez JM. Changes in body composition during the initial hours of life in breast-fed healthy term newborns. Biol Neonate 2000;77(1):12-6.

(20) Kramer MS, Guo T, Platt RW, Shapiro S, Collet JP, Chalmers B, et al. Breastfeeding and infant growth: biology or bias? Pediatrics 2002 Aug;110(2 Pt 1):343-7.

(21) Macdonald PD, Ross SR, Grant L, Young D. Neonatal weight loss in breast and formula fed infants. Arch Dis Child Fetal Neonatal Ed 2003 Nov;88(6):F472-F476.

(22) Yaseen H, Salem M, Darwich M. Clinical presentation of hypernatremic dehydration in exclusively breast-fed neonates. The Indian Journal of Pediatrics 2004;71(12):1059-62. 
PREGUNTA CLÍNICA Nº 9

¿Qué datos se deberían recoger en la historia clínica para valorar adecuadamente la lactancia materna?

¿Cómo se deberían recoger esos datos?

\section{1- Introducción}

Para poder prestar un apoyo eficaz al inicio de la lactancia o durante la misma, es necesario, como en cualquier otro proceso asistencial, obtener una historia clínica y realizar una exploración. Por ello, es importante conocer qué datos de la anamnesis son importantes y cómo recogerlos de forma respetuosa. De igual forma interesa conocer qué datos de la exploración de la madre, del bebé y de la observación de la toma son necesarios para apoyar de forma eficaz la lactancia. 


\subsection{GPC Base}

Tabla 2- Resumen de GPC Base

\begin{tabular}{|c|c|c|c|c|}
\hline $\begin{array}{l}\text { Guía } \\
\text { (Enfoque) }\end{array}$ & $\begin{array}{l}\text { Resumen sobre la evidencia } \\
\text { (Calidad de la evidencia) }\end{array}$ & $\begin{array}{l}\text { Recomendaciones } \\
\text { (Grado) }\end{array}$ & $\begin{array}{l}\text { Referencias bibliográficas } \\
\text { (Tipo de publicación) }\end{array}$ & Comentarios \\
\hline $\begin{array}{l}\text { NICE_2006 } \\
\text { (Actualización } \\
\text { 2011) }\end{array}$ & $\begin{array}{l}\text { Evaluar una lactancia eficaz } \\
\text { La experiencia de una mujer con la lactancia debería ser } \\
\text { comentada cada vez que se tiene contacto para valorar si la } \\
\text { lactancia es efectiva e identificar cualquier necesidad de } \\
\text { apoyo adicional. El progreso con la lactancia materna } \\
\text { debería ser valorado y documentado en el plan de cuidado } \\
\text { postnatal en cada visita [D(GPP)] } \\
\text { Si la madre percibe que tiene leche insuficiente, se debería } \\
\text { evaluar su técnica de lactancia y la salud del bebé. Se } \\
\text { debería proporcionar tranquilidad para apoyar a la mujer y } \\
\text { para que gane confianza en su capacidad para producir la } \\
\text { suficiente leche para su bebé [C]. }\end{array}$ & $\begin{array}{l}\text { No se encontraron estudios sobre cuándo se } \\
\text { debía preguntar a una mujer lactante si tenía } \\
\text { problemas con la lactancia materna. }\end{array}$ & & \\
\hline $\begin{array}{l}\text { Perinatal } \\
\text { Services } \\
\text { BC_2013 }\end{array}$ & $\begin{array}{l}\text { Se debería realizar una evaluación de la madre y del niño } \\
\text { en los períodos de tiempo claves mediante observación y } \\
\text { conversación }(A)^{*}\end{array}$ & $\begin{array}{l}\text { La evaluación es compleja e incluye la valoración } \\
\text { de la madre, el niño y de cómo se acoplan de } \\
\text { forma conjunta para permitir la lactancia materna: } \\
\text { los datos se obtienen mediante la entrevista y la } \\
\text { observación de una toma. } \\
\text { 1. El proceso de amamantamiento } \\
\text { - La madre coloca al bebé para facilitar un agarre } \\
\text { optimo y confortable durante la sesión de } \\
\text { lactancia. } \\
\text { - El patrón de succión del niño indica que se oye } \\
\text { cómo traga y que hay transferencia de leche } \\
\text { (38,69) } \\
\text { - El amamantamiento incluye ambos pechos hasta } \\
\text { que la lactancia esté bien establecida. } \\
\text { - El bebé muestra señales de estar saciado. } \\
\text { - La madre y el niño interaccionan de forma } \\
\text { positiva durante y después de la toma. } \\
\text { 2. Evaluación de la madre } \\
\text { - La transición maternal de la lactogénesis I a la } \\
\text { lactogénesis II, que se indica por congestión del } \\
\text { pecho, ocurre generalmente en } 72 \text { horas pero } \\
\text { puede tardar más si la madre es primípara, no ha }\end{array}$ & $\begin{array}{l}\text { 38. Riordan J \& Wambach, K. } \\
\text { (2010). Breastfeeding and } \\
\text { human lactation (4th Ed.). } \\
\text { Boston: Jones and Bartlett } \\
\text { Publishers. } \\
\text { 65. Dewey KG, Nommsen- } \\
\text { Rivers LA, Heinig MJ, Cohen } \\
\text { RJ. (2003). Risk factors for } \\
\text { suboptimal infant } \\
\text { breastfeeding behavior, } \\
\text { delayed onset of lactation, and } \\
\text { excess neonatal weight loss. } \\
\text { Pediatrics 11(3), 607-609. } \\
\text { http://www.pediatrics.org/cgi/c } \\
\text { ontent/ full/112/3/607. } \\
\text { 66. Manganaro R, Mami C, } \\
\text { Marrone T, Marseglia L \& } \\
\text { Gemelli M. (2001). Incidence } \\
\text { of dehydration and } \\
\text { hypernatremia in exclusively } \\
\text { breast-fed infants. Journal of } \\
\text { Pediatrics 139(5), 673-675. }\end{array}$ & \\
\hline
\end{tabular}




\begin{tabular}{|c|c|c|c|c|}
\hline $\begin{array}{l}\text { Guía } \\
\text { (Enfoque) }\end{array}$ & $\begin{array}{l}\text { Resumen sobre la evidencia } \\
\text { (Calidad de la evidencia) }\end{array}$ & $\begin{array}{l}\text { Recomendaciones } \\
\text { (Grado) }\end{array}$ & $\begin{array}{l}\text { Referencias bibliográficas } \\
\text { (Tipo de publicación) }\end{array}$ & Comentarios \\
\hline & & $\begin{array}{l}\text { amamantado antes, ha sido separada de su bebé } \\
\text { o ha tenido una cesárea ( } 38,65,66) \text {. } \\
\text { - Evidencia de congestión de las mamas } \\
\text { - Pezones doloridos y "anomalías" en los pezones } \\
\text { que pueden interferir con la lactancia y/o la } \\
\text { transferencia de la leche. La distorsión del pezón } \\
\text { cuando el bebé suelta el pecho indica } \\
\text { generalmente un mal agarre. } \\
\text { - Sentimientos y preocupaciones sobre su } \\
\text { autoconfianza, la producción de leche, el proceso } \\
\text { del amamantamiento, su bebé y el apoyo de la } \\
\text { familia y amigos. } \\
\text { - Conocimiento sobre pistas de la alimentación del } \\
\text { bebé: frecuencia de alimentaciónn, duración y } \\
\text { variaciones, y signos de una hidratación adecuada } \\
\text { del bebé. } \\
\text { 3. Valoración del bebé } \\
\text { - Se despierta de forma espontánea cada } 2 \text { h y } \\
\text { media- } 3 \text { horas, } 24 \text { horas al día para comer. } \\
\text { - Muestra pistas de la disposición para comer al } \\
\text { menos } 8 \text { veces al día. } \\
\text { - Se muestra alerta al principio de la toma: } \\
\text { contento, relajado y somnoliento al final de la } \\
\text { toma. } \\
\text { - Capacidad para succionar de forma efectiva para } \\
\text { transferir la leche y estimular la producción de } \\
\text { leche. } \\
\text { - Presenta membranas mucosas húmedas y una } \\
\text { piel elástica y turgente. } \\
\text { - La cantidad de orina y el número de } \\
\text { deposiciones indican una ingesta adecuada } \\
\text { (69,70). Las recomendaciones por edad se } \\
\text { muestran en la tabla } 1 . \\
\text { - Monitorizar la pérdida y ganancia de peso del } \\
\text { bebé. }\end{array}$ & $\begin{array}{l}\text { 69. Riordan J \& Gill-Hopple K. } \\
\text { (2002). Testing relationships of } \\
\text { breastmilk indicators with } \\
\text { actual breastmilk intake. } \\
\text { Presentation at National } \\
\text { Institute of Nursing Research, } \\
\text { Washington, DC September } \\
\text { 26, 2002. } \\
\text { 70. Nommsen-Rivers LA, } \\
\text { Heinig MJ, Cohen RJ \& Dewey } \\
\text { KG. (2008). Newborn wet and } \\
\text { soiled diaper counts and } \\
\text { timing of onset of lactation as } \\
\text { indicators of breastfeeding } \\
\text { inadequacy. Journal of Human } \\
\text { Lactation 24(1), 27-33. }\end{array}$ & \\
\hline
\end{tabular}

* Grado A: Hay buena evidencia para recomendar la acción clínica preventiva. 
Tabla 3. Resumen de otros documentos

\begin{tabular}{|c|c|c|c|c|}
\hline $\begin{array}{l}\text { Guía } \\
\text { (Enfoque) }\end{array}$ & $\begin{array}{l}\text { Resumen sobre la evidencia } \\
\text { (Calidad de la evidencia) }\end{array}$ & $\begin{array}{l}\text { Recomendaciones } \\
\text { (Grado) }\end{array}$ & $\begin{array}{l}\text { Referencias bibliográficas } \\
\text { (Tipo de publicación) }\end{array}$ & Comentarios \\
\hline $\begin{array}{l}\text { Ministerio de } \\
\text { Sanidad, } \\
\text { Política Social } \\
\text { e lgualdad, } \\
2011 .\end{array}$ & $\begin{array}{l}\text { Del documento del Ministerio sobre la IHAN } \\
\text { Para el paso 5: } \\
\text { La ayuda práctica individual con la técnica de la lactancia y el } \\
\text { apoyo psicológico para aumentar la confianza de la madre } \\
\text { pueden ser muy útiles para tener éxito con la lactancia }(3,4) \text {. } \\
\text { Esta ayuda adecuada, incluso durante la corta estancia } \\
\text { hospitalaria, puede tener un efecto que perdura meses } \\
\text { después (5). Hay pruebas claras de la efectividad del apoyo } \\
\text { profesional en la duración de cualquier lactancia (6), aunque } \\
\text { la fuerza de este efecto sobre la frecuencia de lactancia } \\
\text { materna exclusiva es incierta (7). } \\
\text { Las madres necesitan apoyo para lactar con éxito (8) y dicho } \\
\text { apoyo consigue lactancias más prolongadas (9). La } \\
\text { trasferencia de leche se produce con una adecuada coloca- } \\
\text { ción y agarre al pecho. La postura que mejor facilita el agarre } \\
\text { eficaz varia de una mujer a otra ( } 3,10) \text {. La adecuada } \\
\text { colocación al pecho y el agarre adecuado minimizan lesiones } \\
\text { en el pezón (10). } \\
\text { La técnica de lactancia efectiva incrementa su duración } \\
\text { (3,11). Las intervenciones coordinadas durante el embarazo, } \\
\text { nacimiento e infancia (atención prenatal y postnatal) pueden } \\
\text { aumentar el inicio, la duración y la exclusividad de la } \\
\text { lactancia materna (12). }\end{array}$ & $\begin{array}{l}\text { Del documento del Ministerio sobre la IHAN } \\
\text { Paso 4. Ayudar a las madres a iniciar la } \\
\text { lactancia tras el parto. Este Paso implica: Colocar } \\
\text { a los bebés en contacto piel con piel con sus } \\
\text { madres inmediatamente después del parto, por lo } \\
\text { menos durante una hora, y ayudar a las madres a } \\
\text { reconocer cuándo sus bebés están listos para } \\
\text { amamantar, ofreciendo ayuda en caso necesario. } \\
\text { Paso 5. Mostrar a las madres cómo amamantar } \\
\text { y cómo mantener la lactancia incluso si tienen } \\
\text { que separarse de sus hijos. }\end{array}$ & $\begin{array}{l}\text { (3) Perez-Escamilla R. } \\
\text { Determinants of lactation } \\
\text { performance across time in an } \\
\text { urban population from Mexico. } \\
\text { Soc Sci Med. 1993; 37(8):1069- } \\
\text { 1078. } \\
\text { (4) Grassley J, Eschiti V. } \\
\text { Grandmother breastfeeding } \\
\text { support: what do mothers need } \\
\text { and want? Birth. 2008 } \\
\text { Dec;35(4):329-35 } \\
\text { (5) LeFevre M, Kruse J, Sweig } \\
\text { S: Selection of infant feeding } \\
\text { methods: A population based } \\
\text { study in a rural area. J Fam } \\
\text { Pract 1987; 24: 487-91. } \\
\text { (6) Graffy J, Taylor J. What } \\
\text { information, advice and support } \\
\text { do women want with } \\
\text { breastfeefing. Birth.2005;32:179- } \\
\text { 89. } \\
\text { (7) Hill LF. A salute to La Leche }\end{array}$ & $\begin{array}{l}\text { La Iniciativa para la } \\
\text { Humanización de la } \\
\text { Asistencia al Nacimiento } \\
\text { y la Lactancia (IHAN) ha } \\
\text { sido lanzada por la OMS } \\
\text { y UNICEF para animar a } \\
\text { los hospitales, servicios } \\
\text { de salud, y en particular } \\
\text { las salas de maternidad a } \\
\text { adoptar las prácticas que } \\
\text { protejan, promuevan y } \\
\text { apoyen la lactancia } \\
\text { materna exclusiva desde } \\
\text { el nacimiento. } \\
\text { Se ha identificado un } \\
\text { manual para la } \\
\text { capacitación en la } \\
\text { consejería de lactancia } \\
\text { materna, con la } \\
\text { participación de la OMS y } \\
\text { UNICEF, en el que se } \\
\text { indica que obtener una } \\
\text { historia clínica de }\end{array}$ \\
\hline $\begin{array}{l}\text { IHAN. } \\
\text { Hospitales } \\
\text { IHAN. Guía } \\
\text { detallada } \\
\text { para la } \\
\text { aplicación } \\
\text { paso por } \\
\text { paso }\end{array}$ & $\begin{array}{l}\text { Se distinguen los pasos a incluir en los Hospitales (que son } \\
\text { 10) de los Centros de Salud (que son 7). }\end{array}$ & $\begin{array}{l}\text { En los hospitales: } \\
\text { La valoración adecuada de la lactancia requiere } \\
\text { realizar una buena anamnesis y una exploración } \\
\text { que permitan detectar los signos de un } \\
\text { amamantamiento eficaz. La observación de una } \\
\text { toma completa es esencial para comprobar que } \\
\text { existe una adecuada transferencia láctea y } \\
\text { diagnosticar la causa de las dificultades si las } \\
\text { hubieses, por lo que debe ser realizada por un } \\
\text { profesional cualificado, en la primera toma. } \\
\text { Posteriormente, se realizarán evaluaciones de la } \\
\text { toma o de la postura al pecho todas las veces que } \\
\text { sea necesario, preferiblemente } 2-3 \text { veces al día, y } \\
\text { desde luego, ante la aparición de problemas con la }\end{array}$ & $\begin{array}{l}\text { 1968 Jul; } 73(1): 161-2 \text {. } \\
\text { (8) Bergh A-M. The role of a } \\
\text { nongovernmental organization in } \\
\text { breast feeding education. J Nutr } \\
\text { Educ 19: } 117,1987 \text {. } \\
\text { (9) Blazquez MJ, Aguayo J, } \\
\text { Ramos ML. Grupos de apoyo a } \\
\text { la lactancia materna. En } \\
\text { Asociación Española de } \\
\text { Pediatría. Manual de Lactancia } \\
\text { Materna. Ed Panamericana } \\
\text { 2008; } \text { p 133. } \\
\text { (10) Thompson M: The } \\
\text { effectiveness of mother-to- } \\
\text { mother help: Research on the La }\end{array}$ & $\begin{array}{l}\text { las preguntas pertinentes } \\
\text { de una manera } \\
\text { sistemática, para lo que } \\
\text { se proporciona una serie } \\
\text { de consejos y una ficha } \\
\text { para recordar cuáles son } \\
\text { las preguntas que deben } \\
\text { hacerse. }\end{array}$ \\
\hline
\end{tabular}




\begin{tabular}{|c|c|c|}
\hline $\begin{array}{l}\text { Estrategia } \\
\text { centros de } \\
\text { salud IHAN. } \\
\text { Revisada, } \\
\text { actualizada y } \\
\text { ampliada } \\
\text { para la } \\
\text { atención } \\
\text { integral en } \\
\text { los centros } \\
\text { de salud. } \\
\text { Manual para } \\
\text { la } \\
\text { acreditación } \\
\text { IHAN. }\end{array}$ & $\begin{array}{l}\text { lactancia. } \\
\text { Esta evaluación debe ser estandarizada, quedar } \\
\text { registrada y deberá reflejar: Anamnesis materna; } \\
\text { Exploración física, Evaluación de la madre y del } \\
\text { lactante para valorar la ingesta, evaluación } \\
\text { estandarizada de la toma que valore: postura, } \\
\text { agarre y síntomas de transferencia eficaz de leche. } \\
\text { En los centros de salud: } \\
\text { La valoración adecuada de la lactancia requiere } \\
\text { realizar una buena anamnesis y una exploración } \\
\text { que permitan detectar los signos de un } \\
\text { ammanantamiento eficaz. La observación de una } \\
\text { toma completa es esencial para comprobar que } \\
\text { existe una adecuada transferencia láctea y para } \\
\text { diagnosticar la causa de las dificultades si las } \\
\text { hubiesese, por lo que debe ser realizada por un } \\
\text { profesional cualificado en la primera visita al centro } \\
\text { de salud. } \\
\text { Posteriormente se realizarán evaluaciones de la } \\
\text { toma o de la postura al pecho todas las veces que } \\
\text { sea necesario, ante la aparición de problemas con } \\
\text { la lactancia. } \\
\text { Se recomienda que esta evaluación sea } \\
\text { estandarizada y que se registre dicha evaluación. }\end{array}$ & $\begin{array}{l}\text { Leche League International } \\
\text { program. Birth Fam J 3: } 1 \text {, } \\
\text { Winter 1976-1977. } \\
\text { (11) Hellman LM, Kohl SG, } \\
\text { Palmer J: Early hospital } \\
\text { discharge in obstetrics. Lancet } \\
\text { 1962; } \\
\text { I: 227-32. } \\
\text { (12) Ladas AK. How to help } \\
\text { mothers breastfeed: deductions } \\
\text { from a survey. Clin Pediatr } \\
\text { (Phila). 1970;9(12):702-5. }\end{array}$ \\
\hline
\end{tabular}

Se ha identificado un manual para la capacitación en la consejería de lactancia materna elaborado con la participación de la OMS y UNICEF (1) en el que se indica que obtener una historia clínica de lactancia significa hacer las preguntas pertinentes de una manera sistemática, para lo que se proporciona una ficha de historia clínica de la lactancia que incluye toda la información que debería recogerse (Figura 1), así como una serie de consejos de cómo hacer una entrevista con habilidades de comunicación (Figura 2). 


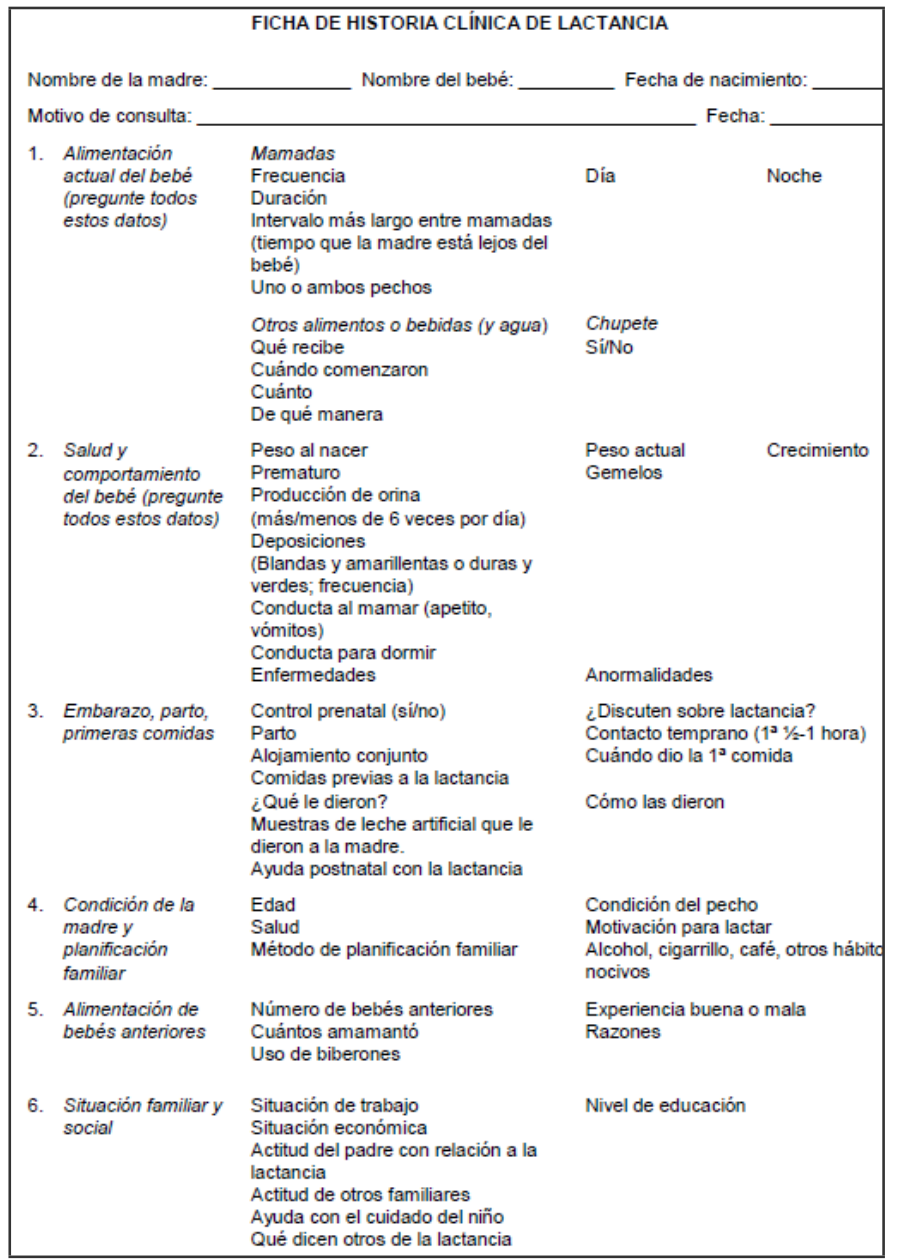

Figura 1: Datos a recoger en la historia clínica

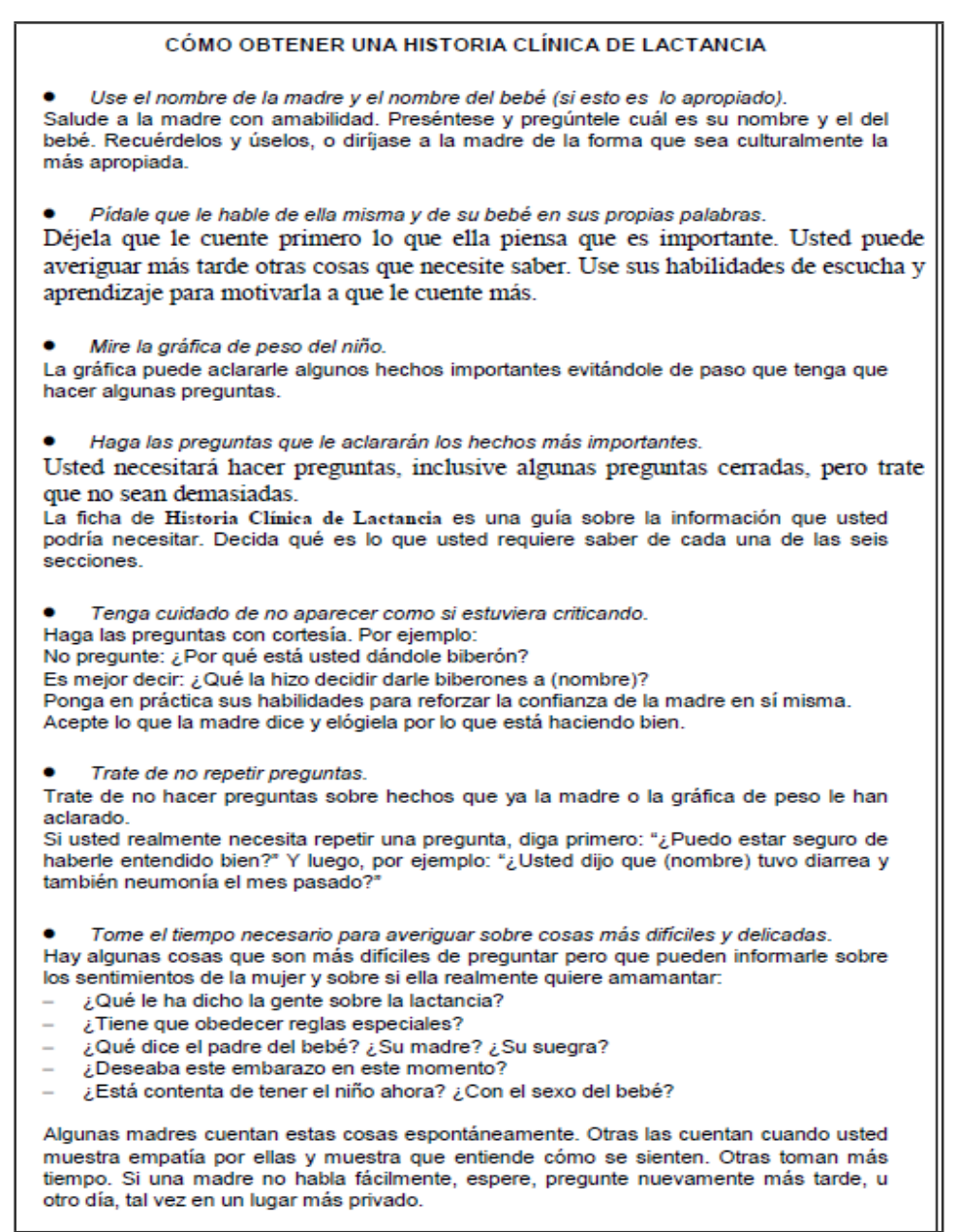

Figura 2: Cómo obtener una historia clínica de lactancia 


\subsection{Revisiones sistemáticas}

No se han identificado revisiones sistemáticas sobre los datos que hay que recoger ni sobre cómo se deben recoger esos datos.

\subsection{Resumen de GPC base y RS disponibles}

La guía NICE (2) indica que la experiencia de una mujer con la lactancia debería ser comentada cada vez que se tiene contacto con ella, para valorar si la lactancia es efectiva e identificar cualquier necesidad de apoyo adicional, y que el progreso con la lactancia materna debería ser valorado y documentado en el plan de cuidado postnatal en cada visita (recomendación de buena práctica).

La guía Perinatal Care Services (3) recomienda realizar una evaluación de la madre y del recién nacido en los períodos de tiempo claves mediante la observación y conversación con la misma (recomendación de grado A), indicando además cuáles son los aspectos relacionados con el proceso de amamantamiento, con la madre y el niño que han de evaluarse.

En la estrategia IHAN para hospitales y centros de salud $(4 ; 5)$ se señala que la valoración adecuada de la lactancia requiere realizar una buena anamnesis y una exploración que permitan detectar los signos de un amamantamiento eficaz, y que la evaluación debe ser estandarizada, quedar registrada y deberá reflejar: anamnesis materna, exploración física, evaluación de la madre y lactante para valorar la ingesta y evaluación estandarizada de la toma.

\subsection{Conclusión (marcar con una X):}

X Adopción GPC/Revisión sistemática

Elaboración parcial

Elaboración de novo

ACTUALIZADO A FECHA DE: 31 de Octubre de 2016 


\section{De la Evidencia a la Recomendación}

\section{¿Qué datos se deberían recoger en la historia clínica para valorar adecuadamente la lactancia materna?}

¿Cómo se deberían recoger esos datos?

Redacción de la recomendación $\quad$ Recomendaciones de buena práctica

$\checkmark$ Se deberían recoger los datos de interés para el período neonatal inmediato que se indican en la ficha de historia clínica de lactancia de la Organización Mundial de la Salud (ver anexo 7)

$\checkmark$ En el informe de alta de la maternidad debería aparezca toda la información relevante para facilitar el seguimiento en Atención Primaria.

$\checkmark$ Para recoger la historia de lactancia se deberían utilizar las habilidades en comunicación propuestas en el Manual para Consejería en Lactancia Materna de la Organización Mundial de la Salud (ver anexo 7).

Razonamiento/Justificación de la recomendación
Se considera que la ficha de lactancia de la OMS contiene toda la información que puede ser necesaria recoger.

Gran parte de esta información se podrá obtener de la historia clínica de la madre. Sin embargo, es muy posible que no sea necesario obtener toda la información en la maternidad.

Dada la importancia de un correcto apoyo a la lactancia y las dificultades de tiempo que a veces se sufren durante la asistencia sanitaria, sería de interés que en el informe de alta de la maternidad constara toda la información posible (antecedentes maternos, problemas previos e historia reproductiva, medicaciones otros hijos amantados, experiencia con lactancias anteriores), y que el resto de datos fueran completados en atención primaria según fuera siendo necesario. Así se garantizaría la continuidad de la asistencia y que los datos recogidos no se perderían entre la maternidad y la atención primaria o entre los diferentes profesionales sanitarios que atienden a la madre y a su hijo (matronas, enfermeras y pediatras).

\section{Consideraciones para la implementación}

Se recomienda que para poder facilitar la continuidad de la asistencia sanitaria a la diada madre/hijo, los datos sobre la lactancia materna sean accesibles y se puedan compartir entre los profesionales sanitarios que atienden tanto a la madre como al lactante

\section{Factibilidad}




\section{ANEXO I: HOJA PARA LA RECOGIDA DE LA HISTORIA CLÍNICA}

\section{FICHA DE HISTORIA CLÍNICA DE LACTANCIA}

Nombre de la madre: Nombre del bebé: Fecha de nacimiento:

Motivo de consulta: Fecha:

1. Alimentación actual Mamadas del bebé (pregunte Frecuencia todos estos datos)

Duración

Intervalo más largo entre mamadas

(tiempo que la madre está lejos del bebé)

Uno o ambos pechos

Otros alimentos o bebidas ( $y$ agua)

Qué recibe

Cuándo comenzaron

Cuánto

De qué manera

2. Salud $y$ comportamiento del bebé (pregunte todos estos datos)

\section{Peso al nacer}

Prematuro

Producción de orina

(más/menos de 6 veces por día)

Deposiciones

(Blandas y amarillentas o duras y verdes; frecuencia)

Conducta al mamar (apetito, vómitos)

Conducta para dormir

Enfermedades

3. Embarazo, parto, primeras comidas

Control prenatal (sí/no)

Parto

Alojamiento conjunto

Comidas previas a la lactancia ¿Qué le dieron?

Muestras de leche artificial que le dieron a la madre.

Ayuda postnatal con la lactancia

4. Condición de la madre $y$ planificación familiar

5. Alimentación de bebés anteriores

6. Situación familiar y social
Edad

Salud

Método de planificación familiar

Número de bebés anteriores

Cuántos amamantó

Uso de biberones

Situación de trabajo

Situación económica

Actitud del padre con relación a la

lactancia

Actitud de otros familiares

Ayuda con el cuidado del niño

Qué dicen otros de la lactancia
Día

Noche

Chupete

Si/No

Peso actual

Gemelos

Crecimiento

Anormalidades

¿Discuten sobre lactancia?

Contacto temprano ( $1^{a} 1 / 2-1$ hora)

Cuándo dio la $1^{\mathrm{a}}$ comida

Cómo las dieron

Condición del pecho

Motivación para lactar

Alcohol, cigarrillo, café, otros hábitos nocivos

Experiencia buena o mala

Razones

Nivel de educación 


\section{6- BIBLIOGRAFÍA}

(1) Consejería en Lactancia Materna: Curso de Capacitación. Manual del Participante. $1993 . \quad$ Disponible en: http://www.who.int/maternal_child_adolescent/documents/pdfs/bc_participants m anual es.pdf.

(2) NICE. Postnatal care up to 8 weeks after birth. Julio 2006 (actualizado en Febrero de 2015). Disponible en: http://guidance.nice.org.uk/CG37.

(3) Perinatal Services BC. Health Promotion Guideline. Breastfeeding Healthy Term Infants. 2013 Feb.

(4) IHAN. Hospitales IHAN. Guía detallada para la aplicación paso por paso. Disponible en: https://www.ihan.es/docs/documentacionacreditacion/hospitales/generales/00.Guia detallada hospital.pdf.

(5) IHAN. Guía detallada para la aplicación paso por paso. Centros de Salud IHAN. Disponible en: https://www.ihan.es/docs/documentacionacreditacion/centros salud/Manual para la acreditacion IHAN en AP 2015.pd f. 


\section{¿Se debe realizar la observación y valoración de la toma con una herramienta estandarizada durante la estancia en la maternidad a las madres que amamantan?}

\section{1- PREGUNTA CLÍNICA EN FORMATO PICO}

Tabla 1-Componentes de la pregunta clínica en formato PICO

\begin{tabular}{|l|l|}
\hline Pacientes & Madres de recién nacidos sanos a término y que amamantan \\
\hline Intervención & $\begin{array}{l}\text { Realizar la observación de la toma con una herramienta } \\
\text { estandarizada durante la estancia en la maternidad }\end{array}$ \\
\hline Comparación & $\begin{array}{l}\text { Realizar la observación de la toma sin una herramienta } \\
\text { estandarizada durante la estancia en la maternidad }\end{array}$ \\
\hline Resultados & $\begin{array}{l}\text { Tasa de lactancia materna exclusiva al alta } \\
\text { Tasa de lactancia materna a los } 6 \text { meses } \\
\text { Tasa de lactancia materna exclusiva a los } 6 \text { meses } \\
\text { Satisfacción materna (con la lactancia) } \\
\text { Complicaciones de las mamas (grietas, ingurgitaciones) } \\
\text { Peso del bebé (48-72h.) } \\
\text { Duración de la lactancia } \\
\text { Frecuencia de tomas }\end{array}$ \\
\hline Tipo de estudio & $\begin{array}{l}\text { RS de ECA, ECA, RS de estudios observacionales o estudios } \\
\text { observacionales }\end{array}$ \\
\hline
\end{tabular}

\section{2- INTRODUCCIÓN}

Para comprobar que la lactancia se instaura adecuadamente es necesario observar y valorar las tomas durante la estancia en el hospital. Generalmente, esta observación se realiza de forma no sistematizada, por lo que se utilizan criterios subjetivos con una amplia variabilidad entre observadores, lo que dificulta el diagnóstico de los posibles problemas y, por tanto, su adecuado tratamiento. Por ello convendría saber si utilizar una herramienta estandarizada para la observación de la toma puede ayudarnos a identificar mejor las dificultades en el amamantamiento. 


\section{ESTRATEGIA DE ELABORACIÓN DE LA PREGUNTA}

\subsection{GPC Base}

Tabla 2- Resumen de GPC Base

\begin{tabular}{|c|c|c|c|c|}
\hline $\begin{array}{l}\text { Guía } \\
\text { (Enfoque) }\end{array}$ & $\begin{array}{l}\text { Resumen sobre la evidencia } \\
\text { (Calidad de la evidencia) }\end{array}$ & $\begin{array}{l}\text { Recomendaciones } \\
\text { (Grado) }\end{array}$ & $\begin{array}{l}\text { Referencias bibliográficas } \\
\text { (Tipo de publicación) }\end{array}$ & Comentarios \\
\hline $\begin{array}{l}\text { NICE_2006 } \\
\text { (Actualizació } \\
\text { n 2011) }\end{array}$ & - & $\begin{array}{l}\text { Evaluar una lactancia eficaz } \\
\text { Si la madre percibe que tiene leche insuficiente, se } \\
\text { debería evaluar su técnica de lactancia y la salud } \\
\text { del bebé. Se debería proporcionar tranquilidad } \\
\text { para apoyar a la mujer y para que gane confianza } \\
\text { en su capacidad para producir la suficiente leche } \\
\text { para su bebé [C]. }\end{array}$ & - & \\
\hline $\begin{array}{l}\text { Perinatal } \\
\text { Services } \\
\text { BC_2013 }\end{array}$ & $\begin{array}{l}\text { Cuestionarios y herramientas para la evaluación de la } \\
\text { lactancia materna } \\
\text { 1. Breastfeeding Attrition Prediction Tool (BAPT) }(1,2,3) \\
\text { 2. Modified BAPT Tool (4) } \\
\text { 3. Maternal Breastfeeding Evaluation Scale(MBFES) }(5,6) \\
\text { 4. Breastfeeding Self-Efficacy Scale (BSES) (8) } \\
\text { 5. LATCH breastfeeding assessment tool (9) } \\
\text { 6. Infant Breastfeeding Assessment Tool (IBFAT) (12) }\end{array}$ & $\begin{array}{l}\text { Se debería realizar la evaluación de la madre y del } \\
\text { niño en los períodos de tiempo claves mediante } \\
\text { observación y entrevista }(A)^{*} \\
\text { La evaluación es compleja e incluye la valoración } \\
\text { de la madre, el niño y de cómo se acoplan de } \\
\text { forma conjunta para permitir la lactancia materna. } \\
\text { No hay recomendaciones específicas sobre las } \\
\text { herramientas validadas, pero incluyen una lista } \\
\text { (Apéndice E). }\end{array}$ & $\begin{array}{l}\text { *Source: From Hewat (2010). } \\
\text { In J. Riordan \& K Wambach } \\
\text { Eds., Breastfeeding and } \\
\text { Human Lactation, 4rd Ed., } \\
\text { Boston: Jones and Bartlett } \\
\text { Publishers. Permission from J } \\
\text { Riordan and K Wambach. } \\
\text { Update (R.Hewat) March } \\
\text { 2011. } \\
\text { 1. Janke J. (1992). Prediction } \\
\text { of breast-feeding attrition: } \\
\text { instrument development. } \\
\text { Applied Nurs Rese 5:48-63. } \\
\text { 2. Janke J. } \\
\text { (1994).Development of the } \\
\text { breast-feeding attrition } \\
\text { prediction tool. Nurs Res } \\
34: 100-104 \text {. } \\
\text { 3. Riordan JM, Koehn M. } \\
\text { (1997). Reliability and validity } \\
\text { testing of three breastfeeding } \\
\text { assessment tools. JOGN Nurs } \\
\text { 26:181-187. } \\
4 \text {. Dick MJ, et al. (2002). } \\
\text { Predicting early breastfeeding } \\
\text { attrition. J of Hum Lact 18:21- }\end{array}$ & $\begin{array}{l}\text { Cada herramienta sirve } \\
\text { para valorar un aspecto } \\
\text { específico. Unas valoran } \\
\text { la satisfacción materna, } \\
\text { otras el riesgo de destete } \\
\text { o la necesidad de ayuda. } \\
\text { La evaluación de la toma } \\
\text { es compleja y no hay una } \\
\text { herramienta que cubra } \\
\text { eficazmente todos los } \\
\text { aspectos. }\end{array}$ \\
\hline
\end{tabular}




\begin{tabular}{|c|c|c|c|c|}
\hline $\begin{array}{l}\text { Guía } \\
\text { (Enfoque) }\end{array}$ & $\begin{array}{l}\text { Resumen sobre la evidencia } \\
\text { (Calidad de la evidencia) }\end{array}$ & $\begin{array}{l}\text { Recomendaciones } \\
\text { (Grado) }\end{array}$ & $\begin{array}{l}\text { Referencias bibliográficas } \\
\text { (Tipo de publicación) }\end{array}$ & Comentarios \\
\hline
\end{tabular}


Tabla 3. Resumen de otros documentos

\begin{tabular}{|c|c|c|c|c|}
\hline $\begin{array}{l}\text { Guía } \\
\text { (Enfoque) }\end{array}$ & $\begin{array}{l}\text { Resumen sobre la evidencia } \\
\text { (Calidad de la evidencia) }\end{array}$ & $\begin{array}{l}\text { Recomendaciones } \\
\text { (Grado) }\end{array}$ & $\begin{array}{l}\text { Referencias bibliográficas } \\
\text { (Tipo de publicación) }\end{array}$ & Comentarios \\
\hline $\begin{array}{l}\text { Ministerio de } \\
\text { Sanidad, } \\
\text { Política } \\
\text { Social e } \\
\text { lgualdad, } \\
2011 .\end{array}$ & $\begin{array}{l}\text { Documento del Ministerio sobre la IHAN } \\
\text { Para el paso 5: } \\
\text { La ayuda práctica individual con la técnica de la lactancia y el } \\
\text { apoyo psicológico para aumentar la confianza de la madre } \\
\text { pueden ser muy útiles para tener éxito con la lactancia }(3,4) \text {. } \\
\text { Esta ayuda adecuada, incluso durante la corta estancia } \\
\text { hospitalaria, puede tener un efecto que perdura meses } \\
\text { después (5). Hay pruebas claras de la efectividad del apoyo } \\
\text { profesional en la duración de cualquier lactancia (6), aunque } \\
\text { la fuerza de este efecto sobre la frecuencia de lactancia } \\
\text { materna exclusiva es incierta (7). } \\
\text { Las madres necesitan apoyo para lactar con éxito (8) y dicho } \\
\text { apoyo consigue lactancias más prolongadas (9). La } \\
\text { trasferencia de leche se produce con una adecuada coloca- } \\
\text { ción y agarre al pecho. La postura que mejor facilita el agarre } \\
\text { eficaz varia de una mujer a otra ( } 3,10) \text {. La adecuada } \\
\text { colocación al pecho y el agarre adecuado minimizan lesiones } \\
\text { en el pezón (10). } \\
\text { La técnica de lactancia efectiva incrementa su duración } \\
\text { (3,11). Las intervenciones coordinadas durante el embarazo, } \\
\text { nacimiento e infancia (atención prenatal y postnatal) pueden } \\
\text { aumentar el inicio, la duración y la exclusividad de la } \\
\text { lactancia materna (12). }\end{array}$ & $\begin{array}{l}\text { Documento del Ministerio sobre la IHAN } \\
\text { Paso 4. Ayudar a las madres a iniciar la } \\
\text { lactancia tras el parto. Este Paso implica: Colocar } \\
\text { a los bebés en contacto piel con piel con sus } \\
\text { madres inmediatamente después del parto, por lo } \\
\text { menos durante una hora, y ayudar a las madres a } \\
\text { reconocer cuándo sus bebés están listos para } \\
\text { amamantar, ofreciendo ayuda en caso necesario. } \\
\text { Paso 5. Mostrar a las madres cómo amamantar } \\
\text { y cómo mantener la lactancia incluso si tienen } \\
\text { que separarse de sus hijos. }\end{array}$ & $\begin{array}{l}\text { (3) Perez-Escamilla R. } \\
\text { Determinants of lactation } \\
\text { performance across time in an } \\
\text { urban population from Mexico. } \\
\text { Soc Sci Med. 1993; 37(8):1069- } \\
\text { 1078. } \\
\text { (4) Grassley J, Eschiti V. } \\
\text { Grandmother breastfeeding } \\
\text { support: what do mothers need } \\
\text { and want? Birth. 2008 } \\
\text { Dec;35(4):329-35 } \\
\text { (5) LeFevre M, Kruse J, Sweig } \\
\text { S: Selection of infant feeding } \\
\text { methods: A population based } \\
\text { study in a rural area. J Fam } \\
\text { Pract 1987; 24: 487-91. } \\
\text { (6) Graffy J, Taylor J. What } \\
\text { information, advice and support } \\
\text { do women want with } \\
\text { breastfeefing. Birth.2005;32:179- } \\
\text { 89. } \\
\text { (7) Hill LF. A salute to La Leche } \\
\text { League International. J Pediatr. } \\
\text { 1968 Jul;73(1):161-2. }\end{array}$ & $\begin{array}{l}\text { La Iniciativa para la } \\
\text { Humanización de la } \\
\text { Asistencia al Nacimiento } \\
\text { y la Lactancia (IHAN) ha } \\
\text { sido lanzada por la OMS } \\
\text { y UNICEF para animar a } \\
\text { los hospitales, servicios } \\
\text { de salud, y en particular } \\
\text { las salas de maternidad a } \\
\text { adoptar las prácticas que } \\
\text { protejan, promuevan y } \\
\text { apoyen la lactancia } \\
\text { materna exclusiva desde } \\
\text { el nacimiento. } \\
\text { Se ha identificado un } \\
\text { manual para la } \\
\text { capacitación en la } \\
\text { consejería de lactancia } \\
\text { materna, con la } \\
\text { participación de la OMS y } \\
\text { UNICEF, en el que se } \\
\text { indica que obtener una } \\
\text { historia clínica de }\end{array}$ \\
\hline $\begin{array}{l}\text { IHAN. } \\
\text { Hospitales } \\
\text { IHAN. Guía } \\
\text { detallada } \\
\text { para la } \\
\text { aplicación } \\
\text { paso por } \\
\text { paso }\end{array}$ & $\begin{array}{l}\text { Se distinguen los pasos IHAN a seguir en los Hospitales (que } \\
\text { son 10) y Centros de Salud (que son } 7 \text { ). }\end{array}$ & $\begin{array}{l}\text { En los hospitales: } \\
\text { La valoración adecuada de la lactancia requiere } \\
\text { realizar una buena anamnesis y una exploración } \\
\text { que permitan detectar los signos de un } \\
\text { amamantamiento eficaz. La observación de una } \\
\text { toma completa es esencial para comprobar que } \\
\text { existe una adecuada transferencia láctea y } \\
\text { diagnosticar la causa de las dificultades si las } \\
\text { hubieses, por lo que debe ser realizada por un } \\
\text { profesional cualificado, en la primera toma. } \\
\text { Posteriormente, se realizarán evaluaciones de la } \\
\text { toma o de la postura al pecho todas las veces que } \\
\text { sea necesario, preferiblemente } 2-3 \text { veces al día, y } \\
\text { desde luego, ante la aparición de problemas con la }\end{array}$ & $\begin{array}{l}\text { nongovernmental organization in } \\
\text { breast feeding education. J Nutr } \\
\text { Educ 19: } 117,1987 . \\
\text { (9) Blazquez MJ, Aguayo J, } \\
\text { Ramos ML. Grupos de apoyo a } \\
\text { la lactancia materna. En } \\
\text { Asociación Española de } \\
\text { Pediatría. Manual de Lactancia } \\
\text { Materna. Ed Panamericana } \\
\text { 2008; } p \text { 133. } \\
\text { (10) Thompson M: The } \\
\text { effectiveness of mother-to- } \\
\text { mother help: Research on the La } \\
\text { Leche League International } \\
\text { program. Birth Fam J 3: } 1 \text {, }\end{array}$ & $\begin{array}{l}\text { las preguntas pertinentes } \\
\text { de una manera } \\
\text { sistemática, para lo que } \\
\text { se proporciona una serie } \\
\text { de consejos y una ficha } \\
\text { para recordar cuáles son } \\
\text { las preguntas que deben } \\
\text { hacerse. }\end{array}$ \\
\hline
\end{tabular}




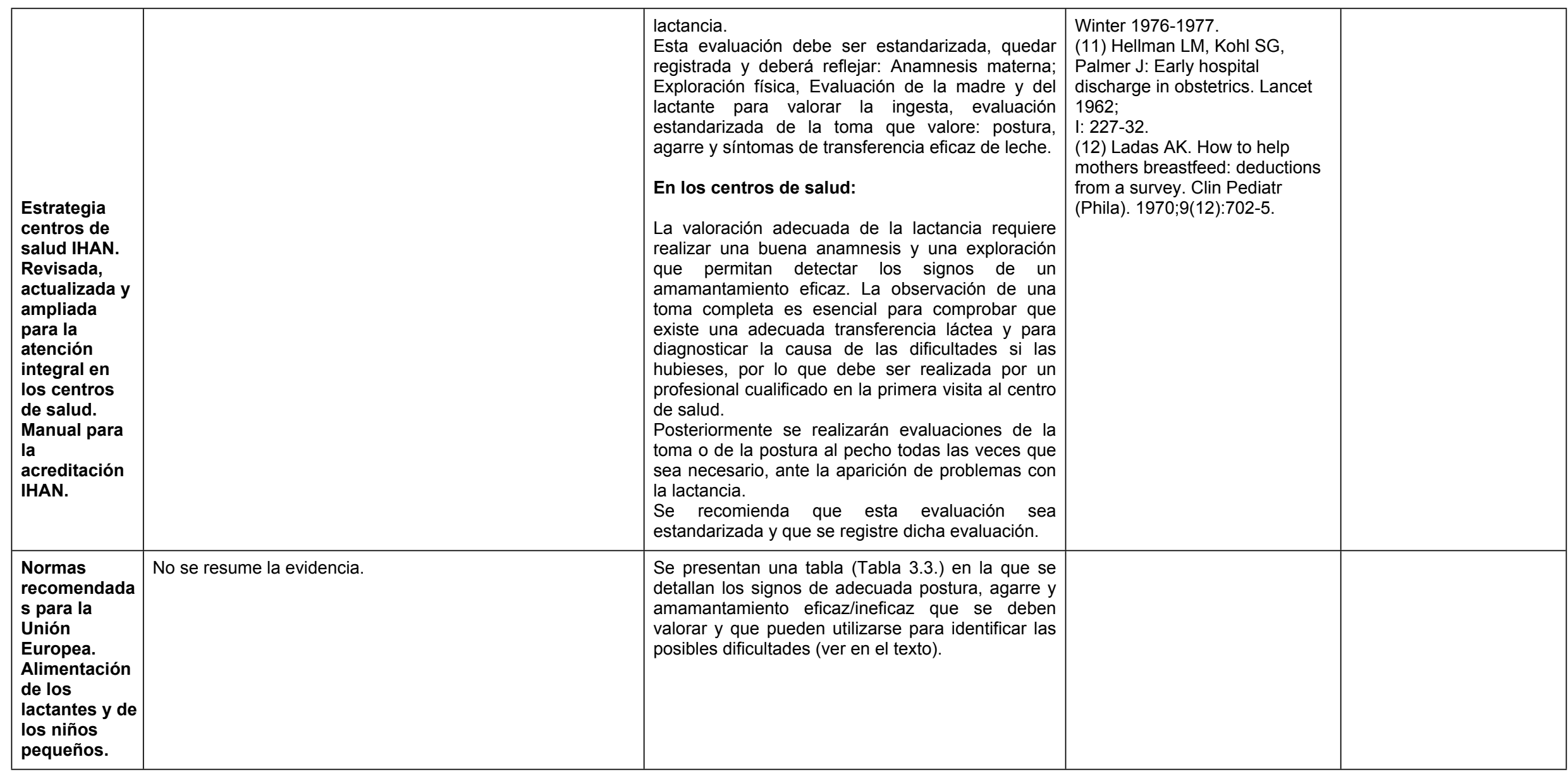

En la guía NICE (1) se indica que el éxito de la lactancia materna no se puede determinar por una única medida cuantitativa y que debe reflejar de forma individual los aspectos relacionados con la actividad del niño a la hora de alimentarse y la satisfacción de la madre con la técnica que sigue para alimentar al niño. En esta guía se presentan las herramientas que existen para evaluar la lactancia materna junto con las características básicas de cada una de ellas (Figura 1). 


\begin{tabular}{|c|c|c|c|}
\hline \multicolumn{4}{|c|}{$\begin{array}{c}\text { Table 6-3 } \\
\text { Breastfeeding Assessment Tools }\end{array}$} \\
\hline Tool & Focus & Scored by & Measures \\
\hline $\begin{array}{l}\text { BAPT:Breastfeeding Attrition } \\
\text { Prediction Tool }\end{array}$ & $\begin{array}{l}\text { Mother's knowledge } \\
\text { ff and attitudes } \\
\text { oward breastfeeding } \\
\text { that may predict } \\
\text { early weaning }\end{array}$ & Mother & $\begin{array}{l}\text { Attitude;subjective } \\
\text { horm;control }\end{array}$ \\
\hline $\begin{array}{l}\text { BFAT:Infant Breastfeeding } \\
\text { Assessment Tool }\end{array}$ & Infant & $\begin{array}{l}\text { Mother or } \\
\text { hurse }\end{array}$ & Signaling;rooting;sucking \\
\hline $\begin{array}{l}\text { ATCH: Breastfeeding Charting } \\
\text { System }\end{array}$ & Infant and mother & $\begin{array}{l}\text { Mother or } \\
\text { purse }\end{array}$ & $\begin{array}{l}\text { atch on; audible } \\
\text { swallowing; type of nipple; } \\
\text { comfort of breasts; hold: } \\
\text { amount of assistance } \\
\text { equired }\end{array}$ \\
\hline MBA: Mother-Baby Assessment & Infant and mother & Nurse & $\begin{array}{l}\text { Readiness; position;latch } \\
\text { pn; milk transfer; outcome }\end{array}$ \\
\hline $\begin{array}{l}\text { MBFES: Maternal Breastfeeding } \\
\text { Evaluation Scale }\end{array}$ & Mother and infant & Mother & $\begin{array}{l}\text { Matemal enjoyment/role } \\
\text { attainment; infant } \\
\text { satisfaction/growth; } \\
\text { ifestyle/maternal body } \\
\text { mage. }\end{array}$ \\
\hline $\begin{array}{l}\text { PEBPT; Potential Early } \\
\text { Breastfeeding Problem Tool }\end{array}$ & Mother & Mother & $\begin{array}{l}\text { Breastfeeding } \\
\text { problems among } \\
\text { postpartum women }\end{array}$ \\
\hline
\end{tabular}

Figura 1: herramientas para evaluar la lactancia materna (Obtenido de la guía NICE 2006)

En la guía PC services de 2013 (2) también se hace un resumen de las herramientas que existen para evaluar la lactancia materna, destacando en este caso el objetivo de cada herramienta junto con la fiabilidad y validez de cada una de ellas (Figura 2). 


\begin{tabular}{|c|c|c|c|}
\hline Title & Purpose & Reliability & Validity \\
\hline $\begin{array}{l}\text { Breastfe日ding } \\
\text { Attrition } \\
\text { Prediction Tool } \\
\text { (BAPT) } 1,2,3 \text {. } \\
\text { Modified BAPT } \\
\text { Tool4. }\end{array}$ & $\begin{array}{l}\text { To identify women at risk for earty, } \\
\text { unintended weaning. Four factors } \\
\text { measure negative and positive } \\
\text { Dreastfeeding attitude, perceived } \\
\text { maternal control and social and } \\
\text { professional support. }\end{array}$ & $\begin{array}{l}\text { Cronbach alphas for } \\
\text { all scales, } .79-.837 ; \\
80-.93^{3} \text { and } .81-.86^{4}\end{array}$ & $\begin{array}{l}\text { Prediction validity: } 3 \text { of } 4 \text { scales related } \\
\text { to } 8 \text { week feeding outcome }{ }^{1} \text { and negative } \\
\text { sentiment scale predicted } \theta a r l y ~ u n i n t e n d e d \\
\text { weaning2. } \\
\text { Modified BAPT: } 2 \text { scales predicted } 78 \% \text { of } \\
\text { women who discontinued breastfe日ding at } 8 \\
\text { weeks and } 68 \% \text { of those still breastfeeding }\end{array}$ \\
\hline $\begin{array}{l}\text { Maternal } \\
\text { Breastfeøding } \\
\text { Evaluation } \\
\text { Scale(MBFES) } \\
\text { 5,6 }\end{array}$ & $\begin{array}{l}\text { To measure a mother's overall } \\
\text { evaluation of the breastfeeding } \\
\text { experience using a } 30 \text { item Likert } \\
\text { scale. Subscales include: maternal } \\
\text { enjoyment/role attainment, infant } \\
\text { satisfaction/growth, and lifestyle/ } \\
\text { maternal body image. }\end{array}$ & $\begin{array}{l}\text { Test-retest } \\
\text { correlations: } .82 \text { to } .93 \text {. } \\
\text { Cronbach alphas for } \\
\text { subscales: } .80 \text { to } .93^{5} \\
\text { and } .73 \text { to } .83^{6}\end{array}$ & $\begin{array}{l}\text { Items developed from qualitative study. }{ }^{7} \\
\text { Predictive validity: Significant positiv } \theta \\
\text { correlation of total scale and subscales with } \\
\text { maternal satisfaction and breastfeeding } \\
\text { intent and duration. } 5,6\end{array}$ \\
\hline $\begin{array}{l}\text { Breastfeeding } \\
\text { Self-Efficacy } \\
\text { Scale (BSES) }\end{array}$ & $\begin{array}{l}\text { To assess and measure confidence } \\
\text { in breastfeeding mothers. Factors } \\
\text { include techniques/maternal skills } \\
\text { and attitudes and beliefs. }\end{array}$ & Cronbach alpha: .96. & $\begin{array}{l}\text { Content validity. } \\
\text { Predictive validity: Feeding method (breast } \\
\text { or bottle) at } 6 \text { weiks postpartum. }{ }^{8}\end{array}$ \\
\hline $\begin{array}{l}\text { LATCH } \\
\text { breastfeeding } \\
\text { assessment } \\
\text { tool }^{9}\end{array}$ & $\begin{array}{l}\text { To assess effective breastfeeding } \\
\text { in first week after birth for latch-on, } \\
\text { audible swallowing, nipple type, } \\
\text { comfort of breast/nipple, and help } \\
\text { needed to position baby. }\end{array}$ & $\begin{array}{l}\text { Interrater reliability: } \\
\text { Mothers' and nurses' } \\
\text { total scores positively } \\
\text { correlated. }{ }^{10}\end{array}$ & $\begin{array}{l}\text { Requires further testing but mothers' } \\
\text { total scores positively correlated with } \\
\text { breastfeeding at } 6 \text { we日ks postpartum. }{ }^{10} \\
\text { Score of } 29 \text { at } 16-24 \text { hours post-delivery } \\
\text { a moderate predictor of breastfeeding } \\
\text { duration at } 6 \text { weeks. }{ }^{11}\end{array}$ \\
\hline $\begin{array}{l}\text { Infant } \\
\text { Breastfeeding } \\
\text { Assessment Tool } \\
\text { (IBFAT). }{ }^{12}\end{array}$ & $\begin{array}{l}\text { To assess and measure infant } \\
\text { breastfeeding competence. Four } \\
\text { subscales measure readiness to } \\
\text { feød, rooting, fixing and sucking. } \\
\text { Score range } 0 \text { to } 12 \text {. }\end{array}$ & $\begin{array}{l}\text { Interrater reliability: } \\
91 \% \text { agreement in co- } \\
\text { assessed feeds }{ }^{12} \\
\text { Pairwise correlations } \\
\text { of raters } .5813\end{array}$ & $\begin{array}{l}\text { Content validity and observation in clinical } \\
\text { practic } .^{12}\end{array}$ \\
\hline
\end{tabular}

Figura 2: herramientas para evaluar la lactancia materna (Obtenido de PC Services 2013)

En el Manual para la capacitación en consejería de lactancia materna (3) se incluye una ficha de observación de las tomas (Figura 3), aunque también se ha encontrado una herramienta posterior de UNICEF para ser utilizada el $5^{\circ}$ día de vida, en la que se indican las preguntas que se deben hacer a una mujer que amamanta y las ocasiones en las que se debe observar una toma (Figura 4). 


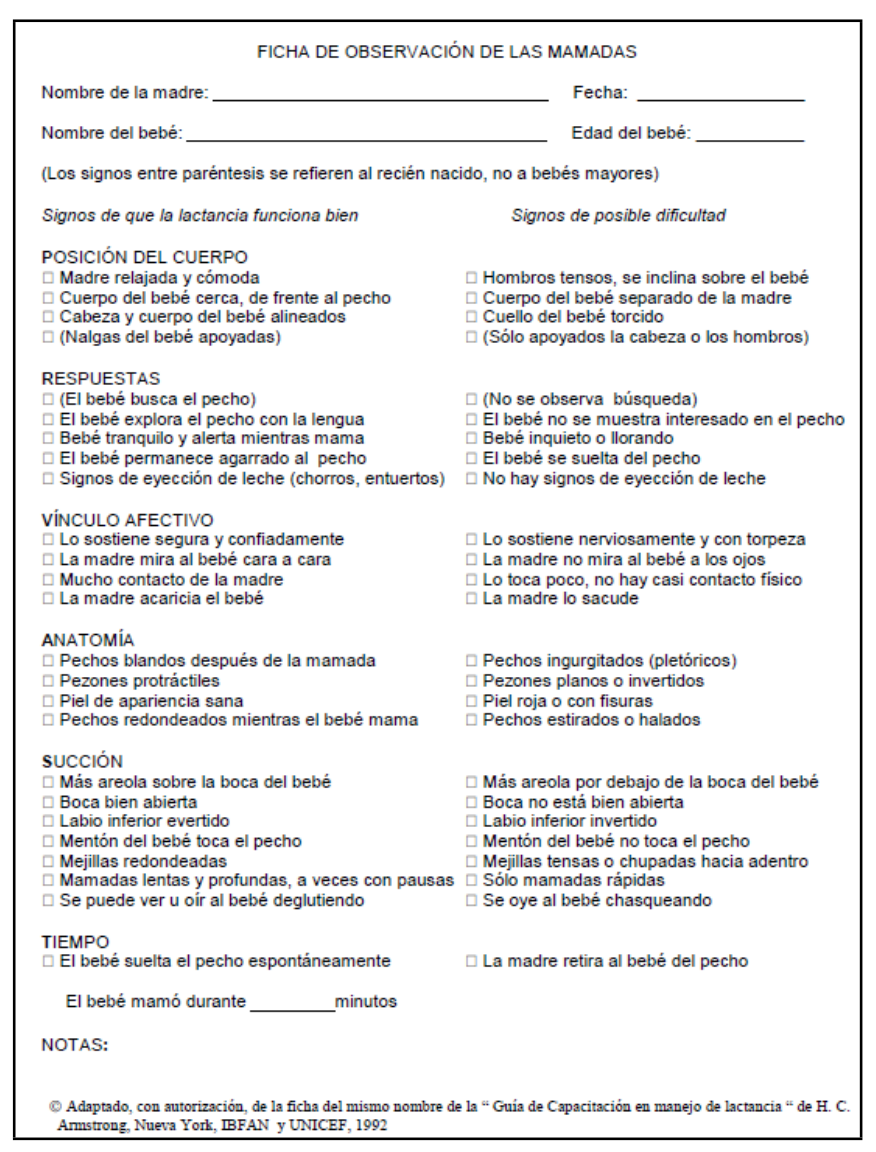

Figura 3: ficha observación toma (Manual participante)

\begin{tabular}{|c|c|c|c|c|}
\hline Breastfeeding assessment form & \multicolumn{4}{|c|}{ 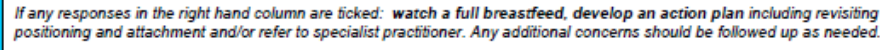 } \\
\hline $\begin{array}{l}\text { Baby's name: } \\
\text { Baby's age: } \\
\text { Date of birth: }\end{array}$ & $\begin{array}{l}\text { Birth weight: } \\
\text { Gestation: } \\
\text { Current weight: }\end{array}$ & & \begin{tabular}{|l} 
Assessment carried out by: \\
Date:
\end{tabular} & \\
\hline What to observe/ask about & \multirow{2}{*}{$\begin{array}{l}\text { Answer indicating effective feeding } \\
\text { At least 5-8 heavy wet nappies in } 24 \text { hours* }\end{array}$} & $\checkmark$ & \multirow{2}{*}{$\begin{array}{l}\text { Answer suggestive of a problem } \\
\text { Fewer than } 5 \text {-6 wet nappies in } 24 \text { hours, or nappies that } \\
\text { do not feel heavy" }\end{array}$} & $\checkmark$ \\
\hline Urine output & & & & \\
\hline Appearance and frequency of stools & \multirow{6}{*}{$\begin{array}{l}2 \text { or more in } 24 \text { hours; normal appearance (i.e. } \\
\text { at least \&2 coin size, yellow, soptrunny)" } \\
\text { Normal skin colour; alert; good tone } \\
\text { If re-weighed not lost more than } 10 \% \text { of birth } \\
\text { weight }-5 \text { see Weight Guidelines } \\
\text { At least } 8 \text { feeds in a } 24 \text { hour period" } \\
\text { Generally calm and relaxed } \\
\text { Initial rapid sucks changing to slower sucks with } \\
\text { pauses and soft swallowing" }\end{array}$} & & \multirow{6}{*}{$\begin{array}{l}\text { Fewer than } 2 \text { in } 24 \text { hours or abnormal appearance" } \\
\text { Jaundiced worsening or not improving: baby lethargic. } \\
\text { not waking to feed; poor tone } \\
\text { Weight loss greater than } 10 \% \\
\text { Fewer than } 8 \text { feeds in last } 24 \text { hours* } \\
\text { Baby comes on and off the breast requentily during the } \\
\text { feed, or refuses to breastfeed } \\
\text { No change in sucking pattern, or noisy } \\
\text { feeding (e.g. clicking)" }\end{array}$} & \\
\hline Baby's colour, alertness and tone & & & & \\
\hline Weight (following initial post-birth loss) & & & & \\
\hline Number of feeds in last 24 hours & & & & \\
\hline Baby's behaviour during feeds & & & & \\
\hline Sucking pattern during feed & & & & \\
\hline Length of feed & \multirow{6}{*}{$\begin{array}{l}\text { Baby feeds for } 5 \text { - } 30 \text { minutes at most feeds } \\
\text { Baby lets go spontaneously, or does so when } \\
\text { breast is gently lifede } \\
\text { Second breast offered. Baby feeds from second } \\
\text { breast or not, acoording to oppeetite } \\
\text { Baby content after most feeds } \\
\text { Same shape as when feed began, or slightly } \\
\text { elongated } \\
\text { | Breasts and nipples comfortable } \\
\text { None used }\end{array}$} & & \multirow{6}{*}{$\begin{array}{l}\text { Baby consistently feeds for less than } 5 \text { minutes or } \\
\text { longer than } 40 \text { minutes } \\
\text { Baby does not release the breast spontaneously. } \\
\text { mother removes baby } \\
\text { Mother restricts baby to one breast per feed, or insists } \\
\text { on two breasts per feed } \\
\text { Baby unsettled after feeding } \\
\text { Misshapen or pinched at the end of feeds } \\
\text { Nipples sore or damaged; engorgement or mastitis } \\
\text { Yes (state which) } \\
\text { Ask whyy Dificilty with attachment? } \\
\text { Baby not growing? Baby unsettled? }\end{array}$} & \\
\hline End of the feed & & & & \\
\hline Offer of second breast? & & & & \\
\hline Baby's behaviour after feeds & & & & \\
\hline Shape of either nipple at end of feed & & & & \\
\hline $\begin{array}{l}\text { Mother's report on her breasts and nipples } \\
\text { Use of dummy / nipple shields / formula? }\end{array}$ & & & & \\
\hline \multicolumn{5}{|c|}{$\begin{array}{l}\text { 'This assessment tool was developed for use on or around day } 5 \text {. If the tool is used at other tir } \\
\text { Wet nappies: Day } 1-2=1-2 \text { or more }\end{array}$} \\
\hline
\end{tabular}

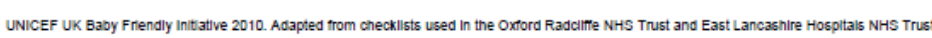

Figura 4: ficha observación toma (Manual participante)

Por último, en el documento sobre las normas recomendadas para la Unión Europea para la alimentación de los lactantes y de los niños pequeños (4), se recogen cuáles son los signos de adecuada postura, agarre y amamantamiento eficaz/ineficaz que se deben observar en la evaluación de una toma y que pueden ser útiles para actuar de forma específica y resolver las dificultades identificadas (Figura 5). 
Tabla 3.3. Signos de adecuada postura y agarre y de amamantamiento eficaz/ineficaz.

\begin{tabular}{|c|c|}
\hline Signos de amamantamiento adecuado & Signos de posible dificultad \\
\hline \multicolumn{2}{|c|}{ Postura de la madre y del bebé } \\
\hline प Madre relajada y cómoda & $\square \quad$ Hombros tensos, inclinados hacia el bebé \\
\hline$\square$ Bebé en estrecho contacto con su madre & Bebé lejos del cuerpo de la madre \\
\hline ૫ Cabeza y cuerpo del bebé alineados, frente & Cabeza y cuello del bebé girados \\
\hline & La barbilla del bebé no toca el pecho \\
\hline ૫ La barbilla del bebé toca el pecho & Solo se sujetan la cabeza y el cuello del bebé \\
\hline$\square \quad$ Cuerpo del bebé bien sujeto & El bebé se acerca al pecho con el labio \\
\hline 口 El bebé se acerca al pecho con la nariz & inferior/barbilla frente al pezón \\
\hline $\begin{array}{l}\text { frente al pezón } \\
\text { Contacto visual entre la madre y el bebé }\end{array}$ & $\square \quad$ No hay contacto visual madre-bebé \\
\hline \multicolumn{2}{|c|}{ Lactante } \\
\hline$\square$ Boca bien abierta & $\square$ Boca poco abierta \\
\hline Labios superior e inferior evertidos & 口 Labios apretados o invertidos \\
\hline La lengua rodea el pezón y la areola* & No se ve la lengua* \\
\hline Mejillas llenas y redondeadas al mamar & Mejillas hundidas al mamar \\
\hline $\begin{array}{l}\text { Más areola visible por encima del labio } \\
\text { superior }\end{array}$ & $\begin{array}{l}\text { Más areola por debajo del labio inferior } \\
\text { Movimientos de succión superficiales y rápidos }\end{array}$ \\
\hline $\begin{array}{l}\text { Movimientos de succión lentos y profundas, } \\
\text { con pausas }\end{array}$ & Se oyen ruidos de chupeteo o chasquidos \\
\hline 口 Puede verse $u$ oirse tragar al bebé & \\
\hline \multicolumn{2}{|c|}{ Signos de transferencia eficaz de leche } \\
\hline$\square \quad$ Humedad alrededor de la boca del bebé & $\begin{array}{l}\text { Bebé intranquilo o exigente, agarra y suelta el } \\
\text { pecho intermitentemente }\end{array}$ \\
\hline $\begin{array}{l}\text { El bebe relaja progresivamente brazos y } \\
\text { piernas }\end{array}$ & $\begin{array}{l}\text { pecho intermitentemente } \\
\text { La madre siente dolor o molestias en el pech }\end{array}$ \\
\hline El pecho se ablanda progresivamente & \\
\hline Sale leche del otro pecho & El pecho está rojo, hinchado y/o dolorido \\
\hline $\begin{array}{l}\text { La madre nota signos del reflejo de } \\
\text { eyección** }\end{array}$ & $\begin{array}{l}\text { La madre no refiere signos del reflejo de } \\
\text { eyección** }\end{array}$ \\
\hline $\begin{array}{l}\text { El bebé suelta espontáneamente el pecho al } \\
\text { finalizar la toma }\end{array}$ & ¿ La madre ha de retirar al bebé del pecho \\
\hline
\end{tabular}

finalizar la toma

* Este signo puede no observarse durante la succión y solo verse durante la búsqueda y el agarre

* La madre siente sed, relajación o somnolencia, contracciones uterinas (entuertos) y aumento de los loquios durante el amamantamiento.

Figura 5: ficha para la observación de la toma de la UE 


\subsection{Revisiones sistemáticas}

Se ha identificado una revisión sistemática publicada en 2010 (5) sobre las herramientas de evaluación de la autoeficacia de la lactancia materna GRABS, IIFAS, MBFES, BSES, BSES-SF, BPEBI y BAPT, con el objetivo de contrastar su utilidad clínica y propiedades psicométricas. Sin embargo, esta revisión no incluye las herramientas como el LATCH, IBFAT o MBE, que son herramientas que sirven para evaluar la eficacia de una toma. 


\subsection{Resumen de GPC base y RS disponibles}

La guía NICE (1) recomienda la evaluación de la técnica de lactancia y la salud del recién nacido cuando la madre percibe que tiene leche insuficiente (Grado $\mathrm{C}$ ), y se hace un resumen de las herramientas que existen para valorar la eficacia de la lactancia materna.

La guía Perinatal Care Services (2) recomienda realizar la evaluación de la madre y del niño mediante observación y entrevista en períodos de tiempo claves (Grado A), indicando que se debe valoración a la madre, al niño y cómo se acoplan ambos de forma conjunta para permitir la lactancia materna. En esta guía también se incluye una tabla en la que se resumen las herramientas que existen para valorar la eficacia de la lactancia materna.

En la estrategia IHAN para los hospitales (6) se especifica que la observación de una toma completa es esencial para comprobar que existe una adecuada transferencia láctea y diagnosticar la causa de las dificultades, si las hubiese, por lo que debe ser realizado por un profesional cualificado en la primera toma. Posteriormente, se realizarán evaluaciones todas las veces que sea necesario. También se señala que la evaluación de la toma debe ser estandarizada, quedar registrada y valorar la postura, el agarre y los signos de transferencia eficaz de leche. En cuanto a los centros de salud, se señala que la observación de una toma completa es esencial para comprobar que existe una adecuada transferencia láctea y para diagnosticar la causa de las dificultades si las hubieses, por lo que debe ser realizada por un profesional cualificado en la primera visita al centro de salud, y también se recomienda que esta evaluación sea estandarizada y que se registre dicha evaluación (7).

Por último, en el documento de las normas recomendadas para la Unión Europea sobre la alimentación de los lactantes y de los niños pequeños (4) se recogen cuáles son los signos de adecuada postura, agarre y amamantamiento eficaz/ineficaz que se deben evaluar en la observación de una toma y que pueden ser útiles para actuar de forma específica y resolver las dificultades identificadas.

En resumen, todas las guías anteriores afirman la necesidad de evaluar la toma pero no se decantan por ninguna de las herramientas estandarizadas disponibles.

Por otro lado, se han identificado varias RS sobre la utilidad clínica y propiedades psicométricas de las herramientas de evaluación de la lactancia materna existentes (5;8-10), aunque en una de ellas se describen sólo las herramientas de evaluación de la autoeficacia de la lactancia materna (5). Las tres revisiones restantes (8-10) concluyen en general que ninguna de las herramientas existentes tiene un desarrollo psicométrico adecuado y probado, y que todas estas herramientas deberían ser utilizadas con precaución.

\subsection{Conclusión (marcar con una $\mathrm{X}$ ):}

\begin{tabular}{|l|l|}
\hline & Adopción GPC/Revisión sistemática \\
\hline$X$ & Elaboración parcial \\
\hline & Elaboración de novo \\
\hline
\end{tabular}




\subsection{Diseño de la estrategia de búsqueda de estudios individuales}

\begin{tabular}{|l|l|}
\hline Criterios de selección de estudios & $\begin{array}{l}\text { ECA o estudios observacionales, en el caso de no } \\
\text { haber ECA }\end{array}$ \\
\hline Período de búsqueda & Sin límite-08 Noviembre 2013 \\
\hline Bases de datos & Cochrane Library \\
& MEDLINE, via Pubmed \\
& EMBASE, via Ovid \\
& Cinahl, via EBSCOhost databases \\
& PsylNFO, via OVID \\
\hline
\end{tabular}

Ver estrategias de búsqueda de estudios originales en el ANEXO I. 


\section{4- RESUMEN DE LA EVIDENCIA}

Dentro de las herramientas existentes, hay algunas que evalúan actitudes maternas, conocimientos o la confianza y satisfacción de la madre, mientras que otras permiten valorar la eficacia de la lactancia materna, definida como "proceso interactivo entre la madre y el bebé que tiene lugar cuando hay transferencia directa de leche del pecho de la madre al bebé, de una forma y en una cantidad que satisface las necesidades de ambos, siendo los cuatro atributos de una lactancia materna la posición al lactar, el agarre al pecho, la succión y la transferencia de leche"(11).

Entre los instrumentos que evalúan la eficacia de la lactancia materna se encuentran "The infant breastfeeding assessment tool" (IBFAT), el LATCH y el "The Mother Baby Assessment Tool" (MBA) (11).

En referencia a la existencia de herramientas validadas en español, se han identificado tres artículos que estudian la fiabilidad y validez de dos de estos instrumentos. Uno de ellos evalúa el LATCH (11) y los otros dos el BSES-SF $(12 ; 13)$, instrumento que valora la autoeficacia de la lactancia materna y no la toma, por lo que no se ha tenido finalmente en cuenta para responder a esta pregunta.

En cuanto a el LATCH, esta herramienta incluye en su evaluación a la madre y al hijo y recoge información referente al agarre del pecho, a una deglución audible, el tipo de pezón, la comodidad y la ausencia de dolor, así como si se precisa ayuda externa en el mantenimiento de la posición. Se caracteriza por su sencillez y similitud con los aspectos que los profesionales suelen tener en cuenta a la hora de valorar la lactancia materna, y permite identificar mujeres con riesgo de abandono de la lactancia. Sin embargo, existe controversia sobre la fiabilidad y validez de esta herramienta. Riordan et al, (14) encontraron baja fiabilidad interobservador en 23 observaciones que en el caso de la herramienta LATCH oscilaba entre 0,11 y 0,46. El porcentaje de acuerdo entre observadores era altamente variable, siendo mayor para la puntuación sobre el tipo de pezón, por lo que los autores sugerían que no era fiable. Sin embargo, Riordan et al, 2001 (15) publicaron otro estudio posterior que encontraba correlación positiva entre las puntuaciones de madres y enfermeras $(r=0,58)$, y que ambas se correlacionaban de forma positiva con la duración de la lactancia materna $(r=0,22$ y $r=0,26$, respectivamente), concluyendo que estos resultados apoyaban la validez de la herramienta LATCH. Un estudio posterior (16) ha encontrado correlación positiva y significativa entre observadores en 46 observaciones, siendo mayores del $80 \%$ cuando se consideran las puntuaciones totales (entre $85 \%$ y $91 \%$ para el LATCH).

En el estudio identificado con la versión española del LATCH (11), se aplica la herramienta en 20 diadas madre-hijo en tres sesiones de lactancia materna con el fin de evaluar, además de la fiabilidad, si la puntuación obtenida con el instrumento mejora a lo largo del tiempo a medida que se van solventando las dificultades que el propio instrumento va reflejando.

Este estudio se hizo con mujeres que dieron a luz por cesárea, lo que permitía evaluar la lactancia a las $24 \mathrm{~h}, 48 \mathrm{~h}$ y $96 \mathrm{~h}$ tras el nacimiento. En este estudio se calcularon tanto la $r$ de Spearman de las puntuaciones de los dos evaluadores en cada evaluación así como el porcentaje de acuerdo entre los evaluadores.

De todos los aspectos que se evalúan con el LATCH hay dos que no mejoran durante la estancia hospitalaria: el tipo de pezón y la comodidad o confort. Sin embargo, en la tercera evaluación (que es la que se espera que sea capaz de predecir la duración de la lactancia materna y de identificar posibles dificultades y complicaciones al alta) los 
porcentajes de acuerdo entre evaluadores fueron mayores, superando en todos los casos el $80 \%$ de acuerdo.

La conclusión que hacen los autores del estudio es que la evaluación de la lactancia materna según el LATCH el día de alta médica es fiable en todos sus componentes, aunque hay dos que deben ser mejorados.

Los autores indican que cuando las enfermeras de puerperio o matronas utilizan el LATCH no hacen nada diferente que no hicieran antes, sólo que la valoración que se realiza no se expresa sólo de forma narrativa en las historias clínicas, sino también a través de cifras, lo que resulta muy útil para resumir información, transmitirla de forma rápida y sobre todo, de forma comparable y repetible.

En un trabajo reciente realizado en Italia, se estudió la relación entre la puntuación obtenida a las 24 horas tras el parto y la lactancia mixta al alta médica, determinándose además los puntos de corte que podrían identificar mujeres con mayor riesgo de lactancia materna no exclusiva al alta hospitalaria. Se observó que en las 299 diadas incluidas en el estudio el ratio de lactancia mixta se relacionaba de forma inversa con la puntuación del LATCH, siendo mayor la puntuación obtenida por madres con lactancia exclusiva versus madres con lactancia mixta $(7,6$ vs 6,9$)$. En el análisis multivariante se observó que la lactancia mixta se asociaba con cesárea, madre primípara y tratamiento del niño con fototerapia (17).

ACTUALIZADO A FECHA DE: 31 de Octubre de 2016 


\section{5- DE LA EVIDENCIA A LA RECOMENDACIÓN (Tabla EtR)}

¿Se debe realizar la observación y valoración de la toma con una herramienta estandarizada durante la estancia en la maternidad a las madres que amamantan?

Población: Madres de recién nacidos sanos a término que amamantan y sus hijos

Intervención: Observación de la toma con herramienta estandarizada

Comparación: Observación de la toma sin herramienta estandarizada

Perspectiva: Clínica

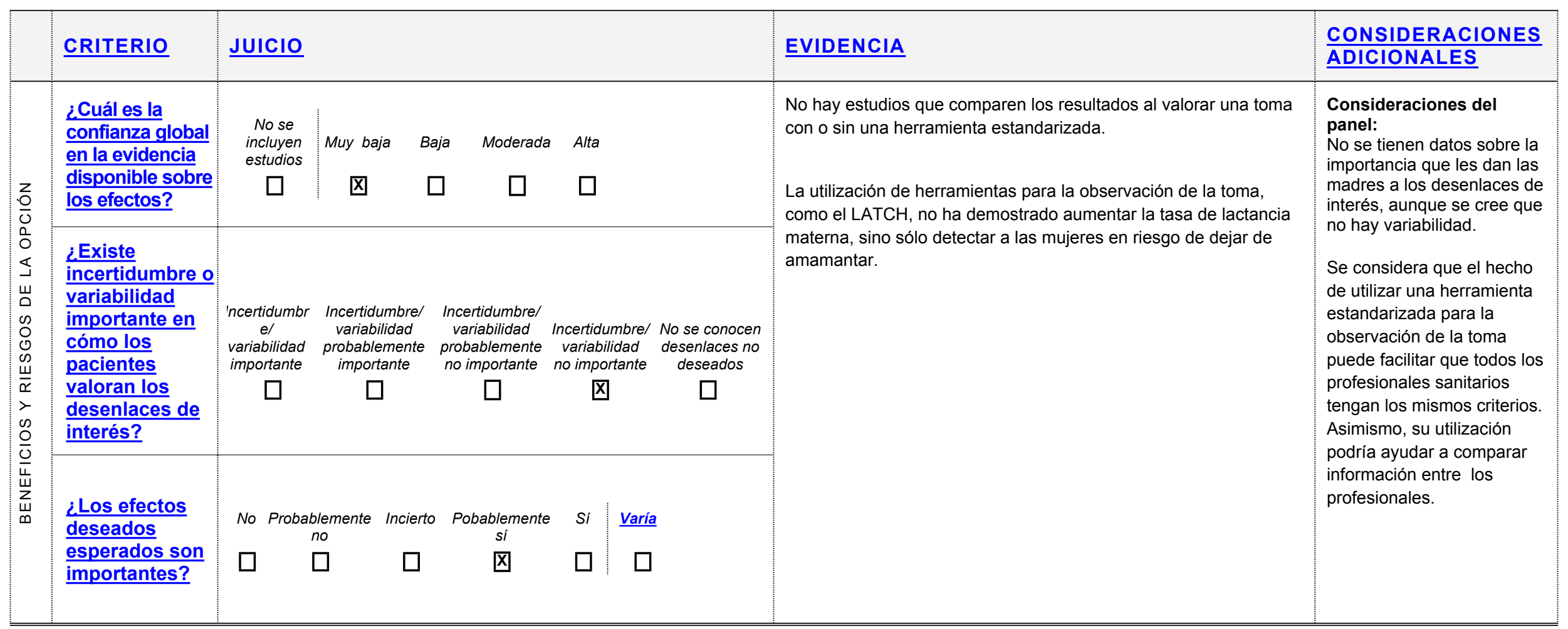




\begin{tabular}{|c|c|c|c|c|c|c|c|}
\hline CRITERIO & $\underline{\text { JUICIO }}$ & & & & & EVIDENCIA & $\begin{array}{l}\text { CONSIDERACIONES } \\
\text { ADICIONALES }\end{array}$ \\
\hline $\begin{array}{l}\frac{\text { ¿Los efectos }}{\text { no deseados }} \\
\text { esperados } \\
\text { son } \\
\text { pequeños? }\end{array}$ & $\begin{array}{c}\text { No } \begin{array}{c}\text { Probablemente } \\
\text { no }\end{array} \\
\square \quad \square\end{array}$ & $\begin{array}{c}\text { Incierto } \\
\square\end{array}$ & $\begin{array}{c}\text { Pobablemente } \\
\text { si } \\
\text { 囚 }\end{array}$ & $\begin{array}{l}\text { Si } \\
\square\end{array}$ & $\frac{\frac{\text { Varía }}{}}{\square}$ & & \\
\hline
\end{tabular}




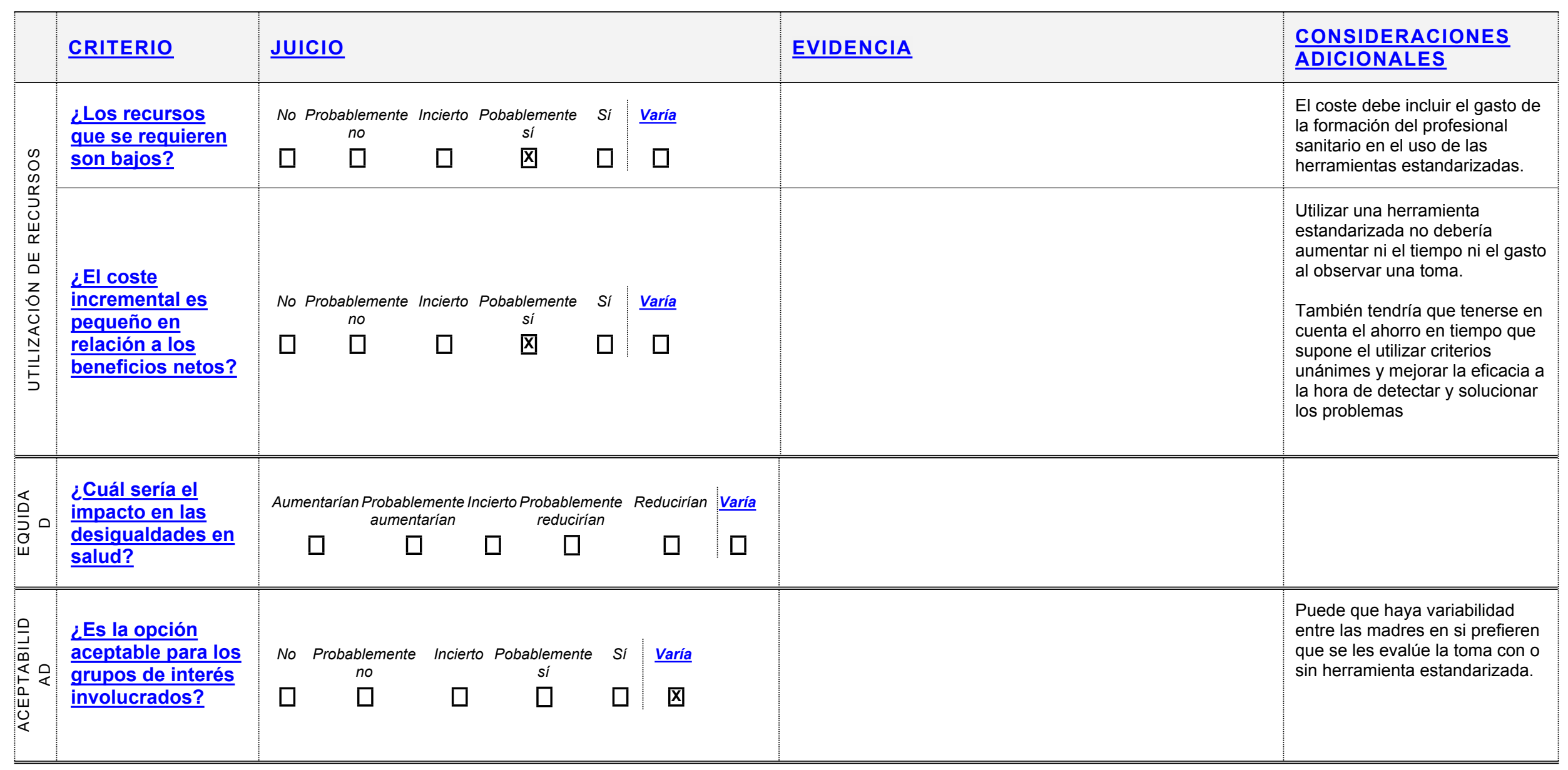




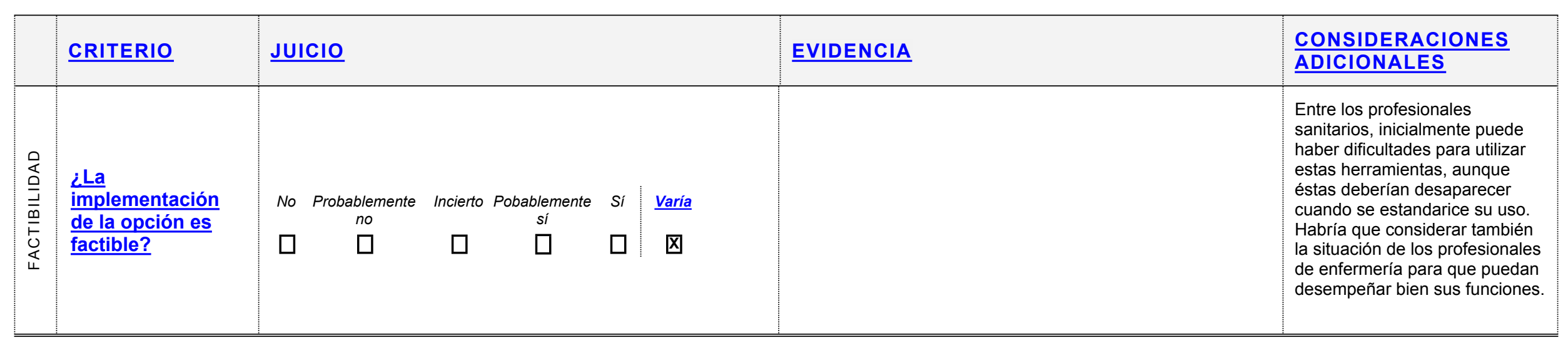

\begin{tabular}{|c|c|c|c|c|c|}
\hline $\begin{array}{l}\text { Balance de las } \\
\text { consecuencias } \\
\end{array}$ & $\begin{array}{l}\text { Las consecuencias no } \\
\text { deseadas superan } \\
\text { claramente las } \\
\text { consecuencias deseadas } \\
\text { en la mayoría de los } \\
\text { escenarios }\end{array}$ & $\begin{array}{c}\text { Las consecuencias no } \\
\text { deseadas probablemente } \\
\text { superan las } \\
\text { consecuencias deseadas } \\
\text { en la mayoría de los } \\
\text { escenarios }\end{array}$ & $\begin{array}{c}\text { El balance entre las } \\
\text { consecuencias deseadas y } \\
\text { no deseadas está muy } \\
\text { equilibrado o es incierto }\end{array}$ & $\begin{array}{c}\text { Las consecuencias } \\
\text { deseadas } \\
\text { probablemente superan } \\
\text { las consecuencias no } \\
\text { deseadas en la mayoría } \\
\text { de los escenarios }\end{array}$ & $\begin{array}{c}\text { Las consecuencias } \\
\text { deseadas claramente } \\
\text { superan las } \\
\text { consecuencias no } \\
\text { deseadas en la mayoría } \\
\text { de los escenarios }\end{array}$ \\
\hline
\end{tabular}

$\square$ $\square$

$\square$

囚

$\square$

\begin{tabular}{|c|c|c|c|c|}
\hline $\begin{array}{l}\text { Tipo de } \\
\text { recomendación }\end{array}$ & Se recomienda no ofrecer la opción & Se sugiere no ofrecer la opción & Se sugiere ofrecer la opción & $\begin{array}{l}\text { Se recomienda } \\
\text { ofrecer la opción }\end{array}$ \\
\hline
\end{tabular}

$\square$

$\square$ 


Recomendación

Recomendación

\section{Recomendaciones de buena práctica}

V Al menos en una de las tomas durante la estancia hospitalaria, los profesionales sanitarios deberían utilizar una herramienta estandarizada de observación de la toma que ofrezca criterios objetivos de valoración.

V Se proponen como posibles herramientas para la observación, la Escala de Evaluación de Lactancia Materna LATCH, la Ficha para la Observación de la Toma de la Unión Europea o la Ficha del Manual para la Capacitación en la Consejería de Lactancia Materna de la OMS y UNICEF (ver Anexo 8).

V Los profesionales sanitarios deberían recibir formación sobre cómo utilizar estas herramientas estandarizadas.

La utilización de una herramienta estandarizada a la hora de realizar la observación de una toma puede ayudar a los profesionales sanitarios a tener en cuenta todos los aspectos importantes relacionados con el amamantamiento. Esta información se recogería de forma estandarizada, lo que facilitaría la comparación de la información entre los profesionales sanitarios

\section{Consideraciones de}

\section{subgrupos}

Consideraciones para No se ha identificado qué herramienta es la mejor para ayudar a observar una la toma, pero se proponen: el LATCH, traducida al la implementación español y fácil de recoger y la ficha de la Unión Europea, que ayuda a identificar si la causa de las dificultades es la postura, el agarre o la escasa transferencia de leche.

Se considera necesario que la observación de la toma la realicen profesionales expertos y que se facilite formación sobre el uso de estas herramientas.

\section{Monitorización y}

evaluación

\section{Prioridades para la} investigación
Se identifica la necesidad de estudios para valorar la fiabilidad y validez de las herramientas que existen y si su utilización sirve para aumentar las tasas de lactancia materna.

*En esta situación, se podría no realizar recomendaciones o se podría hacerlo en el contexto de investigación. 


\section{6- ANEXOS}

\section{ANEXO I, ESTRATEGIAS DE BÚSQUEDA}

\section{Cochrane Library}

\section{Searched 08/11/2013}

\#1 "breast feeding" or breastfeeding or "breast feed" or breastfeed or "breast fed" or breast fed:ti,ab,kw or lactation:ti,ab,kw (Word variations have been searched) \#2 "observation":ti,ab,kw or "assessment":ti,ab,kw (Word variations have been searched)

\#3 \#1 and \#2

\#4 MeSH descriptor: [Maternal-Child Health Centers] explode all trees

\#5 MeSH descriptor: [Maternal Health Services] explode all trees

\#6 \#4 or \#5

\#7 \#3 and \#6

\section{MEDLINE, via Ovid}

\section{Searched 08/11/2013}

\#1 ("breast feeding" or breastfeeding or "breast feed" or breastfeed or "breast fed" or breastfed).ti,ab,kw.

\#2 lactation.ti,ab,kw.

\#3 1 or 2

\#4 (observation or evaluation or assessment).ti,ab,kw.

\#5 3 and 4

\#6 limit 5 to human

\#7 Maternal Health Services/

\#8 6 and 7

\section{EMBASE, via Ovid \\ Searched 08/11/2013}

\#1 ("breast feeding" or breastfeeding or "breast feed" or breastfeed or "breast fed" or breastfed).ti,ab,kw.

\#2 lactation.ti,ab,kw.

\#3 1 or 2

\#4 (observation or evaluation or assessment).ti,ab,kw.

\#5 3 and 4

\#6 limit 5 to human

\#7 maternity ward/

\#8 6 and 7

\section{Cinahl, via EBSCOhost databases \\ Searched 08/11/2013}

\#1 (MH "Breast Feeding")

\#2 "breast feeding" OR breastfeeding OR "breast feed" OR breastfeed OR "breast fed"

OR breastfed

\#3 (MH "Lactation")

\#4 lactation

\#5 S1 OR S2 OR S3 OR S4

\#6 (MH "Evaluation") OR evaluation 
\#7 assessment

\#8 observation

\#9 S6 OR S7 OR S8

\#10 S5 AND S9

\#11 (MH "Maternal Health Services")

\#12 "maternity ward"

\#13 S11 OR S12

\#14 S10 AND S13

\section{Para la subpregunta de las herramientas:}

\section{Cochrane Library \\ Searched 08/11/2013}

\#1 "breast feeding" or breastfeeding or "breast feed" or breastfeed or "breast fed" or breast fed:ti,ab,kw or lactation:ti,ab,kw (Word variations have been searched)

\#2 assessment:ti,ab,kw and tool or tools:ti,ab,kw (Word variations have been searched)

\#3 evaluation:ti,ab,kw and tool or tools:ti,ab,kw (Word variations have been searched)

\#4 \#2 or \#3

\#5 \#1 and \#4

\section{MEDLINE, via Pubmed}

Searched 08/11/2013

(("breast feeding"[MeSH Terms] OR ("breast"[All Fields] AND "feeding"[All Fields]) OR "breast feeding"[All Fields] OR "breastfeeding"[All Fields] OR "breastfeed"[All Fields] OR ("breast"[All Fields] AND "feed"[All Fields]) OR "breast feed"[All Fields] OR "breastfed"[All Fields] OR ("breast"[All Fields] AND "fed"[All Fields]) OR "breast fed"[All Fields]) OR ("lactation"[MeSH Terms] OR "lactation"[All Fields])) AND ((assessment[All Fields] AND (tool[All Fields] OR tools[All Fields])) OR (evaluation[All Fields] AND (tool[All Fields] OR tools[All Fields]))) Filters: Humans; Field: Title/Abstract

\section{EMBASE, via Ovid}

Searched 08/11/2013

\#1 ("breast feeding" or breastfeeding or "breast feed" or breastfeed or "breast fed" or breastfed).ti,ab,kw.

\#2 lactation.ti,ab,kw.

\#3 1 or 2

\#4 (assessment and (tool or tools)).ti,ab,kw.

\#5 (evaluation and (tool or tools)).ti,ab,kw.

\#6 4 or 5

\#7 3 and 6

\#8 limit 7 to human

\section{Cinahl, via EBSCOhost databases}

Searched 08/11/2013

\#1 (MH "Breast Feeding")

\#2 "breast feeding" OR breastfeeding OR "breast feed" OR breastfeed OR "breast fed" OR breastfed 
GPC Lactancia Materna-Pregunta 10. Observación y valoración de la toma.

\#3 (MH "Lactation")

\#4 lactation

\#5 S1 OR S2 OR S3 OR S4

\#6 assessment AND (tool OR tools)

\#7 evaluation AND (tool OR tools)

\#8 S6 OR S7 


\section{ANEXO II, POSIBLES HERRAMIENTAS ESTANDARIZADAS PARA LA OBSERVACIÓN DE UNA TOMA}

\section{Opción 1}

\section{Escala LATCH (Adaptado de Báez León, 2008)}

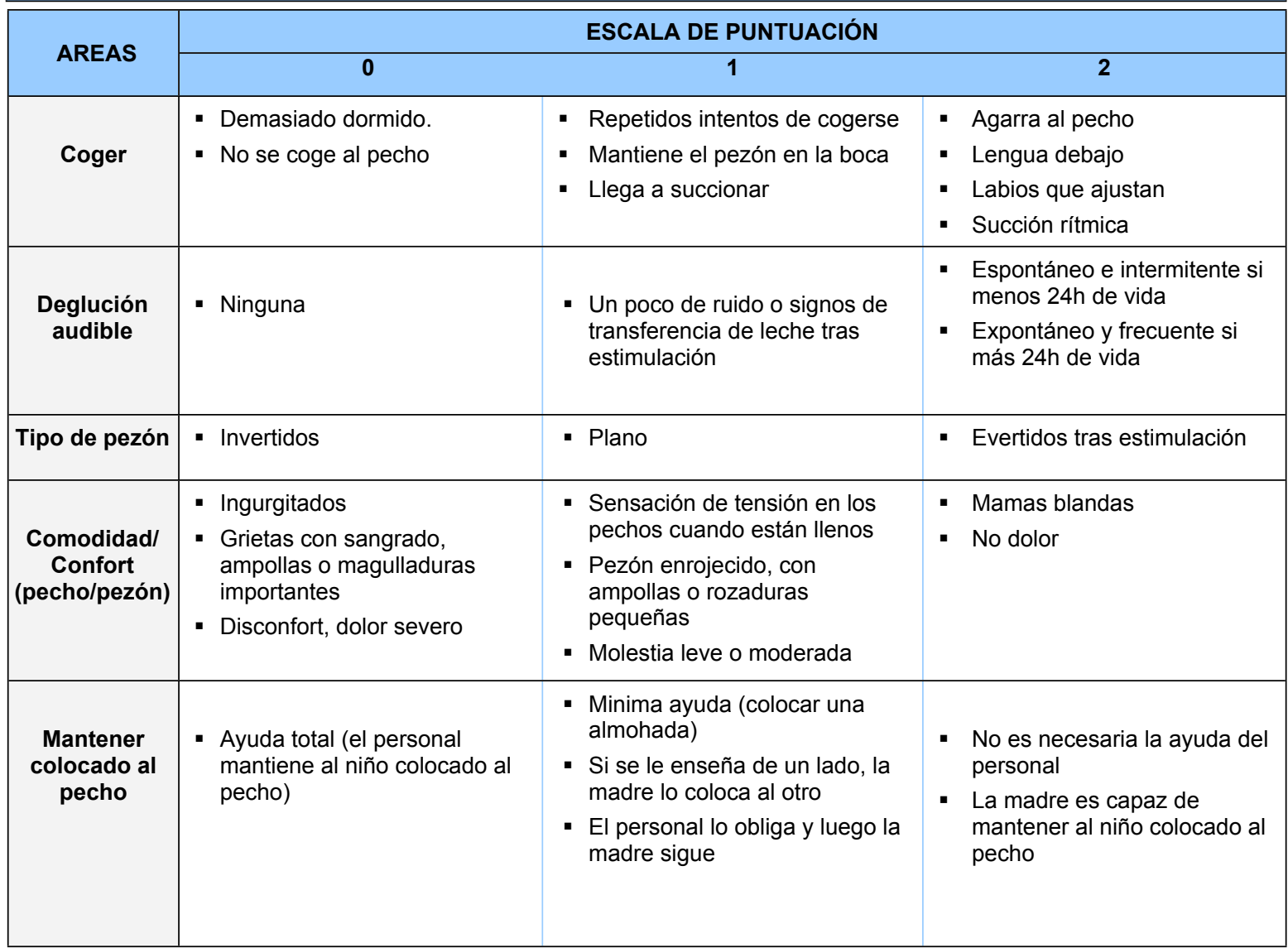




\section{Opción 2}

\section{Ficha para la observación de la toma de la Unión Europea}

Tabla 3.3. Signos de adecuada postura y agarre y de amamantamiento eficaz/ineficaz.

\begin{tabular}{|c|c|}
\hline Signos de amamantamiento adecuado & Signos de posible dificultad \\
\hline \multicolumn{2}{|c|}{ Postura de la madre y del bebé } \\
\hline Madre relajada y cómoda & $\square \quad$ Hombros tensos, inclinados hacia el bebé \\
\hline Bebé en estrecho contacto con su madre & Bebé lejos del cuerpo de la madre \\
\hline$\square \quad$ Cabeza y cuerpo del bebé alineados, frente & $\square \quad$ Cabeza y cuello del bebé girados \\
\hline al pecho & La barbilla del bebé no toca el pecho \\
\hline La barbilla del bebé toca el pecho & $\square \quad$ Solo se sujetan la cabeza y el cuello del bebé \\
\hline Cuerpo del bebé bien sujeto & $\square \quad$ El bebé se acerca al pecho con el labio \\
\hline El bebé se acerca al pecho con la nariz & inferior/barbilla frente al pezón \\
\hline frente al pezón & $\square \quad$ No hay contacto visual madre-bebé \\
\hline Contacto visual entre la madre y el bebé & \\
\hline \multicolumn{2}{|c|}{ Lactante } \\
\hline$\square \quad$ Boca bien abierta & $\square \quad$ Boca poco abierta \\
\hline Labios superior e inferior evertidos & Labios apretados o invertidos \\
\hline La lengua rodea el pezón y la areola* & $\square \quad$ No se ve la lengua* \\
\hline Mejillas llenas y redondeadas al mamar & $\square \quad$ Mejillas hundidas al mamar \\
\hline$\square \quad$ Más areola visible por encima del labio & $\square \quad$ Más areola por debajo del labio inferior \\
\hline superior & $\square$ Movimientos de succión superficiales y rápidos \\
\hline $\begin{array}{l}\text { Movimientos de succión lentos y profundas, } \\
\text { con pausas }\end{array}$ & $\square \quad$ Se oyen ruidos de chupeteo o chasquidos \\
\hline Puede verse u oírse tragar al bebé & \\
\hline \multicolumn{2}{|c|}{ Signos de transferencia eficaz de leche } \\
\hline$\square \quad$ Humedad alrededor de la boca del bebé & $\square \quad$ Bebé intranquilo o exigente, agarra y suelta el \\
\hline El bebé relaja progresivamente brazos y & pecho intermitentemente \\
\hline piernas & $\square \quad$ La madre siente dolor o molestias en el pecho o \\
\hline El pecho se ablanda progresivamente & \\
\hline Sale leche del otro pecho & E El pecho está rojo, hinchado y/o dolorido \\
\hline $\begin{array}{l}\text { La madre nota signos del reflejo de } \\
\text { eyección } * *\end{array}$ & $\begin{array}{l}\square \quad \text { La madre no refiere signos del reflejo de } \\
\text { eyección** }\end{array}$ \\
\hline $\begin{array}{l}\text { El bebé suelta espontáneamente el pecho al } \\
\text { finalizar la toma }\end{array}$ & $\square \quad$ La madre ha de retirar al bebé del pecho \\
\hline
\end{tabular}

* Este signo puede no observarse durante la succión y solo verse durante la búsqueda y el agarre.

** La madre siente sed, relajación o somnolencia, contracciones uterinas (entuertos) y aumento de los loquios durante el amamantamiento. 


\section{Opción 3}

Ficha para la observación de la toma del Manual para la capacitación en la consejería de lactancia materna de la OMS y UNICEF

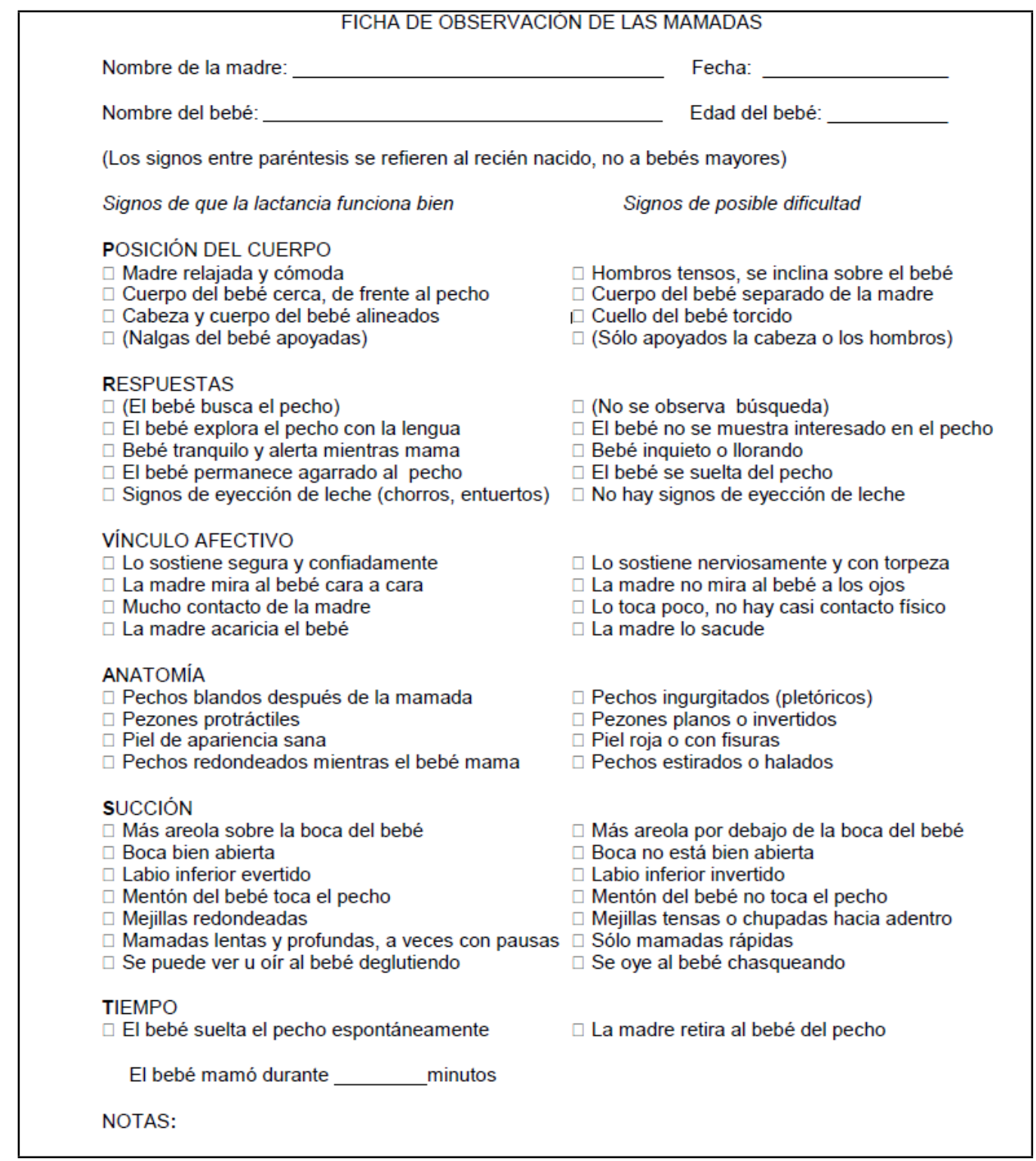

Adaptado, con autorización de la ficha del mismo nombre de la "Guía de Capacitación en manejo de lactancia" de HC Armstrong, Nueva York, IBFAN y UNICEF, 1992 


\section{7- BIBLIOGRAFÍA}

(1) NICE. Postnatal care up to 8 weeks after birth. Julio 2006 (actualizado en Febrero de 2015). Disponible en: http://guidance.nice.org.uk/CG37.

(2) Perinatal Services BC. Health Promotion Guideline. Breastfeeding Healthy Term Infants. 2013 Feb.

(3) Consejería en Lactancia Materna: Curso de Capacitación. Manual del Participante. $1993 . \quad$ Disponible en: http://www.who.int/maternal child adolescent/documents/pdfs/bc participants manual es.pdf.

(4) Infant and young child feeding: standard recommendations for the European Union. European Commission. Karolinska Institutet. Institute for Child Health IRCCS Burlo Garofolo. WHO. 2006 Disponible en: http://www.ihan.es/cd/documentos/Rec UE en.pdf.

(5) Ho YJ, McGrath JM. A review of the psychometric properties of breastfeeding assessment tools. J Obstet Gynecol Neonatal Nurs 2010 Jul;39(4):386-400.

(6) IHAN. Hospitales IHAN. Guía detallada para la aplicación paso por paso. Disponible en: https://www.ihan.es/docs/documentacionacreditacion/hospitales/generales/00.Guia detallada hospital.pdf.

(7) IHAN. Guía detallada para la aplicación paso por paso. Centros de Salud IHAN. Disponible en: https://www.ihan.es/docs/documentacionacreditacion/centros salud/Manual para la acreditacion IHAN en AP 2015. pdf.

(8) Pados BF, Park J, Estrem H, Awotwi A. Assessment Tools for Evaluation of Oral Feeding in Infants Younger Than 6 Months. Adv Neonatal Care 2016 Apr;16(2):143-50.

(9) Howe TH, Lin KC, Fu CP, Su CT, Hsieh CL. A review of psychometric properties of feeding assessment tools used in neonates. J Obstet Gynecol Neonatal Nurs 2008 May;37(3):338-49.

(10) Lewallen LP. A review of instruments used to predict early breastfeeding attrition. J Perinat Educ 2006;15(1):26-41.

(11) Báez León C, Blasco Contreras R, Martín Sequeros E, del Pozo Ayuso ML, Sánchez Conde Al, Vargas Hormigos C. Validación al castellano de una escala de evaluación de la lactancia materna: el LATCH. Análisis de fiabilidad. Index de Enfermería [Index Enferm] 2008; 17(3):205-209. Index Enferm 2008;17(3):205-9.

(12) Oliver-Roig A, d'Anglade-Gonzalez ML, Garcia-Garcia B, Silva-Tubio JR, Richart-Martinez M, Dennis CL. The Spanish version of the Breastfeeding SelfEfficacy Scale-Short Form: reliability and validity assessment. Int J Nurs Stud 2012 Feb;49(2):169-73.

(13) Llopis-Rabout-Coudray M, López-Osuna C, Durá-Rayo M, Richart-Martínez M, Oliver-Roig A. Fiabilidad y validez de la versión española de una escala de autoeficacia en la lactancia materna. Matronas Prof 2011;12(1):3-8.

(14) Riordan JM, Koehn M. Reliability and validity testing of three breastfeeding assessment tools. J Obstet Gynecol Neonatal Nurs 1997 Mar;26(2):181-7.

(15) Riordan J, Bibb D, Miller M, Rawlins T. Predicting breastfeeding duration using the LATCH breastfeeding assessment tool. J Hum Lact 2001 Feb;17(1):20-3.

(16) Altuntas N, Turkyilmaz C, Yildiz H, Kulali F, Hirfanoglu I, Onal E, et al. Validity and reliability of the infant breastfeeding assessment tool, the mother baby 
GPC Lactancia Materna-Pregunta 10. Observación y valoración de la toma.

assessment tool, and the LATCH scoring system. Breastfeed Med 2014 May;9(4):191-5.

(17) Tornese G, Ronfani L, Pavan C, Demarini S, Monasta L, Davanzo R. Does the LATCH score assessed in the first 24 hours after delivery predict non-exclusive breastfeeding at hospital discharge? Breastfeed Med 2012 Dec;7(6):423-30. 
PREGUNTAS CLÍNICAS № 11 Y 12

\section{¿Se debe recomendar la extracción del calostro en la maternidad cuando el recién nacido no realiza tomas efectivas?}

\section{¿Cuál es la forma más eficaz de extraer el calostro?}

\section{Pregunta clínica en formato PICO}

Comparación 1. Extracción vs. no extracción de calostro en la maternidad

Tabla 1. Componentes de la pregunta clínica en formato PICO

\begin{tabular}{|l|l|}
\hline Pacientes & RN sanos a término parto vaginal \\
\hline Exposición & Extracción calostro en la maternidad \\
\hline Comparación & No extracción calostro en la maternidad \\
\hline Desenlaces & $\begin{array}{l}\text { Lactogénesis II (critica) } \\
\text { Producción de leche/ volumen (critica) } \\
\text { Peso del RN (crítica) } \\
\text { Tasa de LME al alta (critica) } \\
\text { Tasa de LME a los 3 meses (importante) } \\
\text { Tasa de LM a los 3 meses (critica) } \\
\text { Satisfacción materna (crítica) }\end{array}$ \\
\hline Tipo de estudio & $\begin{array}{l}\text { GPC, RS, ECA y estudios observacionales (en caso de no encontrar } \\
\text { ECAs) }\end{array}$ \\
\hline
\end{tabular}

Comparación 2. Extracción manual vs. extracción con sacaleches del calostro

Tabla 2. Componentes de la pregunta clínica en formato PICO

\begin{tabular}{|l|l|}
\hline Pacientes & RN sanos a término parto vaginal \\
\hline Exposición & Extracción manual \\
\hline Comparación & Extracción con sacaleches \\
\hline Desenlaces & $\begin{array}{l}\text { Lactogénesis II (critica) } \\
\text { Producción de leche/ volumen (critica) } \\
\text { Peso del RN (crítica) } \\
\text { Tasa de LME al alta (critica) } \\
\text { Tasa de LME a los 3 meses (importante) } \\
\text { Tasa de LM a los 3 meses (importante) } \\
\text { Satisfacción materna (critica) } \\
\text { Dolor en las mamas (crítica) }\end{array}$ \\
\hline Tipo de estudio & $\begin{array}{l}\text { GPC, RS, ECA y estudios observacionales (en caso de no encontrar } \\
\text { ECAs) }\end{array}$ \\
\hline
\end{tabular}


GPC Lactancia Materna - Preguntas 11 y 12. Extracción de calostro y métodos de extracción.

\section{Introducción}

Sabemos que realizar tomas frecuentes durante los primeros días de vida favorece la instauración adecuada de la lactancia. Sin embargo, algunos recién nacidos realizan pocas tomas eficaces, bien porque están excesivamente adormilados o porque tienen dificultades con el agarre al pecho. Nos planteamos si la extracción manual de calostro y su administración, además de evitar la pérdida excesiva de peso en estos recién nacidos, podría estimular y mejorar la producción de leche. 


\section{Estrategia de elaboración de la pregunta}

\subsection{GPC}

Tabla 3. IHAN

\begin{tabular}{|l|l|l|l|l|}
\hline & Evidencia & Recomendación & Referencia & \\
\hline UNICEF/ OMS & & & & \\
\hline
\end{tabular}

Tabla 4. GPC de base (seleccionadas con el AGREE)

\begin{tabular}{|c|c|c|c|c|}
\hline Guía & Evidencia & Recomendación & Referencias & Comentarios \\
\hline NICE 2006 & $\begin{array}{l}\text { ¿Se debería enseñar a todas las mujeres } \\
\text { que deseen amamantar a extraer la leche } \\
\text { materna? } \\
\text { No se identificaron estudios que abordasen } \\
\text { esta pregunta. La RS llevada a cabo para la } \\
\text { guía de lactancia del Ministerio de Salud de } \\
\text { Singapur (Ministerio de Salud de Singapur } \\
\text { 2002) apoyó la recomendación de la ILCA } \\
\text { que recomienda que se debe enseñar a } \\
\text { todas las madres a realizar la expresión, } \\
\text { recogida y almacenamiento de la leche } \\
\text { materna. } \\
\text { El masaje del pecho y la expresión manual } \\
\text { de la leche materna puede ser útil para } \\
\text { estimular la eyección de leche, incrementar } \\
\text { la producción de leche y aliviar los } \\
\text { conductos bloqueados. } \\
\text { ¿Cuál es el mejor método para la } \\
\text { extracción de la leche materna? } \\
\text { En la guía publicada por la National }\end{array}$ & $\begin{array}{l}\text { Se debería enseñar a todas las mujeres que } \\
\text { amamantan a extraer el calostro y la leche, así } \\
\text { como sobre su correcto almacenamiento. } \\
\text { D(GPP)] } \\
\text { La expresión de la leche se puede realizar } \\
\text { manualmente o con un sacaleches. } \\
\text { Los hospitales deberían disponer de sacaleches, } \\
\text { en particular para aquellas mujeres que han sido } \\
\text { separadas de sus RN, para establecer la } \\
\text { lactancia. Aquellas mujeres que utilicen un } \\
\text { sacaleches deben ser enseñadas sobre cómo } \\
\text { hacerlo. [D(GPP)]. } \\
\text { La ingurgitación mamaria debe tratarse con } \\
\text { masaje de la mama, y si es necesario, expresión } \\
\text { manual. (A) }\end{array}$ & $\begin{array}{l}\text { Department of Health. 2005, Birth } \\
\text { to Five. London: Department of } \\
\text { Health. } \\
\text { Singapore Ministry of Health } 2002 \text {, } \\
\text { Management of breastfeeding for } \\
\text { healthy fullterm infants. Singapore: } \\
\text { Singapore Ministry of Health. }\end{array}$ & \\
\hline
\end{tabular}




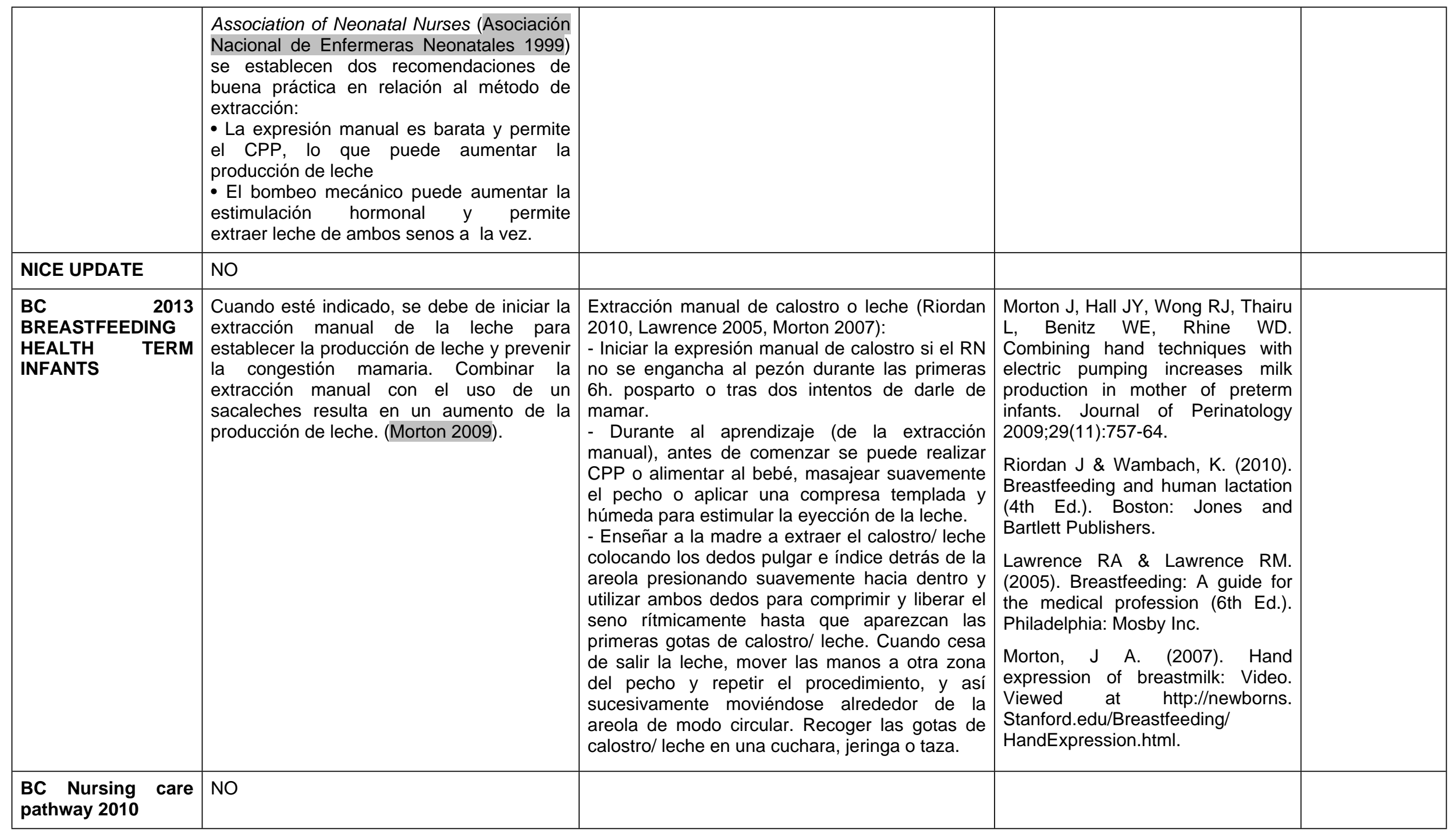


Tabla 5. Resumen de GPC del SNS

\begin{tabular}{|l|l|l|l|l|}
\hline Guía & Evidencia & Recomendación & Referencias & Comentarios \\
\hline GPC parto & No & & & \\
\hline GPC embarazo & No & & & \\
\hline
\end{tabular}

Tabla 6. Resúmenes otras guías/ docs. de referencia

\begin{tabular}{|c|c|c|c|c|}
\hline Guía & Evidencia & Recomendación & Referencias & Comentarios \\
\hline $\begin{array}{l}\text { ABM } 2 \\
\text { "protocolo } \\
\text { de regreso } \\
\text { a casa" } \\
(2007)\end{array}$ & & $\begin{array}{l}\text { Todas las madres que están amamantando deben de } \\
\text { recibir instrucción sobre la técnica para extraer la leche } \\
\text { manualmente (con bomba o sin ella), de modo que } \\
\text { puedan aliviar la mastitis puerperal, incrementar su } \\
\text { suministro de leche o prepararse para usar una bomba. } \\
\text { Además, puede ser que necesite que se le enseñe a usar } \\
\text { la bomba con el objeto de que pueda mantener su } \\
\text { suministro lácteo y obtener leche para alimentar al bebé } \\
\text { en caso de que ella y el niño se encuentren separados o } \\
\text { si el bebé no puede alimentarse directamente del pecho } \\
\text { (American Academy of Pediatrics 2006, American } \\
\text { Academy of Pediatrics 2005, WHO 1990, Schanler 2005, } \\
\text { Nyqvist 1994, Auerbach 1994, Forte 1986, Chamberlain } \\
\text { 2006). }\end{array}$ & $\begin{array}{l}\text { American Academy of Pediatrics and } \\
\text { the American College of Obstetrics } \\
\text { and Gynecologists. Breastfeeding } \\
\text { Handbook for Physicians. Schanler } \\
\text { RJ, ed. Elk Grove Village, IL: } \\
\text { American Academy of Pediatrics, } \\
2006 \text {. } \\
\text { American Academy of Pediatrics } \\
\text { Section on Breastfeeding. Policy } \\
\text { statement: Breastfeeding and the use } \\
\text { of human milk. Pediatrics } \\
2005 ; 115: 496-506 \text {. } \\
\text { World Health Organization, United } \\
\text { Nations Children's Fund. Protecting, } \\
\text { promoting and supporting } \\
\text { breastfeeding: The special role of } \\
\text { maternity services (A joint } \\
\text { WHO/UNICEF statement). Int J } \\
\text { Gynaecol Obstet 1990;31:171-183. } \\
\text { Schanler RJ. Post-discharge nutrition } \\
\text { for the preterm infant. Acta Paediatr } \\
2005 ; 94 \text { (Suppl 449):68-73. } \\
\text { Nyqvist KH. Mother's advice about } \\
\text { facilitating breastfeeding in a neonatal } \\
\text { intensive care unit. J Hum Lact }\end{array}$ & \\
\hline
\end{tabular}




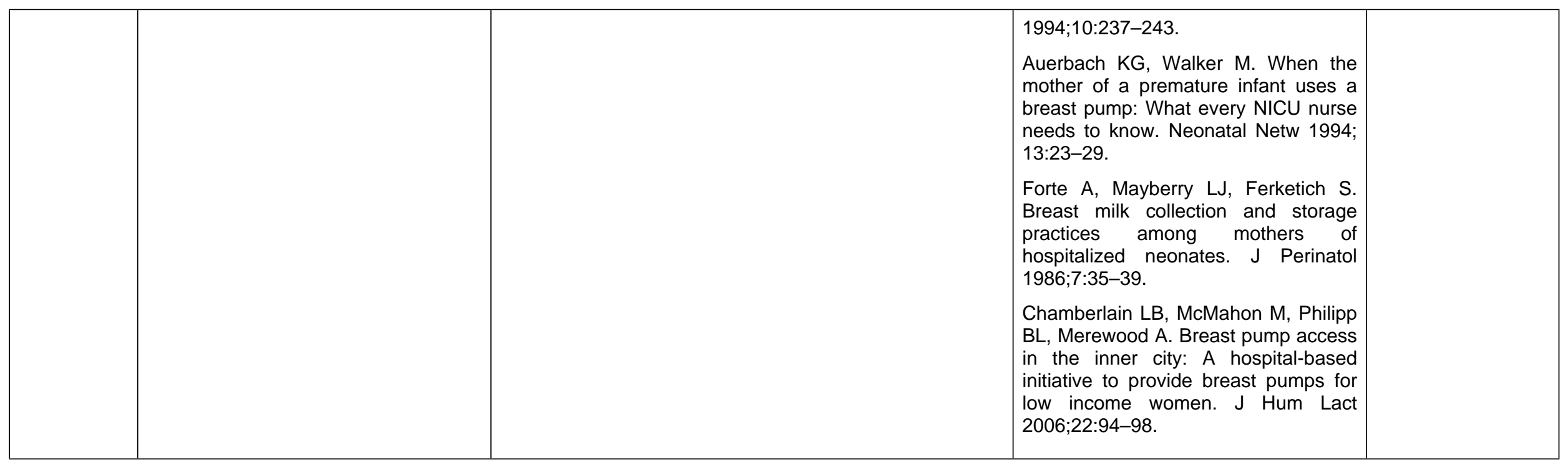

\subsection{Revisiones sistemáticas}

En cuanto a la evidencia de RS, se ha localizado una RS cualitativa (1) y una revisión no sistemática (2) que evalúan el impacto de la extracción de leche en el éxito de la lactancia materna. Se han identificado los estudios que hacían referencia a la extracción temprana de calostro para su valoración individual.

También se ha localizado una revisión Cochrane (3) que evalúa el método más adecuado para la extracción de calostro y leche y de la cual se han identificado los estudios más relevantes para su inclusión en esta revisión. 


\title{
3.3. Resumen de GPC base y RS disponibles
}

\begin{abstract}
La GPC de NICE (4) establece una recomendación de consenso en la que se indica que se debería enseñar a todas las mujeres que amamantan a extraer el calostro y la leche, así como sobre su correcto almacenamiento. Además, los hospitales deberían disponer de extractores de leche, en particular para aquellas mujeres que han sido separadas de sus recién nacidos para ayudar a establecer la lactancia. Las mujeres que utilicen un extractor de leche deben ser enseñadas sobre cómo hacerlo.
\end{abstract}

Por su parte, la guía del PSBC (5) en base a la evidencia de tres estudios (6-8) establece que se debe de comenzar la extracción manual del calostro si el recién nacido no se engancha al pezón durante las primeras seis horas tras el nacimiento o tras dos intentos de darle de mamar. Se debe enseñar a la madre a extraer el calostro colocando los dedos pulgar e índice detrás de la areola presionando suavemente hacia dentro y utilizando ambos dedos para comprimir y liberar el seno rítmicamente hasta que aparezcan las primeras gotas de calostro/ leche. Cuando cesa de salir la leche, se debe mover las manos a otra zona del pecho y repetir el procedimiento, y así sucesivamente moviéndose alrededor de la areola de modo circular. Recoger las gotas de calostro/ leche en una cuchara, jeringa o taza. Para facilitar el aprendizaje, se puede estimular la eyección de la leche realizando CPP, alimentando al recién nacido, masajeando suavemente el pecho o aplicando una compresa templada y húmeda.

De modo similar, el protocolo 2 de la ABM (9) apunta que todas las madres que están amamantando deben recibir instrucciones sobre la técnica para extraerse la leche de forma manual (con bomba o sin ella), de modo que puedan aliviar la mastitis puerperal, incrementar su suministro de leche o prepararse para usar un extractor de leche. Además, puede ser que necesiten que se le enseñe a usar la bomba con el objeto de que puedan mantener su suministro lácteo y obtener leche para alimentar al recién nacido en caso de separación o si el recién nacido no puede alimentarse directamente del pecho (10-12).

En cuanto a la evidencia de RS, se ha localizado una RS cualitativa (1) y una revisión no sistemática (2) que evalúan el impacto de la extracción de leche en el éxito de la lactancia materna. Se han identificado los estudios que hacían referencia a la extracción temprana de calostro para su valoración individual.

También se ha localizado una revisión Cochrane (3) que evalúa el método más adecuado para la extracción de calostro y leche y de la cual se han identificado los estudios más relevantes para su inclusión en esta revisión.

\subsection{Conclusión}

Para la elaboración de esta pregunta tomamos de base, por un lado, la guía del Perinatal Care Services (13) para las indicaciones de extracción de calostro en la maternidad. En cuanto al método más adecuado, tomamos como base la revisión Cochrane de Becker (3).

\section{C1. Extracción vs no extracción del calostro durante la estancia en la maternidad} Adopción GPC/Revisión sistemática

X Elaboración parcial

Elaboración de novo 
C2. Extracción manual vs extracción con sacaleches del calostro

Adopción GPC/Revisión sistemática

X Elaboración parcial

Elaboración de novo

\subsection{Diseño de la estrategia de búsqueda de estudios individuales}

\section{C1. Extracción vs no extracción del calostro durante la estancia en la maternidad}

Criterios de selección de estudios

Tipo de estudios: ECA y estudios observacionales

Participantes: madres que amamantan durante la estancia en la maternidad

Exposición/ comparación: extracción vs. no extracción del calostro Medidas de resultado:

- Lactogénesis II (critica)

-Producción de leche/ volumen (critica)

-Tasa de LME al alta (critica)

-Tasa de LME a los 3 meses (importante)

- Tasa de LM a los 3 meses (critica)

-Satisfacción materna

\section{Período de}

Hasta 19/02/15

búsqueda

Bases de datos

Cochrane Library, Medline (Pubmed), Embase OVID), Cinalh (EBSCO)

\section{C2. Extracción manual vs extracción con sacaleches del calostro}

\begin{tabular}{|l|l|}
\hline $\begin{array}{l}\text { Criterios de } \\
\text { selección de } \\
\text { estudios }\end{array}$ & $\begin{array}{l}\text { Tipo de estudios: ECA y estudios observacionales } \\
\text { Participantes: madres que amamantan durante la estancia en la maternidad } \\
\text { Intervención/ comparación: extracción del calostro manual vs sacaleches } \\
\text { Medidas de resultado: } \\
\text {-Lactogénesis II (critica) } \\
\text {-Producción de leche/ volumen (critica) } \\
\text {-Tasa de LME al alta (critica) } \\
\text {-Tasa de LME a los 3 meses (importante) } \\
\text {-Tasa de LM a los 3 meses (critica) } \\
\text {-Dolor en las mamas } \\
\text {-Satisfacción materna }\end{array}$ \\
\hline $\begin{array}{l}\text { Período de } \\
\text { búsqueda }\end{array}$ & Hasta 19/02/15 \\
\hline Bases de datos & Cochrane Library, Medline (Pubmed), Embase OVID), Cinalh (EBSCO) \\
\hline
\end{tabular}

Ver estrategias de búsqueda de estudios originales en el ANEXO I. 


\section{4- Resumen de la evidencia (Tablas de estudios individuales y valoración de calidad en el ANEXO X)}

\subsection{GRADE Evidence Profile}

Comparación 1.1: Extracción vs no extracción de calostro durante la estancia en la maternidad

Bibliografía: Chapman DJ, Young S, Ferris AM, Pérez-Escamilla R. Impact of breast pumping on lactogenesis stage II after cesarean delivery: a randomized clinical trial. Pediatrics. 2001 Jun;107(6):E94.

\begin{tabular}{|c|c|c|c|c|c|c|c|c|c|c|c|c|}
\hline \multirow{2}{*}{\multicolumn{7}{|c|}{ Quality assessment }} & \multicolumn{4}{|c|}{ Resumen de los Resultados } & \multirow{3}{*}{ Calidad } & \multirow{3}{*}{ Importancia } \\
\hline & & & & & & & \multicolumn{2}{|c|}{ № de pacientes } & \multicolumn{2}{|c|}{ Magnitud del efecto } & & \\
\hline $\begin{array}{l}\text { № de } \\
\text { estudios }\end{array}$ & Diseño & $\begin{array}{l}\text { Riesgo de } \\
\text { sego }\end{array}$ & Inconsistencia & $\begin{array}{l}\text { Evidencia } \\
\text { indirecta }\end{array}$ & Imprecisión & $\begin{array}{c}\text { Otras } \\
\text { consideraciones }\end{array}$ & Extracción & $\begin{array}{l}\text { No extraccion del } \\
\text { calostro en la } \\
\text { maternidad }\end{array}$ & $\begin{array}{l}\text { Relativa } \\
(95 \% \mathrm{Cl})\end{array}$ & Absoluta por 1000 & & \\
\hline \multicolumn{13}{|c|}{ Transferencia de leche 7-10 días postparto (mejor indicado con valores más altos) } \\
\hline $1^{1}$ & ECA & No serio & \begin{tabular}{|l|l} 
serio & $s$
\end{tabular} & Serio $^{2}$ & No serio & Otros $^{3}$ & 30 & 30 & - & $\begin{array}{c}\text { DM 1,8 más (de } 18,17 \\
\text { menos a } 21,77 \text { más) }\end{array}$ & BAJA & CRITICA \\
\hline \multicolumn{13}{|c|}{ Duración LM (mejor indicado con valores más altos) } \\
\hline 11 & ECA & Serio & \begin{tabular}{|l|l} 
serio & 5
\end{tabular} & Serio ${ }^{2}$ & $\begin{array}{l}\text { No } \\
\text { calculable }\end{array}$ & no & 28 & 28 & - & $\begin{array}{c}\text { VER RESUMEN DE } \\
\text { EVIDENCIA }\end{array}$ & BAJA & CRITICA \\
\hline \multicolumn{13}{|c|}{ Duración LME (mejor indicado con valores más altos) } \\
\hline $1^{1}$ & ECA & No serio & \begin{tabular}{|l|l} 
serio \\
\end{tabular} & Serio $^{2}$ & No serio & no & 28 & 28 & - & $\begin{array}{c}\text { DM 0,4 más (de } 0,52 \\
\text { menos a } 1,32 \text { más) }\end{array}$ & MODERADA & CRITICA \\
\hline
\end{tabular}

1 Chapman 2001

2 Población indirecta, ya que se trata de niños de muy bajo peso al nacer que estan ingresados en la UCIN

${ }^{3}$ El método para calcular la transferencia de leches es impreciso, según el grupo elaborador de la guía.

${ }^{4}$ No se puede calcular la imprecisión ya que no se proporcionan datos del IC

Comparación 1.2: Extracción temprana vs. extracción tardía del calostro en la maternidad

Bibliografía: Parker LA, Sullivan S, Krueger C, Kelechi T \& Mueller M. Effect of early breast milk expression on milk volume and timing of lactogenesis stage Il among mothers of very low birth weight infants: a pilot study. Journal of Perinatology 2012; 32(3): 205-209.

\begin{tabular}{|c|c|c|c|c|c|c|c|c|c|c|c|c|}
\hline \multirow{2}{*}{\multicolumn{7}{|c|}{ Evaluación de la calidad }} & \multicolumn{4}{|c|}{ Resumen de los resultados } & \multirow{3}{*}{ Calidad } & \multirow{3}{*}{$\begin{array}{c}\text { Importanci } \\
\text { a }\end{array}$} \\
\hline & & & & & & & \multicolumn{2}{|c|}{ № de pacientes } & \multicolumn{2}{|c|}{ Magnitud del efecto } & & \\
\hline \begin{tabular}{|l|} 
№ de \\
estudios
\end{tabular} & Diseño & $\begin{array}{l}\text { Riesgo de } \\
\text { sesgo }\end{array}$ & Inconsistencia & \begin{tabular}{|l|} 
Evidencia \\
indirecta
\end{tabular} & Imprecisión & \begin{tabular}{|c|} 
Otras \\
consideraciones
\end{tabular} & \begin{tabular}{|c|} 
Extracción: \\
inicio temprano
\end{tabular} & Inicio tardío & $\begin{array}{l}\text { Relativa } \\
\text { (95\% Cl) }\end{array}$ & Absoluta por 1000 & & \\
\hline \multicolumn{13}{|c|}{ Produccion de leche dia 7 (mejor indicado con valores más altos) } \\
\hline 11 & ECA & Serio $^{2}$ & \begin{tabular}{|l|l} 
No serio & $s$
\end{tabular} & Serio $^{3}$ & No calculable r & none & 10 & 10 & & $\begin{array}{l}\text { Ver resumen de } \\
\text { evidencia }\end{array}$ & Muy baja & CRITICA \\
\hline
\end{tabular}




\begin{tabular}{|c|c|c|c|c|c|c|c|c|c|c|c|c|}
\hline \multicolumn{13}{|c|}{ Producción de leche a las 3 semanas (mejor indicado con valores más altos) } \\
\hline $11^{1}$ & ECA & Serio ${ }^{2}$ & No serio & Serio $^{3}$ & No calculable r & none & 10 & 10 & - & $\begin{array}{l}\text { Ver resumen de } \\
\text { evidencia }\end{array}$ & Muy baja & CRITICA \\
\hline \multicolumn{13}{|c|}{ Producción de leche dia a las 6 semanas (mejor indicado con valores más altos) } \\
\hline 11 & ECA & Serio $^{2}$ & No serio & Serio $^{3}$ & No calculable & none & 10 & 10 & - & $\begin{array}{c}\text { Ver resumen de } \\
\text { evidencia }\end{array}$ & Muy baja & CRITICA \\
\hline \multicolumn{13}{|c|}{ Inicio lactogénesis II (semanas (mejor indicado con valores más bajos) } \\
\hline $1^{11}$ & ECA & Serio ${ }^{2}$ & No serio & Serio $^{3}$ & No calculable & none & 10 & 10 & - & $\begin{array}{l}\text { Ver resumen de } \\
\text { evidencia }\end{array}$ & Muy baja & CRITICA \\
\hline
\end{tabular}

${ }^{1}$ Paker 2012

${ }^{2}$ No queda claro como se ha llevado a cabo el proceso de aleatorización, ni tampoco el cegamiento de las personas que analizan los resultados

${ }^{3} \mathrm{RN}$ de muy bajo peso al nacer

\section{Comparación 2. Extracción manual vs. extracción con sacaleches}

\section{Bibliografía:}

Flaherman VJ, Gay B, Scott C, Avins A, Lee KA \& Newman TB. Randomised trial comparing hand expression with breast pumping for mothers of term newborns feeding poorly. Arch Dis Child Fetal Neonatal Ed 2012;97:F18-F23

Ohyama M, Watabe H, \& Hayasaka Y. Manual expression and electric breast pumping in the first $48 \mathrm{~h}$ after delivery. Pediatrics International 2010; $52(1)$ : 39-

43.

\begin{tabular}{|c|c|c|c|c|c|c|c|c|c|c|c|c|}
\hline \multirow{2}{*}{\multicolumn{7}{|c|}{ Quality assessment }} & \multicolumn{4}{|c|}{ Resumen de resultados } & \multirow{3}{*}{ Calidad } & \multirow{3}{*}{ Importancia } \\
\hline & & & & & & & \multicolumn{2}{|c|}{ № de pacientes } & \multicolumn{2}{|c|}{ Magnitud del efecto } & & \\
\hline \begin{tabular}{|c|}
$\begin{array}{c}\text { № de } \\
\text { estudios }\end{array}$ \\
\end{tabular} & Diseño & $\begin{array}{c}\text { Riesgo } \\
\text { de sesgo }\end{array}$ & Inconsistencia & $\begin{array}{l}\text { Evidencia } \\
\text { indirecta }\end{array}$ & Imprecisión & $\begin{array}{c}\text { Otras } \\
\text { consideraciones }\end{array}$ & $\begin{array}{c}\text { Expresion } \\
\text { manual }\end{array}$ & Sacaleches & $\begin{array}{l}\text { Relativa } \\
(95 \% \mathrm{Cl})\end{array}$ & Absoluta por 1000 & & \\
\hline \multicolumn{13}{|c|}{ Dolor en las mamas (mejor indicado con valores más bajos) } \\
\hline \multirow[t]{2}{*}{21} & \multirow[t]{2}{*}{ ECA } & \multirow[t]{2}{*}{ Serio $^{2}$} & \multirow[t]{2}{*}{ No serio } & \multirow[t]{2}{*}{ No serio } & \multirow[t]{2}{*}{ Muy seria ${ }^{3}$} & \multirow[t]{2}{*}{ no } & $\begin{array}{c}9 / 46 \\
(19,6 \%)\end{array}$ & $\begin{array}{c}3 / 44 \\
(6,8 \%) \\
\end{array}$ & \multirow[t]{2}{*}{$\begin{array}{c}\text { RR } 2,56(0,35 \mathrm{a} \\
18,58)\end{array}$} & $\begin{array}{c}106 \text { más por } 1000 \text { (de } 44 \text { menos a } \\
1000 \text { más) }\end{array}$ & \multirow{2}{*}{ MUY BAJA } & \multirow[t]{2}{*}{ CRITICA } \\
\hline & & & & & & & & $7,6 \%$ & & \begin{tabular}{|c|}
119 más por 1000 (de 49 menos a \\
1000 más)
\end{tabular} & & \\
\hline \multicolumn{13}{|c|}{ LM a los 2 meses (mejor indicado con valores más altos) } \\
\hline \multirow[t]{2}{*}{$1^{4}$} & \multirow[t]{2}{*}{ ECA } & \multirow[t]{2}{*}{ No serio } & \multirow[t]{2}{*}{ No serio } & \multirow[t]{2}{*}{ No serio } & \multirow[t]{2}{*}{ No serio } & \multirow[t]{2}{*}{ no } & $\begin{array}{c}34 / 35 \\
(97,1 \%)\end{array}$ & $\begin{array}{l}24 / 33 \\
(72,7 \%)\end{array}$ & \multirow[t]{2}{*}{$\begin{array}{c}\text { RR } 1,34(1,08 \mathrm{a} \\
1,66)\end{array}$} & $\begin{array}{l}247 \text { más por } 1000 \text { (de } 58 \text { más a } \\
480 \text { más) }\end{array}$ & \multirow[t]{2}{*}{ ALTA } & \multirow[t]{2}{*}{ IMPORTANTE } \\
\hline & & & & & & & & $72.7 \%$ & & $\begin{array}{l}247 \text { más por } 1000 \text { (de } 58 \text { más a } \\
480 \text { más) }\end{array}$ & & \\
\hline \multicolumn{13}{|c|}{ Transferencia de leche (aumento de peso en gr). (mejor indicado con valores más altos) } \\
\hline $1^{4}$ & ECA & No serio & No serio & Serio 5 & $\begin{array}{l}\text { No } \\
\text { calculable }\end{array}$ & no & \begin{tabular}{|c|} 
Mediana: \\
$0(-4$ a 14$)$ \\
\end{tabular} & \begin{tabular}{|l} 
Mediana: \\
0 (-8 a 98$)$ \\
\end{tabular} & $\mathrm{P}=0,72$ & Ver resumen de evidencia & BAJA & IMPORTANTE \\
\hline \multicolumn{13}{|c|}{ Volumen de leche (ml.) (mejor indicado con valores más altos) } \\
\hline $1^{4}$ & ECA & No serio & No serio & No serio & No & no & Mediana: & Mediana: & $\mathrm{P}=0,07$ & Ver resumen de evidencia & MODERADA & IMPORTANTE \\
\hline
\end{tabular}




\begin{tabular}{|l|l|l|l|l|l|l|l|l|l|l|l|}
\hline & & & & & \\
\hline
\end{tabular}

1 Ohyama 2010, Flaherman 2012

2 uno de los estudios no es aleatorizado y no ha habido cegamiento en ninguno de los dos por parte de las personas que analizan los resultados. Tampoco de los participantes y profesionales debido a la naturaleza de la intervención.

${ }^{3}$ cruza la linea de no efecto, $y$ además el IC es muy amplio

${ }^{4}$ Flaherman 2012

${ }^{5}$ el método para valorar la transferencia de leche tiene alto riesgo de error, según el grupo elaborador de la guía

${ }^{6}$ no se puede calcular la incertidumbre ya que el dato reportado es la mediana, al ser una distribución no normal

7 Ohyama 2010

${ }^{8}$ no se ha llevado a cabo aleatorización ni tampoco cegamiento

${ }^{9} \mathrm{RN}$ de muy bajo peso al nacer ingresados en la UCIN 


\subsection{Resumen de la evidencia}

\section{¿Se debe recomendar la extracción del calostro en la maternidad cuando el recién nacido no realiza tomas efectivas?}

En la búsqueda se ha localizado un ensayo piloto (14). Además se ha incluido un ECA anterior que no se había considerado en la Guía de la PSBC (15).

En un ECA (15) $(n=60)$ no hubo diferencias significativas en relación a la transferencia de leche, calculada como $\mathrm{ml} / \mathrm{kg} / \mathrm{día}$ a los 7-10 días tras el nacimiento, entre el grupo que realizó una extracción con extractor de leche entre las $24-72$ horas posparto y el grupo control $(148,4 \pm 42,3$ vs. $146,6 \pm 36,4 ; p=0,92)$.

En cuanto al mantenimiento de la lactancia materna, en un ECA (15) $(n=60)$ no hubo diferencias significativas en la mediana de la duración de la lactancia materna exclusiva entre las mujeres que realizaron extracción del calostro utilizando un extractor de leche entre las 24-72 horas postparto y las que no $(3,2 \pm 1,8$ meses vs. $2,8 \pm 1,7$ meses; $p=0,44)$. Tampoco se encontraron diferencias significativas en la mediana de la duración de la lactancia materna global entre ambos grupos (5,9 vs. 6,7 meses, $p=0,76)$.

En cuanto a los beneficios del inicio temprano de la extracción del calostro, se ha localizado un ensayo piloto (14) llevado a cabo con 20 madres de recién nacidos con muy bajo peso al nacer que fueron aleatorizadas a un grupo de inicio temprano (extracción en la primera hora tras el parto) o inicio tardío (de una a seis horas tras el parto). Se observó que las mujeres que realizaban la primera extracción de leche durante la primera hora tras el parto experimentaban antes el inicio de la lactogénesis II respecto a las mujeres que realizaban la primera extracción entra la primera y sexta hora $(80,4 \mathrm{~h}$. vs. $136,8 \mathrm{~h}$., $p=0,03)$. También se observó que la producción de leche $(\mathrm{ml})$ era significativamente mayor en las mujeres del grupo de inicio temprano a las tres semanas $(613,0 \mathrm{ml}$ vs. $267,2 \mathrm{ml}, p=0,01)$, aunque no a los 7 días $(355,0 \mathrm{ml}$ vs. $188,8 \mathrm{ml}, p=0,1)$ ni a las 6 semanas $(451,0 \mathrm{ml}$ vs. $209,95 \mathrm{ml}$, $p=0,07)$.

\section{¿Cuáles son los mejores métodos que existen para extraer el calostro?}

En la búsqueda realizada se ha identificado 1 ECA (16) y un ensayo cruzado (17) sobre este tema.

Los resultados en relación a la producción de leche son contradictorios. En un ECA (16) $(n=68)$ no hubo diferencias entre la extracción manual y la extracción con extractor de leche [mediana: $0,5 \mathrm{ml}$. (0 a 5) vs. 1 ( 0 a $40) ; p=0,07]$. Sin embargo en un estudio cruzado realizado con recién nacidos pretérmino $(n=11)$ durante las primeras 48 horas posparto (17) las mujeres obtuvieron el doble de leche cuando utilizaron la extracción manual que cuando utilizaron un extractor de leche eléctrico [mediana: 2 ml. $(0$ a 012,6$)$ vs. $0,6 \mathrm{ml}$. $(0$ a 7,2$) ; p<0,05$. Los resultados de un ECA (16) $(n=68)$ muestran que tampoco hay diferencias en relación a la transferencia de leche entre ambos grupos [mediana: 0 g. (-4 a 14) vs. 0

\section{Calidad baja}

Calidad moderada

\section{Calidad baja}

Calidad muy baja Calidad muy baja

Calidad moderada

\section{Calidad baja}

Calidad 
g. $(-8$ a 98$) ; 0,72]$.

baja

En cuanto a la duración de la lactancia, si se observaron diferencias significativas en un ECA (16) que comparaba la extracción de leche

Calidad manual frente al uso de extractor de leche en un grupo de 68 madres de recién nacidos sanos a término (12-36 horas) que no realizaban tomas efectivas. Al cabo de dos meses, el $96,1 \%$ de las madres que usaron la técnica de extracción manual continuaban amamantando frente al $72,7 \%$ de las madres que utilizaron extractor de leche (RR 1,$34 ; p=0,02)$.

Finalmente, los datos de dos ensayos $(16 ; 17) \quad(n=90)$ no mostraron diferencias significativas en cuanto a las molestias en las mamas entre ambos métodos de extracción (RR 2,56; IC95\% de 0,35 a 18,58

ACTUALIZADO A FECHA DE: 31 de Octubre de 2016 


\section{De la evidencia a la recomendación (Tabla de EtR)}

\section{¿Se debe recomendar la extracción del calostro en la maternidad cuando el recién nacido no realiza tomas efectivas?}

Población: Madres de RN sanos a término

Intervención: Extracción/Extracción temprana de calostro

Comparación: No extracción temprana de calostro/extracción tardía de calostro

Perspectiva: clínica

C1.: extracción vs no extracción de la leche durante la estancia en la maternidad

C2.: extracción temprana de calostro vs. extracción tardía de calostro

\begin{tabular}{|c|c|c|c|c|c|c|c|c|c|c|c|}
\hline & CRITERIO & \multicolumn{5}{|l|}{ JUICIO } & \multicolumn{4}{|l|}{ EVIDENCIA } & $\begin{array}{l}\text { CONSIDERACIONES } \\
\text { ADICIONALES }\end{array}$ \\
\hline & \multirow{15}{*}{$\begin{array}{l}\frac{\text { ¿Cuál es la confianza }}{\text { global en la evidencia }} \\
\text { disponible sobre los } \\
\text { efectos? }\end{array}$} & \multicolumn{5}{|c|}{ Extracción vs no extracción } & \multicolumn{4}{|c|}{ Extracción vs no extracción } & \\
\hline & & $\begin{array}{c}\text { No se } \\
\text { incluyen }\end{array}$ & Muy baja & Baja & Moderada & Alta & Desenlaces & $\begin{array}{l}\text { Importancia } \\
\text { relativa }\end{array}$ & $\begin{array}{c}\text { Certeza de la } \\
\text { evidencia }\end{array}$ & $\begin{array}{c}\text { Tamaño del } \\
\text { efecto* }\end{array}$ & \\
\hline & & & & & & & 1. Inicio lactogenesis & Crítica & No hay evidencia & - & \\
\hline & & & & $\mathrm{x}$ & & & 2. Produccion de leche & Crítica & No hay evidencia & - & \\
\hline & & \multicolumn{5}{|c|}{ Extraccion temprana vs. extracción tardia } & $\begin{array}{l}\text { 3. Peso del RN a las } 48- \\
\text { 72h. }\end{array}$ & Crítica & No hay evidencia & - & \\
\hline & & \multirow{3}{*}{\begin{tabular}{|c|} 
No se \\
incluyen \\
estudios
\end{tabular}} & \multirow[b]{2}{*}{ Muy baja } & \multirow{3}{*}{ Baja } & \multirow{3}{*}{ Moderada } & \multirow[b]{2}{*}{ Alta } & 4. LME al alta & Critica & No hay evidencia & - & \\
\hline & & & & & & & \multirow{2}{*}{\begin{tabular}{|l|} 
5. LME a los 3 meses \\
6. Duración LME
\end{tabular}} & \multirow{2}{*}{$\begin{array}{l}\text { Importante } \\
\text { Importante }\end{array}$} & \multirow{2}{*}{$\begin{array}{c}\text { No hay evidencia } \\
\text { Moderada }\end{array}$} & - & \\
\hline & & & $x$ & & & & & & & $\begin{array}{c}\text { No hay } \\
\text { diferencias }\end{array}$ & \\
\hline & & & & & & & 7. Duración LM & Importante & Baja & $\begin{array}{c}\text { No hay } \\
\text { diferencias }\end{array}$ & \\
\hline & & & & & & & 8. LM a los 3 meses & Importante & Moderada & $\begin{array}{l}\text { No hay } \\
\text { diferencias }\end{array}$ & \\
\hline & & & & & & & 9. Satisfacción materna & Critica & No hay evidencia & - & \\
\hline & & & & & & & $\begin{array}{l}\text { 10. Molestias en las } \\
\text { mamas }\end{array}$ & Crítica & Moderada & $\begin{array}{l}\text { Beneficio } \\
\text { modesto- } \\
\text { importante }\end{array}$ & \\
\hline & & & & & & & Extracción tempra & vs. extrac & ión tardia & & \\
\hline & & & & & & & Desenlaces & $\begin{array}{l}\text { Importancia } \\
\text { relativa }\end{array}$ & $\begin{array}{l}\text { Certeza de la } \\
\text { evidencia }\end{array}$ & $\begin{array}{c}\text { Tamaño del } \\
\text { efecto* }\end{array}$ & \\
\hline ๓ & & & & & & & 1. Inicio lactogenesis & Crítica & Muy baja & $\begin{array}{c}\text { Beneficio } \\
\text { modesto- } \\
\text { importante }\end{array}$ & \\
\hline
\end{tabular}




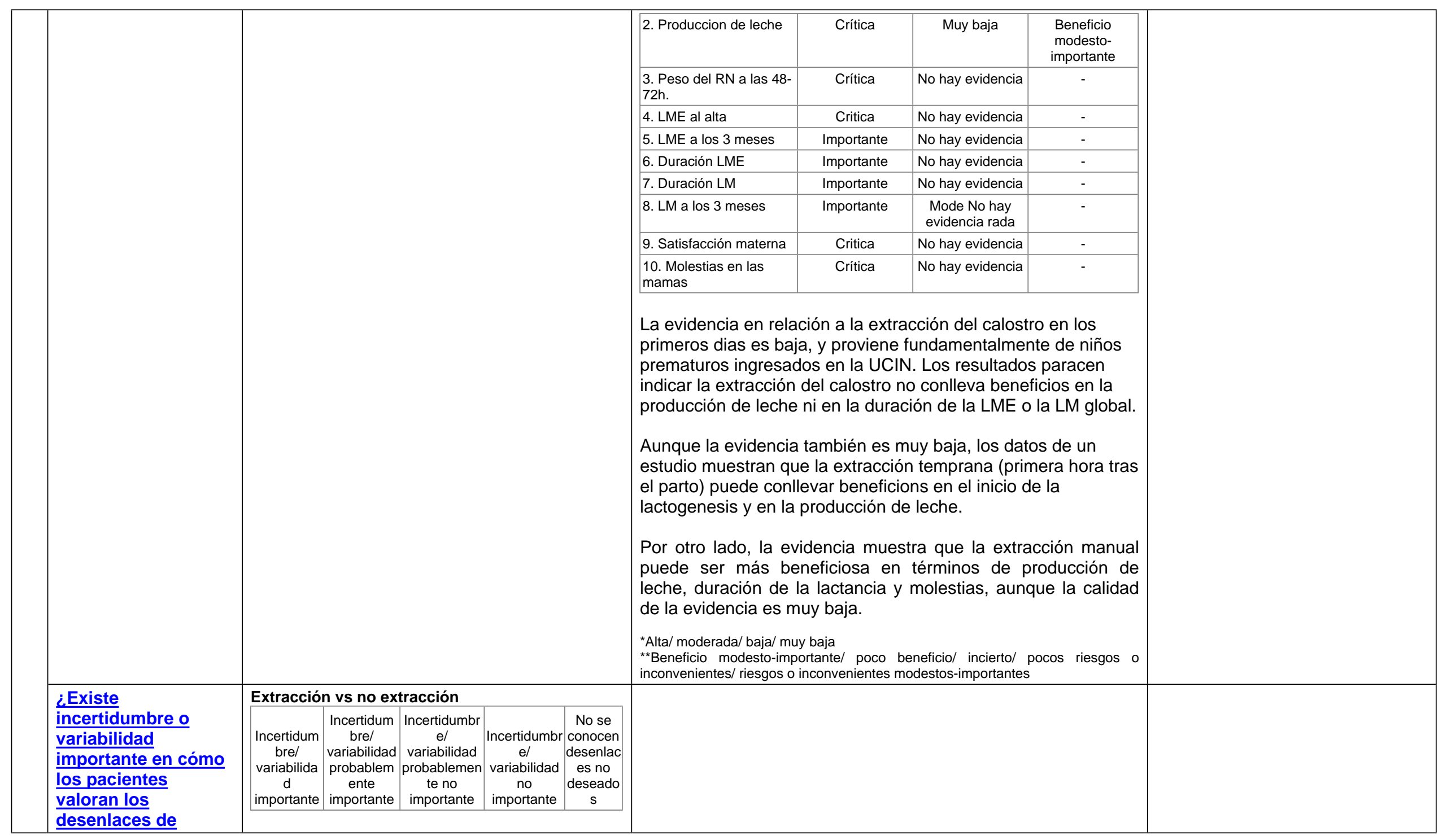




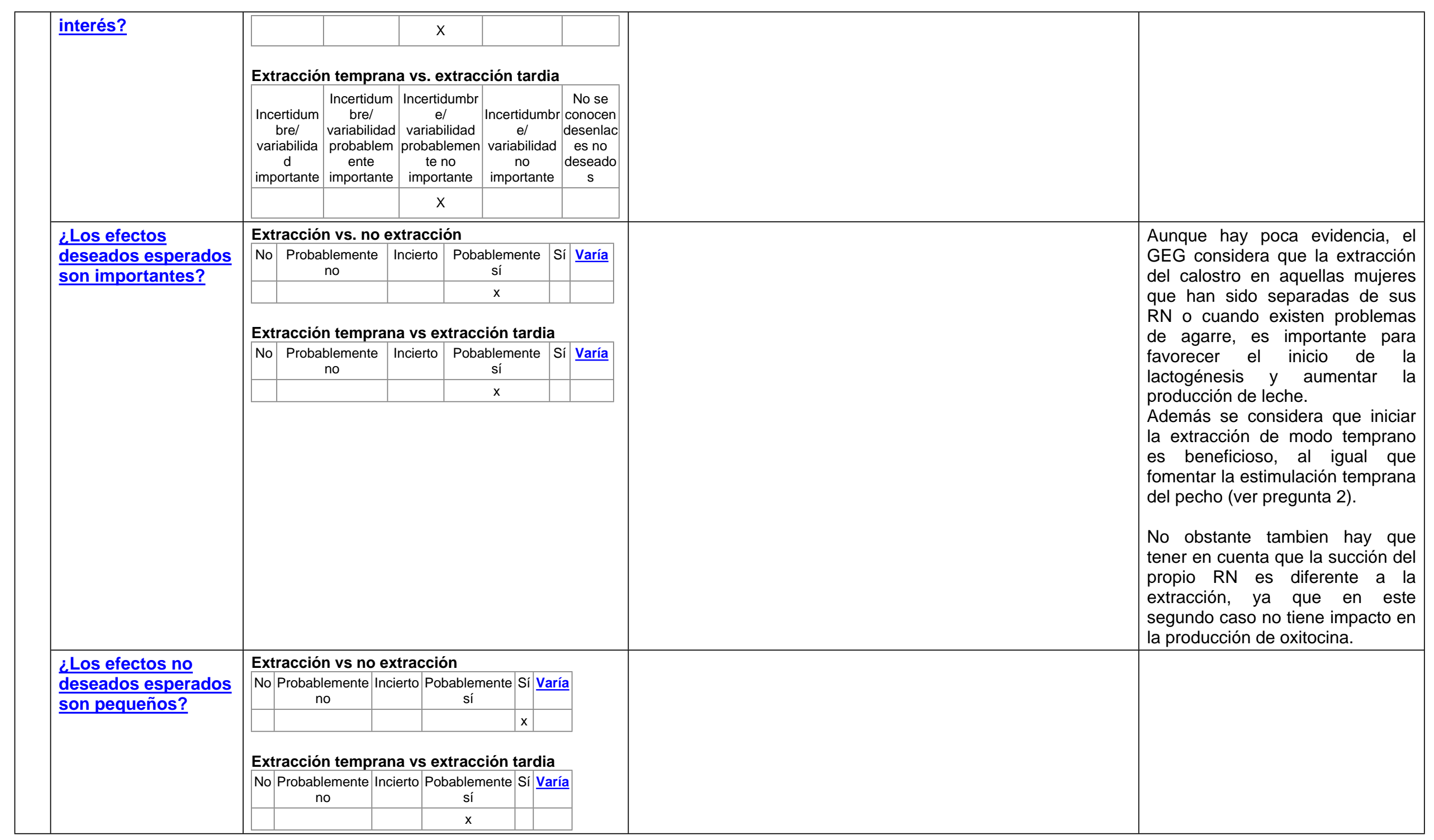




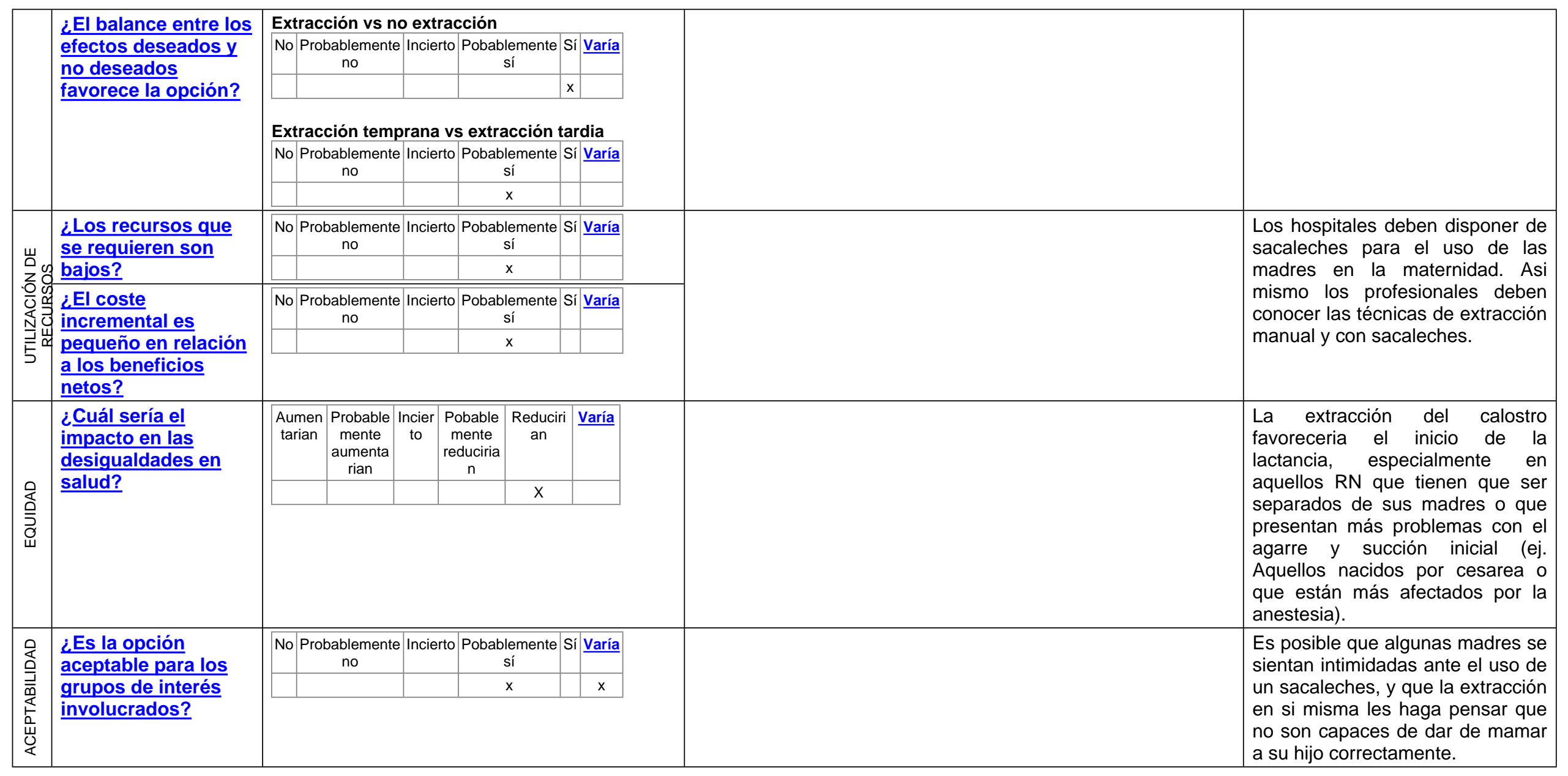




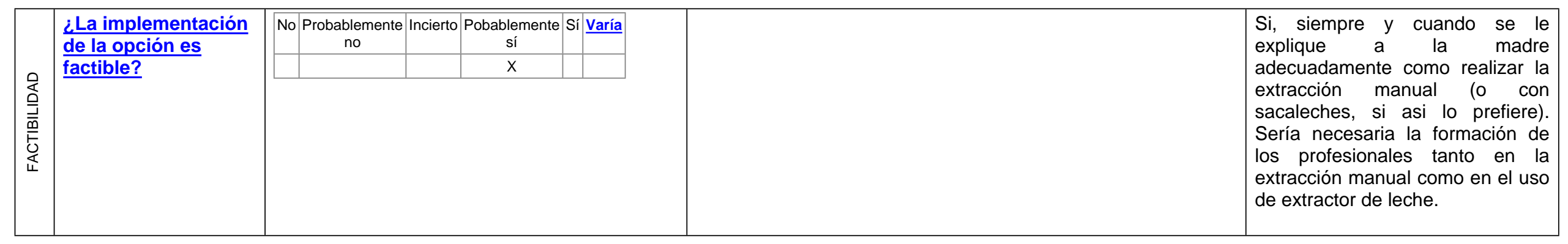

\section{¿Cuál es la forma más eficaz de extraer el calostro?}

Población: Madres de RN sanos a término

Intervención: Extracción temprana de calostro

Comparación: No extracción temprana de calostro

Perspectiva: clínica

C2: extracción manual vs. extracción con sacaleches

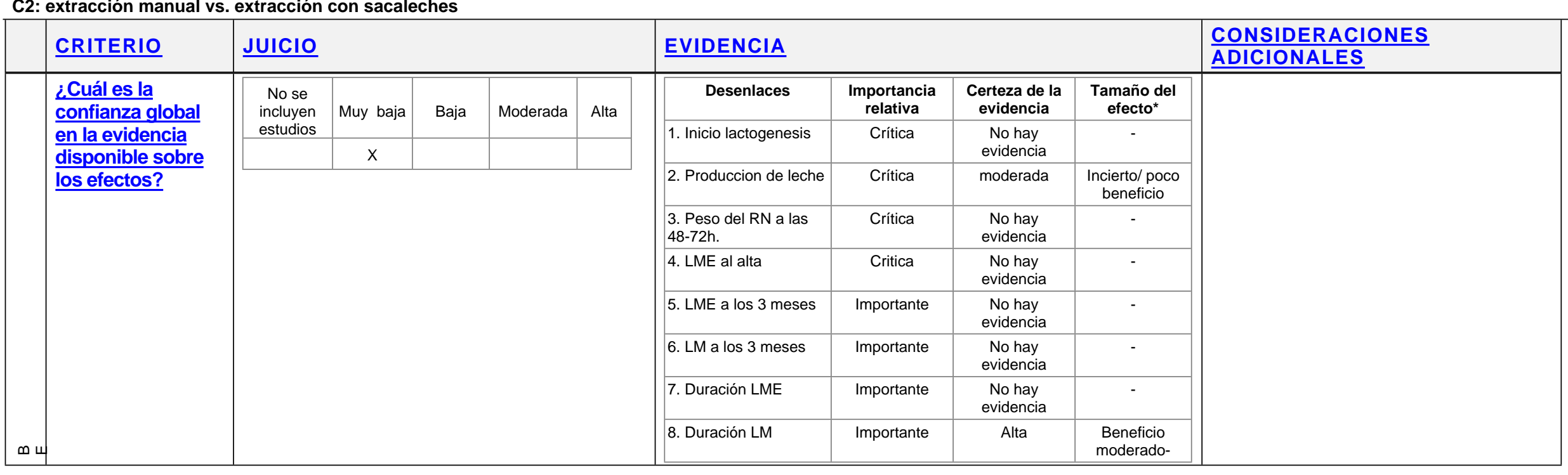




\begin{tabular}{|c|c|c|c|c|c|c|c|c|c|c|c|c|c|c|c|}
\hline & & & & & & & & & & & & & & importante & \\
\hline & & & & & & & & & & & $\begin{array}{l}\text { 9. Satisfacción } \\
\text { materna }\end{array}$ & Critica & $\begin{array}{l}\text { No hay } \\
\text { evidencia }\end{array}$ & - & \\
\hline & & & & & & & & & & & $\begin{array}{l}\text { 10. Molestias en las } \\
\text { mamas }\end{array}$ & Crítica & Muy baja & $\begin{array}{l}\text { No hay } \\
\text { diferencias }\end{array}$ & \\
\hline & & & & & & & & & & & $\begin{array}{l}{ }^{*} \text { Alta/ moderada/ baja/ } \\
{ }^{* \star B} \text { Beneficio modesto-i } \\
\text { inconvenientes/ riesgo }\end{array}$ & $\begin{array}{l}\text { aja } \\
\text { ante/ poc } \\
\text { onvenier }\end{array}$ & $\begin{array}{l}\text { ficio/ inciert } \\
\text { destos-impo }\end{array}$ & $\begin{array}{l}\text { ocos riesgos o } \\
\text { es }\end{array}$ & \\
\hline & $\begin{array}{l}\frac{\text { ¿Existe }}{\text { incertidumbre o }} \\
\text { variabilidad } \\
\text { importante en } \\
\text { cómo los } \\
\text { pacientes valoran }\end{array}$ & & \begin{tabular}{|l|} 
ertidum \\
bre/ \\
iabilida \\
d \\
portant \\
e \\
\end{tabular} & $\begin{array}{l}\text { Incertidur } \\
\text { bre/ } \\
\text { variabilid } \\
d \\
\text { d } \\
\text { probabler } \\
\text { ente } \\
\text { important }\end{array}$ & \begin{tabular}{|r|} 
Incer \\
varia \\
prob \\
nt \\
impc
\end{tabular} & $\begin{array}{l}\text { ertidumbr } \\
\text { e/ } \\
\text { riabilidad } \\
\text { bableme } \\
\text { nte no } \\
\text { portante }\end{array}$ & $\begin{array}{r}\text { Incertic } \\
\text { re } \\
\text { variabi } \\
\text { nc } \\
\text { import }\end{array}$ & $\begin{array}{l}\text { idumb } \\
\text { el } \\
\text { jilidad } \\
0 \\
\text { tante }\end{array}$ & 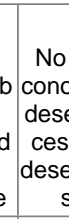 & $\begin{array}{l}\text { o se } \\
\text { ocen } \\
\text { senla } \\
\text { s no } \\
\text { seado } \\
\text { s }\end{array}$ & & & & & \\
\hline & $\begin{array}{l}\text { los desenlaces } \\
\text { de interés? }\end{array}$ & & & & & $x$ & & & & & & & & & \\
\hline & $\frac{\text { ¿Los efectos }}{\text { deseados }}$ & No & Probat & $\begin{array}{l}\text { ablemente } \\
\text { no }\end{array}$ & Incier & Pok & $\begin{array}{c}\text { bablem } \\
\text { sí }\end{array}$ & ente & & Varía & & & & & $\begin{array}{l}\text { El GEG indica que la extracción } \\
\text { manual está más recomendada en los }\end{array}$ \\
\hline & esperados son & & & & & & & & $\mathrm{x}$ & & & & & & primeros días debido a la pequeña \\
\hline & importantes? & & & & & & & & & & & & & & $\begin{array}{l}\text { cantidad de calostro que se extrae, y } \\
\text { que es más dificil de recoger si se } \\
\text { utiliza un sacaleches. }\end{array}$ \\
\hline & $\frac{\text { ¿Los efectos no }}{\text { deseados }}$ & No $\mathrm{F}$ & $\begin{array}{r}\text { Probabl } \\
n\end{array}$ & \begin{tabular}{l|l} 
lemente & Ir \\
no &
\end{tabular} & cierto & $\begin{array}{r}\text { Pobable } \\
\text { sí }\end{array}$ & emente & Sí $\underline{\underline{V}}$ & Varía & & $\begin{array}{l}\text { No se observan } \\
\text { mamas al usar u }\end{array}$ & $\begin{array}{l}\text { rencias } \\
\text { otro } \mathrm{m}\end{array}$ & relación & $\begin{array}{l}\text { lolor en las } \\
\text { uno de los }\end{array}$ & \\
\hline & esperados son & & & & & & & $x$ & & & estudios (Flaherr & 2012) & nujeres e & I grupo que & \\
\hline & pequeños? & & & & & & & & & & $\begin{array}{l}\text { uso la extracciór } \\
\text { leve. }\end{array}$ & nual re & ron dolor & te era muy & \\
\hline & $\frac{\text { ¿El balance entre }}{\text { los efectos }}$ & No $\mathrm{F}$ & $\begin{array}{r}\text { Probabl } \\
n\end{array}$ & \begin{tabular}{ll|l} 
lemente & Ir \\
no &
\end{tabular} & cierto & $\begin{array}{r}\text { Pobable } \\
\text { sí }\end{array}$ & emente & Sí $\underline{\underline{V}}$ & Varía & & & & & & \\
\hline & deseados y no & & & & & & & $\mathrm{x}$ & & & & & & & \\
\hline & $\begin{array}{l}\frac{\text { deseados }}{\text { favorece la }} \\
\text { opción? } \\
\end{array}$ & & & & & & & & & & & & & & \\
\hline 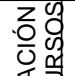 & $\frac{\text { ¿Los recursos }}{\text { que se requieren }}$ & No F & $\begin{array}{r}\text { Probabl } \\
n\end{array}$ & \begin{tabular}{l|l} 
lemente & Ir \\
no &
\end{tabular} & cierto & $\begin{array}{r}\text { Pobable } \\
\text { sí }\end{array}$ & emente & Sí $\underline{\mathbf{V}}$ & Varía & & & & & & $\begin{array}{l}\text { Los hospitales deben disponer de } \\
\text { sacaleches para el uso de las madres }\end{array}$ \\
\hline Nㅜ일 & son bajos? & & & & & $\mathrm{x}$ & $x$ & & & & & & & & en la maternidad. Asi mismo los \\
\hline 5殅 & $\frac{\text { ¿El coste }}{\text { incremental es }}$ & No $\mathrm{F}$ & $\begin{array}{r}\text { Probabl } \\
n\end{array}$ & \begin{tabular}{ll|l} 
lemente & Ir \\
no &
\end{tabular} & cierto & $\begin{array}{r}\text { Pobable } \\
\text { sí }\end{array}$ & emente & & Varía & & & & & & $\begin{array}{l}\text { profesionales deben conocer las } \\
\text { técnicas de extracción manual y con }\end{array}$ \\
\hline
\end{tabular}




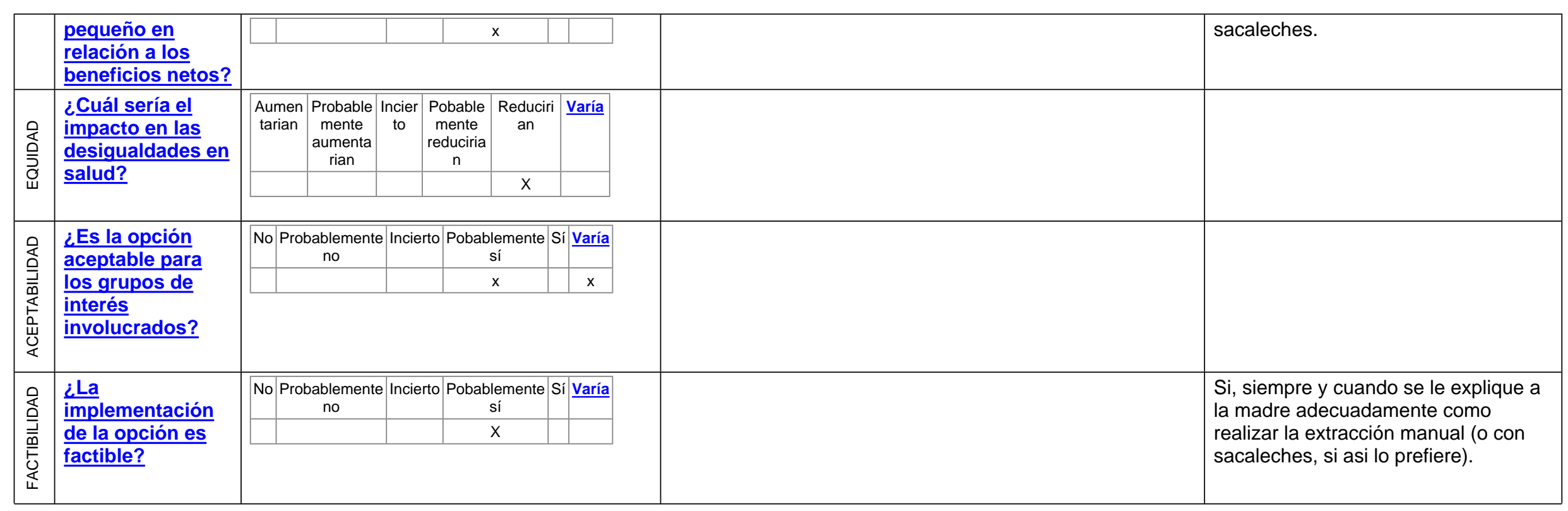

\begin{tabular}{|c|c|c|c|c|c|}
\hline \multirow[t]{2}{*}{$\begin{array}{l}\text { Balance de las } \\
\text { consecuencias }\end{array}$} & $\begin{array}{l}\text { Las consecuencias } \\
\text { no deseadas } \\
\text { superan claramente } \\
\text { las consecuencias } \\
\text { deseadas en la } \\
\text { mayoría de los } \\
\text { escenarios }\end{array}$ & $\begin{array}{c}\text { Las consecuencias } \\
\text { no deseadas } \\
\text { probablemente } \\
\text { superan las } \\
\text { consecuencias } \\
\text { deseadas en la } \\
\text { mayoría de los } \\
\text { escenarios }\end{array}$ & $\begin{array}{c}\text { El balance entre las } \\
\text { consecuencias } \\
\text { deseadas y no } \\
\text { deseadas está muy } \\
\text { equilibrado o es } \\
\text { incierto }\end{array}$ & $\begin{array}{l}\text { Las consecuencias } \\
\text { deseadas } \\
\text { probablemente } \\
\text { superan las } \\
\text { consecuencias no } \\
\text { deseadas en la } \\
\text { mayoría de los } \\
\text { escenarios }\end{array}$ & $\begin{array}{l}\text { Las consecuencias } \\
\text { deseadas } \\
\text { claramente superan } \\
\text { las consecuencias } \\
\text { no deseadas en la } \\
\text { mayoría de los } \\
\text { escenarios }\end{array}$ \\
\hline & & & & $X$ & \\
\hline C1.2 & & & & $X$ & \\
\hline C2 & & & & $X$ & \\
\hline
\end{tabular}




\begin{tabular}{|c|c|c|c|c|c|}
\hline \multirow[t]{4}{*}{$\frac{\text { Tipo de }}{\text { recomendación }}$} & \multirow[b]{2}{*}{ C1.1 } & $\begin{array}{l}\text { Se recomienda no } \\
\text { ofrecer la opción }\end{array}$ & $\begin{array}{l}\text { Se sugiere no ofrecer la } \\
\text { opción }\end{array}$ & $\begin{array}{l}\text { Se sugiere ofrecer la } \\
\text { opción }\end{array}$ & $\begin{array}{l}\text { Se recomienda ofrecer } \\
\text { la opción }\end{array}$ \\
\hline & & & & & $\mathrm{X}$ \\
\hline & C1.2 & & & $\mathrm{X}$ & \\
\hline & $\mathrm{C} 2$ & & & & $\mathrm{X}$ \\
\hline $\begin{array}{l}\text { Recomendación } \\
\text { (Texto) }\end{array}$ & \multicolumn{5}{|c|}{$\begin{array}{l}\text { Se sugiere que las madres de recién nacidos que no hayan comenzado a succionar de forma eficaz o hayan sido separados, se } \\
\text { extraigan el calostro precozmente. } \\
\text { Recomendación débil a favor } \\
\text { Se sugiere la extracción manual del calostro porque optimiza la cantidad extraída. } \\
\text { En el caso de que la madre no se sienta a gusto utilizando la técnica manual, se le debería ofrecer un extractor de leche. }\end{array}$} \\
\hline Justificación & \multicolumn{5}{|c|}{$\begin{array}{l}\text { La evidencia proviene fundamentalmente de estudios con RN prematuros que son separados de sus madres la nacer. No obstante, } \\
\text { también hay RN sanos a término que no realizan una succión correcta en las primeras horas, por lo que puede ser conveniente } \\
\text { que las madres de estos niños realicen la extracción temprana del calostro para aumentar la producción de leche y favorecer el } \\
\text { inicio de la lactogenesis. } \\
\text { En cuanto al método más adecuado, la extracción manual parace estar indicada para los primeros días. No obstante se puede } \\
\text { ofrecer a las madres ambas opciones. }\end{array}$} \\
\hline \multicolumn{6}{|l|}{$\begin{array}{l}\text { Consideraciones de } \\
\text { subgrupos }\end{array}$} \\
\hline $\begin{array}{l}\text { Consideraciones para } \\
\text { la implementación } \\
\end{array}$ & \multicolumn{5}{|c|}{$\begin{array}{l}\text { Es preferible que sea la madre la que elija el método para la extracción de leche. No obstante en la extracción temprana (antes de } \\
\text { la subida de la leche o en los primeros momentos de la lactogénesis II) la técnica manual puede ser más apropiada para extraer el } \\
\text { calostro. } \\
\text { La madre debe de ser informada de que la capacidad gástrica del recién nacido es pequeña y de que no necesita preocuparse por } \\
\text { el volumen extraído, ya que es adecuado para sus necesidades y que por eso es importante que las tomas sean frecuentes. } \\
\text { Los profesionales deben conocer y poder explicar a la madre ambas técnicas de extracción. }\end{array}$} \\
\hline $\begin{array}{l}\text { Monitorización y } \\
\text { evaluación } \\
\end{array}$ & \multicolumn{5}{|c|}{-} \\
\hline Prioridades para la & \multicolumn{5}{|c|}{ Una parte importante de los estudios han sido realizados con bebés prematuros y/o de bajo peso, por lo que se recomienda } \\
\hline
\end{tabular}


GPC Lactancia Materna - Preguntas 11 y 12. Extracción de calostro y métodos de extracción. 


\section{ANEXOS}

Anexo I. Estrategias de búsqueda

Anexo II. Valoración de la calidad de los estudios

Anexo III. Tablas de estudios individuales

Anexo IV. Forest plots

\section{ANEXO I. ESTRATEGIAS DE BÚSQUEDA}

\section{Cochrane Library \\ Searched 19/02/2015 \\ Updated search 19/02/2015 a xx/xx/xxxx}

\#1 colostrum:ti,ab,kw or milk or breast or breastmilk or breast-milk:ti,ab,kw (Word variations have been searched) 27022

\#2 express* or pump*:ti,ab,kw (Word variations have been searched) 25013

\#3 \#1 and \#2 1408

\#4 early:ti,ab,kw (Word variations have been searched) 60735

\#5 \#3 and \#4 280

\#6 mother or mothers or infant or infants:ti,ab,kw (Word variations have been searched) $\quad 40407$

\#7 \#5 and \#6 55

MEDLINE, via Pubmed

Searched 19/02/2015

Updated search 19/02/2015 a xx/xx/xxxx

\#1 "Search (colostrum[Title/Abstract]) OR colostrum[MeSH Terms]" 7524

\#2 "Search ((milk[Title/Abstract] OR breast[Title/Abstract] OR breastmilk[Title/Abstract] OR breast-milk[Title/Abstract])) OR (milk OR breast OR breastmilk OR breast-milk[MeSH Terms])" 461757

\#3 "Search \#1 OR \#2" 465745

\#4 "Search ((express*[Title/Abstract] OR pump*[Title/Abstract])) OR (express* OR pump*[MeSH Terms])" 2126534

\#5 "Search (early[Title/Abstract]) OR early[MeSH Terms]"

1096265

\#6 "Search \#4 AND \#5" 179951

\#7 "Search \#3 AND \#6" 6283

\#8 "Search ((mother[Title/Abstract] OR mothers[Title/Abstract] OR infant[Title/Abstract] OR infants[Title/Abstract])) OR (mother OR mothers OR infant OR infants[MeSH Terms])"

1126176

\#9 "Search \#7 AND \#9" 436

EMBASE, via Ovid

Searched 19/02/2015

Updated search 19/02/2015 a xx/xx/xxxx

\#1 colostrum.ti,ab,kw. 6454

\#2 (milk or breast or breastmilk or breast-milk).ti,ab,kw.

506099

\#3 1 or 2

509598

\#4 (express* or pump*).ti,ab,kw.

2370338

\#5 early.ti,ab,kw.

1472173 
GPC Lactancia Materna - Preguntas 11 y 12. Extracción de calostro y métodos de extracción.
\#6 4 and 5
212607
\#7 3 and 6
8453
\#8 (mother or mothers or infant or infants).ti,ab,kw.
541676
\#9 7 and 8
462

CINAHL, via EBSCOhost databases

Searched 19/02/2015

Updated search 19/02/2015 a xx/xx/xxxx

S1 colostrum 7,811

S2 milk OR breast OR breastmilk OR breast-milk 520,991

S3 S1 OR S2 525,067

S4 express* or pump* 2,170,382

S5 early $1,223,551$

S6 S4 AND S5 189,696

S7 S3 AND S6 $\quad 6,810$

S8 mother or mothers or infant or infants $1,283,234$

S9 S7 AND S8 532

Cinahl 100 


\section{ANEXO II. EVALUACIÓN DE LA CALIDAD DE LOS ESTUDIOS}

\section{Revisiones sistemáticas - AMSTAR}

No hay RS

\section{ECAs - Risk of bias - Cochrane}

\begin{tabular}{|c|c|c|c|c|c|c|}
\hline $\begin{array}{l}\text { Referencia } \\
\text { (Cita Abreviada) }\end{array}$ & $\begin{array}{l}\text { Random sequence } \\
\text { generation (selection } \\
\text { bias) }\end{array}$ & $\begin{array}{l}\text { Allocation } \\
\text { conceallement } \\
\text { (selection bias) }\end{array}$ & $\begin{array}{l}\text { Blinding } \\
\text { (performance bias } \\
\text { and detection bias) } \\
\text { All outcomes }\end{array}$ & $\begin{array}{l}\text { Incomplete outcome } \\
\text { data (attrition bias) } \\
\text { All outcomes }\end{array}$ & $\begin{array}{l}\text { Selective reporting } \\
\text { (reporting bias) }\end{array}$ & Other bias \\
\hline Chapman 2001 & $\begin{array}{l}\text { Riesgo poco claro } \\
\text { "participants were } \\
\text { randomly assigned, on } \\
\text { an alternating basis, to } \\
\text { either the intervention } \\
\text { or control group. After } \\
\text { the first } 4 \text { participants } \\
\text { were enrolled, } \\
\text { randomization was } \\
\text { stratified by parity and } \\
\text { type of cesarean } \\
\text { delivery (ie, scheduled } \\
\text { vs unscheduled) to } \\
\text { ensure that the } \\
\text { potentially confounding } \\
\text { combinations of parity } \\
\text { and delivery type were } \\
\text { evenly distributed } \\
\text { among study groups." }\end{array}$ & $\begin{array}{l}\text { Riesgo poco claro } \\
\text { No indicado }\end{array}$ & $\begin{array}{l}\text { Riesgo poco claro } \\
\text { No indicado }\end{array}$ & Bajo riesgo de sesgo & $\begin{array}{l}\text { Alto riesgo de sesgo } \\
\text { Resultados mal } \\
\text { reportados, sin SD ni } \\
\text { IC. }\end{array}$ & Bajo riesgo \\
\hline Parker 2012 & $\begin{array}{l}\text { Bajo riesgo } \\
\text { "Following delivery, }\end{array}$ & Bajo riesgo & $\begin{array}{l}\text { Alto riesgo/ riesgo } \\
\text { poco claro }\end{array}$ & Bajo riesgo de sesgo & $\begin{array}{l}\text { Alto riesgo de sesgo } \\
\text { No se reportan bien }\end{array}$ & $\begin{array}{l}\text { Alto riesgo } \\
\text { Es una muestra }\end{array}$ \\
\hline
\end{tabular}




\begin{tabular}{|c|c|c|c|c|c|c|}
\hline & $\begin{array}{l}\text { mothers were } \\
\text { randomized to one of } \\
\text { the two groups using a } \\
\text { sequentially numbered } \\
\text { envelope system." }\end{array}$ & & $\begin{array}{l}\text { No se menciona nada } \\
\text { sobre el cegamiento } \\
\text { de las personas que } \\
\text { evaluan los resultados. } \\
\text { Dada lanaturaleza de } \\
\text { la intervención no es } \\
\text { posible el cegamiento } \\
\text { de profesionales y } \\
\text { madres. }\end{array}$ & & $\begin{array}{l}\text { los resultados, no hay } \\
\text { SD. }\end{array}$ & $\begin{array}{l}\text { pequeña y la } \\
\text { población es indirecta } \\
\text { (RN de muy bajo peso } \\
\text { al nacer) }\end{array}$ \\
\hline Flaherman 2012 & $\begin{array}{l}\text { Bajo riesgo } \\
\text { The allocation } \\
\text { sequence for } \\
\text { randomisation was } \\
\text { generated by an } \\
\text { independent } \\
\text { biostatistician; }\end{array}$ & $\begin{array}{l}\text { Bajo riesgo } \\
\text { Assignments were } \\
\text { placed into sealed } \\
\text { opaque envelopes by } \\
\text { an independent } \\
\text { administrative } \\
\text { assistant. Immediately } \\
\text { following enrolment, } \\
\text { the study investigator } \\
\text { opened sequential } \\
\text { envelopes in the } \\
\text { presence of a second } \\
\text { clinician and revealed } \\
\text { the randomization arm. } \\
\text { Thus we had complete } \\
\text { allocation } \\
\text { concealment, }\end{array}$ & $\begin{array}{l}\text { Alto riesgo } \\
\text { no blinding was } \\
\text { possible. }\end{array}$ & $\begin{array}{l}\text { Bajo riesgo de sesgo } \\
\text { para todos los } \\
\text { desenlaces excepto } \\
\text { para transferencia de } \\
\text { leche }\end{array}$ & Bajo riesgo de sesgo & Bajo riesgo de sesgo \\
\hline Ohyama 2010 & $\begin{array}{l}\text { Riesgo poco claro } \\
\text { NO hay aleatorización } \\
\text { como tal, las mujeres } \\
\text { entran de modo } \\
\text { secuencia al } \\
\text { extracción manual o } \\
\text { con sacaleches, y } \\
\text { después usan el } \\
\text { método alternativo }\end{array}$ & Alto riesgo de sesgo & $\begin{array}{l}\text { Alto riesgo de sesgo } \\
\text { No hay cegamiento }\end{array}$ & $\begin{array}{l}\text { Bajo riesgo de sesgo } \\
\text { para todos los } \\
\text { desenlaces excepto } \\
\text { para transferencia de } \\
\text { leche }\end{array}$ & Bajo riesgo de sesgo & $\begin{array}{l}\text { Alto riesgo de sesgo } \\
\text { Es posible que exista } \\
\text { contaminación al } \\
\text { pasar de un método } \\
\text { de extracción al otro, } \\
\text { no hay periodo de } \\
\text { washout. }\end{array}$ \\
\hline
\end{tabular}




\section{Estudios de cohortes}

No se han incluido estudios descriptivos

\section{Estudios descriptivos}

No se han incluido estudios descriptivos 


\section{ANEXO III. Tabla de estudios para la pregunta}

\section{Tabla de ECAs}

\begin{tabular}{|c|c|c|c|c|c|c|}
\hline $\begin{array}{l}\text { Referencia } \\
\text { (Cita } \\
\text { Abreviada) }\end{array}$ & $\begin{array}{l}\text { Estudio (Diseño y } \\
\text { objetivo) }\end{array}$ & $\begin{array}{l}\text { Población } \\
\text { (noy } y \\
\text { características) }\end{array}$ & $\begin{array}{l}\text { Descripción de las } \\
\text { intervenciones } \\
\text { comparaciones, } \\
\text { exposiciones o pruebas } \\
\text { a estudio }\end{array}$ & $\begin{array}{l}\text { Resultados } \\
\text { (Estimadores de resultados- } \\
\text { Magnitud del efecto) }\end{array}$ & $\begin{array}{l}\text { Conclusiones } \\
\text { (conclusiones) }\end{array}$ & $\begin{array}{l}\text { Comentarios } \\
\text { Calidad de la evidencia Financiación } \\
\text { comentarios) }\end{array}$ \\
\hline $\begin{array}{l}\text { Chapman } \\
2001\end{array}$ & $\begin{array}{l}\text { Diseño } \\
\text { ECA } \\
\text { Objetivo } \\
\text { Evaluar el efecto } \\
\text { de la extracción de } \\
\text { leche antes del } \\
\text { inicio de la } \\
\text { lactogénesis }\end{array}$ & $\begin{array}{l}\mathbf{N} \\
60 \\
\text { Características } \\
\text { Parto por cesárea, } \\
\text { con intención de } \\
\text { dar de mamar > } 10 \\
\text { días, sin problemas } \\
\text { médicos. RN sanos } \\
\text { a término }\end{array}$ & $\begin{array}{l}\text { Intervención } \\
\text { Extracción leche con } \\
\text { sacaleches eléctrico } \\
\text { simultáneo (Medela) } 3 \\
\text { veces/día tras una toma } \\
\text { durante } 10-15 \text { " entre las } \\
\text { 24-72h. posparto (6 } \\
\text { sesiones) } \\
\text { Comparación } \\
\text { No extracción de la leche. } \\
\text { Se hace la misma } \\
\text { intervención pero sin } \\
\text { succión (6 "sesiones") }\end{array}$ & 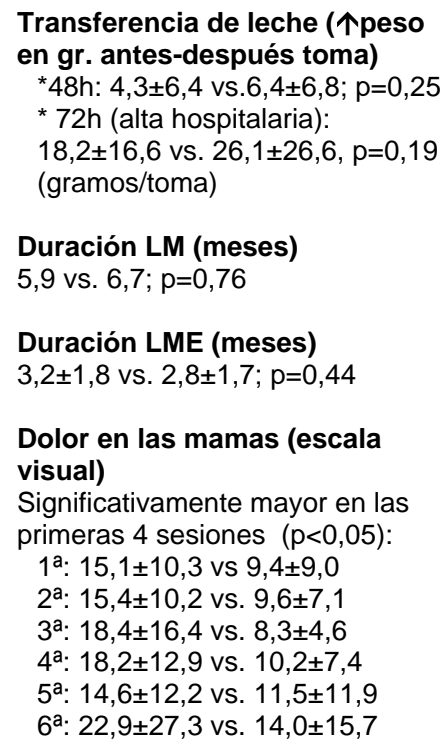 & $\begin{array}{l}\text { No hay diferencias } \\
\text { significativas en la } \\
\text { transferencia de leche ni } \\
\text { en la duración de la LM } \\
\text { (cualquier tipo) entre las } \\
\text { mujeres que hacen uso } \\
\text { del sacaleches y las que } \\
\text { no. }\end{array}$ & $\begin{array}{l}(+) \\
(-) \text { Parto por cesárea (evidencia } \\
\text { indirecta), muestra de conveniencia } \\
\text { (-) No se indica si hay conflicto de } \\
\text { interés pero los sacaleches los } \\
\text { facilita la empresa } \\
\text { Conflicto de interés } \\
\text { No indicado } \\
\text { Financiación } \\
\text { Univ. Connecticut, Hartford Hospital. } \\
\text { Calidad } \\
\text { Baja - ver RoB }\end{array}$ \\
\hline Parker 2012 & $\begin{array}{l}\text { Diseño } \\
\text { ECA } \\
\text { Objetivo } \\
\text { Recoger datos } \\
\text { preliminares sobre } \\
\text { la factibilidad y el }\end{array}$ & $\begin{array}{l}\mathbf{N} \\
20 \text { díadas madre- } \\
\text { RN } \\
\text { Características }\end{array}$ & $\begin{array}{l}\text { Intervención } \\
\text { Inicio temprano de la } \\
\text { extracción del calostro } \\
\text { tras el parto (primera } \\
\text { hora) } \\
\text { Comparación }\end{array}$ & $\begin{array}{l}\text { Inicio de la lactogénesis II (h.) } \\
80,4 \text { vs. } 136,8 ; p=0,03 \\
\text { Volumen de leche a los } 7 \text { días } \\
\text { (ml/24h) } \\
355 \text { vs. } 188,9 ; p=0,06\end{array}$ & $\begin{array}{l}\text { El inicio temprano de la } \\
\text { extracción del calostro } \\
\text { (en la primera hora tras } \\
\text { el parto) incrementa el } \\
\text { volumen de leche y } \\
\text { favorece que la } \\
\text { lactogénesis II se }\end{array}$ & $\begin{array}{l}\text { (+) primer ECA } \\
(-) \text { ensayo piloto, con muy pocas } \\
\text { mujeres, población indirecta } \\
\text { Financiación } \\
\text { No indicado }\end{array}$ \\
\hline
\end{tabular}




\begin{tabular}{|c|c|c|c|c|c|c|}
\hline $\begin{array}{l}\text { Referencia } \\
\text { (Cita } \\
\text { Abreviada) }\end{array}$ & $\begin{array}{l}\text { Estudio (Diseño y } \\
\text { objetivo) }\end{array}$ & $\begin{array}{l}\text { Población } \\
\text { ( } \mathrm{n}^{\circ} \mathrm{y} \\
\text { características) }\end{array}$ & $\begin{array}{l}\text { Descripción de las } \\
\text { intervenciones } \\
\text { comparaciones, } \\
\text { exposiciones o pruebas } \\
\text { a estudio }\end{array}$ & $\begin{array}{l}\text { Resultados } \\
\text { (Estimadores de resultados- } \\
\text { Magnitud del efecto) }\end{array}$ & $\begin{array}{l}\text { Conclusiones } \\
\text { (conclusiones) }\end{array}$ & $\begin{array}{l}\text { Comentarios } \\
\text { Calidad de la evidencia Financiación } \\
\text { comentarios) }\end{array}$ \\
\hline & $\begin{array}{l}\text { efecto del inicio } \\
\text { temprano de la } \\
\text { extracción de } \\
\text { calostro en el inicio } \\
\text { de la lactogénesis } \\
\text { II y el volumen de } \\
\text { leche en madres } \\
\text { de niños de muy } \\
\text { bajo peso al nacer }\end{array}$ & & $\begin{array}{l}\text { Inicio tardio de la } \\
\text { extracción del calostro } \\
\text { tras el parto (1-6 horas) }\end{array}$ & $\begin{array}{l}\text { Volumen de leche a las } 3 \\
\text { semanas (ml/24h.) } \\
613,0 \text { vs. } 267,2 ; p=0,01 \\
\text { Volumen de leche a las } 6 \\
\text { semanas (ml/24h.) } \\
451,0 \text { vs. } 209,95 ; p=0,07\end{array}$ & produzca antes. & $\begin{array}{l}\text { Conflicto de interés } \\
\text { No hay } \\
\text { Calidad } \\
\text { Moderada - ver RoB }\end{array}$ \\
\hline Ohyama 2010 & $\begin{array}{l}\text { Diseño } \\
\text { Ensayo cruzado } \\
\text { Objetivo } \\
\text { Comparar la } \\
\text { efectividad y el } \\
\text { confort de la } \\
\text { extracción de } \\
\text { leche manual o } \\
\text { con bomba en las } \\
\text { 48h. posparto }\end{array}$ & $\begin{array}{l}\mathbf{N} \\
11 \\
\text { Características } \\
\text { Madres de RN } \\
\text { admitidos en la } \\
\text { UCIN tras el } \\
\text { nacimiento (48h) }\end{array}$ & $\begin{array}{l}\text { Intervención } \\
\text { Extracción leche manual } \\
\text { (técnica Marmet) } \\
\text { Comparación } \\
\text { Extracción con } \\
\text { sacaleches eléctrico } \\
\text { (Symphony pump) }\end{array}$ & $\begin{array}{l}\text { Volumen de leche (ml.) } \\
\text { Mediana: } 2 \text { ( } 0 \text { a } 12,6) \text { vs. } 0,6 \text { ( } 0 \text { a } \\
7,2) ; p<0,05 \\
\text { Molestias en las mamas (\% de } \\
\text { mujeres que experimentan dolor) } \\
64 \% \text { vs. } 10 \% ; p<0,05\end{array}$ & $\begin{array}{l}\text { La extracción manual se } \\
\text { asocia con mayor } \\
\text { volumen de leche } \\
\text { extraído, aunque es más } \\
\text { molesto para las mujeres } \\
\text { que la extracción con } \\
\text { sacaleches eléctrico. No } \\
\text { obstante las molestias } \\
\text { reportadas son leves. }\end{array}$ & $\begin{array}{l}\text { (+) Periodo inmediato posparto } \\
\text { (-) Muestra pequeña } \\
\text { Conflicto de interés } \\
\text { No indicado, pero los sacaleches } \\
\text { proporcionados por la empresa } \\
\text { Financiación } \\
\text { No indicado } \\
\text { Calidad } \\
\text { Baja - ver RoB }\end{array}$ \\
\hline $\begin{array}{l}\text { Flaherman } \\
2012\end{array}$ & $\begin{array}{l}\text { Diseño } \\
\text { ECA } \\
\text { Objetivo } \\
\text { Comparar } \\
\text { extracción de } \\
\text { leche manual o } \\
\text { con bomba } \\
\text { bilateral eléctrica } \\
\text { en RN sanos a } \\
\text { término que se } \\
\text { alimentan de modo } \\
\text { inefectivo en las } \\
\text { 12-36h. posparto }\end{array}$ & $\begin{array}{l}\mathbf{N} \\
68 \\
\text { Características } \\
\text { RN sanos a } \\
\text { término que se } \\
\text { alimentan de modo } \\
\text { inefectivo }\end{array}$ & $\begin{array}{l}\text { Intervención } \\
\text { Extracción leche manual } \\
\text { Comparación } \\
\text { Extracción con } \\
\text { sacaleches bilateral } \\
\text { eléctrico }\end{array}$ & 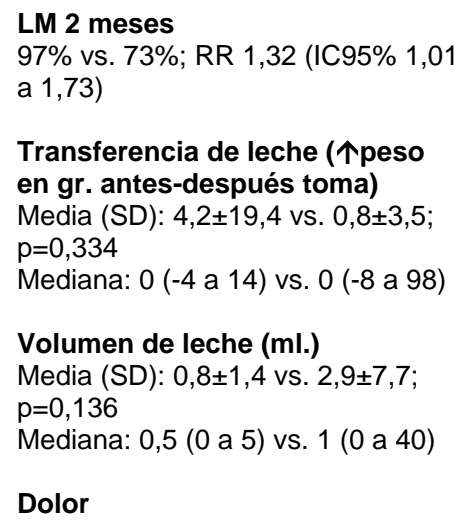 & $\begin{array}{l}\text { Las mujeres asignadas } \\
\text { al grupo de extracción } \\
\text { manual en el posparto } \\
\text { inmediato tenían más } \\
\text { probabilidades continuar } \\
\text { con la LM durante dos } \\
\text { meses }\end{array}$ & $\begin{array}{l}\text { (+) Periodo inmediato posparto } \\
\text { (-) Muestra pequeña, datos finales } \\
\text { de } 48 \text { madres }(70,6 \%) \\
\text { Conflicto de interés } \\
\text { No tiene } \\
\text { Financiación } \\
\text { National Centre for research } \\
\text { resources \& national institute of } \\
\text { children health and human } \\
\text { development } \\
\text { Calidad } \\
\text { Baja }\end{array}$ \\
\hline
\end{tabular}




\begin{tabular}{|c|c|c|c|c|c|c|}
\hline $\begin{array}{l}\text { Referencia } \\
\text { (Cita } \\
\text { Abreviada) }\end{array}$ & $\begin{array}{l}\text { Estudio (Diseño y } \\
\text { objetivo) }\end{array}$ & $\begin{array}{l}\text { Población } \\
\text { (no y } \\
\text { características) }\end{array}$ & $\begin{array}{l}\text { Descripción de las } \\
\text { intervenciones } \\
\text { comparaciones, } \\
\text { exposiciones o pruebas } \\
\text { a estudio }\end{array}$ & $\begin{array}{l}\text { Resultados } \\
\text { (Estimadores de resultados- } \\
\text { Magnitud del efecto) }\end{array}$ & $\begin{array}{l}\text { Conclusiones } \\
\text { (conclusiones) }\end{array}$ & $\begin{array}{l}\text { Comentarios } \\
\text { Calidad de la evidencia Financiación } \\
\text { comentarios) }\end{array}$ \\
\hline & & & & $\begin{array}{l}5,7 \% \text { vs. } 6,1 \% \text {; ns } \\
\text { Formula @ } 1 \text { semana } \\
56,3 \% \text { vs. } 58,6 \% ; \text { ns }\end{array}$ & & \\
\hline
\end{tabular}




\section{ANEXO IV. FOREST PLOTS}

Comparación 1. Extracción vs. no extracción del calostro en la maternidad Transferencia de lecha a los 7-10 días tras el parto

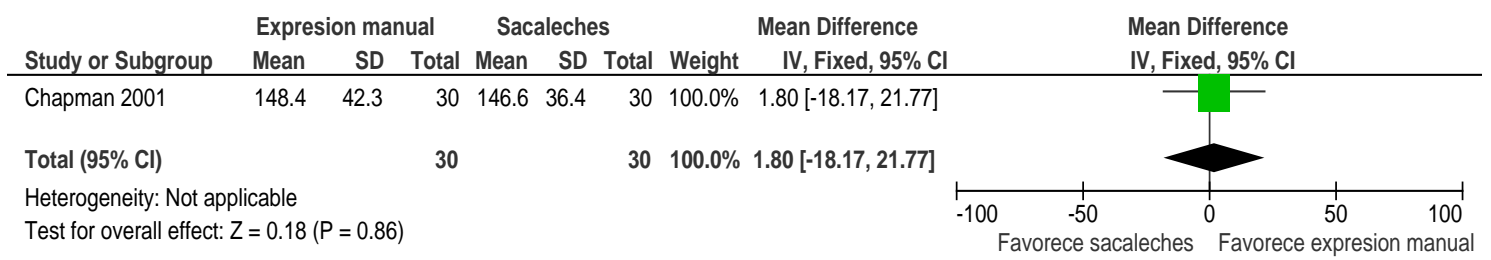

Comparación 1. Extracción vs. no extracción del calostro en la maternidad Duración de la LME

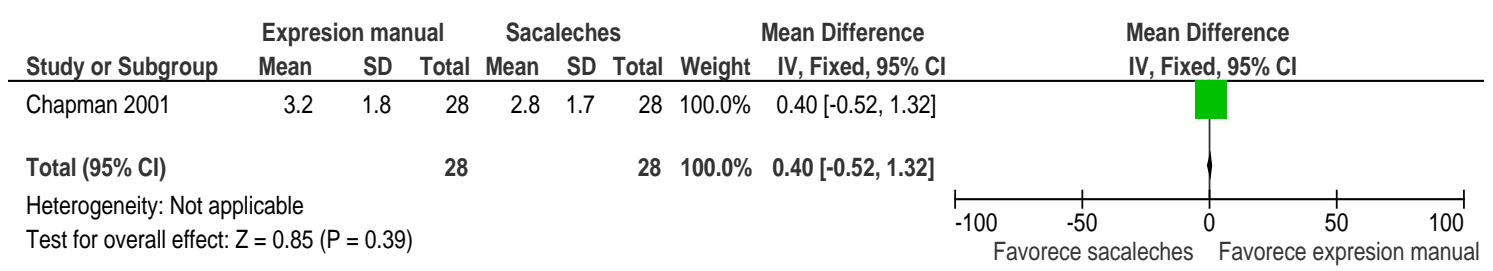

\section{Comparación 2. Extracción manual vs. extracción con sacaleches} Molestias en las mamas

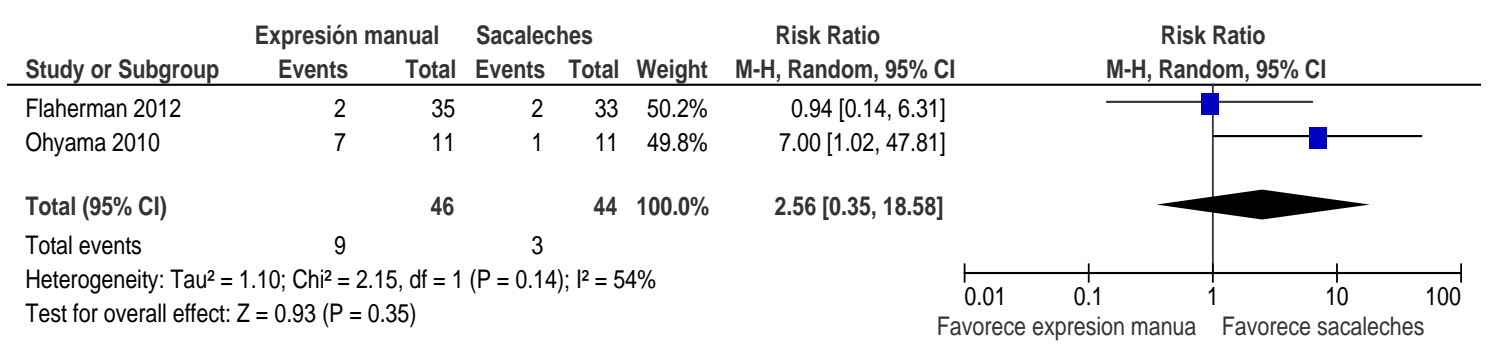

Comparación 2. Extracción manual vs. extracción con sacaleches Lactancia materna a los 2 meses

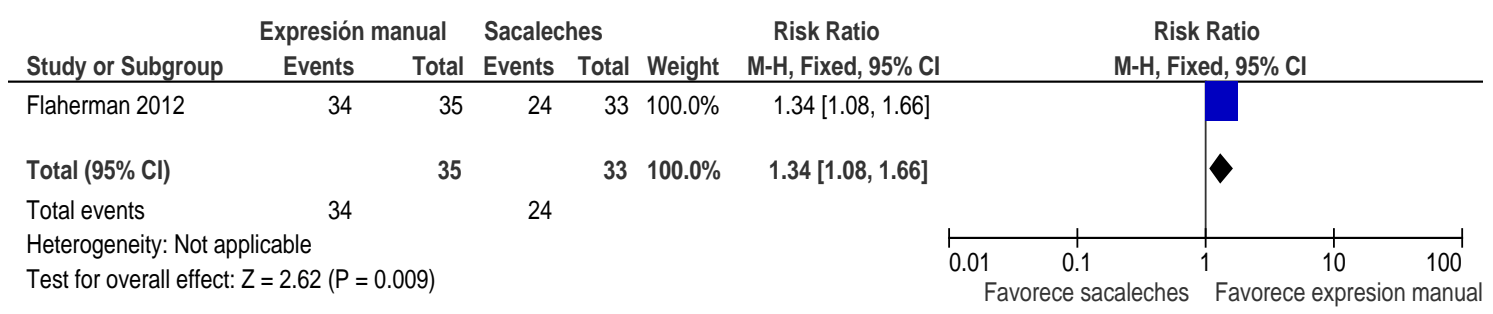




\section{Bibliografía}

(1) Johns HM, Forster DA, Amir LH, McLachlan HL. Prevalence and outcomes of breast milk expressing in women with healthy term infants: a systematic review. BMC pregnancy and childbirth 2013;13(1):212.

(2) Flaherman VJ, Lee HC. "Breastfeeding" by feeding expressed mother's milk. Pediatric Clinics of North America 2013;60(1):227-46.

(3) Becker GE, Remmington S, Remmington T. Early additional food and fluids for healthy breastfed full-term infants. Cochrane Database Syst Rev 2011;(12):CD006462.

(4) NICE. Postnatal care up to 8 weeks after birth. Julio 2006 (actualizado en Febrero de 2015). Disponible en: http://guidance.nice.org.uk/CG37.

(5) Perinatal Services BC. Health Promotion Guideline. Breastfeeding Healthy Term Infants. 2013 Feb.

(6) Riordan J, Wambach K. Breastfeeding and human lactation. Jones \& Bartlett Learning; 2010.

(7) Lawrence RA, Lawrence RM. Breastfeeding, a guide for the medical profession. 2005. Mosby, Philadelphia.

(8) Morton, J A. (2007). Hand expression of breastmilk: Video. Disponible en: http://newborns. tanford.edu/Breastfeeding/ HandExpression.html.

(9) Evans A., Marinelli K.A., Taylor J.S. and The Academy of Breastfeeding Medicine. ABM Clinical Protocol \#2: Guidelines for Hospital Discharge of the Breastfeeding Term Newborn and Mother: "The Going Home Protocol", Revised 2014. Breastfeeding Medicine. Volume 9, Number 1, 2014.

(10) American Academy of Pediatrics and the American College of Obstetrics and Gynecologists. Breastfeeding Handbook for Physicians. Schanler RJ, ed. Elk Grove Village, IL: American Academy of Pediatrics, 2006.

(11) AMERICAN ACADEMY OF PEDIATRICS. Breastfeeding and the Use of Human Milk. Pediatrics 2005 Feb 1;115(2):496-506.

(12) Schanler RJ. Postâ€ $\square$ discharge nutrition for the preterm infant. Acta paediatrica 2005;94(s449):68-73.

(13) Perinatal Services BC Health Promotion Guideline. Breastfeeding Healthy Term Infants. March 2015. Disponible en: http://www.perinatalservicesbc.ca/Documents/Guidelines-

Standards/HealthPromotion/BreastfeedingHealthyTermInfantGuideline.pdf.

(14) Parker LA, Sullivan S, Krueger C, Kelechi T, Mueller M. Effect of early breast milk expression on milk volume and timing of lactogenesis stage II among mothers of very low birth weight infants: a pilot study. Journal of Perinatology 2012;32(3):205-9.

(15) Chapman DJ, Young S, Ferris AM, Pérez-Escamilla R. Impact of breast pumping on lactogenesis stage II after cesarean delivery: a randomized clinical trial. Pediatrics 2001;107(6):e94.

(16) Flaherman VJ, Gay B, cott C, vins A, ee KA, ewman TB. Randomised trial comparing hand expression with breast pumping for mothers of term newborns feeding poorly. Archives of Disease in Childhood-Fetal and Neonatal Edition 2012;fetalneonatal209213.

(17) Ohyama M, Watabe H, Hayasaka $Y$. Manual expression and electric breast pumping in the first $48 \mathrm{~h}$ after delivery. Pediatrics International 2010;52(1):3943. 
GPC Lactancia Materna - Preguntas 11 y 12. Extracción de calostro y métodos de extracción. 


\section{PREGUNTA CLÍNICA № 13}

\section{¿Se debe evitar la administración rutinaria de suplementos al recién nacido amamantado?}

\section{1- Pregunta clínica en formato PICO}

Tabla 1- Componentes de la pregunta clínica en formato PICO

\begin{tabular}{|l|l|}
\hline Pacientes & $\begin{array}{l}\text { Madres de recién nacidos sanos a término que amamantan y } \\
\text { los recién nacidos }\end{array}$ \\
\hline Intervención & $\begin{array}{l}\text { Lactancia materna exclusiva en las primeras semanas } \\
\text { evitando la utilización de suplementos }\end{array}$ \\
\hline Comparación & $\begin{array}{l}\text { Administración de cualquier tipo de suplementos en el niño } \\
\text { amamantado: agua, suero glucosado o sucedáneos de leche } \\
\text { materna como alimentos pre-lácteos (antes de la primera } \\
\text { toma de pecho), suplementos (después de la primera toma } \\
\text { de leche materna) o suplementación con la propia leche } \\
\text { materna }\end{array}$ \\
\hline Resultados & \begin{tabular}{l} 
Tasa de lactancia materna exclusiva al alta (CRITICA) \\
Tasa de lactancia materna exclusiva al mes (CRITICA) \\
Tasa de lactancia materna a los 4 meses (IMPORTANTE) \\
Tasa de lactancia materna exclusiva a los 4 meses \\
(IMPORTANTE) \\
Satisfacción materna (CRITICA) \\
Complicaciones de las mamas (grietas, ingurgitaciones) \\
(IMPORTANTES) \\
$\begin{array}{l}\text { Pérdida ponderal del bebé (48-72h) (CRITICA) } \\
\text { Hipoglucemias (IMPORTANTE) } \\
\text { Frecuencia de tomas (IMPORTANTE) }\end{array}$ \\
\hline Tipo de estudio
\end{tabular} $\begin{array}{l}\text { RS de ECA, ECA, RS de estudios observacionales o } \\
\text { estudios observacionales }\end{array}$ \\
\hline
\end{tabular}

\section{2- Introducción}

La utilización rutinaria de suplementos ha sido una práctica habitual en muchas maternidades intentando favorecer el descanso materno y evitar la pérdida excesiva de peso y la deshidratación en el recién nacido. Esta pregunta se plantea para valorar cómo repercute la administración de los suplementos en la lactancia y cómo apoyar a las madres para evitar su utilización rutinaria. 


\section{ESTRATEGIA DE ELABORACION DE LA PREGUNTA}

\subsection{GPC Base}

Tabla 2- Resumen de GPC Base

\begin{tabular}{|c|c|c|c|c|}
\hline $\begin{array}{c}\text { Guía } \\
\text { (Enfoque) }\end{array}$ & $\begin{array}{l}\text { Resumen sobre la evidencia } \\
\text { (Calidad de la evidencia) }\end{array}$ & $\begin{array}{l}\text { Recomendaciones } \\
\text { (Grado) }\end{array}$ & $\begin{array}{l}\text { Referencias bibliográficas } \\
\text { (Tipo de publicación) }\end{array}$ & Comentarios \\
\hline $\begin{array}{l}\text { NICE_2006 } \\
\text { (Actualiz. } \\
\text { 2011) (1) }\end{array}$ & $\begin{array}{l}\text { - Una revisión sistemática (72) evaluó el efecto de la } \\
\text { alimentación suplementaria durante los primeros días de } \\
\text { la vida en la duración total de lactancia materna y la tasa } \\
\text { de lactancia materna exclusiva entre los lactantes sanos, } \\
\text { donde solo se incluyó un ECA con } 170 \text { bebés. La } \\
\text { conclusión de los autores fue que sigue existiendo una } \\
\text { considerable incertidumbre sobre el efecto de la breve } \\
\text { exposición al agua, los sucedáneos de la leche materna, } \\
\text { o cualquier otro líquido sobre el éxito y la duración de la } \\
\text { lactancia materna. } \\
\text { - Se incluyó un ECA (116) que determina si la asignación } \\
\text { de una alimentación mixta en una clínica de lactancia } \\
\text { materna en la primera semana después del parto } \\
\text { aumentará la lactancia materna exclusiva al mes. } \\
\text { Resultados a las } 4 \text { semanas post- parto indicaron que el } \\
\text { grupo de intervención era más probable que finalizase } \\
\text { con lactancia materna exclusiva y menos probable que } \\
\text { se suplementase con agua y té. } \\
\text { En una RS (Donnelly et al } 2000 \text { ) se observó que la } \\
\text { distribución al alta hospitalaria de los paquetes } \\
\text { comerciales que contienen fórmula artificial o material } \\
\text { promocional para la misma (9 ECA con datos de } 3730 \\
\text { mujeres) parece reducir el número de mujeres que } \\
\text { amamantan exclusivamente a 0-2 semanas, } 3-6 \\
\text { semanas y de } 8 \text { a } 10 \text { semanas, pero no tuvo ningún } \\
\text { efecto significativo a la terminación temprana de la } \\
\text { lactancia materna no exclusiva. }\end{array}$ & $\begin{array}{l}\text { No se recomienda la suplementación con } \\
\text { líquidos diferentes a la leche materna. [C] } \\
\text { No se recomienda administrarse formulas a los } \\
\text { bebés con leche materna en el hospital, a } \\
\text { menos que esté médicamente indicado.[B] } \\
\text { Los paquetes comerciales, que contiene la } \\
\text { leche de fórmula o la publicidad de fórmula no } \\
\text { deben ser distribuidos. [A] } \\
\text { Suplementación - lactancia mediante fórmulas } \\
\text { A todas las madres y cuidadores que están } \\
\text { utilizando suplementos en la alimentación de } \\
\text { sus bebés se les debe ofrecer el asesoramiento } \\
\text { adecuado y adaptado a la alimentación con } \\
\text { fórmula para asegurar que este se lleve a cabo } \\
\text { con la mayor seguridad posible, con el fin de } \\
\text { mejorar el desarrollo infantil y la salud, y } \\
\text { cumplir con las necesidades nutricionales. } \\
\text { [D(GPP)] } \\
\text { Una mujer que desea alimentar a su bebe } \\
\text { mediante fórmula de leche, se les debe } \\
\text { enseñar cómo hacerlo, utilizando alimentos y las } \\
\text { cantidades medidas de la fórmula } \\
\text { correctamente, ya que basa en las instrucciones } \\
\text { del fabricante, y también cómo limpiar y } \\
\text { esterilizar los biberones y las tetinas y cómo } \\
\text { almacenar la leche de fórmula ( } 8 \text { ). [D(GPP)] } \\
\text { Las madres y miembros de la familia deben } \\
\text { saber que la leche, ya sea fórmula o leche } \\
\text { extraída no deben ser calentados en el }\end{array}$ & $\begin{array}{l}72 \text { Szajewska H, Horvath A, Koletzko } \\
\text { B et al. Effects of brief exposure to } \\
\text { water, breast-milk substitutes, or other } \\
\text { liquids on the success and duration of } \\
\text { breastfeeding: a systematic review. } \\
2006 \text {. Acta Paediatrica 95:145-152. } \\
\text { (se basa en Martin 1997) } \\
\text { 116. Hopkinson J and Konefal GM. } \\
\text { Assignment to a hospital-based } \\
\text { breastfeeding clinic and exclusive } \\
\text { breastfeeding among immigrant } \\
\text { Hispanic mothers: a randomized, } \\
\text { controlled trial. Journal of Human } \\
\text { Lactation 2009;25:287-296. (I:+/- } \\
\text { educación para fomentar el EBF + } \\
\text { otras acciones con citas postparto; C: } \\
\text { routine care que incluye regalo de } \\
\text { fórmulas al alta) } \\
\text { Donnelly, A., Snowden, H. M., } \\
\text { Renfrew, M. J., \& Woolridge, M. W. } \\
\text { "Commercial hospital discharge packs } \\
\text { for breastfeeding women," in Cochrane } \\
\text { Database of Systematic Reviews } \\
\text { 2000, Issue 2, Chichester, John Wiley } \\
\text { \& Sons. (Policy, datos institucionales) } \\
\text { 8. Department of Health (2005) Bottle } \\
\text { feeding. London: Department of } \\
\text { Health. Available from: www.dh.gov.uk }\end{array}$ & \\
\hline
\end{tabular}




\begin{tabular}{|c|c|c|c|c|}
\hline $\begin{array}{l}\text { Guía } \\
\text { (Enfoque) }\end{array}$ & $\begin{array}{l}\text { Resumen sobre la evidencia } \\
\text { (Calidad de la evidencia) }\end{array}$ & $\begin{array}{l}\text { Recomendaciones } \\
\text { (Grado) }\end{array}$ & $\begin{array}{l}\text { Referencias bibliográficas } \\
\text { (Tipo de publicación) }\end{array}$ & Comentarios \\
\hline & & $\begin{array}{l}\text { microondas . [C] } \\
\text { Hay que advertir a las mujeres lactantes que } \\
\text { deseen obtener información sobre la forma de } \\
\text { preparar los alimentos con fórmula acerca de } \\
\text { cómo hacer esto. [D(GPP)] }\end{array}$ & & \\
\hline $\begin{array}{l}\text { National } \\
\text { Health and } \\
\text { Medical } \\
\text { Research } \\
\text { Council } \\
\text { (2012) Infant } \\
\text { Feeding } \\
\text { Guidelines. } \\
\text { Canberra: } \\
\text { National } \\
\text { Health and } \\
\text { Medical } \\
\text { Research } \\
\text { Council (2) }\end{array}$ & $\begin{array}{l}\text { La duración de la lactancia se reduce por el uso de } \\
\text { alimentos previos a la lactancia (Evidencia Grado C) } \\
\text { (127). } \\
\text { Ofrecer suplementos - agua, glucosa o fórmula para } \\
\text { niños - cuando no hay ninguna indicación médica, se ha } \\
\text { demostrado que afecta negativamente al éxito del inicio } \\
\text { y mantenimiento de la lactancia.(214, 215) } \\
\text { La alimentación con fórmula en el hospital disminuyó la } \\
\text { probabilidad de lactancia a los } 6 \text { meses de edad (215). } \\
\text { Hay pruebas sugestivas que apoyan la hipótesis de que } \\
\text { el uso de alimentos prelácteos tiene efectos nocivos } \\
\text { sobre la duración de la lactancia (Evidencia Grado } \\
\text { C).(214,215) } \\
\text { No se recomiendan alimentos prelácteos debidos a su } \\
\text { influencia en el inicio de la lactancia y en la morbilidad } \\
\text { perinatal y mortalidad.(444-446) } \\
\text { Las fórmulas a base de leche de vaca son convenientes } \\
\text { para los primeros } 12 \text { meses de vida, a menos que el } \\
\text { bebé no puede tomar productos a base de leche de vaca } \\
\text { por razones médicas, culturales o religiosas, casos en los } \\
\text { que se pueden utilizar fórmulas especiales bajo } \\
\text { supervisión médica. }\end{array}$ & $\begin{array}{l}\text { Alimentación preláctea } \\
\text { - Si se necesita alimentación suplementaria en } \\
\text { el hospital, sólo debería darse por indicaciones } \\
\text { médicas específicas y con el consentimiento de } \\
\text { la madre. } \\
\text { En el marco de la IHAN, paso seis: 'No dar a los } \\
\text { recién nacidos otro alimento o bebida que no } \\
\text { sea leche materna, a menos que esté } \\
\text { médicamente indicado. }\end{array}$ & $\begin{array}{l}\text { 127. W orld Health Organization/ } \\
\text { UNICEF. The Baby-Friendly Hospital } \\
\text { Initiative: Revised, updated and } \\
\text { expanded for integrated care. Geneva: } \\
\text { WHO, 2008. } \\
\text { 214. Fewtrell MS, Lucas A, Morgan } \\
\text { JB. Factors associated with weaning in } \\
\text { full term and preterm infants. Arch Dis } \\
\text { Child Fetal Neonatal Ed } \\
\text { 2003;88(4):F296-301. } \\
\text { 215. Forde KA, Miller LJ. 2006-07 } \\
\text { north metropolitan Perth breastfeeding } \\
\text { cohort study: how long are mothers } \\
\text { breastfeeding? Breastfeed Rev } \\
\text { 2010;18(2):14-24. } \\
\text { 444. Duong DV, Binns CW, Lee AH. } \\
\text { Breast-feeding initiation and exclusive } \\
\text { breast-feeding in rural Vietnam. Public } \\
\text { Health Nutr 2004;7(6):795-9. } \\
\text { 445. Qiu L, Xie X, Lee A, Binns CW. } \\
\text { Infants' first feeds in Hangzhou, PR } \\
\text { China. Asia Pac J Clin Nutr } \\
\text { 2007;16(Suppl. 1):458-61. } \\
\text { 446. X u F, Binns C, Wu J, Yihan R, } \\
\text { Zhao Y, Lee A. Infant feeding practices } \\
\text { in Xinjiang Uygur Autonomous Region, } \\
\text { People's Republic of China. Public } \\
\text { Health Nutr 2007:10(2):198-202. }\end{array}$ & \\
\hline
\end{tabular}


Tabla 3. Resumen de GPC del SNS

\begin{tabular}{|c|c|c|c|c|}
\hline $\begin{array}{l}\text { Guía } \\
\text { (Enfoque) }\end{array}$ & $\begin{array}{l}\text { Resumen sobre la evidencia } \\
\text { (Calidad de la evidencia) }\end{array}$ & $\begin{array}{l}\text { Recomendaciones } \\
\text { (Grado) }\end{array}$ & $\begin{array}{l}\text { Referencias bibliográficas } \\
\text { (Tipo de publicación) }\end{array}$ & Comentarios \\
\hline $\begin{array}{l}\text { IHAN Calidad } \\
\text { en la } \\
\text { asistencia } \\
\text { profesional al } \\
\text { nacimiento y } \\
\text { la lactancia- } \\
2011 \text { (3) }\end{array}$ & $\begin{array}{l}\text { La administración de alimentos prelácteos y de } \\
\text { suplementos en RN sanos a término cuando no existe } \\
\text { justificación médica se asocia con abandono precoz de } \\
\text { la lactancia materna. } \\
\text { En un estudio longitudinal realizado en Israel se objetivó } \\
\text { que los RN que recibían una o más tomas prelácteas } \\
\text { tenían menos probabilidades de recibir LM completa a } \\
\text { las seis semanas (6). } \\
\text { En un estudio transversal que describe la asociación } \\
\text { entre la administración de alimentos prelácteos, tanto de } \\
\text { agua como sucedáneos de leche materna, se concluye } \\
\text { que es un factor de riesgo para el abandono precoz de } \\
\text { la lactancia materna (7). } \\
\text { En un estudio prospectivo realizado con } 521 \text { RN suecos } \\
\text { se encontró una fuerte asociación entre la } \\
\text { administración de suplementos en el hospital y el } \\
\text { abandono de la LM antes de los } 3 \text { meses (12). } \\
\text { La administración de suplementos, particularmente } \\
\text { cuando son más de tres, se asocia significativamente } \\
\text { con el abandono de la LM, independientemente de la } \\
\text { forma de administración (14). }\end{array}$ & $\begin{array}{l}\text { Paso 6. «No dar a los recién nacidos más } \\
\text { que leche materna, sin ningún otro alimento } \\
\text { o bebida, a no ser que esté médicamente } \\
\text { indicado» }\end{array}$ & $\begin{array}{l}\text { 6. Dollberg S, Lahav S, Mimouni FB. A } \\
\text { comparison of intakes of breast-fed and } \\
\text { bottlefed infants during the first two days of } \\
\text { life. J Am Coll Nutr. } 2001 \text { Jun;20(3):209-11. } \\
\text { (7) Pérez-Escamilla R, Segura-Millán S, } \\
\text { Canahuati J, Allen H. Prelacteal feeds are } \\
\text { negatively associated with breast-feeding } \\
\text { outcomes in Honduras. J Nutr. } 1996 \\
\text { Nov;126(11):2765-73. } \\
\text { (12) Blomquist HK, Jonsbo F, Serenius F, } \\
\text { Persson LA. Supplementary feeding in the } \\
\text { maternity ward shortens the duration of } \\
\text { breast feeding. Acta Paediatr 1994; 83: } 1122- \\
6 \\
\text { (14) Howard CR, Howard FM, Lanphear B, } \\
\text { Eberly S, de Blieck EA et al. Randomized } \\
\text { clinical trial of pacifier use and bottle-feeding } \\
\text { or cup feeding and their effect on } \\
\text { breastfeeding. Pediatrics 2003; } 111: 511-518\end{array}$ & \\
\hline
\end{tabular}




\subsection{Revisiones sistemáticas}

Tabla 4- Resumen de RS actuales

\begin{tabular}{|c|c|c|c|c|c|c|}
\hline $\begin{array}{l}\text { Referencia } \\
\text { (Cita } \\
\text { Abreviada) }\end{array}$ & $\begin{array}{l}\text { Estudio (Diseño y } \\
\text { objetivo) }\end{array}$ & $\begin{array}{l}\text { Población } \\
\text { (no y características) }\end{array}$ & $\begin{array}{l}\text { Descripción de } \\
\text { las } \\
\text { intervenciones } \\
\text { comparaciones, } \\
\text { exposiciones o } \\
\text { pruebas a } \\
\text { estudio }\end{array}$ & $\begin{array}{l}\text { Resultados } \\
\text { (Estimadores de resultados-Magnitud del efecto) }\end{array}$ & $\begin{array}{l}\text { Conclusiones } \\
\text { (conclusiones) }\end{array}$ & $\begin{array}{l}\text { Comentarios } \\
\text { Calidad de la } \\
\text { evidencia } \\
\text { Financiación } \\
\text { comentarios) }\end{array}$ \\
\hline Becker 2011 (4) & $\begin{array}{l}\text { Diseño } \\
\text { Metaanálisis ECA } \\
\text { Objetivo } \\
\text { Realizar un } \\
\text { metaanálisis sobre } \\
\text { el efecto beneficioso } \\
\text { y dañino de la } \\
\text { suplementación en } \\
\text { lactantes a término } \\
\text { y examinar la } \\
\text { duración y tipo de } \\
\text { suplementación }\end{array}$ & $\begin{array}{l}6 \text { estudios } \mathrm{N}=814 \text {, en } \\
\text { dos estudios incluían } \\
\text { niños sanos a término }\end{array}$ & $\begin{array}{l}\text { Comparación } \\
\text { entre lactancia } \\
\text { materna exclusiva } \\
\text { y lactancia con } \\
\text { líquidos en el } \\
\text { recién nacido o } \\
\text { sólidos adicionales } \\
\text { en el bebé a partir } \\
\text { de cuatro meses. }\end{array}$ & $\begin{array}{l}\text { Duración de la lactancia materna } \\
\text { Morbilidad infantil: fiebre, nivel plasmático de glucosa, cambio } \\
\text { en el peso } \\
\text { Dos ensayos que presentaban datos de los primeros días } \\
\text { después del nacimiento no indican que la administración de } \\
\text { líquidos adicionales fuera beneficioso. } \\
\text { En la duración de lactancia materna había una diferencia } \\
\text { significativa a favor de la lactancia materna exclusiva hasta la } \\
\text { semana } 20 \text {, siendo el RR de } 1,45 \text { (IC } 95 \% \text { de } 1,05 \text { a } 1,99 \text { ). } \\
\text { Morbilidad infantil ( } 3 \text { ECA), } 1 \text { ECA en recién nacido encontró } \\
\text { una diferencia estadísticamente significativa, pero no } \\
\text { clínicamente relevante en la temperatura a las } 72 \text { horas, y } \\
\text { unos niveles de glucosa en suero mayores en los lactantes } \\
\text { recién nacidos a término sanos amamantados suplementados } \\
\text { con glucosa en su primera alimentación adicional temprana } \\
\text { con líquidos a las } 24 \text { horas, aunque no a las } 48 \text { horas. } \\
2 \text { ECA con lactantes de cuatro a seis meses de edad no } \\
\text { indican ningún beneficio para lactantes suplementados por } 26 \\
\text { semanas, ni los riesgos relacionados con la morbilidad o } \\
\text { cambio de peso. } \\
\text { Ninguno de los ensayos informó sobre los la mortalidad infantil } \\
\text { o la ictericia fisiológica }\end{array}$ & $\begin{array}{l}\text { No fue posible evaluar } \\
\text { plenamente los } \\
\text { beneficios o riesgos de } \\
\text { la suplementación ni } \\
\text { determinar el impacto } \\
\text { del momento y el tipo } \\
\text { de suplementación. } \\
\text { El uso breve de agua } \\
\text { adicional o agua con } \\
\text { glucosa no mostró } \\
\text { beneficios para los } \\
\text { recién nacidos, y se } \\
\text { observan posibles } \\
\text { efectos negativos } \\
\text { sobre la duración de la } \\
\text { lactancia materna. } \\
\text { Para los niños de } \\
\text { cuatro a seis meses, } \\
\text { no se encontraron } \\
\text { beneficios de los } \\
\text { alimentos adicionales } \\
\text { ni cualquier riesgo } \\
\text { relacionado con la } \\
\text { morbilidad o cambio } \\
\text { de peso. }\end{array}$ & $\begin{array}{l}\text { RS de } \\
\text { buena } \\
\text { calidad }\end{array}$ \\
\hline
\end{tabular}




\subsection{Resumen de GPCs base y RSs disponibles}

La guía de NICE (1) recomienda seguir los pasos de la iniciativa del hospital amigo de los niños y con ella el paso número 6 , donde se recomienda no dar suplementación con líquidos diferentes a la leche materna en general y no administrar formulas a los recién nacidos amamantados con leche materna durante la estancia hospitalaria, a menos que esté médicamente indicado. Se trata de recomendaciones basadas en los resultados de dos ECA recogidos en sendas $\mathrm{RS}$. También se realiza una recomendación de no distribuir paquetes comerciales que contengan leche de fórmula o publicidad de fórmula, basándose en una RS que incluye 9 ECA.

En la guía del Perinatal Care Services (5) no se evalúa esta cuestión, por lo que hemos resumido los resultados de la GPC sobre lactancia australiana (2), que también se adhiere a las recomendaciones de la iniciativa IHAN, apoyándose en estudios observacionales realizados en Asia.

En el documento del IHAN (3) sobre Cuidados en el Nacimiento recoge paso 6 de «No dar a los recién nacidos más que leche materna, sin ningún otro alimento o bebida, a no ser que esté médicamente indicado» y resume la evidencia procedente de estudios observacionales y descriptivos europeos y del oriente medio, así como en un ensayo cuasiexperimental.

En todas las guías se recomienda en contra de la utilización de suplementos durante la estancia hospitalaria, a menos que exista una justificación médica, basándose en diferentes estudios observacionales y ECA.

En la búsqueda preliminar de revisiones se ha identificado una revisión sistemática publicada en 2011, cuyo objetivo era realizar un metaanálisis sobre el efecto beneficioso y dañino de la suplementación en lactantes a término y examinar la duración y tipo de suplementación (4)

En la revisión sistemática se incluyeron 6 estudios $(\mathrm{N}=814)$. Dos de ellos incluían niños sanos a término, población de interés para nuestra pregunta clínica. El estudio realiza un análisis de comparación entre lactancia materna exclusiva y lactancia con líquidos o sólidos adicionales en el recién nacido a partir de cuatro meses. En relación a desenlaces sobre lactancia y, concretamente, a la duración de la misma, se observa una diferencia significativa a favor de la lactancia materna exclusiva hasta la semana 20. En la revisión finalmente se concluye que el uso breve de agua adicional o de agua con glucosa no muestra beneficios para los recién nacidos, observándose posibles efectos negativos sobre la duración de la lactancia materna.

En la búsqueda preliminar también se ha identificado otra revisión sistemática publicada en 2012 (6), cuyo objetivo era evaluar los efectos publicados en ECA y estudios observacionales sobre la lactancia materna exclusiva durante seis meses, la lactancia materna exclusiva durante tres y cuatro meses y lactancia mixta (introducción de líquidos o alimentos sólidos complementarios con la lactancia) hasta los seis meses sobre la salud infantil, el crecimiento y el desarrollo, y en la salud materna, aunque finalmente no utilizada para responder a esta pregunta debido a que no contempla resultados sobre lactancia de nuestro interés. 


\subsection{Conclusión (marcar con una X):}

\begin{tabular}{|l|l|}
\hline $\mathrm{X}$ & Adopción GPC/Revisión sistemática \\
\hline & Elaboración parcial \\
\hline & Elaboración de novo \\
\hline
\end{tabular}

\subsection{Diseño de la estrategia de búsqueda de estudios individuales}

\begin{tabular}{|l|l|}
\hline Criterios de selección de estudios & ECA, estudios de cohortes \\
\hline Período de búsqueda & $2010-$ Marzo 2014 \\
\hline Bases de datos & Co6-2012 \\
\hline & Cochrane Library \\
& MEDLINE, via Pubmed \\
& EMBASE, via Ovid \\
& Cinahl, via EBSCOhost databases \\
& PsylNFO, via OVID \\
\hline
\end{tabular}

Ver estrategias de búsqueda de estudios originales en el ANEXO I. 


\section{4- Resumen de la evidencia (Tablas de estudios individuales y valoración de calidad en el ANEXO X)}

\section{1- GRADE Evidence Profile}

Comparación 1: Lactancia exclusiva vs. Lactancia no exclusiva

Bibliografía: Becker 2011 (4) + Howard 2003 (7)

\begin{tabular}{|c|c|c|c|c|c|c|c|c|c|c|c|c|}
\hline \multirow{2}{*}{\multicolumn{7}{|c|}{ Evaluación de la calidad }} & \multicolumn{4}{|c|}{ Resumen de los Resultados } & \multirow[b]{3}{*}{ Calidad } & \multirow[b]{3}{*}{ Importancia } \\
\hline & & & & & & & \multicolumn{2}{|c|}{ № de pacientes } & \multicolumn{2}{|c|}{ Magnitud del efecto } & & \\
\hline $\begin{array}{c}\text { № de } \\
\text { estudios }\end{array}$ & Diseño & $\begin{array}{c}\text { Riesgo de } \\
\text { sesgo }\end{array}$ & Inconsistencia & $\begin{array}{l}\text { Evidencia } \\
\text { indirecta }\end{array}$ & Imprecisión & $\begin{array}{c}\text { Otras } \\
\text { consideraciones }\end{array}$ & $\begin{array}{c}\text { Lactancia } \\
\text { materna } \\
\text { exclusiva } \\
\text { (evitar } \\
\text { suplementos) } \\
\end{array}$ & $\begin{array}{c}\text { Uso } \\
\text { temprano de } \\
\text { suplemento }\end{array}$ & $\begin{array}{l}\text { Relativa } \\
(95 \% \mathrm{Cl})\end{array}$ & Absoluta por 1000 & & \\
\hline \multicolumn{13}{|c|}{ Proporción de niños lactantes a los 3 meses } \\
\hline 11 & ECA & No serio ${ }^{2}$ & No seria & No seria & Seria $^{3}$ & Poco probable & $\begin{array}{c}65 / 87 \\
(74,7 \%) \\
\end{array}$ & $\begin{array}{c}42 / 83 \\
(50,6 \%) \\
\end{array}$ & $\begin{array}{l}\text { RR } 1,48 \text { (de } \\
1,16 \text { a } 1,89) \\
\end{array}$ & $\begin{array}{l}243 \text { más de } 1000 \\
\text { (de } 81 \text { a } 450 \text { más) }\end{array}$ & MODERADA & CRITICA \\
\hline \multicolumn{13}{|c|}{ Duración de lactancia materna (en cualquier tiempo, durante 52 semanas) } \\
\hline $11^{4}$ & ECA & No serio & No seria & No seria $^{5}$ & Seria $^{3}$ & Poco probable & 216 & 481 & $\begin{array}{c}\text { HR } 1,53^{6} \\
\text { (de } 1,24 \text { a } 1,89 \text { ) }\end{array}$ & $\mathrm{N} / \mathrm{A}$ & MODERADA & CRITICA \\
\hline \multicolumn{13}{|c|}{ Duración de lactancia materna exclusiva (en cualquier tiempo, durante 52 semanas) } \\
\hline $11^{4}$ & ECA & No serio & No seria & No seria ${ }^{5}$ & Seria ${ }^{3}$ & Poco probable & 216 & 481 & $\begin{array}{c}\text { HR } 1,49^{6} \\
\text { (de } 1,23 \text { a } 1,80 \text { ) }\end{array}$ & $\mathrm{N} / \mathrm{A}$ & MODERADA & CRITICA \\
\hline \multicolumn{13}{|c|}{ Diferencia de peso $(\mathrm{g})(6 \mathrm{~h}, 12 \mathrm{~h}, 24 \mathrm{~h}, 48 \mathrm{~h}, 72 \mathrm{~h})$} \\
\hline 11 & ECA & No serio ${ }^{2}$ & No seria & No seria & Muy Seria ${ }^{7}$ & Poco probable & 87 & 83 & & \begin{tabular}{|c|} 
DM $-3,00$ (de $-26,83$ \\
a 20,83$)$
\end{tabular} & BAJA & IMPORTANTE \\
\hline \multicolumn{13}{|c|}{ Número de episodios de Hipoglucemia (definido como glucosa sérica $<2,2 \mathrm{mmol} / \mathrm{L}$ ) a las $48 \mathrm{~h}$ postnatales } \\
\hline 11 & ECA & No serio ${ }^{2}$ & No seria & No seria & Muy Seria ${ }^{3}$ & Poco probable & $\begin{array}{c}3 / 87 \\
(3,4 \%)\end{array}$ & $\begin{array}{c}1 / 83 \\
(1,2 \%)\end{array}$ & $\begin{array}{c}\text { RR 2,86 } \\
\text { (de } 0,30 \text { a } \\
26,97 \text { ) }\end{array}$ & $\begin{array}{c}227 \text { más de } 1000 \\
\text { (de } 8 \text { menos a } 313 \\
\text { más) }\end{array}$ & BAJA & IMPORTANTE \\
\hline
\end{tabular}

1. Martin-Calama $1998{ }^{2}$. Cierto riesgo por riesgo de sesgo no claro ${ }^{3}$. Pocos eventos y/o tamaño mediano-pequeño ${ }^{4}$. Howard $2003 .{ }^{5}$ también incluidos recién nacidos a las 36 semanas de embarazo. Razones para la suplementación: $51 \%$ demanda materna, $33 \%$ indicación médica por $>10 \%$ de pérdida de peso e hipoglucemia, $16 \%$ desconocido. ${ }^{6}$. A favor de lactancia exclusiva, sin suplementación; ${ }^{7}$ estimación de un posible efecto tanto deseado como no deseado, pequeño tamaño muestral. 


\section{2- Resumen de la Evidencia}

Se utilizó como base de la evidencia la RS publicada en 2011 (4), aunque también se realizó una actualización de la búsqueda de nuevos estudios publicados hasta la actualidad. La RS seleccionada (4) excluyó un ECA (7) por incluir recién nacidos a término, que en este caso sí se ha incluido para responder a nuestra pregunta, puesto que el criterio de inclusión comprendía a niños sanos lactantes desde la semana 36 hasta 42, considerando como válida su representatividad para responder a esta pregunta.

La revisión de Becker (4) considera como desenlaces principales la duración de lactancia, incidencia de la morbilidad infantil (infecciones gastrointestinales, de oído, asma y eczema), mortalidad e ictericia. Y como desenlaces secundarios, el cambio en el peso, la duración de la estancia hospitalaria, la satisfacción materna y los niveles de bilirrubina sérica.

En un ECA publicado en 1997 que incluía 170 participantes (8) se observó que la proporción de niños lactantes a los 3 meses era favorable al grupo de lactancia materna exclusiva en comparación con el de lactancia mixta, que incluía suplementación con agua glucosada en los tres primeros días postnatales además de la lactancia materna, RR 1.48 (IC 95\% de 1,16 a 1,89), con 243 recién nacidos más por 1000 amantados a los 3 meses en el grupo de lactancia exclusiva (IC95\% de 81 a 450 más por 1000). En el ECA excluido en la RS (7) y que ha sido tenido en cuenta, se muestra una mayor duración de lactancia materna y de lactancia materna exclusiva en el grupo de recién nacidos que no recibieron suplementación, siendo el HR de 1,53 (IC9\% de 1,24 a 1,89) y 1,49 (IC95\% de 1,23 a 1,80), respectivamente.

Por otro lado y en relación a resultados de seguridad temprana, el ECA publicado en 1997 (8) no mostró diferencias entre las poblaciones de estudio en relación a la diferencia de peso $(\mathrm{g})$ a las $72 \mathrm{~h}$, siendo la DM de $-3,00$ (IC95\% de $-26,83$ a 20,83) y en el número de episodios de hipoglucemia a las $48 \mathrm{~h}$ postnatales (definido como glucosa sérica $<2,2 \mathrm{mmol} / \mathrm{L}$ ) de RR 2,86 (IC95\% de 0,30 a 26,97).

Calidad moderada

\section{Calidad} moderada

\section{Calidad baja Calidad baja}

Cabe mencionar la identificación de estudios observacionales prospectivos (9-11) publicados recientemente, no resumidos en la tabla de perfil de evidencia GRADE, aunque referidos en las tablas de estudios individuales (ver Anexos), que muestran resultados en la misma dirección que las observadas en los ECA contemplados.

\section{Resultados de la actualización de la búsqueda a octubre de 2016}

En la actualización de la búsqueda se ha identificado la actualización de la revisión Cochrane utilizada para responder a esta pregunta (4). En esta actualización (12) se incluyen dos estudios (13;14) que evalúan el efecto de administrar $10 \mathrm{ml}$ de fórmula mediante jeringa tras cada toma en lactantes que pierden un 5\% o más de peso en las primeras $24-48 \mathrm{~h}$ de vida. En estos estudios se presta apoyo a la lactancia materna, aunque a ninguna madre se le ofrecen alternativas como observación y mejora de la técnica de lactancia, extracción manual del calostro etc. Lo 
que concluyen ambos estudios es que la suplementación temprana limitada en niños que han perdido el $5 \%$ de peso o más en las primeras 24-48h obtiene mayores tasas de lactancia materna (incluida lactancia materna exclusiva) a la semana y a largo plazo, aunque los mismos autores de la revisión Cochrane señalan que existen dudas en cuanto a la calidad de estos dos ensayos y que no se puede recomendar un cambio en la práctica habitual en base a sus resultados.

ACTUALIZADO A FECHA DE: 31 de Octubre de 2016 


\section{5- De la evidencia a la recomendación (Tabla de EtR)}

\section{¿Se debe evitar la administración rutinaria de suplementos al recién nacido amamantado?}

Población: Madres de bebés sanos nacidos a término que amamantan y sus bebés

Intervención: Lactancia materna exclusiva, evitando la suplementación

Comparación: Administración de cualquier tipo de suplementos en el niño amamantado

Perspectiva: Clínica

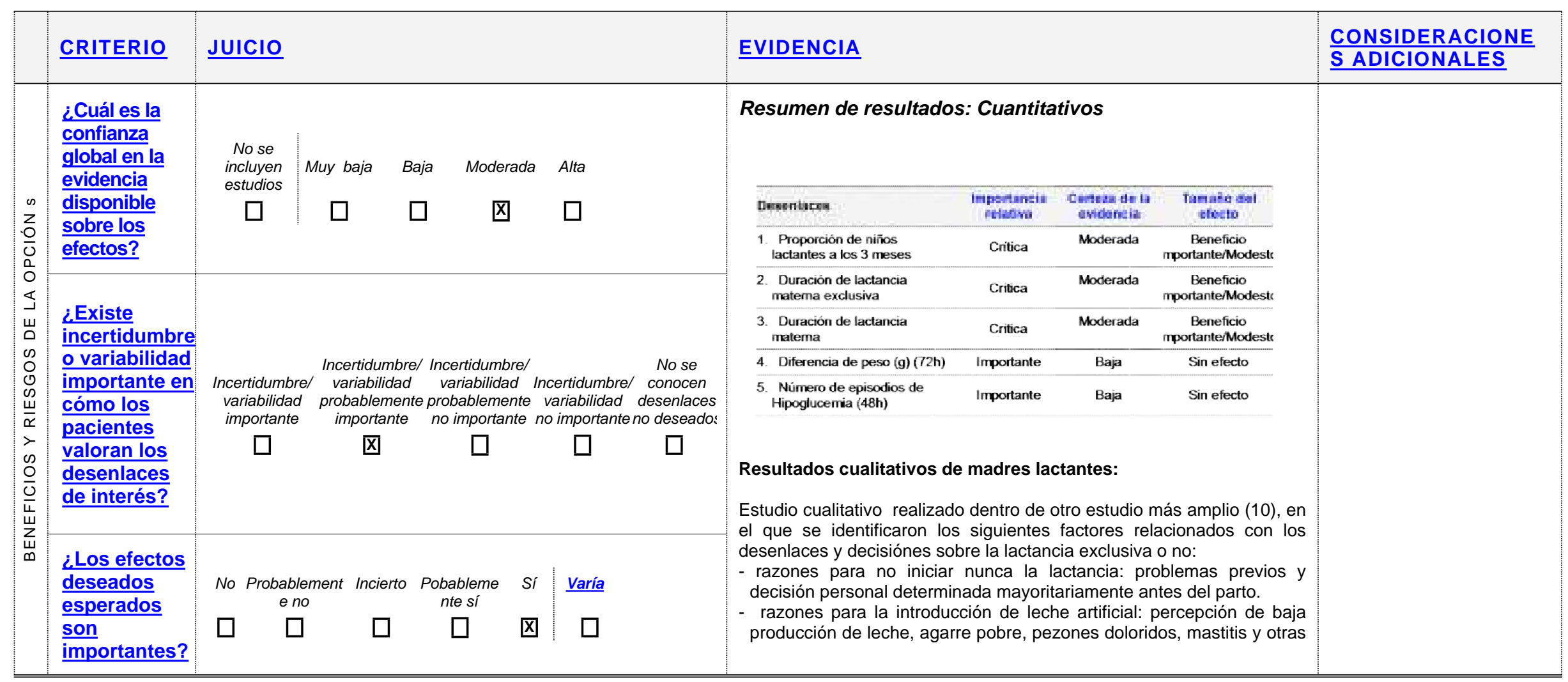




\begin{tabular}{|c|c|c|c|c|c|c|c|c|}
\hline & CRITERIO & JUICIO & & & & & EVIDENCIA & $\frac{\text { CONSIDERACIONE }}{\text { SADICIONALES }}$ \\
\hline & $\begin{array}{l}\text { ¿Los } \\
\text { efectos no } \\
\text { deseados } \\
\text { esperados } \\
\text { son } \\
\text { pequeños? }\end{array}$ & $\begin{array}{c}\text { No Probablement } \\
\text { eno } \\
\square \quad \square\end{array}$ & $\begin{array}{c}\text { Incierto } \\
\square\end{array}$ & $\begin{array}{c}\text { Pobablemente } \\
\text { sí } \\
\text { 囚 }\end{array}$ & $\begin{array}{l}\text { sí } \\
\square\end{array}$ & $\frac{\text { Varía }}{\square}$ & infeciones y recien nacidos pretermino o con ictericia. & \\
\hline & $\begin{array}{l}\frac{\text { ¿El balance }}{\text { entre los }} \\
\text { efectos } \\
\text { deseados y } \\
\frac{\text { no }}{\text { deseados }} \\
\text { favorece la } \\
\text { opción? }\end{array}$ & $\begin{array}{c}\text { No Probablement } \\
\text { eno } \\
\square \quad \square\end{array}$ & $\begin{array}{c}\text { Incierto } \\
\square\end{array}$ & $\begin{array}{c}\text { Pobablemente } \\
\text { sí } \\
\square\end{array}$ & \begin{tabular}{l|} 
si \\
囚
\end{tabular} & $\frac{\text { Varía }}{\square}$ & & \\
\hline $\begin{array}{l}0 \\
0 \\
0 \\
\text { D } \\
\\
0 \\
0\end{array}$ & $\begin{array}{l}\frac{\text { ¿Los }}{\text { recursos }} \\
\text { que se } \\
\text { requieren } \\
\text { son bajos? }\end{array}$ & $\begin{array}{c}\text { No Probablemente } \\
\text { no } \\
\square \quad \square\end{array}$ & $\begin{array}{c}\text { Incierto } \\
\square\end{array}$ & $\begin{array}{c}\text { Pobablemente } \\
\text { sí } \\
\square\end{array}$ & $\begin{array}{l}\text { Sí } \\
\text { 凶 }\end{array}$ & $\frac{\underline{\text { Varía }}}{\square}$ & & $\begin{array}{l}\text { La no } \\
\text { suplementación } \\
\text { implica un menor } \\
\text { uso de recursos. }\end{array}$ \\
\hline 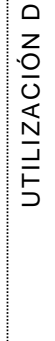 & $\begin{array}{l}\frac{\text { ¿El coste }}{\text { increment }} \\
\text { al es } \\
\text { pequeño } \\
\text { en } \\
\text { relación a } \\
\frac{\text { los }}{\text { beneficios }} \\
\text { netos? }\end{array}$ & $\begin{array}{l}\text { No Probablemente } \\
\text { no } \\
\square \quad \square\end{array}$ & $\begin{array}{c}\text { Incierto } \\
\square\end{array}$ & $\begin{array}{c}\text { Pobablemente } \\
\text { sí } \\
\square\end{array}$ & $\begin{array}{l}\text { Si } \\
\text { 囚 }\end{array}$ & $\frac{\underline{\text { Varía }}}{\square}$ & & \\
\hline
\end{tabular}




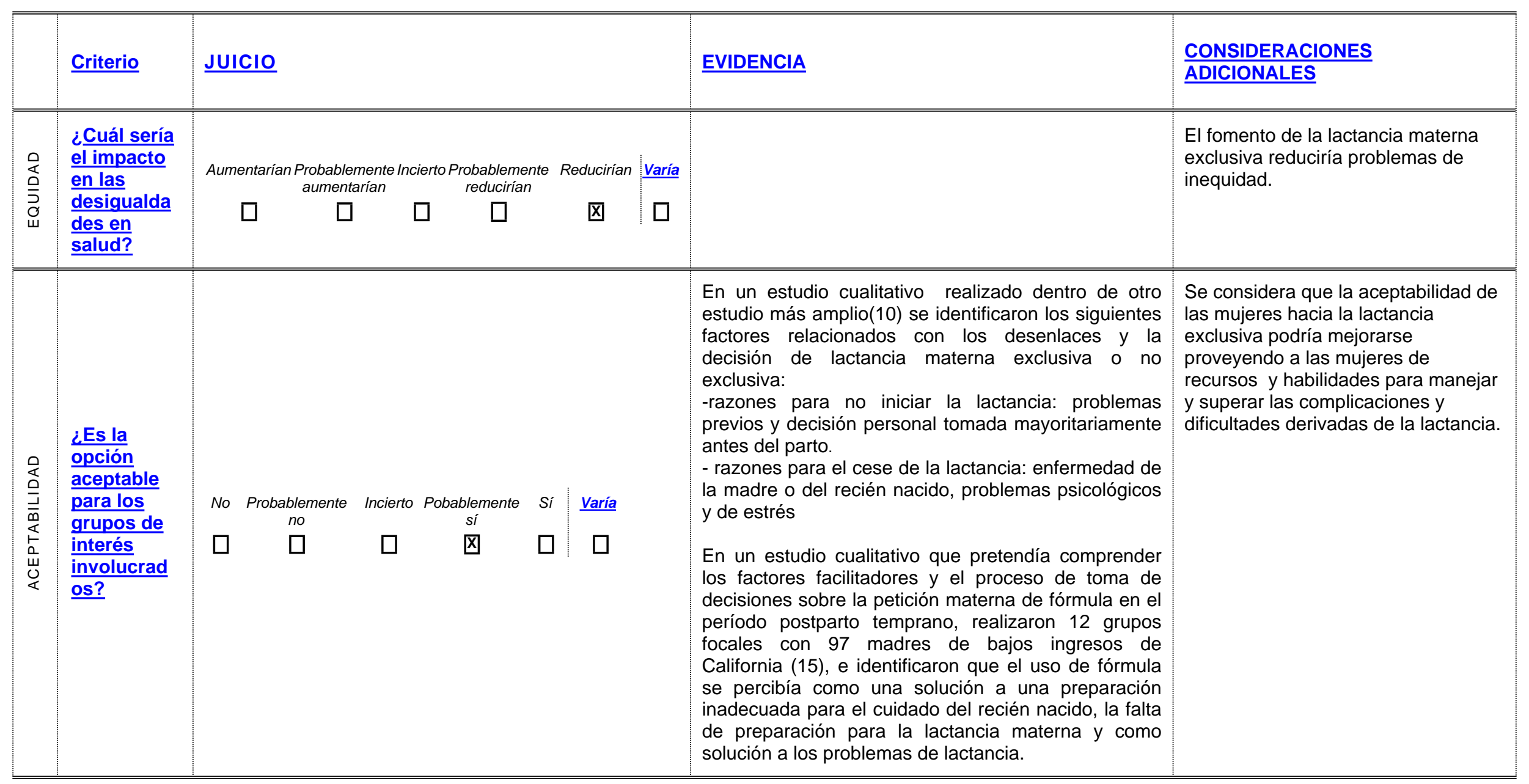




\begin{tabular}{|c|c|c|c|c|c|c|c|c|}
\hline 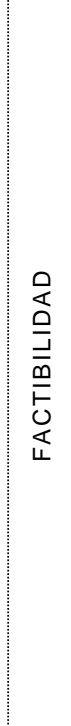 & $\begin{array}{l}\frac{\text { ¿La }}{\text { implementa }} \\
\text { ción de la } \\
\text { opción es } \\
\text { factible? }\end{array}$ & & $\begin{array}{c}\text { Probablemente } \\
\text { no } \\
\square\end{array}$ & $\begin{array}{c}\text { Incierto Pobablemente } \\
\text { si } \\
\square \\
\square\end{array}$ & $\square$ & $\frac{\underline{\text { Varía }}}{\square}$ & $\begin{array}{l}\text { Datos cualitativos de un estudio de } 2012 \text { (10) } \\
\text { realizado en una cohorte de más de } 5.000 \text { madres } \\
\text { lactantes muestran 'que un mayor soporte e } \\
\text { información hubiesen ayudado a las mujeres a seguir } \\
\text { con la lactancia' } \\
\text { Un estudio cualitativo de } 2014 \text { (15), con } 12 \text { grupos } \\
\text { focales y } 97 \text { participantes de bajos ingresos en } \\
\text { California, identifico que las decisiones sobre la } \\
\text { alimentación del recién nacido estaban influenciadas } \\
\text { por entender la fórmula como una solución a los } \\
\text { problemas de lactancia, una preparación inadecuada } \\
\text { para el cuidado del recién nacido (la necesidad de } \\
\text { descanso y las expectativas poco realistas sobre la } \\
\text { conducta infantil) y la falta de preparación para el } \\
\text { proceso de la lactancia. } \\
\text { Otros dos estudio transversales coinciden en } \\
\text { reportar similares razones para el fallo de la } \\
\text { lactancia materna exclusiva ( (16), (17)) }\end{array}$ & $\begin{array}{l}\text { Sería necesario garantizar desde las } \\
\text { etapas del embarazo que las mujeres } \\
\text { reciben la información necesaria para } \\
\text { el éxito y el mantenimiento de la } \\
\text { lactancia materna exclusiva. }\end{array}$ \\
\hline
\end{tabular}

\begin{tabular}{|c|c|c|c|c|c|}
\hline \multirow[t]{2}{*}{$\begin{array}{l}\text { Balance de las } \\
\text { consecuencias } \\
\end{array}$} & $\begin{array}{l}\text { Las consecuencias no } \\
\text { deseadas superan } \\
\text { claramente las } \\
\text { consecuencias deseadas } \\
\text { en la mayoría de los } \\
\text { escenarios }\end{array}$ & $\begin{array}{l}\text { Las consecuencias no } \\
\text { deseadas probablemente } \\
\text { superan las } \\
\text { consecuencias deseadas } \\
\text { en la mayoría de los } \\
\text { escenarios }\end{array}$ & $\begin{array}{c}\text { El balance entre las } \\
\text { consecuencias deseadas y } \\
\text { no deseadas está muy } \\
\text { equilibrado o es incierto }\end{array}$ & $\begin{array}{l}\text { Las consecuencias } \\
\text { deseadas } \\
\text { probablemente superan } \\
\text { las consecuencias no } \\
\text { deseadas en la mayoría } \\
\text { de los escenarios }\end{array}$ & $\begin{array}{c}\text { Las consecuencias } \\
\text { deseadas claramente } \\
\text { superan las } \\
\text { consecuencias no } \\
\text { deseadas en la mayoría } \\
\text { de los escenarios }\end{array}$ \\
\hline & $\square$ & $\square$ & $\square$ & 凶 & $\square$ \\
\hline
\end{tabular}




\section{Recomendación \\ (Texto)}

\section{Justificación}

\section{Consideraciones de}

subgrupos

Consideraciones para la implementación

Para conseguir una adecuada adhesión a esta recomendación, es importante garantizar que las mujeres reciban la información y el apoyo necesario para resolver las dificultades que pueden presentarse con la lactancia.

\section{Monitorización y}

evaluación

\section{Prioridades para la}

investigación

\section{Recomendación fuerte en contra}

Se recomienda evitar la administración de suplementos si no existe indicación médica que lo justifique.

La evidencia de moderada calidad apunta a que la lactancia exclusiva, en comparación con la administración de suplementos durante el periodo postparto temprano favorece el inicio y mantenimiento de la lactancia sin comprometer la seguridad del recién nacido.

Son necesarios estudios que evalúen la relación entre el uso de alimentación preláctea/suplementación durante la estancia hospitalaria y la iniciación y duración de la lactancia materna. 


\section{ANEXO I, ESTRATEGIAS DE BÚSQUEDA}

\section{Cochrane Library}

\section{Searched 14/03/2014}

\section{Updated search 14/03/2014 a 20/10/2014}

\#1 MeSH descriptor: [Milk, Human] explode all trees 707

\#2 "breast milk" or breast-milk or (breast and milk) 1608

\#3 MeSH descriptor: [Breast Feeding] explode all trees 1212

\#4 breastfeeding or "breast feeding" or breastfeed or "breast feed" or breastfed or "breast fed" 3375

\#5 MeSH descriptor: [Lactation] explode all trees 439

\#6 lactation 1458

\#7 \#1 or \#2 or \#3 or \#4 or \#5 or \#6 4827

\#8 MeSH descriptor: [Infant Nutritional Physiological Phenomena] explode all trees 1767

\#9 MeSH descriptor: [Infant Formula] explode all trees 353

\#10 MeSH descriptor: [Food, Formulated] explode all trees 1013

\#11 MeSH descriptor: [Dietary Supplements] explode all trees 6564

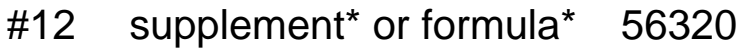

\#13 \#8 or \#9 or \#10 or \#11 or \#12 57883

\#14 \#7 and \#13 3096

\#15 MeSH descriptor: [Infant] explode all trees 12656

\#16 \#14 and \#15 Publication Date from 2012 to $2014 \quad 117$

\section{MEDLINE, via Pubmed}

\section{Searched 14/03/2014}

\section{Updated search 14/03/2014 a 20/10/2014}

\#1 "Milk, Human"[Mesh]

\#2 "breast milk"[All Fields] OR "breast milks"[All Fields] OR "human milk"[All Fields]

\#3 $\quad$ "Breast Feeding"[Mesh]

\#4 "breast feeding"[All Fields] OR "breastfeeding"[All Fields] OR "breast feed"[All Fields] "breast feeding"[All Fields] OR "breastfeed"[All Fields] OR "breast fed"[All Fields] OR breastfed[All Fields] "lactation"[MeSH Terms] OR "lactation"[All Fields]

\#6 \#1 OR \#2 OR \#3 OR \#4 OR \#5

\#7 $\quad$ "Infant Nutritional Physiological Phenomena"[Mesh]

\#8 "Infant Formula"[Mesh]

\#9 "Food, Formulated"[Mesh]

\#10 "Dietary Supplements"[Mesh]

$\# 11$ (supplement ${ }^{\star}$ OR formula*)

\#12 \#7 OR \#8 OR \#9 OR \#10 OR \#11

\#13 \#6 AND \#12

\#14 \#13 Filters: Systematic Reviews; Clinical Trial; Publication date from 2012/01/01 to 2014/12/31; Infant: birth-23 months; Newborn: birth-1 month; Field: Title/Abstract $\mathbf{3 3 7}$ 


\section{CINAHL, via EBSCOhost databases}

\section{Searched 14/03/2014}

\section{Updated search 14/03/2014 a 20/10/2014}

\#1 (MH "Milk, Human") 2523

\#2 "breast milk" OR "breast milks" OR "human milk" 2115

\#3 (MH "Breast Feeding") 11378

\#4 "breast feeding" OR breastfeeding OR "breast feed" OR breastfeed OR "breast fed" OR breastfed 14132

\#5 (MH "Lactation") 1548

\#6 lactation 2887

\#7 \#1 OR \#2 OR \#3 OR \#4 OR \#5 OR \#6 16616

\#8 (MH "Infant Nutritional Physiology") 339

\#9 (MH "Infant Formula") OR (MH "Infant Feeding, Supplemental") 2176

\#10 (MH "Food, Formulated") OR (MH "Dietary Supplements") 8304

\#11 supplement ${ }^{*}$ OR formula* 51711

\#12 \#8 OR \#9 OR \#10 OR \#1151908

\#13 \#7 AND \#12 2768

\#14 \#13 Limitadores - Fecha de publicación: 20120101-20141231; Grupos de edad: Infant, Newborn: birth-1 month, Infant: 1-23 months 65

\section{EMBASE, via Ovid}

Searched 14/03/2014

\section{Updated search 14/03/2014 a 20/10/2014}

\#1 breast milk/ 19514

\#2 ("breast milk" or "breast milks" or "human milk").ti,ab. 17640

\#3 \#1 or \#2 25388

\#4 breast feeding/ or lactation/ 69785

\#5 ("breast feeding" or breastfeeding or "breast feed" or breastfeed or "breast fed" or breastfed or lactation).ti,ab. 57580

\#6 \#4 or \#5 85454

\#7 \#3 or \#6 98607

\#8 artificial milk/ 9174

\#9 infant nutrition/ 10445

\#10 elemental diet/ 2703

$\# 11$ diet supplementation/ 61837

\#12 \#8 or \#9 or \#10 or \#11 81652

\#13 (supplement ${ }^{*}$ or formula*).ti,ab. 481836

\#14 (food $^{\star}$ or feed ${ }^{\star}$ or diet $^{\star}$ ).ti,ab. 958620

\#15 \#13 and \#14 99135

\#16 \#12 or \#15 147596

\#17 \#7 and \#16 16759

\#18 limit \#17 to (yr="2012 - 2014" and infant <to one year>) 200 


\section{ANEXO II, Tabla de estudios individuales para la pregunta}

\begin{tabular}{|c|c|c|c|c|c|c|}
\hline $\begin{array}{l}\text { Referencia } \\
\text { (Cita } \\
\text { Abreviada) }\end{array}$ & $\begin{array}{l}\text { Estudio (Diseño y } \\
\text { objetivo) }\end{array}$ & $\begin{array}{l}\text { Población } \\
\text { (no y características) }\end{array}$ & $\begin{array}{l}\text { Descripción de las intervenciones } \\
\text { comparaciones, exposiciones o } \\
\text { pruebas a estudio }\end{array}$ & $\begin{array}{l}\text { Resultados } \\
\text { (Estimadores de resultados-Magnitud del } \\
\text { efecto) }\end{array}$ & $\begin{array}{l}\text { Conclusiones } \\
\text { (conclusiones) }\end{array}$ & $\begin{array}{l}\text { Comentarios } \\
\text { Calidad de la } \\
\text { evidencia } \\
\text { Financiación } \\
\text { comentarios) }\end{array}$ \\
\hline $\begin{array}{l}\text { Martin Calama } \\
1997(8)\end{array}$ & $\begin{array}{l}\text { Diseño: ECA } \\
\text { Objetivo } \\
\text { determinar el efecto } \\
\text { de la alimentación } \\
\text { con agua } \\
\text { glucosada en los } \\
\text { recién nacidos } \\
\text { lactantes }\end{array}$ & $\begin{array}{l}\text { RN a término por } \\
\text { parto vaginal, sin } \\
\text { anomalías congénitas } \\
\text { y sin factores de } \\
\text { riesgo para hipo o } \\
\text { hiperglicemia. }\end{array}$ & $\begin{array}{l}\text { Intervención: Agua glucosada al } 5 \% \text { a } \\
\text { través del biberón durante los primeros } \\
\underline{3 \text { días junto a la lactancia materna. }} \\
\text { Control: Grupo sin agua glucosada o } \\
\text { cualquier otra solución alternativa a la } \\
\text { leche humana. }\end{array}$ & $\begin{array}{l}\text { - Cambio de peso, glucosa plasmática, } \mathrm{T}^{\mathrm{a}} \\
\text { rectal } \\
\text { Tras } 5 \text { meses sin contacto mediante la } \\
\text { entrevista telefónica: a tiempos de } \\
4,8,12,16 \text { y } 20 \text { semanas: } \\
\text { - duración de lactancia materna exclusiva } \\
\text { - duración hasta la introducción de formula } \\
\text { infantil } \\
\text { - duración hasta el destete completo }\end{array}$ & $\begin{array}{l}\text { La supresión de la } \\
\text { alimentación con agua } \\
\text { de glucosa en los } \\
\text { primeros días de vida, } \\
\text { aumenta la } \\
\text { probabilidad de una } \\
\text { lactancia exitosa. }\end{array}$ & $\begin{array}{l}\text { Aleatoriz: } \\
\text { OSA } \\
\text { cegamiento } \\
\text { y Datos } \\
\text { incompletos: } \\
\text { no claro } \\
\text { Sesgo de } \\
\text { información: } \\
\text { bajo riesgo } \\
\text { Otros } \\
\text { sesgos: } \\
\text { posible } \\
\text { riesgo de } \\
\text { memoria y } \\
\text { falta de } \\
\text { consenso en } \\
\text { la } \\
\text { consideració } \\
\text { n de riesgo } \\
\text { de nivel bajo } \\
\text { de glucosa } \\
\text { sanguínea } \\
\text { en los } \\
\text { primeros } \\
\text { días tras } \\
\text { nacimiento }\end{array}$ \\
\hline $\begin{array}{l}\text { Howard CR, } \\
2003 \text { (7) (7) }\end{array}$ & $\begin{array}{l}\text { Diseño: ECA } \\
\text { Objetivo: evaluar } \\
\text { los efectos de la } \\
\text { introducción de } \\
\text { chupete temprano } \\
\text { vs. tardío y de dos } \\
\text { tipos de exposición } \\
\text { a pezones } \\
\text { artificiales (vaso vs. }\end{array}$ & $\begin{array}{l}700 \text { recién nacidos } \\
\text { (36-42 semanas, } \\
\text { peso al nacer } \geq 2200 \\
\text { g) } \\
\text { Madres con intención } \\
\text { de amamantar. } \\
\text { Subgrupo de } 481 \\
\text { niños que reciben } \\
\text { suplementos }\end{array}$ & $\begin{array}{l}\text { asignación a diferentes grupos de } \\
\text { forma de suplementación } \\
\text { (vaso/biberón), aunque esta } \\
\text { intervención fue realizado sólo en los } \\
\text { niños que necesitaron suplementos: } \\
\text { a) biberón/chupete temprano }(n=169) \text {, } \\
\text { b)Biberón/introducción tardía chupete } \\
\text { ( } n=167) ; \text { c)vaso/uso temprano chupete } \\
(n=185) ; d) \text { vaso/uso tardío de chupete } \\
(n=179) \text {. }\end{array}$ & $\begin{array}{l}\text { Suplementos Vs. No suplementos } \\
\text { Duración lactancia materna exclusiva: } \\
\text { HR } 1,49 \text { (IC95\% de } 1,23 \text { a 1,80) } \\
\text { Duración full breastfeeding: } \\
\text { HR } 1,50 \text { (IC95\% de } 1,24 \text { a 1,81) } \\
\text { Duración de cualquier tipo de lactancia } \\
\text { materna: } \\
\text { HR } 1,53 \text { (IC95\% de } 1,24 \text { a 1,89) }\end{array}$ & $\begin{array}{l}\text { La alimentación } \\
\text { mediante suplementos } \\
\text { tuvo un efecto } \\
\text { perjudicial sobre la } \\
\text { duración de la } \\
\text { lactancia materna. } \\
\text { Conclusiones sobre } \\
\text { uso de chupete y } \\
\text { forma de administrar }\end{array}$ & \\
\hline
\end{tabular}




\begin{tabular}{|c|c|c|c|c|c|c|}
\hline $\begin{array}{l}\text { Referencia } \\
\text { (Cita } \\
\text { Abreviada) }\end{array}$ & $\begin{array}{l}\text { Estudio (Diseño y } \\
\text { objetivo) }\end{array}$ & $\begin{array}{l}\text { Población } \\
\text { (no y características) }\end{array}$ & $\begin{array}{l}\text { Descripción de las intervenciones } \\
\text { comparaciones, exposiciones o } \\
\text { pruebas a estudio }\end{array}$ & $\begin{array}{l}\text { Resultados } \\
\text { (Estimadores de resultados-Magnitud del } \\
\text { efecto) }\end{array}$ & $\begin{array}{l}\text { Conclusiones } \\
\text { (conclusiones) }\end{array}$ & $\begin{array}{l}\text { Comentarios } \\
\text { Calidad de la } \\
\text { evidencia } \\
\text { Financiación } \\
\text { comentarios) }\end{array}$ \\
\hline & $\begin{array}{l}\text { biberón para la } \\
\text { provisión de } \\
\text { suplementos en el } \\
\text { hospital) sobre la } \\
\text { duración de la } \\
\text { lactancia materna e }\end{array}$ & & $\begin{array}{l}\text { e)chupete temprano sin } \\
\text { suplementos }(n=104) \text { y f)chupete tardío } \\
\text { sin suplementos }(n=112) \\
\\
\text { Los datos se recogen a las } 2,5,10 \text {, } \\
16,24,38 \text { y } 52 \text { semanas. } \\
\text { Los efectos de la intervención en la } \\
\text { duración de la lactancia fueron } \\
\text { evaluados con regresión logística y } \\
\text { análisis de supervivencia. }\end{array}$ & $\begin{array}{l}\text { Biberón vs. vaso: reportado en otra } \\
\text { pregunta } \\
\text { Introducción temprana de chupete vs. } \\
\begin{array}{l}\text { introducción tardía } \\
\text { reportado en otra pregunta }\end{array} \\
\begin{array}{l}\text { Análisis de subgrupos: } \\
\text { En niños nacidos por cesárea: } \\
\text { sí hay diferencias según biberón } \\
\text { vs. vaso }\end{array} \\
\leq 3 \text { suplementos vs. } \geq 3 \text { suplementos: hay } \\
\text { diferencias significativas. }\end{array}$ & $\begin{array}{l}\text { los suplementos } \\
\text { resumidos en otras } \\
\text { preguntas. }\end{array}$ & \\
\hline
\end{tabular}

\section{Estudios observacionales}

\begin{tabular}{|c|c|c|c|}
\hline $\begin{array}{l}\text { Referencia } \\
\text { (Cita } \\
\text { Abreviada) }\end{array}$ & $\begin{array}{l}\text { Estudio (Diseño y } \\
\text { objetivo) }\end{array}$ & $\begin{array}{l}\text { Población } \\
\text { (no y características) }\end{array}$ & $\begin{array}{l}\text { Descripción de las intervenciones } \\
\text { comparaciones, exposiciones o } \\
\text { pruebas a estudio }\end{array}$ \\
\hline $\begin{array}{l}\text { Chantry, } 2014 \\
\text { (9) }\end{array}$ & $\begin{array}{l}\text { Diseño: estudio } \\
\text { prospectivo de } \\
\text { cohorte longitudinal } \\
\text { Objetivo } \\
\text { Evaluar la } \\
\text { suplementación de } \\
\text { RNs con fórmula } \\
\text { durante la estancia } \\
\text { hospitalaria y } \\
\text { determinar si la } \\
\text { suplementación } \\
\text { hospitalaria con } \\
\text { fórmula acorta la } \\
\text { duración de la } \\
\text { lactancia después } \\
\text { de ajustar por la } \\
\text { intención de }\end{array}$ & $\begin{array}{l}448 \text { madres } \\
\text { primerizas que tenían } \\
\text { la intención preparto } \\
\text { de amamantar, entre } \\
32 \text { y } 40 \text { semanas de } \\
\text { gestación al momento } \\
\text { de la entrevista, en } \\
\text { espera de su primer } \\
\text { único bebé nacido } \\
\text { vivo, de habla } \\
\text { Inglesa o española. } \\
\text { Datos hospitalarios de } \\
n=407 \text { y de } 393 \text { a los } \\
60 \text { días }\end{array}$ & $\begin{array}{l}\text { Expuestos: recién nacidos que } \\
\text { recibieron suplementación durante la } \\
\text { estancia hospitalaria } \\
\text { Controles: RN que recibieron lactancia } \\
\text { materna exclusiva durante la } \\
\text { hospitalización. } \\
\text { Se utilizó el estadístico X2 para } \\
\text { evaluar las diferencias significativas en } \\
\text { la prevalencia de suplementación de } \\
\text { fórmula en el hospital entre los } \\
\text { diferentes estratos (de características } \\
\text { maternales, del parto, del bebé y de } \\
\text { estancia hospitalaria) y a través del } \\
\text { análisis de regresión logística } \\
\text { determinar si estas diferencias } \\
\text { persistieron después del ajustarlo por } \\
\text { intención de amamantar (IFI: infant }\end{array}$ \\
\hline
\end{tabular}

Resultados

(Estimadores de resultados-Magnitud del efecto)

$210(53 \%)$ bebes fueron amamantados exclusivamente durante la estancia de maternidad y $183(47 \%)$ recibieron la suplementación con fórmula en el

hospital, a las $24 h(n=114), 48 h(n=48)$ y $72 \mathrm{~h}(\mathrm{n}=21)$ tras el nacimiento.

USO DE SUPLEMENTACIÓN Las razones más citadas por las madres para la suplementación fueron: percepción de suministro insuficiente de leche $(18 \%)$, signos de ingesta inadecuada (16\%), y un mal agarre o $(14 \%)$.

RESULTADOS DE LACTANCIA

- La prevalencia de lactancia materna no exclusiva a los 30 . suplementados. RRA 1,8 (IC 95\%, 1,4 a
Conclusiones (conclusiones)

Entre las mujeres que decidieron amamanta exclusivamente, la suplementación con ormula en el hospita se asoció con un riesgo casi 2 veces mayor de no amamantar exclusivamente durante los días 30-60 y un riesgo casi 3 veces mayor de dejar de amamantar para el día 60 , incluso después de ajustar por despuês de ajusta lactancia.
Comentarios Calidad de la Financiación comentarios) 


\begin{tabular}{|c|c|c|c|c|c|}
\hline & amamantar. & & $\begin{array}{l}\text { feeding intention) } \\
\text { Se realizó un análisis de regresión } \\
\text { logística para calcular el crudo y OR } \\
\text { para cada resultado de la lactancia en } \\
\text { la suplementación hospitalaria frente a } \\
\text { los grupos alimentados con leche } \\
\text { materna exclusivamente durante la } \\
\text { hospitalización. } \\
\text { Variables de confusión utilizados para } \\
\text { el ajuste del modelo: rango IFI, la } \\
\text { educación materna (algún o ausencia } \\
\text { de estudios universidad), origen étnico, } \\
\text { edad, estado de seguro de salud, y la } \\
\text { duración de la estancia en la } \\
\text { maternidad }\end{array}$ & $\begin{array}{l}2,3 \text { ). } \\
\text { Cese de lactancia a los } 60 \text { días: } 32,8 \% \\
\text { frente a } 10,5 \% \text { entre el grupo } \\
\text { suplementado con fórmula d en el hospital } \\
\text { frente a los alimentados con leche } \\
\text { materna exclusivamente, } \\
\text { respectivamente, RRA } 2,7 \text { (IC } 95 \%, 1,7 \text { a } \\
4,5 \text { ). } \\
\text { Las probabilidades de los dos resultados } \\
\text { adversos aumentaron con la mayor } \\
\text { alimentación de suplementos en el } \\
\text { hospital (días sin amamantación materna } \\
\text { exclusiva } 30-60, P=0,003 \text { y cese de } \\
\text { lactancia, } P=0,011 \text { ). }\end{array}$ & $\begin{array}{l}\text { Las estrategias deben } \\
\text { buscar evitar la } \\
\text { innecesaria } \\
\text { suplementación con } \\
\text { fórmula en el hospital } \\
\text { y apoyar la lactancia } \\
\text { materna cuando la } \\
\text { suplementación con } \\
\text { fórmula es inevitable. }\end{array}$ \\
\hline Parry 2013 (11) & $\begin{array}{l}\text { Diseño: estudio } \\
\text { prospectivo de } \\
\text { cohorte longitudinal } \\
\text { Describir el patrón } \\
\text { de la } \\
\text { suplementación de } \\
\text { bebés sanos a } \\
\text { termino } \\
\text { Identificar factores } \\
\text { asociados a la } \\
\text { suplementación } \\
\text { hospitalaria y } \\
\text { evaluar el gradiente } \\
\text { dosis-respuesta } \\
\text { entre la cantidad de } \\
\text { suple y duración de } \\
\text { cualquier lactancia }\end{array}$ & $\begin{array}{l}1246 \text { diadas madre- } \\
\text { hijo en hongkong } \\
\text { Seguimento de } 12 \\
\text { meses hasta el } \\
\text { destete }\end{array}$ & $\begin{array}{l}\text { Analisis de regresión logística multiple } \\
\text { Cox para determinar los asociados con } \\
\text { la suplementación durante la estancia } \\
\text { hospitalaria. } \\
\text { Análisis de regresión Cox para } \\
\text { explorar el impacto de impacto de la } \\
\text { suplementación hospitlaria en la } \\
\text { duración de la lactancia. } \\
\text { Análisis ajustados por factores } \\
\text { sociodemográficas. Para el resultado } \\
\text { de HR presentado: tipo de parto } \\
\text { (instrumental y cesárea), peso del } \\
\text { recién nacido, iniciación en sala de } \\
\text { partos, nivel de educación maternal, } \\
\text { experiencia previa en lactancia, } \\
\text { planificación de amamantación } \\
\text { exclusiva. }\end{array}$ & $\begin{array}{l}\text { Suplementación: } \\
\text { Asoc +: parto vaginal asistido, cesarea, } \\
\text { mayor peso al nacer } \\
\text { Asocia -: iniciación en sala de partos } \\
\text { Cualquier suplementación durante } 48 \mathrm{~h} \\
\text { asociado a una menor duración HR: } \\
\text { No hubo relación gradiante dosis- } \\
\text { respuesta } \\
\text { Es sustancialmente menos probable en } \\
\text { cualquier punto de tiempo que los } \\
\text { neonatos que recibieron suplementos } \\
\text { estén siendo amamantados en } \\
\text { comparación con sus homólogos } \\
\text { alimentados con leche materna } \\
\text { exclusivamente: HR ajustado:1,51 (IC95\% } \\
1,07 \text { a 1,80) }\end{array}$ & $\begin{array}{l}\text { La suplementación } \\
\text { durante la estancia } \\
\text { hospitalaria es comun } \\
\text { en Hong Kong y } \\
\text { parace que perjudica } \\
\text { la duración de la } \\
\text { lactancia } \\
\text { La falta de un efecto } \\
\text { dosis-respuesta entre } \\
\text { las cantidades de } \\
\text { suplementos } \\
\text { administrados en el } \\
\text { período post-parto } \\
\text { temprano y la duración } \\
\text { de la lactancia } \\
\text { materna sugiere que } \\
\text { no existe ningún } \\
\text { umbral por debajo del } \\
\text { cual la suplementación } \\
\text { con fórmula puede ser } \\
\text { considerado seguro. }\end{array}$ \\
\hline
\end{tabular}




\begin{tabular}{|c|c|c|c|c|c|c|c|c|}
\hline Forde 2010 (10) & $\begin{array}{l}\text { Diseño: estudio } \\
\text { prospectivo de } \\
\text { cohorte longitudinal } \\
\text { Estudio de de } \\
\text { indicadores } \\
\text { basales de } \\
\text { lactancia y } \\
\text { factores que } \\
\text { contribuyen a la } \\
\text { iniciación, } \\
\text { exclusividad y } \\
\text { duración de la } \\
\text { lactancia }\end{array}$ & $\begin{array}{l}\text { Cohorte de } 3828 \\
\text { bebés nacidos } \\
\text { durante el } 2006 \text { en } \\
\text { Australia. }\end{array}$ & $\begin{array}{l}\text { Seguimiento: hasta } 4 \text { meses tras } \\
\text { alta hospitalaria en } 4 \text { citas }\end{array}$ & 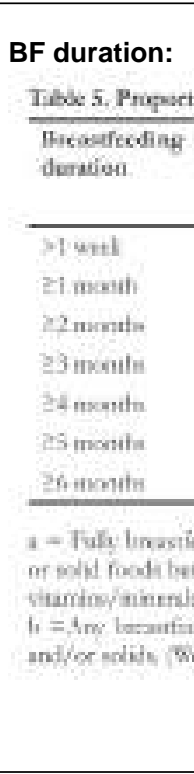 & 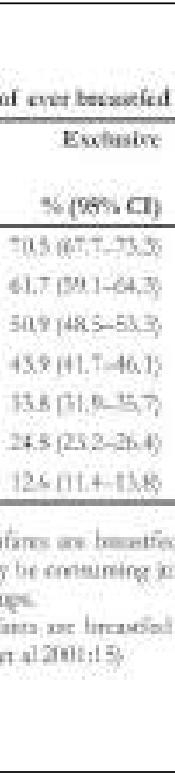 & 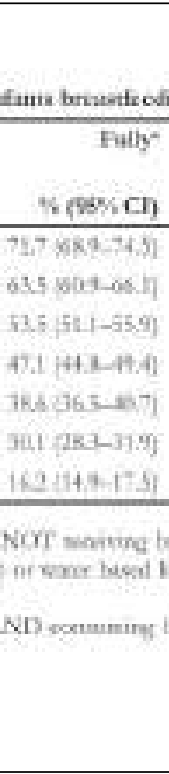 & 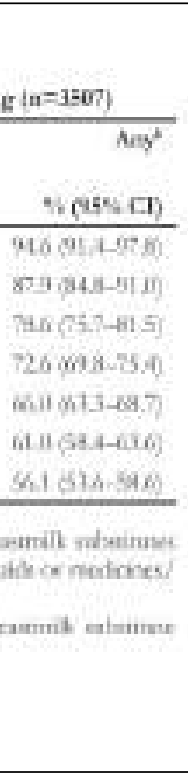 & $\begin{array}{l}\text { Limitaciones } \\
\text { del estudio: } \\
\text { solo el } 10 \% \\
\text { de mujeres } \\
\text { que cesan la } \\
\text { lactancia } \\
\text { antes de los } \\
6 \text { meses } \\
\text { tuvo } \\
\text { información } \\
\text { que podría } \\
\text { haber } \\
\text { evitado } \\
\text { dicho } \\
\text { desenlace } \\
\text { - 40\% de la } \\
\text { población } \\
\text { total a } \\
\text { estudio con } \\
\text { datos } \\
\text { incompletos } \\
\text { sobre la } \\
\text { introducción } \\
\text { de sólidos }\end{array}$ \\
\hline
\end{tabular}




\section{ANEXO III. Forest-Plot}

1. Proporción de niños amamantados exclusivamente con leche materna a los 3 meses

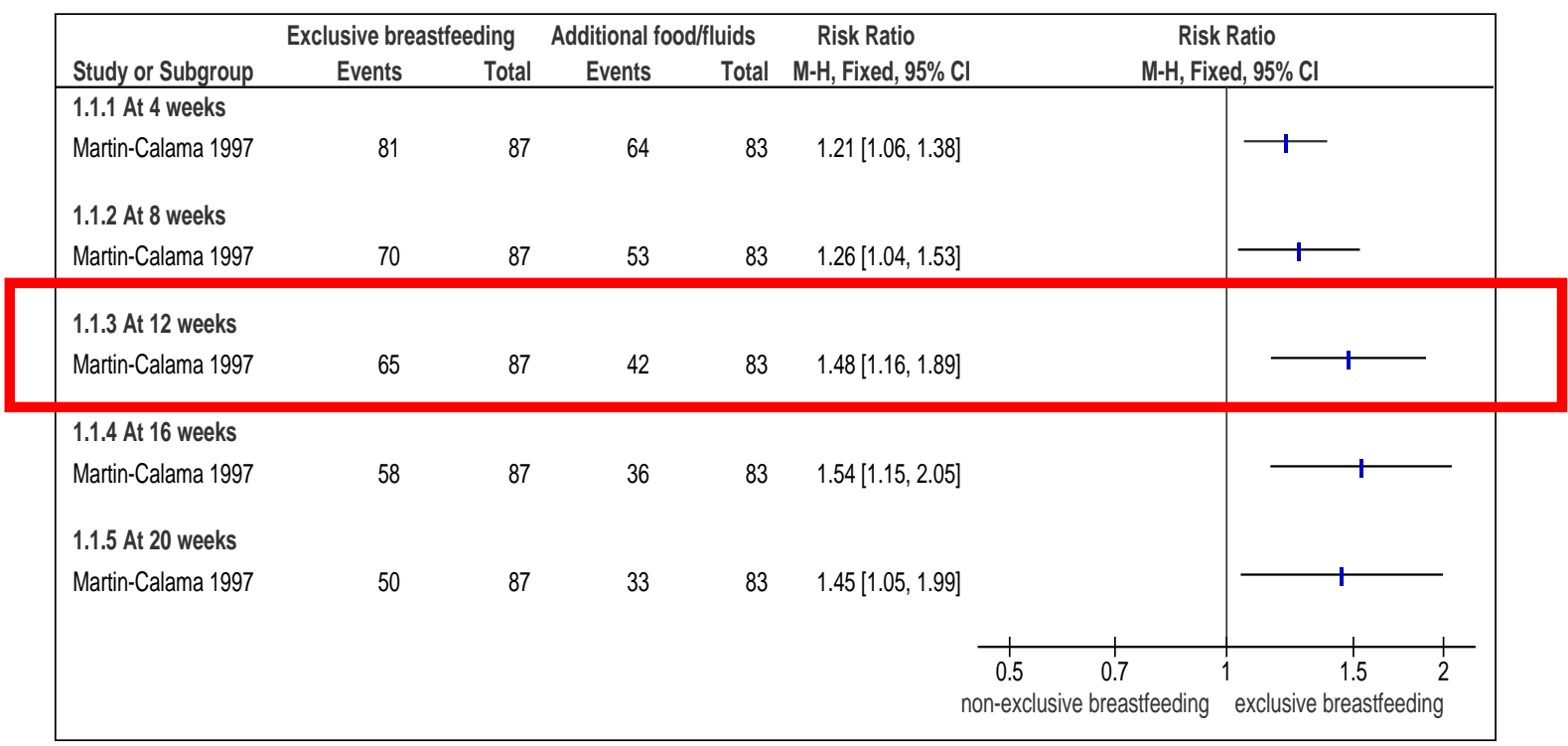

\section{2.- Duración de Lactania de cualquier tipo (overall BF)}

\begin{tabular}{|c|c|c|c|c|c|c|c|}
\hline Study or Subgroup & log[Hazard Ratio] & SE & Weight & $\begin{array}{l}\text { Hazard Ratio } \\
\text { IV, Fixed, 95\% Cl }\end{array}$ & \multicolumn{3}{|c|}{$\begin{array}{l}\text { Hazard Ratio } \\
\text { IV, Fixed, } 95 \% \mathrm{Cl}\end{array}$} \\
\hline Howard 2003 & 0.4253 & 0.1072 & $100.0 \%$ & $1.53[1.24,1.89]$ & & & \\
\hline Total $(95 \% \mathrm{Cl})$ & & & $100.0 \%$ & $1.53[1.24,1.89]$ & & & \\
\hline \multicolumn{5}{|c|}{$\begin{array}{l}\text { Heterogeneity: Not applicable } \\
\text { Test for overall effect: } Z=3.97(P<0.0001)\end{array}$} & $\begin{array}{cc}0.2 & 0.5 \\
\text { early supplemental }\end{array}$ & $\begin{array}{lr}1 & 1 \\
\text { exclusiv }\end{array}$ & $\begin{array}{l}1 \\
5 \\
\text { astfeeding }\end{array}$ \\
\hline
\end{tabular}

\section{3.- Duración de Lactancia materna exclusiva}

\begin{tabular}{|c|c|c|c|c|c|c|}
\hline Study or Subgroup & log[Hazard Ratio] & SE & Weight & $\begin{array}{l}\text { Hazard Ratio } \\
\text { IV, Fixed, } 95 \% \text { CI }\end{array}$ & \multicolumn{2}{|c|}{$\begin{array}{l}\text { Hazard Ratio } \\
\text { IV, Fixed, } 95 \% \text { CI }\end{array}$} \\
\hline Howard 2003 & 0.3988 & 0.0978 & $100.0 \%$ & $1.49[1.23,1.80]$ & & - \\
\hline Total $(95 \% \mathrm{Cl})$ & & & $100.0 \%$ & $1.49[1.23,1.80]$ & & \\
\hline \multicolumn{5}{|c|}{$\begin{array}{l}\text { Heterogeneity: Not applicable } \\
\text { Test for overall effect: } Z=4.08(P<0.0001)\end{array}$} & $\begin{array}{cc}0.5 & 0.7 \\
\text { early supplementa }\end{array}$ & $\begin{array}{lll}1 & 1.5 & 2 \\
\text { exclusive breastfeeding }\end{array}$ \\
\hline
\end{tabular}


4.-Cambio de peso (g) (6h, 12h, 24h, 48h, 72h)

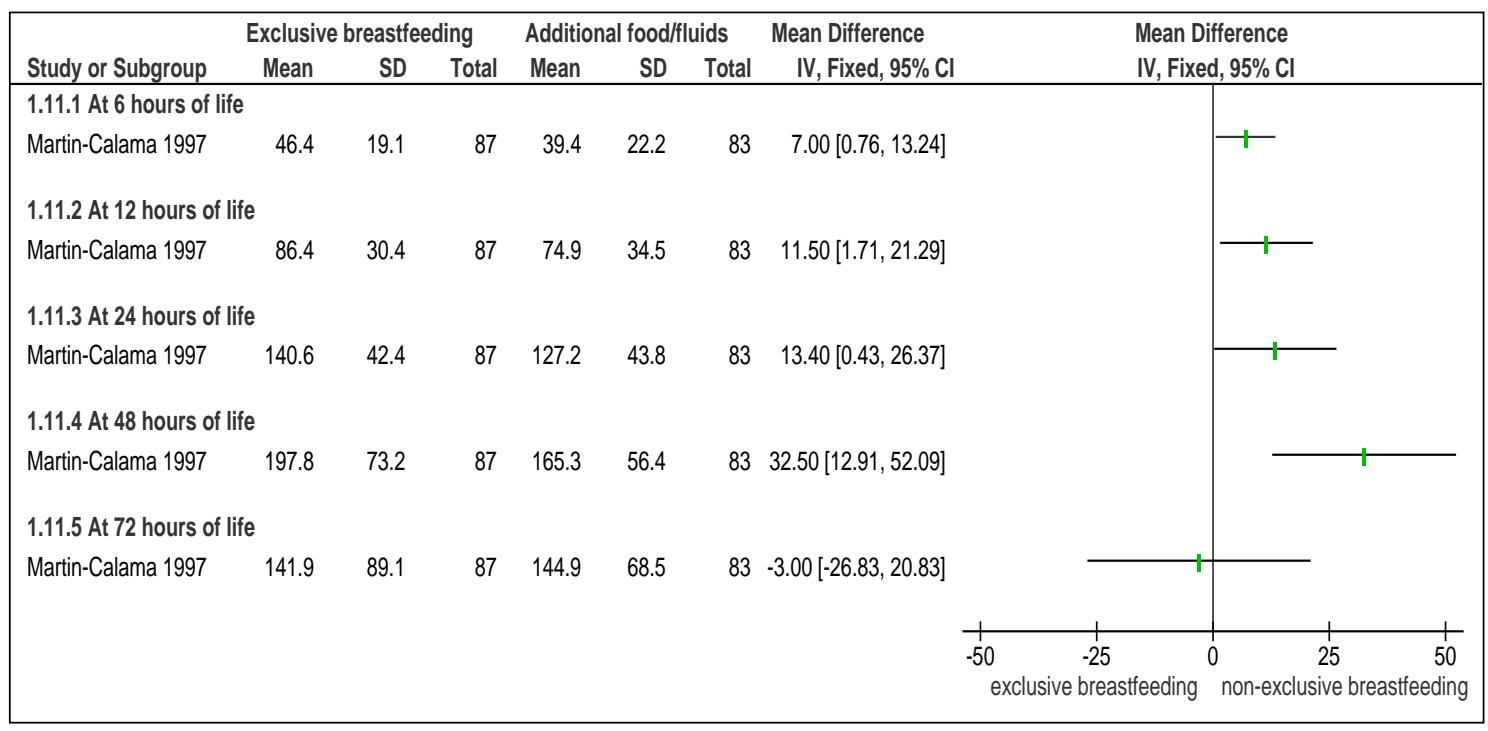

Kramer 2012 (6)

Exclusive versus mixed breastfeeding 3-7 months, developed countries, observational studies

Monthly weight gain 3-8 months (g/mo)

\begin{tabular}{|c|c|c|c|c|c|c|c|c|c|c|c|c|}
\hline \multirow[b]{2}{*}{ Study or Subgroup } & \multicolumn{2}{|c|}{ EBF } & \multicolumn{3}{|r|}{ MBF } & \multirow[b]{2}{*}{ Total } & \multirow[b]{2}{*}{ Weight } & \multirow{2}{*}{\multicolumn{2}{|c|}{$\begin{array}{l}\text { Mean Difference } \\
\text { IV, Random, } 95 \% \mathrm{Cl}\end{array}$}} & \multirow{2}{*}{\multicolumn{2}{|c|}{$\begin{array}{c}\text { Mean Difference } \\
\text { IV, Random, } 95 \% \mathrm{Cl}\end{array}$}} & \\
\hline & Mean & SD & Total & Mean & SD & & & & & & & \\
\hline Akeson 1996a & 498 & 118 & 10 & 438 & 127 & 9 & $4.2 \%$ & $60.00[-50.60,170.60]$ & & & & \\
\hline Kramer 2000a & 612.2 & 180 & 619 & 641 & 186 & 2836 & $36.4 \%$ & $-28.80[-44.55,-13.05]$ & & - & & \\
\hline WHO 1994a & 463 & 142 & 200 & 470 & 159 & 158 & $24.6 \%$ & $-7.00[-38.65,24.65]$ & & & & \\
\hline WHO 1997 & 418.75 & 100.39 & 179 & 413.8 & 100.39 & 377 & $34.8 \%$ & $4.95[-12.91,22.81]$ & & & & \\
\hline Total $(95 \% \mathrm{Cl})$ & & & 1008 & & & 3380 & $100.0 \%$ & $-7.95[-31.84,15.93]$ & & & & \\
\hline $\begin{array}{l}\text { Heterogeneity: } \text { Tau }^{2}= \\
\text { Test for overall effect: }\end{array}$ & $\begin{array}{l}343.59 ; C \\
Z=0.65(\end{array}$ & $\begin{array}{l}\mathrm{Ch}^{2}=9.55 \\
(\mathrm{P}=0.51)\end{array}$ & 55, $d f=$ & $3(P=0$ & $0.02) ; 1^{2}=$ & $69 \%$ & & & $\longmapsto_{-100}$ & $\begin{array}{l}-50 \\
\text { Favours MBF }\end{array}$ & $\begin{array}{lr} & 50 \\
\text { Favours EBF }\end{array}$ & 100 \\
\hline
\end{tabular}

Weight-for-length z-score $<-2$ at 6 months

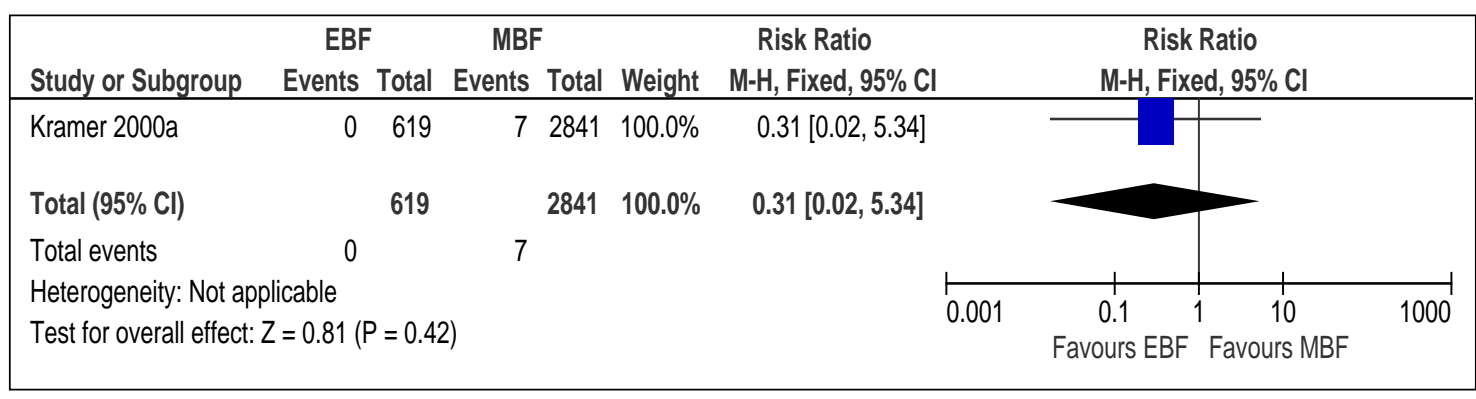




\section{5.- Número de episodios de Hipoglucemia (definido como glucosa sérica $<2,2$ $\mathrm{mmol} / \mathrm{L})$}

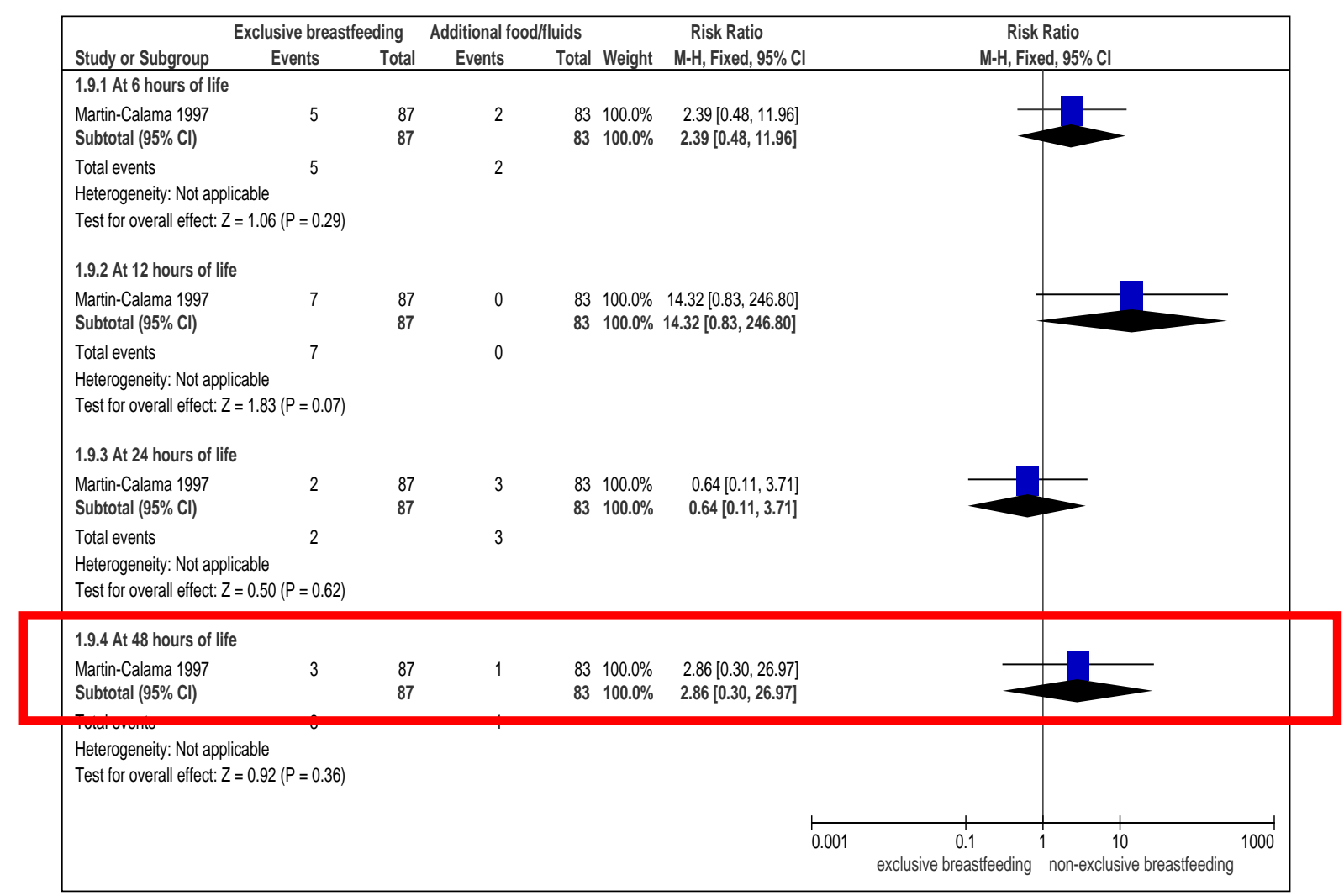




\section{ANEXO IV. Evaluación de la calidad}

\section{Revisiones sistemáticas - AMSTAR}

BECKER 2011 (4),

1. ¿Se brindó un diseño "a priori"?

La pregunta de la investigación y los criterios de inclusión deberían establecerse antes de llevar a cabo la revisión Sí

2. ¿Hubo duplicación en la selección de estudios y extracción de datos? Debería haber al menos dos personas independientes a cargo de la extracción de datos, y debería existir un procedimiento consensuado para los desacuerdos Sí

3. ¿Se realizó una búsqueda exhaustiva de literatura?

Deberían consultarse al menos dos fuentes electrónicas. El informe debe incluir los años y las bases de datos utilizadas (por ej. Central, EMBASE y MEDLINE). Deben especificarse las palabras clave y/o los términos MESH y, de ser posible, debe proveerse la estrategia de búsqueda. Todas las búsquedas deberían ser complementadas con consultas a contenidos actuales, revisiones, libros de textos, registros especializados, o expertos en el campo particular de estudio, y mediante la revisión de las referencias en los estudios encontrados Sí

4. ¿Se utilizó el estado de publicación (es decir, literatura gris) como criterio de inclusión?

Los autores deberían especificar que buscaron informes sin tener en cuenta el tipo de publicación. Los autores deberían especificar si excluyeron o no algún informe (de la revisión sistemática), en función del estado de publicación, idioma, etc. No responde

5. ¿Se brindó una lista de estudios (incluidos y excluidos)?

Debería proveerse una lista de estudios incluidos y excluidos Sí

6. ¿Se brindaron las características de los estudios incluidos?

De manera adjunta tal como una tabla, deberían proveerse los datos de los estudios originales sobre los participantes, las intervenciones y los resultados. Deberían informarse los rangos de las características en todos los estudios analizados, por ej, la edad, la raza, el sexo, los datos socioeconómicos relevantes, el estado de enfermedad, la duración, la severidad, o cualquier otra enfermedad Sí

7. ¿Se evaluó y documentó la calidad científica de los estudios

incluidos? Deberían proveerse métodos "a priori" (por ej, para estudios de efectividad si el autor o los autores eligen incluir sólo estudios aleatorizados, de doble ciego, controlados con placebo, u ocultamiento de las asignaciones como criterios de inclusión). Para otros tipos de estudios, serán relevantes los ítems alternativos Sí

8. ¿Se utilizó de manera adecuada la calidad científica de los estudios incluidos al formular las conclusiones?

El rigor metodológico y la calidad científica de los estudios deberían considerarse en el análisis y las conclusiones de la revisión, y plantearse explícitamente al formular las recomendaciones Sí

9. ¿Fueron adecuados los métodos utilizados para combinar los hallazgos de los estudios?

Para los resultados conjuntos, debería hacerse una prueba para garantizar que los estudios pudieron combinarse y para evaluar sus homogeneidad (es decir, la prueba chi-cuadrado para la homogeneidad, $\mathrm{I}^{2}$ ). Si existe heterogeneidad debería utilizarse un modelo de efectos aleatorios y/o debería considerarse lo adecuado de la combinación (es decir, ¿fue adecuado combinar los resultados?) Sí

10. ¿Se valoró la probabilidad de sesgo de publicación?

Una evaluación de sesgo de publicación debería incluir una combinación de ayudas gráficas (por ej. un gráfico en embudo - funnel plot - , otras pruebas disponibles) y/o pruebas estadísticas (por ej. prueba de regresión de Egger)Sí

11. ¿Se planteó el conflicto de intereses?

Deberían reconocerse claramente las fuentes posibles de apoyo tanto en la revisión sistemática como en los estudios incluidosSí 


\section{0- BIBLIOGRAFÍA}

(1) NICE. Postnatal care up to 8 weeks after birth. Julio 2006 (actualizado en Febrero de 2015). Disponible en: http://guidance.nice.org.uk/CG37.

(2) National Health and Medical Research Council. Infant Feeding Guidelines. 2012.

(3) Aguayo Maldonado J, Arana Cañedo Argüelles C, Arena Ansótegui J, Canduela Martínez V, Flores Antón B, Gómez Papí A, Hernández Aguilar MT, Lasarte Velillas JJ, Lozano de la Torre MJ, Martín Calama J, Navas Lucena V. IHAN Calidad en la asistencia profesional al nacimiento y la lactancia. Ministerio de Sanidad, Política Social e Igualdad. Informes, estudios e investigación. 2011.

(4) Becker GE, Remmington S, Remmington T. Early additional food and fluids for healthy breastfed full-term infants. Cochrane Database Syst Rev 2011;(12):CD006462.

(5) Perinatal Services BC. Health Promotion Guideline 1. Safe Sleep Environment Guideline For Infants 0 to 12 months of age. February 2011. Disponible en: http://www.perinatalservicesbc.ca/NR/rdonlyres/D799441C-3E00-49EE-BDF72A3196B971F0/0/HPGuidelinesSafeSleep1.pdf.

(6) Kramer MS, Kakuma R. Optimal duration of exclusive breastfeeding. Cochrane Database of Systematic Reviews 2012 Aug;(8).

(7) Howard CR, Howard FM, Lanphear B, Eberly S, deBlieck EA, Oakes D, et al. Randomized clinical trial of pacifier use and bottle-feeding or cupfeeding and their effect on breastfeeding. Pediatrics 2003 Mar;111(3):511-8.

(8) Martin-Calama J, Bunuel J, Valero MT, Labay M, Lasarte JJ, Valle F, et al. The effect of feeding glucose water to breastfeeding newborns on weight, body temperature, blood glucose, and breastfeeding duration. J Hum Lact 1997 Sep;13(3):209-13.

(9) Chantry CJ, Dewey KG, Peerson JM, Wagner EA, Nommsen-Rivers LA. Inhospital formula use increases early breastfeeding cessation among first-time mothers intending to exclusively breastfeed. J Pediatr 2014 Jun;164(6):133945.

(10) Forde KA, Miller LJ. 2006-07 north metropolitan Perth breastfeeding cohort study: how long are mothers breastfeeding? Breastfeed Rev 2010 Jul;18(2):1424.

(11) Parry JE, Ip DK, Chau PY, Wu KM, Tarrant M. Predictors and consequences of in-hospital formula supplementation for healthy breastfeeding newborns. J Hum Lact 2013 Nov;29(4):527-36.

(12) Smith HA, Becker GE. Early additional food and fluids for healthy breastfed fullterm infants. Cochrane Database Syst Rev 2016 Aug 30;(8):CD006462.

(13) Flaherman VJ, Aby J, Burgos AE, Lee KA, Cabana MD, Newman TB. Effect of early limited formula on duration and exclusivity of breastfeeding in at-risk infants: an RCT. Pediatrics 2013 Jun;131(6):1059-65.

(14) Strañak Z, Feyereislova S, Cerna M, Kollarova J, Feyereisl J. Limited Amount of Formula May Facilitate Breastfeeding: Randomized, Controlled Trial to Compare Standard Clinical Practice versus Limited Supplemental Feeding. PLoS One 2016;11(2):e0150053.

(15) DaMota K, Banuelos J, Goldbronn J, Vera-Beccera LE, Heinig MJ. Maternal request for in-hospital supplementation of healthy breastfed infants among lowincome women. J Hum Lact 2012 Nov;28(4):476-82. 
(16) Yaqub A, Gul S. Reasons for failure of exclusive breastfeeding in children less than six months of age. J Ayub Med Coll Abbottabad 2013 Jan;25(1-2):165-7.

(17) Augustin AL, Donovan K, Lozano EA, Massucci DJ, Wohlgemuth F. Still nursing at 6 months: a survey of breastfeeding mothers. MCN Am J Matern Child Nurs 2014 Jan;39(1):50-5. 
PREGUNTA CLÍNICA № 14

\section{¿Cuándo está indicada la administración de suplementos en recién nacidos sanos?}

\section{Pregunta clínica en formato PICO}

Tabla 1. Componentes de la pregunta clínica en formato PICO

\begin{tabular}{|c|c|}
\hline Pacientes & RN sanos a término, sin riesgo de hipoglucemia \\
\hline Intervención & Administración de suplementos \\
\hline Comparación & No administración de suplementos \\
\hline Resultados & $\begin{array}{l}\text {-Tasa de LME al alta (crítica) } \\
\text {-Duración de la lactancia materna (crítica) } \\
\text {-Peso del bebé (48-72h.) (crítica) } \\
\text {-Complicaciones de las mamas (crítica) } \\
\text {-Satisfacción materna (con los cuidados recibidos) (crítica) } \\
\text { - Hipoglucemia (crítica) } \\
\text { - Ictericia (crítica) } \\
\text {-Deshidratación (crítica) } \\
\text {-Tasa de LM a los } 4 \text { meses (importante) } \\
\text {-Tasa de LME a los } 4 \text { meses (importante) }\end{array}$ \\
\hline Tipo de estudio & GPC, RS, ECAs y estudios observacionales \\
\hline
\end{tabular}

\section{Introducción}

La utilización de suplementos (leche materna extraída o fórmula) durante la estancia hospitalaria es una práctica frecuente, que en ocasiones no está justificada y que puede suponer un riesgo para el recién nacido y para el éxito de la lactancia. Conocer cuáles son las circunstancias en las que los beneficios de suplementar la lactancia materna superan a los riesgos puede ser de gran utilidad para los profesionales, sin olvidar que la administración de dichos suplementos siempre debe de ir acompañada del apoyo y las medidas necesarias para solucionar los problemas de lactancia y que la demanda de suplementos de una madre que previamente ha sido adecuadamente informada y apoyada, debe ser atendida y respetada. 


\section{Estrategia de elaboración de la pregunta}

\subsection{GPC}

Tabla 2. GPC de base (seleccionadas con el AGREE)

\begin{tabular}{|c|c|c|c|c|}
\hline Guía & Evidencia & Recomendación & Referencias & Comentarios \\
\hline NICE 2006 & $\begin{array}{l}\text { ¿En qué circunstancias debe un bebé recibir } \\
\text { alimentos suplementarios? } \\
\text { La OMS/UNICEF recomiendan la administración de } \\
\text { suplementos solo cuando es médicamente necesario, } \\
\text { como se señala en el paso } 6 \text { de la IHAN. } \\
\text { No se ha identificado ningún estudio que aborde } \\
\text { específicamente las circunstancias para la } \\
\text { suplementación. } \\
\text { Un documento de Newman (Newman 1996) que fue } \\
\text { revisado en la narrativa de la pregunta } 6.3 .4 .2 \text { sobre la } \\
\text { suficiencia de la leche materna se describe un árbol de } \\
\text { decisión para la evaluación de la alimentación } \\
\text { adecuada. Con base en la experiencia adquirida en la } \\
\text { Clínica de Lactancia Materna del Hospital para Niños } \\
\text { Enfermos, Toronto, el autor mantiene que la } \\
\text { deshidratación y la pérdida excesiva de peso eran } \\
\text { potencialmente problemas prevenibles. Las graves } \\
\text { consecuencias de la ingesta insuficiente son la } \\
\text { deshidratación hipernatrémica severa, pérdida de peso } \\
\text { severa y la hiperbilirrubinemia severa con posible daño } \\
\text { irreversible al cerebro de un RN o de otros órganos } \\
\text { vitales. } \\
\text { Dyson et al (2006) (Dyson 2006) revisaron cinco ECA y } \\
\text { dos ensayos controlados no aleatorios y concluyeron } \\
\text { que los suplementos en el período neonatal se deben } \\
\text { dar sólo cuando existen indicaciones médicas de peso, } \\
\text { lo que apoya la recomendación de la OMS/UNICEF que } \\
\text { se incluye en los } 10 \text { pasos de la estrategia IHAN. Si se } \\
\text { administran suplementos por razones médicas o por } \\
\text { elección materna es menos probable que la LM se vea }\end{array}$ & $\begin{array}{ll}\text { Solo se requiere la } & \text { la } \\
\text { administración } & \text { de } \\
\text { suplementos si } & \text { es } \\
\text { médicamente necesario. }\end{array}$ & $\begin{array}{l}\text { Dyson, Renfrew, McFadden, } \\
\text { McCormick, Herbert and Thomas 2006, } \\
\text { Effectiveness of public health } \\
\text { interventions to promote the duration of } \\
\text { breastfeeding: systematic review. } \\
\text { London: National Institute for Health and } \\
\text { Clinical Excellence. } \\
\text { Newman, J. 1996, "Decision tree and } \\
\text { postpartum management for preventing } \\
\text { dehydration in the "breastfed" baby", } \\
\text { Journal of Human Lactation, vol. 12, no. } \\
\text { 2, pp. 129-135. }\end{array}$ & \\
\hline
\end{tabular}




\begin{tabular}{|c|c|c|c|c|}
\hline & $\begin{array}{l}\text { afectada si solo se da un pequeño número de } \\
\text { suplementos en los primeros cinco días. }\end{array}$ & & & \\
\hline NICE UPDATE 2011 & No hay nueva evidencia. & & & \\
\hline $\begin{array}{l}\text { BC } 2013 \\
\text { BREASTFEEDING } \\
\text { HEALTH TERM } \\
\text { INFANTS }\end{array}$ & $\begin{array}{l}\text { Hay muy pocas condiciones médicas, permanentes o } \\
\text { temporales, en las que la LM no está recomendada. } \\
\text { Antes de empezar a administrar suplementos se debe } \\
\text { evaluar a la madre y al RN, incluyendo la observación } \\
\text { de la toma, para determinar que la suplementación es } \\
\text { apropiada y necesaria. Se deben considerar los } \\
\text { beneficios de la leche materna y los posibles riesgos } \\
\text { asociados con el uso de sucedáneos a la hora de } \\
\text { formular recomendaciones sobre alimentación infantil } \\
\text { (ABM } 32009 \text {, WHO/UNICEF 2009, American Academy } \\
\text { of Pediatrics 2005). }\end{array}$ & $\begin{array}{ll}\text { Muy pocos } \mathrm{RN} & \text { a término } \\
\text { sanos } & \text { requieren } \\
\text { suplementos } & \end{array}$ & $\begin{array}{l}\text { American Academy of Pediatrics (2005). } \\
\text { Policy Statement: Breastfeeding and the } \\
\text { Use of Human Milk. Pediatrics, 115(2), } \\
\text { 496-506. } \\
\text { The Academy of Breastfeeding } \\
\text { Medicine (2009, revised). Clinical } \\
\text { protocol \#3: Hospital guidelines for the } \\
\text { use of supplementary feedings in the } \\
\text { healthy term breastfed neonate. } \\
\text { Breastfeeding Medicine, 4(3), 175-182. } \\
\text { http://www.bfmed.org/Resources/Protoc } \\
\text { ols.aspx } \\
\text { World Health Organization/UNICEF } \\
\text { (2009). Acceptable medical reasons for } \\
\text { use of breast-milk substitutes. Geneva, } \\
\text { Switzerland: } \\
\text { WHO/NMH/NHD/09.01 } \\
\text { WHO/FCH/CAH/09,01. } \\
\text { htpp://whqlibdoc.who.int/hq/2009/WHO_ } \\
\text { FCH_CAH_09.01_eng.pdf }\end{array}$ & \\
\hline
\end{tabular}

Tabla 3. Resumen de GPC del SNS

\begin{tabular}{|c|c|c|c|c|}
\hline Guía & Evidencia & Recomendación & Referencias & Comentarios \\
\hline GPC parto & No & & & \\
\hline GPC embarazo & No & & & \\
\hline
\end{tabular}


Tabla 4. Otros documentos de sociedades/ organismos de referencia

\begin{tabular}{|c|c|c|c|}
\hline Guía & Evidencia & Referencias & Comentarios \\
\hline $\begin{array}{l}\text { ABM } 3 \\
\text { alimentación } \\
\text { suplementaria } \\
2009\end{array}$ & $\begin{array}{l}\text { I. Indicaciones para alimentación suplementaria: } \\
\text { 1. Separación } \\
\text { II. Posibles indicaciones para alimentación suplementaria (Powers } \\
\text { 1997): } \\
\text { II.1. Indicaciones para los bebés } \\
\text { - La hipoglucemia asintomática documentada por medición de glucosa en } \\
\text { la sangre efectuada en el laboratorio (no por métodos de detección de } \\
\text { cabecera) que no responde a una frecuencia de lactancia apropiada. Los } \\
\text { lactantes sintomáticos deben ser tratados con glucosa por vía intravenosa. } \\
\text { (Ver el protocolo ABM sobre Hipoglucemia para más detalles) (Wight } \\
\text { 2006a, Wight } 2006 \text { b) } \\
\text { - Evidencia clínica y de laboratorio de deshidratación significativa (por } \\
\text { ejemplo, >10\% de pérdida de peso, sodio alto, alimentación pobre, } \\
\text { letargia, etc.) que no mejora después de una evaluación especializada y } \\
\text { un manejo apropiado de la lactancia (Yaseen } 2004, \text { Neifert } 2001 \text { ). } \\
\text { - La pérdida de peso del } 8-10 \% \text { acompañada de retraso en la lactogénesis } \\
\text { II (día } 5 \text { - } 120 \text { horas - o después) } \\
\text { - Movimientos intestinales lentos o presencia continua de meconio en las } \\
\text { heces en el día } 5 \text { (120 horas) (Neifert } 2001 \text {, ILCA } 2005 \text { ) } \\
\text { - Alimentación insuficiente a pesar de que la producción de leche es } \\
\text { adecuado (transferencia pobre de leche) (Neifert } 2001 \text { ) } \\
\text { - Hiperbilirrubinemia } \\
\text { - Ictericia "Neonatal" por inanición donde el consumo de leche es } \\
\text { pobre a pesar de una intervención apropiada (favor de ver el } \\
\text { Protocolo ABM de Ictericia en el lactante alimentado al seno materno) } \\
\text { - Ictericia relacionada con la lactancia cuando los niveles llegan a } \\
\text { >20-25 mg/dL ( } \mu \text { mol/L) en un lactante que por lo demás, muestra un } \\
\text { crecimiento adecuado y en el que una interrupción de la lactancia } \\
\text { puede ser útil ya sea por razones de diagnóstico y/o tratamiento } \\
\text { II.2. Indicaciones Maternas } \\
\text { - Separación de la madre y el lactante } \\
\text { - Retraso en la Lactogenesis II (día } 3-5 \text { o después - } 72-120 \text { horas - y un } \\
\text { consumo inadecuado del bebé (Neifert } 2001 \text { ) } \\
\text { - Retención de placenta (la lactogénesis probablemente ocurra después de } \\
\text { que los fragmentos de la placenta sean removidos) } \\
\text { - Síndrome de Sheehan (hemorragia posparto seguida por la ausencia de }\end{array}$ & 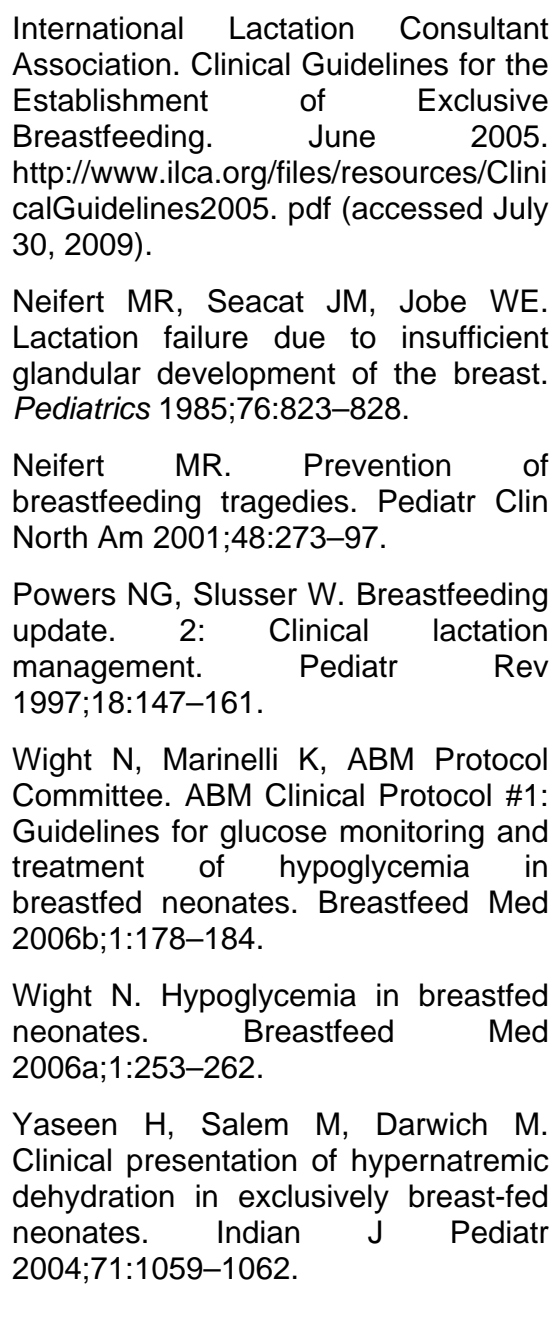 & $\begin{array}{l}\text { Protocolo ABM hipoglucemia (ABM } \\
\text { 1) } \\
\text { A. En RN sin síntomas clínicos: } \\
\text { 1. Continuar la LM o administrar a 1- } \\
5 \text { mL/kg de leche materna extraída o } \\
\text { suplemento (aprox. cada 1-2h.). } \\
\text { 2. Comprobar de nuevo la } \\
\text { concentración de glucosa en sangre } \\
\text { antes de cada toma hasta que el } \\
\text { valor sea aceptable y estable. } \\
\text { 3. Evitar tomas forzadas. } \\
\text { 4. Si el nivel de glucosa sigue siendo } \\
\text { bajo, comenzar la administración IV } \\
\text { de glucosa. } \\
5 \text {. La lactancia materna puede } \\
\text { continuar durante la administración } \\
\text { de glucosa IV. } \\
6 \text {. Documentar la respuesta al } \\
\text { tratamiento. } \\
\text { B. RN con síntomas clínicos o } \\
\text { niveles de glucosa en plasma <20-25 } \\
\text { mg/dL (<1,1 a } 1,4 \text { mmol/L): } \\
\text { 1. Iniciar solución de glucosa al } 10 \% \\
\text { por vía intravenosa. } \\
2 . \text { No confiar en la alimentación oral } \\
\text { o intragástrico para corregir } \\
\text { hipoglucemia extrema o clínicamente } \\
\text { significativa. } \\
3 \text {. La concentración de glucosa en } \\
\text { bebés que han tenido } \\
\text { signos clínicos deben mantenerse a } \\
>45 \text { mg/dl (>2,5 mmol/L). } \\
4 \text {. Ajustar la administración IV según } \\
\text { la concentración de glucosa en } \\
\text { sangre. } \\
5 \text {. Fomentar la lactancia frecuente. }\end{array}$ \\
\hline
\end{tabular}




\begin{tabular}{|c|c|c|c|}
\hline & $\begin{array}{l}\text { lactogénesis) } \\
\text { - Insuficiencia glandular primaria, ocurre en menos del } 5 \% \text { de las mujeres } \\
\text { (Insuficiencia primaria de la lactancia) evidenciada por el pobre desarrollo } \\
\text { mamario durante el embarazo e indicaciones mínimas de lactogénesis } \\
\text { - Patología o cirugía mamaria previa resultando en la producción escasa } \\
\text { de leche (Neifert 1985) } \\
\text { - Dolor intolerable durante los periodos de alimentación que no se alivia } \\
\text { con ninguna intervención }\end{array}$ & & $\begin{array}{l}\text { 6. Monitorizar la concentración de } \\
\text { glucosa antes de las tomas, mientras } \\
\text { se } \\
\text { disminuye el tratamiento por vía } \\
\text { intravenosa hasta que los valores } \\
\text { se estabilicen. } \\
\text { 7. Documentar la respuesta al } \\
\text { tratamiento. }\end{array}$ \\
\hline WHO 2009 & $\begin{array}{l}\text { Madres para quienes la lactancia no está contraindicada, aunque } \\
\text { presentan condiciones médicas preocupantes } \\
\text { •Absceso mamario: el amamantamiento debería continuar con el lado } \\
\text { no afectado; el amamantamiento con el pecho afectado puede } \\
\text { reiniciarse una vez se ha iniciado el tratamiento (WHO 1986); } \\
\text {-Mastitis - si la lactancia es muy dolorosa, debe extraerse la leche para } \\
\text { evitar que progrese la afección (WHO 2008); }\end{array}$ & 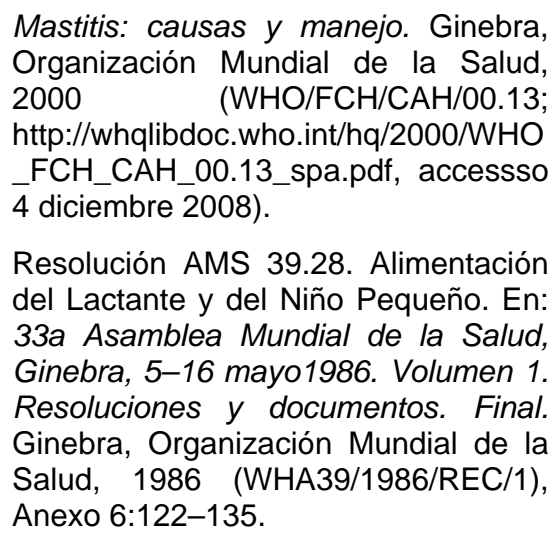 & \\
\hline $\begin{array}{l}\text { American } \\
\text { Academy of } \\
\text { Pediatrics } 2012\end{array}$ & NA & & $\begin{array}{l}\text { Solo indica contraindicaciones para } \\
\text { la LM }\end{array}$ \\
\hline
\end{tabular}

\subsection{Revisiones sistemáticas}

No se han localizado RS. 


\subsection{Resumen de GPC base disponibles}

La GPC de NICE (1) recomienda no administrar suplementos salvo que sea médicamente necesario en base al paso 6 de la estrategia de la IHAN y no encuentra ningún estudio que estudie de modo específico las circunstancias para la suplementación.

En la actualización de la GPC de NICE (2) tampoco se encuentran estudios.

La guía $B C(3)$ concluye que muy pocos $\mathrm{RN}$ sanos y a término requieren suplementos, ya que hay muy pocas condiciones médicas, permanentes o temporales, en las que la LM no está recomendada. Antes de empezar a administrar suplementos se debe evaluar a la madre y al RN, incluyendo la observación de la toma, para determinar que la suplementación es apropiada y necesaria. Se deben considerar los beneficios de la leche materna y los posibles riesgos asociados con el uso de sucedáneos a la hora de formular recomendaciones sobre alimentación infantil (4-6).

El protocolo de la ABM "alimentación suplementaria" (4) enumera una lista de posibles indicaciones para la administración de suplementos, clasificándolos por indicaciones de la madre y del niño (7-13).

En cuanto a las indicaciones de la madre se incluye:

- Separación de la madre y el lactante.

- Retraso en la lactogénesis II (día 3-5 - 72-120 horas - o después) asociado a la ingesta insuficiente de leche.

- Retención de placenta (la lactogénesis probablemente ocurra después de que los fragmentos de la placenta sean removidos).

- Síndrome de Sheehan (hemorragia posparto seguida por la ausencia de lactogénesis).

- Insuficiencia glandular primaria, ocurre en menos del $5 \%$ de las mujeres (Insuficiencia primaria de la lactancia) evidenciada por el pobre desarrollo mamario durante el embarazo e indicaciones mínimas de lactogénesis.

- Patología o cirugía mamaria previa resultando en la producción escasa de leche.

- Dolor intolerable durante los periodos de alimentación que no se alivia con ninguna intervención.

En relación a las indicaciones del niño se incluye:

-La hipoglucemia asintomática documentada por medición de glucosa en la sangre efectuada en el laboratorio (no por métodos de detección de cabecera) que no responde a una frecuencia de lactancia apropiada. En concreto, en el protocolo 1 de la ABM sobre hipoglucemia (14) se establece lo siguiente:

oEn RN sin síntomas clínicos: continuar la LM o administrar de $1-5 \mathrm{ml} / \mathrm{kg}$ de leche materna extraída o suplemento (aprox. cada 1-2h.), evitando las tomas forzadas y comprobando la concentración de glucosa en sangre antes de cada toma hasta que el valor sea aceptable y estable. Si el nivel de glucosa sigue siendo bajo, comenzar la administración IV de glucosa, continuando con la LM.

oEn $\mathrm{RN}$ con síntomas clínicos o con niveles de glucosa en plasma $<20-25$ $\mathrm{mg} / \mathrm{dl}(<1,1$ a $1,4 \mathrm{mmol} / \mathrm{l})$ : iniciar administración de solución de glucosa al $10 \%$ por vía intravenosa, fomentando la LM frecuente y monitorizando la concentración de glucosa antes de las tomas, mientras se disminuye el tratamiento por vía intravenosa hasta que los valores se estabilicen.

-Evidencia clínica y de laboratorio de deshidratación significativa (por ejemplo, $>10 \%$ de pérdida de peso, sodio alto, alimentación pobre, letargia, etc.) que no mejora después de una evaluación especializada y un manejo apropiado de la 
lactancia.

- La pérdida de peso del 8-10 \% acompañada de retraso en la lactogénesis II (día 5 - 120 horas - o después)

- Movimientos intestinales lentos o presencia continua de meconio en las heces en el día 5 (120 horas).

- Alimentación insuficiente a pesar de que la producción el suministro de leche es adecuada (transferencia pobre de leche).

- Hiperbilirrubinemia

- Ictericia "Neonatal" por inanición donde el consumo de leche es pobre a pesar de una intervención apropiada (favor de ver el Protocolo ABM de Ictericia en el lactante alimentado al seno materno).

- Ictericia relacionada con la lactancia cuando los niveles llegan a >20-25 $\mathrm{mg} / \mathrm{dL}(\mu \mathrm{mol} / \mathrm{L})$ en un lactante que por lo demás, muestra un crecimiento adecuado y en el que una interrupción de la lactancia puede ser útil ya sea por razones de diagnóstico y/o tratamiento.

La OMS (5) señala las condiciones médicas que pueden presentar madres sanas y que pueden requerir la administración de suplementos aunque la lactancia no está contraindicada. En el caso de absceso mamario el amamantamiento debería continuar con el lado no afectado mientras que el amamantamiento con el pecho afectado puede reiniciarse una vez se ha iniciado el tratamiento. En el caso de mastitis, si la lactancia es muy dolorosa debe extraerse la leche para evitar que progrese la afección.

En la búsqueda no se han localizado revisiones sistemáticas.

En resumen, las GPC y otros documentos de referencia evaluados concluyen que la leche materna es la mejor opción de alimentación para los recién nacidos, y que únicamente un pequeño porcentaje de niños requerirán alimentación suplementaria. Son muy pocas las razones por las cuales es necesario la administración de suplementos en madres y niños sanos.

\subsection{Conclusión}

x Adopción GPC/Revisión sistemática

Elaboración parcial

Elaboración de novo

ACTUALIZADO A FECHA DE: 31 de Octubre de 2016 


\section{De la evidencia a la recomendación (Tabla de EtR)}

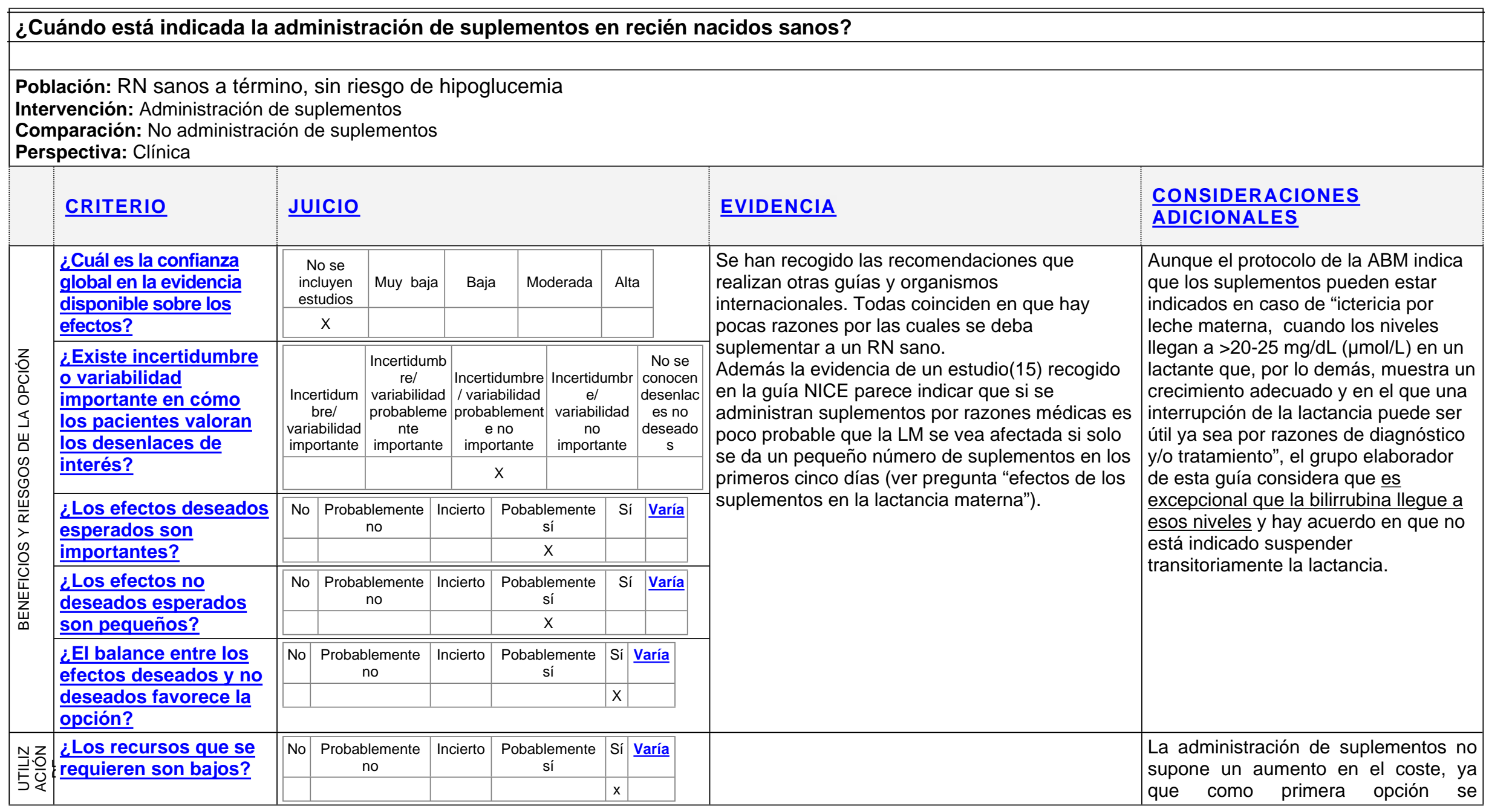




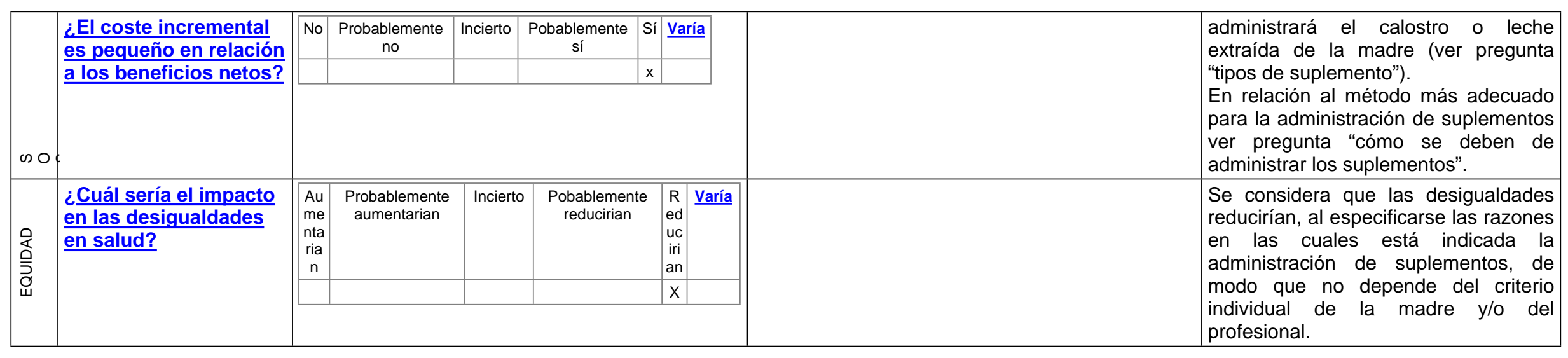




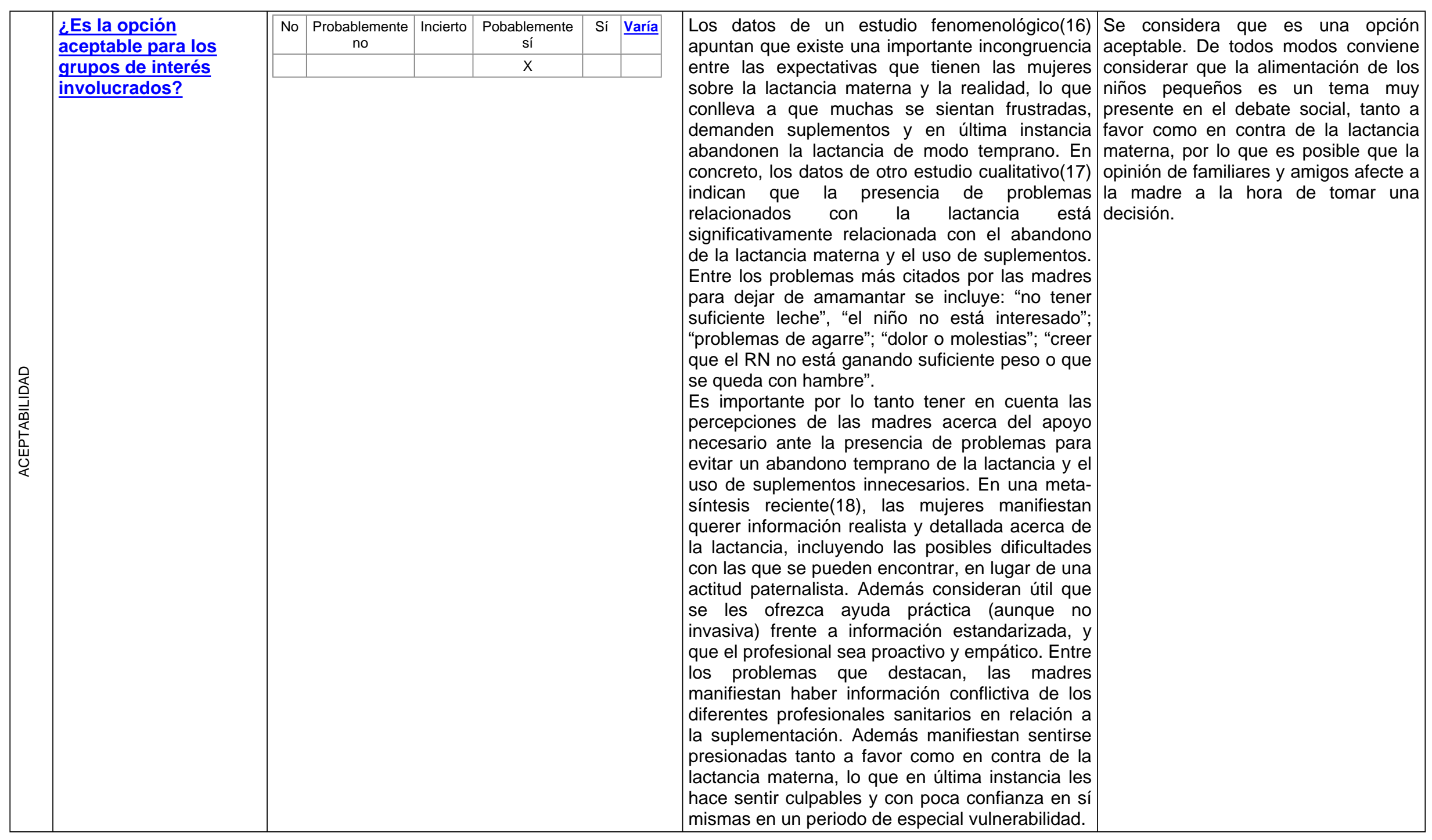




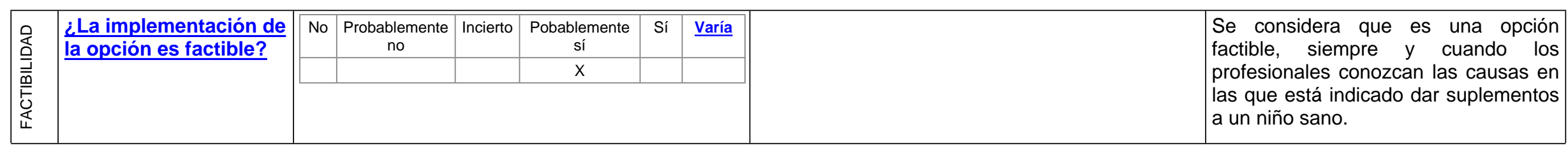

\begin{tabular}{|c|c|c|c|c|c|c|c|c|}
\hline $\begin{array}{l}\text { Balance de las } \\
\text { consecuencias }\end{array}$ & $\begin{array}{l}\text { Las consecuencias no } \\
\text { deseadas superan } \\
\text { claramente las } \\
\text { consecuencias deseadas } \\
\text { en la mayoría de los } \\
\text { escenarios }\end{array}$ & \multicolumn{2}{|c|}{$\begin{array}{l}\text { Las consecuencias no } \\
\text { deseadas } \\
\text { probablemente superan } \\
\text { las consecuencias } \\
\text { deseadas en la mayoría } \\
\text { de los escenarios }\end{array}$} & \multicolumn{2}{|c|}{$\begin{array}{c}\text { El balance entre las } \\
\text { consecuencias } \\
\text { deseadas y no } \\
\text { deseadas está muy } \\
\text { equilibrado o es incierto }\end{array}$} & \multicolumn{2}{|c|}{$\begin{array}{l}\text { Las consecuencias } \\
\text { deseadas } \\
\text { probablemente superan } \\
\text { las consecuencias no } \\
\text { deseadas en la mayoría } \\
\text { de los escenarios }\end{array}$} & $\begin{array}{c}\text { Las consecuencias } \\
\text { deseadas claramente } \\
\text { superan las } \\
\text { consecuencias no } \\
\text { deseadas en la mayoría } \\
\text { de los escenarios } \\
\mathbf{X}\end{array}$ \\
\hline $\begin{array}{l}\text { Tipo de } \\
\text { recomendación }\end{array}$ & \multicolumn{2}{|c|}{$\begin{array}{l}\text { Se recomienda no ofrecer la } \\
\text { opción }\end{array}$} & \multicolumn{2}{|c|}{ Se sugiere no ofrecer la opción } & \multicolumn{2}{|c|}{ Se sugiere ofrecer la opción } & \multicolumn{2}{|c|}{$\begin{array}{l}\text { Se recomienda ofrecer la } \\
\text { opción } \\
\mathbf{X}\end{array}$} \\
\hline & \multicolumn{8}{|c|}{$\begin{array}{l}\text { Recomendación de buena práctica } \\
\text { Condiciones médicas del recién nacido sano que pueden requerir suplementos temporalmente (leche materna extraída o } \\
\text { de fórmula) } \\
\text { •El diagnóstico de hipoglucemia debe realizarse siempre mediante análisis de laboratorio. La tira reactiva es una técnica de } \\
\text { cribado. } \\
\checkmark \quad \text { En recién nacidos con factores de riesgo de hipoglucemia sin síntomas clínicos se recomienda continuar la lactancia } \\
\text { materna o administrar a } 1-5 \mathrm{ml} / \mathrm{kg} \text { de leche materna extraída o de fórmula cada } 1-2 \mathrm{~h} \text {. Se controlará la glucemia hasta que } \\
\text { el valor sea aceptable y estable. Si el nivel de glucosa sigue siendo bajo, será necesaria la administración intravenosa de } \\
\text { glucosa, continuando con la lactancia materna. } \\
\quad \text { En recién nacidos con síntomas clínicos o con niveles de glucosa en plasma }<20-25 \text { mg/dl (<1,1 a } 1,4 \text { mmol/l) se iniciará } \\
\text { la administración de solución de glucosa al } 10 \% \text { por vía intravenosa. Se recomendará mantener la lactancia materna y } \\
\text { monitorizar la glucemia antes de las tomas con la frecuencia necesaria, mientras se disminuye el tratamiento por vía } \\
\text { intravenosa hasta que los valores se estabilicen. } \\
\text { •Evidencia clínica y de laboratorio de deshidratación (por ejemplo,>10\% de pérdida de peso, sodio alto, alimentación pobre etc.), } \\
\text { junto con la valoración y el manejo apropiado de las dificultades de la lactancia. } \\
\text { •Hiperbilirrubinemia o ictericia neonatal por ingesta de leche insuficiente a pesar de una intervención adecuada. En el recién } \\
\text { nacido la ictericia se acompaña de una pérdida excesiva de peso de más del } 8-10 \% \text { o escasa ganancia ponderal }\end{array}$} \\
\hline
\end{tabular}




\begin{tabular}{|c|c|}
\hline & $\begin{array}{l}\text { posteriormente. En la madre puede acompañarse de retraso en la subida de la leche o lactogénesis II más allá del quinto día } \\
\text { postparto. } \\
\text { - Movimientos intestinales lentos o presencia contínua de meconio en las deposiciones en el quinto día. } \\
\text {-Alimentación insuficiente a pesar de que el suministro de leche es adecuado (transferencia pobre de leche). } \\
\text { Condiciones de madres sanas cuyos hijos pueden requerir suplementos temporalmente } \\
\text {-RRetraso en la lactogénesis II (día } 3 \text { a } 5 \text { ) y un consumo inadecuado en el recién nacido. } \\
\text { - Retención de placenta (la lactogénesis probablemente ocurra después de que los fragmentos de placenta sean retirados) } \\
\text { - Insuficiencia glandular primaria (insuficiencia primaria de la lactancia) que ocurre en menos del } 5 \% \text { de las mujeres. Se } \\
\text { manifiesta por un pobre desarrollo mamario durante el embarazo y señales mínimas de lactogénesis. } \\
\text {-Patología o cirugía mamaria que ocasiona hipogalactia. } \\
\text {-Dolor intolerable durante los periodos de alimentación que no se alivia con ninguna intervención. } \\
\text { Necesidad de separación de la madre y del recién nacido }\end{array}$ \\
\hline Justificación & $\begin{array}{l}\text { Muy pocos recién nacidos sanos y a término requieren suplementos, ya que hay muy pocas condiciones médicas, permanentes o } \\
\text { temporales, en las que la lactancia materna no está recomendada. Antes de empezar a administrar suplementos se debe evaluar } \\
\text { a la madre y al RN, incluyendo la observación de la toma, para determinar que la suplementación es apropiada y necesaria. Se } \\
\text { deben considerar los beneficios de la leche materna y los posibles riesgos asociados con el uso de sucedáneos a la hora de } \\
\text { formular recomendaciones sobre la alimentación del lactante. }\end{array}$ \\
\hline $\begin{array}{l}\text { Consideraciones de } \\
\text { subgrupos }\end{array}$ & $\begin{array}{l}\text { Hay muchas madres que se sienten frustradas cuando reciben del profesional sanitario la recomendación de dar un suplemento } \\
\text { de agua o leche a su hijo recién nacido. Las razones en las que éstos se basan, les confunden, y les hacer dudar de su capacidad } \\
\text { de amamantar quitándoles seguridad acerca de la calidad y cantidad de su leche y poniendo en riesgo la continuidad de la } \\
\text { lactancia materna cuando apenas ha comenzado. }\end{array}$ \\
\hline $\begin{array}{l}\text { Consideraciones } \\
\text { para la } \\
\text { implementación }\end{array}$ & $\begin{array}{l}\text { Es necesario que los profesionales sanitarios conozcan los motivos médicos en los que puede ser necesario administrar } \\
\text { suplementos a un recién nacido sano, para evitar su uso innecesario. Así mismo los profesionales deben saber que la mayoría de } \\
\text { los problemas se pueden prevenir con un inicio precoz de la lactancia y un buen apoyo a la madre que amamanta. Por lo tanto, } \\
\text { deben de estar preparados para prestar el apoyo necesario a las madres, teniendo en cuenta sus necesidades individuales y } \\
\text { respondiendo a sus dudas y preocupaciones. } \\
\begin{array}{l}\text { Además cuando sea necesaria la administración de suplementos los profesionales deben de saber transmitir confianza a las } \\
\text { madres y prestarles el apoyo y el seguimiento adecuados para superar sus dificultades. El protocolo de la ABM establece una } \\
\text { serie de motivos inapropiados para la administración de suplementos y las consecuencias que conllevan (ver anexo 12). }\end{array}\end{array}$ \\
\hline & \\
\hline
\end{tabular}


Prioridades para la

investigación 


\section{Anexos}

Anexo I. Estrategias de búsqueda

Anexo II. Valoración de la calidad de los estudios

\section{Anexo I. Estrategias de búsqueda}

Es la estrategia general de las preguntas de suplementos.

\section{Anexo II. Valoración de la calidad de los estudios}

En esta pregunta se ha adoptado las evidencias de las GPC por lo que no hay tablas de la calidad de los estudios. 


\section{Bibliografía}

(1) NICE. Postnatal care up to 8 weeks after birth. Julio 2006 (actualizado en Febrero de 2015). Disponible en: http://guidance.nice.org.uk/CG37.

(2) National Institute for Clinical Excellence (NICE). Recommendation for Guidance Executive Review of Clinical Guideline (CG37) - Postnatal care. 2012. Disponible en: http://www.nice.org.uk/guidance/cg37/resources/cg37-postnatalcare-review-decision-march-20122.

(3) Perinatal Services BC Health Promotion Guideline. Breastfeeding Healthy Term Infants. March $2015 . \quad$ Disponible en: http://www.perinatalservicesbc.ca/Documents/GuidelinesStandards/HealthPromotion/BreastfeedingHealthyTermInfantGuideline.pdf.

(4) Academy of Breastfeeding Medicine Protocol Committee. ABM clinical protocol\# 3: hospital guidelines for the use of supplementary feedings in the healthy term breastfed neonate, revised 2009. 2009.

(5) World Health Organization and UNICEF. Baby-friendly hospital initiative : revised, updated and expanded for integrated care. Section 3, Breastfeeding promotion and support in a baby-friendly hospital: a 20-hour course for maternity staff. 2009.

(6) Ketan G, Ketan S. American Academy of Pediatrics: Breastfeeding and the Use of Human Milk. Pediatrics 2005;115(2):496-506.

(7) Neifert MR, Seacat JM, Jobe WE. Lactation failure due to insufficient glandular development of the breast. Pediatrics 1985;76(5):823-8.

(8) Powers NG, Slusser W. Breastfeeding update 2: clinical lactation management. Pediatrics in Review 1997;18(5):147-61.

(9) Neifert MR. Prevention of breastfeeding tragedies. Pediatric Clinics of North America 2001;48(2):273-97.

(10) Yaseen H, Salem M, Darwich M. Clinical presentation of hypernatremic dehydration in exclusively breast-fed neonates. The Indian Journal of Pediatrics 2004;71(12):1059-62.

(11) International Lactation Consultant Association. Clinical Guidelines for the Establishment of Exclusive Breastfeeding. June 2005. Disponible en: http://www.breastcrawl.org/pdf/ilca-clinical-guidelines-2005.pdf. $\mathrm{h}$.

(12) Wight N, Marinelli KA. ABM Protocols: ABM Clinical Protocol\# 1: Guidelines for Glucose Monitoring and Treatment of Hypoglycemia in Breastfed Neonates. Breastfeeding Medicine 2006;1(3):178-84.

(13) Wight NE. Hypoglycemia in breastfed neonates. Breastfeeding Medicine 2006;1(4):253-62.

(14) Wight N, Marinelli KA, the Academy of Breastfeeding Medicine. ABMProtocol. ABM Clinical Protocol \#1: Guidelines for Blood Glucose Monitoring and Treatment of Hypoglycemia in Term and Late-Preterm Neonates, Revised 2014. Breastfeeding Medicine 2014;9(4):173-9.

(15) Dyson L, Renfrew MJ, McFadden A, McCormick F, Herbert G, Thomas J. Effectiveness of public health interventions to promote the duration of breastfeeding: systematic review. London: National Institute for Health and Clinical Excellence 2006.

(16) Mozingo JN, Davis MW, Droppleman PG, Merideth A. "It Wasn't Working": Women's Experiences with Short-Term Breastfeeding. MCN: The American Journal of Maternal/Child Nursing 2000;25(3):120-6. 
(17) Odom EC, Li R, Scanlon KS, Perrine CG, Grummer-Strawn L. Reasons for earlier than desired cessation of breastfeeding. Pediatrics 2013;131(3):e726e732.

(18) Schmied V, Beake S, Sheehan A, McCourt C, Dykes F. Womens perceptions and experiences of breastfeeding support: A metasynthesis. Birth $2011 ; 38(1): 49-60$. 


\section{PREGUNTA CLÍNICA № 15}

\section{¿Cuál es el suplemento más adecuado en recién nacidos sanos?}

\section{1- PREGUNTA CLÍNICA EN FORMATO PICO}

\begin{tabular}{|c|c|}
\hline Pacientes & $\begin{array}{l}\text { Recién nacidos sanos a término que están siendo } \\
\text { amamantados }\end{array}$ \\
\hline Intervención & $\begin{array}{l}\text { Leche materna extraída de la propia madre, leche materna } \\
\text { donada de bancos de leche, suero glucosado, fórmula de } \\
\text { inicio, fórmula hidrolizada con alto grado de hidrólisis, fórmula } \\
\text { hipoalergénica (parcialmente hidrolizada) }\end{array}$ \\
\hline Comparación & $\begin{array}{l}\text { Leche materna extraída de la propia madre, leche materna de } \\
\text { bancos de leche, suero glucosado, fórmula de inicio, fórmula } \\
\text { hidrolizada con alto grado de hidrólisis, fórmula } \\
\text { hipoalergénica (parcialmente hidrolizada) }\end{array}$ \\
\hline Resultados & $\begin{array}{l}\text { Sobre el lactante: } \\
\text { - Hipoglucemia } \\
\text { - Pérdida de peso mayor del } 10 \% \text { en las primeras } 48- \\
\text { - } 72 \text { horas } \\
\text { - Riericia } \\
\text { - Riesgo de cualquier tipo de alergia } \\
\text { - Riesgo de alergia a la leche de vaca } \\
\text { - Riesgo de dermatitis atópica } \\
\text { - Riesgo de rinitis alérgica } \\
\text { - Riesgo de asma } \\
\text { Sobre la lactancia materna: } \\
\text { - Tasa de lactancia materna exclusiva al alta } \\
\text { - Tospitalaria } \\
\text { - Tasa de lactancia materna exclusiva al mes } \\
\text { - Tasa de cualquier tipo de lactancia materna a los 4-6 }\end{array}$ \\
\hline Tipo de estudio & $\begin{array}{l}\text { RS de ECA, ECA, RS de estudios observacionales o estudios } \\
\text { observacionales }\end{array}$ \\
\hline
\end{tabular}

\section{2- INTRODUCCIÓN}

En las maternidades se utilizan diferentes alternativas para suplementar a los recién nacidos amamantados: leche materna, agua, suero glucosado, formula de inicio o formulas hidrolizadas. Nos planteamos cuál de todas estas alternativas es la más adecuada para suplementar a los recién nacidos amantados que lo precisen. 


\section{ESTRATEGIA DE ELABORACIÓN DE LA PREGUNTA}

\subsection{GPC Base}

Tabla 2- Resumen de GPC Base

\begin{tabular}{|c|c|c|c|c|}
\hline $\begin{array}{l}\text { Guía } \\
\text { (Enfoque) }\end{array}$ & $\begin{array}{l}\text { Resumen sobre la evidencia } \\
\text { (Calidad de la evidencia) }\end{array}$ & $\begin{array}{l}\text { Recomendaciones } \\
\text { (Grado) }\end{array}$ & $\begin{array}{l}\text { Referencias bibliográficas } \\
\text { (Tipo de publicación) }\end{array}$ & Comentarios \\
\hline $\begin{array}{l}\text { NICE_2006 } \\
\text { (Actualiz. } \\
\text { 2011) }\end{array}$ & $\begin{array}{l}\text { La administración de suplementos con líquidos que no sean } \\
\text { leche materna influyen de forma negativa sobre la duración } \\
\text { de la lactancia (Nivel 2) } \\
\text { Si se requiere la administración de suplementos, la guía } \\
\text { basada en la evidencia del Ministerio de Salud de Singapur } \\
\text { recomienda que se proporcione calostro o leche materna } \\
\text { como primera opción. }\end{array}$ & $\begin{array}{l}\text { 28. Si el recién nacido no está tomando suficiente } \\
\text { leche directamente desde el pecho, y se requiere } \\
\text { suplementación, se debería suministrar leche } \\
\text { materna extraída mediante taza o biberón [B] } \\
\text { 29. No se recomienda suplementar con otros } \\
\text { fluidos que no sean leche materna [C] }\end{array}$ & $\begin{array}{l}\text { Singapore Ministry of Health } \\
2002 \text { (Guía de práctica clínica) }\end{array}$ & $\begin{array}{l}\text { NICE publicó en } 2010 \text { un } \\
\text { documento sobre los } \\
\text { bancos de leche, en el } \\
\text { que señala que "Está } \\
\text { ampliamente reconocido } \\
\text { que no hay suficiente } \\
\text { evidencia de calidad sobre } \\
\text { la efectividad de la leche } \\
\text { donada para mejorar los } \\
\text { resultados en salud. } \\
\text { También hay } \\
\text { preocupación en que tanto } \\
\text { la investigación en } \\
\text { relación a la efectividad de } \\
\text { la leche donada y el } \\
\text { acceso a la misma está } \\
\text { siendo restringida por falta } \\
\text { de comprensión del } \\
\text { proceso de donación de } \\
\text { leche a los bancos, y } \\
\text { específicamente sobre los } \\
\text { procesos para asegurar la } \\
\text { seguridad de la leche } \\
\text { donada"(disponible en: } \\
\text { http://www.ncbi.nlm.nih.g } \\
\text { ov/pubmedhealth/PMH003 } \\
\text { 3790/). } \\
\text { En el "NICE pathway } \\
\text { about infant feeding and } \\
\text { maternal nutrition in } \\
\text { postnatal care" se señala } \\
\text { que se advierta a las }\end{array}$ \\
\hline
\end{tabular}




\begin{tabular}{|c|c|c|c|c|}
\hline $\begin{array}{c}\text { Guía } \\
\text { (Enfoque) }\end{array}$ & $\begin{array}{l}\text { Resumen sobre la evidencia } \\
\text { (Calidad de la evidencia) }\end{array}$ & $\begin{array}{l}\text { Recomendaciones } \\
\text { (Grado) }\end{array}$ & $\begin{array}{l}\text { Referencias bibliográficas } \\
\text { (Tipo de publicación) }\end{array}$ & Comentarios \\
\hline & & & & $\begin{array}{l}\text { madres que no hay } \\
\text { evidencia suficiente sobre } \\
\text { la prevención de } \\
\text { enfermedad alérgica por } \\
\text { parte de los hidrolizados } \\
\text { parciales o extensos. } \\
\text { (disponible en: } \\
\text { http://pathways.nice.org.uk } \\
\text { /pathways/postnatal- } \\
\text { care/infant-feeding-and- } \\
\text { maternal-nutrition-in- } \\
\text { postnatal-care). }\end{array}$ \\
\hline $\begin{array}{l}\text { Perinatal } \\
\text { Services BC } \\
2011\end{array}$ & $\begin{array}{l}\text { Las intervenciones dirigidas a niños con hipoglucemia } \\
\text { documentada varían en función de las circunstancias } \\
\text { individuales. Entre estas intervenciones se encuentra el } \\
\text { aumento de la frecuencia de tomas, la suplementación } \\
\text { enteral con leche materna extraída (de la madre o leche } \\
\text { pasteurizada procedente de bancos de leche) o, si es } \\
\text { necesario, un sustituto de la leche materna (89). } \\
\text { Los recién nacidos con hipoglucemia sintomática, y aquellos } \\
\text { con hipoglucemia asintomática que no respondieron a la } \\
\text { suplementación enteral, reciben generalmente tratamiento } \\
\text { con dextrosa de forma intravenosa (89). } \\
\text { Para niños diagnosticados de hipoglucemia: apoyar a la } \\
\text { madre y asegurar que no hay nada malo con su leche; } \\
\text { iniciar y mantener tomas tempranas y frecuentes; si es } \\
\text { necesario, empezar intervenciones para ayudar a establecer } \\
\text { el suministro de leche materna90. } \\
\text { En ictericia de aparición precoz por falta de ingesta de leche } \\
\text { materna: } \\
\text { La suplementación no está generalmente indicada, pero si } \\
\text { es necesaria, suplementar con la leche materna extraída o } \\
\text { leche pasteurizada procedente de bancos de leche, o con } \\
\text { sustituto de leche materna. No se recomienda la } \\
\text { suplementación con suero glucosado } 93,95 \text {. }\end{array}$ & & $\begin{array}{l}\text { 89. Canadian Paediatric } \\
\text { Society: Fetus and Newborn } \\
\text { Committee. (2004 (Guía) } \\
\text { 90. The Academy of } \\
\text { Breastfeeding Medicine (2006 } \\
\text { (Guía) } \\
\text { 93. Canadian Paediatric } \\
\text { Society (CPS): Fetus and } \\
\text { Newborn Committee. (2007 } \\
\text { (Guía) } \\
\text { 95. Deshpande PG. (2008, } \\
\text { updated } 2010 \text { (artículo online) }\end{array}$ & \\
\hline
\end{tabular}

\subsection{Otros documentos}




\begin{tabular}{|c|c|c|c|c|}
\hline $\begin{array}{l}\text { Guía } \\
\text { (Enfoque) }\end{array}$ & $\begin{array}{l}\text { Resumen sobre la evidencia } \\
\text { (Calidad de la evidencia) }\end{array}$ & $\begin{array}{l}\text { Recomendaciones } \\
\text { (Grado) }\end{array}$ & $\begin{array}{l}\text { Referencias bibliográficas } \\
\text { (Tipo de publicación) }\end{array}$ & Comentarios \\
\hline Iniciativa IHAN & $\begin{array}{l}\text { En relación a la elección del tipo de suplementos, la } \\
\text { leche humana extraída de la propia madre es el suplemento } \\
\text { de elección (19), pero la obtención de suficiente calostro en } \\
\text { los primeros días puede ser difícil. Si esto ocurre es } \\
\text { necesario tranquilizar y transmitir confianza a la madre. Si el } \\
\text { volumen de calostro materno es insuficiente, se prefiere la } \\
\text { utilización de leche humana pasteurizada donada a otros } \\
\text { suplementos. El médico debe sopesar los riesgos y } \\
\text { beneficios potenciales de otros suplementos como fórmulas } \\
\text { estándar o hidrolizadas, en función de los recursos } \\
\text { disponibles, factores de riesgo como historia familiar de } \\
\text { atopia, edad del lactante, cantidades requeridas y su } \\
\text { impacto potencial en el establecimiento de la lactancia. }\end{array}$ & $\begin{array}{l}\text { Paso } 6 \text { de la estrategia IHAN: «No dar a los recién } \\
\text { nacidos más que leche materna, sin ningún otro } \\
\text { alimento o bebida, a no ser que esté médicamente } \\
\text { indicado» }\end{array}$ & $\begin{array}{l}\text { (12) Blomquist HK (1994) } \\
\text { (17) Powers NG, } 1997 \text { (Guía) } \\
\text { (19) American Academy of } \\
\text { Pediatrics (1997) (Policy } \\
\text { Statement) }\end{array}$ & $\begin{array}{l}\text { Define: } \\
\text { - Alimentos prelácteos: } \\
\text { administración de agua, } \\
\text { suero glucosado o } \\
\text { sucedáneos de leche } \\
\text { materna antes de la } \\
\text { primera toma de pecho. } \\
\text { - Suplementos: } \\
\text { administración de agua, } \\
\text { suero glucosado o } \\
\text { sucedáneos de leche } \\
\text { materna después de la } \\
\text { primera toma de leche } \\
\text { materna. }\end{array}$ \\
\hline $\begin{array}{l}\text { ABM Clinical } \\
\text { Protocol \#3, } \\
2009\end{array}$ & \multicolumn{2}{|c|}{$\begin{array}{l}\text { Elección del tipo de suplemento } \\
\text { 1. La leche materna extraída es la primera opción para la suplementación } 19,41 \text {, pero puede que en los primeros } \\
\text { días no se cuente con suficiente cantidad de calostro ( } 0-72 \mathrm{~h} \text { ). La madre puede necesitar consuelo y educación si } \\
\text { se presentan estas dificultades. En los primeros días la extracción manual puede permitir obtener mayores } \\
\text { cantidades que una bomba de extracción } 42 \text {. Masajearse el pecho, junto con la extracción con bomba mecánica } \\
\text { puede aumentar también la cantidad de leche disponible } 43 \text {. } \\
\text { 2. Si el volumen de calostro de la madre no cubre las necesidades de su hijo, es preferible que se utilice leche } \\
\text { donada pasteurizada que otro tipo de suplementos. } 41 \\
\text { 3. Es mejor utilizar fórmulas de hidrolizados de proteínas que cualquier leche artificial estándar, puesto que se } \\
\text { evita la exposición a las proteínas de la leche de vaca, se reducen los niveles de bilirrubina más rápidamente } 44 \text { y } \\
\text { puede llevar al mensaje psicológico que la suplementación es una terapia temporal. } \\
\text { 4. El médico debe sopesar los riesgos y beneficios potenciales de la utilización de otros suplementos, como } \\
\text { fórmulas estándar, fórmulas de soja o hidrolizados de proteínas, dependiendo de los recursos disponibles, los } \\
\text { factores de riesgo familiares como la atopía, la edad del niño, la cantidad que necesita, y el impacto potencial } \\
\text { sobre el establecimiento de la lactancia materna. } \\
\text { Volumen de los suplementos } \\
\text { 1. Varios estudios proporcionan una idea de la cantidad que se toma al pecho en cada momento. En un estudio se }\end{array}$} & $\begin{array}{l}\text { 19. American Academy of } \\
\text { Pediatrics, Section on } \\
\text { Breastfeeding. } \\
\text { Policy statement: } \\
\text { Breastfeeding and the use of } \\
\text { human milk. } \\
\text { Pediatrics 2005;115:496-506. } \\
\text { 41. Global Strategy for Infant } \\
\text { and Young Child Feeding. } \\
\text { World Health } \\
\text { Organization/UNICEF, } \\
\text { Geneva, 2003. } \\
\text { 42. Morton J, 2007. } \\
\text { 43. Morton J, 2007. } \\
\text { 44. Gourley GR, } 1999 \\
\text { 45. Saint L, } 1984 \\
\text { 46. Casey CE,1986 } \\
\text { 47. Evans KC, } 2003 \\
\text { 48. Dollberg S, } 2001 \\
\end{array}$ & $\begin{array}{l}\text { Necesidades de } \\
\text { investigación } \\
\text { Se requiere investigación } \\
\text { para establecer } \\
\text { recomendaciones } \\
\text { basadas en la evidencia } \\
\text { sobre el volumen de } \\
\text { suplementación apropiado } \\
\text { para condiciones } \\
\text { espefícifcas y si varía en } \\
\text { función de si se trata de } \\
\text { calostro o leche de } \\
\text { fórmula. Otras preguntas } \\
\text { específicas incluyen: ¿El } \\
\text { volumen de suplemento } \\
\text { debería ser independiente } \\
\text { del peso del niño o un } \\
\text { volumen por kg? ¿La } \\
\text { suplementación debería } \\
\text { "maquillar" la pérdida }\end{array}$ \\
\hline
\end{tabular}




\begin{tabular}{|c|c|c|c|}
\hline $\begin{array}{l}\text { Guía } \\
\text { (Enfoque) }\end{array}$ & $\begin{array}{l}\text { Resumen sobre la evidencia } \\
\text { (Calidad de la evidencia) }\end{array}$ & $\begin{array}{l}\text { Referencias bibliográficas } \\
\text { (Tipo de publicación) }\end{array}$ & Comentarios \\
\hline & 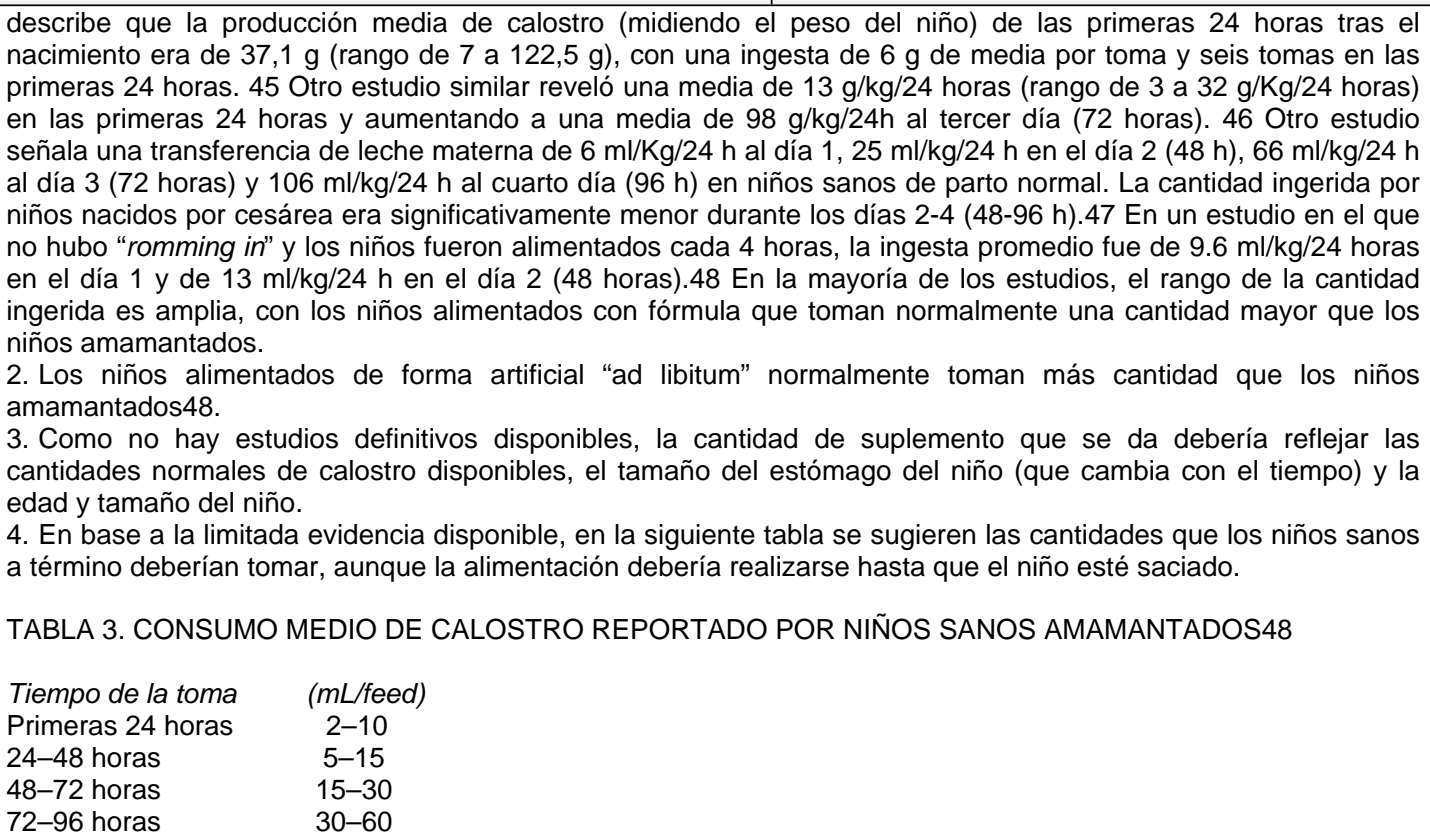 & & $\begin{array}{l}\text { acumulada de peso? } \\
\text { ¿Los intervalos de } \\
\text { alimentación deberían ser } \\
\text { diferentes para los } \\
\text { suplementos? }\end{array}$ \\
\hline
\end{tabular}




\subsection{Revisiones sistemáticas}

Se han identificado varias revisiones sistemáticas que abordan el efecto del uso de diferentes fórmulas y líquidos adicionales en la salud del niño y en el éxito de la lactancia materna. Dos de estas revisiones $(1 ; 2)$ abordan el uso temprano de alimentos y de líquidos adicionales en niños sanos a término amamantados, y otras cuatro revisiones comparan la utilización de fórmulas parcialmente hidrolizadas frente a fórmulas con alto grado de hidrólisis o fórmulas estándar (3-5), aunque una de ellas también compara la utilización de estas fórmulas frente a leche materna donada (3). La revisión de Iskedjian $\mathrm{M}$ et al se centra en medir el efecto de la utilización de fórmulas hidrolizadas en la prevención de dermatitis atópica y la de Szajewska $\mathrm{H}$ et al en la prevención de cualquier enfermedad alérgica (4).

Se ha identificado también otra revisión sistemática (de Silva D, 2014) sobre la prevención primaria de alergia alimentaria en niños y adultos, en la que entre otros aspectos, se resume la evidencia que existe en relación a las alternativas que existen a la fórmula de inicio estándar.

Por otro lado, se han identificado otras revisiones que abordan la utilización de fórmulas de soja para la prevención de alergia e intolerancia alimentaria (6), así como el uso de fórmulas basadas en aminoácidos para niños con alergia a la leche de vaca (7). En cuanto a la leche materna donada, se han identificado tres revisiones, todas ellas en prematuros o niños con bajo peso al nacer, (8-10), así como una revisión más antigua sobre la prevención de enterocolitis necrotizante en niños prematuros (11).

Las revisiones que responden realmente a la pregunta son las revisiones de Osborn et al, 2006, Szajewska et al, 2010 y la revisión de Becker et al, 2011. La revisión de Osborn (3) concluye que hay evidencia limitada que apoye que la alimentación prolongada con fórmulas hidrolizadas en comparación con fórmulas estándar reduce el riesgo de cualquier alergia y de alergia a la leche de vaca en los lactantes de alto riesgo de enfermedad alérgica que no pueden alimentarse con lactancia materna exclusiva. Sin embargo, en vista de los problemas metodológicos y la inconsistencia de los resultados, también señalan que se requieren mejores ECA que comparen fórmulas de suero parcialmente hidrolizado con fórmulas de caseína con alto grado de hidrólisis y fórmulas estándar. El metaanálisis de Szajewska et al (4) compara el uso de fórmula de suero parciamente hidrolizado frente al uso de fórmula estándar y de caseína o de suero con alto grado de hidrólisis. Los autores del metaanálisis concluyen que hay evidencia para recomendar el uso de fórmulas de suero parcialmente hidrolizado para prevenir enfermedad alérgica, particularmente dermatitis atópica, aunque también señala que muchos de los estudios tienen serias limitaciones metodológicas. Finalmente, de estas dos revisiones se ha elegido la de Osborn DA para la presentación de los datos en el perfil de evidencia GRADE. 
Tabla 3- Resumen de RS actuales

\begin{tabular}{|c|c|c|c|c|c|c|}
\hline $\begin{array}{l}\text { Referencia } \\
\text { (Cita } \\
\text { Abreviada) }\end{array}$ & $\begin{array}{l}\text { Estudio (Diseño y } \\
\text { objetivo) }\end{array}$ & $\begin{array}{l}\text { Población } \\
\text { (no y características) }\end{array}$ & $\begin{array}{l}\text { Descripción de las intervenciones } \\
\text { comparaciones, exposiciones o } \\
\text { pruebas a estudio }\end{array}$ & $\begin{array}{l}\text { Resultados } \\
\text { (Estimadores de resultados-Magnitud del } \\
\text { efecto) }\end{array}$ & $\begin{array}{l}\text { Conclusiones } \\
\text { (conclusiones) }\end{array}$ & $\begin{array}{l}\text { Comentarios } \\
\text { Calidad de la } \\
\text { evidencia } \\
\text { Financiación } \\
\text { comentarios) }\end{array}$ \\
\hline $\begin{array}{l}\text { Osborn DA, } \\
2006\end{array}$ & $\begin{array}{l}\text { Metaanálisis de } \\
\text { ECA } \\
\text { Objetivos: } \\
\text { determinar el efecto } \\
\text { de fórmulas } \\
\text { hidrolizadas en } \\
\text { alergia e } \\
\text { intolerancia } \\
\text { alimentaria en } \\
\text { lactantes y niños en } \\
\text { comparación al uso } \\
\text { de fórmulas de vaca } \\
\text { adaptadas o leche } \\
\text { humana. } \\
\text { Si las fórmulas } \\
\text { hidrolizadas son } \\
\text { efectivas, } \\
\text { determinar cuál es } \\
\text { la más efectiva } \\
\text { (tanto parcial como } \\
\text { con alto grado de } \\
\text { hidrólisis). } \\
\text { Determinar que } \\
\text { niños se benefician } \\
\text { (bajo o alto riesgo } \\
\text { de enfermedad } \\
\text { alérgica, con } \\
\text { exposición breve o } \\
\text { larga de fórmula). }\end{array}$ & $\begin{array}{l}22 \text { estudios } \\
\text { cumplieron con los } \\
\text { criterios de inclusión } \\
\text { De alto riesgo: } 12 \\
\text { estudios } \\
\text { Riesgo no } \\
\text { especificado: } 5 \\
\text { De bajo riesgo: } 1\end{array}$ & $\begin{array}{l}\text { Comparaciones que se estudian: } \\
\text { 1. Exposición temprana breve vs. } \\
\text { leche materna } \\
\text { 2. Exposición prolongada fórmula } \\
\text { hidrolizada vs. leche materna } \\
\text { 3. Exposición temprana breve de } \\
\text { fórmula hidrolizada vs. fórmula de } \\
\text { leche de vacafórmula estándar } \\
\text { 4. Exposición prolongada fórmula } \\
\text { hidrolizada vs. fórmula leche de } \\
\text { vaca } \\
\text { 5. Exposición prolongada fórmula } \\
\text { hidrolizada vs. fórmula leche de } \\
\text { vaca } \\
\text { 6. Exposición prolongada fórmula } \\
\text { hidrolizada vs. fórmula leche de } \\
\text { vaca- niños de alto riesgo } \\
\text { 7. Exposición prolongada fórmula } \\
\text { con alto grado de hidrólisis vs. } \\
\text { fórmula leche de vaca } \\
\text { 8. Exposición prolongada fórmula } \\
\text { parcialmente hidrolizada vs. } \\
\text { fórmula leche de vaca } \\
\text { 9. Exposición prolongada fórmula } \\
\text { con alto grado de hidrólisis vs. } \\
\text { fórmula parcialmente hidrolizada } \\
\text { 10. Exposición prolongada sólo } \\
\text { fórmula hidrolizada vs. fórmula } \\
\text { leche de vaca } \\
\text { Y otros análisis de subgrupos. }\end{array}$ & 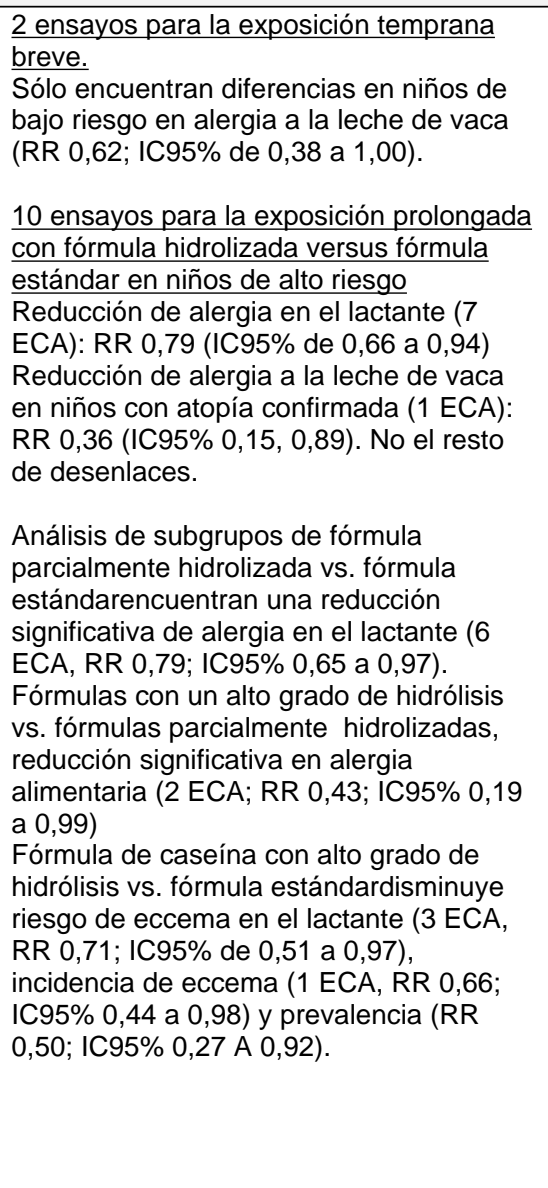 & $\begin{array}{l}\text { No hay evidencia } \\
\text { para apoyar el uso } \\
\text { de fórmula } \\
\text { hidrolizada para la } \\
\text { prevención de } \\
\text { alergia en } \\
\text { comparación a } \\
\text { lactancia materna } \\
\text { exclusiva. En niños } \\
\text { de alto riesgo que } \\
\text { no pueden ser } \\
\text { amamantados de } \\
\text { forma exclusiva, } \\
\text { hay evidencia } \\
\text { limitada sobre el } \\
\text { efecto de la } \\
\text { exposición } \\
\text { prolongada con } \\
\text { fórmula hidrolizada } \\
\text { en comparación a } \\
\text { fórmula } \\
\text { estándaren reducir } \\
\text { la alergia en el } \\
\text { lactante y en el } \\
\text { niño y alergia a la } \\
\text { leche de vaca en } \\
\text { el lactante. En } \\
\text { vista a los } \\
\text { problemas } \\
\text { metodológicos y la } \\
\text { inconsistencia de } \\
\text { los resultados, se } \\
\text { necesitan ECA } \\
\text { más grandes y } \\
\text { bien diseñados } \\
\text { que comparen } \\
\text { fórmulas de suero }\end{array}$ & \\
\hline
\end{tabular}




\begin{tabular}{|c|c|c|c|c|c|c|}
\hline $\begin{array}{l}\text { Referencia } \\
\text { (Cita } \\
\text { Abreviada) }\end{array}$ & $\begin{array}{l}\text { Estudio (Diseño y } \\
\text { objetivo) }\end{array}$ & $\begin{array}{l}\text { Población } \\
\text { (no y características) }\end{array}$ & $\begin{array}{l}\text { Descripción de las intervenciones } \\
\text { comparaciones, exposiciones o } \\
\text { pruebas a estudio }\end{array}$ & $\begin{array}{l}\text { Resultados } \\
\text { (Estimadores de resultados-Magnitud del } \\
\text { efecto) }\end{array}$ & $\begin{array}{l}\text { Conclusiones } \\
\text { (conclusiones) }\end{array}$ & $\begin{array}{l}\text { Comentarios } \\
\text { Calidad de la } \\
\text { evidencia } \\
\text { Financiación } \\
\text { comentarios) }\end{array}$ \\
\hline & & & & & $\begin{array}{l}\text { parcialmente } \\
\text { hidrolizado o de } \\
\text { caseína con alto } \\
\text { grado de hidrólisis } \\
\text { a fórmulas de } \\
\text { estándar. }\end{array}$ & \\
\hline Becker 2011 & $\begin{array}{l}\text { Diseño } \\
\text { Metanálisis ECA } \\
\text { Objetivo } \\
\text { Realizar un } \\
\text { metaanálisis sobre } \\
\text { el efecto beneficioso } \\
\text { y dañino de la } \\
\text { suplementación en } \\
\text { lactantes a término } \\
\text { y examinar la } \\
\text { duración y tipo de } \\
\text { suplementación }\end{array}$ & $\begin{array}{l}6 \text { estudios } \mathrm{N}=814 \text {, en } \\
\text { dos estudios incluían } \\
\text { niños sanos a término }\end{array}$ & $\begin{array}{l}\text { Comparación entre lactancia materna } \\
\text { exclusiva y lactancia con líquidos en el } \\
\text { recién nacido o sólidos adicionales en } \\
\text { el bebe a partir de cuatro meses }\end{array}$ & $\begin{array}{l}\text { Duración de lactancia materna } \\
\text { Morbilidad infantil: fiebre, nivel plasmático } \\
\text { de glucosa, cambio en el peso } \\
\text { En la duración de lactancia materna ( } 1 \\
\text { ECA), había una diferencia significativa a } \\
\text { favor de la lactancia materna exclusiva } \\
\text { hasta la semana } 20 \text { (RR } 1,45 \text {, (IC } 95 \% \\
1,05 \text { a } 1,99) \text { ) versus los que recibían } \\
\text { suero glucosado. } \\
\text { Morbilidad infantil ( } 3 \text { ECA), } 1 \text { ECA en } \\
\text { recién nacido encontró una diferencia } \\
\text { estadísticamente significativa pero no } \\
\text { clínicamente en la temperatura a las } 72 \\
\text { horas en los amamantados de forma } \\
\text { exclusiva y unos niveles de glucosa en } \\
\text { suero mayores en los lactantes recién } \\
\text { nacidos a término sanos amamantados y } \\
\text { suplementados con glucosa en su primera } \\
\text { alimentación adicional temprana con } \\
\text { líquidos a las } 24 \text { horas, aunque no a las } \\
48 \text { horas. } \\
2 \text { ECA con lactantes de cuatro a seis } \\
\text { meses de edad no indican ningún } \\
\text { beneficio para los lactantes } \\
\text { suplementados por } 26 \text { semanas, ni en los } \\
\text { riesgos relacionados con la morbilidad o } \\
\text { cambio de peso. } \\
\text { Ninguno de los ensayos informó sobre los } \\
\text { la mortalidad infantil o la ictericia } \\
\text { fisiológica. }\end{array}$ & $\begin{array}{l}\text { No fue posible } \\
\text { evaluar } \\
\text { completamente los } \\
\text { beneficios o } \\
\text { perjuicios de la } \\
\text { suplementación o } \\
\text { determinar el } \\
\text { impacto del } \\
\text { momento y el tipo } \\
\text { de } \\
\text { suplementación. } \\
\text { El uso breve de } \\
\text { agua adicional o } \\
\text { agua con glucosa } \\
\text { no mostro } \\
\text { beneficios para los } \\
\text { recién nacidos y se } \\
\text { observan posibles } \\
\text { efectos negativos } \\
\text { sobre la duración } \\
\text { de la lactancia } \\
\text { materna. } \\
\text { Para los lactantes } \\
\text { de cuatro a seis } \\
\text { meses, no se } \\
\text { encontraron } \\
\text { beneficios de los } \\
\text { alimentos } \\
\text { adicionales ni } \\
\text { cualquier riesgo } \\
\text { relacionado con la } \\
\text { morbilidad o } \\
\text { cambio de peso. }\end{array}$ & \\
\hline
\end{tabular}




\begin{tabular}{|c|c|c|c|c|c|c|}
\hline $\begin{array}{l}\text { Referencia } \\
\text { (Cita } \\
\text { Abreviada) }\end{array}$ & $\begin{array}{l}\text { Estudio (Diseño y } \\
\text { objetivo) }\end{array}$ & $\begin{array}{l}\text { Población } \\
\text { (no y características) }\end{array}$ & $\begin{array}{l}\text { Descripción de las intervenciones } \\
\text { comparaciones, exposiciones o } \\
\text { pruebas a estudio }\end{array}$ & $\begin{array}{l}\text { Resultados } \\
\text { (Estimadores de resultados-Magnitud del } \\
\text { efecto) }\end{array}$ & $\begin{array}{l}\text { Conclusiones } \\
\text { (conclusiones) }\end{array}$ & $\begin{array}{l}\text { Comentarios } \\
\text { Calidad de la } \\
\text { evidencia } \\
\text { Financiación } \\
\text { comentarios) }\end{array}$ \\
\hline $\begin{array}{l}\text { Szajewska H, } \\
2010\end{array}$ & $\begin{array}{l}\text { Metaanálisis } \\
\text { Objetivo: revisar de } \\
\text { forma sistemática } \\
\text { los datos sobre la } \\
\text { eficacia de las } \\
\text { fórmulas de suero } \\
\text { parcialmente } \\
\text { hidrolizadas en } \\
\text { reducir el riesgo de } \\
\text { alergia en niños } \\
\text { sanos con alto } \\
\text { riesgo de } \\
\text { enfermedad } \\
\text { alérgica. }\end{array}$ & $\begin{array}{l}15 \text { ECA incluidos, } \\
\text { algunos con } \\
\text { potenciales } \\
\text { limitaciones } \\
\text { metodológicas como } \\
\text { ocultación de la } \\
\text { secuencia } \\
\text { inadecuada, no } \\
\text { análisis por intención } \\
\text { de tratar y } \\
\text { cegamiento no } \\
\text { verdadero. }\end{array}$ & $\begin{array}{l}\text { Fórmula de suero parcialmente } \\
\text { hidrolizada vs. fórmula estándar } \\
\text { Fórmula de suero parcialmente } \\
\text { hidrolizada vs. fórmula de suero con } \\
\text { alto grado de hidrólisis } \\
\text { Fórmula de suero parcialmente } \\
\text { hidrolizada vs. fórmula de caseína con } \\
\text { alto grado de hidrólisis. }\end{array}$ & $\begin{array}{l}\text { Fórmula de suero parcialmente } \\
\text { hidrolizada vs. fórmula estándar: todas las } \\
\text { alergias y eccema/dermatitis atópica, se } \\
\text { asocia con reducción del riesgo casi en } \\
\text { todos los puntos temporales. } \\
\text { Fórmula de suero parcialmente } \\
\text { hidrolizada vs. fórmula de suero con alto } \\
\text { grado de hidrólisis. } \\
\text { No hay diferencias significativas salvo } \\
\text { para reducción de incidencia acumulada } \\
\text { de enfermedad alérgica de } 0 \text { a } 36 \text { meses } \\
\text { de edad. } \\
\text { No hay diferencias entre fórmula de suero } \\
\text { parcialmente hidrolizada vs. fórmula de } \\
\text { caseína con alto grado de hidrólisis (datos } \\
\text { no presentados en el artículo pero } \\
\text { disponibles bajo petición). }\end{array}$ & $\begin{array}{l}\text { El uso de fórmula } \\
\text { de suero } \\
\text { parcialmente } \\
\text { hidrolizada en } \\
\text { comparación con } \\
\text { fórmula estándar } \\
\text { es efectiva en } \\
\text { prevenir alergia en } \\
\text { niños con alto } \\
\text { riesgo. Estos } \\
\text { resultados deben } \\
\text { interpretarse con } \\
\text { precaución debido } \\
\text { a falta de rigor } \\
\text { metodológico en } \\
\text { muchos ensayos. } \\
\text { La evidencia más } \\
\text { fuerte proviene de } \\
\text { un ECA bien } \\
\text { diseñado y } \\
\text { realizado y } \\
\text { financiado de } \\
\text { forma } \\
\text { independiente. }\end{array}$ & $\begin{array}{l}\text { La revisión fue } \\
\text { financiada por } \\
\text { una beca del } \\
\text { instituto de } \\
\text { nutrición de } \\
\text { Nestlé, aunque } \\
\text { los autores } \\
\text { señalan que el } \\
\text { Instituto no } \\
\text { participó en } \\
\text { ninguna de las } \\
\text { etapas de la } \\
\text { revisión. }\end{array}$ \\
\hline
\end{tabular}




\subsection{Resumen de GPC base y RS disponibles}

La guía NICE (12) no recomienda la suplementación con otros líquidos que no sean leche materna (Grado C).

La guía Perinatal Care services (13), cuando menciona la administración de suplementos indica que se utilice, en este orden, leche extraída de la madre, leche donada pasteurizada o un sustituto de la leche materna, y no recomienda el uso de suero glucosado.

La iniciativa IHAN (14) señala que el suplemento de elección es la leche humana extraída de la propia madre, y que en segundo lugar está la leche humana donada pasteurizada. También se indica que el médico debe sopesar los riesgos y beneficios potenciales de la utilización de otros suplementos (por ejemplo fórmula estándar o hidrolizada) en función de los recursos disponibles, factores de riesgo como historia familiar de atopia, edad del lactante, cantidad requerida e impacto potencial en el establecimiento de la lactancia.

La American Academy of Breastfeeding (15) señala, en este orden, la utilización como suplemento de leche materna extraída, leche donada pasteurizada y las fórmulas hidrolizadas frente a las fórmulas estándar. Señala además que el uso de suero glucosado no es apropiado, y también sugiere cuál podría ser el volumen de calostro a administrar según las horas de vida del recién nacido.

\subsection{Conclusión (marcar con una $\mathrm{X}$ ):}

\begin{tabular}{|l|l|}
\hline & Adopción GPC/Revisión sistemática \\
\hline$X$ & Elaboración parcial \\
\hline & Elaboración de novo \\
\hline
\end{tabular}

\subsection{Diseño de la estrategia de búsqueda de estudios individuales}

\begin{tabular}{|l|l|}
\hline Criterios de selección de estudios & ECA \\
\hline Período de búsqueda & 2010- en adelante \\
\hline Bases de datos & Cochrane Library \\
& MEDLINE, via Pubmed \\
& EMBASE, via Ovid \\
& Cinahl, via EBSCOhost databases \\
& PsyINFO, via OVID \\
\hline
\end{tabular}

Ver estrategias de búsqueda de estudios originales en el ANEXO I. 


\section{4- Resumen de la evidencia}

\section{1- GRADE Evidence Profile}

Comparación 2: Fórmula de suero parcialmente hidrolizado vs. fórmula estándar Bibliografía: Osborn 2006

\begin{tabular}{|c|c|c|c|c|c|c|c|c|c|c|c|c|}
\hline \multirow{2}{*}{\multicolumn{7}{|c|}{ Evaluación de la calidad }} & \multicolumn{4}{|c|}{ Resumen de los Resultados } & \multirow{3}{*}{ Calidad } & \multirow{3}{*}{ Importancia } \\
\hline & & & & & & & \multicolumn{2}{|c|}{ № de pacientes } & \multicolumn{2}{|c|}{ Magnitud del efecto } & & \\
\hline $\begin{array}{c}\text { № de } \\
\text { estudios }\end{array}$ & Diseño & $\begin{array}{c}\text { Riesgo de } \\
\text { sesgo }\end{array}$ & Inconsistencia & \begin{tabular}{|l|}
$\begin{array}{l}\text { Evidencia } \\
\text { indirecta }\end{array}$ \\
\end{tabular} & Imprecisión & \begin{tabular}{|c|} 
Otras \\
consideraciones
\end{tabular} & $\begin{array}{l}\text { Grupo } \\
\text { expuesto }\end{array}$ & $\begin{array}{l}\text { Grupo no } \\
\text { expuesto }\end{array}$ & $\begin{array}{l}\text { Relativa } \\
(95 \% \mathrm{Cl})\end{array}$ & Absoluta por 1000 & & \\
\hline \multicolumn{13}{|c|}{ Cualquier alergia en el lactante (incidencia) } \\
\hline 6 & ECA & Serio ${ }^{2}$ & No seria & Seria $^{3}$ & No seria & Probable $^{4}$ & 679 & 712 & $\begin{array}{l}\text { RR } 0,73 \text { (de } \\
0,59 \text { a } 0,90)\end{array}$ & $\begin{array}{c}61 \text { menos por } 1000 \text { (de } 93 \\
\text { menos a } 23 \text { menos) }\end{array}$ & MUY BAJA & IMPORTANTE \\
\hline \multicolumn{13}{|c|}{ Cualquier alergia en el niño (incidencia) } \\
\hline $2^{5}$ & ECA & No serio & Seria ${ }^{6}$ & Seria $^{3}$ & Seria $^{7}$ & Poco probable & 261 & 249 & $\begin{array}{l}\text { RR } 0,68 \text { (de } \\
0,31 \text { a } 1,52 \text { ) }\end{array}$ & $\begin{array}{l}113 \text { menos por } 1000 \text { (de } \\
244 \text { menos a } 184 \text { más) }\end{array}$ & MUY BAJA & IMPORTANTE \\
\hline \multicolumn{13}{|c|}{ Eccema/dermatitis atópica en el lactante (incidencia) } \\
\hline $6^{8}$ & ECA & No serio & No seria & Seria $^{3}$ & Seria ${ }^{7}$ & Probable $^{4}$ & 628 & 642 & $\begin{array}{l}\text { RR } 0,84 \text { (de } \\
0,65 \text { a } 1,09)\end{array}$ & $\begin{array}{c}25 \text { menos por } 1000 \text { (de } 55 \\
\text { menos a } 14 \text { más) }\end{array}$ & MUY BAJA & IMPORTANTE \\
\hline \multicolumn{13}{|c|}{ Alergia a la leche de vaca en el lactante (incidencia) } \\
\hline $1^{9}$ & ECA & No serio & No seria & Seria $^{3}$ & Seria ${ }^{10}$ & Probable ${ }^{11}$ & 32 & 35 & $\begin{array}{l}\text { RR } 0,36 \text { (de } \\
0,15 \text { a } 0,89 \text { ) }\end{array}$ & $\begin{array}{l}274 \text { menos por } 1000 \text { (de } \\
364 \text { menos a } 47 \text { menos) }\end{array}$ & MUY BAJA & CRITICA \\
\hline
\end{tabular}

${ }^{1}$ de Seta, 1994; Lam, 1992; Marini, 1992; Vanderplas, 1992; von Berg, 2003; Willems, 1993; ${ }^{2}$ Riesgo de sesgos en la mayoría de los estudios incluidos; ${ }^{3}$ Se trata de estudios sobre el uso prolongado de fórmulas; ${ }^{4}$ La mayoría de los estudios, o no reportan conflictos de interés ni financiación o ésta proviene de Nestlé ; ${ }^{5}$ Marini, $1996 ;$ von Berg, $2003 ;{ }^{6}$ Inconsistencia entre estudios;

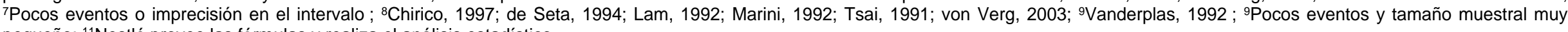
pequeño; ${ }^{11}$ Nestlé provee las fórmulas y realiza el análisis estadístico. 
Comparación 3: Fórmulas con alto grado de hidrólisis (de suero o caseína) vs. Fórmula de suero parcialmente hidrolizado Bibliografía: Osborn 2006a

\begin{tabular}{|c|c|c|c|c|c|c|c|c|c|c|c|c|}
\hline \multirow{2}{*}{\multicolumn{7}{|c|}{ Evaluación de la calidad }} & \multicolumn{4}{|c|}{ Resumen de los Resultados } & \multirow[b]{3}{*}{ Calidad } & \multirow[b]{3}{*}{ Importancia } \\
\hline & & & & & & & \multicolumn{2}{|c|}{\begin{tabular}{|l|l} 
№ de pacientes & \\
\end{tabular}} & \multicolumn{2}{|c|}{ Magnitud del efecto } & & \\
\hline $\begin{array}{l}\text { № de } \\
\text { estudios }\end{array}$ & Diseño & $\begin{array}{c}\text { Riesgo de } \\
\text { sesgo }\end{array}$ & Inconsistencia & $\begin{array}{l}\text { Evidencia } \\
\text { indirecta }\end{array}$ & Imprecisión & $\begin{array}{c}\text { Otras } \\
\text { consideraciones }\end{array}$ & $\begin{array}{c}\text { Fórmula e con } \\
\text { alto grado de } \\
\text { hidrólisis }\end{array}$ & \begin{tabular}{|c|}
$\begin{array}{c}\text { Fórmula de } \\
\text { suero } \\
\text { parcialmente } \\
\text { hidrolizado }\end{array}$ \\
\end{tabular} & $\begin{array}{l}\text { Relativa } \\
(95 \% \mathrm{Cl})\end{array}$ & Absoluta por 1000 & & \\
\hline \multicolumn{13}{|c|}{ Cualquier alergia en el lactante (incidencia) } \\
\hline $3^{1}$ & ECA & Serio ${ }^{2}$ & No seria & Seria $^{3}$ & No seria & Probable $^{4}$ & 1193 & 613 & $\begin{array}{l}\text { RR } 0,93 \text { (de } \\
0,75 \text { a } 1,16)\end{array}$ & $\begin{array}{l}12 \text { menos por } 1000 \text { (de } \\
42 \text { menos a } 27 \text { más) }\end{array}$ & MUY BAJA & IMPORTANTE \\
\hline \multicolumn{13}{|c|}{ Cualquier alergia en el niño (incidencia) } \\
\hline 15 & ECA & No serio & No seria & Seria $^{3}$ & Seria ${ }^{6}$ & Poco probable & 440 & 221 & $\begin{array}{l}\text { RR } 0,93 \text { (de } \\
0,74 \text { a } 1,18 \text { ) } \\
\end{array}$ & $\begin{array}{l}23 \text { menos por } 1000 \text { (de } \\
85 \text { menos a } 59 \text { más) }\end{array}$ & BAJA & IMPORTANTE \\
\hline \multicolumn{13}{|c|}{ Eccema/dermatitis atópica en el lactante (incidencia) } \\
\hline $4^{7}$ & ECA & Serio $^{2}$ & No seria & Seria ${ }^{3}$ & No seria & Probable $^{4}$ & 1221 & 644 & $\begin{array}{l}\text { RR } 0,89 \text { (de } \\
0,73 \text { a } 1,10)\end{array}$ & $\begin{array}{c}20 \text { menos por } 1000 \text { (de } 49 \\
\text { menos a } 8 \text { más) }\end{array}$ & MUY BAJA & IMPORTANTE \\
\hline \multicolumn{13}{|c|}{ Alergia a la leche de vaca en el lactante (incidencia) } \\
\hline $1^{8}$ & ECA & \begin{tabular}{|l|} 
Serio $^{2}$ \\
\end{tabular} & No serio & Seria $^{3}$ & Seria ${ }^{6}$ & Probable $^{4}$ & 161 & 85 & $\begin{array}{l}\text { RR } 0,13 \text { (de } \\
0,01 \text { a } 1,16 \text { ) }\end{array}$ & $\begin{array}{l}41 \text { menos por } 1000 \text { (de } \\
47 \text { menos a } 8 \text { más) }\end{array}$ & MUY BAJA & CRITICA \\
\hline \multicolumn{13}{|c|}{ Alergia alimentaria en el lactante (incidencia) } \\
\hline $2^{9}$ & ECA & Serio & No serio & Seria $^{3}$ & Seria ${ }^{6}$ & Probable 4 & 211 & 130 & $\begin{array}{l}\text { RR } 0,49 \text { (de } \\
0,19 \text { a } 0,99)\end{array}$ & $\begin{array}{l}61 \text { menos por } 1000 \text { (de } \\
87 \text { menos a } 1 \text { menos) }\end{array}$ & MUY BAJA & CRITICA \\
\hline
\end{tabular}

${ }^{1}$ Halken, 2000; Odaleus, 1997; von Berg, 2003; ${ }^{2}$ Riesgo de sesgos en la mayoría de los estudios incluidos; ${ }^{3}$ Se trata de estudios sobre el uso prolongado de las fórmulas; ${ }^{4}$ estudios financiados en su mayoría por industria de alimentación infantil; ${ }^{5}$ von Berg, 2003; ${ }^{6}$ Pocos eventos; ${ }^{7}$ Halken, 2000; Nentwich, 2001; Oldaeus, 1997 ; von Berg, $2003 ;{ }^{8}$ Halken, $2000 ;{ }^{9}$ Halken, $2000 ;$ Oldaeus, 1997. 


\section{2- Resumen de la Evidencia}

\section{Administración de suplementos durante la estancia en el hospital}

La revisión de Becker aborda el efecto de la exposición a líquidos en los primeros días tras el nacimiento sobre la lactancia materna (2) y la revisión de Osborn (3) estudia, entre otros aspectos, el efecto de la exposición temprana y breve a fórmulas hidrolizadas sobre el desarrollo posterior de enfermedad alérgica en el niño.

Suero glucosado versus otro tipo de suplemento (leche materna extraída, leche donada de banco, diferentes fórmulas)

No se han identificado estudios que comparen la administración de suero glucosado frente a leche extraída de la propia madre, leche donada de banco o al uso de diferentes fórmulas de inicio. Lo único que se ha encontrado son 4 estudios sobre el efecto de la suplementación con agua y/o suero glucosado sobre la lactancia materna (16-19). De estos estudios sólo uno (16) aportaba datos del efecto de la suplementación con suero glucosado al 5\% (administrado con biberón cuando el niño se encontraba nervioso tras la toma en los primeros tres días) en la duración de la lactancia materna. Así, la probabilidad de seguir con lactancia materna era significativamente mayor en el grupo que recibió suero glucosado como suplemento, siendo a las 20 semanas el RR de 1,48 (IC95\% de 1,05 a 1,99).

En relación al número de episodios de hipoglucemia, definida por un nivel de glucosa en sangre inferior a $2,2 \mathrm{mmol} / \mathrm{L}$, la diferencia no fue significativa a las $6,12,24$ y 48 horas tras el nacimiento, no llegándose en ningún caso a niveles de glucosa inferiores a $1,7 \mathrm{mmol} / \mathrm{L}$ o a presentar síntomas de hipoglucemia.

En cuanto a la pérdida de peso, ésta fue significativamente mayor en los niños con lactancia materna exclusiva a las $\mathbf{4 8}$ horas tras el nacimiento (DM de 32,50 g; IC95\% de 12,91 a 52,09 g). Sin embargo, a las 72 horas no había diferencias significativas (DM de $-3,00 \mathrm{~g}$; IC95\% de $-26,83$ a $20,83 \mathrm{~g}$ ). De la misma manera, en el estudio de Nicoll (17) la diferencia en el porcentaje de pérdida de peso entre el grupo con lactancia materna exclusiva y el grupo con agua o suero glucosado no fue significativa a los tres ni a los cinco días tras el nacimiento (DM de 1,03\% (IC95\% de $-0,18$ a 2,24 ) y de $0,20 \%$ (IC95\% -1,28 a 1,58), respectivamente.

Fórmula hidrolizada vs. fórmula estándar o leche donada de banco

En la revisión de Osborn et al, 2006 se describen 2 ensayos que estudian el efecto de una exposición breve y temprana a fórmula hidrolizada en los primeros días versus el uso de fórmula estándar o leche materna donada de banco en el desarrollo de enfermedad alérgica en niños con riesgo no definido $(20 ; 21)$. Estos estudios no encuentran diferencias significativas en el desarrollo de alergia en el lactante, aunque sí diferencias al límite de la significación en el desarrollo de alergia a la leche de vaca en el niño con el uso de fórmulas hidrolizadas versus fórmula estándar de leche de vaca ( 1 estudio, $n=3473$, RR 0,$62 ;$ IC95\% de 0,38 a 1,00) (datos no representados en un perfil de evidencia GRADE).

Calidad muy baja para ambas 


\section{Uso prolongado de diferentes tipos de fórmulas}

Aunque en este caso lo que se quería valorar era si había evidencia en relación a cuál es el mejor suplemento que se le puede administrar a un niño amamantado que lo necesita por indicación médica, se ha considerado la inclusión de los estudios sobre el uso prolongado de diferentes tipos de fórmulas como evidencia indirecta de la pregunta de interés, ya que los pocos estudios que existen sobre el uso temprano y breve de diferentes suplementos no son de buena calidad y el riesgo de alergia de los niños no está definido.

Los resultados que se presentan a continuación se han obtenido de la revisión de Osborn (3).

Fórmula de suero parcialmente hidrolizado versus fórmula estándar de leche de vaca

En niños de alto riesgo (con al menos un familiar de primer grado con enfermedad alérgica), se encontró una reducción significativa de la cualquier alergia en el lactante ( 6 estudios, 1391 niños, RR 0,79; IC $95 \%$ de 0,65 a 0,97 ), pero no en la incidencia de alergia en el niño, de eccema en el lactante, en la prevalencia de eccema en el niño. Un estudio reportó una reducción significativa en lactantes con alergia a la leche de vaca y atopía confirmada (RR 0,36; IC95\% de 0,15 a 0,89). Ningún estudio elegible examinó el efecto de alimentación prolongada con fórmula hidrolizada en alergia después de la niñez.

Fórmulas de alto grado de hidrólisis versus fórmula estándar (datos no presentados en perfil de evidencia GRADE)

El análisis de ensayos de fórmulas de suero de alto grado de hidrólisis versus fórmula estándar no encontró diferencias significativas en la prevención de ninguna de las enfermedades alérgicas.

Por otro lado, en el análisis de ensayos de fórmulas de caseína extensivamente hidrolizadas versus fórmula estándar sí se encontró una reducción significativa en la incidencia de alergia en el niño (1 estudio, RR 0,72 , IC95\% de 0,53 a 0,97), así como en el eccema en el lactante (3 estudios, 1237 niños; RR 0,71, IC95\% de 0,51 a 0,97) y en la incidencia (1 estudio, RR 0,66, IC95\% de 0,44 a 0,98) y prevalencia (1 estudio, RR $0,50, \mathrm{IC} 95 \%$ de 0,27 a 0,92 ) de eccema en la infancia.

Fórmulas de alto grado de hidrólisis versus fórmula de suero parcialmente hidrolizada

El uso de fórmulas de alto grado de hidrólisis en comparación con fórmulas parcialmente hidrolizadas supuso una reducción significativa del riesgo de alergia alimentaria en los lactantes (2 estudios, 341 niños; RR $0,43, I C 95 \%$ de 0,19 a 0,99$)$. En el caso de la alergia a la leche de vaca el RR fue de 0,13 (IC95\% de 0,01 a 1,16), lo que suponía 41 casos menos por 1000 (de 47 menos a 8 más). Sin embargo, no se encontraron diferencias significativas en el riesgo de desarrollar cualquier otra

\section{Calidad muy baja para todas}

Calidad muy baja en ambas

Calidad baja 


\section{alergia.}

Cabe destacar que la FDA (Food and Drug Administration) en la revisión que realizó para valorar la inclusión de una declaración sobre salud en las etiquetas de fórmulas hidrolizadas sobre la eficacia de estas fórmulas en la prevención de dermatitis atópica en niños de alto riesgo, concluye que hay poca y muy poca evidencia que demuestre que la utilización de fórmulas de suero parcialmente hidrolizado versus fórmulas estándar en niños sanos no amamantados de forma exclusiva y con historia familiar de alergia reduce el riesgo de desarrollar dermatitis atópica en el primer año y desde primer al tercer año de vida, respectivamente (22).

\section{ACTUALIZADO A FECHA DE: 31 de Octubre de 2016}




\section{5- De la evidencia a la recomendación (Tabla de EtR)}

\section{¿Cuál es el suplemento más adecuado en recién nacidos sanos?}

\section{ADMINISTRACIÓN DE SUPLEMENTOS PRIMEROS DÍAS DE VIDA}

Población: Recién nacidos sanos a término amamantados que necesitan suplementos

Intervención: suero glucosado

Comparación: otro tipo de suplementos (leche extraída de la propia madre, leche donada de banco o diferentes tipos de fórmulas)

Perspectiva: Clínica

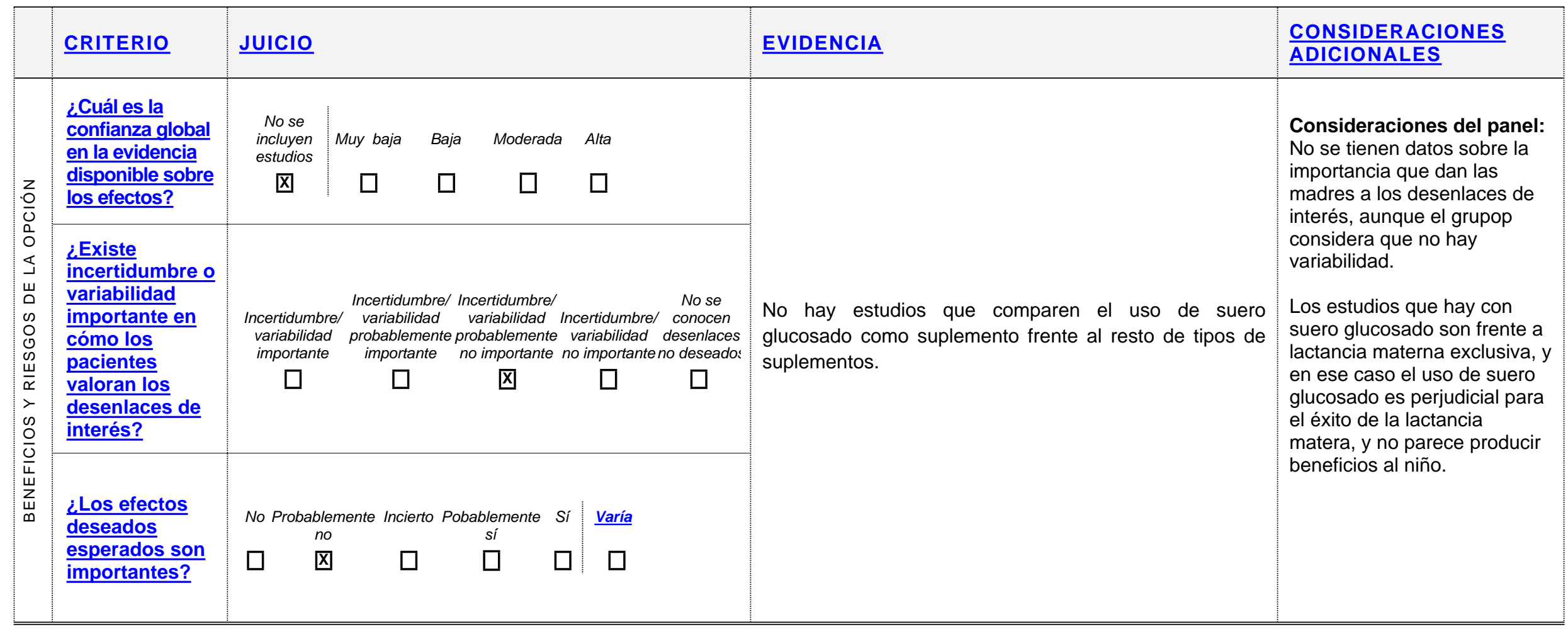




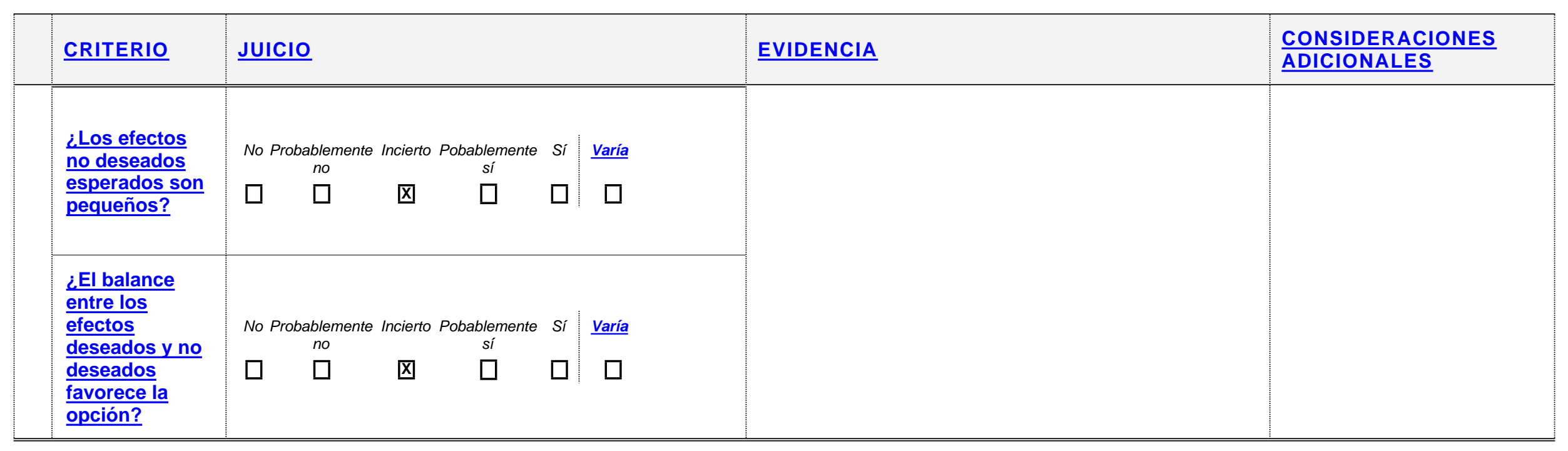


Población: Recién nacidos sanos a término amamantados que necesitan suplemento Intervención: suero glucosado

Comparación: Otro tipo de suplementos

Perspectiva: Clínica

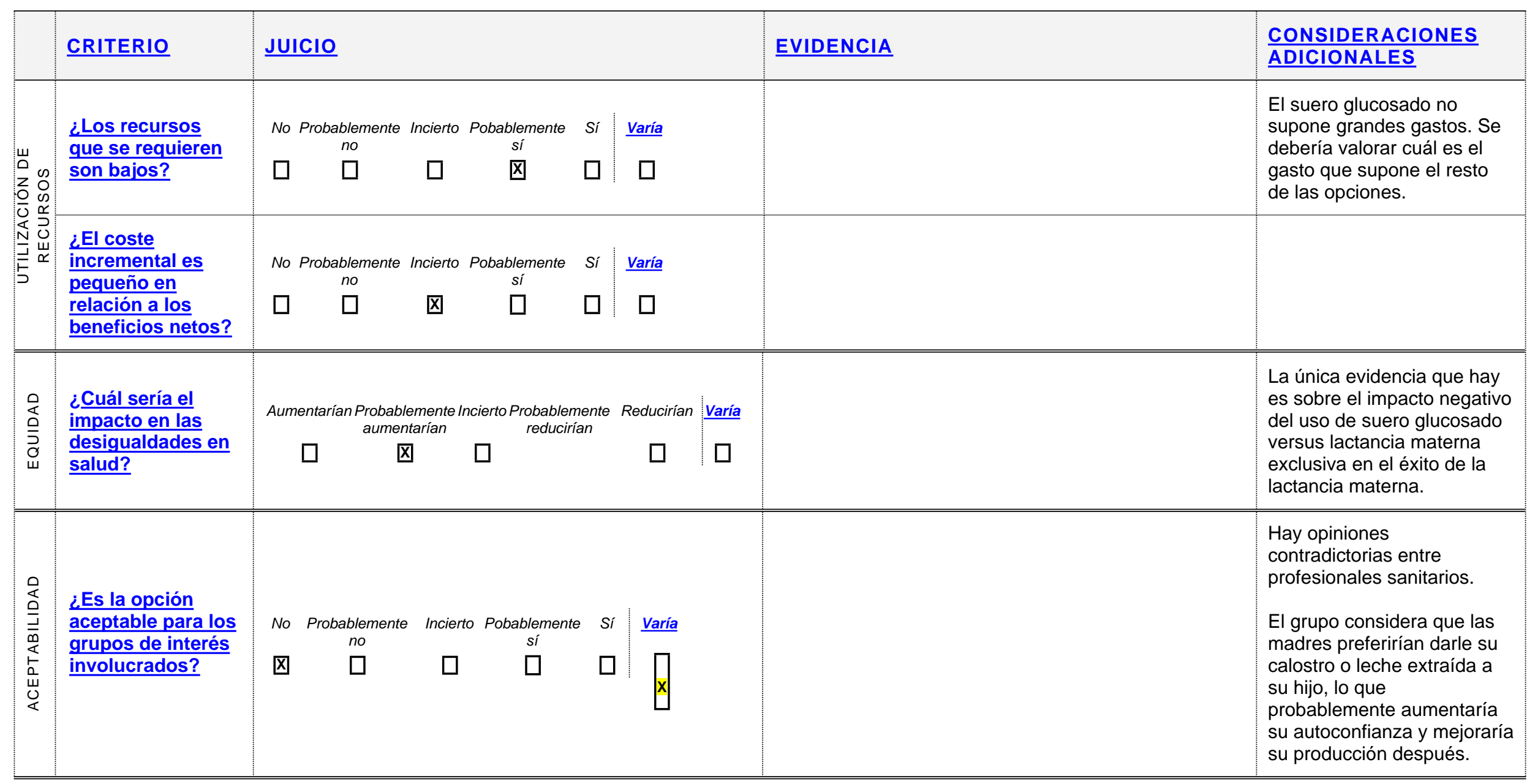




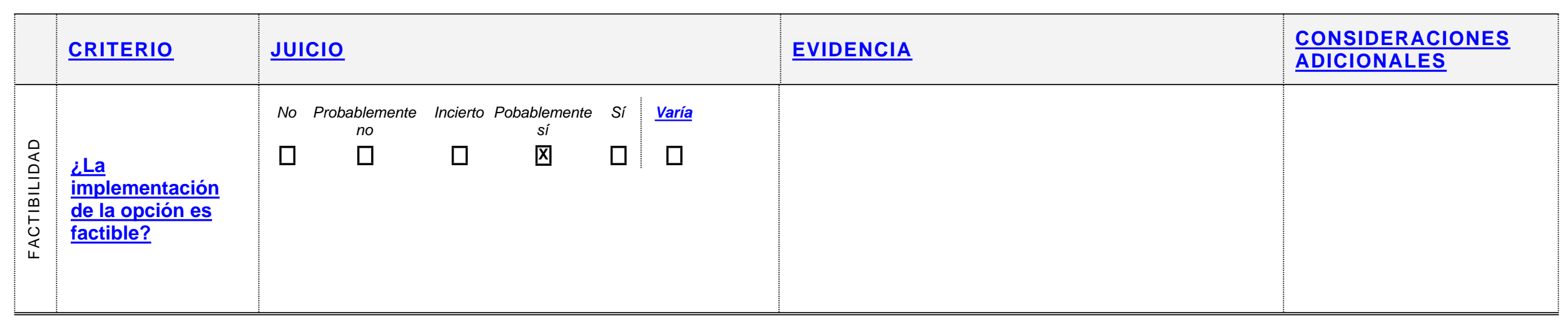

\begin{tabular}{cccccc}
\hline \hline Balance de las & Las consecuencias no & Las consecuencias no & El balance entre las & Las consecuencias & Las consecuencias \\
consecuencias & deseadas superan & deseadas probablemente consecuencias deseadas y & deseadas & deseadas claramente \\
& claramente las & superan las & no deseadas está muy & probablemente superan & superan las \\
& $\begin{array}{c}\text { consecuencias deseadas } \\
\text { en la mayoría de los }\end{array}$ & $\begin{array}{c}\text { consecuencias deseadas } \\
\text { en la mayoría de los }\end{array}$ & $\begin{array}{c}\text { equilibrado o es incierto } \\
\text { las consecuencias no }\end{array}$ & consecuencias no \\
& escenarios & escenarios & deseadas en la mayoría & deseadas en la mayoría \\
& & de los escenarios & de los escenarios
\end{tabular}

$\square$

$\square$ 囚

$\square$

$\square$

\begin{tabular}{llcc}
\hline \hline$\underline{\text { Tipo de }}$ Secomendación & Se recomienda no ofrecer la opción & Se sugiere no ofrecer la opción & Se sugiere ofrecer la opción \\
ofrecer la opción
\end{tabular}




\section{ADMINISTRACIÓN DE SUPLEMENTOS PRIMEROS DÍAS DE VIDA}

Pacientes: Recién nacidos sanos a término amamantados que necesitan suplementos; Intervención: Leche materna donada Comparación: Fórmula (estándar o con proteínas hidrolizadas) Perspectiva: Clínica

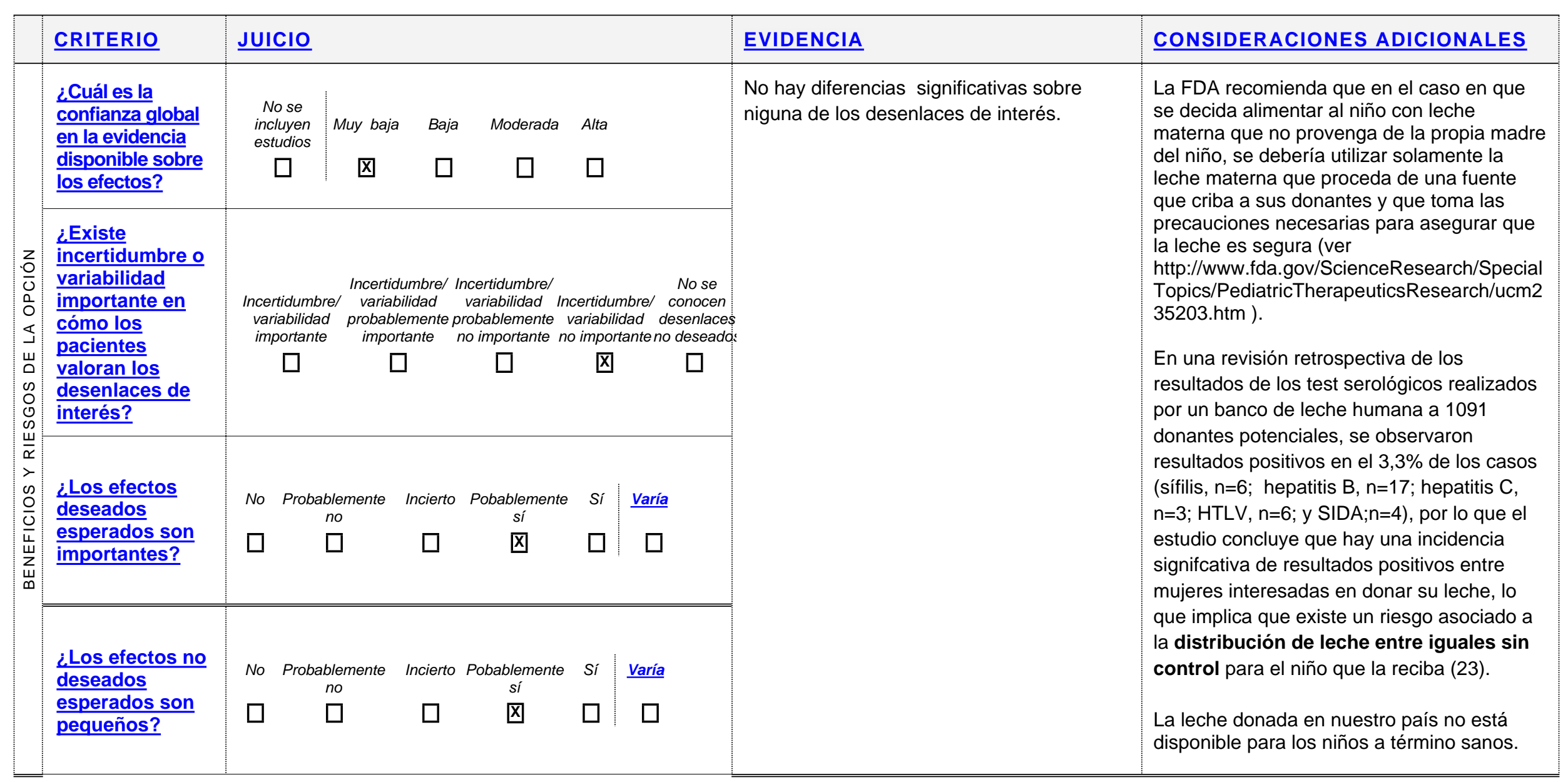




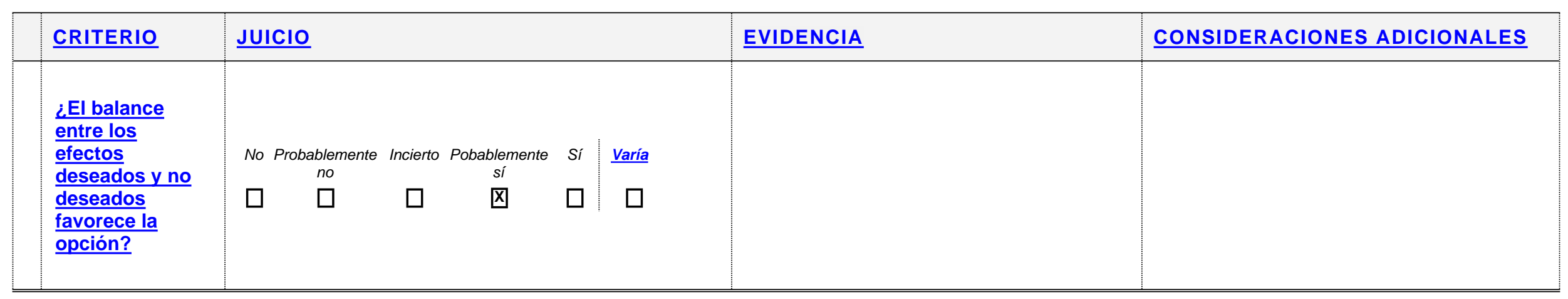


Población: Recién nacidos sanos a término amamantados que necesitan suplementos Intervención: Leche materna donada

Comparación: Fórmula (estándar o con proteínas hidrolizadas)

Perspectiva: Clínica

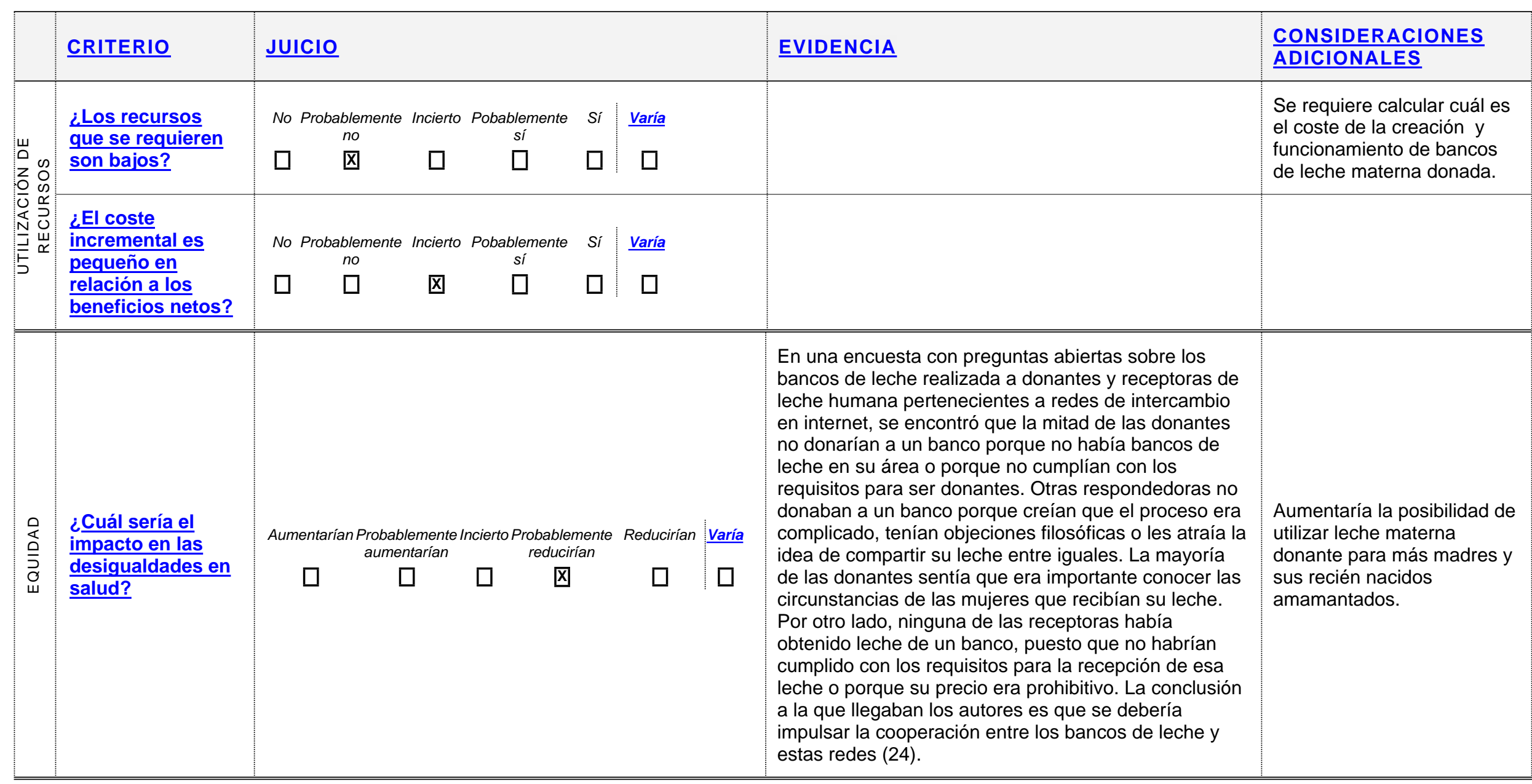




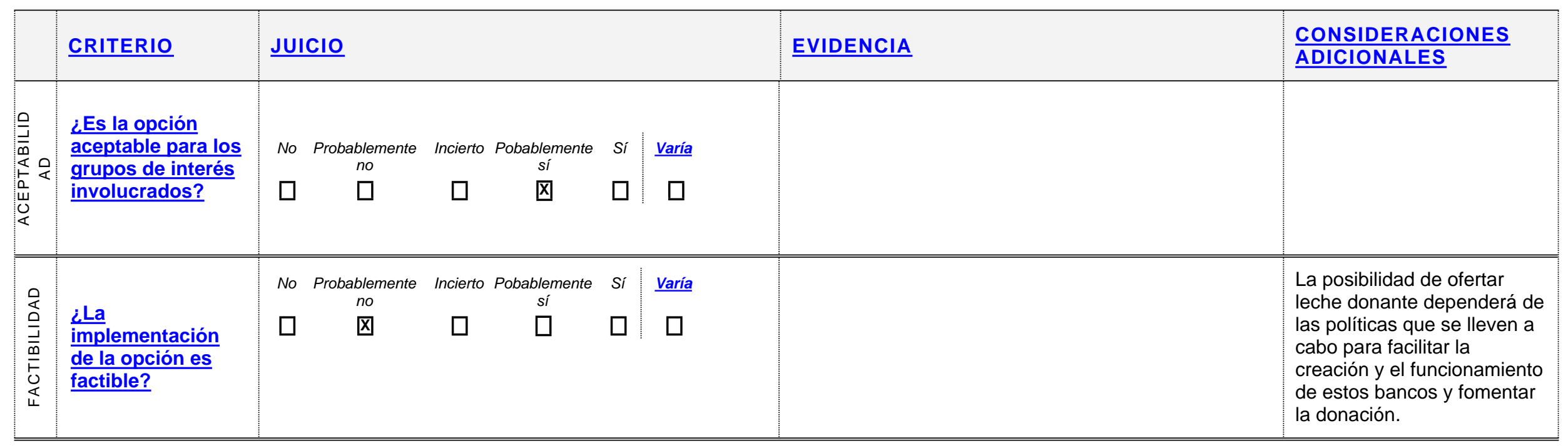

\begin{tabular}{|c|c|c|c|c|c|}
\hline $\begin{array}{l}\text { Balance de las } \\
\text { consecuencias }\end{array}$ & $\begin{array}{l}\text { Las consecuencias no } \\
\text { deseadas superan } \\
\text { claramente las } \\
\text { consecuencias deseadas } \\
\text { en la mayoría de los } \\
\text { escenarios }\end{array}$ & $\begin{array}{l}\text { Las consecuencias no } \\
\text { deseadas probablemente } \\
\text { superan las } \\
\text { consecuencias deseadas } \\
\text { en la mayoría de los } \\
\text { escenarios }\end{array}$ & $\begin{array}{c}\text { El balance entre las } \\
\text { consecuencias deseadas y } \\
\text { no deseadas está muy } \\
\text { equilibrado o es incierto }\end{array}$ & $\begin{array}{c}\text { Las consecuencias } \\
\text { deseadas } \\
\text { probablemente superan } \\
\text { las consecuencias no } \\
\text { deseadas en la mayoría } \\
\text { de los escenarios }\end{array}$ & $\begin{array}{c}\text { Las consecuencias } \\
\text { deseadas claramente } \\
\text { superan las } \\
\text { consecuencias no } \\
\text { deseadas en la mayoría } \\
\text { de los escenarios }\end{array}$ \\
\hline
\end{tabular}

$\square$

$\square$

$\square$

凶

$\square$

Tipo de $\quad$ Se recomienda no ofrecer la opción Se sugiere no ofrecer la opción Se sugiere ofrecer la opción

$\square$ 


\section{¿Cuál es el suplemento más adecuado en recién nacidos sanos?}

\section{ADMINISTRACIÓN DE SUPLEMENTOS PRIMEROS DÍAS DE VIDA}

Población: Recién nacidos sanos a término amamantados que necesitan suplementos

Intervención: Fórmula de suero parcialmente hidrolizado

Comparación: Fórmulas estándar

Perspectiva: Clínica

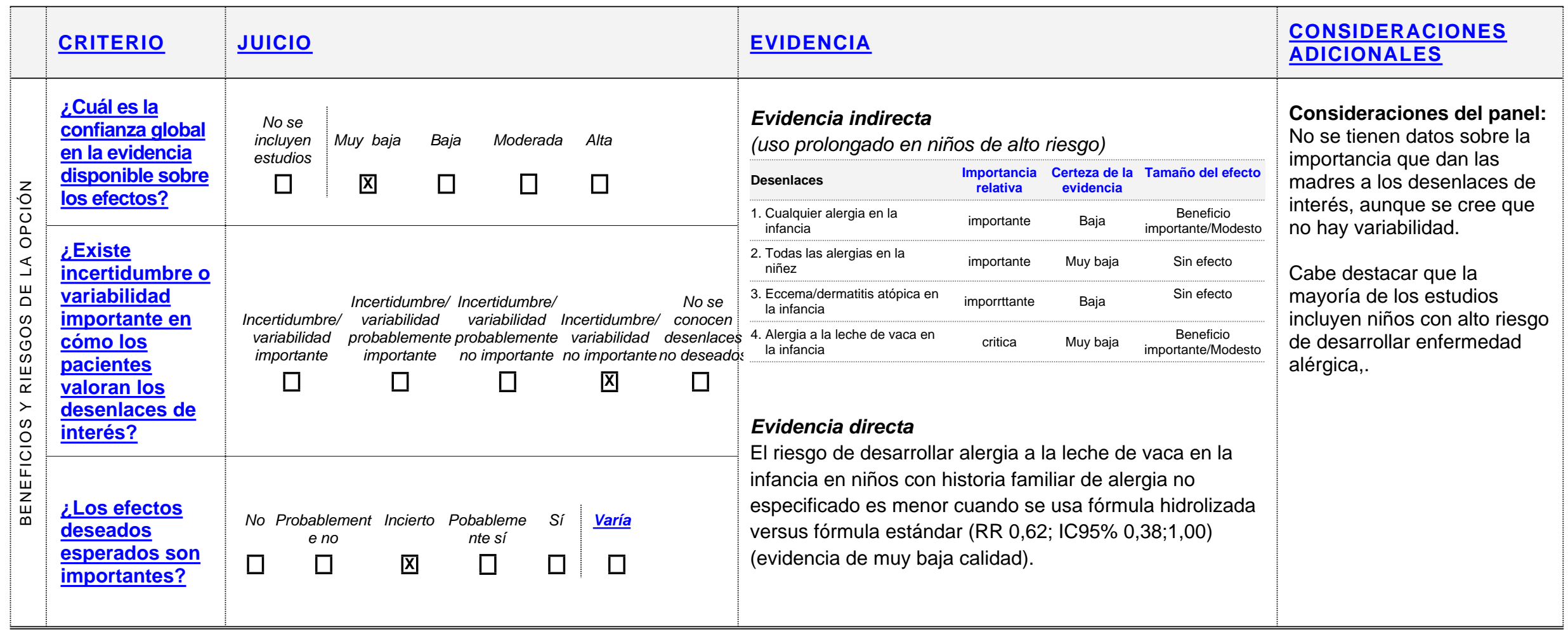




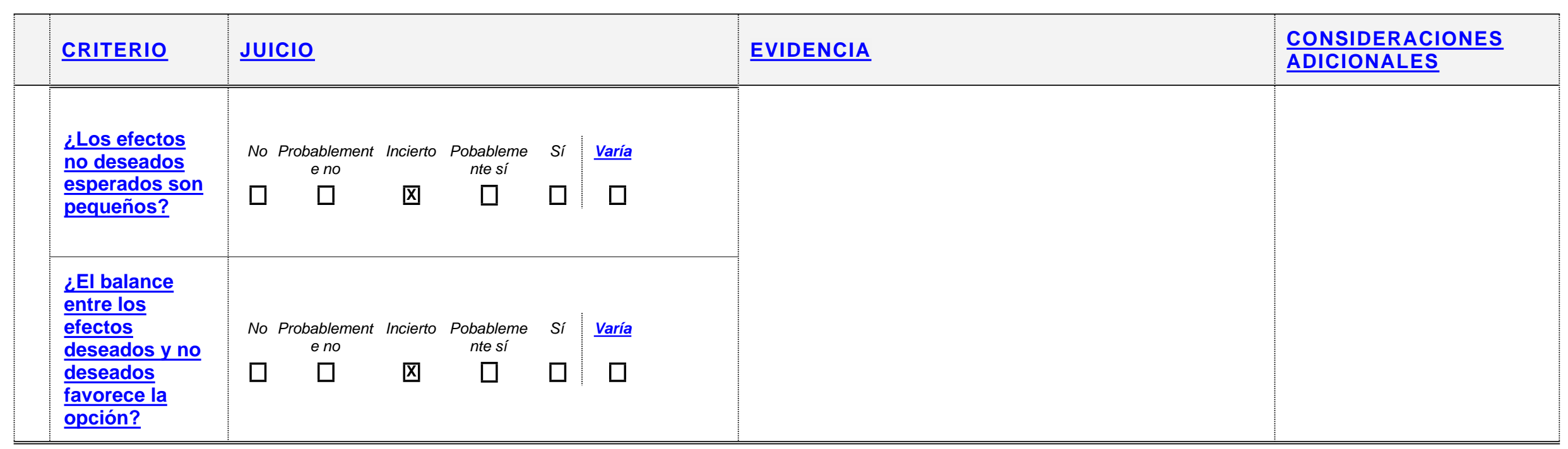


Población: Recién nacidos sanos a término que amamantan y que necesitan suplementos Intervención: Fórmula de suero parcialmente hidrolizado

Comparación: Fórmulas estándar

Perspectiva: Clínica

\begin{tabular}{|c|c|c|c|c|c|c|c|c|}
\hline & CRITERIO & JUICIO & & & & & EVIDENCIA & $\begin{array}{l}\text { CONSIDERACIONES } \\
\text { ADICIONALES }\end{array}$ \\
\hline \multirow{2}{*}{ 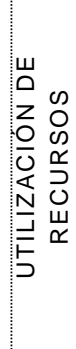 } & $\begin{array}{l}\text { ¿Los recursos } \\
\text { que se requieren } \\
\text { son bajos? }\end{array}$ & $\begin{array}{c}\text { No Probablemente } \\
\text { no } \\
\square \quad \square\end{array}$ & Incierto & $\begin{array}{cc}\text { Pobablemente } & \text { Sí } \\
\text { sí } & \\
\square & \square\end{array}$ & $\frac{\text { Varía }}{\square}$ & & & $\begin{array}{l}\text { Las fórmulas hidrolizadas } \\
\text { son más caras que las } \\
\text { estándar. }\end{array}$ \\
\hline & $\begin{array}{l}\frac{\text { ¿El coste }}{\text { incremental es }} \\
\text { pequeño en } \\
\text { relación a los } \\
\text { beneficios netos? }\end{array}$ & $\begin{array}{c}\text { No Probablemente } \\
\text { no } \\
\square \quad \square\end{array}$ & Incierto & $\begin{array}{cc}\begin{array}{c}\text { Pobablemente } \\
\text { sí }\end{array} & \text { Sí } \\
\bigotimes & \square\end{array}$ & $\frac{\text { Varía }}{\square}$ & & & $\begin{array}{l}\text { La evidencia que hay sobre } \\
\text { los beneficios es de muy } \\
\text { baja calidad y el efecto es } \\
\text { pequeño. }\end{array}$ \\
\hline 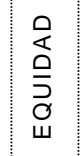 & $\begin{array}{l}\text { ¿Cuál sería el } \\
\text { impacto en las } \\
\text { desigualdades en } \\
\underline{\text { salud? }}\end{array}$ & \multicolumn{3}{|c|}{ 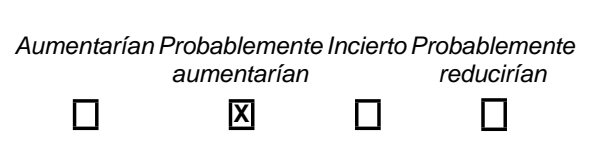 } & $\begin{array}{l}\text { Reducirían } \\
\square\end{array}$ & $\frac{\text { Varía }}{\square}$ & & $\begin{array}{l}\text { Las formulas hidrolizadas } \\
\text { son muy caras }\end{array}$ \\
\hline
\end{tabular}




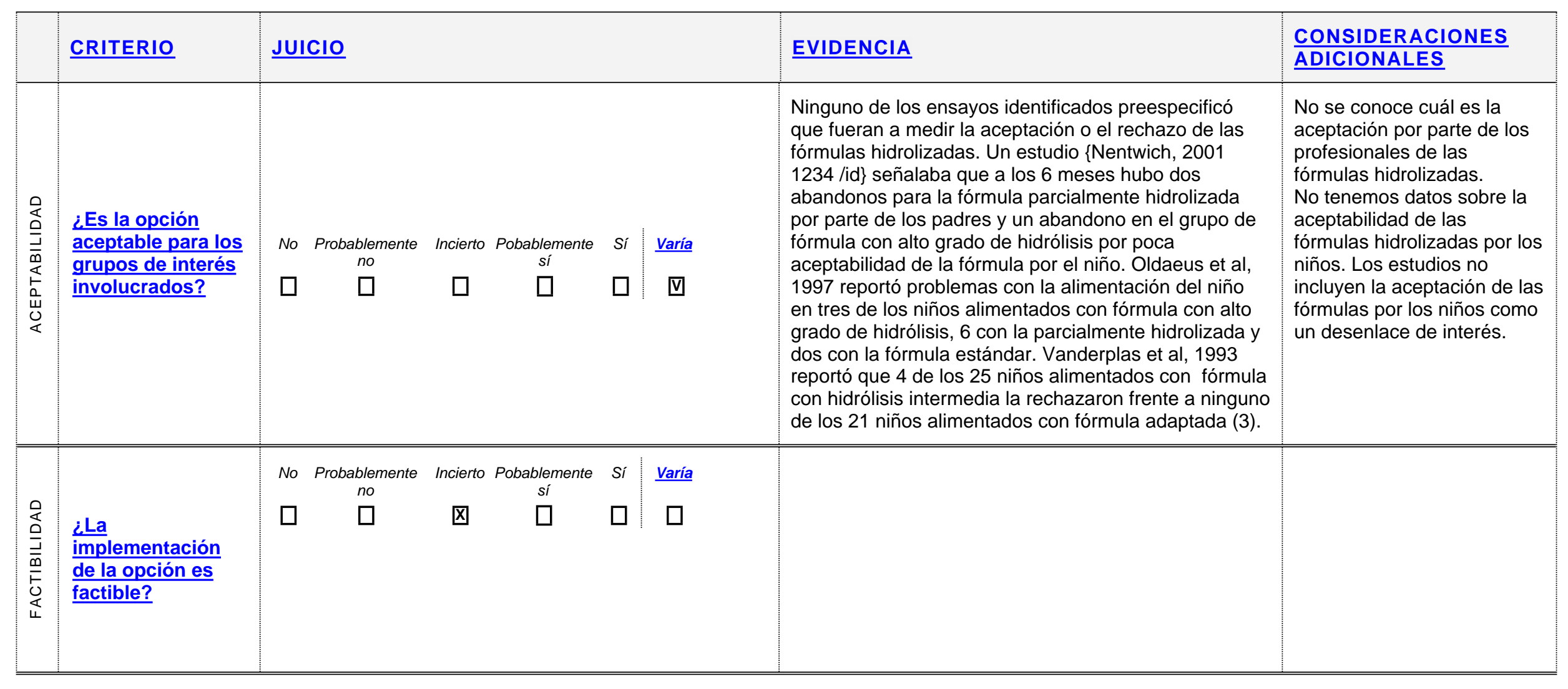

Balance de las consecuencias
Las consecuencias no deseadas superan claramente las

consecuencias deseadas en la mayoría de los escenarios
Las consecuencias no deseadas probablemente

$$
\text { superan las }
$$

El balance entre las consecuencias deseadas en la mayoría de los escenarios
Las consecuencias deseadas probablemente superan las consecuencias no deseadas en la mayoría de los escenarios
Las consecuencias deseadas claramente superan las consecuencias no deseadas en la mayoría de los escenarios 
$\square$

$\square$

$\square$

区

$\square$

\begin{tabular}{lccc}
\hline \hline Tipo de & Se recomienda no ofrecer la opción & Se sugiere no ofrecer la opción & Se sugiere ofrecer la opción \\
recomendación & $\square$ & Se recomienda \\
ofrecer la opción
\end{tabular}




\section{¿Cuál es el suplemento más adecuado en recién nacidos sanos?}

Población: Recién nacidos sanos a término amamantados y que necesitan suplementos

Intervención: Fórmulas con un alto grado de hidrólisis Comparación: Fórmulas parcialmente hidrolizadas

Perspectiva: Clínica

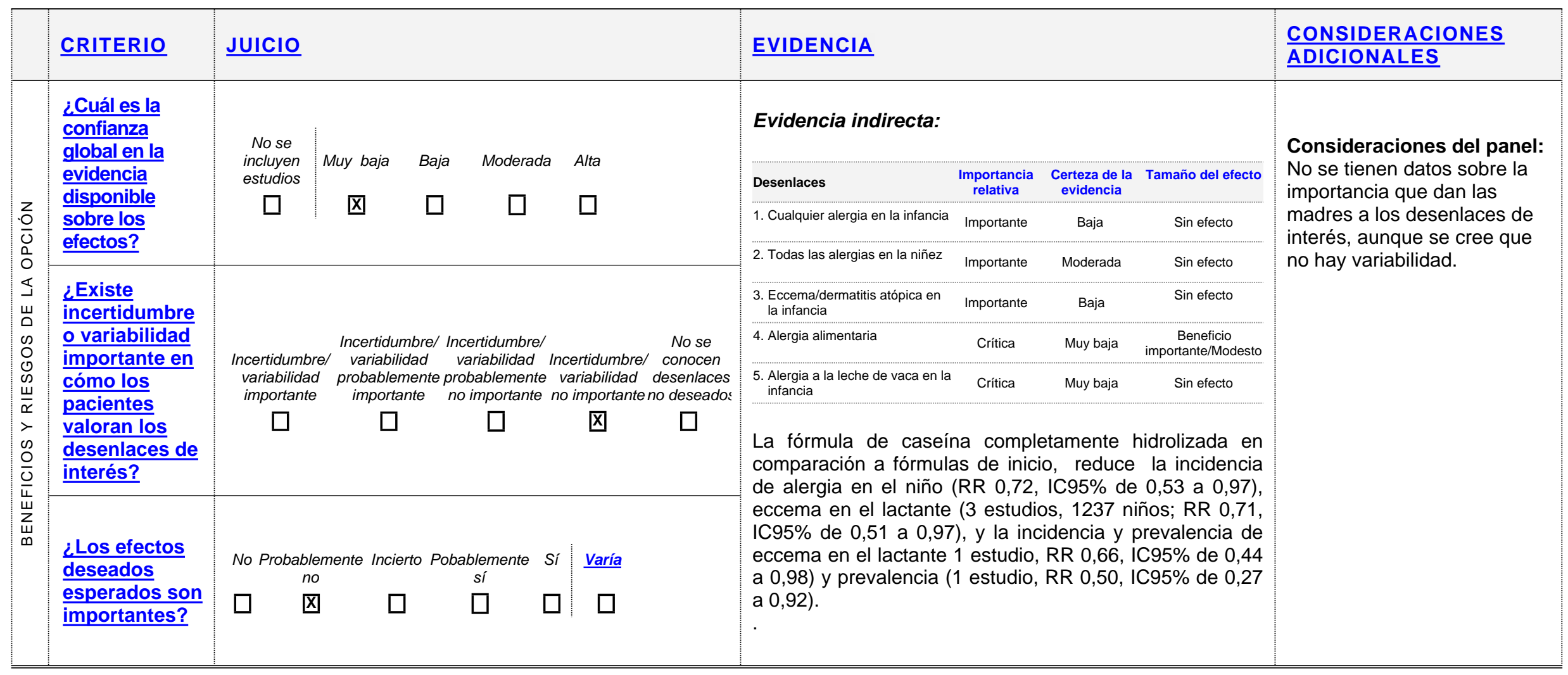




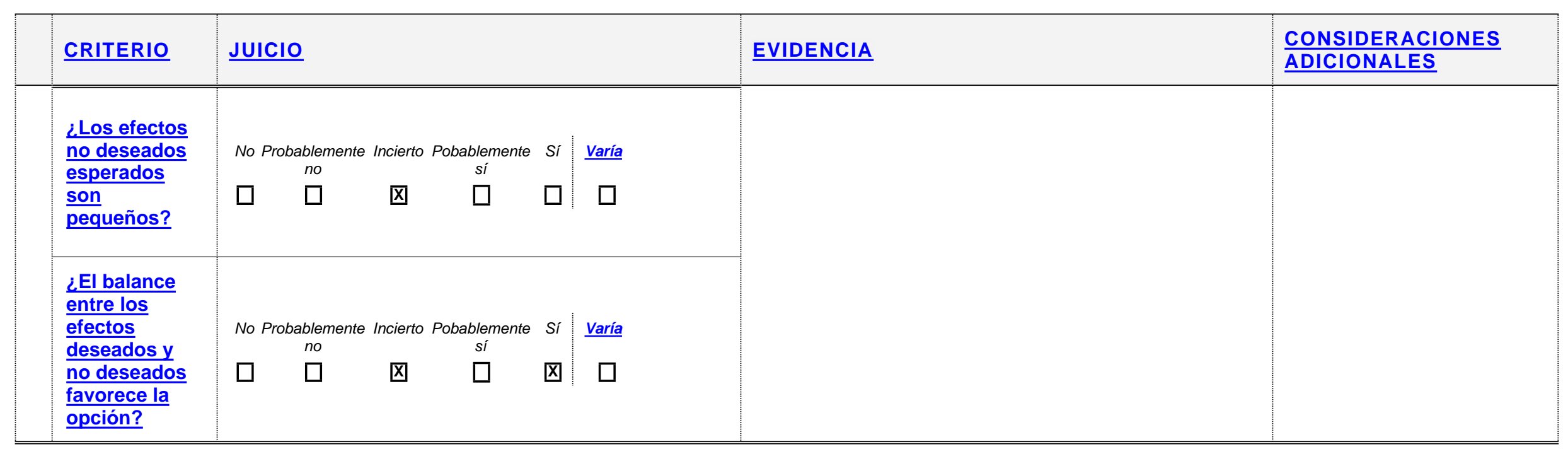

\begin{tabular}{|c|c|c|c|c|c|c|c|}
\hline & CRITERIO & $\underline{\text { JUICIO }}$ & & & & EVIDENCIA & $\begin{array}{l}\text { CONSIDERACIONES } \\
\text { ADICIONALES }\end{array}$ \\
\hline \multirow{2}{*}{ 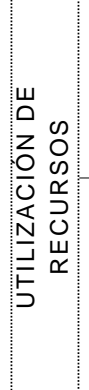 } & $\begin{array}{l}\text { ¿Los recursos } \\
\text { que se requieren } \\
\text { son bajos? }\end{array}$ & $\begin{array}{c}\text { No Probablemente } \\
n o \\
\square \quad \square\end{array}$ & $\begin{array}{cc}\text { Incierto } & \text { Pobablemente } \\
& \text { si } \\
\square & \square\end{array}$ & $\begin{array}{l}\text { Si } \\
\square\end{array}$ & $\frac{\text { Varía }}{\square}$ & & $\begin{array}{l}\text { Las formulas completamente } \\
\text { hidrolizadas son más caras } \\
\text { que las parcialmente } \\
\text { hidrolizadas }\end{array}$ \\
\hline & $\begin{array}{l}\frac{\text { EEl coste }}{\text { incremental es }} \\
\text { pequeño en } \\
\text { relación a los } \\
\text { beneficios netos? }\end{array}$ & $\begin{array}{l}\text { No Probablemente } \\
n o \\
\square \quad \square\end{array}$ & $\begin{array}{cc}\text { Incierto } & \text { Pobablemente } \\
& \text { si } \\
\square & \square\end{array}$ & $\begin{array}{l}\text { Si } \\
\square\end{array}$ & $\frac{\frac{\text { Varia }}{\square}}{\square}$ & & $\begin{array}{l}\text { Si no hay efecto no } \\
\text { compensaría. }\end{array}$ \\
\hline
\end{tabular}




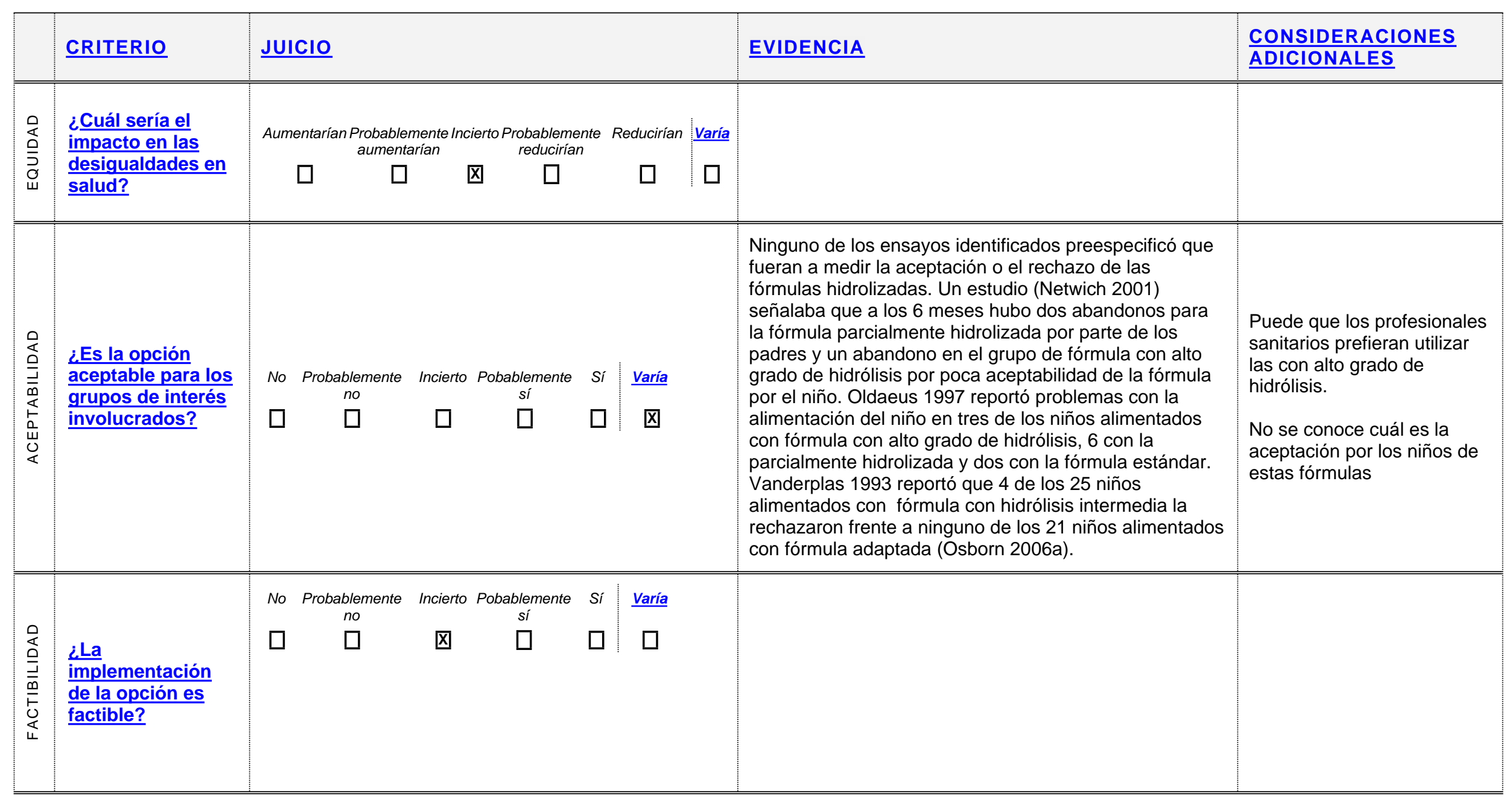




\begin{tabular}{|c|c|c|c|c|c|}
\hline \multirow[t]{2}{*}{$\begin{array}{l}\text { Balance de las } \\
\text { consecuencias } \\
\end{array}$} & $\begin{array}{l}\text { Las consecuencias no } \\
\text { deseadas superan } \\
\text { claramente las } \\
\text { consecuencias deseadas } \\
\text { en la mayoría de los } \\
\text { escenarios }\end{array}$ & $\begin{array}{l}\text { Las consecuencias no } \\
\text { deseadas probablemente } \\
\text { superan las } \\
\text { consecuencias deseadas } \\
\text { en la mayoría de los } \\
\text { escenarios }\end{array}$ & $\begin{array}{c}\text { El balance entre las } \\
\text { consecuencias deseadas y } \\
\text { no deseadas está muy } \\
\text { equilibrado o es incierto }\end{array}$ & $\begin{array}{l}\text { Las consecuencias } \\
\text { deseadas } \\
\text { probablemente superan } \\
\text { las consecuencias no } \\
\text { deseadas en la mayoría } \\
\text { de los escenarios }\end{array}$ & $\begin{array}{c}\text { Las consecuencias } \\
\text { deseadas claramente } \\
\text { superan las } \\
\text { consecuencias no } \\
\text { deseadas en la mayoría } \\
\text { de los escenarios }\end{array}$ \\
\hline & $\square$ & $\square$ & 囚 & $\square$ & $\square$ \\
\hline & \multicolumn{2}{|l|}{$\square$} & $\square$ & $\square$ & $\square$ \\
\hline
\end{tabular}




\section{Recomendaciones en relación a todas las comparaciones}

\section{Recomendaciones Recomendación de buena práctica}

$\checkmark$ No utilizar suero glucosado para la suplementación de recién nacidos a término sanos.

Recomendación fuerte a favor

En caso de existir una indicación médica para la suplementación, se recomienda el uso de leche materna extraída como primera opción.

\section{$\underline{\text { Recomendación de buena práctica }}$}

$\checkmark$ No utilizar leche donada que no provenga de bancos de leche materna y por tanto no haya pasado los controles de calidad preceptivos.

Recomendación débil a favor

Se sugieren las fórmulas de inicio como suplemento de elección cuando no se disponga de leche materna extraída en niños sanos y sin historia familiar de atopía.

\section{$\underline{\text { Recomendación débil a favor }}$}

Se sugiere el uso de fórmulas hidrolizadas en niños con historia familiar de primer grado de atopía (padres o hermanos con dermatitis atópica, rinitis alérgica, asma o alergia alimentaria). 
Justificación Se considera que la primera opción como suplemento es la leche materna extraída de la propia madre o la leche materna donada de banco que haya pasado los controles de calidad oportunos. No existen estudios que comparen la utilización de suero glucosado frente a otro tipo de suplementos, y como existen otras alternativas más seguras, no se recomienda su utilización. En cuanto al tipo de fórmula a utilizar, la evidencia parece indicar de forma débil que las fórmulas hidrolizadas pueden prevenir la aparición de enfermedad alérgica en el niño, sobre todo en niños de alto riesgo. Entre las fórmulas parcialmente hidrolizadas o con alto grado de hidrólisis, la evidencia sugiere que entre ambos tipos de fórmulas no hay diferencias, salvo un posible efecto protector frente al desarrollo de alergia alimentaria a favor de las fórmulas con alto grado de hidrólisis (sobre todo caseína), aunque con un intervalo de confianza al 95\% amplio que incluye al 1 (evidencia de muy baja calidad). Por ello, no se hace una recomendación a favor de una u otra fórmula en niños de alto riesgo. Siguen siendo necesarios estudios que demuestren la superioridad de las fórmulas con alto grado de hidrólisis frente a las fórmulas parcialmente hidrolizadas y estudien la aceptación de estas fórmulas por el lactante.

\section{Consideraciones de}

$\underline{\text { subgrupos }}$

Consideraciones para Se recomienda que se proporcione ayuda práctica a las madres para que aprendan a extraerse el calostro o la leche para que en la implementación caso de ser necesario se lo administren a sus hijos.

Se recomienda prestar especial apoyo a las familias con riesgo de atopía, explicando las particulares ventajas que la lactancia materna tiene en esa circunstancia.

Se recomienda a las instituciones que impulsen la creación de nuevos bancos de leche materna en el SNS y mejoren su capacidad de procesamiento y de distribución, así como las medidas necesarias para facilitar a las mujeres la donación de su leche.

\section{Monitorización y}

\section{evaluación}

\section{Prioridades para la} investigación
1) Se necesitan estudios de mejor calidad metodológica y mayor tiempo de seguimiento que valoren la eficacia de los diferentes tipos de fórmulas en la prevención de enfermedades alérgicas en el niño y más allá de la infancia.

2) Se necesitan estudios sobre el coste-efectividad del uso de fórmulas parcialmente hidrolizadas versus fórmulas estándar en niños de alto riesgo de desarrollar enfermedad alérgica

3) Se necesitan estudios que aborden la aceptabilidad de los diferentes tipos de fórmulas por los niños. 


\section{ANEXO I, ESTRATEGIAS DE BÚSQUEDA}

\section{Cochrane Library}

\section{Searched 14/03/2014}

\section{Updated search 14/03/2014 a xx/xx/xxxx}

\#1 MeSH descriptor: [Milk, Human] explode all trees 707

\#2 "breast milk" or breast-milk or (breast and milk) 1608

\#3 MeSH descriptor: [Breast Feeding] explode all trees 1212

\#4 breastfeeding or "breast feeding" or breastfeed or "breast feed" or breastfed or "breast fed" 3375

\#5 MeSH descriptor: [Lactation] explode all trees 439

\#6 lactation 1458

\#7 \#1 or \#2 or \#3 or \#4 or \#5 or \#6 4827

\#8 MeSH descriptor: [Infant Nutritional Physiological Phenomena] explode all trees 1767

\#9 MeSH descriptor: [Infant Formula] explode all trees 353

\#10 MeSH descriptor: [Food, Formulated] explode all trees 1013

\#11 MeSH descriptor: [Dietary Supplements] explode all trees 6564

\#12 supplement $^{*}$ or formula ${ }^{*} 56320$

\#13 \#8 or \#9 or \#10 or \#11 or \#12 57883

\#14 \#7 and \#13 3096

\#15 MeSH descriptor: [Infant] explode all trees 12656

\#16 \#14 and \#15

\section{MEDLINE, via Pubmed}

\section{Searched 14/03/2014}

\section{Updated search 14/03/2014 a xx/xx/xxxx}

\#1 "Milk, Human"[Mesh]

\#2 "breast milk"[All Fields] OR "breast milks"[All Fields] OR "human milk"[All Fields]

\#3 "Breast Feeding"[Mesh]

\#4 "breast feeding"[All Fields] OR "breastfeeding"[All Fields] OR "breast

feed"[All Fields] "breast feeding"[All Fields] OR "breastfeed"[All Fields] OR

"breast fed"[All Fields] OR breastfed[All Fields]

\#5 "lactation"[MeSH Terms] OR "lactation"[All Fields]

\#6 \#1 OR \#2 OR \#3 OR \#4 OR \#5

\#7 Infant Nutritional Physiological Phenomena"[Mesh]

\#8 "Infant Formula"[Mesh]

\#9 "Food, Formulated"[Mesh]

\#10 "Dietary Supplements"[Mesh]

\#11 (supplement* OR formula*)

\#12 \#7 OR \#8 OR \#9 OR \#10 OR \#11

\#13 \#6 AND \#12

\#14 \#13 Filters: Systematic Reviews; Clinical Trial; Infant: birth-23 months;

Newborn: birth-1 month; Field: Title/Abstract

CINAHL, via EBSCOhost databases

Searched 14/03/2014

Updated search 14/03/2014 a xx/xx/xxxx

\#1 (MH "Milk, Human") 2523 
\#2 $\quad$ "breast milk" OR "breast milks" OR "human milk" 2115

\#3 (MH "Breast Feeding") 11378

\#4 "breast feeding" OR breastfeeding OR "breast feed" OR breastfeed OR "breast fed" OR breastfed 14132

\#5 (MH "Lactation") 1548

\#6 lactation 2887

\#7 \#1 OR \#2 OR \#3 OR \#4 OR \#5 OR \#6 16616

\#8 (MH "Infant Nutritional Physiology") 339

\#9 (MH "Infant Formula") OR (MH "Infant Feeding, Supplemental") 2176

\#10 (MH "Food, Formulated") OR (MH "Dietary Supplements") 8304

$\# 11$ supplement ${ }^{*}$ OR formula* 51711

\#12 \#8 OR \#9 OR \#10 OR \#11 51908

\#13 \#7 AND \#12 2768

\#14 \#13 Limitadores - Grupos de edad: Infant, Newborn: birth-1 month, Infant: 1-23 months

\section{EMBASE, via Ovid}

\section{Searched 14/03/2014}

\section{Updated search 14/03/2014 a xx/xx/xxxx}

\#1 breast milk/ 19514

\#2 ("breast milk" or "breast milks" or "human milk").ti,ab. 17640

\#3 \#1 or \#2 25388

\#4 breast feeding/ or lactation/ 69785

\#5 ("breast feeding" or breastfeeding or "breast feed" or breastfeed or "breast fed" or breastfed or lactation).ti,ab. 57580

\#6 \#4 or \#5 85454

\#7 \#3 or \#6 98607

\#8 artificial milk/ 9174

\#9 infant nutrition/ 10445

$\# 10$ elemental diet/ 2703

$\# 11$ diet supplementation/ 61837

\#12 \#8 or \#9 or \#10 or \#11 81652

\#13 (supplement $^{*}$ or formula*).ti,ab. 481836

\#14 (food $^{*}$ or feed ${ }^{*}$ or $\operatorname{diet}^{\star}$ ).ti,ab. 958620

\#15 \#13 and \#14 99135

\#16 \#12 or \#15 147596

\#17 \#7 and \#16 16759

\#18 limit \#17 to infant <to one year> 


\section{1- BIBLIOGRAFÍA}

(1) Szajewska H, Horvath A, Koletzko B, Kalisz M. Effects of brief exposure to water, breast-milk substitutes, or other liquids on the success and duration of breastfeeding: a systematic review. Acta Paediatr 2006 Feb;95(2):145-52.

(2) Becker GE, Remmington S, Remmington T. Early additional food and fluids for healthy breastfed full-term infants. Cochrane Database Syst Rev 2011;(12):CD006462.

(3) Osborn DA, Sinn J. Formulas containing hydrolysed protein for prevention of allergy and food intolerance in infants. Cochrane Database Syst Rev 2006;(4):CD003664.

(4) Szajewska H, Horvath A. Meta-analysis of the evidence for a partially hydrolyzed $100 \%$ whey formula for the prevention of allergic diseases. Curr Med Res Opin 2010 Feb;26(2):423-37.

(5) Alexander DD, Cabana MD. Partially hydrolyzed $100 \%$ whey protein infant formula and reduced risk of atopic dermatitis: a meta-analysis. J Pediatr Gastroenterol Nutr 2010 Apr;50(4):422-30.

(6) Osborn DA, Sinn J. Soy formula for prevention of allergy and food intolerance in infants. Cochrane Database Syst Rev 2006;(4):CD003741.

(7) Hill DJ, Murch SH, Rafferty K, Wallis P, Green CJ. The efficacy of amino acidbased formulas in relieving the symptoms of cow's milk allergy: a systematic review. Clin Exp Allergy 2007 Jun;37(6):808-22.

(8) Quigley MA, Henderson G, Anthony MY, McGuire W. Formula milk versus donor breast milk for feeding preterm or low birth weight infants. Cochrane Database Syst Rev 2007;(4):CD002971.

(9) Boyd CA, Quigley MA, Brocklehurst P. Donor breast milk versus infant formula for preterm infants: systematic review and meta-analysis. Arch Dis Child Fetal Neonatal Ed 2007 May;92(3):F169-F175.

(10) Henderson G, Anthony MY, McGuire W. Formula milk versus maternal breast milk for feeding preterm or low birth weight infants. Cochrane Database Syst Rev 2007;(4):CD002972.

(11) McGuire W, Anthony MY. Donor human milk versus formula for preventing necrotising enterocolitis in preterm infants: systematic review. Arch Dis Child Fetal Neonatal Ed 2003 Jan;88(1):F11-F14.

(12) NICE. Postnatal care up to 8 weeks after birth. Julio 2006 (actualizado en Febrero de 2015). Disponible en: http://guidance.nice.org.uk/CG37.

(13) Perinatal Services BC. Health Promotion Guideline. Breastfeeding Healthy Term Infants. 2013 Feb.

(14) IHAN. Hospitales IHAN. Guía detallada para la aplicación paso por paso. Disponible en: https://

(15) Academy of Breastfeeding Medicine Protocol Committee. ABM clinical protocol\# 3: hospital guidelines for the use of supplementary feedings in the healthy term breastfed neonate, revised 2009. 2009.

(16) Martin-Calama J, Bunuel J, Valero MT, Labay M, Lasarte JJ, Valle F, et al. The effect of feeding glucose water to breastfeeding newborns on weight, body temperature, blood glucose, and breastfeeding duration. J Hum Lact 1997 Sep;13(3):209-13.

(17) Nicoll A, Ginsburg R, Tripp JH. Supplementary feeding and jaundice in newborns. Acta Paediatr Scand 1982 Sep;71(5):759-61. 
(18) Ojofeitimi EO, Elegbe IA. The effect of early initiation of colostrum feeding on proliferation of intestinal bacteria in neonates. Clin Pediatr (Phila) 1982 Jan;21(1):39-42.

(19) Schutzman DL, Hervada AR, Branca PA. Effect of water supplementation of full-term newborns on arrival of milk in the nursing mother. Clin Pediatr (Phila) 1986 Feb;25(2):78-80.

(20) Juvonen P, Mansson M, Andersson C, Jakobsson I. Allergy development and macromolecular absorption in infants with different feeding regimens during the first three days of life. A three-year prospective follow-up. Acta Paediatr 1996 Sep;85(9):1047-52.

(21) Saarinen KM, Juntunen-Backman K, Jarvenpaa $A L$, Klemetti $P$, Kuitunen $P$, Lope L, et al. Breast-feeding and the development of cows' milk protein allergy. Adv Exp Med Biol 2000;478:121-30.

(22) Chung CS, Yamini S, Trumbo PR. FDA's health claim review: whey-protein partially hydrolyzed infant formula and atopic dermatitis. Pediatrics 2012 Aug;130(2):e408-e414.

(23) Cohen RS, Xiong SC, Sakamoto P. Retrospective review of serological testing of potential human milk donors. Arch Dis Child Fetal Neonatal Ed 2010 Mar;95(2):F118-F120.

(24) Gribble KD. Peer-to-peer milk donors' and recipients' experiences and perceptions of donor milk banks. J Obstet Gynecol Neonatal Nurs 2013 Jul;42(4):451-61. 


\section{PREGUNTA №16}

¿Cómo deben administrarse los suplementos?

\section{1- PREGUNTA CLÍNICA EN FORMATO PICO}

Tabla 1- Componentes de la pregunta clínica en formato PICO

\begin{tabular}{|l|l|}
\hline Pacientes & $\begin{array}{l}\text { Madres sanas y recién nacidos sanos a término } \\
\text { amamantados }\end{array}$ \\
\hline Intervención & $\begin{array}{l}\text { Cuchara, vaso, cuentagotas, jeringa, relactador, alimentación } \\
\text { con dedo, biberón, paladai }\end{array}$ \\
\hline Comparación & $\begin{array}{l}\text { Cuchara, vaso, cuentagotas, jeringa, relactador, alimentación } \\
\text { con dedo, biberón, paladai }\end{array}$ \\
\hline Resultados & $\begin{array}{l}\text { Tasa de lactancia materna exclusiva al alta/a la semana } \\
\text { Tasa de lactancia materna a los 4-6 meses } \\
\text { Tasa de lactancia materna exclusiva a los 4-6 meses } \\
\text { Satisfacción materna } \\
\text { Complicaciones de las mamas (grietas, ingurgitaciones) } \\
\text { Peso del recién nacido (48-72h.) }\end{array}$ \\
\hline Tipo de estudio & $\begin{array}{l}\text { RS de ECA, ECA, RS de estudios observacionales o estudios } \\
\text { observacionales }\end{array}$ \\
\hline
\end{tabular}

\section{2- INTRODUCCIÓN}

Aunque la utilización de tetinas es la forma más aceptada en nuestro entorno para administrar suplementos a los recién nacidos amamantados, es conocido que su utilización puede interferir con la lactancia y que existen diferentes alternativas. Teniendo en cuenta que cuando existe una indicación médica para suplementar a un recién nacido lo prioritario es que tome dicho suplemento nos planteamos cuál es la forma más adecuada de administrarlo. 


\section{ESTRATEGIA DE ELABORACION DE LA PREGUNTA}

\subsection{GPC Base}

Tabla 2- Resumen de GPC Base

\begin{tabular}{|c|c|c|c|c|}
\hline $\begin{array}{c}\text { Guía } \\
\text { (Enfoque) }\end{array}$ & $\begin{array}{l}\text { Resumen sobre la evidencia } \\
\text { (Calidad de la evidencia) }\end{array}$ & $\begin{array}{l}\text { Recomendaciones } \\
\text { (Grado) }\end{array}$ & $\begin{array}{l}\text { Referencias bibliográficas } \\
\text { (Tipo de publicación) }\end{array}$ & Comentarios \\
\hline $\begin{array}{l}\text { NICE_2006 } \\
\text { (Actualiz. } \\
\text { 2011) }\end{array}$ & $\begin{array}{l}\text { Si los suplementos son necesarios, la suplementación por } \\
\text { vaso puede mejorar la duración de la lactancia materna. Sin } \\
\text { embargo, esto puede ser beneficioso solo entre recién } \\
\text { nacidos nacidos por cesárea [Nivel 1+] } \\
\text { Un artículo publicado por Newman (Newman 1996) } \\
\text { describía un árbol de decisión para valorar una alimentación } \\
\text { adecuada, basándose en la experiencia adquirida en el } \\
\text { Breastfeeding Clinic of the Hospital for Sick Children de } \\
\text { Toronto. El método preferido en clínica para suplementar a } \\
\text { un recién nacido deshidratado que puede ser recolocado y } \\
\text { reengancharse al pecho, pero que aún no mama bien, es el } \\
\text { suplementador o relactador colocado en el pecho. } \\
\text { Se coloca una sonda en el pezón unida a un recipiente de } \\
\text { leche materna extraída para que cuando el niño succiona } \\
\text { reciba leche materna, tanto directamente como a través del } \\
\text { relactador. Si la recolocación, el reenganche y la } \\
\text { compresión de la mama no son efectivas y el recién nacido } \\
\text { no está haciendo un buen agarre, se recomienda la } \\
\text { alimentación por dedo o vaso. La alimentación por dedo es } \\
\text { una técnica en la que se utiliza una sonda o una jeringuilla } \\
\text { que se coloca como ayuda junto al dedo índice o meñique } \\
\text { del cuidador. Esto permite la alimentación sin el uso de una } \\
\text { tetina artificial. } \\
\text { Howard et al (1999) examinaron el efecto de dos métodos } \\
\text { para administrar líquido adicional sobre la lactancia materna } \\
\text { (en vaso o biberón) durante el período postnatal, así como } \\
\text { el efecto de la introducción temprana (2-5 días) versus } \\
\text { tardía " más de } 4 \text { semanas) del uso del chupete. El } \\
\text { reclutamiento tuvo lugar de forma antenatal entre mujeres } \\
\text { que pretendían amamantar y estaban indecisas o querían }\end{array}$ & $\begin{array}{l}\text { Si el recién nacido no está tomando suficiente } \\
\text { leche directa desde el pecho y es necesario } \\
\text { administrar suplementos, se debería proporcionar } \\
\text { leche maternal extraída mediante taza o biberón } \\
\text { [B]. } \\
\text { Todos los proveedores de salud deberían } \\
\text { implementar un programa estructurado } \\
\text { externamente evaluado que promoviera la } \\
\text { lactancia materna, utilizando la iniciativa IHAN } \\
\text { como mínimo estándar [A]. }\end{array}$ & $\begin{array}{l}\text { Newman J,1996 } \\
\text { Howard CR, } 1999 \text { (Ensayo) } \\
\text { Dyson R, } 2006 \text { (RS) }\end{array}$ & \\
\hline
\end{tabular}




\begin{tabular}{|c|c|c|c|c|}
\hline $\begin{array}{c}\text { Guía } \\
\text { (Enfoque) }\end{array}$ & $\begin{array}{l}\text { Resumen sobre la evidencia } \\
\text { (Calidad de la evidencia) }\end{array}$ & $\begin{array}{l}\text { Recomendaciones } \\
\text { (Grado) }\end{array}$ & $\begin{array}{l}\text { Referencias bibliográficas } \\
\text { (Tipo de publicación) }\end{array}$ & Comentarios \\
\hline & 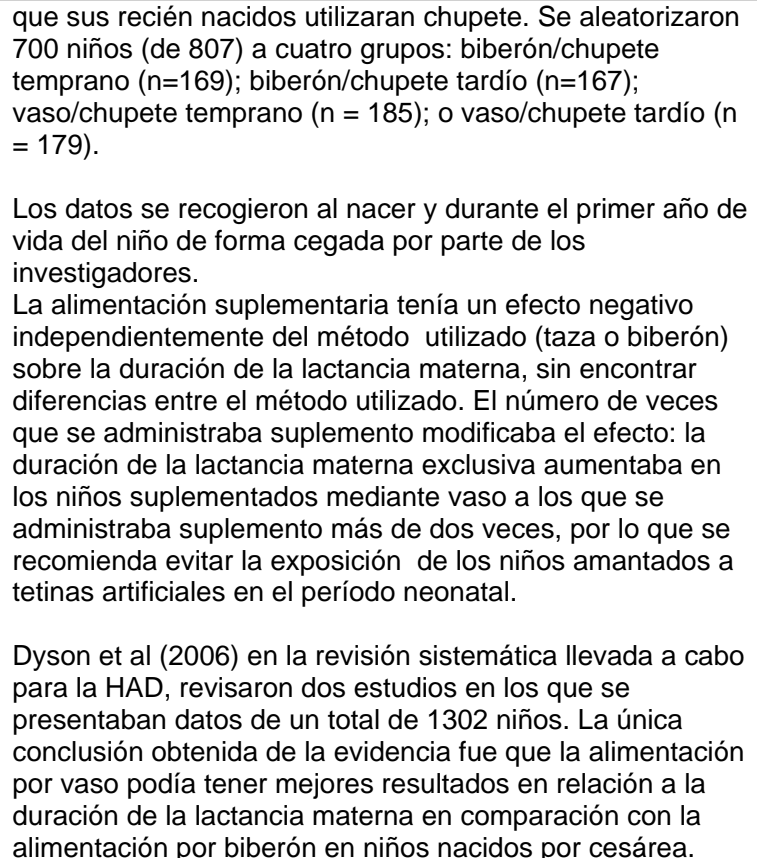 & & & \\
\hline
\end{tabular}




\subsection{Otros documentos}

\begin{tabular}{|c|c|c|c|c|}
\hline $\begin{array}{c}\text { Guía } \\
\text { (Enfoque) }\end{array}$ & $\begin{array}{l}\text { Resumen sobre la evidencia } \\
\text { (Calidad de la evidencia) }\end{array}$ & $\begin{array}{l}\text { Recomendaciones } \\
\text { (Grado) }\end{array}$ & $\begin{array}{l}\text { Referencias bibliográficas } \\
\text { (Tipo de publicación) }\end{array}$ & Comentarios \\
\hline $\begin{array}{l}\text { Documento } \\
\text { Ministerio } \\
\text { sobre IHAN } \\
\\
\text { Guía detallada } \\
\text { IHAN en } \\
\text { Hospitales }\end{array}$ & $\begin{array}{l}\text { Muchos profesionales piensan que los biberones con tetinas } \\
\text { son el único modo de administrar suplementos cuando el } \\
\text { lactante no puede tomar directamente el pecho } \\
\text { Cuando sea necesario administrar suplementos se pueden } \\
\text { utilizar diversas técnicas: relactador, vaso, cuchara o gotero, } \\
\text { alimentación por dedo o biberón (14, 19). No existe } \\
\text { evidencia acerca de la seguridad o eficacia de la mayoría de } \\
\text { los métodos ni de su efecto sobre el amamantamiento. Sin } \\
\text { embargo cuando la limpieza o refrigeración no son óptimas, } \\
\text { la mejor opción puede ser el vaso (20). El vaso es seguro } \\
\text { para los RN y puede ayudar a preservar la duración del } \\
\text { amamantamiento en los RN que requieran administración } \\
\text { de múltiples suplementos (14). }\end{array}$ & $\begin{array}{l}\text { Si por razones médicas son necesarios los } \\
\text { suplementos, existen diversas alternativas a las } \\
\text { tetinas: vasos, cucharas, jeringas y cuenta gotas } \\
\text { que pueden utilizarse en función de la edad de } \\
\text { gestación y de los motivos por los que se } \\
\text { necesitan suplementos (Documento Ministerio). } \\
\text { Paso } 9 \text { de la estrategia IHAN: } \\
\text { Se recomienda evitar en lo posible el uso de } \\
\text { tetinas y chupetes mientras el bebé está } \\
\text { aprendiendo a mamar. Hay alternativas a las } \\
\text { tetinas: pueden usarse jeringa o vasito. Ambas } \\
\text { pueden utilizarse para ofertar suplementos de } \\
\text { manera transitoria (Guía detallada Hospitales } \\
\text { IHAN; pg 40). }\end{array}$ & $\begin{array}{l}\text { (14) Howard CR (2003) (ECA) } \\
\text { (19) American Academy of } \\
\text { Pediatrics (1997) (Policy } \\
\text { Statement) } \\
\text { (20) United Nations Children's } \\
\text { Fund (1996) }\end{array}$ & \\
\hline $\begin{array}{l}\text { ABM Clinical } \\
\text { Protocol \#3, } \\
2009\end{array}$ & $\begin{array}{l}\text { Métodos para administrar suplementos } \\
\text { 1. Cuando se necesite administrar suplementos, hay varios } \\
\text { métodos entre los que se puede escoger: relactador al } \\
\text { pecho, alimentación por vaso, cuchara, gotero, alimentación } \\
\text { por dedo, alimentación por jeringa directamente a la boca o } \\
\text { por biberón49. } \\
\text { 2. Hay poca evidencia sobre la seguridad o eficacia de la } \\
\text { mayoría de los métodos alternativos y su efecto sobre la } \\
\text { lactancia maternal: sin embargo, cuando la limpieza no es } \\
\text { óptima, la alimentación por vaso es la opción } \\
\text { recomendada41. } \\
\text { 3. La alimentación por vaso ha demostrado seguridad tanto } \\
\text { para niños prematuros y nacidos a término, y que pueden } \\
\text { ayudar a preservar la duración de la lactancia materna entre } \\
\text { los que requieren múltiple uso de suplementos50-55. }\end{array}$ & & $\begin{array}{l}\text { 41. Global Strategy for Infant } \\
\text { 49. Wight NE,2001 } \\
\text { 50. Howard CR, } 1999 \\
\text { 51. Howard CR, } 2003 \\
\text { 52. Kramer MS, } 2001 \\
\text { 53. Marinelli KA, } 2001 \\
\text { 54. Malhotra N, } 1999 \\
\text { 55. Lang S,1994; } \\
\text { 56. Cloherty M, } 2005\end{array}$ & $\begin{array}{l}\text { Necesidades en } \\
\text { invesgación } \\
\text { Falta investigación sobre } \\
\text { cuál es el método óptimo } \\
\text { para la suplementación. } \\
\text { ¿Son algunos métodos } \\
\text { mejores que otros para } \\
\text { niños con determinadas } \\
\text { características, edades y } \\
\text { recursos?; ¿Qué métodos } \\
\text { interfieren menos con el } \\
\text { establecimiento de la } \\
\text { lactancia materna? }\end{array}$ \\
\hline
\end{tabular}




\begin{tabular}{|c|c|c|c|c|}
\hline $\begin{array}{c}\text { Guía } \\
\text { (Enfoque) }\end{array}$ & $\begin{array}{l}\text { Resumen sobre la evidencia } \\
\text { (Calidad de la evidencia) }\end{array}$ & $\begin{array}{l}\text { Recomendaciones } \\
\text { (Grado) }\end{array}$ & $\begin{array}{l}\text { Referencias bibliográficas } \\
\text { (Tipo de publicación) }\end{array}$ & Comentarios \\
\hline & 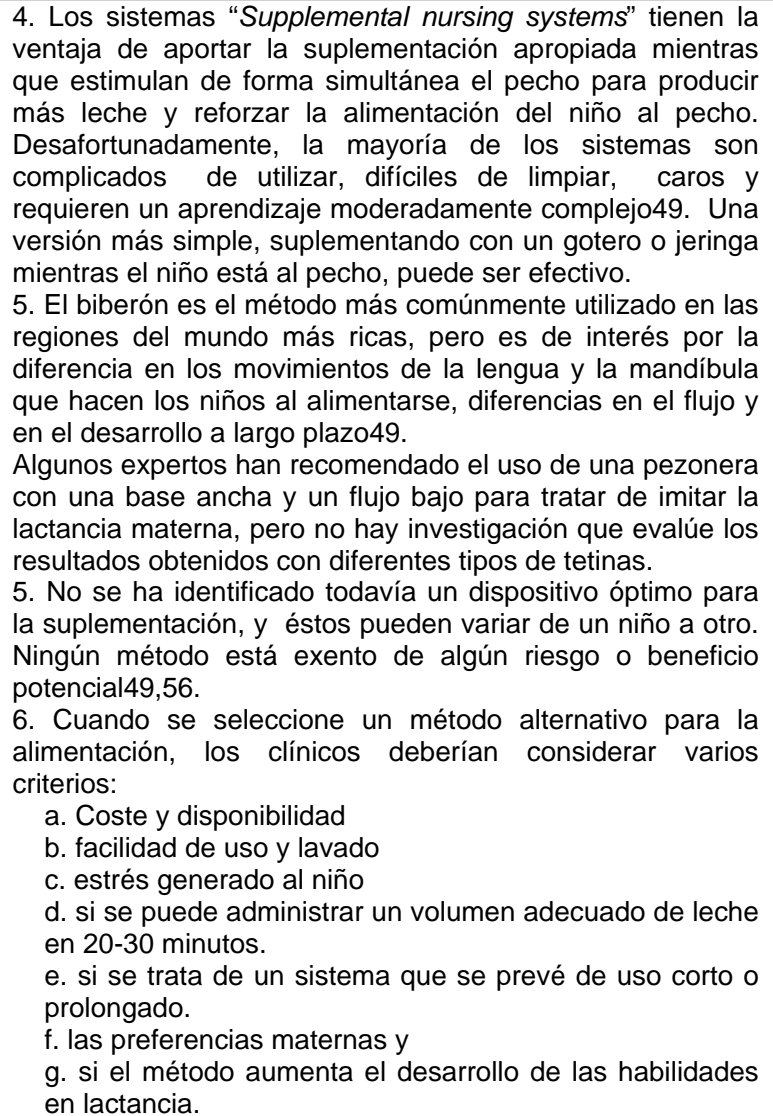 & & & \\
\hline
\end{tabular}




\subsection{Revisiones sistemáticas}

En la búsqueda realizada se han identificado dos revisiones sistemáticas Cochrane relacionadas con la forma de administración de los suplementos $(1 ; 2)$. La primera revisión trata de la forma de administrar los suplementos en los recién nacidos que no pueden alimentarse solamente con lactancia materna (1) y la segunda sobre evitar el uso de los biberones durante el establecimiento de la lactancia materna en los niños prematuros (2).

Se ha seleccionado la revisión de Flint et al, 2007, en la que se compara la alimentación con taza versus otras formas de alimentación enteral complementaria en recién nacidos que no pueden amamantar de forma total (fully breastfeed). Sin embargo, esta revisión excluye los dos artículos de Howard (3;4), el primero de ellos (3) porque comparan dos grupos de recién nacidos que son alimentados de forma exclusiva con fórmula que es administrada mediante vaso o biberón, y el segundo (4) porque el estudio no cumple con los criterios de inclusión al no tratarse de niños "unable to fully breastfeed", aunque es el estudio al que se hace referencia en el documento de la OMS (sobre la iniciativa Baby Friendly) (4). También excluye el estudio de Malhotra et al, 1999, que describe la diferencia en el volumen y tiempo que se tarda en administrar la leche mediante el uso de biberón, vaso o paladai, por su mala calidad metodológica (5).

Las características de la revisión de Flint et al, 2007, se resumen en la siguiente tabla.

Tabla 3- Resumen de RS actuales

\begin{tabular}{|c|c|c|c|c|c|c|}
\hline $\begin{array}{l}\text { Referencia } \\
\text { (Cita } \\
\text { Abreviada) }\end{array}$ & $\begin{array}{l}\text { Estudio (Diseño y } \\
\text { objetivo) }\end{array}$ & $\begin{array}{l}\text { Población } \\
\text { (no y características) }\end{array}$ & $\begin{array}{l}\text { Descripción de las intervenciones } \\
\text { comparaciones, exposiciones o } \\
\text { pruebas a estudio }\end{array}$ & $\begin{array}{l}\text { Resultados } \\
\text { (Estimadores de resultados-Magnitud del } \\
\text { efecto) }\end{array}$ & $\begin{array}{l}\text { Conclusiones } \\
\text { (conclusiones) }\end{array}$ & $\begin{array}{l}\text { Comentarios } \\
\text { Calidad de la } \\
\text { evidencia } \\
\text { Financiación } \\
\text { comentarios) }\end{array}$ \\
\hline Flint A, 2007 & $\begin{array}{l}\text { Revisión sistemática } \\
\text { con metanálisis } \\
\text { Objetivo: determinar } \\
\text { el efecto de la } \\
\text { alimentación con } \\
\text { taza versus otras } \\
\text { formas de } \\
\text { alimentación enteral } \\
\text { complementaria en } \\
\text { recién nacidos que } \\
\text { no pueden } \\
\text { alimentarse } \\
\text { solamente con la }\end{array}$ & $\begin{array}{l}\text { La revision incluye } 4 \\
\text { ECAs: } \\
\text { - Collins } 2004 \\
\text { ( }(n=319) \\
\text { - Gilks } 2004(n=54) \\
\text { - Mosley } 2001(n=16) \\
\text { - Rocha } 2002(n=83)\end{array}$ & $\begin{array}{l}\text { Tipos de intervención: alimentación } \\
\text { oral, tanto de leche materna extraída o } \\
\text { de la combinación de leche materna } \\
\text { extraída y fórmula artificial, vía taza (o } \\
\text { forma similar para que el niño sorba la } \\
\text { leche) versus otras formas de } \\
\text { administrar el suplemento (por sonda o } \\
\text { biberón) }\end{array}$ & $\begin{array}{l}\text { Los resultados principales son para taza } \\
\text { vs biberón: } \\
\text { - Ganancia de peso: ns ( } 1 \text { estudio) } \\
\text { - Tiempo para alimentarse con ganancia } \\
\text { de peso aceptable ( } 15-30 \mathrm{~g} / \mathrm{d} \text { dia) } \\
\text { - \% sin lactancia materna al alta } \\
\text { hospitalaria, a los tres y seis meses: } \\
\text { - RR } 0,82 \text { (IC95\% } 0,62 ; 1,09) \\
\text { - } \quad \text { RR } 0,88 \text { (IC95\%: } 0,76 ; 1,03) \\
\text { - RR 0,91 (IC95\% de 0,78 a1,05) } \\
\text { - } \% \text { sin lactancia casi exclusiva al alta, } 3 \\
\text { y } 6 \text { meses: } \\
\text { - RR 0,75 (0,61,,92), NNT } 7,3(4,6 \text { a } \\
\text { 22,3) (4 estudios) }\end{array}$ & $\begin{array}{l}\text { No se puede } \\
\text { recomendar la } \\
\text { alimentación por } \\
\text { taza frente a la } \\
\text { alimentación por } \\
\text { biberón porque no } \\
\text { proporciona } \\
\text { beneficio en el } \\
\text { mantenimiento de } \\
\text { la lactancia tras el } \\
\text { alta hospitalaria y } \\
\text { puede llevar a } \\
\text { prolongar la } \\
\text { estancia en el }\end{array}$ & $\begin{array}{l}\text { Todos los niños } \\
\text { incluidos son } \\
\text { prematuros. } \\
\text { Los autores } \\
\text { tenían intención } \\
\text { inicial de ver si } \\
\text { los resultados } \\
\text { variaban entre: } \\
\text {-niños } \\
\text { prematuros vs. } \\
\text { nacidos a } \\
\text { término } \\
\text { - Niños con }\end{array}$ \\
\hline
\end{tabular}




\begin{tabular}{|c|c|c|c|c|c|c|}
\hline $\begin{array}{l}\text { Referencia } \\
\text { (Cita } \\
\text { Abreviada) }\end{array}$ & $\begin{array}{l}\text { Estudio (Diseño y } \\
\text { objetivo) }\end{array}$ & $\begin{array}{l}\text { Población } \\
\text { (no y características) }\end{array}$ & $\begin{array}{l}\text { Descripción de las intervenciones } \\
\text { comparaciones, exposiciones o } \\
\text { pruebas a estudio }\end{array}$ & $\begin{array}{l}\text { Resultados } \\
\text { (Estimadores de resultados-Magnitud del } \\
\text { efecto) }\end{array}$ & $\begin{array}{l}\text { Conclusiones } \\
\text { (conclusiones) }\end{array}$ & $\begin{array}{l}\text { Comentarios } \\
\text { Calidad de la } \\
\text { evidencia } \\
\text { Financiación } \\
\text { comentarios) }\end{array}$ \\
\hline & lactancia materna & & & $\begin{array}{l}\text { - Ns para } 3 \text { y } 6 \text { meses ( } 1 \text { estudio) } \\
\text { - Duración estancia: } 1 \text { estudio (Collins } \\
\text { 2004): } 59 \text { (37-85) días vs. } 48 \text { (33-65) } \\
\text { días }\end{array}$ & hospital. & $\begin{array}{l}\text { malformaciones } \\
\text { oral-facial vs. } \\
\text { normales } \\
\text { El estudio de } \\
\text { Collins } 2004 \\
\text { incluye niños } \\
\text { prematuros de } \\
\text { edad inferior a } \\
34 \text { semanas. }\end{array}$ \\
\hline
\end{tabular}




\subsection{Resumen de GPCs base y RSs disponibles}

La guía de NICE (6) indica que se debería proporcionar leche extraída mediante taza o biberón (Grado B).

La iniciativa IHAN (7) señala que la mejor forma de administración de suplementos puede ser el vaso y que se debe evitar el uso de tetinas al existir otros métodos alternativos.

La American Academy of Breastfeeding (8) describe los métodos que hay para la administración de suplementos e indica varios criterios que pueden tenerse en cuenta a la hora de escoger el método a utilizar.

La revisión sistemática seleccionada (1),, que incluye datos obtenidos en niños prematuros, concluye que no se puede recomendar la alimentación por taza frente a la alimentación por biberón porque no proporciona beneficio en el mantenimiento de la lactancia tras el alta hospitalaria y puede llevar a prolongar la estancia en el hospital.

\subsection{Conclusión (marcar con una $\mathrm{X}$ ):}

\begin{tabular}{|l|l|}
\hline & Adopción GPC/Revisión sistemática \\
\hline$X$ & Elaboración parcial \\
\hline & Elaboración de novo \\
\hline
\end{tabular}

\subsection{Diseño de la estrategia de búsqueda de estudios individuales}

\begin{tabular}{|l|l|}
\hline Criterios de selección de estudios & ECAS, ensayos clínicos \\
\hline Período de búsqueda & 2006-marzo 2014 \\
\hline Bases de datos & Cochrane Library \\
& MEDLINE, via Pubmed \\
& EMBASE, via Ovid \\
& Cinahl, via EBSCOhost databases \\
& PsyINFO, via OVID \\
\hline
\end{tabular}

Ver estrategias de búsqueda de estudios originales en el ANEXO I. 


\section{4- Resumen de la evidencia (Tablas de estudios individuales y valoración de calidad en el ANEXO X)}

\section{1- GRADE Evidence Profile}

Comparación 1: Taza vs. Biberón

Bibliografía: Howard CR, Howard FM, Lanphear B, Eberly S, deBlieck EA, Oakes D, Lawrence RA. Randomized clinical trial of pacifier use and bottle feeding or cupfeeding and their effect on breastfeeding. Pediatrics $2003 ; 111 ; 511$.

\begin{tabular}{|c|c|c|c|c|c|c|c|c|c|c|c|c|}
\hline \multirow{2}{*}{\multicolumn{7}{|c|}{ Evaluación de la calidad }} & \multicolumn{4}{|c|}{ Resumen de los Resultados } & \multirow{3}{*}{ Calidad } & \multirow{3}{*}{ Importancia } \\
\hline & & & & & & & \multicolumn{2}{|c|}{ № de pacientes } & \multicolumn{2}{|c|}{ Magnitud del efecto } & & \\
\hline $\begin{array}{c}\text { № de } \\
\text { estudios }\end{array}$ & Diseño & \begin{tabular}{|c|}
$\begin{array}{c}\text { Riesgo de } \\
\text { sesgo }\end{array}$ \\
\end{tabular} & Inconsistencia & \begin{tabular}{|c|}
$\begin{array}{c}\text { Evidencia } \\
\text { indirecta }\end{array}$ \\
\end{tabular} & Imprecisión & $\begin{array}{c}\text { Otras } \\
\text { consideraciones }\end{array}$ & $\begin{array}{c}\text { Suplementos con } \\
\text { biberón }\end{array}$ & $\begin{array}{l}\text { Suplementos con } \\
\text { vaso }\end{array}$ & $\begin{array}{l}\text { Relativa } \\
(95 \% \mathrm{Cl})\end{array}$ & $\begin{array}{l}\text { Absoluta } \\
\text { por } 1000\end{array}$ & & \\
\hline \multicolumn{13}{|c|}{ Duración de la lactancia materna exclusiva* } \\
\hline 1 & ECA & Serio ${ }^{1}$ & No seria & Seria ${ }^{2}$ & No seria & Poco probable & $230^{3}$ & $251^{3}$ & $\begin{array}{l}\text { HR } 1,06 \text { (de } \\
0,88 \text { a } 1,27)\end{array}$ & - & BAJA & CRITICA \\
\hline \multicolumn{13}{|c|}{ Duración de cualquier lactancia materna* } \\
\hline 1 & ECA & \begin{tabular}{|l|l} 
Serio $^{1}$ \\
\end{tabular} & No seria & Seria $^{2}$ & No seria & Poco probable & $230^{4}$ & $251^{4}$ & $\begin{array}{l}\text { HR 0,92 (de } \\
0,76 \text { a } 1,12)\end{array}$ & - & BAJA & IMPORTANTE \\
\hline
\end{tabular}




\section{2- Resumen de la Evidencia}

Además de la revisión Cochrane mencionada y de los artículos de Howard (4) y de Malhotra et al, 1999 (5), se han identificado tres estudios adicionales que no han sido incluidos en el perfil de evidencia GRADE. Se trata de un estudio longitudinal (9) que describe la asociación entre la lactancia materna exclusiva y la lactancia con suplementación en el hospital (taza vs. biberón) con la competencia del niño y su comportamiento a la hora de succionar y con la producción de leche materna; un segundo estudio piloto, no aleatorizado, que evalúa el uso del paladai (pequeña taza con un pico en forma de "lámapara de Aladino", utilizada como dispositivo de alimentación tradicionalmente en la india) en comparación al biberón para alimentar a niños prematuros (10) y un tercer estudio en prematuros tardíos que compara la alimentación en taza vs. biberón y su efecto sobre la lactancia materna exclusiva y de cualquier tipo de lactancia al alta, a los 3 y a los 6 meses (11).

El único estudio que responde específicamente a nuestra pregunta es el estudio de Howard 2003 (4), que aunque incluye la suplementación de niños tanto con dificultades médicas como por petición de la madre, es el único que compara la administración de suplementos mediante taza o biberón en niños sanos nacidos a término y amamantados.

De los 700 niños incluidos el 69\% ( $n=481)$ recibió suplementos, siendo la indicación de tipo médico sólo en el $33 \%$ de los casos (ejemplo: hipoglicemia o pérdida de peso mayor o igual del 10\%). En el $51 \%$ de los casos los suplementos fueron administrados por petición de la madre y la causa no fue documentada en el $16 \%$ de los casos. No se registraron diferencias entre los grupos en la frecuencia de tomas en el hospital o en la ocurrencia de problemas tempranos con la lactancia materna (lesiones en el pezón, pérdida de peso del niño desde el nacimiento, problemas con el agarre, tipo de suplemento administrado o número de veces que fue amamantado o número de suplementos que recibió en el hospital), aunque los autores no proporcionan los datos concretos.

Los análisis ajustados no encontraron diferencias significativas en la duración de cualquier tipo de lactancia materna (overall breastfeeding) y en la duración de la lactancia materna exclusiva.

Sin embargo, en el subgrupo de madres que dieron a luz por cesárea la alimentación por taza llevó al aumento de la duración de lactancia materna, prolongando la lactancia materna exclusiva 10 días y cualquier tipo de lactancia materna 10 semanas. Además, era más probable que la indicación de la administración de suplementos fuera médica en este subgrupo (33\% vs $20 \%$ ), aunque en el análisis realizado en base al tipo de indicación para la suplementación no se observaron diferencias entre grupos.

También se observó que cuando el recién nacido recibía suplementos más de tres veces, la duración de la lactancia exclusiva aumentaba de forma significativa en aquellos en los que los suplementos habían sido administrados con taza, aunque no había efecto sobre la duración de cualquier tipo de lactancia materna. Además, se encontraron

Calidad
baja
Calidad
baja
Calidad
muy baja
subgrupo)


diferencias significativas en el volumen total de suplementos administrados cuando se utilizaba vaso $(67 \pm 67 \mathrm{ml})$ versus biberón (121 $\pm 167 \mathrm{ml}$ ).

\section{Resultados de la actualización de la búsqueda a octubre de 2016}

(12) utilizada para responder a esta pregunta, publicada en 2016 y que incluye un estudio (11) que ya ha sido tenido en cuenta en la GPC.

Por otro lado, se ha identificado un ECA realizado en Tailandia (13) que compara el uso de sonda con jeringa adosada al pecho frente al vaso en madres en las que no se detecta producción de leche a las 42-48 horas tras el nacimiento. Se incluyeron mujeres que dieron a luz sin complicaciones, por parto vaginal o por cesárea. A los niños se les administró fórmula (no leche extraída) mediante vaso o sonda con jeringa adosada al pecho después de las tomas y se observó que la puntuación para el agarre a las 66-72 horas postparto era mejor cuando se suplementaba mediante sonda y jeringa, siendo la puntuación total del LATCH de 8 y 7 , respectivamente $(p=0,039)$. Sin embargo, no se sabe si hay diferencias en los resultados en lactancia. Además, en este caso el uso de jeringa con sonda adosada al pecho puede tener ventajas frente al uso del vaso si se administra como suplemento fórmula y las madres no se extraen la leche materna tras la toma. Por lo tanto, los resultados de este estudio no modifican las recomendaciones formuladas en la guía.

ACTUALIZADO A FECHA DE: 31 de Octubre de 2016 


\section{5- De la evidencia a la recomendación (Tabla de EtR)}

\section{¿Cómo deben administrarse los suplementos?}

Población: madres sanas y recién nacidos sanos a término y amamantados

Intervención: Cuchara, vaso o taza, paladai, cuentagotas, jeringa, relactador, alimentación con dedo, biberón

Comparación: Cuchara, vaso, paladai, cuentagotas, jeringa, relactador, alimentación con dedo, biberón

Perspectiva: Clínica

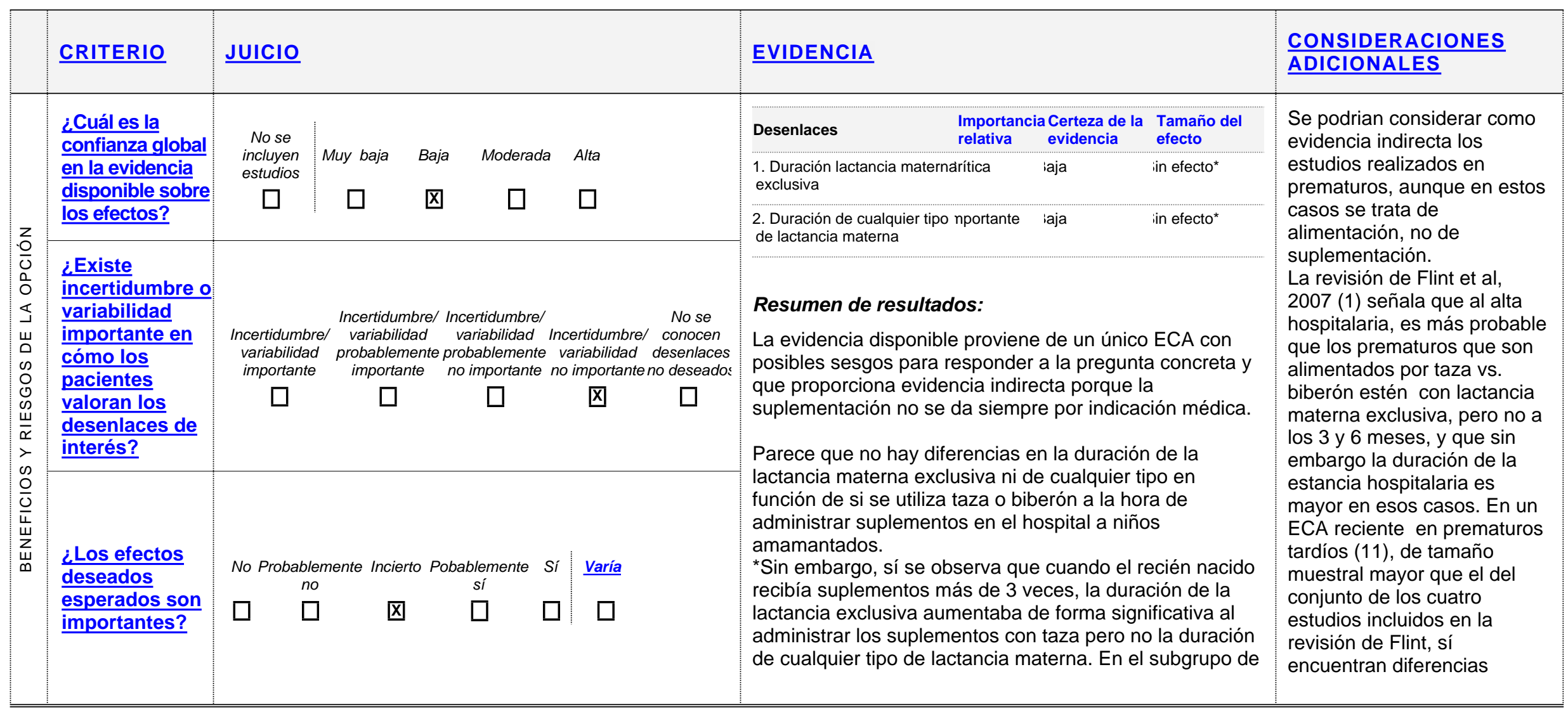




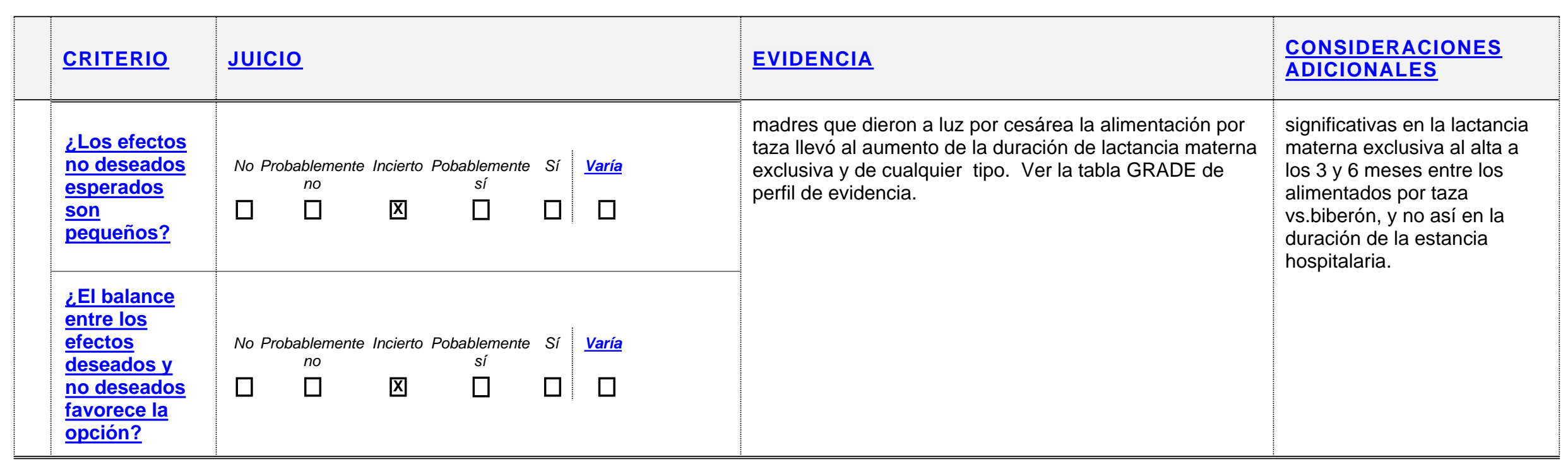


¿Cómo deben administrarse los suplementos?

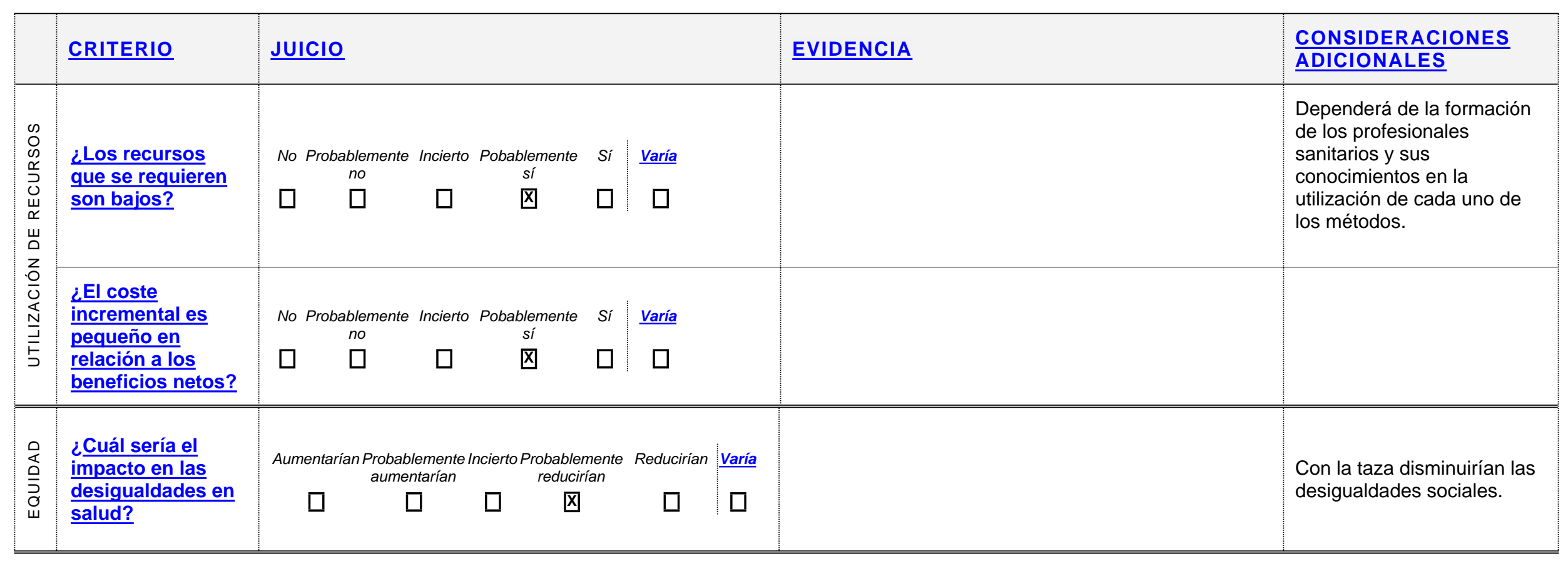




\begin{tabular}{|c|c|c|c|c|c|c|}
\hline & $\underline{\text { CRITERIO }}$ & $\underline{\mathrm{JUICIO}}$ & & & EVIDENCIA & $\begin{array}{l}\text { CONSIDERACIONES } \\
\text { ADICIONALES }\end{array}$ \\
\hline 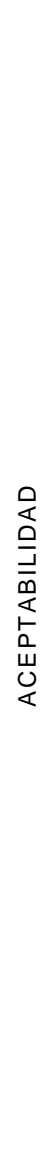 & $\begin{array}{l}\text { ¿Es la opción } \\
\text { aceptable para los } \\
\text { grupos de interés } \\
\text { involucrados? }\end{array}$ & $\begin{array}{c}\text { No } \quad \text { Probablemente } \\
\text { no } \\
\square \quad \square\end{array}$ & $\begin{array}{ccc}\text { Incierto } & \text { Pobablemente } & \text { Si } \\
& \text { sí } & \\
\square & \square & \square\end{array}$ & $\begin{array}{l:l}\text { Si } & \frac{\text { Varía }}{\square} \\
\square\end{array}$ & $\begin{array}{l}\text { Profesionales sanitarios } \\
\text { En un estudio realizado en Toronto (Canadá) sobre las } \\
\text { creencias y prácticas de pediatras y enfermeras en } \\
\text { relación a los métodos utilizados para administrar } \\
\text { suplementos a los recién nacidos, se encontró que el } \\
44 \% \text { de las enfermeras de la zona postparto y el } 56,2 \% \\
\text { de los pediatras estaban de acuerdo con que la } \\
\text { alimentación frecuente con biberón llevaba al } \\
\text { fenómeno de la confusión del pezón, frente al } 15 \% \text { de } \\
\text { las enfermeras del nivel II. El método de } \\
\text { suplementación más utilizado era el biberón, seguido } \\
\text { por el vaso y la alimentación por dedo. En cuanto a la } \\
\text { seguridad, todas las enfermeras apoyaban la idea de } \\
\text { que el biberón es relativamente seguro para el niño y } \\
\text { conveniente para el personal de enfermería y menos } \\
\text { enfermeras pensaban que la administración por taza } \\
\text { era seguro para el niño y conveniente para el personal. } \\
\text { No creer en el fenómeno de la confusión no tenía } \\
\text { efecto en la elección del método por las enfermeras de } \\
\text { segundo nivel, pero sí por las del área postparto, } \\
\text { siendo más probable que en ese caso eligieran el } \\
\text { biberón y la alimentación por dedo como método (14). } \\
\text { Madres } \\
\text { En un estudio cualitativo realizado en el Reino Unido } \\
\text { (15), en el que se entrevistaron madres y diferentes } \\
\text { tipos de profesionales sanitarios (matronas, pediatras, } \\
\text { enfermeras...), uno de los temas principales fue el } \\
\text { debate en torno al uso de taza versus biberón, siendo } \\
\text { tres las categorías identificadas: la dificultad para } \\
\text { "volver" al pecho, la facilidad de uso del método y la } \\
\text { necesidad de conocimientos y habilidades. }\end{array}$ & $\begin{array}{l}\text { Se cree que todas las } \\
\text { madres que amamantan, en } \\
\text { el caso en el que se tengan } \\
\text { que administrar } \\
\text { suplementos, preferirían que } \\
\text { se administraran con el } \\
\text { sistema que vaya a } \\
\text { favorecer la duración de la } \\
\text { lactancia materna. }\end{array}$ \\
\hline
\end{tabular}




\begin{tabular}{|c|c|c|c|c|c|c|}
\hline & CRITERIO & \multicolumn{3}{|l|}{$\underline{\text { JUICIO }}$} & EVIDENCIA & $\begin{array}{l}\text { CONSIDERACIONES } \\
\text { ADICIONALES }\end{array}$ \\
\hline 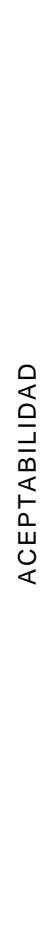 & & & & & $\begin{array}{l}\text { En el hospital se utilizan el vaso, biberón, jeringa, } \\
\text { alimentación por dedo, tubos naso y orogástricos y el } \\
\text { sistema "supplemental nursing system". } \\
\text { Tanto madres como profesionales sanitarios expresan } \\
\text { preocupación sobre la posible confusión tetina-pezón, } \\
\text { aunque algunos profesionales dudan de su existencia } \\
\text { real. A algunos profesionales sanitarios les preocupa la } \\
\text { posible dificultad de volver al pecho tras el uso del } \\
\text { vaso, aunque otros profesionales no le encuentran } \\
\text { desventajas al vaso. } \\
\text { Tanto madres como profesionales creen que el biberón } \\
\text { puede ser el método más fácil de usar. El } \\
\text { derramamiento de leche con el vaso se considera } \\
\text { como un problema por ambos. Los profesionales creen } \\
\text { que el uso del vaso consume mucho tiempo, aunque } \\
\text { creen que el niño puede controlar mejor la cantidad de } \\
\text { leche que toma (frente al uso de jeringa). } \\
\text { El estudio muestra que las ventajas y desventajas de } \\
\text { los métodos no se discuten con las madres y que no } \\
\text { hay consistencia en el método utilizado para cada niño, } \\
\text { lo que causa angustia a la madre. Nadie señala la } \\
\text { necesidad de experiencia para utilizar el biberón, pero } \\
\text { sí para el uso del vaso. Algunos profesionales señalan } \\
\text { que no se debería enseñar a las madres a utilizar el } \\
\text { vaso. }\end{array}$ & \\
\hline 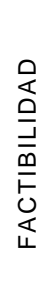 & $\begin{array}{l}\frac{\text { La }}{\text { implementación }} \\
\text { de la opción es } \\
\text { factible? }\end{array}$ & $\begin{array}{cc}\text { No } & \text { Probablemente } \\
& \text { no } \\
\square & \square\end{array}$ & $\begin{array}{ccc}\text { Incierto Pobablemente } & \text { Sí } \\
& \text { sí } & \\
\square & \square & \square\end{array}$ & $\begin{array}{l:l}\text { Si } & \frac{\text { Varía }}{\square} \\
\square & \text { 区 }\end{array}$ & $\begin{array}{l}\text { En el estudio de Cloherty M, } 2005 \text { (15), se concluye } \\
\text { que existe la necesidad urgente de determinar cuál es } \\
\text { el mejor método para administrar suplementos, para } \\
\text { que se pueda proporcionar información precisa a las } \\
\text { madres, así como idear políticas apropiadas y destinar } \\
\text { recursos y personal cualificado para ello. }\end{array}$ & $\begin{array}{l}\text { La implementación } \\
\text { dependerá de las } \\
\text { necesidades de formación } \\
\text { de los profesionales para el } \\
\text { uso adecuado de cada } \\
\text { método, de la disponibilidad } \\
\text { de los diferentes métodos en } \\
\text { el hospital etc. }\end{array}$ \\
\hline
\end{tabular}




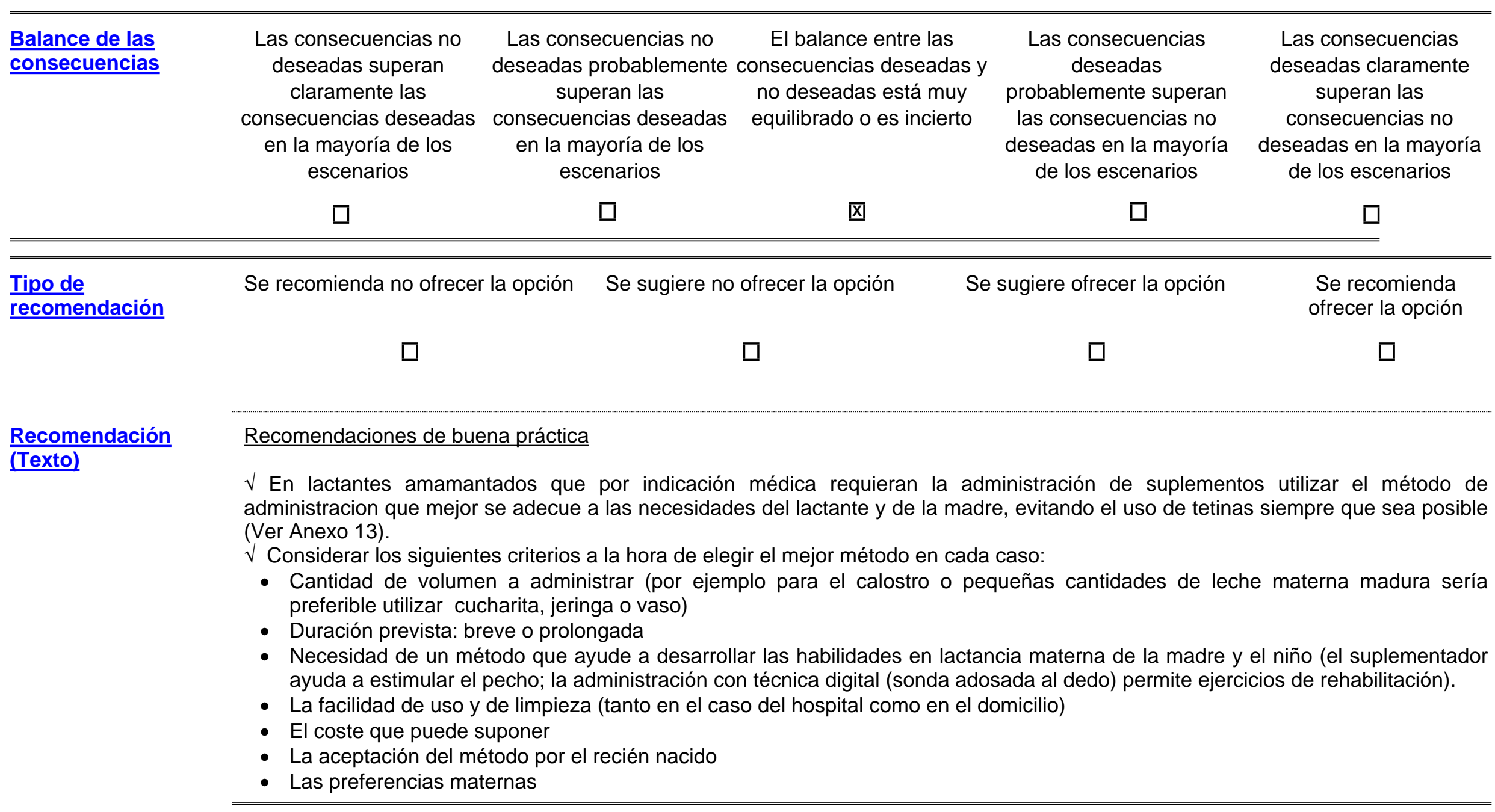


Justificación No se han encontrado estudios que demuestren que un método sea mejor que otro. Sí que parece que la suplementación mediante vaso puede ser mejor que mediante biberón si se administran más de tres suplementos. Sin embargo, la evidencia es de baja o muy baja calidad. Por ello, se ha redactado una recomendación de buena práctica clínica, en la que se proponen los criterios que pueden ayudar a elegir entre los métodos que existen y que han sido adaptados desde el protocolo clínico de la ABM.

Los estudios cualitativos señalan que existe preocupación por el tema de la confusión de la tetina y el pezón, aunque algunos profesionales también creen que la "vuelta al pecho" puede verse dificultada por el uso del vaso.

\section{Consideraciones de} subgrupos

Consideraciones para La posibilidad de poder elegir entre los diferentes métodos dependerá de su disponibilidad y de las rutinas y prácticas hospitalarias.

Es importante que el personal reciba formación que le capacite para la utilización del método más idóneo de suplementación del recién nacido. El método debe así adaptarse a las necesidades y capacidades del recién nacido y de sus padres, y no a la comodidad o falta de formación del personal.

Los profesionales deben proporcionar información y ayuda a las madres y familia para que puedan elegir y utilizar entre los diferentes sistemas de administración de suplementos el que mejor se adapte a sus necesidades.

\section{Monitorización y}

evaluación

Prioridades para la investigación
Falta investigación sobre cuál es el método óptimo para la suplementación, para determinar si algún método es mejor que otro en cada situación o para niños con determinadas características y edad, o para saber qué métodos interfieren menos con el establecimiento de la lactancia materna. 


\section{ANEXO I, ESTRATEGIAS DE BÚSQUEDA}

\section{Cochrane Library}

Searched 24/03/2014

Updated search 24/03/2014 a xx/xx/xxxx

\#1 bottle and feeding:ti,ab,kw or tube and feeding:ti,ab,kw or cup and feeding:ti,ab,kw or spoon and feeding:ti,ab,kw or (syringe or syringes) and feeding:ti,ab,kw Publication Date from 2006 to 2014 (Word variations have been searched)

\#2 bowl and feeding:ti,ab,kw or dropper and feeding:ti,ab,kw or (tube or finger) and feeder:ti,ab,kw or glass and feeding:ti,ab,kw or paladai:ti,ab,kw (Word variations have been searched)

\#3 infant or baby or babies:ti,ab,kw (Word variations have been searched) \#4 (\#1 or \#2) and \#3 (137)

\section{MEDLINE, via Pubmed}

\section{Searched 24/03/2014}

Updated search 24/03/2014 a xx/xx/xxxx

\#1 ("tube"[All Fields] AND "feeding"[All Fields]) OR "tube feeding"[All Fields]

\#2 "bottle feeding"[MeSH Terms] OR ("bottle"[All Fields] AND "feeding"[All Fields]) OR "bottle feeding"[All Fields]

\#3 cup[All Fields] AND feeding[All Fields]

\#4 spoon[All Fields] AND feeding[All Fields]

\#6 ("syringes"[MeSH Terms] OR "syringes"[All Fields] OR "syringe"[All Fields]) AND feeding[All Fields]

\#7 \#1 OR \#2 OR \#3 OR \#4 OR \#5 OR \#6

\#8 \#7 ("2006/01/01"[PDat] : "2014/12/31"[PDat])

\#9 bowl[All Fields] AND feeding[All Fields]

\#10 dropper[All Fields] AND feeding[All Fields]

\#11 finger[All Fields] AND feeding[All Fields]

\#12 ("glass"[MeSH Terms] OR "glass"[All Fields]) AND feeding[All Fields]

\#13 paladai[All Fields]

\#14 (tube[All Fields] OR ("fingers"[MeSH Terms] OR "fingers"[All Fields] OR "finger"[All Fields])) AND feeder[All Fields]

\#15 \#8 OR \#9 OR \#10 OR \#11 OR \#12 OR \#13 OR \#14

\#16 Filters: Clinical Trial; Systematic Reviews; Humans; Newborn: birth-1 month; Infant:

birth-23 months; Field: Title/Abstract (188)

\section{EMBASE, via Ovid}

\section{Searched 24/03/2014}

Updated search 24/03/2014 a xx/xx/xxxx

\#1 ((tube and feeding) or "tube feeding").ti,ab,kw.

\#2 ("bottle feeding" or (bottle and feeding)).ti,ab,kw.

\#3 (cup and feeding).ti,ab,kw.

\#4 (spoon and feeding).ti,ab,kw.

\#5 ((syringe or syringes) and feeding).ti,ab,kw.

\#6 1 or 2 or 3 or 4 or 5

\#7 limit 6 to yr="2006 -Current"

\#8 (bowl and feeding).ti,ab,kw.

\#9 (drooper and feeding).ti,ab,kw. 
\#10 (glass and feeding).ti,ab,kw.

\#11 (finger and feeding).ti,ab,kw.

\#12 paladai.ti,ab,kw

\#13 ((tube or finger) and feeder).ti,ab,kw.

\#14 7 or 8 or 9 or 10 or 11 or 12 or 13

\#15 limit 14 to infant <to one year> (172)

Cinahl, via EBSCOhost databases

Searched 24/03/2014

Updated search 24/03/2014 a xx/xx/xxxx

\#1 Tl tube feeding OR AB tube feeding OR MH tube feeding

\#2 TI bottle feeding OR AB bottle feeding OR MH bottle feeding

\#3 TI cup feeding OR AB cup feeding OR MH cup feeding

\#4 TI spoon feeding OR AB spoon feeding OR MH spoon feeding

\#5 TI ((syringe OR syringes) AND feeding) OR AB ((syringe OR syringes) AND feeding) OR $\mathrm{MH}$ ((syringe OR syringes) AND feeding)

\#6 TI bowl feeding OR AB bowl feeding OR MH bowl feeding

\#7 TI dropper feeding OR AB dropper feeding OR MH dropper feeding

\#8 TI glass feeding OR AB glass feeding OR MH glass feeding

\#9 TI paladai OR AB paladai OR MH paladai

\#10 Tl finger feeding OR AB finger feeding OR MH finger feeding

\#11 Tl ((tube OR finger OR fingers) AND feeder) OR AB ((tube OR finger OR fingers) AND feeder) OR MH ((tube OR finger OR fingers) AND feeder)

\#12 \#1 OR \#2 OR \#3 OR \#4 OR \#5

\#13 \#12 Limitadores - Fecha de publicación: 20060101-20141231

\#14 \#6 OR \#7 OR \#8 OR \#9 OR \#10 OR \#11 OR \#13

\#15 \#14 Limitadores - Grupos de edad: Infant, Newborn: birth-1 month, Infant: 1-23 months (387) 


\section{ANEXO II, Tabla de estudios individuales para la pregunta}

\begin{tabular}{|c|c|c|c|c|c|c|}
\hline $\begin{array}{l}\text { Referencia } \\
\text { (Cita Abreviada) }\end{array}$ & $\begin{array}{l}\text { Estudio (Diseño y } \\
\text { objetivo) }\end{array}$ & $\begin{array}{l}\text { Población } \\
\text { (noy características) }\end{array}$ & $\begin{array}{l}\text { Descripción de las intervenciones } \\
\text { comparaciones, exposiciones o } \\
\text { pruebas a estudio }\end{array}$ & $\begin{array}{l}\text { Resultados } \\
\text { (Estimadores de resultados-Magnitud del } \\
\text { efecto) }\end{array}$ & $\begin{array}{l}\text { Conclusiones } \\
\text { (conclusiones) }\end{array}$ & $\begin{array}{l}\text { Comentarios } \\
\text { Calidad de la } \\
\text { evidencia } \\
\text { Financiación } \\
\text { comentarios) }\end{array}$ \\
\hline Howard CR, 2003 & $\begin{array}{l}\text { Diseño: ECA } \\
\text { Objetivo: evaluar los } \\
\text { efectos de dos tipos de } \\
\text { exposición a pezones } \\
\text { artificiales sobre la } \\
\text { duración de la lactancia } \\
\text { materna (vaso vs. biberón } \\
\text { para la provisión de } \\
\text { suplementos en el } \\
\text { hospital) e introducción de } \\
\text { chupete temprano (2 a } 5 \\
\text { días) vs. tardío ( }>4 \\
\text { semanas) }\end{array}$ & $\begin{array}{l}700 \text { recién nacidos ( } 36- \\
42 \text { semanas, peso al } \\
\text { nacer } \geq 2200 \mathrm{~g})\end{array}$ & $\begin{array}{l}\text { Asignación aleatoria a cuatro grupo de } \\
\text { intervenciones: a) biberón/chupete } \\
\text { temprano }(n=169) \text {, Biberón/introducción } \\
\text { tardía chupete }(n=167) ; \text { vaso/uso } \\
\text { temprano chupete }(n=185) ; \text { vaso/uso } \\
\text { tardío de chupete }(n=179) \text {. } \\
\text { La intervención vaso/biberón fue } \\
\text { realizado sólo en los niños que } \\
\text { necesitaron suplementos: Vaso ( } n=251) \\
\text { y biberón ( } n=230) \text {. } \\
\text { Los datos se recogen a las } 2,5,10,16 \text {, } \\
24,38 \text { y } 52 \text { semanas. } \\
\text { Los efectos de la initervención en la } \\
\text { duración de la lactancica fueron } \\
\text { evaluados con regresión logística y } \\
\text { análisis de supervivencia. }\end{array}$ & 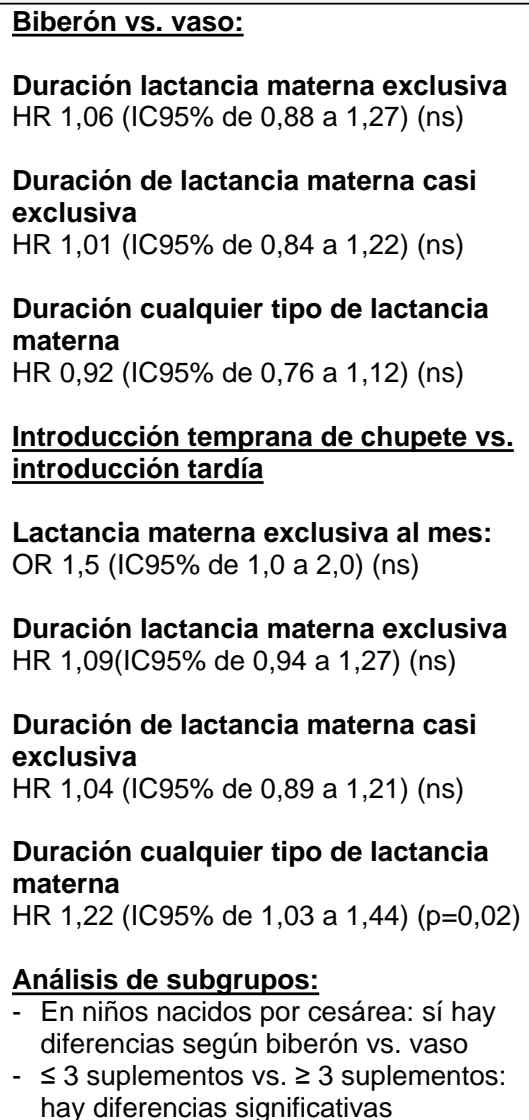 & $\begin{array}{l}\text { La administración } \\
\text { de suplementos } \\
\text { mediante vaso no } \\
\text { produce beneficios } \\
\text { en población de } \\
\text { niños sanos } \\
\text { amamantados, } \\
\text { pero puede haber } \\
\text { beneficiado a las } \\
\text { díadas madre-hijo } \\
\text { que requerían } \\
\text { suplementación } \\
\text { múltiple o habían } \\
\text { nacido por } \\
\text { cesárea. El uso de } \\
\text { chupete en el } \\
\text { período neonatal } \\
\text { era perjudicial para } \\
\text { la lactancia } \\
\text { materna exclusiva } \\
\text { y la duración de } \\
\text { cualquier tipo de } \\
\text { lactancia materna. } \\
\\
\text { Estos resultados } \\
\text { apoyan las } \\
\text { recomendaciones } \\
\text { de evitar la } \\
\text { exposición a } \\
\text { pezones artificiales } \\
\text { en los } \\
\text { amamantados en } \\
\text { el período } \\
\text { neonatal. }\end{array}$ & \\
\hline
\end{tabular}




\section{1- BIBLIOGRAFÍA}

(1) Flint A, New K, Davies MW. Cup feeding versus other forms of supplemental enteral feeding for newborn infants unable to fully breastfeed. Cochrane Database of Systematic Reviews 2007.

(2) Collins CT, Makrides M, Gillis J, McPhee AJ. Avoidance of bottles during the establishment of breast feeds in preterm infants. Cochrane Database of Systematic Reviews 2008.

(3) Howard CR, de Blieck EA, ten Hoopen CB, Howard FM, Lanphear BP, Lawrence RA. Physiologic stability of newborns during cup- and bottle-feeding. Pediatrics 1999 Nov;104(5 Pt 2):1204-7.

(4) Howard CR, Howard FM, Lanphear B, Eberly S, deBlieck EA, Oakes D, et al. Randomized clinical trial of pacifier use and bottle-feeding or cupfeeding and their effect on breastfeeding. Pediatrics 2003 Mar;111(3):511-8.

(5) Malhotra N, Vishwambaran L, Sundaram KR, Narayanan I. A controlled trial of alternative methods of oral feeding in neonates. Early human development 1999;54:29-38.

(6) NICE. Postnatal care up to 8 weeks after birth. Julio 2006 (actualizado en Febrero de 2015). Disponible en: http://guidance.nice.org.uk/CG37.

(7) IHAN. Hospitales IHAN. Guía detallada para la aplicación paso por paso. Disponible en: https://

(8) Academy of Breastfeeding Medicine Protocol Committee. ABM clinical protocol\# 3: hospital guidelines for the use of supplementary feedings in the healthy term breastfed neonate, revised 2009. 2009.

(9) Huang YY, Gau ML, Huang CM, Lee JT. Supplementation with cup-feeding as a substitute for bottle-feeding to promote breastfeeding. Chang Gung Med J 2009 Jul;32(4):423-31.

(10) Aloysius A, Hickson M. Evaluation of paladai cup feeding in breast-fed preterm infants compared with bottle feeding. Early human development 2007;83:61921.

(11) Yilmaz G, Caylan N, Karacan CD, Bodur I, Gokcay G. Effect of cup feeding and bottle feeding on breastfeeding in late preterm infants: a randomized controlled study. J Hum Lact 2014 May;30(2):174-9.

(12) Flint A, New K, Davies MW. Cup feeding versus other forms of supplemental enteral feeding for newborn infants unable to fully breastfeed. Cochrane Database Syst Rev 2016 Aug 31;(8):CD005092.

(13) Puapornpong P, Raungrongmorakot K, Hemachandra A, Ketsuwan S, Wongin S. Comparisons of Latching on between Newborns Fed with Feeding Tubes and Cup Feedings. J Med Assoc Thai 2015 Oct;98 Suppl 9:S61-S65.

(14) Al-Sahab B, Feldman M, Macpherson A, Ohlsson A, Tamim H. Which method of breastfeeding supplementation is best? The beliefs and practices of paediatricians and nurses. Paediatr Child Health 2010 Sep;15(7):427-31.

(15) Cloherty M, Alexander J, Holloway I, Galvin K, Inch S. The cup-versus-bottle debate: a theme from an ethnographic study of the supplementation of breastfed infants in hospital in the United kingdom. J Hum Lact 2005 May;21(2):151-62. 


\section{PREGUNTA CLIINICA № 17}

¿Cuáles son las mejores estrategias estructuradas para el apoyo y protección de la lactancia materna durante la estancia en el hospital?

\section{1- Pregunta clínica en formato PICO}

Tabla 1- Componentes de la pregunta clínica en formato PICO

\begin{tabular}{|l|l|}
\hline Pacientes & $\begin{array}{l}\text { Madres de bebés sanos nacidos a término que amamantan } \\
\text { y sus bebés }\end{array}$ \\
\hline Intervención & $\begin{array}{l}\text { Medidas de apoyo y protección a la lactancia materna } \\
\text { durante la estancia en el hospital }\end{array}$ \\
\hline Comparación & Atención habitual \\
\hline Resultados & $\begin{array}{l}\text { Tasa de lactancia materna exclusiva al alta } \\
\text { Tasa de lactancia materna exclusiva al mes } \\
\text { Tasa de lactancia materna exclusiva a los } 4 \text { meses } \\
\text { Tasa de lactancia materna exclusiva a los } 6 \text { meses } \\
\text { Tasa de cualquier lactancia materna a los 4 meses } \\
\text { Tasa de cualquier lactancia materna a los } 6 \text { meses } \\
\text { Satisfacción materna } \\
\text { Complicaciones de las mamas (grietas, ingurgitaciones) } \\
\text { Pérdida ponderal del recién nacido (48-72h.) } \\
\text { Frecuencia de tomas }\end{array}$ \\
\hline Tipo de estudio & $\begin{array}{l}\text { RS de ECA, ECA, RS de estudios observacionales o } \\
\text { estudios observacionales }\end{array}$ \\
\hline
\end{tabular}

\section{2- Introducción}

En 1989, la OMS y UNICEF, tras identificar que las prácticas inadecuadas en las maternidades contribuían a la caída de las tasas de lactancia materna, elaboraron un documento sobre "Protección, Promoción y Apoyo de la Lactancia Natural. La función especial de los servicios de maternidad". En dicho documento se establecieron los "Diez pasos hacia una feliz lactancia natural" de la IHAN. Posteriormente, en 1998, la OMS publicó el documento "Pruebas científicas de los diez pasos hacia una feliz lactancia natural" que recogió la evidencia científica sobre la eficacia de la aplicación de estos diez pasos. Transcurridos más de 15 años de esta publicación, interesa conocer si una estrategia como la que propone IHAN sigue siendo recomendable. 


\section{ESTRATEGIA DE ELABORACIÓN DE LA PREGUNTA}

\subsection{GPC Base}

Tabla 2- Resumen de GPC Base

\begin{tabular}{|c|c|c|c|c|}
\hline $\begin{array}{l}\text { Guía } \\
\text { (Enfoque) }\end{array}$ & $\begin{array}{l}\text { Resumen sobre la evidencia } \\
\text { (Calidad de la evidencia) }\end{array}$ & $\begin{array}{l}\text { Recomendaciones } \\
\text { (Grado) }\end{array}$ & $\begin{array}{l}\text { Referencias bibliográficas } \\
\text { (Tipo de publicación) }\end{array}$ & Comentarios \\
\hline $\begin{array}{l}\text { NICE_2006 } \\
\text { (Actualiz. } \\
\text { 2011) }\end{array}$ & $\begin{array}{l}\text { 6.3.3 Los factores ambientales (prácticas hospitalarias, } \\
\text { iniciativa IHAN, rooming-in) facilitan la lactancia } \\
\text { materna efectiva? } \\
\text { 6.3.3.1 Evidencia sobre la efectividad clínica. } \\
\text { Hay estudios que analizan el impacto de la organización } \\
\text { hospitalaria sobre el inicio y duración de la lactancia } \\
\text { materna, particularmente en relación a la iniciativa IHAN y } \\
\text { los } 10 \text { pasos que promueve. } \\
\text { En un estudio observacional en Escocia (Broadfoot et al. } \\
\text { 2005) se evaluó el efecto de la iniciativa IHAN en las tasas } \\
\text { de lactancia materna, observándose que las mujeres que } \\
\text { dieron a luz en un hospital IHAN acreditado eran un } 28 \% \\
\text { más probable (OR } 1,28 ; \text { IC95\%: } 1,24-1,31 \text { ) que estuvieran } \\
\text { amamantando a los } 7 \text { días. Estos resultados fueron } \\
\text { ajustados por la edad de la madre, tamaño del hospital, año } \\
\text { de nacimiento e índice de privación (deprivation index). } \\
\text { En una revisión sistemática Fairbank et al (2000) evaluaron } \\
\text { la efectividad de las intervenciones para promover el inicio } \\
\text { de la lactancia materna, encontrando que los cambios } \\
\text { institucionales p ara promover la lactancia materna, tanto } \\
\text { como parte de la iniciativa IHAN como de forma } \\
\text { independiente, pueden ser efectivas para aumentar el inicio } \\
\text { y duración de la lactancia maternal, sobre todo en países en } \\
\text { vías de desarrollo (rooming in o un conjunto de } \\
\text { intervenciones). } \\
\text { Un ensayo controlado no aleatorizado (Cattaneo and } \\
\text { Buzetti, 2001), hizo una valoración previa y posterior a un } \\
\text { programa de educación en cascada basado en la iniciativa } \\
\text { IHAN. Todos los hospitales mejoraron el cumplimiento de }\end{array}$ & $\begin{array}{l}\text { El apoyo a la lactancia materna debería estar } \\
\text { disponible independientemente del lugar en el que } \\
\text { se localicen los cuidados (A). } \\
\text { Todos los proveedores de salud (hospitalaria y } \\
\text { primaria) deberían tener una política escrita sobre } \\
\text { lactancia materna que debe ser comunicada a los } \\
\text { trabajadores y a los padres. Cada proveedor } \\
\text { debería identificar un profesional sanitario líder } \\
\text { responsable de implementar esta política [D } \\
\text { (GPP)]. } \\
\text { Todos los proveedores de salud de las } \\
\text { maternidades (tanto si trabajan en el hospital o en } \\
\text { atención primaria), deberían implementar un } \\
\text { programa estructurado externamente evaluado } \\
\text { que promueva la lactancia materna, utilizando la } \\
\text { iniciativa IHAN (www.babyfriendly.org.uk) como } \\
\text { mínimo estándar [A]. } \\
\text { Los profesionales sanitarios deberían tener tiempo } \\
\text { suficiente, como prioridad, para apoyar a las } \\
\text { mujeres y los niños durante el inicio y la } \\
\text { continuación de la lactancia materna [D(GPP)] }\end{array}$ & & $\begin{array}{l}\text { Comentan que se deben } \\
\text { hacer estudios de coste } \\
\text { efectividad de la } \\
\text { estrategia IHAN en } \\
\text { comparación con otro } \\
\text { programa, o frente al } \\
\text { estándar de tratamiento. } \\
\text { Entre los resultados se } \\
\text { deberían incluir las tasas } \\
\text { de inicio y duración de } \\
\text { lactancia materna } \\
\text { exclusiva, y se debería } \\
\text { intentar construir también } \\
\text { medidas de resultados } \\
\text { económicos de salud } \\
\text { como los QALY. }\end{array}$ \\
\hline
\end{tabular}




\begin{tabular}{|c|c|c|c|c|}
\hline $\begin{array}{l}\text { Guía } \\
\text { (Enfoque) }\end{array}$ & $\begin{array}{l}\text { Resumen sobre la evidencia } \\
\text { (Calidad de la evidencia) }\end{array}$ & $\begin{array}{l}\text { Recomendaciones } \\
\text { (Grado) }\end{array}$ & $\begin{array}{l}\text { Referencias bibliográficas } \\
\text { (Tipo de publicación) }\end{array}$ & Comentarios \\
\hline & 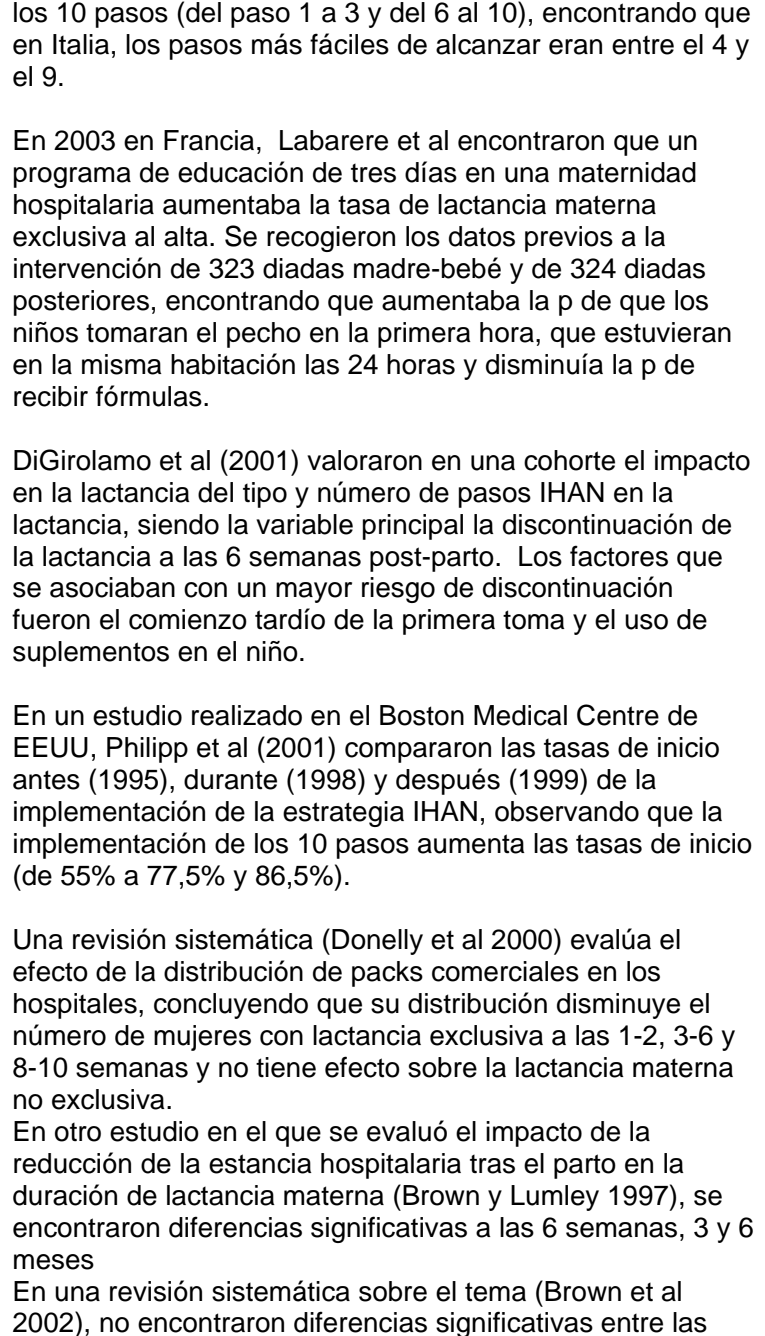 & & & \\
\hline
\end{tabular}




\begin{tabular}{|c|c|c|c|c|}
\hline $\begin{array}{c}\text { Guía } \\
\text { (Enfoque) }\end{array}$ & $\begin{array}{l}\text { Resumen sobre la evidencia } \\
\text { (Calidad de la evidencia) }\end{array}$ & $\begin{array}{l}\text { Recomendaciones } \\
\text { (Grado) }\end{array}$ & $\begin{array}{l}\text { Referencias bibliográficas } \\
\text { (Tipo de publicación) }\end{array}$ & Comentarios \\
\hline & $\begin{array}{l}\text { mujeres que les dieron el alta temprana y el grupo control, } \\
\text { aunque la heterogeneidad entre estudios era alta. En otra } \\
\text { cohorte longitudinal (Waldenstrom 2004), una experiencia } \\
\text { más positiva de lactancia materna se asoció con una } \\
\text { estancia hospitalaria más corta. Los autores concluyen que } \\
\text { las características de las madres y su experiencia con la } \\
\text { primera toma puede ser un predictor más importante de la } \\
\text { duración de la lactancia que la duración de la estancia } \\
\text { hospitalaria. } \\
\text { La Task Force canadiense de Medicina Preventiva (Palda et } \\
\text { al. 2003) actualizaron su revisión de 2000, incluyendo } \\
\text { recomendaciones en contra de proveer de packs } \\
\text { comerciales al alta a las nuevas madres y recomiendan } \\
\text { roomin-in y contacto temprano maternal para promover la } \\
\text { lactancia materna. } \\
\text { 6.3.3.2 Evidence Surrounding the Cost-Effectiveness of } \\
\text { the Baby Friendly Hospital Initiative } \\
\text { Al no haber estudios de coste-efectividad, se realiza un } \\
\text { modelo propio, concluyendo que la implementación de la } \\
\text { estrategia IHAN en Inglaterra y Escocia probablemente } \\
\text { suponga un ahorro en un período de } 15 \text { años, asumiendo } \\
\text { que todas las unidades implementan la estrategia } \\
\text { rápidamente, con un mayor nivel de costes en los primeros } \\
\text { años. }\end{array}$ & & & \\
\hline $\begin{array}{l}\text { Perinatal } \\
\text { Services BC } \\
2011\end{array}$ & $\begin{array}{l}\text { En 2004, Health Canada recomendaba la lactancia materna } \\
\text { exclusiva durante los primeros } 6 \text { meses de la vida del niño y } \\
\text { la continuación de la lactancia materna hasta los dos años } \\
\text { de edad (1) y de forma subsecuente la promocionaba y } \\
\text { apoyaba por asociaciones de profesionales sanitarios y } \\
\text { organizaciones (2-6). } \\
\text { Para promocionar el inicio de la lactancia materna y el } \\
\text { aumento de la duración, la implementación de las mejores } \\
\text { prácticas basadas en la evidencia por los profesionales de } \\
\text { la salud es crítica. Una estrategia para promoionar la mejor } \\
\text { práctica es la iniciativa IHAN 7,8 (ver el Apéndice A). } \\
\text { El objetivo de esta guía Provincial BC para recién nacidos a } \\
\text { término es: } \\
\text { - Facilitar los cuidados para la lactancia maternal óptimos y }\end{array}$ & $\begin{array}{l}\text { Recomendación 2: } \\
\text { Las mejores prácticas basadas en la evidencia de } \\
\text { la iniciativa IHAN deberían ser utilizadas por los } \\
\text { proveedores de salud cuando se trata del cuidado } \\
\text { de las madres y de sus bebés (A). } \\
\text { Principios a seguir: } \\
\text { - Promover la lactancia materna exclusiva } \\
\text { durante los primeros seis meses de vida del niño } \\
\text { y lactancia continua por dos años o más (1-6). } \\
\text { - Apoyar a la madre que amamanta a lo largo de } \\
\text { todo el continuo de la asistencia sanitaria de } \\
\text { acuerdo con sus objetivos y proveer una } \\
\text { asistencia basada en la mejor evidencia, }\end{array}$ & $\begin{array}{l}\text { 1. United Nations Children's } \\
\text { Fund/World Health } \\
\text { Organization (2006). } \\
\text { 2. World Health Organization. } \\
\text { (1981). } \\
\text { 3. World Health Assembly } \\
\text { Resolutions. (1980 to 2005). } \\
\text { 4. World Health } \\
\text { Organization/United Nations } \\
\text { Children's Fund. (1990). } \\
\text { 5. World Health } \\
\text { Organization/United Nations } \\
\text { Children's Fund (2005) }\end{array}$ & \\
\hline
\end{tabular}




\begin{tabular}{|c|c|c|c|c|}
\hline $\begin{array}{c}\text { Guía } \\
\text { (Enfoque) }\end{array}$ & $\begin{array}{l}\text { Resumen sobre la evidencia } \\
\text { (Calidad de la evidencia) }\end{array}$ & $\begin{array}{l}\text { Recomendaciones } \\
\text { (Grado) }\end{array}$ & $\begin{array}{l}\text { Referencias bibliográficas } \\
\text { (Tipo de publicación) }\end{array}$ & Comentarios \\
\hline & $\begin{array}{l}\text { consistentes a las mujeres y a sus niños por todos los } \\
\text { profesionales sanitarios tanto en los hospitales como en } \\
\text { atención primaria. } \\
\text { - Aumentar el número de niños amamantados de forma } \\
\text { exclusive desde el nacimiento al alta hospitalaria y por los } \\
\text { primeros seis meses de vida con la introducción de } \\
\text { nutrientes y alimentación complementaria segura junto con } \\
\text { lactancia materna continuada hasta los dos años o más. } \\
\text { Estas recomendaciones se basan en la evidencia actual y } \\
\text { las mejores prácticas de la Iniciativa IHAN. Estas son } \\
\text { consistentes con la iniciativa canadiense IHAN7, las } \\
\text { recomendaciones del Ministerio de Salud de BC; } 9,10 \\
\text { Perinatal Services BC (PSBC) education Breastfeeding: } \\
\text { Making a Difference@;11el BC Baby-Friendly Network } \\
\text { Resouce Binder,12 y los documentos canadienses Nutrition } \\
\text { for Healthy Term Infants2 y Family-Centred Maternity and } \\
\text { Newborn Care: National Guidelines.13 } \\
\text { Las definiciones de lactancia materna utilizadas en esta } \\
\text { guía fueron definidas por el BCC ( Appendix B) y en base a } \\
\text { la toma de leche materna por parte del bebé. Estos han sido } \\
\text { adoptados por las provincias y territorios a través de } \\
\text { Canadá, son utilizados enel PSBC Perinatal Data Registry } \\
\text { (BCPDR),15 y se basan en las definiciones de la OMS } 16 .\end{array}$ & $\begin{array}{l}\text { valoración de sus necesidades, análisis de los } \\
\text { datos obtenidos y un plan de acción desarrollado } \\
\text { con la madre. } \\
\text { - Utilizar los principios para educación de } \\
\text { personas adultas cuando trabaje con padres. } \\
\text { Reconocer que el periodo postparto es una } \\
\text { continuación de la experiencia del nacimiento. } \\
\text { Determinar el conocimiento de los padres; } \\
\text { después añadir sobre sus conocimientos y } \\
\text { habilidades.Centrarse en atender a las } \\
\text { necesidades de la madre y de la familia, su interés } \\
\text { por aprender, y la información necesaria para } \\
\text { poder tomar una decisión informada. } \\
\text { - Respetar la decisión de los padres cuando se } \\
\text { basa en conocimientos precisos (es } \\
\text { profesionalmente ético y facilita la discusión } \\
\text { respetuosa). } \\
\text { Lactancia materna tras el nacimiento y mejores } \\
\text { prácticas hospitalarias: } \\
\text { - contacto piel con piel tras nacimiento vaginal y } \\
\text { por cesárea. } \\
\text { - habilidad del niño por encontrar el pezón de la } \\
\text { madre y succionar de forma efectiva. } \\
\text { - ofrecer solo leche materna o leche humana } \\
\text { donada. } \\
\text { - tomas tempranas y frecuentes para estimular la } \\
\text { producción de la leche y el confort maternal. } \\
\text { - mantener el bebé al lado de la cama } 24 \text { horas al } \\
\text { día. } \\
\text { - observar y educar sobre el comportamiento de } \\
\text { los bebés y las señales de hambre } \\
\text { - evitar el uso de chupetes y tetinas hasta que la } \\
\text { lactancia esté bien establecida. }\end{array}$ & $\begin{array}{l}\text { 6. World Health Organization } \\
\text { (2001). } \\
\text { 7. World Health } \\
\text { Organization/United Nations } \\
\text { Children's Fund (1989). } \\
\text { 8. World Health Organization. } \\
\text { Vallenas C \& Savage F. } \\
\text { (1998). } \\
\text { 9. Merewood A (2005) } \\
\text { (Observacional) } \\
\text { 10. Philipp BL, (2001) } \\
\text { (Observacional) } \\
\text { 11. Hannula L (2008) (RS) } \\
\text { 12. Murray EK (2007). } \\
\text { 13. Breastfeeding Committee } \\
\text { for Canada (2002). } \\
\text { 14. Breastfeeding Committee } \\
\text { for Canada (2011). } \\
\text { 15. Accreditation Canada. } \\
\text { (2011). } \\
\text { 16. Breastfeeding Committee } \\
\text { for Canada (2008). } \\
\text { 17. BC Baby-Friendly Network. } \\
\text { (2010). }\end{array}$ & \\
\hline
\end{tabular}




\subsection{Revisiones sistemáticas}

En la búsqueda realizada se ha identificado una revisión sistemática publicada en 2012 que considera la evidencia existente sobre la eficacia de los programas estructurados en las maternidades para el apoyo en el inicio y duración de la lactancia materna exclusiva versus la atención estándar (1). También se identificó una revisión narrativa publicada en 2013 sobre el impacto de la iniciativa IHAN en el sistema sanitario de Australia (2).

En la revisión sistemática de Beake et al, 2012 los autores incluyeron los artículos que valoraban la eficacia de los programas implementados en el ámbito hospitalario para apoyar el inicio y duración de la lactancia materna exclusiva, excluyendo los estudios que evaluaban únicamente la estrategia de los 7 pasos desarrollada por UNICEF en 1998 para los centros de salud (1).

Debido a la variabilidad en las intervenciones, y en la medición de los resultados, los autores de la revisión no pudieron meta-analizar los datos de los estudios y resumieron los resultados de forma descriptiva en tablas, teniendo en cuenta si los estudios presentaban datos sobre la tasa de inicio de lactancia materna, de lactancia materna a la semana, a los 2 meses, hasta los 5 meses y a los 6 meses de edad.

Tabla 3- Resumen de RS actuales

\begin{tabular}{|c|c|c|c|c|c|c|}
\hline $\begin{array}{l}\text { Referencia } \\
\text { (Cita } \\
\text { Abreviada) }\end{array}$ & $\begin{array}{l}\text { Estudio (Diseño } \\
\text { y objetivo) }\end{array}$ & $\begin{array}{l}\text { Población } \\
\text { (no y características) }\end{array}$ & $\begin{array}{l}\text { Descripción de las intervenciones } \\
\text { comparaciones, exposiciones o } \\
\text { pruebas a estudio }\end{array}$ & $\begin{array}{l}\text { Resultados } \\
\text { (Estimadores de resultados-Magnitud } \\
\text { del efecto) }\end{array}$ & $\begin{array}{l}\text { Conclusiones } \\
\text { (conclusiones) }\end{array}$ & $\begin{array}{l}\text { Comentarios } \\
\text { Calidad de la } \\
\text { evidencia } \\
\text { Financiación } \\
\text { comentarios) }\end{array}$ \\
\hline Beake S, 2012 & $\begin{array}{l}\text { Diseño } \\
\text { Revisión } \\
\text { sistemática } \\
\text { Objetivo } \\
\text { Considerar la } \\
\text { evidencia de } \\
\text { programas } \\
\text { estructurados vs } \\
\text { no estructurados } \\
\text { para apoyar el } \\
\text { inicio y duración } \\
\text { de la lactancia } \\
\text { materna exclusiva } \\
\text { en las } \\
\text { maternidades. }\end{array}$ & $\begin{array}{l}26 \text { estudios, entre } \\
\text { ellos: } \\
-5 \text { revisiones } \\
\text { sistemáticas } \\
-1 \text { ECA } \\
-2 \text { ensayos } \\
\text { controlados } \\
\text { - Un estudio } \\
\text { transversal } \\
\text { - Dos estudios } \\
\text { descriptivos } \\
-15 \text { estudios de } \\
\text { cohortes }\end{array}$ & $\begin{array}{l}\text { Se describen los resultados de los } \\
\text { estudios, no se hacen metaanálisis. } \\
\text { Los datos se proporcionan por } \\
\text { separado para las tasas al inicio, a la } \\
\text { semana (o al alta), hasta los dos } \\
\text { meses, de los dos a los cinco y a los } \\
\text { seis meses de edad. }\end{array}$ & $\begin{array}{l}\text { En general, aumento de las tasas de } \\
\text { lactancia materna, en todos los } \\
\text { momentos, incluso de lactancia materna } \\
\text { exclusiva. } \\
\text { No se han evaluado en general los } \\
\text { costes de la implementación de estos } \\
\text { programas, y los estudios en su mayoría } \\
\text { son de baja calidad, no ajustan por } \\
\text { factores de confusión, y cuando se } \\
\text { evalúan los resultados antes y después } \\
\text { de implementar un programa } \\
\text { estructurado o conseguir la acreditación, } \\
\text { no se tiene en cuenta el nivel de } \\
\text { implementación de los pasos, que es } \\
\text { muy importante. }\end{array}$ & $\begin{array}{l}\text { A pesar de la baja } \\
\text { calidad general de los } \\
\text { estudios, los programas } \\
\text { estructurados en } \\
\text { comparación con la } \\
\text { asistencia sanitaria } \\
\text { habitual influencian de } \\
\text { forma positiva el inicio y } \\
\text { duración de la lactancia } \\
\text { exclusiva y de cualquier } \\
\text { tipo. En sistemas } \\
\text { sanitarios con bajas } \\
\text { tasas de inicio y } \\
\text { duración, los programas } \\
\text { estructurados pueden } \\
\text { tener un beneficio } \\
\text { mayor. }\end{array}$ & $\begin{array}{l}\text { Pocos de los } \\
\text { estudios } \\
\text { incluidos en esta } \\
\text { revisión } \\
\text { controlan los } \\
\text { resultados por } \\
\text { factores de } \\
\text { confusión, por lo } \\
\text { que se tienen } \\
\text { que considerar } \\
\text { el impacto de } \\
\text { posibles sesgos. }\end{array}$ \\
\hline
\end{tabular}




\subsection{Resumen de GPC base y RS disponibles}

La guía NICE (3) recomienda que todos los proveedores de atención a la maternidad (tanto hospitalaria como de atención primaria) deberían implementar un programa estructurado evaluado externamente que fomente la lactancia materna, utilizando la iniciativa IHAN como el mínimo estándar (Recomendación grado A).

La guía del Perinatal Care services (4) indica que se deberían utilizar las mejores prácticas basadas en la evidencia y en base a la iniciativa IHAN por todos los proveedores en salud para atender a las madres y a sus hijos (Recomendación grado A).

\subsection{Conclusión (marcar con una X):}

\begin{tabular}{|l|l|}
\hline & Adopción GPC/Revisión sistemática \\
\hline$X$ & Elaboración parcial \\
\hline & Elaboración de novo \\
\hline
\end{tabular}

\subsection{Diseño de la estrategia de búsqueda de estudios individuales}

\begin{tabular}{|l|l|}
\hline Criterios de selección de estudios & ECA, estudios de cohortes \\
\hline Período de búsqueda & 2010-Marzo 2014 \\
\hline Bases de datos & Cochrane Library \\
& MEDLINE, via Pubmed \\
& EMBASE, via Ovid \\
& Cinahl, via EBSCOhost databases \\
& PsylNFO, via OVID \\
\hline
\end{tabular}

Ver estrategias de búsqueda de estudios originales en el ANEXO I. 


\section{4- Resumen de la evidencia (Tablas de estudios individuales y valoración de calidad en el ANEXO X)}

\section{1- GRADE Evidence Profile}

Comparación 1: Programas estructurados para el apoyo de la lactancia materna vs. Atención habitual

Bibliografía: Cattaneo A, 2001; Gau ML, 2004; Labarere J, 2003; Zimmerman DR, 1999; Venancio SI, 2012; Chien LY, 2007; Braun ML, 2003; Hawkins SS, 2014; Kramer MS, 2001; Merten S, 2005; Duyan Camurdan A, 2007; Dulon M, 2003; Shinwell 2006.

\begin{tabular}{|c|c|c|c|c|c|c|c|c|c|c|c|c|}
\hline \multirow{2}{*}{\multicolumn{7}{|c|}{ Evaluación de la calidad }} & \multicolumn{4}{|c|}{ Resumen de los Resultados } & \multirow{3}{*}{ Calidad } & \multirow{3}{*}{ Importancia } \\
\hline & & & & & & & \multicolumn{2}{|c|}{ № de pacientes } & \multicolumn{2}{|c|}{ Magnitud del efecto } & & \\
\hline $\begin{array}{c}\text { № de } \\
\text { estudios }\end{array}$ & Diseño & $\begin{array}{c}\text { Riesgo de } \\
\text { sesgo }\end{array}$ & Inconsistencia & \begin{tabular}{|l} 
Evidencia \\
indirecta
\end{tabular} & Imprecisión & \begin{tabular}{|c|} 
Otras \\
consideraciones
\end{tabular} & $\begin{array}{c}\text { Grupo } \\
\text { expuesto }\end{array}$ & $\begin{array}{l}\text { Grupo no } \\
\text { expuesto }\end{array}$ & $\begin{array}{l}\text { Relativa } \\
(95 \% \mathrm{Cl})\end{array}$ & $\begin{array}{c}\text { Absoluta por } \\
1000\end{array}$ & & \\
\hline \multicolumn{13}{|c|}{ Tasa de lactancia materna exclusiva al alta hospitalaria o hasta una semana tras el nacimiento } \\
\hline 51 & $\begin{array}{l}\text { Estudios } \\
\text { observacionales }\end{array}$ & Serio ${ }^{2}$ & \begin{tabular}{|l|l} 
No seria & 1
\end{tabular} & No seria & No seria & Ninguna $^{3}$ & \multicolumn{2}{|c|}{ № total:74.326 } & \multicolumn{2}{|c|}{ Ver resumen de evidencia } & MUY BAJA & CRITICA \\
\hline \multicolumn{13}{|c|}{ Tasa de lactancia materna exclusiva al mes } \\
\hline $3^{4}$ & $\begin{array}{l}\text { Estudios } \\
\text { observacionales }\end{array}$ & Serio 2 & No seria & No seria & No seria & Ninguna ${ }^{3}$ & \multicolumn{2}{|c|}{ № total:6.232 } & \multicolumn{2}{|c|}{ Ver resumen de evidencia } & MUY BAJA & CRITICA \\
\hline \multicolumn{13}{|c|}{ Tasa de lactancia materna exclusiva a los 3 meses } \\
\hline $1^{5}$ & ECA & No serio & No seria & Seria ${ }^{6}$ & No seria & Poco probable & $\begin{array}{c}3.839 / 8.865 \\
(43,3 \%)\end{array}$ & $\begin{array}{c}572 / 8.930 \\
(6,4 \%)\end{array}$ & $\begin{array}{l}\text { OR } 6,77 \text { (de } \\
6,16 \text { a } 7,42)\end{array}$ & - & MODERADA & CRITICA \\
\hline \multicolumn{13}{|c|}{ Tasa de lactancia materna exclusiva a los 4 meses } \\
\hline $2^{7}$ & $\begin{array}{l}\text { Estudios } \\
\text { observacionales }\end{array}$ & Serio ${ }^{2}$ & No seria & No seria & No seria & Ninguna $^{3}$ & \multicolumn{2}{|c|}{ № total: 3.416} & \multicolumn{2}{|c|}{ Ver resumen de evidencia } & MUY BAJA & CRITICA \\
\hline \multicolumn{13}{|c|}{ Tasa de lactancia materna exclusiva a los 6 meses } \\
\hline $1^{5}$ & ECA & Serio $^{8}$ & No seria & Seria ${ }^{6}$ & No seria & Poco probable & $\begin{array}{c}700 / 8.865 \\
(7,9 \%)\end{array}$ & $\begin{array}{c}54 / 8.930 \\
(0,6 \%)\end{array}$ & $\begin{array}{l}\mathrm{OR}^{*} 14,09 \text { (de } \\
10,67 \text { a } 18,62)\end{array}$ & - & BAJA & IMPORTANTE \\
\hline $3^{9}$ & \begin{tabular}{|l|} 
Estudios \\
observacionales
\end{tabular} & Serio ${ }^{2}$ & No seria & No seria & No seria & Ninguna & \multicolumn{2}{|c|}{ № total: 3.037} & \multicolumn{2}{|c|}{ Ver resumen de evidencia } & MUY BAJA & IMPORTANTE \\
\hline \multicolumn{13}{|c|}{ Tasa de cualquier tipo de lactancia materna a los 3 meses } \\
\hline $1^{5}$ & ECA & No serio & \begin{tabular}{|l|l} 
No seria & $s$
\end{tabular} & Seria ${ }^{6}$ & No seria & Poco probable & $\begin{array}{l}4.601 / 8.865 \\
(51,9 \%)\end{array}$ & $\begin{array}{c}2.527 / 8.930 \\
(28,3 \%)\end{array}$ & $\begin{array}{l}\text { OR } 0,28 \text { (de } \\
0,16 \text { a } 0,49)\end{array}$ & - & MODERADA & IMPORTANTE \\
\hline \multicolumn{13}{|c|}{ Tasa de cualquier tipo de lactancia materna a los 4 meses } \\
\hline $3^{10}$ & \begin{tabular}{|l|} 
Estudios \\
observacionales
\end{tabular} & Serio ${ }^{2}$ & No seria & No seria & No seria & Ninguna $^{3}$ & \multicolumn{2}{|c|}{ № total: 5.149} & \multicolumn{2}{|c|}{ Ver resumen de evidencia } & MUY BAJA & IMPORTANTE \\
\hline
\end{tabular}




\begin{tabular}{|c|c|c|c|c|c|c|c|c|c|c|c|c|}
\hline $1^{5}$ & ECA & No serio & No seria & Seria $^{6}$ & No seria & Poco probable & $\begin{array}{c}4.344 / 8.865 \\
(49,8 \%)\end{array}$ & $\begin{array}{c}3.224 / 8.930 \\
(36,1 \%)\end{array}$ & $\begin{array}{c}\mathrm{OR}^{\star} 1,70 \text { (de } \\
1,60 \text { a } 1,89)\end{array}$ & - & MODERADA & IMPORTANTE \\
\hline
\end{tabular}

pasos IHAN experimentados y aumento tasa latancimmerman DR, 1999; Venancio SI, 2012; ${ }^{2}$ Existe riesto de sesgo en los estudios; ${ }^{3}$ Podría haber efecto dosis respuesta entre número de

Braun ML, 2003; Gau ML, 2004; Hawkins SS, 2014; ${ }^{5}$ Kramer MS, 2001; 6 Problemas de validez externa de los resultados; 7 Merten S, 2005 ; Duyan Camurdan A, 2007; 8 Los autores señalan que la

estimación del OR para la lactancia exclusiva a los 6 meses es poco fiable debido a las bajas tasas registradas en el grupo control; 9 Dulon M, 2003; Duyan Camurdan A, 2007; Shinwell 2006; 10

Braun ML, 2003; Dulon M, 2003; Merten S, 2005. * Cálculos de OR sin ajustar. 


\section{2- Resumen de la Evidencia}

Los desenlaces considerados en la revisión de Beake (1) como desenlaces principales son la tasa de inicio de lactancia materna así como la tasa de lactancia materna, exclusiva y de cualquier tipo, en diferentes puntos de tiempo (a la semana o alta hospitalaria, hasta los dos meses, hasta los 5 meses o a los 6 meses de edad) y la duración de la lactancia materna exclusiva o lactancia materna de cualquier tipo. Los autores también consideraron otros desenlaces secundarios, como los relacionados con la salud materno-infantil, el conocimiento de las madres, sus actitudes y habilidades con la lactancia tras la introducción de un programa estructurado, la experiencia de las mujeres en referencia al apoyo recibido por parte de los profesionales y por los grupos de apoyo entre iguales, los problemas con la lactancia materna y el impacto de estas estrategias de apoyo sobre los recursos sanitarios.

Los autores realizaron una búsqueda de estudios publicados entre 1992 y 2010, incluyendo finalmente en su revisión 26 artículos: 5 revisiones sistemáticas, un ECA, dos ensayos controlados, un estudio transversal, dos estudios descriptivos y 15 estudios de cohortes.

Las 5 revisiones sistemáticas identificadas (5-9) concluyen que las intervenciones dirigidas a apoyar el inicio y la duración de la lactancia materna son efectivas. Beake et al señalan que de los artículos que estas revisiones incluyen, ellos sólo seleccionan 9 (1).

La conclusión final a la que llegan Beake et al es que la mayoría de los estudios incluidos encuentran un aumento significativo de las tasas de inicio de lactancia materna tras la introducción de un programa de lactancia estructurado en el hospital o en las maternidades, aunque el tamaño del efecto varía entre estudios y no en todos se controla el análisis por factores de confusión.

Los estudios incluidos evalúan tanto el efecto de la implantación de la estrategia IHAN sobre las tasas de lactancia, así como las diferencias entre hospitales con alto cumplimiento de los pasos IHAN versus los de bajo cumplimiento y el efecto de la implementación de la intervención educativa de la estrategia IHAN o de intervenciones educativas similares sobre las tasas de lactancia materna.

En nuestro caso, los desenlaces de interés que se han tenido en cuenta han sido la tasa de lactancia materna exclusiva al alta hospitalaria, la tasa de lactancia materna exclusiva al mes, a los cuatro y a los seis meses, así como la tasa de cualquier tipo de lactancia materna a los cuatro y seis meses. Asimismo, también se han presentado los datos del único ECA realizado hasta la fecha (10) que evalúa el efecto de la implementación de un programa estructurado en la lactancia materna a los 3 y 6 meses de edad.

En la actualización de la búsqueda de Beake et al, se han identificado otros 5 estudios que aportan datos en relación a los desenlaces mencionados (11-15). Los estudios que describían únicamente los niveles de cumplimiento de los pasos IHAN por los hospitales o los que daban datos del impacto de la implementación de la iniciativa sólo sobre las tasas de inicio de lactancia materna no han sido incluidos. En esta 
actualización también se ha identificado una revisión sistemática sobre las barreras y facilitadores identificados en la literatura para implementar la estrategia IHAN, así como una metasíntesis de estudios cualitativos que exploran las opiniones y experiencias de profesionales sanitarios sobre la iniciativa y un estudio cualitativo sobre las experiencias de mujeres que han dado a luz en un hospital que se encontraba en el proceso de obtención de dicha acreditación. Los resultados de estos estudios han sido tenidos en cuenta en la elaboración de las recomendaciones.

En cuanto a la lactancia materna exclusiva al alta hospitalaria, son 5 los estudios que describen el efecto de un programa estructurado sobre las tasas de lactancia materna exclusiva a la semana o al alta hospitalaria. Entre estos estudios se encuentra un ensayo controlado (16) en el que los autores asignan 8 hospitales a dos grupos de estudio: el grupo 1 (4 hospitales del Sur de Italia) y grupo 2 (4 hospitales del Norte y Centro de Italia). En la fase 1 del estudio, los autores describen cuál es la tasa de lactancia materna basal en ambos grupos de hospitales. A continuación, en el grupo 1 se implementa una intervención, basada en el curso de 18 horas de UNICEF, para la capacitación en lactancia materna de los profesionales sanitarios, y posteriormente se miden las tasas de lactancia materna en ambos grupos de hospitales (Fase 2). A continuación la intervención se implementa en los hospitales del grupo 2 y tras 4-5 meses se vuelven a medir los resultados en lactancia materna en los hospitales de ambos grupos (Fase 3). Lo que los autores de este estudio encuentran es que la tasa de lactancia materna exclusiva en la primera semana aumenta en ambos grupos de estudio tras la intervención (del $41 \%$ al $77 \%$ en el grupo $1 \mathrm{y}$ del $23 \%$ al $73 \%$ en el grupo 2 ).

Dos de los cuatro estudios restantes incluidos valoran el cambio producido en la tasa de lactancia exclusiva antes y después de la implementación de la estrategia estructurada, siendo la recogida de datos retrospectiva en uno de ellos (17). La tasa de lactancia materna exclusiva aumenta en ambos casos, del $15,8 \%$ al $35,2 \%$ (18) y del $36 \%$ al $55 \%$ (17), respectivamente. El tercer estudio evalúa la implementación de la estrategia IHAN en 7 hospitales mediante un estudio pre-post comparando los datos de esos hospitales con los datos de otros 7 hospitales control, y observa que la tasa de lactancia materna exclusiva a la semana aumenta de un $30 \%$ a un $50 \%$ en los hospitales del grupo intervención, manteniéndose constante en los hospitales del grupo control, de un 24\% a un 23\%), entre los años 1999 y 2002 (19). El último estudio (14), encuentra que el porcentaje de niños con lactancia materna exclusiva un día después del alta hospitalaria era mayor si estos nacían en un centro acreditado IHAN frente a los que lo hacían en un centro no acreditado (13,8\% vs. $6,6 \%)$.

En cuanto a los resultados sobre la tasa de lactancia materna exclusiva al mes, de los cuatro estudios que inicialmente aportan datos $(11 ; 15 ; 19 ; 20)$, sólo tres se refieren a la lactancia materna exclusiva $(15 ; 19 ; 20)$. Braun et al describen que para los niños nacidos de forma previa a la implementación de la iniciativa IHAN el HR para no estar amamantando de forma exclusiva al mes era de 1,66 (IC95\% 1,40; 1,98) en comparación a los nacidos en el período post-implementación. En el estudio de Gau et al, la lactancia materna exclusiva al mes aumentaba entre 1999 a 2002 en los hospitales intervenidos (del 16\% al 23\%) en comparación a los no acreditados (del $6 \%$ al $5 \%$ ). Y por último, en el

Calidad muy baja

Calidad muy baja 
estudio de Hawkins, aunque dar a luz en un hospital acreditado IHAN no se asociaba de forma significativa con la duración de la lactancia materna exclusiva igual o superior a las 4 semanas, el número de prácticas de la iniciativa que la madre experimentaba sí se asociaba de forma significativa $(p<0,001)$. Los autores sugieren que posiblemente lo que aumenta la tasa de lactancia materna no sea tener o no tener la acreditación IHAN, sino más bien el número experimentado de prácticas hospitalarias que apoyan la lactancia materna. De hecho, el estudio de Chien et al encuentra una relación dosis respuesta entre el número de pasos IHAN experimentados por las madres en los hospitales y la tasa de lactancia materna al mes y a los tres meses de dar a luz (21).

De los 7 estudios incluidos en la revisión de Beake et al, tres de los estudios aportan datos sobre el efecto de la estrategia estructurada sobre la tasa de cualquier tipo de lactancia materna a los 4 meses de edad $(20 ; 22 ; 23)$ y sólo dos la tasa de lactancia materna exclusiva a los 4 meses $(22 ; 24)$.

En lo que a la tasa de lactancia materna exclusiva a los 4 meses se refiere, en el estudio de Merten et al, la tasa aumentaba del $49 \%$ al $60 \%$ (22), y en el estudio de Duyan-Camurdan (24) del $45,5 \%$ al $53,7 \%$.

El único ECA, de buena calidad identificado que evalúa el efecto de la implementación de un programa estructurado de apoyo al inicio y mantenimiento de la lactancia materna (10), mide la tasa de lactancia materna exclusiva a los 3 meses, observando que tras la implementación del programa ésta aumenta de un $6,4 \%$ a un $43,3 \%$.

En cuanto a la tasa de cualquier tipo de lactancia materna a los 4 meses de edad, en el estudio de Dulon esta tasa aumenta de un 42,1\% a un $49,5 \%$, y en el estudio de Merten de un $60 \%$ a un $72 \%$. Por otro lado, en el estudio de Braun se obtiene que el OR para la discontinuación de cualquier tipo de lactancia materna a los 4 meses es de 1,55 (IC95\% de 1,16 a 2,01) cuando no hay un programa estructurado para el apoyo de la lactancia materna. Asimismo, en el único ECA que se ha encontrado que valore el efecto de la implementación de una estrategia estructurada para el apoyo de la lactancia materna, la tasa de cualquier tipo de lactancia materna a los 3 meses aumenta del $36,1 \%$ al $49,8 \%$ (OR 0,52; IC95\% de 0,39 a 0,71$)$.

En el ECA de Kramer la proporción de mujeres con lactancia materna exclusiva a los 6 meses era más de 12 veces mayor en el grupo experimental frente al control $(7,9 \%$ vs $0,6 \%)$, y en los 3 estudios observacionales que incluían la medición de este desenlace, las tasas de lactancia materna exclusiva a los 6 meses aumentaban en dos de ellos y en el último no había diferencias significativas.

En cuanto a la proporción de mujeres con cualquier tipo de lactancia a los 6 meses también era mayor en el grupo experimental (OR 1,7; IC95\% de 1,6 a 1,89$)$.

En cuanto la pérdida de peso fisiológica del recién nacido en los primeros días, en la actualización de los estudios publicados desde 2010 se ha identificado un estudio (25), no incluido en la tabla GRADE, que mide la pérdida fisiológica del peso en los primeros 7 días de vida de los niños nacidos en un hospital IHAN. En este estudio, que incluye 121 niños, observan que la máxima pérdida de peso de los lactantes

Calidad muy baja

Calidad moderada Calidad muy baja

Calidad moderada

\section{Calidad baja}

Calidad muy baja

Calidad moderada

Calidad muy baja 
amamantados de este hospital no supera en ningún caso el $10 \%$ descrito en otros estudios, por lo que se concluye que la existencia de políticas de apoyo a la lactancia materna se asocia a una menor pérdida de peso en los lactantes amamantados.

\section{ACTUALIZADO A FECHA DE: 31 de Octubre de 2016}




\section{5- De la evidencia a la recomendación (Tabla de EtR)}

\section{¿Cuáles son las mejores estrategias estructuradas para el apoyo y protección de la lactancia materna durante la estancia en el hospital?}

Población: Madres de recién nacidos sanos a término que amamantan y sus bebés

Intervención: Medidas de apoyo y protección a la lactancia materna durante la estancia en el hospital

Perspectiva: Clínica

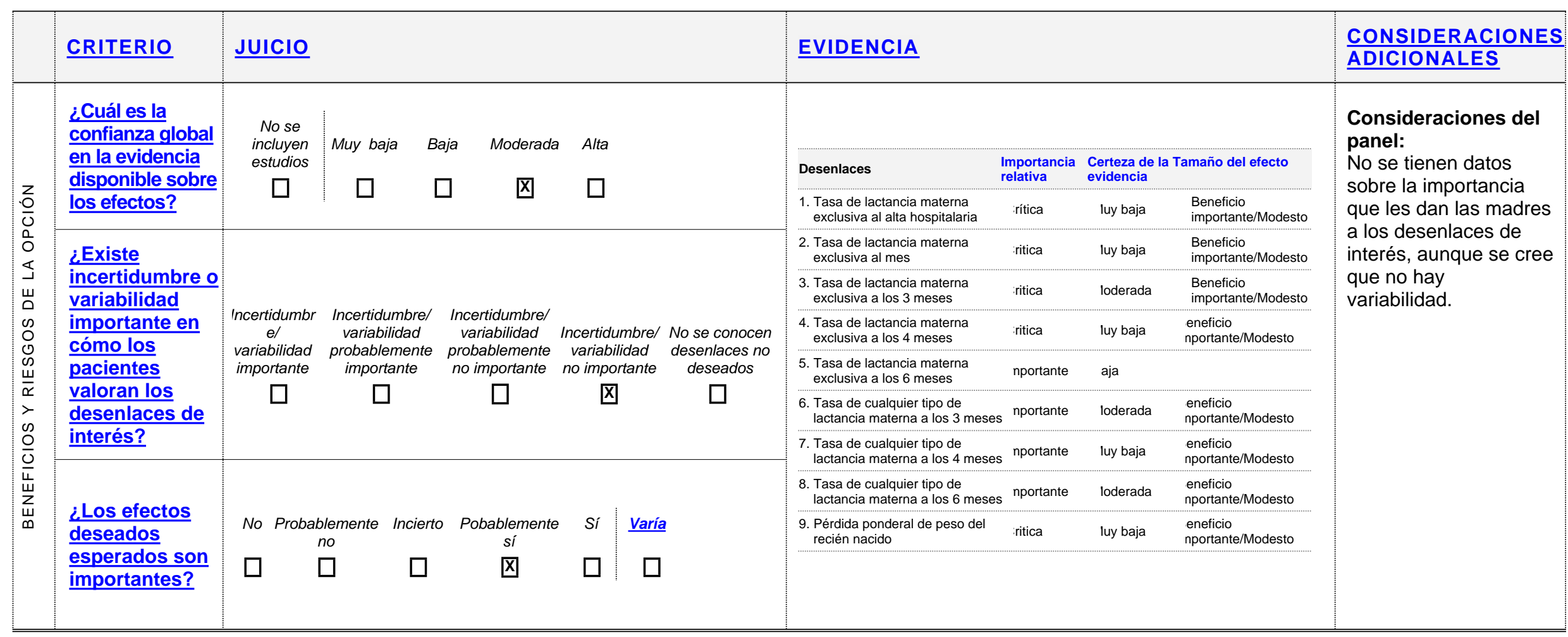




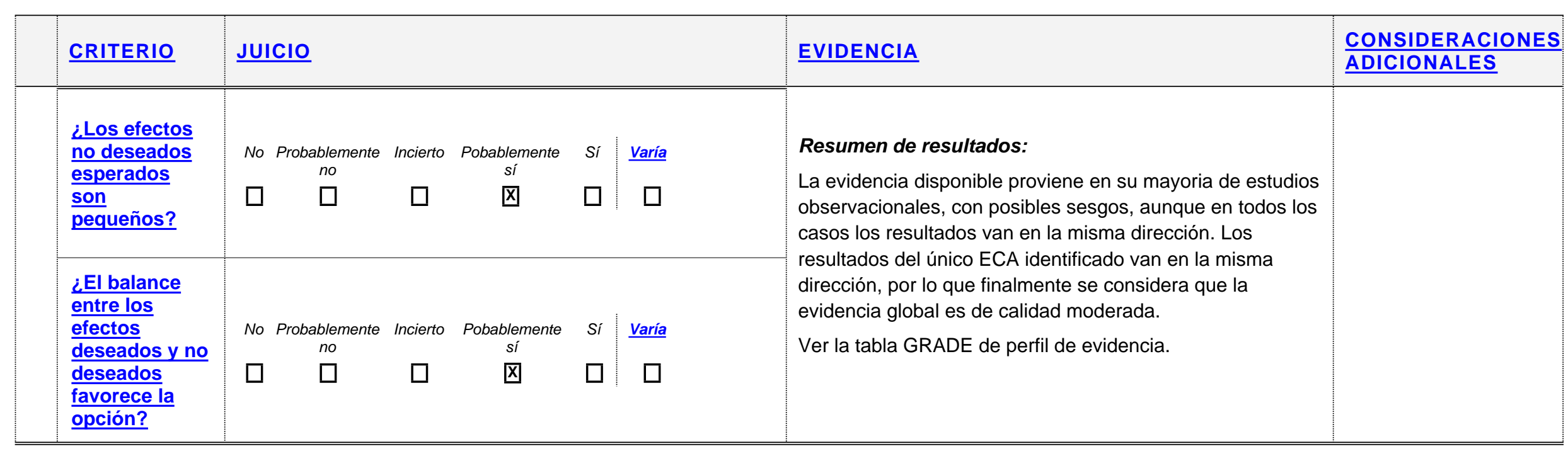


¿Cuáles son las mejores estrategias estructuradas para el apoyo y protección de la lactancia materna durante la estancia en el hospital?

\begin{tabular}{|c|c|c|c|c|c|c|c|c|}
\hline & CRITERIO & JUICIO & & & & & EVIDENCIA & $\begin{array}{l}\text { CONSIDERACIONES } \\
\text { ADICIONALES }\end{array}$ \\
\hline \multirow[b]{2}{*}{ 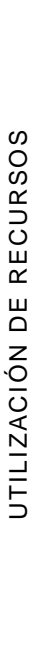 } & $\begin{array}{l}\text { ¿Los recursos } \\
\text { que se requieren } \\
\text { son bajos? }\end{array}$ & $\begin{array}{c}\text { No Probablemente } \\
\text { no } \\
\square \quad \square\end{array}$ & $\begin{array}{c}\text { Incierto } \\
\square\end{array}$ & $\begin{array}{c}\text { Pobablemente } \\
\text { sí } \\
\square\end{array}$ & $\begin{array}{l}\text { Sí } \\
\square\end{array}$ & $\begin{array}{c}\text { Varía } \\
\square\end{array}$ & & \\
\hline & $\begin{array}{l}\frac{\text { ¿El coste }}{\text { incremental es }} \\
\text { pequeño en } \\
\text { relación a los } \\
\text { beneficios netos? }\end{array}$ & $\begin{array}{c}\text { No Probablemente } \\
\text { no } \\
\square \quad \square\end{array}$ & $\begin{array}{c}\text { Incierto } \\
\text { 囚 }\end{array}$ & $\begin{array}{c}\text { Pobablemente } \\
\text { sí } \\
\square\end{array}$ & & $\frac{\text { Varía }}{\square}$ & $\begin{array}{l}\text { En cuanto al impacto de este tipo de estrategias en los } \\
\text { recursos, la guía NICE incluye un modelo para valorar } \\
\text { el coste-efectividad de la implementación de la } \\
\text { estrategia IHAN en Inglaterra y Escocia, en el que } \\
\text { valoran el ahorro en los costes teniendo en cuenta la } \\
\text { disminución del número de otitis y gastroenteritis en } \\
\text { los niños con lactancia materna y la reducción del uso } \\
\text { de fórmulas y tetinas debido al aumento de la tasa de } \\
\text { la lactancia materna. } \\
\text { Los costes dependerán de los cambios que haya que } \\
\text { hacer en la organización (para permitir el rooming in, } \\
\text { más personal para vigilar el contacto piel con piel, } \\
\text { realizar observaciones de tomas etc.), los cursos que } \\
\text { se deben impartir a los profesionales sanitarios etc. }\end{array}$ & \\
\hline
\end{tabular}




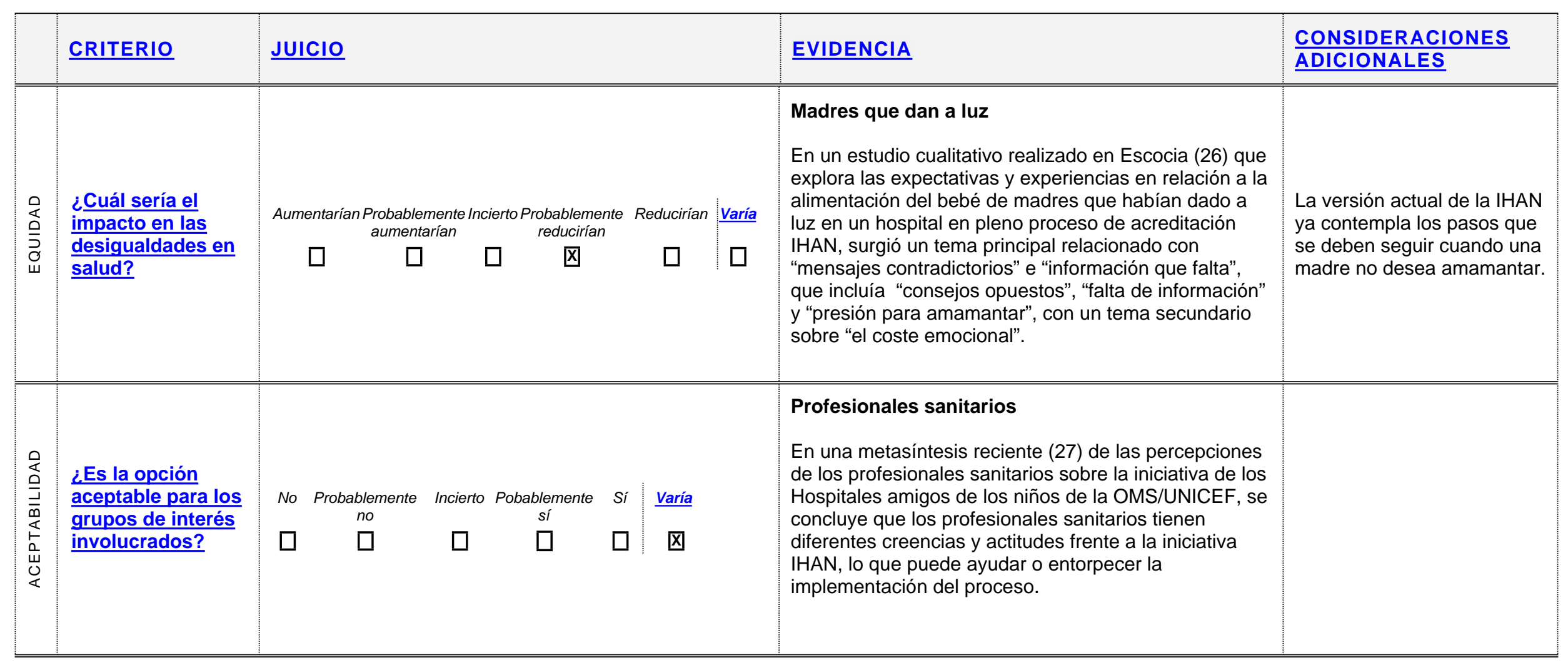




\begin{tabular}{|c|c|c|c|c|c|c|}
\hline & CRITERIO & $\underline{\text { JUICIO }}$ & & & EVIDENCIA & $\begin{array}{l}\text { CONSIDERACIONES } \\
\text { ADICIONALES }\end{array}$ \\
\hline 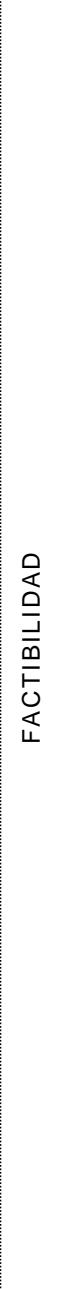 & $\begin{array}{l}\text { ¿La } \\
\text { implementación } \\
\text { de la opción es } \\
\text { factible? }\end{array}$ & $\begin{array}{cc}\text { No } & \text { Probablemente } \\
& \text { no } \\
\square & \square\end{array}$ & $\begin{array}{ccc}\text { Incierto Pobablemente } & \text { Si } \\
& \text { sí } & \\
\square & \bigotimes & \square\end{array}$ & $\frac{\text { Varía }}{\square}$ & $\begin{array}{l}\text { Se ha descrito que la introducción de la iniciativa a } \\
\text { nivel local requiere una planificación detallada, una } \\
\text { amplia colaboración y un líder entusiasta y } \\
\text { comprometido que dirija el proceso de cambio. Los } \\
\text { autores señalan la importancia de pensar de forma } \\
\text { más creativa a la hora de trasladar esta política global } \\
\text { a un cambio efectivo a nivel local (27). } \\
\text { El estudio cualitativo realizado en Escocia (26) } \\
\text { concluye que la interpretación de las } \\
\text { recomendaciones de la iniciativa IHAN pueden estar } \\
\text { restringiendo las discusiones prenatales sobre la } \\
\text { alimentación infantil, y que se debe cambiar el } \\
\text { mensaje sobre la alimentación infantil para que el foco } \\
\text { se centre en la mujer, incluyendo en la discusión la } \\
\text { realidad de cada método de alimentación infantil. } \\
\text { Añaden que es importante que se siga } \\
\text { promocionando la lactancia materna, pero que sin } \\
\text { embargo se necesita proveer de toda la información } \\
\text { sobre la alimentación del bebé así como dar apoyo } \\
\text { también a aquellas mujeres que no quieren } \\
\text { amamantar. } \\
\text { En una revisión reciente, en la que organizan las } \\
\text { barreras y facilitadores identificados en la literatura en } \\
\text { tres niveles (nivel sociopolítico, organizativo y nivel } \\
\text { individual) (28), señalan que a nivel sociopolítico, se } \\
\text { deberían promulgar leyes para la protección de la } \\
\text { lactancia materna (como por ejemplo las bajas } \\
\text { maternales), las costumbres sociales en relación a la } \\
\text { alimentación infantil, la integración de los servicios } \\
\text { sanitarios pre, peri y postnatales, el respaldo y apoyo } \\
\text { de las autoridades a la iniciativa IHAN, la necesidad } \\
\text { de una educación adecuada en los programas de } \\
\text { capacitación para los profesionales sanitarios y la } \\
\text { fuerza y visibilidad del marketing que realiza la } \\
\text { industria de fórmulas infantiles, entre otros. }\end{array}$ & $\begin{array}{l}\text { La implementación es } \\
\text { factible, pero requiere } \\
\text { recursos y una buena } \\
\text { estrategia de } \\
\text { implementación para que } \\
\text { ésta sea efectiva y } \\
\text { satisfactoria para todos los } \\
\text { grupos de interés. } \\
\text { En un artículo en el que se } \\
\text { estudia si el haber } \\
\text { experimentado las prácticas } \\
\text { de la iniciativa IHAN se } \\
\text { asocia con el cumplimiento } \\
\text { de las expectativas que } \\
\text { tenían las madres lactantes } \\
\text { en relación al tiempo que } \\
\text { querían amamantar de } \\
\text { forma exclusiva, se encontró } \\
\text { por ejemplo que de las } 1457 \\
\text { madres incluidas en el } \\
\text { estudio, más del } 85 \% \\
\text { pensaba dar lactancia } \\
\text { exclusiva durante } 3 \text { meses o } \\
\text { más y que sólo el } 32,4 \% \\
\text { alcanó la duración } \\
\text { pretendida (29). }\end{array}$ \\
\hline
\end{tabular}




\begin{tabular}{|c|c|c|c|c|}
\hline & CRITERIO & JUICIO & EVIDENCIA & $\begin{array}{l}\text { CONSIDERACIONES } \\
\text { ADICIONALES }\end{array}$ \\
\hline 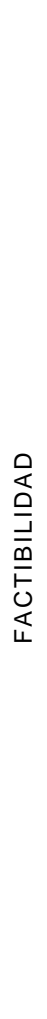 & & & $\begin{array}{l}\text { A nivel organizativo, se identifica la necesidad de } \\
\text { realizar el audit y el feedback del proceso, la } \\
\text { disponibilidad de recursos económicos y humanos, la } \\
\text { fuerza del liderazgo en el proceso de implementación, } \\
\text { que se trate de un proceso participativo y } \\
\text { multidisciplinar y que se den los cambios } \\
\text { organizativos necesarios para poder llevar a cabo la } \\
\text { implementación de todos los pasos. } \\
\text { A nivel del profesional sanitario, se identifican como } \\
\text { barreras el nivel de conocimientos sobre lactancia } \\
\text { materna y sus actitudes hacia la lactancia materna en } \\
\text { general o hacia la iniciativa IHAN (ser reacio a } \\
\text { promocionar la lactancia sin tener en cuenta si se } \\
\text { hace sentir culpable a las mujeres o sin respetar sus } \\
\text { creencias culturales), así como la sobreutilización de } \\
\text { biberones y chupetes fácilmente accesibles. El } \\
\text { facilitador más mencionado es el acceso por parte de } \\
\text { los profesionales sanitarios, a cursos educativos sobre } \\
\text { capacitación en lactancia materna. Desde el punto de } \\
\text { vista de las madres, entre los factores que impiden la } \\
\text { implementación de la iniciativa se encuentra su } \\
\text { conocimiento sobre la lactancia materna y la iniciativa } \\
\text { IHAN, sus creencias culturales relacionadas con la } \\
\text { lactancia, la experiencia vivida en el parto y la } \\
\text { existencia o no de apoyo por parte de la familia o de } \\
\text { otros grupos de apoyo, una preparación prenatal } \\
\text { inadecuada y la inconsistencia de la información } \\
\text { aportada por los diferentes profesionales sanitarios. }\end{array}$ & $\begin{array}{l}\text { Se encuentra una relación } \\
\text { dosis respuesta entre el } \\
\text { número de las prácticas } \\
\text { experimentadas y el } \\
\text { alcanzar la intención de } \\
\text { amamantar de forma } \\
\text { exclusiva. Sin embargo, } \\
\text { puede que esta asociación } \\
\text { se explique sólo por uno de } \\
\text { las prácticas, que es la de } \\
\text { no recibir alimentación } \\
\text { suplementaria (la única que } \\
\text { en el análisis multivariables } \\
\text { que se asocia de forma } \\
\text { independiente (OR 2,3; } \\
\text { IC95\% } 1,8 ; 3,1) \text {. }\end{array}$ \\
\hline
\end{tabular}




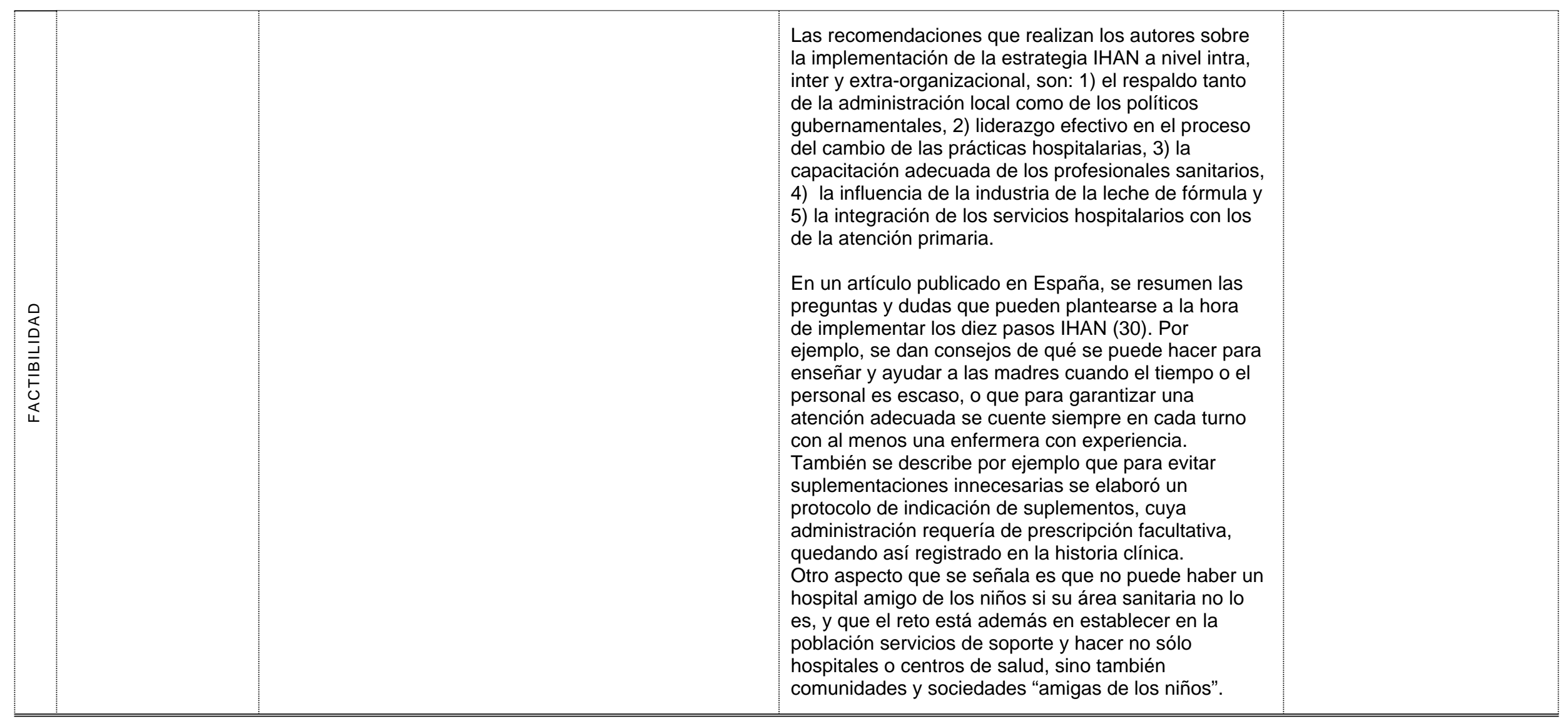




\begin{tabular}{|c|c|c|c|c|c|}
\hline \multirow[t]{2}{*}{$\begin{array}{l}\text { Balance de las } \\
\text { consecuencias }\end{array}$} & $\begin{array}{l}\text { Las consecuencias no } \\
\text { deseadas superan } \\
\text { claramente las } \\
\text { consecuencias deseadas } \\
\text { en la mayoría de los } \\
\text { escenarios }\end{array}$ & $\begin{array}{l}\text { Las consecuencias no } \\
\text { deseadas probablemente } \\
\text { superan las } \\
\text { consecuencias deseadas } \\
\text { en la mayoría de los } \\
\text { escenarios }\end{array}$ & $\begin{array}{c}\text { El balance entre las } \\
\text { consecuencias deseadas y } \\
\text { no deseadas está muy } \\
\text { equilibrado o es incierto }\end{array}$ & $\begin{array}{l}\text { Las consecuencias } \\
\text { deseadas } \\
\text { probablemente superan } \\
\text { las consecuencias no } \\
\text { deseadas en la mayoría } \\
\text { de los escenarios }\end{array}$ & $\begin{array}{c}\text { Las consecuencias } \\
\text { deseadas claramente } \\
\text { superan las } \\
\text { consecuencias no } \\
\text { deseadas en la mayoría } \\
\text { de los escenarios }\end{array}$ \\
\hline & $\square$ & $\square$ & $\square$ & 囚 & $\square$ \\
\hline & $\square$ & & $\square$ & $\square$ & 囚 \\
\hline \multirow{2}{*}{$\begin{array}{l}\text { Recomendación } \\
\text { (Texto) }\end{array}$} & \multicolumn{5}{|c|}{$\underline{\text { Recomendación fuerte a favor }}$} \\
\hline & \multicolumn{5}{|c|}{$\begin{array}{l}\text { Se recomienda que todas las maternidades implementen un programa estructurado, con evaluación externa, que promueva y apoye } \\
\text { la lactancia materna, utilizando la iniciativa IHAN como mínimo estándar. }\end{array}$} \\
\hline Justificación & \multicolumn{5}{|c|}{$\begin{array}{l}\text { A pesar de que la evidencia apunta a que la iniciativa IHAN aumenta las tasas de lactancia materna exclusiva, se han descrito en la } \\
\text { literatura numerosas barreras que pueden complicar el proceso de la implementación y que pueden hacer que el proceso no sea } \\
\text { efectivo. Además, también se ha descrito que el hecho de que un centro esté acreditado como centro IHAN no significa que las } \\
\text { madres que amamantan experimenten todos los pasos descritos, por lo que se necesita monitorizar el cumplimiento de cada paso pol } \\
\text { parte del hospital y de los profesionales sanitarios. }\end{array}$} \\
\hline
\end{tabular}




\section{Consideraciones de}

\section{subgrupos}

Consideraciones para la implementación
- Se recomienda que la implementación sea un proceso participativo y multidisciplinar y que sea dirigido por profesionales sanitarios con experiencia y capacidad de liderazgo.

- Se recomienda que la organización provea los recursos necesarios (cambios organizativos, formación adecuada a los profesionales sanitarios) para que la implementación del programa sea efectiva.

- Se recomienda que el programa incluya las exigencias de la acreditación que aseguran la evaluación externa y los criterios de calidad de reconocimiento mundial.

- Se recomienda que tras la implementación de un programa estructurado de estas características se monitorice de forma continua la cumplimentación de los 10 pasos que propone la iniciativa.

\begin{tabular}{ll} 
Monitorización y & $\begin{array}{l}\text { Se debe diseñar una estrategia que permita monitorizar tanto la implementación como el cumplimiento de todos los pasos IHAN, para } \\
\text { evaluación }\end{array}$ \\
\hline
\end{tabular}

Prioridades para la Se necesitan estudios cuantitativos que demuestren que en los centros en los que se ha implementado la iniciativa de la investigación OMS/UNICEF, los niños amamantados pierden menos peso que los niños amamantados que han nacido en centros no acreditaos, 0 incluso hacer la comparación teniendo en cuenta el número de pasos experimentados por las madres y no sólo por ser centros acreditados. 


\section{ANEXO I, ESTRATEGIAS DE BÚSQUEDA}

\section{Cochrane Library}

Searched 26/03/2014

Updated search 26/03/2014 a xx/xx/xxxx

\#1 "breast feeding" or breastfeeding or "breast feed" or breastfeed or "breast fed" or breast fed:ti,ab,kw or lactation:ti,ab,kw (Word variations have been searched) 3285

\#2 support:ti,ab,kw or promotion:ti,ab,kw (Word variations have been searched) 46697

\#3 \#1 and \#2 563

\#4 programm*:ti,ab,kw (Word variations have been searched) 10108

\#5 \#2 and \#4 1836

\#6 \#1 and \#5 49

\#7 "baby friendly" 53

\#8 \#6 or \#7 Publication Date from 2010 to 201427

\section{MEDLINE, via Pubmed}

\section{Searched 26/03/2014}

Updated search 26/03/2014 a xx/xx/xxxx

\#1 "breast feeding"[MeSH Terms] OR "breast feeding"[All Fields] OR "breastfeeding"[All

Fields] OR "breast feeding"[All Fields] OR "breastfeed"[All Fields] OR "breast feed"[All Fields]

OR "breastfed" [All Fields] OR "breast fed"[All Fields]

\#2 "lactation"[MeSH Terms] OR "lactation"[All Fields]

\#3 \#1 OR \#2

\#4 support* OR promot* Field: Title/Abstract

\#5 programm* Field: Title/Abstract

\#6 \#4 AND \#5

\#7 \#3 AND \#6

\#8 \#7 Filters: Publication date from 2010/01/01 to 2014/12/31

\#9 ("infant, newborn"[MeSH Terms] OR ("infant"[All Fields] AND "newborn"[All Fields])

OR "newborn infant"[All Fields] OR "baby"[All Fields] OR "infant"[MeSH Terms] OR

"infant"[All Fields]) AND friendly[All Fields] AND ("hospitals"[MeSH Terms] OR "hospitals"[All

Fields] OR "hospital"[All Fields]) AND initiative[All Fields] Filters: Publication date from $2010 / 01 / 01$ to $2014 / 12 / 31$

\#10 \#8 OR \#9 262

\section{EMBASE, via Ovid}

\section{Searched 26/03/2014}

Updated search 26/03/2014 a xx/xx/xxxx

\#1 ("breast feeding" or breastfeeding or "breast feed" or breastfeed or "breast fed" or breast fed).ti,ab,kw.

\#2 lactation.ti,ab,kw.

\#3 \#1 OR \#2

\#4 (support* or promot*).ti,ab,kw.

\#5 "programm*".ti,ab,kw.

\#6 \#4 AND \#5

\#7 \#3 AND \#6

\#8 (baby and friendly and hospital and initiative).ti,ab,kw.

\#9 \#7 OR \#8

\#10 limit \#9 to yr="2010 -Current" 326 


\section{Cinahl, via EBSCOhost databases}

\section{Searched 26/03/2014}

Updated search 26/03/2014 a xx/xx/xxxx

\#1 "breast feeding" or breastfeeding or "breast feed" or breastfeed or "breast fed" or breast fed

\#2 (MH "Breast Feeding")

\#3 \#1 OR \#2

\#4 lactation

\#5 (MH "Lactation")

\#6 \#4 OR \#5

\#7 \#3 OR \#6

\#8 support $^{\star}$ OR promot ${ }^{\star}$

$\# 9$ programm*

\#10 \#8 AND \#9

\#11 \#7 AND \#10

\#12 "baby friendly"

\#13 \#11 OR \#12

\#14 Limitadores - Fecha de publicación: 20100101-20141231

Modos de búsqueda - Booleano/Frase

\#15 \#13 AND \#14 178 


\section{ANEXO II, Tabla de estudios individuales para la pregunta}

\begin{tabular}{|c|c|c|c|c|c|c|}
\hline $\begin{array}{l}\text { Referencia } \\
\text { (Cita Abreviada) }\end{array}$ & $\begin{array}{l}\text { Estudio (Diseño y } \\
\text { objetivo) }\end{array}$ & $\begin{array}{l}\text { Población } \\
\text { (nº y características) }\end{array}$ & $\begin{array}{l}\text { Descripción de las intervenciones } \\
\text { comparaciones, exposiciones o } \\
\text { pruebas a estudio }\end{array}$ & $\begin{array}{l}\text { Resultados } \\
\text { (Estimadores de resultados-Magnitud del } \\
\text { efecto) }\end{array}$ & $\begin{array}{l}\text { Conclusiones } \\
\text { (conclusiones) }\end{array}$ & $\begin{array}{l}\text { Comentarios } \\
\text { Calidad de la } \\
\text { evidencia } \\
\text { Financiación } \\
\text { comentarios) }\end{array}$ \\
\hline $\begin{array}{l}\text { Zimmerman DR, } \\
1999\end{array}$ & $\begin{array}{l}\text { Diseño: estudio de cohorte } \\
\text { Objetivo: aumentar las } \\
\text { tasas de lactancia en un } \\
\text { hospital del centro. }\end{array}$ & $\begin{array}{l}\text { Pre-intervention } 188 \\
\text { infants vs. } \\
\text { post-intervention } \\
405 \text { infants; } \\
\text { Mujeres de ingresos } \\
\text { bajos. }\end{array}$ & $\begin{array}{l}\text { Los datos se recogen al alta } \\
\text { hospitalaria. } \\
\text { La intervención es educación y apoyo a } \\
\text { las madres vs. no educación y apoyo a } \\
\text { las madres. } \\
\text { La intervención consiste en educación } \\
\text { prenatal para todas las madres } \\
\text { embarazadas, packs de regalo } \\
\text { postparto y grupos de apoyo. } \\
\text { Durante el estudio, la tasa de inicio de } \\
\text { lactancia materna aumentó del }\end{array}$ & $\begin{array}{l}\text { Aumento del \% de lactancia materna a la } \\
\text { semana de cualquier tipo y de lactancia } \\
\text { materna exclusiva: } \\
\text { 1. Cualquier tipo de lactancia materna a la } \\
\text { semana: } 50 \% \text { vs. } 67 \%, \mathrm{P}<0.05 \\
\text { 2. Lactancia materna exclusiva a la } \\
\text { semana: } 36 \% \text { vs. } 55 \%, \mathrm{P}<0.05 \\
\\
\text { Aumento a los } 2 \text { semanas postparto: } \\
\text { 1. Cualquier tipo de lactancia materna: } \\
35 \% \text { vs. } 57 \% \text {, p }<0,05 \\
\text { 2. Lactancia materna exclusiva: } 20 \% \text { vs. } \\
30 \%, \mathrm{p}<0,05\end{array}$ & $\begin{array}{l}\text { Intervenciones } \\
\text { relativamente } \\
\text { baratas pueden } \\
\text { tener un impacto } \\
\text { significativo en el } \\
\text { inicio de la } \\
\text { lactancia materna, } \\
\text { incluso en una } \\
\text { población con alto } \\
\text { riesgo de no } \\
\text { amamantar. }\end{array}$ & $\begin{array}{l}\text { Educación de } \\
\text { las mujeres, } \\
\text { packs regalo, } \\
\text { etc. } \\
\text { Las figuras de } \\
\text { las tablas no } \\
\text { son las mismas } \\
\text { que las del } \\
\text { abstract. La } \\
\text { iniciación se } \\
\text { contempla al } \\
\text { alta. }\end{array}$ \\
\hline Kramer MS, 2001 & $\begin{array}{l}\text { Diseño: ECA tipo cluster } \\
\text { Objetivo: valorar los } \\
\text { efectos de la promoción de } \\
\text { la lactancia materna en su } \\
\text { duración y exclusividad y } \\
\text { sobre las infecciones } \\
\text { gastrointestinales y } \\
\text { respiratorias y el eeccema } \\
\text { atópico en los niños. }\end{array}$ & $\begin{array}{l}17046 \text { díadas madre- } \\
\text { hijo (niños sanos de } \\
\text { más de } 2,500 \mathrm{~kg} \text { y } \\
\text { madres sanas que } \\
\text { quieren dar el pecho } \\
\text { Seguimiento: } 16491 \\
\text { (96,7\%) a los } 12 \\
\text { meses. }\end{array}$ & $\begin{array}{l}\text { Aleatorización de los centros } \\
\text { Intervención: } n=16 \\
\text { Control: } n=15 \\
\text { La intervención se basa en los } \\
\text { estándares de la estrategia IHAN, y no } \\
\text { sólo se centra en el hospital, sino en la } \\
\text { atención posterior a la estancia } \\
\text { hospitalaria. }\end{array}$ & $\begin{array}{l}\text { Resultados: } \\
\text { Lactancia exclusiva a los } 3 \text { meses: } 43,3 \% \\
\text { vs } 6,4 \% \text { ( } p>0,001 \text { ) } \\
\text { Lactancia predominante a los } 3 \\
\text { meses: } 51,9 \% \text { vs. } 28,3 \% \text { ( } p>0,001) \\
\text { Lactancia exclusiva a los } 6 \text { meses: } 7,9 \% \\
\text { vs. } 0,6 \% \text { ( } p>0,001 \text { ) } \\
\text { Lactancia predominante a los } 6 \text { meses: } \\
\text { 10,6\% vs. } 1,6 \% \text { ( } p=0,003 \text { ). } \\
\text { Miden otros resultados: uno o más } \\
\text { episodios de infección gastrointestinal, } 2 \text { o } \\
\text { más episodios del tracto respiratorio y } \\
\text { eccema atópico, cada uno en los primeros } \\
12 \text { meses de vida. } \\
\text { Para lactancia materna, resultados } \\
\text { ajustados por el peso del niño al nacer, la } \\
\text { edad de la madre, historia previa de } \\
\text { lactancia materna durante } 3 \text { meses o más }\end{array}$ & $\begin{array}{l}\text { La intervención } \\
\text { aumenta la } \\
\text { duración y } \\
\text { exclusividad de la } \\
\text { lactancia y } \\
\text { disminuye el riesgo } \\
\text { de infecciones } \\
\text { gastrointestinales y } \\
\text { de eccema atópico } \\
\text { en el primer año } \\
\text { de vida. }\end{array}$ & \\
\hline Cattaneo A, 2001 & $\begin{array}{l}\text { Diseño: Ensayo clínico } \\
\text { controlado no aleatorizado }\end{array}$ & $\begin{array}{l}\text { Se divide la } \\
\text { intervención en dos } \\
\text { grupos de hospitales: }\end{array}$ & $\begin{array}{l}\text { La intervención educativa consiste en un } \\
\text { curso para la capacitación de } \\
\text { profesionales que de forma subsecuente }\end{array}$ & $\begin{array}{l}\text { Prácticas hospitalarias: aumenta el } \\
\text { cumplimiento con los diez pasos de la } \\
\text { estrategia IHAN. }\end{array}$ & $\begin{array}{l}\text { Un curso de } \\
\text { capacitación de al }\end{array}$ & $\begin{array}{l}\text { La intervención } \\
\text { solo es en el } \\
\text { hospital. Se }\end{array}$ \\
\hline
\end{tabular}




\begin{tabular}{|c|c|c|c|c|c|c|}
\hline $\begin{array}{l}\text { Referencia } \\
\text { (Cita Abreviada) }\end{array}$ & $\begin{array}{l}\text { Estudio (Diseño y } \\
\text { objetivo) }\end{array}$ & $\begin{array}{l}\text { Población } \\
\text { (no y características) }\end{array}$ & $\begin{array}{l}\text { Descripción de las intervenciones } \\
\text { comparaciones, exposiciones o } \\
\text { pruebas a estudio }\end{array}$ & $\begin{array}{l}\text { Resultados } \\
\text { (Estimadores de resultados-Magnitud del } \\
\text { efecto) }\end{array}$ & $\begin{array}{l}\text { Conclusiones } \\
\text { (conclusiones) }\end{array}$ & $\begin{array}{l}\text { Comentarios } \\
\text { Calidad de la } \\
\text { evidencia } \\
\text { Financiación } \\
\text { comentarios) }\end{array}$ \\
\hline & $\begin{array}{l}\text { Objetivo: valorar la } \\
\text { efectividad de entrenar al } \\
\text { staff en la mejora de las } \\
\text { tasas de lactancia materna }\end{array}$ & $\begin{array}{l}\text { grupo } 1 \text { que incluye } \\
\text { tres hospitales } \\
\text { generales y uno } \\
\text { universitario en el sur } \\
\text { de Italia, y el grupo } 2 \text {, } \\
\text { con tres hospitales } \\
\text { generales y uno } \\
\text { universitario del centro } \\
\text { y norte de Italia. Entre } \\
\text { los grupos de } \\
\text { hospitales, hay } \\
\text { diferencias en las } \\
\text { características de los } \\
\text { partos, } \mathrm{n}^{\circ} \text { de } \\
\text { nacimientos etc. } \\
571 \text { trabajadores } \\
\text { sanitarios } \\
2669 \text { diadas madre- } \\
\text { hijo }\end{array}$ & $\begin{array}{l}\text { darán el curso a los trabajadores en } \\
\text { salud, con una versión ligeramente } \\
\text { adaptada del curso de } 18 \text { horas de } \\
\text { Unicef sobre el manejo y Promoción de } \\
\text { la lactancia materna. }\end{array}$ & $\begin{array}{l}\text { Conocimiento de los trabajadores: } \\
\text { aumentan de } 0,41 \text { a } 0,72 \text { en grupo } 1 \text { y de } \\
0,53 \text { a } 0,75 \text { en el grupo } 2 \text {. } \\
\text { Tasas de lactancia materna exclusiva al } \\
\text { alta hospitalaria: de } 41 \text { a } 77 \% \text { y de } 23 \% \text { a } \\
73 \% \text {. } \\
\text { Tasa de lactancia exclusiva y } \\
\text { predominante a los } 3 \text { meses: de } 37 \% \text { a } \\
50 \% \\
\text { Tasa de cualquier lactancia materna a los } \\
6 \text { meses: } 43 \text { a } 63 \% \text { y de } 41 \% \text { a } 64 \% \text {. } \\
\text { Cuatro factores se asocian con lactancia } \\
\text { exclusiva al alta: primera toma en la } \\
\text { primera hora, rooming in, no uso de } \\
\text { chupete e instrucciones de cómo extraer } \\
\text { la leche materna. Agrupadas, se asocian } \\
\text { de forma signficativa con un OR de } 6,78 \\
\text { (5,65 a } 8,14 \text { ) con lactancia materna } \\
\text { exclusiva al alta. }\end{array}$ & $\begin{array}{l}\text { menos tres días } \\
\text { con psesiones } \\
\text { prácticas y } \\
\text { habilidades para } \\
\text { aconsejar es } \\
\text { efectivo en } \\
\text { cabmiar las } \\
\text { prácticas } \\
\text { hospitarlias, el } \\
\text { conocimento de } \\
\text { los trabajadores y } \\
\text { las tasas dee } \\
\text { lactancia materna. }\end{array}$ & $\begin{array}{l}\text { hacen dos } \\
\text { grupos, pero } \mathrm{n}\end{array}$ \\
\hline Labarere J, 2003 & $\begin{array}{l}\text { Diseño: estudio } \\
\text { retrospectivo con dos } \\
\text { muestras transversales. } \\
\text { Objetivo: estimar si un } \\
\text { programa de capacitación } \\
\text { de tres días para } \\
\text { profesionales sanitarios } \\
\text { puede cambiar las } \\
\text { prácticas en las } \\
\text { maternidades y en la tasa } \\
\text { de lactancia materna } \\
\text { exclusiva. }\end{array}$ & $\begin{array}{l}\text { Niños en el grupo pre- } \\
\text { intervención: } 323 \text {. } \\
\qquad \text { VS. } \\
\text { Niños en el grupo post- } \\
\text { intervención: } 324\end{array}$ & $\begin{array}{l}\text { Datos recogidos de historia. } \\
\text { Intervención: educación del personal } \\
\text { sanitario vs. no educación del personal } \\
\text { sanitario } \\
\text { La intervención educativa no es de la } \\
\text { iniciativa IHAN, y dura tres días. }\end{array}$ & $\begin{array}{l}\text { Aumento en \% de lactancia materna } \\
\text { exclusiva al alta hospitalaria: } \\
15,8 \% \text { (IC95\% 12,0-20,2) vs. } 35,2 \% \\
(\text { IC95\% 30,0-40,6) }(\mathrm{p}<0,01) \text {. } \\
\text { Este resultado persiste tras el análisis } \\
\text { multivariante (OR 2,74 }(1,72 ; 4,37) \text {. }\end{array}$ & $\begin{array}{l}\text { Un programa de } \\
\text { capacitación para } \\
\text { profesionales } \\
\text { sanitarios puede } \\
\text { ser efectivo en } \\
\text { mejorar las } \\
\text { prácticas en las } \\
\text { maternidades y } \\
\text { aumentar la tasa } \\
\text { de lactancia } \\
\text { materna exclusiva } \\
\text { al alta hospitalaria. }\end{array}$ & \\
\hline Braun MLG, 2003 & $\begin{array}{l}\text { Diseño: estudio } \\
\text { observacional prospectivo }\end{array}$ & $\begin{array}{l}\text { Cohorte pre-IHAN: } 187 \\
\text { vs. Cohorte post-IHAN: }\end{array}$ & $\begin{array}{l}\text { Estudio de tipo antes y después que } \\
\text { sigue de forma prospectiva dos }\end{array}$ & $\begin{array}{l}\text { Mayores tasas de lactancia materna. } \\
\text { Duración media de lactancia materna }\end{array}$ & $\begin{array}{l}\text { Aumento } \\
\text { significativo, sobre }\end{array}$ & $\begin{array}{l}\text { Estudio de } \\
\text { pequeño }\end{array}$ \\
\hline
\end{tabular}




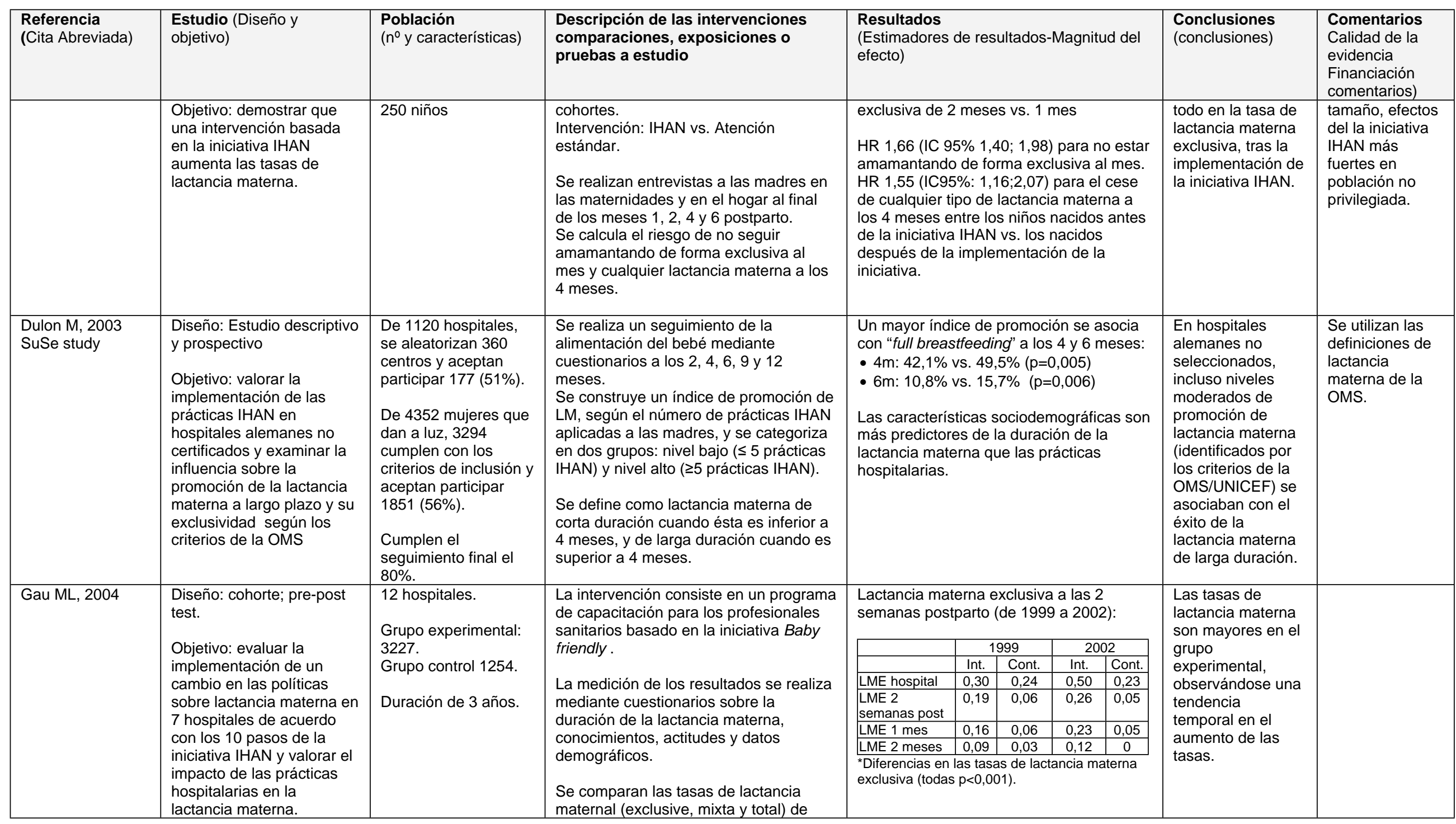




\begin{tabular}{|c|c|c|c|c|c|c|}
\hline $\begin{array}{l}\text { Referencia } \\
\text { (Cita Abreviada) }\end{array}$ & $\begin{array}{l}\text { Estudio (Diseño y } \\
\text { objetivo) }\end{array}$ & $\begin{array}{l}\text { Población } \\
\text { (nº y características) }\end{array}$ & $\begin{array}{l}\text { Descripción de las intervenciones } \\
\text { comparaciones, exposiciones o } \\
\text { pruebas a estudio }\end{array}$ & $\begin{array}{l}\text { Resultados } \\
\text { (Estimadores de resultados-Magnitud del } \\
\text { efecto) }\end{array}$ & $\begin{array}{l}\text { Conclusiones } \\
\text { (conclusiones) }\end{array}$ & $\begin{array}{l}\text { Comentarios } \\
\text { Calidad de la } \\
\text { evidencia } \\
\text { Financiación } \\
\text { comentarios) }\end{array}$ \\
\hline & & & $\begin{array}{l}\text { ambos grupos en cuatro tiempos } \\
\text { diferentes (durante la estancia en el } \\
\text { hospital, a las } 2 \text { semanas, a } 1 \text { y } 2 \text { meses } \\
\text { postparto). }\end{array}$ & & & \\
\hline Merten S, 2005 & $\begin{array}{l}\text { Diseño: transversal } \\
\text { retrospectivo } \\
\text { Objetivo: describir los } \\
\text { resultados de un estudio } \\
\text { nacional sobre la } \\
\text { prevalencia y duración de } \\
\text { la lactancia materna en } \\
2003 \text { en Suiza y analizar la } \\
\text { influencia del cumplimiento } \\
\text { con las recomendaciones } \\
\text { de UNICEF por parte del } \\
\text { hospital en el que tiene } \\
\text { lugar el nacimiento. }\end{array}$ & $\begin{array}{l}3032 \text { madres }(74 \% \text { de } \\
\text { las contactadas) } \\
\text { participan. } \\
\text { Válidos } 2861 \\
\text { cuestionarios de niños } \\
\text { nacidos en } 145 \\
\text { servicios diferentes. } \\
\text { Una parte es } \\
\text { retrospectiva y la otra } \\
\text { parte es transversal } \\
\text { (recuerdo de } 24 \text { horas). }\end{array}$ & $\begin{array}{l}\text { Se valora la asociación de las tasas de } \\
\text { lactancia materna con haber nacido o no } \\
\text { en un hospital acreditado IHAN. } \\
45 \text { hospitales ya acreditados y } 31 \text { en } \\
\text { proceso (de 145). } \\
\text { Se compara la duración de lactanca } \\
\text { materna exclusiva, full y cualquier tipo } \\
\text { de lactancia materna, según el tipo de } \\
\text { hospital en el que dio a luz la madre } \\
\text { (IHAN vs no IHAN). } \\
\text { Se hace análisis de regresión de cox. }\end{array}$ & $\begin{array}{l}\text { Diferencias en la duración de la lactancia } \\
\text { materna exclusiva, full breastfeeding y } \\
\text { cualquier tipo de lactancia materna según } \\
\text { se trate de un hospital IHAN o en proceso } \\
\text { de serlo vs. hospitales no IHAN. } \\
\text { La mediana para la duración era de: } \\
\text { Lactancia materna exclusiva: } 12 \text { semanas } \\
\text { vs. } 8 \text { semanas (IHAN vs. No IHAN) } \\
\text { Full breastfeeding: } 20 \text { semanas vs. } 17 \\
\text { semanas. } \\
\text { Teniendo en cuenta los tres tipos de } \\
\text { hospital (IHAN, en proceso IHAN, no } \\
\text { IHAN): } \\
\text { - \% lactancia materna exclusiva en } \\
\text { menores de } 4 \text { meses: } 60 \% \text { vs. } 51 \% \\
\text { vs, } 49 \%, \text { respectivamente. } \\
\text { - \% lactancia materna exclusiva menores } \\
\text { de } 6 \text { meses: } 42 \% \text { vs. } 36 \% \text { vs. } 34 \% \text {, } \\
\text { respectivamente. } \\
\text { - \% Fully breastfeed en menores de } 4 \\
\text { meses: } 72 \text { v. } 64 \text { vs } 60 ; \\
\text { - \% Fully breastfeed en menores de } 6 \\
\text { meses: } 51 \% \text { vs. } 46 \% \text { vs. } 42 \% \text {. }\end{array}$ & $\begin{array}{l}\text { Los resultados } \\
\text { apoyan la hipótesis } \\
\text { de que el aumento } \\
\text { en las tasas de } \\
\text { lactancia en Suiza } \\
\text { desde } 1994 \text { se } \\
\text { deben en parte al } \\
\text { aumento del } \\
\text { número de } \\
\text { servicios con la } \\
\text { certificación IHAN. }\end{array}$ & $\begin{array}{l}\text { Las definiciones } \\
\text { del tipo de } \\
\text { lactancia } \\
\text { materna se } \\
\text { basan en las } \\
\text { definiciones de } \\
\text { la OMS. } \\
\text { Para estimar la } \\
\text { extensión del } \\
\text { posible impacto } \\
\text { del sesgo de } \\
\text { recuerdo, se } \\
\text { validaron los } \\
\text { resultados del } \\
\text { análisis } \\
\text { retrospectivo } \\
\text { con los del } \\
\text { análisis de } 24 \\
\text { horas de } \\
\text { recuerdo. }\end{array}$ \\
\hline $\begin{array}{l}\text { Duyan Camurdan } \\
\text { A, } 2007\end{array}$ & $\begin{array}{l}\text { Diseño: Estudio antes y } \\
\text { después en el mismo } \\
\text { hospital (descriptivo } \\
\text { transversal) } \\
\text { Objetivo: evaluar los } \\
\text { efectos de la iniciativa } \\
\text { IHAN en la lactancia } \\
\text { materna. }\end{array}$ & $\begin{array}{l}\text { PrelHAN: } 258 \text { niños } \\
\text { nacidos entre } \\
\text { noviembre de } 2001 \text { y } \\
\text { febrero de } 2002 \\
\text { PostlHAN: } 297 \text { niños } \\
\text { nacidos entre } \\
\text { noviembre de } 2002 \text { y } \\
\text { febrero de } 2003\end{array}$ & $\begin{array}{l}\text { Se compara un grupo de niños nacidos } \\
\text { antes y después de la implantación de la } \\
\text { iniciativa IHAN, mediante las tasas de } \\
\text { lactancia materna exclusiva en los } \\
\text { primeros meses de vida y la lactancia } \\
\text { materna de larga duración. } \\
\text { Se hace una regresión de Cox. }\end{array}$ & $\begin{array}{l}\text { Lactancia materna exclusiva (pre vs. } \\
\text { post): } \\
15 \text { días: } 93,1 \% \text { vs. } 97,4 \% \\
2 \text { meses: } 62,2 \% \text { vs. } 76,1 \% \\
4 \text { meses: } 45,6 \% \text { vs. } 53,7 \% \\
6 \text { meses: } 9,8 \% \text { vs. } 9,3 \% \\
\\
\text { Duración de la lactancia materna: } \\
\text { Mediana de duración en meses Pre vs. } \\
\text { Post: } 17,83 \pm 0,6 \text { vs. } 21,17 \pm 0,42 \\
\text { Tras ajustar: la estrategia IHAN aumenta }\end{array}$ & $\begin{array}{l}\text { La tasa de } \\
\text { lactancia materna } \\
\text { aumenta tras la } \\
\text { implementación de } \\
\text { la iniciativa IHAN. }\end{array}$ & $\begin{array}{l}\text { Los datos se } \\
\text { obtienen de las } \\
\text { historias, no se } \\
\text { hacen } \\
\text { cuestionarios } \\
\text { específicos para } \\
\text { recogerlos. }\end{array}$ \\
\hline
\end{tabular}




\begin{tabular}{|c|c|c|c|c|c|c|}
\hline $\begin{array}{l}\text { Referencia } \\
\text { (Cita Abreviada) }\end{array}$ & $\begin{array}{l}\text { Estudio (Diseño y } \\
\text { objetivo) }\end{array}$ & $\begin{array}{l}\text { Población } \\
\text { (nº y características) }\end{array}$ & $\begin{array}{l}\text { Descripción de las intervenciones } \\
\text { comparaciones, exposiciones o } \\
\text { pruebas a estudio }\end{array}$ & $\begin{array}{l}\text { Resultados } \\
\text { (Estimadores de resultados-Magnitud del } \\
\text { efecto) }\end{array}$ & $\begin{array}{l}\text { Conclusiones } \\
\text { (conclusiones) }\end{array}$ & $\begin{array}{l}\text { Comentarios } \\
\text { Calidad de la } \\
\text { evidencia } \\
\text { Financiación } \\
\text { comentarios) }\end{array}$ \\
\hline & & & & $\begin{array}{l}1,5 \text { veces (IC95\% 1,16; } 2,03) \text { la duración } \\
\text { de la lactancia materna. El parto vaginal } \\
\text { también se asocia con una mayor } \\
\text { duración (OR 1,6 (IC95\%:1,22; 2,18)). }\end{array}$ & & \\
\hline Chien LY, 2007 & $\begin{array}{l}\text { Diseño: estudio } \\
\text { observacional longitudinal } \\
\text { Objetivo: examinar la } \\
\text { asociación entre el número } \\
\text { de prácticas de IHAN que } \\
\text { las madres han } \\
\text { experienciado y el inicio de } \\
\text { lactancia durante la } \\
\text { estancia en el hospital, al } \\
\text { mes y a los } 3 \text { meses tras } \\
\text { parto. }\end{array}$ & $\begin{array}{l}3670 \text { cuestionarios que } \\
\text { son enviados. Se } \\
\text { recogen } 2079 \text { (56,6\%). } \\
\text { Madres que dieron a } \\
\text { luz a niños sin } \\
\text { anomalías congénitas } \\
\text { en hospitales de } \\
\text { Taiwan desde junio a } \\
\text { octubre de } 2003 \text {, } \\
\text { inclusive. } \\
2079 \text { madres participan } \\
\text { en el cuestionario } \\
\text { postal. }\end{array}$ & $\begin{array}{l}\text { Cuestionarios (al mes y a los tres meses } \\
\text { tras el parto) que recogen los } 10 \text { pasos } \\
\text { IHAN, en lenguaje adaptado para las } \\
\text { madres. } \\
\text { Miden la lactancia exclusiva y la parcial. } \\
\text { La variable dependiente es ordinal, y de } \\
\text { tres niveles: lactancia materna } \\
\text { exclusiva, lactancia materna parcial y } \\
\text { sin lactancia. }\end{array}$ & $\begin{array}{l}\text { Encuentra una relación dosis repuesta } \\
\text { entre el número de los } 10 \text { pasos IHAN y la } \\
\text { lactancia durante la estancia en el } \\
\text { hospital, al mes y a los } 3 \text { meses de vida. } \\
\text { Por cada paso adicional de la iniciativa } \\
\text { IHAN que se cumple, el OR para lactancia } \\
\text { al mes es de } 1,22(1,17-1,20) \text { y a los tres } \\
\text { meses es de } 1,19(1,15-1,29) \text {. }\end{array}$ & $\begin{array}{l}\text { Existe una relación } \\
\text { dosis respuesta } \\
\text { entre el número de } \\
\text { las } 10 \text { prácticas } \\
\text { experimentadas y } \\
\text { la lactancia } \\
\text { materna. Sin } \\
\text { embargo, muy } \\
\text { pocas mujeres en } \\
\text { Taiwan } \\
\text { experimentaron los } \\
10 \text { pasos. Se } \\
\text { necesita prestar } \\
\text { más atención para } \\
\text { implementar los } 10 \\
\text { pasos. }\end{array}$ & $\begin{array}{l}\text { Se les pregunta } \\
\text { el hospital en el } \\
\text { que dan a luz a } \\
\text { las madres. } \\
\text { Se encuentra } \\
\text { una relación } \\
\text { dosis respuesta } \\
\text { entre el número } \\
\text { de los pasos } \\
\text { experimentados } \\
\text { por la madre y la } \\
\text { lactancia } \\
\text { materna. }\end{array}$ \\
\hline Tarrant M, 2011 & $\begin{array}{l}\text { Diseño: Estudio } \\
\text { prospectivo } \\
\text { Objetivo: Examinar el } \\
\text { impacto de las prácticas } \\
\text { hospitalarias de la } \\
\text { iniciativa IHAN sobre la } \\
\text { duración de la lactancia } \\
\text { materna. }\end{array}$ & $\begin{array}{l}1242 \text { diadas madre- } \\
\text { hijo. } \\
\text { Seguimiento de } 12 \\
\text { meses. }\end{array}$ & $\begin{array}{l}\text { Se incluyen } 6 \text { variables predictoras (6 } \\
\text { prácticas IHAN). } \\
\text { El punto de corte de } 8 \text { semanas se } \\
\text { escoge por ser la mediana del grupo (el } \\
\text { número de semanas con CUALQUIER } \\
\text { tipo de lactancia materna). }\end{array}$ & $\begin{array}{l}\text { Lactancia materna de } 8 \text { semanas de } \\
\text { duración o más: } 46,6 \% \\
\text { Sólo al } 4,8 \% \text { de las mujeres } \\
\text { experimentaron los } 6 \text { pasos IHAN. } \\
\text { Tras ajustar el análisis por las } 6 \text { prácticas } \\
\text { y otras variables confusoras, la lactancia } \\
\text { materna exclusiva en el hospital protege } \\
\text { frente al cese de la lactancia a las } 8 \\
\text { semanas (OR } 0,61 ; \text { IC95\%: } 0,42 ; 0,88) \\
\text { Mujeres que experimentan las } 6 \text { prácticas } \\
\text { hospitalarias vs. las que experimentan } 1 \text { o } \\
\text { menos: OR } 3,13(1,41 ; 6,95)\end{array}$ & $\begin{array}{l}\text { La mayor } \\
\text { exposición a las } \\
\text { prácticas IHAN } \\
\text { aumenta la tasa de } \\
\text { LM. Se requiere } \\
\text { apoyo institucional } \\
\text { y administrativo } \\
\text { para asegurar que } \\
\text { todas las mujeres } \\
\text { reciben el apoyo } \\
\text { deacuerdo con las } \\
\text { recomendaciones } \\
\text { de la OMS. }\end{array}$ & $\begin{array}{l}\text { En Japón, los } \\
\text { permisos de } \\
\text { maternidad son } \\
\text { de } 8 \text { semanas. }\end{array}$ \\
\hline $\begin{array}{l}\text { García De León- } \\
\text { González R, } 2011\end{array}$ & $\begin{array}{l}\text { Diseño: estudio } \\
\text { prospectivo }\end{array}$ & $\begin{array}{l}\text { Muestra aleatoria de } \\
1273 \text { niños seguidos } \\
\text { en centros primeros }\end{array}$ & $\begin{array}{l}\text { Intervención para mejorar la } \\
\text { implementación de la iniciativa IHAN } \\
\text { entre los años } 1997 \text { y } 2005 .\end{array}$ & $\begin{array}{l}\text { Tasas de lactancia materna antes y } \\
\text { después (desde } 1997 \text { hasta 2005). }\end{array}$ & $\begin{array}{l}\text { Esta intervención } \\
\text { basada en la } \\
\text { participación, }\end{array}$ & $\begin{array}{l}\text { Los datos de } \\
\text { lactancia } \\
\text { materna se }\end{array}$ \\
\hline
\end{tabular}




\begin{tabular}{|c|c|c|c|c|c|c|c|c|c|}
\hline \multirow[t]{2}{*}{$\begin{array}{l}\text { Referencia } \\
\text { (Cita Abreviada) }\end{array}$} & $\begin{array}{l}\text { Estudio (Diseño y } \\
\text { objetivo) }\end{array}$ & $\begin{array}{l}\text { Población } \\
\text { (nº y características) }\end{array}$ & $\begin{array}{l}\text { Descripción de las intervenciones } \\
\text { comparaciones, exposiciones o } \\
\text { pruebas a estudio }\end{array}$ & \multicolumn{4}{|c|}{$\begin{array}{l}\text { Resultados } \\
\text { (Estimadores de resultados-Magnitud del } \\
\text { efecto) }\end{array}$} & $\begin{array}{l}\text { Conclusiones } \\
\text { (conclusiones) }\end{array}$ & $\begin{array}{l}\text { Comentarios } \\
\text { Calidad de la } \\
\text { evidencia } \\
\text { Financiación } \\
\text { comentarios) }\end{array}$ \\
\hline & $\begin{array}{l}\text { Objetivo: describir el } \\
\text { proceso de } \\
\text { implementación y el efecto } \\
\text { de una intervención de } \\
\text { mejora de la calidad para } \\
\text { alcanzar el cumplimiento } \\
\text { de la iniciativa IHAN. }\end{array}$ & $\begin{array}{l}\text { entre } 1997 \text { y } 2005 \text { del } \\
\text { hospital de Yecla. }\end{array}$ & $\begin{array}{l}\text { La intervención consistió en: } \\
\text { Capacitación orientada en el proceso, } \\
\text { audit y feedback, ciclos de mejora de la } \\
\text { calidad, inversión de recursos para el } \\
\text { apoyo de la lactancia materna. } \\
\text { La variable resultado es cualquier tipo } \\
\text { de lactancia materna. }\end{array}$ & \multicolumn{4}{|c|}{$\begin{array}{l}\text { La probabilidad de ser amamantado en el } \\
\text { primer mes (lactancia materna de } \\
\text { cualquier tipo) era } 45 \% \text { mayor para los } \\
\text { niños nacidos en } 2005 \text { que en } 1997 \text { (OR } \\
0,55 ; \text { IC } 95 \% 0,38 ; 0,79) \text { y } 86 \% \text { mayor para } \\
\text { ser amamantados a los } 7 \text { meses. } \\
\text { A los } 3 \text { meses: OR } 0,29(0,21 ; 0,40) \text { y a } \\
\text { los } 5 \text { meses OR } 0,22(\text { IC95\% } 0,16 ; 0,3) \text {. }\end{array}$} & $\begin{array}{l}\text { capacitación, audit } \\
\text { y feedback son } \\
\text { útiles para } \\
\text { implementar la } \\
\text { iniciativa IHAN que } \\
\text { se asocia con } \\
\text { aumentos en la } \\
\text { tasa de lactancia } \\
\text { materna. }\end{array}$ & $\begin{array}{l}\text { obtienen en su } \\
\text { mayoría de las } \\
\text { historias } \\
\text { clínicas. }\end{array}$ \\
\hline Venancio SI, 2012 & $\begin{array}{l}\text { Diseño: estudio } \\
\text { retrospectivo. } \\
\\
\text { Objetivo: Valorar la } \\
\text { influencia del IHAN en los } \\
\text { indicadores de lactancia } \\
\text { materna en Brasil, } \\
\text { utilizando los datos de la } \\
\text { segunda encuesta sobre la } \\
\text { prevalencia de lactancia } \\
\text { materna realizada en } \\
2008 .\end{array}$ & $\begin{array}{l}\text { Datos de } 64 \\
\text { barrios/distritos. } \\
65936 \text { niños menores } \\
\text { de } 1 \text { año cubiertos por } \\
\text { la campaña de } \\
\text { vacunación en } 2008 .\end{array}$ & $\begin{array}{l}\text { Se les pregunta a las madres el nombre } \\
\text { del servicio en el que el niño nació. } \\
\text { Se separa a las madres en dos grupos } \\
\text { de comparación según si habían dado a } \\
\text { luz en un centro certificado IHAN o no. }\end{array}$ & \multicolumn{4}{|c|}{$\begin{array}{l}\text { Lactancia materna exclusiva } 1 \text { día tras alta } \\
\text { hospitalaria (preguntado cuando el niño } \\
\text { tiene } 4 \text { meses): } 13,8 \% \text { vs. } 6,6 \% \\
\text { Lactancia materna exclusiva hasta los } 2,3 \\
\text { y } 6 \text { meses: } 13 \% \text { más, } 8 \% \text { más y } 6 \% \text { más } \\
\text { respectivamente, en el grupo de madres } \\
\text { atendidas en un centro IHAN. }\end{array}$} & $\begin{array}{l}\text { La iniciativa IHAN } \\
\text { ha tenido un } \\
\text { impacto en varios } \\
\text { de los indicadores } \\
\text { de lactancia } \\
\text { materna. Los } \\
\text { autores esperan } \\
\text { que los resultados } \\
\text { de este estudio } \\
\text { sirvan para que los } \\
\text { políticos y } \\
\text { profesionales } \\
\text { sanitarios sean } \\
\text { conscientes de la } \\
\text { importancia y } \\
\text { potencial de esta } \\
\text { estrategia. }\end{array}$ & \\
\hline \multirow[t]{9}{*}{$\begin{array}{l}\text { Zakarija Gkovic } \\
2012\end{array}$} & \multirow{9}{*}{$\begin{array}{l}\text { Diseño: estudio de } \\
\text { cohortes prospectivo } \\
\text { Objetivo: evaluar el } \\
\text { impacto del curso de } \\
\text { capacitación de la iniciativa } \\
\text { IHAN en las prácticas } \\
\text { hospitalarioas y las tasa de } \\
\text { lactancia materna en los } \\
\text { primeros } 12 \text { meses de } \\
\text { vida. }\end{array}$} & \multirow{9}{*}{$\begin{array}{l}\text { Muestra consecutiva } \\
\text { de mujeres en las } \\
\text { maternidades. } \\
773 \text { madres ( } 338 \text { pre } \\
\text { y } 385 \text { post) } \\
\text { Se excluyen las } \\
\text { madres que han dado } \\
\text { a luz al menos } 24 \\
\text { horas antes. } \\
\text { Contacto telefónico } \\
\text { tras el alta a los } 3,6 \text { y }\end{array}$} & \multirow{9}{*}{$\begin{array}{l}\text { Mediciones al alta hospitalaria, a los } 3,6 \\
\text { y } 12 \text { meses de vida. } \\
\text { Se miden las prácticas hospitalarias ( } 6 \\
\text { de los } 10 \text { pasos IHAN) y la alimentación } \\
\text { infantil. } \\
80 \% \text { de los profesionales sanitarios del } \\
\text { hospital universitario de Spliz (Croacia) } \\
\text { completan el curso de } 20 \text { horas de la } \\
\text { iniciativa. }\end{array}$} & \multicolumn{4}{|c|}{$\begin{array}{l}\text { Lactancia materna exclusiva durante las } \\
\text { primeras } 48 \mathrm{~h}: 6 \% \text { vs. } 11.7 \%(p<0,005) \text {. } \\
\text { No hay diferencias al alta hospitalaria, a } \\
\text { los } 3,6 \text { y } 12 \text { meses de vida. }\end{array}$} & \multirow{9}{*}{$\begin{array}{l}\text { La capaictación de } \\
\text { los profesionales } \\
\text { sanitairos, en base } \\
\text { a la iniciativa } \\
\text { IHAN, se asocia } \\
\text { con mejora } \\
\text { significativa en la } \\
\text { implementación de } \\
\text { prácticas y de } \\
\text { tasas de inicio de } \\
\text { lactancia materna } \\
\text { exclusiva. La alta } \\
\text { tasa de } \\
\text { suplementación en }\end{array}$} & \multirow[t]{9}{*}{$\begin{array}{l}\text { Definición de la } \\
\text { OMS para la } \\
\text { lactancia } \\
\text { materna. }\end{array}$} \\
\hline & & & & & Tipo lact & \% pre & \% post & & \\
\hline & & & & \multirow{3}{*}{$\mathrm{p}=0,13$} & Exclusiva & & & & \\
\hline & & & & & Complemt & $\frac{10,5}{14,0}$ & 4,7 & & \\
\hline & & & & & Ninguna & 35,5 & 31,3 & & \\
\hline & & & & \multirow{4}{*}{$\begin{array}{l}6 \text { meses } \\
p=0,08\end{array}$} & Exclusiva & 9,3 & 14,2 & & \\
\hline & & & & & Predomın & $\frac{4,9}{569}$ & & & \\
\hline & & & & & \begin{tabular}{|l} 
Complemt \\
Ninguna
\end{tabular} & $\begin{array}{l}56,9 \\
28,9\end{array}$ & $\begin{array}{l}59,2 \\
24,9\end{array}$ & & \\
\hline & & & & & & & & & \\
\hline
\end{tabular}




\begin{tabular}{|c|c|c|c|c|c|c|}
\hline $\begin{array}{l}\text { Referencia } \\
\text { (Cita Abreviada) }\end{array}$ & $\begin{array}{l}\text { Estudio (Diseño y } \\
\text { objetivo) }\end{array}$ & $\begin{array}{l}\text { Población } \\
\text { (nº y características) }\end{array}$ & $\begin{array}{l}\text { Descripción de las intervenciones } \\
\text { comparaciones, exposiciones o } \\
\text { pruebas a estudio }\end{array}$ & $\begin{array}{l}\text { Resultados } \\
\text { (Estimadores de resultados-Magnitud del } \\
\text { efecto) }\end{array}$ & $\begin{array}{l}\text { Conclusiones } \\
\text { (conclusiones) }\end{array}$ & $\begin{array}{l}\text { Comentarios } \\
\text { Calidad de la } \\
\text { evidencia } \\
\text { Financiación } \\
\text { comentarios) }\end{array}$ \\
\hline & & 12 meses. & & & $\begin{array}{l}\text { el hospital puede } \\
\text { explicar en parta la } \\
\text { falta de mejora en } \\
\text { las tasas de } \\
\text { lactancia exclusiva } \\
\text { y duración tras el } \\
\text { alta. }\end{array}$ & \\
\hline Hawkins SS, 2014 & $\begin{array}{l}\text { Diseño: estudio cuasi } \\
\text { experimental, } \\
\text { Objetivo: examinar el } \\
\text { cumplimiento con los } \\
\text { pasos de la iniciativa IHAN } \\
\text { así como evaluar el IHAN y } \\
\text { sus componentes sobre el } \\
\text { inicio y duración de la } \\
\text { lactancia materna en } \\
\text { general y de acuerdo con } \\
\text { el nivel educativo de las } \\
\text { madres. }\end{array}$ & $\begin{array}{l}915 \text { madres que } \\
\text { dieron a luz en } 4 \\
\text { hospitales } \\
\text { acreditados o que } \\
\text { fueron acreditados y } \\
1099 \text { madres de } 6 \\
\text { servicios no } \\
\text { acreditados. }\end{array}$ & $\begin{array}{l}\text { Se calcula un Score de prácticas de } \\
\text { lactancia materna con los } 7 \text { pasos IHAN } \\
\text { que responden las madres, y cuya } \\
\text { puntuación va del } 0 \text { al } 7 \text {. } \\
\text { Se pregunta si recibieron un pack de } \\
\text { regalo con fórmula. }\end{array}$ & $\begin{array}{l}34,6 \% \text { de las madres de los centros IHAN } \\
\text { dijeron haber experimentado los } 7 \text { pasos, } \\
\text { y } 28,4 \% \text { recibieron un pack de regalo con } \\
\text { fórmula. } \\
\text { Entre las madres con bajo nivel educativo, } \\
\text { la iniciativa IHAN aumenta el inicio de la } \\
\text { lactancia por } 8,6 \% \text { (cada paso se asocia } \\
\text { con un aumento medio en el inicio de } \\
16,2 \% \text { ). En las madres con alto nivel } \\
\text { educativo, no había efecto. } \\
\text { Regresión logística para lactancia materna } \\
\text { exclusiva } \geq 4 \text { semanas: la iniciativa IHAN } \\
\text { no se asocia de forma significativa, ni para } \\
\text { todas las madres ni para el subgrupo de } \\
\text { madres con } 12 \text { años o menos de estudios. } \\
\text { Sin embargo, sí se asocia con la } \\
\text { puntuación que da la madre sobre las } \\
\text { prácticas experimentadas y con que se le } \\
\text { hubiera regalado un pack con fórmula en } \\
\text { el hospital. } \\
\text { Para cualquier tipo de lactancia } \geq \text { que } 4 \\
\text { semanas ocurre igual. }\end{array}$ & $\begin{array}{l}\text { El cumplimiento de } \\
\text { las prácticas IHAN } \\
\text { debe ser } \\
\text { monitorizado, } \\
\text { puesto que un } \\
\text { mayor nivel de } \\
\text { cumplimiento con } \\
\text { las prácticas de la } \\
\text { iniciativa puede } \\
\text { tener un impacto } \\
\text { mayor en las tasas } \\
\text { de lactancia y } \\
\text { reducir } \\
\text { potencialmente las } \\
\text { diferencias } \\
\text { socioeconómicas } \\
\text { en la lactancia } \\
\text { materna. }\end{array}$ & $\begin{array}{l}\text { Lactancia } \\
\text { materna } \\
\text { exclusiva } \\
\text { definida por que } \\
\text { el niño tome sólo } \\
\text { leche materna } \\
\text { por } 4 \text { semanas o } \\
\text { más. } \\
\text { Sí hay } \\
\text { asociación entre } \\
\text { el número de } \\
\text { prácticas } \\
\text { hospitalarias } \\
\text { experimentadas } \\
\text { por las madres } \\
\text { con la tasa de } \\
\text { lactancia } \\
\text { materna a las } \\
\text { cuatro semanas. }\end{array}$ \\
\hline
\end{tabular}




\section{1- BIBLIOGRAFÍA}

(1) Beake S, Pellowe C, Dykes F, Schmied V, Bick D. A systematic review of structured compared with non-structured breastfeeding programmes to support the initiation and duration of exclusive and any breastfeeding in acute and primary health care settings. Maternal and Child Nutrition 2012 Apr;8(2):141-61.

(2) Atchan M, Davis D, Foureur M. The impact of the Baby Friendly health Initiative in the Australian health care system: A critical narrative review of the evidence. BREASTFEED REV 2013 Jul;21(2):15-22.

(3) NICE. Postnatal care up to 8 weeks after birth. Julio 2006 (actualizado en Febrero de 2015). Disponible en: http://guidance.nice.org.uk/CG37.

(4) Perinatal Services BC. Health Promotion Guideline. Breastfeeding Healthy Term Infants. 2013 Feb.

(5) Fairbank L., O'Meara S., Renfrew M.J.,Woolridge M.,Sowden A.J. \& ListerSharp D. A systematic review to evaluate the effectiveness of interventions to promote the initiation of breastfeeding. Health Technology Assessment 2000;4:1-171.

(6) Britton C, McCormick FM, Renfrew MJ, Wade A, King SE. Support for breastfeeding mothers. Cochrane Database Syst Rev 2007;(1):CD001141.

(7) Spiby H, McCormick F, Wallace L, Renfrew MJ, D'Souza L, Dyson L. A systematic review of education and evidence-based practice interventions with health professionals and breast feeding counsellors on duration of breast feeding. Midwifery 2009 Feb;25(1):50-61.

(8) Hannula L, Kaunonen M, Tarkka MT. A systematic review of professional support interventions for breastfeeding. J Clin Nurs 2008 May;17(9):1132-43.

(9) DeMott K., Bick D., Norman R., Ritchie G., Turnbull N., Adams C. et al. (2006) Clinical Guidelines and Evidence Review for Postnatal Care: Routine postnatal care of recently delivered women and their babies. National Collaborating Centre for Primary Care (NICE Postnatal Care Guideline).

(10) Kramer MS, Chalmers B, Hodnett ED, Sevkovskaya Z, Dzikovich I, Shapiro S, et al. Promotion of Breastfeeding Intervention Trial (PROBIT): a randomized trial in the Republic of Belarus. JAMA 2001 Jan 24;285(4):413-20.

(11) García-De-León-González R, Oliver-Roig A, Hernández-Martinez M, MercaderRodriguez B, Muñoz-Soler V, Maestre-Martínez MI, et al. Becoming babyfriendly in Spain: A quality-improvement process. Acta Paediatrica, International Journal of Paediatrics 2011 Mar;100(3):445-50.

(12) Tarrant M, Wu KM, Fong DY, Lee IL, Wong EM, Sham A, et al. Impact of babyfriendly hospital practices on breastfeeding in Hong Kong. Birth (Berkeley, Calif 2011 Sep;38(3):238-45.

(13) Zakarija-Grkovic I, Segvic O, Bozinovic T, Cuze A, Lozancic T, Vuckovic A, et al. Hospital practices and breastfeeding rates before and after the UNICEF/WHO 20-hour course for maternity staff. Journal of human lactation : official journal of International Lactation Consultant Association 2012 Aug;28(3):389-99.

(14) Venancio SI, Saldiva SRDM, Escuder MML, Giugliani ERJ. The Baby-Friendly Hospital Initiative shows positive effects on breastfeeding indicators in Brazil. Journal of Epidemiology and Community Health 2012 Oct;66(10):914-8.

(15) Hawkins SS, Stern AD, Baum CF, Gillman MW. Compliance with the BabyFriendly Hospital Initiative and impact on breastfeeding rates. Archives of Disease in Childhood: Fetal and Neonatal Edition 2014 Mar;99(2):F138-F143. 
(16) Cattaneo A, Buzzetti R. Effect on rates of breast feeding of training for the baby friendly hospital initiative. BMJ 2001 Dec 8;323(7325):1358-62.

(17) Zimmerman DR. You can make a difference: increasing breastfeeding rates in an inner-city clinic. J Hum Lact 1999 Sep;15(3):217-20.

(18) Labarere J, Castell M, Fourny M, Durand M, Pons JC. A training program on exclusive breastfeeding in maternity wards. Int J Gynaecol Obstet 2003 Oct;83(1):77-84.

(19) Gau ML. Evaluation of a lactation intervention program to encourage breastfeeding: a longitudinal study. Int J Nurs Stud 2004 May;41(4):425-35.

(20) Braun ML, Giugliani ER, Soares ME, Giugliani C, de Oliveira AP, Danelon CM. Evaluation of the impact of the baby-friendly hospital initiative on rates of breastfeeding. Am J Public Health 2003 Aug;93(8):1277-9.

(21) Chien LY, Tai CJ, Chu KH, Ko YL, Chiu YC. The number of Baby Friendly hospital practices experienced by mothers is positively associated with breastfeeding: a questionnaire survey. Int J Nurs Stud 2007 Sep;44(7):1138-46.

(22) Merten S, Dratva J, Ackermann-Liebrich U. Do baby-friendly hospitals influence breastfeeding duration on a national level? Pediatrics 2005 Nov;116(5):e702e708.

(23) Dulon $M$, Kersting $M$, Bender R. Breastfeeding promotion in non-UNICEFcertified hospitals and long-term breastfeeding success in Germany. Acta Paediatr 2003 Jun;92(6):653-8.

(24) Duyan CA, Ozkan S, Yuksel D, Pasli F, Sahin F, Beyazova U. The effect of the baby-friendly hospital initiative on long-term breast feeding. Int $\mathrm{J}$ Clin Pract 2007 Aug;61(8):1251-5.

(25) Grossman X, Chaudhuri JH, Feldman-Winter L, Merewood A. Neonatal weight loss at a US Baby-Friendly Hospital. J Acad Nutr Diet 2012 Mar;112(3):410-3.

(26) Lagan BM, Symon A, Dalzell J, Whitford H. 'The midwives aren't allowed to tell you': perceived infant feeding policy restrictions in a formula feeding culture the Feeding Your Baby Study. Midwifery 2014 Mar;30(3):e49-e55.

(27) Schmied V, Thomson G, Byrom A, Burns E, Sheehan A, Dykes F. A metaethnographic study of health care staff perceptions of the WHO/UNICEF Baby Friendly Health Initiative. Women Birth 2014 Dec;27(4):242-9.

(28) Semenic S, Childerhose JE, Lauziere J, Groleau D. Barriers, facilitators, and recommendations related to implementing the Baby-Friendly Initiative (BFI): an integrative review. J Hum Lact 2012 Aug;28(3):317-34.

(29) Perrine CG, Scanlon KS, Li R, Odom E, Grummer-Strawn LM. Baby-Friendly hospital practices and meeting exclusive breastfeeding intention. Pediatrics 2012 Jul;130(1):54-60.

(30) Flores B, Temboury MC, Muñoz MC, Román E. Dificultades frecuentes para la acreditación como Hospital Amigo de los Niños: nuestro abordaje. Rev Calidad Asistencial 2008;23(6):264-70. 
PREGUNTA CLÍNICA № 18

¿Cuáles son las mejores estrategias estructuradas para el apoyo y protección de la lactancia materna en los centros de salud?

\section{1- Pregunta clínica en formato PICO}

Tabla 1- Componentes de la pregunta clínica en formato PICO

\begin{tabular}{|l|l|}
\hline Pacientes & $\begin{array}{l}\text { Madres de bebés sanos nacidos a término que amamantan } \\
\text { y sus bebés }\end{array}$ \\
\hline Intervención & $\begin{array}{l}\text { Medidas de apoyo y protección a la lactancia materna en la } \\
\text { atención primaria }\end{array}$ \\
\hline Comparación & Atención habitual \\
\hline Resultados & $\begin{array}{l}\text { Tasa de lactancia materna exclusiva al mes } \\
\text { Tasa de lactancia materna exclusiva a los 4 meses } \\
\text { Tasa de lactancia materna exclusiva a los } 6 \text { meses } \\
\text { Tasa de cualquier lactancia materna a los 4 meses } \\
\text { Tasa de cualquier lactancia materna a los 6 meses } \\
\text { Satisfacción materna } \\
\text { Complicaciones de las mamas (grietas, ingurgitaciones) }\end{array}$ \\
\hline Tipo de estudio & $\begin{array}{l}\text { RS de ECA, ECA, RS de estudios observacionales o } \\
\text { estudios observacionales }\end{array}$ \\
\hline
\end{tabular}

\section{2- Introducción}

Durante los últimos años se han desarrollado en España los siete pasos de la estrategia IHAN para los Centros de Salud. Teniendo en cuenta que la gran mayoría de los problemas de lactancia se manifiestan tras el alta hospitalaria y que son una causa frecuente de destete precoz, interesa conocer si implantar un programa estructurado para la promoción, protección y apoyo a la lactancia en Atención Primaria podría mejorar las tasas de lactancia materna. 


\section{ESTRATEGIA DE ELABORACION DE LA PREGUNTA}

\subsection{GPC Base}

Tabla 2- Resumen de GPC Base

\begin{tabular}{|c|c|c|c|c|}
\hline $\begin{array}{c}\text { Guía } \\
\text { (Enfoque) }\end{array}$ & $\begin{array}{l}\text { Resumen sobre la evidencia } \\
\text { (Calidad de la evidencia) }\end{array}$ & $\begin{array}{l}\text { Recomendaciones } \\
\text { (Grado) }\end{array}$ & $\begin{array}{l}\text { Referencias bibliográficas } \\
\text { (Tipo de publicación) }\end{array}$ & Comentarios \\
\hline $\begin{array}{l}\text { NICE_2006 } \\
\text { (Actualiz. } \\
\text { 2011) }\end{array}$ & $\begin{array}{l}\text { Además de lo que se dice de la aplicación de la iniciativa en } \\
\text { los hospitales, en la actualización de la guía se identifica } \\
\text { una revisión sistemática de } 2008 \text { sobre la efectividad de las } \\
\text { intervenciones en atención primaria para promocionar la } \\
\text { lactancia materna. En esta revisión los autores concluyen } \\
\text { que las intervenciones sobre la lactancia son más efectivas } \\
\text { que la atención habitual en aumentar las tasas de lactancia } \\
\text { materna a corto y largo plazo, y que la combinación de } \\
\text { intervenciones pre y postnatales y la inclusión de apoyo no } \\
\text { profesional en una intervención multifactorial puede ser } \\
\text { beneficiosa. }\end{array}$ & $\begin{array}{l}\text { El apoyo a la lactancia materna debería estar } \\
\text { disponible independientemente del lugar en el que } \\
\text { se localicen los cuidados (A). } \\
\text { Todos los proveedores de salud (hospitalaria y } \\
\text { primaria) deberían tener una política escrita sobre } \\
\text { lactancia materna que debe ser comunicada a los } \\
\text { trabajadores y a los padres. Cada proveedor } \\
\text { debería identificar un profesional sanitario líder } \\
\text { responsable de implementar esta política [D } \\
\text { (GPP)]. } \\
\text { Todos los proveedores de salud de las } \\
\text { maternidades (tanto si trabajan en el hospital o en } \\
\text { atención primaria), deberían implementar un } \\
\text { programa estructurado externamente evaluado } \\
\text { que promueva la lactancia materna, utilizando la } \\
\text { iniciativa IHAN (www.babyfriendly.org.uk) como } \\
\text { mínimo estándar [A]. } \\
\text { Los profesionales sanitarios deberían tener tiempo } \\
\text { suficiente, como prioridad, para apoyar a las } \\
\text { mujeres y los niños durante el inicio y la } \\
\text { continuación de la lactancia materna [D(GPP)] }\end{array}$ & & $\begin{array}{l}\text { Comentan que se deben } \\
\text { hacer estudios de coste } \\
\text { efectividad de la } \\
\text { estrategia IHAN en } \\
\text { comparación con otro } \\
\text { programa, o frente al } \\
\text { estándar de tratamiento. } \\
\text { Entre los resultados se } \\
\text { deberían incluir las tasas } \\
\text { de inicio y duración de } \\
\text { lactancia materna } \\
\text { exclusiva, y se debería } \\
\text { intentar construir también } \\
\text { medidas de resultados } \\
\text { económicos de salud } \\
\text { como los QALY. }\end{array}$ \\
\hline $\begin{array}{l}\text { Perinatal } \\
\text { Services BC } \\
2011\end{array}$ & $\begin{array}{l}\text { En 2004, Health Canada recomendaba la lactancia materna } \\
\text { exclusiva durante los primeros } 6 \text { meses de la vida del niño y } \\
\text { la continuación de la lactancia materna hasta los dos años } \\
\text { de edad (1) y de forma subsecuente la promocionaba y } \\
\text { apoyaba por asociaciones de profesionales sanitarios y } \\
\text { organizaciones (2-6). } \\
\text { Para promocionar el inicio de la lactancia materna y el } \\
\text { aumento de la duración, la implementación de las mejores } \\
\text { prácticas basadas en la evidencia por los profesionales de }\end{array}$ & $\begin{array}{l}\text { Recomendación 2: } \\
\text { Las mejores prácticas basadas en la evidencia de } \\
\text { la iniciativa IHAN deberían ser utilizadas por los } \\
\text { proveedores de salud cuando se trata del cuidado } \\
\text { de las madres y de sus bebés }(\mathrm{A}) \text {. } \\
\text { Principios a seguir: } \\
\text { - Promover la lactancia materna exclusiva }\end{array}$ & $\begin{array}{l}\text { 1. United Nations Children's } \\
\text { Fund/World Health } \\
\text { Organization (2006). } \\
\text { 2. World Health Organization. } \\
\text { (1981). } \\
\text { 3. World Health Assembly } \\
\text { Resolutions. (1980 to 2005). } \\
\text { 4. World Health }\end{array}$ & \\
\hline
\end{tabular}




\begin{tabular}{|c|c|c|c|c|}
\hline $\begin{array}{c}\text { Guía } \\
\text { (Enfoque) }\end{array}$ & $\begin{array}{l}\text { Resumen sobre la evidencia } \\
\text { (Calidad de la evidencia) }\end{array}$ & $\begin{array}{l}\text { Recomendaciones } \\
\text { (Grado) }\end{array}$ & $\begin{array}{l}\text { Referencias bibliográficas } \\
\text { (Tipo de publicación) }\end{array}$ & Comentarios \\
\hline & $\begin{array}{l}\text { la salud es crítica. Una estrategia para promocionar la mejor } \\
\text { práctica es la iniciativa IHAN 7,8 (ver el Apéndice A). }\end{array}$ & $\begin{array}{l}\text { durante los primeros seis meses de vida del niño } \\
\text { y lactancia continua por dos años o más (1-6). } \\
\text { - Apoyar a la madre que amamanta a lo largo de } \\
\text { todo el continuo de la asistencia sanitaria de } \\
\text { acuerdo con sus objetivos y proveer una } \\
\text { asistencia basada en la mejor evidencia, } \\
\text { valoración de sus necesidades, análisis de los } \\
\text { datos obtenidos y un plan de acción desarrollado } \\
\text { con la madre. } \\
\text { - Utilizar los principios para educación de } \\
\text { personas adultas cuando trabaje con padres. } \\
\text { Reconocer que el periodo postparto es una } \\
\text { continuación de la experiencia del nacimiento. } \\
\text { Determinar el conocimiento de los padres; } \\
\text { después añadir sobre sus conocimientos y } \\
\text { habilidades. Centrarse en atender a las } \\
\text { necesidades de la madre y de la familia, su interés } \\
\text { por aprender, y la información necesaria para } \\
\text { poder tomar una decisión informada. } \\
\text { - Respetar la decisión de los padres cuando se } \\
\text { basa en conocimientos precisos (es } \\
\text { profesionalmente ético y facilita la discusión } \\
\text { respetuosa). }\end{array}$ & $\begin{array}{l}\text { Organization/United Nations } \\
\text { Children's Fund. (1990). } \\
\text { 5. World Health } \\
\text { Organization/United Nations } \\
\text { Children's Fund (2005) } \\
\text { 6. World Health Organization } \\
\text { (2001). } \\
\text { 7. World Health } \\
\text { Organization/United Nations } \\
\text { Children's Fund (1989). } \\
\text { 8. World Health Organization. } \\
\text { Vallenas C \& Savage F. } \\
\text { (1998). }\end{array}$ & \\
\hline
\end{tabular}

\subsection{Revisiones sistemáticas}

En la búsqueda realizada se ha identificado una revisión (1) sobre la eficacia de las intervenciones en atención primaria para promocionar la lactancia materna. En ella tratan de incluir los estudios en los que la intervención se originó en un contexto sanitario, considerando para dicha revisión a las maternidades como atención primaria. Consideran el apoyo a la lactancia materna a nivel de sistema (como la iniciativa IHAN y los programas educativos de los profesionales sanitarios). En sus conclusiones, los autores afirman que las intervenciones para promover la lactancia materna son más efectivas que la atención habitual a la hora de aumentar las tasas de lactancia materna a corto y largo plazo, aunque los estudios son muy heterogéneos y siendo difícil asegurar que las intervenciones se inician en la atención primaria. Por ello no se ha tenido en cuenta esta revisión. 


\subsection{Resumen de GPC base y RS disponibles}

La guía NICE (2) recomienda que todos los proveedores de atención a la maternidad (tanto hospitalaria como de atención primaria) deberían implementar un programa estructurado evaluado externamente que fomente la lactancia materna, utilizando la iniciativa IHAN como el mínimo estándar (Recomendación grado A).

La guía del Perinatal Care services (3) indica que se deberían utilizar las mejores prácticas basadas en la evidencia y en base a la iniciativa IHAN por todos los proveedores en salud para atender a las madres y a sus hijos (Recomendación grado A).

\subsection{Conclusión (marcar con una X):}

\begin{tabular}{|l|l|}
\hline & Adopción GPC/Revisión sistemática \\
\hline & Elaboración parcial \\
\hline$x$ & Elaboración de novo \\
\hline
\end{tabular}

\subsection{Diseño de la estrategia de búsqueda de estudios individuales}

\begin{tabular}{|l|l|}
\hline Criterios de selección de estudios & ECA, estudios observacionales \\
\hline Período de búsqueda & Hasta 31 de mayo de 2016 \\
\hline Bases de datos & Cochrane Library \\
& MEDLINE, via Pubmed \\
& EMBASE, via Ovid \\
& Cinahl, via EBSCOhost databases \\
& PsyINFO, via OVID \\
\hline
\end{tabular}

Ver estrategias de búsqueda de estudios originales en el ANEXO I. 


\section{4- Resumen de la evidencia (Tablas de estudios individuales y valoración de calidad en el ANEXO X)}

\section{1- GRADE Evidence Profile}

Comparación 1: Programas estructurados para el apoyo de la lactancia materna en centros de salud/atención primaria vs. Atención habitual Bibliografía: Cattaneo A, 2016; Kramer MS, 2001; Corriveau SK, 2013; Baerug A, 2016; Rosen-Carole C, 2016.

\begin{tabular}{|c|c|c|c|c|c|c|c|c|c|c|c|c|}
\hline \multirow{2}{*}{\multicolumn{7}{|c|}{ Evaluación de la calidad }} & \multicolumn{4}{|c|}{ Resumen de los Resultados } & \multirow{3}{*}{ Calidad } & \multirow{3}{*}{ Importancia } \\
\hline & & & & & & & \multicolumn{2}{|c|}{ № de pacientes } & \multicolumn{2}{|c|}{ Magnitud del efecto } & & \\
\hline $\begin{array}{c}\begin{array}{c}\text { № de } \\
\text { estudios }\end{array} \\
\end{array}$ & Diseño & \begin{tabular}{|c|} 
Riesgo de \\
sesgo
\end{tabular} & Inconsistencia & \begin{tabular}{|l|}
$\begin{array}{l}\text { Evidencia } \\
\text { indirecta }\end{array}$ \\
\end{tabular} & Imprecisión & \begin{tabular}{|c|} 
Otras \\
consideraciones
\end{tabular} & $\begin{array}{c}\text { Grupo } \\
\text { expuesto }\end{array}$ & $\begin{array}{l}\text { Grupo no } \\
\text { expuesto }\end{array}$ & $\begin{array}{l}\text { Relativa } \\
(95 \% \mathrm{Cl}) \\
\end{array}$ & \begin{tabular}{|c|} 
Absoluta por \\
1000 \\
\end{tabular} & & \\
\hline \multicolumn{13}{|c|}{ Tasa de lactancia materna exclusiva a los 3 meses } \\
\hline 11 & ECA & No serio & No seria & Seria $^{2}$ & No seria & Poco probable & $\begin{array}{c}3.839 / 8.865 \\
(43,3 \%)\end{array}$ & $\begin{array}{c}572 / 8.930 \\
(6,4 \%)\end{array}$ & $\begin{array}{l}\text { OR } 6,77 \text { (de } \\
6,16 \text { a } 7,42 \text { ) }\end{array}$ & - & MODERADA & CRITICA \\
\hline \multicolumn{13}{|c|}{ Tasa de lactancia materna exclusiva a los 4 meses } \\
\hline $1^{3}$ & $\begin{array}{l}\text { Estudios } \\
\text { observacionales }\end{array}$ & Serio 4 & No seria & No seria & No seria & Poco probable & \multicolumn{2}{|c|}{ № total: 757} & \multicolumn{2}{|c|}{ Ver resumen de evidencia } & MUY BAJA & CRITICA \\
\hline \multicolumn{13}{|c|}{ Tasa de lactancia materna exclusiva a los 6 meses } \\
\hline 11 & ECA & Serio $^{5}$ & No seria & Seria $^{2}$ & No seria & Poco probable & $\begin{array}{c}700 / 8.865 \\
(7,9 \%)\end{array}$ & $\begin{array}{c}54 / 8.930 \\
(0,6 \%)\end{array}$ & $\begin{array}{l}\mathrm{OR}^{*} 14,09 \text { (de } \\
10,67 \text { a } 18,62)\end{array}$ & - & BAJA & CRITICA \\
\hline $3^{6}$ & \begin{tabular}{|l|} 
Estudios \\
observacionales
\end{tabular} & Serio $^{7}$ & No seria & No seria & No seria & Poco probable & \multicolumn{2}{|c|}{ № total: 7883} & \multicolumn{2}{|c|}{ Ver resumen de evidencia } & MUY BAJA & CRITICA \\
\hline \multicolumn{13}{|c|}{ Tasa de cualquier lactancia materna a los 6 meses } \\
\hline $1^{8}$ & \begin{tabular}{|l} 
Estudios \\
observacionales
\end{tabular} & Serio 9 & No seria & No seria & No seria & Poco probable & $\begin{array}{c}11 \% \\
(214 / 1948) \\
\end{array}$ & $\begin{array}{c}7 \% \\
(136 / 1948) \\
\end{array}$ & - & - & MUY BAJA & IMPORTANTE \\
\hline \multicolumn{13}{|c|}{ Tasa de cualquier lactancia materna a los 6 meses } \\
\hline $11^{10}$ & $\begin{array}{l}\text { Estudios } \\
\text { observacionales }\end{array}$ & Serio 9 & No seria & No seria & Seria ${ }^{11}$ & Poco probable & Dos meses & Un mes & - & - & MUY BAJA & IMPORTANTE \\
\hline
\end{tabular}




\section{2- Resumen de la Evidencia}

Como ya se ha mencionado en la pregunta anterior, el único ECA, de buena calidad identificado que evalúa el efecto de la implementación de un programa estructurado de apoyo al inicio y mantenimiento de la lactancia materna es el ECA de Kramer (4). En este ECA, aunque la intervención se basó en la estrategia IHAN, como en esa época los grupos de apoyo no existían en Bielorrusia, el paso 10 (apoyo postnatal) se expandió para incluir a las policlínicas. De ahí que la tasa de lactancia materna exclusiva a los 3 meses aumenta de un $6,4 \%$ a un $43,3 \%$, y la proporción de mujeres con lactancia materna exclusiva a los 6 meses era más de 12 veces mayor en el grupo experimental frente al control $(7,9 \%$ vs $0,6 \%)$.

En relación a la implementación específica de programas estructurados en los centros de salud, se han identificado cuatro estudios, dos realizados en EEUU $(5 ; 6)$, uno realizado en Noruega (7) y el otro en Italia (8).

El objetivo del primer estudio era determinar si la implementación de un programa basado en el protocolo clínico de la ABM "The BreastfeedingFriendly Physician's Office, Part 1: Optimizing Care for Infants and Children" (9) en atención primaria aumentaba las tasas de lactancia materna. En este estudio, con un diseño retrospectivo tipo antes-después, se incluyeron los datos de 757 diadas madre-hijo. Los datos de lactancia materna se recogieron en la estancia hospitalaria, la primera visita del recién nacido al pediatra, y a los 2, 4 y 6 meses de vida, encontrándose que en todos los casos, la tasa de lactancia materna exclusiva aumentaba tras la implementación del programa, al menos en un $10 \%$ (5).

El estudio realizado en Noruega (7) en el que se valora la efectividad de implementación de la iniciativa IHAN en los Servicios de Salud comunitarios (54 municipalidades), se encontró que la tasa de lactancia materna exclusiva a los 6 meses era del 17,9\% en el grupo intervención frente al $14,1 \%$ en el grupo control (OR 1,33; IC95\% de 1,03 a 1,72), aunque a los 12 meses no había diferencias. El grupo control recibía la atención estándar, que comprendía la atención prenatal y el cuidado tras el alta hospitalaria durante la infancia y la adolescencia, así como las consultas a las 6 semanas, a los 3, 4, 5, 6, 7-8, 10 y 11-12 meses para vacunaciones, medidas antropométricas, cribado y consejo en lactancia materna. El estudio se hizo en municipalidades en las que no se había introducido todavía en IHAN en los Servicios de salud comunitarios (rurales o distritos rurales o semiurbanos).

El estudio de Rosen-Carole (6), en el que se pretendía evaluar el efecto de la iniciativa IHAN sobre el conocimiento y actitudes de los proveedores y el personal de una red de centros de salud, así como las tasas de lactancia materna, indica que la duración de la lactancia en el primer año de vida pasa de una media de un mes tanto en el período preiniciativa como durante la implementación, a una duración media de dos meses durante el período postintervención $(p=0,10)$.

Sin embargo, en un estudio controlado no aleatorizado realizado en Italia

\section{Calidad}

muy baja

Calidad

muy baja 
sobre la efectividad de la iniciativa IHAN para los centros de salud en aumentar la tasa de lactancia materna exclusiva a los 6 meses de vida (8), no se observaron diferencias significativas. En este estudio, la implementación de la estrategia se hizo por etapas, primero en el grupo de intervención temprana y después en el de intervención tardía.

\section{ACTUALIZADO A FECHA DE: 31 de Octubre de 2016}




\section{5- De la evidencia a la recomendación (Tabla de EtR)}

\section{¿Cuáles son las mejores estrategias estructuradas para el apoyo y protección de la lactancia materna en los centros de salud?}

Población: Madres de recién nacidos sanos a término que amamantan y sus bebés

Intervención: Medidas de apoyo y protección a la lactancia materna durante la estancia en el hospital

Comparación: Atención habitual

Perspectiva: Clínica

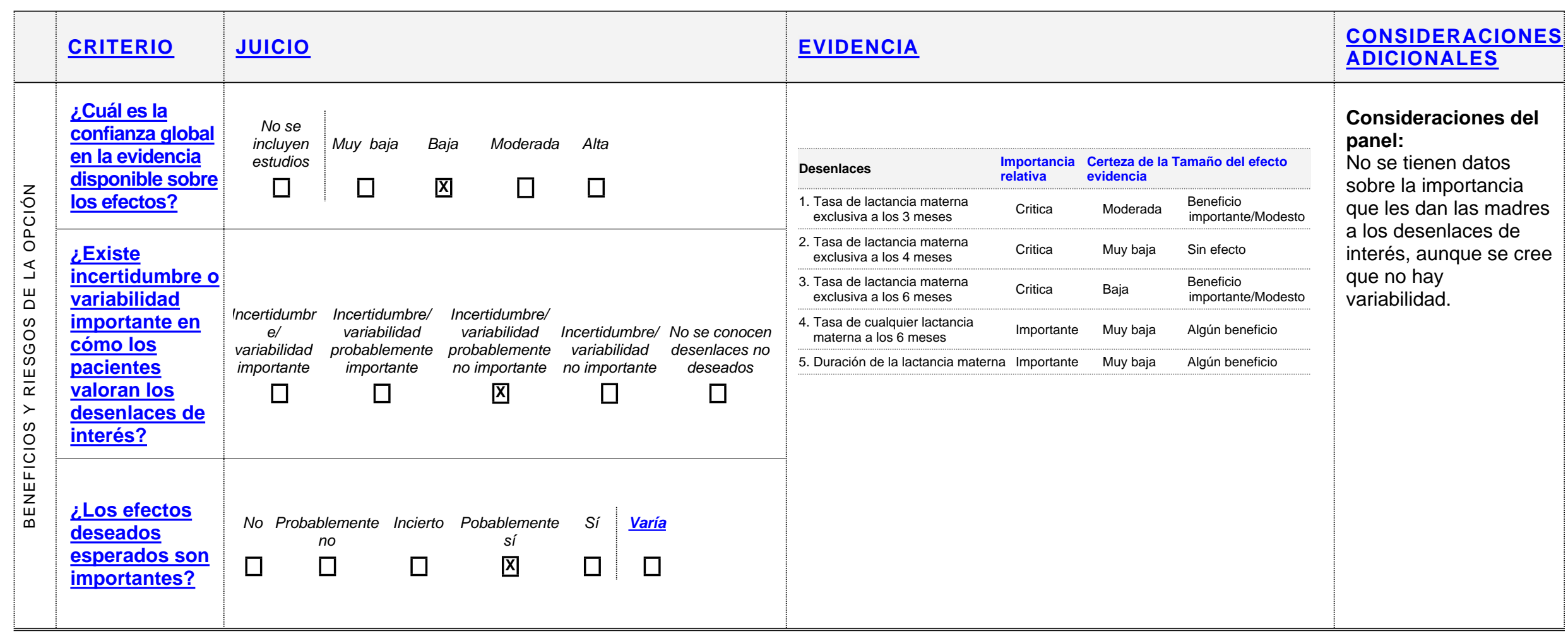




\begin{tabular}{|c|c|c|c|c|c|c|c|}
\hline CRITERIO & \multicolumn{5}{|l|}{ JUICIO } & EVIDENCIA & $\begin{array}{l}\text { CONSIDERACIONES } \\
\text { ADICIONALES }\end{array}$ \\
\hline $\begin{array}{l}\text { ¿Los efectos } \\
\text { no deseados } \\
\text { esperados } \\
\text { son } \\
\text { pequeños? }\end{array}$ & $\begin{array}{c}\text { No Probablemente } \\
\text { no } \\
\square \quad \square\end{array}$ & $\begin{array}{c}\text { Incierto } \\
\square\end{array}$ & $\begin{array}{c}\text { Pobablemente } \\
\text { sí } \\
\text { 凹 }\end{array}$ & $\begin{array}{l}\text { Sí } \\
\square\end{array}$ & $\frac{\underline{\text { Varía }}}{\square}$ & & \\
\hline
\end{tabular}




\section{¿Cuáles son las mejores estrategias estructuradas para el apoyo y protección de la lactancia materna en los centros de salud?}

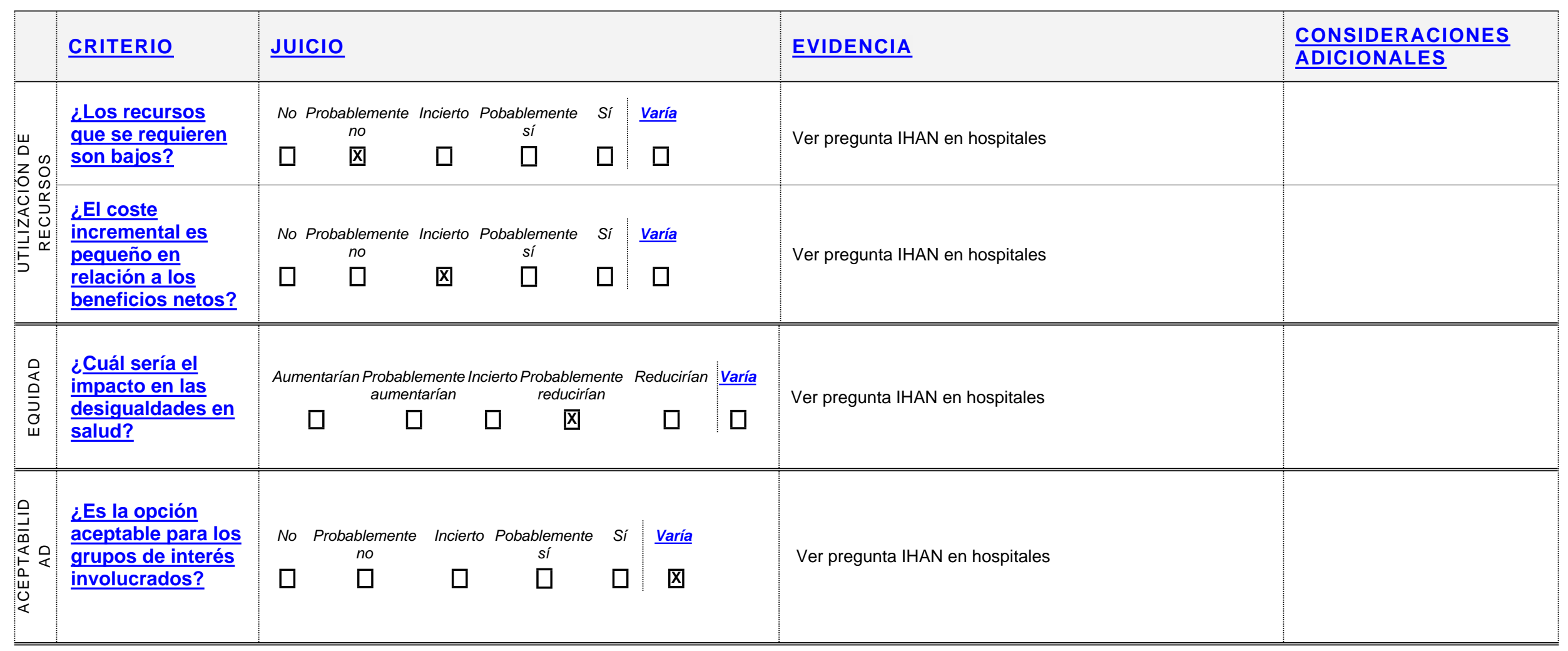




\begin{tabular}{|c|c|c|c|c|c|c|}
\hline & CRITERIO & $\underline{\text { JUICIO }}$ & & & EVIDENCIA & $\begin{array}{l}\text { CONSIDERACIONES } \\
\text { ADICIONALES }\end{array}$ \\
\hline 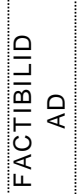 & $\begin{array}{l}\frac{\text { ¿La }}{\text { implementación }} \\
\text { de la opción es } \\
\text { factible? }\end{array}$ & $\begin{array}{cc}\text { No } & \text { Probablemente } \\
& \text { no } \\
\square & \square\end{array}$ & $\begin{array}{c}\text { Incierto Pobablemente } \\
\text { sí } \\
\square\end{array}$ & \begin{tabular}{c|c} 
Si & Varía \\
$\square$ & $\square$
\end{tabular} & & \\
\hline
\end{tabular}

\begin{tabular}{|c|c|c|c|c|c|}
\hline \multirow[t]{2}{*}{$\begin{array}{l}\text { Balance de las } \\
\text { consecuencias }\end{array}$} & $\begin{array}{l}\text { Las consecuencias no } \\
\text { deseadas superan } \\
\text { claramente las } \\
\text { consecuencias deseadas } \\
\text { en la mayoría de los } \\
\text { escenarios }\end{array}$ & $\begin{array}{l}\text { Las consecuencias no } \\
\text { deseadas probablemente } \\
\text { superan las } \\
\text { consecuencias deseadas } \\
\text { en la mayoría de los } \\
\text { escenarios }\end{array}$ & $\begin{array}{c}\text { El balance entre las } \\
\text { consecuencias deseadas y } \\
\text { no deseadas está muy } \\
\text { equilibrado o es incierto }\end{array}$ & $\begin{array}{l}\text { Las consecuencias } \\
\text { deseadas } \\
\text { probablemente superan } \\
\text { las consecuencias no } \\
\text { deseadas en la mayoría } \\
\text { de los escenarios }\end{array}$ & $\begin{array}{c}\text { Las consecuencias } \\
\text { deseadas claramente } \\
\text { superan las } \\
\text { consecuencias no } \\
\text { deseadas en la mayoría } \\
\text { de los escenarios }\end{array}$ \\
\hline & $\square$ & $\square$ & $\square$ & 囚 & $\square$ \\
\hline & \multicolumn{2}{|l|}{$\square$} & $\square$ & $\square$ & 囚 \\
\hline \multirow{2}{*}{$\frac{\text { Recomendación }}{\text { (Texto) }}$} & \multicolumn{5}{|c|}{$\underline{\text { Recomendación fuerte a favor }}$} \\
\hline & \multicolumn{5}{|c|}{$\begin{array}{l}\text { Se recomienda que todos los centros de salud implementen un programa estructurado, con evaluación externa, que promueva y } \\
\text { apoye la lactancia materna, utilizando la iniciativa IHAN como mínimo estándar (ver los siete pasos IHAN en el Anexo 14). }\end{array}$} \\
\hline
\end{tabular}


Justificación A pesar de que no hay tantos estudios sobre la eficacia de la implementación de una estrategia estructurada en los centros de salud en aumentar las tasas de lactancia materna exclusiva, los estudios identificados encuentran que su implementación lleva al aumento de la tasa de lactancia materna exclusiva a los 6 meses. Además, sí que existe evidencia de la eficacia de la implementación de la iniciativa IHAN en las maternidades, así como evidencia de que en general, cualquier estrategia de apoyo aumenta dichas tasas, por lo que se recomienda su implementación.

\section{Consideraciones de}

subgrupos

Consideraciones para la implementación
- Se recomienda que la implementación sea un proceso participativo y multidisciplinar y que sea dirigido por un profesional sanitario con experiencia y capacidad de liderazgo.

- Se recomienda que la organización provea los recursos necesarios (cambios organizativos, formación adecuada a los profesionales sanitarios) para que la implementación del programa sea efectiva.

- Se recomienda que el programa incluya las exigencias de la acreditación que aseguran la evaluación externa y los criterios de calidad de reconocimiento mundial.

- Se recomienda que tras la implementación de un programa estructurado de estas características se monitorice de forma continua la cumplimentación de los 7 pasos que propone la iniciativa.

Monitorización y
evaluación Se debe diseñar una estrategia que permita monitorizar tanto la implementación como el cumplimiento de todos los pasos.

$\begin{array}{ll}\begin{array}{l}\text { Prioridades para la } \\ \text { investigación }\end{array} & \begin{array}{l}\text { Se necesitan estudios que demuestren que en los centros en los que se ha implementado la iniciativa de la OMS/UNICEF hay un } \\ \text { aumento de las tasas de lactancia materna, así como una mayor satisfacción de las madres. }\end{array}\end{array}$ 


\section{ANEXO I, ESTRATEGIAS DE BÚSQUEDA}

Cochrane

\#1 breastfeeding or breast-feeding or "breast feeding" or lactation:ti,ab,kw and friendly and (initiative or baby or protocol):ti,ab,kw and "primary care" or "health center" or "health systems" or (primary and (health or care or center or services)):ti,ab,kw (Word variations have been searched) 8

Pubmed

\#1 Search breastfeeding[Title/Abstract] OR breast-feeding[Title/Abstract] OR "breast feeding"[Title/Abstract] OR lactation[Title/Abstract] 55703

\#2 Search friendly AND (baby OR initiative OR protocol) 2024

\#3 Search "primary care"[Title/Abstract] OR "health center"[Title/Abstract] OR "health systems"[Title/Abstract] OR (primary AND (health OR care OR center OR services)) 511406

\#4 Search \#1 AND \#2 AND \#3 61

Embase

1 (breastfeeding or breast-feeding or "breast feeding" or lactation).ti,ab,kw. 65799

2 (friendly and (initiative or baby or protocol)).af. 2292

3 ("primary care" or "health center" or "health systems" or (primary and (health or care or center or services))).af. 888879

$4 \quad 1$ and 2 and $3 \quad 62$

Cinhal

S1 breastfeeding or breast-feeding or "breast feeding" or lactation

17148

S2 friendly and (initiative or baby or protocol) 730

S3 "primary care" or "health center" or "health systems" or (primary and (health or care or center or services)) 95555

S4 S1 AND S2 AND S3 25 


\section{ANEXO II, Tabla de estudios individuales para la pregunta}

\begin{tabular}{|c|c|c|c|c|c|c|}
\hline $\begin{array}{l}\text { Referencia } \\
\text { (Cita Abreviada) }\end{array}$ & $\begin{array}{l}\text { Estudio (Diseño y } \\
\text { objetivo) }\end{array}$ & $\begin{array}{l}\text { Población } \\
\text { (no y características) }\end{array}$ & $\begin{array}{l}\text { Descripción de las intervenciones } \\
\text { comparaciones, exposiciones o } \\
\text { pruebas a estudio }\end{array}$ & $\begin{array}{l}\text { Resultados } \\
\text { (Estimadores de resultados-Magnitud del } \\
\text { efecto) }\end{array}$ & $\begin{array}{l}\text { Conclusiones } \\
\text { (conclusiones) }\end{array}$ & $\begin{array}{l}\text { Comentarios } \\
\text { Calidad de la } \\
\text { evidencia } \\
\text { Financiación } \\
\text { comentarios) }\end{array}$ \\
\hline Kramer MS, 2001 & $\begin{array}{l}\text { Diseño: ECA tipo cluster } \\
\text { Objetivo: valorar los } \\
\text { efectos de la promoción de } \\
\text { la lactancia materna en su } \\
\text { duración y exclusividad y } \\
\text { sobre las infecciones } \\
\text { gastrointestinales y } \\
\text { respiratorias y el eeccema } \\
\text { atópico en los niños. }\end{array}$ & $\begin{array}{l}17046 \text { díadas madre- } \\
\text { hijo (niños sanos de } \\
\text { más de } 2,500 \mathrm{~kg} \text { y } \\
\text { madres sanas que } \\
\text { quieren dar el pecho } \\
\text { Seguimiento: } 16491 \\
(96,7 \% \text { ) a los } 12 \\
\text { meses. }\end{array}$ & $\begin{array}{l}\text { Aleatorización de los centros } \\
\text { Intervención: } n=16 \\
\text { Control: } n=15 \\
\text { La intervención se basa en los } \\
\text { estándares de la estrategia IHAN, y no } \\
\text { sólo se centra en el hospital, sino en la } \\
\text { atención posterior a la estancia } \\
\text { hospitalaria. }\end{array}$ & $\begin{array}{l}\text { Resultados: } \\
\text { Lactancia exclusiva a los } 3 \text { meses: } 43,3 \% \\
\text { vs } 6,4 \% \text { ( } p>0,001 \text { ) } \\
\text { Lactancia predominante a los } 3 \\
\text { meses: } 51,9 \% \text { vs. } 28,3 \% \text { ( } p>0,001 \text { ) } \\
\text { Lactancia exclusiva a los } 6 \text { meses: } 7,9 \% \\
\text { vs. } 0,6 \% \text { ( } p>0,001 \text { ) } \\
\text { Lactancia predominante a los } 6 \text { meses: } \\
\text { 10,6\% vs. } 1,6 \% \text { ( } p=0,003 \text { ). } \\
\text { Miden otros resultados: uno o más } \\
\text { episodios de infección gastrointestinal, } 2 \text { o } \\
\text { más episodios del tracto respiratorio y } \\
\text { eccema atópico, cada uno en los primeros } \\
12 \text { meses de vida. } \\
\\
\text { Para lactancia materna, resultados } \\
\text { ajustados por el peso del niño al nacer, la } \\
\text { edad de la madre, historia previa de } \\
\text { lactancia materna durante } 3 \text { meses o más }\end{array}$ & $\begin{array}{l}\text { La intervención } \\
\text { aumenta la } \\
\text { duración y } \\
\text { exclusividad de la } \\
\text { lactancia y } \\
\text { disminuye el riesgo } \\
\text { de infecciones } \\
\text { gastrointestinales y } \\
\text { de eccema atópico } \\
\text { en el primer año } \\
\text { de vida. }\end{array}$ & \\
\hline Corriveau 2013 & $\begin{array}{l}\text { Realizado en EEUU } \\
\text { Estudio retrospectivo tipo } \\
\text { antes-después } \\
\text { Objetivo: determinar si la } \\
\text { implementación de un } \\
\text { programa basado en el } \\
\text { protocolo clínico de la ABM } \\
\text { en atención primaria } \\
\text { aumenta las tasas de } \\
\text { lactancia materna. }\end{array}$ & 757 diadas madre-hijo & $\begin{array}{l}\text { Datos de lactancia materna recogidos } \\
\text { en la estancia hospitalaria, la primera } \\
\text { visita del recién nacido al pediatra y a } \\
\text { los } 2,4 \text { y } 6 \text { meses de vida. }\end{array}$ & $\begin{array}{l}\text { Tasa de lactancia materna exclusiva } \\
\text { aumenta tras la implementación del } \\
\text { programa al menos en un } 10 \% \text { en todas } \\
\text { las visitas (aunque no ocurre lo mismo } \\
\text { con cualquier tipo de lactancia materna). }\end{array}$ & $\begin{array}{l}\text { En aquellas } \\
\text { familias que } \\
\text { reciben cuidados } \\
\text { por parte de una } \\
\text { atención primaria } \\
\text { pediátrica en la } \\
\text { que se ha } \\
\text { implementado el } \\
\text { protocolo clínico } \\
\text { de la ABM pueden } \\
\text { aumentar las tasas } \\
\text { de lactancia } \\
\text { materna exclusiva. }\end{array}$ & $\begin{array}{l}\text { No recibieron } \\
\text { financiación } \\
\text { externa. }\end{array}$ \\
\hline $\begin{array}{l}\text { Rosen-Carole } \\
2015\end{array}$ & $\begin{array}{l}\text { Estudio realizado en } \\
\text { EEUU, de tipo antes y } \\
\text { después. }\end{array}$ & $\begin{array}{l}\mathrm{N}=1948 \text { madres } \\
\text { Basal, y durante dos } \\
\text { períodos de la iniciatival }\end{array}$ & $\begin{array}{l}\text { Se evalúan las tasas de lactancia } \\
\text { materna antes y durante la } \\
\text { implementación IHAN, realizando }\end{array}$ & $\begin{array}{l}\text { El inicio y duración de lactancia materna } \\
\text { mejora en el curso de la implementación } \\
\text { del programa, aumenta de media la }\end{array}$ & $\begin{array}{l}\text { La implementación } \\
\text { de la IHAN en una } \\
\text { red de atención }\end{array}$ & $\begin{array}{l}\text { Los autores } \\
\text { declaran no } \\
\text { tener conflictos }\end{array}$ \\
\hline
\end{tabular}




\begin{tabular}{|c|c|c|c|c|c|c|}
\hline $\begin{array}{l}\text { Referencia } \\
\text { (Cita Abreviada) }\end{array}$ & $\begin{array}{l}\text { Estudio (Diseño y } \\
\text { objetivo) }\end{array}$ & $\begin{array}{l}\text { Población } \\
\text { (nº y características) }\end{array}$ & $\begin{array}{l}\text { Descripción de las intervenciones } \\
\text { comparaciones, exposiciones o } \\
\text { pruebas a estudio }\end{array}$ & $\begin{array}{l}\text { Resultados } \\
\text { (Estimadores de resultados-Magnitud del } \\
\text { efecto) }\end{array}$ & $\begin{array}{l}\text { Conclusiones } \\
\text { (conclusiones) }\end{array}$ & $\begin{array}{l}\text { Comentarios } \\
\text { Calidad de la } \\
\text { evidencia } \\
\text { Financiación } \\
\text { comentarios) }\end{array}$ \\
\hline & $\begin{array}{l}\text { Objetivo: evaluar el efecto } \\
\text { de la iniciativa IHAN en el } \\
\text { conocimiento y las } \\
\text { actitudes de los } \\
\text { proveedores de salud y el } \\
\text { el personal, así como las } \\
\text { tasas de lactancia materna } \\
\text { de pacientes en una red de } \\
\text { "Federally Qualified Health } \\
\text { Center network" sin } \\
\text { consultores de lactancia } \\
\text { entre el personal. }\end{array}$ & $\begin{array}{l}\text { (respuesta inicial, al } \\
\text { mes, a los } 2,46,9 \text { y } \\
12 \text { meses). }\end{array}$ & $\begin{array}{l}\text { también } 136 \text { encuestas a proveedores } \\
\text { de atención primaria antes y después de } \\
\text { ser expuestos a un méodulo de } \\
\text { educación en lactancia. }\end{array}$ & $\begin{array}{l}\text { duración de lactancia en un mes en } \\
\text { comparación con las tasas basales } \\
\text { ( } p=0.01 \text { ) (inicial, al mes, a los } 2,4 \text { y } 6 \\
\text { meses). } \\
\text { Preintervención: } \\
38 \% \text { inicial, } 25 \% \text { al mes y sólo } 6 \% \text { a los } 6 \\
\text { meses. } \\
\text { A los } 2 \text { años de la iniciativa: } \\
57 \% \text { inicial, } 11 \% \text { a los } 6 \text { meses. } \\
\text { Se observan una mejoría significativa en } \\
\text { el conocimiento de los proveedores y del } \\
\text { personal y las actitudes. }\end{array}$ & $\begin{array}{l}\text { primaria con } \\
\text { múltiples } \\
\text { especialidades. }\end{array}$ & $\begin{array}{l}\text { de interés y no } \\
\text { haber recibido } \\
\text { financiación } \\
\text { para el estudio } \\
\text { ni para la } \\
\text { elaboración del } \\
\text { artículo. } \\
\text { Las tasas de } \\
\text { lactancia se } \\
\text { basan en el } \\
\text { reporte por parte } \\
\text { de los padres } \\
\text { (revisión de } \\
\text { historias } \\
\text { clínicas). }\end{array}$ \\
\hline Baerug A, 2016 & $\begin{array}{l}\text { Realizado en Noruega } \\
\text { Estudio pragmático cluster } \\
\text { cuasialeatorizado } \\
\text { Objetivo: valorar la } \\
\text { efectividad de } \\
\text { implementación de la } \\
\text { iniciativa IHAN en los } \\
\text { Servicios de Salud } \\
\text { comunitarios (54 } \\
\text { municipalidades) }\end{array}$ & $\begin{array}{l}54 \text { municipalidades de } \\
\text { noruega } \\
\text { De las } 3948 \text { mujeres } \\
\text { invitadas a participar, } \\
\text { contestaron al } \\
\text { cuestionario } 1051 \text { del } \\
\text { grupo intervención y } \\
981 \text { del grupo control. }\end{array}$ & $\begin{array}{l}\text { El grupo control recibía atención } \\
\text { estándar (atención prenatal y cuidado } \\
\text { tras el alta hospitalaria durante la } \\
\text { infancia y adolescencia), así como las } \\
\text { consultas a las } 6 \text { semanas, y } \\
3,4,5,6,7,8,10 \text { y } 12 \text { meses para } \\
\text { vacunaciones etc. } \\
\text { El estudio se hizo en municipalidades en } \\
\text { las que no se había introducido todavía } \\
\text { en IHAN en los Servicios de Salud } \\
\text { Comunitarios (rurales o distritos rurales } \\
\text { o semiurbanos). }\end{array}$ & $\begin{array}{l}\text { La tasa de lactancia materna exclusiva a } \\
\text { los } 6 \text { meses es del } 17,9 \% \text { en el grupo } \\
\text { intervención frente al } 14,1 \% \text { en e grupo } \\
\text { control (OR } 1,33 ; \text { IC } 95 \% \text { del } 1,03 \text { al } 1,72 \text { ). } \\
\text { A los } 12 \text { meses no hay diferencias. }\end{array}$ & $\begin{array}{l}\text { La IHAN a nivel de } \\
\text { los servicios de } \\
\text { salud comunitarios } \\
\text { aumenta las tasas } \\
\text { de lactancia } \\
\text { materna exclusiva } \\
\text { a los } 6 \text { meses de } \\
\text { vida del niño. }\end{array}$ & $\begin{array}{l}\text { Ensayo } \\
\text { financiado por la } \\
\text { Fundación } \\
\text { EXTRA Noruega } \\
\text { para la salud y } \\
\text { rehabilitación, la } \\
\text { unidad nacional } \\
\text { noruega sobre } \\
\text { lactancia del } \\
\text { hospital } \\
\text { universitario de } \\
\text { Oslo y también } \\
\text { por la Dirección } \\
\text { de Salud y el } \\
\text { Miniserio de } \\
\text { Salud y } \\
\text { bienestar } \\
\text { Noruego. }\end{array}$ \\
\hline Cattaneo A, 2016 & $\begin{array}{l}\text { Realizado en Italia } \\
\text { Estudio controlado no } \\
\text { aleatorizado } \\
\text { Objetivo: analizar la } \\
\text { efectividad de la } \\
\text { implementación de la }\end{array}$ & $\begin{array}{l}5094 \text { diadas madre/hijo } \\
\text { en tres cohortes fueron } \\
\text { seguidas hasta los } 12 \\
\text { meses tras el } \\
\text { nacimiento en } 3 \text { rondas } \\
\text { de colección de datos: } \\
\text { basal, tras la }\end{array}$ & $\begin{array}{l}\text { La implementación de la estrategia se } \\
\text { hizo por etapas: primero en el grupo de } \\
\text { intervención temprana y después en el } \\
\text { de intervención tardía. }\end{array}$ & $\begin{array}{l}\text { No se observan diferencias significativas } \\
\text { en aumentar la tasa de lactancia materna } \\
\text { exclusiva a los } 6 \text { meses de vida } \\
\text { El ratio de lactancia materna a los } 6 \\
\text { meses es el outcome principal. La basal, a } \\
\text { los } 3 \text { y } 12 \text { meses también se midió. }\end{array}$ & & $\begin{array}{l}\text { Financiación por } \\
\text { parte del } \\
\text { Instituto de } \\
\text { Salud Maternal } \\
\text { e Infatil IRCCS } \\
\text { de IRCCS Burlo } \\
\text { Garofolo y por }\end{array}$ \\
\hline
\end{tabular}




\begin{tabular}{|c|c|c|c|c|c|c|}
\hline $\begin{array}{l}\text { Referencia } \\
\text { (Cita Abreviada) }\end{array}$ & $\begin{array}{l}\text { Estudio (Diseño y } \\
\text { objetivo) }\end{array}$ & $\begin{array}{l}\text { Población } \\
\text { (noy características) }\end{array}$ & $\begin{array}{l}\text { Descripción de las intervenciones } \\
\text { comparaciones, exposiciones o } \\
\text { pruebas a estudio }\end{array}$ & $\begin{array}{l}\text { Resultados } \\
\text { (Estimadores de resultados-Magnitud del } \\
\text { efecto) }\end{array}$ & $\begin{array}{l}\text { Conclusiones } \\
\text { (conclusiones) }\end{array}$ & $\begin{array}{l}\text { Comentarios } \\
\text { Calidad de la } \\
\text { evidencia } \\
\text { Financiación } \\
\text { comentarios) }\end{array}$ \\
\hline & $\begin{array}{l}\text { iniciativa IHAN en los } \\
\text { centros de salud sobre la } \\
\text { lactancia materna } \\
\text { exclusiva a los } 6 \text { meses. }\end{array}$ & $\begin{array}{l}\text { impelemntación en el } \\
\text { grupo de intervención } \\
\text { temprana y tras la } \\
\text { implmenentación en el } \\
\text { grupo de intervención } \\
\text { tardía. } 689 \text { diadas } \\
\text { (14\%) no completaron } \\
\text { el estudio. }\end{array}$ & & & & $\begin{array}{l}\text { fondos del } \\
\text { Comité italiano } \\
\text { para UNICEF y } \\
\text { por cada Local } \\
\text { Health Authority } \\
\text { (LHA) } \\
\text { participante. }\end{array}$ \\
\hline
\end{tabular}




\section{1- BIBLIOGRAFÍA}

(1) Chung M, Raman G, Trikalinos T, Lau J, Ip S. Interventions in primary care to promote breastfeeding: an evidence review for the U.S. Preventive Services Task Force. Ann Intern Med 2008 Oct 21;149(8):565-82.

(2) NICE. Postnatal care up to 8 weeks after birth. Julio 2006 (actualizado en Febrero de 2015). Disponible en: http://guidance.nice.org.uk/CG37.

(3) Perinatal Services BC. Health Promotion Guideline. Breastfeeding Healthy Term Infants. 2013 Feb.

(4) Kramer MS, Chalmers B, Hodnett ED, Sevkovskaya Z, Dzikovich I, Shapiro S, et al. Promotion of Breastfeeding Intervention Trial (PROBIT): a randomized trial in the Republic of Belarus. JAMA 2001 Jan 24;285(4):413-20.

(5) Corriveau SK, Drake EE, Kellams AL, Rovnyak VG. Evaluation of an office protocol to increase exclusivity of breastfeeding. Pediatrics 2013 May;131(5):942-50.

(6) Rosen-Carole C, Waltermaurer E, Goudreault M, Larimer A, Pokharel-Wood M, Rajupet S, et al. Assessing the Efficacy of a Breastfeeding-Friendly Quality Improvement Project in a Large Federally Qualified Health Center Network. J Hum Lact 2015 Oct 23.

(7) Baerug A, Langsrud O, Loland BF, Tufte E, Tylleskar T, Fretheim A. Effectiveness of Baby-friendly community health services on exclusive breastfeeding and maternal satisfaction: a pragmatic trial. Matern Child Nutr 2016 Apr 8.

(8) Cattaneo A, Bettinelli ME, Chapin E, Macaluso A, Cordova do Espirito SL, Murante AM, et al. Effectiveness of the Baby Friendly Community Initiative in Italy: a non-randomised controlled study. BMJ Open 2016;6(5):e010232.

(9) Grawey AG, Marinelli KA, Holmes AV and the Academy of Breastfeeding Medicine. ABM Critical Protocol \#14: Breastfeeding-Friendly Physician's Office: Optimizing Care for Infants and Children, Revised 2013. Breastfeeding Medicine. Volume 8, Number 2, 2013. 
PREGUNTA № 19

¿Cómo interpretar la pérdida de peso del recién nacido sano amamantado en los primeros días?

\section{1- PREGUNTA CLÍNICA EN FORMATO PICO}

Tabla 1- Componentes de la pregunta clínica en formato PICO

\begin{tabular}{|l|l|}
\hline Pacientes & Recién nacido a término sano amamantado \\
\hline Intervención & Manejo adecuado de la lactancia materna \\
\hline Resultados & $\begin{array}{l}\text { Pérdida normal de peso del recién nacido amamantado en } \\
\text { los primeros días }\end{array}$ \\
\hline Tipo de estudio & RS de estudios observacionales o estudios observacionales \\
\hline
\end{tabular}

\section{2- INTRODUCCIÓN}

La pérdida de peso en el recién nacido es un motivo frecuente de preocupación para los padres y en muchas ocasiones también para los profesionales. De hecho, es uno de los motivos más frecuentes por lo que se administran suplementos. Se plantea si el disponer de unas gráficas de pérdida de peso neonatal sería de utilidad en la valoración del recién nacido y si evitaría la administración de algunos suplementos innecesarios. 


\section{ESTRATEGIA DE ELABORACION DE LA PREGUNTA}

3.1. GPC Base

Tabla 2- Resumen de GPC Base

\begin{tabular}{|c|c|c|c|c|}
\hline $\begin{array}{l}\text { Guía } \\
\text { (Enfoque) }\end{array}$ & $\begin{array}{l}\text { Resumen sobre la evidencia } \\
\text { (Calidad de la evidencia) }\end{array}$ & $\begin{array}{l}\text { Recomendaciones } \\
\text { (Grado) }\end{array}$ & $\begin{array}{l}\text { Referencias bibliográficas } \\
\text { (Tipo de publicación) }\end{array}$ & Comentarios \\
\hline $\begin{array}{l}\text { NICE_2006 } \\
\text { (Actualiz. } \\
\text { 2011) }\end{array}$ & $\begin{array}{l}\text { 2.8.1. Monitorización rutinaria del peso de los niños } \\
\text { Los bebés sanos normalmente pierden peso en la primera } \\
\text { semana de vida. Esta pérdida de peso es generalmente } \\
\text { transitoria y no tiene importancia, pero puede ser exagerada } \\
\text { si hay dificultades en el establecimiento de la alimentación o } \\
\text { si el niño está enfermo. } \\
\text { En el pasado, los niños eran pesados al menos dos veces } \\
\text { en los primeros } 10 \text { días tras el nacimiento (al nacimiento y } \\
\text { antes de ser trasnferidos de la matrona al "health visitor" } \\
\text { alrededor de los } 10-14 \text { días tras el parto. } \\
\text { Hay un debate sobre los beneficios y riesgos de pesar de } \\
\text { forma rutinaria a los niños en las primeras semanas de vida. } \\
\text { Los que se oponen consideran que pesar de forma rutinaria } \\
\text { a los niños puede causar daños porque: } \\
\text { - Intervenciones innecesarias debidas a un error en la } \\
\text { medición del peso (por ejemplo, causado por procesos } \\
\text { fisiológicos normales (micciones, deposiciones) que no } \\
\text { son tenidos en cuenta). } \\
\text { - Se crea ansiedad a los padres } \\
\text { - Potencial para interferir con la lactancia materna } \\
\text { exclusiva. } \\
\text { Dewey et al (2002) presentaron resultados preliminares de } \\
\text { un estudio prospectivo poblacional sobre la incidencia de y } \\
\text { los factores de riesgo para la ingesta insuficiente de leche } \\
\text { en un estudio realizado en California. } 280 \text { diadas madre hijo } \\
\text { fueron reclutados en } 24 \text { horas tras el nacimiento. } \\
\text { Se dotó de ayuda para la lactancia por profesionales } \\
\text { sanitarios entrenados durante la estancia hospitalaria y en } \\
\text { el hogar de la mujer los días } 3,4 \text { y } 14 \text {, según necesidad. } \\
\text { Los resultados preliminares que se reportaron fueron los }\end{array}$ & $\begin{array}{l}\text { No hay recomendaciones en cuanto a cómo alorar } \\
\text { la pérdida de peso en el recién nacido. }\end{array}$ & $\begin{array}{l}\text { Dewey KG, } 2003 \\
\text { Martín Calama J, } 1997\end{array}$ & \\
\hline
\end{tabular}




\begin{tabular}{|c|c|c|c|c|}
\hline $\begin{array}{c}\text { Guía } \\
\text { (Enfoque) }\end{array}$ & $\begin{array}{l}\text { Resumen sobre la evidencia } \\
\text { (Calidad de la evidencia) }\end{array}$ & $\begin{array}{l}\text { Recomendaciones } \\
\text { (Grado) }\end{array}$ & $\begin{array}{l}\text { Referencias bibliográficas } \\
\text { (Tipo de publicación) }\end{array}$ & Comentarios \\
\hline & $\begin{array}{l}\text { siguientes: } \\
\text { - Retraso en el inicio de la producción de leche es común } \\
\text { (24\%), especialmente en las primíparas ( } 34 \% \text { ) } \\
\text { - La pérdida de peso mayor al } 10 \% \text { ocurría en el } 12 \% \text { de } \\
\text { los niños en el día } 3 \text { y era } 6 \text { veces más probable si había } \\
\text { retraso en la producción de leche ( } 35 \text { vs. } 5,6 \%) \text {. } \\
\text { - El retraso en la producción de leche era un factor de } \\
\text { riesgo clave para el uso subsecuente de fórmula } \\
\text { - La mitad de los niños puntuaron menos de } 10 \text { puntos en } \\
\text { el IIFAT el día } 1 \text {, disminuyendo el \% al } 22 \% \text { el día } 3 \text { y al } \\
14 \% \text { el día } 7 \text {. } \\
\text { - La mayoría de las mujeres (81\%) reportaron problemas } \\
\text { con la lactancia el día } 3 \text {. } \\
\text { Se señaló la necesidad de asegurar que las mujeres eran } \\
\text { seguidas sobre el tercer día postparto, particularmente las } \\
\text { primíparas y las que dieron a luz por cesárea. } \\
\text { Las mujeres del estudio eran de alto nivel de estudios y de } \\
\text { apoyo social, factores ambos asociados con mayores } \\
\text { porcentajes y duración de la lactancia materna. } \\
\text { Un estudio español (Martín-Calama } 1997) \text { evaluó el efecto } \\
\text { de suplementar con suero glucosado a recién nacidos } \\
\text { amamantados. } 180 \text { recién nacidos fueron asignados de } \\
\text { forma aleatoria a dos grupos. Un grupo recibía suero } \\
\text { glucosado al } 5 \% \text { ad libitum a través de un biberón en los } 3 \\
\text { primeros días de vida. El segundo grupo no recibía } \\
\text { suplementos durante el mismo período. Hubo una mayor } \\
\text { pérdida de peso en los primeros } 48 \text { h pero no a las } 72 h \text {. La } \\
\text { pérdida de peso no excedió en ningún caso el } 7 \% \text { en ambos } \\
\text { grupos. }\end{array}$ & & & \\
\hline $\begin{array}{l}\text { Perinatal } \\
\text { Services BC } \\
2012\end{array}$ & $\begin{array}{l}\text { Monitorización de la pérdida y ganancia de peso del } \\
\text { niño } \\
\text { Pérdida y ganancia de peso en el niño } \\
\text { La pérdida de peso es variable en la primera semana de } \\
\text { vida. Las pérdidas mayores del } 7 \% \text { (26) o 10\% (71,72) en } \\
\text { los primeros } 4 \text { días postparto para niños nacidos por vía } \\
\text { vaginal o en los primeros } 5 \text { días si fueron nacidos por } \\
\text { cesárea (66) indican valoración continuada del proceso de } \\
\text { la lactancia materna y la posible corrección de la técnica de }\end{array}$ & $\begin{array}{l}\text { La derivación a un profesional sanitario de } \\
\text { lactancia materna yy/o a un médico está indicada } \\
\text { en las siguientes situaciones (65): } \\
\text { - Retraso en la lactogénesis y pérdida continua } \\
\text { de peso en el niño } \\
\text { - Retraso en la lactogénesis y output inadecuado } \\
\text { en el niño } \\
\text { - Output inadecuado en el niño y pérdida de peso } \\
\text { continua en el niño }\end{array}$ & $\begin{array}{l}\text { 26. American Academy of } \\
\text { Pediatrics (2005). } \\
\text { 38. Riordan J \& Wambach } \\
\text { (2010). } \\
\text { 39. Lawrence RA \& Lawrence } \\
\text { RM. (2005). } \\
\text { 65. Dewey KG et al, (2003). } \\
\text { 71. Registered Nurses } \\
\text { Association of Ontario. (2003). } \\
\text { 72. International Lactation }\end{array}$ & \\
\hline
\end{tabular}




\begin{tabular}{|c|c|c|c|c|}
\hline $\begin{array}{c}\text { Guía } \\
\text { (Enfoque) }\end{array}$ & $\begin{array}{l}\text { Resumen sobre la evidencia } \\
\text { (Calidad de la evidencia) }\end{array}$ & $\begin{array}{l}\text { Recomendaciones } \\
\text { (Grado) }\end{array}$ & $\begin{array}{l}\text { Referencias bibliográficas } \\
\text { (Tipo de publicación) }\end{array}$ & Comentarios \\
\hline & $\begin{array}{l}\text { lactancia materna hasta que la ganancia de peso es } \\
\text { satisfactoria }(72,73) \text {. } \\
\text { Los parámetros de la pérdida de peso del niño y cuándo } \\
\text { debería empezar a ganar peso no están basados en la } \\
\text { evidencia todavía }(73-75) \text {. Sin embargo, existe un consenso } \\
\text { general de que la pérdida de peso en el nacimiento debería } \\
\text { recuperarse en aproximadamente } 2 \text { semanas }(38,39,73) \text {. }\end{array}$ & & $\begin{array}{l}\text { Consultants Association. } \\
\text { (2005) } \\
\text { 73. Noel-Weiss J et al (2008). } \\
\text { 74. Macdonald PD, (2003). } \\
\text { 75. lyer NP et al (2008). }\end{array}$ & \\
\hline
\end{tabular}

\subsection{Otros documentos}

\begin{tabular}{|c|c|c|c|c|}
\hline $\begin{array}{l}\text { Guía } \\
\text { (Enfoque) }\end{array}$ & $\begin{array}{l}\text { Resumen sobre la evidencia } \\
\text { (Calidad de la evidencia) }\end{array}$ & $\begin{array}{l}\text { Recomendaciones } \\
\text { (Grado) }\end{array}$ & $\begin{array}{l}\text { Referencias bibliográficas } \\
\text { (Tipo de publicación) }\end{array}$ & Comentarios \\
\hline $\begin{array}{l}\text { Documento } \\
\text { Ministerio } \\
\text { sobre IHAN, } \\
2011\end{array}$ & $\begin{array}{l}\text { Las pérdidas de peso entre el } 8-10 \% \text { pueden considerarse } \\
\text { dentro de límites normales si no existen problemas y el } \\
\text { examen físico es normal, pero es indicación de evaluación } \\
\text { cuidadosa y de posible asistencia técnica. } \\
\text { En la mayoría de los casos, aunque puede ser necesaria la } \\
\text { evaluación de la técnica de la lactancia, no está indicada la } \\
\text { administración de suplementos, como cuando la pérdida } \\
\text { de peso es < al } 7 \% \text { y no existe hemólisis u otra patología } \\
\text { (5). } \\
\text { Existen algunas situaciones que nos pueden plantear la } \\
\text { indicación de suplementos, como la pérdida de peso } \\
\text { superior al } 8-10 \% \text { asociada a retraso en la lactogénesis } \\
\text { (después del } 5 \text { día) }\end{array}$ & $\begin{array}{l}\text { Lo que se debería hacer: } \\
\text { 7. Antes de administrar suplementos es necesario } \\
\text { evaluar una toma (postura, agarre y transferencia } \\
\text { de leche) (19). La mayoría de los RN que } \\
\text { permanecen con sus madres y maman } \\
\text { adecuadamente pierden < del } 7 \% \text { del peso del } \\
\text { peso de nacimiento. Una pérdida ponderal } \\
\text { superior puede indicar una transferencia } \\
\text { inadecuada de leche o una producción baja de la } \\
\text { misma. Las pérdidas de peso entre el } 8-10 \% \\
\text { pueden considerarse dentro de límites normales si } \\
\text { no existen problemas y el examen físico es normal } \\
\text { pero es indicación de evaluación cuidadosa y de } \\
\text { posible asistencia técnica. } \\
\text { 8. El pediatra debe ser avisado si: } \\
\text { El RN muestra signos de enfermedad además de } \\
\text { ingesta inadecuada. } \\
\text { La pérdida de peso del RN es superior al } 7 \%\end{array}$ & $\begin{array}{l}\text { 5. Lang S et al, } 1994 \\
\text { 19. Ryan K et al, } 1997 .\end{array}$ & \\
\hline $\begin{array}{l}\text { ABM Clinical } \\
\text { Protocol \#3, } \\
2009\end{array}$ & $\begin{array}{l}\text { Los recién nacidos pierden peso debido a una diuresis } \\
\text { fisiológica de liquido extracelular siguiendo la transición a la } \\
\text { vida extrauterina (8). La máxima pérdida de peso normal es } \\
\text { de } 5.5-6.6 \% \text { del peso al nacer en bebés que fueron } \\
\text { amamantados exclusivamente de manera óptima } \\
(14,15,21,22) \text { y ocurre entre los dos y tres días de vida }(48- \\
72 \text { horas después de nacer) }(14,15,21) \text {. Los bebés } \\
\text { amamantados de forma óptima recuperan el peso al nacer }\end{array}$ & $\begin{array}{l}\text { - Entre } 48 \text { y } 72 \text { horas de vida nadir entre } 5,5 \text { y } \\
\text { 6,6\% } \\
\text { - Recuperación del peso promedio: } 8,3 \text { días } \\
\text { (97,5\% lo recuperado en } 21 \text { días). }\end{array}$ & $\begin{array}{l}\text { 8. Zangen } S \text {, et al } 2001 \\
\text { 14. Marchini G et al, } 1997 \\
\text { 15. Rodriquez } \mathrm{G} \text { et al, } 2000 \\
\text { 21. MacDonald } \mathrm{P} \text { et al, } 2003 \\
\text { 22. Martens PJ et al, } 2000 .\end{array}$ & \\
\hline
\end{tabular}




\begin{tabular}{|c|c|c|c|}
\hline $\begin{array}{c}\text { Guía } \\
\text { (Enfoque) }\end{array}$ & $\begin{array}{c}\text { Resumen sobre la evidencia } \\
\text { (Calidad de la evidencia) }\end{array}$ & $\begin{array}{c}\text { Recomendaciones } \\
\text { (Grado) }\end{array}$ & $\begin{array}{c}\text { Referencias bibliográficas } \\
\text { (Tipo de publicación) }\end{array}$ \\
\hline & $\begin{array}{l}\text { en un promedio (intervalo de confianza de 95\%) de 8.3 días } \\
\text { (7.7-8.9) con el 97.5\% recuperando su peso al nacer a los } \\
21 \text { días (21). El porcentaje de pérdida de peso debe ser } \\
\text { observado muy de cerca para detectar los valores extremos, } \\
\text { pero la mayoría de los bebés amamantados no requerirán el } \\
\text { uso de suplementos. }\end{array}$ & & \\
\hline
\end{tabular}

\subsection{Revisiones sistemáticas}

Se ha identificado una revisión sistemática publicada en 2008 (1), que encuentra que la pérdida media de peso se sitúa entre el 5,7\% y el $6,6 \%$ (desviación estándar alrededor del $2 \%$ ), y que el peso de nacimiento se recupera en las primeras dos semanas de vida.

Tabla 3- Resumen de RS actuales

\begin{tabular}{|c|c|c|c|c|c|c|}
\hline $\begin{array}{l}\text { Referencia } \\
\text { (Cita } \\
\text { Abreviada) }\end{array}$ & $\begin{array}{l}\text { Estudio (Diseño y } \\
\text { objetivo) }\end{array}$ & $\begin{array}{l}\text { Población } \\
\text { (no y características) }\end{array}$ & $\begin{array}{l}\text { Descripción de las intervenciones } \\
\text { comparaciones, exposiciones o } \\
\text { pruebas a estudio }\end{array}$ & $\begin{array}{l}\text { Resultados } \\
\text { (Estimadores de resultados-Magnitud del } \\
\text { efecto) }\end{array}$ & $\begin{array}{l}\text { Conclusiones } \\
\text { (conclusiones) }\end{array}$ & $\begin{array}{l}\text { Comentarios } \\
\text { Calidad de la } \\
\text { evidencia } \\
\text { Financiación } \\
\text { comentarios) }\end{array}$ \\
\hline $\begin{array}{l}\text { Noel Weiss J et } \\
\text { al, } 2008\end{array}$ & $\begin{array}{l}\text { Diseño: RS } \\
\text { Objetivo: } \\
\text { establecer la } \\
\text { referencia de } \\
\text { pérdida de peso en } \\
\text { las dos primeras } \\
\text { semanas tras el } \\
\text { nacimiento } \\
\text { realizando una RS } \\
\text { de estudios que } \\
\text { reportan el peso al } \\
\text { nacer de los niños } \\
\text { amamantados de } \\
\text { forma exclusiva. }\end{array}$ & $\begin{array}{l}11 \text { estudios cumplen } \\
\text { los criterios de } \\
\text { inclusión. }\end{array}$ & $\begin{array}{l}\text { Las definiciones, tipos de mediciones y } \\
\text { formas de reporte varían entre los } \\
\text { estudios. } 10 \text { son observacionales y un } \\
\text { estudio era un ECA que proporcionaba } \\
\text { datos en la rama control que fueron } \\
\text { utilizados. }\end{array}$ & $\begin{array}{l}\text { La pérdida media de peso se sitúa entre } \\
\text { el } 5,7 \% \text { y el } 6,6 \% \text {, con desviaciones } \\
\text { estándar sobre el } 2 \% \text {.El rango de la } \\
\text { mediana de la pérdida de peso se sitúan } \\
\text { entre } 3,2 \% \text { y } 8,3 \% \text {, estando en la mayoría } \\
\text { sobre el } 6 \% \text {. La mayoría de los niños de } \\
\text { estos estudios recuperan el peso de } \\
\text { nacimiento en las dos primeras semanas } \\
\text { postparto. Parece que los días } 2 \text { y } 3 \text { tra el } \\
\text { parto son los días en los que se da la } \\
\text { máxima pérdida de peso. }\end{array}$ & $\begin{array}{l}\text { Los métodos para } \\
\text { reportar la pérdida } \\
\text { de peso eran } \\
\text { inconsistentes. El } \\
\text { máximo del } 7 \% \\
\text { recomendado por } \\
\text { cuatro guías } \\
\text { parece basarse en } \\
\text { la pérdida media } \\
\text { de peso y no tiene } \\
\text { en cuenta la } \\
\text { desviación } \\
\text { estándar. }\end{array}$ & $\begin{array}{l}\text { Se necesitan } \\
\text { más estudios } \\
\text { para entender } \\
\text { las causas de la } \\
\text { pérdida de peso } \\
\text { neonatal y sus } \\
\text { implicaciones en } \\
\text { la } \\
\text { morbimortalidad. }\end{array}$ \\
\hline
\end{tabular}




\subsection{Resumen de GPCs base y RSs disponibles}

La guía de NICE no hace recomendaciones relacionadas con la interpretación de la pérdida de peso del recién nacido en los primeros días (2).

La iniciativa IHAN señala que una pérdida ponderal superior al $7 \%$ puede indicar una transferencia inadecuada de leche o una producción baja de la misma. Si no existen problemas y el examen físico es normal, las pérdidas de peso entre el 8 y $10 \%$ pueden considerarse dentro de los límites normales, aunque es indicación de evaluación cuidadosa y de posible asistencia técnica (3).

La American Academy of Breastfeeding (4) señala que la pérdida de peso nadir se da entre las 48 y $72 \mathrm{~h}$ de vida y que ésta se sitúa entre el 5,5 y el $6,6 \%$, y que su recuperación se da en un promedio de 8,3 días, recuperándolo en los primeros 21 días el $97,5 \%$ de los niños.

La Perinatal Services $B C$ (5) señala que la derivación a un profesional sanitario de lactancia materna está indicada cuando se da un retraso en la lactogénesis y una pérdida continua del peso del niño, o el output en el niño es inadecuado y la pérdida de peso es continua.

La revisión sistemática identificada (1) encuentra que la pérdida media de peso se sitúa entre el 5,7\% y el 6,6\% (desviación estándar alrededor del $2 \%$ ), y que el peso de nacimiento se recupera en las primeras dos semanas de vida. Asimismo, concluye que se necesita más investigación para entender las causas de la pérdida de peso neonatal y sus implicaciones en morbi-mortalidad.

\subsection{Conclusión (marcar con una X):}

\begin{tabular}{|l|l|} 
& Adopción GPC/Revisión sistemática \\
\hline $\mathrm{X}$ & Elaboración parcial \\
\hline & Elaboración de novo
\end{tabular}

\subsection{Diseño de la estrategia de búsqueda de estudios individuales}

\begin{tabular}{|l|l|}
\hline Criterios de selección de estudios & Estudios observacionales \\
\hline Período de búsqueda & 2008-junio de 2015 \\
\hline Bases de datos & Cochrane Library \\
& MEDLINE, via Pubmed \\
& EMBASE, via Ovid \\
& Cinahl, via EBSCOhost databases \\
& PsylNFO, via OVID \\
\hline
\end{tabular}

Ver estrategias de búsqueda de estudios originales en el ANEXO I. 
4- Resumen de la evidencia (Tablas de estudios individuales y valoración de calidad en el ANEXO X)

4.1- GRADE Evidence Profile

No procede. 


\section{2- Resumen de la Evidencia}

En el estudio de mayor calidad incluido (6) en esta revisión, 971 recién nacidos eran pesados al nacer, a las 48 horas y a los cinco, siete y diez días de vida, encontrándose que la pérdida media de peso era diferente según el tipo de alimentación, siendo mayor en niños con lactancia materna $(6,6 \%)$ versus lactancia artificial $(3,5 \%)$. La mediana del tiempo para recuperar el peso al nacer era de 8,3 días (P97,5 de 21) y de 6,5 días (P97,5 de 16,7), respectivamente. Sin embargo, no queda claro que en este estudio el manejo de la lactancia materna fuera óptimo. Además, los niños eran pesados con poca frecuencia.

En 2015 Bertini y colaboradores (7) recogieron de forma retrospectiva el peso de 1760 recién nacidos a término, por parto vaginal y sin malformaciones, asfixia neonatal u otras complicaciones, cada 12 horas. Todos los niños fueron puestos en CPP tras el parto y tomaron lactancia materna exclusiva, $\mathrm{Y}$ el alta hospitalaria se producía entre las 48 y 72 horas tras el parto.

La pérdida media de peso estuvo cerca del $6 \%( \pm 1,73 \%)$, no habiendo niños que perdieran más del $10 \%$, lo que concuerda con los resultados de estudios anteriores (8;9).

El tiempo medio hasta alcanzar el peso nadir fue de $43,72 \mathrm{~h}( \pm 11.61)$, al igual que en otros estudios $(6 ; 8 ; 9)$. El $72 \%$ de los niños ya estaba recuperando peso antes del alta médica (48-72 horas), y casi todos los demás habían ganado peso al día siguiente de haber recibido el alta.

Los autores elaboraron una gráfica para realizar el seguimiento de la pérdida de peso en las primeras 72 horas de vida de un niño cuya madre ha recibido un apoyo adecuado a la lactancia materna.

En el estudio de Crossland et al (8), en el que también se construyó una gráfica sobre la pérdida de peso de recién nacidos sanos amamantados en las primeras dos semanas de vida. En los primeros días los resultados fueron similares a los de Bertini, si bien el número de niños incluidos fue menor (111 niños amamantados). Se encontró que los niños amamantados pierden una media del $6,4 \%$ del peso al nacer (IC95\% de 5,5 a 7,3\%), y que el $54 \%$ de los niños tardó más de ocho días en recuperar su peso de nacimiento.

En este caso, el estudio se realizó en un hospital con una política de apoyo a la lactancia materna., y los autores concluyeron que si el peso no empieza a aumentar para el sexto día de vida, se debería considerar la existencia de problemas con la alimentación.

Sin embargo, en la práctica habitual no todos los niños nacen por un parto natural ni inician de forma temprana la lactancia materna, por lo que es probable que pierdan algo más de peso o que tarden más tiempo en recuperarlo. En un estudio reciente (10), que incluía niños nacidos por parto vaginal o por cesárea, se construyeron también los nomogramas para representar la pérdida de peso en los primeros días observándose que a las 48 horas tras el nacimiento el $5 \%$ de los bebés nacidos por vía vaginal y el $10 \%$ de los nacidos por cesárea habían perdido más del $10 \%$ del peso al nacer, y que a las 72 horas el $25 \%$ de los nacidos por cesárea había perdido más del $10 \%$. En este caso, no se conoce cuál fue el apoyo prestado a la lactancia materna y la pérdida de datos para el cálculo de las curvas fue mucho mayor. 
En otro estudio retrospectivo (11) se encontró que la pérdida de peso $\geq$ al $5 \%$ en el primer día predice una pérdida ponderal nadir del $10 \%$ con un OR de 4,06 (IC95\% de 3,69 a 4,46), por lo que los autores concluyen que este punto de corte se podría utilizar para identificar aquellos niños que podrían beneficiarse de intervenciones dirigidas al apoyo de la lactancia materna y prevención de pérdida excesiva de peso.

ACTUALIZADO A FECHA DE: 31 de Octubre de 2016 


\section{5- De la evidencia a la recomendación (Tabla de EtR)}

\section{¿Cómo interpretar la pérdida de peso del recién nacido sano amamantado en los primeros días?}

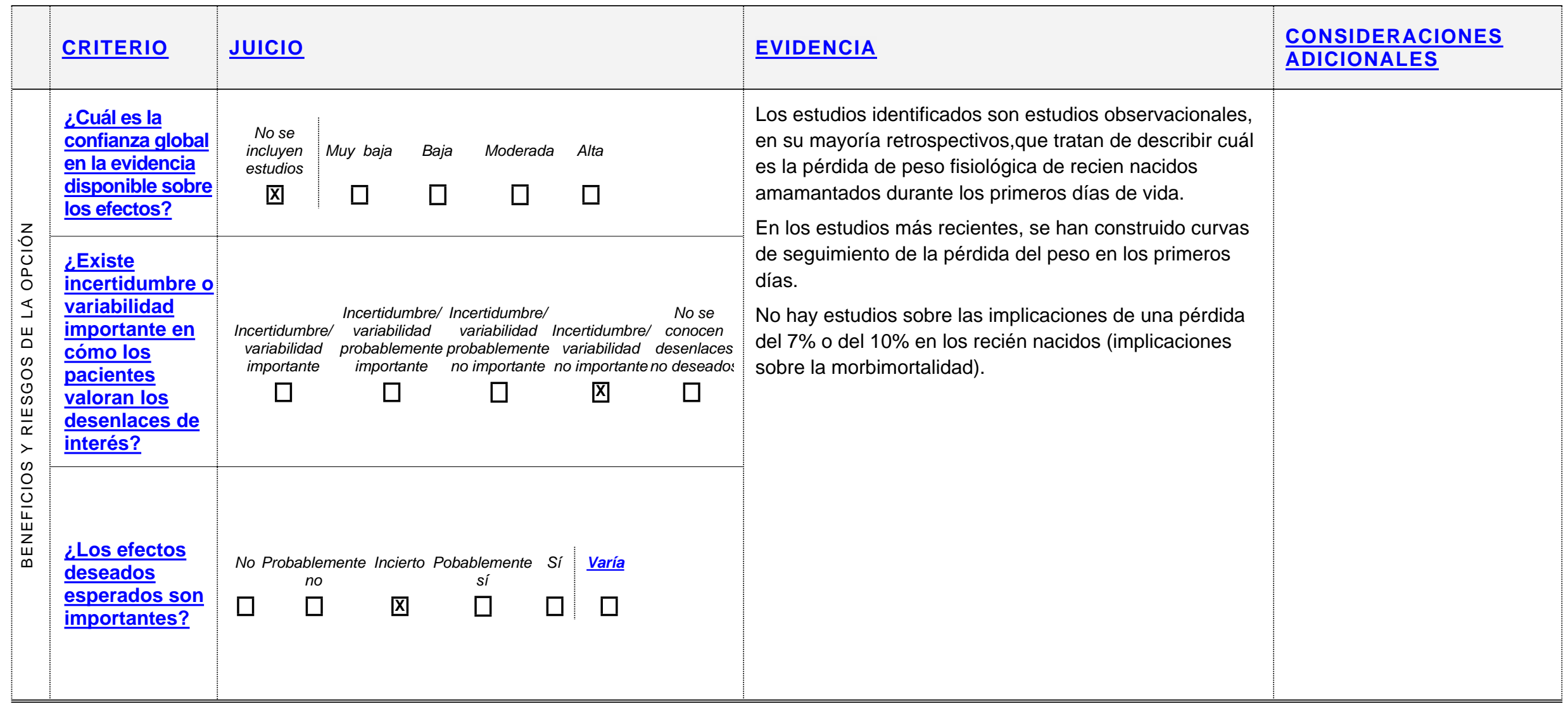




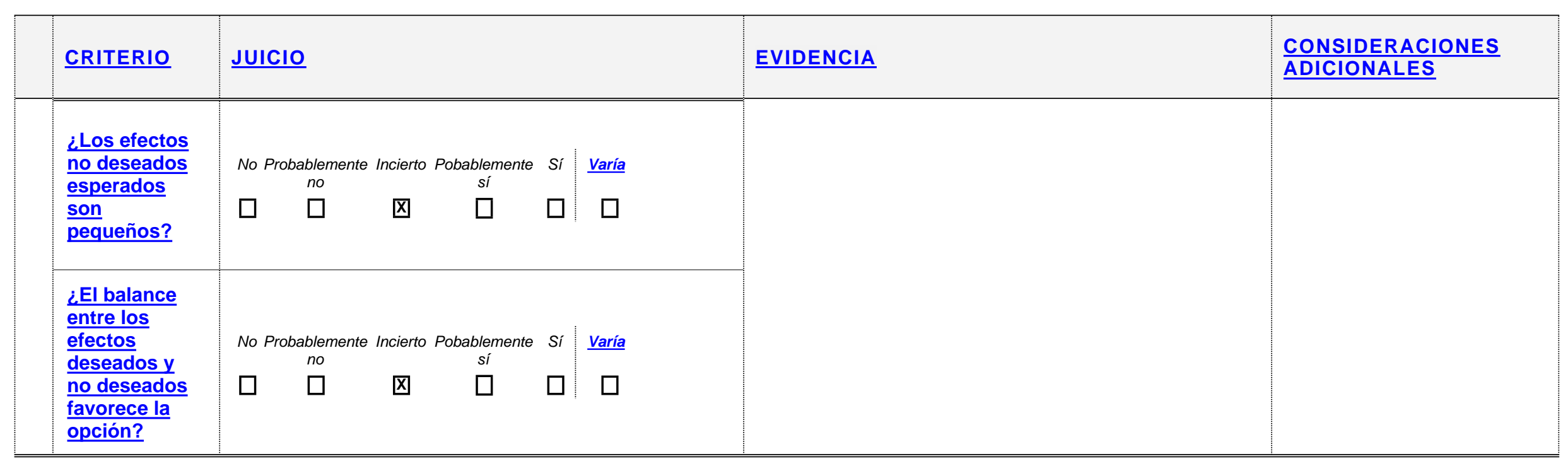


¿Cómo interpretar la pérdida de peso del recién nacido sano amamantado en los primeros días?

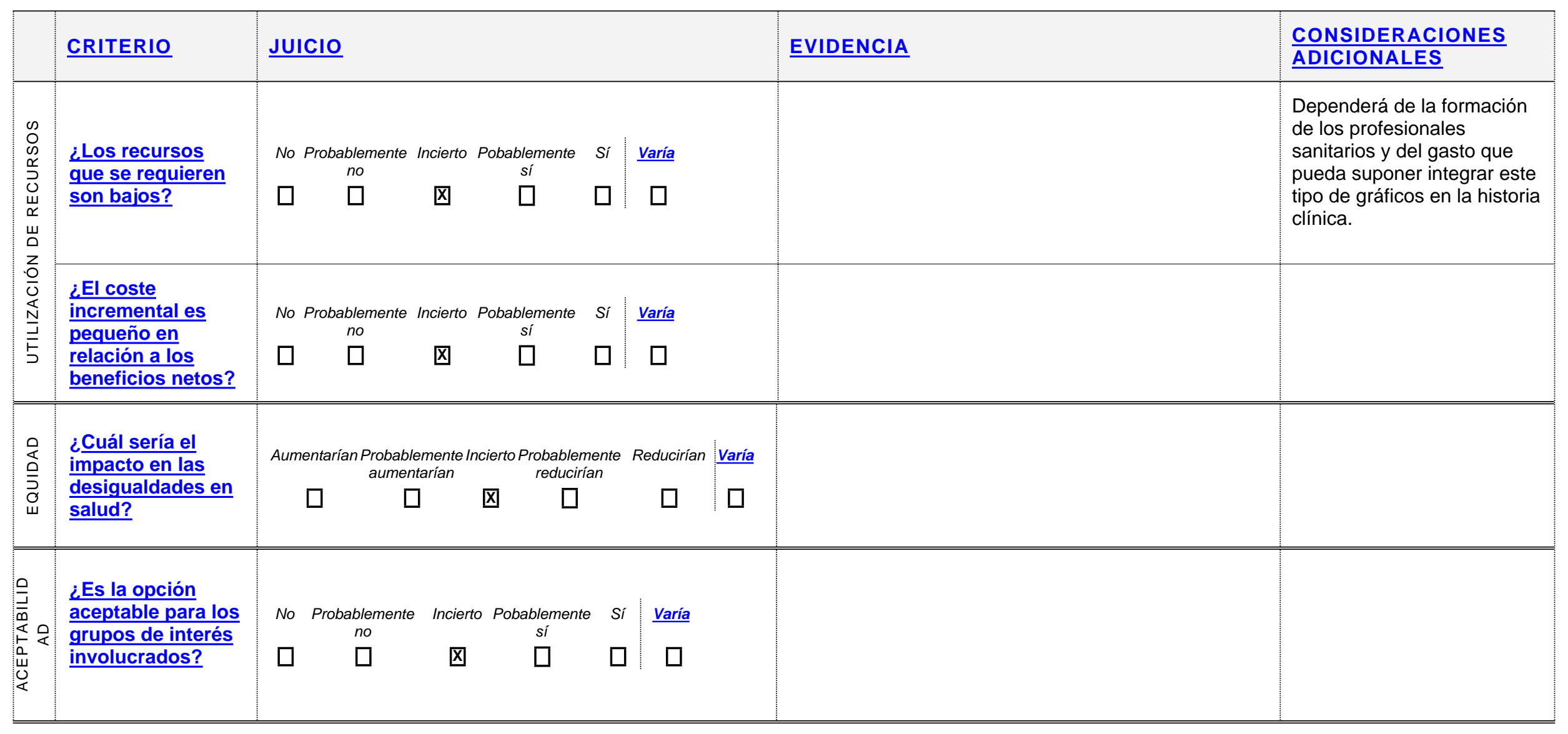




\begin{tabular}{|c|c|c|c|c|c|c|c|}
\hline & $\underline{\text { CRITERIO }}$ & $\underline{\text { JUICIO }}$ & & & & EVIDENCIA & $\begin{array}{l}\text { CONSIDERACIONES } \\
\text { ADICIONALES }\end{array}$ \\
\hline 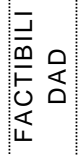 & $\begin{array}{l}\text { ¿La } \\
\text { implementación } \\
\text { de la opción es } \\
\text { factible? }\end{array}$ & $\begin{array}{cc}\text { No } & \text { Probablemente } \\
& \text { no } \\
\square & \square\end{array}$ & $\begin{array}{c}\text { Incierto Pobablemente } \\
\text { sí } \\
\square \quad \square\end{array}$ & $\begin{array}{l}\text { Si } \\
\square\end{array}$ & $\frac{\underline{\text { Varía }}}{\square}$ & & \\
\hline
\end{tabular}

\begin{tabular}{|c|c|c|}
\hline $\begin{array}{l}\text { Balance de las } \\
\text { consecuencias }\end{array}$ & $\begin{array}{l}\text { Las consecuencias no } \\
\text { deseadas superan } \\
\text { claramente las } \\
\text { consecuencias deseadas } \\
\text { en la mayoría de los } \\
\text { escenarios }\end{array}$ & $\begin{array}{l}\text { Las consecuencias no } \\
\text { deseadas probablemente } \\
\text { superan las } \\
\text { consecuencias deseadas } \\
\text { en la mayoría de los } \\
\text { escenarios }\end{array}$ \\
\hline
\end{tabular}

El balance entre las consecuencias deseadas y no deseadas está muy equilibrado o es incierto
Las consecuencias

$$
\text { deseadas }
$$

probablemente superan las consecuencias no deseadas en la mayoría de los escenarios
Las consecuencias deseadas claramente superan las consecuencias no deseadas en la mayoría de los escenarios

\section{$\square$}

$\square$

凶

$\square$

\begin{tabular}{|c|c|c|c|c|}
\hline$\frac{\text { Tipo de }}{\text { recomendación }}$ & Se recomienda no ofrecer la opción & Se sugiere no ofrecer la opción & Se sugiere ofrecer la opción & $\begin{array}{l}\text { Se recomienda } \\
\text { ofrecer la opción }\end{array}$ \\
\hline
\end{tabular}

$\square$ $\square$ $\square$ $\square$ 


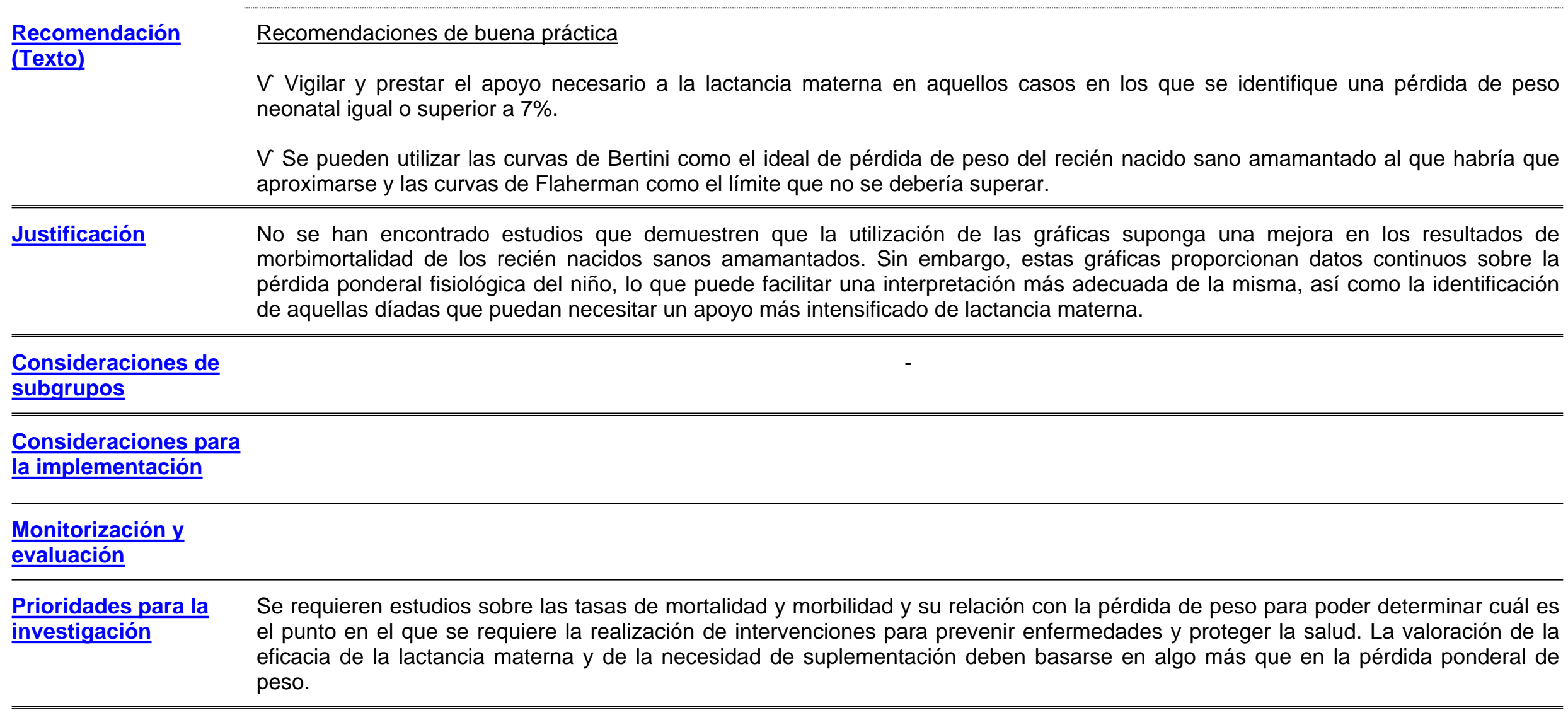




\section{ANEXO I, ESTRATEGIAS DE BÚSQUEDA}

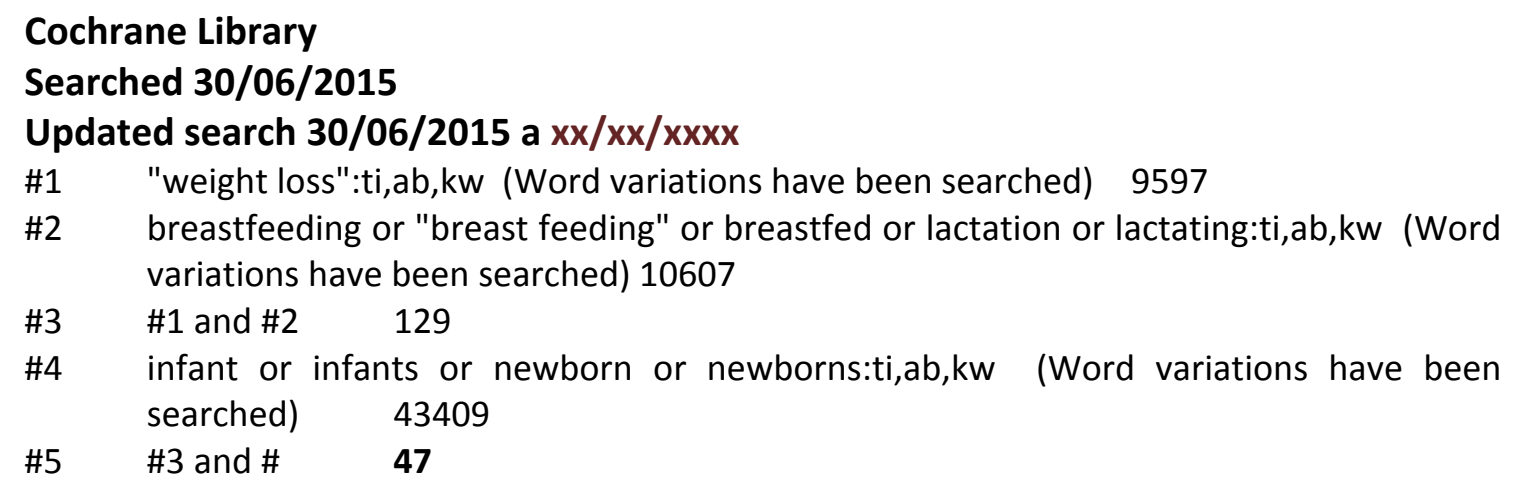

\section{MEDLINE, via Pubmed}

Searched 30/06/2015

Updated search 30/06/2015 a xx/xx/xxxx

\#1 Search "weight loss"[Title/Abstract] 64508

\#2 Search (breastfeeding[Title/Abstract] OR "breast feeding"[Title/Abstract] OR breastfed[Title/Abstract] OR lactation[Title/Abstract] OR lactating[Title/Abstract]) 68535

\#3 Search \#1 AND \#2 635

\#4 Search \#1 AND \#2 Filters: Newborn: birth-1 month; Infant: birth-23 months 221

\#5 Search (infant[Title/Abstract] OR infants[Title/Abstract] OR newborn[Title/Abstract] OR newborns[Title/Abstract]) 434726

\#6 $\quad$ Search \#3 AND \#5 261

\#7 Search \#5 OR \#6 297

\section{EMBASE, via Ovid}

Searched 30/06/2015

Updated search 30/06/2015 a xx/xx/xxxx

$1 \quad$ "weight loss".ti,ab,kw. 99453

2 (breastfeeding or "breast feeding" or breastfed or lactation or lactating).ti,ab,kw. 80400

$3 \quad 1$ and $2 \quad 736$

$4 \quad \operatorname{limit} 3$ to infant $<$ to one year $>54$

5 (infant or infants or newborn or newborns).ti,ab,kw. 538757

$6 \quad 3$ and $5 \quad 311$

$7 \quad 4$ or $6 \quad 318$

\section{CINAHL, via EBSCOhost databases}

\section{Searched 30/06/2015}

\section{Updated search 30/06/2015 a xx/xx/xxxx}

S1 TI "weight loss" OR AB "weight loss" 9291

S2 TI ( breastfeeding or "breast feeding" or breastfed or lactation or lactating ) OR AB ( breastfeeding or "breast feeding" or breastfed or lactation or lactating ) 11368 \#1 AND \#2 127 
GPC Lactancia Materna- Pregunta 19. Pérdida peso primeros días.

S4 S3 Limitadores - Grupos de edad: Infant, Newborn: birth-1 month, Infant: 1-23 months 63

S5 TI (infant or infants or newborn or newbornsnfant ) OR AB ( infant or infants or newborn or newborns ) 50,839

S6 S3 AND S5 76

S7 $\quad$ S4 OR S6 $\quad 82$ 


\section{1- BIBLIOGRAFÍA}

(1) Noel-Weiss J, Courant G, Woodend AK. Physiological weight loss in the breastfed neonate: a systematic review. Open Med 2008;2(4):e99-e110.

(2) NICE. Postnatal care up to 8 weeks after birth. Julio 2006 (actualizado en Febrero de 2015). Disponible en: http://guidance.nice.org.uk/CG37.

(3) Estrategia centros de salud IHAN. Revisada, actualizada y ampliada para la atención integral en los centros de salud. Manual para la acreditación IHAN. España. 2014. Disponible en:

https://www.ihan.es/docs/documentacionacreditacion/centros salud/Manual para la acreditacion IHAN en AP 2015. pdf.

(4) ABM Clinical Protocol \#3: Hospital Guidelines for the Use of Supplementary Feedings in the Healthy Term Breastfed Neonate, Revised 2009. BREASTFEEDING MEDICINE. Volume 4, Number 3, 2009.

(5) Perinatal Services BC Health Promotion Guideline. Breastfeeding Healthy Term Infants. March 2015. Disponible en:

http://www.perinatalservicesbc.ca/Documents/Guidelines-

Standards/HealthPromotion/BreastfeedingHealthyTermInfantGuideline.pdf.

(6) Macdonald PD, Ross SR, Grant L, Young D. Neonatal weight loss in breast and formula fed infants. Arch Dis Child Fetal Neonatal Ed 2003 Nov;88(6):F472F476.

(7) Bertini G, Breschi R, Dani C. Physiological weight loss chart helps to identify high-risk infants who need breastfeeding support. Acta Paediatr 2015 Oct;104(10):1024-7.

(8) Crossland DS, Richmond S, Hudson M, Smith K, Abu-Harb M. Weight change in the term baby in the first 2 weeks of life. Acta Paediatr 2008 Apr;97(4):425-9.

(9) Grossman X, Chaudhuri JH, Feldman-Winter L, Merewood A. Neonatal weight loss at a US Baby-Friendly Hospital. J Acad Nutr Diet 2012 Mar;112(3):410-3.

(10) Flaherman VJ, Schaefer EW, Kuzniewicz MW, Li SX, Walsh EM, Paul IM. Early weight loss nomograms for exclusively breastfed newborns. Pediatrics 2015 Jan;135(1):e16-e23.

(11) Flaherman VJ, Kuzniewicz MW, Li S, Walsh E, McCulloch CE, Newman TB. First-day weight loss predicts eventual weight nadir for breastfeeding newborns. Arch Dis Child Fetal Neonatal Ed 2013 Nov;98(6):F488-F492. 


\section{PREGUNTA CLÍNICA № 20}

¿Qué curvas de crecimiento reflejan mejor el crecimiento normal de un niño sano? ¿Cuáles son los parámetros que se deben monitorizar?

\section{1- Pregunta clínica en formato PICO}

Tabla 1- Componentes de la pregunta clínica en formato PICO

\begin{tabular}{|l|l|}
\hline Pacientes & Niño sano \\
\hline Intervención & $\begin{array}{l}\text { Monitorización del crecimiento con estándares basados en } \\
\text { condiciones ideales de crecimiento (curvas de la OMS) }\end{array}$ \\
\hline Comparación & $\begin{array}{l}\text { Monitorización del crecimiento con estándares construidos } \\
\text { con datos poblacionales (estándares locales) }\end{array}$ \\
\hline Resultados & $\begin{array}{l}\text { Detección de problemas de ingesta insuficiente de leche o } \\
\text { detectar situaciones en que sea preciso hacer un estudio } \\
\text { más a fondo para encontrar la causa del problema. }\end{array}$ \\
\hline Tipo de estudio & Estudios observacionales \\
\hline
\end{tabular}

\section{2- Introducción}

Se han venido utilizando gráficas de crecimiento basadas en poblaciones infantiles con diferentes patrones de alimentación que han generado incertidumbre sobre el patrón de crecimiento de algunos lactantes amamantados. Se plantea si utilizar gráficas basadas en poblaciones con buenas condiciones sociosanitarias y una alimentación óptima con lactancia materna, establecería un estándar de crecimiento fiable. 


\section{ESTRATEGIA DE ELABORACIÓN DE LA PREGUNTA}

\subsection{GPC Base}

Tabla 2- Resumen de GPC Base

\begin{tabular}{|c|c|c|c|c|}
\hline $\begin{array}{c}\text { Guía } \\
\text { (Enfoque) }\end{array}$ & $\begin{array}{l}\text { Resumen sobre la evidencia } \\
\text { (Calidad de la evidencia) }\end{array}$ & $\begin{array}{l}\text { Recomendaciones } \\
\text { (Grado) }\end{array}$ & $\begin{array}{l}\text { Referencias bibliográficas } \\
\text { (Tipo de publicación) }\end{array}$ & Comentarios \\
\hline $\begin{array}{l}\text { NICE_2006 } \\
\text { (Actualiz. } \\
\text { 2011) }\end{array}$ & $\begin{array}{l}\text { La monitorización rutinaria del crecimiento, incluyendo la talla (longitud) y } \\
\text { peso, está ampliamente aceptada y forma parte del seguimiento } \\
\text { estándar de la salud del niño. } \\
\text { La monitorización del crecimiento se ha utilizado como una herramienta } \\
\text { de "screening" para identificar trastornos y enfermedades que pueden } \\
\text { afectar al crecimiento. La Fundación de Crecimiento del niño organizó en } \\
\text { julio de } 1998 \text { un encuentro de pediatras, endocrinos, médicos de salud } \\
\text { pública, médicos de familia y enfermeras de varias disciplinas para } \\
\text { considerar si la monitorización del crecimiento podía considerarse como } \\
\text { un programa de screening (Elliman Hall 2003). Tras examinar la } \\
\text { evidencia, se desarrollaron una serie de recomendaciones para la } \\
\text { práctica clínica. También se señaló la necesidad de investigación y de un } \\
\text { debate futuro. Los participantes del encuentro, denominados "Coventry } \\
\text { Consensus", señalaron lo siguiente para recién nacidos normales: } \\
\text { 1. El peso al nacer, recogido de forma correcta y en relación con la edad } \\
\text { gestacional, es un primer paso esencial en la monitorización del } \\
\text { crecimiento. } \\
\text { 2. La medición de la longitud en el neonato normal no forma parte de un } \\
\text { programa nacional de monitorización del crecimiento } \\
\text { 3. No se ha encontrado una justificación para monitorizar la longitud en } \\
\text { los primeros dos años de vida. } \\
\text { El grupo también consideró la monitorización posterior del peso. Se } \\
\text { reconoció que la ganancia de peso en las primeras semanas de vida } \\
\text { puede ser una causa de preocupación, encontrando poca evidencia } \\
\text { sobre la frecuencia óptima de medición del peso en el neonato. Se } \\
\text { consideró que las consultas rutinarias de atención primaria a los } 2,3,4 \\
\text {,8 y } 12 \text { meses de vida (vacunación y vigilancia) eran una oportunidad } \\
\text { para pesar al niño, si así estaba indicado. Sin embargo, no hay evidencia } \\
\text { de que pesar de forma regular a un bebé sano tiene algún beneficio. Las } \\
\text { recomendaciones del grupo sobre la medición del peso de forma } \\
\text { rutinaria fueron las siguientes: } \\
1 \text {. Los bebés deberían ser pesados (desnudos) en las visitas rutinarias } \\
\text { de vacunación y vigilancia. }\end{array}$ & & $\begin{array}{l}\text { Elliman D\& Hall D. } 2003 . \\
\text { Health for all children. } 4^{\text {th }} \text { edn. } \\
\text { Oxford: Oxford University } \\
\text { Press. } \\
\text { Panpanich R\& Garner, P. } \\
\text { 1999. "Growth monitoring in } \\
\text { children." In Cochrane } \\
\text { Database of Systema tic } \\
\text { Reviews 1999, issue 4, } \\
\text { Chichester, John Wiley \& Sons } \\
\text { Ltd. } \\
\text { Sachs, M., Dykes, F., \& } \\
\text { Carter, B. 2005, "Weight } \\
\text { monitoring of breastfed babies } \\
\text { in the UK: centile charts, } \\
\text { scales and weighing } \\
\text { frequency", Maternal and Child } \\
\text { Nutrition, vol.1, no.2,pp.63-7 } \\
\text { 6. } \\
\text { Cole, T.J., Paul A.A. \& } \\
\text { Whitehead, T.J. 2002, "Weight } \\
\text { reference charts for British } \\
\text { long-term breastfed infants," } \\
\text { Acta Paediatrica, vol, 91 (12), } \\
\text { pp. 1296-1300. }\end{array}$ & \\
\hline
\end{tabular}




\begin{tabular}{|c|c|c|c|c|}
\hline $\begin{array}{c}\text { Guía } \\
\text { (Enfoque) }\end{array}$ & $\begin{array}{l}\text { Resumen sobre la evidencia } \\
\text { (Calidad de la evidencia) }\end{array}$ & $\begin{array}{l}\text { Recomendaciones } \\
\text { (Grado) }\end{array}$ & $\begin{array}{l}\text { Referencias bibliográficas } \\
\text { (Tipo de publicación) }\end{array}$ & Comentarios \\
\hline & $\begin{array}{l}\text { 2. De forma habitual, los niños que están creciendo no deberían ser } \\
\text { pesados más de una vez cada } 15 \text { días hasta los } 6 \text { meses de vida y de } \\
\text { forma mensual después, puesto que esto solo aumenta la ansiedad de } \\
\text { los padres. } \\
\text { Una revisión Cochrane sobre la monitorización del crecimiento en niños } \\
\text { (Panpanich and Garner, 1999) encontró dos ECA realizados en países } \\
\text { en desarrollo, concluyendo que no había suficiente información para } \\
\text { asegurar que la monitorización rutinaria del crecimiento tiene beneficios } \\
\text { sobre la salud del niño en cualquier escenario. } \\
\text { En relación a las gráficas de crecimiento, el "Joint Working Party on Chidl } \\
\text { Health Surveillance" recomendó la utilización de las gráficas de } 1990 \text {. } \\
\text { También advirtieron que los niños normales no tienen por qué seguir } \\
\text { siempre las líneas de crecimiento que se muestran en los gráficos. } \\
\text { En una revisión de gráficas de crecimiento existentes en el RU, Sachs et } \\
\text { al } 2005 \text { describieron la base de datos de la gráfica } 1990 \text { del RU. Se trata } \\
\text { de una gráfica que combina los datos transversales del "British } \\
\text { Standards Institute" de } 163 \text { niños de } 0 \text { a } 3 \text { meses y } 90 \text { niños de } 3 \text { a } 6 \\
\text { meses de vida con datos longitudinales del estudio de crecimiento infantil } \\
\text { de Cambridge, que incluye } 252 \text { niños reclutados entre } 1984 \text { y } 1988 \text {. Más } \\
\text { del } 98 \% \text { de los niños de ambas muestras eran de raza blanca y estatus } \\
\text { socioeconómico relativamente alto.120 de los niños del estudio de } \\
\text { Cambridge fueron amamantados al menos durante } 24 \text { semanas, siendo } \\
\text { introducidos los sólidos a las } 15 \text { semanas de media. } \\
\text { En } 2002 \text { se elaboraron unas nuevas gráficas basadas exclusivamente en } \\
\text { niños amamantados (Cole, Paul Whitehead } 2002 \text { ), utilizando los datos } \\
\text { de los } 120 \text { niños del estudio de Cambridge amamantados. Se ha } \\
\text { argumentado que estas gráficas son las que se deberían utilizar en el } \\
\text { RU. Sin embargo, no se ha probado si su uso mejora la precisión en las } \\
\text { derivaciones, afectan a la duración de la lactancia o a la confianza de los } \\
\text { padres, y si son generalizables. } \\
\text { La guía NICE señala que al tiempo que se estaba elaborando esta guía, } \\
\text { se acababan de lanzar las gráficas de crecimiento de la OMS, cuyo uso } \\
\text { todavía no había sido evaluado en el RU. }\end{array}$ & & & \\
\hline $\begin{array}{l}\text { Guía de } \\
\text { Práctica } \\
\text { Clínica sobre } \\
\text { la Prevención } \\
\text { y el } \\
\text { Tratamiento } \\
\text { de la }\end{array}$ & $\begin{array}{l}\text { La medición del SP y la OB en niños y niñas y adolescentes es difícil } \\
\text { porque no se dispone de una definición estandarizada de la OB infantil } \\
\text { que se aplique en todo el mundo, obligando a los profesionales a utilizar } \\
\text { unas curvas y tablas de referencia que sean válidas y útiles en su entorno. } \\
\text { Un segundo problema es seleccionar unos puntos de corte que definan las } \\
\text { categorías de normopeso, SO y OB. En el momento de la elaboración de } \\
\text { este documento no existe un consenso internacional sobre todos estos }\end{array}$ & $\begin{array}{l}\text { V Se recomienda utilizar las curvas } \\
\text { y las tablas de crecimiento del } \\
\text { estudio semilongitudinal } \\
\text { de Hernández et al. (1988) para } \\
\text { realizar el diagnóstico de sobrepeso } \\
\text { y obesidad en la infancia y } \\
\text { adolescencia. }\end{array}$ & $\begin{array}{l}56,43 \\
59,61-71 \\
72-85 \\
86-87 \\
53,58\end{array}$ & \\
\hline
\end{tabular}




\begin{tabular}{|c|c|c|c|c|}
\hline $\begin{array}{c}\text { Guía } \\
\text { (Enfoque) }\end{array}$ & $\begin{array}{l}\text { Resumen sobre la evidencia } \\
\text { (Calidad de la evidencia) }\end{array}$ & $\begin{array}{l}\text { Recomendaciones } \\
\text { (Grado) }\end{array}$ & $\begin{array}{l}\text { Referencias bibliográficas } \\
\text { (Tipo de publicación) }\end{array}$ & Comentarios \\
\hline $\begin{array}{l}\text { Obesidad } \\
\text { Infantojuvenil }\end{array}$ & 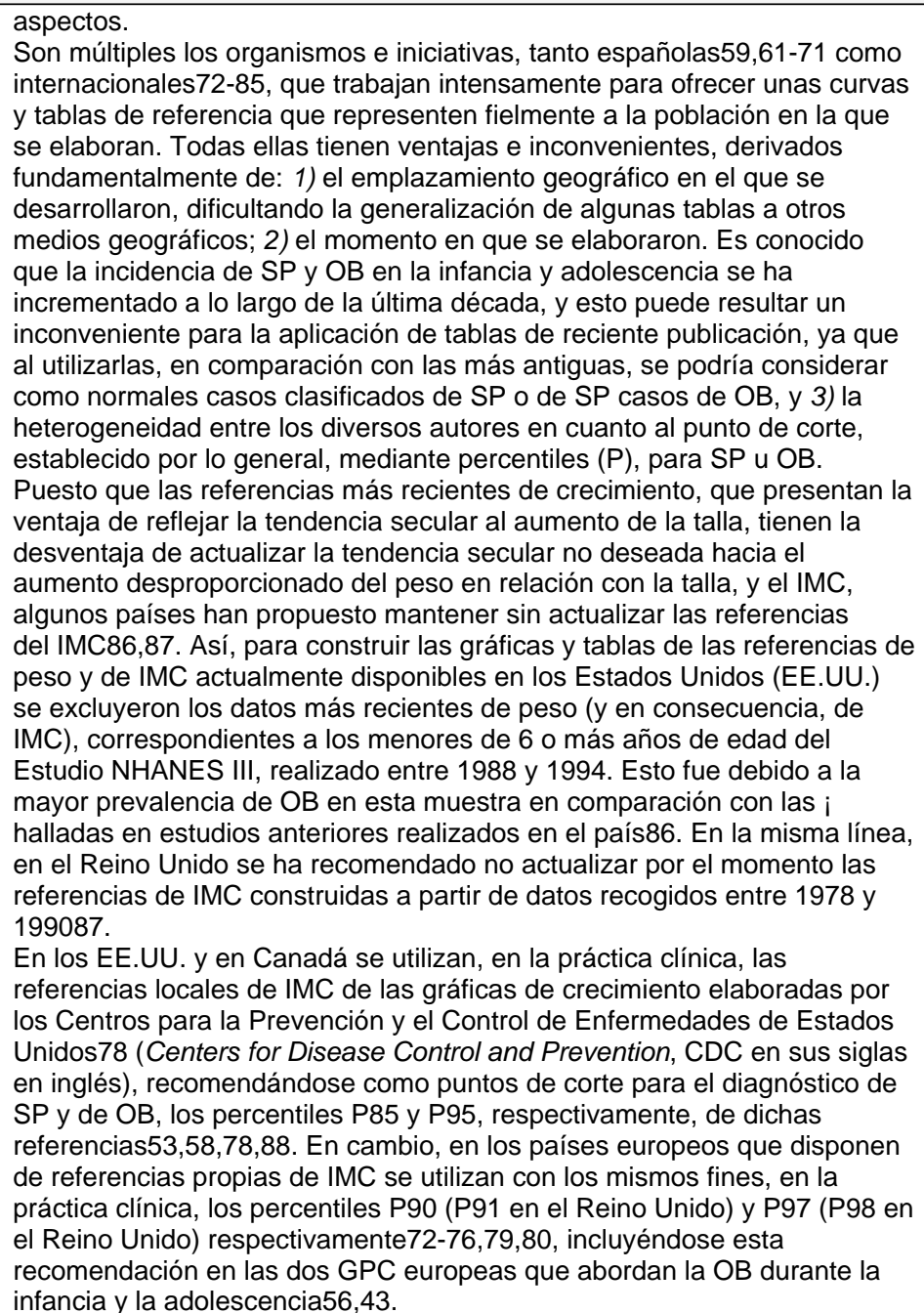 & $\begin{array}{l}\text { V Para el diagnóstico de sobrepeso, } \\
\text { el IMC debe ser igual o superior al } \\
\text { P90 e inferior al P97 para su edad y } \\
\text { sexo en las curvas y tablas de } \\
\text { crecimiento del estudio } \\
\text { semilongitudinal de Hernández et al. } \\
\text { (1988). } \\
\text { V Para el diagnóstico de obesidad, } \\
\text { el IMC debe ser igual o superior al } \\
\text { P97 para su edad y sexo en las } \\
\text { curvas y tablas de crecimiento del } \\
\text { estudio semilongitudinal de } \\
\text { Hernández et al. (1988). }\end{array}$ & & \\
\hline
\end{tabular}




\begin{tabular}{|c|c|c|c|c|}
\hline $\begin{array}{c}\text { Guía } \\
\text { (Enfoque) }\end{array}$ & $\begin{array}{l}\text { Resumen sobre la evidencia } \\
\text { (Calidad de la evidencia) }\end{array}$ & $\begin{array}{l}\text { Recomendaciones } \\
\text { (Grado) }\end{array}$ & $\begin{array}{l}\text { Referencias bibliográficas } \\
\text { (Tipo de publicación) }\end{array}$ & Comentarios \\
\hline & $\begin{array}{l}\text { De entre las referencias de IMC disponibles en España59,61-71 han sido } \\
\text { tres las que han tenido el mayor apoyo entre los miembros del grupo de } \\
\text { trabajo de la GPC: 1) las incluidas en las «Curvas y tablas de crecimiento } \\
\text { (Estudios longitudinal y transversal)» del Instituto de Investigación sobre } \\
\text { Crecimiento y Desarrollo de la Fundación Faustino Orbegozo, publicadas } \\
\text { en 200467; 2) las derivadas de los datos del «Estudio transversal español } \\
\text { de crecimiento 2008», publicadas en 200869, y 3) las contempladas en las } \\
\text { «Curvas y tablas de crecimiento» del estudio semilongitudinal del Instituto } \\
\text { de Investigación sobre Crecimiento y Desarrollo de la Fundación Faustino } \\
\text { Orbegozo, publicadas en 198859. } \\
\text { En el momento de la elaboración de esta GPC, no ha podido establecerse } \\
\text { un acuerdo unánime sobre qué patrón de referencia se debe considerar } \\
\text { como válido. En este contexto, y ante la necesidad de ofrecer a todos los } \\
\text { profesionales de la salud responsables de la atención sanitaria de la } \\
\text { población infantojuvenil de España un patrón de referencia, se propone la } \\
\text { utilización de las tablas del estudio semilongitudinal, iniciado en 1978-80, } \\
\text { de la Fundación Faustino Orbegozo, elaboradas por Hernández et al.59. } \\
\text { Estas tablas están realizadas en España antes del inicio del incremento de } \\
\text { SP-OB, por lo que son más directamente aplicables que las de otros } \\
\text { países. }\end{array}$ & & & \\
\hline
\end{tabular}

\subsection{Otros documentos}

\begin{tabular}{|c|c|c|c|c|}
\hline $\begin{array}{l}\text { Guía } \\
\text { (Enfoque) }\end{array}$ & $\begin{array}{l}\text { Resumen sobre la evidencia } \\
\text { (Calidad de la evidencia) }\end{array}$ & $\begin{array}{l}\text { Recomendaciones } \\
\text { (Grado) }\end{array}$ & $\begin{array}{l}\text { Referencias bibliográficas } \\
\text { (Tipo de publicación) }\end{array}$ & Comentarios \\
\hline $\begin{array}{l}\text { Iniciativa IHAN } \\
\text { (De las guías } \\
\text { detalladas } \\
\text { para los } \\
\text { hospitales y } \\
\text { para los } \\
\text { centros de } \\
\text { salud). }\end{array}$ & $\begin{array}{l}\text { El control de peso del bebé debe contrastarse con las } \\
\text { gráficas de la OMS. Durante las primeras } 4 \text { semanas de } \\
\text { vida, el lactante debe ganar por lo menos } 20 \text { gr/día (las } \\
\text { niñas algo menos). Debe tomarse como referencia el menor } \\
\text { peso postparto, no el peso al nacimiento. Si la ganancia } \\
\text { ponderal es menor, los profesionales deben evaluar la } \\
\text { eficacia de la lactancia y corregir la técnica si fuese } \\
\text { necesario. Si la ganancia de peso continua siendo } \\
\text { inadecuada, se deben descartar problemas médicos. } \\
\text { - El peso no debe ser usado como única medida de éxito } \\
\text { de la lactancia. Los profesionales deben valorar las } \\
\text { excretas y el estado de bienestar del recién nacido y } \\
\text { enseñar a las madres su uso para valorar la lactancia. }\end{array}$ & & & \\
\hline
\end{tabular}




\begin{tabular}{|c|c|c|c|c|}
\hline $\begin{array}{c}\text { Guía } \\
\text { (Enfoque) }\end{array}$ & $\begin{array}{l}\text { Resumen sobre la evidencia } \\
\text { (Calidad de la evidencia) }\end{array}$ & $\begin{array}{l}\text { Recomendaciones } \\
\text { (Grado) }\end{array}$ & $\begin{array}{l}\text { Referencias bibliográficas } \\
\text { (Tipo de publicación) }\end{array}$ & Comentarios \\
\hline & $\begin{array}{l}\text { - Las tablas de la OMS indican el percentil de peso de un } \\
\text { lactante comparado con el peso medio de niños/as de su } \\
\text { misma edad óptimamente alimentados. No son una } \\
\text { herramienta para saber cuándo suplementar con leche de } \\
\text { fórmula o introducir la alimentación complementaria. }\end{array}$ & & & \\
\hline
\end{tabular}

\subsection{Revisiones sistemáticas}

Hay revisiones sistemáticas sobre la utilidad de la monitorización del crecimiento en los niños, pero no sobre cuál es la mejor curva a utilizar. 


\subsection{Resumen de GPC base y RS disponibles}

Las guías consultadas no realizan distinciones en el tipo de gráfica a utilizar según el tipo de alimentación que el niño reciba. Lo que sí se discute es qué gráfica es la que mejor refleja el patrón normal de crecimiento de un niño sano.

La guía NICE (1) recomienda la utilización de las gráficas UK 1990, aunque señala que al tiempo que se estaba elaborando esta guía se acababan de lanzar las gráficas de crecimiento de la OMS, cuyo uso todavía no había sido evaluado en el RU.

En la estrategia IHAN (2) se recomienda el uso de las gráficas de la OMS. En cuanto a las mediciones, se señala que como referencia inicial se debe tomar el menor peso postparto, no el peso de nacimiento, y que si la ganancia ponderal es menor, se debe evaluar la eficacia de la lactancia y corregir la técnica si fuera necesario. Si así el niño sigue sin ganar peso, entonces se deberían descartar problemas médicos. Por otro lado, se indica que el peso no debe usarse como única medida del éxito de la lactancia materna.

En la GPC española sobre la obesidad infantojuvenil (3), se recomienda utilizar las curvas y las tablas de crecimiento del estudio semilongitudinal de Hernández et al (4). para realizar el diagnóstico de sobrepeso y obesidad en la infancia y adolescencia, y los P90 y P97 para el diagnóstico de sobrepeso y obesidad.

\subsection{Conclusión (marcar con una $\mathrm{X}$ ):}

\begin{tabular}{|l|l|}
\hline $\mathrm{X}$ & Adopción GPC/Revisión sistemática \\
\hline & Elaboración parcial \\
\hline & Elaboración de novo \\
\hline
\end{tabular}

\subsection{Diseño de la estrategia de búsqueda de estudios individuales}

\begin{tabular}{|l|l|}
\hline Criterios de selección de estudios & estudios observacionales \\
\hline Período de búsqueda & \\
\hline Bases de datos & Cochrane Library \\
& CINAHL, via EBSCOhost databases \\
& EMBASE, via Ovid \\
& MEDLINE, via Pubmed \\
\hline
\end{tabular}

Ver estrategias de búsqueda de estudios originales en el ANEXO I. 


\section{4- Resumen de la evidencia}

\section{1- Resumen de la Evidencia}

\section{Parámetros de crecimiento en el seguimiento del niño}

El parámetro de crecimiento más utilizado en el seguimiento del niño es el peso para la edad. Se trata de la variable más sensible para detectar cambios en el estado nutricional del niño, aunque también hay que considerar la longitud/talla para la valoración clínica a largo plazo (5). La relación entre el peso y la longitud/talla se utiliza con menor frecuencia, aunque se trata de un parámetro muy útil para detectar de forma la malnutrición aguda. De hecho, en la última encuesta realizada por la OMS se recoge que este parámetro es utilizado por el $70 \%$ de los países que han adoptado los estándares de la OMS (5), cuando en 2004 sólo era utilizado por el $23 \%$ de los mismos (6). Lo que casi nunca se ha utilizado es el IMC para la edad, aunque un $29 \%$ de países lo han introducido recientemente en sus programas (5). El cálculo del IMC es muy sencillo $(\mathrm{kg} / \mathrm{m} 2)$, pero éste varía con la edad, con lo que debe interpretarse mediante percentiles o calculando la puntuación z. Cuando el índice está elevado puede deberse tanto a un exceso de masa grasa (obesidad) como a un exceso de masa magra (constitución atlética), lo que puede diferenciarse si se mide el perímetro del brazo y el pliegue tricipital (7).

En cuanto a los puntos de corte, aunque los más utilizados han sido los percentiles (6), en la actualidad la mayoría de los países optan por la clasificación de la puntuación z (5).

Los percentiles 95-97 y 3-5 son utilizados a menudo para clasificar a los niños que están en riesgo de bajo peso o de obesidad. Estos puntos de corte se establecen de forma arbitraria, y no se basan en estudios que hayan investigado la asociación entre los puntos de corte con el riesgo de presentar resultados negativos en salud (7).

En cuanto a las puntuaciones $z$, los puntos de corte utilizados son las puntuaciones $z$ superiores a 2 e inferiores a -2(8).

\section{Patrones de referencia para monitorizar el crecimiento del niño}

En España, ha habido una larga tradición de estudios de crecimiento. Uno de los grupos que más ha trabajado en este área es el grupo de Bilbao, (9). (10).

Otros grupos españoles de Madrid, Zaragoza, Barcelona y Andalucía también llevaron a cabo estudios transversales a partir de 2000(11). La integración de los datos de estas regiones permitió observar que no hay diferencias entre las regiones españolas, que ha habido una aceleración secular positiva de la talla de unos $2 \mathrm{~cm}$ así como un incremento significativo del sobrepeso y la obesidad en los últimos 15 años.

Junto con los resultados de los estudios transversales se han publicado los resultados de los estudios longitudinales de Zaragoza, Bilbao y Barcelona en la publicación "Estudios Españoles de Crecimiento 2010" (12). Estos estudios longitudinales han permitido elaborar gráficas diferenciadas según el patrón de maduración en varones y mujeres. 
Los estudios comparativos con poblaciones de otros países indican que la población española ha alcanzado la talla de los países desarrollados de Europa y América, aunque siguen observándose diferencias importantes con la población de Países Bajos, Alemania y los Países Nórdicos (12).

Como patrones de referencia utilizados a nivel internacional se encuentra la versión de 2000 del estudio de crecimiento del CDC de niños norteamericanos. En Europa se ha elaborado un patrón multicéntrico para niños de 0 a 3 años de edad, llamado Euro-Growth 2000. La OMS propuso también unos nuevos patrones de referencia internacionales prescriptivos que describen cómo deberían crecer los niños en condiciones ideales, que construyeron bajo la premisa de que cuando las necesidades de salud y ambientales se cumplen, los niños de todo el mundo crecen de forma similar (13). Para la elaboración de las curvas de crecimiento se consideraron los datos de los niños de madres que no fumaran ni antes ni después del parto, de embarazo único y que no hubiera morbilidades significativas que pudieran afectar al crecimiento. Como parte de selección de los lugares para el estudio, se realizaron encuestas para identificar las características socioeconómicas que se podrían utilizar para seleccionar los grupos cuyo crecimiento no estaba limitado por factores ambientales. En cuanto a la alimentación, para la inclusión en el estudio se debía cumplir lo siguiente: 1) lactancia materna exclusiva o predominante al menos los 4 primeros meses (120 días); 2) introducción de la alimentación complementaria entre los cuatro y seis meses y 3) lactancia materna parcial hasta los 12 meses (365 días).

De los 1743 niños reclutados, $903(51,8 \%)$ completaron el seguimiento . El $75 \%$ de los niños fueron amamantados de forma exclusiva o predominante al menos durante 4 meses, el 99,5\% empezó la alimentación complementaria a los 6 meses y el 68,3\% fue parcialmente amamantado hasta los 12 meses de vida. El grado de cumplimiento variaba con respecto al lugar.Asimismo, era menos probable que las madres que cumplían con los criterios alimentarios trabajaran o fueran primíparas y más probable que hubieran tenido un parto vaginal. El uso de chupete era más prevalente en las no cumplidoras.

Para conseguir un alto nivel de cumplimiento de estos tres criterios es fundamental la consejería en lactancia materna, que era proporcionada por consejeras expertas y se basaba en la ayuda con el inicio de la lactancia materna tras el parto, la prevención y resolución de los problemas con la lactancia materna y el mantenimiento de la lactancia materna exclusiva/predominante los primeros 4 meses y la lactancia parcial los primeros 12 meses de vida. (14).

Para las edades de 5 a 19 años, la OMS creó unas nuevas tablas tomando como base los datos del NCHS de 1979, en las que la obesidad era muy poco prevalente y en las que se había alcanzado la talla máxima por el fenómeno de la aceleración secular del crecimiento.. En esta misma línea, la GPC de Obesidad Infantojuvenil (3) recomienda utilizar las curvas y tablas de crecimiento del estudio semilongitudinal de Hernández et al 1988 para realizar el diagnóstico de sobrepeso y obesidad en la infancia y la adolescencia, puesto que entonces la prevalencia de la obesidad era mucho menor, aun sabiendo que desde que fueron publicadas se ha dado un aumento secular en la talla. 
Aunque se trata de patrones y curvas ampliamente utilizados, en realidad no se conoce su sensibilidad, especificidad y valor predictivo, ni cuál es el impacto que tiene su uso sobre los resultados en la salud del niño. Lo que sí se encuentra en la literatura es que según el estándar de crecimiento que se aplique, el número de niños clasificados como de bajo peso, sobrepeso u obesidad varía, lo que puede tener sus implicaciones en la toma de decisiones.

En Francia se describió que las diferencias más importantes al utilizar la curva local o la curva de la OMS se encontraron en los primeros seis meses de vida(15)

Los datos de otro estudio longitudinal francés posterior (16) observaron las mismas tendencias que las descritas anteriormente, aunque las diferencias eran menos importantes porque la puntuación z variaba entre $-0,4$ y $+0,4, y$ no entre $-0,80 y+0,80(15)$.

La desvinculación que aparece al principio de la vida entre los valores de referencia franceses y los de la OMS también se observa en estudios realizados en otros países. (17).

(18). En el análisis secundario de los datos de un estudio realizado en Nigeria se observó que la introducción de las curvas de la OMS y de las puntuaciones $z$ del peso para la talla podía implicar la inclusión de muchos más niños en el programa de tratamiento de malnutrición aguda severa que con las curvas del NCHS (25754 vs.2989, respectivamente)(19), siendo la precisión pronóstica de las gráficas de peso para la talla (en puntuación z o percentiles) de la OMS para la mortalidad por malnutrición mejor que la de la NCHS(20).

En otro estudio realizado en Canadá en un centro hospitalario terciario (21) se observó que en general los percentiles del peso para la edad eran superiores al utilizar la curva de la OMS como referencia en comparación con la curva del CDC, aunque entre el primer y sexto mes de vida éstos eran más bajos con los estándares de la OMS. En edades más tempranas (menores de 6 meses) el número de niños que se situaban por debajo del percentil 3 era mayor si se consideraba el estándar de la OMS $(19,7 \%$ vs. $15,2 \%)$, aunque para los niños mayores de 6 meses ocurría justo lo contrario ( $19,1 \%$ vs $28,6 \%$ ).

En cuanto a la longitud, el riesgo de retraso en el crecimiento (por debajo del percentil 3) era mayor si se tenían en cuenta las curvas OMS en todos los casos, siendo el riesgo de sobrepeso u obesidad ( $\geq \mathrm{P} 85$ ) mayor al utilizar los estándares de la OMS $(21.0 \%$ vs $16.6 \%)$, y menor el de emaciación (<P5) (18,6\% vs $23,0 \%)$. El IMC para la edad y el peso para la longitud de la OMS presentaban una alta correlación $\left(r^{2}=0.83\right)$ aunque no eran intercambiables, puesto que en un $9 \%$ de todos los niños y en un $16 \%$ de los niños de seis meses o menos, los percentiles de ambos parámetros se diferenciaban en más de 25 puntos porcentuales.

En un estudio con niños flamencos de 0 a 3 años de edad (22) se encontró que la longitud media de los lactantes amamantados se acercaba de forma razonable al patrón estándar de la OMS, aunque no el peso, el IMC o el perímetro craneal. , por lo que los autores concluían que la comparación de los lactantes amamantados se ajustaba mejor al patrón local de referencia que a los de la OMS.

En un estudio en el que se compara el ajuste de los datos de dos 
cohortes del Reino Unido (ALSPAC y GMS) con el patrón de referencia nacional UK 1990 y el de la OMS (23), se observa que las dos cohortes se ajustan relativamente bien al patrón nacional. En relación a las curvas de la OMS, , los niños del RU presentaban de media un mayor peso al nacer. Hasta los 4 meses de vida, ambas cohortes eran similares en peso a la mediana de OMS, siendo el riesgo de ser clasificado de bajo peso a los 12 meses menor teniendo en cuenta la curva de la OMS (RR 0,15; IC95\% de 0,07 a 0,32), y como obeso a los 4 o 5 años de edad mayor (RR 1,35; IC95\% de 1,02 a 1,78).

En España, concretamente en Aragón, se realizó un estudio que pretendía evaluar las diferencias en la interpretación del peso en una muestra de niños, desde el nacimiento hasta los 18 meses de edad, según se utilizaran los estándares nacionales o los internacionales (24). Las mayores diferencias se daban a partir de los 6 meses de edad. Los autores concluyeron que en general, las gráficas de la OMS y de Carrascosa-Ferrández eran las que menos niños y niñas dejaban por debajo de los límites de la normalidad. En También se observó que las puntuaciones típicas medias de peso variaban según el referente utilizado, y que iban aumentando cuando se comparaban los datos de la muestra con los valores de referencia de la OMS. Con respecto a los valores de referencia de Sobradillo (estudio transversal) y CarrascosaFerrández, los valores disminuían de forma progresiva, encontrándose las menores diferencias con los valores de las curvas de Sobradillo (Estudio longitudinal) y EuroGrowth.

En un estudio posterior(25), se concluye que para que las curvas españloas actuales puedan servir como patrones de referencia convendría excluir en su elaboración a todos los pacientes con obesidad, ya que de otra manera, podrían llegar a considerarse como estudios meramente descriptivos de una población con una reconocida tendencia al exceso de peso corporal, y por lo tanto, su aplicabilidad clínica quedaría en entredicho.

\section{Consideraciones a tener en cuenta al utilizar las gráficas de la OMS}

Todos los autores alertan de la posibilidad de que el mal uso de las curvas de la OMS lleve a la administración innecesaria de suplementos o de leche artificial a lactantes amamantados menores de seis meses.

Para evitarlo, se deben tener en cuenta los siguientes aspectos:

1. La monitorización del crecimiento es insuficiente si se utiliza de forma aislada para valorar el estado nutricional y de salud del niño. Previo a las mediciones se debe realizar una valoración clínica, de desarrollo y comportamiento, así como de la alimentación del niño.

2. Existe un $3 \%$ de niños cuyo crecimiento se sitúa por debajo del percentil 3 y otro $3 \%$ que se sitúa por encima del percentil 97 . Estos niños están creciendo perfectamente, solo que se trata de niños que son constitucionalmente pequeños o grandes.

3. Una medida aislada, y a menudo incluso dos muy próximas en el tiempo, nunca será suficiente para señalar si el niño crece bien o no: sólo puede ser utilizado como alerta, nunca como criterio de toma de decisiones. Sólo los cambios en la velocidad del crecimiento pueden ayudar en la toma de decisiones y para ello es necesario contar con al 
menos tres mediciones en el niño para poder construir un perfil de desarrollo.

4. De forma previa a la toma de cualquier decisión, es necesario que los datos del crecimiento se utilicen junto con la valoración clínica, nutricional y de comportamiento del niño. Así, por ejemplo, la medición del peso para la edad sólo puede ser útil en manos de una consultora experta en lactancia materna, que combinará dicha medición con consejos con el manejo de la lactancia materna.

Para conseguir una lactancia materna exclusiva durante al menos 4 meses, en el estudio de la OMS fue necesario un apoyo intensivo por parte de consejeras expertas en lactancia materna que incluía visitas a domicilio a las 24 horas tras el parto, a los 7, 14 y 30 días postparto y de forma mensual hasta los seis meses de vida del niño. Además se proporcionó una línea de 24 horas disponible para todas las madres y visitas a domicilio adicionales cuando se daban problemas con la lactancia materna. En la vida real, la mayoría de las mujeres no cuentan con este apoyo intensivo. Asimismo, incluso con ese apoyo intensivo, en el estudio de la OMS no se consiguió que todos los niños inicialmente reclutados fueran amamantados de forma exclusiva o predominante al menos los primeros cuatro meses de vida. Por ello, el apoyo a la lactancia materna es crucial, y se necesitan esfuerzos intensivos para mantener la lactancia materna exclusiva hasta los 4 o 6 meses de vida del niño (7).

En un ECA cruzado realizado en Malawi (26) se encontró que cuando se utilizaban las curvas de la OMS con respecto a las del NCHS, aumentaba tanto la preocupación de los profesionales sanitarios (aOR 4,4; IC95\% de 2,4 a 8,1 ), como el porcentaje de derivaciones (OR 5,1; IC95\% de 2,4 a $10,8)$ y la administración de consejos alimentarios que podían llevar a la interrupción de la lactancia materna exclusiva (OR 2,4; IC95\% de 1,2 a 4,9 ). Por ello, los autores concluyen que el uso de las curvas de la OMS podría aumentar las derivaciones inapropiadas y debilitar las ya bajas tasas de lactancia materna exclusiva existentes, y que para prevenirlo tanto las guías como los cursos de capacitación en el uso de estas gráficas deberían enfatizar la importancia de tener en cuenta a la hora de interpretar los resultados la tendencia del crecimiento, la idoneidad de la lactancia materna y el estado clínico del niño.

Como complemento a las curvas estándares de crecimiento de la OMS, se ha desarrollado un proyecto internacional para cubrir la parte fetal y de recién nacidos que no incluida en las curvas de la OMS (NTERGROWTH21st). El consorcio implementó 3 estudios que incluyeron datos relacionados con la salud, crecimiento y la nutrición desde el embarazo hasta las primeras etapas de la infancia de unas 60.000 mujeres y recién nacidos en cinco continentes. https://intergrowth21.tghn.org/.

ACTUALIZADO A FECHA DE: 31 de Octubre de 2016 


\section{5- De la evidencia a la recomendación (Tabla de EtR)}

¿Qué curvas de crecimiento reflejan mejor el crecimiento normal de un niño sano? ¿Cuáles son los parámetros que se deben monitorizar?

Población: Niños sanos

Intervención: Monitorización del crecimiento con estándares basados en condiciones idelaes de crecimiento (curvas de la OMS)

Comparación: Monitorización del crecimiento con estándares construidos con datos poblacionales (estándares locales)

Perspectiva: Clínica

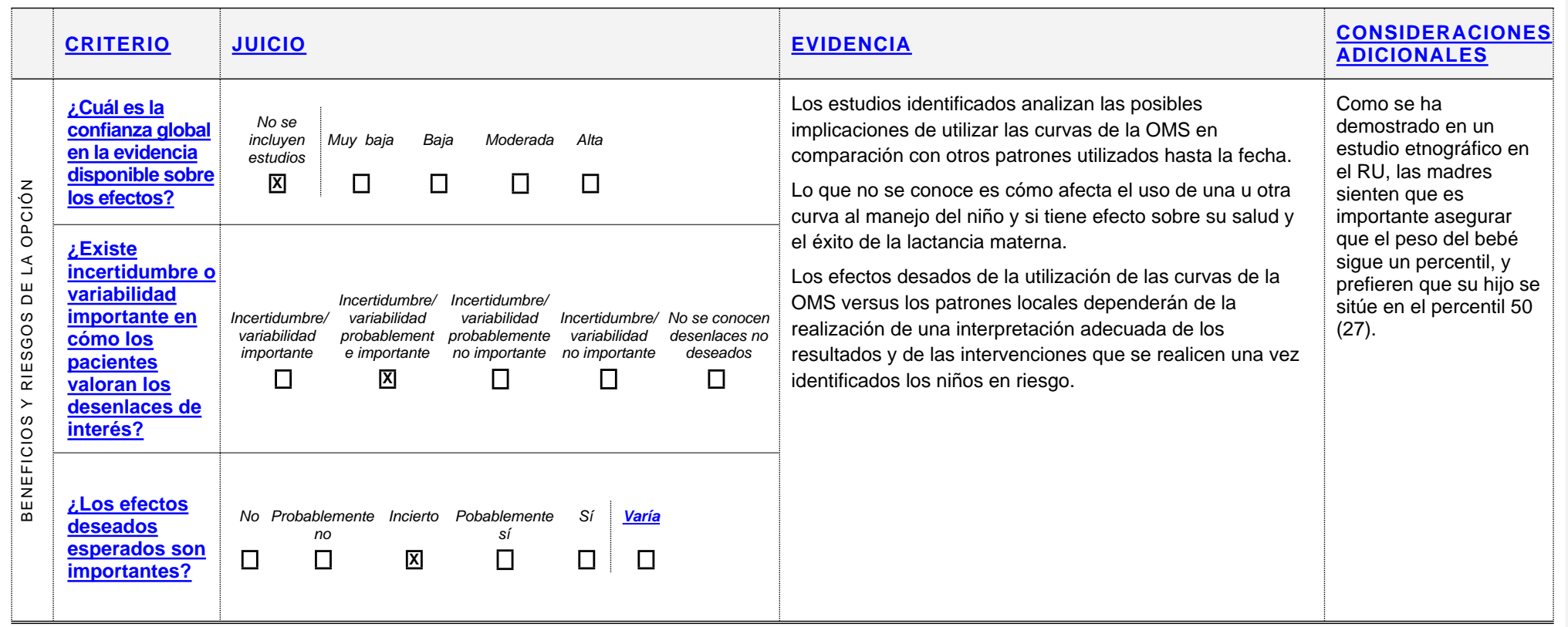

\section{Commented [NeM1]}

CAMBIAR CON LO QUE SE DECIDA AL INICIO 


\begin{tabular}{|c|c|c|c|c|c|c|c|}
\hline CRITERIO & \multicolumn{5}{|l|}{ JUICIO } & EVIDENCIA & $\begin{array}{l}\text { CONSIDERACIONES } \\
\text { ADICIONALES }\end{array}$ \\
\hline $\begin{array}{l}\text { ¿Los efectos } \\
\text { no deseados } \\
\text { esperados } \\
\text { son } \\
\text { pequeños? }\end{array}$ & $\begin{array}{c}\text { No Probablemente } \\
\text { no } \\
\square \quad \square\end{array}$ & $\begin{array}{c}\text { Incierto } \\
\text { 囚 }\end{array}$ & $\begin{array}{c}\text { Pobablemente } \\
\text { sí } \\
\square\end{array}$ & $\begin{array}{l}\text { Sí } \\
\square\end{array}$ & $\frac{\underline{\text { Varía }}}{\square}$ & & \\
\hline
\end{tabular}


¿Qué parámetros y tablas de crecimiento deben utilizarse para evaluar si el lactante amamantado se está alimentando correctamente?

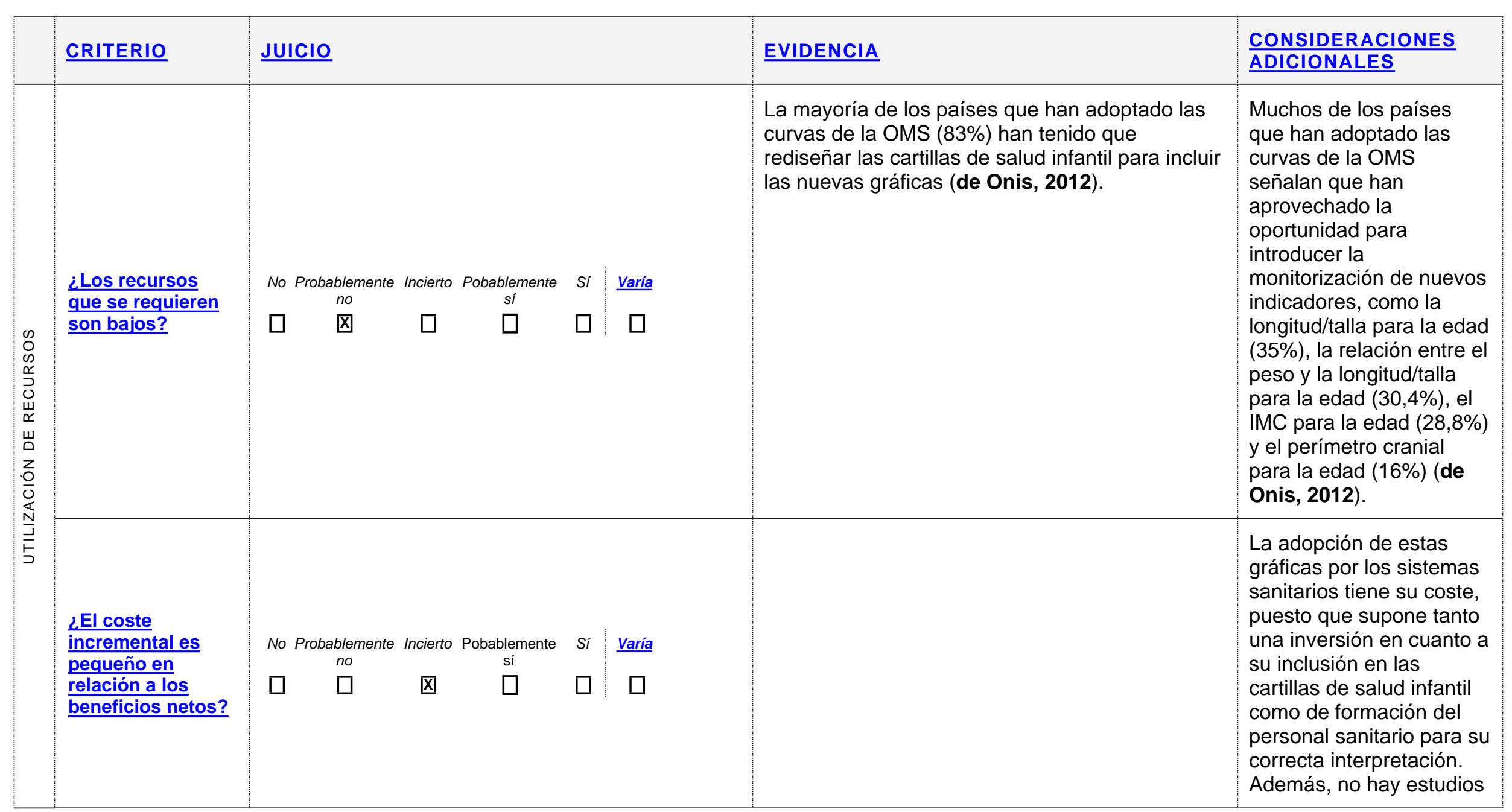




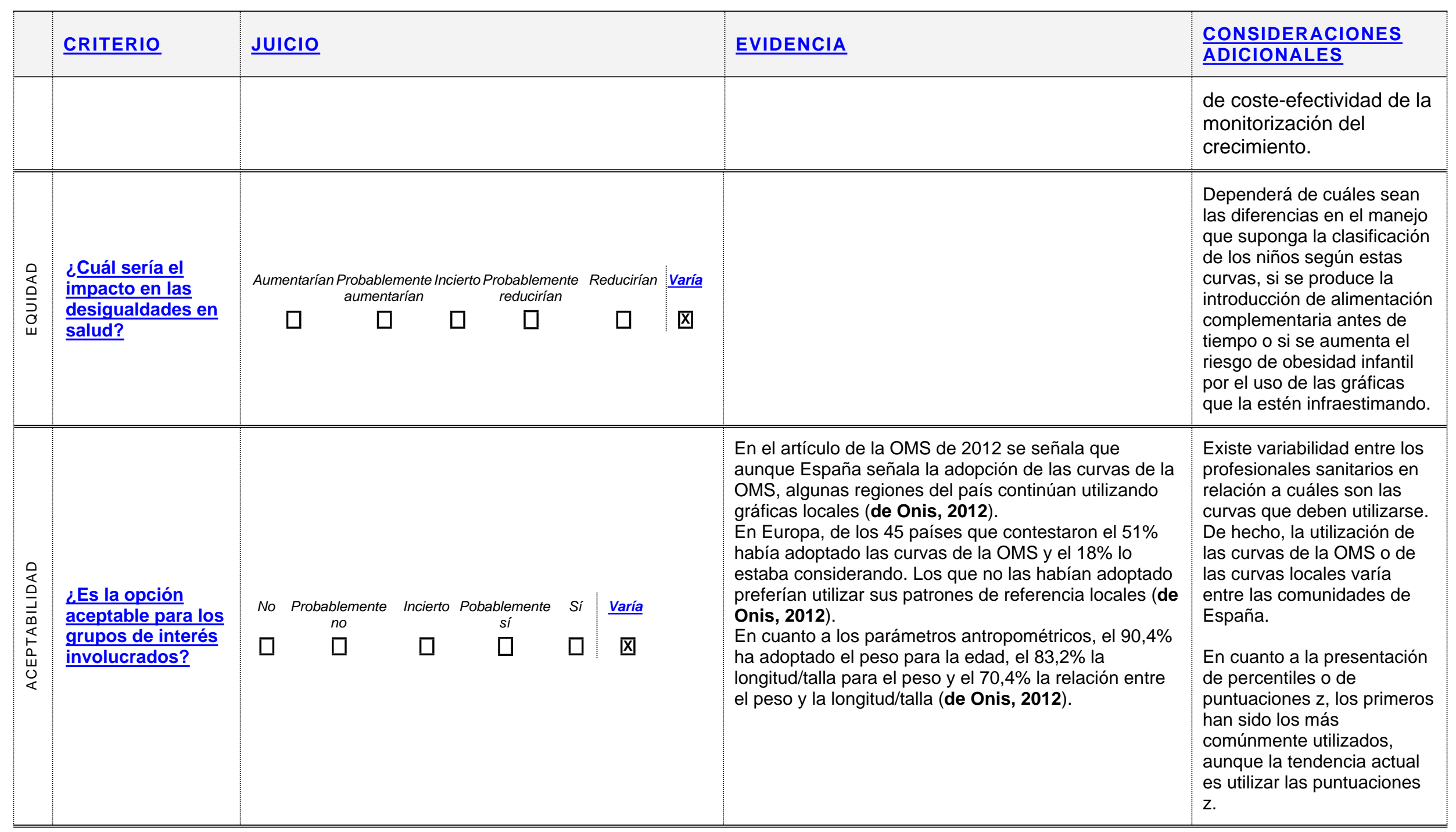




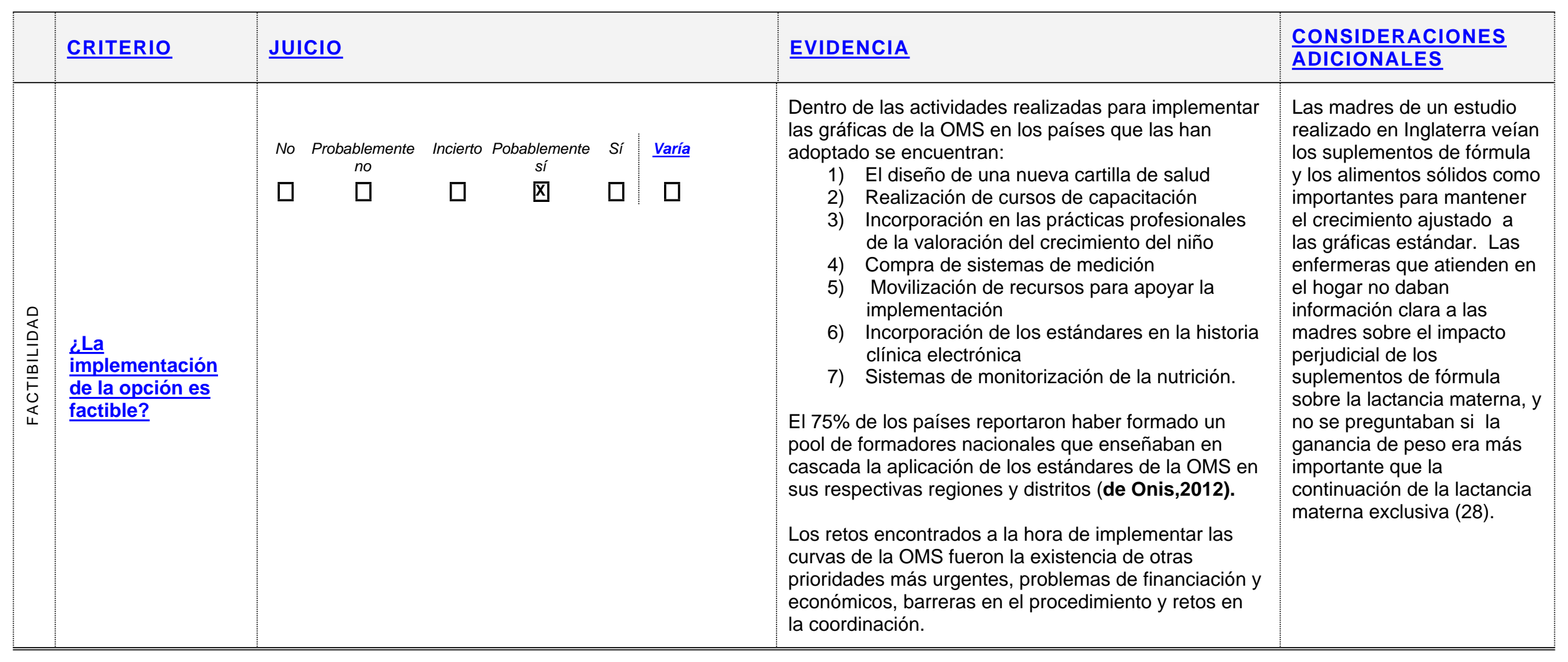

\begin{tabular}{|c|c|c|c|c|c|}
\hline \multirow[t]{2}{*}{$\begin{array}{l}\text { Balance de las } \\
\underline{\text { consecuencias }}\end{array}$} & $\begin{array}{l}\text { Las consecuencias no } \\
\text { deseadas superan } \\
\text { claramente las } \\
\text { consecuencias deseadas } \\
\text { en la mayoría de los } \\
\text { escenarios }\end{array}$ & $\begin{array}{l}\text { Las consecuencias no } \\
\text { deseadas probablemente } \\
\text { superan las } \\
\text { consecuencias deseadas } \\
\text { en la mayoría de los } \\
\text { escenarios }\end{array}$ & $\begin{array}{c}\text { El balance entre las } \\
\text { consecuencias deseadas y } \\
\text { no deseadas está muy } \\
\text { equilibrado o es incierto }\end{array}$ & $\begin{array}{c}\text { Las consecuencias } \\
\text { deseadas } \\
\text { probablemente superan } \\
\text { las consecuencias no } \\
\text { deseadas en la mayoría } \\
\text { de los escenarios }\end{array}$ & $\begin{array}{c}\text { Las consecuencias } \\
\text { deseadas claramente } \\
\text { superan las } \\
\text { consecuencias no } \\
\text { deseadas en la mayoría } \\
\text { de los escenarios }\end{array}$ \\
\hline & $\square$ & $\square$ & $\square$ & $\square$ & $\square$ \\
\hline
\end{tabular}




\begin{tabular}{|c|c|c|c|c|}
\hline \multirow[t]{2}{*}{$\begin{array}{l}\text { Tipo de } \\
\text { recomendación }\end{array}$} & Se recomienda no ofrecer la opción & Se sugiere no ofrecer la opción & Se sugiere ofrecer la opción & $\begin{array}{l}\text { Se recomienda } \\
\text { ofrecer la opción }\end{array}$ \\
\hline & $\square$ & $\square$ & $\square$ & $\square$ \\
\hline $\begin{array}{l}\text { Recomendación } \\
\text { (Texto) }\end{array}$ & \multicolumn{4}{|c|}{$\begin{array}{l}\sqrt{ } \text { Se deberían utilizar las curvas de la OMS para realizar el seguimiento del crecimiento del lactante, así como los puntos de corte } \\
\text { establecidos por los mismos, puesto que son las únicas curvas que muestran cuál debería de ser el crecimiento de un niño en } \\
\text { condiciones óptimas. } \\
\checkmark \text { Se deberían recoger al menos el peso para la edad y la relación longitud/peso para la edad. }\end{array}$} \\
\hline
\end{tabular}

Justificación Los estudios locales son muy útiles para conocer la situación de un entorno determinado. Sin embargo, su utilización como patrón comparativo no es deseable, puesto que los datos estadísticos obtenidos dependen de la situación nutricional de la población estudiada. Si utilizamos patrones en países que presentan una alta prevalencia de desnutrición, ésta se verá infravalorada; por el contrario, en países en los que la prevalencia de sobrepeso y obesidad es alta, lo que se verá infraestimada será la prevalencia de sobrepeso y obesidad.

El peso debería compararse junto con la talla del niño, para evitar una mala interpretación de los datos. Por otro lado, si se identifica un problema potencial, se debería acompañar de una valoración de la clínica y la alimentación del niño.

\section{Consideraciones de}

\section{$\underline{\text { subgrupos }}$}

Consideraciones para La valoración del crecimiento se debe realizar en el contexto general de la valoración clínica del niño y de las características de su la implementación alimentación, incluyendo la valoración de la eficacia de la lactancia materna.

Se debe formar a los profesionales para saber interpretar estar curvas de forma adecuada.

Monitorización y

evaluación

Prioridades para la

investigación

Se necesita investigación que estudie el impacto de la utilización de las curvas de crecimiento sobre la salud del niño y el éxito de la lactancia materna 


\section{ANEXO I, ESTRATEGIAS DE BÚSQUEDA}

\section{Cochrane Library}

\section{Searched 09/12/2014}

Updated search $x x / x x / x x x x$

\#1 "growth charts" or "growth charts" or "growth standards" or "growth standard" or "growth curve" or "growth curves":ti,ab,kw and breastfeeding or "breast feeding" or lactation:ti,ab,kw and infant or infants:ti,ab,kw (Word variations have been searched) 13

\section{MEDLINE, via Pubmed}

Searched 09/12/2014

\section{Updated search $\mathrm{xx} / \mathrm{xx} / \mathrm{xxxx}$}

\#1 (("growth chart" OR "growth charts" OR "growth standard" OR "growth standards" OR "growth curve" OR "growth curves") AND (breastfeeding OR "breast feeding" OR lactation) AND (infant OR infants)) Field: Title/Abstract 110

\section{EMBASE, via Ovid}

\section{Searched 09/12/2014}

Updated search $x x / x x / x x x x$

\#1 ("growth chart" or "growth charts" or "growth standard" or "growth standards" or "growth curve" or "growth curves").ti,ab,kw. 12095

\#2 (breastfeeding or "breast feeding" or lactation).ti,ab,kw. 56175

\#3 (infant or infants).ti,ab,kw. 336070

\#4 \#1 AND \#2 AND \#3 151

\section{CINAHL, via EBSCOhost databases}

\section{Searched 09/12/2014}

Updated search $\mathrm{xx} / \mathrm{xx} / \mathrm{xxxx}$

S1 ( "growth chart" OR "growth charts" OR "growth standard" OR "growth standards" OR "growth curve" OR "growth curves" ) AND ( breastfeeding OR "breast feeding" OR lactation ) AND ( infant OR infants ) 267

Cinahl 


\section{1- BIBLIOGRAFÍA}

(1) NICE. Postnatal care up to 8 weeks after birth. Julio 2006 (actualizado en Febrero de 2015). Disponible en: http://guidance.nice.org.uk/CG37.

(2) Estrategia centros de salud IHAN. Revisada, actualizada y ampliada para la atención integral en los centros de salud. Manual para la acreditación IHAN. España. 2014. Disponible en:

https://www.ihan.es/docs/documentacionacreditacion/centros salud/Manual para la acreditacion IHAN en AP 2015. pdf.

(3) Grupo de trabajo de la Guía de Práctica Clínica sobre la Prevención y el Tratamiento de la Obesidad Infantojuvenil. Centro Cochrane Iberoamericano, coordinador. Guía de Práctica Clínica sobre la Prevención y el Tratamiento de la Obesidad Infantojuvenil. Plan de Calidad para el Sistema Nacional de Salud del Ministerio de Sanidad y Política Social. Agència d ìAvaluació de Tecnologia i Recerca Mèdiques; 2009. Guías de Práctica Clínica en el SNS: AATRM № 2007/25. d ìAvaluació de Tecnologia i Recerca Mèdiques; 2009. Guías de Práctica Clínica en el SNS: AATRM № 2007/25.

(4) Hernández M, Castellet J, Narvaiza JL, Rincón JM, Ruiz I, Sánchez E, Sobradillo B, Zurimendi A. Curvas y tablas de crecimiento (0-18 años). Instituto de Investigación sobre Crecimiento y Desarrollo. Fundación Faustino Orbegozo, Bilbao, ISBN: 84-7391-177-6, 1988, 1-32.

(5) de Onis M, Onyango A, Borghi E, Siyam A, Blossner M, Lutter C. Worldwide implementation of the WHO Child Growth Standards. Public Health Nutr 2012 Sep;15(9):1603-10.

(6) de Onis M, Wijnhoven TM, Onyango AW. Worldwide practices in child growth monitoring. J Pediatr 2004 Apr;144(4):461-5.

(7) Cattaneo A, Guoth-Gumberger M. The new WHO Child Growth Standards: possible effects on exclusive breastfeeding in the first six months. BREASTFEED REV 2008 Nov;16(3):9-12.

(8) Organización Mundial de la Salud. Curso de capacitación sobre la evaluación del crecimiento del niño. Ginebra, OMS, 2008. Disponible en: http://www.who.int/childgrowth/training/c interpretando.pdf.

(9) Sobradillo B, Aguirre A, Aresti U, Bilbao A, Fernández-Ramos C, Lizárraga A, Lorenzo H, Madariaga L, Rica I, Ruiz I, Sánchez E, Santamaría C, Serrano JM, Zabala A, Zurimendi B, Hernández M. Curvas y tablas de crecimiento. Estudios longitudinal y transversal. Bilbao: Fundación Faustino Orbegozo, Bilbao, ISBN 84-607-9967-0, 2004, 1-31.

(10) Fernández C, Lorenzo H, Vrotsou K, Aresti U, Rica I, Sánchez E. Estudio de Crecimiento de Bilbao. Curvas y Tablas de Crecimiento (Estudio transversal). Fundación Faustino Orbegozo, Bilbao, ISBN 978-84-615-7707-1, 2011, 1-35.

(11) Carrascosa A, Fernández JM, Fernández C, Ferrández A, López-Siguero JP. Estudio transversal español de crecimiento 2008. Parte II: valores de talla, peso e índice de masa corporal desde el nacimiento a la talla adulta. An Pediatr 2008;68:552-69.

(12) Carrascosa A, Fernández JM, Ferrández A, López-Siguero JP, López D, Sánchez E y Grupo Colaborador. Estudios Españoles de Crecimiento 2010. Disponible 
http://www.seep.es/privado/documentos/Publicaciones/Estudios Espa\%C3\%B 1oles de Crecimiento 2010.pdf.

(13) Assessment of differences in linear growth among populations in the WHO Multicentre Growth Reference Study. Acta Paediatr Suppl 2006 Apr;450:56-65.

(14) Breastfeeding in the WHO Multicentre Growth Reference Study. Acta Paediatr Suppl 2006 Apr;450:16-26.

(15) de Onis M, Garza C, Onyango AW, Rolland-Cachera MF. Les standards de croissance de l'Organisation mondiale de la santé pour les nourrissons et les jeunes enfants. Arch Pediatr 2009 Jan;16(1):47-53.

(16) Deheeger M, Rolland-Cachera MF. Etude longitudinale de la croissance d'enfants parisiens suivis de l'age de 10 mois à 18 ans. Arch Pediatr 2004 Sep;11(9):1139-44.

(17) de Onis M, Onyango AW, Borghi E, Garza C, Yang H. Comparison of the World Health Organization (WHO) Child Growth Standards and the National Center for Health Statistics/WHO international growth reference: implications for child health programmes. Public Health Nutr 2006 Oct;9(7):942-7.

(18) Prost MA, Jahn A, Floyd S, Mvula H, Mwaiyeghele E, Mwinuka V, et al. Implication of new WHO growth standards on identification of risk factors and estimated prevalence of malnutrition in rural Malawian infants. PLoS One 2008;3(7):e2684.

(19) Isanaka S, Villamor E, Shepherd S, Grais RF. Assessing the impact of the introduction of the World Health Organization growth standards and weight-forheight $\mathrm{z}$-score criterion on the response to treatment of severe acute malnutrition in children: secondary data analysis. Pediatrics 2009 Jan;123(1):e54-e59.

(20) Lapidus N, Luquero FJ, Gaboulaud V, Shepherd S, Grais RF. Prognostic accuracy of WHO growth standards to predict mortality in a large-scale nutritional program in Niger. PLoS Med 2009 Mar 3;6(3):e39.

(21) Nash A, Secker D, Corey M, Dunn M, O'Connor DL. Field testing of the 2006 World Health Organization growth charts from birth to 2 years: assessment of hospital undernutrition and overnutrition rates and the usefulness of BMI. JPEN J Parenter Enteral Nutr 2008 Mar;32(2):145-53.

(22) Roelants M, Hauspie R, Hoppenbrouwers K. Breastfeeding, growth and growth standards: Performance of the WHO growth standards for monitoring growth of Belgian children. Ann Hum Biol 2010 Jan;37(1):2-9.

(23) Wright C, Lakshman R, Emmett P, Ong KK. Implications of adopting the WHO 2006 Child Growth Standard in the UK: two prospective cohort studies. Arch Dis Child 2008 Jul;93(7):566-9.

(24) Ayerza CA, Rodriguez MG, Samper Villagrasa MP, Fuertes Fernandez-Espinar $\mathrm{J}$, Broto CP, Collado Hernandez MP, et al. Diferencias entre los estándares de referencia para el peso en niños de hasta 18 meses de edad. Nutr Hosp 2010 Sep;25(5):838-44.

(25) Durá T. Grupo Colaborador de Navarra. ¿Son válidas las curvas y tablas de crecimiento españolas actuales? Nutr Hosp 2012;27(1):244-51.

(26) Ahmad UN, Yiwombe M, Chisepo P, Cole TJ, Heikens GT, Kerac M. Interpretation of World Health Organization growth charts for assessing infant malnutrition: a randomised controlled trial. J Paediatr Child Health 2014 Jan;50(1):32-9.

(27) Sachs M, Dykes F, Carter B. Weight monitoring of breastfed babies in the United Kingdom--interpreting, explaining and intervening. Matern Child Nutr 2006 Jan;2(1):3-18. 
GPC Lactancia Materna- Pregunta 20. Monitorización del crecimiento.

(28) Sachs M, Dykes F, Carter B. Weight monitoring of breastfed babies in the UK centile charts, scales and weighing frequency. Matern Child Nutr 2005 Apr;1(2):63-76. 
PREGUNTA CLÍNICA № 21

¿Qué hacer ante un recién nacido adormilado que no demanda o que no hace tomas efectivas?

\section{Pregunta clínica en formato PICO}

Tabla 1. Componentes de la pregunta clínica en formato PICO

\begin{tabular}{|l|l|}
\hline Pacientes & RN sanos a término sano y sin factores de riesgo de hipoglucemia \\
\hline Exposición & RN adormilado que no demanda o que no hace tomas efectivas \\
\hline Comparación & RN que hace tomas efectivas frecuentes \\
\hline Desenlaces & $\begin{array}{l}\text {-Hipoglucemia } \\
\text {-Pérdida ponderal } \\
\text {-Ictericia } \\
\text {-Deshidratación }\end{array}$ \\
\hline Tipo de estudio & GPC, RS, ECA, estudios observacionales y estudios descriptivos \\
\hline
\end{tabular}

\section{Introducción}

Algunos recién nacidos están excesivamente adormilados en los primeros días y realizan pocas tomas. Estas situaciones causan gran preocupación a las madres y a los profesionales y, en ocasiones pueden suponer un riesgo. Nos planteamos qué medidas se pueden adoptar para asegurar el aporte nutricional al recién nacido sin interferir con la instauración de la lactancia. 


\section{Estrategia de elaboración de la pregunta}

\subsection{GPC}

Tabla 2. IHAN

\begin{tabular}{|c|c|c|}
\hline & & Referencia \\
\hline UNICEF/ OMS & 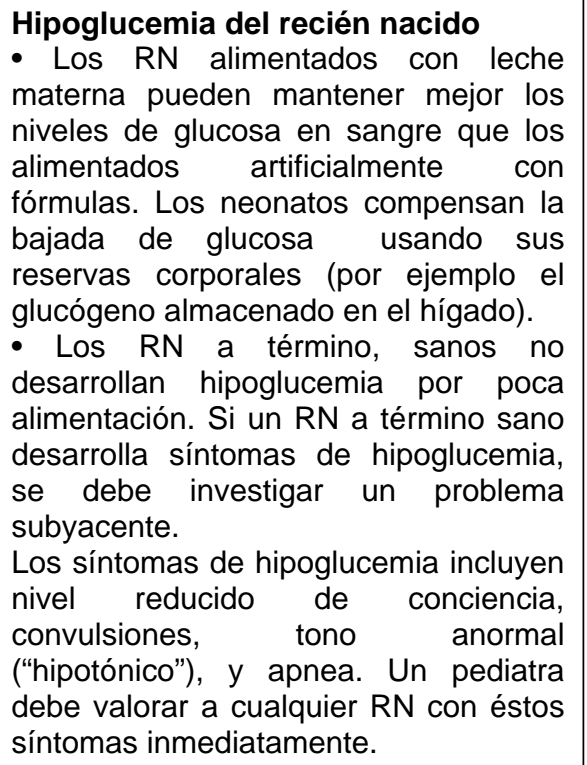 & $\begin{array}{l}\text { "UNICEF/OMS. Iniciativa } \\
\text { Hospital Amigo del Niño, } \\
\text { revisada, actualizada y ampliada } \\
\text { para la atención integral, } \\
\text { Sección 3, Lactancia Promoción } \\
\text { y Apoyo en un Hospital Amigo } \\
\text { del Niño. Diciembre 2008". } \\
\text { Washington, D.C. OPS @ } 2008\end{array}$ \\
\hline
\end{tabular}

Tabla 3. GPC de base (seleccionadas con el AGREE)

\begin{tabular}{|c|c|c|c|c|}
\hline Guía & Evidencia & Recomendación & Referencias & Comentarios \\
\hline NICE & $\begin{array}{l}\text { Bebés adormilados } \\
\text { No se ha encontrado literatura en relación con los RN } \\
\text { somnolientos y la lactancia. Glover (Glover 1995) } \\
\text { desarrolló un diagrama de flujo diseñado para ayudar al } \\
\text { personal de enfermería en la toma de decisiones con } \\
\text { respecto a la suplementación. Un punto de buena }\end{array}$ & $\begin{array}{l}\text { Bebé adormilado } \\
\text { Se debe informar a las madres que } \\
\text { realizar CPP o masajear los pies } \\
\text { del bebé es útil para despertarle. La } \\
\text { salud general del bebé debe } \\
\text { evaluarse si no hay mejoría. }\end{array}$ & $\begin{array}{l}\text { Glover, J. 1995, "Supplementation of } \\
\text { breastfeeding newborns: a flow chart } \\
\text { for decision making", Journal of Human } \\
\text { Lactation, vol. 11, no. 2, pp. 127-131. }\end{array}$ & \\
\hline
\end{tabular}




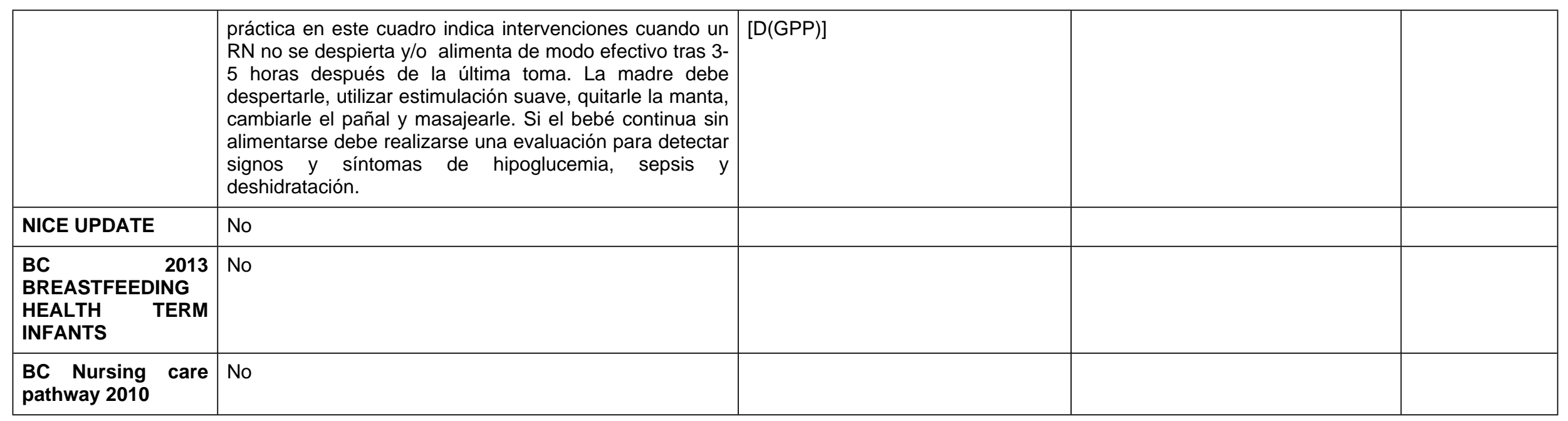

Tabla 4. Resumen de GPC del SNS

\begin{tabular}{|l|l|l|l|l|}
\hline Guía & Evidencia & Recomendación & Referencias & Comentarios \\
\hline GPC parto & NO & & & \\
\hline GPC embarazo & NO & & & \\
\hline
\end{tabular}

Tabla 5. Resúmenes otras guías/ docs. de referencia

\begin{tabular}{|c|c|c|c|c|}
\hline Guía & Evidencia & Recomendación & Referencias & Comentarios \\
\hline $\begin{array}{l}\text { ABM } \\
(2014, \\
\text { actualizaci } \\
\text { ón) (Wight } \\
2014)\end{array}$ & $\begin{array}{l}\text { La hipoglucemia transitoria en el periodo } \\
\text { inmediato al nacimiento es frecuente y se } \\
\text { presenta en casi todos los mamíferos. En los RN } \\
\text { sanos a término, incluso si no se les proporciona } \\
\text { alimentación enteral en las primeras horas, dicho } \\
\text { fenómeno es auto-limitado y forma parte de la } \\
\text { adaptación del RN a la vida extrauterina, ya que } \\
\text { los niveles de glucosa se elevan } \\
\text { espontáneamente en las primeras } 24 \text { horas de }\end{array}$ & $\begin{array}{l}\text { La LM temprana y exclusiva cumple las } \\
\text { necesidades metabólicas y nutricionales } \\
\text { de un RN sano y a término. Los RN } \\
\text { sanos a término no desarrollan } \\
\text { hipoglucemia clínicamente significativa } \\
\text { como resultado de una alimentación } \\
\text { escasa durante un tiempo limitado (III). } \\
\text { El CPP facilita el inicio y establecimiento }\end{array}$ & $\begin{array}{l}\text { Adamkin DH, Committee on Fetus and Newborn. } \\
\text { Postnatal glucose homeostasis in late-preterm and } \\
\text { term infants. Pediatrics } 2011 ; 127: 575-579 . \\
\text { Srinivasan G, Pildes RS, Cattamanchi G, et al. Plasma } \\
\text { glucose values in normal neonates: A new look. J } \\
\text { Pediatr 1986;109:114-117. } \\
\text { Hawdon JM, Ward Platt MP, Aynsley-Green A. } \\
\text { Patterns of metabolic adaptation for preterm and term }\end{array}$ & \\
\hline
\end{tabular}




\begin{tabular}{|c|c|c|}
\hline 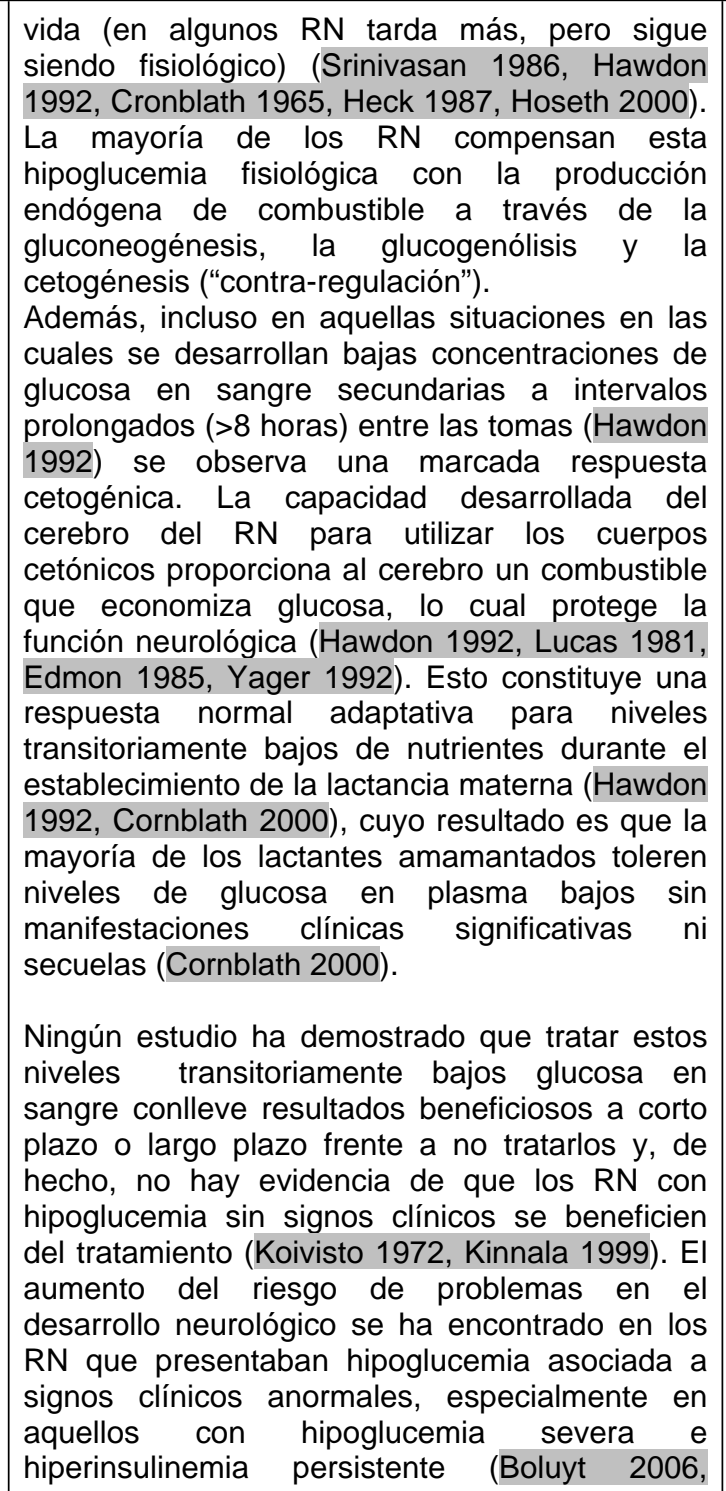 & $\begin{array}{l}\text { de la lactancia, reduce el riesgo de } \\
\text { hipoglucemia, mantiene la temperatura } \\
\text { corporal del RN y reduce la pérdida } \\
\text { energética, a la vez que estimula la } \\
\text { succión y la producción de leche (II-2, } \\
\text { IIII). } \\
\text { Se deben realizar tomas frecuentes, al } \\
\text { menos } 10-12 \text { diarias en los primeros } \\
\text { días tras el nacimiento (III). No } \\
\text { obstante, es habitual que los RN a } \\
\text { término hagan una primera toma } \\
\text { inmediatamente tras el parto y después } \\
\text { duerman de modo prolongado (hasta 8- } \\
10 \text { horas) hasta que vuelvan a estar de } \\
\text { nuevo activos y empiecen a succionar } \\
\text { de nuevo con mayor frecuencia. Estos } \\
\text { RN cuentan con una respuesta } \\
\text { metabólica de protección durante este } \\
\text { tiempo, por lo que no es necesario } \\
\text { forzar las tomas. No obstante, se debe } \\
\text { realizar un estudio clínico en un RN } \\
\text { inusual y excesivamente adormilado. } \\
\text { En RN sanos y a término, no es } \\
\text { necesario dar suplementos de agua o } \\
\text { formula, y además su administración } \\
\text { puede interferir en el establecimiento } \\
\text { de la LM y en los mecanismos } \\
\text { reguladores compensatorios (II-2, III). } \\
\text { La monitorización de la glucosa debe de } \\
\text { Ilevarse a cabo solo en RN con factores } \\
\text { de resgo o en aquellos con signos } \\
\text { clínicos compatibles con hipoglucemia. } \\
\end{array}$ & $\begin{array}{l}\text { infants in the first neonatal week. Arch Dis Child } \\
\text { 1992;67(4 Spec No):357-365. } \\
\text { Cornblath M, Reisner SH. Blood glucose in the neonate } \\
\text { and its clinical significance. N Engl J Med } \\
\text { 1965;273:378-381. } \\
\text { Heck LJ, Erenberg A. Serum glucose levels in term } \\
\text { neonates during the first } 48 \text { hours of life. J Pediatr } \\
\text { 1987;110:119-122. } \\
\text { Hoseth E, Joergensen A, Ebbesen F, et al. Blood } \\
\text { glucose levels in a population of healthy, breast fed, } \\
\text { term infants of appropriate size for gestational age. } \\
\text { Arch Dis Child Fetal Neonatal Ed 2000;83:F117-F119. } \\
\text { Lucas A, Boyes S, Bloom SR, et al. Metabolic and } \\
\text { endocrine responses to a milk feed in six-day-old term } \\
\text { infants: Differences between bereast and cow's milk } \\
\text { formula feeding. Acta Paediatr Scand 1981;70:195- } \\
\text { 200. } \\
\text { Edmond J, Auestad N, Robbins RA, et al. Ketone body } \\
\text { metabolism in the neonate: Development and the effect } \\
\text { of diet. Fed Proc 1985;44:2359-2364. } \\
\text { Yager JY, Heitjan DF, Towfighi J, Vannucci RC. Effect } \\
\text { of insulin-induced and fasting hypoglycemia on } \\
\text { perinatal hypoxic-ischemic brain damage. Pediatr Res } \\
\text { 1992;31:138-142. } \\
\text { Cornblath M, Hawdon JM, Williams AF, et al. } \\
\text { Controversies regarding definition of neonatal } \\
\text { hypoglycemia: Suggested operational thresholds. } \\
\text { Pediatrics 2000;105:1141-1145. } \\
\text { Boluyt N, van Kempen A, Offringa M. M. } \\
\text { Neurodevelopment after neonatal hypoglycemia: A } \\
\text { systematic review and design of an optimal future } \\
\text { study. Pediatrics 2006;117:2231-2243. } \\
\text { Koivisto M, Blanco-Sequeiros M, Krause U. Neonatal } \\
\text { symptomatic and asymptomatic hypoglycaemia: A } \\
\text { follow-up study of 151 children. Dev Med Child Neurol } \\
\text { 1972;14:603-614. } \\
\text { Kinnala A, Rikalainen H, Lapinleimu H, et al. Cerebral } \\
\text { magnetic resonance imaging and ultrasonography } \\
\text { findings after neonatal hypoglycemia. Pediatrics }\end{array}$ \\
\hline
\end{tabular}




\begin{tabular}{|c|c|}
\hline $\begin{array}{l}\text { Koivisto 1972, Kinnala 1999, Dalgic 2002, Burns } \\
2008 \text {, Menni 2001). Los episodios únicos, breves } \\
\text { y transitorios de hipoglucemia tienen poca } \\
\text { probabilidad de causar daño neurológico } \\
\text { permanente (Williams 1997, Eidelman 1991, } \\
\text { Hawdon 1994, Wight 2006). Por lo tanto, la } \\
\text { monitorización de la glucosa en RN sanos y a } \\
\text { término es innecesaria y potencialmente } \\
\text { perjudicial para el bienestar de los padres y el } \\
\text { adecuado establecimiento de la lactancia } \\
\text { materna (Williams 1997, Eidelman 1991, } \\
\text { Hawdon 1994, Wight 2006, Hawdon 1993, } \\
\text { Hawdon 1993b). } \\
\text { Teniendo esto en cuenta, se concluye que la } \\
\text { monitorización rutinaria de la glucosa en sangre } \\
\text { en RN sanos y a término, no solo es innecesaria, } \\
\text { sino que además puede perjudicar el } \\
\text { establecimiento de la relación madre-hijo y de la } \\
\text { lactancia (Adamkin 2011, Hawdon 1994, } \\
\text { Hawdon 1993, Hawdon 1993b, Section on } \\
\text { Breastfeeding 2012, Haninger 2001). La OMS } \\
\text { (Williams 1997), la Academia Americana de } \\
\text { Pediatría (Adamkin 2011, Section on } \\
\text { Breastfeeding 2012), el Institute of Health } \\
\text { americano (Hay 2009) y el National Childbirth } \\
\text { Trust en el Reino Unido (National Childbirth Trust } \\
\text { 2003) concluyen que: (1) la LM temprana y } \\
\text { exclusive satisfice las necesidades nutricionales } \\
\text { del RN y que (2) los RN Ranos y a término no } \\
\text { desarrollan hipoglucemia clínicamente } \\
\text { significativa como resultado de una alimentación } \\
\text { escasa durante un tiempo limitado. }\end{array}$ & $\begin{array}{l}\text { 1999;103:724-729. } \\
\text { Dalgic N, Ergenekon E, Soysal S, et al. Transient } \\
\text { neonatal hypoglycemia-Long-term effects on } \\
\text { neurodevelopmental outcome. J Pediatr Endocrinol } \\
\text { Metab 2002;15:319-324. } \\
\text { Burns C, Rutherford M, Boardman J, et al. Patterns of } \\
\text { cerebral injury and neurodevelopmental outcomes after } \\
\text { symptomatic neonatal hypoglycemia. Pediatrics } \\
\text { 2008;122:65-74. } \\
\text { Menni F, deLonlay P, Sevin C, et al. Neurologic } \\
\text { outcomes of } 90 \text { neonates and infants with persistent } \\
\text { hyperinsulinemic hypoglycemia. Pediatrics } \\
\text { 2001;107:476-479. } \\
\text { Williams AF. Hypoglycemia of the Newborn: Review of } \\
\text { the Literature. World Health Organization, Geneva, } \\
\text { 1997. } \\
\text { Eidelman Al. Hypoglycemia and the breastfed neonate. } \\
\text { Pediatr Clin North Am 2001;48:377-387. } \\
\text { Hawdon JM, Ward Platt MP, Aynsley-Green A. } \\
\text { Prevention and management of neonatal } \\
\text { hypoglycaemia. Arch Dis Child Fetal Neonatal Ed } \\
\text { 1994;70:F60-F64; discussion F65. } \\
\text { Wight N. Hypoglycemia in breastfed neonates. } \\
\text { Breastfeed Med 2006;1:253-262. } \\
\text { Hawdon JM, Platt MP, Aynsley-Green A. Neonatal } \\
\text { hypoglycaemia-Blood glucose monitoring and baby } \\
\text { feeding. Midwifery 1993;9:3-6. } \\
\text { Hawdon J. Neonatal hypoglycemia: The consequences } \\
\text { of admission to the special care nursery.Child } \\
\text { Health1993;(Feb):48-51. } \\
\text { Hay WW, Raju T, Higgens R, et al. Knowledge gaps } \\
\text { and research needs for understanding and treating } \\
\text { neonatal hypoglycemia: Workshop report from Eunice } \\
\text { Kennedy Shriver National Institute of Child Health and } \\
\text { Human Development. J Pediatr 2009;155:612-617. } \\
\text { Section on Breastfeeding. Breastffeeding and the use of } \\
\text { human milk. Pediatrics 2012;129:e827-e841. } \\
\text { Haninger NC, Farley CL. Screening for hypoglycemia in } \\
\text { healthy term neonates: Effects on breastfeeding. J }\end{array}$ \\
\hline
\end{tabular}




\begin{tabular}{|c|c|c|}
\hline & & $\begin{array}{l}\text { Midwifery Womens Health } 2001 ; 46: 292-301 \text {. } \\
\text { National Childbirth Trust, United Kingdom. } \\
\text { Hypoglycemia of the newborn: Guidelines for the } \\
\text { appropriate blood glucose screening of breast-fed and } \\
\text { bottle-fed babies in the UK. Midwives 1997;110:248- } \\
249 \text {. }\end{array}$ \\
\hline $\begin{array}{l}\text { ABM } 3 \\
\text { protocol } \\
(2009)\end{array}$ & $\begin{array}{l}\text { Hay situaciones clínicas comunes donde la } \\
\text { evaluación y el manejo de la lactancia pueden } \\
\text { ser necesarios, pero NO ESTA INDICADO el uso } \\
\text { de suplementos, incluyendo: } \\
\text { 1.- El niño adormilado que ha sido alimentado } \\
\text { menos de } 8 \text { a } 12 \text { veces en las primeras } 24-48 \\
\text { horas, con menos del } 7 \% \text { de pérdida de peso y } \\
\text { sin señales de enfermedad. } \\
\text { *Los RN normalmente tienen sueño después de } \\
\text { un periodo inicial de alerta de aproximadamente } \\
2 \text { horas después de nacer (Emde } 1975 \text {, Stern } \\
1969 \text { ). Después tienen ciclos variables de sueño- } \\
\text { vigilia, con uno o dos periodos adicionales de } \\
\text { vigilia en las próximas } 10 \text { horas ya sea que sean } \\
\text { alimentados o no (Emde } 1975 \text { ). } \\
\text { *Es más adecuado poner atención cuidadosa a } \\
\text { las señales tempranas de hambre del bebé y } \\
\text { darle la oportunidad de ser amamantado cada } 2- \\
3 \text { horas, que automáticamente utilizar } \\
\text { suplementos después de } 6 \text {, } 8 \text {, 12 o hasta } 24 \\
\text { horas. } \\
\text { *La regla general en la primera semana es: "iUn } \\
\text { niño despierto es un niño hambriento!" } \\
\text { *El incremento del tiempo de CPP puede } \\
\text { alentarlo a que coma con mayor frecuencia. }\end{array}$ & $\begin{array}{l}\text { Emde R, Swedberg J, Suzuki B. Human wakefulness } \\
\text { and biological rhythms after birth. Arch Gen Psychiatry } \\
\text { 1975;32: 780-783. } \\
\text { Stern E, Parmalee A, Akiyama Y, et al. Sleep cycle } \\
\text { characteristics in infants. Pediatrics 1969;43:67-70. }\end{array}$ \\
\hline
\end{tabular}

\subsection{Revisiones sistemáticas}

No se han localizado RS sistemáticas que evalúen de modo específico cómo manejar un RN adormilado que no hace tomas relevantes. 
Sin embargo si se localizó una RS (1) que evaluaba cómo manejar la hipoglucemia en RN sanos a término, de la cual se obtuvieron los estudios relevantes en los que se incluían a RN que hacían largos intervalos entre tomas. 


\title{
3.3. Resumen de GPCs base y RSs disponibles
}

\begin{abstract}
Las GPC NICE (2) aborda esta pregunta pero no encuentra estudios en relación a los RN adormilados que no reclaman el pecho o con succión poco vigorosa, aunque hace referencia a una estrategia propuesta por Glover (3) para el manejo de la lactancia en RN somnolientos. En este cuadro se indica que cuando un RN no se despierta y/o alimenta de modo efectivo tras 3-5 horas después de la última toma, la madre debe tratar de despertarle, utilizando estimulación suave, quitándole la manta, cambiándole el pañal y masajeándolo. Si el recién nacido continúa sin alimentarse debe realizarse una evaluación para detectar signos y síntomas de la hipoglucemia, sepsis y deshidratación.
\end{abstract}

En cuanto a la aparición de episodios de hipoglucemia, el protocolo 1 de la ABM (4) indica que un RN sano y a término amamantado no desarrolla hipoglucemia independientemente de que sea o no alimentado salvo que haya un problema subyacente. La hipoglucemia transitoria en el periodo inmediato al nacimiento es frecuente y se presenta en casi todos los mamíferos. En los $\mathrm{RN}$ sanos a término, incluso si no se les proporciona alimentación enteral en las primeras horas, dicho fenómeno es auto-limitado, dado que los niveles de glucosa se elevan espontáneamente al cabo de 24 horas. Esto se debe a que los RN amamantados tienen un mecanismo autorregulador de la glucemia en sangre y utilizan los cuerpos cetónicos para proteger la función neurológica.

Por su parte, el protocolo 3 de la ABM (5) indica que los $R N$ normalmente experimentan un periodo de sueño tras el periodo inicial de alerta (de aproximadamente 2 horas tras el nacimiento). Después tienen ciclos variables de sueño-vigilia, con uno o dos periodos adicionales de vigilia en las siguientes 10 horas tanto si son alimentados como si no. Esta guía concluye que no está indicado el uso rutinario de suplementos en $\mathrm{RN}$ adormilados que han hecho menos de 8 a 12 tomas en las primeras 24-48 horas, si la pérdida de peso es menor del $7 \%$ y no hay indicios de enfermedad. Es más adecuado poner atención cuidadosa a las señales tempranas de hambre del recién nacido y darle la oportunidad de ser amamantado cada 2-3 horas, que utilizar sistemáticamente suplementos después de 6,8 , 12 o hasta 24 horas. Además sugiere incrementar el tiempo de CPP ya que puede alentarlo a tomar con mayor frecuencia.

No se han localizado RS sistemáticas que evalúen de modo específico cómo manejar un RN adormilado que no hace tomas relevantes. Sin embargo si se localizó una RS (1) que evaluaba cómo manejar la hipoglucemia en $\mathrm{RN}$ sanos a término. Esta revisión incluye el estudio de Hawdon (6), incluido en el protocolo de la ABM, que concluyó que en RN sanos y a término los intervalos prolongados entre tomas (hasta 8 horas) no estaban asociados con niveles de glucosa bajos en los primeros siete días de vida.

\subsection{Conclusión}

Se ha elaborado una revisión parcial en base a la guía NICE (2).

Adopción GPC/Revisión sistemática

\begin{tabular}{l|l}
$X$ & Elaboración parcial \\
& Elaboración de novo
\end{tabular}




\subsection{Diseño de la estrategia de búsqueda de estudios individuales}

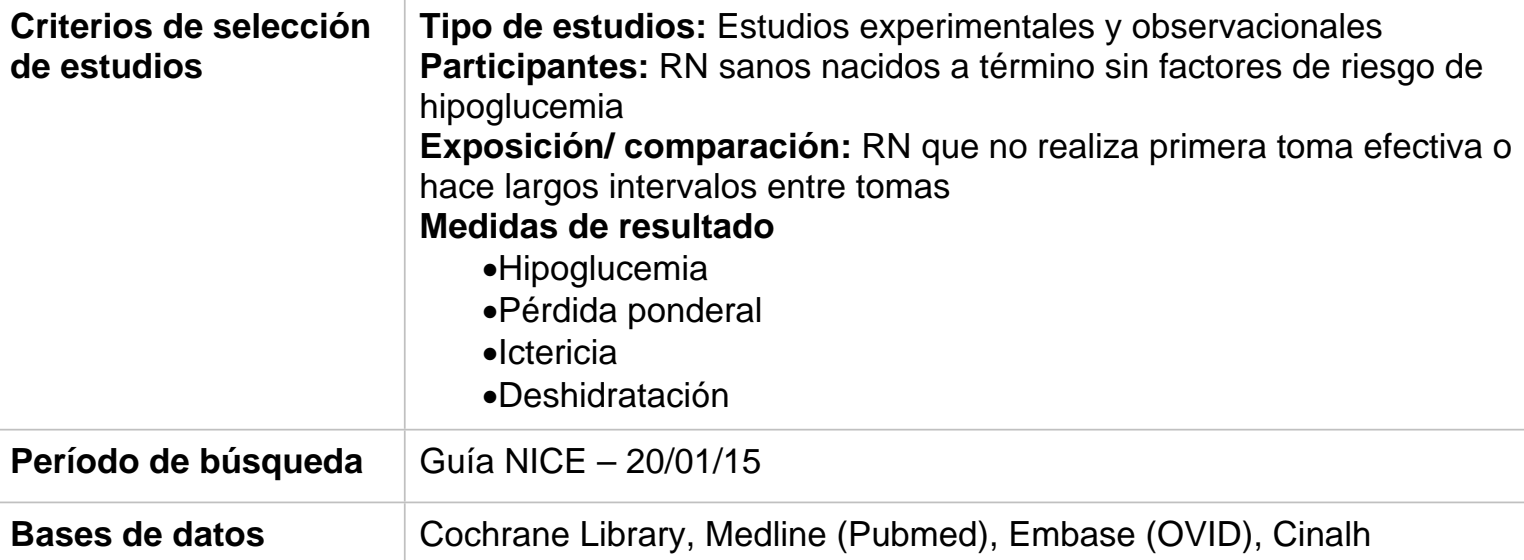

Ver estrategias de búsqueda de estudios originales en el ANEXO I

\section{4- Resumen de la evidencia (Tablas de estudios individuales y valoración de calidad en el ANEXO X)}

\subsection{GRADE Evidence Profile}

Se ha localizado un estudio (6) pero no proporciona datos susceptibles de MA. Incluido en resumen de la evidencia.

\subsection{Resumen de la evidencia}

No se han localizado estudios que evalúen de modo específico a recién nacidos adormilados que no hacen tomas frecuentes.

No obstante, en la pregunta sobre cuánto tiempo se puede esperar hasta que el recién nacido se agarre al pecho, se ha visto que los recién nacidos que no se alimentan durante las primeras horas de vida generalmente no desarrollan hipoglucemia.

De modo similar otro estudio (6) concluyó que en $\mathrm{RN}$ sanos y a término los intervalos prolongados entre tomas (hasta 8 horas) no estaban asociados con niveles de glucosa bajos en los primeros siete días de vida, aunque el estudio

no proporciona datos. 


\section{De la evidencia a la recomendación (Tabla EtR)}

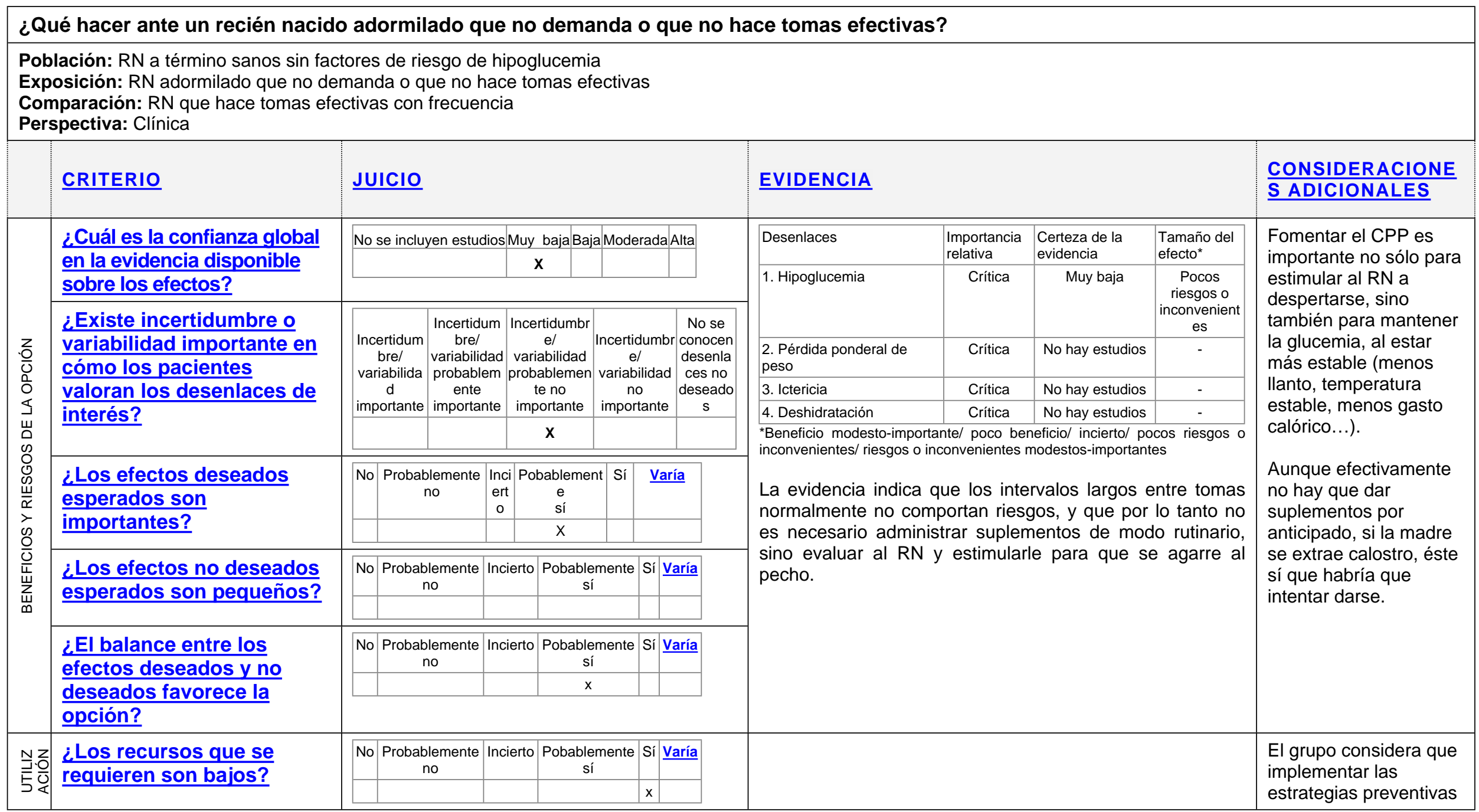




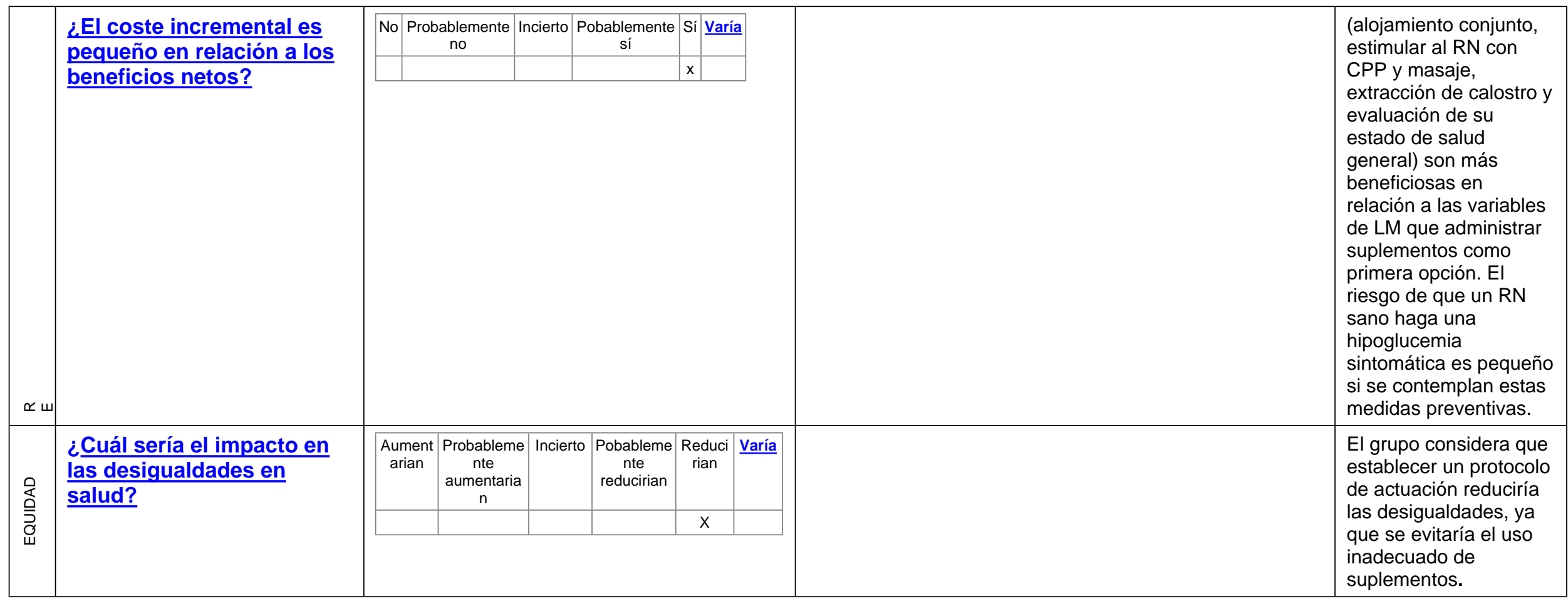




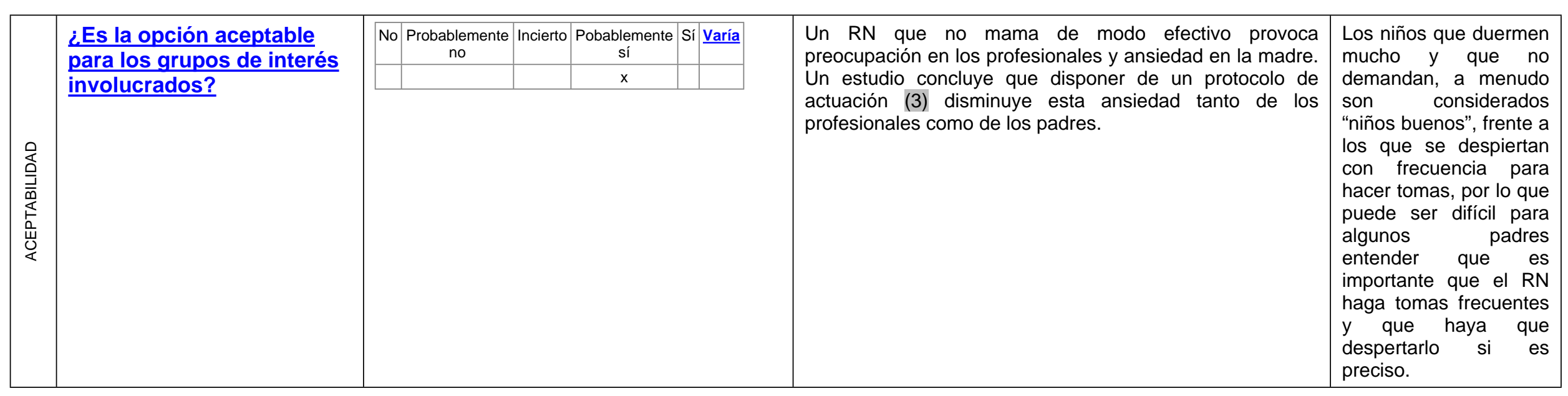




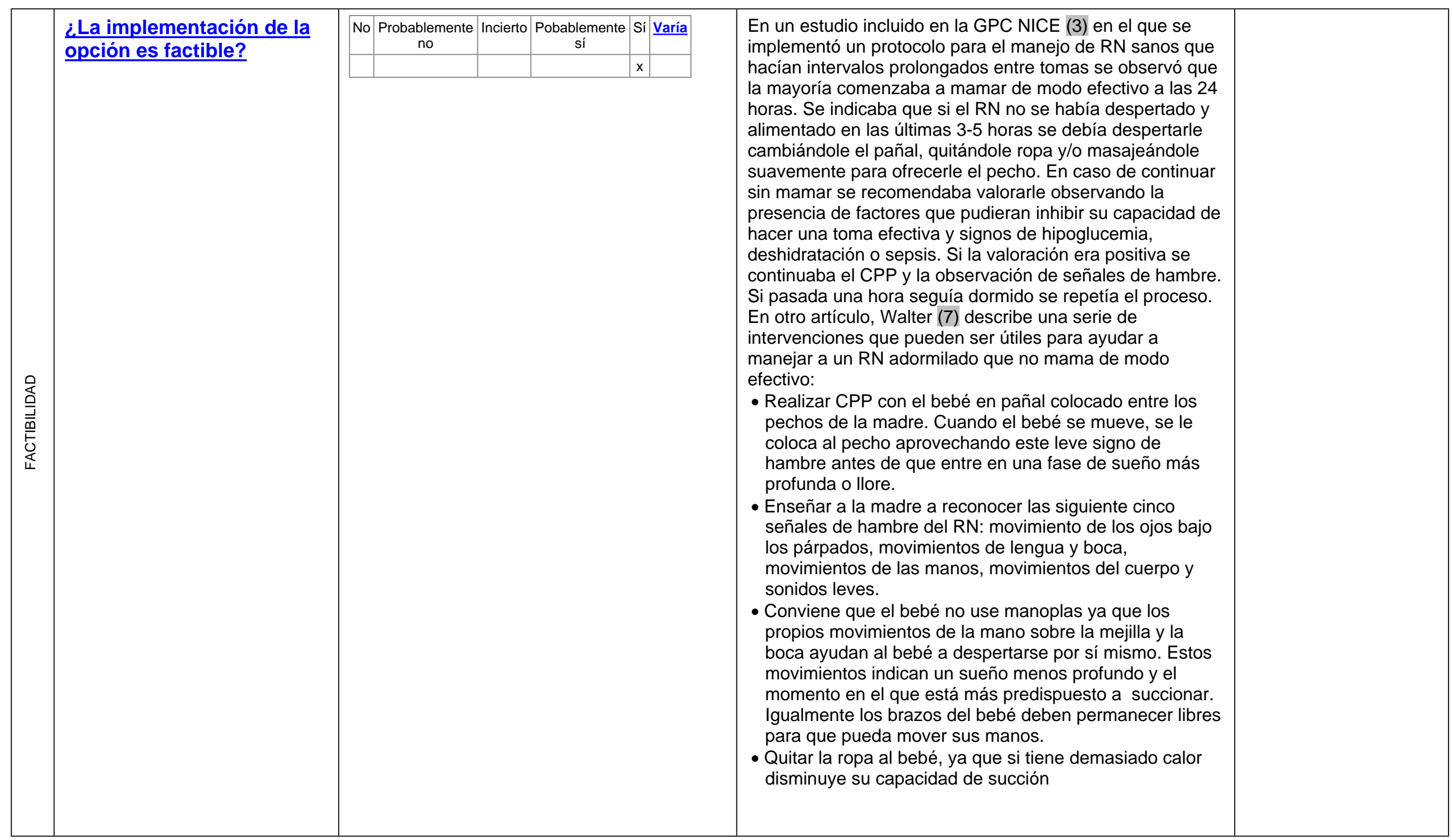




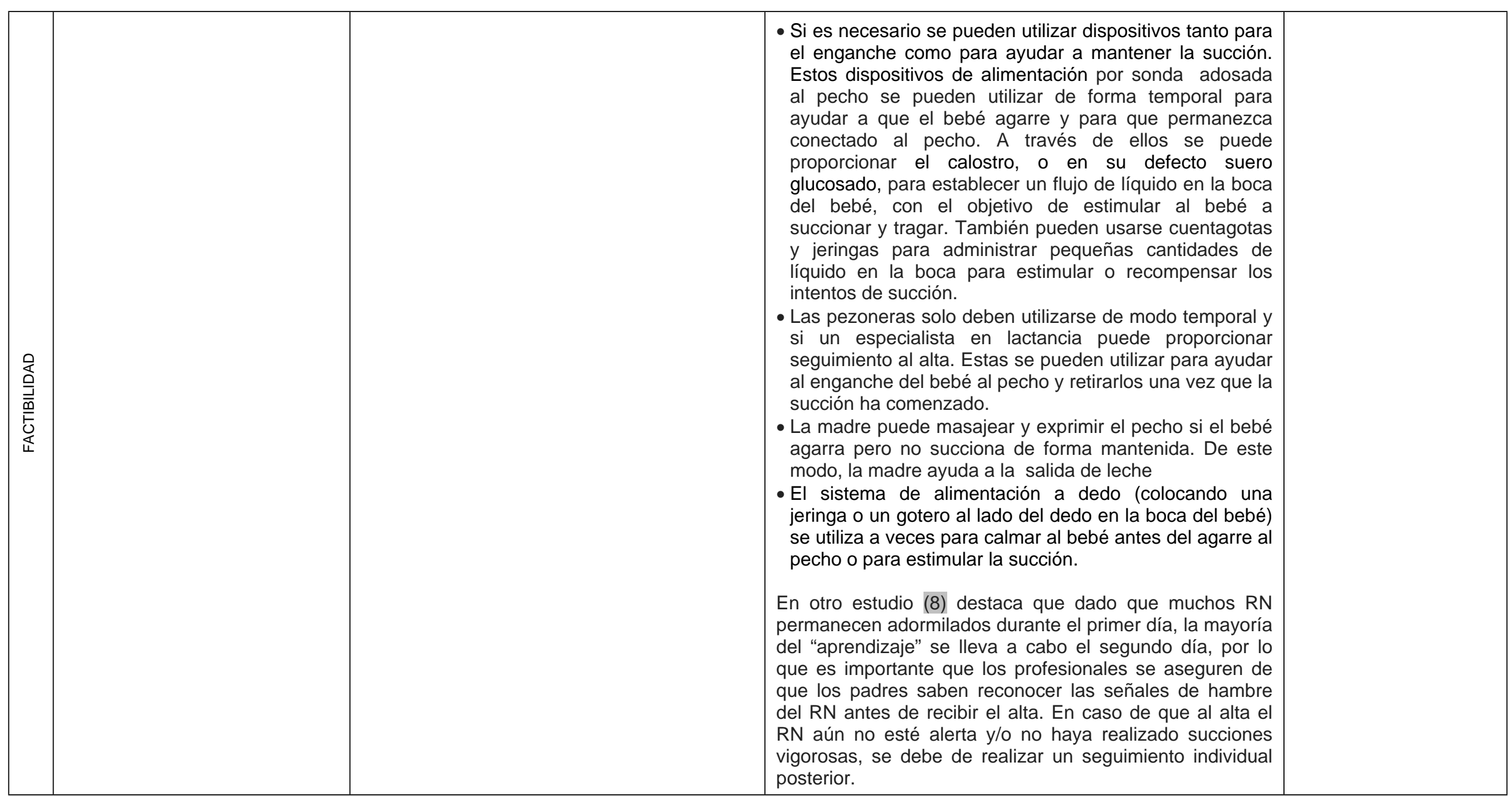




\begin{tabular}{|c|c|c|c|c|c|c|c|}
\hline $\begin{array}{l}\text { Balance de las } \\
\underline{\text { consecuencias }}\end{array}$ & $\begin{array}{l}\text { Las consecuencias no } \\
\text { deseadas superan } \\
\text { claramente las } \\
\text { consecuencias deseadas } \\
\text { en la mayoría de los } \\
\text { escenarios }\end{array}$ & $\begin{array}{l}\text { Las consecuencias no } \\
\text { deseadas probablemente } \\
\text { superan las consecuencias } \\
\text { deseadas en la mayoría de } \\
\text { los escenarios }\end{array}$ & \multicolumn{2}{|c|}{$\begin{array}{l}\text { El balance entre las } \\
\text { consecuencias } \\
\text { deseadas y no } \\
\text { deseadas está muy } \\
\text { equilibrado o es } \\
\text { incierto }\end{array}$} & \multicolumn{2}{|c|}{$\begin{array}{c}\text { Las consecuencias } \\
\text { deseadas } \\
\text { probablemente } \\
\text { superan las } \\
\text { consecuencias no } \\
\text { deseadas en la } \\
\text { mayoría de los } \\
\text { escenarios } \\
\text { X }\end{array}$} & $\begin{array}{c}\text { Las } \\
\text { consecuencias } \\
\text { deseadas } \\
\text { claramente } \\
\text { superan las } \\
\text { consecuencias no } \\
\text { deseadas en la } \\
\text { mayoría de los } \\
\text { escenarios }\end{array}$ \\
\hline
\end{tabular}




\begin{tabular}{|c|c|}
\hline Recomendación (Texto) & $\begin{array}{l}\text { Recomendación de buena práctica } \\
\sqrt{ } \text { Estimular a los recién nacidos que no se despierten espontáneamente a las tres o cinco horas de la última toma mediante } \\
\text { contacto piel con piel, masaje de los pies, cambio de pañal o retirada de ropa y ayudarles a engancharse al pecho si es } \\
\text { preciso. } \\
\text { Recomendación fuerte en contra } \\
\text { No se recomienda la administración rutinaria de suplementos. } \\
\text { Recomendación fuerte a favor } \\
\text { Hasta conseguir una toma eficaz se recomienda que la madre se extraiga calostro para estimular y mantener la producción } \\
\text { de leche y se la ofrezca al recién nacido con vasito, cucharita o jeringa. } \\
\text { Recomendación de buena práctica } \\
\text { En caso de que el recién nacido agarre el pecho pero no realice succiones efectivas la madre puede comprimir el pecho } \\
\text { mientras el RN succiona para ayudar a la salida de la leche, relajando la compresión durante las pausas. } \\
\text { Recomendación e buena práctica } \\
\text { En caso de que fuera necesario, se podrían instilar gotas de leche materna en la boca del recién nacido para estimular y } \\
\text { mantener la succión. La administración de estas gotas puede realizarse con jeringa, "finger", cuentagotas o sonda adosada } \\
\text { al pecho. En algunas ocasiones puede ser útil el uso de pezoneras, que se retirarán en cuanto sea posible. } \\
\text { Recomendación de buena práctica } \\
\sqrt{ } \text { Se debería posponer el alta hospitalaria del recién nacido que no realice tomas eficaces, salvo que pueda garantizarse un } \\
\text { seguimiento ambulatorio adecuado desde atención primaria. }\end{array}$ \\
\hline Justificación & $\begin{array}{l}\text { Teniendo en cuenta que los RN sanos que son amamantados en general no desarrollan hipoglucemia por falta de } \\
\text { alimentación, no es aconsejable administrar suplementos de modo rutinario ya que puede interferir en la instauración de la } \\
\text { lactancia. Es más conveniente estimular al RN para que se enganche al pecho y valorar de modo regular que su estado de } \\
\text { salud es adecuado. }\end{array}$ \\
\hline
\end{tabular}




\begin{tabular}{|c|c|}
\hline $\begin{array}{l}\text { Consideraciones de } \\
\text { subgrupos }\end{array}$ & $\begin{array}{l}\text { En relación a las cesárea, va a depender de varios: si lleva muchas horas de epidural, si lleva muchas horas de trabajo de } \\
\text { parto, si es una cesárea electiva, si es cesárea programada (nalgas, posición transversa,...) y las cesáreas urgentes, en la } \\
\text { que puede que lleve muchas horas y que le han pinchado en la cabeza al feto varias veces (para saber las reservas de } \\
\text { oxígeno) y en la que se utiliza más anestesia, incluso a veces hay que usar anestesia general. En esos casos, se necesita } \\
\text { más tiempo para los dos (madre/hijo/a). Hay RN que maman bien desde el momento que les pones al pecho, sin embargo } \\
\text { otros, es como que les están muy afectados y por lo tanto necesitan más apoyo. }\end{array}$ \\
\hline $\begin{array}{l}\text { Consideraciones para la } \\
\text { implementación }\end{array}$ & $\begin{array}{l}\text { - Hay que valorar al RN de modo regular para comprobar que no hay signos de hipoglucemia ni de deshidratación. } \\
\text { - Es importante explicar a las madres que el RN debe de hacer tomas frecuentes y que si es preciso hay que despertarle. } \\
\text { Por otro lado, la extracción del calostro y de la leche está indicada en los casos en los que el RN no hace tomas } \\
\text { efectivas para garantizar el aporte nutricional del RN y estimular la producción de la leche en la madre (ver capítulo } \\
\text { extracción). } \\
\text { - Los profesionales deben conocer y poder explicar a la madre ambas técnicas de extracción. } \\
\text { - Es importante antes de recibir el alta hospitalaria, que los padres sepan reconocer las señales precoces de hambre del } \\
\text { RN y cómo despertarle en caso necesario (ver Anexo 6). }\end{array}$ \\
\hline Monitorización y evaluación & - \\
\hline $\begin{array}{l}\text { Prioridades para la } \\
\text { investigación }\end{array}$ & - \\
\hline
\end{tabular}


GPC Lactancia Materna - Pregunta 21. Recién nacido adormilado.

\section{ANEXOS}

Anexo I. Estrategias de búsqueda

Anexo II. Valoración de la calidad de los estudios

Anexo III. Tablas de estudios individuales

Anexo IV. Forest plots 


\section{ANEXO I. ESTRATEGIAS DE BÚSQUEDA}

\section{Cochrane Library \\ Searched 06/11/2014 \\ Updated search 06/11/2014 a xx/xx/xxxx}

\#1 sleep* or doz* or drows* or slumberous:ti,ab,kw and baby or babies or newborn or newborns:ti,ab,kw (Word variations have been searched)

\#2 breastfeeding or "breast feeding" or breastfeed or "breast feed" or breastfed or "breast fed" or lactation:ti,ab,kw (Word variations have been searched) 3236

\#3 \#1 and \#2 32

\section{MEDLINE, via Pubmed}

Searched 06/11/2014

Updated search 06/11/2014 a xx/xx/xxxx

\#1 sleep* or dozing or drows* Field: Title/Abstract 120624

\#2 baby OR babies Or newborn Or newborns Field: Title/Abstract 171385

\#3 \#1 AND \#2 1785

\#4 "lactation"[MeSH Terms] OR "lactation"[All Fields] OR "breast feeding"[MeSH Terms] OR ("breast"[All Fields] AND "feeding"[All Fields]) OR "breast feeding"[All Fields] 72849

\#5 "breast feed"[All Fields] OR "breastfeeding"[All Fields] OR "breastfeed"[All Fields] OR "breast fed"[All Fields] OR breastfed[All Fields] 21278

\#6 \#4 OR \#5 78870

\#7 \#3 AND \#6 Field: Title/Abstract 162

\section{EMBASE, via Ovid}

\section{Searched 06/11/2014}

Updated search 06/11/2014 a xx/xx/xxxx

\#1 (sleep* or dozing or drows*).ti,ab,kw. 163295

\#2 (baby or babies or newborn or newborns).ti,ab,kw. 208902

\#3 \#1 AND \#2 2401

\#4 (lactation or "breast feed" or "breastfeeding" or breastfeed or "breast fed" or breastfed or "breast feeding").ti,ab,kw. 59786

\#5 lactation/ 39127

\#6 breast feeding/ 35356

\#7 \#4 OR \#5 OR \#6 87325

\#8 \#3 AND \#7 229

\section{CINAHL, via EBSCOhost databases}

\section{Searched 06/11/2014}

Updated search 06/11/2014 a xx/xx/xxxx

S1 ( sleep* or dozing or drows* ${ }^{*}$ AND ( baby OR babies OR newborn OR newborns ) 1,282

S2 (MH "Lactation") 1,575

S3 (MH "Breast Feeding") 11,583

S4 S2 OR S3 12,439

S5 lactation OR "breast feeding" OR breastfeeding OR breastfeed OR "breast feed" OR brastfed OR "breast fed" 15,489

S6 S4 OR S5 15,489

S7 S1 AND S6 153 


\section{ANEXO II. EVALUACIÓN DE LA CALIDAD DE LOS ESTUDIOS}

\section{Revisiones sistemáticas - AMSTAR}

No hay RS.

\section{ECAs - Risk of bias - Cochrane}

No hay.

\section{Estudios de cohortes}

No hay

\section{Estudios de casos-control}

No hay

\section{Estudios transversales}

NOS scale modificada para estudios transversales

\begin{tabular}{|c|c|}
\hline & Hawdon 1992 \\
\hline \multicolumn{2}{|l|}{ Selection: (Maximum 5 stars) } \\
\hline \multicolumn{2}{|l|}{ 1) Representativeness of the sample: } \\
\hline \multicolumn{2}{|l|}{ a) Truly representative of the average in the target population. ${ }^{*}$ (all subjects or random sampling) } \\
\hline b) Somewhat representative of the average in the target population. ${ }^{*}$ (non-random sampling) & * \\
\hline \multicolumn{2}{|l|}{ c) Selected group of users. } \\
\hline \multicolumn{2}{|l|}{ d) No description of the sampling strategy. } \\
\hline \multicolumn{2}{|l|}{ 2) Sample size: } \\
\hline a) Justified and satisfactory. ${ }^{*}$ & * \\
\hline \multicolumn{2}{|l|}{ b) Not justified. } \\
\hline \multicolumn{2}{|l|}{ 3) Non-respondents: } \\
\hline a) Comparability between respondents and non-respondents characteristics is established, and the response rate is satisfactory. ${ }^{*}$ & \\
\hline b) The response rate is unsatisfactory, or the comparability between respondents and non-respondents is unsatisfactory. & \\
\hline c) No description of the response rate or the characteristics of the responders and the non-responders. & \\
\hline
\end{tabular}




\begin{tabular}{|c|c|}
\hline \multicolumn{2}{|l|}{ 4) Ascertainment of the exposure (risk factor): } \\
\hline a) Validated measurement tool. ${ }^{* *}$ & ** \\
\hline \multicolumn{2}{|l|}{ b) Non-validated measurement tool, but the tool is available or described. ${ }^{*}$} \\
\hline \multicolumn{2}{|l|}{ c) No description of the measurement tool. } \\
\hline \multicolumn{2}{|c|}{ Comparability: (Maximum 2 stars) } \\
\hline \multicolumn{2}{|c|}{ 1) The subjects in different outcome groups are comparable, based on the study design or analysis. Confounding factors are controlled. } \\
\hline a) The study controls for the most important factor (select one). ${ }^{*}$ & - \\
\hline b) The study control for any additional factor. * & - \\
\hline \multicolumn{2}{|l|}{ Outcome: (Maximum 3 stars) } \\
\hline \multicolumn{2}{|l|}{ 1) Assessment of the outcome: } \\
\hline \multicolumn{2}{|l|}{ a) Independent blind assessment. ** } \\
\hline \multicolumn{2}{|l|}{ b) Record linkage. ** } \\
\hline c) Self report. * & *⿻一丿火 \\
\hline \multicolumn{2}{|l|}{ d) No description. } \\
\hline \multicolumn{2}{|c|}{ 2) Statistical test: } \\
\hline \multicolumn{2}{|c|}{$\begin{array}{l}\text { a) The statistical test used to analyze the data is clearly described and appropriate, and the measurement of the association is presented, } \\
\text { including confidence intervals and the probability level ( } p \text { value). * }\end{array}$} \\
\hline b) The statistical test is not appropriate, not described or incomplete. & X \\
\hline
\end{tabular}




\section{ANEXO III. TABLAS DE ESTUDIOS}

\begin{tabular}{|c|c|c|c|c|c|c|}
\hline $\begin{array}{l}\text { Referencia } \\
\text { (Cita } \\
\text { Abreviada) }\end{array}$ & $\begin{array}{l}\text { Estudio (Diseño y } \\
\text { objetivo) }\end{array}$ & $\begin{array}{l}\text { Población } \\
\text { (nº y } \\
\text { características) }\end{array}$ & $\begin{array}{l}\text { Descripción de las } \\
\text { intervenciones } \\
\text { comparaciones, } \\
\text { exposiciones o pruebas } \\
\text { a estudio }\end{array}$ & $\begin{array}{l}\text { Resultados } \\
\text { (Estimadores de resultados- } \\
\text { Magnitud del efecto) }\end{array}$ & $\begin{array}{l}\text { Conclusiones } \\
\text { (conclusiones) }\end{array}$ & $\begin{array}{l}\text { Comentarios } \\
\text { Calidad de la evidencia Financiación } \\
\text { comentarios) }\end{array}$ \\
\hline Hawdon 1992 & $\begin{array}{l}\text { Diseño } \\
\text { Estudio transversal } \\
\text { Objetivo } \\
\text { Determinar el } \\
\text { efecto de las } \\
\text { variaciones en el } \\
\text { intervalo entre } \\
\text { tomas en el patrón } \\
\text { de adaptación } \\
\text { metabólica }\end{array}$ & $\begin{array}{l}\mathbf{N} \\
218 \text { RN } \\
\text { Características } \\
\text { RN a término < } 1 \\
\text { semana }\end{array}$ & $\begin{array}{l}\text { Exposición } \\
\text { RN que hacen intervalos } \\
\text { prolongados entre tomas, } \\
\text { hasta } 8 \text { horas }\end{array}$ & $\begin{array}{l}\text { Resultados } \\
\text { No hay datos tabulados. } \\
\text { *Definición hipoglucemia en RN a } \\
\text { término: } 5 \mathrm{~h} .<1,9 \mathrm{mmol} / /(<35 \\
\mathrm{mg} / \mathrm{dl}) ;<48 \mathrm{~h} .<1,6 \mathrm{mmol} / \mathrm{l}(<30 \\
\mathrm{mg} / \mathrm{dll}) ; \geq 48 \mathrm{~h} .<2,2 \mathrm{mmol} / \mathrm{l} .(<40 \\
\mathrm{mg} / \mathrm{dl})\end{array}$ & $\begin{array}{l}\text { Conclusión } \\
\text { El intervalo entre tomas } \\
\text { es el mayor } \\
\text { determinante de la } \\
\text { concentración de } \\
\text { glucosa en sangre. No } \\
\text { obstante los intervalos } \\
\text { prolongados entre tomas } \\
\text { de hasta } 8 \text { horas no } \\
\text { están asociados con } \\
\text { concentraciones } \\
\text { excesivamente bajas de } \\
\text { glucosa en sangre }\end{array}$ & $\begin{array}{l}\text { Comentarios } \\
\text { (-) no hay datos tabulados para este } \\
\text { desenlace, incluye RN sanos y pre- } \\
\text { término } \\
\text { Conflicto de interés } \\
\text { No indicado } \\
\text { Financiación } \\
\text { Scientific and Research } \\
\text { Committee of Newcastle Health } \\
\text { Authority and by a Foundation for } \\
\text { the Study of Infant Deaths training } \\
\text { fellowship } \\
\text { Calidad } \\
\text { NOS scale, estudios transversals: } 6\end{array}$ \\
\hline
\end{tabular}




\section{Bibliografía}

(1) Hewitt V, Watts R, Robertson J, Haddow G. Nursing and midwifery management of hypoglycaemia in healthy term neonates. International Journal of Evidenceâ€ $\square$ Based Healthcare 2005;3(7):169-205.

(2) NICE. Postnatal care up to 8 weeks after birth. Julio 2006 (actualizado en Febrero de 2015). Disponible en: http://guidance.nice.org.uk/CG37.

(3) Glover J. Supplementation of breastfeeding newborns: a flow chart for decision making. Journal of Human Lactation 1995;11(2):127-31.

(4) Wight N, Marinelli KA, the Academy of Breastfeeding Medicine. ABMProtocol. ABM Clinical Protocol \#1: Guidelines for Blood Glucose Monitoring and Treatment of Hypoglycemia in Term and Late-Preterm Neonates, Revised 2014. Breastfeeding Medicine 2014;9(4):173-9.

(5) Academy of Breastfeeding Medicine Protocol Committee. ABM clinical protocol\# 3: hospital guidelines for the use of supplementary feedings in the healthy term breastfed neonate, revised 2009. 2009.

(6) Hawdon JM, Platt MW, Aynsley-Green A. Patterns of metabolic adaptation for preterm and term infants in the first neonatal week. Archives of disease in childhood 1992;67(4 Spec No):357-65.

(7) Walker M. Breastfeeding the sleepy baby. Journal of Human Lactation 1997;13(2):151-3.

(8) Biancuzzo M. Breastfeeding education for early discharge: a three-tiered approach. The Journal of perinatal \& neonatal nursing 1997;11(2):10-22. 


\section{PREGUNTA CLÍNICA № 23}

¿Es necesario realizar una frenotomía al lactante amamantado que presenta anquiloglosia?

\section{1- Pregunta clínica en formato PICO}

Tabla 1- Componentes de la pregunta clínica en formato PICO

\begin{tabular}{|l|l|}
\hline Pacientes & $\begin{array}{l}\text { Madre sana con problemas de lactancia que amamanta a un } \\
\text { bebe sano con anquiloglosia }\end{array}$ \\
\hline Intervención & Frenotomía \\
\hline Comparación & Medidas de apoyo para mejorar la lactancia \\
\hline Resultados & $\begin{array}{l}\text { Tasa de lactancia materna exclusiva al alta } \\
\text { Tasa de lactancia materna exclusiva al mes } \\
\text { Tasa de lactancia materna a los 4 meses } \\
\text { Tasa de lactancia materna exclusiva a los 4 meses } \\
\text { Satisfacción materna } \\
\text { Complicaciones de las mamas (dolor, grietas, ingurgitacion, } \\
\text { mastitis...) } \\
\text { Pérdida ponderal del bebé (48-72h.) } \\
\text { Ganancia ponderal a las 8 semanas o curva de peso }\end{array}$ \\
\hline Tipo de estudio & $\begin{array}{l}\text { RS de ECA, ECA, RS de estudios observacionales o } \\
\text { estudios observacionales }\end{array}$ \\
\hline
\end{tabular}

\section{2- Introducción}


3. ESTRATEGIA DE ELABORACIÓN DE LA PREGUNTA

\subsection{GPC Base}

Tabla 2- Resumen de GPC Base

\begin{tabular}{|c|c|c|c|c|}
\hline $\begin{array}{l}\text { Guía } \\
\text { (Enfoque) }\end{array}$ & $\begin{array}{l}\text { Resumen sobre la evidencia } \\
\text { (Calidad de la evidencia) }\end{array}$ & $\begin{array}{l}\text { Recomendaciones } \\
\text { (Grado) }\end{array}$ & $\begin{array}{c}\text { Referencias } \\
\text { bibliográficas } \\
\text { (Tipo de } \\
\text { publicación) }\end{array}$ & Comentarios \\
\hline NICE, 2006 & 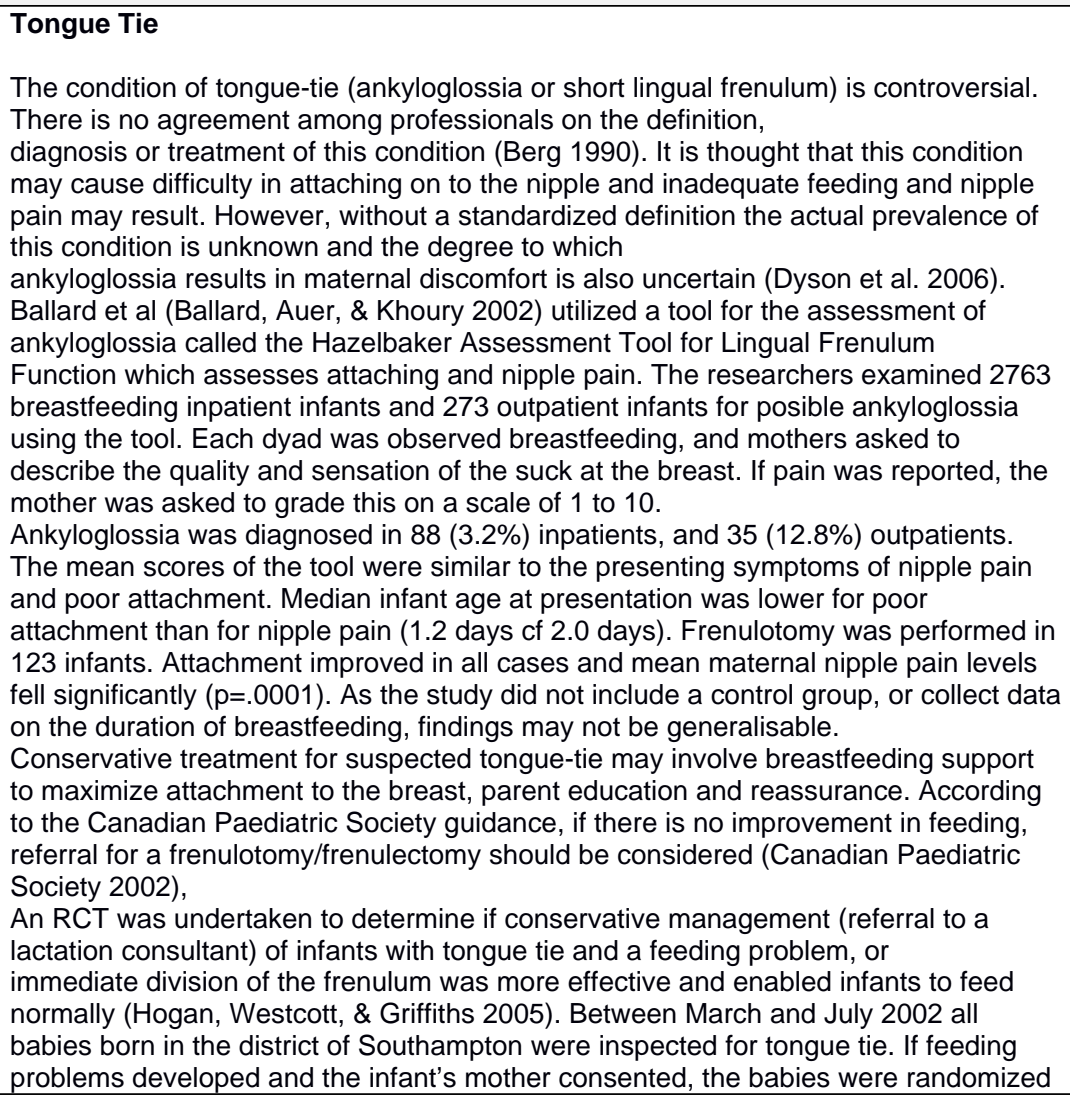 & $\begin{array}{l}\text { 42. Evaluation for ankyloglossia should be made if } \\
\text { breastfeeding concerns persist after a review of } \\
\text { positioning and attachment by a skilled health care } \\
\text { professional or peer counsellor. [D(GPP)] } \\
\text { 43. Babies who appear to have ankyloglossia should } \\
\text { be evaluated further (non-urgent action; refer to NICE } \\
\text { Interventional Procedure on Tongue Tie (National } \\
\text { Institute for Health \& Clinical Excellence, 2005). } \\
\text { [D(GPP) }\end{array}$ & & \\
\hline
\end{tabular}




\begin{tabular}{|c|c|c|c|c|}
\hline $\begin{array}{c}\text { Guía } \\
\text { (Enfoque) }\end{array}$ & $\begin{array}{l}\text { Resumen sobre la evidencia } \\
\text { (Calidad de la evidencia) }\end{array}$ & $\begin{array}{l}\text { Recomendaciones } \\
\text { (Grado) }\end{array}$ & $\begin{array}{c}\text { Referencias } \\
\text { bibliográficas } \\
\text { (Tipo de } \\
\text { publicación) }\end{array}$ & Comentarios \\
\hline & 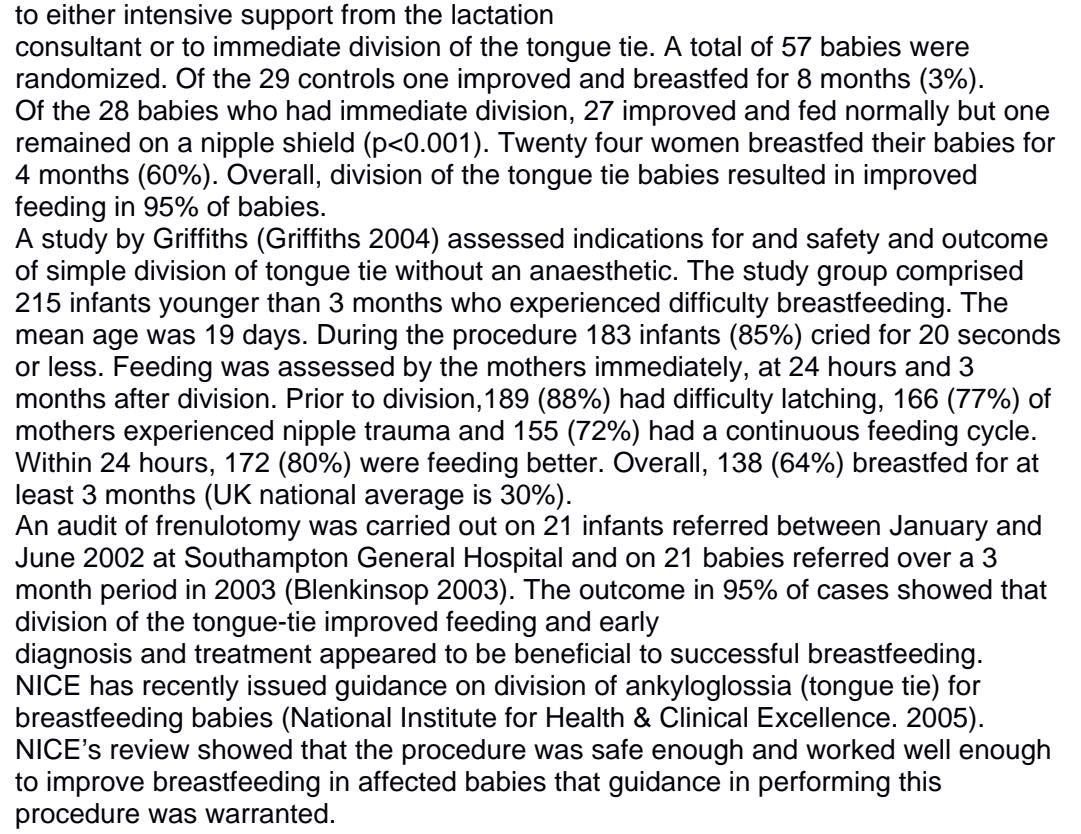 & & & \\
\hline $\begin{array}{l}\text { Division of } \\
\text { ankyloglos } \\
\text { sia } \\
\text { (tongue- } \\
\text { tie) for } \\
\text { breastfeed } \\
\text { ing. } \\
\text { Interventio } \\
\text { nal } \\
\text { procedure } \\
\text { guidance } \\
\text { no. } 149 \\
\text { (2005). } \\
\text { Available } \\
\text { from: } \\
\text { www.nice. } \\
\text { org.uk/IPG }\end{array}$ & $\begin{array}{l}\text { 2.3 Efficacy } \\
2.3 .1 \text { One randomised controlled trial compared division of tongue-tie with } 48 \text { hours of } \\
\text { intensive support from a lactation consultant. Mothers reported that } 95 \% \text { ( } 19 / 20) \text { of } \\
\text { babies had improved breastfeeding } 48 \text { hours after tongue-tie division, compared with } \\
5 \% \text { ( } 1 / 20) \text { of babies in the control group }(\mathrm{p}<0.001) \text {. } \\
2.3 .2 \text { In one case series of } 215 \text { babies, } 80 \%(173 / 215) \text { of mothers reported improved } \\
\text { breastfeeding } 24 \text { hours after the procedure. In another case series of } 123 \text { babies, } \\
100 \% \text { ( } 70 / 70) \text { of mothers reported improved latch after the procedure, and the } 53 \\
\text { mothers with nipple pain noted significant improvement immediately after the } \\
\text { procedure. In a third case series, } 100 \% \text { ( } 36 / 36) \text { of babies were reported to have } \\
\text { normal tongue motion at } 3 \text { months. For more details, refer to the Sources of } \\
\text { evidence. } \\
2.3 .3 \text { There were conflicting opinions among the Specialist Advisors and some stated } \\
\text { that it is difficult to be certain whether any perceived improvement in breastfeeding is } \\
\text { due to division of the tongue-tie. } \\
2.4 \text { Safety } \\
2.4 .1 \text { Few adverse effects were reported. One case series reported that, after the }\end{array}$ & $\begin{array}{l}\text { 1.1 Current evidence suggests that there are no major } \\
\text { safety concerns about division of ankyloglossia } \\
\text { (tongue-tie) and limited evidence suggests that this } \\
\text { procedure can improve breastfeeding. This evidence is } \\
\text { adequate to support the use of the procedure provided } \\
\text { that normal arrangements are in place for consent, } \\
\text { audit and clinical governance. } \\
1.2 \text { Division of ankyloglossia (tongue-tie) for } \\
\text { breastfeeding should only be performed by registered } \\
\text { healthcare professionals who are properly trained. } \\
1.3 \text { Publication of further controlled trials on the effect } \\
\text { of the procedure on successful long-term } \\
\text { breastfeeding will be useful. }\end{array}$ & & \\
\hline
\end{tabular}




\begin{tabular}{|c|c|c|c|c|}
\hline $\begin{array}{c}\text { Guía } \\
\text { (Enfoque) }\end{array}$ & $\begin{array}{l}\text { Resumen sobre la evidencia } \\
\text { (Calidad de la evidencia) }\end{array}$ & $\begin{array}{l}\text { Recomendaciones } \\
\text { (Grado) }\end{array}$ & $\begin{array}{l}\text { Referencias } \\
\text { bibliográficas } \\
\text { (Tipo de } \\
\text { publicación) }\end{array}$ & Comentarios \\
\hline 149 & $\begin{array}{l}\text { procedure, } 2 \% \text { ( }(4 / 215) \text { of babies had an ulcer under the tongue for more than } 48 \\
\text { hours. Two studies, including a total of } 159 \text { babies, stated that there were no } \\
\text { complications. } \\
\text { 2.4.2 Two studies reported that } 8 \% \text { ( } 3 / 36 \text { ) and } 18 \% \text { ( } 39 / 215 \text { ) of babies slept through } \\
\text { the procedure. For more details, refer to the Sources of evidence. } \\
\text { 2.4.3 The Specialist Advisors stated that adverse effects were likely to be rare. } \\
\text { Potential adverse events include bleeding, infection, ulceration, pain, damage to the } \\
\text { tongue and submandibular ducts, and recurrence of the tongue-tie. }\end{array}$ & & & \\
\hline $\begin{array}{l}\text { Protocolo } \\
\text { ABM \#11, } \\
2004\end{array}$ & Este protocolo de 2004 está en revisión. & & & \\
\hline $\begin{array}{l}\text { Perinatal } \\
\text { Services } \\
\text { BC, } 2012\end{array}$ & $\begin{array}{l}\text { Ankyloglossia (Tongue Tie) } \\
\text { Observed when the infant is unable to adequately extend or elevate tongue due to a } \\
\text { short lingual frenulum attached to tip of the tongue that restricts tongue movement96 } \\
\text { as it may contribute to breastfeeding problems such as ineffective milk transfer, low } \\
\text { intake of breastmikik resulting in insufficient weight gain, low maternal milk supply, } \\
\text { sore or damaged nipples, blocked ducts, and breast infections } 38,39,97 \\
\text { Partial ankyloglossia occurs in approximately } 3.2 \% \text { to } 4.8 \% \text { of term infants and in } \\
12.8 \% \text { of infants with breastfeeding problems } 97,98 \text {. Complete ankyloglossia (fusion } \\
\text { of tongue to the mouth floor) is exceptionally rare97 } \\
\text { Treatment is not necessary if breastfeeding proceeds successfully96,97 } \\
\text { If feeding problems persist refer the infant to a physician for further assessment and } \\
\text { posible frenotomy } 96 \text { as outlined in the American Academy of Breastfeeding Guideline } \\
\text { Protocol \#11 } 97 \text { and in Lawrence and Lawrence, } 39 \text { to improve breastfeeding } \\
\text { effectiveness } 99 \text {. }\end{array}$ & $\begin{array}{l}\text { Recommendation 7: } \\
\text { Provide support for infants identified with specific } \\
\text { challenges (A). }\end{array}$ & $\begin{array}{l}\text { 38. Riordan J \& } \\
\text { Wambach, K. } \\
\text { (2010). } \\
\text { 39. Lawrence RA et } \\
\text { al, 2005. } \\
\text { 96. Canadian } \\
\text { Paediatric Society, } \\
\text { (2002). } \\
\text { 97. The Academy } \\
\text { of Breastfeeding } \\
\text { Medicine (2004). } \\
\text { 99. Geddes DT et } \\
\text { al, 2008. }\end{array}$ & \\
\hline $\begin{array}{l}\text { Estrategia } \\
\text { centros de } \\
\text { salud } \\
\text { IHAN. } 2014\end{array}$ & $\begin{array}{l}\text { Si hay problemas de dolor o grietas, el personal debe examinar la boca del recién } \\
\text { nacido en busca de frenillo sublingual o muguet. }\end{array}$ & & & \\
\hline
\end{tabular}




\subsection{Revisiones sistemáticas}

Tabla 4- Resumen de RS actuales

\begin{tabular}{|c|c|c|c|c|c|c|}
\hline $\begin{array}{l}\text { Referencia } \\
\text { (Cita } \\
\text { Abreviada) }\end{array}$ & $\begin{array}{l}\text { Estudio (Diseño y } \\
\text { objetivo) }\end{array}$ & $\begin{array}{l}\text { Población } \\
\text { (no y características) }\end{array}$ & $\begin{array}{l}\text { Descripción de las intervenciones } \\
\text { comparaciones, exposiciones o pruebas } \\
\text { a estudio }\end{array}$ & $\begin{array}{l}\text { Resultados } \\
\text { (Estimadores de resultados- } \\
\text { Magnitud del efecto) }\end{array}$ & Conclusiones (conclusiones) & \begin{tabular}{|l} 
Comentarios \\
Calidad de la evidencia \\
Financiación
\end{tabular} \\
\hline $\begin{array}{l}\text { Francis et al. } \\
2015\end{array}$ & \begin{tabular}{|l|} 
Diseño \\
Revisión \\
sistemática \\
Objetivo \\
El objetivo de este \\
artículo fue \\
investigar los \\
beneficios del \\
tratamiento \\
quirúrgico en \\
recién nacidos y \\
bebés con \\
anquiloglosia que \\
presentan \\
dificultades en la \\
lactancia.
\end{tabular} & $\begin{array}{l}29 \text { estudios, entre } \\
\text { ellos: } \\
\text { - } 5 \text { ECA } \\
\text { - } 1 \text { cohorte } \\
\quad \text { retrospectivo } \\
\text { - } 23 \text { serie de casos } \\
\\
\text { Calidad de los } \\
\text { estudios: } \\
3 \text { ECA, de buena } \\
\text { calidad } \\
1 \text { ECA de calidad } \\
\text { justa } \\
1 \text { ECA de mala } \\
\text { calidad } \\
\text { Un estudio de } \\
\text { cohorte retrospectivo } \\
\text { de mala calidad }\end{array}$ & $\begin{array}{l}\text { Los datos de eficacia del tratamiento se } \\
\text { extrajeron de estudios con diseños } \\
\text { comparativos (ensayos controlados } \\
\text { aleatorios [ECA], ensayos no aleatorios, } \\
\text { estudios de cohorte prospectivos o } \\
\text { retrospectivos). Los efectos adversos fueron } \\
\text { recogidos de todos los tipos de estudio, } \\
\text { incluidos series de casos y reporte de } \\
\text { casos } \\
\text { Los principales variables de resultados } \\
\text { de interés fueron } \\
\quad \quad \text { Dolor en el pezón aportado por la } \\
\quad \quad \text { madre asociado con la lactancia } \\
\quad \text { materna, } \\
\quad \text { Eficacia de la lactancia } \\
\quad \text { - Duración de la lactancia } \\
\text { Una heterogeneidad considerable de los } \\
\text { diseño de los estudios y las variables de } \\
\text { resultado hizo imposible de realizar ningún } \\
\text { metanálisis. Por lo tanto, las características } \\
\text { de las poblaciones e intervenciones fueron } \\
\text { resumidos y se utilizaron estadísticas } \\
\text { descriptivas para informar los resultados } \\
\text { 2 ECA compararon frenotomia vs. } \\
\text { Tratamiento simulado, } 1 \text { ECA frenotomia vs } \\
\text { to usual care,1 ECA frenotomia vs consulta } \\
\text { intensiva de lactancia, } 1 \text { ECA utilizó un } \\
\text { diseño cruzado para comparar frenotomía } \\
\text { seguida de placebo o placebo seguido por } \\
\text { frenotomía. El estudio de cohorte } \\
\text { retrospectivo compara frenotomía con } \\
\text { cuidados habituales. }\end{array}$ & $\begin{array}{l}\text { En el análisis final de esta RS } \\
\text { se han incluido los } 3 \text { ECA de } \\
\text { buena calidad, y el de calidad } \\
\text { justa. } \\
\text { Los ECA de buena calidad } \\
\text { eran relativamente } \\
\text { consistentes en demostrar la } \\
\text { mejora en la eficacia de la } \\
\text { lactancia materna } \\
\text { inmediatamente o dentro de } \\
\text { los } 5 \text { días de realizada la } \\
\text { frenotomía en comparación } \\
\text { con el tratamiento simulado o } \\
\text { ninguna intervención, } \\
\text { respectivamente } \\
\\
\text { Estos mismos estudios } \\
\text { tuvieron resultados dispares } \\
\text { con respecto a si la } \\
\text { frenotomía disminuía el dolor } \\
\text { del pezón materno. Sólo uno } \\
\text { de ellos realizado en bebés } \\
\text { de } 6 \text { días de edad mostró una } \\
\text { reducción significativa en el } \\
\text { dolor. Aquellos ECA con } \\
\text { frenotomías realizadas en } \\
\text { lactantes con unas semanas } \\
\text { más de vida no informaron } \\
\text { reducción del dolor en forma } \\
\text { inmediata o a los } 5 \text { días }\end{array}$ & $\begin{array}{l}\text { la fuerza de la evidencia sobre la } \\
\text { eficacia del tratamiento quirúrgico en } \\
\text { bebes con anquiloglosia en mejorar } \\
\text { la lactancia es baja tanto para la } \\
\text { mejora de la lactancia materna } \\
\text { como para la reducción del dolor del } \\
\text { pezón materno e insuficiente para } \\
\text { evaluar el efecto de la frenotomía en } \\
\text { la duración de la lactancia materna } \\
\text { ya que se basa en estudios } \\
\text { pequeños y de metodología } \\
\text { heterogénea, lo que significa que la } \\
\text { investigación futura podría cambiar } \\
\text { nuestra comprensión de la } \\
\text { estimación del efecto. } \\
\text { Los autores destacan lagunas } \\
\text { importantes en la evidencia actual:. } \\
\text { la ausencia de estudios que } \\
\text { comparen la intervención quirúrgica } \\
\text { con enfoques mas conservadores } \\
\text { como la consulta de lactancia, y de } \\
\text { estudios comparativos que evalúen } \\
\text { la eficacia de los tratamientos no } \\
\text { quirúrgicos para anquiloglosia, la } \\
\text { escasez de datos sobre el papel de } \\
\text { la edad del bebe en la eficacia de la } \\
\text { frenotomía, la falta de resultados de } \\
\text { eficacia a largo plazo y la necesidad } \\
\text { de un enfoque estandarizado para el } \\
\text { diagnóstico y la clasificación de la } \\
\text { anquiloglosia. }\end{array}$ & $\begin{array}{l}\text { Financiación: } \\
\text { Este proyecto fue } \\
\text { apoyado por contrato } \\
\text { de la Agency for } \\
\text { Healthcare Research } \\
\text { and Quality } \\
\\
\text { Conflicto de } \\
\text { intereses: Los autores } \\
\text { han indicado que no } \\
\text { tienen conflictos de } \\
\text { interés potenciales a } \\
\text { revelar. } \\
\text { Los resultados } \\
\text { reportados en la RS } \\
\text { son de estudios } \\
\text { identificados por un } \\
\text { informe de la Agency } \\
\text { for Healthcare } \\
\text { Research and Quality } \\
\text { (AHRQ)-commissioned } \\
\text { systematic review, de } \\
\text { intervenciones para } \\
\text { niños y bebes con } \\
\text { anquiloglosia } \\
\text { congénita }\end{array}$ \\
\hline
\end{tabular}


En la búsqueda realizada se han identificado cuatro revisiones sistemáticas (RS) sobre la eficacia del tratamiento con frenotomía, en bebes con anquiloglosia y dificultades en la lactancia materna(1-4). De estas cuatro revisiones se ha seleccionado la RS de mayor calidad (puntuación AMSTAR de 9) y búsqueda más reciente(1). Las tres RS restantes tenían menor calidad metodológica, (puntuaciones AMSTAR de tres(2), cinco(4) y siete(3) y carencias en la descripción de la búsqueda o en la presentación de la calidad de los estudios incluidos.

En la RS de Francis et al, 2015(1) los autores incluyeron los resultados reportados en estudios identificados por un informe de la Agency for Healthcare Research and Quality (AHRQ)-commissioned systematic review, de intervenciones para niños y bebes con anquiloglosia congénita(5).

Los datos de eficacia del tratamiento se extrajeron de estudios con diseños comparativos (ensayos controlados aleatorios (ECA), ensayos no aleatorios, estudios de cohorte prospectivos o retrospectivos. Los efectos adversos fueron recogidos de todo tipo de estudios, incluidos series de casos y reporte de casos. La alta heterogeneidad en el diseño de los estudios y en los desenlaces de los estudios incluidos hizo imposible a los autores realizar un metaanálisis, por lo que resumieron las características de cada estudio en tablas descriptivas.

En la RS de Francis et al(1) se seleccionaron 29 estudios, entre los que se encontraban cinco ECA (tres realizados en el Reino Unido(6-8), uno en EEUU(9) y el último en Israel(10), un estudio de cohortes retrospectivo de EEUU(11) y 23 series de casos.

De los cinco ECA incluidos, dos compararon la frenotomía vs tratamiento simulado (tener a los niños en la habitación donde se realizaba la intervención la misma cantidad de tiempo que los niños que sí eran intervenidos)(6;9), uno la frenotomía vs. cuidados habituales(7) (apoyo con la lactancia), otro la frenotomía vs. la consulta intensiva de lactancia(8) y el último ECA, de diseño cruzado que compara frenotomía seguida de tratamiento simulado vs. tratamiento simulado seguido de frenotomía(10). El estudio de cohortes retrospectivo comparó frenotomía vs. no intervención(11).

Las principales variables de resultados evaluadas en los estudios comparativos fueron el dolor en el pezón asociado a la lactancia materna y reportado por la madre, y la eficacia y la duración de la lactancia materna. En el análisis final los autores de la RS(1) incluyeron cuatro ECA, 3 de buena calidad( $6 ; 7 ; 9)$ y el último de calidad justa(8), descartando el ECA de diseño cruzado.

Los cuatro ECA seleccionados eran diferentes en cuanto al tipo de población, edad (desde una edad media de 6(9) a 33 días(6), una mediana de 11 días(7) o un rango de edad entre los 3 y 70 días(8)). Los datos de género sólo se reportaron completos en dos de los cuatro ECA(6;9).

El grado de anquiloglosia fue medido en dos ECA(7;9) mediante la escala HATLFF (Hazelbaker Assessment Tool for Lingual Frenulum Function), no utilizándose criterios uniformes para el diagnóstico de la anquiloglosia. La frenotomía fue realizada por diferentes profesionales (desde cirujanos pediátricos, consultores en lactancia y/o otorrinolaringólogos), tanto en hospitales de tercer nivel como consulta externas, y los estudios no daban demasiados detalles de la intervención realizada. 
En un ECA(6), doble ciego, realizado en Reino Unido, incluyó bebes de menos de 4 meses de edad con anguiloglosia y dificultades con la lactancia materna, nacidos entre octubre 2003 y abril 2004. Los bebes fueron asignados al grupo intervención con frenotomía (Gl: $n=27)$ o al grupo control que recibió una simulación del tratamiento (GC: $n=30$ ). La distribución de niños y niñas fue similar (niño/niña Gl: 21/6; GC: 19/11) con una edad media de 33 días en el grupo intervenido y de 28 en el grupo control. Una vez terminado el estudio, a los bebes del grupo control se les practicó la frenotomía.

En un segundo ECA(7) simple ciego, llevado a cabo en un hospital clínico del Reino Unido, entre octubre de 2011 y junio de 2013 , se reclutaron aquellos recién nacidos que presentaban dificultades con la lactancia y anquiloglosia (puntuación HATLFF entre 6-12 y puntuación LATCH $\leq 8$ (Latch, Audible swallowing, nipple Type, Comfort, Hold)). Los participantes fueron asignados de forma aleatoria al grupo con frenotomía (GI $\mathrm{n}=55$ ) 0 al grupo con cuidados habituales (GC n=52). La edad media de los bebes fue de 11 días en ambos grupos (RIC del GI de 8 a 14; RIC del GC de 8 a $16 ; p=0,94)$. Cabe destacar el cruce de grupos en este estudio, ya que el $17 \%$ de los niños asignados a la atención habitual solicitaron una frenotomía antes de los cinco días debido a lactancia dolorosa, y a las ocho semanas sólo ocho de los niños del grupo control no habían recibido una frenotomía (15\%).

El tercer ECA(9) fue realizado en lactantes con anquiloglosia significativa según los criterios HATLFF (puntuación en la función $>11$ y puntaje de apariencia $<8$ ), con dificultad para la lactancia materna y reporte materno de dolor en el pezón, y que fueron asignados de forma aleatoria al grupo intervención con frenotomía $(n=30)$ o al grupo control con un procedimiento simulado $(n=28)$. La edad promedio de estos bebés fue de $6 \pm 6,9$ días. Los propios autores reconocen el cruce significativo del grupo control, puesto que 27 (96\%) de las madres del grupo simulado decidieron realizar una frenotomía a sus bebes antes de las dos semanas de seguimiento.

El cuarto ECA(8), realizado en el Reino Unido, incluyó niños con anquiloglosia y problemas con la lactancia materna nacidos entre marzo 2002 a julio 2002. La edad media en el momento de la aleatorización fue de 20 días (mediana 15 días, rango de 3 a 70). 28 niños fueron asignados al grupo intervención ( 20 alimentados sólo al pecho y 8 con biberón) y 29 al grupo control (20 alimentados solo al pecho y 9 con biberón). Se trata de un estudio con importantes limitaciones, como la falta de cegamiento, un esquema poco claro de aleatorización y un cruce del grupo control tras la evaluación de los resultados a las $48 \mathrm{~h}$.

En el estudio de cohorte retrospectivo(11) se incluyeron 367 niños con anquiloglosia que nacieron en un hospital de EEUU entre abril de 2006 y febrero de 2011. De estos niños, $302(82,3 \%)$ fueron tratados mediante frenotomía y $65(17,7 \%)$ no. La edad media de los niños incluidos en el estudio fue de 18 días. Del total de la cohorte (367 niños), 91 madres $(24,9 \%)$ aceptaron participar en una encuesta telefónica de seguimiento. De las 91 encuestadas, en 82 casos $(90,1 \%)$ sus bebes habían sido intervenidos mediante una frenotomía y en 9 casos $(9,9 \%)$ no recibieron dicha intervención.

La mayoría de los estudios que reportan daños señalan explícitamente que éstos no fueron significativos o fueron mínimos. El sangrado fue el daño más frecuente, aunque fue descrito como menor, limitado y el esperado ante una intervención quirúrgica menor. 
La conclusión de los autores es que una pequeña cantidad de evidencia sugiere que la frenotomía puede estar asociada con mejora en la lactancia materna (reportada por las madres) y en el dolor en los pezones, aunque la fuerza de la evidencia es baja e insuficiente para evaluar el efecto de la frenotomía en la duración de la lactancia, ya que se basa en estudios pequeños de seguimiento a corto plazo, y de metodología heterogénea.

Los autores destacan la ausencia de estudios que comparen la intervención quirúrgica con enfoques más conservadores, como la consulta de lactancia, y de estudios comparativos que evalúen la eficacia de los tratamientos no quirúrgicos para anquiloglosia, la escasez de datos sobre el papel de la edad en la eficacia de la frenotomía, la falta de resultados de eficacia a largo plazo y la necesidad de criterios uniformes para el diagnóstico y la clasificación de la anquiloglosia. 


\subsection{Resumen de GPC base y RS disponibles}

La guía NICE señala que se debería realizar una evaluación de anquiloglosia si persisten los problemas con la lactancia una vez que se ha revisado la posición y el agarre por un profesional sanitario cualificado o un orientador entre iguales (peer counserlor) (recomendación de buena práctica)(12).

También señalan que los niños con posible anquiloglosia deberían ser evaluados en mayor profundidad (recomendación de buena práctica), haciendo referencia a un "guidance" de un procedimiento publicado en 2005 en el que se dice que la evidencia actual sugiere que no hay mayores problemas de seguridad con la frenotomía y que una evidencia limitada sugiere que este procedimiento puede mejorar la lactancia materna. Además se señala que sólo la deberían realizar profesionales sanitarios registrados y adiestrados de forma adecuada y que sería de utilidad la publicación de más ensayos controlados sobre el efecto del procedimiento sobre el éxito de la lactancia a largo plazo (13).

En la Perinatal Services $B C$, se indica que el tratamiento no es necesario si la lactancia materna transcurre con normalidad, y que si los problemas con la alimentación persisten, se derive a un médico para una valoración más profunda y posible frenotomía para mejorar la efectividad de la lactancia (14).

En la estrategia IHAN se señala que si hay problemas de dolor o grietas, el personal debe examinar la boca del recién nacido en busca de frenillo sublingual o muguet (15).

La conclusión a la que llegan los autores de la revisión sistemática (1) es que una pequeña cantidad de evidencia sugiere que la frenotomía puede estar asociada con una mejora de la lactancia materna (reportada por las madres) y del dolor en los pezones, aunque la fuerza de la evidencia es baja e insuficiente para evaluar el efecto de la frenotomía en la duración de la lactancia, ya que se basa en estudios pequeños de seguimiento a corto plazo, y de metodología heterogénea. Los autores destacan la ausencia de estudios que comparen la intervención quirúrgica con enfoques más conservadores, como la consulta de lactancia, y de estudios comparativos que evalúen la eficacia de los tratamientos no quirúrgicos para anquiloglosia, la escasez de datos sobre el papel de la edad en la eficacia de la frenotomía, la falta de resultados de eficacia a largo plazo y la necesidad de criterios uniformes para el diagnóstico y la clasificación de la anquiloglosia.

\subsection{Conclusión (marcar con una $\mathrm{X}$ ):}

\begin{tabular}{|l|l|}
\hline & Adopción GPC/Revisión sistemática \\
\hline$X$ & Elaboración parcial (desde la fecha final de la revisión de Francis et al, 2015) \\
\hline & Elaboración de novo \\
\hline
\end{tabular}

\subsection{Diseño de la estrategia de búsqueda de estudios individuales}


GPC Lactancia Materna- Pregunta 23. Frenotomía

\begin{tabular}{|l|l|}
\hline Criterios de selección de estudios & ECA, estudios de cohortes \\
\hline Período de búsqueda & Desde enero de 2014 en adelante \\
\hline Bases de datos & Cochrane, PUMBED y EMBASE y CINHAL \\
\hline
\end{tabular}

Ver estrategias de búsqueda de estudios originales en el ANEXO I.

Se incluye una búsqueda de revisiones sistemáticas primero y luego se elimina el filtro de Revisiones sistemáticas, limitando la búsqueda desde 2014 en adelante para localizar nuevos estudios publicados a partir de la revisión incluida. 


\section{4- Resumen de la evidencia (Tablas de estudios individuales y valoración de calidad en el ANEXO II)}

\section{1- GRADE Evidence Profile}

Comparación: Eficacia de la frenotomía en mejorar la lactancia en niños con anquiloglosia vs. tratamiento control (simulado o cuidados habituales) Bibliografía: Buryk 20111; Berry $2012^{2}$; Emond 2014; ; Hogan 20054; Steehler 20125; Martinelli $2015^{11 .}$

\begin{tabular}{|c|c|c|c|c|c|c|c|c|c|c|c|c|}
\hline \multirow{2}{*}{\multicolumn{7}{|c|}{ Evaluación de la calidad }} & \multicolumn{4}{|c|}{ Resumen de los Resultados } & \multirow{3}{*}{ Calidad } & \multirow{3}{*}{ Importancie } \\
\hline & & & & & & & \multicolumn{2}{|c|}{ № de pacientes } & \multicolumn{2}{|c|}{ Magnitud del efecto } & & \\
\hline \begin{tabular}{|c|}
$\begin{array}{c}\text { № de } \\
\text { estudios }\end{array}$ \\
esto
\end{tabular} & Diseño & \begin{tabular}{|c|} 
Riesgo de \\
sesgo
\end{tabular} & Inconsistencia & $\begin{array}{l}\text { Evidencia } \\
\text { indirecta }\end{array}$ & Imprecisión & $\begin{array}{c}\text { Otras } \\
\text { consideraciones }\end{array}$ & $\begin{array}{c}\text { Grupo } \\
\text { expuesto }\end{array}$ & $\begin{array}{l}\text { Grupo no } \\
\text { expuesto }\end{array}$ & $\begin{array}{l}\text { Relativa } \\
\text { (95\% Cl) }\end{array}$ & $\begin{array}{c}\text { Absoluta por } \\
1000\end{array}$ & & \\
\hline \multicolumn{13}{|c|}{ Dolor en el pezón materno (medido por VAS 2,3 /MPQ-SF'1) } \\
\hline $3^{1,2,3}$ & ECA & No seria & \begin{tabular}{|l|l} 
Seria & 6 \\
\end{tabular} & No seria & Seria $^{7}$ & Ninguna & 97 & 94 & \multicolumn{2}{|c|}{ Ver resumen de la evidencia } & BAJA & CRITICO \\
\hline \multicolumn{13}{|c|}{ Eficacia de la lactancia por reporte materno a corto plazo (0-5 días) ( $\left.\mathrm{BSES}^{3}\right)$} \\
\hline $3^{2.3 .4}$ & ECA & Seria ${ }^{8}$ & \begin{tabular}{|l|l} 
No seria & i
\end{tabular} & No seria & Seria ${ }^{9}$ & Ninguna & 108 & 111 & \multicolumn{2}{|c|}{ Ver resumen de la evidencia } & BAJA & CRITICO \\
\hline \multicolumn{13}{|c|}{ Eficacia de la lactancia por observadores independientes (0-5 dias) (medida por IBFAT ${ }^{1.2 .3}$, LATCH $^{2,3}$ ) } \\
\hline $3^{1,2,3}$ & ECA & No seria & \begin{tabular}{|l|l} 
Seria & 6 \\
\end{tabular} & No seria & Seria ${ }^{7}$ & \begin{tabular}{|l|l} 
Ninguna & \\
\end{tabular} & 110 & 110 & \multicolumn{2}{|c|}{$\begin{array}{c}\text { Ver resumen de la } \\
\text { evidencia }\end{array}$} & BAJA & CRITICO \\
\hline \multicolumn{13}{|c|}{ Eficacia de la lactancia a largo plazo (medida por IBFAT ${ }^{1.2 .3}$, LATCH $^{2,3}$, BSES $^{3}$ ) } \\
\hline $3^{1,2,3}$ & ECA & \begin{tabular}{|l|} 
Muy \\
seria $^{10}$
\end{tabular} & \begin{tabular}{|l|l} 
Seria & 6 \\
\end{tabular} & No seria & Seria ${ }^{7}$ & Ninguna & \multicolumn{2}{|c|}{$N$ total $=219$} & \multicolumn{2}{|c|}{$\begin{array}{c}\text { Ver resumen de la } \\
\text { evidencia }\end{array}$} & MUY BAJA & CRITICO \\
\hline \multicolumn{13}{|c|}{ Duración de la lactancia } \\
\hline $3^{1,2,3}$ & ECA & $\begin{array}{l}\text { Muy } \\
\text { seria }^{10}\end{array}$ & Seria ${ }^{6}$ & No seria & Seria $^{7}$ & Ninguna & \multicolumn{2}{|c|}{$\mathrm{N}$ total $=219$} & \multicolumn{2}{|c|}{$\begin{array}{c}\text { Ver resumen de la } \\
\text { evidencia }\end{array}$} & MUY BAJA & CRITICO \\
\hline $1^{5}$ & $\begin{array}{l}\text { Estudios } \\
\text { observacional }\end{array}$ & Seria ${ }^{11}$ & No seria & No seria & No seria & Ninguna & 82 & 9 & & 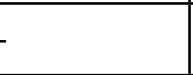 & MUY BAJA & CRITICO \\
\hline \multicolumn{13}{|c|}{ Peso del bebe ( $\mathrm{kg}$, a las ocho semanas) } \\
\hline \begin{tabular}{|l|}
$1^{3}$ \\
\end{tabular} & ECA & $\begin{array}{l}\text { Muy } \\
\text { seria }^{12}\end{array}$ & No seria & No seria & Seria $^{7}$ & Ninguna & 53 & 52 & \multicolumn{2}{|c|}{-} & MUY BAJA & CRITICO \\
\hline
\end{tabular}

${ }^{6}$ Variabilidad en los resultados; ${ }^{7}$ Pocos pacientes; ${ }^{8}$ Uno de los estudios sin cegamiento y dudosa aleatorización; ${ }^{9}$ Pocos pacientes, evaluación subjetiva: ${ }^{10}$ Cruce de grupo control $(2$ ECA / 1 ECA no discrimina datos entre grupos control e intervención; ${ }^{11}$ Alto riesgo de sesgo, desigual distribución entre los grupos intervención y control; ${ }^{12} \mathrm{Cruce}$ de grupo control, riesgo de sesgo. 


\section{2- Resumen de la evidencia}

En la actualización de la búsqueda de la RS de Francis et al (1) (de enero de 2014 a julio de 2015) se identificó un estudio longitudinal prospectivo (16) realizado en un Hospital de Sau Paulo, en el que se observaron los cambios en los patrones de lactancia materna tras realizar una frenotomía en relación a dos desenlaces no incluidos en los estudios de la RS(1) seleccionada: número de succiones y la pausa en segundos entre los grupos de succiones. De 109 recién nacidos con anquiloglosia, 14 accedieron a la cirugía. Como grupo control se eligieron 14 niños con características similares. La frenotomía se realizó a los 45 días de vida de los lactantes, y los resultados se midieron a los 30 y 75 días de vida (antes y después de la intervención). Además las madres respondieron a un cuestionario de 16 preguntas sobre los diversos síntomas relacionados con la lactancia materna. Sin embargo, los desenlaces que se midieron fueron el número de succiones y la pausa entre los grupos de succiones, por lo que no han sido incluidos en esta revisión.

A continuación se describen los resultados encontrados por la revisión seleccionada y el estudio longitudinal posterior identificado.

\section{Dolor en el pezón materno}

Son tres los ECA de buena calidad que ofrecen resultados sobre el dolor en el pezón de madres de lactantes con anquiloglosia(6;7;9), para lo que se utilizó la escala visual analógica VAS(6;7) o la forma resumida del SFMPQ (The short-form McGill Pain Questionnaire)(9).

De estos tres estudios, el primero(9), que incluye niños de 6 días de edad, señala que sí existen diferencias a favor de la frenotomía, mientras que los otros dos $(6 ; 7)$ no encuentran diferencias significativas en lactantes con unas semanas más de vida entre el grupo de intervención y el grupo control en la reducción del dolor de forma inmediata ${ }^{6} \mathrm{o}$ a los 5 dias(7).

En el primer estudio(9) el dolor materno del pezón se registró mediante el cuestionario MPQ-SF, cuya puntuación oscila de 0 a 50 , y que fue cumplimentado por las madres. Las madres del grupo intervenido reportaron significativamente menos dolor en los pezones inmediatamente después de la intervención que las madres del grupo control (puntuación media de $4.9 \pm 1.46$ vs $13.5 \pm 1.5$, respectivamente; $p<0.001$ ). A los dos meses de la intervención, las madres de ambos grupos no presentaban dolor (datos no reportados), aunque cabe recordar el cruce significativo del grupo control al grupo intervención.

El segundo $\mathrm{ECA}(6)$ no encontró diferencias significativas en la reducción del dolor en el pezón materno inmediatamente después de la intervención entre el grupo intervención $(n=14)$ y el grupo control $(n=14)$. En este caso el grado de dolor fue medido por las puntuaciones VAS, que oscilan entre 0 y 10 puntos (cambio medio de la puntuación ( \pm SD) de-2,5 $\pm 1,9$ y $-1,3 \pm$ 1,5 , respectivamente; GI vs GC $p=0,13$; IC $95 \%-0.3$ a 2.4 ).

En el tercer $\operatorname{ECA}(7)$ se realizaron mediciones del dolor en el pezón materno a los cinco días y a las 8 semanas posteriores a la frenotomía utilizando la escala VAS. A los cinco días después del procedimiento no hubo diferencias significativas en la reducción de las puntuaciones de dolor entre las madres a cuyos niños se les realizó una frenotomía y las del grupo control (mediana de -2 (RIC de-3 a 0,4) vs. -1 (RIC de $-13,5$ a 
1), respectivamente; $p<0,09)$. A las 8 semanas tampoco hubo mejoras significativas entre ambos grupos (mediana de -2 (RIC de -3 a -1 ) vs. -2 (de-3,5 a -0,61), respectivamente; $p<0,83$ ). Sin embargo, cabe destacar el alto cruce de pacientes del grupo control al grupo intervención que se dio en este estudio.

\section{Eficacia en la lactancia materna}

En los cuatro estudios que presentan datos sobre la eficacia de la lactancia se utilizaron desenlaces semejantes, aunque la estrategia para valorarlos difiere entre ellos. En un ECA la evaluación fue realizada por un observador independiente(9), en otro ECA se utilizó el reporte materno(8) y en los dos restantes ambas modalidades $(6 ; 7)$. Por otro lado, tres de ellos presentan resultados a corto y a largo plazo(6;7;9).

\section{Eficacia en la lactancia materna a corto plazo reportado por un observador externo}

Tres ECA utilizaron un revisor independiente cegado para evaluar este desenlace(6;7;9). De estos tres estudios, el primero(9) señala que sí existen diferencias a favor de la frenotomía, mientras que los otros $\operatorname{dos}(6 ; 7)$ no encuentran diferencias significativas entre el grupo de intervención y el grupo control.

Un ECA(9) informó una mejoría significativa de la eficacia en la lactancia basada en las puntuaciones de IBFAT (Infant Breast Feeding Assessment Tool, puntuaciones de 0 a 15), inmediatamente después de realizada la frenotomía en comparación con el tratamiento simulado (Gl 9.3 (SD: 0.69) a 11.6 (SD: 0.81 ) GC: 8.48 (SD: 0.73 ) a 8.07 (SD:0.86) GI vs. GC: $\mathrm{p}=0.029$ ).

Por el contrario, en los otros dos $\operatorname{ECA}(6 ; 7)$ los observadores no detectaron una diferencia significativa en la mejora de la lactancia materna entre ambos grupos. En uno de ellos(6) el observador no reporta una mejoría en la lactancia inmediatamente después de la frenotomía (valoraciones IBFAT y LATCH) [GI: 13/26 (50\%) GC: 12/30 (40\%) GI vs GC, $p=$ no significativo] y el otro(7) reporta un cambio no significativo en las puntuaciones de LATCH e IBFAT a los 5 días después de la intervención (Mediana LATCH GI vs. GC: 1 (RIC de 0 a 2) vs. 1 (RIC de 0 a 2); $p=0,52$; Mediana IBFAT GI vs. GC: 0 (RIC de $-1,8$ a 1,0) vs. 0 (RIC de 0 a 1$) ; p=0,36)$.

\section{Eficacia en la lactancia materna a corto plazo reportado por las madres}

\section{Calidad} baja

Tres ECA utilizan el reporte materno como un resultado de eficacia en la lactancia(6-8), en uno de ellos como variable de resultado primaria(8), encontrando los tres una mejora significativa en el grupo con frenotomía versus el grupo control.

En un ECA(6) las madres informan una mejora significativa en la lactancia inmediatamente después de la frenotomía comparado con el grupo control que había recibido tratamiento simulado (GI vs. GC: $78 \%(21 / 27)$ vs. $47 \%$ $(14 / 30) ; p<0.02)$.

Otro $\operatorname{ECA}(7)$ encontró que las madres cuyos hijos habían recibido frenotomía mejoraban la autoeficacia en la lactancia materna (medida por 
The short-form McGill Pain Questionnaire- BSES-SF) de forma significativa a los 5 días después de la intervención en comparación con el grupo control (Cambio en la puntuación entre el día 0 y el $5^{\circ}$ día; Mediana del GI vs. GC= 9 (RIC de 1,08 a 12,03) vs. 1 (RIC de- 4 a 7,5); $p=0,0002$ ).

En el tercer ECA, el $96 \%$ de los lactantes frenotomizados (19 de 28 alimentados al pecho y 8 al biberón) habían mejorado su alimentación dentro de las 48 horas, en comparación con el 3\% del grupo control (solo 1 de 29 alimentado al pecho), diferencia estadisticamente significativa $(p<0.001)$ (tener en cuenta las limitaciones de diseño de este estudio).

\section{Eficacia de la lactancia a largo plazo reportado por un observador externo}

\section{Calidad muy baja}

Dos ECA $(7 ; 9)$ presentan datos de eficacia a largo plazo, sin encontrar diferencias significativas entre los grupos.

El primer ECA(9) no encuentra diferencias estadísticamente significativas entre los grupos de tratamiento para las puntuaciones del IBFAT 2 semanas después de la intervención ni a los 2 meses (datos no reportados), aunque al $96 \%$ de los niños del grupo control se les había realizado una frenotomía antes de las dos semanas de seguimiento, con lo que los resultados a largo plazo no pueden abordarse de forma adecuada.

El otro $\operatorname{ECA}(7)$ no encontró diferencias en la eficacia de la lactancia materna a las 8 semanas, según los resultados obtenidos con la herramienta LATCH (datos no reportados). En este ECA también hubo un importante cruce del grupo control (sólo el 15\% del grupo de comparación no había recibido una frenotomía a las ocho semanas), por lo que los resultados son difícilmente interpretables.

\section{Eficacia de la lactancia a largo plazo reportado por las madres}

Son dos los $\operatorname{ECA}(6 ; 7)$ que presentan datos de reporte materno, uno de ellos no encuentran diferencias significativas(7) (es uno de los estudios con cruce importante de grupo control) y otro es favorable a la intervención(6).

En el primero(6), aunque se contacta telefónicamente con las madres a los 3 meses de la intervención, los resultados no se estratifican por grupo de tratamiento, y reportan que en general, el 92\% (54/59) de los pacientes informó una mejor alimentación, así como una resolución completa de los problemas con la lactancia materna en el 56\% (33/59) de los casos, no habiendo mejoría en el $8 \%(5 / 59)$.

En el segundo ECA(7) las madres informaron una mejora de las puntuaciones BSES-SF no significativa entre el grupo con frenotomía y el control (Mediana del GI vs. GC: 3 (RIC de 0 a 13) vs. 10 (RIC de 2 a 18); $p=0,082$ ), aunque cabe recordar el cruce importante del grupo control al grupo intervención.

\section{Duración de la lactancia materna}

Tres $\operatorname{ECA}(6 ; 7 ; 9)$ y la cohorte retrospectiva(11) presentan datos de duración de la lactancia materna posterior a la frenotomía. Uno de los

\section{Calidad \\ muy baja}

\section{Calidad \\ muy baja}


ECA(7) incluye tanto lactancia materna exclusiva como no exclusiva, y los otros dos ECA y la cohorte solo lactancia materna exclusiva(6;9).

En el ECA de Buryc(9), el $66 \%$ de los bebes con frenotomía continuaban con la lactancia materna a los dos meses (36/58), el $44 \%$ a los seis meses (23/58) y el $28 \%$ a los doce meses (14/58) (pérdidas de seguimiento de 1,6, y 14 pacientes, respectivamente). Como afirman los autores, debido al importante cruce del grupo control no pueden comparar los resultados de ambos grupos, pero consideran que los resultados se asemejan a la media nacional de $43 \%$ y $23 \%$, respectivamente.

El ECA de Berry(6) reporta que el 65\% (38/59) de todos los lactantes continuaban con la lactancia materna a los 3 meses de edad y el $51 \%$ (30/59) en la segunda llamada telefónica de seguimiento (edad promedio de 4,5 meses), pero no reporta los datos separados por grupo.

En el tercer ECA(7), más del $80 \%$ de los bebes de ambos grupos continuaban con la lactancia materna exclusiva y no exclusiva a las 8 semanas (GI vs. GC: $43(82,7 \%$ ) vs. 40 (80\%); OR 0,84 (IC 95\% de 0.31 a 2.27); $p=0,73$ ). Si consideramos la lactancia exclusiva, el $57,7 \%$ del grupo intervención $(30 / 52)$ y el $64 \%$ del grupo control $(32 / 50)$ continuaban con la misma (OR:1,30; IC95\% de 0,59 a 2,89; $\mathrm{p}=0.51$ ). Sin embargo, cabe recordar el cruce que se produce del grupo control descrito anteriormente, lo que imposibilita la comparación real entre los dos grupos.

En el estudio de cohorte retrospectivo(11), la lactancia materna continuó en el $82,9 \%$ de los lactantes frenotomizados una media de 7,09 meses, en comparación con el $66,7 \%$ de los bebes no tratados que amamantaron una media de 6,28 meses. Haber realizado la frenotomía en la primera semana de vida frente a más tarde, no afectó al total de meses de lactancia materna (media de 7,11 meses vs. 7,06 meses; $p<0,90$ ).

\section{Peso del niño a las 8 semanas}

Calidad

El único ECA que remite datos de peso o de ganancia ponderal a las 8 muy baja semanas es el estudio de Emond(7), en el que no se encontraron diferencias significativas (Mediana de GI vs GC: $5 \mathrm{~kg}$ (RIC de 5 a 6 ) vs. 5 $\mathrm{kg}$ (RIC de 5 a 6 ), respectivamente; $p=0,54$ ), aunque como ya se ha mencionado, se trata de un estudio con un alto porcentaje de cruce explicado anteriormente.

\section{ACTUALIZADO A FECHA DE: 31 de Octubre de 2016}




\section{5- De la evidencia a la recomendación (Tabla de EtR)}

\section{¿Es necesario realizar una frenotomía al lactante amamantado que presenta anquiloglosia?}

Población: Madre sana con problemas de lactancia que amamanta y niños sanos que presentan anquiloglosia

Intervención: Frenotomía

Comparación: Medidas de apoyo para mejorar la lactancia (éxito lactancia, dolor...)

Perspectiva: Clínica

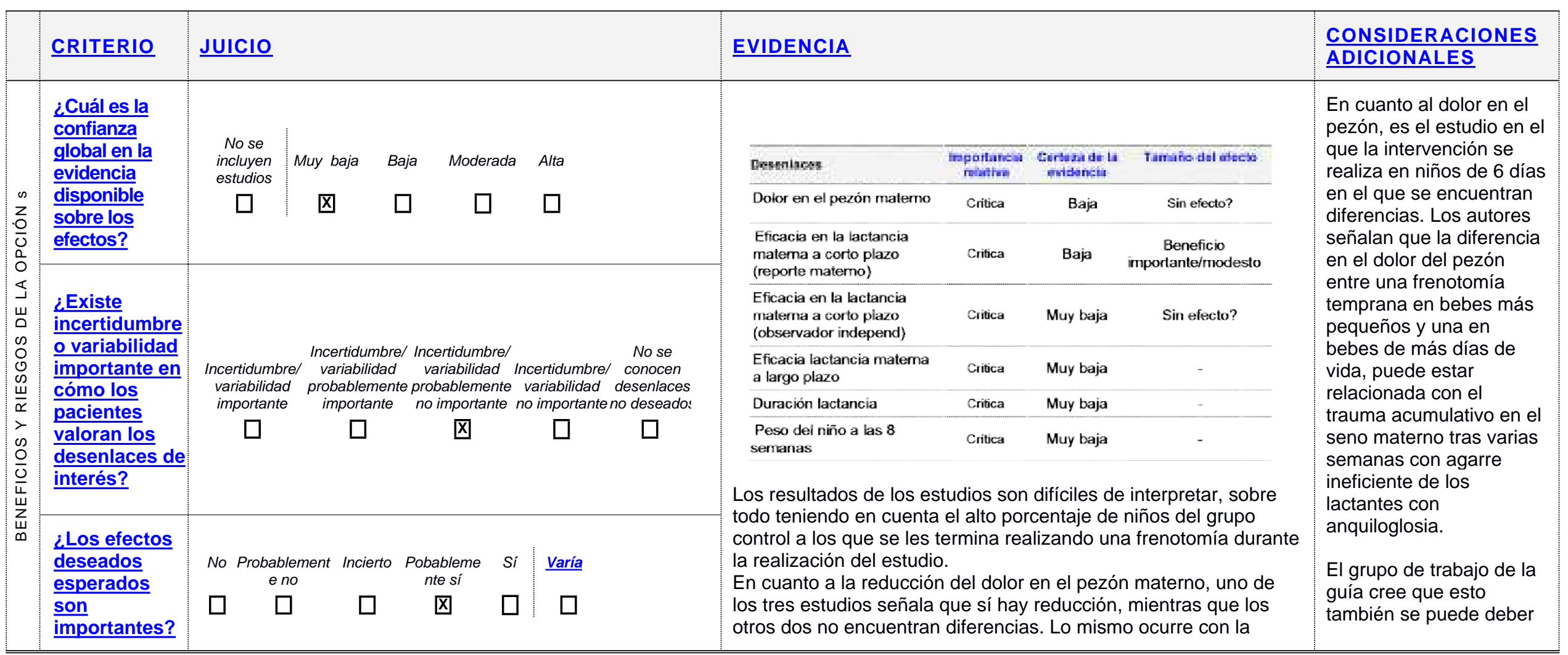




\begin{tabular}{|c|c|c|c|c|c|c|c|c|}
\hline & CRITERIO & \multicolumn{5}{|l|}{ JUICIO } & EVIDENCIA & $\begin{array}{l}\text { CONSIDERACIONES } \\
\text { ADICIONALES }\end{array}$ \\
\hline & $\begin{array}{l}\frac{\text { ¿Los efectos }}{\text { no deseados }} \\
\text { esperados } \\
\text { son } \\
\text { pequeños? }\end{array}$ & $\begin{array}{c}\text { No Probablement } \\
\text { e no } \\
\square \quad \square\end{array}$ & $\begin{array}{c}\text { Incierto } \\
\square\end{array}$ & $\begin{array}{c}\text { Pobableme } \\
\text { nte sí } \\
\square\end{array}$ & $\begin{array}{l}\text { Sí } \\
\text { 囚 }\end{array}$ & $\begin{array}{c}\text { Varía } \\
\square\end{array}$ & \multirow{2}{*}{$\begin{array}{l}\text { eficacia en la lactancia materna a corto plazo reportado por un } \\
\text { observador independiente. Sin embargo, cuando esta es } \\
\text { reportada por la madre, los tres estudios que reportan estos datos } \\
\text { coinciden en que sí hay beneficios. } \\
\text { En cuanto a efectos adversos de la intervención, estos no son } \\
\text { importantes. }\end{array}$} & \multirow[t]{2}{*}{$\begin{array}{l}\text { a que el patrón de } \\
\text { succión en el bebé ya } \\
\text { está más estructurado y } \\
\text { es más difícil que lo } \\
\text { modifique }\end{array}$} \\
\hline & $\begin{array}{l}\frac{\text { ¿El balance }}{\text { entre los }} \\
\frac{\text { efectos }}{\text { deseados y }} \\
\frac{\text { no deseados }}{\text { favorece la }} \\
\text { opción? }\end{array}$ & $\begin{array}{c}\text { No Probablement } \\
\text { e no } \\
\square \quad \\
\square\end{array}$ & $\begin{array}{c}\text { Incierto } \\
\text { 囚 }\end{array}$ & $\begin{array}{c}\text { Pobableme } \\
\text { nte sí } \\
\square\end{array}$ & \multicolumn{2}{|c|}{$\begin{array}{l:l}\text { Vaía } & \text { Varía } \\
\square & \square\end{array}$} & & \\
\hline \multirow{2}{*}{ 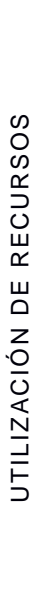 } & $\begin{array}{l}\frac{\text { ¿Los }}{\text { recursos }} \\
\frac{\text { que se }}{\text { requieren }} \\
\frac{\text { son bajos? }}{\text { ren }}\end{array}$ & $\begin{array}{c}\text { No Probablemente } \\
\text { no } \\
\square \quad \square\end{array}$ & $\begin{array}{c}\text { Incierto } \\
\square\end{array}$ & $\begin{array}{c}\text { Pobablemente } \\
\text { sí } \\
\bigotimes\end{array}$ & $\begin{array}{l}\text { Sí } \\
\square\end{array}$ & $\frac{\text { Varía }}{\square}$ & & \multirow{2}{*}{$\begin{array}{l}\text { Habría que comparar } \\
\text { cuál es el coste de } \\
\text { realizar una } \\
\text { frenotomía versus el } \\
\text { coste de un apoyo } \\
\text { "intensivo" a la } \\
\text { lactancia materna } \\
\text { que ayude a } \\
\text { solucionar los } \\
\text { problemas con la } \\
\text { lactancia que ocurren } \\
\text { en estos niños. }\end{array}$} \\
\hline & 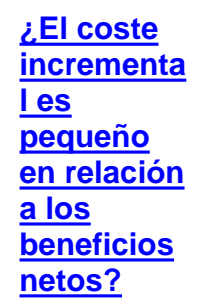 & $\begin{array}{c}\text { No Probablemente } \\
\text { no } \\
\square \quad \square\end{array}$ & $\begin{array}{c}\text { Incierto } \\
\square\end{array}$ & $\begin{array}{c}\text { Pobablemente } \\
\text { sí } \\
\text { 冈 }\end{array}$ & \multicolumn{2}{|c|}{$\begin{array}{c:c}\text { Si } & \text { Varía } \\
\square & \square\end{array}$} & & \\
\hline
\end{tabular}




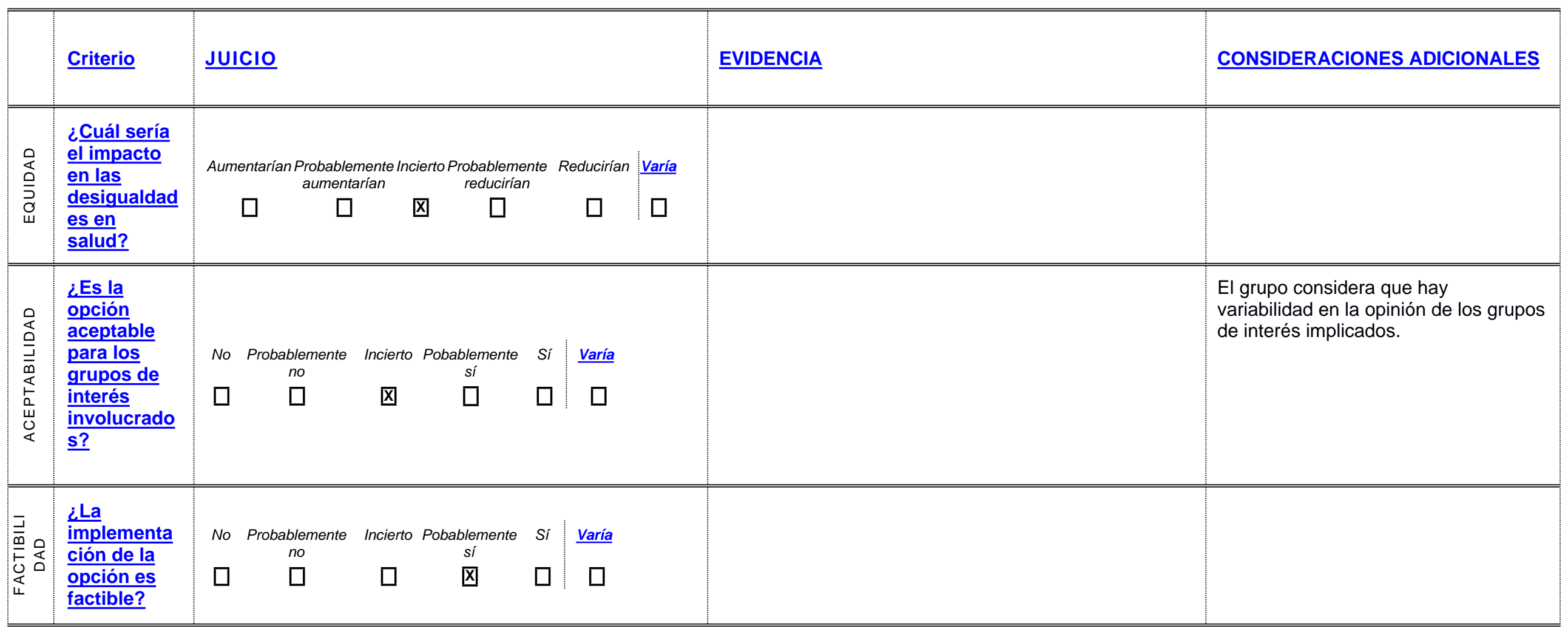




\begin{tabular}{|c|c|c|c|c|c|}
\hline \multirow[t]{2}{*}{$\begin{array}{l}\text { Balance de las } \\
\text { consecuencias }\end{array}$} & $\begin{array}{l}\text { Las consecuencias no } \\
\text { deseadas superan } \\
\text { claramente las } \\
\text { consecuencias deseadas } \\
\text { en la mayoría de los } \\
\text { escenarios }\end{array}$ & $\begin{array}{c}\text { Las consecuencias no } \\
\text { deseadas probablemente } \\
\text { superan las } \\
\text { consecuencias deseadas } \\
\text { en la mayoría de los } \\
\text { escenarios }\end{array}$ & $\begin{array}{c}\text { El balance entre las } \\
\text { consecuencias deseadas y } \\
\text { no deseadas está muy } \\
\text { equilibrado o es incierto }\end{array}$ & $\begin{array}{l}\text { Las consecuencias } \\
\text { deseadas } \\
\text { probablemente superan } \\
\text { las consecuencias no } \\
\text { deseadas en la mayoría } \\
\text { de los escenarios }\end{array}$ & $\begin{array}{c}\text { Las consecuencias } \\
\text { deseadas claramente } \\
\text { superan las } \\
\text { consecuencias no } \\
\text { deseadas en la mayoría } \\
\text { de los escenarios }\end{array}$ \\
\hline & $\square$ & $\square$ & 囚 & $\square$ & $\square$ \\
\hline$\frac{\text { Tipo de }}{\text { recomendación }}$ & Se recomienda no ofrece & Se sugiere no & ofrecer la opción & sugiere ofrecer la opción & $\begin{array}{l}\text { Se recomienda } \\
\text { ofrecer la opción }\end{array}$ \\
\hline
\end{tabular}

recomendación

$\square$

$\square$

$\square$

$\square$

\section{Recomendación (Texto)}

\section{Recomendación de buena práctica}

Antes de practicar una frenotomía, en los lactantes con anquiloglosia se debería realizar una historia de lactancia y una evaluación en profundidad de las tomas por profesionales expertos en lactancia materna.

Si con las medidas de apoyo que se instauren los problemas persisten, se debería realizar una frenotomía por profesionales expertos para mejorar la efectividad de la lactancia.

Justificación

La evidencia de calidad global muy baja señala que las madres refieren una reducción del dolor y una mejora de la lactancia postfrenotomía. Sin embargo, no hay estudios que comparen la frenotomía con la intervención de profesionales especializados y tampoco existen criterios uniformes para el diagnóstico y clasificación de la anquiloglosia ni sobre si la edad del lactante influye en el éxito de la intervención.

Consideraciones de Podría ser que el éxito de la intervención dependiera del grado o tipo de anquiloglosia que presenta el lactante que tiene problemas subgrupos de lactancia, aunque esto no se ha podido evaluar en los estudios identificados.

Consideraciones para - Creación de Consultas de lactancia atendidas por profesionales especializados en lactancia materna.

la implementación

- Formación de cirujanos y pediatras en el tratamiento quirúrgico de la anquiloglosia.

\section{Monitorización y}

evaluación 
Prioridades para la

investigación
- Son necesarios estudios que unifiquen los criterios diagnósticos y los diferentes grados o tipos de la anquiloglosia

- Son necesarios estudios controlados que comparen el éxito de la frenotomía versus estrategias más conservadoras, como la evaluación y apoyo por un profesional experto en lactancia materna, y que además analicen si el éxito de las diferentes intervenciones depende del grado de anguiloglosia, de la edad a la que se interviene etc. 


\section{ANEXO I, ESTRATEGIAS DE BÚSQUEDA}

\section{Cochrane Library \\ Searched 07/07/2015 \\ Updated search 07/07/2015 a xx/xx/xxxx}

\#1 tongue-tie or ankyloglossia or frenulum:ti,ab,kw and frenotomy or frenulotomy or frenuplasty:ti,ab,kw (Word variations have been searched)

12

RS 3

\section{MEDLINE, via Pubmed}

Searched 07/07/2015

Updated search 07/07/2015 a xx/xx/xxxx

\#1 Search (tongue-tie[Title/Abstract] OR ankyloglossia[Title/Abstract] OR frenulum[Title/Abstract]) 712

\#2 Search (frenotomy[Title/Abstract] OR frenulotomy[Title/Abstract] OR frenuloplasty[Title/Abstract]) 125

\#3 \#1 AND \#2 79

\#4 Search \#3 Filters: Systematic Reviews; Meta-Analysis 7

\#5 ((review[Title/Abstract] OR reviews[Title/Abstract])) OR (meta-analysis[Title/Abstract] OR metaanalysis[Title/Abstract] OR "meta analysis"[Title/Abstract]) 1153602

\#6 \#3 AND \#5 16

\#7 \#4 OR \#6 16

\section{EMBASE, via Ovid}

\section{Searched 07/07/2015}

Updated search 07/07/2015 a xx/xx/xxxx

\#1 (tongue-tie or ankyloglossia or frenulum).ti,ab,kw. 944

\#2 (frenomoty or frenulotomy or frenoloplasty).ti,ab,kw. 32

\#3 \#1 AND \#2 26

\#4 limit 3 to meta analysis 0

\#5 limit 3 to "systematic review" 1

\#6 4 or 51

\#7 (review or reviews or meta-analysis or metaanalysis or "meta analysis").ti,ab,kw. 1482234

\#8 3 and 7

\#9 6 or 8

4

\section{4}

\section{CINAHL, via EBSCOhost databases}

\section{Searched 07/07/2015}

Updated search 07/07/2015 a xx/xx/xxxx

S1 tongue-tie OR ankyloglossia OR frenulum 158

S2 frenotomy OR frenulotomy OR frenuloplasty 32

S3 S1 AND S2 26

S4 S3 Limitadores - Tipo de publicación: Meta Analysis, Systematic Review 2

S5 (review OR reviews ) OR ( meta-analysis OR metaanalysis OR "meta analysis")

S6 S3 AND S5 5

S7 S4 OR S6 $\quad 5$ 


\section{ANEXO II, Tabla de estudios individuales para la pregunta}

\begin{tabular}{|c|c|c|c|c|c|c|}
\hline $\begin{array}{l}\text { Referencia } \\
\text { (Cita } \\
\text { Abreviada) }\end{array}$ & $\begin{array}{l}\text { Estudio (Diseño y } \\
\text { objetivo) }\end{array}$ & $\begin{array}{l}\text { Población } \\
\text { (no y características) }\end{array}$ & $\begin{array}{l}\text { Descripción de las intervenciones } \\
\text { comparaciones, exposiciones o } \\
\text { pruebas a estudio }\end{array}$ & $\begin{array}{l}\text { Resultados } \\
\text { (Estimadores de resultados-Magnitud } \\
\text { del efecto) }\end{array}$ & Conclusiones (conclusiones) & $\begin{array}{l}\text { Comentarios } \\
\text { Calidad de la } \\
\text { evidencia } \\
\text { Financiación } \\
\text { comentarios) }\end{array}$ \\
\hline $\begin{array}{l}\text { Berry et al. } \\
2012\end{array}$ & $\begin{array}{l}\text { ECA doble ciego } \\
\text { Objetivo: } \\
\text { Investigar si un } \\
\text { reporte por parte de } \\
\text { la madre de una } \\
\text { mejora en la } \\
\text { lactancia después } \\
\text { del tratamiento de la } \\
\text { anquiloglosia con } \\
\text { frenotomía es } \\
\text { debido a un efecto } \\
\text { placebo. }\end{array}$ & $\begin{array}{l}\text { País: UK } \\
\text { Periodo de reclutamiento: } \\
\text { Bebes nacidos en un hospital } \\
\text { entre octubre } 2003 \text { a abril } \\
2004 \\
\text { Criterios de inclusión de } \\
\text { los lactantes } \\
\text { - Edad < } 4 \text { meses } \\
\text { - Síntomas de problemas en } \\
\text { la lactancia } \\
\text { - Presencia de anquiloglosia } \\
\text { Criterios de exclusión: } \\
\text { - Alimentación por biberón } \\
\text { - Negativa a participar } \\
\text { - Bebes que no se alimentan } \\
\text { Edad promedio (rango): } \\
\text { Gl: } 33 \text { días (6-115) } \\
\text { GC: } 28 \text { días (5-111) } \\
\text { Sexo, n=masculino: } \\
\text { Gl: } 21 / \text { GC: } 19 \\
\text { Grado de anquiloglosia: NR }\end{array}$ & $\begin{array}{l}\text { Intervención: Frenotomía } \\
\text { El frenillo sostenido con el dedo índice } \\
\text { izquierdo manteniendo el labio inferior } \\
\text { con el pulgar se dividió completamente } \\
\text { con tijeras estériles. el piso de la boca se } \\
\text { comprimió con gasa estéril. } \\
\text { Anestesia /duración: NR } \\
\text { Profesional: consultor en lactancia o } \\
\text { cirujano pediátrico } \\
\text { Aleatorización: Los bebes fueron } \\
\text { asignados al azar a tratamiento inmediato } \\
\text { con frenotomía (grupo intervención Gl) o } \\
\text { simulación }{ }^{* \star} \text { (grupo control GC). La } \\
\text { aleatorización fue generada por } \\
\text { computadora (n=60) y un ayudante } \\
\text { independiente la colocó len sobres } \\
\text { sellados. **EI tratamiento o cirugía } \\
\text { simulada consistió en tener a los bebes } \\
\text { en la habitación de intervención la misma } \\
\text { cantidad de tiempo que los que recibieron } \\
\text { cirugía y después dárselos de vuelta a } \\
\text { sus madres } \\
\text { Grupos comparados: (n=57): } \\
\text { Gl: intervención } n=27 \\
\text { GC: simulación } n=30 \\
3 \text { del Gl fallaron en el cegamiento } \\
\text { Tanto las madres como el observador } \\
\text { estaban cegados al grupo. Todos los } \\
\text { niños tuvieron una alimentación de } \\
\text { muestra de } 2 \text { minutos en la cual el } \\
\text { observador evalúa la alimentación } \\
\text { mediante LATCH, IBFAT y el dolor por } \\
\text { VAS. } \\
\text { Posteriormente a la intervención el } \\
\text { observador registra nuevamente las } \\
\text { puntuaciones de los cuestionarios y }\end{array}$ & $\begin{array}{l}\text { Variables de resultado primarias, } \\
\text { Mejora subjetiva de las madres en la } \\
\text { lactancia; } n(\%) \\
\text { GI: } 21(78 \%) \\
\text { GC: } 14(47 \%) \\
\text { GI vs GC: } p<0.02 ; 95 \% \mathrm{Cl}(6-51 \%) \\
\text { Mejora objetiva del observador en la } \\
\text { lactancia; } n(\%) \text { : } \\
\text { GI: } 13 / 26(50 \%) \\
\text { GC: } 12 / 30(40 \$) \\
\text { GI vs GC, } p=\text { no significativo } \\
\text { Variable de resultado secundaria, } \\
\text { Puntuación media dolor maternal } \\
\text { ( } n=28) \\
\text { GI } 1.6 \\
\text { GC: } 2.9 \\
\text { Cambio medio en el dolor } \pm \text { SD: } \\
\text { Gl: }-2.5 \pm 1.9 \\
\text { GC: }-1.3 \pm 1.5 \\
\text { GI vs GC: } p=0.13 \text { (95\% Cl: }-0.3,2.4) \\
\text { tLa edad media de los bebés cuyas madres } \\
\text { informaron resolución completa de los } \\
\text { problemas de alimentación fue de } 8 \text { días } \\
\text { más joven que aquellos cuyas madres } \\
\text { informaron ninguna mejora (26 días vs, a } 34 \\
\text { días). No hay madres que reportaran una } \\
\text { peor alimentación. } \\
\text { Seguimiento a los } 3 \text { meses } \\
\text { Reporte materno de mejora en la } \\
\text { lactancia } n \text { (\%): } \\
\text { GI + GC: } 54 / 59 \text { (92) } \\
\text { Total resolución de los problemas: } \\
\text { GI + GC: } 33 / 59 \text { ( } 56) \\
\text { Sin mejora } \\
\text { GI + GC: } 5 / 59 \text { (8) } \\
\text { Madres que continúan la lactancia a } \\
\text { los } 3 \text { meses: }\end{array}$ & \begin{tabular}{|l} 
El reporte materno de la \\
mejora inmediata en la \\
lactancia después de la \\
frenotomía es un efecto real y \\
no un efecto placebo. \\
La realización de la frenotomía \\
estimula a las madres a seguir \\
con la lactancia a tasas de casi \\
el doble de la media nacional \\
en UK. Esta es la única \\
medición objetiva de éxito que \\
este estudio encontró. \\
La anquiloglosia es una causa \\
reversible de dificultades en la \\
lactancia materna que \\
asesores cualificados deberían \\
vigilar y aconsejar el momento \\
oportuno para la realización de \\
una frenotomía, intervención \\
simple, segura y exitosa.
\end{tabular} & $\begin{array}{l}\text { Financiamiento: } \\
\text { NR (Los autores no } \\
\text { tienen competencia } \\
\text { en intereses } \\
\text { financieros) } \\
\text { Aunque el estudio } \\
\text { muestra los } \\
\text { resultados a los } 3 \\
\text { meses de } \\
\text { seguimiento, los } \\
\text { datos no son } \\
\text { proporcionados por } \\
\text { grupo de } \\
\text { tratamiento. }\end{array}$ \\
\hline
\end{tabular}




\begin{tabular}{|c|c|c|c|c|c|c|}
\hline $\begin{array}{l}\text { Referencia } \\
\text { (Cita } \\
\text { Abreviada) }\end{array}$ & $\begin{array}{l}\text { Estudio (Diseño y } \\
\text { objetivo) }\end{array}$ & $\begin{array}{l}\text { Población } \\
\text { (no y características) }\end{array}$ & $\begin{array}{l}\text { Descripción de las intervenciones } \\
\text { comparaciones, exposiciones o } \\
\text { pruebas a estudio }\end{array}$ & $\begin{array}{l}\text { Resultados } \\
\text { (Estimadores de resultados-Magnitud } \\
\text { del efecto) }\end{array}$ & Conclusiones (conclusiones) & $\begin{array}{l}\text { Comentarios } \\
\text { Calidad de la } \\
\text { evidencia } \\
\text { Financiación } \\
\text { comentarios) }\end{array}$ \\
\hline & & & $\begin{array}{l}\text { también los cambios subjetivos } \\
\text { inmediatos } \\
\text { verbalizados por las madres } \\
\text { Los cambios subjetivos inmediatos } \\
\text { verbalizadas por las madres incluyen una } \\
\text { mejor agarre, reducción del dolor, el bebé } \\
\text { succiona de manera diferente, la } \\
\text { sensación de una alimentación " más } \\
\text { eficaz ", y un avance, más relajado. } \\
\text { Variables de resultado: } \\
\text { Primarias: mejoría subjetiva y objetiva en } \\
\text { la lactancia } \\
\text { Secundaria: la puntuación del dolor } \\
\text { maternal. } \\
\text { Herramientas } \\
\text { LATCH } \\
\text { The Infant Breastfeeding Assessment } \\
\text { Tool (IBFAT) } \\
\text { Escala VAS: puntuación de dolor maternal } \\
\text { numérico de } 1 \text { a } 10, . \\
\text { Seguimiento } \\
\text { El seguimiento se realizó mediante } \\
\text { Ilamada telefónica a las } 24 \text { hs. para } \\
\text { registrar cualquier cambio subjetivo en la } \\
\text { alimentación y cualquier complicación. } \\
\text { Una segunda llamada telefónica a los } 3 \\
\text { meses después de la frenotomía }\end{array}$ & $\begin{array}{l}\text { GI + GC: } 38 / 59 \text { (65) } \\
\text { Lactancia a la segunda llamada } \\
\text { (media de edad } 4.5 \text { meses, } \mathrm{n}(\%) \text { : } \\
\text { Gl+ GC: } 30 / 59(51) \\
\text { Efectos adversos } \mathbf{n}(\%) \text { : pequeño } \\
\text { sangrado post intervención } \\
\text { GI + GC: } 3 \text { (5) reportados } \\
\text { inmediatamente } \\
\text { Ninguna de las complicaciones fue } \\
\text { significativas y los bebes continuaron } \\
\text { alimentándose al día siguiente de la } \\
\text { intervención }\end{array}$ & & \\
\hline $\begin{array}{l}\text { Buryk et al. } \\
2011\end{array}$ & $\begin{array}{l}\text { ECA simple } \\
\text { cegamiento } \\
\text { Objetivo principal } \\
\text { determinar si la } \\
\text { frenotomía realizada } \\
\text { en bebés con } \\
\text { anquiloglosia mejora } \\
\text { el dolor en el pezón } \\
\text { materno y la } \\
\text { capacidad de }\end{array}$ & $\begin{array}{l}\text { País: USA } \\
\text { Periodo de reclutamiento: } \\
\text { Diciembre } 2007 \text { a diciembre } \\
2008 \text {, Bebes nacidos en } \\
\text { hospital o clínica } \\
\text { otorrinologica } \\
\text { Criterios de inclusión } \\
\text { Informe materno de dolor en } \\
\text { el pezón }\end{array}$ & $\begin{array}{l}\text { Intervención frenotomía: } \\
\text { El tejido fue aplastado con cabezal recto } \\
\text { para proporcionar anestesia y se realizo } \\
\text { una incisión en el frenillo con tijera } \\
\text { recta. En ocasiones, la presión directa con } \\
\text { los dedos necesitaba ser aplicada para la } \\
\text { hemostasia. } \\
\text { Duración: } 5 \text { minutos } \\
\text { Anestesia: NR } \\
\text { Tipo de profesional: otorrinolaringologo }\end{array}$ & $\begin{array}{l}\text { Dolor del pezón materno, (SF-MPQ) } \\
\text { después de frenotomía: } \\
\text { GI: } 16.77 \text { (SD: } 1.88 \text { ) a } 4.9 \text { (SD: } 1.46) \\
\text { GC: } 19.25 \text { (SD: } 1.9 \text { ) a } 13.5 \text { (SD: } 1.5) \\
\text { p Gl vs GC: } p<0.001 \\
\text { Efecto tamaño: } 0.38 \\
\text { Puntuaciones IBAT, después de } \\
\text { frenotomía mean } \pm \text { SE } \\
\text { Gl 9.3 (SD: } 0.69 \text { ) a } 11.6 \text { (SD: } 0.81) \\
\text { GC: } 8.48 \text { (SD: } 0.73 \text { ) a } 8.07 \text { (SD:0.86) }\end{array}$ & $\begin{array}{l}\text { Cuando se realiza una } \\
\text { frenotomía en bebes con una } \\
\text { anquiloglosia clínicamente } \\
\text { significativa, hay una mejora } \\
\text { clara e inmediata en el dolor en } \\
\text { el pezón de la madre y en las } \\
\text { puntuaciones de lactancia } \\
\text { materna } \\
\text { La frenotomía es un } \\
\text { procedimiento rápido, sencillo }\end{array}$ & $\begin{array}{l}\text { Financiación NR } \\
\text { En este estudio se } \\
\text { produce un cruce } \\
\text { del grupo control y } \\
\text { hay fallas de } \\
\text { cegamiento en el } \\
\text { seguimiento } \\
\text { reconocido por los } \\
\text { autores }\end{array}$ \\
\hline
\end{tabular}




\begin{tabular}{|c|c|c|c|c|c|c|}
\hline $\begin{array}{l}\text { Referencia } \\
\text { (Cita } \\
\text { Abreviada) }\end{array}$ & $\begin{array}{l}\text { Estudio (Diseño y } \\
\text { objetivo) }\end{array}$ & $\begin{array}{l}\text { Población } \\
\text { (no y características) }\end{array}$ & $\begin{array}{l}\text { Descripción de las intervenciones } \\
\text { comparaciones, exposiciones o } \\
\text { pruebas a estudio }\end{array}$ & $\begin{array}{l}\text { Resultados } \\
\text { (Estimadores de resultados-Magnitud } \\
\text { del efecto) }\end{array}$ & Conclusiones (conclusiones) & $\begin{array}{l}\text { Comentarios } \\
\text { Calidad de la } \\
\text { evidencia } \\
\text { Financiación } \\
\text { comentarios) }\end{array}$ \\
\hline & $\begin{array}{l}\text { amamantar. } \\
\text { Objetivo } \\
\text { secundario: } \\
\text { determinar si la } \\
\text { frenotomía mejora la } \\
\text { duración de la } \\
\text { lactancia materna. }\end{array}$ & $\begin{array}{l}\text { Dificultad para la lactancia } \\
\text { materna combinada con } \\
\text { anquiloglosia significativa,(la } \\
\text { anquiloglosia medida por } \\
\text { HATLFF } \\
\text { Criterios de exclusión: } \\
\text { Bebe mayor de } 30 \text { días; } \\
\text { Anomalías craneofaciales } \\
\text { (incluyendo labio leporino o } \\
\text { paladar hendido) } \\
\text { Bebés neurológicamente } \\
\text { comprometidos; } \\
\text { Cualesquier otra contra } \\
\text { indicación para la Lactancia } \\
\text { Materna. } \\
\text { (Ninguno de los pacientes } \\
\text { cumplieron con los criterios } \\
\text { de exclusión) } \\
\text { Promedio de edad de los } \\
\text { bebes al enrolamiento en } \\
\text { días } \pm \text { SD (rango): } \\
\text { Gl+GC: } 6.0 \pm 6.9 \text { (1 }-35) \\
\text { Gl } 6.2 \pm 6.9 \text { GC: } 6.0 \pm 7.0 \\
\text { Sexo de los bebes mujer: } \\
\text { Gl: } 11 \text { (37) GC: } 9 \text { ( } 32) \\
\text { Grado de anquiloglosia: NR }\end{array}$ & 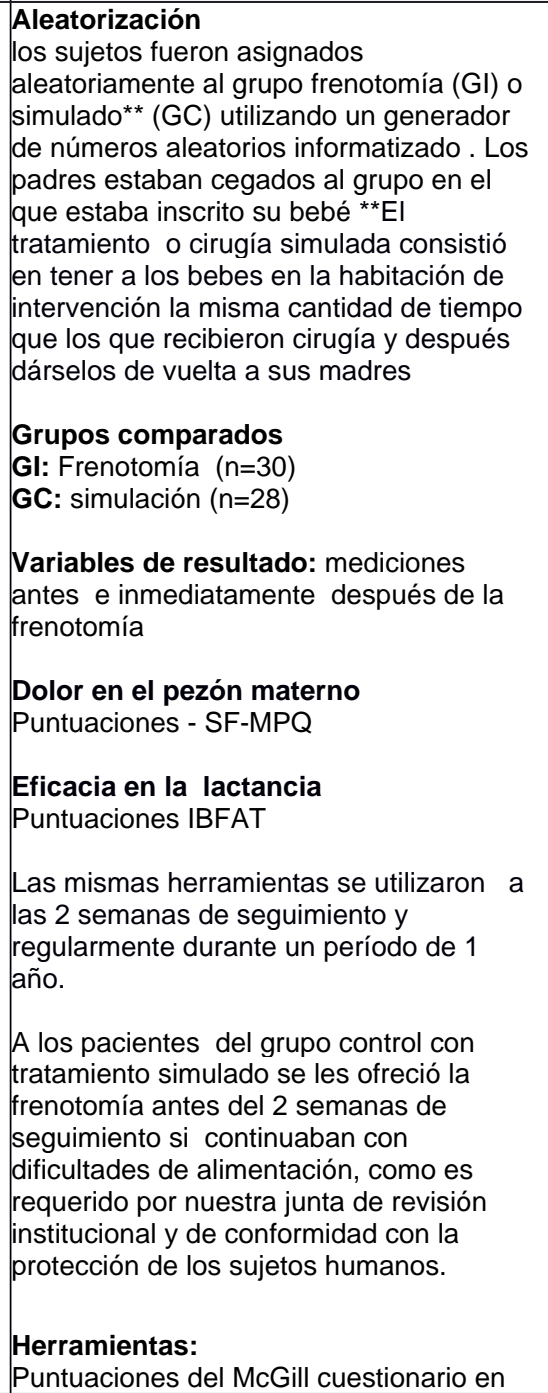 & $\begin{array}{l}\text { Gl vs. GC: } \mathrm{p}=0.029 \\
\text { Efecto tamaño: } 0.31 \\
\text { Continúan con la lactancia } \mathbf{n}(\%): \\
\text { Dos meses: GI+GC: } 36 / 58(66) \\
\text { Seis meses: GI+GC: } 23 / 58 \text { (44) } \\
\text { Doce meses Gl+GC: } 14 / 58(28) \\
\text { (Hubo } 1,6, \text { y } 14 \text { perdidas de pacientes } \\
\text { durante el seguimiento, } \\
\text { respectivamente) } \\
\text { Los datos se analizaron sobre la base } \\
\text { de intención de tratar; Todos menos } 1 \\
\text { de los padres del grupo placebo } \\
\text { eligió la frenotomía antes o en el } \\
\text { momento de la 2-semanas de } \\
\text { seguimiento. } \\
\text { No hubo diferencias estadística mente } \\
\text { significativas entre los grupos de } \\
\text { tratamiento para las puntuaciones del } \\
\text { SF-MPQ e IBFAT después después } \\
\text { de } 2 \text { semanas de la intervención } \\
\text { (datos no reportados) } \\
\text { Además, no hubo diferencia entre los } \\
\text { grupos en la duración de la lactancia } \\
\text { materna ( } \mathrm{p}=0.43 \text { ). } \\
\text { Efectos adversos: } \\
\text { no se produjeron complicaciones }\end{array}$ & $\begin{array}{l}\text { y sin complicaciones. } \\
\text { Estudios adicionales deben } \\
\text { realizarse para determinar el } \\
\text { momento óptimo de frenotomía } \\
\text { y la herramienta ideal para } \\
\text { detectar un grado de } \\
\text { anquiloglosia significativo. } \\
\text { No se pudo abordar } \\
\text { adecuadamente los resultados } \\
\text { a largo plazo de la frenotomía } \\
\text { debido al cruce significativo del } \\
\text { grupo control. No creemos que } \\
\text { haya ninguna manera de } \\
\text { abordar éticamente esta } \\
\text { cuestión en un ensayo } \\
\text { aleatorio. }\end{array}$ & \\
\hline
\end{tabular}




\begin{tabular}{|c|c|c|c|c|c|c|}
\hline $\begin{array}{l}\text { Referencia } \\
\text { (Cita } \\
\text { Abreviada) }\end{array}$ & $\begin{array}{l}\text { Estudio (Diseño y } \\
\text { objetivo) }\end{array}$ & $\begin{array}{l}\text { Población } \\
\text { (no y características) }\end{array}$ & $\begin{array}{l}\text { Descripción de las intervenciones } \\
\text { comparaciones, exposiciones o } \\
\text { pruebas a estudio }\end{array}$ & $\begin{array}{l}\text { Resultados } \\
\text { (Estimadores de resultados-Magnitud } \\
\text { del efecto) }\end{array}$ & Conclusiones (conclusiones) & $\begin{array}{l}\text { Comentarios } \\
\text { Calidad de la } \\
\text { evidencia } \\
\text { Financiación } \\
\text { comentarios) }\end{array}$ \\
\hline & & & $\begin{array}{l}\text { forma abreviada (SF-MPQ) } \\
\text { Herramienta de Evaluación de la } \\
\text { Lactancia Materna (IBFAT) } \\
\text { HATLFF Hazelbaker Assessment Tool for } \\
\text { Lingual Frenulum Function utilizado para } \\
\text { medir el grado de anquiloglosia. } \\
\text { Mide apariencia y función (0-2) los } \\
\text { umbrales utilizados por este estudio } \\
\text { fueron una puntuación en la función } \\
\text { mayor a } 11 \text { y un puntaje de apariencia } \\
\text { inferior a } 8 . \\
\text { Ultimo seguimiento post-tratamiento: } \\
12 \text { meses (n GI + GC: } 44 \text { ) }\end{array}$ & & & \\
\hline $\begin{array}{l}\text { Autor: } \\
\text { Emond, et } \\
\text { al.2013 }\end{array}$ & $\begin{array}{l}\text { Diseño ECA } \\
\text { Los investigadores } \\
\text { estaban blindados al } \\
\text { tratamiento } \\
\text { las madres no } \\
\text { Objetivos } \\
\text { Determinar si la } \\
\text { frenotomía } \\
\text { inmediata era mejor } \\
\text { que el apoyo } \\
\text { habitual a la } \\
\text { lactancia en bebes } \\
\text { con anquiloglosia } \\
\text { Si las madres } \\
\text { podrían continuar la } \\
\text { lactancia en bebes } \\
\text { con anquiloglosia } \\
\text { después de cinco } \\
\text { días sin frenotomía }\end{array}$ & $\begin{array}{l}\text { País: UK } \\
\text { Enrolamiento: Octubre } 2011 \\
\text { a junio } 2013 \text { nacidos en } \\
\text { Hospital clínico } \\
\text { Criterios de inclusión } \\
\text { - Bebes con anquiloglosia y } \\
\text { problemas en la alimentación } \\
\text { materna } \\
\text { - puntuaciones HATLFF } \\
\text { entre } 6-12 \text { y LATCH } \leq 8 \\
\text { Criterios de exclusión } \\
\text { - Bebes mayores } \geq 2 \\
\text { semanas de edad } \\
\text { - Prematuros de < } 37 \\
\text { semanas } \\
\text { - malformaciones congénitas } \\
\text { orofaciales } \\
\text { - Perdida de peso del bebe } \\
(>10 \% \text { después de nacer) } \\
\text { - Anquiloglosia severa } \\
\text { (HATLFF < } 6 \text { ) } \\
\text { Edad media en días a los } 5 \\
\text { días de seguimiento : } \\
\text { Gl: } 11 \text { (8-14) }\end{array}$ & $\begin{array}{l}\text { Intervención: frenotomía,no aclara } \\
\text { profesional ni duración } \\
\text { Las madres fueron asignadas al azar a el } \\
\text { grupo de intervención con frenotomía } \\
\text { inmediata, o grupo control con atención } \\
\text { postnatal estándar ( } n=107 \text { ) } \\
\text { Las madres del grupo control que aún } \\
\text { experimentaban problemas en la lactancia } \\
\text { en la evaluación a los } 5 \text { días se les dio la } \\
\text { opción de frenotomía. } \\
\text { La prueba final de evaluación a las } 8 \\
\text { semanas se llevó a cabo inicialmente por } \\
\text { teléfono, y los que estaban todavía en } \\
\text { lactancia se evaluaron de nuevo en casa } \\
\text { Grupos comparados: } \\
\text { Gl: frenotomía (n=55) } \\
\text { GC: cuidados habituales ( } n=52 \text { ) } \\
\text { seguimiento post-tratamiento: } \\
5 \text { días, y } 8 \text { semanas } \\
\text { Variable de resultado primaria Eficacia } \\
\text { de la lactancia: puntuación LATCH }\end{array}$ & 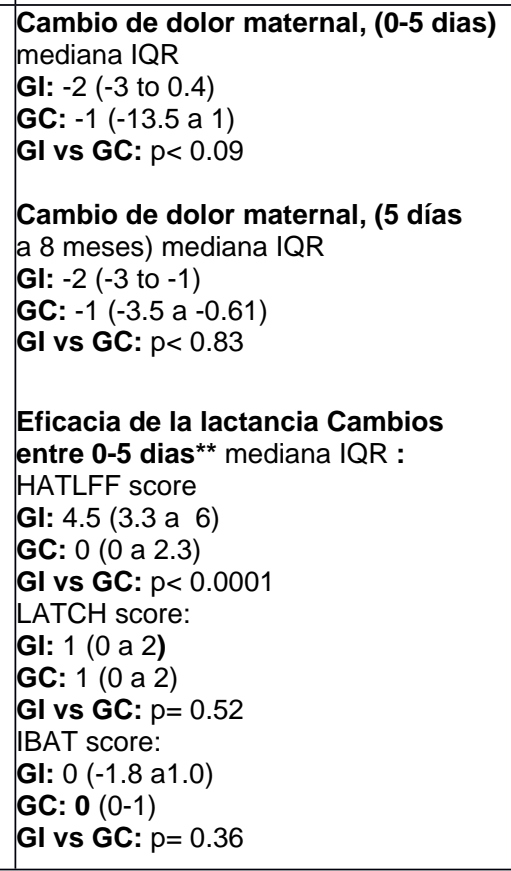 & $\begin{array}{l}\text { La frenotomía temprana no dio } \\
\text { lugar a una mejora objetiva en } \\
\text { la lactancia materna, pero era } \\
\text { asociado con un mejor auto- } \\
\text { eficacia. } \\
\text { La anquiloglosia es una } \\
\text { patología común y difícil de } \\
\text { medir objetivamente, y su } \\
\text { impacto en la alimentación es } \\
\text { complicado de evaluar. } \\
\text { Aunque la mayoría de las } \\
\text { madres de bebes con } \\
\text { anquiloglosia leve-moderada } \\
\text { cumplió con su asignación al } \\
\text { azar este ensayo no pudo } \\
\text { demostrar su objetivo de una } \\
\text { mejora sostenida en el tiempo } \\
\text { de la lactancia materna } \\
\text { después del procedimiento } \\
\text { debido a que la mayoría de las } \\
\text { madres del grupo control } \\
\text { terminaron decidiendo realizar } \\
\text { la frenotomía }\end{array}$ & $\begin{array}{l}\text { Financiación: } \\
\text { NIHR National } \\
\text { Institute for Health } \\
\text { Research (parte } \\
\text { del NHSNational } \\
\text { Health Service) } \\
\text { De los } 52 \\
\text { asignados al azar a } \\
\text { la atención } \\
\text { habitual, } 9 \text { (17\%) } \\
\text { de las madres no } \\
\text { podía esperar } \\
\text { hasta } 5 \text { días } \\
\text { (debido a } \\
\text { alimentación } \\
\text { dolorosa) y pidió } \\
\text { frenotomía } \\
\text { temprana. } \\
\\
\text { Evaluaciones de } \\
\text { ocho semanas se } \\
\text { lograron en } 52 \\
\text { (95\%) del grupo de } \\
\text { intervención } \\
\text { y } 50 \text { ( } 96 \%) \text { del } \\
\text { grupo de }\end{array}$ \\
\hline
\end{tabular}




\begin{tabular}{|c|c|c|c|c|c|c|}
\hline $\begin{array}{l}\text { Referencia } \\
\text { (Cita } \\
\text { Abreviada) }\end{array}$ & $\begin{array}{l}\text { Estudio (Diseño y } \\
\text { objetivo) }\end{array}$ & $\begin{array}{l}\text { Población } \\
\text { (no y características) }\end{array}$ & $\begin{array}{l}\text { Descripción de las intervenciones } \\
\text { comparaciones, exposiciones o } \\
\text { pruebas a estudio }\end{array}$ & $\begin{array}{l}\text { Resultados } \\
\text { (Estimadores de resultados-Magnitud } \\
\text { del efecto) }\end{array}$ & Conclusiones (conclusiones) & $\begin{array}{l}\text { Comentarios } \\
\text { Calidad de la } \\
\text { evidencia } \\
\text { Financiación } \\
\text { comentarios) } \\
\end{array}$ \\
\hline & & $\begin{array}{l}\text { GC: } 11(8-16) \\
\text { Sexo:NR } \\
\text { Tipo de anquiloglosia NR } \\
\text { Metodo de alimentación } n \\
\text { (\%) Biberón } \\
\text { GI: } 1(1.8) \\
\text { GC: } 0 \\
\text { Biberón y pecho } \\
\text { Gl: } 10(18.2) \\
\text { GC: } 5(9.6) \\
\text { Pecho solo } \\
\text { Gl: } 44(80) \\
\text { GC: } 47(90.4) \text { OR } 2.35(0.76 \\
\text { a } 7.31) \mathrm{p}=0.13\end{array}$ & $\begin{array}{l}\text { Variables de resultado secundarias } \\
\text { Eficacia de la lactancia materna LATCH a } \\
\text { las } 8 \text { semanas, } \\
\text { Puntuación IBFAT, BSES-SF a los } 5 \text { días } \\
\text { y } 8 \text { semanas } \\
\text { Otros variables de interés HATLFF a } \\
\text { los } 5 \text { dias } \\
\text { Peso bebe a las } 8 \text { semanas } \\
\text { Herramientas } \\
\text { HATLFF formato corto para medir el } \\
\text { grado de anquiloglosia. } \\
\text { LATCH para medir la eficacia de la } \\
\text { lactancia materna (puntuacion de } \leq 8 \\
\text { indica dificultades en la lactancia. } \\
\text { IBFAT fue agregado como resultado } \\
\text { secundario, ya que es más adecuado } \\
\text { para evaluar el comportamiento de la } \\
\text { lactancia materna de los recién nacidos. } \\
\text { BSES-SF La forma de puntuación de } \\
\text { corta se añadió como un resultado } \\
\text { secundario para medir la confianza de la } \\
\text { madre en su capacidad para amamantar a } \\
\text { su bebé recién nacido, además de la } \\
\text { evaluación de un observador externo de } \\
\text { la efectividad de la lactancia materna. } \\
\text { Dolor Visual Analogue Scale (VAS) } \\
\text { Las entrevistas cualitativas } \\
\text { A las } 8 \text { semanas, se invitó a todas las } \\
\text { madres a ser entrevistadas por un } \\
\text { investigador.Se seleccionaron } 20 \\
\text { madres. Las entrevistas telefónicas } \\
\text { exploraron sus opiniones sobre el juicio, el } \\
\text { proceso de intervención, la aceptabilidad }\end{array}$ & 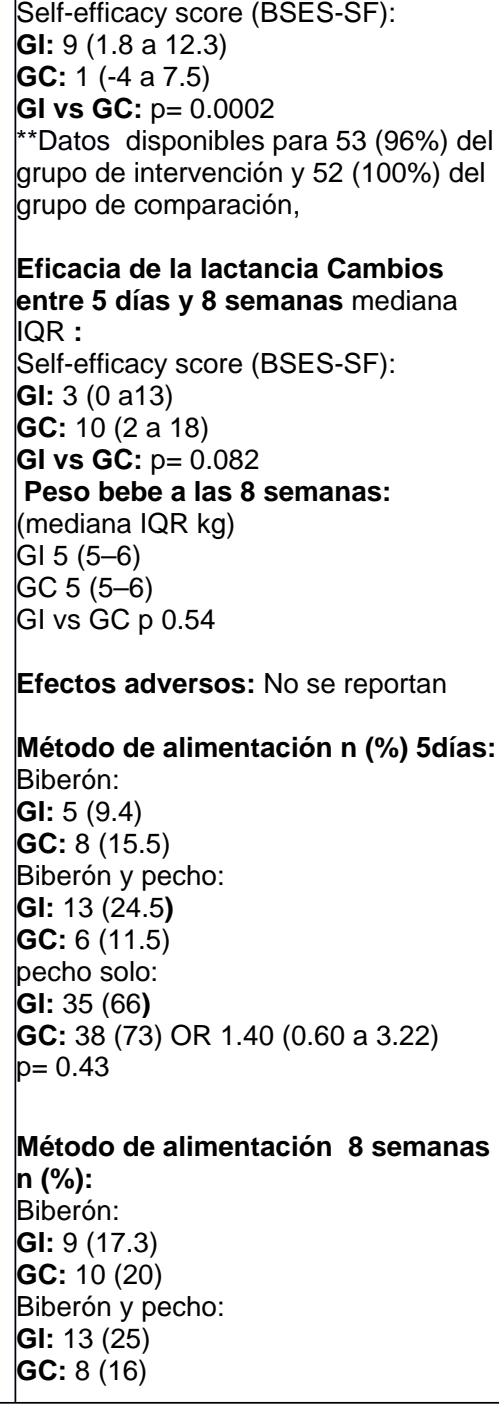 & & $\begin{array}{l}\text { comparación, pero } \\
\text { sólo } 8(15 \%) \text { del } \\
\text { grupo de } \\
\text { comparación no } \\
\text { habían recibido un } \\
\text { frenotomía }\end{array}$ \\
\hline
\end{tabular}




\begin{tabular}{|c|c|c|c|c|c|c|}
\hline $\begin{array}{l}\text { Referencia } \\
\text { (Cita } \\
\text { Abreviada) }\end{array}$ & $\begin{array}{l}\text { Estudio (Diseño y } \\
\text { objetivo) }\end{array}$ & $\begin{array}{l}\text { Población } \\
\text { (no y características) }\end{array}$ & $\begin{array}{l}\text { Descripción de las intervenciones } \\
\text { comparaciones, exposiciones o } \\
\text { pruebas a estudio }\end{array}$ & $\begin{array}{l}\text { Resultados } \\
\text { (Estimadores de resultados-Magnitud } \\
\text { del efecto) }\end{array}$ & Conclusiones (conclusiones) & $\begin{array}{l}\text { Comentarios } \\
\text { Calidad de la } \\
\text { evidencia } \\
\text { Financiación } \\
\text { comentarios) }\end{array}$ \\
\hline & & & $\begin{array}{l}\text { de la asignación al azar y su actitud hacia } \\
\text { frenotomía. Ellos fueron grabadas } \\
\text { digitalmente, transcritas y analizados }\end{array}$ & $\begin{array}{l}\text { pecho solo: } \\
\text { GI: } 30 \text { (57.7) } \\
\text { GC: } 32 \text { (64) OR } 1.30 \text { (0.59 a 2.89) } \\
\text { p= } 0.51\end{array}$ & & \\
\hline $\begin{array}{l}\text { Hogan et al., } \\
2005\end{array}$ & $\begin{array}{l}\text { Diseño ECA } \\
\text { País: UK } \\
\text { Reclutamiento: } \\
\text { Marzo } 2002 \text { a julio } \\
2002 \text { en consulta } \\
\text { externa } \\
\text { Objetivos: } \\
\text { determinar si, en } \\
\text { los recién nacidos } \\
\text { con anquiloglosia y } \\
\text { un problema de } \\
\text { alimentación, una f } \\
\text { frenotomía } \\
\text { inmediata funciona } \\
\text { mejor que el } \\
\text { tratamiento médico } \\
\text { actual (referencia } \\
\text { a un especialista en } \\
\text { lactancia) en lograr } \\
\text { que los bebés se } \\
\text { alimenten } \\
\text { normalmente. }\end{array}$ & $\begin{array}{l}\text { Criterios de inclusión: } \\
\text { - bebes nacidos con } \\
\text { anquiloglosia en } 5 \text { meses } \\
\text { - Problemas de alimentación } \\
\text { Criterios de exclusión: } \\
\text { - demandas una frenotomía } \\
\text { inmediata } \\
\text { - sin problemas de } \\
\text { alimentación } \\
\text { Edad media en días bebes } \\
\text { randomizados (rango): } \\
\text { GI: } 20 \text { GC: } 18 \text { GI+ GC: (3- } \\
\text { 70) } \\
\text { Sexo, n (\%): masculino } \\
\text { GI: } 14 \text { GC: NR } \\
\text { Tipo de anquiloglosia } \\
\text { Longitud del frenillo (cm), } \\
25 \%: 5 \text { pecho /1 biberón } \\
50 \%: 11 \text { pecho /2 biberón } \\
75 \%: 9 \text { pecho / } 8 \text { biberón } \\
100 \%: 15 \text { pecho /8 biberón }\end{array}$ & $\begin{array}{l}\text { Intervención frenotomía poner el dedo } \\
\text { índice izquierdo sobre el frenillo mientras } \\
\text { se mantiene el labio inferior con el pulgar } \\
\text { izquierdo se realiza la insicion con unas } \\
\text { tijeras estériles con extremos romos } \\
\text { afilados y se comprime el piso de boca } \\
\text { con gasa. Realizada por consultores de } \\
\text { lactancia o cirujanos pediátricos, no } \\
\text { reportan duración ni anestesia } \\
\text { El grupo de aleatorización se determinó } \\
\text { mediante la apertura de un sobre cerrado } \\
\text { que había sido preparado previamente } \\
\text { por un asistente que no era parte del } \\
\text { estudio. El grupo control recibe por medio } \\
\text { de consultores de lactancia cuidados } \\
\text { intensivos de soporte consejo y ayuda Si } \\
\text { no mejoran sus problemas a las } 48 \mathrm{~h} \text { se } \\
\text { les ofrece una frenotomía } \\
\text { Grupos comparados ( } \mathrm{n}=\text { ) } \\
\text { Gl: frenotomía ( } \mathrm{n}=28,20 \text { pecho, } 8 \\
\text { biberón) } \\
\text { GC: control (n=29, } 20 \text { pecho, } 9 \text { biberón) } \\
\text { Variables de resultado: la madre era la } \\
\text { que evaluaba mejoras en la lactancia } \\
\text { tanto las que daban pecho como biberón } \\
\text { Seguimiento post tratamiento: } \\
\text { Llamada telefónica a las } 24 \mathrm{~h} \\
\text { semanalmente por cuatro semanas y } \\
\text { después a los cuatro meses . No hubo } \\
\text { perdidas }\end{array}$ & $\begin{array}{l}\text { Mejora en la alimentación: } \mathrm{n}(\%) \\
\text { G I: } 27 / 28(96) \\
\text { GC: } 1 / 29(3) \\
\text { GI vs GC : } P<0,001 . \\
\text { Todas las madres del grupo control } \\
\text { requirieron frenotomía y después de } \\
\text { su realización } 27 / 28 \text { mejoraron } \\
\text { Efectos adversos: NR }\end{array}$ & $\begin{array}{l}\text { la frenotomía fue segura y } \\
\text { mejoró significativamente la } \\
\text { alimentación para la madre y el } \\
\text { bebé. La frenotomía fue } \\
\text { significativamente mejor que el } \\
\text { apoyo especializado intensivo, } \\
\text { por un consultor profesional de } \\
\text { la lactancia. } \\
\text { RECOMENDACIóN } \\
\text { A los bebés con anquiloglosia } \\
\text { sintomáticos se les debería } \\
\text { indicar una frenotomía Esta } \\
\text { debe ser realizada por un } \\
\text { profesional entrenado, que } \\
\text { pueda dar un buen diagnóstico } \\
\text { y después proporcionar apoyo } \\
\text { continuo a la madre y al bebe }\end{array}$ & $\begin{array}{l}\text { Financiación NR } \\
\text { Limitaciones del } \\
\text { estudio: pequeña } \\
\text { muestra y medidas } \\
\text { subjetivas } \\
\text { IEstudio sin } \\
\text { cegamiento con } \\
\text { aleatorizacion } \\
\text { dudosa y cruce del } \\
\text { grupo control } \\
\text { No hubo relación } \\
\text { entre la longitud de } \\
\text { la lengua de } \\
\text { corbata y la } \\
\text { dificultad en la } \\
\text { alimentación } \\
\text { algunos bebés con } \\
100 \% \text { alimentaban } \\
\text { sin síntomas. y se } \\
\text { encontraron } \\
\text { problemas en } \\
\text { bebés con } 25 \% \text { de } \\
\text { longitud }\end{array}$ \\
\hline $\begin{array}{l}\text { Steehler et } \\
\text { al., } 2012\end{array}$ & $\begin{array}{l}\text { Diseño: estudio de } \\
\text { cohorte } \\
\text { retrospectivo }\end{array}$ & $\begin{array}{l}\text { Criterios de inclusión: } \\
\text { - Registros médicos de } \\
\text { neonatos y bebes con } \\
\text { dificultades en el enganche }\end{array}$ & $\begin{array}{l}\text { Intervención: frenotomía } \\
\text { Se utiliza lidocaína viscosa tópica } \\
\text { aplicado en el frenillo lingual con } \\
\text { aplicadores de algodón incision con tijeras }\end{array}$ & $\begin{array}{l}\text { Datos de la encuesta telefónica } \\
\text { Continúan la lactancia } n(\%): \\
\text { GI: } 68(82.9)\end{array}$ & $\begin{array}{l}\text { Basándose en las } \\
\text { observaciones maternas, } \\
\text { cuando se realiza frenotomía } \\
\text { en los recién nacidos con }\end{array}$ & Financiación NR \\
\hline
\end{tabular}




\begin{tabular}{|c|c|c|c|c|c|c|}
\hline $\begin{array}{l}\text { Referencia } \\
\text { (Cita } \\
\text { Abreviada) }\end{array}$ & $\begin{array}{l}\text { Estudio (Diseño y } \\
\text { objetivo) }\end{array}$ & $\begin{array}{l}\text { Población } \\
\text { (no y características) }\end{array}$ & $\begin{array}{l}\text { Descripción de las intervenciones } \\
\text { comparaciones, exposiciones o } \\
\text { pruebas a estudio }\end{array}$ & $\begin{array}{l}\text { Resultados } \\
\text { (Estimadores de resultados-Magnitud } \\
\text { del efecto) }\end{array}$ & Conclusiones (conclusiones) & $\begin{array}{l}\text { Comentarios } \\
\text { Calidad de la } \\
\text { evidencia } \\
\text { Financiación } \\
\text { comentarios) }\end{array}$ \\
\hline & $\begin{array}{l}\text { Pais:USA } \\
\text { Enrolamiento: } \\
\text { Abril } 2006 \text { a Febrero } \\
2011\end{array}$ & $\begin{array}{l}\text { y dolor en la lactancia } \\
\text { debido a la sospecha de } \\
\text { anquiloglosia } \\
\text { Diagnostico confirmado por } \\
\text { otorrinolaringologos } \\
\text { pediatras } \\
\text { Criterios de exclusión: NR } \\
\text { Edad, media } \\
\text { Gl+GC: } 18 \text { días } \\
\text { Sexo, } \mathbf{n}(\%): \\
\text { Masculino } \\
\text { Gl+GC: } 216(58.9) \\
\text { Femenino } \\
\text { Gl+GC: } 151 \text { (14.1) }\end{array}$ & $\begin{array}{l}\text { para liberar el frenillo. } \\
\text { tipo de profesional y tpo de duración NR } \\
\\
\text { Grupos comparados }(n): \\
\text { GI: Frenotomía }(n=302) \\
\text { GC: No intervención }(n=65) \\
\text { Ultimo seguimiento post-tratamiento: } \\
3 \text { meses a cinco años } \\
\text { Participan en encuesta telefónica: } \\
\text { Gl: } 82 \text { con frenotomía } \\
\text { GC: } 9 \text { con cuidados habituales }\end{array}$ & $\begin{array}{l}\text { GC: } 6 \text { (66.7) } \\
\text { Promedio en meses } \\
\text { GI: } 7.09 \\
\text { GC: } 6.28 \\
\text { frenotomía antes de la semana de } \\
\text { vida, continúan con la lactancia } \\
\text { Gl: } 7.11 \text { meses } \\
\text { después de la semana de vida: } \\
\text { Gl: } 7.06 \text { meses } \\
\text { p=0.90 no significativo } \\
\text { Capacidad para alimentarse del bebe } \\
\text { (reporte materno post frenotomía) } \mathbf{n} \\
\text { (\%): } \\
\text { Gl: } 66 \text { (80.4) } \\
\text { Antes de una semana de vida; } \\
\text { Gl: } 37 / 43 \text { (86) } \\
\text { Después de una semana de vida; } \\
\text { Gl: } 29 / 39 \text { (74.3) } \\
\text { P<0.003 } \\
\text { Efectos adversos : } n(\%): \\
\text { anquiloglosia recurrente; } 8 \text { (2.6\%) } \\
\text { reoperación }\end{array}$ & $\begin{array}{l}\text { anquiloglosia y dificultades en } \\
\text { la alimentación en la primera } \\
\text { semana de vida, hay más } \\
\text { beneficios } \\
\text { Independientemente después } \\
\text { del momento de la } \\
\text { intervención, la } \\
\text { frenotomía ayuda a mejorar la } \\
\text { lactancia materna para el } \\
\text { bebé y la madre. } \\
\text { La frenotomía tiene un alto } \\
\text { grado de satisfacción materna, } \\
\text { es bien tolerada y se ha } \\
\text { demostrado que mejora la } \\
\text { lactancia materna, y disminuye } \\
\text { el dolor y las dificultades } \\
\text { asociadas a la lactancia }\end{array}$ & $\begin{array}{l}\text { Los datos que se } \\
\text { presentan son } \\
\text { basados en la } \\
\text { encuesta telefónica } \\
\text { de seguimiento } \\
\text { en donde la } \\
\text { distribución en } \\
\text { grupos intervención } \\
\text { y control es muy } \\
\text { desigual } \\
\text { (Gl } 82 / \text { GC 9) lo } \\
\text { que limita su } \\
\text { comparación }\end{array}$ \\
\hline $\begin{array}{l}\text { Martinelli et } \\
\text { al } 2015\end{array}$ & \begin{tabular}{|l|} 
Diseño estudio \\
observacional \\
Objetivo \\
Comprobar dos \\
hipótesis 1) La \\
frenotomía mejora \\
los patrones de \\
succión y de \\
lactancia en los \\
bebés con \\
anquiloglosia \\
2) los síntomas \\
durante la lactancia \\
materna reportada \\
por las madres \\
disminuyeron \\
después de la \\
frenotomía lingual.
\end{tabular} & $\begin{array}{l}\text { Bebes nacidos en hospital } \\
\text { Sau Paolo Brasil de enero a } \\
\text { mayo } 2011 \\
\text { Criterios de inclusión } \\
\text { bebes con anquiloglosia } \\
\text { medida por un patologo } \\
\text { especialista en lenguaje de } \\
\text { un hospital publico } \\
\text { Criterios de exclusión } \\
\text { Complicaciones perinatales } \\
\text { Anomalias craniofaciales } \\
\text { Síndromes genéticos visibles } \\
\text { Edad: } 30 \text { días } \\
\text { Sexo: Gl } 10 \text { niños } 4 \text { niñas } \\
\text { Grado de anquiloglosia: NR }\end{array}$ & $\begin{array}{l}\text { Intervención: frenotomía realizada a los } \\
45 \text { días de vida } \\
\text { La lengua del niño fue levantada hacia } \\
\text { arriba. Se usaron tijeras estériles para } \\
\text { liberar el frenillo, la sutura no fue } \\
\text { necesario. } \\
\text { Profesional: otorrinolaringologo utilizando } \\
\text { anestesia local } \\
\text { Grupos a comparar } \\
\text { Gl: frenotomía } \mathrm{N}=14 \\
\text { GC sin intervención } \mathrm{N}=14 \\
\text { Variable de resultados } \\
\text { Numero de succiones } \\
\text { Pausa entre los grupos de succiones } \\
\text { (segundos) } \\
\text { Se midieron las variables a los } 30 \text { y a los }\end{array}$ & $\begin{array}{l}\text { Numero de succiones } \\
\text { Gl } 30 \text { días } 19.36 \pm 13.02 \text { / Gl } 75 \text { días } \\
53.76 \pm 7.99 p<0.001 \\
\text { GC } 30 \text { días } 55.76 \pm 21.00 \text { / GC } 75 \\
\text { dias } 54.50 \pm 20.88 \text { p }>0.05 \\
\text { Pausa entre los sucks } \\
\text { Gl } 30 \text { días } 6.14 \pm 2.47 \text { / Gl } 75 \text { días } 3.88 \\
\pm 0.88 p<0.013 \\
\text { GC } 30 \text { días } 00 \pm 0.63 \text { / GC } 75 \text { días } 00 \pm \\
0.63 \text { p } 0.05 \\
\text { Las } 14 \text { madres de bebes intervenidos } \\
\text { reportaron una mejora en la lactancia } \\
\text { al responder el cuestionario a los } 75 \\
\text { días, el único síntoma reportado por } \\
\text { una de las madres fue el hipo. Los } \\
\text { otros síntomas reportados por las } \\
\text { madres antes de la frenotomía** } \\
\text { estaban ausentes después de la } \\
\text { misma. } \\
\text { ^^Antes de la frenotomía lingual, los }\end{array}$ & $\begin{array}{l}\text { Conclusión: Después de la } \\
\text { frenotomía, los bebés con } \\
\text { anquiloglosia aumentaron el } \\
\text { número de succiones y } \\
\text { disminuyeron la duración de la } \\
\text { pausa entre los grupos de } \\
\text { succión. Por otra parte, todos } \\
\text { los síntomas reportados por } \\
\text { las madres de bebés con } \\
\text { anquiloglosia mejoraron } \\
\text { después realizada la } \\
\text { frenotomía. }\end{array}$ & $\begin{array}{l}\text { Financiacion: NR } \\
\text { Las madres fueron } \\
\text { conscientes del } \\
\text { procedimiento de } \\
\text { sus bebes } \\
\\
\text { La población en } \\
\text { estudio es muy } \\
\text { pequeña y no } \\
\text { queda claro como } \\
\text { recluta los } \\
\text { controles }\end{array}$ \\
\hline
\end{tabular}




\begin{tabular}{|c|c|c|c|c|c|c|}
\hline $\begin{array}{l}\text { Referencia } \\
\text { (Cita } \\
\text { Abreviada) }\end{array}$ & $\begin{array}{l}\text { Estudio (Diseño y } \\
\text { objetivo) }\end{array}$ & $\begin{array}{l}\text { Población } \\
\left(n^{\circ} \text { y características }\right)\end{array}$ & $\begin{array}{l}\text { Descripción de las intervenciones } \\
\text { comparaciones, exposiciones o } \\
\text { pruebas a estudio }\end{array}$ & $\begin{array}{l}\text { Resultados } \\
\text { (Estimadores de resultados-Magnitud } \\
\text { del efecto) }\end{array}$ & Conclusiones (conclusiones) & \begin{tabular}{|l|} 
Comentarios \\
Calidad de la \\
evidencia \\
Financiación \\
comentarios) \\
\end{tabular} \\
\hline & & & $\begin{array}{l}75 \text { días de vida. } \\
* \text { se midió en segundos utilizando una } \\
\text { cronómetro y sacando el promedio de los } \\
\text { tres primeros grupos de succiones } \\
\text { Cuestionario (16 preguntas) } \\
\text { A los } 30 \text { días de vida de los bebes las } \\
\text { madres contestaron a un cuestionario } \\
\text { sobre lactancia elaborado por los autores } \\
\text { de respuestas SI o NO. } \\
\text { Solo las madres del grupo intervención } \\
\text { volvió a responder el cuestionario a los } 75 \\
\text { días }(n=14)\end{array}$ & $\begin{array}{l}\text { síntomas principales reportados } \\
\text { fueron: fatiga, pausas más largas entre } \\
\text { succiones para el descanso, poco } \\
\text { tiempo entre las comidas (menos de } \\
\text { una hora), menos de dos horas de } \\
\text { sueño entre comidas, resbale del } \\
\text { pezón, masticación del pezón, hipo, } \\
\text { sonidos, dolor en el pezón, } \\
\text { regurgitación y tos. }\end{array}$ & & \\
\hline
\end{tabular}


8. ANEXO III. Forest-Plot.

No procede. 


\section{ANEXO IV. Evaluación de la calidad}

AMSTAR Herramienta de medición para evaluar revisiones sistemáticas

\begin{tabular}{|c|c|c|c|c|}
\hline AMSTAR & $\begin{array}{c}\text { Francis } 2015 \\
\text { (9) }\end{array}$ & $\begin{array}{l}\text { Ito } 2014 \\
\text { (7) }\end{array}$ & $\begin{array}{l}\text { Power } 2014 \\
\text { (3) }\end{array}$ & $\begin{array}{c}\text { Suter } \\
2009 \\
(5)\end{array}$ \\
\hline $\begin{array}{l}\text { 1. ¿Se brindó un diseño "a priori”? } \\
\text { La pregunta de la investigación y los criterios de } \\
\text { inclusión deberían establecerse antes de llevar } \\
\text { a cabo la revisión }\end{array}$ & Sí & $\mathrm{Si}$ & $\mathrm{Si}$ & $\mathrm{Si}$ \\
\hline $\begin{array}{l}\text { 2. ¿Hubo duplicación en la selección de } \\
\text { estudios y extracción de datos? Debería haber } \\
\text { al menos dos personas independientes a cargo } \\
\text { de la extracción de datos, y debería existir un } \\
\text { procedimiento consensuado para los } \\
\text { desacuerdos }\end{array}$ & Sí & No responde & No responde & $\mathrm{Si}$ \\
\hline $\begin{array}{l}\text { 3. ¿Se realizó una búsqueda exhaustiva de } \\
\text { literatura? } \\
\text { Deberían consultarse al menos dos fuentes } \\
\text { electrónicas. El informe debe incluir los años y } \\
\text { las bases de datos utilizadas (por ej. Central, } \\
\text { EMBASE y MEDLINE). Deben especificarse las } \\
\text { palabras clave y/o los términos MESH y, de ser } \\
\text { posible, debe proveerse la estrategia de } \\
\text { búsqueda. Todas las búsquedas deberían ser } \\
\text { complementadas con consultas a contenidos } \\
\text { actuales, revisiones, libros de textos, registros } \\
\text { especializados, o expertos en el campo } \\
\text { particular de estudio, y mediante la revisión de } \\
\text { las referencias en los estudios encontrados }\end{array}$ & Sí & $\mathrm{Si}$ & $\begin{array}{l}\text { No } \\
\text { Describe } \\
\text { búsqueda sin } \\
\text { fechas }\end{array}$ & $\mathrm{Si}$ \\
\hline $\begin{array}{l}\text { 4. ¿Se utilizó el estado de publicación (es decir, } \\
\text { literatura gris) como criterio de inclusión? } \\
\text { Los autores deberían especificar que buscaron } \\
\text { informes sin tener en cuenta el tipo de } \\
\text { publicación. Los autores deberían especificar si } \\
\text { excluyeron o no algún informe (de la revisión } \\
\text { sistemática), en función del estado de } \\
\text { publicación, idioma, etc. }\end{array}$ & No responde & No responde & No responde & $\begin{array}{l}\text { No } \\
\text { responde }\end{array}$ \\
\hline $\begin{array}{l}\text { 5. ¿Se brindó una lista de estudios (incluidos y } \\
\text { excluidos)? } \\
\text { Debería proveerse una lista de estudios } \\
\text { incluidos y excluidos }\end{array}$ & Sí & No & No & No \\
\hline $\begin{array}{l}\text { 6. ¿Se brindaron las características de los } \\
\text { estudios incluidos? De manera adjunta tal } \\
\text { como una tabla, deberían proveerse los datos } \\
\text { de los estudios originales sobre los } \\
\text { participantes, las intervenciones y los }\end{array}$ & Sí & Si & Si & Si \\
\hline
\end{tabular}




\begin{tabular}{|c|c|c|c|c|}
\hline $\begin{array}{l}\text { resultados. Deberían informarse los rangos de } \\
\text { las características en todos los estudios } \\
\text { analizados, por ej, la edad, la raza, el sexo, los } \\
\text { datos socioeconómicos relevantes, el estado de } \\
\text { enfermedad, la duración, la severidad, o } \\
\text { cualquier otra enfermedad }\end{array}$ & & & & \\
\hline $\begin{array}{l}\text { 7. ¿Se evaluó y documentó la calidad científica } \\
\text { de los estudios incluidos? Deberían proveerse } \\
\text { métodos "a priori" (por ej, para estudios de } \\
\text { efectividad si el autor o los autores eligen } \\
\text { incluir sólo estudios aleatorizados, de doble } \\
\text { ciego, controlados con placebo, u ocultamiento } \\
\text { de las asignaciones como criterios de inclusión). } \\
\text { Para otros tipos de estudios, serán relevantes } \\
\text { los ítems alternativos }\end{array}$ & Sí & $\mathrm{Si}$ & No & No \\
\hline $\begin{array}{l}\text { 8. ¿Se utilizó de manera adecuada la calidad } \\
\text { científica de los estudios incluidos al formular } \\
\text { las conclusiones? El rigor metodológico y la } \\
\text { calidad científica de los estudios deberían } \\
\text { considerarse en el análisis y las conclusiones de } \\
\text { la revisión, y plantearse explícitamente al } \\
\text { formular las recomendaciones }\end{array}$ & Sí & $\mathrm{Si}$ & No & No \\
\hline $\begin{array}{l}\text { 9. ¿Fueron adecuados los métodos utilizados } \\
\text { para combinar los hallazgos de los estudios? } \\
\text { Para los resultados conjuntos, debería hacerse } \\
\text { una prueba para garantizar que los estudios } \\
\text { pudieron combinarse y para evaluar sus } \\
\text { homogeneidad (es decir, la prueba chi- } \\
\text { cuadrado para la homogeneidad, } \text { I }^{2} \text { ). Si existe } \\
\text { heterogeneidad debería utilizarse un modelo } \\
\text { de efectos aleatorios y/o debería considerarse } \\
\text { lo adecuado de la combinación (es decir, ¿fue } \\
\text { adecuado combinar los resultados?) }\end{array}$ & Sí & $\mathrm{Si}$ & $\begin{array}{l}\text { No aplicable } \\
\text { (no se } \\
\text { combinaron) }\end{array}$ & $\begin{array}{l}\text { No } \\
\text { aplicable } \\
\text { (no se } \\
\text { combinar } \\
\text { on) }\end{array}$ \\
\hline $\begin{array}{l}\text { 10. ¿Se valoró la probabilidad de sesgo de } \\
\text { publicación? } \\
\text { Una evaluación de sesgo de publicación debería } \\
\text { incluir una combinación de ayudas gráficas (por } \\
\text { ej. un gráfico en embudo - funnel plot - , otras } \\
\text { pruebas disponibles) y/o pruebas estadísticas } \\
\text { (por ej. prueba de regresión de Egger) }\end{array}$ & No & $\begin{array}{l}\text { No } \\
\text { responde }\end{array}$ & $\begin{array}{l}\text { No } \\
\text { responde }\end{array}$ & $\begin{array}{l}\text { No } \\
\text { responde }\end{array}$ \\
\hline $\begin{array}{l}\text { 11. ¿Se planteó el conflicto de intereses? } \\
\text { Deberían reconocerse claramente las fuentes } \\
\text { posibles de apoyo tanto en la revisión } \\
\text { sistemática como en los estudios incluidos }\end{array}$ & Sí & $\mathrm{Si}$ & $\mathrm{Si}$ & $\mathrm{Si}$ \\
\hline
\end{tabular}




\section{0, BIBLIOGRAFÍA}

(1) Francis DO, Krishnaswami S, McPheeters M. Treatment of ankyloglossia and breastfeeding outcomes: a systematic review. Pediatrics 2015 Jun;135(6):e1458-e1466.

(2) Power RF, Murphy JF. Tongue-tie and frenotomy in infants with breastfeeding difficulties: achieving a balance. Arch Dis Child 2015 May;100(5):489-94.

(3) Ito $Y$. Does frenotomy improve breast-feeding difficulties in infants with ankyloglossia? Pediatr Int 2014 Aug;56(4):497-505.

(4) Suter VG, Bornstein MM. Ankyloglossia: facts and myths in diagnosis and treatment. J Periodontol 2009 Aug;80(8):1204-19.

(5) Francis DO, Chinnadurai S, Morad A, Epstein RA, Kohanim S, Krishnaswami S, et al. Treatments for Ankyloglossia and Ankyloglossia With Concomitant Lip-Tie [Internet]. AHRQ Comparative Effectiveness Reviews 2015 May.

(6) Berry J, Griffiths M, Westcott C. A double-blind, randomized, controlled trial of tongue-tie division and its immediate effect on breastfeeding. Breastfeed Med 2012 Jun;7(3):18993.

(7) Emond A, Ingram J, Johnson D, Blair P, Whitelaw A, Copeland M, et al. Randomised controlled trial of early frenotomy in breastfed infants with mild-moderate tongue-tie. Arch Dis Child Fetal Neonatal Ed 2014 May;99(3):F189-F195.

(8) Hogan M, Westcott C, Griffiths M. Randomized, controlled trial of division of tongue-tie in infants with feeding problems. J Paediatr Child Health 2005 May;41(5-6):246-50.

(9) Buryk M, Bloom D, Shope T. Efficacy of neonatal release of ankyloglossia: a randomized trial. Pediatrics 2011 Aug;128(2):280-8.

(10) Dollberg S, Botzer E, Grunis E, Mimouni FB. Immediate nipple pain relief after frenotomy in breast-fed infants with ankyloglossia: a randomized, prospective study. J Pediatr Surg 2006 Sep;41(9):1598-600.

(11) Steehler MW, Steehler MK, Harley EH. A retrospective review of frenotomy in neonates and infants with feeding difficulties. Int J Pediatr Otorhinolaryngol 2012 Sep;76(9):123640.

(12) NICE. Postnatal care up to 8 weeks after birth. Julio 2006 (actualizado en Febrero de 2015). Disponible en: http://guidance.nice.org.uk/CG37.

(13) Division of ankyloglossia (tongue-tie) for breastfeeding. Interventional procedure guidance no. 149 (2005). Disponible en: www.nice.org.uk/IPG149.

(14) Perinatal Services BC. Health Promotion Guideline. Breastfeeding Healthy Term Infants. 2013 Feb.

(15) Estrategia centros de salud IHAN. Revisada, actualizada y ampliada para la atención integral en los centros de salud. Manual para la acreditación IHAN. España. 2014. Disponible en:

https://www.ihan.es/docs/documentacionacreditacion/centros salud/Manual para la acreditacion IHAN en AP 2015.pdf.

(16) Martinelli R, archesan R, archesan I, usmao R, onório $H$, erretin-Felix G. The effects of frenotomy on breastfeeding. J Appl Oral Sci 2015;23(2):153-7. 
PREGUNTA CLÍNICA № 24

¿Qué métodos son más eficaces para la extracción de la leche?

\section{Pregunta clínica en formato PICO}

\section{Comparación 1: Extracción manual versus Extracción eléctrica}

Tabla 1. Componentes de la pregunta clínica en formato PICO

\begin{tabular}{|l|l|}
\hline Pacientes & Madres de lactantes sanos a término \\
\hline Intervención & Extractor de leche eléctrico \\
\hline Comparación & Extracción manual \\
\hline Desenlaces & $\begin{array}{l}\text { Lactogénesis II (critica) } \\
\text { Producción de leche/ volumen (critica) } \\
\text { Peso del RN (crítica) } \\
\text { Tasa de LME al alta (critica) } \\
\text { Tasa de LME a los 3 meses (importante) } \\
\text { Tasa de LM a los 3 meses (critica) } \\
\text { Satisfacción materna (crítica) }\end{array}$ \\
\hline Tipo de estudio & RS, ECA y estudios observacionales (en caso de no encontrar ECAs) \\
\hline
\end{tabular}

Comparación 2: Extracción eléctrica simple frente a extracción eléctrica doble o simultánea

Tabla 2. Componentes de la pregunta clínica en formato PICO

\begin{tabular}{|l|l|}
\hline Pacientes & Madres de lactantes sanos a término \\
\hline Intervención & Extractor de leche eléctrico con extracción simple \\
\hline Comparación & Extractor de leche eléctrico con extracción doble o simultánea \\
\hline Desenlaces & $\begin{array}{l}\text { Lactogénesis II (critica) } \\
\text { Producción de leche/ volumen (critica) } \\
\text { Peso del RN (crítica) } \\
\text { Tasa de LME al alta (critica) } \\
\text { Tasa de LME a los 3 meses (importante) } \\
\text { Tasa de LM a los 3 meses (critica) } \\
\text { Satisfacción materna (crítica) }\end{array}$ \\
\hline Tipo de estudio & RS, ECA y estudios observacionales (en caso de no encontrar ECAs) \\
\hline
\end{tabular}

Comparación 3: Extracción combinada frente a extracción manual

Tabla 3. Componentes de la pregunta clínica en formato PICO

\begin{tabular}{|l|l|}
\hline Pacientes & Madres de lactantes sanos a término \\
\hline Intervención & Extracción combinada \\
\hline Comparación & Extracción manual \\
\hline
\end{tabular}




\begin{tabular}{|c|c|}
\hline Desenlaces & $\begin{array}{l}\text { Lactogénesis II (critica) } \\
\text { Producción de leche/ volumen (critica) } \\
\text { Peso del RN (crítica) } \\
\text { Tasa de LME al alta (critica) } \\
\text { Tasa de LME a los } 3 \text { meses (importante) } \\
\text { Tasa de LM a los } 3 \text { meses (critica) } \\
\text { Satisfacción materna (crítica) }\end{array}$ \\
\hline Tipo de estudio & RS, ECA y estudios observacionales (en caso de no encontrar ECAs) \\
\hline
\end{tabular}

\section{Comparación 4: Extracción combinada frente a extracción eléctrica}

Tabla 4. Componentes de la pregunta clínica en formato PICO

\begin{tabular}{|l|l|}
\hline Pacientes & Madres de lactantes sanos a término \\
\hline Intervención & Extracción combinada \\
\hline Comparación & Extracción con extractor de leche eléctrico \\
\hline Desenlaces & $\begin{array}{l}\text { Lactogénesis II (critica) } \\
\text { Producción de leche/ volumen (critica) } \\
\text { Peso del RN (crítica) } \\
\text { Tasa de LME al alta (critica) } \\
\text { Tasa de LME a los 3 meses (importante) } \\
\text { Tasa de LM a los 3 meses (critica) } \\
\text { Satisfacción materna (crítica) }\end{array}$ \\
\hline Tipo de estudio & RS, ECA y estudios observacionales (en caso de no encontrar ECAs), \\
\hline
\end{tabular}

\section{Introducción}




\section{Estrategia de elaboración de la pregunta}

\subsection{GPC}

Tabla 5. GPC de base (seleccionadas con el AGREE)

\begin{tabular}{|c|c|c|c|c|}
\hline Guía & Evidencia & Recomendación & Referencias & Comentarios \\
\hline NICE 2006 & $\begin{array}{l}\text { ¿Cuál es el mejor método para la } \\
\text { extracción de la leche materna? } \\
\text { En la guía publicada por la National } \\
\text { Association of Neonatal Nurses (Asociación } \\
\text { Nacional de Enfermeras Neonatales 1999) } \\
\text { se establecen dos recomendaciones de } \\
\text { buena práctica en relación al método de } \\
\text { extracción: } \\
\text { - La extracción manual es barata y permite } \\
\text { el CPP, lo que puede aumentar la } \\
\text { producción de leche } \\
\text { - El bombeo mecánico puede aumentar la } \\
\text { estimulación hormonal y permite } \\
\text { extraer leche de ambos senos a la vez. }\end{array}$ & $\begin{array}{l}\text { La extracciónde la leche se puede realizar } \\
\text { manualmente o con un sacaleches. } \\
\text { Los hospitales deberían disponer de sacaleches, } \\
\text { en particular para aquellas mujeres que han sido } \\
\text { separadas de sus RN, para establecer la } \\
\text { lactancia. Aquellas mujeres que utilicen un } \\
\text { sacaleches deben ser enseñadas sobre cómo } \\
\text { hacerlo. [D(GPP)]. }\end{array}$ & $\begin{array}{l}\text { Department of Health. 2005, Birth } \\
\text { to Five. London: Department of } \\
\text { Health. } \\
\text { Singapore Ministry of Health 2002, } \\
\text { Management of breastfeeding for } \\
\text { healthy fullterm infants. Singapore: } \\
\text { Singapore Ministry of Health. }\end{array}$ & \\
\hline NICE UPDATE & - & & & \\
\hline $\begin{array}{l}\text { BC } 2013 \\
\text { BREASTFEEDING } \\
\text { HEALTH TERM } \\
\text { INFANTS }\end{array}$ & $\begin{array}{l}\text { Cuando esté indicado, se debe de iniciar la } \\
\text { extracción manual de la leche para } \\
\text { establecer la producción de leche y prevenir } \\
\text { la congestión mamaria. Combinar la } \\
\text { extracción manual con el uso de un } \\
\text { sacaleches resulta en un aumento de la } \\
\text { producción de leche. (Morton 2009). }\end{array}$ & $\begin{array}{l}\text { Extracción manual de calostro o leche (Riordan } \\
2010 \text {, Lawrence } 2005 \text {, Morton } 2007 \text { ): } \\
\text { - Iniciar la extracciónmanual de calostro si el RN } \\
\text { no se engancha al pezón durante las primeras } \\
6 \text { h. posparto o tras dos intentos de darle de } \\
\text { mamar. } \\
\text { - Durante al aprendizaje (de la extracción } \\
\text { manual), antes de comenzar se puede realizar } \\
\text { CPP o alimentar al bebé, masajear suavemente } \\
\text { el pecho o aplicar una compresa templada y } \\
\text { húmeda para estimular la eyección de la leche. } \\
\text { - Enseñar a la madre a extraer el calostro/ leche } \\
\text { colocando los dedos pulgar e índice detrás de la } \\
\text { areola presionando suavemente hacia dentro y }\end{array}$ & $\begin{array}{l}\text { Morton J, Hall JY, Wong RJ, Thairu } \\
\text { L, Benitz WE, Rhine WD. } \\
\text { Combining hand techniques with } \\
\text { electric pumping increases milk } \\
\text { production in mother of preterm } \\
\text { infants. Journal of Perinatology } \\
2009 ; 29(11): 757-64 \text {. } \\
\text { Riordan J \& Wambach, K. (2010). } \\
\text { Breastfeeding and human lactation } \\
\text { (4th Ed.). Boston: Jones and } \\
\text { Bartlett Publishers. } \\
\text { Lawrence RA \& Lawrence RM. } \\
\text { (2005). Breastfeeding: A guide for }\end{array}$ & \\
\hline
\end{tabular}




\begin{tabular}{|c|c|c|c|}
\hline & & $\begin{array}{l}\text { utilizar ambos dedos para comprimir y liberar el } \\
\text { seno rítmicamente hasta que aparezcan las } \\
\text { primeras gotas de calostro/ leche. Cuando cesa } \\
\text { de salir la leche, mover las manos a otra zona } \\
\text { del pecho y repetir el procedimiento, y así } \\
\text { sucesivamente moviéndose alrededor de la } \\
\text { areola de modo circular. Recoger las gotas de } \\
\text { calostro/ leche en una cuchara, jeringa o taza. }\end{array}$ & $\begin{array}{l}\text { the medical profession (6th Ed.). } \\
\text { Philadelphia: Mosby Inc. } \\
\text { Morton, J A. (2007). Hand } \\
\text { expression of breastmilk: Video. } \\
\text { Viewed at http://newborns. } \\
\text { Stanford.edu/Breastfeeding/ } \\
\text { HandExpression.html. }\end{array}$ \\
\hline $\begin{array}{l}\text { BC Nursing } \\
\text { pathway } 2010\end{array}$ & NO & & \\
\hline
\end{tabular}

Tabla 6. Resumen de GPC del SNS

\begin{tabular}{|l|l|l|l|l|}
\hline Guía & Evidencia & Recomendación & Referencias & Comentarios \\
\hline GPC parto & - & & & \\
\hline GPC embarazo & - & & & \\
\hline
\end{tabular}

Tabla 7. Resúmenes otras guías/ docs. de referencia

\begin{tabular}{|c|c|c|c|c|}
\hline Guía & Evidencia & Recomendación & Referencias & Comentarios \\
\hline $\begin{array}{l}\text { ABM } 2 \\
\text { "protocolo } \\
\text { de regreso } \\
\text { a casa" } \\
(2007)\end{array}$ & & $\begin{array}{l}\text { Todas las madres que están amamantando deben de } \\
\text { recibir instrucción sobre la técnica para extraer la leche } \\
\text { manualmente (con bomba o sin ella), de modo que } \\
\text { puedan aliviar la mastitis puerperal, incrementar su } \\
\text { suministro de leche o prepararse para usar una bomba. } \\
\text { Además, puede ser que necesite que se le enseñe a usar } \\
\text { la bomba con el objeto de que pueda mantener su } \\
\text { suministro lácteo y obtener leche para alimentar al bebé } \\
\text { en caso de que ella y el niño se encuentren separados o } \\
\text { si el bebé no puede alimentarse directamente del pecho } \\
\text { (American Academy of Pediatrics 2006, American } \\
\text { Academy of Pediatrics 2005, WHO 1990, Schanler 2005, } \\
\text { Nyqvist 1994, Auerbach 1994, Forte 1986, Chamberlain } \\
\text { 2006). }\end{array}$ & $\begin{array}{l}\text { American Academy of Pediatrics and } \\
\text { the American College of Obstetrics } \\
\text { and Gynecologists. Breastfeeding } \\
\text { Handbook for Physicians. Schanler } \\
\text { RJ, ed. Elk Grove Village, IL: } \\
\text { American Academy of Pediatrics, } \\
2006 \text {. } \\
\text { American Academy of Pediatrics } \\
\text { Section on Breastfeeding. Policy } \\
\text { statement: Breastfeeding and the use } \\
\text { of human milk. Pediatrics } \\
2005 ; 115: 496-506 .\end{array}$ & \\
\hline
\end{tabular}




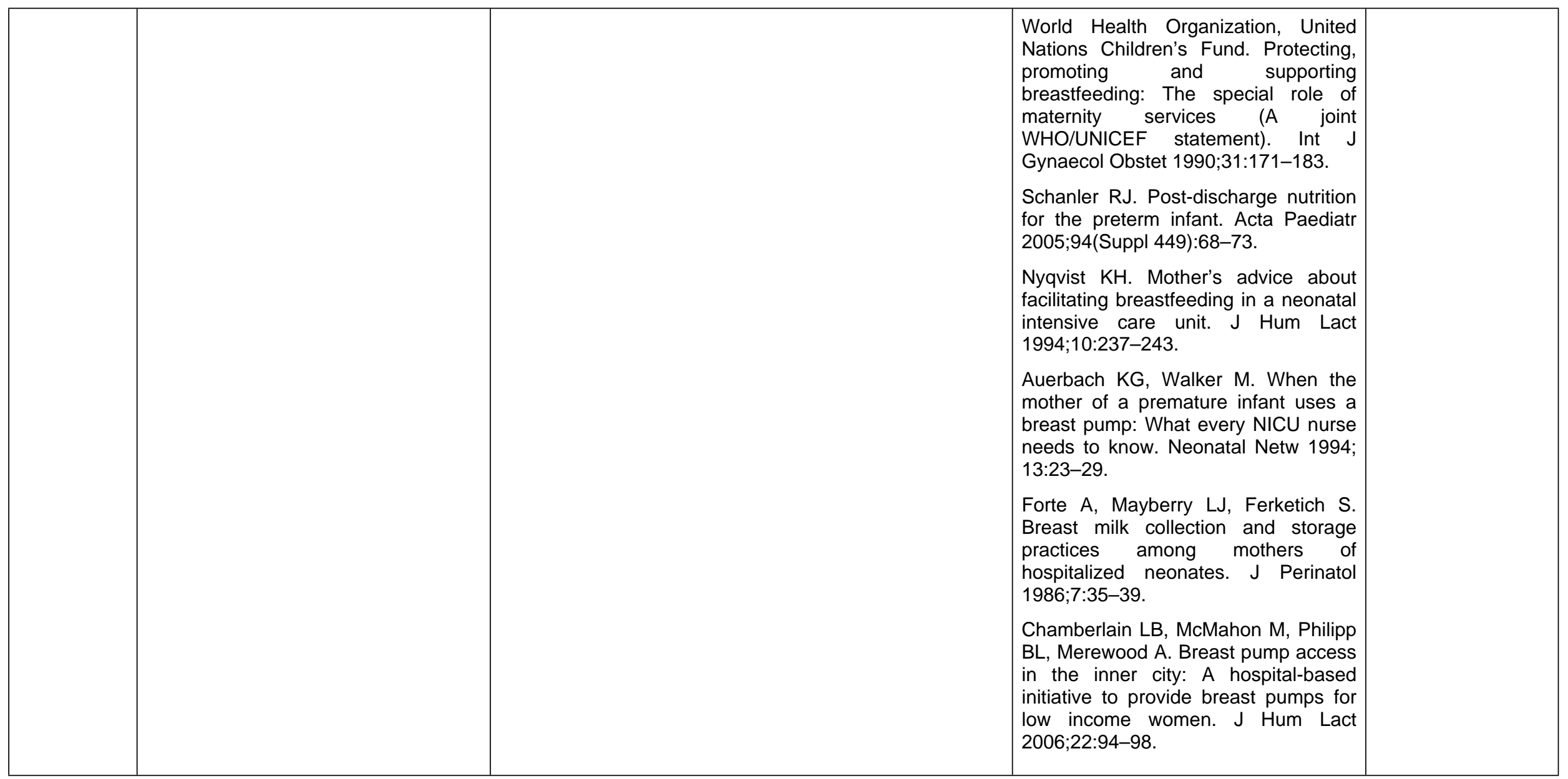

\subsection{Revisiones sistemáticas}


Se ha identificado una revisión Cochrane de 2015 (1) que tiene como objetivo valorar la aceptabilidad, efectividad, seguridad de los métodos que existen para la extracción de la leche materna, así como su efecto sobre la composición de la leche, la contaminación y costes. Esta revisión incluye tanto a madres de niños pre-término como madres de niños sanos a término. La conclusión a la que llegan los autores es que el método más apropiado para la extracción de la leche puede depender del tiempo desde el nacimiento, el objetivo de la extracción y de la madre y niño individuales.

Intervenciones de bajo coste, como iniciación temprana cuando no hay alimentación al pecho, escuchar música relajante, masajear y calentar el pecho, extracción manual y extractor de leche de menor coste pueden ser tan o más efectivos que los extractor de leche eléctricos grandes para algunos de los desenlaces de interés.

Los pequeños tamaños de los estudios, las amplias desviaciones estándar y la diversidad de las intervenciones llevan a la precaución a la hora de aplicar estos resultados más allá de los métodos testados en los escenarios específicos.

Tabla 8. Resumen de RS

\begin{tabular}{|c|c|c|c|c|c|c|}
\hline $\begin{array}{l}\text { Referencia } \\
\text { (Cita } \\
\text { Abreviada) }\end{array}$ & $\begin{array}{l}\text { Estudio } \\
\text { (Diseño y } \\
\text { objetivo) }\end{array}$ & $\begin{array}{l}\text { Población } \\
\text { ( } \mathrm{n}^{\circ} \mathrm{y} \\
\text { características) }\end{array}$ & $\begin{array}{l}\text { Intervención/ } \\
\text { Comparación. } \\
\text { exposiciones o } \\
\text { pruebas a estudio }\end{array}$ & $\begin{array}{l}\text { Resultados } \\
\text { (Estimadores de resultados-Magnitud } \\
\text { del efecto) }\end{array}$ & $\begin{array}{l}\text { Conclusiones } \\
\text { (Conclusiones) }\end{array}$ & $\begin{array}{l}\text { Comentarios } \\
\text { (Calidad de la evidencia, } \\
\text { financiación comentarios) }\end{array}$ \\
\hline $\begin{array}{l}\text { Becker GE et } \\
\text { al, } 2015\end{array}$ & $\begin{array}{l}\text { Diseño: RS } \\
\text { Objetivo: } \\
\text { Valorar la } \\
\text { aceptabilidad, } \\
\text { efectividad, } \\
\text { seguridad, } \\
\text { efecto sobre la } \\
\text { composición de } \\
\text { la leche, } \\
\text { contaminación y } \\
\text { costes de los } \\
\text { métodos de } \\
\text { extracción de } \\
\text { leche materna }\end{array}$ & $\begin{array}{l}\text { N: } 34 \text { estudios } \\
\text { con } 1998 \\
\text { participantes, de } \\
\text { los cuales } \\
\text { proveen datos } \\
\text { para el análisis } 17 \\
\text { ensayos que } \\
\text { incluyen } 961 \\
\text { participantes. } \\
\text { Características: } \\
\text { Incluyen estudios } \\
\text { que cuentan tanto } \\
\text { con madres de } \\
\text { niños prematuros } \\
\text { como madres de } \\
\text { niños sanos a } \\
\text { término. }\end{array}$ & $\begin{array}{l}8 \text { estudios comparan } \\
\text { uno o más tipos de } \\
\text { extractor de lechees } \\
\text { frente la extracción } \\
\text { manual y } 14 \text { estudios } \\
\text { comparan un tipo de } \\
\text { extractor de leche } \\
\text { frente a otro, con tres } \\
\text { de estos estudios } \\
\text { comparando tanto la } \\
\text { extracción manual y } \\
\text { múltiples tipos de } \\
\text { extractor de lechees. } \\
15 \text { estudios } \\
\text { compararon un } \\
\text { protocolo específico o } \\
\text { protocolos de }\end{array}$ & $\begin{array}{l}\text { Sólo uno de los } 17 \text { estudios que } \\
\text { examinan la satisfacción/aceptabilidad } \\
\text { maternal proveían datos de forma } \\
\text { analizable, reportando que las madres } \\
\text { asignadas al grupo de extracción } \\
\text { estaban más de acuerdo con la frase } \\
\text { "no quiero que me vean extrayéndome } \\
\text { la leche" que las madres del grupo de } \\
\text { extracción manual (DM - } 0,70 ; \text { IC } 95 \% \text { de } \\
-1,25 \text { a - } 0,15 \text { ), y las madres encontraron } \\
\text { que las instrucciones dadas para la } \\
\text { extracción manual eran más claras que } \\
\text { para el uso de extractor de leche (DM } \\
0,40 ; \text { IC } 95 \% \text { de } 0,05 \text { a } 0,75 \text { ). } \\
\text { No se encontraron diferencias entre los } \\
\text { métodos en relación a los efectos } \\
\text { adversos de contaminación de la leche } \\
\text { o nivel de dolor en el pecho o pezón o }\end{array}$ & $\begin{array}{l}\text { El método más apropiado } \\
\text { para la extracción de la } \\
\text { leche puede depender del } \\
\text { tiempo desde el } \\
\text { nacimiento, el objetivo de } \\
\text { la extracción y de la } \\
\text { madre y niño individuales. } \\
\text { Intervenciones de bajo } \\
\text { coste, como iniciación } \\
\text { temprana cuando no hay } \\
\text { alimentación al pecho, } \\
\text { escuchar música } \\
\text { relajante, masajear y } \\
\text { calentar el pecho, } \\
\text { manual y extractor de } \\
\text { lechees de menor coste } \\
\text { pueden ser tan o más } \\
\text { efectivos que los extractor }\end{array}$ & \\
\hline
\end{tabular}




\begin{tabular}{|c|c|c|c|c|c|c|}
\hline $\begin{array}{l}\text { Referencia } \\
\text { (Cita } \\
\text { Abreviada) }\end{array}$ & $\begin{array}{l}\text { Estudio } \\
\text { (Diseño y } \\
\text { objetivo) }\end{array}$ & $\begin{array}{l}\text { Población } \\
\text { (no y } \\
\text { características) }\end{array}$ & $\begin{array}{l}\text { Intervención// } \\
\text { Comparación. } \\
\text { exposiciones o } \\
\text { pruebas a estudio }\end{array}$ & $\begin{array}{l}\text { Resultados } \\
\text { (Estimadores de resultados-Magnitud } \\
\text { del efecto) }\end{array}$ & $\begin{array}{l}\text { Conclusiones } \\
\text { (Conclusiones) }\end{array}$ & $\begin{array}{l}\text { Comentarios } \\
\text { (Calidad de la evidencia, } \\
\text { financiación comentarios) }\end{array}$ \\
\hline & & $\begin{array}{l}\text { Incluyen estudios } \\
\text { aleatorizado so } \\
\text { cuasialeatorizados } \\
\text { que comparan la } \\
\text { utilización de } \\
\text { dichos métodos a } \\
\text { cualquier período } \\
\text { tras el nacimiento. }\end{array}$ & $\begin{array}{l}\text { extracción secuencial } \\
\text { o simultáneo (5 } \\
\text { estudios), extracción } \\
\text { de más de } 4 \text { veces } \\
\text { por día versus menos } \\
\text { de } 3 \text { veces por día (1 } \\
\text { estudio), provisión de } \\
\text { educación para la } \\
\text { extracción y apoyo a } \\
\text { madres de niños } \\
\text { pretérmino (1 estudio) } \\
\text { provisión de } \\
\text { relajación a madres } \\
\text { de niños pretérmino } \\
\text { (2 estudios), } \\
\text { comenzar con la } \\
\text { extracción en la } \\
\text { primera hora tras el } \\
\text { parto versus entre } 1 \text { y } \\
6 \text { horas ( } 1 \text { estudio), } \\
\text { masaje antes o } \\
\text { durante la extracción } \\
\text { (2 estudios), la } \\
\text { combinación de la } \\
\text { extracción manual } \\
\text { con extractor de } \\
\text { leche frente al uso de } \\
\text { solo extractor de } \\
\text { leche etc. }\end{array}$ & $\begin{array}{l}\text { daño. } \\
\text { Para los resultados secundarios, se } \\
\text { obtuvo un mayor volumen cuando se } \\
\text { proveía de una cinta de relajación o } \\
\text { intervenciones para escuchar música a } \\
\text { las madres de niños en unidades } \\
\text { neonatales, cuando el pecho era } \\
\text { calentado antes de la extracción o era } \\
\text { masajeado mientras se extraía la leche. } \\
\text { Con la iniciación de la extracción en los } \\
60 \text { minutos postparto en madres de } \\
\text { niños con muy bajo peso al nacer se } \\
\text { obtuvieron mayores volúmenes de leche } \\
\text { en la primera semana que en el grupo } \\
\text { que comenzó la extracción más tarde. } \\
\text { No se reportaron aspectos económicos. } \\
15 \text { de los } 25 \text { estudios que evaluaban } \\
\text { extractor de lechees habían sido } \\
\text { financiados por la industria. }\end{array}$ & $\begin{array}{l}\text { de lechees eléctricos } \\
\text { grandes para algunos de } \\
\text { los desenlaces de interés. } \\
\\
\text { Los pequeños tamaños } \\
\text { de los estudios, las } \\
\text { amplias desviaciones } \\
\text { estándar y la diversidad } \\
\text { de las intervenciones } \\
\text { llevan a la precaución a la } \\
\text { hora de aplicar estos } \\
\text { resultados más allá de los } \\
\text { métodos testados en los } \\
\text { escenarios específicos. }\end{array}$ & \\
\hline
\end{tabular}




\title{
3.3. Resumen de GPC base y RS disponibles
}

Según la guía NICE (2) en relación a cuál es el mejor método para la extracción de la leche materna, se señala que en la guía publicada por la National Association of Neonatal Nurses (3) se establecen dos recomendaciones de buena práctica en relación al método de extracción:

- La extracción manual es barata y permite el CPP, lo que puede aumentar la producción de leche

- El bombeo mecánico puede aumentar la estimulación hormonal y permite extraer leche de ambos senos a la vez.

En la Perinatal Services BC (4)se señala que cuando esté indicado, se debe de iniciar la extracción manual de la leche para establecer la producción y prevenir la congestión mamaria, y que la combinación de la extracción manual con el uso de un sacaleches resulta en un aumento de la producción de leche (5).

La revisión de Becker et al, 2015 (1) señala que el método más apropiado para la extracción de la leche puede depender del tiempo desde el nacimiento, el objetivo de la extracción y de la madre y niño individuales. También indica que intervenciones de bajo coste, como la iniciación temprana cuando no hay alimentación al pecho, escuchar música relajante, masajear y calentar el pecho, la extracción manual y el uso de extractor de lechees de leche de menor coste pueden ser tan o más efectivos que los extractor de lechees de leche eléctricos grandes para algunos de los desenlaces de interés. Los pequeños tamaños de los estudios, las amplias desviaciones estándar y la diversidad de las intervenciones llevan a la precaución a la hora de aplicar estos resultados más allá de los métodos testados en los escenarios específicos

\subsection{Conclusión}

\begin{tabular}{|c|l|}
\hline & Adopción GPC/Revisión sistemática \\
\hline $\mathrm{X}$ & Elaboración parcial (a partir de la revisión sistemática de Becker et al, 2015). \\
\hline & Elaboración de novo \\
\hline
\end{tabular}

\subsection{Diseño de la estrategia de búsqueda de estudios individuales}

\author{
Criterios de selección \\ de estudios
}

Período de búsqueda

Bases de datos 


\section{4- Resumen de la evidencia (Tablas de estudios individuales y valoración de calidad en el ANEXO X)}

\subsection{GRADE Evidence Profile}

Comparación 1: Cualquier extractor de leche de leche eléctrico frente a extracción manual Bibliografía: Flaherman VJ et al, 2012; Garza C et al, 1982

\begin{tabular}{|c|c|c|c|c|c|c|c|c|c|c|c|c|}
\hline \multirow{2}{*}{\multicolumn{7}{|c|}{ Evaluación de la calidad }} & \multicolumn{4}{|c|}{ Resumen de los Resultados } & \multirow[b]{3}{*}{ Calidad } & \multirow[b]{3}{*}{ Importancia } \\
\hline & & & & & & & \multicolumn{2}{|c|}{\begin{tabular}{|l|} 
№ de pacientes \\
\end{tabular}} & \multicolumn{2}{|c|}{ Magnitud del efecto } & & \\
\hline $\begin{array}{l}\text { No } \\
\text { estudios }\end{array}$ & Diseño & $\begin{array}{l}\text { Riesgo } \\
\text { sesgo }\end{array}$ & de Inconsistencia & $\begin{array}{l}\text { Evidencia } \\
\text { indirecta }\end{array}$ & Imprecisión & $\begin{array}{l}\text { Otras } \\
\text { consideraciones }\end{array}$ & \begin{tabular}{|c|}
$\begin{array}{c}\text { Extractor de } \\
\text { leche } \\
\text { eléctrico }\end{array}$ \\
\end{tabular} & $\begin{array}{l}\text { Extracción } \\
\text { manual }\end{array}$ & $\begin{array}{l}\text { Relativa } \\
(95 \% \mathrm{Cl})\end{array}$ & $\begin{array}{c}\text { Absoluta por } \\
1000\end{array}$ & & \\
\hline \multicolumn{13}{|c|}{ Satisfacción materna en madres con niños a término y problemas de succión a las 12-36 horas postparto (autoeficacia) (menor puntuación, peor resultado) } \\
\hline 11 & ECA & Serio $^{2}$ & No seria & No seria & Seria $^{3}$ & Ninguna & $\begin{array}{c}35 \\
\text { (Media 2,3) } \\
\end{array}$ & $\begin{array}{c}33 \\
\text { (Media 3) } \\
\end{array}$ & \begin{tabular}{|c|} 
DM de $-0,70$ (de \\
$-1,25$ a $-0,15)$ \\
\end{tabular} & - & BAJA & CRITICA \\
\hline \multicolumn{13}{|c|}{ Satisfacción con las instrucciones en madres con niños a término y problemas de succión a las 12-36 horas postparto (mayor puntuación, peor resultado) } \\
\hline $1^{1}$ & ECA & Serio $^{2}$ & No seria & No seria & \begin{tabular}{|l|l|l} 
Seria $^{3}$ &
\end{tabular} & Ninguna & $\begin{array}{c}35 \\
\text { (Media 4,5) }\end{array}$ & $\begin{array}{c}33 \\
\text { (Media 4,1) }\end{array}$ & $\begin{array}{c}\begin{array}{c}\text { DM de } 0,40 \\
\text { (de } 0,05 \mathrm{a} \\
0,75)\end{array} \\
\end{array}$ & - & BAJA & IMPORTANTE \\
\hline \multicolumn{13}{|c|}{ Efectos adversos en la madre/hijo ( a término) } \\
\hline $1^{1}$ & ECA & Serio $^{2}$ & No seria & No seria & Seria $^{3}$ & Ninguna & 35 & 33 & $\begin{array}{c}\text { DM de } 0,02 \\
\text { (de -0,67 a } \\
0,71) \\
\end{array}$ & - & BAJA & IMPORTANTE \\
\hline \multicolumn{13}{|c|}{ Volumen de leche (cc) por una extracción a las 12-36 horas postparto } \\
\hline $1^{1}$ & ECA & Serio $^{2}$ & \begin{tabular}{l|l} 
No seria \\
\end{tabular} & No seria & Seria $^{3}$ & Ninguna & $\begin{array}{c}35 \\
\text { (Media 0,8) }\end{array}$ & $\begin{array}{c}33 \\
\text { (Media 2,9) } \\
\end{array}$ & $\begin{array}{c}\text { DM de }-2,10 \\
(-4,77 \text { a } 0,57)\end{array}$ & - & BAJA & CRITICA \\
\hline \multicolumn{13}{|c|}{ Nitrógeno total (mg/dl de leche) } \\
\hline $1^{4}$ & ECA & $\begin{array}{l}\text { Muy } \\
\text { serio }^{5}\end{array}$ & No seria & No seria & Seria $^{3}$ & Ninguna & $\begin{array}{c}18 \\
\text { (Media } \\
210) \\
\end{array}$ & $\begin{array}{c}18 \\
\text { (Media 220) }\end{array}$ & $\begin{array}{c}\text { DM de }-10 \\
\text { (de -23,07 a } \\
3,07) \\
\end{array}$ & - & MUY BAJA & IMPORTANTE \\
\hline
\end{tabular}

${ }^{1}$ Flaherman VJ et al, 2012; ${ }^{2}$ Riesgo de sesgo en el diseño del estudio; ${ }^{3 P}$ ocas madres en cada grupo; ${ }^{4}$ Garza $\mathrm{C}$ et al, $1982 ;{ }^{5}$ ECA cruzado con alto riesgo de sesgo

De las Comparaciones 2,3 y 4 no hay estudios que incluyan madres de niños sanos a término, sólo en prematuros y para las Comparaciones 2 y 4 (ver Resumen de evidencia). 


\section{Otras comparaciones encontradas en estudios con madres de niños a término:}

Comparación 5: Cualquier extractor de leche de leche eléctrico pequeño o con batería frente a cualquier otro extractor de leche eléctrico pequeño o con

batería

Bibliografía: Francis J et al, 2008

\begin{tabular}{|c|c|c|c|c|c|c|c|c|c|c|c|c|}
\hline \multirow{2}{*}{\multicolumn{7}{|c|}{ Evaluación de la calidad }} & \multicolumn{4}{|c|}{ Resumen de los Resultados } & \multirow{3}{*}{ Calidad } & \multirow{3}{*}{ Importancia } \\
\hline & & & & & & & \multicolumn{2}{|c|}{ № de pacientes } & \multicolumn{2}{|c|}{ Magnitud del efecto } & & \\
\hline $\begin{array}{c}\begin{array}{c}\text { № de } \\
\text { estudios }\end{array} \\
\end{array}$ & Diseño & $\begin{array}{c}\text { Riesgo de } \\
\text { sesgo }\end{array}$ & Inconsistencia & \begin{tabular}{|l|}
$\begin{array}{l}\text { Evidencia } \\
\text { indirecta }\end{array}$ \\
\end{tabular} & Imprecisión & \begin{tabular}{|c|} 
Otras \\
consideraciones
\end{tabular} & $\begin{array}{c}\begin{array}{c}\text { Extractor de } \\
\text { leche } 1\end{array} \\
\end{array}$ & \begin{tabular}{|c|} 
Extractor de \\
leche 2
\end{tabular} & $\begin{array}{l}\text { Relativa } \\
(95 \% \mathrm{CI})\end{array}$ & $\begin{array}{c}\text { Absoluta por } \\
1000\end{array}$ & & \\
\hline \multicolumn{13}{|c|}{ Volumen de leche en una extracción (ml) (Small electric UNO frente Small electric Swing) } \\
\hline $1^{1}$ & ECA & Serio $^{2}$ & \begin{tabular}{|l|} 
No seria \\
\end{tabular} & No seria & Seria $^{3}$ & Ninguna & $\begin{array}{l}20 \text { (media de } \\
65 \text { ) }\end{array}$ & $\begin{array}{l}20 \text { (media de } \\
80)\end{array}$ & $\begin{array}{c}\mathrm{DM}-15 \text { (de -38 } \\
, 93 \text { a 83) }\end{array}$ & - & BAJA & CRITICA \\
\hline \multicolumn{13}{|c|}{ Cambio en la producción de leche en 24 horas (gramos) (Medela vs Playtex) } \\
\hline $1^{4}$ & ECA & Serio ${ }^{2,5}$ & \begin{tabular}{|l|} 
No seria \\
\end{tabular} & No seria & Seria $^{3}$ & Ninguna $^{6}$ & $\begin{array}{l}29 \text { (media } \\
\text { de } 205 \mathrm{~g} \text { ) }\end{array}$ & $\begin{array}{l}30 \text { (media } \\
\text { de } 143 \mathrm{~g} \text { ) }\end{array}$ & $\begin{array}{c}\text { DM de } 62 \text { (de } \\
-46,02 \text { a } \\
170,02)\end{array}$ & - & BAJA & CRITICA \\
\hline \multicolumn{13}{|c|}{ Minutos para realizar una extracción (Small electric UNO frente Small electric Swing) } \\
\hline $1^{1}$ & ECA & Serio $^{2}$ & \begin{tabular}{|l|} 
No seria \\
\end{tabular} & No seria & Seria $^{3}$ & Ninguna & $\begin{array}{l}20 \text { (media } \\
\text { de } 18 \text { ) }\end{array}$ & $\begin{array}{l}20 \text { (Media } \\
\text { de 14) }\end{array}$ & $\begin{array}{l}\text { DM de } 4 \text { (de } \\
1,19 \text { a } 6,81) \\
\end{array}$ & - & BAJA & IMPORTANTE \\
\hline \multicolumn{13}{|c|}{ Efectos en los niveles hormonales (tiempo para la eyección de leche) (Small electric UNO frente Small electric Swing) } \\
\hline $1^{1}$ & ECA & Serio $^{2}$ & No seria & No seria & Seria $^{3}$ & Ninguna & $\begin{array}{l}20 \text { (Media de } \\
94 \text { ) }\end{array}$ & $\begin{array}{c}20 \\
\text { (Media de } \\
87 \text { ) }\end{array}$ & $\begin{array}{c}\text { DM de } 7 \text { (de - } \\
21,23 \mathrm{a} \\
35,23)\end{array}$ & - & BAJA & IMPORTANTE \\
\hline
\end{tabular}

sujetador comercial especial elástico sesgo en el estudio; ${ }^{3}$ Pocos pacientes en cada grupo e intervalo de confianza de la diferencia de medias impreciso; ${ }^{4} \mathrm{Hopkinson} \mathrm{J}$ et al, $2009 ;{ }^{5}$ Uso de un

uno de los extractor de lechees testados, aunque los resultados no apoyan precisamente al producto, por ello no se baja la calidad.

Comparación 6: Cualquier extractor de leche de leche eléctrico grande frente a cualquier extractor de leche eléctrico pequeño o de batería Bibliografía: Francis J et al, 2008 


\begin{tabular}{|c|c|c|c|c|c|c|c|c|c|c|c|c|}
\hline \multirow[b]{2}{*}{$\begin{array}{c}\text { № de } \\
\text { estudios }\end{array}$} & \multirow[b]{2}{*}{ Diseño } & \multirow[b]{2}{*}{$\begin{array}{l}\text { Riesgo de } \\
\text { sesgo }\end{array}$} & \multirow[b]{2}{*}{ Inconsistencia } & \multirow[b]{2}{*}{$\begin{array}{l}\text { Evidencia } \\
\text { indirecta }\end{array}$} & \multirow[b]{2}{*}{ Imprecisión } & \multirow[b]{2}{*}{$\begin{array}{c}\text { Otras } \\
\text { consideraciones }\end{array}$} & \multicolumn{2}{|l|}{ № de pacientes } & \multicolumn{2}{|c|}{ Magnitud del efecto } & & \\
\hline & & & & & & & $\begin{array}{c}\text { Extractor de } \\
\text { leche eléctrico } \\
\text { grande }\end{array}$ & \begin{tabular}{|c|} 
Extractor de \\
leche \\
eléctrico \\
pequeño
\end{tabular} & $\begin{array}{l}\text { Relativa } \\
(95 \% \mathrm{CI})\end{array}$ & $\begin{array}{l}\text { Absoluta por } \\
1000\end{array}$ & & \\
\hline \multicolumn{13}{|c|}{ Volumen de leche (ml) en una extracción (Whittlestone frente a UNO) } \\
\hline 11 & ECA & Serio ${ }^{2}$ & No seria & No seria & Seria $^{3}$ & Ninguna & 20 (media 85) & 20 (media 65) & \begin{tabular}{|c|} 
DM 20 (de 1,28 \\
a 38,72$)$
\end{tabular} & - & BAJA & CRITICA \\
\hline \multicolumn{13}{|c|}{ Volumen de leche (ml) en una extracción (Whittlestone frente a Swing) } \\
\hline $1^{1}$ & ECA & Serio $^{2}$ & No seria & No seria & Seria $^{3}$ & Ninguna & 20 (media 85) & $\begin{array}{l}20 \text { (media } \\
48)\end{array}$ & $\begin{array}{c}\text { DM } 5 \text { (de - } \\
21,30 \text { a } \\
31,30) \\
\end{array}$ & - & BAJA & CRITICA \\
\hline \multicolumn{13}{|c|}{ Minutos para una extracción (Whittlestone versus UNO) } \\
\hline 11 & ECA & Serio ${ }^{2}$ & No seria & No seria & Seria $^{3}$ & Ninguna & 20 (media 12) & $\begin{array}{ll}20 & \text { (media } \\
18) & \\
\end{array}$ & $\begin{array}{l}\text { DM de }-6 \text { (de } \\
-8,81 \text { a }-3,19)\end{array}$ & - & BAJA & IMPORTANTE \\
\hline \multicolumn{13}{|c|}{ Minutos para una extracción (Whittlestone frente a Swing) } \\
\hline 11 & ECA & Serio $^{2}$ & No seria & No seria & Seria $^{3}$ & Ninguna & 20 (media 12) & $\begin{array}{l}20 \text { (media } \\
14)\end{array}$ & $\begin{array}{l}\text { DM -2 (de - } \\
4,48 \text { a } 0,48)\end{array}$ & - & BAJA & IMPORTANTE \\
\hline \multicolumn{13}{|c|}{ Niveles hormonales madre (tiempo de eyección de la leche en segundos) (Whittlestone versus UNO) } \\
\hline 11 & ECA & Serio $^{2}$ & No seria & No seria & \begin{tabular}{|l|l|l} 
Seria $^{3}$ & \\
\end{tabular} & Ninguna & $\begin{array}{c}20 \text { (media de } \\
68 \text { ) }\end{array}$ & $\begin{array}{l}20 \text { (media } \\
\text { de 94) }\end{array}$ & $\begin{array}{c}\text { DM de }-26 \\
\text { (de }-54,49 \text { a } \\
2,49) \\
\end{array}$ & - & BAJA & IMPORTANTE \\
\hline \multicolumn{13}{|c|}{ Niveles hormonales madre (tiempo de eyección de la leche en segundos) (Whittlestone versus Swing) } \\
\hline $1^{1}$ & ECA & Serio $^{2}$ & No seria & No seria & \begin{tabular}{|l|l|l} 
Seria $^{3}$ & \\
\end{tabular} & Ninguna & \begin{tabular}{|c|}
20 (media de \\
68 ) \\
\end{tabular} & $\begin{array}{l}20 \text { (media } \\
\text { de } 87 \text { ) }\end{array}$ & $\begin{array}{l}\text { DM -19 (de - } \\
42,86 \text { a } 4,86 \text { ) }\end{array}$ & - & BAJA & IMPORTANTE \\
\hline
\end{tabular}




\subsection{Resumen de la evidencia}

De los estudios incluidos en la revisión Cochrane seleccionada para responder a esta pregunta (1) sólo 12 incluyen niños sanos a término (617). Sin embargo, solo en cuatro de estos estudios se reportaron datos analizables mediante RevMan sobre los desenlaces de interés $(9-11 ; 13)$.

Comparación 1: Cualquier extractor de leche de leche eléctrico frente a extracción manual

Son dos los estudios que presentan datos para esta comparación en niños nacidos a término $(9 ; 11)$. El volumen de leche en una extracción a las 12-36 horas postparto tiende a ser mayor cuando se utiliza la extracción manual frente a un extractor de leche de leche eléctrico (1 estudio, DM de $-2,10$ cc; IC95\% de $-4,77$ a 0,57).

Asimismo, a los dos meses, es más probable que las madres asignadas al grupo de extracción manual sigan con la lactancia materna que las asignadas al grupo de extracción eléctrica (1 estudio, 96,1\% versus $72,7 \%, p=0,02)(9)$.

En cuanto a la satisfacción materna, las madres asignadas al grupo de extracción con extractor de leche de leche eléctrico estaban más de acuerdo con la frase "no quiero que me vean extrayéndome la leche" que las madres del grupo con extracción manual (1 estudio, DM -0,70; IC95\% de $-1,25$ a $-0,15)$. Asimismo, las madres encontraron que las instrucciones dadas para la extracción manual eran más claras que para el uso de extractor de leche de leche (1 estudio, DM 0,40; IC95\% de $0,05$ a 0,75$)$.

No se han encontrado estudios para la Comparación 3 (Extracción combinada versus Extracción manual).

Para las Comparaciones 2 (Extracción eléctrica simple versus doble) y 4 (Extracción combinada versus extracción eléctrica), solo se han encontrado estudios en prematuros.

\section{Comparación 2: Extracción eléctrica simple versus extracción eléctrica doble}

Se observa que no existen diferencias en la cantidad de leche extraída, aunque sí en el tiempo necesario para realizar las extracciones a lo largo de la semana entre la extracción simultánea versus la extracción secuencial $(7,3$ horas versus 11,1 horas de media por semana; DM de 3,50 horas (IC95\% de $-5,61$ a $-1,39$ ).

\section{Comparación 4: Extracción combinada versus extracción eléctrica}

\section{Comparación 4: Extracción combinada versus extracción eléctrica}

El único estudio incluido en la revisión Cochrane (18) que comparaba la extracción combinada manual y con extractor de leche frente a sólo el uso de extractor de leche eléctrico, reportó que la extracción manual combinada con la extracción mediante extractor de leche eléctrico grande producía mayor volumen de leche (aunque no significativo) en cada

Calidad

baja para todos los desenlaces

Calidad muy baja

Calidad muy baja 
extracción durante cinco semanas de uso. Sin embargo, los datos que proveían no fueron suficientes para su inclusión en el análisis de la revisión Cochrane.

En cuanto a otros estudios realizados en niños nacidos a término, se han encontrado estudios que comparan la eficacia de diferentes extractores de leche eléctricos pequeños o con batería, o estudios que comparan cualquier extractor de leche eléctrico grande frente a extractores de leche eléctricos pequeños o con batería.

Comparación 5: Cualquier extractor de leche de leche eléctrico pequeño o con batería frente a cualquier otro extractor de leche de leche eléctrico pequeño o con batería

Son dos los estudios que presentan datos para esta comparación en niños sanos a término $(10 ; 13)$. Con el extractor de leche eléctrico pequeño UNO se obtiene menos cantidad de leche en una única extracción que con el extractor de leche Swing (1 estudio, DM $-15 \mathrm{ml}$; IC95\% de -38,93 a 83). Con el extractor de leche de Medela se obtiene mayor cambio en la producción de leche en $\mathbf{2 4}$ horas que con extractor de leche de Playtex (1 estudio, DM de 62 gramos; IC95\% de 46,02 a 170,02). En cuanto al tiempo para realizar una extracción, con el extractor de leche eléctrico UNO se necesita más tiempo que con el extractor de leche Swing (1 estudio, DM de 4 minutos; IC95\% de 1,19 a 6,81 ), y lo mismo ocurre con el tiempo para la eyección de la leche (1 estudio, DM de 7 minutos; IC95\% de -21,23 a 35,23).

Comparación 6: Cualquier extractor de leche de leche eléctrico grande frente a extractor de leche de leche eléctrico pequeño o con batería

En este caso, es uno el estudio que presenta datos para esta comparación (10). En cuanto al volumen de leche obtenido en una extracción la diferencia es significativa a favor del extractor de leche eléctrico grande frente a cualquier extractor de leche eléctrico pequeño UNO (1 estudio, DM de $20 \mathrm{ml}$; IC95\% de 1,28 a 38,72), aunque no en el caso del extractor de leche eléctrico pequeño Swing (1 estudio, DM de 5 $\mathrm{ml}$; IC95\% de $-21,30$ a 31,3$)$. El tiempo que se tarda en realizar una extracción también es menor con el extractor de leche eléctrico grande en comparación con el extractor de leche pequeño UNO (1 estudio, DM de $-6 \mathrm{~min}$; IC95\% de -8,81 a -3,19), aunque no en comparación con el extractor de leche pequeño Swing (1 estudio, DM de $-2 \mathrm{~min}$; IC95\% de $4,48$ a 0,48$)$.

Otras comparaciones reportadas en estudios realizados con madres de niños prematuros.

En relación a los niños prematuros, también se han identificado otros estudios que comparan el uso de cualquier extractor de leche manual frente a la extracción manual y cualquier extractor de leche manual frente a cualquier otro extractor de leche manual.

Adición de otras técnicas al método de extracción (Comparación 7)

Calidad

baja para todos los desenlaces

Calidad baja para todos los desenlaces 
Por otro lado, también se han identificado estudios en prematuros que comparan la eficacia en el aumento de la producción de leche de la adición de otras técnicas a la extracción, como por ejemplo el uso de técnicas de relajación, la administración de instrucciones, la adición de masaje en el pecho o del calentamiento del mismo.

En el caso de la adición de técnicas de relajación a cualquier método de extracción, se incluyen dos estudios: el de (19;20). En el primer estudio (19), el volumen de leche por extracción aumenta en el grupo que utiliza una cinta de relajación durante la extracción (DM de 34,70 ml $(9,51$ a 59,89$)$ frente al grupo en el que no se utiliza. En el segundo estudio (20), el volumen de leche producido durante el primer día es mayor en el grupo en el que se realizan tres intervenciones para escuchar música de 12 minutos de duración (DM de $17 \mathrm{ml}$ (IC95\% de 9,27 a 24,73) frente a los que no lo hacen, diferencia que aumenta al quinto (DM de $85,10 \mathrm{ml}$; IC95\% de 63,13 a 107,07) y décimo día (DM de $277,40 \mathrm{ml}$; IC95\% de 207,75 a 347,05), respectivamente. En cuanto al contenido en grasa de la leche extraída ( $\mathbf{g} / \mathrm{ml}$ al día), el estudio de Keith (20) registra un aumento al primer, quinto y décimo día en el grupo que recibe la técnica de relajación frente al grupo que no la recibe (DM de 8,60 g/l por día (IC95\% de 3,66 a 13,54); DM de 12 g/l día (IC95\% de 5,17 a 18,83) y DM de $14 \mathrm{~g} / \mathrm{l}$ por día (IC95\% de 2,25 a 25,75), respectivamente).

En el caso de la comparación entre el método de extracción con o sin instrucciones específicas, en el estudio de Ahmed 2008 se encuentran diferencias significativas en la transferencia al amamantamiento a favor del programa de lactancia materna (RR de 2; IC95\% de 1,25 a 3,21).

En relación a la adición o no de masaje en el pecho, en el único ECA cruzado (21) se encuentra que la cantidad de leche extraída (ml obtenidos en dos extracciones) es mayor cuando cualquier método de extracción es acompañado de masaje en el pecho (DM de 4,82 ml (IC95\% de 1,25 a 8,39). El contenido en grasa también aumenta (DM del crematocrito de 1,92\% (IC95\% de 1,02 a 2,82).

Y por último, en el estudio de Yigit 2012 (22) se señala que cualquier método que ayude a calentar el pecho aumenta el volumen de leche extraída (ml) de la primera a la sexta extracción, siendo las DM entre el pecho calentado y el pecho control de $9,64 \mathrm{ml}$ (IC95\% de $-0,50$ a 19,78) y de $13,02 \mathrm{ml}$ (IC95\% de 3,81 a 22,23), respectivamente.

\section{Resultados de la actualización de la búsqueda a octubre de 2016}

En la actualización de la búsqueda se ha identificado la actualización de la revisión de Becker et al, 2015 (23). Sin embargo, aunque en esta actualización se incluyen siete nuevos ensayos, las conclusiones de la revisión no cambian. Los autores sólo añaden que se necesitan más estudios con financiación independiente sobre la extracción manual y el efecto de la relajación y otras técnicas que no tienen potencial comercial sobre el aumento del volumen extraído.

Calidad muy baja

Calidad muy baja para todos los desenlaces

Calidad muy baja 


\section{De la evidencia a la recomendación (Tabla de EtR)}

\section{¿Qué métodos son más eficaces para la extracción de la leche?}

Población: Madres de RN sanos a término

Intervención/comparación: distintos métodos de extracción de leche

Perspectiva: clínica

C1.: Extracción eléctrica vs. Extracción manual; C2.: extracción eléctrica simple vs. doble; G3: Extracción combinada vs. extracción manual; C4: Extracción combinada vs. extracción eléctrica;

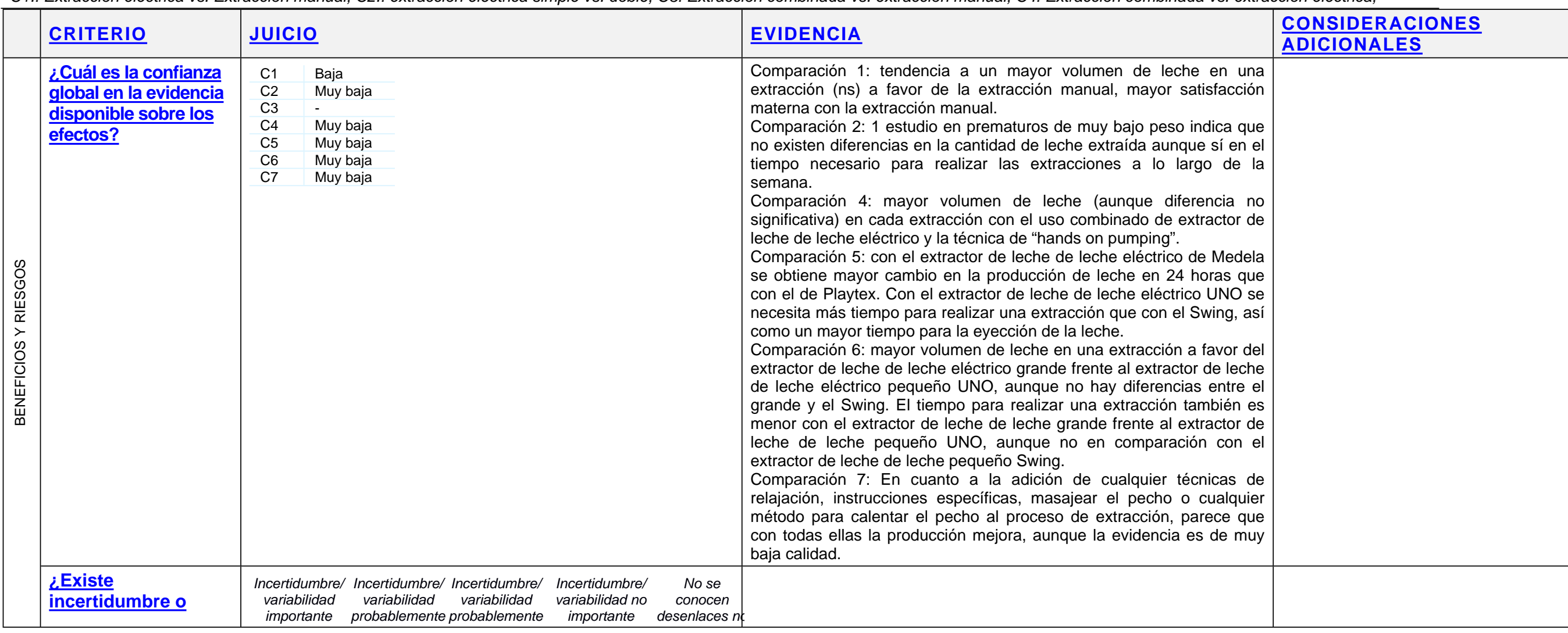




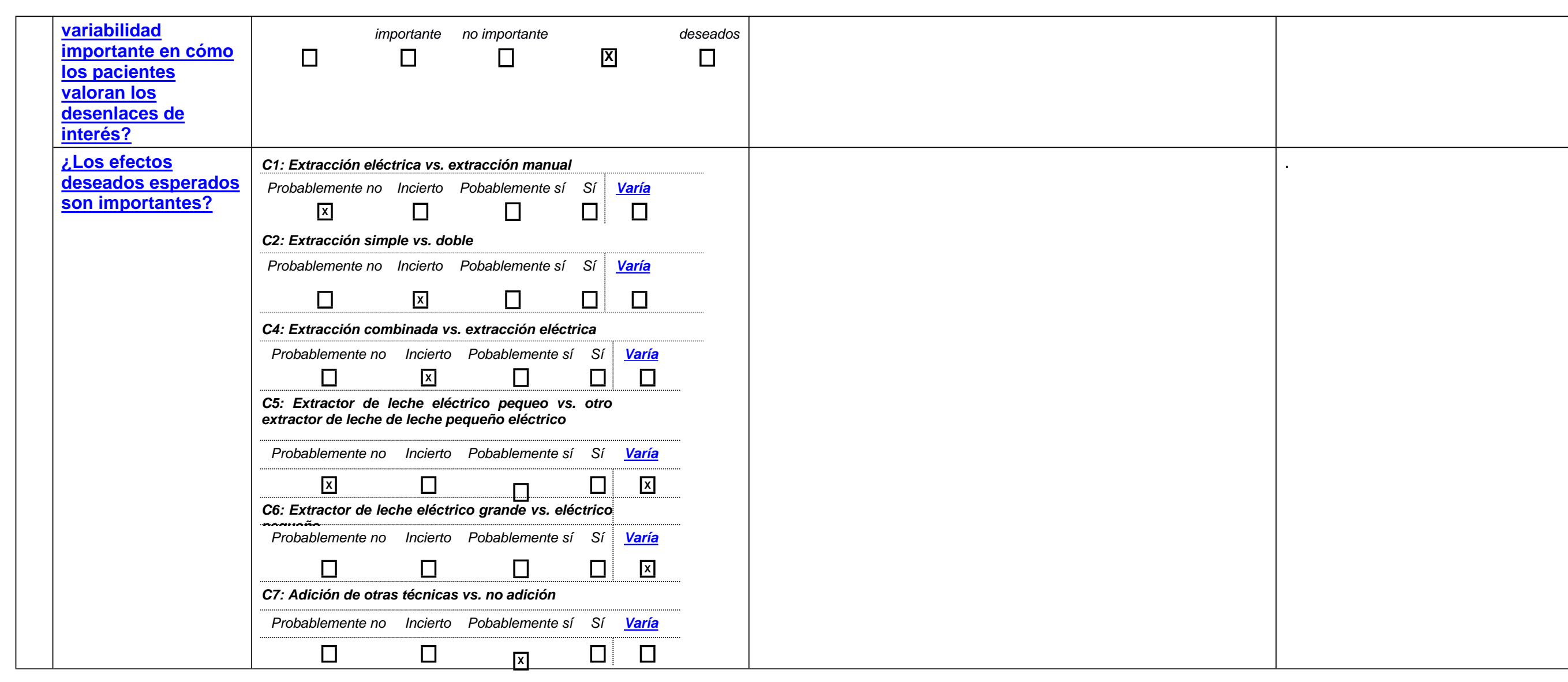




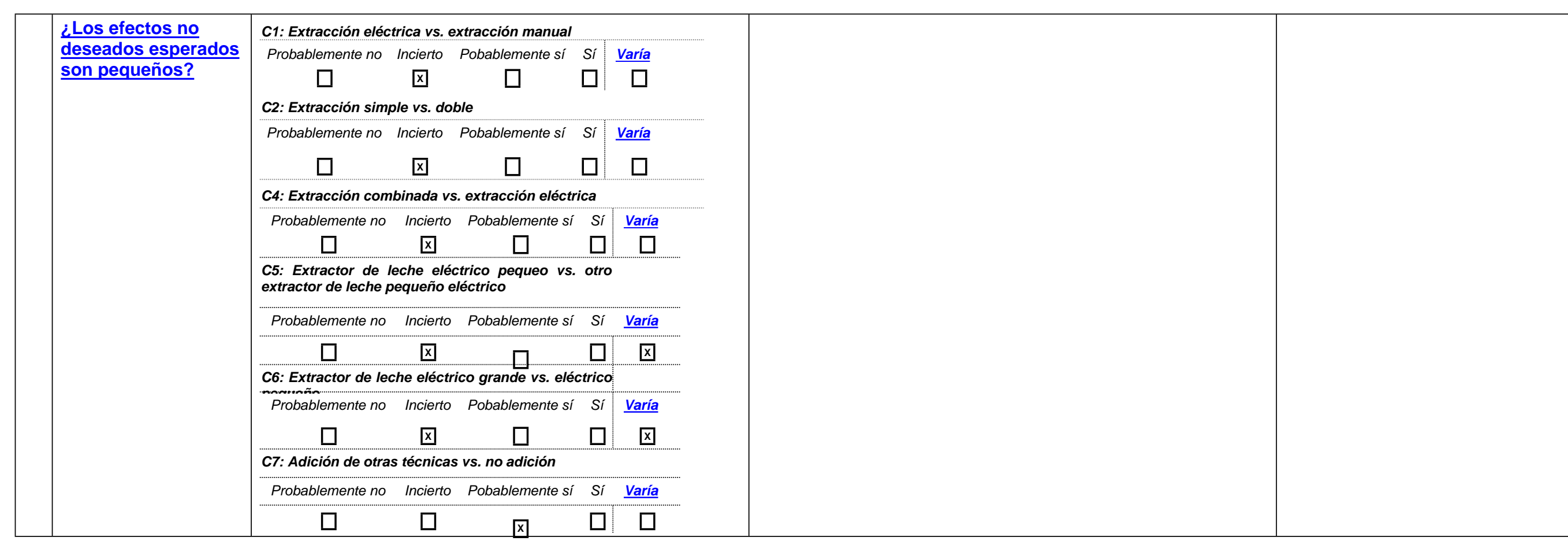




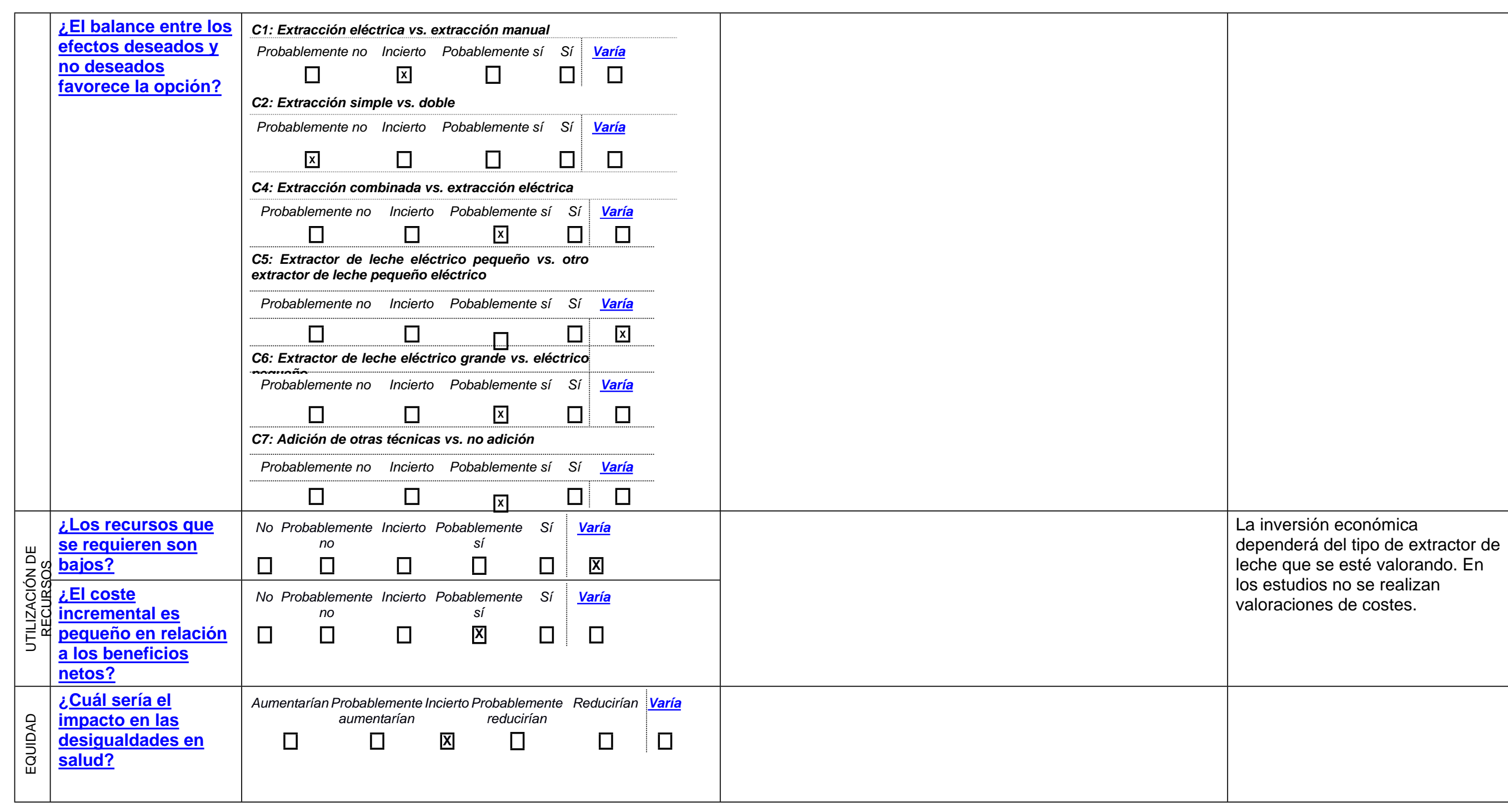




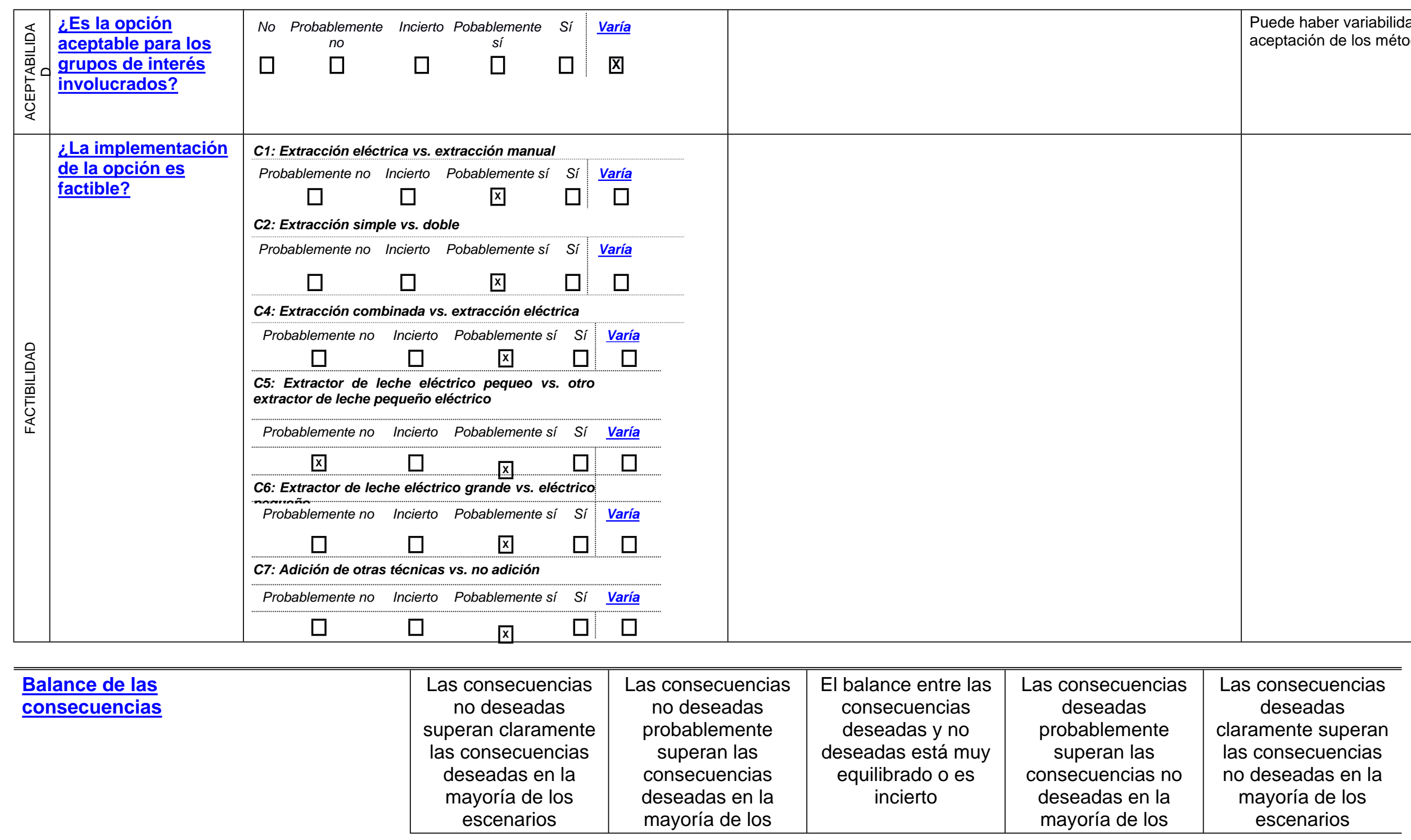




\begin{tabular}{|c|c|c|c|}
\hline & escenarios & & escenarios \\
\hline C1 & & & $\mathrm{X}$ \\
\hline C4 & & & $x$ \\
\hline C6 & & $x$ & \\
\hline C7 & & & $x$ \\
\hline
\end{tabular}

\begin{tabular}{|c|c|c|c|c|c|}
\hline \multirow[t]{6}{*}{$\begin{array}{l}\text { Tipo de } \\
\text { recomendación }\end{array}$} & & $\begin{array}{l}\text { Se recomienda no } \\
\text { ofrecer la opción }\end{array}$ & $\begin{array}{l}\text { Se sugiere no ofrecer la } \\
\text { opción }\end{array}$ & $\begin{array}{l}\text { Se sugiere ofrecer la } \\
\text { opción }\end{array}$ & $\begin{array}{l}\text { Se recomienda ofrecer } \\
\text { la opción }\end{array}$ \\
\hline & $\mathrm{C} 1$ & & & & \\
\hline & $\mathrm{C} 2$ & & & & \\
\hline & C5 & & & & \\
\hline & C6 & & & & \\
\hline & C7 & & & $x$ & \\
\hline
\end{tabular}

$\underline{\text { Recomendación }}$

\section{Recomendación de buena práctica}

Ante la poca evidencia disponible, a la hora de seleccionar el método de extracción optar por aquel que mejor se adecúe a las necesidades y preferencias de la madre, explicándole de forma detallada cómo se debe realizar la extracción con el método seleccionado.

\section{Recomendación débil a favor}

Se sugiere la realización de masajes en el pecho antes o durante la extracción, la utilización de técnicas de relajación, así como el calentamiento del pecho, independientemente del método de extracción considerado, para conseguir aumentar el volumen de leche extraída.

\section{Justificación}

La extracción de la leche es una intervención compleja de naturaleza individual. Los resultados de estudios individuales pueden no ser generalizables a otras culturas y situaciones. Los resultados de la revisión Cochrane (Becker et al, 2015) sugieren que el mejor método para la extracción de la leche puede depender en cada caso del tiempo desde el nacimiento, el objetivo de la extracción y 


\begin{tabular}{|c|c|}
\hline & $\begin{array}{l}\text { de la madre individual. } \\
\text { La extracción manual puede ser más adecuada para los primeros días para iniciar la producción de leche, y particularmente } \\
\text { cuando los constituyentes de la leche pueden ser importantes. Un extractor de leche eléctrico grande puede ser útil si la cantidad } \\
\text { es el principal objetivo, aunque puede tener un mayor riesgo de lesión para la madre que la extracción manual. } \\
\text { Si un extractor de leche eléctrico es demasiado caro, los extractores de leche manuales pueden ser tan efectivos en relación al } \\
\text { volumen obtenido una vez que la producción de leche está establecida. La extracción manual o masaje de las mamas en } \\
\text { combinación con la extracción puede ser beneficioso para aumentar la producción de leche. } \\
\text { Las limitaciones metodológicas de algunos ensayos de tamaño pequeño, las amplias desviaciones estándar, el pequeño número } \\
\text { de estudios revisados para cada resultado y la diversidad en la naturaleza, duración y frecuencia de las intervenciones llevan a ser } \\
\text { cautelosos a la hora de aplicar los resultados más allá de los equipos testados en los escenarios específicos. }\end{array}$ \\
\hline $\begin{array}{l}\text { Consideraciones para } \\
\text { la implementación }\end{array}$ & $\begin{array}{l}\text { La publicación de este tipo de estudios no debería dar a entender que la extracción manual o con extractor de leche es una parte } \\
\text { normal de la lactancia materna, sino más bien a que se trata de una intervención cuya aplicación debería estar justificada antes de } \\
\text { ser recomendada a una madre. } \\
\text { Los profesionales deben conocer y poder explicar a la madre las posibles técnicas de extracción a utilizar. }\end{array}$ \\
\hline $\begin{array}{l}\text { Monitorización y } \\
\text { evaluación }\end{array}$ & - \\
\hline
\end{tabular}


GPC Lactancia Materna - pregunta 24. Métodos aumento producción de leche

\section{ANEXOS}




\section{ANEXO I. EVALUACIÓN DE LA CALIDAD DE LOS ESTUDIOS}

\section{Revisiones sistemáticas - AMSTAR}

BECKER 2015 (1)

\section{1. ¿Se brindó un diseño "a priori"?}

La pregunta de la investigación y los criterios de inclusión deberían establecerse antes de llevar a cabo la revisión Sí

2. ¿Hubo duplicación en la selección de estudios y extracción de datos? Debería haber al menos dos personas independientes a cargo de la extracción de datos, y debería existir un procedimiento consensuado para los desacuerdos Sí

3. ¿Se realizó una búsqueda exhaustiva de literatura?

Deberían consultarse al menos dos fuentes electrónicas. El informe debe incluir los años y las bases de datos utilizadas (por ej. Central, EMBASE y MEDLINE). Deben especificarse las palabras clave y/o los términos MESH y, de ser posible, debe proveerse la estrategia de búsqueda. Todas las búsquedas deberían ser complementadas con consultas a contenidos actuales, revisiones, libros de textos, registros especializados, o expertos en el campo particular de estudio, y mediante la revisión de las referencias en los estudios encontrados Sí

4. ¿Se utilizó el estado de publicación (es decir, literatura gris) como criterio de inclusión?

Los autores deberían especificar que buscaron informes sin tener en cuenta el tipo de publicación. Los autores deberían especificar si excluyeron o no algún informe (de la revisión sistemática), en función del estado de publicación, idioma, etc. Sí

5. ¿Se brindó una lista de estudios (incluidos y excluidos)?

Debería proveerse una lista de estudios incluidos y excluidos Sí

6. ¿Se brindaron las características de los estudios incluidos?

De manera adjunta tal como una tabla, deberían proveerse los datos de los estudios originales sobre los participantes, las intervenciones y los resultados. Deberían informarse los rangos de las características en todos los estudios analizados, por ej, la edad, la raza, el sexo, los datos socioeconómicos relevantes, el estado de enfermedad, la duración, la severidad, o cualquier otra enfermedad Sí

\section{7. ¿Se evaluó y documentó la calidad científica de los estudios}

incluidos? Deberían proveerse métodos "a priori" (por ej, para estudios de efectividad si el autor o los autores eligen incluir sólo estudios aleatorizados, de doble ciego, controlados con placebo, u ocultamiento de las asignaciones como criterios de inclusión). Para otros tipos de estudios, serán relevantes los ítems alternativos Sí

8. ¿Se utilizó de manera adecuada la calidad científica de los estudios incluidos al formular las conclusiones?

El rigor metodológico y la calidad científica de los estudios deberían considerarse en el análisis y las conclusiones de la revisión, y plantearse explícitamente al formular las recomendaciones Sí

9. ¿Fueron adecuados los métodos utilizados para combinar los hallazgos de los estudios?

Para los resultados conjuntos, debería hacerse una prueba para garantizar que los estudios pudieron combinarse y para evaluar sus homogeneidad (es decir, la prueba chi-cuadrado para la homogeneidad, ${ }^{2}$ ). Si existe heterogeneidad debería utilizarse un modelo de efectos aleatorios y/o debería considerarse lo adecuado de la combinación (es decir, ¿fue adecuado combinar los resultados?) Sí

10. ¿Se valoró la probabilidad de sesgo de publicación?

Una evaluación de sesgo de publicación debería incluir una combinación de ayudas gráficas (por ej. un gráfico en embudo - funnel plot - , otras pruebas disponibles) y/o pruebas estadísticas (por ej. prueba de regresión de Egger). Sí

11. ¿Se planteó el conflicto de intereses?

Deberían reconocerse claramente las fuentes posibles de apoyo tanto en la revisión sistemática como en los estudios incluidos. Sí 


\section{ECAs - Risk of bias - Cochrane}

Figure 2. 'Risk of bias' summary: review authors' judgements about each risk of bias item for each included study.

\begin{tabular}{|c|c|c|c|c|c|c|c|}
\hline & 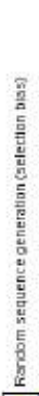 & 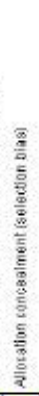 & 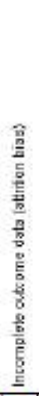 & 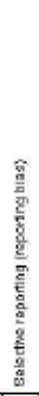 & 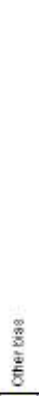 & 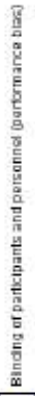 & 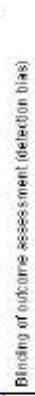 \\
\hline Ahrred 2008 & $?$ & 3 & 다 & ? & ? & $?$ & $?$ \\
\hline Nuspach 1980 & 당 & 당 & 하 & 라 & 당 & 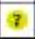 & - \\
\hline Beinate- $\theta$ arcia 2012 & (ㄷ) & (2) & 당 & () & $\theta$ & $?$ & 3 \\
\hline B00 2007 & 7 & ? & 당 & $\theta$ & e & a & 3 \\
\hline Bounte 1905 & 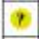 & (당 & 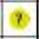 & 단 & $?$ & 9 & (c) \\
\hline Burken 2013 & C) & ? & 7 & e & ? & 2 & 3 \\
\hline $\cos 181508$ & ? & ? & () & 라 & (ㄷ) & 9 & 8 \\
\hline Do Carratho 1 res & 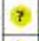 & 3 & • & ? & 3 & 3 & 3 \\
\hline Feller 1908 & $?$ & ? & () & ? & () & $?$ & $?$ \\
\hline Fentell 2001 a & (ㄷ) & (-) & - & (3) & (4) & 3 & 3 \\
\hline Fontell $200 \mathrm{~d}$ & () & ? & 다 & e & () & 3 & 8 \\
\hline Flahenrim 2012 & (ㄷ) & (8) & 다 & ? & 2 & 3 & 8 \\
\hline Francis 2008 & 다 & 3 & - & - & (4) & 2 & 3 \\
\hline Garas 1902 & 3 & 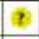 & $?$ & 앙 & $?$ & 2 & 3 \\
\hline Groh-Wango 1005 & 7 & () & 다 & e & 당 & ? & (c) \\
\hline Hewes 2008 & $?$ & $a$ & (당 & e & $\theta$ & 9 & 3 \\
\hline Hill I 1800 & 3 & (-) & () & ? & () & $?$ & • \\
\hline Hopkinson 2009 & (단 & (둔 & () & 라 & 0 & 8 & C \\
\hline Jares 2007 & $?$ & ? & ? & 3 & 단 & 3 & 3 \\
\hline Kein 2012 & (1) & 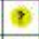 & 다 & ? & 라 & 9 & () \\
\hline Neer 2000 & $?$ & e & 3 & (당 & (9) & 3 & ? \\
\hline Meier 2012 & () & ? & 8 & ? & () & 3 & $a$ \\
\hline Mersmsm 1994 & (단 & a) & 다 & 라 & (ㄷ) & 당 & ? \\
\hline Parher 2012 & 두 & - & 7 & 3 & 2 & 2 & 3 \\
\hline Psul 1906 & 3 & 7 & $?$ & 앙 & ? & 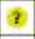 & $a$ \\
\hline Pessoto 2010 & 7 & - & 당 & 2 & 다 & 2 & C \\
\hline Ptony 1997 & - & 0 & 8 & e단 & $?$ & 9 & 9 \\
\hline Frime 2012 & (2) & ( & () & ㄹ & 7 & 3 & 9 \\
\hline Rosmusgen 2011 & 8 & 2 & (ㄷ) & 당 & (ㄷ) & 8 & ( \\
\hline Slusher 2007 & (ㄷ) & 3 & 당 & ? & (당 & 3 & 3 \\
\hline Et:4traysen 2010 & 3 & 7 & 8 & 3 & 3 & 2 & 3 \\
\hline Stute 1908 & (ㄷ) & 2 & 다 & 당 & (9) & 3 & (อ \\
\hline non 2012 & (ㄷ) & 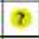 & 다 & - & 다 & 3 & 3 \\
\hline Zinamian 1992 & 2 & 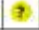 & 2 & 라 & 2 & 3 & 8 \\
\hline
\end{tabular}




\section{ANEXO III. Tabla de estudios para la pregunta}

\section{Tabla de ECAs}

\begin{tabular}{|c|c|c|c|c|c|c|}
\hline $\begin{array}{l}\text { Referencia } \\
\text { (Cita } \\
\text { Abreviada) }\end{array}$ & $\begin{array}{l}\text { Estudio (Diseño y } \\
\text { objetivo) }\end{array}$ & $\begin{array}{l}\text { Población } \\
\text { (no y } \\
\text { características) }\end{array}$ & $\begin{array}{l}\text { Descripción de las } \\
\text { intervenciones } \\
\text { comparaciones, } \\
\text { exposiciones o pruebas } \\
\text { a estudio }\end{array}$ & $\begin{array}{l}\text { Resultados } \\
\text { (Estimadores de resultados- } \\
\text { Magnitud del efecto) }\end{array}$ & $\begin{array}{l}\text { Conclusiones } \\
\text { (conclusiones) }\end{array}$ & $\begin{array}{l}\text { Comentarios } \\
\text { Calidad de la evidencia Financiación } \\
\text { comentarios) }\end{array}$ \\
\hline Garza 1982 & ECA cruzado & $\begin{array}{l}18 \text { Madres } \\
\text { asignadas al azar a } \\
\text { comparar el efecto } \\
\text { del método y } \\
\text { almacenamiento } \\
\text { de la leche } \\
\text { extraída sobre la } \\
\text { composición } \\
\text { nutritiva. }\end{array}$ & $\begin{array}{l}\text { Un experimento examina } \\
\text { el método de extraccióny } \\
\text { dos el almacenaje de la } \\
\text { leche. } \\
\text { El primero aborda la } \\
\text { extracción manual frente } \\
\text { a extracción con } \\
\text { sacaleches. }\end{array}$ & $\begin{array}{l}\text { Se miden la calidad nutricional y el } \\
\text { volumen de leche extraído. }\end{array}$ & - & $\begin{array}{l}\text { Poca información sobre el diseño } \\
\text { del estudio y de sus resultados. }\end{array}$ \\
\hline Francis 2008 & $\begin{array}{l}\text { ECA que compara } \\
3 \text { bombas } \\
\text { eléctricas } \\
\text { diferentes. }\end{array}$ & $\begin{array}{l}60 \text { madres } \\
\text { lactantes de niños } \\
\text { a término al tercer } \\
\text { día postparto }\end{array}$ & $\begin{array}{l}\text { Se asignan las madres a } \\
\text { uno de los tres grupos: } \\
\text { 1. Avent ISIS IQ Uno } \\
\text { 2. Medela Swing } \\
\text { 3. Whittlestone single } \\
\text { electric }\end{array}$ & $\begin{array}{l}60 \text { días de duración del estudio. } \\
\text { Tiempo de eyección de la leche } \\
\text { primera semana postparto } \\
\text { Tiempo medio para vaciar el pecho, } \\
\text { volumen de leche extraída en ml, } \\
\text { tiempo para extraerse la leche, flujo } \\
\text { de leche y crecimiento del niño }\end{array}$ & - & $\begin{array}{l}\text { Estudio publicado como poster en } \\
\text { una conferencia. } \\
\text { Datos enviados por el autor a los } \\
\text { revisores Cochrane. } \\
24 \text { de las } 60 \text { madres abandonan el } \\
\text { estudio (riesgo de datos } \\
\text { incompletos: attrition bias), reporte } \\
\text { selectivo (reporting bias) }\end{array}$ \\
\hline $\begin{array}{l}\text { Hopkinson } \\
2009\end{array}$ & $\begin{array}{l}\text { ECA cruzado a las } \\
5 \text { semanas } \\
\text { postparto } \\
\text { Objetivo: evaluar el } \\
\text { impacto de una } \\
\text { nueva bomba } \\
\text { sobre la extracción } \\
\text { de leche, el } \\
\text { contenido en } \\
\text { grasa, la respuesta } \\
\text { hormonal, la }\end{array}$ & $\begin{array}{l}69 \text { madres, } 34 \text { para } \\
\text { el protocolo } \\
\text { completo (con } \\
\text { análisis de sangre) } \\
\text { y } 35 \text { sin análisis de } \\
\text { sangre. }\end{array}$ & $\begin{array}{l}\text { Comparación entre } \\
\text { bomba eléctrica estándar } \\
\text { con una bomba eléctrica } \\
\text { nueva empezando a las } 3 \\
\text { semanas postparto con } \\
\text { madres de niños a } \\
\text { término y cruce a las } 2 \\
\text { semanas de uso. } \\
\text { Madres aleatorizadas a } \\
\text { uno de los dos bombas } \\
\text { para uso durante } 2 \\
\text { semanas, una vez por la }\end{array}$ & $\begin{array}{l}\text { La respuesta de prolactina mayor } \\
\text { con la bomba nueva }(p=0.005) \text {. } \\
\text { La extracción de leche eficiente } \\
\text { mejor }(p=0,001) \text { con la bomba } \\
\text { estándar. } \\
\text { Estimulación de producción de } \\
\text { leche durante } 24 \text { horas no difiere. } \\
\text { Las mujeres seleccionaron de } \\
\text { forma equiparable los dos extractor } \\
\text { de lechees. } \\
\text { El comportamiento alimentario a los } \\
6 \text { meses no se relaciona con el }\end{array}$ & $\begin{array}{l}\text { Ambas bombas tienen } \\
\text { efectos comparables } \\
\text { sobre la lactancia en el } \\
\text { tiempo. }\end{array}$ & $\begin{array}{l}\text { Según la revisión Cochrane, el } \\
\text { riesgo de sesgos es bajo. } \\
\text { Resultados obtenidos del abstract. }\end{array}$ \\
\hline
\end{tabular}




\begin{tabular}{|c|c|c|c|c|c|c|}
\hline $\begin{array}{l}\text { Referencia } \\
\text { (Cita } \\
\text { Abreviada) }\end{array}$ & $\begin{array}{l}\text { Estudio (Diseño y } \\
\text { objetivo) }\end{array}$ & $\begin{array}{l}\text { Población } \\
\text { (no } y \\
\text { características) }\end{array}$ & $\begin{array}{l}\text { Descripción de las } \\
\text { intervenciones } \\
\text { comparaciones, } \\
\text { exposiciones o pruebas } \\
\text { a estudio }\end{array}$ & $\begin{array}{l}\text { Resultados } \\
\text { (Estimadores de resultados- } \\
\text { Magnitud del efecto) }\end{array}$ & $\begin{array}{l}\text { Conclusiones } \\
\text { (conclusiones) }\end{array}$ & $\begin{array}{l}\text { Comentarios } \\
\text { Calidad de la evidencia Financiación } \\
\text { comentarios) }\end{array}$ \\
\hline & $\begin{array}{l}\text { satisfacción } \\
\text { materna, } \\
\text { producción de } \\
\text { leche a largo plazo } \\
\text { y duración de la } \\
\text { lactancia tras la } \\
\text { vuelta al trabajo. }\end{array}$ & & $\begin{array}{l}\text { mañana y otra vez más } \\
\text { tarde. Pump in style } \\
\text { (Medela) versus Embrace } \\
\text { (Playtex). } \\
\text { Tras el estudio se les } \\
\text { pregunta a las madres } \\
\text { con qué bomba se } \\
\text { quedarían. }\end{array}$ & extractor de leche utilizado. & & \\
\hline $\begin{array}{l}\text { Flaherman } \\
2012\end{array}$ & $\begin{array}{l}\text { Diseño } \\
\text { ECA } \\
\text { Objetivo } \\
\text { Comparar } \\
\text { extracción de } \\
\text { leche manual o } \\
\text { con bomba } \\
\text { bilateral eléctrica } \\
\text { en RN sanos a } \\
\text { término que se } \\
\text { alimentan de modo } \\
\text { inefectivo en las } \\
\text { 12-36h. posparto }\end{array}$ & $\begin{array}{l}\mathbf{N} \\
68 \\
\text { Características } \\
\text { RN sanos a } \\
\text { término que se } \\
\text { alimentan de modo } \\
\text { inefectivo }\end{array}$ & $\begin{array}{l}\text { Intervención } \\
\text { Extracción leche manual } \\
\text { Comparación } \\
\text { Extracción con } \\
\text { sacaleches bilateral } \\
\text { eléctrico }\end{array}$ & $\begin{array}{l}\text { LM } 2 \text { meses } \\
\text { 97\% vs. } 73 \% \text {; RR 1,32 (IC95\% 1,01 } \\
\text { a 1,73) } \\
\text { Transferencia de leche ( } \uparrow \text { peso } \\
\text { en gr. antes-después toma) } \\
\text { Media (SD): } 4,2 \pm 19,4 \text { vs. } 0,8 \pm 3,5 ; \\
\text { p=0,334 } \\
\text { Mediana: } 0 \text { (-4 a 14) vs. } 0 \text { (-8 a 98) } \\
\text { Volumen de leche (ml.) } \\
\text { Media (SD): } 0,8 \pm 1,4 \text { vs. } 2,9 \pm 7,7 ; \\
\text { p=0,136 } \\
\text { Mediana: } 0,5 \text { ( } 0 \text { a } 5 \text { ) vs. } 1 \text { ( } 0 \text { a } 40) \\
\text { Dolor } \\
5,7 \% \text { vs. } 6,1 \% \text {; ns } \\
\text { Formula @ } 1 \text { semana } \\
56,3 \% \text { vs. } 58,6 \% ; n s\end{array}$ & $\begin{array}{l}\text { Las mujeres asignadas } \\
\text { al grupo de extracción } \\
\text { manual en el posparto } \\
\text { inmediato tenían más } \\
\text { probabilidades continuar } \\
\text { con la LM durante dos } \\
\text { meses }\end{array}$ & $\begin{array}{l}\text { (+) Periodo inmediato posparto } \\
\text { (-) Muestra pequeña, datos finales } \\
\text { de } 48 \text { madres }(70,6 \%) \\
\text { Conflicto de interés } \\
\text { No tiene } \\
\text { Financiación } \\
\text { National Centre for research } \\
\text { resources \& national institute of } \\
\text { children health and human } \\
\text { development } \\
\text { Calidad } \\
\text { Baja }\end{array}$ \\
\hline
\end{tabular}




\section{Bibliografía}

(1) Becker GE, Smith HA, Cooney F. Methods of milk expression for lactating women. Cochrane Database Syst Rev 2015;2:CD006170.

(2) NICE. Postnatal care up to 8 weeks after birth. Julio 2006 (actualizado en Febrero de 2015). Disponible en: http://guidance.nice.org.uk/CG37.

(3) National Association of Neonatal Nurses 1999, early discharge of the term newborn. Glenview (IL): National Association of Neonatal Nurses.

(4) Perinatal Services BC. Health Promotion Guideline. Breastfeeding Healthy Term Infants. 2013 Feb.

(5) Morton J, Hall JY, Wong RJ, Thairu L, Benitz WE, Rhine WD. Combining hand techniques with electric pumping increases milk production in mothers of preterm infants. J Perinatol 2009 Nov;29(11):757-64.

(6) Auerbach KG. Sequential and simultaneous breast pumping: a comparison. Int J Nurs Stud 1990;27(3):257-65.

(7) Boutte CA, Garza C, Fraley JK, Stuff JE, Smith EO. Comparison of hand- and electric-operated breast pumps. Hum Nutr Appl Nutr 1985 Dec;39(6):426-30.

(8) Fewtrell M, Lucas P, Collier S, Lucas A. Randomized study comparing the efficacy of a novel manual breast pump with a mini-electric breast pump in mothers of term infants. J Hum Lact 2001 May;17(2):126-31.

(9) Flaherman VJ, Gay B, cott C, vins A, ee KA, ewman TB. Randomised trial comparing hand expression with breast pumping for mothers of term newborns feeding poorly. Archives of Disease in Childhood-Fetal and Neonatal Edition 2012;fetalneonatal209213.

(10) Francis J. Maternal/infant lactation characteristics (MILC) study: a comparison of single electric pumping devices. Journal of Human Lactation 2008;24(1):107.

(11) Garza C, Johnson CA, Harrist R, Nichols BL. Effects of methods of collection and storage on nutrients in human milk. Early Hum Dev 1982 Jul;6(3):295-303.

(12) Hayes DK, Prince CB, Espinueva V, Fuddy LJ, Li R, Grummer-Strawn LM. Comparison of manual and electric breast pumps among WIC women returning to work or school in Hawaii. Breastfeed Med 2008 Mar;3(1):3-10.

(13) Hopkinson J, Heird W. Maternal response to two electric breast pumps. Breastfeed Med 2009 Mar;4(1):17-23.

(14) Pittard WB, III, Geddes KM, Brown S, Mintz S, Hulsey TC. Bacterial contamination of human milk: container type and method of expression. Am J Perinatol 1991 Jan;8(1):25-7.

(15) Prime DK, Garbin CP, Hartmann PE, Kent JC. Simultaneous breast expression in breastfeeding women is more eficacious than sequential breast expression. Breastfeeding Medicine 2012;7(6):442-7.

(16) Rasmussen KM, Dieterich CM, Zelek ST, Altabet JD, Kjolhede CL. Interventions to increase the duration of breastfeeding in obese mothers: the Bassett Improving Breastfeeding Study. Breastfeed Med 2011 Apr;6(2):69-75.

(17) Zinaman MJ, Hughes V, Queenan JT, Labbok MH, Albertson B. Acute prolactin and oxytocin responses and milk yield to infant suckling and artificial methods of expression in lactating women. Pediatrics 1992 Mar;89(3):437-40.

(18) Stellwagen LM, Vaucher YE, Chan CS, Kim JH. Does hand expression improve human milk production in pump dependent mothers of VLBW infants? Pediatric Academic Societies' 2010 Annual Meeting;2010 May 1-4; Vancouver, Canada. 2010. 
(19) Feher SD, Berger LR, Johnson JD, Wilde JB. Increasing breast milk production for premature infants with a relaxation/imagery audiotape. Pediatrics 1989 Jan;83(1):57-60.

(20) Keith DR, Weaver BS, Vogel RL. The effect of music-based listening interventions on the volume, fat content, and caloric content of breast milkproduced by mothers of premature and critically ill infants. Adv Neonatal Care 2012 Apr;12(2):112-9.

(21) Stutte PC, Bowles BC, Morman GY. The effects of breast massage on volume and fat content of human milk. Genesis 1988;10(2):22-5.

(22) Yigit F, Cigdem Z, Temizsoy E, Cingi ME, Korel O, Yildirim E, et al. Does warming the breasts affect the amount of breastmilk production? Breastfeed Med 2012 Dec;7(6):487-8.

(23) Becker GE, Smith HA, Cooney F. Methods of milk expression for lactating women. Cochrane Database Syst Rev 2016 Sep 29;9:CD006170. 


\section{PREGUNTA CLÍNICA № 25}

¿Son eficaces los galactogogos para aumentar la producción de leche? ¿Cuál es el galactogogo más eficaz?

\section{1- Pregunta clínica en formato PICO}

Tabla 1- Componentes de la pregunta clínica en formato PICO

\begin{tabular}{|l|l|}
\hline Pacientes & $\begin{array}{l}\text { Madre sana (de niño sano a término) que amamanta, que ha } \\
\text { trabajado adecuadamente la técnica de lactancia y que } \\
\text { presenta hipogalactia }\end{array}$ \\
\hline $\begin{array}{l}\text { Intervención/ } \\
\text { Comparación }\end{array}$ & $\begin{array}{l}\text { Dogmatil, domperidona, metoclopramida, tratamiento } \\
\text { hormonal, galactogogos herbales, placebo }\end{array}$ \\
\hline Resultados & $\begin{array}{l}\text { Volumen de leche, pérdida ponderal del niño en los primeros } \\
\text { días, niveles de prolactina, efectos adversos galactogogos, } \\
\text { duración lactancia materna (exclusiva y no exclusiva), } \\
\text { lactancia materna exclusiva al mes, a los 4 meses, a los } 6 \\
\text { meses, problemas en las mamas (dolor, grietas etc) }\end{array}$ \\
\hline Tipo de estudio & $\begin{array}{l}\text { RS de ECA, ECA, RS de estudios observacionales o } \\
\text { estudios observacionales }\end{array}$ \\
\hline
\end{tabular}

\section{2- Introducción}




\section{ESTRATEGIA DE ELABORACIÓN DE LA PREGUNTA}

\subsection{GPC Base}

Tabla 2- Resumen de GPC Base

\begin{tabular}{|c|c|c|c|c|}
\hline $\begin{array}{l}\text { Guía } \\
\text { (Enfoque) }\end{array}$ & $\begin{array}{l}\text { Resumen sobre la evidencia } \\
\text { (Calidad de la evidencia) }\end{array}$ & $\begin{array}{l}\text { Recomendaciones } \\
\text { (Grado) }\end{array}$ & $\begin{array}{c}\text { Referencias } \\
\text { bibliográficas } \\
\text { (Tipo de } \\
\text { publicación) }\end{array}$ & Comentarios \\
\hline NICE & - & & & \\
\hline $\begin{array}{l}\text { Protocolo } \\
\text { ABM \#9 }\end{array}$ & $\begin{array}{l}\text { La versión anterior del protocolo utilizó la evidencia } \\
\text { existente que mostraba la efectividad en la } \\
\text { prescripción de los galactogogos y describía cuándo } \\
\text { y cómo usarlos (9). Los datos actuales sugieren que } \\
\text { debemos tener mayor precaución al recomendar } \\
\text { estos medicamentos para inducir o aumentar la tasa } \\
\text { de secreción láctea en mujeres en etapa de } \\
\text { lactancia, particularmente en mujeres sin factores de } \\
\text { riesgo específicos para un suministro insuficiente de } \\
\text { leche. } \\
\text { La teoría detrás de los galactogogos farmacéuticos } \\
\text { es que los antagonistas de la dopamina aumentan la } \\
\text { secreción de prolactina (14) y subsecuentemente } \\
\text { aumentan la tasa total de síntesis láctea. Sin } \\
\text { embargo, no existe evidencia sobre una correlación } \\
\text { directa entre los niveles séricos de prolactina y un } \\
\text { aumento en el volumen de leche en mujeres que } \\
\text { amamantan (10,12). } \\
\text { Potenciales Indicaciones para los Galactogogos } \\
\text { Los galactogogos se han usado comúnmente para } \\
\text { aumentar la decaída tasa de producción de leche, } \\
\text { frecuentemente debido a los efectos de enfermedad } \\
\text { y hospitalización materna o infantil o por separación } \\
\text { regular como el trabajo o la escuela. Un área muy } \\
\text { común donde se utilizan es en la unidad de }\end{array}$ & $\begin{array}{l}\text { Las siguientes recomendaciones, basadas en la evidencia } \\
\text { actual, aplican a mujeres que experimentan dificultades por una } \\
\text { baja tasa de producción de leche (ej. el bebé no está ganando } \\
\text { peso normalmente o se están usando suplementos por la baja } \\
\text { producción de leche, durante ya sea el inicio o el mantenimiento } \\
\text { del suministro lácteo). } \\
\text { 1. Evaluar y aumentar la frecuencia y rigurosidad de la remoción } \\
\text { de leche. Utilice medidas no farmacológicas para incrementar la } \\
\text { tasa total de síntesis de leche materna. } \\
\text { a. En mujeres con lactantes sanos a término: Mejore las } \\
\text { prácticas de Lactancia Materna (Nivel de Evidencia I). } \\
\text { i. Recomiende el contacto piel con piel entre la } \\
\text { madre y el bebe para facilitar las alimentaciones } \\
\text { frecuentes y estimular la liberación de oxitocina (el } \\
\text { reflejo de eyección de leche (REL) (MER en } \\
\text { inglés)(34). } \\
\text { ii. Aliente a la madre a realizarse un auto-masaje } \\
\text { mamario para mejorar la liberación de oxitocina } \\
\text { (REL) y la remoción de leche. } \\
\text { iii. Revise o enseñe técnicas de relajación para } \\
\text { facilitar la liberación de oxitocina (REL) y mejorar la } \\
\text { remoción de leche. } \\
\text { iv. Ayude a la diada madre-hijo a llevar a cabo un } \\
\text { agarre óptimo (10,24-25). } \\
\text { v. Resuelva el dolor de pezón, si aplica, usando las } \\
\text { siguientes estrategias: } \\
\text { 1) Agarre óptimo }\end{array}$ & $\begin{array}{l}\text { 9. Academy of } \\
\text { Breastfeeding } \\
\text { Medicine. } 2004 . \\
\text { 10. Anderson } \\
\text { PO et al, } 2007 \\
\text { 11. Campbell- } \\
\text { Yeo ML et al, } \\
\text { 2010; } \\
\text { 12. Lawrence } \\
\text { RA, 2005 (guía) } \\
\text { 14. Murray L et } \\
\text { al, 2009 } \\
\text { 15. Da Silva OP, } \\
\text { et al, 2001; } \\
\text { 16. Ehrenkrantz } \\
\text { RA et al, 1986 } \\
\text { 17. Guzman V } \\
\text { et al, } 1979 \text {; } \\
\text { 18. Kauppila A, } \\
\text { et al,1985. } \\
\text { 19. Liu JH et al, } \\
\text { 1990. } \\
\text { 20. Toppare MF, } \\
\text { et al,1994. } \\
\text { 22. Hansen WF, } \\
\text { et al, 2005. } \\
\text { 23. Lewis PJ et }\end{array}$ & $\begin{array}{l}\text { Recomendaciones } \\
\text { para las } \\
\text { Siguientes } \\
\text { Investigaciones } \\
\text { Los estudios que } \\
\text { existen sobre esta } \\
\text { materia no pueden } \\
\text { ser considerados } \\
\text { concluyentes y } \\
\text { muchas de las } \\
\text { recomendaciones } \\
\text { están basadas } \\
\text { principalmente en } \\
\text { opiniones de } \\
\text { expertos, estudios } \\
\text { pequeños y } \\
\text { estudios en los que } \\
\text { el apoyo no- } \\
\text { farmacológico para } \\
\text { la lactancia fue sub- } \\
\text { óptimo. La mayoría } \\
\text { de los estudios se } \\
\text { han hecho en } \\
\text { madres de infantes } \\
\text { pre-termino que } \\
\text { utilizan sacaleches }\end{array}$ \\
\hline
\end{tabular}




\begin{tabular}{|c|c|c|c|c|}
\hline $\begin{array}{l}\text { Guía } \\
\text { (Enfoque) }\end{array}$ & $\begin{array}{l}\text { Resumen sobre la evidencia } \\
\text { (Calidad de la evidencia) }\end{array}$ & $\begin{array}{l}\text { Recomendaciones } \\
\text { (Grado) }\end{array}$ & $\begin{array}{c}\text { Referencias } \\
\text { bibliográficas } \\
\text { (Tipo de } \\
\text { publicación) } \\
\end{array}$ & Comentarios \\
\hline & $\begin{array}{l}\text { cuidados intensivos neonatales, donde el objetivo ha } \\
\text { sido estimular el inicio de la activación secretora o } \\
\text { aumentar la disminuida secreción de leche en estas } \\
\text { madres. Las madres que no están amamantando } \\
\text { pero están extrayéndose leche manualmente o por } \\
\text { medio de bomba sacaleche, frecuentemente } \\
\text { experimentan una disminución en la producción de } \\
\text { leche después de varias semanas. Los } \\
\text { galactogogos también se han usado en casos de } \\
\text { mamás que amamantan a hijos adoptivos (inducción } \\
\text { de lactancia en mujeres que no han estado } \\
\text { embarazadas del hijo actual) y en re-lactancia } \\
\text { (restablecimiento de la secreción láctea después del } \\
\text { destete). } \\
\text { Muchos especialistas médicos en lactancia materna } \\
\text { y asesores de lactancia han recomendado estos } \\
\text { medicamentos y hierbas, generalmente como la } \\
\text { última opción cuando otras medidas no } \\
\text { farmacológicas no han resultado en un aumento en } \\
\text { el volumen de leche. Sin embargo, algunos } \\
\text { proveedores podrían hacer recomendaciones } \\
\text { inapropiadas de galactogogos antes de enfatizar las } \\
\text { principales maneras de aumentar la tasa total de } \\
\text { síntesis láctea (por ej. alimentaciones frecuentes y } \\
\text { remoción completa de leche a intervalos regulares) } \\
\text { o evaluar otros factores médicos que potencialmente } \\
\text { podrían estar involucrados. } \\
\text { Galactogogos farmacéuticos } \\
\text { Los galactogogos farmacéuticos disponibles son } \\
\text { todos antagonistas de la dopamina e incrementan } \\
\text { los niveles de prolactina a través de este mecanismo } \\
\text { (12). Algunos estudios antiguos han documentado } \\
\text { un aumento en los niveles basales de prolactina en } \\
\text { mujeres que amamantan con metoclopramida o }\end{array}$ & $\begin{array}{l}\text { 2) Diagnóstico y manejo de otras causas de } \\
\text { dolor } \\
\text { 3) Refiera a un especialista en lactancia si es } \\
\text { necesario } \\
\text { vi. Enfatice una frecuencia y duración de la } \\
\text { lactancia sin restricciones (si el lactante ha } \\
\text { mostrado que puede transferir leche de una manera } \\
\text { efectiva) (24,25). } \\
\text { vii. Aconseje a la madre a reducir o terminar con el } \\
\text { uso innecesario de suplementos (35) y provea de } \\
\text { estrategias para hacerlo. } \\
\text { 1) Disminución gradual de la cantidad de } \\
\text { suplemento } \\
\text { 2) Uso de un "sistema para suplementar" } \\
\text { (sonda en un pecho conectada a una fuente } \\
\text { suplementaria de leche) si es apropiado. } \\
\text { b. En mujeres con bebés que no pueden extraer la leche } \\
\text { de manera efectiva o no son capaces de alimentarse del } \\
\text { seno materno (ej. prematuro, hospitalizado, hipotónico) } \\
\text { i. Recomendar y enseñar la extracción manual } \\
\text { suave de calostro: el volumen extraído de calostro } \\
\text { es mayor por extracción manual que el volumen } \\
\text { extraído por bombas sacaleches con ciclos } \\
\text { automáticos, de tamaño estándar (36); están } \\
\text { disponibles videos e ilustraciones fotográficas sobre } \\
\text { extracción manual en } \\
\text { http://newborns.stanford.edu/Breastfeeding/HandEx } \\
\text { pression.html (37) y en } \\
\text { http://www.breastfeeding.com/helpme/helpme_vide } \\
\text { o_hand_expression.html. (38). } \\
\text { ii. Si está disponible, recomendar extracción de } \\
\text { leche con una bomba sacaleches con ciclos } \\
\text { automáticos, de tamaño estándar, capaz de drenar } \\
\text { ambos senos al mismo tiempo (“grado hospitalario", } \\
\text { es decir, con la características adecuadas para ser } \\
\text { usada en el hospital) (Nivel de Evidencia Il-2) (39). }\end{array}$ & $\begin{array}{l}\text { al, } 1980 . \\
\text { 24. Sakha K et } \\
\text { al, } 2008 . \\
\text { 25. Seema, } \\
\text { Patwari AK et al, } \\
\text { 1997. } \\
\text { 28. Kim-Godwin } \\
\text { YS, 2003 } \\
\text { 29. Koletzko B, } \\
\text { 2000 } \\
\text { 30. Mennella } \\
\text { JA, } 1993 \\
\text { 31. Di Pierro F, } \\
\text { 2008 } \\
\text { 32. Swafford S, } \\
\text { 2000 } \\
\text { 33. Tiran D, } \\
\text { 2003 } \\
\text { 34. Uvna"s, } \\
\text { 2003. } \\
\text { 35. Academy of } \\
\text { Breastfeeding } \\
\text { Medicine 2009. } \\
\text { Breastfeed Med } \\
\text { 2009 } \\
\text { 36. Ohyama M, } \\
\text { 2010 } \\
\text { 37. Morton J. } \\
\text { 2010. } \\
\text { 38. } \\
\text { Breastfeeding.C } \\
\text { om, } 2010 . \\
\text { 39. Green D, } \\
\text { 1982 } \\
\text { 40. Jones E, } \\
\text { 2001 } \\
\end{array}$ & $\begin{array}{l}\text { mecánicos en lugar } \\
\text { de madres con } \\
\text { infantes a término } \\
\text { cuyos problemas } \\
\text { generalmente } \\
\text { aparecen en los } \\
\text { primeros días o } \\
\text { semanas postparto. } \\
\text { Claramente se } \\
\text { necesitan estudios } \\
\text { bien diseñados, con } \\
\text { poder adecuado, } \\
\text { aleatorios, } \\
\text { controlados, que } \\
\text { utilicen dosis } \\
\text { adecuadas de } \\
\text { galactogogos en } \\
\text { poblaciones de } \\
\text { mujeres en las que } \\
\text { tanto el grupo } \\
\text { experimental como } \\
\text { el control, reciban } \\
\text { apoyo apropiado y } \\
\text { moderno en } \\
\text { lactancia. Se } \\
\text { necesita realizar } \\
\text { estos estudios en } \\
\text { madres de infantes } \\
\text { a término y pre- } \\
\text { término y se } \\
\text { necesitan medir } \\
\text { indicadores } \\
\text { clínicamente } \\
\text { relevantes como la } \\
\text { ganancia de peso } \\
\text { del infante, la }\end{array}$ \\
\hline
\end{tabular}




\begin{tabular}{|c|c|c|c|c|}
\hline $\begin{array}{c}\text { Guía } \\
\text { (Enfoque) }\end{array}$ & $\begin{array}{l}\text { Resumen sobre la evidencia } \\
\text { (Calidad de la evidencia) }\end{array}$ & $\begin{array}{l}\text { Recomendaciones } \\
\text { (Grado) }\end{array}$ & $\begin{array}{l}\text { Referencias } \\
\text { bibliográficas } \\
\text { (Tipo de } \\
\text { publicación) }\end{array}$ & Comentarios \\
\hline & $\begin{array}{l}\text { domperidona (15-20). Sin embargo, solamente hay } \\
\text { pocos estudios aleatorios, ciegos, controlados por } \\
\text { placebo, de estos agentes y estos estudios son } \\
\text { pequeños. } \\
\text { Domperidona } \\
\text { Hay } 2 \text { estudios aleatorios bien diseñados, ciegos, } \\
\text { controlados por placebo de domperidona. Uno de } \\
\text { los estudios, publicado en } 2010 \text { ( } \mathrm{n}=46 \text { ), muestra que } \\
\text { domperidona está asociada a un aumento } \\
\text { significativo en el volumen de leche extraída en } \\
\text { mujeres con lactantes prematuros menores de } 31 \\
\text { semanas de gestación; el estudio concluyo a los } 14 \\
\text { días, así que no se pudieron evaluar efectos a largo } \\
\text { plazo (11). Un estudio muy pequeño (n=6) sugiere } \\
\text { que hay mujeres que individualmente pueden } \\
\text { "responder" o "no-responder" y que las primíparas } \\
\text { pueden responder a domperidona con niveles más } \\
\text { altos de prolactina que las multíparas. } \\
\text { Metoclopramida } \\
\text { En el caso de metoclopramida, solamente se han } \\
\text { publicado cuatro estudios aleatorios, ciegos, } \\
\text { controlados por placebo y cada uno tiene algún } \\
\text { problema en el diseño, una muestra pequeña y/o la } \\
\text { selección de los pacientes (22-25). En un estudio } \\
\text { controlado aleatorio versus placebo del } 2008 \\
\text { realizado en } 20 \text { madres en proceso de re-lactancia, } \\
\text { la metoclopramida no produjo un efecto } \\
\text { estadísticamente significativo en la ganancia de } \\
\text { peso: } 10 \text { madres recibieron metoclopramida y } 10 \\
\text { placebo; todas recibieron un curso de consejería } \\
\text { estandarizada sobre técnicas óptimas de lactancia } \\
\text { materna ( } 24 \text { ). Estos resultados replicaron un estudio }\end{array}$ & $\begin{array}{l}\text { iii. Recomendar "manos durante la extracción con } \\
\text { sacaleche" (una combinación de extracción manual } \\
\text { con extracción doble); esta técnica fue superior a } \\
\text { solamente extracción doble en un estudio aleatorio, } \\
\text { controlado (40) y en un estudio observacional (41) } \\
\text { (Nivel de Evidencia I y II-3). } \\
\text { iv. Recomendar que las mujeres ajusten el } \\
\text { sacaleche eléctrico a un vacio máximo confortable, } \\
\text { el cual aumenta la tasa de flujo y la producción de } \\
\text { leche y minimiza la aparición de daño tisular (Nivel } \\
\text { de Evidencia II-1) (42). } \\
\text { v. Recomendar la extracción manual si no está } \\
\text { disponible un sacaleche con "grado hospitalario" o } \\
\text { si la mujer prefiere la técnica manual; la extracción } \\
\text { manual requiere de instrucción y de un periodo de } \\
\text { práctica hasta que la madre se vuelva competente. } \\
\text { vi. La extracción con sacaleche con pedal no } \\
\text { requiere de electricidad y puede ser otra alternativa } \\
\text { disponible. } \\
\text { 2. Evaluar a la madre en búsqueda de causas "médicas" de } \\
\text { hipogalactia: embarazo, medicamentos, insuficiencia glandular } \\
\text { primaria de la mama, cirugía de mama, síndrome de ovario } \\
\text { poliquístico, hipotiroidismo, retención de placenta, quiste de teca } \\
\text { luteínica, pérdida de secreción de prolactina posterior a } \\
\text { hemorragia postparto, tabaquismo intenso o ingesta de alcohol } \\
\text { u otras condiciones pertinentes. Trate la condición como se } \\
\text { indica, si el tratamiento está disponible (12) (Nivel de Evidencia } \\
\text { II-2, II-3 y III). } \\
\text { 3. Debido a que el estado actual de la investigación de todos los } \\
\text { galactogogos es relativamente poco concluyente y todos los } \\
\text { agentes tienen potenciales efectos adversos, la ABM no puede } \\
\text { recomendar ningún galactogogo farmacológico o herbal } \\
\text { especifico en este momento. }\end{array}$ & $\begin{array}{l}\text { 41. Morton J, } \\
2009 \\
\text { 42. Kent JC, } \\
2008 .\end{array}$ & $\begin{array}{l}\text { necesidad de } \\
\text { alimentación } \\
\text { artificial (otros } \\
\text { suplementos } \\
\text { diferentes a la leche } \\
\text { de la propia madre), } \\
\text { cuantificación de la } \\
\text { síntesis materna de } \\
\text { leche y efectos } \\
\text { adversos de los } \\
\text { fármacos. }\end{array}$ \\
\hline
\end{tabular}




\begin{tabular}{|c|c|c|c|c|}
\hline $\begin{array}{l}\text { Guía } \\
\text { (Enfoque) }\end{array}$ & $\begin{array}{l}\text { Resumen sobre la evidencia } \\
\text { (Calidad de la evidencia) }\end{array}$ & $\begin{array}{l}\text { Recomendaciones } \\
\text { (Grado) }\end{array}$ & $\begin{array}{c}\text { Referencias } \\
\text { bibliográficas } \\
\text { (Tipo de } \\
\text { publicación) }\end{array}$ & Comentarios \\
\hline & $\begin{array}{l}\text { anterior con un total de } 50 \text { madres (25). Todos los } \\
\text { cuatro estudios con mayor calidad (22-25) no } \\
\text { encontraron diferencias en los volúmenes de leche } \\
\text { y/o duración de la lactancia materna entre } \\
\text { metoclopramida y placebo. Dos encontraron que la } \\
\text { consejería o instrucciones para una lactancia óptima } \\
\text { tuvieron una asociación positiva con un incremento } \\
\text { estadísticamente significativo de peso en el lactante } \\
\text { (y correspondiente disminución en el uso de } \\
\text { alimentación suplementaria) (24,25). } \\
\text { Los otros dos no evaluaron ni dieron asistencia con } \\
\text { rutinas óptimas de lactancia materna (22,23). } \\
\\
\text { Hierbas, alimentos y bebidas como } \\
\text { galactogogos } \\
\text { En culturas no-occidentales, las parturientas son } \\
\text { asistidas de diferentes maneras con la intención de } \\
\text { facilitar su transición a la maternidad y de optimizar } \\
\text { la lactancia materna. Muchas culturas mantienen a } \\
\text { las madres en un ambiente muy cálido e insisten en } \\
\text { un periodo de reposo de aproximadamente } 1 \text { mes. } \\
\text { Muchas también tienen alimentos tradicionales y } \\
\text { hierbas para las parturientas que sirven para } \\
\text { aumentar las fuerzas de la madre y mejorar la } \\
\text { lactancia (28). Muchos de estos remedios de hierbas } \\
\text { se han usado a través de la historia para mejorar el } \\
\text { suministro de leche. Algunas hierbas mencionadas } \\
\text { como galactogogos incluyen fenogreco (alholva), } \\
\text { galega o ruda cabruna, cardo mariano o lechero } \\
\text { (Silybum marianum), avenas, diente de león, mijo, } \\
\text { algas marinas, anís, albahaca, cardo bendito, } \\
\text { semillas de hinojo, malvavisco y muchos otros. } \\
\text { Aunque la cerveza se usa en algunas culturas, el } \\
\text { alcohol realmente puede reducir la producción de } \\
\text { leche. Un componente de la cebada (aun en la }\end{array}$ & $\begin{array}{l}\text { 4. El proveedor de salud que pone en la balanza los potenciales } \\
\text { riesgos versus los beneficios de estos agentes y decide } \\
\text { prescribir un galactogogo, deberá apegarse a las guías que se } \\
\text { mencionan más adelante (Nivel de Evidencia III) (Vea el } \\
\text { Apéndice sobre los detalles para prescribir galactogogos } \\
\text { específicos). } \\
\text { 5. Informar a las mujeres sobre los datos disponibles acerca de } \\
\text { la eficacia, horario de uso y duración de la terapia con } \\
\text { galactogogos (Nivel de Evidencia I) (10). (Se presenta } \\
\text { información específica en el Apéndice). } \\
\text { 6. Informar a las mujeres sobre los datos disponibles referentes } \\
\text { a los potenciales efectos adversos de los galactogogos. (vea } \\
\text { Apéndice sobre los detalles de galactogogos específicos): } \\
\text { a. Investigar si la madre tiene alergias al medicamento, } \\
\text { contraindicaciones al medicamento o interacciones } \\
\text { farmacológicas con el medicamento elegido o con otra } \\
\text { sustancia. } \\
\text { b. Provea de cuidados continuos, supervisión de cuidados } \\
\text { continuos o transferencia de cuidados tanto a la madre } \\
\text { como el infante para asegurarse de un seguimiento y } \\
\text { atención de cualquier efecto secundario. } \\
\text { c. Prescribir galactogogos a la mínima dosis posible por el } \\
\text { periodo de tiempo más corto; no exceder de la dosis } \\
\text { terapéutica recomendada. } \\
\text { d. Considerar descontinuar gradualmente el fármaco (retiro } \\
\text { gradual) al final del tratamiento; algunos estudios } \\
\text { suspenden el fármaco al concluir el tratamiento y otros lo } \\
\text { descontinúan gradualmente, sin una ventaja evidente en } \\
\text { ninguno de los métodos. } \\
\text { e. Si la producción de leche decae al suspender el fármaco } \\
\text { y mejora otra vez al reanudarlo, intente disminuir } \\
\text { gradualmente a la mínima dosis efectiva y luego } \\
\text { descontinúe el fármaco posteriormente. } \\
\text { f. Considerar obtener documentación por escrito de }\end{array}$ & & \\
\hline
\end{tabular}




\begin{tabular}{|c|c|c|c|c|}
\hline $\begin{array}{l}\text { Guía } \\
\text { (Enfoque) }\end{array}$ & $\begin{array}{l}\text { Resumen sobre la evidencia } \\
\text { (Calidad de la evidencia) }\end{array}$ & $\begin{array}{l}\text { Recomendaciones } \\
\text { (Grado) }\end{array}$ & $\begin{array}{c}\text { Referencias } \\
\text { bibliográficas } \\
\text { (Tipo de } \\
\text { publicación) }\end{array}$ & Comentarios \\
\hline & $\begin{array}{l}\text { cerveza sin alcohol) puede incrementar la secreción } \\
\text { de prolactina, pero no hay "estudios sistemáticos" y } \\
\text { "no hay datos duros para un efecto causal" (29,30). } \\
\text { Se desconocen los mecanismos de acción de la } \\
\text { mayoría de hierbas. La mayoría no han sido } \\
\text { evaluadas científicamente, pero su uso tradicional } \\
\text { sugiere su seguridad y posible eficacia. Los estudios } \\
\text { disponibles de hierbas, medicinas basadas en } \\
\text { hierbas o galactogogos herbales sufren de las } \\
\text { mismas deficiencias de los estudios de agentes } \\
\text { farmacológicos: pequeño número de sujetos, falta } \\
\text { de información sobre asesoría de lactancia, falta de } \\
\text { aleatorización, controles o enmascaramiento (ciego) } \\
\text { [Nivel de Evidencia Il-1, (31), II-3 (32)]." El efecto } \\
\text { placebo puede ser la razón de las impresiones } \\
\text { positivas generalizadas (experiencia anecdótica) del } \\
\text { fenogreco en el aumento de los volúmenes de leche } \\
\text { [Nivel de Evidencia III, comunicación personal con } \\
\text { K.A. Marinelli (2010), N. Wight (2010), C. Smillie } \\
\text { (2009) y N.G. Powers (2010)]. Los datos mínimos } \\
\text { específicos sobre estas hierbas se presentan en el } \\
\text { Apéndice. } \\
\text { Es importante tomar nota de que se requiere } \\
\text { precaución en el uso de preparaciones herbales } \\
\text { debido a la falta de estandarización en la } \\
\text { preparación de las dosis (diferente al entorno de } \\
\text { investigación) posibles contaminantes, potenciales } \\
\text { alergias e interacciones farmacológicas. Varias } \\
\text { hierbas que se toman vía oral aumentan los niveles } \\
\text { sanguíneos de warfarina, heparina y otros } \\
\text { anticoagulantes en los pacientes. Hay varios } \\
\text { reportes de reacciones alérgicas severas al } \\
\text { fenogreco (33). } \\
\text { * Los Niveles de Evidencia están basados en } \\
\text { "Calidad de la Evidencia" del Grupo de Trabajo para } \\
\text { Servicios de Prevención de los Estados Unidos }\end{array}$ & consentimiento informado al usar algún galactogogo. & & \\
\hline
\end{tabular}


GPC Lactancia Materna- Pregunta 25. Galactogogos.

\begin{tabular}{|l|l|l|c|}
\hline $\begin{array}{c}\text { Guía } \\
\text { (Enfoque) }\end{array}$ & \multicolumn{1}{|c|}{$\begin{array}{c}\text { Resumen sobre la evidencia } \\
\text { (Calidad de la evidencia) }\end{array}$} & $\begin{array}{c}\text { Referencias } \\
\text { bibliográficas } \\
\text { (Tipo de } \\
\text { publicación) }\end{array}$ & $\begin{array}{c}\text { Comentaciones } \\
\text { (Grado) }\end{array}$ \\
\hline & $\begin{array}{l}\text { (www.ncbi.nlm.nih.gov/books/NBK15430, último } \\
\text { acceso el 20 de diciembre del 2010). }\end{array}$ & \\
\hline $\begin{array}{l}\text { Perinatal } \\
\text { Services } \\
\text { BC, 2012 }\end{array}$ & $\begin{array}{l}\text { Domperidone may enhance maternal breastmilk } \\
\text { supply but is controversial and is not addressed in } \\
\text { this guideline. }\end{array}$ & & \\
\hline
\end{tabular}




\subsection{Revisiones sistemáticas}

Tabla 3- Resumen de RS actuales

\begin{tabular}{|c|c|c|c|c|c|c|}
\hline $\begin{array}{l}\text { Referencia } \\
\text { (Cita } \\
\text { Abreviada) }\end{array}$ & $\begin{array}{l}\text { Estudio } \\
\text { (Diseño y } \\
\text { objetivo) }\end{array}$ & $\begin{array}{l}\text { Población } \\
\text { (no y características) }\end{array}$ & $\begin{array}{l}\text { Descripción de las } \\
\text { intervenciones } \\
\text { comparaciones, } \\
\text { exposiciones o pruebas a } \\
\text { estudio }\end{array}$ & $\begin{array}{l}\text { Resultados } \\
\text { (Estimadores de resultados- } \\
\text { Magnitud del efecto) }\end{array}$ & $\begin{array}{l}\text { Conclusiones } \\
\text { (conclusiones) }\end{array}$ & $\begin{array}{l}\text { Comentarios } \\
\text { Calidad de la } \\
\text { evidencia } \\
\text { Financiación } \\
\text { comentarios) }\end{array}$ \\
\hline $\begin{array}{l}\text { Paul C, } \\
2015\end{array}$ & $\begin{array}{l}\text { Diseño } \\
\text { Revisión } \\
\text { sistemática } \\
\text { Objetivo } \\
\text { Evaluar la } \\
\text { relación } \\
\text { riesgo- } \\
\text { beneficio del } \\
\text { uso de } \\
\text { domperidona } \\
\text { como } \\
\text { estimulante de } \\
\text { la producción } \\
\text { de leche. }\end{array}$ & $\begin{array}{l}9 \text { estudios, entre ellos: } \\
\text { - } 2 \text { revisiones } \\
\text { sistemáticas (RS) } \\
\text { con metanálisis } \\
\text { (Donovan } 2012 \text { y } \\
\text { Osadchy 2012) } \\
\text { cuyas características } \\
\text { se detallan en las } \\
\text { tablas } \\
\text { correspondientes. } \\
\text { - } 4 \text { ensayos clínicos } \\
\text { controlados doble } \\
\text { ciego que evaluaron } \\
\text { eficacia y seguridad. } \\
\text { Incluyeron } 124 \\
\text { madres de hijos a } \\
\text { término, pre-término, } \\
\text { post parto vaginal o } \\
\text { post cesárea. } \\
\text { - } 3 \text { ensayos clínicos } \\
\text { sin grupo control que } \\
\text { incluyeron } 53 \text { hijos } \\
\text { expuestos a } \\
\text { domperidona y cuyos } \\
\text { resultados fueron } \\
\text { utilizados para } \\
\text { evaluar la seguridad. }\end{array}$ & $\begin{array}{l}\text { Intervención: domperidona } 30 \\
\text { ó } 40 \text { mg al día durante } 4 \text { a } 14 \\
\text { días ( } n=60) \text {. } \\
\text { Comparación: placebo ( } \mathrm{n}= \\
64) \text {. } \\
\text { Pruebas de estudio: no se } \\
\text { realizó metanálisis. Los } \\
\text { resultados se presentan de } \\
\text { forma descriptiva. Los } \\
\text { resultados de eficacia: } \\
\text { volumen de leche y niveles de } \\
\text { prolactina, se proporcionan a } \\
\text { diferentes puntos de corte } \\
\text { (4,7,10,14 días).Los } \\
\text { resultados de seguridad se } \\
\text { presentan de forma separada } \\
\text { para la madre y el hijo. }\end{array}$ & $\begin{array}{l}\text { Resultados de eficacia: } \\
\text { Los } 4 \text { ensayos clínicos controlados } \\
\text { demostraron de forma consistente } \\
\text { un aumento en la producción de } \\
\text { lechede las madres tratadas con } \\
\text { domperidona. Este beneficio se } \\
\text { observó en todos los puntos de } \\
\text { corte }(4,7,10,14 \text { días) y de forma } \\
\text { similar en madres de hijos a } \\
\text { término, pre-término, post parto } \\
\text { vaginal o post cesárea. } \\
\text { Los } 3 \text { ensayos clínicos controlados } \\
\text { que evaluaron los niveles de } \\
\text { prolactina reportaronun incremento } \\
\text { significativo en las madres tratadas } \\
\text { con domperidona. Este incremento } \\
\text { fue de } 300 \% \text { a } 800 \% \text { en los niveles } \\
\text { de prolactina después del } \\
\text { tratamiento con respecto a los } \\
\text { niveles basales. } \\
\text { Resultados de seguridad: } \\
\text { Un ensayo clínico controlado } \\
\text { reportó que el } 32 \% \text { de madres } \\
\text { presentaron boca seca. No se } \\
\text { reportaron otros efectos adversos } \\
\text { tanto en la madre como en los } \\
\text { lactantes. }\end{array}$ & $\begin{array}{l}\text { A pesar de la falta de } \\
\text { metanálisis, los } \\
\text { estudios son } \\
\text { consistentes en } \\
\text { demostrar un } \\
\text { incremento en la } \\
\text { producción de leche y } \\
\text { en los niveles de } \\
\text { prolactina de las } \\
\text { madres tratadas con } \\
\text { domperidona. } \\
\text { Además, los estudios } \\
\text { no reportaron efectos } \\
\text { adversos importantes } \\
\text { tanto en las madres } \\
\text { como en los niños. }\end{array}$ & $\begin{array}{l}\text { Los ensayos } \\
\text { clínicos incluidos } \\
\text { en la revisión son } \\
\text { pequeños y no } \\
\text { evaluaron los } \\
\text { desenlaces a } \\
\text { largo plazo. } \\
\text { Además, aunque } \\
\text { los estudios no } \\
\text { reportaron efectos } \\
\text { adversos, se } \\
\text { conoce que el } \\
\text { tratamiento con } \\
\text { domperidona a } \\
\text { largo plazo puede } \\
\text { tener efectos } \\
\text { adversos } \\
\text { cardiovasculares. }\end{array}$ \\
\hline
\end{tabular}


GPC Lactancia Materna- Pregunta 25. Galactogogos.

\begin{tabular}{|c|c|c|c|c|c|c|}
\hline $\begin{array}{l}\text { Referencia } \\
\text { (Cita } \\
\text { Abreviada) }\end{array}$ & $\begin{array}{l}\text { Estudio } \\
\text { (Diseño } \\
\text { objetivo) }\end{array}$ & $\begin{array}{l}\text { Población } \\
\text { (no y características) }\end{array}$ & $\begin{array}{l}\text { Descripción de las } \\
\text { intervenciones } \\
\text { comparaciones, exposiciones } \\
\text { o pruebas a estudio }\end{array}$ & $\begin{array}{l}\text { Resultados } \\
\text { (Estimadores de resultados- } \\
\text { Magnitud del efecto) }\end{array}$ & $\begin{array}{l}\text { Conclusiones } \\
\text { (conclusiones) }\end{array}$ & $\begin{array}{l}\text { Comentarios } \\
\text { Calidad de la } \\
\text { evidencia } \\
\text { Financiación } \\
\text { comentarios) }\end{array}$ \\
\hline $\begin{array}{l}\text { Donovan TJ, } \\
2012\end{array}$ & $\begin{array}{l}\text { Diseño } \\
\text { Revisión } \\
\text { sistemática } \\
\text { con } \\
\text { metanálisis } \\
\text { Objetivo } \\
\text { Evaluar el } \\
\text { efecto de } \\
\text { cualquier } \\
\text { medicación } \\
\text { administrada } \\
\text { durante } 7 \text { o } \\
\text { más días } \\
\text { sobre el } \\
\text { volumen de } \\
\text { leche y la } \\
\text { duración de la } \\
\text { lactancia en } \\
\text { madres de } \\
\text { hijos pre- } \\
\text { término que } \\
\text { presentan } \\
\text { producción } \\
\text { insuficiente de } \\
\text { leche. }\end{array}$ & $\begin{array}{l}\text { Dos ensayos clínicos } \\
\text { controlados doble } \\
\text { ciego que incluyeron } \\
59 \text { parejas madre- } \\
\text { hijo. Los hijos pre- } \\
\text { término (<31 } \\
\text { semanas) fueron } \\
\text { incluidos en el } \\
\text { estudio desde el } \\
\text { nacimiento hasta el } \\
\text { alta hospitalaria. Las } \\
\text { madres incluidas } \\
\text { presentaron una } \\
\text { producción baja de } \\
\text { leche a pesar de los } \\
\text { consejos de lactancia } \\
\text { o una falla en la } \\
\text { lactancia durante más } \\
\text { de dos semanas } \\
\text { post-parto. }\end{array}$ & $\begin{array}{l}\text { Intervención: domperidona } 30 \\
\text { mg al día durante } 7 \text { a } 14 \text { días } \\
(\mathrm{n}=27) \text {. } \\
\text { Comparación: placebo ( } \mathrm{n}=32) \text {. } \\
\text { Pruebas de estudio: Se realizó } \\
\text { metanálisis de los resultados de } \\
\text { los dos estudios incluidos } \\
\text { reportándose el cambio en el } \\
\text { volumen de leche antes y } \\
\text { después del tratamiento. Además } \\
\text { se describieron otros desenlaces } \\
\text { relacionados con la seguridad. }\end{array}$ & $\begin{array}{l}\text { Resultados de eficacia: } \\
\text { Se observó un incremento de } 99,5 \\
\text { ml (IC95\% }-1,9 \text { a } 200,9 ; I^{2}=63 \% ; p= \\
0,055) \text { en la producción diaria de } \\
\text { leche de las madres tratadas con } \\
\text { domperidona. } \\
\text { Ambos estudios reportaron que no } \\
\text { se observaron diferencias } \\
\text { significativas en la lactancia } \\
\text { materna en ambos grupos después } \\
\text { de la intervención. } \\
\text { Resultados de seguridad: } \\
\text { No se reportaron efectos adversos } \\
\text { en la madre ni en los lactantes. }\end{array}$ & $\begin{array}{l}\text { El tratamiento con } \\
\text { domperidona en } \\
\text { madres de hijos pre- } \\
\text { término mostró un } \\
\text { incremento modesto } \\
\text { del volumen de leche } \\
\text { materna sin } \\
\text { evidenciar diferencias } \\
\text { en la lactancia ni en } \\
\text { la aparición de } \\
\text { efectos adversos. }\end{array}$ & $\begin{array}{l}\text { Se observó una } \\
\text { heterogeneidad } \\
\text { alta entre los } \\
\text { estudios lo que } \\
\text { sugiere una } \\
\text { variabilidad } \\
\text { importante en } \\
\text { las } \\
\text { características } \\
\text { de las madres } \\
\text { incluidas y } \\
\text { métodos de } \\
\text { lactancia. Los } \\
\text { ensayos clínicos } \\
\text { incluidos en la } \\
\text { revisión son } \\
\text { pequeños y no } \\
\text { evaluaron los } \\
\text { desenlaces a } \\
\text { largo plazo. }\end{array}$ \\
\hline
\end{tabular}




\begin{tabular}{|c|c|c|c|c|c|c|}
\hline $\begin{array}{l}\text { Referencia } \\
\text { (Cita } \\
\text { Abreviada) }\end{array}$ & $\begin{array}{l}\text { Estudio } \\
\text { (Diseño y } \\
\text { objetivo) }\end{array}$ & $\begin{array}{l}\text { Población } \\
\text { (no y características) }\end{array}$ & $\begin{array}{l}\text { Descripción de las } \\
\text { intervenciones } \\
\text { comparaciones, exposiciones } \\
\text { o pruebas a estudio }\end{array}$ & $\begin{array}{l}\text { Resultados } \\
\text { (Estimadores de resultados- } \\
\text { Magnitud del efecto) }\end{array}$ & $\begin{array}{l}\text { Conclusiones } \\
\text { (conclusiones) }\end{array}$ & $\begin{array}{l}\text { Comentarios } \\
\text { Calidad de la } \\
\text { evidencia } \\
\text { Financiación } \\
\text { comentarios) }\end{array}$ \\
\hline $\begin{array}{l}\text { Zuppa A, } \\
2010\end{array}$ & $\begin{array}{l}\text { Diseño } \\
\text { Revisión } \\
\text { sistemática } \\
\text { Objetivo } \\
\text { Evaluar el } \\
\text { efecto de los } \\
\text { medicamentos } \\
\text { y las hierbas } \\
\text { utilizados } \\
\text { como } \\
\text { galactogogos } \\
\text { sobre la } \\
\text { producción de } \\
\text { leche, así } \\
\text { como sus } \\
\text { efectos } \\
\text { adversos. }\end{array}$ & $\begin{array}{l}\text { La revisión incluyó tanto } \\
\text { estudios } \\
\text { observacionales como } \\
\text { ensayos clínicos, entre } \\
\text { ellos: } \\
\text { - } 4 \text { ensayos clínicos } \\
\text { aleatorizados doble } \\
\text { ciego que evaluaron la } \\
\text { metoclopramida en } \\
115 \text { madres de hijos } \\
\text { pre-término o a } \\
\text { término, post parto } \\
\text { vaginal o cesárea. } \\
\text { - } 2 \text { ensayos clínicos } \\
\text { aleatorizados doble } \\
\text { ciego que evaluaron la } \\
\text { domperidona en } 52 \\
\text { madres de hijos pre- } \\
\text { término y a término. } \\
\text { - ensayos clínicos } \\
\text { aleatorizados que } \\
\text { evaluaron el sulpiride } \\
\text { en } 312 \text { madres } \\
\text { primíparas y } \\
\text { multiparas. } \\
2 \text { ensayos clínicos } \\
\text { aleatorizados doble } \\
\text { ciego que evaluaron la } \\
\text { oxitocina en madres } \\
\text { de hijos pre-término } \\
\text { (n= } 62 \text { ). } \\
1 \text { ensayo clínicos } \\
\text { aleatorizado doble } \\
\text { ciego que evaluó la } \\
\text { hormona del }\end{array}$ & $\begin{array}{l}\text { Intervención: medicamentos } \\
\text { utilizados como galactogogos: } \\
\text { - metoclopramida30 mg/d } \\
\text { durante } 7 \text { a } 21 \text { días después del } \\
\text { parto. } \\
\text { - domperidona30mg/d durante } 7 \\
\text { días. } \\
\text { - sulpiride } 100 \text { a } 150 \mathrm{mg} / \mathrm{d} \text { durante } \\
5 \text { a } 28 \text { días después del parto. } \\
\text { - oxitocina spray nasal } 40 \mathrm{U} / \mathrm{ml} \text { ó } \\
100 \text { } \mu \mathrm{l} / \mathrm{spray} \text { durante } 5 \text { días } \\
\text { después del parto. } \\
\text { - hormona del crecimiento } 0,1 \text { ó } \\
\text { 0,2 IU/kg/d durante } 7 \text { días } \\
\text { después del parto. } \\
\text { - hormona liberadora de } \\
\text { tirotropina } 10 \text { ó } 60 \text { mg/d durante } \\
28 \text { días después del parto. } \\
\text { Comparación: placebo. } \\
\text { Pruebas de estudio: No se } \\
\text { realizó metanálisis. Los resultados } \\
\text { se presentan de forma } \\
\text { descriptiva. Los principales } \\
\text { desenlacesson: } \\
\text { - metoclopramida: volumen de } \\
\text { leche, niveles de prolactina y } \\
\text { duración de la lactancia. } \\
\text { - domperidona: volumen de leche } \\
\text { y niveles de prolactina. } \\
\text { - sulpiride: volumen de leche, } \\
\text { niveles de prolactina y duración } \\
\text { de la lactancia. } \\
\text { - oxitocina: volumen y calidad de }\end{array}$ & $\begin{array}{l}\text { Resultados de eficacia: } \\
\text { - metoclopramida: } 2 \text { ensayos } \\
\text { clínicos mostraron un incremento } \\
\text { en el volumen de leche y los } \\
\text { niveles de prolactina. } 1 \text { ensayo } \\
\text { clínico no mostró diferencias en el } \\
\text { volumen de leche y } 1 \text { no mostró } \\
\text { diferencias en la duración de la } \\
\text { lactancia. } \\
\text { - domperidona: los } 2 \text { ensayos } \\
\text { clínicos mostraron un incremento } \\
\text { en el volumen de leche y } 1 \text { de } \\
\text { ellos mostró un incremento en los } \\
\text { niveles de prolactina. } \\
\text { - sulpiride: los } 4 \text { ensayos clínicos } \\
\text { mostraron un incremento en el } \\
\text { volumen de leche, } 3 \text { mostraron un } \\
\text { incremento en los niveles de } \\
\text { prolactina y } 1 \text { no mostró } \\
\text { diferencias en la duración de la } \\
\text { lactancia. } \\
\text { - oxitocina: } 1 \text { de los dos ensayos } \\
\text { clínicos mostró un incremento en } \\
\text { el volumen de leche. } \\
\text { - hormona del crecimiento: el } \\
\text { ensayo clínico mostró un } \\
\text { incremento en el volumen de } \\
\text { leche. } \\
\text { - hormona liberadora de } \\
\text { tirotropina: el ensayo clínico } \\
\text { mostró un incremento en los } \\
\text { niveles de prolactina sin cambios } \\
\text { en el volumen de leche. } \\
\text { Resultados de seguridad: }\end{array}$ & $\begin{array}{l}\text { Los resultados a partir } \\
\text { de estudios pequeños } \\
\text { sugieren que el } \\
\text { tratamiento con } \\
\text { metoclopramida, } \\
\text { domperidona, } \\
\text { sulpiride, oxitocina, } \\
\text { hormona del } \\
\text { crecimiento y } \\
\text { hormona liberadora } \\
\text { de tirotropina podrían } \\
\text { incrementar el } \\
\text { volumen de leche y } \\
\text { los niveles de } \\
\text { prolactina sin } \\
\text { evidenciar cambios } \\
\text { en la calidad de la } \\
\text { leche ni en la } \\
\text { duración de la } \\
\text { lactancia.La } \\
\text { presencia de efectos } \\
\text { adversos moderados } \\
\text { desaconsejaría el } \\
\text { tratamiento con } \\
\text { metoclopramida, } \\
\text { sulpiride o hormonas. }\end{array}$ & $\begin{array}{l}\text { Los ensayos } \\
\text { clínicos } \\
\text { incluidos en } \\
\text { la revisión } \\
\text { son } \\
\text { pequeños y } \\
\text { no evaluaron } \\
\text { los } \\
\text { desenlaces a } \\
\text { largo plazo } \\
\text {.El balance } \\
\text { entre riesgos } \\
\text { y beneficios } \\
\text { no parece } \\
\text { estar a favor } \\
\text { del } \\
\text { tratamiento } \\
\text { con } \\
\text { metocloprami } \\
\text { da, sulpiride } \\
\text { ni hormonas. } \\
\text { Esta revisión } \\
\text { no incluyó } \\
\text { ensayos } \\
\text { clínicos } \\
\text { sobre } \\
\text { hierbas. }\end{array}$ \\
\hline
\end{tabular}


GPC Lactancia Materna- Pregunta 25. Galactogogos.

\begin{tabular}{|c|c|c|c|c|c|c|}
\hline $\begin{array}{l}\text { Referencia } \\
\text { (Cita } \\
\text { Abreviada) }\end{array}$ & $\begin{array}{l}\text { Estudio } \\
\text { (Diseño y } \\
\text { objetivo) }\end{array}$ & $\begin{array}{l}\text { Población } \\
\text { (no y características) }\end{array}$ & $\begin{array}{l}\text { Descripción de las } \\
\text { intervenciones } \\
\text { comparaciones, exposiciones } \\
\text { o pruebas a estudio }\end{array}$ & $\begin{array}{l}\text { Resultados } \\
\text { (Estimadores de resultados- } \\
\text { Magnitud del efecto) }\end{array}$ & $\begin{array}{l}\text { Conclusiones } \\
\text { (conclusiones) }\end{array}$ & $\begin{array}{l}\text { Comentarios } \\
\text { Calidad de la } \\
\text { evidencia } \\
\text { Financiación } \\
\text { comentarios) }\end{array}$ \\
\hline & & $\begin{array}{l}\text { crecimiento en madres } \\
\text { de hijos pre-término } \\
(n=20) . \\
\text { - } 1 \text { ensayos clínico } \\
\text { controlado que evaluó } \\
\text { la hormona liberadora } \\
\text { de tirotropina en } \\
\text { madres con lactancia } \\
\text { insuficiente }(n=16) \text {. }\end{array}$ & $\begin{array}{l}\text { la leche. } \\
\text { - hormona del crecimiento: } \\
\text { volumen de leche. } \\
\text { - hormona liberadora de } \\
\text { tirotropina: volumen y calidad } \\
\text { de la de leche y niveles de } \\
\text { prolactina. }\end{array}$ & $\begin{array}{l}\text { - metoclopramida, sulpiride y } \\
\text { hormonas: efectos adversos } \\
\text { moderados en madres e hijos. }\end{array}$ & & \\
\hline
\end{tabular}


GPC Lactancia Materna- Pregunta 25. Galactogogos.

\begin{tabular}{|c|c|c|c|c|c|c|}
\hline $\begin{array}{l}\text { Referencia } \\
\text { (Cita } \\
\text { Abreviada) }\end{array}$ & $\begin{array}{l}\text { Estudio } \\
\text { (Diseño } \\
\text { objetivo) }\end{array}$ & $\begin{array}{l}\text { Población } \\
\text { (no y características) }\end{array}$ & $\begin{array}{l}\text { Descripción de las } \\
\text { intervenciones } \\
\text { comparaciones, exposiciones } \\
\text { o pruebas a estudio }\end{array}$ & $\begin{array}{l}\text { Resultados } \\
\text { (Estimadores de resultados- } \\
\text { Magnitud del efecto) }\end{array}$ & $\begin{array}{l}\text { Conclusiones } \\
\text { (conclusiones) }\end{array}$ & $\begin{array}{l}\text { Comentarios } \\
\text { Calidad de la } \\
\text { evidencia } \\
\text { Financiación } \\
\text { comentarios) }\end{array}$ \\
\hline $\begin{array}{l}\text { Doggrell S, } \\
2014\end{array}$ & $\begin{array}{l}\text { Diseño } \\
\text { Revisión } \\
\text { sistemática } \\
\text { Objetivo } \\
\text { Evaluar los } \\
\text { efectos } \\
\text { adversos de la } \\
\text { domperidona } \\
\text { sobre la } \\
\text { función } \\
\text { cardiaca. }\end{array}$ & $\begin{array}{l}\text { La revisión incluyó } 6 \\
\text { estudios que } \\
\text { evaluaron los efectos } \\
\text { adversos de la } \\
\text { domperidona utilizada } \\
\text { como galactogogo, } \\
\text { entre ellos: } \\
\text { - } 2 \text { revisiones } \\
\text { sistemáticas (RS) con } \\
\text { metanálisis (Osadchy } \\
2012 \text { y Zuppa 2010) } \\
\text { cuyas características } \\
\text { se detallan en las } \\
\text { tablas } \\
\text { correspondientes. } \\
\text { - } 3 \text { ensayos clínicos } \\
\text { aleatorizados doble } \\
\text { ciego que evaluaron la } \\
\text { domperidona frente a } \\
\text { placebo en } 77 \text { madres } \\
\text { sin alteraciones } \\
\text { cardiacas. } \\
\text { - } 1 \text { ensayo clínico } \\
\text { aleatorizado doble } \\
\text { ciego que evaluó la } \\
\text { domperidona frente } \\
\text { a la metoclopramida } \\
\text { en } 65 \text { madres de } \\
\text { hijos hospitalizados } \\
\text { en cuidados } \\
\text { intensivos sin } \\
\text { alteraciones } \\
\text { cardiacas. }\end{array}$ & $\begin{array}{l}\text { Intervención: domperidona } 30 \text { ó } \\
40 \mathrm{mg} \text { al día durante } 4 \text { a } 14 \text { días } \\
(\mathrm{n}=68) \text {. } \\
\text { Comparación: placebo }(\mathrm{n}=40) \\
\text { o metoclopramida } 30 \mathrm{mg} \text { al día } \\
\text { durante } 10 \text { días ( } \mathrm{n}=35) . \\
\text { Pruebas de estudio: No se } \\
\text { realizó metanálisis. Los } \\
\text { resultados se presentan de } \\
\text { forma descriptiva. }\end{array}$ & $\begin{array}{l}\text { Resultados de seguridad: } \\
\text { No se reportaron efectos adversos } \\
\text { en la madre ni en los lactantes. } \\
\text { Particularmente, el estudio que } \\
\text { evaluó la domperidona frente a la } \\
\text { metoclopramida reportó una menor } \\
\text { frecuencia de efectos adversos en } \\
\text { las madres tratadas con } \\
\text { domperidona. }\end{array}$ & $\begin{array}{l}\text { El uso de } \\
\text { domperidona como } \\
\text { galactogogo no ha } \\
\text { mostrado efectos } \\
\text { adversos cardiacos. } \\
\text { Sin embargo, son } \\
\text { necesarios estudios } \\
\text { que incluyan un } \\
\text { mayor tamaño de } \\
\text { muestra y } \\
\text { seguimiento a largo } \\
\text { plazo para evaluar } \\
\text { otros posibles efectos } \\
\text { adversos. }\end{array}$ & $\begin{array}{l}\text { Es muy poco } \\
\text { probable que las } \\
\text { madres tratadas } \\
\text { con } \\
\text { domperidona } \\
\text { presenten } \\
\text { alteraciones } \\
\text { cardiacas. Sin } \\
\text { embargo, se } \\
\text { debe brindar } \\
\text { especial } \\
\text { atención a las } \\
\text { madres con QT } \\
\text { prolongado y } \\
\text { otras } \\
\text { alteraciones } \\
\text { cardiacas en } \\
\text { quienes el uso } \\
\text { de domperidona } \\
\text { podría generar } \\
\text { efectos } \\
\text { adversos } \\
\text { importantes. }\end{array}$ \\
\hline
\end{tabular}




\begin{tabular}{|c|c|c|c|c|c|c|}
\hline $\begin{array}{l}\text { Referencia } \\
\text { (Cita } \\
\text { Abreviada) }\end{array}$ & $\begin{array}{l}\text { Estudio } \\
\text { (Diseño y } \\
\text { objetivo) }\end{array}$ & $\begin{array}{l}\text { Población } \\
\text { (noy características) }\end{array}$ & $\begin{array}{l}\text { Descripción de las } \\
\text { intervenciones } \\
\text { comparaciones, exposiciones } \\
\text { o pruebas a estudio }\end{array}$ & $\begin{array}{l}\text { Resultados } \\
\text { (Estimadores de resultados- } \\
\text { Magnitud del efecto) }\end{array}$ & $\begin{array}{l}\text { Conclusiones } \\
\text { (conclusiones) }\end{array}$ & $\begin{array}{l}\text { Comentarios } \\
\text { Calidad de la } \\
\text { evidencia } \\
\text { Financiación } \\
\text { comentarios) }\end{array}$ \\
\hline $\begin{array}{l}\text { Mortel M, } \\
2013\end{array}$ & $\begin{array}{l}\text { Diseño } \\
\text { Revisión } \\
\text { sistemática } \\
\text { Objetivo } \\
\text { Evaluar la } \\
\text { eficacia de } \\
\text { los } \\
\text { galactogog } \\
\text { os } \\
\text { herbales. }\end{array}$ & $\begin{array}{l}\text { La revisión incluyó seis } \\
\text { estudios, entre ellos: } \\
\text { - } 2 \text { ensayos clínicos } \\
\text { aleatorizados doble ciego } \\
\text { que evaluaron el } \\
\text { shataravi( } n=62) \text { frente al } \\
\text { placebo }(n=62) \text { en } \\
\text { madres de hijos a } \\
\text { término con lactancia } \\
\text { inadecuada durante los } \\
14 \text { días a } 6 \text { meses post- } \\
\text { parto. } \\
-1 \text { ensayo clínico } \\
\text { aleatorizado con tres } \\
\text { brazos: torbangun }(n= \\
25), \text { fenogreco ( } n=25) \text { y } \\
\text { Moloco+B12 ( } n=25) \text { en } \\
\text { madres de hijos a } \\
\text { término sanos. } \\
\text { - } 1 \text { ensayo clínico } \\
\text { controlado que evaluó } \\
\text { una combinación de } 13 \\
\text { hierbas japonesas }(n= \\
41) \text { frente a ergometrina } \\
(n=41) \text { en madres de } \\
\text { hijos a término sanos. } \\
-1 \text { ensayo clínico } \\
\text { aleatorizado que evaluó } \\
\text { el cardo de leche }(n=25) \\
\text { frente a placebo ( } n=25) \\
\text { en madres de hijos a } \\
\text { término sanos. } \\
-1 \text { ensayo clínico } \\
\text { aleatorizado con tres }\end{array}$ & $\begin{array}{l}\text { Intervención: hierbas utilizadas } \\
\text { como galactogogos: } \\
\text { - shatavari dos cucharitas de } 100 \\
\text { g de una combinación que } \\
\text { contiene } 15 \% \text { de shatavari, dos } \\
\text { veces al día o } 60 \mathrm{mg} / \mathrm{kg} \text { peso al } \\
\text { día durante } 30 \text { días. } \\
\text { - torbangun } 150 \mathrm{~g} \text { al día, } 6 \text { días a } \\
\text { la semana durante } 28 \text { días. } \\
\text { - combinación de } 13 \text { hierbas } \\
\text { japonesas } 6 \text { g al día durante } 6 \\
\text { días. } \\
\text { - cardo de leche420mg al día } \\
\text { durante } 63 \text { días. } \\
\text { - fenogreco, tres tazas de un té } \\
\text { que contiene } 100 \mathrm{~g} \text { de } \\
\text { fenogreco al día, no se reportó } \\
\text { la duración de la intervención. } \\
\text { Comparación: placebo, } \\
\text { fenogreco, moloco+B12 o } \\
\text { ergometrina. } \\
\text { Pruebas de estudio: No se } \\
\text { realizó metanálisis y se } \\
\text { presentaron los resultados de } \\
\text { forma descriptiva. Los desenlaces } \\
\text { principales evaluados en cada } \\
\text { estudio fueron: } \\
\text { - shatavari: niveles de prolactina. } \\
\text { - torbangun: volumen y calidad } \\
\text { de la leche. } \\
\text { - combinación de } 13 \text { hierbas } \\
\text { japonesas: volumen de leche y } \\
\text { niveles de prolactina y }\end{array}$ & 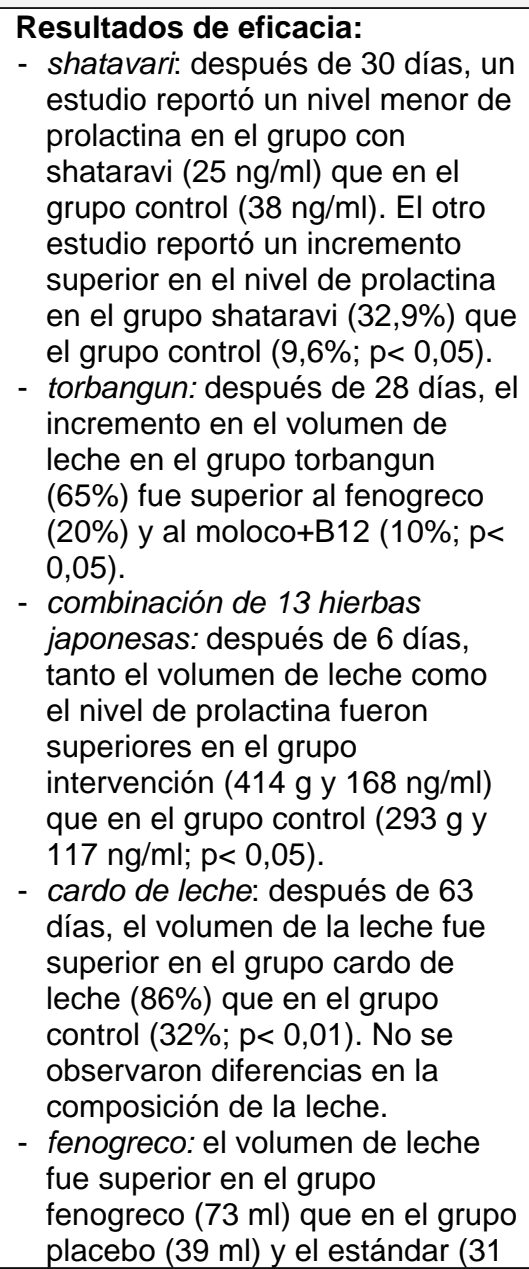 & $\begin{array}{l}\text { Debido a la escasa } \\
\text { evidencia sobre las } \\
\text { hierbas utilizadas } \\
\text { como galactogogos } \\
\text { su utilización es } \\
\text { difícilmente } \\
\text { recomendable. Sin } \\
\text { embargo, los estudios } \\
\text { apuntan a un efecto } \\
\text { beneficioso de las } \\
\text { hierbas sobre el } \\
\text { volumen de leche y } \\
\text { los niveles de } \\
\text { prolactina sin la } \\
\text { aparición de efectos } \\
\text { adversos. }\end{array}$ & $\begin{array}{l}\text { Los estudios } \\
\text { presentaron } \\
\text { diseños } \\
\text { diferentes con } \\
\text { una duración de } \\
\text { tratamiento } \\
\text { variable entre } 3 \\
\text { y } 60 \text { días. } \\
\text { Además los } \\
\text { estudios son } \\
\text { pequeños y no } \\
\text { evaluaron los } \\
\text { desenlaces a } \\
\text { largo plazo. }\end{array}$ \\
\hline
\end{tabular}




\begin{tabular}{|c|c|c|c|c|c|c|}
\hline $\begin{array}{l}\text { Referencia } \\
\text { (Cita } \\
\text { Abreviada) }\end{array}$ & $\begin{array}{l}\text { Estudio } \\
\text { (Diseño y } \\
\text { objetivo) }\end{array}$ & $\begin{array}{l}\text { Población } \\
\text { (no y características) }\end{array}$ & $\begin{array}{l}\text { Descripción de las } \\
\text { intervenciones } \\
\text { comparaciones, exposiciones } \\
\text { o pruebas a estudio }\end{array}$ & $\begin{array}{l}\text { Resultados } \\
\text { (Estimadores de resultados- } \\
\text { Magnitud del efecto) }\end{array}$ & $\begin{array}{l}\text { Conclusiones } \\
\text { (conclusiones) }\end{array}$ & $\begin{array}{l}\text { Comentarios } \\
\text { Calidad de la } \\
\text { evidencia } \\
\text { Financiación } \\
\text { comentarios) }\end{array}$ \\
\hline & & $\begin{array}{l}\text { brazos: fenogreco } \\
(n=22), \text { placebo }(n=22) \text { y } \\
\text { consejo estándar }(n=22) \\
\text { en madres de hijos a } \\
\text { término sanos. }\end{array}$ & $\begin{array}{l}\text { oxitocina. } \\
\text { - cardo de leche: volumen y } \\
\text { calidad de la leche. } \\
\text { - fenogreco: volumen de leche. }\end{array}$ & $\begin{array}{l}\text { ml; } \mathrm{p}<0,05) \\
\text { Resultados de seguridad: } \\
\text { No se reportaron efectos adversos } \\
\text { en la madre ni en los lactantes. }\end{array}$ & & \\
\hline
\end{tabular}

Se han identificado ocho revisiones sistemáticas (RS) que evaluaron el efecto de los galactogogos en madres con lactancia insuficiente (1-8). De estas revisiones tres evaluaron el efecto de la domperidona (Paul 2015, Donovan 2012, Osadchy 2012), tres el efecto de los galactogogos herbales (2-4)) y dos incluyeron tanto estudios sobre medicamentos como galactogogos herbales $(7 ; 8)$.

De las tres RS que evaluaron la eficacia de la domperidona, se han considerado las RS de Paul 2015 (1), que incluyen tanto madres de niños prematuros como de niños nacidos a término, y Donovan 2012 (6), que incluye sólo prematuros. La RS de Donovan 2012 presenta una mayor calidad metodológica y la de Paul 2015 incluye estudios que no se tuvieron en cuenta en la revisión de Donovan 2012 . La RS Osadchy 2012 (5) incluyó una menor cantidad de estudios que la RS Paul 2015 y su calidad metodológica fue peor que la revisión de RS Donovan 2012.

De las tres RS que evaluaron el efecto de los galactogogos herbales sólo se ha considerado la RS Mortel 2013 (3). Ninguna de las tres revisiones realizó metanálisis de los resultados. La RS Yadav 2014 (2) evaluó los beneficios del consumo de fenogreco en personas sanas y pacientes con diversas enfermedades, mencionando sólo que las madres lactantes podrían beneficiarse de preparados a partir de semillas de fenogreco. La RS Zapantis 2012 (4) incluyó los mismos ensayos clínicos incluidos en la RS Mortel 2013 (3).

De las dos RS que evaluaron el efecto de los medicamentos y/o galactogogos herbales, sólo se ha considerado la RS Zuppa 2010 (8) que, además de la domperidona, incluyó ensayos clínicos controlados que evaluaron la metoclopramida, el sulpiride y el tratamiento hormonal. Los estudios sobre galactogogos herbales incluidos en la RS Zuppa 2010 no fueron considerados en la elaboración de la pregunta puesto que la RS Mortel 2013 evaluó los galactogogos herbales con mayor calidad metodológica. La RS Forinash 2012 (7) sólo incluyó estudios que evaluaron los medicamentos y galactogogos herbales disponibles en Estados Unidos.

Asimismo, se ha identificado la RS Doggrell 2014 et al (9) que evaluó la seguridad del tratamiento con domperidona en pacientes con diversas patologías. La revisión incluye un apartado sobre la seguridad de la domperidona como galactogogo, que es el que se ha utilizado para el desarrollo de esta pregunta. 


\subsection{Resumen de GPC base y RS disponibles}

El protocolo de la ABM (Protocolo \#9) (10) señala que debido a que el estado actual de la investigación de todos los galactogogos es relativamente poco concluyente y todos los agentes tienen potenciales efectos adversos, no se puede recomendar ningún galactogogo farmacológico o herbal específico en este momento.

También indica que el proveedor de salud que pone en balanza los potenciales riesgos y beneficios de estos agentes y decide prescribir un galactogogo deberá apegarse a las guías que se mencionan más adelante (ver apéndice sobre los detalles para prescribir galactogogos específicos).

En cuanto a las revisiones seleccionadas, la revisión de Paul C 2015 (1) concluye que a pesar de la falta de metaanálisis, los estudios son consistentes en demostrar un incremento en la producción de leche y en los niveles de prolactina de las madres tratadas con domperidona. Además, los estudios no reportaron efectos adversos importantes tanto en las madres como en los niños. En la revisión de Donovan TJ, 2012 (6) se concluye que la domperidona muestra un incremento modesto del volumen de leche materna en madres de hijos pretérmino, sin evidenciar diferencias en la lactancia ni en la aparición de efectos adversos. En cuanto a la seguridad, la revisión de Doggrell S, 2014 (9) señala que el uso de la domperidona como galactogogo no ha mostrado efectos adversos cardíacos. Sin embargo, son necesarios estudios que incluyan un mayor tamaño de muestra y seguimiento a largo plazo para evaluar otros posibles efectos adversos.

Por otro lado, la revisión de Zuppa (8) sugiere que el tratamiento con metoclopramida, domperidona, sulpiride, oxitocina, hormona del crecimiento y hormona liberadora de tirotropina podrían incrementar el volumen de leche y los niveles de prolactina sin evidenciar cambios en la calidad de la leche ni en la duración de la lactancia, y señalan que la presencia de efectos adversos moderados desaconsejaría el tratamiento con metoclopramida, sulpiride o hormonas.

En cuanto a los galactogogos herbales, la revisión de Mortel M (3) sugiere que debido a la escasa evidencia sobre las hierbas utilizadas como galactogogos su utilización es difícilmente recomendable. Sin embargo, los estudios apuntan a un efecto beneficioso de las hierbas sobre el volumen de leche y los niveles de prolactina sin la aparición de efectos adversos.

\subsection{Conclusión (marcar con una $\mathrm{X}$ ):}

\begin{tabular}{|l|l|}
\hline & Adopción GPC/Revisión sistemática \\
\hline $\mathrm{X}$ & Elaboración parcial \\
\hline & Elaboración de novo \\
\hline
\end{tabular}

\subsection{Diseño de la estrategia de búsqueda de estudios individuales}

\begin{tabular}{|l|l|}
\hline Criterios de selección de estudios & ECA, estudios de cohortes \\
\hline Período de búsqueda & Desde 2009 en adelante \\
\hline Bases de datos & Cochrane, PUMBED y EMBASE y CINHAL \\
\hline
\end{tabular}


Ver estrategias de búsqueda de estudios originales en el ANEXO I.

Se incluye la búsqueda de revisiones sistemáticas primero y luego se elimina el filtro de Revisiones sistemáticas y se limita desde 2009 en adelante para localizar posibles estudios individuales publicados a partir de la fecha hasta la que se mira en las revisiones incluidas. 
GPC Lactancia Materna- Pregunta 25. Galactogogos.

\section{2- Resumen de la evidencia}

\section{1- GRADE Evidence Profile}

Comparación 1: Domperidona 30-40 mg/día entre 2 y 14 días postparto vs. placebo

Bibliografía: Paul C, 2015; Donovan TJ, 2012; Doggrell S, 2014.

\begin{tabular}{|c|c|c|c|c|c|c|c|c|c|c|c|c|}
\hline \multirow{2}{*}{\multicolumn{7}{|c|}{ Evaluación de la calidad }} & \multicolumn{4}{|c|}{ Resumen de los Resultados } & \multirow{3}{*}{ Calidad } & \multirow{3}{*}{ Importancia } \\
\hline & & & & & & & \multicolumn{2}{|c|}{ № de pacientes } & \multicolumn{2}{|c|}{ Magnitud del efecto } & & \\
\hline $\begin{array}{c}\text { № de } \\
\text { estudios }\end{array}$ & Diseño & $\begin{array}{c}\text { Riesgo de } \\
\text { sesgo }\end{array}$ & Inconsistencia & \begin{tabular}{|c|}
$\begin{array}{c}\text { Evidencia } \\
\text { indirecta }\end{array}$ \\
\end{tabular} & Imprecisión & \begin{tabular}{|c|} 
Otras \\
consideraciones
\end{tabular} & $\begin{array}{c}\text { Grupo } \\
\text { domperidona }\end{array}$ & \begin{tabular}{|c|} 
Grupo \\
placebo
\end{tabular} & $\begin{array}{l}\text { Relativa } \\
(95 \% \mathrm{Cl})\end{array}$ & $\begin{array}{c}\text { Absoluta por } \\
1000\end{array}$ & & \\
\hline \multicolumn{13}{|c|}{ Lactancia materna, exclusiva o no (hijos pre-término) } \\
\hline 21 & ECA & \begin{tabular}{|l|} 
Serio $^{2}$ \\
\end{tabular} & Seria $^{3}$ & Seria ${ }^{4}$ & Seria $^{5}$ & Ninguna & $12 / 22(54,6 \%)$ & $12 / 23(52,2 \%)$ & $\begin{array}{l}\text { RR } 1,05 \text { (de } \\
0,61 \text { a } 1,81 \text { ) }\end{array}$ & $\begin{array}{c}26 \text { más por } \\
1000 \text { (de } 203 \\
\text { menos a } 423 \\
\text { más) }\end{array}$ & MUY BAJA & IMPORTANTE \\
\hline \multicolumn{13}{|c|}{ Volumen de leche (ml/día) en madres de hijos a término postcesárea } \\
\hline $2^{6}$ & ECA & \begin{tabular}{|l|} 
Serio $^{2}$ \\
\end{tabular} & \begin{tabular}{|l|l|} 
No seria & 1
\end{tabular} & No seria & Seria $^{7}$ & Ninguna & $\begin{array}{l}\text { № total: } 39 \\
\text { № total: } 17 \text { (8 } \\
\text { multiparas y } 9 \\
\text { primíparas) }\end{array}$ & $\begin{array}{l}\text { № total: } 38 \\
\text { № total: } 15 \text { (7 } \\
\text { multíparas y } 8 \\
\text { primíparas). }\end{array}$ & \multicolumn{2}{|c|}{$\begin{array}{l}\text { Volumen medio de leche al día } 4 \\
\text { (Jantarasaengaram } 2012 \text { ): } \\
\text { Domperidona: } 191,3 \mathrm{ml} / \mathrm{d} \text { vs. } \\
\text { placebo: } 91,4 \mathrm{ml} / \mathrm{d} ; \mathrm{P}=0,003 \text {. } \\
\\
\text { Volumen medio de leche } \\
\text { (Petralgia 1985): } \\
\text { Multíparas (del } 2^{\circ} \text { al } 5^{\circ} \text { día) } \\
\text { - Domperidona: de } 105 \pm 35 \text { a } \\
475 \pm 51 \mathrm{ml} / \mathrm{día} \\
\text { - Placebo: } 3 \text { de } 17 \text { menos de } \\
20 \mathrm{ml} / \text { toma en } 2 \text { días, valores } \\
\text { medios mucho más bajos } \\
\text { Primíparas (del } 2^{\circ} \text { al } 10^{\circ} \text { día) } \\
\text { - Domperidona: aumento de } \\
371-417 \mathrm{ml} / \mathrm{día} \text { a } 631-708 \\
\text { ml/día. } \\
\text { - Placebo: } 335 \pm 30 \text { a } 398 \pm \\
45 \mathrm{ml} / \mathrm{día}\end{array}$} & BAJA & CRITICA \\
\hline \multicolumn{13}{|c|}{ Niveles de prolactina en madres de hijos a término } \\
\hline $1^{8}$ & ECA & \begin{tabular}{|l|} 
Serio $^{2}$ \\
\end{tabular} & & No seria & Seria $^{7}$ & Ninguna & $\begin{array}{l}\text { № total: } 17 \\
\text { Multiparas: } 8\end{array}$ & $\begin{array}{l}\text { № total: } 15 \\
\text { Multiparas: } 7\end{array}$ & $\begin{array}{l}\text { - Multíparas (I): } \\
\text { alto al día } 5 \text { con }\end{array}$ & $\begin{array}{l}\text { Jivel } 97 \% \text { más } \\
\text { oarado con el }\end{array}$ & BAJA & IMPORTANTE \\
\hline
\end{tabular}


GPC Lactancia Materna- Pregunta 25. Galactogogos.

\begin{tabular}{|c|c|c|c|c|c|c|c|c|c|c|c|}
\hline & & & & & & & Primiparas: 9 & Primíparas: & $\begin{array}{l}\text { día 2. } \mathrm{P}<0,05 \text {. } \\
\text { Multíparas }(\mathrm{C}) \text { : Nivel } 55 \% \text { más } \\
\text { alto al día } 5 \text { comparado con el } \\
\text { día 2. } \mathrm{P}<0,01 \text {. } \\
\text {-En las Primíparas, el nivel de } \\
\text { prolactina al día } 5 \text { fue } 169 \mathrm{ng} / \mathrm{mL} \\
\text { en el grupo domperidona vs. } 84 \\
\text { ng/mL en el grupo placebo; } \mathrm{P}= \\
\text { no reportado. }\end{array}$ & & \\
\hline \multicolumn{12}{|c|}{ Efectos adversos en la madre o el hijo } \\
\hline $44^{9}$ & ECA & Serio ${ }^{2}$ & No seria & No seria & Seria $^{10}$ & Ninguna & № total: 60 & № total: 64 & \begin{tabular}{|l|} 
Boca seca en $7 / 60$ vs. $0 / 64$ \\
Dolor abdominal: $1 / 60$ vs. $0 / 64$
\end{tabular} & BAJA & CRITICO \\
\hline
\end{tabular}

${ }^{1}$ Campbell-Yeo 2010; Da Silva 2001; ${ }^{2}$ Riesgo de sesgos en los estudios; ${ }^{3} E n$ el estudio de Campbell-Yeo se observó un incremento en la lactancia materna y el ensayo de Da Silva no se observaron diferencias; ${ }^{4}$ Solo se evaluaron niños pretérmino; 5 No se cuenta con estimadores de precisión de los resultados y el número de eventos observados por Campbell-Yeo es igual en ambos grupos. ${ }^{6}$ Jantarasaengaram 2012; Petralgia 1985; ${ }^{7}$ El número de sujetos evaluados es pequeño. ${ }^{8}$ Petralgia $1985 ; 9$ Jantarasaengaram 2012 , Campbell-Yeo 2010 , Da Silva 2001, Petraglia 1985; ${ }^{10}$ No se cuenta con estimadores de precisión. 
Comparación 2: Metoclopramida vs. placebo

Bibliografía: Zuppa A, 2010.

\begin{tabular}{|c|c|c|c|c|c|c|c|c|c|c|c|c|}
\hline \multirow{2}{*}{\multicolumn{7}{|c|}{ Evaluación de la calidad }} & \multicolumn{4}{|c|}{ Resumen de los Resultados } & \multirow{3}{*}{ Calidad } & \multirow{3}{*}{ Importancia } \\
\hline & & & & & & & \multicolumn{2}{|c|}{ № de pacientes } & \multicolumn{2}{|c|}{\begin{tabular}{|l|} 
Magnitud del efecto \\
\end{tabular}} & & \\
\hline $\begin{array}{c}\text { № de } \\
\text { estudios }\end{array}$ & Diseño & $\begin{array}{c}\text { Riesgo de } \\
\text { sesgo }\end{array}$ & Inconsistencia & $\begin{array}{l}\begin{array}{l}\text { Evidencia } \\
\text { indirecta }\end{array} \\
\end{array}$ & Imprecisión & \begin{tabular}{|c|} 
Otras \\
consideraciones
\end{tabular} & Metoclopramida & Placebo & $\begin{array}{l}\text { Relativa } \\
(95 \% \mathrm{Cl})\end{array}$ & $\begin{array}{c}\text { Absoluta por } \\
1000\end{array}$ & & \\
\hline \multicolumn{13}{|c|}{\begin{tabular}{|l|} 
Duración de la lactancia (hijos pre-término) \\
\end{tabular}} \\
\hline $2^{1}$ & ECA & Serio $^{2}$ & No seria & Seria $^{3}$ & Seria ${ }^{4}$ & Ninguna & \begin{tabular}{|l|} 
Hansen 2005 \\
total: 28 \\
Lewis 1980 \\
$8 / 10$ lactantes a \\
las 6 semanas \\
$4 / 10$ lactantes a \\
los 3 meses \\
\end{tabular} & \begin{tabular}{|l|} 
Hansen 2005 \\
№ total: 29 \\
Lewis 1980 \\
$9 / 10$ lactantes \\
a las 6 \\
semanas \\
4/10 lactantes \\
a los 3 meses \\
\end{tabular} & $\begin{array}{l}\frac{\text { Hansen } 2005}{\text { Mediana de } 8,8} \\
\text { semanas con } m \\
8,6(5,6-16,9) \mathrm{c} \\
\text { hay diferencias } \\
\end{array}$ & $\begin{array}{l}25-75 ; 3,4-12 \text { ) } \\
\text { toclopramida y } \\
\text { placebo (no }\end{array}$ & MUY BAJA & IMPORTANTE \\
\hline \multicolumn{13}{|c|}{ Volumen de leche, hijos a término } \\
\hline $2^{5}$ & ECA & Serio $^{2}$ & No seria & No seria & Seria ${ }^{6}$ & Ninguna & № total: 18 & № total: 20 & $\begin{array}{l}\text { De Gezelle } 19 \\
\text { mayor a los } 21 \\
\text { Kauppila } 1985 \\
285 \text { a } 530 \mathrm{ml} / \mathrm{d}\end{array}$ & $\begin{array}{l}\text { Volumen } 50 \% \\
\text { as } \\
\text { Incremento de } \\
<0,01)\end{array}$ & MUY BAJA & CRITICO \\
\hline \multicolumn{13}{|c|}{ Niveles de prolactina, hijos a término } \\
\hline $1^{7}$ & ECA & Serio $^{2}$ & - & No seria & Seria ${ }^{8}$ & Ninguna & № total:11 & № total:14 & $\begin{array}{l}\text { Incremento de } \\
(p<0,001) \\
\text { Nivel de prolad } \\
\text { Placebo): } 210, \\
p<0,001\end{array}$ & $\begin{array}{l}57,5 \text { a } 315 \text { U/l } \\
\text { רa día } 21 \text { (I vs. } \\
\text { U/l vs. } 68,5 \text { U/l; }\end{array}$ & BAJA & IMPORTANTE \\
\hline \multicolumn{13}{|c|}{ Efectos adversos en el hijo, hijos a término } \\
\hline $2^{9}$ & $\begin{array}{l}\text { Estudios } \\
\text { observacionales }\end{array}$ & Serio ${ }^{10}$ & No seria & No seria & Seria ${ }^{6}$ & Ninguna & № total: 54 & & $\begin{array}{l}\text { Malestar int } \\
\text { moderado }(1 / 1 \\
\text { metoclopramid }\end{array}$ & $\begin{array}{l}\text { tinal leve- } \\
\text { en grupo con } \\
15 \mathrm{mg} \text { ) }\end{array}$ & MUY BAJA & CRITICA \\
\hline \multicolumn{13}{|c|}{ Efectos adversos en la madre } \\
\hline $2^{11}$ & \begin{tabular}{|l|} 
Estudios \\
observacionales
\end{tabular} & Serio $^{10}$ & No seria & No seria & Seria ${ }^{6}$ & Ninguna & № total: 60 & & $\begin{array}{l}\text { Cansancio, ce } \\
\text { somnolencia, } \\
\text { intestinales y ex }\end{array}$ & $\begin{array}{l}\text { lea, ansiedad, } \\
\text { tiga, trastornos } \\
\text { apiramidales }\end{array}$ & MUY BAJA & CRITICA \\
\hline
\end{tabular}


GPC Lactancia Materna- Pregunta 25. Galactogogos.

y los estudios son pequeños; ${ }^{7}$ Kauppila A, $1985 ;{ }^{8}$ El tamaño de muestra del estudio es muy pequeño; ${ }^{9}$ Kauppilaa ${ }^{1981}$; Kauppilab ${ }^{1981 ;}{ }^{10}$ Existe riesgo de sesgo en los estudios; ${ }^{11}$ Kauppila a, 1981; Ehrenkranz RA, 1986

Comparación 3: Metoclopramida 30mg vs. domperidona $30 \mathrm{mg}$,

Bibliografía: Ingram J, 2012.

\begin{tabular}{|c|c|c|c|c|c|c|c|c|c|c|c|c|}
\hline \multirow{2}{*}{\multicolumn{7}{|c|}{ Evaluación de la calidad }} & \multicolumn{4}{|c|}{ Resumen de los Resultados } & \multirow{3}{*}{ Calidad } & \multirow{3}{*}{ Importancia } \\
\hline & & & & & & & \multicolumn{2}{|c|}{\begin{tabular}{|l|}
$№$ de pacientes \\
\end{tabular}} & \multicolumn{2}{|c|}{ Magnitud del efecto } & & \\
\hline $\begin{array}{c}\begin{array}{c}\text { № de } \\
\text { estudios }\end{array} \\
\end{array}$ & Diseño & $\begin{array}{c}\text { Riesgo de } \\
\text { sesgo }\end{array}$ & Inconsistencia & \begin{tabular}{|l}
$\begin{array}{l}\text { Evidencia } \\
\text { indirecta }\end{array}$ \\
\end{tabular} & Imprecisión & \begin{tabular}{|c|} 
Otras \\
consideraciones
\end{tabular} & \begin{tabular}{|c|} 
Grupo \\
metoclopramida
\end{tabular} & $\begin{array}{c}\text { Grupo } \\
\text { domperidona }\end{array}$ & $\begin{array}{l}\text { Relativa } \\
(95 \% \mathrm{Cl}) \\
\end{array}$ & \begin{tabular}{|c|} 
Absoluta por \\
1000
\end{tabular} & & \\
\hline \multicolumn{13}{|c|}{ Volumen de leche a los 10 días de inicio del tratamiento (hijos pre-término) } \\
\hline $11^{1}$ & ECA & Serio $^{2}$ & - & Seria $^{3}$ & Seria ${ }^{4}$ & Ninguna & № total: 34 & № total: 31 & \multicolumn{2}{|c|}{$\begin{array}{l}\text { Aumento del volumen medio de } \\
\text { leche de } 93,7 \% \text { en el grupo } \\
\text { metoclopramida y } 96,3 \% \text { en el } \\
\text { grupo domperidona; } P=\text { no } \\
\text { reportado. }\end{array}$} & MUY BAJA & CRITICA \\
\hline
\end{tabular}

${ }^{1}$ Ingram J, 2012; ${ }^{2}$ Riesgo de sesgos; ${ }^{3}$ El estudio se ha realizado en hijos pre-término (28 semanas de gestación) hospitalizados en la unidad de cuidados intensivos; ${ }^{4}$ No se cuenta con estimadores de precisión de los resultados y el número de pacientes es pequeño. 
Comparación 4: Sulpiride vs. placebo

Bibliografía: Zuppa A, 2010.

\begin{tabular}{|c|c|c|c|c|c|c|c|c|c|c|c|c|}
\hline \multirow{2}{*}{\multicolumn{7}{|c|}{ Evaluación de la calidad }} & \multicolumn{4}{|c|}{$\begin{array}{c}\text { Resumen de los Resultados } \\
\end{array}$} & \multirow{3}{*}{ Calidad } & \multirow{3}{*}{ Importancia } \\
\hline & & & & & & & \multicolumn{2}{|c|}{ № de pacientes } & \multicolumn{2}{|c|}{ Magnitud del efecto } & & \\
\hline $\begin{array}{c}\text { № de } \\
\text { estudios }\end{array}$ & Diseño & \begin{tabular}{|c|}
$\begin{array}{c}\text { Riesgo de } \\
\text { sesgo }\end{array}$ \\
\end{tabular} & Inconsistencia & \begin{tabular}{|l|}
$\begin{array}{l}\text { Evidencia } \\
\text { indirecta }\end{array}$ \\
\end{tabular} & Imprecisión & \begin{tabular}{|c|} 
Otras \\
consideraciones \\
\end{tabular} & Sulpiride & Placebo & $\begin{array}{l}\text { Relativa } \\
(95 \% \mathrm{Cl})\end{array}$ & \begin{tabular}{l|l|} 
Absoluta \\
por 1000
\end{tabular} & & \\
\hline \multicolumn{13}{|c|}{ Duración de la lactancia, madres primíparas (a término) } \\
\hline $1^{1}$ & ECA & Serio $^{2}$ & - & No seria & Seria $^{3}$ & Ninguna & $\begin{array}{c}11 / 20(55 \%) \\
\text { lactantes al } \\
\text { mes }\end{array}$ & $\begin{array}{c}7 / 22(30 \%) \\
\text { lactantes al } \\
\text { mes }\end{array}$ & $\begin{array}{l}\text { RR 1,73 (de } \\
0,83 \text { a 3,58) }\end{array}$ & $\begin{array}{l}232 \text { más por } \\
1000 \text { (de } 54 \\
\text { menos a } 821 \\
\text { más) con } \\
\text { lactancia de } \\
\text { cada } 1000\end{array}$ & BAJA & IMPORTANTE \\
\hline \multicolumn{13}{|c|}{ Volumen de leche, madres primíparas y multíparas (a término) } \\
\hline $44^{4}$ & ECA & No serio & No seria & No seria ${ }^{5}$ & Seria ${ }^{6}$ & Ninguna & № total: 145 & № total: 115 & $\begin{array}{l}\text { Media sulpiride } \\
\text { Incremento de } \\
\text { ml/d vs. D } \\
\text { incremento de } 9\end{array}$ & $\begin{array}{l}\text { vs. placebo } \\
212 \text { a } 1211,7 \\
\text { isminución } \\
16,0 \mathrm{ml} / \mathrm{d}\end{array}$ & \begin{tabular}{|l|} 
MODERADA \\
\end{tabular} & CRITICA \\
\hline \multicolumn{13}{|c|}{ Niveles de prolactina (a término) } \\
\hline $3^{7}$ & ECA & No serio & No seria & No seria ${ }^{5}$ & Seria ${ }^{6}$ & Ninguna & № total:125 & № total:93 & $\begin{array}{l}\text { Media sulpiride } \\
\text { Incremento a } \\
\text { Disminución a } 4\end{array}$ & $\begin{array}{l}\text { vs. placebo } \\
402 \mu \mathrm{g} / \mathrm{l} \quad \text { vs. } \\
7,8 \mu \mathrm{g} / \mathrm{l}\end{array}$ & MODERADA & IMPORTANTE \\
\hline \multicolumn{13}{|c|}{ Efectos adversos en la madre } \\
\hline $1^{6}$ & ECA & Serio $^{2}$ & - & No seria & Seria ${ }^{4}$ & Ninguna & $3 / 14$ & $0 / 12$ & Cefalea y fatiga & moderada & BAJA & CRITICA \\
\hline
\end{tabular}

${ }^{1}$ Aono T,1982; ' 2 Riesgo de sesgos; ${ }^{3}$ El tamaño de muestra del estudio es muy pequeño; ${ }^{4}$ Aono T, 1979; Ylikorkala O, 1982; Polatti F, 1982; Aono T,1982; ${ }^{5}$ Los estudios de Aono son en niños a término; los de Ylikorkala y Polatti no lo sabemos, aunque presuponemos que no son niños pretérmino; 6 No se cuenta con estimadores de precisión de los resultados y los estudios son pequeños, además el intervalo es muy amplio y se solapa entre intervención y placebo; ${ }^{7}$ Aono T, 1979; Ylikorkala O, 1982; Polatti F, $1982 ;{ }^{6}$ Ylikorkala O, 1982. 
Comparación 5: Tratamiento hormonal (oxitocina, hormona del crecimiento, hormona liberadora de tirotropina) vs. placebo

Bibliografía: Zuppa A, 2010.

\section{Oxitocina vs. Placebo}

\begin{tabular}{|c|c|c|c|c|c|c|c|c|c|c|c|c|}
\hline \multirow{2}{*}{\multicolumn{7}{|c|}{ Evaluación de la calidad }} & \multicolumn{4}{|c|}{ Resumen de los Resultados } & \multirow[b]{3}{*}{ Calidad } & \multirow{3}{*}{ Importancia } \\
\hline & & & & & & & \multicolumn{2}{|c|}{ № de pacientes } & \multicolumn{2}{|c|}{ Magnitud del efecto } & & \\
\hline $\begin{array}{c}\text { № de } \\
\text { estudios }\end{array}$ & Diseño & $\begin{array}{c}\text { Riesgo de } \\
\text { sesgo }\end{array}$ & Inconsistencia & $\begin{array}{l}\text { Evidencia } \\
\text { indirecta }\end{array}$ & Imprecisión & \begin{tabular}{|c|} 
Otras \\
consideraciones
\end{tabular} & $\begin{array}{c}\text { Grupo } \\
\text { expuesto }\end{array}$ & $\begin{array}{l}\text { Grupo no } \\
\text { expuesto }\end{array}$ & $\begin{array}{l}\text { Relativa } \\
(95 \% \mathrm{Cl})\end{array}$ & $\begin{array}{c}\text { Absoluta por } \\
1000\end{array}$ & & \\
\hline \multicolumn{13}{|c|}{ Volumen de leche, madres de hijos pretérmino y a término } \\
\hline $2^{1}$ & ECA & No serio & \begin{tabular}{|l|l} 
Seria $^{2}$ & \\
\end{tabular} & Seria $^{3}$ & Seria ${ }^{4}$ & Ninguna & № total: 33 & № total: 30 & \multicolumn{2}{|c|}{$\begin{array}{l}\text { Media tto hormonal vs. } \\
\text { placebo } \\
\text { Fewtrell } 2006 \text { (pretérmino): } \\
\text { sin diferencias } \\
\text { Ruis } 1981 \text { (pretérmino): } \\
\text { Incremento } 3,5 \text { veces mayor } \\
\text { con tto hormonal }\end{array}$} & $\begin{array}{l}\text { MUY } \\
\text { BAJA }\end{array}$ & CRITICA \\
\hline
\end{tabular}

${ }^{1}$ Fewtrell MS, 2006; Ruis H, 1981; ${ }^{2}$ Uno de los estudios no mostró diferencias en el volumen de leche y el otro sí; ${ }^{3}$ Estudios realizados en niños pre-término; ${ }^{4}$ No se cuenta con estimadores de precisión de los resultados y los estudios son pequeños.

\section{Hormona del crecimiento vs. Placebo}

\begin{tabular}{|c|c|c|c|c|c|c|c|c|c|c|c|c|}
\hline \multirow{2}{*}{\multicolumn{7}{|c|}{ Evaluación de la calidad }} & \multicolumn{4}{|c|}{ Resumen de los Resultados } & \multirow[b]{3}{*}{ Calidad } & \multirow{3}{*}{ Importancia } \\
\hline & & & & & & & \multicolumn{2}{|c|}{\begin{tabular}{|l|} 
\\
№ de pacientes \\
\end{tabular}} & \multicolumn{2}{|c|}{ Magnitud del efecto } & & \\
\hline $\begin{array}{c}\text { № de } \\
\text { estudios }\end{array}$ & Diseño & \begin{tabular}{|c|} 
Riesgo de \\
sesgo
\end{tabular} & Inconsistencia & \begin{tabular}{|l|} 
Evidencia \\
indirecta
\end{tabular} & Imprecisión & $\begin{array}{c}\text { Otras } \\
\text { consideraciones }\end{array}$ & $\begin{array}{c}\text { Grupo } \\
\text { expuesto }\end{array}$ & \begin{tabular}{|l|} 
Grupo no \\
expuesto
\end{tabular} & $\begin{array}{l}\text { Relativa } \\
\text { (95\% Cl) }\end{array}$ & \begin{tabular}{|c|} 
Absoluta por \\
1000
\end{tabular} & & \\
\hline \multicolumn{13}{|c|}{ Volumen de leche, madres de hijos pretérmino y a término } \\
\hline $1^{1}$ & ECA & No serio & No seria & Seria $^{2}$ & Seria ${ }^{3}$ & Ninguna & № total: 10 & № total: 10 & \multicolumn{2}{|c|}{\begin{tabular}{|l|} 
Gunn 1996 (pretérmino): \\
Incremento de 139 a $175 \mathrm{ml} / \mathrm{d}$ \\
vs. Incremento de 93 a 102 \\
$\mathrm{ml} / \mathrm{d}$
\end{tabular}} & BAJA & CRITICA \\
\hline
\end{tabular}

${ }^{1}$ Gunn AJ, 1996; ${ }^{2}$ Niños pretérmino; ${ }^{3}$ No se cuenta con estimadores de precisión de los resultados y los estudios son pequeños 
GPC Lactancia Materna- Pregunta 25. Galactogogos.

\section{Hormona liberadora de tirotropina vs. Placebo}

\begin{tabular}{|c|c|c|c|c|c|c|c|c|c|c|c|c|}
\hline \multirow{2}{*}{\multicolumn{7}{|c|}{ Evaluación de la calidad }} & \multicolumn{4}{|c|}{ Resumen de los Resultados } & \multirow{3}{*}{ Calidad } & \multirow{3}{*}{ Importancia } \\
\hline & & & & & & & \multicolumn{2}{|c|}{ № de pacientes } & \multicolumn{2}{|c|}{ Magnitud del efecto } & & \\
\hline \begin{tabular}{|c|} 
№ de \\
estudios \\
\end{tabular} & Diseño & \begin{tabular}{|c|}
$\begin{array}{c}\text { Riesgo de } \\
\text { sesgo }\end{array}$ \\
\end{tabular} & Inconsistencia & \begin{tabular}{|l|}
$\begin{array}{l}\text { Evidencia } \\
\text { indirecta }\end{array}$ \\
\end{tabular} & Imprecisión & $\begin{array}{c}\begin{array}{c}\text { Otras } \\
\text { consideraciones }\end{array} \\
\end{array}$ & $\begin{array}{c}\text { Grupo } \\
\text { expuesto }\end{array}$ & \begin{tabular}{|l|}
$\begin{array}{l}\text { Grupo no } \\
\text { expuesto }\end{array}$ \\
\end{tabular} & $\begin{array}{l}\text { Relativa } \\
(95 \% \mathrm{Cl}) \\
\end{array}$ & \begin{tabular}{|c|} 
Absoluta por \\
1000
\end{tabular} & & \\
\hline \multicolumn{13}{|c|}{ Volumen de leche, madres de hijos pretérmino y a término } \\
\hline 11 & ECA & No serio & \begin{tabular}{|l|l|} 
No seria \\
\end{tabular} & Seria $^{2}$ & Muy seria ${ }^{3}$ & Ninguna & № total:4 & № total: 4 & \multicolumn{2}{|c|}{$\begin{array}{l}\text { Zarate } 1976 \text { (no se sabe si } \\
\text { son a término o no): sin } \\
\text { diferencias }\end{array}$} & $\begin{array}{l}\text { MUY } \\
\text { BAJA }\end{array}$ & CRITICA \\
\hline \multicolumn{13}{|c|}{ Niveles de prolactina, madres primíparas (hormona liberadora de tirotropina, no se reportó si los hijos eran o no a término) } \\
\hline 11 & ECA & No serio & No seria & Seria $^{2}$ & Muy seria ${ }^{3}$ & Ninguna & № total:4 & № total:4 & \multicolumn{2}{|c|}{$\begin{array}{l}\text { Los niveles de prolactina } \\
\text { fueron significativamente } \\
\text { superiores en las mujeres } \\
\text { tratadas }\end{array}$} & $\begin{array}{l}\text { MUY } \\
\text { BAJA }\end{array}$ & IMPORTANTE \\
\hline
\end{tabular}

'Zarate A, 1976; ${ }^{2}$ No se sabe si se trata de niños pretérmino o no; ${ }^{3}$ No se cuenta con estimadores de precisión de los resultados y muy pocos pacientes

Comparación 6: Tratamiento con hierbas (shatavari, torbangun, combinación de 13 hierbas japonesas, cardo de leche, fenogreco) (en general, tratamiento de un mes o más de duración) vs. Control

Bibliografía: Mortel M, 2013; Ghasemi V, 2015, Manjula 2014.

1. Fenogreco vs. Placebo

\begin{tabular}{|c|c|c|c|c|c|c|c|c|c|c|c|c|}
\hline \multirow{2}{*}{\multicolumn{7}{|c|}{ Evaluación de la calidad }} & \multicolumn{4}{|c|}{ Resumen de los Resultados } & \multirow{3}{*}{ Calidad } & \multirow{3}{*}{ Importancia } \\
\hline & & & & & & & \multicolumn{2}{|c|}{ № de pacientes } & \multicolumn{2}{|c|}{ Magnitud del efecto } & & \\
\hline $\begin{array}{c}\begin{array}{c}\text { No } \\
\text { estudios } \\
\text { estudios }\end{array} \\
\end{array}$ & Diseño & \begin{tabular}{|c|}
$\begin{array}{c}\text { Riesgo de } \\
\text { sesgo }\end{array}$ \\
\end{tabular} & Inconsistencia & \begin{tabular}{|l|}
$\begin{array}{l}\text { Evidencia } \\
\text { indirecta }\end{array}$ \\
\end{tabular} & Imprecisión & $\begin{array}{c}\text { Otras } \\
\text { consideraciones }\end{array}$ & Fenogreco & Control & $\begin{array}{l}\text { Relativa } \\
(95 \% \text { Cl) }\end{array}$ & \begin{tabular}{|c|}
$\begin{array}{c}\text { Absoluta por } \\
1000\end{array}$ \\
\end{tabular} & & \\
\hline \multicolumn{13}{|c|}{ Peso del recién nacido en niños a término al mes de inicio del tratamiento } \\
\hline 11 & ECA & No serio & No seria & No seria & Seria ${ }^{2}$ & Ninguna & № total: 39 & № total: 39 & \multicolumn{2}{|c|}{$6,383 \mathrm{~g}$ vs. $6018 \mathrm{~g}(\mathrm{p}<0,001)$} & MODERADA & IMPORTANTE \\
\hline \multicolumn{13}{|c|}{ Volumen de leche, niños a término } \\
\hline $2^{3}$ & ECA & Serio $^{4}$ & Seria ${ }^{5}$ & No seria & Seria $^{2}$ & Ninguna & № total: 47 & № total: 47 & \multicolumn{2}{|c|}{$\begin{array}{l}\left(\begin{array}{l}(F e n o g r e c o \\
(p<0,05)\end{array}\right. \\
\text { Damanik 2006: de } 467 \text { a } 400 \mathrm{ml} / \mathrm{d}\end{array}$} & MUY BAJA & CRITICA \\
\hline
\end{tabular}


\begin{tabular}{|l|l|l|l|l|l|l|l|l|l|}
\hline & & & & & & & & \\
\hline
\end{tabular}

15 minutos en el día $3 ; 5$ En un estudio disminuye y en otro aumenta;

\section{Gossypium vs. Placebo}

\begin{tabular}{|c|c|c|c|c|c|c|c|c|c|c|c|c|}
\hline \multirow{2}{*}{\multicolumn{7}{|c|}{ Evaluación de la calidad }} & \multicolumn{4}{|c|}{ Resumen de los Resultados } & \multirow{3}{*}{ Calidad } & \multirow{3}{*}{ Importancia } \\
\hline & & & & & & & \multicolumn{2}{|c|}{ № de pacientes } & \multicolumn{2}{|c|}{ Magnitud del efecto } & & \\
\hline $\begin{array}{c}\text { № de } \\
\text { estudios }\end{array}$ & Diseño & $\begin{array}{c}\text { Riesgo de } \\
\text { sesgo }\end{array}$ & Inconsistencia & \begin{tabular}{|l}
$\begin{array}{l}\text { Evidencia } \\
\text { indirecta }\end{array}$ \\
\end{tabular} & Imprecisión & \begin{tabular}{|c|} 
Otras \\
consideraciones
\end{tabular} & Tt con hierbas & Control & $\begin{array}{l}\text { Relativa } \\
\text { (95\% Cl) }\end{array}$ & $\begin{array}{c}\text { Absoluta por } \\
1000\end{array}$ & & \\
\hline \multicolumn{13}{|c|}{ Peso del recién nacido en niños a término al mes de inicio del tratamiento } \\
\hline $1^{1}$ & ECA & Serio $^{2}$ & \begin{tabular}{|l|} 
No seria \\
\end{tabular} & No seria & Seria $^{3}$ & Ninguna & № total: 30 & № total: 15 & 5790 vs 5940 & $=0,65$ & BAJA & IMPORTANTE \\
\hline \multicolumn{13}{|c|}{ Volumen necesario de suplemento alimenticio en niños a término } \\
\hline 11 & ECA & Serio ${ }^{2}$ & \begin{tabular}{|l|l|} 
No seria \\
\end{tabular} & Seria $^{4}$ & Seria $^{3}$ & Ninguna & № total: 30 & № total: 15 & $40 \mathrm{vs} 227 \mathrm{~mL}$ & $=0,008$ & MUY BAJA & CRITICA \\
\hline
\end{tabular}

${ }^{1}$ Manjula, 2014; ${ }^{2}$ En el estudio de Manjula et al, 2014 no hay diferencias en el peso pero sí en la cantidad de suplemento que se le da al niño según el grupo al que pertenezca, con lo que comparar el peso si se daba más suplemento a un grupo que otro no tiene mucho sentido en este caso (resultado sesgado); ${ }^{3} \mathrm{El}$ número de sujetos evaluados en los estudios es pequeño, no se cuenta con información sobre los resultados del grupo control en uno de los estudios; ${ }^{4}$ Volumen de suplemento no es evidencia directa de eficacia de galactogogo.

\section{Torbagun vs. Placebo}

\begin{tabular}{|c|c|c|c|c|c|c|c|c|c|c|c|c|}
\hline \multirow{2}{*}{\multicolumn{7}{|c|}{ Evaluación de la calidad }} & \multicolumn{4}{|c|}{ Resumen de los Resultados } & \multirow{3}{*}{ Calidad } & \multirow{3}{*}{ Importancia } \\
\hline & & & & & & & \multicolumn{2}{|c|}{ № de pacientes } & \multicolumn{2}{|c|}{ Magnitud del efecto } & & \\
\hline $\begin{array}{c}\text { № de } \\
\text { estudios }\end{array}$ & Diseño & $\begin{array}{l}\text { Riesgo de } \\
\text { sesgo }\end{array}$ & Inconsistencia & $\begin{array}{l}\text { Evidencia } \\
\text { indirecta }\end{array}$ & Imprecisión & \begin{tabular}{|c|} 
Otras \\
consideraciones
\end{tabular} & Tt con hierbas & Control & $\begin{array}{l}\text { Relativa } \\
\text { (95\% Cl) }\end{array}$ & \begin{tabular}{|c|}
$\begin{array}{c}\text { Absoluta por } \\
1000\end{array}$ \\
\end{tabular} & & \\
\hline \multicolumn{13}{|c|}{ Volumen de leche, niños a término (de día 14 a día 52) } \\
\hline 11 & ECA & Serio $^{2}$ & No seria & No seria & Seria $^{3}$ & Ninguna & № total: 25 & № total: 25 & \multicolumn{2}{|c|}{\begin{tabular}{|l|} 
Damanik 2006: aumento de 361 \\
a $479 \mathrm{ml} / \mathrm{d} ; \quad$ p $<0,05$ en grupo \\
Torbagun vs. disminución de 454 \\
$\mathrm{ml} / \mathrm{d}$ a $385 \mathrm{ml} / \mathrm{d}$ en arupo control.
\end{tabular}} & BAJA & CRITICA \\
\hline
\end{tabular}

${ }^{1}$ Damanik 2006; ${ }^{2}$ Posible riesgo de sesgos; ${ }^{3}$ El número de sujetos evaluados en los estudios es pequeño.

\section{Combinación de 13 hierbas japonesas vs. Placebo}

\begin{tabular}{|c|c|c|c|c|c|c|c|c|c|c|c|c|}
\hline \multirow{2}{*}{\multicolumn{7}{|c|}{ Evaluación de la calidad }} & \multicolumn{4}{|c|}{ Resumen de los Resultados } & \multirow{3}{*}{ Calidad } & \multirow{3}{*}{ Importancia } \\
\hline & & & & & & & \multicolumn{2}{|c|}{ № de pacientes } & \multicolumn{2}{|c|}{ Magnitud del efecto } & & \\
\hline $\begin{array}{c}\text { № de } \\
\text { estudios }\end{array}$ & Diseño & $\begin{array}{l}\text { Riesgo de } \\
\text { sesgo }\end{array}$ & Inconsistencia & \begin{tabular}{|c|} 
Evidencia \\
indirecta
\end{tabular} & Imprecisión & \begin{tabular}{|c|} 
Otras \\
consideraciones
\end{tabular} & Tt con hierbas & Control & $\begin{array}{l}\text { Relativa } \\
\text { (95\% Cl) }\end{array}$ & $\begin{array}{c}\text { Absoluta por } \\
1000\end{array}$ & & \\
\hline
\end{tabular}


GPC Lactancia Materna- Pregunta 25. Galactogogos.

\begin{tabular}{|c|c|c|c|c|c|c|c|c|c|c|c|}
\hline $11^{1}$ & ECA & Serio $^{2}$ & No seria & No seria & Seria $^{3}$ & Ninguna & 41 & 41 & 414 vs $293 \mathrm{~g}(\mathrm{p}<0,05)$ & BAJA & CRITICA \\
\hline \multicolumn{12}{|c|}{ Niveles de prolactina, niños a término } \\
\hline $1^{1}$ & ECA & Serio $^{2}$ & No seria & No seria & Seria $^{3}$ & Ninguna & 41 & 41 & 168 vs $117 \mathrm{ng} / \mathrm{ml}(\mathrm{p}<0,01)$. & BAJA & IMPORTANTE \\
\hline
\end{tabular}

5. Cardo de leche (Sylvarin) vs. Placebo

\begin{tabular}{|c|c|c|c|c|c|c|c|c|c|c|c|c|}
\hline \multirow{2}{*}{\multicolumn{7}{|c|}{ Evaluación de la calidad }} & \multicolumn{4}{|c|}{$\begin{array}{l}\text { Resumen de los Resultados } \\
\end{array}$} & \multirow{3}{*}{ Calidad } & \multirow{3}{*}{ Importancia } \\
\hline & & & & & & & \multicolumn{2}{|c|}{ № de pacientes } & \multicolumn{2}{|c|}{\begin{tabular}{|l|} 
Magnitud del efecto \\
\end{tabular}} & & \\
\hline $\begin{array}{c}\text { № de } \\
\text { estudios }\end{array}$ & Diseño & $\begin{array}{c}\text { Riesgo de } \\
\text { sesgo }\end{array}$ & Inconsistencia & \begin{tabular}{|c|} 
Evidencia \\
indirecta
\end{tabular} & Imprecisión & $\begin{array}{c}\text { Otras } \\
\text { consideraciones }\end{array}$ & Sylvarin & Control & $\begin{array}{l}\text { Relativa } \\
(95 \% \mathrm{Cl})\end{array}$ & $\begin{array}{c}\text { Absoluta por } \\
1000\end{array}$ & & \\
\hline \multicolumn{13}{|c|}{ Volumen de leche, niños a término } \\
\hline 11 & ECA & Serio $^{2}$ & No seria & Seria $^{3}$ & Seria ${ }^{4}$ & Ninguna & 25 & 25 & \multicolumn{2}{|c|}{$\begin{array}{l}\text { A los } 30 \text { días:_990g vs } 650 \mathrm{~g} \\
(\mathrm{p}<0,01) \text {. }\end{array}$} & MUY BAJA & CRITICA \\
\hline
\end{tabular}

1Di Pierro 2008; ${ }^{2}$ Posible riesgo de sesgos; ' Definición de hipoglactia: madres sanas niños sanos pero con producción de leche "borderline" con respecto a lo medido en su hospital. No detallan en qué momento de la lactancia están las madres; ${ }^{4}$ Muy pocos sujetos evaluados.

\begin{tabular}{|c|c|c|c|c|c|c|c|c|c|c|c|c|}
\hline \multirow{2}{*}{\multicolumn{7}{|c|}{ Evaluación de la calidad }} & \multicolumn{4}{|c|}{ Resumen de los Resultados } & \multirow{3}{*}{ Calidad } & \multirow{3}{*}{ Importancia } \\
\hline & & & & & & & \multicolumn{2}{|c|}{ № de pacientes } & \multicolumn{2}{|c|}{ Magnitud del efecto } & & \\
\hline $\begin{array}{c}\text { № de } \\
\text { estudios }\end{array}$ & Diseño & $\begin{array}{c}\text { Riesgo de } \\
\text { sesgo }\end{array}$ & Inconsistencia & \begin{tabular}{|l|} 
Evidencia \\
indirecta
\end{tabular} & Imprecisión & \begin{tabular}{|c|} 
Otras \\
consideraciones
\end{tabular} & Shavatari & Placebo & $\begin{array}{l}\text { Relativa } \\
(95 \% \mathrm{Cl})\end{array}$ & $\begin{array}{c}\text { Absoluta por } \\
1000\end{array}$ & & \\
\hline \multicolumn{13}{|c|}{ Niveles de prolactina, niños a término (shatavari, combinación de 13 hierbas japonesas) } \\
\hline $2^{1}$ & ECA & No serio & \begin{tabular}{|l|} 
Seria \\
2
\end{tabular} & No seria & Seria $^{3}$ & Ninguna & 62 & 62 & \multicolumn{2}{|c|}{$\begin{array}{l}\text { Sharma 1996: } 25 \text { vs } 38 \mathrm{ng} / \mathrm{ml} \text {. } \\
\left.\begin{array}{l}\text { Gupta 2011: } \\
\text { 32.9\% vs } 9.6 \% \\
\text { incremento } \\
\end{array}<0,05\right) .\end{array}$} & BAJA & IMPORTANTE \\
\hline
\end{tabular}

${ }^{1}$ Sharma 1996; Gupta $2011 ;{ }^{2}$ en un estudio aumenta y en otro no; ${ }^{3}$ Pocos pacientes. 


\section{2- Resumen de la Evidencia}

La revisión sistemática de Paul et al, 2015 evaluó la relación riesgobeneficio del uso de domperidona como galactogogo en madres con lactancia materna insuficiente. La búsqueda incluyó estudios publicados hasta el año 2013. En la revisión se incluyeron 2 revisiones sistemáticas $(5 ; 6)$ y 4 ensayos clínicos controlados doble ciego (11-14) que evaluaron el tratamiento con 30 o $40 \mathrm{mg}$ de domperidona al día durante 4 a 14 días frente placebo. Los desenlaces principales de esta revisión fueron el volumen de leche, el aumento de los niveles de prolactina y los efectos adversos. Los autores no realizaron un metaanálisis y los resultados se reportaron de acuerdo a lo observado en los ensayos clínicos. El volumen de leche se reportó antes y después de 4, 7, 10 ó 14 días de tratamiento y los niveles de prolactina antes y después de 7, 10 ó 14 días de tratamiento. Los tres ensayos clínicos sin grupo control fueron incluidos para evaluar los efectos adversos de la domperidona en los hijos.

La revisión sistemática Donovan 2012 evaluó la eficacia y seguridad del tratamiento con domperidona en madres de hijos pre-término. La búsqueda incluyó estudios publicados hasta el año 2011. En la revisión se incluyeron 2 ensayos clínicos controlados doble ciego (12;14). Los ensayos clínicos evaluaron el efecto de la domperidona $30 \mathrm{mg}$ al día durante 7 a 14 días frente al placebo. Los desenlaces principales de esta revisión fueron la lactancia materna, el volumen de leche producido y los efectos adversos. Los autores realizaron un metaanálisis de los resultados sobre volumen de leche.

La revisión sistemática Zuppa 2010 incluyó 4 ensayos clínicos aleatorizados que evaluaron la eficacia y seguridad del tratamiento con metoclopramida $(15 ; 16)(17 ; 18), 4$ que evaluaron el sulpiride (19-22) y 4 el tratamiento hormonal (23-26). Los desenlaces principales de esta revisión fueron la duración de la lactancia materna, el volumen de leche, los niveles de prolactina y los efectos adversos. Los autores no realizaron metanálisis y los resultados se presentaron de forma descriptiva de acuerdo a lo observado en los ensayos clínicos.

La revisión sistemática de Mortel 2013 incluyó 2 ensayos clínicos aleatorizados que evaluaron la eficacia y seguridad del tratamiento con shatavari (27;28), 1 que evaluó el torbangun (29), 1 que evaluó una combinación de 13 hierbas japonesas (30), 1 que evaluó el cardo de leche (31) y 1 que evaluó el fenogreco (32). Los desenlaces principales de esta revisión fueron el volumen de leche y los niveles de prolactina. Los autores no realizaron metaanálisis y los resultados se presentaron de forma descriptiva de acuerdo a lo observado en los ensayos clínicos.

En la actualización de la búsqueda sólo se identificaron dos ensayos clínicos publicados después de las revisiones sistemáticas. El ensayo clínico de Ghasemi 2015 (33) evaluó el efecto del fenogreco sobre el crecimiento de niñas recién nacidas y el ensayo clínico de Manjula 2014 (34) evaluó el efecto del Gossypium herbaceum sobre la ganancia de peso y el volumen medio del suplemento diario.

Para la elaboración de esta pregunta, los desenlaces críticos han sido 
principalmente el incremento en el volumen de leche y los efectos adversos de los galactotogos, aunque también se han considerado otros desenlaces como los niveles de prolactina medidos antes y después del tratamiento, la duración de la lactancia materna etc.

\section{Comparación 1. Domperidona vs. placebo}

En cuanto a la lactancia materna, solo se han obtenido datos de estudios en prematuros. Dos ensayos clínicos controlados doble ciego evaluaron la eficacia de la domperidona $30 \mathrm{mg}$ al día de 7 a 14 días de duración frente al placebo en madres de hijos pre-término (<31 semanas) $(12 ; 14)$. Ambos estudios incluyeron un total de 59 parejas madre-hijo con un seguimiento desde el nacimiento hasta el alta hospitalaria. Las madres incluidas presentaron una producción baja de leche a pesar de los consejos de lactancia o un fallo en la lactancia durante más de dos semanas post-parto. En ambos estudios, el nivel basal de prolactina fue $<100 \mathrm{ng} / \mathrm{ml}$, tanto en el grupo que recibió domperidona como en el grupo placebo (72,1ng/l vs. 50ng/l para el estudio de Campbell-Yeo 2010; $12,9 \mathrm{ng} / \mathrm{l}$ vs. 15,6ng/l para el estudio de Da Silva 2001). Después de 7 a 14 días de tratamiento no se observaron diferencias en el porcentaje de madres con lactancia materna en ambos grupos (domperidona vs. placebo: $54,6 \%$ vs. $52,2 \%$; p no reportado).

En cuanto al volumen de leche, fueron dos los ensayos que evaluaron la eficacia de domperidona (30 o 40mg) frente al placebo en madres de hijos a término $(11 ; 13)$. El estudio de Jantarasaengaram incluyó un total de 77 parejas madre-hijo. El nivel basal de prolactina no se reportó. Después de 4 días de tratamiento se observó un mayor volumen medio de leche en las madres que recibieron domperidona $40 \mathrm{mg}$ durante 4 días frente al grupo control (191,3 ml/d vs. 91,4 ml/d; $p=0,003)$.

El estudio de Petraglia (13) incluyó 32 madres sanas con niños a término que o bien eran multíparas con fallo en la lactogénesis o eran primíparas con lactancia inadecuada durante las dos primeras semanas postparto. En ambos casos el tratamiento con domperidona aumenta el volumen de leche frente a placebo (en multíparas, el tratamiento entre el $2^{\circ}$ y $5^{\circ}$ día postparto aumenta el volumen de leche de 105 a $475 \mathrm{ml}$ frente a valores más bajos para el grupo placebo; en primíparas, el tratamiento durante 10 días con domperidona aumenta el volumen de leche de 371-417 ml/día a 631-708 ml/día, frente al no aumento en el grupo placebo).

En cuanto a los niveles de prolactina, en el ensayo de Petraglia 1985 (13), en el que se distinguió el análisis entre madres multíparas y primíparas, el nivel basal de prolactina en las madres multíparas fue alto, siendo de $129 \mathrm{ng} / \mathrm{ml}$ en grupo tratado frente a $131 \mathrm{ng} / \mathrm{ml}$ en el grupo control. El nivel basal de prolactina en las madres primíparas fue de 68 $\mathrm{ng} / \mathrm{ml}$ en el grupo tratado frente a $79 \mathrm{ng} / \mathrm{ml}$ en el grupo control. En madres multíparas, el nivel de prolactina fue un $97 \%$ más alto al 5 día en comparación con el $2^{\circ}$ día en el grupo que recibió tratamiento $(p<0,05)$ mientras que en el grupo control el incremento fue $55 \%$ más alto al $5^{\circ}$ día en comparación con el $2^{\circ}(p<0,01)$. Respecto a las primíparas, el nivel de prolactina al $5^{\circ}$ día fue superior en las madres que recibieron el tratamiento con domperidona frente al grupo control $(169 \mathrm{ng} / \mathrm{mL}$ frente a $84 \mathrm{ng} / \mathrm{mL}$; $p$ no reportado).

Calidad

muy baja

\section{Calidad baja}


En cuanto a los efectos adversos en la madre o el hijo, después de 4 a 14 días de tratamiento, no se reportaron efectos adversos graves ni moderados en los cuatro ensayos incluidos (11-14). Se reportó boca seca en 7 madres y dolor abdominal en 1 una madre en el grupo de mujeres tratadas con domperidona $(n=60)$ frente a ninguna de las madres del grupo control.

\section{Comparación 2. Metoclopramida vs. placebo}

En cuanto a la duración de la lactancia materna, solo se han encontrado dos ECA que incluyen niños pre-término que evalúan la eficacia de la metoclopramida $30 \mathrm{mg} / \mathrm{d}$ entre 7 y 17 días después del parto frente al placebo $(15 ; 18)$. Ambos estudios incluyeron un total de 77 parejas madre-hijo, no mostrando diferencias significativas en la duración de la lactancia materna. En el ECA de Hansen 2005 la mediana de lactancia materna fue de 8,8 (RIC de 3,4 a 12) semanas con metoclopramida y 8,6 (RIC de 5,6 a 16,9$)$ semanas con placebo $(p=0,09)$. En el ECA de Lewis 1980, no hubo diferencias en el número de niños con lactancia materna tanto a las 6 semanas como a los tres meses de vida ( $8 / 10$ vs. $9 / 10$ y $4 / 10$ vs. $4 / 10$, respectivamente; $p$ no reportado).

En cuanto al volumen de leche, son 2 los ensayos clínicos controlados que evaluaron la eficacia de la metoclopramida $30 \mathrm{mg} / \mathrm{d}$ durante 8 a 21 días después del parto frente al placebo en madres de hijos a término $(16 ; 17)$. Los dos estudios incluyeron un total de 38 parejas madre-hijo. Kauppila 1985 (17) reportó un incremento de 285 a $530 \mathrm{ml} / \mathrm{d}(\mathrm{p}<0,01)$ en el volumen diario de leche y De Gezelle 1983 (16) un volumen 50\% superior en las madres después de 21 días de tratamiento con metoclopramida.

En cuanto a los niveles de prolactina, el ECA de Kauppila 1985 (17) evaluó este desenlace en madres de hijos a término. El nivel basal de prolactina de las madres incluidas fue bajo a moderado, siendo $57,5 \mathrm{U} / \mathrm{l}$ en las mujeres tratadas y $72,8 \mathrm{U} / \mathrm{l}$ en el grupo control. Después 21 días de tratamiento, se observó un incremento en los niveles de prolactina en el grupo tratado con metoclopramida que fue significativamente superior al grupo control (nivel de prolactina el día 21: $210,7 \mathrm{U} / \mathrm{l}$ vs. $68,5 \mathrm{U} / \mathrm{I}$, respectivamente).

En cuanto a los efectos adversos en la madre o el hijo, 3 estudios observacionales evaluaron este desenlace (35-37). Se reportó malestar intestinal leve a moderado en un niño y cansancio, cefalea, ansiedad, somnolencia, fatiga, trastornos intestinales y extrapiramidales en las madres.

\section{Comparación 3. Metoclopramida $30 \mathrm{mg} / \mathrm{d}$ vs. domperidona $30 \mathrm{mg} / \mathrm{d}$ (tratamiento de 10 días de duración)}

Solo se ha encontrado un ECA, que incluye a madres de niños prematuros ingresados en UCl y que evalúa la efiacia de la metoclopramida $30 \mathrm{mg} /$ día frente a la domperidona $30 \mathrm{mg} /$ día durante 10

Calidad muy baja

Calidad muy baja

\section{Calidad baja}

Calidad muy baja 
días después del parto (Ingram 2012). El estudio incluyó un total de 65 parejas madre-hijo, con datos analizables para 65, mostrando un aumento del volumen medio de leche del $93,7 \%$ en el grupo tratado con metoclopramida frente a $96,3 \%$ en el grupo tratado con domperidona ( $p$ no reportado).

\section{Comparación 4. Sulpiride vs. placebo}

En cuanto a la duración de la lactancia materna en primíparas de niños a término, un ensayo clínico controlado evaluó la eficacia del sulpiride $100 \mathrm{mg} / \mathrm{d}$ durante 4 días después del tercer día del parto frente al placebo en primíparas (22). El estudio incluyó un total de 42 parejas madre-hijo. Se reportó una mayor proporción de madres con lactancia materna durante el primer mes en el grupo tratado con sulpiride $(55 \%)$ frente al grupo control (30\%) (sulpiride $=11 / 20$ vs. placebo $=7 / 22 ; p=n o$ reportado).

En cuanto al volumen de leche en madres primíparas y multíparas, son 4 los ensayos clínicos controlados que evaluaron la eficacia del sulpiride 100 a $150 \mathrm{mg} / \mathrm{d}$ durante 5 a 28 días después del parto frente al placebo en madres primíparas y multíparas (19-22). Los cuatro estudios incluyeron un total de 260 parejas madre-hijo. Todos los estudios reportaron un incremento superior en los niveles de prolactina de las madres tratadas con sulpiride frente al placebo. El incremento fue de 212 a $1211,7 \mathrm{ml} / \mathrm{d}$ con sulpiride frente a una disminución o incremento de hasta $916,0 \mathrm{ml} / \mathrm{d}$ en el grupo placebo.

En cuanto a los niveles de prolactina, 3 de los 4 ensayos clínicos descritos en el apartado anterior (19-21) evaluaron este desenlace. Todos los estudios reportaron un incremento en los niveles de prolactina del grupo tratado con sulpiride. De forma cuantitativa el estudio de Ylikorkala 1982 reportó que después de 28 días de tratamiento, se observó un incremento en los niveles de prolactina hasta $402 \mu \mathrm{g} / \mathrm{l}$ en el grupo tratado con sulpiride frente a una disminución a $47,8 \mu \mathrm{g} / \mathrm{l}$ en el grupo placebo $(\mathrm{p}=$ no reportado). Sin embargo, hay que tener en cuenta que se trata de una evidencia indirecta de efecto de los galactogogos.

En cuanto a los efectos adversos en la madre, el ECA de Ylikorkala 1982 (20) reportó cefalea y fatiga moderada en 3 de las 12 madres tratadas con sulpiride y en ninguna del grupo placebo ( $p=$ no reportado). No se reportaron otros efectos adversos.

Comparación 5. Tratamiento hormonal (oxitocina, hormona del crecimiento, hormona liberadora de tirotropina) vs. placebo

Los únicos estudios identificados son estudios que incluyen madres de niños pretérmino.

\section{Oxitocina versus placebo}

Son dos los ensayos clínicos que evalúan la eficacia de la oxitocina spray nasal (40 U/mL o $100 \mu \mathrm{l} / \mathrm{spray})$ durante 5 días después del parto(25;26). 
En cuanto al volumen de leche, en el ensayo de Ruis el volumen acumulado de leche entre el $2^{\circ}$ y $5^{\circ}$ fue mayor en las mujeres tratadas con oxitocina(26). Sin embargo, en el ensayo de Fewtrell(25) no hubo diferencias en el peso medio de leche producida durante los 5 días de tratamiento.

\section{Hormona de crecimiento versus placebo}

El único ensayo identificado evalúa la eficacia de la hormona de crecimiento (1 $016 \mathrm{lU} / \mathrm{kg} / \mathrm{d}$ durante 7 días después del parto) (24), encontrando un aumento en el volumen medio de leche de $139 \mathrm{ml} / \mathrm{d}$ a $175 \mathrm{ml} / \mathrm{d}$ en el grupo tratado con la hormona frente a un aumento de 93 $\mathrm{ml} / \mathrm{d}$ a $102 \mathrm{ml} /$ día $(\mathrm{p}<0,01)$.

$\underline{\text { Hormona liberadora de tirotropina versus placebo }}$

Un único ensayo evalúa la eficacia del tratamiento con hormona liberadora de tirotropina ( $60 \mathrm{mg} / \mathrm{d}$ durante 7 días después del parto) frente placebo (23), sin encontrar diferencias en el volumen medio de leche tras 7 días de tratamiento entre los grupos de comparación.

En cuanto a los niveles de prolactina, el ECA de Zarate 1976 (23) evaluó este desenlace. Los autores reportan que los niveles de prolactina fueron significativamente superiores en las mujeres tratadas con hormona liberadora de tirotropina frente al grupo control ( $p$ no reportado).

Calidad muy baja

\section{Calidad} baja

Calidad muy baja

Calidad muy baja

En cuanto a los efectos adversos, los ensayos clínicos que evaluaron la eficacia del tratamiento hormonal no reportaron efectos adversos. Sin embargo los autores de la RS Zuppa 2010 (8)refieren que sí se han observado efectos adversos sobre la madre y el lactante en otros estudios experimentales y observacionales por lo que el tratamiento hormonal no sería recomendable.

\section{Comparación 6. Tratamiento con hierbas}

Trigonella foenum-graecum (fenogreco) frente a placebo

En cuanto a la ganancia de peso de los recién nacidos a término, dos ensayos clínicos evaluaron la eficacia del tratamiento con hierbas sobre el peso de los recién nacidos. En el estudio de Ghasemi et al, 2015 (33), las madres recibieron $22,5 \mathrm{~g}$ de fenogreco al día durante cuatro semanas. Sólo se incluyeron niñas y se reportó que el peso en el grupo intervención se incrementó de 5,597 a 6,383 gramos después de recibir el tratamiento, mientras que en el grupo control éste se incrementó de 5,510 a 6019 gramos $(p<0,001)$.

En cuanto al volumen de leche, un estudio (29) se encuentra que las madres que toman fenogreco tienen una menor producción de leche que las del grupo control, mientras que en el segundo estudio (32) el volumen medio de leche fue mayor en mujeres con fenogreco.

\section{Gossypium herbaceum frente a placebo}

Calidad

moderada

En el estudio de Manjula 2014 (34), las madres recibieron $30 \mathrm{~g}$ de

Calidad

muy baja 
Gossypium herbaceum al día durante cuatro semanas. El peso en los recién nacidos a las cuatro semanas fue similar (5790 g frente a $5940 \mathrm{~g}$; $p=0,65)$, aunque en este caso a los niños del grupo control se les suministraba suplemento, por lo que este resultado puede estar sesgado.

Calidad

baja

En cuanto a la necesidad de suplemento alimenticio, se reportó que el volumen medio de suplemento necesario tras el tratamiento fue menor en el grupo Gossypium herbaceum que en el grupo control $(40 \mathrm{~mL} / \mathrm{d}$ frente a $227 \mathrm{~mL} / \mathrm{d} ; \mathrm{p}=0,008$ ), aunque hay que tener en cuenta que se trata de una medición indirecta del aumento de la producción de leche.

\section{Coleus amboinicus Lour (Torbangun) frente a placebo}

En cuanto al volumen de leche el día 14 y 28 tras tratamiento con torbangun, éste aumenta de $361 \mathrm{ml} / \mathrm{d}$ a $479 \mathrm{ml} / \mathrm{d}$ frente al grupo control $(p<0,05)(29)$.

\section{Combinación de 13 hierbas japonesas frente a placebo}

El volumen de leche al sexto día (30) aumenta de forma significativa en las madres tratadas con la combinacón de las 13 hierbas japonesas (413,7 gramos vs. 293,3 gramos; $p=0,046)$, aunque cabe destacar que el grupo control fue tratado con un inhibidor de lactancia materna.

Sobre los niveles de prolactina, también se encuentra un incremento superior en las madres tratadas con hierbas frente al grupo control.

\section{Silybum marianum (cardo de leche) frente a placebo}

En el estudio de Di Pierro et al, 2008 (31), el volumen medio de leche fue superior en el grupo intervención frente al grupo control, tanto a los 30 $(989,8 \mathrm{~g}$ vs. $649,8 \mathrm{~g} ; \mathrm{p}<0,01)$ como a los 63 días de tratamiento $(1.119,2 \mathrm{~g}$ vs. $700,6 \mathrm{~g} ; \mathrm{p}<0,01)$.

Asparagus racemosus (Shavatari) frente a placebo

En cuanto a los niveles de prolactina, los ECA de Sharma 1996 (27) y Gupta, 2011 (28) evaluaron este desenlace. Las madres recibieron dos cucharitas de $100 \mathrm{~g}$ de una combinación que contiene $15 \%$ de shatavari, dos veces al día ó $60 \mathrm{mg} / \mathrm{kg}$ peso al día durante 30 días, reportando un incremento superior en los niveles de prolactina de las mujeres que fueron tratadas con hierbas frente al grupo control.

En cuanto a los efectos adversos, los ensayos clínicos que evaluaron la eficacia del tratamiento con galactogogos herbales no reportaron efectos adversos.

\section{Resultados de la actualización de la búsqueda a octubre de 2016}

En la actualización se ha identificado un ECA doble ciego realizado en Tai (38) que compara el uso de cápsulas de jengibre de 500mg (dos veces durante 7 días) frente a placebo en mujeres que amamantan y su efecto sc producción de leche, encontrado diferencias al tercer pero no al séptimo
Calidad

\section{Calidad \\ baja}

Calidad

baja

Calidad

baja

Calidad

muy baja

Calidad

baja 
GPC Lactancia Materna- Pregunta 25. Galactogogos.

tratamiento, por lo que no afecta a las recomendaciones.

ACTUALIZADO A FECHA DE: 31 de Octubre de 2016 


\section{5- De la evidencia a la recomendación (Tabla de EtR)}

\section{¿Cuál es el galactogogo más eficaz?}

Población: Madre sana que amamanta con hipogalactia

Intervención/comparación: Dogmatil, domperidona, metoclopramida, tratamiento hormonal, placebo (en muchos estudios reportan que tanto las mujeres del grupo tratado con galactogogos como las mujeres de los grupos placebo recibían consejo sobre lactancia y se extraían la leche mediante el uso de dispositivos).

Perspectiva: Clínica

C1: Domperidona vs. placebo; C2: Metoclopramida vs. Placebo; C3: Metoclopramida vs. Domperidona; C4: Sulpiride vs. Placebo; C5: Tratamiento hormonal vs. Placebo; C6: Galactogogos herbales vs. Placebo

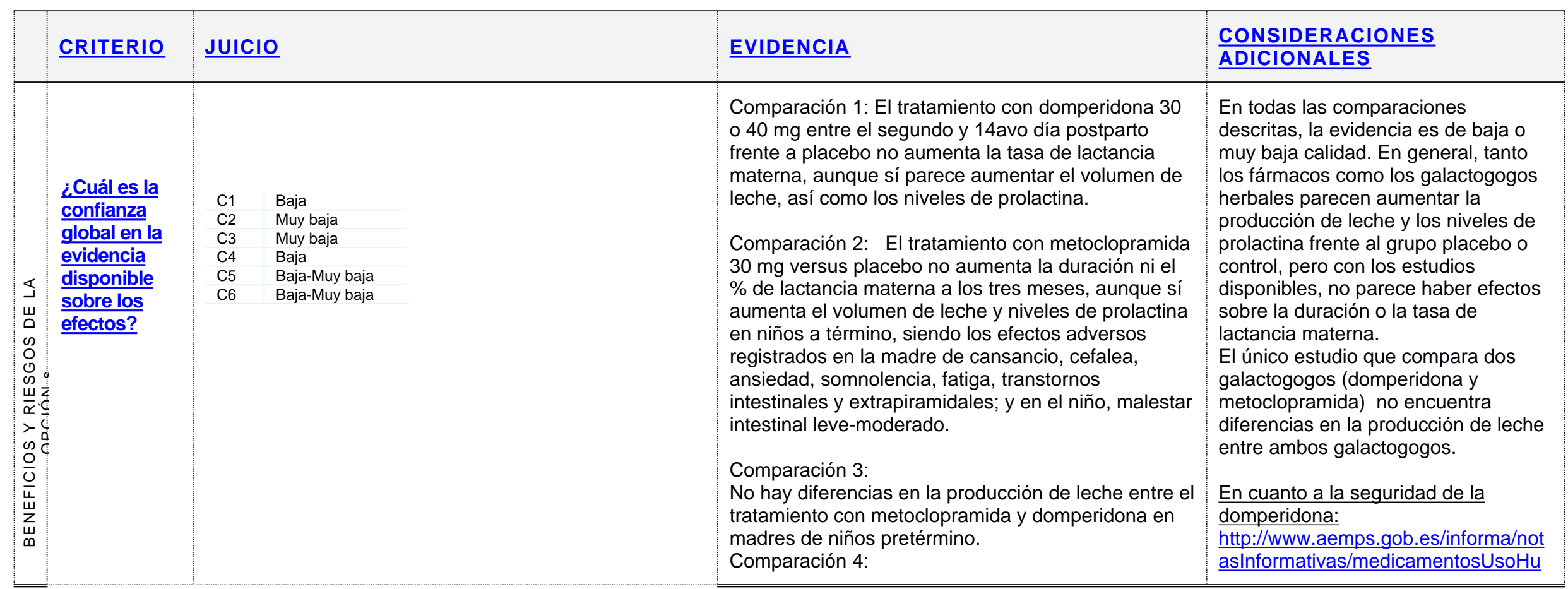




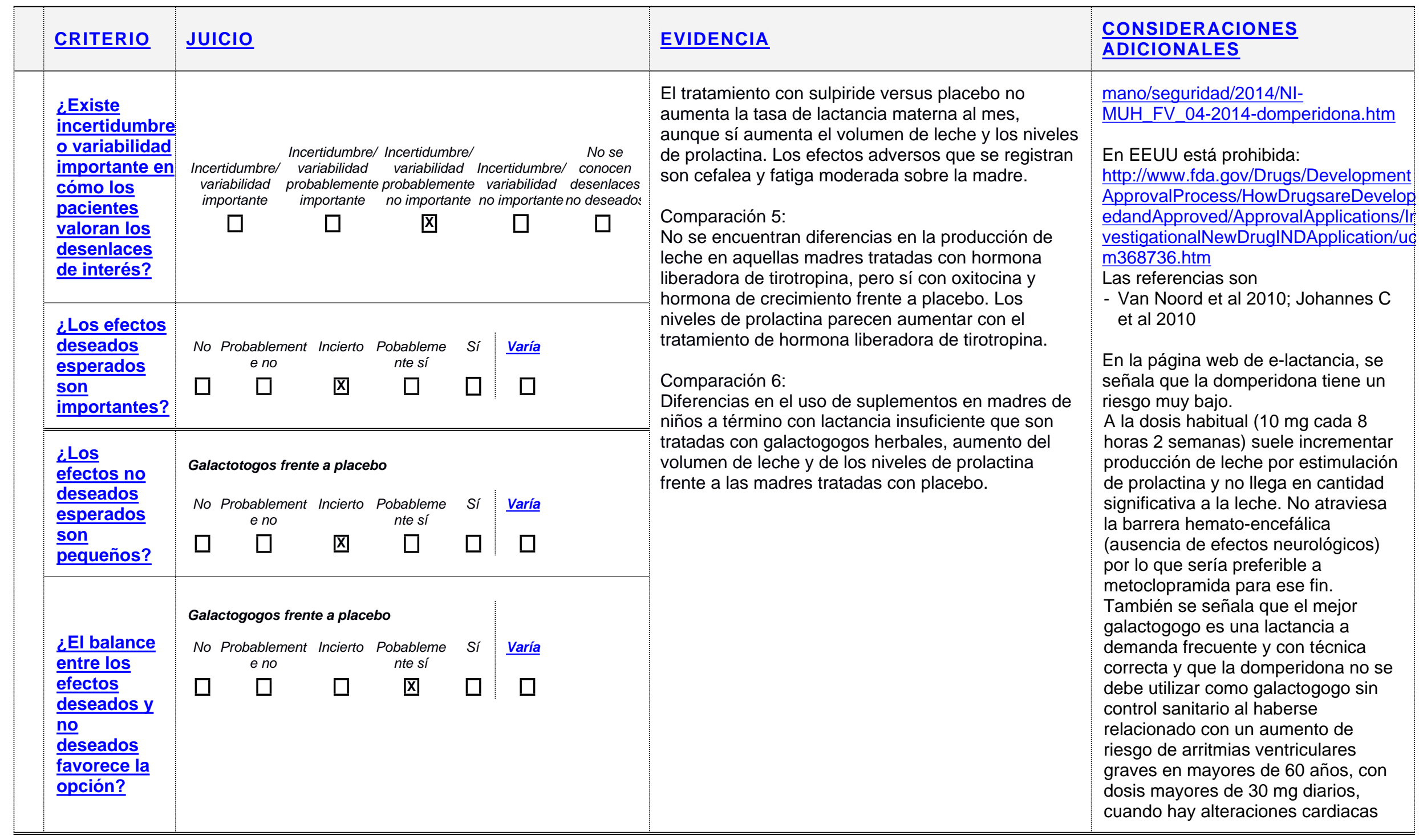


GPC Lactancia Materna- Pregunta 25. Galactogogos.

\begin{tabular}{|c|c|c|c|}
\hline CRITERIO & JUICIO & EVIDENCIA & $\begin{array}{l}\text { CONSIDERACIONES } \\
\underline{\text { ADICIONALES }}\end{array}$ \\
\hline & & & $\begin{array}{l}\text { (QT alargado en el ECG) y asociado } \\
\text { a medicamentos que alargan el QT. } \\
\text { De la metoclopramida, se señala que } \\
\text { el riesgo es muy bajo, y que se } \\
\text { excreta en leche en pequeña } \\
\text { cantidad y no provoca efectos } \\
\text { adversos en los lactantes, salvo leves } \\
\text { molestias intestinales en una } \\
\text { pequeña proporción de ellos. } \\
\text { Dosis de } 10 \text { mg dos a tres veces al } \\
\text { día durante } 2 \text { a } 4 \text { semanas } \\
\text { incrementan la producción de leche } \\
\text { por aumento de la prolactina, pero } \\
\text { sólo si la madre tiene niveles bajos de } \\
\text { prolactina. Este efecto galactogogo } \\
\text { no se encuentra en trabajos bien } \\
\text { diseñados. } \\
\text { Puede provocar efectos neurológicos, } \\
\text { en especial si dosis altas, uso } \\
\text { prolongado (más de un mes) y } \\
\text { especialmente si se toman } \\
\text { antidepresivos al mismo tiempo. } \\
\text { La Domperidona tiene menos efectos } \\
\text { secundarios de tipo neurológico. } \\
\text { También se puede consultar la } \\
\text { página toxnet del NIH de EEUU } \\
\text { (http://toxnet.nlm.nih.gov). }\end{array}$ \\
\hline
\end{tabular}


GPC Lactancia Materna- Pregunta 25. Galactogogos.

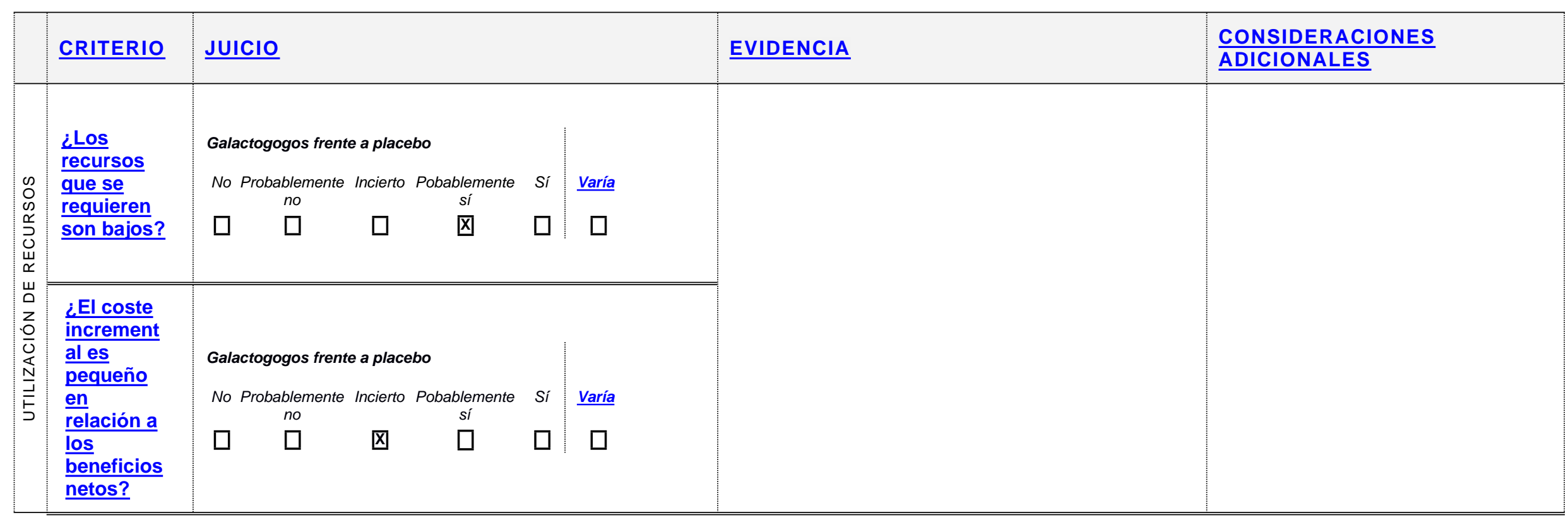


GPC Lactancia Materna- Pregunta 25. Galactogogos.

\begin{tabular}{|c|c|c|c|c|c|}
\hline & $\underline{\text { Criterio }}$ & JUICIO & & EVIDENCIA & $\begin{array}{l}\text { CONSIDERACIONES } \\
\text { ADICIONALES }\end{array}$ \\
\hline 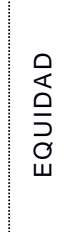 & $\begin{array}{l}\text { ¿Cuál sería } \\
\frac{\text { el impacto }}{\text { en las }} \\
\text { desigualda } \\
\text { des en } \\
\text { salud? }\end{array}$ & 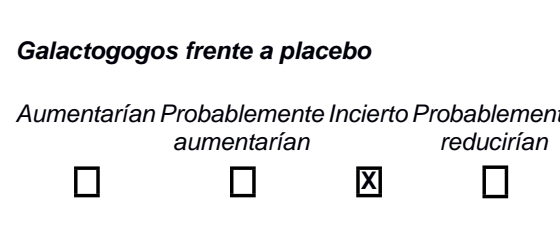 & 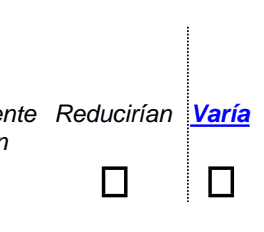 & & \\
\hline
\end{tabular}




\begin{tabular}{|c|c|c|c|c|c|}
\hline \multirow[t]{2}{*}{$\begin{array}{l}\text { Balance de las } \\
\text { consecuencias }\end{array}$} & $\begin{array}{l}\text { Las consecuencias no } \\
\text { deseadas superan } \\
\text { claramente las } \\
\text { consecuencias deseadas } \\
\text { en la mayoría de los } \\
\text { escenarios }\end{array}$ & $\begin{array}{l}\text { Las consecuencias no } \\
\text { deseadas probablemente } \\
\text { superan las } \\
\text { consecuencias deseadas } \\
\text { en la mayoría de los } \\
\text { escenarios }\end{array}$ & $\begin{array}{c}\text { El balance entre las } \\
\text { consecuencias deseadas y } \\
\text { no deseadas está muy } \\
\text { equilibrado o es incierto }\end{array}$ & $\begin{array}{l}\text { Las consecuencias } \\
\text { deseadas } \\
\text { probablemente superan } \\
\text { las consecuencias no } \\
\text { deseadas en la mayoría } \\
\text { de los escenarios }\end{array}$ & $\begin{array}{c}\text { Las consecuencias } \\
\text { deseadas claramente } \\
\text { superan las } \\
\text { consecuencias no } \\
\text { deseadas en la mayoría } \\
\text { de los escenarios }\end{array}$ \\
\hline & $\square$ & $\square$ & 囚 & $\square$ & $\square$ \\
\hline$\frac{\text { Tipo de }}{\text { recomendación }}$ & Se recomienda no ofrecer & Se sugiere no & ofrecer la opción & sugiere ofrecer la opción & $\begin{array}{l}\text { Se recomienda } \\
\text { ofrecer la opción }\end{array}$ \\
\hline
\end{tabular}

凶

\section{Recomendación (Texto)}

\section{Recomendación débil}

Se sugiere el uso de galactogogos para tratar de aumentar la producción de leche si tras haber puesto en práctica el resto de métodos existentes no se han obtenido resultados.

Debido a que la investigación comparativa entre distintos galactogogos no es concluyente, no se puede recomendar ningún galactogogo especifico.

\section{Recomendación de buena práctica}

Cuando tras valorar potenciales riesgos y beneficios de estos agentes se decide prescribir un galactogogo, debería hacerse siguiendo las recomendaciones de las guías que se mencionan en los anexos (ver anexo 16)

Al no estar incluida la indicación como galactogogo en la ficha técnica de estos fármacos, el médico responsable del tratamiento deberá justificar convenientemente en la historia clínica la necesidad del uso del medicamento e informar a la madre de los posibles beneficios y los riesgos potenciales, obteniendo su consentimiento. 
Justificación Ninguno de los medicamentos (domperidona, sulpiride, metocropramida etc) recogen en su ficha técnica la indicación de su uso en la lactancia como galactogogo. El Real Decreto 1015/2009 de 19 de junio, por el que se regula la disponibilidad de medicamentos en situaciones especiales, define su uso en condiciones diferentes a las autorizadas en la ficha técnica, contemplando su utilización cuando hay datos clínicos que avalan su utilidad terapéutica. El médico responsable del tratamiento deberá justificar convenientemente en la historia clínica la necesidad del uso del medicamento e informar a la madre de los posibles beneficios y los riesgos potenciales, obteniendo su consentimiento.

\section{Consideraciones de}

subgrupos

Consideraciones para

la implementación

\section{Monitorización y}

evaluación

Prioridades para la investigación
- La mayoría de los estudios se han hecho en madres de infantes pre-termino que utilizan sacaleches mecánicos en lugar de madres con infantes a término cuyos problemas generalmente aparecen en los primeros días o semanas postparto. Claramente se necesitan estudios bien diseñados, con poder adecuado, aleatorios, controlados, que utilicen dosis adecuadas de galactogogos en poblaciones de mujeres en las que tanto el grupo experimental como el control, reciban apoyo apropiado y moderno en lactancia. Se necesita realizar estos estudios en madres de infantes a término y pre-término y se necesitan medir indicadores clínicamente relevantes como la ganancia de peso del infante, la necesidad de alimentación artificial (otros suplementos diferentes a la leche de la propia madre), cuantificación de la producción materna de leche y efectos adversos de los fármacos.

- Asimismo, es necesario que se hagan estudios en los que quede claramente definido que se entiende por hipogalactia, y cuáles son los criterios diagnósticos de la misma, y en los que la población esté bien definida: pretérmino o a término, edad de lactancia, lactancia directa o madres en extracción, etc. 


\section{ANEXO I, ESTRATEGIAS DE BÚSQUEDA}

\section{Cochrane Library}

\section{Searched 25/06/2015}

\section{Updated search 25/06/2015 a xx/xx/xxxx}

\#1 MeSH descriptor: [Galactogogues] explode all trees 5

\#2 galactogogue or galactogogues:ti,ab,kw (Word variations have been searched) 10

\#3 \#1 or \#2

\#4 lactation:ti,ab,kw or breastfeeding or "breast feeding":ti,ab,kw or breast:ti,ab,kw (Word variations have been searched) 25275

\#5 \#3 AND \#4 9

$\begin{array}{ll}\text { RS } & \mathbf{1} \\ \text { Trials } & 8\end{array}$

\section{MEDLINE, via Pubmed}

Searched 10/11/2014

\section{Updated search 10/11/2014 a xx/xx/xxxx}

\#1 "Galactogogues"[Mesh] 30

\#2 ((galactagogues[Title/Abstract] OR galactogogues[Title/Abstract])) OR (galactagogue[Title/Abstract] OR galactogogue[Title/Abstract])

\#3 \#1 OR \#2

\#4 Search ((lactation[Title/Abstract]) OR (breastfeeding[Title/Abstract] OR "breast feeding"[Title/Abstract])) OR breast[Title/Abstract] 346293

\#5 \#3 AND \#4

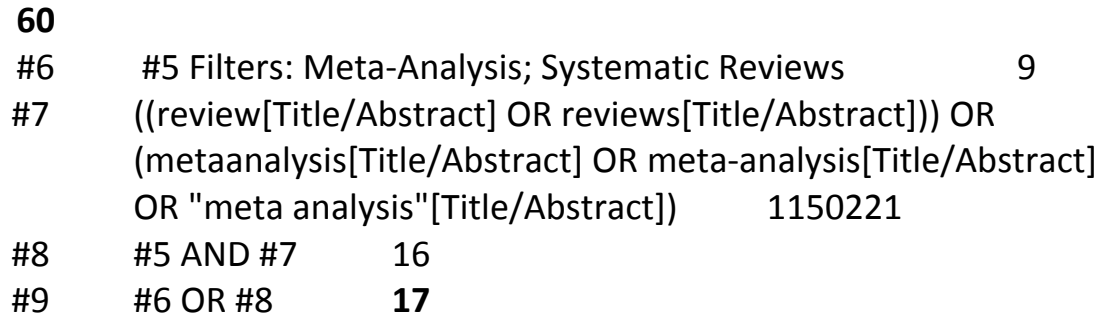

\section{EMBASE, via Ovid}

\section{Searched 10/11/2014}

Updated search 10/11/2014 a xx/xx/xxxx

\#1 galactogogue/ 77

\#2 (galactagogue or galactogogue or galactagogues or galactogogues).ti,ab,kw. 154

\#3 \#1 OR \#2

\#4 (lactation or breastfeeding or "breast feeding" or breast).ti,ab,kw. 465362

\#5 \#3 AND \#4 85

\#6 Limit 5 to meta analysis OR "systematic review" 3

\#7 (review or reviews or metaanalysis or meta-analysis or "meta analysis").ti,ab,kw. 1476201

\#8 \#5 AND \#7 19

\#9 \#6 OR \#9 19 


\section{Updated search 10/11/2014 a xx/xx/xxxx}

\#1 TI ( galactagogue OR galactagogues OR galactogogue OR galactogogues ) OR AB ( galactagogue $O R$ galactagogues OR galactogogue OR galactogogues )

\#2 TI ( lactation OR breastfeeding OR "breast feeding" OR breast ) OR AB ( lactation OR breastfeeding OR "breast feeding" OR breast ) 44861

\#3 \#1 AND \#2 24

\#4 \#3 Limitadores - Tipo de publicación: Systematic Revie 3

\#5 \#3 Limitadores - Tipo de publicación: Meta Analysis 2

\#6 \#4 OR \#5 3

\#7 TI ( review OR reviews OR metaanalysis OR meta-analysis OR "meta analysis" ) OR AB ( review OR reviews OR metaanalysis OR meta-analysis OR "meta analysis" ) 197961

\#8 \#3 AND \#7 6

\#9 \#6 OR \#8 6 


\section{ANEXO II, Tabla de estudios individuales para la pregunta}

\begin{tabular}{|c|c|c|c|c|c|c|}
\hline $\begin{array}{l}\text { Referencia } \\
\text { (Cita Abreviada) }\end{array}$ & $\begin{array}{l}\text { Estudio (Diseño y } \\
\text { objetivo) }\end{array}$ & $\begin{array}{l}\text { Población } \\
\text { (nº y características) }\end{array}$ & $\begin{array}{l}\text { Descripción de las intervenciones } \\
\text { comparaciones, exposiciones o } \\
\text { pruebas a estudio }\end{array}$ & $\begin{array}{l}\text { Resultados } \\
\text { (Estimadores de resultados-Magnitud del } \\
\text { efecto) }\end{array}$ & $\begin{array}{l}\text { Conclusiones } \\
\text { (conclusiones) }\end{array}$ & $\begin{array}{l}\text { Comentarios } \\
\text { Calidad de la } \\
\text { evidencia } \\
\text { Financiación } \\
\text { comentarios) }\end{array}$ \\
\hline \multicolumn{7}{|c|}{ Comparación 1: DOMPERIDONA VS. PLACEBO } \\
\hline $\begin{array}{l}\text { Campbell-Yeo, } \\
2010\end{array}$ & $\begin{array}{l}\text { Diseño: ensayo clínico } \\
\text { aleatorizado doble ciego } \\
\text { Objetivo: evaluar el efecto } \\
\text { de la domperidona sobre la } \\
\text { composición de la leche en } \\
\text { madres de hijos pre- } \\
\text { término. }\end{array}$ & $\begin{array}{l}46 \text { madres de hijos } \\
\text { pre-término (<31 } \\
\text { semanas) que } \\
\text { experimentaron un } \\
\text { fallo en la lactancia } \geq \\
3 \text { semanas. } \\
\\
\text { Criterios de exclusión: } \\
\text { (1) medicación que } \\
\text { altera el efecto de } \\
\text { domperidona, (2) } \\
\text { mastitis, (3) } \\
\text { enfermedad crónica, } \\
\text { (4) cirugía de mama, } \\
\text { (5) intolerancia a la } \\
\text { lactosa, o } \\
\text { (6) medicación previa } \\
\text { con domperidona. }\end{array}$ & $\begin{array}{l}\text { Intervención (I): Domperidona } 30 \text { mg al } \\
\text { día durante } 14 \text { días ( } n=22) \text {. } \\
\text { Comparación (C): Placebo }(n=24) \text {. } \\
\text { Alguna intervención adicional para } \\
\text { mejorar la lactancia: Todas recibieron un } \\
\text { dispositivo para la extracción de leche. } \\
\text { Pruebas de estudio: Análisis por } \\
\text { intención de tratar. Comparación de los } \\
\text { resultados al día } 14 \text { respecto al día } 0 \text {. } \\
\text { Nivel basal de prolactina (I vs. C): } 72,1 \\
\mu g / l \text { vs. } 50,0 \mu g / l\end{array}$ & $\begin{array}{l}\text { 1) Porcentaje de lactantes (cualquier tipo } \\
\text { de lactancia) a las dos semanas después } \\
\text { del fin del estudio (I vs. C): } 86 \% \text { vs. } 63 \% \text {; } \\
P<0,13 \text {. } \\
\text { 2) Diferencia del volumen de leche al día } \\
14 \text { respecto al día } 0 \text { (I vs. C): } \\
\text { - Aumento en la proporción de madres: } \\
267 \% \text { vs. } 19 \% ; P=0,005 \text {. } \\
\text { - Aumento del volumen medio: } 195,8 \mathrm{ml} / \mathrm{d} \\
\text { vs. } 33,1 \mathrm{ml} / \mathrm{d} ; \mathrm{P}=\text { no reportado. } \\
\text { 3) Diferencia del nivel de prolactina al día } \\
14 \text { respecto al día } 0 \text { (I vs. } C): \\
\text { - Aumento del volumen medio: } 96,8 \mu \mathrm{gg} / \mathrm{l} \\
\text { vs. } 16,7 \mu \mathrm{g} / \mathrm{l} ; \mathrm{P}=\text { no reportado. }\end{array}$ & $\begin{array}{l}\text { La domperidona } \\
\text { incrementa el } \\
\text { volumen de leche } \\
\text { en madres de hijos } \\
\text { pre-término que } \\
\text { experimentaron } \\
\text { fallo en la } \\
\text { lactancia, sin } \\
\text { alterar la } \\
\text { composición de } \\
\text { nutrientes de la } \\
\text { leche. }\end{array}$ & $\begin{array}{l}\text { El nivel basal de } \\
\text { prolactina es } \\
\text { medio en el } \\
\text { grupo } \\
\text { intervención y } \\
\text { bajo en el grupo } \\
\text { placebo. }\end{array}$ \\
\hline Da Silva, 2001 & $\begin{array}{l}\text { Diseño: ensayo clínico } \\
\text { aleatorizado doble ciego } \\
\\
\text { Objetivo: evaluar la } \\
\text { efectividad de la } \\
\text { domperidona para } \\
\text { incrementar la producción } \\
\text { de leche en madres de } \\
\text { hijos pre-término. }\end{array}$ & $\begin{array}{l}26 \text { madres de hijos } \\
\text { pre-término } \\
\text { hospitalizados en } \\
\text { unidad de cuidados } \\
\text { intensivos con } \\
\text { lactancia insuficiente. } \\
\text { Criterios de exclusión: } \\
\text { (1) medicación que } \\
\text { altera los niveles de } \\
\text { prolactina, (2) } \\
\text { enfermedad crónica o } \\
\text { debilitante. }\end{array}$ & $\begin{array}{l}\text { Intervención (I): Domperidona } 30 \text { mg al } \\
\text { día durante } 7 \text { días }(n=11) \text {. } \\
\text { Comparación (C): Placebo }(n=9) \text {. } \\
\text { Alguna intervención adicional para } \\
\text { mejorar la lactancia: Todas recibieron } \\
\text { consejo y utilizaron un dispositivo } \\
\text { eléctrico para la extracción de leche. } \\
\text { Pruebas de estudio: Comparación de los } \\
\text { resultados al día } 7 \text { respecto al día } 0 \text {. } \\
\text { Nivel basal de prolactina (I vs. C): } 12,9 \\
\mu \mathrm{g} / \mathrm{l} \text { vs. } 15,6 \mu \mathrm{g} / \mathrm{l}\end{array}$ & $\begin{array}{l}\text { 1) Porcentaje de lactantes al alta } \\
\text { hospitalaria (I vs. C): sin diferencias entre } \\
\text { los grupos (no se reportan más datos). } \\
\text { 2) Diferencia del volumen de leche al día } 7 \\
\text { respecto al día } 0 \text { (I vs. C): } \\
\text { - Aumento del volumen medio: } 49,5 \mathrm{ml} / \mathrm{d} \\
\text { vs. } 8,0 \mathrm{ml} / \mathrm{d} \text {; } P<0,05 \text {. } \\
\text { 3) Nivel de prolactina al día } 5 \text { (I vs. C): } \\
\text { - } 119,3 \mu \mathrm{g} / \mathrm{l} \text { vs. } 18,1 \mu \mathrm{g} / \mathrm{l} ; \mathrm{P}=0,008 \text {. }\end{array}$ & $\begin{array}{l}\text { La domperidona } \\
\text { incrementa el } \\
\text { volumen de leche } \\
\text { a corto plazo y se } \\
\text { detectan bajas } \\
\text { concentraciones } \\
\text { en la leche. }\end{array}$ & $\begin{array}{l}\text { El nivel basal de } \\
\text { prolactina es } \\
\text { bajo en ambos } \\
\text { grupos. }\end{array}$ \\
\hline Petraglia, 1985 & Diseño: ensayo clínico & 32 madres sanas de & Intervención (I): Domperidona 30 mg al & 1) Volumen medio de leche: & Los resultados & El nivel basal de \\
\hline
\end{tabular}


GPC Lactancia Materna- Pregunta 25. Galactogogos.

\begin{tabular}{|c|c|c|c|c|c|c|}
\hline $\begin{array}{l}\text { Referencia } \\
\text { (Cita Abreviada) }\end{array}$ & $\begin{array}{l}\text { Estudio (Diseño y } \\
\text { objetivo) }\end{array}$ & $\begin{array}{l}\text { Población } \\
\text { (nํy características) }\end{array}$ & $\begin{array}{l}\text { Descripción de las intervenciones } \\
\text { comparaciones, exposiciones o } \\
\text { pruebas a estudio }\end{array}$ & $\begin{array}{l}\text { Resultados } \\
\text { (Estimadores de resultados-Magnitud del } \\
\text { efecto) }\end{array}$ & $\begin{array}{l}\text { Conclusiones } \\
\text { (conclusiones) }\end{array}$ & $\begin{array}{l}\text { Comentarios } \\
\text { Calidad de la } \\
\text { evidencia } \\
\text { Financiación } \\
\text { comentarios) }\end{array}$ \\
\hline & $\begin{array}{l}\text { aleatorizado doble ciego } \\
\text { Objetivo: evaluar el efecto } \\
\text { de la domperidona sobre la } \\
\text { lactogénesis y la } \\
\text { galactopoyesis. }\end{array}$ & $\begin{array}{l}\text { hijos a término. } 15 \\
\text { fueron multíparas con } \\
\text { historia de falla en la } \\
\text { lactogénesis y } 17 \\
\text { fueron primíparas con } \\
\text { lactancia inadecuada } \\
\text { durante las dos } \\
\text { primeras semanas } \\
\text { post-parto. }\end{array}$ & $\begin{array}{l}\text { día }(\mathrm{n}=17) \text {. } \\
\text { Multíparas: del día } 2 \text { al } 5 \text { post-parto. } \\
\text { Primíparas: durante } 9 \text { días. } \\
\text { Comparación }(C) \text { : Placebo }(\mathrm{n}=15) \text {. } \\
\text { Alguna intervención adicional para } \\
\text { mejorar la lactancia: No reportado. } \\
\text { Pruebas de estudio: Comparación de los } \\
\text { resultados en el grupo de multíparas vs } \\
\text { placebo y primíparas vs placebo. } \\
\text { Nivel basal de prolactina }(I \mathrm{vs} . \mathrm{C}) \text { : } \\
\text { Multíparas: } 129 \mathrm{ng} / \mathrm{ml} \text { vs. } 131 \mathrm{ng} / \mathrm{ml} \text {. } \\
\text { Primiparas: } 68 \mathrm{ng} / \mathrm{ml} \text { vs. } 79 \mathrm{ng} / \mathrm{ml} \text {. }\end{array}$ & $\begin{array}{l}\text { - Multíparas (I): } 475 \mathrm{ml} / \mathrm{d} \text { al día } 5 \\
\text { comparado con } 105 \mathrm{ml} / \mathrm{d} \text { el día } 2 \text {. } \\
\text { Multíparas (C): No reportado. } \\
\text { - Volumen medio de leche en las } \\
\text { Primíparas al día } 5 \text { (I vs. C): } 673 \mathrm{ml} / \mathrm{d} \text { vs. } \\
398 \mathrm{ml} / \mathrm{d} ; \mathrm{P}<0,01 . \\
\text { 2) Nivel de prolactina: } \\
\text { - Multíparas (I): Nivel } 97 \% \text { más alto al día } \\
5 \text { comparado con el día } 2 \text {. P<0,05. } \\
\text { Multíparas (C): Nivel } 55 \% \text { más alto al día } \\
5 \text { comparado con el día } 2 \text {. P< } 0,01 \text {. } \\
\text {-El nivel de prolactina en las Primíparas al } \\
\text { día } 5 \text { (I vs. C): } 169 \mathrm{ng} / \mathrm{mL} \text { vs. } 84 \mathrm{ng} / \mathrm{mL} ; \\
P=\text { no reportado. }\end{array}$ & $\begin{array}{l}\text { sugieren que la } \\
\text { domperidona es } \\
\text { útil para inducir o } \\
\text { mantener la } \\
\text { lactancia. }\end{array}$ & $\begin{array}{l}\text { prolactina es } \\
\text { alto en las } \\
\text { multíparas y } \\
\text { medio en las } \\
\text { primíparas. }\end{array}$ \\
\hline $\begin{array}{l}\text { Jantarasaengara } \\
\mathrm{m}, 2012\end{array}$ & $\begin{array}{l}\text { Diseño: ensayo clínico } \\
\text { aleatorizado doble ciego } \\
\\
\text { Objetivo: evaluar la } \\
\text { efectividad de la } \\
\text { domperidona para } \\
\text { incrementar la producción } \\
\text { de leche en madres de } \\
\text { hijos a término, post- } \\
\text { cesárea. }\end{array}$ & $\begin{array}{l}45 \text { madres de hijos } \\
\text { sanos nacidos a } \\
\text { término. } \\
\text { Criterios de exclusión: } \\
\text { (1) índice de masa } \\
\text { corporal>24, (2) } \\
\text { pérdida }>11 \text { postparto, } \\
\text { (3) enfermedad } \\
\text { crónica, (4) alergia a la } \\
\text { domperidona, (5) } \\
\text { tabaquismo, (6) } \\
\text { contraindicación de } \\
\text { lactancia }\end{array}$ & $\begin{array}{l}\text { Intervención (I): Domperidona } 40 \text { mg al } \\
\text { día durante } 4 \text { días }(n=22) \text {. } \\
\text { Comparación }(C) \text { : Placebo }(n=23) \text {. } \\
\text { Alguna intervención adicional para } \\
\text { mejorar la lactancia: Todas realizaron la } \\
\text { extracción de leche mediante un } \\
\text { dispositivo eléctrico. } \\
\text { Pruebas de estudio: Comparación de los } \\
\text { resultados entre ambos grupos. } \\
\text { Nivel basal de prolactina: no reportado. }\end{array}$ & $\begin{array}{l}\text { 1) Volumen medio de leche al día } 4 \text { (I vs. } \\
\text { C): } 191,3 \mathrm{ml} / \mathrm{d} \text { vs. } 91,4 \mathrm{ml} / \mathrm{d} ; P=0,003 .\end{array}$ & $\begin{array}{l}\text { La domperidona } \\
\text { puede incrementar } \\
\text { el volumen de } \\
\text { leche en mujeres } \\
\text { post-cesárea con } \\
\text { mínimos efectos } \\
\text { adversos. }\end{array}$ & \\
\hline \multicolumn{7}{|c|}{ COMPARACIÓN 2: Metoclopramida vs. placebo } \\
\hline Hansen, 2005 & $\begin{array}{l}\text { Diseño: ensayo clínico } \\
\text { aleatorizado doble ciego } \\
\text { Objetivo: evaluar la } \\
\text { efectividad de la } \\
\text { metoclopramida para } \\
\text { incrementar la producción }\end{array}$ & $\begin{array}{l}57 \text { madres de hijos } \\
\text { pre-término ( }>23 \text { y<34 } \\
\text { semanas). } \\
\text { Criterios de exclusión: } \\
\text { (1) contraindicación de } \\
\text { lactancia o }\end{array}$ & $\begin{array}{l}\text { Intervención (I): Metoclopramida } 30 \text { mg } \\
\text { al día durante } 10 \text { días }(n=28) \text {. } \\
\text { Comparación }(C) \text { : Placebo }(n=29) \text {. } \\
\text { Alguna intervención adicional para } \\
\text { mejorar la lactancia: Todas las madres }\end{array}$ & $\begin{array}{l}\text { 1) Duración de la lactancia (I vs. C): } 8,8 \\
\text { vs. } 8,6 \text { semanas; } P=0,093 \text {. } \\
\text { 2) Volumen de leche durante los primeros } \\
17 \text { días (I vs. C): sin diferencias; } P=0,26 \text {. }\end{array}$ & $\begin{array}{l}\text { La metoclopramida } \\
\text { no mejora el } \\
\text { volumen de leche } \\
\text { ni la duración de la } \\
\text { lactancia materna. }\end{array}$ & \\
\hline
\end{tabular}


GPC Lactancia Materna- Pregunta 25. Galactogogos.

\begin{tabular}{|c|c|c|c|c|c|c|}
\hline $\begin{array}{l}\text { Referencia } \\
\text { (Cita Abreviada) }\end{array}$ & $\begin{array}{l}\text { Estudio (Diseño y } \\
\text { objetivo) }\end{array}$ & $\begin{array}{l}\text { Población } \\
\text { (nº y características) }\end{array}$ & $\begin{array}{l}\text { Descripción de las intervenciones } \\
\text { comparaciones, exposiciones o } \\
\text { pruebas a estudio }\end{array}$ & $\begin{array}{l}\text { Resultados } \\
\text { (Estimadores de resultados-Magnitud del } \\
\text { efecto) }\end{array}$ & $\begin{array}{l}\text { Conclusiones } \\
\text { (conclusiones) }\end{array}$ & $\begin{array}{l}\text { Comentarios } \\
\text { Calidad de la } \\
\text { evidencia } \\
\text { Financiación } \\
\text { comentarios) }\end{array}$ \\
\hline & $\begin{array}{l}\text { de leche y duración de la } \\
\text { lactancia en madres de } \\
\text { hijos pre-término. }\end{array}$ & $\begin{array}{l}\text { metoclopramida, (2) } \\
\text { infección VIH, (3) } \\
\text { anomalías congénitas }\end{array}$ & $\begin{array}{l}\text { recibieron educación sobre lactancia y } \\
\text { un dispositivo eléctrico para realizar la } \\
\text { extracción de leche. } \\
\text { Pruebas de estudio: Comparación de los } \\
\text { resultados entre ambos grupos. } \\
\text { Nivel basal de prolactina: no reportado. }\end{array}$ & & & \\
\hline Lewis, 1980 & $\begin{array}{l}\text { Diseño: ensayo clínico } \\
\text { aleatorizado } \\
\text { Objetivo: evaluar la } \\
\text { efectividad de la } \\
\text { metoclopramida para la } \\
\text { duración de la lactancia en } \\
\text { madres post-cesárea. }\end{array}$ & $\begin{array}{l}20 \text { madres post- } \\
\text { cesárea. }\end{array}$ & $\begin{array}{l}\text { Intervención (I): Metoclopramida } 30 \text { mg } \\
\text { al día durante } 7 \text { días ( } n=10) \text {. } \\
\text { Comparación (C): Placebo }(n=10) \text {. } \\
\text { Alguna intervención adicional para } \\
\text { mejorar la lactancia: Todas recibieron } \\
\text { consejo diario. } \\
\text { Pruebas de estudio: Comparación de los } \\
\text { resultados entre ambos grupos. } \\
\text { Nivel basal de prolactina: no reportado. }\end{array}$ & $\begin{array}{l}\text { 1) Número de lactantes a las } 6 \text { semanas } \\
\text { de tratamiento (I vs. C): } 8 / 10 \text { vs. } 9 / 10 ; P= \\
\text { no reportado. }\end{array}$ & $\begin{array}{l}\text { La metoclopramida } \\
\text { no es superior al } \\
\text { placebo para } \\
\text { mejorar la } \\
\text { lactancia en } \\
\text { madres post- } \\
\text { cesárea. }\end{array}$ & $\begin{array}{l}\text { La publicación } \\
\text { del estudio es } \\
\text { una carta al } \\
\text { editor. No se } \\
\text { cuenta con } \\
\text { información } \\
\text { sobre la } \\
\text { prolactina basal. }\end{array}$ \\
\hline De Gezelle, 1983 & $\begin{array}{l}\text { Diseño: ensayo clínico } \\
\text { aleatorizado doble ciego } \\
\text { Objetivo: evaluar el efecto } \\
\text { de la metoclopramida } \\
\text { sobre la leche materna. }\end{array}$ & $\begin{array}{l}13 \text { madres sanas } \\
\text { primíparas de hijos } \\
\text { sanos a término. }\end{array}$ & $\begin{array}{l}\text { Intervención (I): Metoclopramida } 30 \mathrm{mg} \\
\text { al día durante } 8 \text { días }(\mathrm{n}=7) \text {. } \\
\text { Comparación }(C) \text { : Placebo }(\mathrm{n}=6) \text {. } \\
\text { Alguna intervención adicional para } \\
\text { mejorar la lactancia: no reportado. } \\
\text { Pruebas de estudio: Comparación de los } \\
\text { resultados entre ambos grupos. } \\
\text { Nivel basal de prolactina: no reportado. }\end{array}$ & $\begin{array}{l}\text { 1) Volumen medio de leche por mujer } \\
\text { durante los días } 3 \text { a } 8 \text { (I vs. C): } \\
-75,4 \mathrm{~g} \text { vs. } 51,1 \mathrm{~g} ; \mathrm{P}<0,01 . \\
\text { 2) Nivel de prolactina al día } 3 \text { (I vs. C): } \\
\text { - } 240,9 \mathrm{ng} / \mathrm{ml} \text { vs. } 225,3 \mathrm{ng} / \mathrm{ml} ; \mathrm{P}=\text { no } \\
\text { reportado. } \\
\text { Nivel de prolactina al día } 28 \text { (I vs. C): } \\
\text { - } 64,1 \mathrm{ng} / \mathrm{ml} \text { vs. } 70,5 \mathrm{ng} / \mathrm{ml} ; P=\text { no } \\
\text { reportado. }\end{array}$ & $\begin{array}{l}\text { La metoclopramida } \\
\text { cumple una } \\
\text { función en la } \\
\text { transición de } \\
\text { calostro a leche } \\
\text { madura. }\end{array}$ & $\begin{array}{l}\text { No se cuenta } \\
\text { con información } \\
\text { sobre la } \\
\text { prolactina basal. }\end{array}$ \\
\hline Kauppila, 1985 & $\begin{array}{l}\text { Diseño: ensayo clínico } \\
\text { aleatorizado doble ciego } \\
\text { Objetivo: evaluar la } \\
\text { efectividad de la } \\
\text { metoclopramida en el } \\
\text { tratamiento de lactancia }\end{array}$ & $\begin{array}{l}33 \text { madres sanas de } \\
25 \text { a } 43 \text { años que } \\
\text { fueron incluidas en el } \\
\text { estudio después de } 4 \\
\text { a } 20 \text { semanas del } \\
\text { parto. }\end{array}$ & $\begin{array}{l}\text { Intervención (I): Metoclopramida } 30 \text { mg } \\
\text { al día durante } 21 \text { días }(n=11) \text {. } \\
\text { Comparación (C): Placebo }(n=14) \text {. } \\
\text { Alguna intervención adicional para } \\
\text { mejorar la lactancia: } \text { No reportado. }\end{array}$ & $\begin{array}{l}\text { 1) Volumen de leche (I vs. C): } \\
\text { - Aumento del volumen de } 285 \mathrm{ml} / \mathrm{d} \text { en el } \\
\text { día } 0 \text { a } 530 \mathrm{ml} / \mathrm{d} \text { en el día } 21 \mathrm{vs} \text {. No } \\
\text { reportado en el grupo control; } P<0,01 \text {. } \\
\text { 2) Nivel de prolactina al día } 21 \text { (I vs. C): } \\
\text { - } 210,7 \text { U/l vs. } 68,5 \mathrm{U} / \mathrm{l} ; \mathrm{P}<0,001 .\end{array}$ & $\begin{array}{l}\text { La metoclopramida } \\
\text { es útil en el } \\
\text { tratamiento de } \\
\text { lactancia } \\
\text { insuficiente. }\end{array}$ & $\begin{array}{l}\text { El nivel basal de } \\
\text { prolactina es } \\
\text { bajo en el grupo } \\
\text { intervención y } \\
\text { medio en el } \\
\text { grupo placebo. }\end{array}$ \\
\hline
\end{tabular}


GPC Lactancia Materna- Pregunta 25. Galactogogos.

\begin{tabular}{|c|c|c|c|c|c|c|}
\hline $\begin{array}{l}\text { Referencia } \\
\text { (Cita Abreviada) }\end{array}$ & $\begin{array}{l}\text { Estudio (Diseño y } \\
\text { objetivo) }\end{array}$ & $\begin{array}{l}\text { Población } \\
\text { (no y características) }\end{array}$ & $\begin{array}{l}\text { Descripción de las intervenciones } \\
\text { comparaciones, exposiciones o } \\
\text { pruebas a estudio }\end{array}$ & $\begin{array}{l}\text { Resultados } \\
\text { (Estimadores de resultados-Magnitud del } \\
\text { efecto) }\end{array}$ & $\begin{array}{l}\text { Conclusiones } \\
\text { (conclusiones) }\end{array}$ & $\begin{array}{l}\text { Comentarios } \\
\text { Calidad de la } \\
\text { evidencia } \\
\text { Financiación } \\
\text { comentarios) }\end{array}$ \\
\hline & insuficiente. & & $\begin{array}{l}\text { Pruebas de estudio: Comparación de los } \\
\text { resultados en madres e hijos entre } \\
\text { ambos grupos. } \\
\text { Nivel basal de prolactina (I vs. C): } 57,5 \\
\text { U/l vs. } 72,8 \mathrm{U} / \mathrm{l} \text {. }\end{array}$ & & & \\
\hline Kauppila (a), 1981 & $\begin{array}{l}\text { Diseño: ensayo clínico } \\
\text { aleatorizado cruzado } \\
\text { Objetivo: evaluar la dosis } \\
\text { de metoclopramida que } \\
\text { puede mejorar la lactancia } \\
\text { insuficiente. }\end{array}$ & $\begin{array}{l}37 \text { madres de hijos a } \\
\text { término. } \\
\text { Criterios de exclusión: } \\
\text { (1) enfermedades que } \\
\text { condicionen una pobre } \\
\text { lactancia }\end{array}$ & $\begin{array}{l}\text { Intervención: La intervención comenzó } \\
\text { de } 13 \text { a } 110 \text { días después del parto. } \\
\text { Metoclopramida } 15 \mathrm{mg}(\mathrm{n}=10 \text { ), } 30 \mathrm{mg} \\
\text { ( } \mathrm{n}=13 \text { ) y } 45 \mathrm{mg}(\mathrm{n}=14 \text { ) al día durante } \\
14 \text { días, seguido de lavado durante } 7 \\
\text { días y placebo durante } 14 \text { días más. } \\
\text { Alguna intervención adicional para } \\
\text { mejorar la lactancia: No reportado. } \\
\text { Pruebas de estudio: Comparación de los } \\
\text { resultados después del tratamiento. } \\
\text { Nivel basal de prolactina: } \\
\text {-Metoclopramida } 15 \mathrm{mg}: 68,9 \mathrm{ng} / \mathrm{ml} . \\
\text {-Metoclopramida } 30 \mathrm{mg}: 77,8 \mathrm{ng} / \mathrm{ml} \text {. } \\
\text {-Metoclopramida } 45 \mathrm{mg}: 44,9 \mathrm{ng} / \mathrm{ml} \text {. }\end{array}$ & 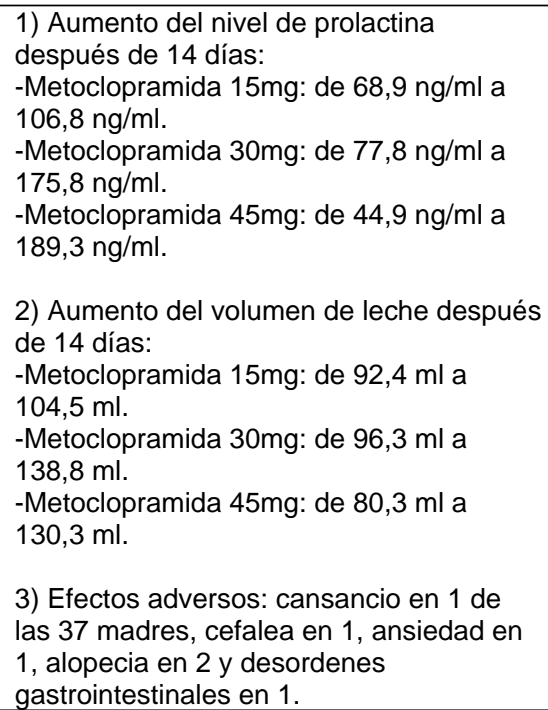 & $\begin{array}{l}\text { Las dosis de } 30 \text { o } \\
45 \text { mg de } \\
\text { metoclopramida } \\
\text { son útiles en el } \\
\text { tratamiento de la } \\
\text { lactancia } \\
\text { insuficiente. Los } \\
\text { eventos adversos } \\
\text { en las madres son } \\
\text { leves y no se } \\
\text { observaron en los } \\
\text { hijos. }\end{array}$ & $\begin{array}{l}\text { El grupo control } \\
\text { fueron las } \\
\text { mismas mujeres } \\
\text { después de una } \\
\text { semana de } \\
\text { lavado. } \\
\text { El nivel basal de } \\
\text { prolactina es } \\
\text { medio en las } \\
\text { mujeres que } \\
\text { recibieron } \\
\text { metoclopramida } \\
15 \text { y } 30 \mathrm{mg} \text { y } \\
\text { bajo en el grupo } \\
\text { de } 45 \mathrm{mg} \text {. }\end{array}$ \\
\hline Kauppila (b), 1981 & $\begin{array}{l}\text { Diseño: estudio } \\
\text { observacional } \\
\text { Objetivo: evaluar la si el } \\
\text { tratamiento con } \\
\text { metoclopramida puede } \\
\text { mejorar la lactancia } \\
\text { insuficiente. }\end{array}$ & \begin{tabular}{l|}
17 madres e hijos \\
sanos. \\
Las madres fueron \\
incluidas después de \\
18 a 141 días del parto. \\
Cada hijo recibió tres \\
días como mínimo de \\
alimentación \\
suplementaria antes de \\
entrar en el estudio.
\end{tabular} & $\begin{array}{l}\text { Intervención: La intervención comenzó } \\
\text { de } 18 \text { a } 141 \text { días después del parto. } \\
\text { Metoclopramida } 30 \mathrm{mg} \text { al día durante } 21 \\
\text { días, seguido de lavado durante } 7 \text { días y } \\
\text { tratamiento durante } 14 \text { días más ( } \mathrm{n}= \\
\text { 17). } \\
\text { Alguna intervención adicional para } \\
\text { mejorar la lactancia: No reportado. } \\
\text { Pruebas de estudio: Comparación de los }\end{array}$ & $\begin{array}{l}\text { 1) Aumento del nivel de prolactina de } 36,6 \\
\mathrm{ng} / \mathrm{ml} \text { a } 56,0 \mathrm{ng} / \mathrm{ml} \text { después de } 42 \text { días. } \\
\text { 2) Efectos adversos: cansancio en } 5 \text { de } \\
\text { las } 14 \text { madres, nauseas en } 2 \text {, cefalea en } 1 \\
\text { y vértigo en } 1 \text {. }\end{array}$ & $\begin{array}{l}\text { Los niveles de } \\
\text { prolactina se } \\
\text { incrementaron. No } \\
\text { se observaron } \\
\text { efectos adversos } \\
\text { relevantes. }\end{array}$ & $\begin{array}{l}\text { El nivel basal de } \\
\text { prolactina es } \\
\text { bajo. }\end{array}$ \\
\hline
\end{tabular}


GPC Lactancia Materna- Pregunta 25. Galactogogos.

\begin{tabular}{|c|c|c|c|c|c|c|}
\hline $\begin{array}{l}\text { Referencia } \\
\text { (Cita Abreviada) }\end{array}$ & $\begin{array}{l}\text { Estudio (Diseño y } \\
\text { objetivo) }\end{array}$ & $\begin{array}{l}\text { Población } \\
\text { (nº y características) }\end{array}$ & $\begin{array}{l}\text { Descripción de las intervenciones } \\
\text { comparaciones, exposiciones o } \\
\text { pruebas a estudio }\end{array}$ & $\begin{array}{l}\text { Resultados } \\
\text { (Estimadores de resultados-Magnitud del } \\
\text { efecto) }\end{array}$ & $\begin{array}{l}\text { Conclusiones } \\
\text { (conclusiones) }\end{array}$ & $\begin{array}{l}\text { Comentarios } \\
\text { Calidad de la } \\
\text { evidencia } \\
\text { Financiación } \\
\text { comentarios) }\end{array}$ \\
\hline & & & $\begin{array}{l}\text { resultados al día } 7 \text { respecto al día } 0 \text {. } \\
\text { Nivel basal de prolactina: } 36,6 \mathrm{ng} / \mathrm{ml} \text {. }\end{array}$ & & & \\
\hline Ehrenkranz, 1986 & $\begin{array}{l}\text { Diseño: estudio } \\
\text { observacional } \\
\text { Objetivo: evaluar el efecto } \\
\text { de la metoclopramida } \\
\text { sobre la producción de } \\
\text { leche en madres de hijos } \\
\text { pre-término. }\end{array}$ & $\begin{array}{l}23 \text { madres de hijos } \\
\text { pre-término }(<34 \\
\text { semanas). } \\
\\
\text { Las madres fueron } \\
\text { incluidas después de } \\
32 \text { días de apoyo a la } \\
\text { lactancia y otras } \\
\text { técnicas para aumentar } \\
\text { la producción de leche. }\end{array}$ & $\begin{array}{l}\text { Intervención: La intervención comenzó } \\
32 \text { días después del parto. } \\
\text { Metoclopramida } 30 \text { mg al día durante } 7 \\
\text { días ( } \mathrm{n}=23 \text { ). } \\
\text { Alguna intervención adicional para } \\
\text { mejorar la lactancia: Todas realizaron } \\
\text { extracción de leche, tanto manual como } \\
\text { mediante un dispositivo eléctrico. } \\
\text { Pruebas de estudio: Comparación de los } \\
\text { resultados al día } 7 \text { respecto al día } 0 \text {. } \\
\text { Nivel basal de prolactina: } 18,1 \mathrm{ng} / \mathrm{ml} \text {. }\end{array}$ & $\begin{array}{l}\text { 1) Aumento del volumen medio de leche } \\
\text { de } 93,3 \mathrm{ml} / \mathrm{d} \text { al día } 0 \text { a } 197,4 \mathrm{ml} / \mathrm{d} \text { al día } 7 \text {. } \\
\text { 2) Aumento del nivel de prolactina de } 18,1 \\
\mathrm{ng} / \mathrm{ml} \text { al día } 0 \text { a } 121,8 \mathrm{ng} / \mathrm{ml} \text { al día } 7 \text {. } \\
\text { 3) Efectos adversos: diarreas en } 1 \text { de las } \\
23 \text { madres y cansancio en } 1 .\end{array}$ & $\begin{array}{l}\text { El incremento en la } \\
\text { producción de } \\
\text { leche puede estar } \\
\text { relacionado al } \\
\text { incremento en los } \\
\text { niveles de } \\
\text { prolactina. }\end{array}$ & $\begin{array}{l}\text { El nivel basal de } \\
\text { prolactina es } \\
\text { bajo. }\end{array}$ \\
\hline \multicolumn{7}{|c|}{ COMPARACIÓN 3: Metoclopramida vs. Domperidona } \\
\hline Ingram, 2012 & $\begin{array}{l}\text { Diseño: ensayo clínico } \\
\text { aleatorizado doble ciego } \\
\text { Objetivo: comparar el } \\
\text { efecto de la } \\
\text { metoclopramida frente a la } \\
\text { domperidona sobre la } \\
\text { producción de leche en } \\
\text { madres de hijos en la } \\
\text { unidad de cuidados } \\
\text { intensivos neonatales. }\end{array}$ & $\begin{array}{l}65 \text { madres de hijos de } \\
\text { edad gestacional } \\
\text { media de } 28 \text { semanas } \\
\text { hospitalizados en } \\
\text { unidad de cuidados } \\
\text { intensivos neonatales. } \\
\text { Criterios de exclusión: } \\
\text { 1) madres < } 16 \text { años. } \\
\text { 2) alergia a } \\
\text { medicamentos. 3) } \\
\text { medicación } \\
\text { concomitante. }\end{array}$ & $\begin{array}{l}\text { Intervención. Metoclopramida } 30 \text { mg al } \\
\text { día durante } 10 \text { días }(n=34) \text {. } \\
\text { Comparación }(C) \text { : Domperidona } 30 \mathrm{mg} \\
\text { al día durante } 10 \text { días }(n=31) \text {. } \\
\text { Alguna intervención adicional para } \\
\text { mejorar la lactancia: No reportado. } \\
\text { Nivel basal de prolactina: no reportado. }\end{array}$ & $\begin{array}{l}\text { 1) Aumento del volumen medio de leche (I } \\
\text { vs C) } 93,7 \% \text { vs } 96,3 \% ; P=\text { no reportado. }\end{array}$ & $\begin{array}{l}\text { Tanto la } \\
\text { metoclopramida } \\
\text { como la } \\
\text { domperidona } \\
\text { incrementaron el } \\
\text { volumen de leche. } \\
\text { No se observaron } \\
\text { diferencias entre } \\
\text { ambos } \\
\text { tratamientos. }\end{array}$ & \\
\hline \multicolumn{7}{|c|}{ COMPARACIÓN 4: Sulpiride vs. Placebo } \\
\hline Aono, 1982 & $\begin{array}{l}\text { Diseño: ensayo clínico } \\
\text { aleatorizado } \\
\text { Objetivo: evaluar el efecto } \\
\text { del sulpiride sobre la } \\
\text { lactancia en mujeres }\end{array}$ & $\begin{array}{l}96 \text { madres de hijos a } \\
\text { término que } \\
\text { presentaron lactancia } \\
\text { insuficiente durante } \\
\text { los } 3 \text { días post-parto. }\end{array}$ & $\begin{array}{l}\text { Intervención (I): La intervención } \\
\text { comenzó tres días después del parto. } \\
\text { Sulpiride } 100 \mathrm{mg} \text { al día durante } 4 \text { días } \\
(\mathrm{n}=48) \text {. } \\
\text { Comparación (C): Placebo }(\mathrm{n}=48) \text {. }\end{array}$ & $\begin{array}{l}\text { 1) Número de lactantes a los } 28 \text { días de } \\
\text { tratamiento (I vs. C): } 11 / 20 \text { (55\%) vs. } 7 / 22 \\
(30 \%) ; P=\text { no reportado. } \\
\text { 2) Volumen medio de leche (I vs. C): } \\
\text { - Aumento de } 15,3 \mathrm{ml} / \mathrm{d} \text { en el día } 0-2 \text { a }\end{array}$ & $\begin{array}{l}\text { Los resultados } \\
\text { sugieren que la } \\
\text { lactancia } \\
\text { insuficiente puede } \\
\text { tratarse con } \\
\text { sulpiride. }\end{array}$ & $\begin{array}{l}\text { La comparación } \\
\text { de los niveles de } \\
\text { prolactina al día } \\
5 \text { aparecen en el } \\
\text { gráfico. }\end{array}$ \\
\hline
\end{tabular}


GPC Lactancia Materna- Pregunta 25. Galactogogos.

\begin{tabular}{|c|c|c|c|c|c|c|}
\hline $\begin{array}{l}\text { Referencia } \\
\text { (Cita Abreviada) }\end{array}$ & $\begin{array}{l}\text { Estudio (Diseño y } \\
\text { objetivo) }\end{array}$ & $\begin{array}{l}\text { Población } \\
\text { (nº y características) }\end{array}$ & $\begin{array}{l}\text { Descripción de las intervenciones } \\
\text { comparaciones, exposiciones o } \\
\text { pruebas a estudio }\end{array}$ & $\begin{array}{l}\text { Resultados } \\
\text { (Estimadores de resultados-Magnitud del } \\
\text { efecto) }\end{array}$ & $\begin{array}{l}\text { Conclusiones } \\
\text { (conclusiones) }\end{array}$ & $\begin{array}{l}\text { Comentarios } \\
\text { Calidad de la } \\
\text { evidencia } \\
\text { Financiación } \\
\text { comentarios) }\end{array}$ \\
\hline & multíparas y primíparas. & & $\begin{array}{l}\text { Alguna intervención adicional para } \\
\text { mejorar la lactancia: Todas recibieron } \\
\text { consejo de enfermería. } \\
\text { Pruebas de estudio: Comparación del } \\
\text { volumen de leche entre ambos grupos. } \\
\text { Nivel basal de prolactina (I vs. C): } \\
108,5 \mathrm{ng} / \mathrm{ml} \text { vs. } 103,5 \mathrm{ng} / \mathrm{ml} .\end{array}$ & $\begin{array}{l}325 \mathrm{ml} / \mathrm{d} \text { en el día } 5 \mathrm{vs} \text {. Aumento de } 15,9 \\
\mathrm{ml} / \mathrm{d} \text { en el día } 0-2 \text { a } 211 \mathrm{ml} / \mathrm{d} \text { en el día } 5 \text {; } \\
\mathrm{P}<0,01 \text {. } \\
\text { 3) Nivel de prolactina al día } 5 \text { ( I vs. C): } \\
138 \mathrm{ng} / \mathrm{ml} \text { vs. } 110 \mathrm{ng} / \mathrm{ml}(P<0,05) .\end{array}$ & & $\begin{array}{l}\text { El nivel basal de } \\
\text { prolactina es } \\
\text { alto en ambos } \\
\text { grupos. }\end{array}$ \\
\hline Aono, 1979 & $\begin{array}{l}\text { Diseño: ensayo clínico } \\
\text { aleatorizado } \\
\text { Objetivo: evaluar el efecto } \\
\text { del sulpiride sobre la } \\
\text { lactancia y los niveles de } \\
\text { prolactina. }\end{array}$ & $\begin{array}{l}130 \text { madres } \\
\text { primíparas de hijos a } \\
\text { término que } \\
\text { presentaron lactancia } \\
\text { insuficiente durante el } \\
\text { primer mes post- } \\
\text { parto. } \\
\text { Criterios de exclusión: } \\
\text { (1) tratamiento } \\
\text { hormonal durante los } \\
\text { dos meses anteriores. }\end{array}$ & $\begin{array}{l}\text { Intervención (l): La intervención } \\
\text { comenzó un mes después del parto. } \\
\text { Sulpiride } 100 \mathrm{mg} \text { al día durante } 7 \text { días } \\
(\mathrm{n}=66) \text {. } \\
\text { Comparación (C): Placebo ( } \mathrm{n}=64) \text {. } \\
\text { Alguna intervención adicional para } \\
\text { mejorar la lactancia: Todas recibieron } \\
\text { consejo de enfermería y extracción } \\
\text { manual de leche. } \\
\text { Pruebas de estudio: Comparación del } \\
\text { volumen de leche entre ambos grupos. } \\
\text { Nivel basal de prolactina (I vs. C): } 114,7 \\
\text { ng/ml vs. } 105,8 \text { ng/ml.. }\end{array}$ & $\begin{array}{l}\text { 1) El volumen medio de leche en el grupo } \\
\text { Intervención acumulado durante los } \\
\text { primeros } 5 \text { días ( } 1211,7 \mathrm{ml} \text { ) fue } 32,3 \% \\
\text { mayor al grupo Control }(916 \mathrm{ml} ; \mathrm{P}<0,01) \text {. } \\
\text { 2) Nivel de prolactina al día } 6 \text { ( I vs. C): } \\
138 \mathrm{ng} / \mathrm{ml} \text { vs. } 93,8 \mathrm{ng} / \mathrm{ml}(\mathrm{P}<0,05) \text {. }\end{array}$ & $\begin{array}{l}\text { Los resultados } \\
\text { sugieren que el } \\
\text { sulpiride promueve } \\
\text { el inicio de la } \\
\text { lactancia debido a } \\
\text { la estimulación de } \\
\text { prolactina. }\end{array}$ & $\begin{array}{l}\text { El análisis del } \\
\text { nivel de } \\
\text { prolactina sólo } \\
\text { se realizó en un } \\
\text { subgrupo de } 20 \\
\text { madres. El nivel } \\
\text { basal de } \\
\text { prolactina fue } \\
\text { alto en ambos } \\
\text { grupos. }\end{array}$ \\
\hline Ylikorkala, 1982 & $\begin{array}{l}\text { Diseño: ensayo clínico } \\
\text { aleatorizado doble ciego } \\
\text { Objetivo: evaluar el efecto } \\
\text { del sulpiride en madres } \\
\text { con lactancia insuficiente. }\end{array}$ & $\begin{array}{l}28 \text { madres que } \\
\text { presentaron lactancia } \\
\text { insuficiente durante el } \\
\text { primer mes post- } \\
\text { parto. } \\
\text { Criterios de exclusión: } \\
\text { (1) enfermedades } \\
\text { causantes de } \\
\text { lactancia insuficiente, }\end{array}$ & $\begin{array}{l}\text { Intervención (I): La intervención } \\
\text { comenzó un mes después del parto. } \\
\text { Sulpiride } 150 \mathrm{mg} \text { al día durante } 28 \text { días } \\
(\mathrm{n}=14) \text {. } \\
\text { Comparación }(\mathrm{C}) \text { : Placebo }(\mathrm{n}=12) \text {. } \\
\text { Alguna intervención adicional para } \\
\text { mejorar la lactancia: No reportado. } \\
\text { Pruebas de estudio: Comparación de los } \\
\text { resultados al día } 56 \text { respecto al día } 28 .\end{array}$ & $\begin{array}{l}\text { 1) Volumen medio de leche al día } 42 \text { (I vs. } \\
\text { C): } \\
\text { - Aumento hasta } 212-265 \mathrm{ml} / \mathrm{d} \text { vs. } \\
\text { Disminución no cuantitativamente } \\
\text { reportada; } P=\text { no reportado. } \\
\text { 2) Nivel de prolactina al día } 14 \text { (I vs. C): } \\
\text { - } 402 \mu \mathrm{g} / \mathrm{l} \text { vs. } 48 \mu \mathrm{g} / \mathrm{l} ; \mathrm{P}<0,001 \text {. } \\
\text { 3) Efectos adversos: } 1 / 14 \text { mujeres con } \\
\text { cefalea y } 2 / 14 \text { con cansancio. }\end{array}$ & $\begin{array}{l}\text { El sulpiride es } \\
\text { efectivo como } \\
\text { tratamiento de } \\
\text { lactancia } \\
\text { inadecuada en el } \\
\text { puerperio. }\end{array}$ & $\begin{array}{l}\text { El nivel basal de } \\
\text { prolactina es } \\
\text { bajo en el grupo } \\
\text { intervención y } \\
\text { medio en el } \\
\text { grupo placebo. }\end{array}$ \\
\hline
\end{tabular}


GPC Lactancia Materna- Pregunta 25. Galactogogos.

\begin{tabular}{|c|c|c|c|c|c|c|}
\hline $\begin{array}{l}\text { Referencia } \\
\text { (Cita Abreviada) }\end{array}$ & $\begin{array}{l}\text { Estudio (Diseño y } \\
\text { objetivo) }\end{array}$ & $\begin{array}{l}\text { Población } \\
\text { (noy características) }\end{array}$ & $\begin{array}{l}\text { Descripción de las intervenciones } \\
\text { comparaciones, exposiciones o } \\
\text { pruebas a estudio }\end{array}$ & $\begin{array}{l}\text { Resultados } \\
\text { (Estimadores de resultados-Magnitud del } \\
\text { efecto) }\end{array}$ & $\begin{array}{l}\text { Conclusiones } \\
\text { (conclusiones) }\end{array}$ & $\begin{array}{l}\text { Comentarios } \\
\text { Calidad de la } \\
\text { evidencia } \\
\text { Financiación } \\
\text { comentarios) } \\
\end{array}$ \\
\hline & & & $\begin{array}{l}\text { Nivel basal de prolactina (I vs. C): } 49 \\
\mu \mathrm{g} / \mathrm{l} \text { vs. } 85 \mu \mathrm{g} / \mathrm{l} \text {. }\end{array}$ & & & \\
\hline \multicolumn{7}{|c|}{ TT hormonal. Vs. placebo } \\
\hline Zarate, 1976 & $\begin{array}{l}\text { Diseño: ensayo clínico } \\
\text { aleatorizado doble ciego. } \\
\text { Objetivo: determinar el } \\
\text { efecto de incrementar la } \\
\text { liberación de prolactina } \\
\text { medianta el tratamiento } \\
\text { con hormona liberadora de } \\
\text { tirotropina (TRH) en } \\
\text { relación con el volumen de } \\
\text { leche. }\end{array}$ & $\begin{array}{l}16 \text { madres sanas } \\
\text { entre } 17 \text { y } 30 \text { años } \\
\text { con producción de } \\
\text { leche insuficiente. } \\
\text { No se reportó si los } \\
\text { hijos fueron a término } \\
\text { o no. } \\
\text { Criterios de inclusión: } \\
\text { (1) menstruación sin } \\
\text { alteraciones, (2) al } \\
\text { menos un embarazo } \\
\text { anterior, (3) buena } \\
\text { lactancia en partos } \\
\text { anteriores. } \\
\text { Criterios de exclusión: } \\
\text { (1) más de dos } \\
\text { partos. }\end{array}$ & $\begin{array}{l}\text { Intervención (l): La intervención se inició } \\
2 \text { días después del nacimiento. El grupo } \\
\text { intervención recibió } 60 \mathrm{mg} \text { de hormona } \\
\text { liberadora de tirotropina (TRH) al día } \\
\text { durante } 7 \text { días }(\mathrm{n}=4) \text {. } \\
\text { Comparación }(\mathrm{C}) \text { : placebo }(\mathrm{n}=4) \text {. } \\
\text { Pruebas de estudio: Comparación de los } \\
\text { resultados entre los grupos. } \\
\text { Alguna intervención adicional para } \\
\text { mejorar la lactancia: No reportado. } \\
\text { Nivel basal de prolactina: } 347 \mathrm{ng} / \mathrm{mL} \text { sin } \\
\text { diferencias entre el grupo intervención y } \\
\text { control }\end{array}$ & $\begin{array}{l}\text { 1) Volumen medio de leche después de } 7 \\
\text { días de tratamiento (I vs. C): } \\
\text { - Sin diferencias; } P=\text { no reportado. }\end{array}$ & $\begin{array}{l}\text { El tratamiento con } \\
\text { TRH no mostró } \\
\text { efecto sobre la } \\
\text { producción de } \\
\text { leche. }\end{array}$ & $\begin{array}{l}\text { Los niveles de } \\
\text { prolactina en el } \\
\text { grupo } \\
\text { intervención y } \\
\text { control sólo se } \\
\text { reportan en un } \\
\text { gráfico. No se } \\
\text { cuenta con los } \\
\text { niveles exactos. } \\
\text { El nivel basal de } \\
\text { prolactina es alto } \\
\text { El efecto sobre } \\
\text { la producción de } \\
\text { leche sólo se } \\
\text { evaluó en un } \\
\text { sub-análisis en } 8 \\
\text { mujeres que } \\
\text { recibieron } \\
\text { tratamiento } \\
\text { durante } 7 \text { días. }\end{array}$ \\
\hline Gunn, 1996 & $\begin{array}{l}\text { Diseño: ensayo clínico } \\
\text { aleatorizado doble ciego. } \\
\\
\text { Objetivo: determinar el } \\
\text { efecto galactopoietico del } \\
\text { tratamiento con hormona } \\
\text { humana de crecimiento } \\
\text { (hGH). }\end{array}$ & $\begin{array}{l}20 \text { madres de hijos } \\
\text { pre-término ( } 26 \text { a } 34 \\
\text { semanas) con } \\
\text { producción } \\
\text { insuficiente de leche. } \\
\text { Criterios de exclusión: } \\
\text { (1) medicación } \\
\text { concomitante, (2) } \\
\text { contraindicación del } \\
\text { tratamiento con hGH. }\end{array}$ & $\begin{array}{l}\text { Intervención (I): La intervención se inició } \\
\text { aproximadamente } 35 \text { días después del } \\
\text { nacimiento. El grupo intervención recibió } \\
\text { hGH 2-16 IU/kg al día durante } 7 \text { días } \\
(n=10) \text {. } \\
\text { Comparación (C): placebo }(n=10) \text {. } \\
\text { Alguna intervención adicional para } \\
\text { mejorar la lactancia: todas se extrajeron } \\
\text { la leche mediante un dispositivo } \\
\text { eléctrico. } \\
\text { Nivel basal de prolactina: no reportado. }\end{array}$ & $\begin{array}{l}\text { 1) Volumen medio de leche después de } 7 \\
\text { días de tratamiento (I vs. C): } \\
\text { - Aumento de } 139 \mathrm{~mL} / \mathrm{d} \text { a } 175 \mathrm{~mL} / \mathrm{d} \text { vs. } \\
\text { aumento de } 93 \mathrm{~mL} / \mathrm{d} \text { a } 102 \mathrm{~mL} / ; \mathrm{P}<0,01 \text {. }\end{array}$ & $\begin{array}{l}\text { El tratamiento con } \\
\text { hGH puede } \\
\text { mejorar la } \\
\text { producción de } \\
\text { leche en madres } \\
\text { con lactancia } \\
\text { insuficiente. }\end{array}$ & \\
\hline Fewtrell, 2006 & Diseño: ensayo clínico & 51 madres de hijos & Intervención (I): La intervención & 1) Peso medio de la leche producida & El uso de oxitocina & \\
\hline
\end{tabular}


GPC Lactancia Materna- Pregunta 25. Galactogogos.

\begin{tabular}{|c|c|c|c|c|c|c|}
\hline $\begin{array}{l}\text { Referencia } \\
\text { (Cita Abreviada) }\end{array}$ & $\begin{array}{l}\text { Estudio (Diseño y } \\
\text { objetivo) }\end{array}$ & $\begin{array}{l}\text { Población } \\
\left.\text { ( } n^{\circ} \text { y características }\right)\end{array}$ & $\begin{array}{l}\text { Descripción de las intervenciones } \\
\text { comparaciones, exposiciones o } \\
\text { pruebas a estudio }\end{array}$ & $\begin{array}{l}\text { Resultados } \\
\text { (Estimadores de resultados-Magnitud del } \\
\text { efecto) }\end{array}$ & $\begin{array}{l}\text { Conclusiones } \\
\text { (conclusiones) }\end{array}$ & $\begin{array}{l}\text { Comentarios } \\
\text { Calidad de la } \\
\text { evidencia } \\
\text { Financiación } \\
\text { comentarios) }\end{array}$ \\
\hline & $\begin{array}{l}\text { aleatorizado doble ciego. } \\
\text { Objetivo: evaluar el efecto } \\
\text { de la oxitocina sobre la } \\
\text { producción de leche en } \\
\text { madres de hijos pre- } \\
\text { término. }\end{array}$ & $\begin{array}{l}\text { pre-término }(<35 \\
\text { semanas) con } \\
\text { producción } \\
\text { insuficiente de leche. }\end{array}$ & $\begin{array}{l}\text { comenzó un mes después del parto. } \\
\text { Oxitocina spray nasal } 100 \mu \mathrm{L} \text { por dosis } \\
5 \text { minutos antes de la lactancia durante } \\
\text { un mínimo de } 5 \text { días }(n=27) \text {. } \\
\text { Comparación (C): Placebo }(n=24) \text {. } \\
\text { Alguna intervención adicional para } \\
\text { mejorar la lactancia: Todas las madres } \\
\text { recibieron consejos de lactancia para } \\
\text { realizar masaje y extracción de leche } \\
\text { mediante un dispositivo eléctrico. } \\
\text { Nivel basal de prolactina: no reportado. }\end{array}$ & $\begin{array}{l}\text { durante los } 5 \text { días de tratamiento (I vs. C): } \\
-667 \mathrm{~g} \text { vs. } 530 \mathrm{~g} ; \mathrm{P}=0,9 \text {. }\end{array}$ & $\begin{array}{l}\text { spray nasal no } \\
\text { influyó sobre la } \\
\text { producción de } \\
\text { leche. }\end{array}$ & \\
\hline Ruis, 1981 & $\begin{array}{l}\text { Diseño: ensayo clínico } \\
\text { aleatorizado doble ciego. } \\
\\
\text { Objetivo: evaluar el efecto } \\
\text { de la oxitocina sobre la } \\
\text { producción de leche en } \\
\text { madres de hijos pre- } \\
\text { término. }\end{array}$ & $\begin{array}{l}12 \text { madres de hijos } \\
\text { pre-término }(<38 \\
\text { semanas) con } \\
\text { producción } \\
\text { insuficiente de leche. } \\
8 \text { fueron primíparas y } \\
4 \text { multíparas. }\end{array}$ & $\begin{array}{l}\text { Intervención (I): La intervención } \\
\text { comenzó inmediatamente después del } \\
\text { parto. Oxitocina spray nasal } 3 \text { U por } \\
\text { dosis antes de cada lactancia durante } 5 \\
\text { días }(n=6) \text {. } \\
\text { Comparación (C): Placebo }(n=6) \text {. } \\
\text { Alguna intervención adicional para } \\
\text { mejorar la lactancia: Todas las madres } \\
\text { recibieron consejos de lactancia. } \\
\text { Además, se realizó extracción manual } \\
\text { de leche } 4 \text { veces al día. } \\
\text { Pruebas de estudio: Comparación de los } \\
\text { resultados de acuerdo a paridad. } \\
\text { Nivel basal de prolactina: no reportado. }\end{array}$ & $\begin{array}{l}\text { 1) Volumen acumulado de leche desde el } \\
\text { 2do al } 5 \text { to día de tratamiento (I vs. C): } \\
\text { - Primíparas: } 1600 \text { a } 2400 \mathrm{~mL} / \mathrm{d} \text { vs. } 300 \text { a } \\
600 \mathrm{~mL} / \mathrm{d} ; \mathrm{P}=0,068 \text {. } \\
\text { - Multíparas: } 1000 \text { a } 1600 \mathrm{~mL} / \mathrm{d} \text { vs. } 600 \text { a } \\
700 \mathrm{~mL} / \mathrm{d} ; \mathrm{P}=\text { no reportado. }\end{array}$ & $\begin{array}{l}\text { La oxitocina en } \\
\text { spray nasal es un } \\
\text { tratamiento } \\
\text { efectivo y seguro } \\
\text { para mejorar la } \\
\text { producción de } \\
\text { leche. }\end{array}$ & $\begin{array}{l}\text { El número de } \\
\text { mujeres } \\
\text { incluidas es muy } \\
\text { escaso. }\end{array}$ \\
\hline \multicolumn{7}{|c|}{ Tt herbales: comparación entre diferentes hierbas } \\
\hline Damanik, 2006 & $\begin{array}{l}\text { Diseño: ensayo clínico } \\
\text { aleatorizado. } \\
\text { Objetivo: evaluar el efecto } \\
\text { del torbangun (Coleus } \\
\text { amboinicus Lour) sobre la }\end{array}$ & $\begin{array}{l}75 \text { madres de hijos a } \\
\text { término }(>37 \text { y }<43 \\
\text { semanas) con intento } \\
\text { de lactancia exclusiva } \\
\text { durante un mínimo de } \\
4 \text { meses. }\end{array}$ & $\begin{array}{l}\text { Intervención (l): Torbangun, } 150 \mathrm{~g} / \mathrm{d} \\
\text { desde el día } 2 \text { al } 30 \text { después del parto } \\
(\mathrm{n}=25) \text {. } \\
\text { Comparación (C1): Fenogreco } 1800 \\
\text { mg/d ( } \mathrm{n}=25) \text {. } \\
\text { Comparación (C2): Moloco+B12, } 60\end{array}$ & $\begin{array}{l}\text { 1) Volumen de leche al día } 14 \text { y } 28: \\
\text { - Torbangun: aumento de } 361 \text { a } 479 \mathrm{~mL} / \mathrm{d} \text {; } \\
\mathrm{P}<0,05 \text {. } \\
\text { - Fenogreco: reducción de } 467 \text { a } 400 \\
\mathrm{~mL} / \mathrm{d} ; \mathrm{P}=\text { no reportado. } \\
\text { - Moloco+B12: reducción de } 454 \text { a } 385\end{array}$ & $\begin{array}{l}\text { El uso de } \\
\text { torbangun puede } \\
\text { ser utilizado como } \\
\text { galactogogo. }\end{array}$ & \\
\hline
\end{tabular}


GPC Lactancia Materna- Pregunta 25. Galactogogos.

\begin{tabular}{|c|c|c|c|c|c|c|}
\hline $\begin{array}{l}\text { Referencia } \\
\text { (Cita Abreviada) }\end{array}$ & $\begin{array}{l}\text { Estudio (Diseño y } \\
\text { objetivo) }\end{array}$ & $\begin{array}{l}\text { Población } \\
\text { (nº y características) }\end{array}$ & $\begin{array}{l}\text { Descripción de las intervenciones } \\
\text { comparaciones, exposiciones o } \\
\text { pruebas a estudio }\end{array}$ & $\begin{array}{l}\text { Resultados } \\
\text { (Estimadores de resultados-Magnitud del } \\
\text { efecto) }\end{array}$ & $\begin{array}{l}\text { Conclusiones } \\
\text { (conclusiones) }\end{array}$ & $\begin{array}{l}\text { Comentarios } \\
\text { Calidad de la } \\
\text { evidencia } \\
\text { Financiación } \\
\text { comentarios) }\end{array}$ \\
\hline & producción de leche. & & $\begin{array}{l}\mu \mathrm{g} / \mathrm{d}(\mathrm{n}=25) \text {. } \\
\text { Alguna intervención adicional para } \\
\text { mejorar la lactancia: Todas se extrajeron } \\
\text { la leche manualmente. } \\
\text { Pruebas de estudio: Comparación de los } \\
\text { resultados al día } 28 \text { comparado con el } \\
\text { día } 14 . \\
\text { Nivel basal de prolactina: no reportado. }\end{array}$ & $\mathrm{mL} / \mathrm{d} ; \mathrm{P}=$ no reportado. & & \\
\hline Ushiroyama, 2007 & $\begin{array}{l}\text { Diseño: ensayo clínico } \\
\text { aleatorizado ciego. } \\
\\
\text { Objetivo: evaluar la } \\
\text { efectividad clínica del } \\
\text { Xiong-gui-tiao-xue-yin } \\
\text { (extracto de } 13 \text { hierbas } \\
\text { tradicionalmente utilizadas } \\
\text { en Japón) sobre la } \\
\text { producción de leche. }\end{array}$ & $\begin{array}{l}82 \text { madres de hijos } \\
\text { parto normal sin } \\
\text { antecedentes de } \\
\text { enfermedad durante } \\
\text { el embarazo. }\end{array}$ & $\begin{array}{l}\text { Intervención (l): Xiong-gui-tiao-xue-yin, } 6 \\
\text { g/d desde el día } 0 \text { al } 6 \text { después del parto } \\
\text { ( } \mathrm{n}=41 \text { ). } \\
\text { Comparación (C): Ergometrina } 0,375 \\
\text { mg/d ( } \mathrm{n}=41 \text { ). } \\
\text { Alguna intervención adicional para } \\
\text { mejorar la lactancia: No reportado. } \\
\text { Todas recibieron cefditoren pivoxil } 300 \\
\text { mg/d (antibiótico) y serrapeptas } 30 \mathrm{mg} / \mathrm{d} \\
\text { (anti-inflamatorio). } \\
\text { Pruebas de estudio: Comparación de los } \\
\text { resultados entre ambos grupos. } \\
\text { Nivel basal de prolactina (I vs. C): } 157,9 \\
\text { ng/mL vs. } 129.1 \text { ng/mL; } \mathrm{P}=0.037 . \\
\text { Xiong-gui-tiao-xue-yin es una } \\
\text { combinación de } 2 \mathrm{~g} \text { de cada uno de los } \\
\text { siguientes: } \\
\text {-Japanese angelica root (dang gui) } \\
\text { - cnidium rhizome (chuan xiong) } \\
\text { - rehmannia root (di huang) } \\
\text { - atractylodes rhizome (bai shu) } \\
\text { - hoelen (fu ling) } \\
\text { - Citrus unshiu peel (chen pi) } \\
\text { - cyperus rhizome (xian fu zI) } \\
\text { - moutan bark (mu dan pi) }\end{array}$ & $\begin{array}{l}\text { 1) Volumen de leche al día } 6 \text { (I vs. C): } \\
\text { - } 413,7 \mathrm{~g} \text { vs } 293,3 \mathrm{~g} ; \mathrm{P}=0,046 . \\
\text { 2) Nivel de prolactina al día } 6 \text { (I vs. C): } \\
-167,5 \mathrm{ng} / \mathrm{mL} \text { vs } 117,1 \mathrm{ng} / \mathrm{mL} ; \mathrm{P}= \\
0,0042 \text {. }\end{array}$ & $\begin{array}{l}\text { El uso de Xiong- } \\
\text { gui-tiao-xue-yin } \\
\text { incrementa los } \\
\text { niveles de } \\
\text { prolactina y puede } \\
\text { tener un efecto } \\
\text { positivo sobre la } \\
\text { producción de } \\
\text { leche. }\end{array}$ & $\begin{array}{l}\text { El nivel basal de } \\
\text { prolactina fue } \\
\text { alto en ambos } \\
\text { grupos. }\end{array}$ \\
\hline
\end{tabular}


GPC Lactancia Materna- Pregunta 25. Galactogogos.

\begin{tabular}{|c|c|c|c|c|c|c|}
\hline $\begin{array}{l}\text { Referencia } \\
\text { (Cita Abreviada) }\end{array}$ & $\begin{array}{l}\text { Estudio (Diseño y } \\
\text { objetivo) }\end{array}$ & $\begin{array}{l}\text { Población } \\
\text { (nํy características) }\end{array}$ & $\begin{array}{l}\text { Descripción de las intervenciones } \\
\text { comparaciones, exposiciones o } \\
\text { pruebas a estudio }\end{array}$ & $\begin{array}{l}\text { Resultados } \\
\text { (Estimadores de resultados-Magnitud del } \\
\text { efecto) }\end{array}$ & $\begin{array}{l}\text { Conclusiones } \\
\text { (conclusiones) }\end{array}$ & $\begin{array}{l}\text { Comentarios } \\
\text { Calidad de la } \\
\text { evidencia } \\
\text { Financiación } \\
\text { comentarios) }\end{array}$ \\
\hline & & & $\begin{array}{l}\text { - lindera root (wu yao) } \\
1.5 \mathrm{~g} \text { de cada uno de los siguientes: } \\
\text { - fruta jujube (da zao) } \\
\text { - siberian motherwort (yi mu cao) } \\
1 \mathrm{~g} \text { de cada uno de los siguientes: } \\
\text { - ginger rizhome (gan jian) } \\
\text { - glycyrrhiza (gan cao) }\end{array}$ & & & \\
\hline \multicolumn{7}{|c|}{ TT HERBAL VS. PLACEBO } \\
\hline Di Pierro, 2008 & $\begin{array}{l}\text { Diseño: ensayo clínico } \\
\text { aleatorizado ciego. } \\
\text { Objetivo: evaluar el efecto } \\
\text { del Silymarin (extracto de } \\
\text { Silybum marianum) sobre } \\
\text { la producción de leche. }\end{array}$ & $\begin{array}{l}50 \text { madres de hijos } \\
\text { sanos con niveles } \\
\text { bajos de producción } \\
\text { de leche }<700 \mathrm{~mL} / \mathrm{d} \text {. }\end{array}$ & $\begin{array}{l}\text { Intervención (I): Silymarin, } 420 \mathrm{mg} / \mathrm{d} \\
\text { durante } 63 \text { días post-parto }(\mathrm{n}=25) \text {. } \\
\text { Comparación (C): Placebo }(\mathrm{n}=25) \text {. } \\
\text { Alguna intervención adicional para } \\
\text { mejorar la lactancia: Todas recibieron } \\
\text { una dieta similar y extracción de la leche } \\
\text { mediante un dispositivo. } \\
\text { Nivel basal de prolactina: no reportado. }\end{array}$ & $\begin{array}{l}\text { 1) Volumen medio de leche fue superior } \\
\text { en el grupo intervención versus el grupo } \\
\text { control ( I vs. C): } \\
\text { - A los } 30 \text { días } 989,8 \mathrm{~g} \text { vs. } 649,8 \mathrm{~g} ; \mathrm{P}< \\
0,01 \text {. } \\
\text { - A los } 63 \text { días } 1119,2 \mathrm{~g} \text { vs. } 700,6 \mathrm{~g} ; \mathrm{P}< \\
0,01 \text {. }\end{array}$ & $\begin{array}{l}\text { El Silymarin podría } \\
\text { considerarse como } \\
\text { tratamiento seguro } \\
\text { y efectivo para } \\
\text { mejorar la } \\
\text { producción de } \\
\text { leche en mujeres } \\
\text { sanas. }\end{array}$ & \\
\hline Turkyilmaz, 2011 & $\begin{array}{l}\text { Diseño: ensayo clínico } \\
\text { aleatorizado doble ciego. } \\
\text { Objetivo: evaluar el efecto } \\
\text { del fenogreco (Trigonella } \\
\text { foenum-graecum) sobre la } \\
\text { producción de leche. }\end{array}$ & $\begin{array}{l}66 \text { madres de hijos } \\
\text { sanos a término. }\end{array}$ & $\begin{array}{l}\text { Intervención (I): Fenogreco, } 600 \mathrm{~mL} / \mathrm{d} \\
\text { durante los tres primeros días post-parto } \\
(\mathrm{n}=22) \text {. } \\
\text { Comparación (C1): Placebo }(\mathrm{n}=22) \text {. } \\
\text { Comparación (C2): sólo consejo ( } \mathrm{n}=22) \text {. } \\
\text { Alguna intervención adicional para } \\
\text { mejorar la lactancia: Todas recibieron } \\
\text { consejo de enfermería y realizaron } \\
\text { extracción de leche mediante un } \\
\text { dispositivo eléctrico. } \\
\text { Nivel basal de prolactina: no reportado. }\end{array}$ & $\begin{array}{l}\text { 1) El volumen medio de leche en las } \\
\text { mujeres que recibieron fenogreco fue } \\
\text { mayor al grupo placebo y al grupo de sólo } \\
\text { consejo }(P<0,05) \text {. No se cuenta con } \\
\text { resultados cuantitativos. }\end{array}$ & $\begin{array}{l}\text { El fenogreco es de } \\
\text { utilidad para } \\
\text { mejorar la } \\
\text { lactancia durante } \\
\text { los primeros días } \\
\text { post-parto. }\end{array}$ & $\begin{array}{l}\text { La información } \\
\text { sobre este } \\
\text { estudio proviene } \\
\text { sólo de un } \\
\text { resumen. }\end{array}$ \\
\hline Ghasemi, 2015 & $\begin{array}{l}\text { Diseño: ensayo clínico } \\
\text { aleatorizado doble ciego. } \\
\text { Objetivo: evaluar el efecto } \\
\text { del fenogreco (Trigonella } \\
\text { foenum-graecum) sobre el }\end{array}$ & $\begin{array}{l}78 \text { madres de hijas } \\
\text { sanas a término. Las } \\
\text { hijas tuvieron de } 0 \text { a } 4 \\
\text { meses. }\end{array}$ & $\begin{array}{l}\text { Intervención (I): Fenogreco } 22,5 \mathrm{~g} / \mathrm{d} \\
\text { durante cuatro semanas }(n=39) \text {. } \\
\text { Comparación }(C) \text { : Placebo }(n=39) \text {. } \\
\text { Alguna intervención adicional para }\end{array}$ & $\begin{array}{l}\text { 1) El peso en el grupo intervención se } \\
\text { incrementó de } 5,282 \mathrm{~g} \text { a } 6,383 \mathrm{~g} \text { después } \\
\text { de } 4 \text { semanas de tratamiento; } \mathrm{P}<0,001 \text {. }\end{array}$ & $\begin{array}{l}\text { El tratamiento con } \\
\text { fenogreco puede } \\
\text { mejorar el peso y } \\
\text { la circunferencia } \\
\text { craneal de los } \\
\text { niños post-parto. }\end{array}$ & . \\
\hline
\end{tabular}


GPC Lactancia Materna- Pregunta 25. Galactogogos.

\begin{tabular}{|c|c|c|c|c|c|c|}
\hline $\begin{array}{l}\text { Referencia } \\
\text { (Cita Abreviada) }\end{array}$ & $\begin{array}{l}\text { Estudio (Diseño y } \\
\text { objetivo) }\end{array}$ & $\begin{array}{l}\text { Población } \\
\text { (noy características) }\end{array}$ & $\begin{array}{l}\text { Descripción de las intervenciones } \\
\text { comparaciones, exposiciones o } \\
\text { pruebas a estudio }\end{array}$ & $\begin{array}{l}\text { Resultados } \\
\text { (Estimadores de resultados-Magnitud del } \\
\text { efecto) }\end{array}$ & $\begin{array}{l}\text { Conclusiones } \\
\text { (conclusiones) }\end{array}$ & $\begin{array}{l}\text { Comentarios } \\
\text { Calidad de la } \\
\text { evidencia } \\
\text { Financiación } \\
\text { comentarios) }\end{array}$ \\
\hline & $\begin{array}{l}\text { crecimiento de hijas recién } \\
\text { nacidas. }\end{array}$ & & $\begin{array}{l}\text { mejorar la lactancia: no reportado. } \\
\text { Nivel basal de prolactina: no reportado. }\end{array}$ & & & \\
\hline Manjula, 2014 & $\begin{array}{l}\text { Diseño: ensayo clínico } \\
\text { aleatorizado ciego } \\
\text { Objetivo: evaluar la } \\
\text { eficacia de Gossypium } \\
\text { herbaceum en madres con } \\
\text { lactancia insufciente. }\end{array}$ & $\begin{array}{l}45 \text { madres de hijos } \\
\text { sanos a término con } \\
\text { lactancia insuficiente. } \\
\text { Criterios de inclusión: } \\
\text { 1) peso superior a } \\
2000 \mathrm{~g} \text { al nacimiento. } \\
\text { 2) falla en alcanzar el } \\
\text { peso al nacimiento a } \\
\text { los } 15 \text { días. } 3 \text { ) entre } \\
10 \text { y } 180 \text { días de } \\
\text { edad. 4) suplemento } \\
\text { de cómo mínimo } 250 \\
\text { mL/d después de } 4 \\
\text { semanas de } \\
\text { nacimiento. }\end{array}$ & $\begin{array}{l}\text { Intervención (I): Gossypium herbaceum } \\
30 \mathrm{~g} \text { al día durante } 1 \text { mes }(\mathrm{n}=30) \text {. } \\
\text { Comparación (C): Placebo }(\mathrm{n}=15) \text {. } \\
\text { Alguna intervención adicional para } \\
\text { mejorar la lactancia: no reportado. } \\
\text { Nivel basal de prolactina (I vs. C): no } \\
\text { reportado. }\end{array}$ & $\begin{array}{l}\text { 1) Ganancia de peso en los hijos después } \\
\text { del tratamiento (I vs. C): } 5790 \text { vs } 5940 \mathrm{~g} \text {; } \\
\mathrm{P}=0,65 \text {. } \\
\text { 2) Volumen medio de suplemento } \\
\text { alimenticio después del tratamiento (I vs. } \\
\text { C): } 40 \text { vs } 227 \mathrm{~mL} / \mathrm{d} ; \mathrm{P}=0,008 \text {. }\end{array}$ & $\begin{array}{l}\text { El Gossypium } \\
\text { herbaceum es } \\
\text { eficaz, segura y } \\
\text { coste-efectiva para } \\
\text { aumentar la } \\
\text { lactancia. }\end{array}$ & \\
\hline Sharma, 1996 & $\begin{array}{l}\text { Diseño: ensayo clínico } \\
\text { aleatorizado doble ciego } \\
\text { multicéntrico. } \\
\text { Objetivo: evaluar el efecto } \\
\text { del shatavari (Asparagus } \\
\text { racemosus) sobre los } \\
\text { niveles de prolactina y su } \\
\text { efecto como galactogogo. }\end{array}$ & $\begin{array}{l}64 \text { madres de hijos } \\
\text { sanos a término con } \\
\text { lactancia insuficiente. } \\
\text { Criterios de exclusión: } \\
\text { 1) hijos con } \\
\text { malformaciones } \\
\text { congénitas }\end{array}$ & $\begin{array}{l}\text { Intervención (I): Shatavari, } 100 \mathrm{~g} / \mathrm{d} \\
\text { desde el día } 2 \text { hasta } 4 \text { semanas post } \\
\text { parto ( } \mathrm{n}=32) \text {. } \\
\text { Comparación (C): Placebo ( } \mathrm{n}=32 \text { ). } \\
\text { Alguna intervención adicional para } \\
\text { mejorar la lactancia: todas recibieron } \\
\text { consejos. } \\
\text { Nivel basal de prolactina (I vs C): } 52,5 \\
\text { vs } 40,5 \mathrm{ng} / \mathrm{mL} \text {. }\end{array}$ & $\begin{array}{l}\text { 1) El nivel medio de prolactina después de } \\
4 \text { semanas de tratamiento (I vs C): } 25 \text { vs } \\
38 \mathrm{ng} / \mathrm{mL} \text {. }\end{array}$ & $\begin{array}{l}\text { El consumo de } \\
\text { shatavari no } \\
\text { presentó efecto } \\
\text { galactogogo. }\end{array}$ & $\begin{array}{l}\text { El nivel basal de } \\
\text { prolactina es } \\
\text { bajo en ambos } \\
\text { grupos. }\end{array}$ \\
\hline Gupta, 2011 & $\begin{array}{l}\text { Diseño: ensayo clínico } \\
\text { aleatorizado doble ciego. } \\
\text { Objetivo: evaluar el efecto } \\
\text { del shatavari (Asparagus } \\
\text { racemosus) sobre los } \\
\text { niveles de prolactina. }\end{array}$ & $\begin{array}{l}60 \text { madres de hijos } \\
\text { sanos a término. } \\
\text { Criterios de inclusión: } \\
\text { (1) madres de } 20 \text { a } 40 \\
\text { años. } \\
\text { (2) hijos > } 6 \text { meses. } \\
\text { (3) uno o más de los }\end{array}$ & $\begin{array}{l}\text { Intervención (I): Shatavari, } 60 \mathrm{mg} / \mathrm{k} / \mathrm{d} \\
\text { durante } 30 \text { días }(n=30) \text {. } \\
\text { Comparación (C): Placebo }(n=30) \text {. } \\
\text { Alguna intervención adicional para } \\
\text { mejorar la lactancia: no reportado. }\end{array}$ & $\begin{array}{l}\text { 1) El nivel medio de prolactina en las } \\
\text { mujeres que recibieron shatavari se } \\
\text { incrementó en } 33 \% ; P<0,05 \text {. } \\
\text { El nivel medio de prolactina en las } \\
\text { mujeres que recibieron placebo se } \\
\text { incrementó en } 10 \% ; P<0,05 \text {. }\end{array}$ & $\begin{array}{l}\text { El consumo de } \\
\text { shatavari } \\
\text { incrementa el nivel } \\
\text { de prolactina. }\end{array}$ & \\
\hline
\end{tabular}


GPC Lactancia Materna- Pregunta 25. Galactogogos.

\begin{tabular}{|c|c|c|c|c|c|c|}
\hline $\begin{array}{l}\text { Referencia } \\
\text { (Cita Abreviada) }\end{array}$ & $\begin{array}{l}\text { Estudio (Diseño y } \\
\text { objetivo) }\end{array}$ & $\begin{array}{l}\text { Población } \\
\text { (nº y características) }\end{array}$ & $\begin{array}{l}\text { Descripción de las intervenciones } \\
\text { comparaciones, exposiciones o } \\
\text { pruebas a estudio }\end{array}$ & $\begin{array}{l}\text { Resultados } \\
\text { (Estimadores de resultados-Magnitud del } \\
\text { efecto) }\end{array}$ & $\begin{array}{l}\text { Conclusiones } \\
\text { (conclusiones) }\end{array}$ & $\begin{array}{l}\text { Comentarios } \\
\text { Calidad de la } \\
\text { evidencia } \\
\text { Financiación } \\
\text { comentarios) }\end{array}$ \\
\hline & & $\begin{array}{l}\text { siguientes: lactancia } \\
\text { insuficiente, llanto } \\
\text { post-lactancia, dolor } \\
\text { en mamas, pérdida } \\
\text { de apetito o ansiedad } \\
\text { en las madres. } \\
\end{array}$ & Nivel basal de prolactina: no reportado. & & & \\
\hline \multicolumn{7}{|c|}{ Comparación dos dosis DOMPERIDONA: } \\
\hline Knoppert, 2013 & $\begin{array}{l}\text { Diseño: ensayo clínico } \\
\text { aleatorizado doble ciego } \\
\text { Objetivo: determinar la } \\
\text { dosis óptima de la } \\
\text { domperidona como } \\
\text { galactogogo. }\end{array}$ & $\begin{array}{l}15 \text { madres de hijos } \\
\text { pre-término (<33 } \\
\text { semanas) en unidad } \\
\text { de cuidados } \\
\text { intensivos. } \\
\text { Criterios de exclusión: } \\
\text { (1) cirugía mamaria, } \\
\text { (2) cáncer de mama, } \\
\text { (3) enfermedad } \\
\text { crónica o debilitante, } \\
\text { (4) arritmia, } \\
\text { (5) medicación que se } \\
\text { metabolice por } \\
\text { CYP3A4, } \\
\text { (6) enterocolitis } \\
\text { necrotizante }\end{array}$ & $\begin{array}{l}\text { Intervención (I): La intervención se inició } \\
\text { entre } 14 \text { y } 21 \text { días post-parto. } \\
\text { Domperidona } 60 \text { mg al día durante } 28 \\
\text { días }(n=7) \text {. } \\
\text { Comparación (C): Domperidona } 30 \mathrm{mg} / \mathrm{d} \\
\text { durante } 28 \text { días ( } \mathrm{n}=8 \text { ). } \\
\text { Alguna intervención adicional para } \\
\text { mejorar la lactancia: Todas realizaron } \\
\text { extracción manual de leche. } \\
\text { Pruebas de estudio: Comparación de los } \\
\text { resultados entre ambos grupos. } \\
\text { Nivel basal de prolactina (I vs. C): } 15,5 \\
\mu \mathrm{g} / \mathrm{l} \text { vs. } 20,5 \mu \mathrm{g} / \mathrm{l} \text {. }\end{array}$ & $\begin{array}{l}\text { 1) Volumen medio de leche (I vs. C): } \\
\text { - Sin diferencias entre los grupos a las } 4 \\
\text { semanas de tratamiento; } P<0,01 . \\
\text { - Intervención: subió de } 300 \text { a } 600 \mathrm{ml} / \mathrm{d} \text {. } \\
\text { - Control: subió de } 180 \text { a } 300 \mathrm{ml} / \mathrm{d} \text {. } \\
\text { 2) Nivel de prolactina (I vs. C): } \\
\text { - Sin diferencias entre los grupos a los } 10 \\
\text { días de tratamiento; } P=\text { no reportado. }\end{array}$ & $\begin{array}{l}\text { La dosis de } 60 \\
\mathrm{mg} / \mathrm{d} \text { de } \\
\text { domperidona se } \\
\text { asoció con un } \\
\text { mayor aumento en } \\
\text { la producción de } \\
\text { leche que la dosis } \\
\text { de } 30 \mathrm{mg} / \mathrm{d} \text {. Esta } \\
\text { superioridad no fue } \\
\text { estadísticamente } \\
\text { significativa. }\end{array}$ & $\begin{array}{l}\text { El nivel basal de } \\
\text { prolactina es } \\
\text { bajo en ambos } \\
\text { grupos. } \\
\text { Los resultados } \\
\text { de producción } \\
\text { de leche están } \\
\text { presentados en } \\
\text { una figura. Los } \\
\text { valores son } \\
\text { aproximados. }\end{array}$ \\
\hline
\end{tabular}

\section{ANEXO III, Forest-Plot}

No procede. 
GPC Lactancia Materna- Pregunta 25. Galactogogos.

\section{ANEXO IV. Evaluación de la calidad}

Valoración AMSTAR de las revisiones sistemáticas identificadas

\section{AMSTAR Herramienta de medición para evaluar revisiones sistemáticas}

\begin{tabular}{|c|c|c|c|c|c|c|}
\hline AMSTAR & $\begin{array}{l}\text { Paul, } \\
2015 \text { (1) }\end{array}$ & $\begin{array}{l}\text { Donovan, } \\
2012(6)\end{array}$ & $\begin{array}{l}\text { Osadchy, } \\
2012 \text { (5) }\end{array}$ & $\begin{array}{l}\text { Zuppa, } \\
2010 \text { (8) }\end{array}$ & $\begin{array}{l}\text { Doggrell, } \\
2014 \text { (9) }\end{array}$ & $\begin{array}{l}\text { Mortel, } \\
2013 \text { (3) }\end{array}$ \\
\hline $\begin{array}{l}\text { 1. ¿Se brindó un diseño “a priori”? } \\
\text { La pregunta de la investigación y los criterios de } \\
\text { inclusión deberían establecerse antes de llevar a } \\
\text { cabo la revisión }\end{array}$ & $\begin{array}{l}\text { No } \\
\text { responde }\end{array}$ & Si & $\begin{array}{l}\text { No } \\
\text { responde }\end{array}$ & No & $\begin{array}{l}\text { No } \\
\text { responde }\end{array}$ & $\begin{array}{l}\text { No } \\
\text { responde }\end{array}$ \\
\hline $\begin{array}{l}\text { 2. ¿Hubo duplicación en la selección de } \\
\text { estudios y extracción de datos? Debería haber } \\
\text { al menos dos personas independientes a cargo de } \\
\text { la extracción de datos, y debería existir un } \\
\text { procedimiento consensuado para los desacuerdos }\end{array}$ & No & $\mathrm{Si}$ & Si & $\begin{array}{l}\text { No } \\
\text { respond } \\
\text { e }\end{array}$ & $\begin{array}{l}\text { No } \\
\text { responde }\end{array}$ & $\begin{array}{l}\text { No } \\
\text { responde }\end{array}$ \\
\hline
\end{tabular}




\begin{tabular}{|c|c|c|c|c|c|c|}
\hline $\begin{array}{l}\text { 3. ¿Se realizó una búsqueda exhaustiva de } \\
\text { literatura? } \\
\text { Deberían consultarse al menos dos fuentes } \\
\text { electrónicas. El informe debe incluir los años y las } \\
\text { bases de datos utilizadas (por ej. Central, EMBASE } \\
\text { y MEDLINE). Deben especificarse las palabras } \\
\text { clave y/o los términos MESH y, de ser posible, } \\
\text { debe proveerse la estrategia de búsqueda. Todas } \\
\text { las búsquedas deberían ser complementadas con } \\
\text { consultas a contenidos actuales, revisiones, libros } \\
\text { de textos, registros especializados, o expertos en } \\
\text { el campo particular de estudio, y mediante la } \\
\text { revisión de las referencias en los estudios } \\
\text { encontrados }\end{array}$ & No & Si & $\mathrm{Si}$ & No & $\begin{array}{l}\text { No } \\
\text { responde }\end{array}$ & No \\
\hline $\begin{array}{l}\text { 4. ¿Se utilizó el estado de publicación (es decir, } \\
\text { literatura gris) como criterio de inclusión? } \\
\text { Los autores deberían especificar que buscaron } \\
\text { informes sin tener en cuenta el tipo de publicación. } \\
\text { Los autores deberían especificar si excluyeron o no } \\
\text { algún informe (de la revisión sistemática), en } \\
\text { función del estado de publicación, idioma, etc. }\end{array}$ & $\begin{array}{l}\text { No } \\
\text { responde }\end{array}$ & $\mathrm{Si}$ & $\begin{array}{l}\text { No } \\
\text { responde }\end{array}$ & $\begin{array}{l}\text { No } \\
\text { respond } \\
\text { e }\end{array}$ & $\begin{array}{l}\text { No } \\
\text { responde }\end{array}$ & $\begin{array}{l}\text { No } \\
\text { responde }\end{array}$ \\
\hline $\begin{array}{l}\text { 5. ¿Se brindó una lista de estudios (incluidos y } \\
\text { excluidos)? } \\
\text { Debería proveerse una lista de estudios incluidos y } \\
\text { excluidos }\end{array}$ & Sí & $\mathrm{Si}$ & No & No & No & No \\
\hline $\begin{array}{l}\text { 6. ¿Se brindaron las características de los } \\
\text { estudios incluidos? De manera adjunta tal como } \\
\text { una tabla, deberían proveerse los datos de los } \\
\text { estudios originales sobre los participantes, las } \\
\text { intervenciones y los resultados. Deberían } \\
\text { informarse los rangos de las características en } \\
\text { todos los estudios analizados, por ej, la edad, la } \\
\text { raza, el sexo, los datos socioeconómicos } \\
\text { relevantes, el estado de enfermedad, la duración, } \\
\text { la severidad, o cualquier otra enfermedad }\end{array}$ & Sí & $\mathrm{Si}$ & Si & $\mathrm{Si}$ & $\mathrm{Si}$ & $\mathrm{Si}$ \\
\hline 7. ¿Se evaluó y documentó la calidad científica & Sí & $\mathrm{Si}$ & $\mathrm{Si}$ & No & $\mathrm{Si}$ & $\mathrm{Si}$ \\
\hline
\end{tabular}




\begin{tabular}{|c|c|c|c|c|c|c|}
\hline $\begin{array}{l}\text { de los estudios incluidos? Deberían proveerse } \\
\text { métodos "a priori" (por ej, para estudios de } \\
\text { efectividad si el autor o los autores eligen incluir } \\
\text { sólo estudios aleatorizados, de doble ciego, } \\
\text { controlados con placebo, u ocultamiento de las } \\
\text { asignaciones como criterios de inclusión). Para } \\
\text { otros tipos de estudios, serán relevantes los ítems } \\
\text { alternativos }\end{array}$ & & & & & & \\
\hline $\begin{array}{l}\text { 9. ¿Fueron adecuados los métodos utilizados } \\
\text { para combinar los hallazgos de los estudios? } \\
\text { Para los resultados conjuntos, debería hacerse una } \\
\text { prueba para garantizar que los estudios pudieron } \\
\text { combinarse y para evaluar sus homogeneidad (es } \\
\text { decir, la prueba chi-cuadrado para la } \\
\text { homogeneidad, } \text { I2). Si existe heterogeneidad }_{\text {debería utilizarse un modelo de efectos aleatorios }} \\
\text { y/o debería considerarse lo adecuado de la } \\
\text { combinación (es decir, ¿fue adecuado combinar } \\
\text { los resultados?) }\end{array}$ & $\begin{array}{l}\text { No } \\
\text { aplicable } \\
\text { (no se } \\
\text { combinar } \\
\text { on) }\end{array}$ & $\mathrm{Si}$ & $\begin{array}{l}\text { No } \\
\text { aplicable } \\
\text { (no se } \\
\text { combinar } \\
\text { on) }\end{array}$ & $\begin{array}{l}\text { No } \\
\text { aplicabl } \\
\text { e (no se } \\
\text { combina } \\
\text { ron) }\end{array}$ & $\begin{array}{l}\text { No aplicable } \\
\text { (no se } \\
\text { combinaron) }\end{array}$ & $\begin{array}{l}\text { No } \\
\text { aplicable } \\
\text { (no se } \\
\text { combinar } \\
\text { on) }\end{array}$ \\
\hline $\begin{array}{l}\text { 10. ¿Se valoró la probabilidad de sesgo de } \\
\text { publicación? } \\
\text { Una evaluación de sesgo de publicación debería } \\
\text { incluir una combinación de ayudas gráficas (por ej. } \\
\text { un gráfico en embudo - funnel plot - , otras } \\
\text { pruebas disponibles) y/o pruebas estadísticas (por } \\
\text { ej. prueba de regresión de Egger) }\end{array}$ & No & $\mathrm{Si}$ & No & No & No & No \\
\hline
\end{tabular}




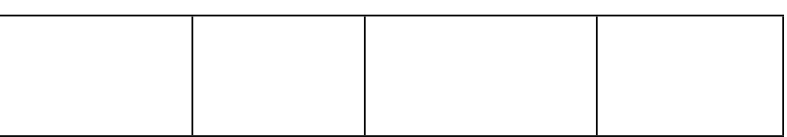

\section{ANEXO V. Tabla sobre galactogogos específicos (Protocolo de la ABM \#9)}

ABM Protocolo Clínico \# 9: Uso de Galactogogos para Iniciar o Aumentar la Tasa de Secreción de Leche Materna (Primera Revisión Enero del 2011)

\section{Apéndice: Galactogogos Específicos}

Tabla 1. Posiblemente Efectivos para Indicaciones Seleccionadas

\begin{tabular}{|c|c|c|c|c|}
\hline & Domperidona & Fenogreco & Metoclopramida & Silymarin $^{3}$ \\
\hline Referencias & $11,44,45,46-52$ & $31,32,53-55$ & $16-20,22-25,56$ & 31,53 \\
\hline $\begin{array}{l}\text { Clase química o } \\
\text { propiedades }\end{array}$ & Antagonista de Dopamina & $\begin{array}{l}\text { Una especie usada } \\
\text { comúnmente; sus } \\
\text { constituyentes activos son } \\
\text { trigonelina, 4-hidroxiiso- } \\
\text { leucina y sotolon }\end{array}$ & $\begin{array}{l}\text { Antagonista de } \\
\text { Dopamina }\end{array}$ & $\begin{array}{l}\text { Flavolignanos (Presumi- } \\
\text { blemente el ingrediente } \\
\text { activo) }\end{array}$ \\
\hline $\begin{array}{l}\text { Nivel de } \\
\text { evidencia }\end{array}$ & $\begin{array}{l}\text { I (un estudio); otros estudios } \\
\text { presentan metodología } \\
\text { inadecuada o tasas altas de } \\
\text { abandono }\end{array}$ & $\begin{array}{l}\text { II-3 (un estudio en mujeres } \\
\text { que amamantan - solo el } \\
\text { resumen) }\end{array}$ & $\begin{array}{l}\text { III (resultados mixtos en } \\
\text { estudios de baja calidad; } \\
\text { es poco claro el efecto } \\
\text { en la tasa total de } \\
\text { secreción de leche) }\end{array}$ & $\begin{array}{l}\text { II-1 (un estudio con mujeres } \\
\text { que amamantan) }\end{array}$ \\
\hline Dosis sugerida & $\begin{array}{l}\text { 10mg, vía oral, } 3 \text { veces/día en } \\
\text { estudio con Nivel l; no se han } \\
\text { estudiado dosis mayores en este } \\
\text { contexto }\end{array}$ & $\begin{array}{l}\text { "3 capsulas" vía oral } \\
\text { (típicamente } 580-610 \mathrm{mg} \text {, } \\
\text { pero no se mencionó en el } \\
\text { articulo) } 3-4 \text { veces/dia; } \\
\text { Infusión de té, } 1 \text { taza, } 3 \\
\text { veces/dia (1/4 cdta de } \\
\text { semillas imbuidas en } 8 \text { oz } \\
\text { de agua por } 10 \mathrm{~min} \text { ) }\end{array}$ & $\begin{array}{l}\text { 10mg, vía oral, 3-4 } \\
\text { veces/dia }\end{array}$ & $\begin{array}{l}\text { Silymarin micronizada, } \\
420 \mathrm{mg} \text {, vía oral, por dia, en } \\
\text { un estudio de diPierro et al } \\
\text { ( } 31 \text { ); anecdótico, te colado } \\
\text { (cocinar a fuego lento } 1 \mathrm{cdta} \\
\text { de semillas trituradas en } 8 \\
\text { oz de agua por } 10 \text { minutos), } \\
2-3 \text { tazas/ día (54) }\end{array}$ \\
\hline $\begin{array}{l}\text { Duración del } \\
\text { tratamiento }\end{array}$ & $\begin{array}{l}\text { Inicio entre 3-4 semanas } \\
\text { postparto y se dió por } 14 \text { días en } \\
\text { el estudio Nivel I. En otros } \\
\text { estudios el rango fue } \\
\text { considerable: Inicio con } \\
\text { Domperidona entre los } 16-117 \\
\text { días postparto y se dió por 2-14 } \\
\text { días }\end{array}$ & 1 semana & $\begin{array}{l}\text { 7-14 dias en varios } \\
\text { estudios }\end{array}$ & $\begin{array}{l}\text { Silymarin Micronizada fue } \\
\text { estudiada por } 63 \text { días. }\end{array}$ \\
\hline $\begin{array}{l}\text { Consideraciones } \\
\text { herbolarias }\end{array}$ & -- & $\begin{array}{l}\text { Se necesitan fuentes } \\
\text { confiables de } \\
\text { preparaciones estándar sin } \\
\text { contaminantes }\end{array}$ & & $\begin{array}{l}\text { Se necesita una fuente } \\
\text { confiable de preparaciones } \\
\text { estándar sin contaminantes }\end{array}$ \\
\hline $\begin{array}{l}\text { Efectos en la } \\
\text { lactancia }\end{array}$ & $\begin{array}{l}\text { Aumento en la tasa de secreción } \\
\text { de leche en madres dependiente } \\
\text { de sacaleches en infantes }\end{array}$ & $\begin{array}{l}\text { Evidencia insuficiente; } \\
\text { probablemente con efecto } \\
\text { placebo significativo }\end{array}$ & $\begin{array}{l}\text { Posible aumento en la } \\
\text { tasa de secreción de } \\
\text { leche; posibles }\end{array}$ & No concluyentes \\
\hline
\end{tabular}




\begin{tabular}{|c|c|c|c|c|}
\hline & $\begin{array}{l}\text { prematuros menores de } 31 \\
\text { semanas de gestación en } \\
\text { unidades de cuidados intensivos } \\
\text { neonatales }\end{array}$ & & $\begin{array}{l}\text { respondedores versus } \\
\text { no respondedores }\end{array}$ & \\
\hline $\begin{array}{l}\text { Efectos } \\
\text { adversos }\end{array}$ & $\begin{array}{l}\text { Maternos: Boca seca, cefalea } \\
\text { (resuelta al disminuir la dosis) y } \\
\text { cólicos abdominales. Aunque no } \\
\text { han sido reportados en estudios } \\
\text { de lactancia, son preocupantes y } \\
\text { ocasionalmente fatales las } \\
\text { arritmias cardiacas por } \\
\text { prolongación del intervalo QTC. } \\
\text { Esto puede ocurrir con } \\
\text { administración oral (44) o IV y } \\
\text { particularmente a dosis altas, o } \\
\text { con el uso concurrente de } \\
\text { fármacos que inhiben el } \\
\text { metabolismo de la domperidona } \\
\text { (vea Interacciones, } \\
\text { inmediatamente abajo), Neonatal: } \\
\text { Niveles muy bajos en la leche y } \\
\text { sin prolongación de QTc en } \\
\text { infantes prematuros que ingirieron } \\
\text { leche materna de madres en } \\
\text { tratamiento con domperidona } \\
\text { (45). }\end{array}$ & $\begin{array}{l}\text { Generalmente bien } \\
\text { tolerado. Diarrea (mas } \\
\text { común), olor corporal } \\
\text { similar a jarabe de arce, } \\
\text { alergia-cruzada con } \\
\text { Asteraceael familia } \\
\text { Compositae (ambrosia y } \\
\text { plantas relacionadas), } \\
\text { cacahuates y familia } \\
\text { Fabacceae como } \\
\text { garbanzo, chícharo, frijol } \\
\text { de soya - posible } \\
\text { anafilaxia. En teoria: } \\
\text { asma, sangrado, mareo, } \\
\text { flatulencia, hipoglucemia, } \\
\text { pérdida de conciencia, } \\
\text { erupción de la piel, } \\
\text { sibilancias - pero no } \\
\text { reportadas en mujeres que } \\
\text { amamantan. }\end{array}$ & $\begin{array}{l}\text { Efectos reversible en el } \\
\text { SNC con el uso a corto } \\
\text { plazo, incluyendo } \\
\text { sedación, ansiedad, } \\
\text { depresión/ ansiedad/ } \\
\text { agitación, inquietud } \\
\text { motora, reacciones } \\
\text { distónicas, síntomas } \\
\text { extrapiramidales. } \\
\text { Reportes raros de } \\
\text { disquinesia tardía } \\
\text { (usualmente } \\
\text { irreversible), causando } \\
\text { que la FDA etiquete este } \\
\text { fármaco con una } \\
\text { "advertencia de riesgo } \\
\text { (black box)" en Estados } \\
\text { Unidos. }\end{array}$ & $\begin{array}{l}\text { Generalmente bien tolerado; } \\
\text { ocasionalmente efectos } \\
\text { adversos gastrointestinales } \\
\text { leves; alergia- cruzada con } \\
\text { la familia Asteraceae/ } \\
\text { Compositae (ambrosia y } \\
\text { plantas relacionadas) - } \\
\text { posible anafilaxia. }\end{array}$ \\
\hline Interacciones & $\begin{array}{l}\text { Incremento en niveles sanguíneos } \\
\text { de domperidona cuando se } \\
\text { combina con sustratos } \\
\text { metabolizados por inhibidores } \\
\text { enzimáticos de CYP } 3 \text { A4, ej. } \\
\text { Fluconazol, jugo de toronja, } \\
\text { ketoconazol, antibióticos } \\
\text { macrólidos y otros }\end{array}$ & $\begin{array}{l}\text { Efecto Hawthorne, } \\
\text { hipoglucemiantes } \\
\text { incluyendo insulina, } \\
\text { antiplaquetarios, aspirina, } \\
\text { heparina, warfarina, } \\
\text { matricaria, aceite de } \\
\text { prímula/ onagra y muchas } \\
\text { otras hierbas }\end{array}$ & $\begin{array}{l}\text { Inhibidores de la } \\
\text { monoamino oxidasa, } \\
\text { tacrolimus, } \\
\text { antihistaminicos, } \\
\text { cualquier fármaco con } \\
\text { efectos en SNC } \\
\text { (incluyendo } \\
\text { antidepresivos) }\end{array}$ & $\begin{array}{l}\text { Precaución con los sustratos } \\
\text { CYP2C9 - puede } \\
\text { incrementar los niveles de } \\
\text { esos fármacos. Posible } \\
\text { incremento en la depuración } \\
\text { de estrógenos (disminución } \\
\text { de los niveles sanguíneos). } \\
\text { Posible incremento en los } \\
\text { niveles de estatinas. }\end{array}$ \\
\hline Comentarios & $\begin{array}{l}\text { a. No aconseje exceder la dosis } \\
\text { máxima recomendada, no se } \\
\text { incrementa la eficacia y si se } \\
\text { incrementan los efectos adversos } \\
\text { b. Generalmente autorizada para }\end{array}$ & $\begin{array}{l}\text { Si la paciente desarrolla } \\
\text { diarrea, puede ayudar el } \\
\text { reducir la dosis. }\end{array}$ & $\begin{array}{l}\text { Algunos estudios } \\
\text { sugieren que es } \\
\text { recomendable la } \\
\text { disminución gradual de } \\
\text { la dosis al final del }\end{array}$ & $\begin{array}{l}\text { No se requiere receta } \\
\text { medica }\end{array}$ \\
\hline
\end{tabular}


GPC Lactancia Materna- Pregunta 25. Galactogogos.

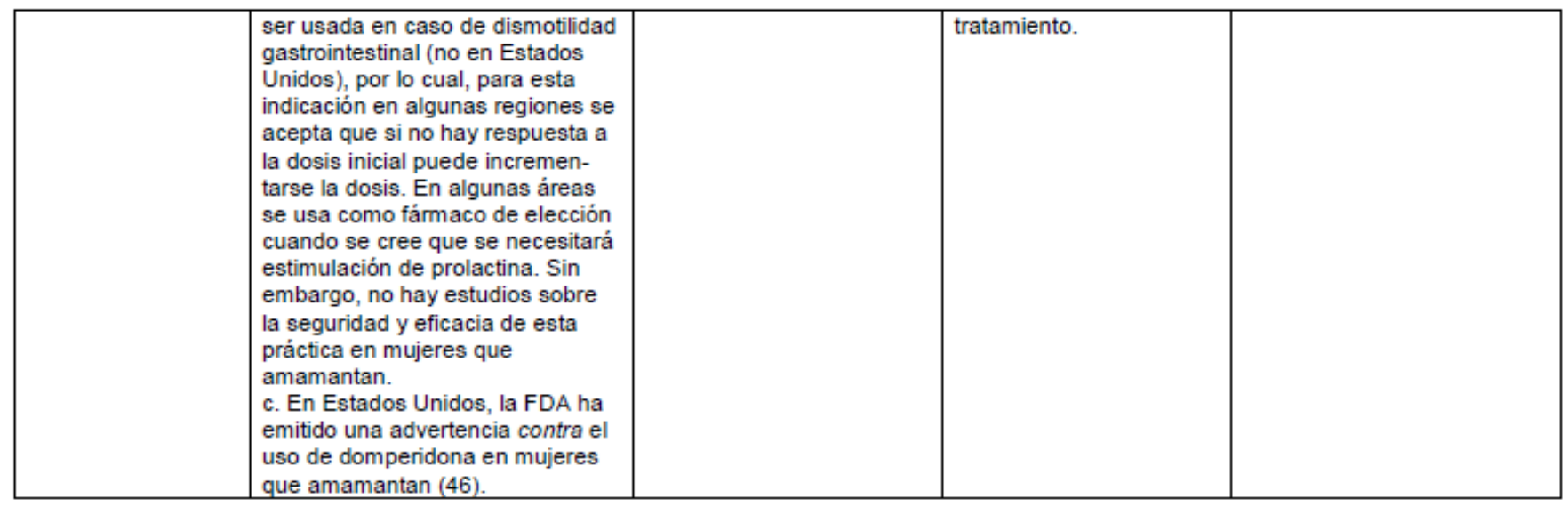

a Silymarin (micronizada) o S. marianum (cardo mariano o lechero)

SNC, sistema nervioso central; CYP, citocromo c, FDA, Oficina de Alimentos y Fármacos en EUA. 


\section{0- BIBLIOGRAFÍA}

(1) Paul C, Zenut M, Dorut A, Coudore MA, Vein J, Cardot JM, et al. Use of domperidone as a galactagogue drug: a systematic review of the benefit-risk ratio. J Hum Lact 2015 Feb;31(1):57-63.

(2) Yadav UC, Baquer NZ. Pharmacological effects of Trigonella foenum-graecum L. in health and disease. Pharm Biol 2014 Feb;52(2):243-54.

(3) Mortel M, Mehta SD. Systematic review of the efficacy of herbal galactogogues. J Hum Lact 2013 May;29(2):154-62.

(4) Zapantis A, Steinberg JG, Schilit L. Use of herbals as galactagogues. J Pharm Pract 2012 Apr;25(2):222-31.

(5) Osadchy A, Moretti ME, Koren G. Effect of domperidone on insufficient lactation in puerperal women: a systematic review and meta-analysis of randomized controlled trials. Obstet Gynecol Int 2012;2012:642893.

(6) Donovan TJ, Buchanan K. Medications for increasing milk supply in mothers expressing breastmilk for their preterm hospitalised infants. Cochrane Database Syst Rev 2012;3:CD005544.

(7) Forinash AB, Yancey AM, Barnes KN, Myles TD. The use of galactogogues in the breastfeeding mother. Ann Pharmacother 2012 Oct;46(10):1392-404.

(8) Zuppa AA, Sindico P, Orchi C, Carducci C, Cardiello V, Romagnoli C. Safety and efficacy of galactogogues: substances that induce, maintain and increase breast milk production. J Pharm Pharm Sci 2010;13(2):162-74.

(9) Doggrell SA, Hancox JC. Cardiac safety concerns for domperidone, an antiemetic and prokinetic, and galactogogue medicine. Expert Opin Drug Saf 2014 Jan;13(1):131-8.

(10) ABM Protocolo Clínico\#9: Uso de Galactogogos para iniciar o aumentar la tasa de secreción de leche materna (Primera Revisión Enero de 2011). Medicina de la lactancia materna. Volumen 6, Numero 1, 2011.

(11) Jantarasaengaram S, Sreewapa P. Effects of domperidone on augmentation of lactation following cesarean delivery at full term. Int J Gynaecol Obstet 2012 Mar;116(3):240-3.

(12) Campbell-Yeo ML, Allen AC, Joseph KS, Ledwidge JM, Caddell K, Allen VM, et al. Effect of domperidone on the composition of preterm human breast milk. Pediatrics 2010 Jan;125(1):e107-e114.

(13) Petraglia F, De L, V, Sardelli S, Pieroni ML, D'Antona N, Genazzani AR. Domperidone in defective and insufficient lactation. Eur J Obstet Gynecol Reprod Biol 1985 May;19(5):281-7.

(14) da Silva OP, Knoppert DC, Angelini MM, Forret PA. Effect of domperidone on milk production in mothers of premature newborns: a randomized, double-blind, placebo-controlled trial. CMAJ 2001 Jan 9;164(1):17-21.

(15) Lewis PJ, Devenish C, Kahn C. Controlled trial of metoclopramide in the initiation of breast feeding. Br J Clin Pharmacol 1980 Feb;9(2):217-9.

(16) de GH, Ooghe W, Thiery M, Dhont M. Metoclopramide and breast milk. Eur J Obstet Gynecol Reprod Biol 1983 Apr;15(1):31-6.

(17) Kauppila A, Anunti P, Kivinen S, Koivisto M, Ruokonen A. Metoclopramide and breast feeding: efficacy and anterior pituitary responses of the mother and the child. Eur J Obstet Gynecol Reprod Biol 1985 Jan;19(1):19-22. 
(18) Hansen WF, McAndrew S, Harris K, Zimmerman MB. Metoclopramide effect on breastfeeding the preterm infant: a randomized trial. Obstet Gynecol 2005 Feb;105(2):383-9.

(19) Aono T, Shioji T, Aki T, Hirota K, Nomura A, Kurachi K. Augmentation of puerperal lactation by oral administration of sulpiride. J Clin Endocrinol Metab 1979 Mar;48(3):478-82.

(20) Ylikorkala O, Kauppila A, Kivinen S, Viinikka L. Sulpiride improves inadequate lactation. Br Med J (Clin Res Ed) 1982 Jul 24;285(6337):249-51.

(21) Polatti F. Sulpiride isomers and milk secretion in puerperium. Clin Exp Obstet Gynecol 1982;9(3):144-7.

(22) Aono T, Aki T, Koike K, Kurachi K. Effect of sulpiride on poor puerperal lactation. Am J Obstet Gynecol 1982 Aug 15;143(8):927-32.

(23) Zarate A, Villalobos H, Canales ES, Soria J, Arcovedo F, MacGregor C. The effect of oral administration of thyrotropin-releasing hormone on lactation. J Clin Endocrinol Metab 1976 Aug;43(2):301-5.

(24) Gunn AJ, Gunn TR, Rabone DL, Breier BH, Blum WF, Gluckman PD. Growth hormone increases breast milk volumes in mothers of preterm infants. Pediatrics 1996 Aug;98(2 Pt 1):279-82.

(25) Fewtrell MS, Loh KL, Blake A, Ridout DA, Hawdon J. Randomised, double blind trial of oxytocin nasal spray in mothers expressing breast milk for preterm infants. Arch Dis Child Fetal Neonatal Ed 2006 May;91(3):F169-F174.

(26) Ruis H, Rolland R, Doesburg W, Broeders G, Corbey R. Oxytocin enhances onset of lactation among mothers delivering prematurely. Br Med J (Clin Res Ed) 1981 Aug 1;283(6287):340-2.

(27) Sharma S, Ramji S, Kumari S, Bapna JS. Randomized controlled trial of Asparagus racemosus (Shatavari) as a lactogogue in lactational inadequacy. Indian Pediatr 1996 Aug;33(8):675-7.

(28) Gupta M, Shaw B. A Double-Blind Randomized Clinical Trial for Evaluation of Galactogogue Activity of Asparagus racemosus Willd. Iran J Pharm Res 2011;10(1):167-72.

(29) Damanik R, Wahlqvist ML, Wattanapenpaiboon N. Lactagogue effects of Torbangun, a Bataknese traditional cuisine. Asia Pac J Clin Nutr 2006;15(2):267-74.

(30) Ushiroyama T, Sakuma K, Souen H, Nakai G, Morishima S, Yamashita Y, et al. Xiong-gui-tiao-xue-yin (Kyuki-chouketsu-in), a traditional herbal medicine, stimulates lactation with increase in secretion of prolactin but not oxytocin in the postpartum period. Am J Chin Med 2007;35(2):195-202.

(31) Di PF, Callegari A, Carotenuto D, Tapia MM. Clinical efficacy, safety and tolerability of BIO-C (micronized Silymarin) as a galactagogue. Acta Biomed 2008 Dec;79(3):205-10.

(32) Turkyilmaz C, Onal E, Hirfanoglu IM, Turan O, Koc E, Ergenekon E, et al. The effect of galactagogue herbal tea on breast milk production and short-term catch-up of birth weight in the first week of life. J Altern Complement Med 2011 Feb;17(2):139-42.

(33) Ghasemi V, Kheirkhah M, Vahedi M. The Effect of Herbal Tea Containing Fenugreek Seed on the Signs of Breast Milk Sufficiency in Iranian Girl Infants. Iran Red Crescent Med J 2015 Aug;17(8):e21848.

(34) Manjula S, Sultana A, Rahman K. Clinical efficacy of Gossypium herbaceum L seeds in perceived insufficient milk (PIM) supply: A randomized single-blind placebo-controlled study. Orient Pharm Exp Med 2013;14(1):77-85. 
(35) Kauppila A, Kivinen S, Ylikorkala O. A dose response relation between improved lactation and metoclopramide. Lancet 1981 May 30;1(8231):1175-7.

(36) Kauppila A, Kivinen S, Ylikorkala O. Metoclopramide increases prolactin release and milk secretion in puerperium without stimulating the secretion of thyrotropin and thyroid hormones. J Clin Endocrinol Metab 1981 Mar;52(3):4369.

(37) Ehrenkranz RA, Ackerman BA. Metoclopramide effect on faltering milk production by mothers of premature infants. Pediatrics 1986 Oct;78(4):614-20.

(38) Paritakul P, Ruangrongmorakot K, Laosooksathit W, Suksamarnwong M, Puapornpong P. The Effect of Ginger on Breast Milk Volume in the Early Postpartum Period: A Randomized, Double-Blind Controlled Trial. Breastfeed Med 2016 Sep;11:361-5. 
PREGUNTA CLÍNICA № 26

¿Qué hacer cuando una madre sufre ingurgitación mamaria?

\section{1- Pregunta clínica en formato PICO}

Tabla 1- Componentes de la pregunta clínica en formato PICO

\begin{tabular}{|l|l|}
\hline Pacientes & Madre sana que amamanta y recién nacido sano \\
\hline Intervención & $\begin{array}{l}\text { Oxitocina intranasal, hojas de col, tratamiento con enzimas } \\
\text { (proteasas), acupuntura, restricción de líquidos }\end{array}$ \\
\hline Comparación & $\begin{array}{l}\text { Atención habitual (apoyo emocional, antiinflamatorios, } \\
\text { analgésicos, frío local entre tomas y calor local antes de las } \\
\text { tomas, masaje y drenaje en las mamas...) }\end{array}$ \\
\hline Resultados & $\begin{array}{l}\text { Tasa de lactancia materna exclusiva al alta } \\
\text { Tasa de lactancia materna exclusiva al mes } \\
\text { Tasa de lactancia materna a los 4 meses } \\
\text { Tasa de lactancia materna exclusiva a los 4 meses } \\
\text { Duración de la lactancia materna (exclusiva y no exclusiva) } \\
\text { Satisfacción materna } \\
\text { Complicaciones de las mamas (dolor, grietas, } \\
\text { ingurgitaciones) } \\
\text { Pérdida ponderal del bebé en los primeros días (48-72h.) }\end{array}$ \\
\hline Tipo de estudio & $\begin{array}{l}\text { RS de ECA, ECA, RS de estudios observacionales o } \\
\text { estudios observacionales }\end{array}$ \\
\hline
\end{tabular}

\section{2- Introducción}




\section{ESTRATEGIA DE ELABORACIÓN DE LA PREGUNTA}

\subsection{GPC Base}

Tabla 2- Resumen de GPC Base

\begin{tabular}{|c|c|c|c|c|}
\hline $\begin{array}{c}\text { Guía } \\
\text { (Enfoque) }\end{array}$ & $\begin{array}{l}\text { Resumen sobre la evidencia } \\
\text { (Calidad de la evidencia) }\end{array}$ & $\begin{array}{l}\text { Recomendaciones } \\
\text { (Grado) }\end{array}$ & $\begin{array}{c}\text { Referencias } \\
\text { bibliográficas } \\
\text { (Tipo de publicación) }\end{array}$ & Comentarios \\
\hline $\begin{array}{l}\text { NICE, } \\
2006\end{array}$ & $\begin{array}{l}\text { Breast engorgement is a common complication of the early } \\
\text { postnatal period and usually occurs between } 2-5 \text { days after } \\
\text { delivery (Kulshi et al, 1978,(Roberts, Reiter, \& Schuster 1995) } \\
\text { peaking on day } 3 \text { (Roberts 1995). It can also occur in women } \\
\text { who are not breastfeeding, however the evidence presented here } \\
\text { is only relevant to women who are breastfeeding. } \\
\text { Engorgement arises either as a result of venous and lymphatic } \\
\text { stasis prior to the onset of milk secretion, or by the obstruction of } \\
\text { the lactiferous ducts following the onset of lactation. If the excess } \\
\text { milk is not removed the alveolar space (where cells excrete milk) } \\
\text { may become over-distended resulting in the breasts feeling hot, } \\
\text { tender, swollen and painful. If left untreated, the over distension } \\
\text { will cause pressure on the surrounding tissue and will occlude } \\
\text { the capillaries. This may result in increased arterial pressure to } \\
\text { the breasts and compression of the connective tissue. The } \\
\text { drainage of the lymph nodes may be impeded with consequent } \\
\text { development of oedema. It is important to treat breast } \\
\text { engorgement because it may lead to physiological changes } \\
\text { including decreased milk output, which could potentially create } \\
\text { an insufficient milk supply. } \\
\text { Treatment } \\
\text { A Cochrane review was identified on interventions to relieve } \\
\text { symptoms of breast engorgement among breastfeeding women } \\
\text { (Snowden, Renfrew, \&Woolridge 2001).Eight trials were included } \\
\text { in the review, providing data on a total of } 424 \text { women. Five trials } \\
\text { compared treatment versus placebo (Serrapeptase (anti- } \\
\text { inflammatory proteolytic enzyme drug), } \\
\text { bromelain/trypsinprotease complex, oxytocin, cabbage leaf }\end{array}$ & $\begin{array}{l}34 \text { Women should be advised that their breasts } \\
\text { may feel tender, firm and painful when milk } \\
\text { 'comes in' at or around } 3 \text { days after birth. [GPP] } \\
35 \text { A woman should be advised to wear a well- } \\
\text { fitting bra which does not restrict her breasts. } \\
\text { [D(GPP)] } \\
36 \text { Breast engorgement should be treated with: } \\
\text { - frequent unlimited breast feeding including } \\
\text { prolonged breastfeeding from the affected } \\
\text { breast } \\
\text { - breast massage and if necessary, hand } \\
\text { expression } \\
\text { - analgesia [A] }\end{array}$ & & $\begin{array}{l}81 \text { Treatment of } \\
\text { engorgement } \\
\text { includes breast } \\
\text { drainage, breast } \\
\text { massage and } \\
\text { analgesia. Cabbage } \\
\text { leaves or cold gel } \\
\text { packs may be } \\
\text { helpful, but the } \\
\text { observed effects } \\
\text { may be as a result } \\
\text { of placebo and } \\
\text { need to be } \\
\text { examined in larger } \\
\text { studies. [Level } 1+]\end{array}$ \\
\hline
\end{tabular}




\begin{tabular}{|c|c|c|c|c|}
\hline $\begin{array}{c}\text { Guía } \\
\text { (Enfoque) }\end{array}$ & $\begin{array}{l}\text { Resumen sobre la evidencia } \\
\text { (Calidad de la evidencia) }\end{array}$ & $\begin{array}{l}\text { Recomendaciones } \\
\text { (Grado) }\end{array}$ & $\begin{array}{c}\text { Referencias } \\
\text { bibliográficas } \\
\text { (Tipo de publicación) }\end{array}$ & Comentarios \\
\hline & $\begin{array}{l}\text { extract and ultrasound). } \\
\text { Two trials compared two treatments against each other (room } \\
\text { temperature cabbage leaves versus chilled cabbage leaves and } \\
\text { chilled cabbage leaves versus gelpacks). One trial compared } \\
\text { intervention (gel packs) versus no treatment. } \\
\text { Only two RCTs showed a direct effect of the intervention tested } \\
\text { on symptoms of engorgement. The first was a study using a } \\
\text { bromelain/trypsin protease complex (Murata, Hanzawa, \& } \\
\text { Nomura } 1965 \text { ). The drug significantly decreased symptoms of } \\
\text { engorgement namely pain and swelling (OR } 8.02,95 \% \text { Cl } 2.76- \\
23.3 \text { ). } \\
\text { The second study used Serrapeptase (Kee et al, } 1989 \text { ). The drug } \\
\text { treatment resulted in a significant improvement in total } \\
\text { improvement rate compiled from the following symptoms; breast } \\
\text { pain, breast swelling and induration of lactation (OR } 3.6,95 \% \text { Cl } \\
1.27-10.26) \text {. Analysis of individual symptoms showed that } \\
\text { Serrapeptase did not have a significant effect compared with } \\
\text { placebo. Serrapeptase and the bromelain/trypsin protease } \\
\text { complex are only licensed for use in Italy and Japan for the } \\
\text { treatment of breast engorgement postpartum. None of the } \\
\text { studies utilising cabbage leaves were able to exclude the } \\
\text { possibility of a placebo effect. Roberts et al } 1995 \mathrm{a} \text { used a self- } \\
\text { administered questionnaire of pain perception (Bourbonnais pain } \\
\text { ruler, analogue scales of breast hardness and engorgement } \\
\text { scales: (Bourbonnais } 1981 \text { )). The tool was used pre and post } \\
\text { treatment with either chilled or room temperature cabbage } \\
\text { leaves. There was no difference in outcome between chilled or } \\
\text { room temperature cabbage leaves; both treatments resulted in a } \\
\text { significant reduction in the post-pain scale rating (chilled cabbage } \\
\text { leaves: } 38 \% \text { decrease in pain; room temperature cabbage } \\
\text { leaves: } 38 \% \text { decrease in pain). Roberts et al (Roberts } 1995 \text { ) } \\
\text { used the same methodology to compare chilled cabbage leaves } \\
\text { with chilled gel packs. There was no significant difference } \\
\text { between the two interventions, although there was a preference } \\
\text { for use of cabbage leaves. Chilled cabbage leaves caused a }\end{array}$ & & & \\
\hline
\end{tabular}




\begin{tabular}{|c|c|c|c|c|}
\hline $\begin{array}{c}\text { Guía } \\
\text { (Enfoque) }\end{array}$ & $\begin{array}{l}\text { Resumen sobre la evidencia } \\
\text { (Calidad de la evidencia) }\end{array}$ & $\begin{array}{l}\text { Recomendaciones } \\
\text { (Grado) }\end{array}$ & $\begin{array}{c}\text { Referencias } \\
\text { bibliográficas } \\
\text { (Tipo de publicación) }\end{array}$ & Comentarios \\
\hline & $\begin{array}{l}\text { decrease in the post-test pain scale compared with the pre-test } \\
\text { by } 30 \% \text {, while chilled gel packs caused a 39\% reduction. } \\
\text { The use of oxytocin (Ingelman et al, 1953), ultrasound } \\
\text { (McLachlan1987;McLachlan et al. 1993), cabbage leaf extract } \\
\text { (Roberts, Reiter, \& Schuster1998) or cold packs (Robson 1990) } \\
\text { had no effect on symptoms of breast engorgement. The } \\
\text { Cochrane reviewers noted that the cold pack study had different } \\
\text { base-line measures between the intervention and control groups. } \\
\text { As outcomes were assessed following breastfeeding, this may } \\
\text { explain the lack of difference because the effect of feeding might } \\
\text { have over-ridden the potential effect of the intervention. The } \\
\text { Cochrane reviewers also noted that the statistical power of the } \\
\text { cabbage leaf extract study (Roberts, Reiter, \& Schuster } \\
\text { 1998)must be questioned because the trial was stopped on } \\
\text { ethical grounds before the planned study size was recruited. } \\
\text { The systematic review undertaken for a breastfeeding guideline } \\
\text { developed by the Singapore Ministry of Health (2002) stated that } \\
\text { central to management of breast engorgement is the need to } \\
\text { ensure that the mother is comfortable, so that she can continue } \\
\text { to nurse and maintain her milk supply. Breast milk drainage } \\
\text { should also be maintained to prevent the development of } \\
\text { backpressure in the ducts, which would cause decreased milk } \\
\text { production. To this end, demand feeding is the most appropriate } \\
\text { management because suckling by the infant is the most effective } \\
\text { mechanism for removal of milk. Additionally, breast massage } \\
\text { effectively increases milk supply and relieves plugged ducts. Pain } \\
\text { may be reduced with the application of cabbage leaves, which } \\
\text { can be used with breast massage, milk expression and } \\
\text { analgesia. Warm packs/hot compresses should be avoided } \\
\text { because although they improve vascular flow, they may } \\
\text { aggravate swelling if the ducts are blocked. Warm packs can be } \\
\text { used if breasts are leaking. } \\
\text { Breast massage and hand expression of breast milk may also be } \\
\text { used to stimulate the milk ejection process, increase milk supply } \\
\text { and relieve blocked ducts. Birth to Five (Department of Health. } \\
\text { 2005) provides both written and pictorial instructions for the }\end{array}$ & & & \\
\hline
\end{tabular}




\begin{tabular}{|c|c|c|c|c|}
\hline $\begin{array}{c}\text { Guía } \\
\text { (Enfoque) }\end{array}$ & $\begin{array}{l}\text { Resumen sobre la evidencia } \\
\text { (Calidad de la evidencia) }\end{array}$ & $\begin{array}{l}\text { Recomendaciones } \\
\text { (Grado) }\end{array}$ & $\begin{array}{c}\text { Referencias } \\
\text { bibliográficas } \\
\text { (Tipo de publicación) }\end{array}$ & Comentarios \\
\hline & expression of breast milk. & & & \\
\hline $\begin{array}{l}\text { NICE } \\
\text { update }\end{array}$ & $\begin{array}{l}\text { One Cochrane review101 on the best forms of treatment for } \\
\text { women who experience breast engorgement was identified. The } \\
\text { authors concluded that although some interventions may be } \\
\text { promising, there is not sufficient evidence from trials on any } \\
\text { intervention to justify widespread implementation. }\end{array}$ & & & \\
\hline $\begin{array}{l}\text { Perinatal } \\
\text { Services } \\
\text { BC } 2013\end{array}$ & $\begin{array}{l}\text { BREAST ENGORGEMENT } \\
\text { (Prevention) } \\
\text { Feed frequently, a minimum of } 5 \text { times in the first } 24 \text { hours } 38 \text { to } \\
\text { prevent infant hypoglycemia, accelerate breastmilk production, } \\
\text { ensure breastmilk drainage, prevent breast distension and } \\
\text { engorgement,61 and stimulate infant digestive peristalsis and } \\
\text { elimination.38 } \\
\text { Where indicated, initiate a hand expression regime for the mother } \\
\text { to establish milk production and prevent engorgement. } \\
\text { (definition) } \\
\text { Breast Engorgement can occur } 3 \text { to } 5 \text { days post-birth; the breast } \\
\text { is enlarged, painful, shiny, and edematous with diffuse red areas. } \\
\text { The nipple may be effaced, milk often does not flow easily, and } \\
\text { the infant can have difficulties latching38 } \\
\text { (causes) } \\
\text { Contributing factors include delayed breastfeeding initiation, } \\
\text { infrequent and/or time restricted feedings, supplementation, } \\
\text { inefficient infant latch, breast surgery, or any situation where milk } \\
\text { stasis occurs. Milk supply can be compromised by unrelieved } \\
\text { engorgement } \\
\text { Care38,39,102 } \\
\text { - Warm shower or apply warm compress or breast soaks before } \\
\text { breastfeeding to facilitate let down } \\
\text { - Massage breast gently and manually express breastmilk or } \\
\text { colostrum to soften the areola before breastfeeding to facilitate } \\
\text { infant latch } \\
\text { - Breastfeed frequently, using the engorged breast first }\end{array}$ & & & \\
\hline
\end{tabular}




\begin{tabular}{|c|c|c|c|c|}
\hline $\begin{array}{c}\text { Guía } \\
\text { (Enfoque) }\end{array}$ & $\begin{array}{l}\text { Resumen sobre la evidencia } \\
\text { (Calidad de la evidencia) }\end{array}$ & $\begin{array}{l}\text { Recomendaciones } \\
\text { (Grado) }\end{array}$ & $\begin{array}{c}\text { Referencias } \\
\text { bibliográficas } \\
\text { (Tipo de publicación) }\end{array}$ & Comentarios \\
\hline & $\begin{array}{l}\text { - Use anti-inflammatory medications, e.g., ibuprofen }(400 \mathrm{mg} \text {. } \\
\text { every } 4-6 \text { hours) which are compatible with breastfeeding } 103 \\
\text { - Additional treatments that some women report as helpful but } \\
\text { determined as ineffective in a review of eight RCTs } 102 \text { are: } \\
\text { application of cold treatments e.g., gel packs, cold packs, or cold } \\
\text { cabbage leaves; used after breastfeeding, Use of oxytocin and } \\
\text { ultrasound. } \\
\text { AREOLAR ENGORGEMENT13 can occur without breast } \\
\text { (peripheral) engorgement. Latch is difficult and painful for the } \\
\text { mother. } \\
\text { Care } \\
\text { - Manual expression or compression of the areola before } \\
\text { breastfeeding38 } \\
\text { - Warm compresses }\end{array}$ & & & \\
\hline $\begin{array}{l}\text { ABM } 20 \\
\text { Congestión } \\
\text { mamaria, } \\
2009\end{array}$ & $\begin{array}{l}\text { Tratamiento } \\
\text { El manejo adecuado de la congestión mamaria es importante } \\
\text { para una lactancia exitosa a largo plazo. } 23,24 \text { Si bien el hecho } \\
\text { de experimentar congestión mamaria puede resultar } \\
\text { temporalmente incómodo para las madres, ello parece estar } \\
\text { relacionado con un decremento en las probabilidades de un } \\
\text { destete precoz. Al mismo tiempo, el hecho de no resolver con } \\
\text { efectividad la congestión mamaria sintomática prolongada puede } \\
\text { tener repercusiones negativas adicionales en el suministro de } \\
\text { leche continuo y adecuado. } \\
\text { Algunas terapias, tanto farmacológicas como no farmacológicas, } \\
\text { han sido promocionadas como intervenciones benéficas para el } \\
\text { tratamiento de la congestión mamaria. } \\
\text { En } 2001 \text {, Snowden y colaboradores } 25 \text { llevaron a cabo una } \\
\text { revisión sistemática de estudios controlados con asignación } \\
\text { tanto aleatoria como "semi-aleatoria" que evaluaron la } \\
\text { efectividad de los tratamientos para la congestión mamaria. } \\
\text { Dicho análisis identificó ocho estudios que incorporaron a } 424 \\
\text { mujeres. Las terapias investigadas que superaron los efectos de } \\
\text { los placebos en la reducción de los síntomas se describen a } \\
\text { continuación: }\end{array}$ & $\begin{array}{l}\text { En la actualidad, la investigación tanto de los } \\
\text { procesos fisiológicos de la congestión mamaria } \\
\text { como de la prevención efectiva y las estrategias } \\
\text { terapéuticas resulta inadecuada. Es preciso } \\
\text { desarrollar un sistema uniforme para medir la } \\
\text { severidad de la congestión mamaria que permita } \\
\text { homologar las medidas y comparar los resultados } \\
\text { entre los estudios. Una vez que se haya } \\
\text { desarrollado un sistema objetivo de medición } \\
\text { clínica a pie de cama y no invasivo, podrán } \\
\text { efectuarse estudios clínicos que evalúen la } \\
\text { correlación de medidas objetivas de la congestión } \\
\text { mamaria y su tratamiento con la duración y los } \\
\text { problemas de la lactancia materna. El } \\
\text { conocimiento acerca de la influencia de las } \\
\text { intervenciones en el parto y acerca de las } \\
\text { características de las mujeres que predisponen al } \\
\text { desarrollo de congestión mamaria significativa } \\
\text { sería de utilidad para identificar a las pacientes en } \\
\text { riesgo de padecerla y a aquellas que pudieran } \\
\text { verse beneficiadas por la asesoría y por un }\end{array}$ & $\begin{array}{l}\text { 23. Stamp GE, } \\
\text { Casanova HT. A } \\
\text { breastfeeding study } \\
\text { in a rural } \\
\text { population in South } \\
\text { Australia. } \\
\text { Rural Remote } \\
\text { Health } \\
2006 ; 495 \text { : } \\
\text { 1-8. } \\
24 \text {. Cooke M, } \\
\text { Sheehan A, } \\
\text { Schmied V. A } \\
\text { description of the } \\
\text { rela- } \\
\text { tionship between } \\
\text { breastfeeding } \\
\text { experiences, } \\
\text { breastfeeding } \\
\text { satisfaction, and } \\
\text { weaning in the first }\end{array}$ & \\
\hline
\end{tabular}




\begin{tabular}{|c|c|c|c|c|}
\hline $\begin{array}{c}\text { Guía } \\
\text { (Enfoque) }\end{array}$ & $\begin{array}{l}\text { Resumen sobre la evidencia } \\
\text { (Calidad de la evidencia) }\end{array}$ & $\begin{array}{l}\text { Recomendaciones } \\
\text { (Grado) }\end{array}$ & $\begin{array}{c}\text { Referencias } \\
\text { bibliográficas } \\
\text { (Tipo de publicación) }\end{array}$ & Comentarios \\
\hline & $\begin{array}{l}\text { 1. Serrapeptase } \circledast \text { (Takeda Chemical Industries, Ltd., Osaka, } \\
\text { Japón) (Danzen), un agente enzimático antiinflamatorio, } 10 \text { mg } \\
\text { tres veces al día, se comparó con placebo tres veces al día } \\
\text { durante tres días. } 26 \text { El grupo con Danzen reportó una mejora } \\
\text { notoria en el } 23 \% \text { de las mujeres en comparación con } \\
\text { únicamente un } 3 \% \text { en el grupo con placebo. En general, el } 86 \% \\
\text { del grupo con el tratamiento activo reportó una mejora evidente o } \\
\text { moderada estadísticamente significativa en comparación con el } \\
60 \% \text { en el grupo con placebo. Si bien los resultados sugieren } \\
\text { que el agente antiinflamatorio puede ser benéfico, el estudio } \\
\text { presenta la limitación significativa de que pocas mujeres } \\
\text { participantes estaban amamantando a su bebé. } \\
2 \text {. Se ha analizado la terapia enzimática utilizando un } \\
\text { comprimido con un complejo de proteasa con cubierta entérica } \\
\text { que contiene } 20,000 \text { unidades de bromelaína y } 2,500 \text { unidades } \\
\text { de tripsina cristalina, otro agente antiinflamatorio.27 A las } \\
\text { mujeres con inflamación o induración mamaria entre el tercer y el } \\
\text { quinto día, además de dolor, se les administraron comprimidos } \\
\text { con el complejo de proteasa o con placebo (aproximadamente } \\
\text { cinco comprimidos por día) durante tres días, para un total de } 16 \\
\text { comprimidos. Se encontró que el complejo de proteasa resultó } \\
\text { efectivo en el } 83 \% \text { de los casos en comparación con el } 33 \% \text { de } \\
\text { las mujeres atendidas con placebo. } \\
3 \text {. La técnica de presión inversa suavizante utiliza una ligera } \\
\text { presión positiva a fin de suavizar un área (aproximadamente de } \\
\text { una a dos pulgadas) cercana a la areola que rodea la base del } \\
\text { pezón. El objetivo consiste en desplazar temporalmente parte de } \\
\text { la inflamación ligeramente hacia atrás, hacia arriba y hacia el } \\
\text { interior de la mama. Se ha demostrado que alejar el edema de la } \\
\text { areola mejora el acoplamiento del lactante durante la congestión } \\
\text { mamaria.28 La base fisiológica de esta técnica consiste en la } \\
\text { presencia de un incremento en la resistencia de los tejidos } \\
\text { subareolares durante la congestión mamaria. } \\
4 \text {. Snowden y colaboradores } 25 \text { concluyeron que no se observa } \\
\text { ningún beneficio con los siguientes tratamientos en comparación } \\
\text { con placebo: hojas de col, extracto de hojas de col, oxitocina, }\end{array}$ & $\begin{array}{l}\text { seguimiento más estrecho. Deben investigarse los } \\
\text { remedios no farmacológicos para el manejo de la } \\
\text { congestión mamaria. Es preciso dar prioridad a } \\
\text { estudios doble ciegos y controlados con placebo } \\
\text { de medicamentos que se sabe son seguros } \\
\text { durante la lactancia y que cuentan con el } \\
\text { potencial para aliviar la congestión mamaria } \\
\text { sintomática. }\end{array}$ & $\begin{array}{l}3 \text { months after birth. } \\
\mathrm{J} \\
\text { Hum Lact } \\
\text { 2003;19:145-156. } \\
\text { 25. Snowden HM, } \\
\text { Renfrew MJ, } \\
\text { Woolridge MW. } \\
\text { Treatments for } \\
\text { breast engorgement } \\
\text { during lactation. } \\
\text { Cochrane Database } \\
\text { Syst } \\
\text { Rev } \\
\text { 2001;(2):CD000046 } \\
\text { 26. Kee WH, Tan } \\
\text { SL, Lee V, et al. } \\
\text { The treatment of } \\
\text { breast en- } \\
\text { gorgement with } \\
\text { Serrapeptase } \\
\text { (Danzen): A } \\
\text { randomized dou- } \\
\text { ble-blind controlled } \\
\text { study. } \\
\text { Singapore Med J } \\
\text { 1989;30:48-54. } \\
\text { 27. Murata T, } \\
\text { Hanzawa M, } \\
\text { Nomura Y. The } \\
\text { clinical effects of } \\
\text { "protease complex" } \\
\text { on postpartum } \\
\text { breast } \\
\text { engorgement. } \\
\mathrm{J} \\
\end{array}$ & \\
\hline
\end{tabular}




\begin{tabular}{|c|c|c|c|c|}
\hline $\begin{array}{l}\text { Guía } \\
\text { (Enfoque) }\end{array}$ & $\begin{array}{l}\text { Resumen sobre la evidencia } \\
\text { (Calidad de la evidencia) }\end{array}$ & $\begin{array}{l}\text { Recomendaciones } \\
\text { (Grado) }\end{array}$ & $\begin{array}{c}\text { Referencias } \\
\text { bibliográficas } \\
\text { (Tipo de publicación) }\end{array}$ & Comentarios \\
\hline & $\begin{array}{l}\text { compresas frías y ultrasonido. } \\
\text { Es posible que algunos tratamientos ayuden a atenuar las } \\
\text { molestias sin aliviar la congestión mamaria en sí. } \\
\text { También es preciso señalar que muchas de las terapias arriba } \\
\text { enumeradas pueden no estar disponibles en ciertos países. } \\
\text { Otras consideraciones } \\
\text { 1. Remedios fitoterapéuticos. En la actualidad, se han descrito } \\
\text { remedios fitoterapéuticos para la congestión mamaria y la } \\
\text { sobreproducción, pero no se cuenta con investigación científica } \\
\text { respecto a su efectividad. } \\
\text { 2. Extracción manual o mecánica. Si el lactante no puede mamar } \\
\text { exitosamente, es preciso tomar medidas para auxiliar a la madre } \\
\text { con la extracción manual o mecánica, ya sea por algunos } \\
\text { minutos a fin de permitir que se suavice y comprima el complejo } \\
\text { pezón-areola o para extraer la leche. Posteriormente, la leche } \\
\text { puede suministrarse al lactante por medio de una taza y se } \\
\text { puede alentar a la madre a amamantar con mayor frecuencia } \\
\text { antes de que recurra la congestión mamaria severa. Todas las } \\
\text { nuevas madres deben asimismo instruirse en la técnica de } \\
\text { extracción manual de la leche. } 29 \\
\text { 3. Antes del alta hospitalaria, debe proporcionarse orientación } \\
\text { preventiva respecto al desarrollo de la congestión mamaria a } \\
\text { todas las madres que amamantan. En muchos países en que las } \\
\text { mujeres pueden tener estancias hospitalarias más prolongadas, } \\
\text { la congestión mamaria puede ocurrir en el hospital donde se } \\
\text { atendió el parto. Sin embargo, muchas mujeres son dadas de } \\
\text { alta antes del tiempo previsto para el máximo nivel de congestión } \\
\text { mamaria sintomática. Las madres deben recibir asesoría } \\
\text { respecto a las opciones de tratamiento sintomático destinadas al } \\
\text { control del dolor. Tanto acetaminofeno (paracetamol) como } \\
\text { ibuprofeno, administrados a dosis adecuadas, son alternativas } \\
\text { seguras para las madres que amamantan. Asimismo, se debe } \\
\text { proporcionar información acerca de los contactos para la } \\
\text { asesoría en apoyo a la lactancia materna. El personal de } \\
\text { salubridad que atiende a la madre o al recién nacido tras el alta } \\
\text { hospitalaria debe preguntar sistemáticamente respecto a la }\end{array}$ & & $\begin{array}{l}\text { Jpn Obstet Gynecol } \\
\text { Soc } \\
\text { 1965;12:139-147. } \\
\text { 28. Cotterman KJ. } \\
\text { Reverse pressure } \\
\text { softening: A simple } \\
\text { tool to } \\
\text { prepare areola for } \\
\text { easier latching } \\
\text { during } \\
\text { engorgement. } \\
\text { J } \\
\text { Hum Lact } \\
\text { 2004;20:227-237. } \\
\text { 29. Hand } \\
\text { expression of } \\
\text { breastmilk. } \\
\text { http://newborns.sta } \\
\text { nford. } \\
\text { edu/Breastfeeding/ } \\
\text { HandExpression.ht } \\
\text { ml (accessed Octo- } \\
\text { ber 16, 2008) }\end{array}$ & \\
\hline
\end{tabular}




\begin{tabular}{|c|c|c|c|c|}
\hline $\begin{array}{c}\text { Guía } \\
\text { (Enfoque) }\end{array}$ & $\begin{array}{l}\text { Resumen sobre la evidencia } \\
\text { (Calidad de la evidencia) }\end{array}$ & $\begin{array}{l}\text { Recomendaciones } \\
\text { (Grado) }\end{array}$ & $\begin{array}{c}\text { Referencias } \\
\text { bibliográficas } \\
\text { (Tipo de publicación) }\end{array}$ & Comentarios \\
\hline & estado de plenitud y congestión mamarias. & & & \\
\hline $\begin{array}{l}\text { Guía del } \\
\text { embarazo, } \\
2014\end{array}$ & $\begin{array}{l}\text { La RS Cochrane de Mangesi (2010) identificó } 8 \text { estudios } \\
\text { que evaluaron una amplia variedad de tratamientos } \\
\text { (acupuntura, aplicación de hojas de repollo, bolsas de gel } \\
\text { frio, tabletas de proteasas, uso de ultrasonidos, u oxitocina } \\
\text { subcutánea). Los estudios se desarrollaron en un periodo } \\
\text { muy amplio de tiempo y la diversidad de desenlaces } \\
\text { evaluados pone en cuestión la aplicabilidad de sus } \\
\text { resultados. } \\
\text { Un ECA que comparó un tratamiento con acupuntura } \\
\text { frente a los cuidados de rutina no mostró diferencias } \\
\text { significativas en el número de mujeres a las que se les } \\
\text { prescribió antibióticos (que los autores de la RS tomaron } \\
\text { como un desenlace secundario de mujeres con mastitis; } \\
210 \text { mujeres; RR } 0,61 ; \text { IC } 95 \% \text { 0,32 a } 1,1 \text { ) ni en el número } \\
\text { de mujeres con un (RR } 0,20 ; \text { IC } 95 \% 0,04 \text { a 1,01). } \\
\text { (Calidad baja). } \\
\text { Otros dos ECA no mostraron diferencias al aplicar hojas } \\
\text { de col frente al uso de bolsas de gel frio en la puntuación } \\
\text { de una escala de dolor, ni en el hecho de aplicar hoja de } \\
\text { col enfriadas o a temperatura ambiente en relación a las } \\
\text { mujeres con dolor.(Calidad muy baja) } \\
\text { En un ECA pequeño (59 participantes) en el que se } \\
\text { comparó la administración de un complejo de proteasa } \\
\text { (una enzima vegetal) frente a placebo, el tratamiento } \\
\text { mostró una mayor proporción con una mejoría del dolor } \\
\text { (RR 0,17; IC } 95 \% 0,04 \text { a } 0,74 \text { ) o de la sensibilidad (RR } \\
0,34 ; \text { IC } 95 \% \text { \% } 0,15 \text { a } 0,79 \text { ). Sin embargo el ECA no } \\
\text { especificaba cuantas de las participantes en el estudio } \\
\text { amamantaban en el momento de realizarse el estudio. } \\
\text { (Calidad muy baja) } \\
\text { Un ECA que evaluó el efecto de aplicar ultrasonidos }\end{array}$ & $\begin{array}{l}\text { Se sugiere recomendar que las mujeres con } \\
\text { ingurgitación mamaria amamanten a sus bebés } \\
\text { de manera frecuente y continuada, con la } \\
\text { posibilidad de realizarse masajes en el pecho y } \\
\text { estimularlo para expulsar la leche manualmente. } \\
\text { (Recomendación Débil). }\end{array}$ & & \\
\hline
\end{tabular}




\begin{tabular}{|c|c|c|c|c|}
\hline $\begin{array}{c}\text { Guía } \\
\text { (Enfoque) }\end{array}$ & $\begin{array}{l}\text { Resumen sobre la evidencia } \\
\text { (Calidad de la evidencia) }\end{array}$ & $\begin{array}{l}\text { Recomendaciones } \\
\text { (Grado) }\end{array}$ & $\begin{array}{c}\text { Referencias } \\
\text { bibliográficas } \\
\text { (Tipo de publicación) }\end{array}$ & Comentarios \\
\hline & $\begin{array}{l}\text { termales frente a realizarlo de manera simulada no mostró } \\
\text { diferencias al final del tratamiento referentes al dolor o la } \\
\text { sensibilidad, ni en la duración de la lactancia materna } \\
\text { de las participantes. La aplicabilidad de los resultados de } \\
\text { este estudio fue muy limitada por su limitado tamaño } \\
\text { muestral (109 mujeres) y el hecho de que la unidad de } \\
\text { aleatorización fuera el pecho y no la mujer. Calidad } \\
\text { muy baja) } \\
\text { En un ensayo en } 45 \text { mujeres, tras tres días de tratamiento } \\
\text { con oxitocina se requirió la continuación del tratamiento en } \\
\text { mayor medida que con placebo, sin que las diferencias } \\
\text { fueran significativas (RR } 3,13 ; \text { IC95\% 0,68 a } \\
\text { 14,44).(Calidad muy baja) } \\
\text { Finalmente, un ECA abierto (88 mujeres) mostró una leve } \\
\text { disminución de la puntuación en una escala de dolor tras } \\
\text { aplicar bolsas de gel frio (de } 1,84 \text { (0,65) puntos a } 1,23 \\
\text { (0,68)) frente a un aumento en la puntuación en el grupo } \\
\text { que no había recibido tratamiento. } \\
\text { La GPC NICE de cuidados durante el puerperio (Demott, } \\
2006 \text { identificó una serie de medidas preventivas para la } \\
\text { ingurgitación en la introducción de una revisión } \\
\text { sistemática sobre intervenciones comunitarias para } \\
\text { promover la duración de la lactancia materna (Renfrew, } \\
2005 \text { ): inicio temprano de la lactancia materna, adquisición } \\
\text { correcta de posturas y unión del bebé durante las tomas, } \\
\text { así como la lactancia espontánea (opinión de expertos) } \\
\text { La guía cita otra revisión sistemática realizada para otra } \\
\text { guía del Ministerio de Sanidad de Singapur en la que se } \\
\text { destacan los siguientes determinantes para el manejo de } \\
\text { la ingurgitación: asegurar que la madre se siente cómoda } \\
\text { para que pueda continuar amamantando y produciendo }\end{array}$ & & & \\
\hline
\end{tabular}




\begin{tabular}{|c|c|c|c|c|}
\hline $\begin{array}{c}\text { Guía } \\
\text { (Enfoque) }\end{array}$ & $\begin{array}{l}\text { Resumen sobre la evidencia } \\
\text { (Calidad de la evidencia) }\end{array}$ & $\begin{array}{l}\text { Recomendaciones } \\
\text { (Grado) }\end{array}$ & $\begin{array}{c}\text { Referencias } \\
\text { bibliográficas } \\
\text { (Tipo de publicación) }\end{array}$ & Comentarios \\
\hline & $\begin{array}{l}\text { leche, y asegurar un amamantamiento continuado } \\
\text { teniendo en cuenta que la succión del bebé es la mejor } \\
\text { manera de garantizar el correcto drenaje de los conductos } \\
\text { mamarios a la vez que el pecho aumenta la producción de } \\
\text { leche. El documento también destaca el papel del masaje } \\
\text { de los pechos o la estimulación para la expulsión manual } \\
\text { de la leche (Singapore Ministry of Health, 2002). }\end{array}$ & & & \\
\hline
\end{tabular}




\subsection{Revisiones sistemáticas}

Tabla 4- Resumen de RS actuales

\begin{tabular}{|c|c|c|c|c|c|c|}
\hline $\begin{array}{l}\text { Referencia } \\
\text { (Cita } \\
\text { Abreviada) }\end{array}$ & $\begin{array}{l}\text { Estudio (Diseño } \\
\text { y objetivo) }\end{array}$ & $\begin{array}{l}\text { Población } \\
\text { (no y características) }\end{array}$ & $\begin{array}{l}\text { Descripción de las } \\
\text { intervenciones } \\
\text { comparaciones, exposiciones } \\
\text { o pruebas a estudio }\end{array}$ & $\begin{array}{l}\text { Resultados } \\
\text { (Estimadores de resultados-Magnitud del } \\
\text { efecto) }\end{array}$ & $\begin{array}{l}\text { Conclusiones } \\
\text { (conclusiones) }\end{array}$ & $\begin{array}{l}\text { Comentarios } \\
\text { Calidad de la } \\
\text { evidencia } \\
\text { Financiación... }\end{array}$ \\
\hline Mangesi L, 2010 & $\begin{array}{l}\text { Diseño } \\
\text { Revisión } \\
\text { sistemática } \\
\text { Objetivo } \\
\text { Considerar la } \\
\text { Identificar la } \\
\text { mejor forma para } \\
\text { el tratamiento de } \\
\text { la congestión } \\
\text { mamaria. }\end{array}$ & $\begin{array}{l}\text { 8 estudios, } 4 \text { ECA y } 4 \\
\text { Cuasi ECA } \\
\text { Criterios inclusión } \\
\text { Los ECA incluyeron } \\
\text { mujeres con } \\
\text { congestión mamaria, } \\
\text { dolor (en ocasiones } \\
\text { con fiebre) durante el } \\
\text { periodo postnatal } \\
\text { temprano (2-5 días } \\
\text { post parto). } \\
\text { Total incluidos: } 744 . \\
\text { - Acupuntura: } 293 ; \\
\text { - Hojas de col: } 62 \\
\text { - Compresas frías: } \\
\text { - } \quad \text { Complejo de } \\
\text { proteasa:59; } \\
\text { - Ultrasonido } \\
\text { termal: } 109 ; \\
\quad \text { Oxitocina: } 45 .\end{array}$ & $\begin{array}{l}\text { Las intervenciones evaluadas } \\
\text { fueron: } \quad \text { Acupuntura versus } \\
\text { - cuidado habitual; } \\
\text { - Hojas de col (hojas } \\
\text { frías versus hojas a temperatura } \\
\text { ambiente y hojas de col versus } \\
\text { bolsas de gel frio); } \\
\text { - } \quad \text { Compresas frías } \\
\text { versus cuidado habitual; } \\
\text { - Complejo de } \\
\text { proteasa versus placebo; } \\
\text { - } \quad \text { Ecografía termal } \\
\text { versus placebo; } \\
\text { Oxitocina subcutánea } \\
\text { versus placebo. }\end{array}$ & $\begin{array}{l}\text { La mayoría de los estudios no } \\
\text { reportaron resultados en los } \\
\text { desenlaces considerados como } \\
\text { primarios y secundarios en la RS, ni en } \\
\text { los considerados como críticos por el } \\
\text { GEG. } \\
\text { En los estudios en donde se evaluaron la } \\
\text { ecografía, las hojas de col, y la oxitocina } \\
\text { no se encontraron diferencias } \\
\text { estadísticamente significativas en cuanto a } \\
\text { una mejoría más rápida de los síntomas } \\
\text { entre las intervenciones evaluadas. Las } \\
\text { mujeres que participaron en estos en } \\
\text { estos ensayos presentaron mejoría de la } \\
\text { sintomatología con el tiempo sin importar } \\
\text { si recibían o no la intervención evaluada. } \\
\text { Respecto a la acupuntura, se encontró } \\
\text { evidencia sobre la mejoría en la } \\
\text { sintomatología en los días siguientes a } \\
\text { recibir el tratamiento. Sin embargo, la } \\
\text { mayoría de las mujeres resolvieron la } \\
\text { sintomatología a los seis días. No se } \\
\text { encontraron diferencias significativas para } \\
\text { otros desenlaces entre los grupos. } \\
\text { Respecto acomplejo de proteasa, el } \\
\text { estudio fue realizado hace más de } \\
\text { cuarenta años y no se tiene evidencia de } \\
\text { que se efectivamente este compuesto se } \\
\text { esté utilizando en la práctica actual. } \\
\text { Finalmente, el estudio que evaluó las } \\
\text { bolsas de gel frio mostró mejoría de los } \\
\text { síntomas, pero dadas las diferencias de } \\
\text { los grupos a nivel basal, estos resultados }\end{array}$ & $\begin{array}{l}\text { No hay evidencia } \\
\text { suficiente para } \\
\text { recomendar la } \\
\text { implementación de un } \\
\text { tratamiento específico } \\
\text { para la congestión } \\
\text { mamaria. Algunos de los } \\
\text { tratamientos evaluados } \\
\text { (ej. hojas de col } \\
\text { aplicadas a la mama) } \\
\text { pueden producir una } \\
\text { mejora en los síntomas y } \\
\text { es poco probable que } \\
\text { tenga efectos adversos. } \\
\text { Dado que la baja calidad } \\
\text { de los estudios incluidos, } \\
\text { los autores señalan la } \\
\text { importancia de las } \\
\text { preferencias de las } \\
\text { mujeres respecto a los } \\
\text { mismos y los mismos } \\
\text { estudios no evalúan las } \\
\text { preferencias respecto a } \\
\text { los mismos. }\end{array}$ & $\begin{array}{l}\text { Problema en el } \\
\text { reporte de los } \\
\text { resultados de los } \\
\text { estudios incluidos } \\
\text { que dificultó la } \\
\text { evaluación del } \\
\text { riesgo de sesgo. }\end{array}$ \\
\hline
\end{tabular}




\begin{tabular}{|l|l|l|l|l|l|}
\hline $\begin{array}{l}\text { Referencia } \\
\text { (Cita } \\
\text { Abreviada) }\end{array}$ & $\begin{array}{l}\text { Estudio (Diseño } \\
\text { y objetivo) }\end{array}$ & $\begin{array}{l}\text { Población } \\
\text { (no y características) }\end{array}$ & $\begin{array}{l}\text { Descripción de las } \\
\text { intervenciones } \\
\text { comparaciones, exposiciones } \\
\text { o pruebas a estudio }\end{array}$ & $\begin{array}{l}\text { Resultados } \\
\text { (Estimadores de resultados-Magnitud del } \\
\text { efecto) }\end{array}$ & $\begin{array}{l}\text { Conclusiones } \\
\text { (conclusiones) }\end{array}$ \\
\hline & & & & $\begin{array}{l}\text { Comentarios } \\
\text { Calidad de la } \\
\text { evidencia } \\
\text { Financiación... }\end{array}$ \\
\hline
\end{tabular}


En la búsqueda realizada se identificó una revisión sistemática (RS) publicada en 2010 cuyo objetivo fue la identificación de los mejores tratamientos para la congestión mamaria en mujeres en periodo de lactancia (1).

Esta revisión incluyó ensayos clínicos aleatorizados (ECA) y cuasi aleatorizados que evaluaran la efectividad de intervenciones farmacológicas (oxitocina subcutánea, complejo de proteasas) e intervenciones no farmacológicas (acupuntura, hojas de col, compresas frías, ecografía termal) en el manejo de la ingurgitación mamaria. 


\subsection{Resumen de GPC base y RS disponibles}

Para el tratamiento de la ingurgitación mamaria, la guía NICE recomienda realizar tomas frecuentes e ilimitadas, incluyendo tomas prologadas del pecho afectado, realizar masaje en el pecho y, si es necesario, realizar la extracción manual de la leche y tomar analgesia (A) (2).

En la guía de la Perinatal Services BC de 2013, para facilitar la salida de la leche, antes de amamantar se recomiendan las duchas calientes o la aplicación de compresas calientes, masajear el pecho y realizar la extracción manual de la leche o calostro para suavizar la areola y facilitar el agarre. También se recomienda amamantar de forma frecuente (primero del pecho ingurgitado) y la toma de antiinflamatorios (por ejemplo ibuprofeno $400 \mathrm{mg}$ cada 4-6 horas). También señala que la aplicación de tratamientos fríos tras la lactancia (packs de gel, packs fríos $u$ hojas frías de col), así como la utilización de oxitocina o ultrasonidos, son tratamientos que algunas mujeres reportan como útiles pero que son inefectivos (3).

En el protocolo 20 de la ABM sobre congestión mamaria, se describen los resultados de la revisión Cochrane publicada en 2001 sobre el uso de Serrapetase ${ }^{\circledR}$, una terapia enzimática, la técnica de la presión inversa suavizante, y se señala también que no se observa ningún beneficio del uso de hojas de col, oxitocina, compresas frías y ultrasonidos. Lo que sí se señala es que si el lactante no puede mamar de forma exitosa, se deben tomar medidas para auxiliar a la madre con la extracción manual o mecánica, ya sea por algunos minutos a fin de permitir que se suavice y comprima el complejo pezón-areola o para extraer la leche. Posteriormente, la leche puede suministrarse al lactante por medio de una taza y se puede alentar a la madre a amamantar con mayor frecuencia antes de que recurra la congestión mamaria severa. Además, se señala que antes del alta hospitalaria, debe proporcionarse orientación preventiva respecto al desarrollo de la congestión mamaria a todas las madres que amamantan y que las madres deben recibir asesoría respecto a las opciones de tratamiento sintomático destinadas al control del dolor (tanto paracetamol como ibuprofeno). Asimismo, se debe proporcionar información acerca de los contactos para la asesoría en apoyo a la lactancia materna. El personal de salubridad que atiende a la madre o al recién nacido tras el alta hospitalaria debe preguntar sistemáticamente respecto a la estado de plenitud y congestión mamarias (4).

En la revisión sistemática Cochrane identificada (1), los autores concluyen que la evidencia identificada sobre los tratamientos para la ingurgitación mamaria son insuficientes para recomendar la implementación masiva de los mismos. Sin embargo, también señalan que algunos tratamientos, como el uso de las hojas de col, pueden ser reconfortantes e improbable que sean dañinos además de ser baratos. Además, hay poca información sobre lo que las mujeres piensan de intervenciones particulares. Por ejemplo, los packs fríos pueden ser relajantes o incómodos para usar. Los ensayos incluidos en la revisión no reportaban los valores y preferencias de las mujeres en relación a las opciones de tratamiento.

\subsection{Conclusión (marcar con una X):}

Adopción GPC/Revisión sistemática 
X Elaboración parcial (desde la fecha final de la revisión de Mangesi 2010 )

Elaboración de novo

\subsection{Diseño de la estrategia de búsqueda de estudios individuales}

\begin{tabular}{|l|l|}
\hline Criterios de selección de estudios & ECA, estudios de cohortes \\
\hline Período de búsqueda & Desde 2009 en adelante \\
\hline Bases de datos & Cochrane, PUMBED y EMBASE y CINHAL
\end{tabular}

Ver estrategias de búsqueda de estudios originales en el ANEXO I.

Se incluye la búsqueda de revisiones sistemáticas, y luego se elimina el filtro de Revisiones sistemáticas y se limita desde 2009 en adelante para localizar nuevos estudios publicados a partir de la fecha de la revisión incluida. 


\section{2- Resumen de la evidencia}

\section{1- GRADE Evidence Profile}

Comparación 1: Acupuntura vs. Cuidados habituales en la ingurgitación mamaria

Bibliografía (RS): Mangesi L, Dowswell T. Treatments for breast engorgement during lactation. Cochrane Database Syst Rev. 2010 Sep 8;(9):CD006946.

\begin{tabular}{|c|c|c|c|c|c|c|c|c|c|c|c|c|}
\hline \multicolumn{7}{|c|}{ Evaluación de la calidad } & \multicolumn{2}{|c|}{ № de pacientes } & \multicolumn{2}{|r|}{ Efecto } & \multirow[b]{2}{*}{ Calidad } & \multirow[b]{2}{*}{ Importancia } \\
\hline $\begin{array}{c}\text { № de } \\
\text { estudios }\end{array}$ & $\begin{array}{c}\text { Diseño } \\
\text { de } \\
\text { estudio }\end{array}$ & $\begin{array}{c}\text { Riesgo de } \\
\text { sesgo }\end{array}$ & Inconsistencia & $\begin{array}{l}\text { Evidencia } \\
\text { indirecta }\end{array}$ & Imprecisión & $\begin{array}{c}\text { Otras } \\
\text { consideraciones }\end{array}$ & Acupuntura & $\begin{array}{l}\text { Cuidado } \\
\text { habitual }\end{array}$ & $\begin{array}{l}\text { Relativo } \\
(95 \% \mathrm{Cl})\end{array}$ & $\begin{array}{l}\text { Absoluto } \\
(95 \% \mathrm{Cl})\end{array}$ & & \\
\hline \multicolumn{13}{|c|}{ Necesidad de antibióticos } \\
\hline 1 & ECA 1 & serio $\underline{2}$ & no serio & no serio & serio $\underline{3}$ & ninguno & $\begin{array}{c}17 / 140 \\
(12.1 \%)\end{array}$ & $\begin{array}{c}14 / 70 \\
(20.0 \%)\end{array}$ & $\begin{array}{c}\text { RR } 0.61 \\
(0.32 \text { a } 1.16) \\
\end{array}$ & $\begin{array}{c}78 \text { menos por } 1000 \text { (de } 32 \\
\text { más a } 136 \text { menos ) }\end{array}$ & BAJA & CRITICO \\
\hline \multicolumn{13}{|c|}{ Absceso mamario } \\
\hline 1 & ECA 1 & serio $\stackrel{2}{2}$ & no serio & no serio & serio $\underline{3}$ & ninguno & $\begin{array}{l}2 / 140 \\
(1.4 \%)\end{array}$ & $5 / 70(7.1 \%)$ & $\begin{array}{c}\mathbf{R R} \mathbf{0 . 2 0} \\
(0.04 \text { a } 1.01)\end{array}$ & $\begin{array}{l}57 \text { menos por } 1000 \text { (de } 1 \\
\text { más a } 69 \text { menos ) }\end{array}$ & BAJA & CRÍTICO \\
\hline \multicolumn{13}{|c|}{ Síntomas al tercer día } \\
\hline 1 & ECA 1 & muy serio $?$ & No serio & no serio & serio $\underline{3}$ & ninguno & $\begin{array}{l}109 / 140 \\
(77.9 \%)\end{array}$ & $\begin{array}{c}58 / 70 \\
(82.9 \%)\end{array}$ & $\begin{array}{c}\text { RR } 0.94 \\
(0.82 \text { a } 1.08)\end{array}$ & $\begin{array}{c}50 \text { menos por } 1000 \text { (de } 66 \\
\text { más a } 149 \text { menos ) }\end{array}$ & MUY BAJA & CRÍTICO \\
\hline \multicolumn{13}{|c|}{ Síntomas al cuarto día } \\
\hline 1 & ECA 1 & muy serio $\stackrel{2}{2}$ & no serio & no serio & no serio & ninguno & $\begin{array}{l}93 / 140 \\
(66.4 \%)\end{array}$ & $\begin{array}{c}57 / 70 \\
(81.4 \%)\end{array}$ & $\begin{array}{c}\text { RR } 0.82 \\
(0.69 \text { a } 0.96) \\
\end{array}$ & $\begin{array}{c}147 \text { menos por } 1000 \text { (de } 33 \\
\text { menos a } 252 \text { menos ) }\end{array}$ & BAJA & IMPORTANTE \\
\hline \multicolumn{13}{|c|}{ Síntomas al quinto día } \\
\hline 1 & ECA 1 & muy serio $?$ & no serio & no serio & no serio 4 & ninguno & $\begin{array}{l}92 / 140 \\
(65.7 \%)\end{array}$ & $\begin{array}{c}55 / 70 \\
(78.6 \%)\end{array}$ & $\begin{array}{c}\text { RR } 0.84 \\
(0.70 \text { a } 0.99)\end{array}$ & $\begin{array}{c}126 \text { menos por } 1000 \text { (de } 8 \\
\text { menos a } 236 \text { menos ) }\end{array}$ & BAJA & IMPORTANTE \\
\hline \multicolumn{13}{|c|}{ Síntomas a los seis días } \\
\hline 1 & ECA 1 & muy serio $\underline{2}$ & no es serio & $\begin{array}{l}\text { no es } \\
\text { serio }\end{array}$ & serio $\underline{3}$ & ninguno & $\begin{array}{l}36 / 140 \\
(25.7 \%)\end{array}$ & $\begin{array}{c}25 / 70 \\
(35.7 \%)\end{array}$ & $\begin{array}{c}\text { RR } 0.72 \\
(0.47 \text { a } 1.10)\end{array}$ & $\begin{array}{c}100 \text { menos por } 1000 \text { (de } 36 \\
\text { más a } 189 \text { menos ) }\end{array}$ & MUY BAJA & IMPORTANTE \\
\hline
\end{tabular}

MD-Diferencia de medias, RR-riesgo relativo

1. Kvist LJ, Hall-Lord ML, Rydhstroem H, Larsson BW. A randomised-controlled trial in Sweden of acupuncture and care interventions for the relief of inflammatory symptoms of the breast during lactation. Midwifery 2007;23:184-95.

2. Dado el tipo de intervención evaluada, el cegamiento tanto de los participantes como de los profesionales que daban las intervenciones no fue realizado. Tampoco se intentó un cegamiento del evaluador de los resultados. Esta falta de cegamiento puede representar una fuente importante de sesgo en la mayoría de los desenlaces dada la subjetividad en los síntomas y su tratamiento. 
3. Bajo número de eventos. Los intervalos de confianza incluyen la ausencia de efecto.

4. Bajo número de eventos. El límite superior del intervalo de confianza cerca de límite de la no significación estadística.

Comparación 2: Hojas de col vs. Otras intervenciones

Bibliografía (RS): Mangesi L, Dowswell T. Treatments for breast engorgement during lactation. Cochrane Database Syst Rev. 2010 Sep 8;(9):CD006946.

\begin{tabular}{|c|c|c|c|c|c|c|c|c|c|c|c|c|}
\hline \multicolumn{7}{|c|}{ Evaluación de la calidad } & \multicolumn{2}{|c|}{ № de pacientes } & \multicolumn{2}{|c|}{ Efecto } & \multirow[b]{2}{*}{ Calidad } & \multirow[b]{2}{*}{ Importancia } \\
\hline $\begin{array}{c}\text { № de } \\
\text { estudios }\end{array}$ & $\begin{array}{c}\text { Diseño } \\
\text { de } \\
\text { estudio }\end{array}$ & $\begin{array}{c}\text { Riesgo } \\
\text { de sesgo }\end{array}$ & Inconsistencia & $\begin{array}{l}\text { Evidencia } \\
\text { indirecta }\end{array}$ & Imprecisión & $\begin{array}{c}\text { Otras } \\
\text { consideraciones }\end{array}$ & $\begin{array}{l}\text { Hojas } \\
\text { de col }\end{array}$ & $\begin{array}{c}\text { Otras } \\
\text { intervenciones }\end{array}$ & $\begin{array}{l}\text { Relativo } \\
(95 \% \mathrm{Cl})\end{array}$ & $\begin{array}{l}\text { Absoluto } \\
(95 \% \mathrm{Cl})\end{array}$ & & \\
\hline \multicolumn{13}{|c|}{ Mejoría del dolor (hojas de col vs. bolsas de gel frio) - no se informa } \\
\hline- & - & - & - & - & - & - & - & - & \multicolumn{2}{|c|}{$\begin{array}{l}\text { No se encontraron diferencias } \\
\text { significativas entre las } \\
\text { intervenciones (resultados no } \\
\text { reportados). }\end{array}$} & MUY BAJA & CRITICO \\
\hline \multicolumn{13}{|c|}{ Mejoría del dolor (hojas de col frio vs. hojas de col a temperatura ambiente) - no se informa } \\
\hline- & - & - & - & - & - & - & - & - & \multicolumn{2}{|c|}{$\begin{array}{l}\text { No se encontraron diferencias } \\
\text { significativas entre las } \\
\text { intervenciones (resultados no } \\
\text { reportados). }\end{array}$} & MUY BAJA & CRITICO \\
\hline
\end{tabular}

MD-Diferencia de medias, RR-riesgo relativo

1. Roberts KL. A comparison of chilled cabbage leaves and chilled gelpaks in reducing breast engorgement. Journal of Human Lactation 1995;11(1):17-20. (a) Roberts KL, Reiter M, Schuster D. A comparison of chilled and room temperature cabbage leaves in treating breast engorgement.Journal of Human Lactation 1995;11:191-4.

2. Alto riesgo de sesgo. No cegamiento, difícil y no realizado. No ajustes realizados. 
Comparación 3: Complejo proteasas vs. placebo

Bibliografía (RS): Mangesi L, Dowswell T. Treatments for breast engorgement during lactation. Cochrane Database Syst Rev. 2010 Sep 8;(9):CD006946.

\begin{tabular}{|c|c|c|c|c|c|c|c|c|c|c|c|c|}
\hline \multicolumn{7}{|c|}{ Evaluación de la calidad } & \multicolumn{2}{|c|}{ № de pacientes } & \multicolumn{2}{|r|}{ Efecto } & \multirow[b]{2}{*}{ Calidad } & \multirow[b]{2}{*}{ Importancia } \\
\hline $\begin{array}{c}\text { № de } \\
\text { estudios }\end{array}$ & $\begin{array}{l}\text { Diseño de } \\
\text { estudio }\end{array}$ & $\begin{array}{l}\text { Riesgo de } \\
\text { sesgo }\end{array}$ & Inconsistencia & $\begin{array}{l}\text { Evidencia } \\
\text { indirecta }\end{array}$ & Imprecisión & $\begin{array}{c}\text { Otras } \\
\text { consideraciones }\end{array}$ & $\begin{array}{l}\text { Complejo } \\
\text { proteasas }\end{array}$ & Placebo & $\begin{array}{l}\text { Relativo } \\
\text { (95\% Cl) }\end{array}$ & $\begin{array}{l}\text { Absoluto } \\
(95 \% \mathrm{Cl})\end{array}$ & & \\
\hline \multicolumn{13}{|c|}{ No mejoría del dolor } \\
\hline 1 & ECA 1 & $\begin{array}{l}\text { muy serio } \\
\underline{\underline{2}}\end{array}$ & no serio & no serio & no serio & ninguno & $2 / 35(5.7 \%)$ & $\begin{array}{c}8 / 24 \\
(33.3 \%)\end{array}$ & $\begin{array}{c}\text { RR } 0.17 \\
\text { (de } 0.04 \text { a } 0.74 \text { ) }\end{array}$ & $\begin{array}{c}277 \text { menos por } 1000 \text { (de } 87 \\
\text { menos a } 320 \text { menos ) }\end{array}$ & BAJA & CRITICO \\
\hline \multicolumn{13}{|c|}{ No mejoría de la congestión mamaria } \\
\hline 1 & ECA 1 & $\begin{array}{l}\text { muy serio } \\
\underline{2}\end{array}$ & no serio & no serio & no Serio & ninguno & $\begin{array}{c}6 / 35 \\
(17.1 \%)\end{array}$ & $\begin{array}{c}12 / 24 \\
(50.0 \%)\end{array}$ & $\begin{array}{c}\text { RR } \mathbf{0 . 3 4} \\
\text { (de } 0.15 \text { a } 0.79)\end{array}$ & $\begin{array}{l}330 \text { menos por } 1000 \text { (de } \\
105 \text { menos a } 425 \text { menos ) }\end{array}$ & BAJA & CRITICO \\
\hline \multicolumn{13}{|c|}{ Puntuación general de recuperación (sin cambio o peor) } \\
\hline 1 & ECA 1 & $\begin{array}{l}\text { muy serio } \\
\underline{2}\end{array}$ & no serio & no serio & no serio & ninguno & $\begin{array}{c}6 / 35 \\
(17.1 \%)\end{array}$ & $\begin{array}{c}16 / 24 \\
(66.7 \%)\end{array}$ & $\begin{array}{c}\text { RR } 0.26 \\
\text { (de } 0.12 \text { a } 0.56 \text { ) }\end{array}$ & $\begin{array}{l}493 \text { menos por } 1000 \text { (de } \\
293 \text { menos a } 587 \text { menos ) }\end{array}$ & BAJA & CRITICO \\
\hline
\end{tabular}

MD-Diferencia de medias, RR-riesgo relativo

1. Murata T, Hanzawa M, Nomura Y. The clinical effects of "Protease complex" on postpartum breast engorgement (based on the double blind method). Journal of Japanese Obstetrical and Gynecological Society 1965;12(3):139-47.

2. Estudio cuasi aleatorizado, la asignación a los diferentes grupos fue realizada en días alternos.

Comparación 4: Ultrasonido térmico vs. Placebo

Bibliografía (RS): Mangesi L, Dowswell T. Treatments for breast engorgement during lactation. Cochrane Database Syst Rev. 2010 Sep 8;(9):CD006946.

\begin{tabular}{|c|c|c|c|c|c|c|c|c|c|c|c|c|}
\hline \multicolumn{7}{|c|}{ Evaluación de la calidad } & \multicolumn{2}{|c|}{ № de pacientes } & \multicolumn{2}{|r|}{ Efecto } & \multirow[b]{2}{*}{ Calidad } & \multirow[b]{2}{*}{ Importancia } \\
\hline $\begin{array}{c}\text { № de } \\
\text { estudios }\end{array}$ & $\begin{array}{l}\text { Diseño de } \\
\text { estudio }\end{array}$ & $\begin{array}{c}\text { Riesgo } \\
\text { de sesgo }\end{array}$ & Inconsistencia & $\begin{array}{l}\text { Evidencia } \\
\text { indirecta }\end{array}$ & Imprecisión & $\begin{array}{c}\text { Otras } \\
\text { consideraciones }\end{array}$ & $\begin{array}{l}\text { Ultrasonido } \\
\text { térmico }\end{array}$ & Placebo & $\begin{array}{l}\text { Relativo } \\
\text { (IC95\%) }\end{array}$ & $\begin{array}{l}\text { Absoluto } \\
\text { (IC95\%) }\end{array}$ & & \\
\hline \multicolumn{13}{|c|}{ Requerimiento de analgésicos } \\
\hline 1 & ECA 1 & serio $\stackrel{2}{2}$ & no serio & serio $\underline{3}$ & serio 4 & ninguno & $\begin{array}{c}14 / 22 \\
(63.6 \%)\end{array}$ & $\begin{array}{c}15 / 23 \\
(65.2 \%)\end{array}$ & $\begin{array}{c}\text { RR } 0.98 \\
\text { (de } 0.63 \text { a 1.51) }\end{array}$ & $\begin{array}{l}13 \text { menos por } 1000 \text { (de } \\
241 \text { menos a } 333 \text { más ) }\end{array}$ & $\begin{array}{l}\text { MUY } \\
\text { BAJA }\end{array}$ & IMPORTANTE \\
\hline
\end{tabular}

CRMD-Diferencia de medias, RR-riesgo relativo

1. McLachlan Z, Milne EJ, Lumley J, Walker BL. Ultrasound treatment for breast engorgement: a randomised double blind trial. Australian Journal of Physiotherapy 1991;37(1):23-9.

2. Ocultación de la secuencia de aleatorización y pérdidas de seguimiento no claras. Mama como unidad de análisis. No ajustes realizados por la no-independencia de los senos. Dificultad en la interpretación de los resultados. Reporte selectivo de los resultados. 
3. Evidencia indirecta de dolor mamario

4. Bajo número de eventos y el intervalo de confianza incluye la ausencia de efecto.

Comparación 5: Oxitocina comparado con placebo en ingurgitación mamaria

Bibliografía (RS): Mangesi L, Dowswell T. Treatments for breast engorgement during lactation. Cochrane Database Syst Rev. 2010 Sep 8;(9):CD006946.

\begin{tabular}{|c|c|c|c|c|c|c|c|c|c|c|c|c|}
\hline \multicolumn{7}{|c|}{ Evaluación de la calidad } & \multicolumn{2}{|c|}{ № de pacientes } & \multicolumn{2}{|r|}{ Efecto } & \multirow[b]{2}{*}{ Calidad } & \multirow[b]{2}{*}{ Importancia } \\
\hline $\begin{array}{c}\text { № de } \\
\text { estudios }\end{array}$ & $\begin{array}{l}\text { Diseño de } \\
\text { estudio }\end{array}$ & $\begin{array}{l}\text { Riesgo de } \\
\text { sesgo }\end{array}$ & Inconsistencia & $\begin{array}{l}\text { Evidencia } \\
\text { indirecta }\end{array}$ & Imprecisión & $\begin{array}{c}\text { Otras } \\
\text { consideraciones }\end{array}$ & Oxitocina & Placebo & $\begin{array}{l}\text { Relativo } \\
\text { (95\% Cl) }\end{array}$ & $\begin{array}{l}\text { Absoluto } \\
\text { (95\% Cl) }\end{array}$ & & \\
\hline \multicolumn{13}{|c|}{ Persistencia de los síntomas tres días después del inicio del tratamiento } \\
\hline 1 & ECA 1 & muy serio $?$ & no serio & serio $\underline{3}$ & serio 4 & ninguno & $\begin{array}{c}5 / 20 \\
(25.0 \%)\end{array}$ & $\begin{array}{c}2 / 25 \\
(8.0 \%)\end{array}$ & $\begin{array}{c}\text { RR } \mathbf{3 . 1 3} \\
\text { (de } 0.68 \text { a 14.44) }\end{array}$ & $\begin{array}{l}170 \text { más por } 1000 \text { (de } \\
26 \text { menos a } 1000 \text { más ) }\end{array}$ & MUY BAJA & CRITICA \\
\hline
\end{tabular}

MD-Diferencia de medias, RR-riesgo relativo

1. Ingelman-Sundberg A. Early puerperal breast engorgement. Acta Paediatrica Scandinavica 1953;32:399-402.

2. Generación y ocultación de la secuencia de aleatorización no adecuada o no realizada. Cegamiento de los evaluadores no claro, así como el manejo de las pérdidas de seguimiento.

3. Evidencia indirecta de la efectividad de la intervención (mejora de los síntomas, dolor, congestión mamaria, etc.)

4. Bajo número de eventos y el intervalo de confianza incluye la ausencia de efecto.

Comparación 6: Bolsas de gel frio vs. Cuidados habituales en ingurgitación mamariaBibliografía (revisiones sistemáticas): Mangesi L, Dowswell T. Treatments for breast engorgement during lactation. Cochrane Database Syst Rev. 2010 Sep 8;(9):CD006946.

\begin{tabular}{|c|c|c|c|c|c|c|c|c|c|c|c|}
\hline \multicolumn{7}{|c|}{ Evaluación de la calidad } & \multicolumn{2}{|c|}{ № de pacientes } & \multirow[b]{2}{*}{ Impacto } & \multirow[b]{2}{*}{ Calidad } & \multirow[b]{2}{*}{ Importancia } \\
\hline $\begin{array}{c}\text { № de } \\
\text { estudios }\end{array}$ & $\begin{array}{l}\text { Diseño de } \\
\text { estudio }\end{array}$ & $\begin{array}{c}\text { Riesgo } \\
\text { de sesgo }\end{array}$ & Inconsistencia & $\begin{array}{l}\text { Evidencia } \\
\text { indirecta }\end{array}$ & Imprecisión & $\begin{array}{c}\text { Otras } \\
\text { consideraciones }\end{array}$ & $\begin{array}{l}\text { Bolsas de } \\
\text { gel frio }\end{array}$ & $\begin{array}{l}\text { Cuidado } \\
\text { habitual }\end{array}$ & & & \\
\hline \multicolumn{12}{|c|}{ Disminución de la intensidad media del dolor } \\
\hline 1 & ECA 1 & $\begin{array}{l}\text { muy serio } \\
\underline{2}\end{array}$ & no serio & no serio & serio 3 & ninguno & & $\begin{array}{c}\text { no } \\
\text { agrupado }\end{array}$ & $\begin{array}{l}\text { Disminución en intensidad media del dolor } \\
\text { post-tratamiento con bolsas de frio: de } 1,84 \\
\text { (DS 0,65) pre-intervención a } 1,79 \text { (DS } 0,72 \text { ) } \\
\text { post-intervención) comparado con un } \\
\text { aumento en el grupo control (de } 1,50 \text { (DS } \\
0,71 \text { ) intervención a } 1,79 \text { (DS } 0,72 \text { ) post } \\
\text { intervención. }\end{array}$ & $\begin{array}{l}\text { MUY } \\
\text { BAJA }\end{array}$ & CRITICA \\
\hline
\end{tabular}

MD-Diferencia de medias, RR-riesgo relativo

1. Robson BA. Breast engorgement in breastfeeding mothers. [thesis]. Personal communication 1990

2. Diferencias a nivel basal entre los grupos. Generación y ocultación de la secuencia de aleatorización no realizada correctamente. No enmascaramiento. No ITT análisis.

3. No se describe un análisis conjunto de los resultados pero existe solapamiento entre los estimadores por lo que se podría intuir una ausencia de efecto. 


\section{2- Resumen de la Evidencia}

La revisión de Mangesi 2010 definió como desenlaces primarios el cese temporal de la lactancia materna, el cese permanente de la misma, y el desarrollo de mastitis. Como desenlaces secundarios la presencia de una temperatura corporal mayor a $38^{\circ} \mathrm{C}$, la opinión maternal sobre el tratamiento, la aceptación maternal del tratamiento, la necesidad de analgesia, el ingreso hospitalario, la confianza materna en cuanto a la continuación de la lactancia materna, y el absceso mamario (1). En esta RS se realizaron búsquedas en diferentes bases de datos hasta febrero de 2010 identificando 23 referencias relacionadas a 19 estudios. Después de la evaluación de su elegibilidad, finalmente incluyeron 8 estudios (512). La gran parte de los estudios evaluaban intervenciones para prevenir de la ingurgitación mamaria o suprimir la lactancia materna.

Respecto a los estudios incluidos, la mayoría de las participantes fueron mujeres con sintomatología de ingurgitación mamaria en el periodo postnatal temprano (2 a 5 días post parto). Todos los estudios fueron realizados en unidades de cuidado postnatal a nivel hospitalario, excepto uno que fue realizado en una clínica de lactancia materna (6).

Los autores de la RS remarcaron que los estudios incluidos cubren un periodo de más de 50 años, en donde las actitudes en frente a la lactancia materna y los tipos de tratamiento disponibles han cambiado considerablemente (1).

Con el fin de actualizar la revisión de Mangesi 2010, se realizó una búsqueda de nuevos estudios publicados desde la fecha de última búsqueda de la RS hasta la actualidad, identificándose un ECA no enmascarado, realizado en Taiwán, cuyo objetivo era evaluar la efectividad de una técnica de medicina tradicional china (Gua-Sha) en mujeres lactantes con ingurgitación mamaria (13). Sin embargo, debido a la escasa relevancia clínica de los resultados recogidos y la poca aplicabilidad de la intervención en nuestro medio, este estudio fue excluido del análisis.

En esta actualización también se identificó otro ensayo clínico cuasi aleatorizado, que evaluó la efectividad de las hojas de col frías respecto a la aplicación de compresas frías y calientes de forma alterna, como tratamiento de la ingurgitación mamaria (14). El estudio fue realizado en la India e incluía mujeres con ingurgitación mamaria sin signos de infección, mastitis, absceso lesiones mamarias, grietas del pezón (o sangrado del mismo). La asignación a cada uno de los grupos se hizo de forma secuencial (30 a cada grupo) y sin enmascaramiento. Al primer grupo de mujeres se les aplicó compresas frías (entre $10^{\circ} \mathrm{C}-18^{\circ} \mathrm{C}$ ) y calientes (entre $43^{\circ} \mathrm{C}-46^{\circ} \mathrm{C}$ ) de forma alterna, reemplazadas cada 1-2 minutos durante 20 minutos. Al segundo grupo se les administró hojas de col frías (refrigeradas durante 20-30 minutos previos a la intervención). Los dos tratamientos se dieron tres veces al día durante dos días consecutivos (6 veces en total). Los desenlaces principales evaluados fueron el dolor y la ingurgitación mamaria, sin llegarse a especificar las escalas utilizadas para tal fin. Los autores reportaron las diferencias en las escalas de dolor e ingurgitación antes y después de la intervención, dentro de cada uno de los grupos, siendo las dos intervenciones igual de efectivas en la resolución de los síntomas. En cuanto a las comparaciones entre los grupos, sólo reportaron los resultados de mejoría en la escala de ingurgitación mamaria. El grupo de mujeres que recibió hojas de col frías reportaron mejores resultados que las compresas frías/calientes en la escala de ingurgitación, durante la tercera y cuarta repetición de la intervención (final del primer día e inicio del segundo). Estas diferencias no se observaron en el resto de las repeticiones. Los autores reportaron de forma narrativa las diferencias, encontrando que las compresas frías/calientes alternadas son más efectivas que las hojas de col en la mejoría del dolor. Este estudio fue excluido del presente análisis por presentar un alto riesgo de sesgo, al ser un ensayo causi aleatorizado sin enmascaramiento. Las escalas utilizadas para medir los desenlaces principales no fueron descritas, lo que genera dudas sobre su validez y dificulta la interpretación de los resultados encontrados con miras a evaluar la 
aplicabilidad clínica de los mismos.

Se identificaron otros dos estudios, una RS sobre tratamiento general de la ingurgitación mamaria publicado en el 2014 (13) y un ECA sobre el uso de hojas del col publicado en 2012 \{Wong, 20121999 /id. Estos dos estudios no pudieron ser localizados para su evaluación.

\section{Acupuntura versus cuidado habitual}

La RS de Mangesi 2010 (1) incluyó dos ECA que evaluaron la efectividad de la acupuntura frente al cuidado habitual en mujeres con ingurgitación mamaria en periodo de lactancia (1). Incluyeron un total 293 mujeres $(5 ; 6)$ que presentaban inflamación mamaria (enrojecimiento, entumecimiento, dolor o pirexia).

En los dos estudios se compararon tres grupos de tratamiento: la acupuntura incluyendo o excluyendo el punto de acupuntura SP6 (que estimula la liberación de oxitocina), y el cuidado habitual. Todos incluían consejo por parte del profesional sanitario. El cuidado habitual podía incluir o no el uso de oxitocina intranasal pautado a discreción del profesional sanitario.

En el estudio de Kvist 2007, los resultados de los desenlaces relacionados con el tiempo de resolución de los síntomas fueron muy similares entre los dos grupos de acupuntura por lo que los autores de la RS decidieron combinarlos para su análisis. El estudio de Kvist 2004 no fue incluido en el metanálisis al no presentar los resultados disgregados para los tres grupos estudiados (1).

La RS reportó resultados para seis desenlaces distintos: tiempo hasta la resolución de los síntomas (a los tres, cuatro y cinco días), persistencia de los síntomas después del sexto día, necesidad de antibióticos, y desarrollo de absceso mamario. Solo estos dos últimos podrían hacer parte del grupo de desenlaces considerados como críticos o importantes por el GEG (dentro del grupo de problemas en las mamas).

Respecto a la necesidad de antibióticos, de un total de 210 mujeres, 31 necesitaron antibióticos (17/140 acupuntura, 14/70 cuidado habitual), sin observarse diferencias significativas entre las intervenciones (RR 0,61; IC95\% $0,32$ a 1,16$)(1)$.

En cuanto al desarrollo de absceso mamario, siete mujeres de 210 presentaron este desenlace (2/140 acupuntura, 5/70 cuidado habitual) sin encontrarse diferencias significativas entre los grupos (RR 0,20; IC95\% 0,04 a 1,01).

Otros desenlaces reportados en la RS y que no hacen del grupo de desenlaces considerados como críticos o importantes para el GEG fueron la resolución de los síntomas a los días tres, cuatro y quinto de inicio de tratamiento. Al tercer día no se encontraron diferencias significativas en cuanto a la resolución de los síntomas entre las intervenciones (RR 0.94; IC95\% 0,82 a 1,08). Sin embargo, al cuarto y quinto día si se observaron diferencias significativas favoreciendo a la acupuntura respecto al cuidado habitual (RR 0,82; IC95\% 0,69 a 0,96 y $R R$ 0,84; IC95\% 0,70 a 1,10 respectivamente). Estas tendencia se diluyen en el tiempo, al no encontrarse diferencias significativas en el riesgo de permanecer con síntomas por un periodo superior a seis días entre las intervenciones evaluadas (RR 0,72; IC95\% 0,47 a 1,10]) (1).

\section{Hojas de col}

Dos estudios identificados en la RS de Mangesi 2010 evaluaron la efectividad de las hojas de col en mujeres con ingurgitación mamaria en periodo de lactancia $(7 ; 8)$. La unidad de análisis de estos estudios fueron las mamas de 62 mujeres y el desenlace principal fue la reducción del dolor. La forma como se presentaron los resultados de este único desenlace en los dos ECA, solo permitió a los autores de la RS hacer un análisis narrativo de los mismos.

\section{Calidad baja}

Calidad baja

Calidad

baja-muy baja 
Uno de los estudios comparó las hojas de col frente a bolsas de gel frio en 34 mujeres con ingurgitación mamaria (8). A cada mujer se le puso las hojas de col en una mama y la bolsa de gel frio en la mama contraria. El estudio reportó una reducción del dolor en ambos grupos sin presentarse diferencias significativas entre las intervenciones (datos no aportados).

En el segundo estudio se compraron las hojas frías de col frente a hojas a temperatura ambiente en un total de 28 mujeres con ingurgitación mamaria (7). En un grupo, las hojas frías de col eran puestas en la mama derecha y las hojas de col a temperatura ambiente en la mama izquierda durante dos horas. En el otro grupo las hojas eran puestas en orden inverso. Los autores tampoco reportaron diferencias significativas en cuanto a la mejoría de dolor entre las dos intervenciones evaluadas (datos no aportados).

\section{Calidad}

muy baja

Calidad

muy baja

\section{Complejo de proteasas}

Los autores de la RS de Mangesi 2010 identificaron un ensayo clínico cuasi aleatorizado que evaluó la efectividad del complejo de proteasas respecto a placebo en 59 mujeres con ingurgitación mamaria a los $3-5$ días post-parto (1). La pauta de tratamiento era de dos tabletas de complejo de proteasas 4 veces al día durante el primer día, y después una tableta cuatro veces al día durante el segundo y tercer día. Los desenlaces estudiados fueron la no mejoría del dolor y de la congestión mamaria.

Respecto a la no mejoría de dolor un total de 10 mujeres no presentaron mejoría del dolor (2/35 complejo proteasas; 8 control) encontrase diferencias significativas entre las intervenciones (RR 0,72; IC95\% 0,04 a 0,74) (1).

Similares resultados se presentaron en cuanto a la no mejoría de la congestión mamaria. Un total de 18 mujeres no presentaron mejoría de la congestión mamaria (6/35 complejo proteasas; $12 / 24$ control) encontrándose diferencias

Calidad baja

\section{Calidad} baja significativas entre las intervenciones evaluadas (RR 0,34; IC95\% 0,15 a 0,79) (1). También se encontraron diferencias significativas en cuanto al no cambio o empeoramiento de los síntomas (RR 0,26; IC95\% 0,12 a 0,56).

\section{Ultrasonido}

La RS de Mangesi 2010 identificó un ECA que evaluó la efectividad del ultrasonido respecto a placebo en 197 mujeres con ingurgitación mamaria que fueron derivadas a fisioterapia para su tratamiento (10).

En este estudio se compararon tres grupos: en el primero, se realizaba una ecografía a ambas mamas; en el segundo se realizaba una simulación de ecografía en ambas mamas, y en el tercero se realizaba en una mama una ecografía y una simulación en la mama contra lateral.

Los desenlaces estudiados fueron el dolor mamario y la turgencia mamaria evaluados a través de una escala análoga visual (EVA). También reportaron la turgencia mamaria evaluada mediante tonometría y el requerimiento de analgésicos.

Respecto al requerimiento de analgésicos, no se encontraron diferencias significativas entre la ecografía y el placebo (RR 0,98; IC95\% de 0,63 a 1,51).

Calidad

muy baja

Respecto al requerimiento de analgésicos, no se encontraron diferencias significativas entre la ecografía y el placebo (RR 0,98; IC95\% de 0,63 a 1,51). Los autores del ECA reportaron de forma narrativa que no se encontraron diferencias en los otros desenlaces evaluados ni tampoco en la duración de la lactancia materna (datos no reportados) (10). 
La RS de Mangesi 2010 identificó un ensayo clínico cuasi aleatorizado, que evaluó la efectividad de la oxitocina administrada a nivel subcutáneo (2.5 I.U) hasta la resolución de los síntomas respecto a placebo (11). El desenlace principal del estudio fue la duración del tratamiento. A los tres días de tratamiento, no se encontraron diferencias significativas en cuanto a la persistencia de los síntomas entre las intervenciones (RR 3,13; IC95\% de 0,68 a 14,44).

\section{Bolsas de gel frio}

Solo un ensayo clínico no enmascarado identificado por la RS de Mangesi 2010, comparó la efectividad de las bolsas de gel frio respecto al cuidado habitual (12). Los resultados fueron descritos de forma narrativa y reportaron una disminución en la intensidad media del dolor post-tratamiento con bolsas de frio (de 1,84 [DS 0,65] pre-intervención a 1,79 [DS 0,72] post-intervención) comparado con un aumento en el grupo control (de 1,50 [DS 0,71] pre-intervención a 1,79 [DS 0,72] post intervención). Los autores de la RS remarcan las importantes limitaciones metodológicas que tiene el presente estudio, en el cual se presenta diferencias entre los grupos a nivel basal(1).

\section{Técnica de la presión inversa suavizante}

En el protocolo de la ABM sobre congestión mamaria (4) se señala que se ha demostrado que alejar el edema de la areola mejora el acoplamiento del lactante durante la congestión mamaria, lo que puede ayudar a favorecer el agarre en estas situaciones.

\section{Resultados de la actualización de la búsqueda a octubre de 2016}

En la actualización de la búsqueda se ha identificado la actualización de la RS incluida para responder a esta pregunta (15). Los autores incluyen un artículo sobre GuaSha (16), ya identificado en la elaboración de la GPC, otro estudio sobre la evaluación de técnicas de masaje y extracción en el tratamiento de la ingurgitación mamaria por termografía (17), otro sobre acupresión o uso de compresas calientes y frías (18), otro estudio previamente excluido por los autores con serrapeptasa (19) y otro sobre la eficacia del extracto de col (20). La conclusión a la que llegan los autores de la revisión es similar, señalando que aunque algunas intervenciones parecen prometedoras para el tratamiento de la ingurgitación mamaria, la evidencia es insuficiente para justificar su implementación generalizada.

También se han identificado dos nuevos estudios individuales posteriores $(21 ; 22)$. En el primer ECA se evalúa la eficacia de combinar el uso de compresas de hojas de malvavisco con compresas calientes (antes de la toma) y frías (entre tomas) en el tratamiento de la ingurgitación mamaria frente a no hacerlo, observando que tras dos días de tratamiento, la adición de las compresas de malvavisco mejoran la severidad de la ingurgitación (puntuación antes y después de la intervención: grupo control de 10,05 a 3,02; grupo intervención de 9,15 a 0,20 , puntuación del checklist de 0 a 19). En el segundo estudio controlado, no aleatorizado, se estudia el efecto preventivo de los cuidados precoces del pecho (masajear con ambas manos los pechos antes de cada toma tres veces al día durante 10 minutos, entre el $2^{\circ}$ y $4^{\circ}$ día postparto) en combinación o no con el uso de hojas de col en mujeres que dan a luz por cesárea, por lo que no corresponde con la pregunta concreta planteada. Por ello, no se considera necesario modificar las recomendaciones formuladas al respecto en la guía.

\section{ACTUALIZADO A FECHA DE: 31 de Octubre de 2016}




\section{5- De la evidencia a la recomendación (Tabla de EtR)}

\section{¿Qué hacer cuando una madre sufre ingurgitación mamaria?}

Población: Madre sana que amamanta y recién nacido sano a término

Intervención: Oxitocina intranasal, hojas de col, tratamiento con enzimas (proteasas), acupuntura, restricción de líquidos

Comparación: Atención habitual (apoyo emocional, antiinflamatorios, analgésicos, frío local entre tomas y calor local antes de las tomas, masaje y drenaje en las mamas...)

Perspectiva: Clínica

C1: Acupuntura vs. cuidados habituales; C2: hojas de col vs. bolsas de gel frío u hojas de col frías; C3: Proteasas vs. placebo; C4: Ultrasonido vs. placebo; C5: Oxitocina vs. placebo; C6: Bolsas de gel frío vs. cuidados habituales

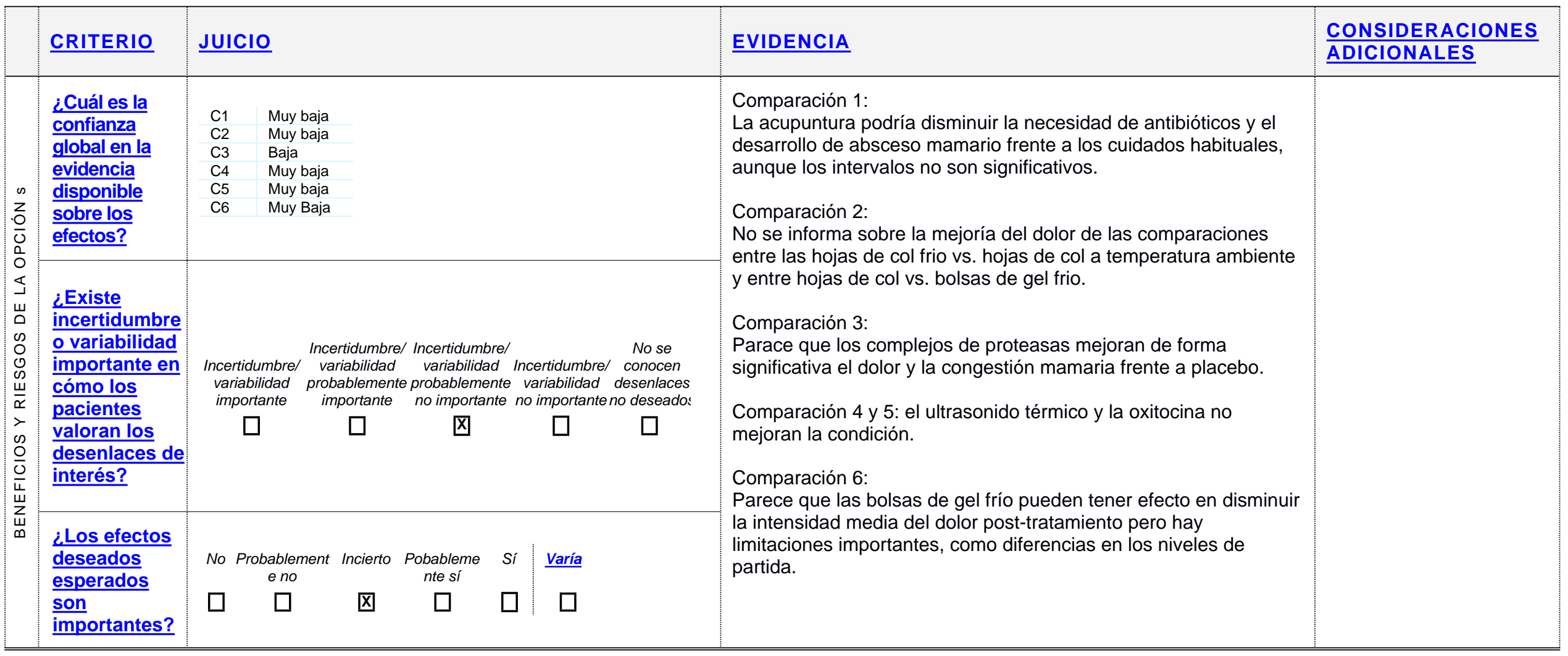




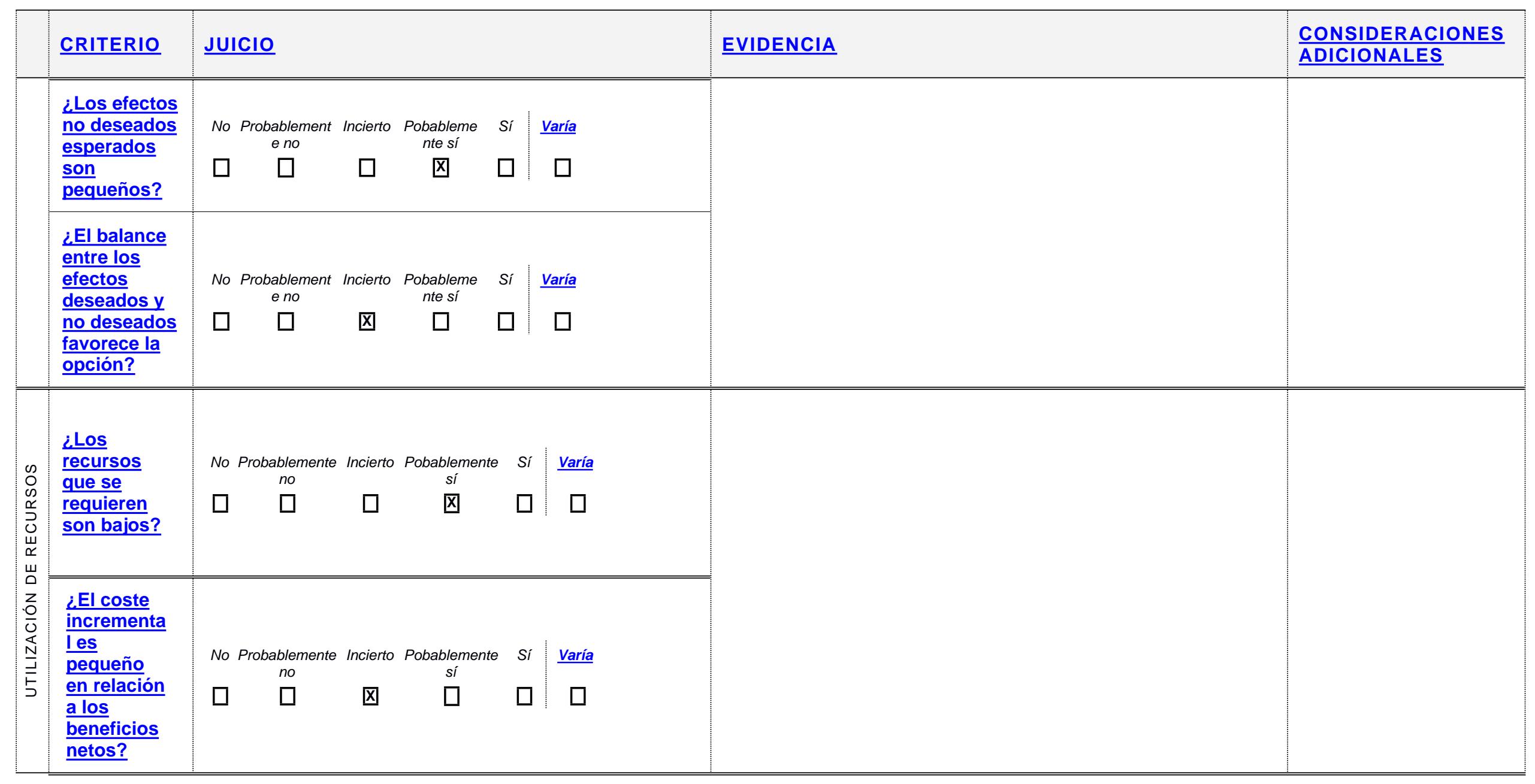




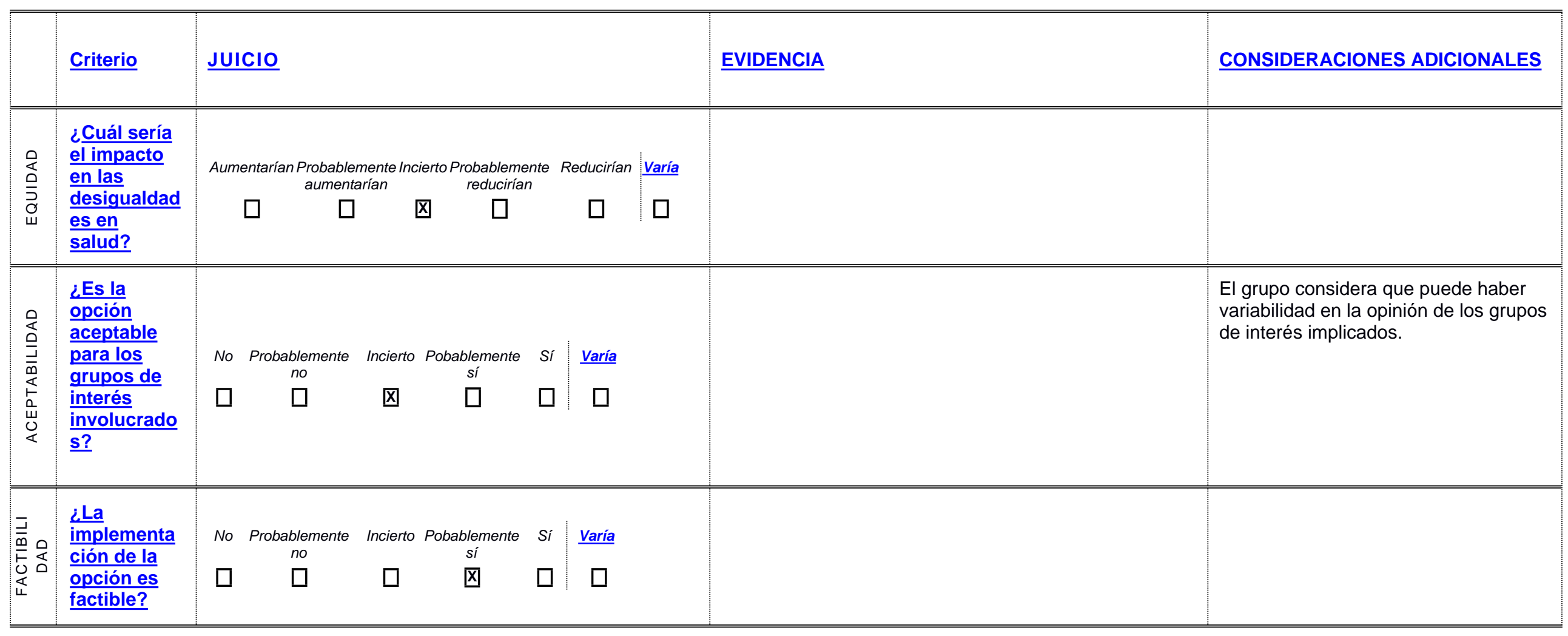




\begin{tabular}{|c|c|c|c|c|c|}
\hline \multirow[t]{2}{*}{$\begin{array}{l}\text { Balance de las } \\
\text { consecuencias }\end{array}$} & $\begin{array}{l}\text { Las consecuencias no } \\
\text { deseadas superan } \\
\text { claramente las } \\
\text { consecuencias deseadas } \\
\text { en la mayoría de los } \\
\text { escenarios }\end{array}$ & $\begin{array}{c}\text { Las consecuencias no } \\
\text { deseadas probablemente } \\
\text { superan las } \\
\text { consecuencias deseadas } \\
\text { en la mayoría de los } \\
\text { escenarios }\end{array}$ & $\begin{array}{c}\text { El balance entre las } \\
\text { consecuencias deseadas y } \\
\text { no deseadas está muy } \\
\text { equilibrado o es incierto }\end{array}$ & $\begin{array}{l}\text { Las consecuencias } \\
\text { deseadas } \\
\text { probablemente superan } \\
\text { las consecuencias no } \\
\text { deseadas en la mayoría } \\
\text { de los escenarios }\end{array}$ & $\begin{array}{c}\text { Las consecuencias } \\
\text { deseadas claramente } \\
\text { superan las } \\
\text { consecuencias no } \\
\text { deseadas en la mayoría } \\
\text { de los escenarios }\end{array}$ \\
\hline & $\square$ & $\square$ & 冈 & $\square$ & $\square$ \\
\hline $\begin{array}{l}\text { Tipo de } \\
\text { recomendación }\end{array}$ & Se recomienda no ofrecer & Se sugiere no & ofrecer la opción & sugiere ofrecer la opción & $\begin{array}{l}\text { Se recomienda } \\
\text { ofrecer la opción }\end{array}$ \\
\hline
\end{tabular}

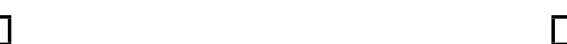

$\square$

\section{Recomendación} $\underline{\text { (Texto) }}$

\section{Recomendación débil}

Se sugiere que antes de la toma, la madre con ingurgitación mamaria se dé una ducha caliente o se aplique compresas calientes, se masajee el pecho y realice una extracción manual que facilite la salida de la leche y el agarre del niño al pecho.

\section{Recomendación de buena práctica}

En caso de necesitar más ayuda, se puede realizar la presión inversa suavizante.

\section{Recomendación fuerte}

Se recomienda aumentar la frecuencia de las tomas. .

Se recomienda, si no hay alergia o contraindicaciones, tomar ibuprofeno para mitigar la inflamación y el dolor producido por la ingurgitación mamaria, o en su defecto paracetamol.

\section{Recomendación de buena práctica}

Descansar y realizar contacto piel con piel para favorecer la liberación de oxitocina.

En caso de necesitar más ayuda, se puede realizar la presión inversa suavizante (ver Anexo 18). 

Justificación
Las guías recomiendan una serie de medidas para facilitar la resolución mecánica de la ingurgitación mamaria. Para el resto de tratamientos, la evidencia que existe es de muy baja o baja calidad. Por ello, no se realiza ninguna recomendación al respecto.

\section{Consideraciones de}

\section{subgrupos}

Consideraciones para Creación de Consultas de lactancia atendidas por profesionales especializados en lactancia materna.

la implementación $\quad$ Formar a los profesionales sanitarios que están en contacto directo con las madres en el puerperio para poder identificar y asesorar en la resolución de una ingurgitación mamaria.

\section{Monitorización y}

evaluación

Prioridades para la investigación
- Se necesitan más estudios de calidad para conocer la eficacia de los distintos tratamientos utilizados en el manejo de la ingurgitación mamaria. 


\section{ANEXO I, ESTRATEGIAS DE BÚSQUEDA}

\section{Cochrane Library}

\section{Searched 30/06/2015}

Updated search 30/06/2015 a xx/xx/xxxx

\#1 breast:ti,ab,kw and engorg*:ti,ab,kw (Word variations have been searched) 65

\#2 lactation:ti,ab,kw or breastfeeding or "breast feeding":ti,ab,kw (Word variations have been searched) $\quad 3601$

\#3 \#1 and \#2 Publication Year from 2009 to 20157

$\begin{array}{ll}\text { RS } & 3 \\ \text { Trials } & 4\end{array}$

\section{MEDLINE, via Pubmed}

\section{Searched 30/06/2015}

Updated search 30/06/2015 a xx/xx/xxxx

\#1 Search (breast[Title/Abstract]) AND engorg*[Title/Abstract] 227

\#2 Search (lactation[Title/Abstract] OR breastfeeding[Title/Abstract] OR "breast feeding"[Title/Abstract]) 51123

\#3 Search \#1 AND \#3 114

\#4 Search \#1 AND \#3 Filters: Publication date from 2009/01/01 to 2015/12/31 16

\#5 Search \#4 Filters: Meta-Analysis; Systematic Reviews. 3

\#6 Search ((review[Title/Abstract] OR reviews[Title/Abstract])) OR (metaanalysis[Title/Abstract] OR metaanalysis[Title/Abstract] OR "meta analysis"[Title/Abstract]) 1151663

\#7 \#4 AND \#6 2

\#8 \#5 OR \#7 3

\section{EMBASE, via Ovid}

Searched 30/06/2015

Updated search 30/06/2015 a xx/xx/xxxx

\#1 breast.ti,ab,kw. 424185

\#2 "engorg*".ti,ab,kw. 4839

\#3 1 and $2 \quad 319$

\#4 (breastfeeding or lactation or "breast feeding").ti,ab,kw. 62194

\#5 3 and $4 \quad 169$

\#6 limit 6 to $y r=" 2009$-Current" $\quad \mathbf{3 0}$

\#7 (review or reviews or meta-analysis or metaanalysis or "meta analysis").ti,ab,kw. 1479016

\#8 \#6 and \#7 2

\#9 limit 6 to meta analysis 1

\#10 limit 6 to "systematic review" 1

\#11 \#9 or \#10 2

\#12 \#8 or \#11 4

CINAHL, via EBSCOhost databases

Searched 30/06/2015

Updated search 30/06/2015 a xx/xx/xxxx 
\#1 breast AND engorg* 118

\#2 breastfeeding or breast feeding or breast-feeding or lactation 16289

\#3 \#1 AND \#2 93

\#4 Limitadores - Fecha de publicación: 20090101-20151231

\#5 \#4 Limitadores - Tipo de publicación: Meta Analysis, Systematic Review 3

\#6 review OR reviews OR metaanalysis OR meta-analysis Or "meta analysis" 253,129

\#7 \#4 AND \#6 4

\#8 \#5 OR \#7 4 


\section{ANEXO II, Tabla de estudios individuales para la pregunta}

\begin{tabular}{|c|c|c|c|c|c|c|}
\hline $\begin{array}{l}\text { Referencia } \\
\text { (Cita Abreviada) }\end{array}$ & $\begin{array}{l}\text { Estudio (Diseño y } \\
\text { objetivo) }\end{array}$ & $\begin{array}{l}\text { Población } \\
\text { (no y características) }\end{array}$ & $\begin{array}{l}\text { Descripción de las intervenciones } \\
\text { comparaciones, exposiciones o } \\
\text { pruebas a estudio }\end{array}$ & $\begin{array}{l}\text { Resultados } \\
\text { (Estimadores de resultados-Magnitud del } \\
\text { efecto) }\end{array}$ & $\begin{array}{l}\text { Conclusiones } \\
\text { (conclusiones) }\end{array}$ & $\begin{array}{l}\text { Comentarios } \\
\text { Calidad de la } \\
\text { evidencia } \\
\text { Financiación } \\
\text { comentarios) }\end{array}$ \\
\hline Kvist, 2004 & $\begin{array}{l}\text { Diseño: ECA } \\
\text { Objetivo: } \\
\text { Evaluación de la } \\
\text { acupuntura } \\
\text { respecto al } \\
\text { cuidado habitual } \\
\text { en el manejo de } \\
\text { ingurgitación } \\
\text { mamaria. }\end{array}$ & $\begin{array}{l}88 \text { mujeres que } \\
\text { acudían a clínicas de } \\
\text { lactancia materna con } \\
\text { inflamación a nivel } \\
\text { mamario } \\
\text { (enrojecimiento, } \\
\text { tumefacción, dolor, } \\
\text { pirexia), la mitad de } \\
\text { las mujeres estaban } \\
\text { dentro de las dos } \\
\text { semanas posteriores } \\
\text { al parto. }\end{array}$ & $\begin{array}{l}\text { Tres brazos de tratamiento. El cuidado } \\
\text { habitual se daba a todas las participantes } \\
\text { e incluía: consejos lactancia materna, la } \\
\text { extracción manual y ducha caliente. } \\
\text { Grupo 1: cuidado habitual +/- spray nasal } \\
\text { de oxitocina a discreción del personal } \\
\text { clínico. } \\
\text { Grupo 2: cuidado habitual + acupuntura } \\
\text { evitando el acupunto SP6 que estimula la } \\
\text { oxitocina. } \\
\text { Grupo 3: cuidado habitual + acupuntura } \\
\text { incluyendo el SP6 sitio. } \\
\text { La acupuntura era realizada por } \\
\text { comadronas con experiencia en la técnica. }\end{array}$ & $\begin{array}{l}\text { Las madres de todos los grupos } \\
\text { expresaron su satisfacción con la lactancia } \\
\text { a pesar de su considerable situación de } \\
\text { malestar. No se encontraron diferencias } \\
\text { significativas entre los grupos respecto al } \\
\text { número de mujeres que necesitaron más } \\
\text { de tres días para mejorarse, ni tampoco } \\
\text { en el índice de severidad al tercer día. Los } \\
\text { autores del estudio remarcan que a pesar } \\
\text { de que estos resultados deben ser } \\
\text { interpretados con cautela, podrían sugerir } \\
\text { que el cuidado habitual puede formar una } \\
\text { parte importante en la mejoría de los } \\
\text { síntomas, así como el tratamiento con } \\
\text { acupuntura o el uso de oxitocina en spray. } \\
\text { La terapia con antibióticos fue utilizada en } \\
\text { el 9\% de las mujeres de este estudio. }\end{array}$ & $\begin{array}{l}\text { En base a los resultados } \\
\text { de este estudio, otro } \\
\text { nuevo estudio fue } \\
\text { diseñado para evaluar la } \\
\text { acupuntura como } \\
\text { tratamiento en la } \\
\text { ingurgitación mamaria } \\
\text { durante el periodo de } \\
\text { lactancia materna }\end{array}$ & NA \\
\hline Kvist, 2007 & $\begin{array}{l}\text { Diseño: Ensayo } \\
\text { aleatorizado, no } \\
\text { ciego de } 3 \text { brazos } \\
\text { controlado. Los } \\
\text { sobres opacos de } \\
\text { asignación al azar } \\
\text { se mezclaron al } \\
\text { azar } \\
\text { Objetivo: } \\
\text { Evaluación de la } \\
\text { acupuntura } \\
\text { respecto al } \\
\text { cuidado habitual } \\
\text { en el manejo de } \\
\text { ingurgitación } \\
\text { mamaria. }\end{array}$ & $\begin{array}{l}205 \text { madres con } 210 \\
\text { episodios de síntomas } \\
\text { inflamatorios de mama } \\
\text { durante la lactancia }\end{array}$ & $\begin{array}{l}\text { Tres brazos de tratamiento. El cuidado } \\
\text { habitual se daba a todas las participantes } \\
\text { e incluía: consejos lactancia materna, la } \\
\text { extracción manual y ducha caliente. } \\
\text { Grupo 1: cuidado habitual +/- spray nasal } \\
\text { de oxitocina a discreción del personal } \\
\text { clínico. } \\
\text { Grupo 2: cuidado habitual + acupuntura } \\
\text { evitando el acupunto SP6 que estimula la } \\
\text { oxitocina. } \\
\text { Grupo 3: cuidado habitual + acupuntura } \\
\text { incluyendo el SP6 sitio. } \\
\text { La acupuntura era realizada por } \\
\text { comadronas con experiencia en la técnica. }\end{array}$ & $\begin{array}{l}\text { Las mujeres que recibieron acupuntura } \\
\text { presentaron una prescripción de } \\
\text { antibióticos menos pero no se encontraron } \\
\text { diferencias significativas entre las } \\
\text { intervenciones (RR } 6,61 ; \text { IC } 95 \% 0,32 \text { a } \\
1,16 \text { ). } \\
\text { Las mujeres que recibieron acupuntura } \\
\text { fueron menos propensas a desarrollar } \\
\text { absceso mamario respecto a las mujeres } \\
\text { que recibieron el cuidado habitual, pero } \\
\text { estas diferencias no fueron } \\
\text { estadísticamente significativas (RR } 0,20 \text {; } \\
\text { IC } 95 \% 0,04 \text { a } 1,01 \text { ). }\end{array}$ & $\begin{array}{l}\text { Si la acupuntura es un } \\
\text { intervención aceptada } \\
\text { por la mujeres, y ésta se } \\
\text { asociada al cuidado } \\
\text { habitual (consejos sobre } \\
\text { mejoría de la posición de } \\
\text { lactancia materna, y de } \\
\text { agarre del bebe) podría } \\
\text { ser más efectiva y } \\
\text { menos invasiva que el } \\
\text { tratamiento con un spray } \\
\text { nasal de oxitocina. } \\
\text { Comadronas, } \\
\text { enfermeras y personal } \\
\text { médico con preparación } \\
\text { en lactancia materna } \\
\text { deben ser los } \\
\text { profesionales } \\
\text { encargados de brindar } \\
\text { los cuidados a las } \\
\text { madres con síntomas }\end{array}$ & $\begin{array}{l}\text { Alto riesgo de } \\
\text { sesgo }\end{array}$ \\
\hline
\end{tabular}




\begin{tabular}{|c|c|c|c|c|c|c|}
\hline $\begin{array}{l}\text { Referencia } \\
\text { (Cita Abreviada) }\end{array}$ & $\begin{array}{l}\text { Estudio (Diseño y } \\
\text { objetivo) }\end{array}$ & $\begin{array}{l}\text { Población } \\
\text { (no y características) }\end{array}$ & $\begin{array}{l}\text { Descripción de las intervenciones } \\
\text { comparaciones, exposiciones o } \\
\text { pruebas a estudio }\end{array}$ & $\begin{array}{l}\text { Resultados } \\
\text { (Estimadores de resultados-Magnitud del } \\
\text { efecto) }\end{array}$ & $\begin{array}{l}\text { Conclusiones } \\
\text { (conclusiones) }\end{array}$ & $\begin{array}{l}\text { Comentarios } \\
\text { Calidad de la } \\
\text { evidencia } \\
\text { Financiación } \\
\text { comentarios) }\end{array}$ \\
\hline & & & & & $\begin{array}{l}\text { inflamatorios a nivel } \\
\text { mamario durante la } \\
\text { lactancia. El uso de } \\
\text { antibióticos debe ser } \\
\text { controlado } \\
\text { estrechamente de tal } \\
\text { forma que ayude a la } \\
\text { reducción la resistencia } \\
\text { a los antibióticos. }\end{array}$ & \\
\hline Roberts KI, 1995 & $\begin{array}{l}\text { Diseño: Ensayo } \\
\text { aleatorizado a dos } \\
\text { grupos de } \\
\text { tratamiento } \\
\text { Objetivo: } \\
\text { Comparar la } \\
\text { efectividad de las } \\
\text { hojas de col frías } \\
\text { y bolsas de gel } \\
\text { frías en la } \\
\text { reducción en el } \\
\text { post parto de la } \\
\text { ingurgitación } \\
\text { mamaria en } \\
\text { mujeres }\end{array}$ & $\begin{array}{l}\text { Muestra de } \\
\text { conveniencia d } 28 \\
\text { mujeres en periodo de } \\
\text { lactancia materna con } \\
\text { ingurgitación mamaria }\end{array}$ & $\begin{array}{l}\text { En un grupo, as hojas de col frio eran } \\
\text { puestas en la mama derecha y hojas de } \\
\text { col a temperatura ambiente eran puestas } \\
\text { en mama izquierda. En el otro grupo las } \\
\text { hojas de col eran puestas en orden } \\
\text { inverso durante dos horas. No se dio } \\
\text { educación sobre lactancia materna como } \\
\text { parte de las intervenciones. }\end{array}$ & $\begin{array}{l}\text { Los evaluaron los niveles de dolor pre y } \\
\text { post-tratamiento. No se encontraron } \\
\text { diferencias significativas entre los niveles } \\
\text { de dolor post-tratamiento para las dos } \\
\text { intervenciones. Se presentó una } \\
\text { disminución estadísticamente significativa } \\
\text { en el dolor con los dos tratamientos, } 68 \% \\
\text { tuvieron una mejoría de los síntomas entre } \\
\text { la primera y segunda hora. La mayoría de } \\
\text { las mujeres prefirieron las hojas de col. }\end{array}$ & - & $\begin{array}{l}\text { Alto riesgo de } \\
\text { sesgo }\end{array}$ \\
\hline $\begin{array}{l}\text { (a)Roberts KI, } \\
1995\end{array}$ & $\begin{array}{l}\text { Diseño: Ensayo } \\
\text { clínico causi } \\
\text { aleatorizado } \\
\text { Objetivo: Evaluar } \\
\text { la efectividad de } \\
\text { las hojas de col } \\
\text { frías y a } \\
\text { temperatura } \\
\text { ambiente en la } \\
\text { reducción de las } \\
\text { molestias } \\
\text { causadas por la } \\
\text { ingurgitación }\end{array}$ & $\begin{array}{l}22 \text { mujeres en periodo } \\
\text { de lactancia materna } \\
\text { posterior al parto. }\end{array}$ & $\begin{array}{l}\text { Las mujeres usaron hojas de col frio en } \\
\text { una mama y hojas de col a temperatura } \\
\text { ambiente en otra, por un periodo de dos } \\
\text { horas. No se dio educación sobre } \\
\text { lactancia materna como parte de las } \\
\text { intervenciones. }\end{array}$ & $\begin{array}{l}\text { Los niveles de dolor pre-tratamiento } \\
\text { fueron comparados con los niveles de } \\
\text { dolor post-tratamiento. No se encontraron } \\
\text { diferencias significativas en los niveles de } \\
\text { dolor posterior al tratamiento entre las dos } \\
\text { intervenciones. Las mujeres reportaron } \\
\text { significativamente menos dolor con los } \\
\text { dos tratamientos. }\end{array}$ & $\begin{array}{l}\text { No es necesario enfriar } \\
\text { las hojas de col para su } \\
\text { uso. }\end{array}$ & $\begin{array}{l}\text { Alto riesgo de } \\
\text { sesgo }\end{array}$ \\
\hline
\end{tabular}




\begin{tabular}{|c|c|c|c|c|c|c|}
\hline $\begin{array}{l}\text { Referencia } \\
\text { (Cita Abreviada) }\end{array}$ & $\begin{array}{l}\text { Estudio (Diseño y } \\
\text { objetivo) }\end{array}$ & $\begin{array}{l}\text { Población } \\
\text { (no y características) }\end{array}$ & $\begin{array}{l}\text { Descripción de las intervenciones } \\
\text { comparaciones, exposiciones o } \\
\text { pruebas a estudio }\end{array}$ & $\begin{array}{l}\text { Resultados } \\
\text { (Estimadores de resultados-Magnitud del } \\
\text { efecto) }\end{array}$ & $\begin{array}{l}\text { Conclusiones } \\
\text { (conclusiones) }\end{array}$ & $\begin{array}{l}\text { Comentarios } \\
\text { Calidad de la } \\
\text { evidencia } \\
\text { Financiación } \\
\text { comentarios) }\end{array}$ \\
\hline & $\begin{array}{l}\text { mamaria en } \\
\text { mujeres después } \\
\text { del parto. }\end{array}$ & & & & & \\
\hline Murata, 1965 & $\begin{array}{l}\text { Diseño: Ensayo } \\
\text { cuasi } \\
\text { aleatorizado. }\end{array}$ & $\begin{array}{l}59 \text { mujeres con } \\
\text { ingurgitación mamaria } \\
\text { durante el tercer y } \\
\text { quinto días posteriores } \\
\text { al parto. }\end{array}$ & $\begin{array}{l}\text { Intervención: } 2 \text { tabletas de complejo de } \\
\text { proteasas cuatro veces al día, después de } \\
\text { cada comida y antes de acostarse a } \\
\text { dormir. Al segundo día y tercer día } 1 \\
\text { tableta al día, cuatro veces al día } \\
\text { Control: placebo. }\end{array}$ & - & - & $\begin{array}{l}\text { Alto riesgo de } \\
\text { sesgo }\end{array}$ \\
\hline $\begin{array}{l}\text { McLachlan Z, } \\
1991\end{array}$ & $\begin{array}{l}\text { Diseño: Ensayo } \\
\text { aleatorizado, } \\
\text { doble ciego, } \\
\text { controlado con } \\
\text { placebo } \\
\text { Objetivo: Evaluar } \\
\text { la efectividad de } \\
\text { la terapia con } \\
\text { ultrasonido termal } \\
\text { como tratamiento } \\
\text { de la ingurgitación } \\
\text { mamaria severa } \\
\text { posterior al parto. }\end{array}$ & $\begin{array}{l}197 \text { mamas de } 109 \\
\text { mujeres que fueron } \\
\text { derivadas al } \\
\text { fisioterapista para el } \\
\text { tratamiento de la } \\
\text { ingurgitación mamaria }\end{array}$ & $\begin{array}{l}\text { Se usaron dos aparatos de ultrasonido } \\
\text { idénticos, uno trabajaba normalmente y } \\
\text { otro fue usado como placebo. }\end{array}$ & $\begin{array}{l}\text { Las dos intervenciones fueron efectivas en } \\
\text { la reducción subjetiva del dolor y el } \\
\text { entumecimiento. }\end{array}$ & $\begin{array}{l}\text { Los resultados de este } \\
\text { estudio muestran que el } \\
\text { efecto de la intervención } \\
\text { no puede ser atribuido al } \\
\text { uso del ultrasonido. }\end{array}$ & \\
\hline $\begin{array}{l}\text { Ingelman- } \\
\text { Sundberg A, } 1953\end{array}$ & $\begin{array}{l}\text { Diseño: Ensayo } \\
\text { cuasi aleatorizado }\end{array}$ & \begin{tabular}{l|}
45 mujeres con \\
presencia de signos \\
importantes de \\
ingurgitación durante el \\
segundo y cuarto día de \\
puerperio.
\end{tabular} & $\begin{array}{l}\text { Intervención: Oxitocina } 2.5 \text { U.I } \\
\text { subcutáneas diarias hasta el } \\
\text { ablandamiento de las mamas. } \\
\text { Control: solución salina }\end{array}$ & - & - & \\
\hline Robson BA, 1990 & $\begin{array}{l}\text { Tesis } \\
\text { Diseño: ensayo } \\
\text { clínico } \\
\text { aleatorizado }\end{array}$ & $\begin{array}{l}88 \text { mujeres en periodo } \\
\text { de lactancia con } \\
\text { diferentes grados de } \\
\text { ingurgitación mamaria. } \\
\text { Todos los partos fueron } \\
\text { por cesárea. }\end{array}$ & $\begin{array}{l}\text { Intervención: bolsas de gel frio durante 15- } \\
20 \text { minutos después de dos tomas } \\
\text { consecutivas. } \\
\text { El grupo control recibió cuidad habitual. }\end{array}$ & - & - & $\begin{array}{l}\text { Alto riesgo de } \\
\text { sesgo. } \\
\text { Muchas mujeres } \\
\text { cambiaron del } \\
\text { grupo de } \\
\text { intervención al } \\
\text { grupo control. }\end{array}$ \\
\hline Chiu JY, 2010 & $\begin{array}{l}\text { Diseño: ensayo } \\
\text { clínico }\end{array}$ & $\begin{array}{l}54 \text { mujeres en postparto } \\
\text { en un hospital }\end{array}$ & $\begin{array}{l}\text { Intervención: Gua-Sha suave y corto } \\
\text { seleccionado los acupuntos adecuados }\end{array}$ & $\begin{array}{l}\text { Cinco minutos después del inicio de la } \\
\text { intervención, el grupo control presentó una }\end{array}$ & $\begin{array}{l}\text { La terapia con Gua-Sha } \\
\text { mejora de forma }\end{array}$ & $\begin{array}{l}\text { Alto riesgo de } \\
\text { sesgo. }\end{array}$ \\
\hline
\end{tabular}




\begin{tabular}{|c|c|c|c|c|c|c|}
\hline $\begin{array}{l}\text { Referencia } \\
\text { (Cita Abreviada) }\end{array}$ & $\begin{array}{l}\text { Estudio (Diseño y } \\
\text { objetivo) }\end{array}$ & $\begin{array}{l}\text { Población } \\
\text { (noy características) }\end{array}$ & $\begin{array}{l}\text { Descripción de las intervenciones } \\
\text { comparaciones, exposiciones o } \\
\text { pruebas a estudio }\end{array}$ & $\begin{array}{l}\text { Resultados } \\
\text { (Estimadores de resultados-Magnitud del } \\
\text { efecto) }\end{array}$ & $\begin{array}{l}\text { Conclusiones } \\
\text { (conclusiones) }\end{array}$ & $\begin{array}{l}\text { Comentarios } \\
\text { Calidad de la } \\
\text { evidencia } \\
\text { Financiación } \\
\text { comentarios) }\end{array}$ \\
\hline & $\begin{array}{l}\text { aleatorizado } \\
\text { Objetivo: } \\
\text { Determinar los } \\
\text { efectos del Gua- } \\
\text { Sha como } \\
\text { tratamiento para } \\
\text { la ingurgitación } \\
\text { mamaria }\end{array}$ & $\begin{array}{l}\text { universitario de III nivel } \\
\text { en Taiwán. } \\
\text { Fueron incluidas } \\
\text { mujeres que hubieran } \\
\text { tenido un parto sin } \\
\text { complicaciones, y que } \\
\text { estuvieran } \\
\text { experimentando } \\
\text { problemas de } \\
\text { ingurgitación mamaria. }\end{array}$ & $\begin{array}{l}\text { para el manejo de los síntomas. Los } \\
\text { acupuntos son descritos como canales de } \\
\text { energía que pasan por debajo de la piel y } \\
\text { recorren el cuerpo mejorando el riego } \\
\text { sanguíneo, la nutrición de los tejidos y } \\
\text { facilitando el funcionamiento normal del } \\
\text { organismo. Así, la estimulación de } \\
\text { acupuntos específicos mediante Gua-Sha, } \\
\text { podría llegar a mejorar la sintomatología. } \\
\text { Los acupuntos elegidos para la } \\
\text { intervención fueron el ST16, CV } 17, \mathrm{ST} 18 \text {, } \\
\text { y el SP17. En cada posición se aplicaron } \\
\text { dos ciclos de fricción suave (siete veces). } \\
\text { La intervención fue realizada por un } \\
\text { profesional con más de } 10 \text { años de } \\
\text { experiencia en medicina tradicional china. } \\
\text { Control: Cuidado habitual que incluía } \\
\text { bolsas calientes y masaje por } 20 \text { minutos. }\end{array}$ & $\begin{array}{l}\text { mejoría significativa en la temperatura de } \\
\text { la mama, la ingurgitación mamaria, el } \\
\text { dolor y la sensación de molestias, pero no } \\
\text { en la temperatura basal. Después de } 30 \\
\text { minutos, se presentaron diferencias } \\
\text { significativas en estos desenlaces } \\
\text { respecto a los valores basales. } \\
\text { En el grupo que recibió terapia Gua-Sha, } \\
\text { presentó mejorías significativas en todos } \\
\text { los desenlaces a los cinco y treinta } \\
\text { minutos posteriores a la intervención. } \\
\text { Posterior a la intervención el grupo que } \\
\text { recibió terapia Gua-Sha mostró una } \\
\text { mejoría significativa de la sintomatología } \\
\text { respecto al grupo control. }\end{array}$ & $\begin{array}{l}\text { significativa la } \\
\text { sintomatología respecto } \\
\text { al tratamiento habitual. }\end{array}$ & $\begin{array}{l}\text { Intervención } \\
\text { poco aplicable } \\
\text { en nuestro } \\
\text { medio. } \\
\text { Desenlaces } \\
\text { evaluados no } \\
\text { relevantes } \\
\text { clínicamente. }\end{array}$ \\
\hline Arora S, 2008 & $\begin{array}{l}\text { Diseño: Ensayo } \\
\text { clínico cuasi } \\
\text { aleatorizado } \\
\\
\text { Objetivo: comprar } \\
\text { las hojas de col } \\
\text { frío respecto a las } \\
\text { compresas frías y } \\
\text { calientes para el } \\
\text { tratamiento de la } \\
\text { ingurgitación } \\
\text { mamaria }\end{array}$ & $\begin{array}{l}60 \text { mujeres en cada } \\
\text { grupo atendidas en } \\
\text { unidad de cuidados } \\
\text { post-natales en India. } \\
\text { Incluyeron mujeres con } \\
\text { ingurgitación mamaria } \\
\text { que no tuvieran signos } \\
\text { de infección mamaria, } \\
\text { mastitis, absceso o } \\
\text { lesiones en cutáneas } \\
\text { mamarias, grietas en el } \\
\text { pezón (o sangrado del } \\
\text { mismo) }\end{array}$ & $\begin{array}{l}\text { Control: A las primeras } 30 \text { mujeres se les } \\
\text { administró de forma alternada compresas } \\
\text { calientes }\left(43^{\circ} \mathrm{C}-46^{\circ} \mathrm{C}\right) \text { y frías }\left(10^{\circ} \mathrm{C}-18^{\circ} \mathrm{C}\right) \text {. } \\
\text { Las compresas eran reemplazadas cada } \\
1-2 \text { minutos. Este proceso se realizaba de } \\
\text { forma continua durante } 20 \text { minutos. } \\
\text { Intervención: después de la primera fase, } \\
30 \text { mujeres eran tratadas con hojas de col } \\
\text { frio, las cuales eran refrigeradas durante } \\
20-30 \text { minutos previos a la intervención. } \\
\text { Las hojas de col eran puestas dentro del } \\
\text { sostenedor de las mujeres durante } 30 \\
\text { minutos. } \\
\text { Ambos tratamientos eran realizados tres } \\
\text { veces al día durante dos días seguidos. } \\
\text { Antes y después de cada intervención, los } \\
\text { resultados de las escalas de dolor (escala } \\
\text { numérica) e ingurgitación (escala de seis } \\
\text { puntos) eran registrados. }\end{array}$ & $\begin{array}{l}\text { Ambas intervenciones fueron efectivas } \\
\text { para mejorar la ingurgitación mamaria y el } \\
\text { dolor en las mujeres }(P \leq 0.001) \text {. los dos } \\
\text { tratamientos fueron iguales de efectivos } \\
\text { en la mejora de la ingurgitación mamaria } \\
(P=0.07) \text {, sin embargo las compresas } \\
\text { frías/calientes fueron más efectivas que } \\
\text { las hojas de col en la mejoría del dolor. ( } P \\
\leq 0.001) \text {. }\end{array}$ & $\begin{array}{l}\text { Las hojas de col frías } \\
\text { son tan efectivas como } \\
\text { las compresas } \\
\text { frías/calientes alternadas } \\
\text { en el tratamiento de la } \\
\text { ingurgitación mamaria. } \\
\text { Las compresas son más } \\
\text { efectivas en la mejora } \\
\text { del dolor. }\end{array}$ & $\begin{array}{l}\text { Alto riesgo de } \\
\text { sesgo }\end{array}$ \\
\hline
\end{tabular}


8. ANEXO III, Forest-Plot

No procede. 


\section{ANEXO IV. Evaluación de la calidad}

\section{Valoración AMSTAR Mangesi 2010}

AMSTAR - a measurement tool to assess the methodological quality of systematic reviews.

\section{Was an 'a priori' design provided?}

The research question and inclusion criteria should be established before the conduct of the review.

Note: Need to refer to a protocol, ethics approval, or pre-determined/a priori published research objectives to score a "yes."

$X$ Yes

$\square$ No

$\square$ Can't answer

$\square$ Not applicable

\section{Was there duplicate study selection and data extraction?}

There should be at least two independent data extractors and a consensus procedure for disagreements should be in place.

Note: 2 people do study selection, 2 people do data extraction, consensus process or one person checks the other's work.

$\mathrm{X}$ Yes

$\square$ No

$\square$ Can't answer

$\square$ Not applicable

\section{Was a comprehensive literature search performed?}

At least two electronic sources should be searched. The report must include years and databases used (e.g., Central, EMBASE, and MEDLINE). Key words and/or MESH terms must be stated and where feasible the search strategy should be provided. All searches should be supplemented by consulting current contents, reviews, textbooks, specialized registers, or experts in the particular field of study, and by reviewing the references in the studies found.

Note: If at least 2 sources + one supplementary strategy used, select "yes" (Cochrane register/Central counts as 2 sources; a grey literature search counts as supplementary).

$\mathrm{X}$ Yes

$\square$ No

$\square$ Can't answer

$\square$ Not applicable

4. Was the status of publication (i.e. grey literature) used as an inclusion criterion? The authors should state that they searched for reports regardless of their publication type. The authors should state whether or not they excluded any reports (from the systematic review), based on their publication status, language etc.

Note: If review indicates that there was a search for "grey literature" or "unpublished literature," indicate "yes." SIGLE database, dissertations, conference proceedings, and trial registries are all considered grey for this purpose. If searching a source that contains both grey and non-grey, must specify that they were searching for grey/unpublished lit.

$X$ Yes

$\square$ No

$\square$ Can't answer

$\square$ Not applicable

5. Was a list of studies (included and excluded) provided?

A list of included and excluded studies should be provided.

Note: Acceptable if the excluded studies are referenced. If there is an electronic link to the list but the link is dead, select "no."

$X$ Yes 
$\square$ No

$\square$ Can't answer

$\square$ Not applicable

\section{Were the characteristics of the included studies provided?}

In an aggregated form such as a table, data from the original studies should be provided on the participants, interventions and outcomes. The ranges of characteristics in all the studies analyzed e.g., age, race, sex, relevant socioeconomic data, disease status, duration, severity, or other diseases should be reported.

Note: Acceptable if not in table format as long as they are described as above.

$\mathrm{X}$ Yes

$\square$ No

$\square$ Can't answer

$\square$ Not applicable

\section{Was the scientific quality of the included studies assessed and documented?}

'A priori' methods of assessment should be provided (e.g., for effectiveness studies if the author(s) chose to include only randomized, double-blind, placebo controlled studies, or allocation concealment as inclusion criteria); for other types of studies alternative items will be relevant.

Note: Can include use of a quality scoring tool or checklist, e.g., Jadad scale, risk of bias, sensitivity analysis, etc., or a description of quality items, with some kind of result for EACH study "Iow" or "high" is fine, as long as it is clear which studies scored "low" and which scored "high"; a summary score/range for all studies is not acceptable).

$X$ Yes

$\square$ No

$\square$ Can't answer

$\square$ Not applicable

8. Was the scientific quality of the included studies used appropriately in formulating conclusions?

The results of the methodological rigor and scientific quality should be considered in the analysis and the conclusions of the review, and explicitly stated in formulating recommendations.

Note: Might say something such as "the results should be interpreted with caution due to poor quality of included studies." Cannot score "yes" for this question if scored "no" for question 7.

$X$ Yes

$\square$ No

$\square$ Can't answer

$\square$ Not applicable

9. Were the methods used to combine the findings of studies appropriate?

For the pooled results, a test should be done to ensure the studies were combinable, to assess their homogeneity (i.e., Chi-squared test for homogeneity, I2). If heterogeneity exists a random effects model should be used and/or the clinical appropriateness of combining should be taken into consideration (i.e., is it sensible to combine?).

Note: Indicate "yes" if they mention or describe heterogeneity, i.e., if they explain that

they cannot pool because of heterogeneity/variability between interventions.

$X$ Yes

$\square$ No

$\square$ Can't answer

$\square$ Not applicable

10. Was the likelihood of publication bias assessed?

An assessment of publication bias should include a combination of graphical aids (e.g., funnel plot, other available tests) and/or statistical tests (e.g., Egger regression test, Hedges-Olken).

Note: If no test values or funnel plot included, score "no". Score "yes" if mentions that publication bias could not be assessed because there were fewer than 10 included studies.

$X$ Yes

$\square$ No 
$\square$ Can't answer

$\square$ Not applicable

11. Was the conflict of interest included?

Potential sources of support should be clearly acknowledged in both the systematic review and the included studies.

Note: To get a "yes," must indicate source of funding or support for the systematic review AND for each of the included studies.
$\square$ Yes
$X$ No
$\square$ Can't answer
$\square$ Not applicable

Shea et al. BMC Medical Research Methodology 2007 7:10 doi:10.1186/1471-2288-7-10

Additional notes (in italics) made by Michelle Weir, Julia Worswick, and Carolyn Wayne based on conversations with

Bev Shea and/or Jeremy Grimshaw in June and October 2008 and July and September 2010 


\section{ANEXO V, Evaluación del riesgo de los estudios individuales}

Kvist 2004

Riesgo de sesgo de los estudios individuales

\begin{tabular}{|l|c|l|}
\hline \multicolumn{1}{|c|}{ Ítem } & \multicolumn{1}{|c|}{ Juicio } & \multicolumn{1}{|c|}{ Descripción } \\
\hline $\begin{array}{l}\text { Generación adecuada de la } \\
\text { secuencia de aleatorización }\end{array}$ & Dudoso & No descrito \\
\hline $\begin{array}{l}\text { Asignación adecuada de la } \\
\text { secuencia de aleatorización }\end{array}$ & $\mathrm{Si}$ & $\begin{array}{l}\text { Sobre opacos abiertos por las } \\
\text { comadronas en orden }\end{array}$ \\
\hline Enmascaramiento - Mujeres & No & No factible \\
\hline $\begin{array}{l}\text { Enmascaramiento - Profesional } \\
\text { sanitario }\end{array}$ & No & $\begin{array}{l}88 \text { mujeres aleatorizadas. Los } \\
\text { denominadores los } \\
\text { resultados no fueron claros. }\end{array}$ \\
\hline Enmascaramiento - Evaluadores & No & \multicolumn{2}{l}{} \\
\hline Pérdidas de seguimiento & Dudoso & \\
\hline
\end{tabular}

\section{Kvist 2007}

\begin{tabular}{|c|c|c|}
\hline Ítem & Juicio & Descripción \\
\hline $\begin{array}{l}\text { Generación adecuada de la } \\
\text { secuencia de aleatorización }\end{array}$ & Si & \\
\hline $\begin{array}{l}\text { Asignación adecuada de la } \\
\text { secuencia de aleatorización? }\end{array}$ & $\mathrm{Si}$ & \\
\hline Enmascaramiento - Mujeres & No & No posible \\
\hline $\begin{array}{l}\text { Enmascaramiento - Profesional } \\
\text { sanitario }\end{array}$ & No & \\
\hline Enmascaramiento - Evaluadores & No & \\
\hline Pérdidas de seguimiento & Si & $\begin{array}{l}205 \text { mujeres ( } 210 \text { episodios). } \\
\text { Dos pérdidas de seguimiento } \\
\text { pero incluidas en el análisis } \\
\text { de los resultados. }\end{array}$ \\
\hline
\end{tabular}

Roberts KI, 1995

\begin{tabular}{|l|l|l|}
\hline \multicolumn{1}{|c|}{ Ítem } & Juicio & Descripción \\
\hline $\begin{array}{l}\text { Generación adecuada de la } \\
\text { secuencia de aleatorización }\end{array}$ & Dudoso & No descrito \\
\hline
\end{tabular}




\begin{tabular}{|c|c|c|}
\hline $\begin{array}{l}\text { Asignación adecuada de la } \\
\text { secuencia de aleatorización }\end{array}$ & No & $\begin{array}{l}\text { Todas las mujeres recibieron } \\
\text { los dos tratamientos, uno en } \\
\text { cada mama }\end{array}$ \\
\hline Enmascaramiento - Mujeres & No & No factible \\
\hline $\begin{array}{l}\text { Enmascaramiento - Profesional } \\
\text { sanitario }\end{array}$ & No & \\
\hline Enmascaramiento - Evaluadores & No & \\
\hline Pérdidas de seguimiento & Si & \\
\hline Libre de otros sesgos & No & $\begin{array}{l}\text { El análisis fue realizado } \\
\text { utilizando como unidad de } \\
\text { análisis las mamas en vez de } \\
\text { las mujeres. La unidad de } \\
\text { análisis elegida es poco } \\
\text { probable que sea } \\
\text { independiente. No ajustes } \\
\text { realizados. }\end{array}$ \\
\hline
\end{tabular}

(a)Roberts KI, 1995

\begin{tabular}{|c|c|c|}
\hline Ítem & Juicio & Descripción \\
\hline $\begin{array}{l}\text { Generación adecuada de la } \\
\text { secuencia de aleatorización }\end{array}$ & No & $\begin{array}{l}\text { Cuasi aleatorización (por } \\
\text { número hospitalario) de cada } \\
\text { una de las mamas }\end{array}$ \\
\hline $\begin{array}{l}\text { Asignación adecuada de la } \\
\text { secuencia de aleatorización }\end{array}$ & No & \\
\hline Enmascaramiento - Mujeres & No & $\begin{array}{l}\text { No factible. Importante riesgo } \\
\text { de sesgo al recibir cada una } \\
\text { de las mujeres las dos } \\
\text { intervenciones }\end{array}$ \\
\hline $\begin{array}{l}\text { Enmascaramiento - Profesional } \\
\text { sanitario }\end{array}$ & No & \\
\hline Enmascaramiento - Evaluadores & No & \\
\hline Pérdidas de seguimiento & $\mathrm{Si}$ & \\
\hline Libre de otros sesgos & No & $\begin{array}{l}\text { El análisis fue realizado } \\
\text { utilizando como unidad de } \\
\text { análisis las mamas en vez de } \\
\text { las mujeres. La unidad de } \\
\text { análisis elegida es poco } \\
\text { probable que sea } \\
\text { independiente. No ajustes } \\
\text { realizados. }\end{array}$ \\
\hline
\end{tabular}


Murata, 1965

\begin{tabular}{|l|c|l|}
\hline \multicolumn{1}{|c|}{ Ítem } & \multicolumn{1}{|c|}{ Juicio } & \multicolumn{1}{|c|}{ Descripción } \\
\hline $\begin{array}{l}\text { Generación adecuada de la } \\
\text { secuencia de aleatorización }\end{array}$ & No & $\begin{array}{l}\text { Cuasi aleatorización, realizada } \\
\text { por días de la semana. }\end{array}$ \\
\hline $\begin{array}{l}\text { Asignación adecuada de la } \\
\text { secuencia de aleatorización }\end{array}$ & No & $\begin{array}{l}\text { El grupo asignado podía ser } \\
\text { anticipado }\end{array}$ \\
\hline Enmascaramiento - Mujeres & Si & Control con placebo \\
\hline $\begin{array}{l}\text { Enmascaramiento - Profesional } \\
\text { sanitario }\end{array}$ & Si & Control con placebo \\
\hline Enmascaramiento - Evaluadores & Si & \\
\hline Pérdidas de seguimiento & Si & \\
\hline
\end{tabular}

McLachlan Z, 1991

\begin{tabular}{|l|c|l|}
\hline \multicolumn{1}{|c|}{ Ítem } & \multicolumn{1}{|c|}{ Juicio } & \multicolumn{1}{|c|}{ Descripción } \\
\hline $\begin{array}{l}\text { Generación adecuada de la } \\
\text { secuencia de aleatorización }\end{array}$ & Si & No reportado \\
\hline $\begin{array}{l}\text { Asignación adecuada de la } \\
\text { secuencia de aleatorización }\end{array}$ & Dudoso & $\begin{array}{l}\text { Cuatro pérdidas de } \\
\text { seguimiento no reportan el } \\
\text { manejo de estos datos } \\
\text { perdidos }\end{array}$ \\
\hline Enmascaramiento - Mujeres & Si \\
\hline $\begin{array}{l}\text { Enmascaramiento - Profesional } \\
\text { sanitario }\end{array}$ & Si & $\begin{array}{l}\text { Resultados difíciles de de } \\
\text { analizar dado que la unidad } \\
\text { de análisis fueron las mamas. }\end{array}$ \\
\hline Pérdidas de seguimiento & Dudoso & \multicolumn{1}{|c|}{} \\
\hline Libre de otros sesgos & & \\
\hline
\end{tabular}

Ingelman-Sundberg A, 1953

\begin{tabular}{|l|c|c|}
\hline \multicolumn{1}{|c|}{ Ítem } & Juicio & Descripción \\
\hline $\begin{array}{l}\text { Generación adecuada de la } \\
\text { secuencia de aleatorización }\end{array}$ & No & Causi aleatorizado \\
\hline
\end{tabular}




\begin{tabular}{|l|c|l|}
\hline $\begin{array}{l}\text { Asignación adecuada de la } \\
\text { secuencia de aleatorización? }\end{array}$ & No & $\begin{array}{l}\text { Se asignaron a los grupos } \\
\text { dependiendo del registro } \\
\text { hospitalario }\end{array}$ \\
\hline Enmascaramiento - Mujeres & $\mathrm{Si}$ & $\mathrm{Si}$ \\
\hline $\begin{array}{l}\text { Enmascaramiento - Profesional } \\
\text { sanitario }\end{array}$ & Dudoso & \begin{tabular}{l} 
No reportado. \\
\hline Enmascaramiento - Evaluadores
\end{tabular} \\
\hline Pérdidas de seguimiento & Dudoso & $\begin{array}{l}\text { No reportan como fueron } \\
\text { manejadas las pérdidas de } \\
\text { seguimiento. }\end{array}$ \\
\hline
\end{tabular}

Robson BA, 1990

\begin{tabular}{|l|c|l|}
\hline \multicolumn{1}{|c|}{ Ítem } & \multicolumn{1}{|c|}{ Juicio } & \multicolumn{1}{|c|}{ Descripción } \\
\hline $\begin{array}{l}\text { Generación adecuada de la } \\
\text { secuencia de aleatorización }\end{array}$ & No & $\begin{array}{l}\text { Tabla de aleatorización pero la } \\
\text { secuencia no se observó en } \\
\text { todos los casos }\end{array}$ \\
\hline $\begin{array}{l}\text { Asignación adecuada de la } \\
\text { secuencia de aleatorización? }\end{array}$ & No & No reportado. \\
\hline Enmascaramiento - Mujeres & No & No \\
\hline $\begin{array}{l}\text { Enmascaramiento - Profesional } \\
\text { sanitario }\end{array}$ & No & $\begin{array}{l}\text { No análisis por intención de } \\
\text { tratar. }\end{array}$ \\
\hline Enmascaramiento - Evaluadores & No & $\begin{array}{l}\text { Diferencias entre los grupos a } \\
\text { nivel basal. Las mujeres en el } \\
\text { grupo control tenían niveles de } \\
\text { dolor más bajos. Esto puede } \\
\text { ser debido a que tres mujeres } \\
\text { de grupo control con síntomas } \\
\text { severos fueron asignadas al } \\
\text { grupo de intervención. }\end{array}$ \\
\hline Pérdidas de seguimiento & &
\end{tabular}

Chiu JY, 2010

\begin{tabular}{|l|c|l|}
\hline \multicolumn{1}{|c|}{ Ítem } & \multicolumn{1}{|c|}{ Juicio } & \multicolumn{1}{|c|}{ Descripción } \\
\hline $\begin{array}{l}\text { Generación adecuada de la } \\
\text { secuencia de aleatorización }\end{array}$ & $\mathrm{Si}$ & $\begin{array}{l}\text { Generada } \\
\text { ordenador }\end{array}$ \\
\hline
\end{tabular}




\begin{tabular}{|l|c|l|}
\hline $\begin{array}{l}\text { Asignación adecuada de la } \\
\text { secuencia de aleatorización? }\end{array}$ & Dudoso & No reportado \\
\hline Enmascaramiento - Mujeres & No & \\
\hline $\begin{array}{l}\text { Enmascaramiento - Profesional } \\
\text { sanitario }\end{array}$ & No & $\begin{array}{l}\text { No reportado. Refieren incluir } \\
\text { pacientes pero no } \\
\text { mencionan cuantas mujeres } \\
\text { fueron asignadas a cada uno } \\
\text { de los grupos. }\end{array}$ \\
\hline Enmascaramiento - Evaluadores & Dudoso \\
\hline Pérdidas de seguimiento & & \\
\hline
\end{tabular}

Arora S, 2008

\begin{tabular}{|c|c|c|}
\hline Ítem & Juicio & Descripción \\
\hline $\begin{array}{c}\text { Generación adecuada de la } \\
\text { secuencia de aleatorización }\end{array}$ & No & $\begin{array}{c}\text { Secuencial, por orden de } \\
\text { llegada se atribuía inicialmente } \\
\text { al control y después a la } \\
\text { intervención }\end{array}$ \\
\hline $\begin{array}{c}\text { Asignación adecuada de la } \\
\text { secuencia de aleatorización? }\end{array}$ & No & \\
\hline $\begin{array}{c}\text { Enmascaramiento - Mujeres } \\
\text { Enmascaramiento - Profesional } \\
\text { sanitario }\end{array}$ & No & \\
\hline $\begin{array}{c}\text { Enmascaramiento - } \\
\text { Evaluadores }\end{array}$ & No & \\
\hline Pérdidas de seguimiento & Yes & \\
\hline
\end{tabular}




\section{1- BIBLIOGRAFÍA}

(1) Mangesi L, Dowswell T. Treatments for breast engorgement during lactation. Cochrane Database Syst Rev 2010;(9):CD006946.

(2) NICE. Postnatal care up to 8 weeks after birth. Julio 2006 (actualizado en Febrero de 2015). Disponible en: http://guidance.nice.org.uk/CG37.

(3) Perinatal Services BC Health Promotion Guideline. Breastfeeding Healthy Term Infants. March 2015. Disponible en: http://www.perinatalservicesbc.ca/Documents/Guidelines-

Standards/HealthPromotion/BreastfeedingHealthyTermInfantGuideline.pdf.

(4) Protocolo de la ABM. Protocolo clínico de la ABM \#20. Congestión mamaria. Breastfeeding Medicine. Volumen 4, Número 2, 2009.

(5) Kvist LJ, Wilde LB, Hall-Lord ML, Rydhstroem H. Effects of acupuncture and care interventions on the outcome of inflammatory symptoms of the breast in lactating women. Int Nurs Rev 2004 Mar;51(1):56-64.

(6) Kvist LJ, Hall-Lord ML, Rydhstroem H, Larsson BW. A randomised-controlled trial in Sweden of acupuncture and care interventions for the relief of inflammatory symptoms of the breast during lactation. Midwifery 2007 Jun;23(2):184-95.

(7) Roberts KL. A comparison of chilled cabbage leaves and chilled gelpaks in reducing breast engorgement. J Hum Lact 1995 Mar;11(1):17-20.

(8) Roberts KL, Reiter M, Schuster D. A comparison of chilled and room temperature cabbage leaves in treating breast engorgement. J Hum Lact 1995 Sep;11(3):191-4.

(9) Murata T, Hanzawa M, Nomura Y. The clinical effects of "protease complex" on postpartum breast engorgement (based on the double blind method). J Jpn Obstet Gynecol Soc 1965 Jul;12(3):139-47.

(10) McLachlan Z, Milne EJ, Lumley J, Walker BL. Ultrasound treatment for breast engorgement: A randomised double blind trial. Aust J Physiother 1991;37(1):238.

(11) Ingleman-Sundberg A. Early puerpereal breast engorgement. Acta Obstet Gynecol Scand 1953;32(4):399-402.

(12) Robson BA. Breast engorgement in breastfeeding mothers. [thesis]. Personal communication 1990.

(13) Smith V. Treatments for breast engorgement during lactation. Practising Midwife.2014;17(9):42-4.

(14) Wong BB, Koh S, Hegney DG. The effectiveness of cabbage leaf application (treatment) on pain and hardness in breast engorgement and its effect on the duration of breastfeeding. JBI Database of Systematic Reviews and Implementation Reports 2012;10(20):1185-213.

(15) Mangesi L, Zakarija-Grkovic I. Treatments for breast engorgement during lactation. Cochrane Database Syst Rev 2016 Jun 28;(6):CD006946.

(16) Chiu JY, Gau ML, Kuo SY, Chang YH, Kuo SC, Tu HC. Effects of Gua-Sha therapy on breast engorgement: a randomized controlled trial. J Nurs Res 2010 Mar;18(1):1-10.

(17) Heberle $A B$, de Moura MA, de Souza MA, Nohama P. Assessment of techniques of massage and pumping in the treatment of breast engorgement by thermography. Rev Lat Am Enfermagem 2014 Mar;22(2):277-85. 
(18) Ahmadi M. The comparison of acupressure (jianjing point) and compress (hot and cold) on breast engorgement in lactating women. Iranian Clinical Trials Register (www.irct.ir/). 2011.

(19) Kee WH, Tan SL, Lee V, Salmon YM. The treatment of breast engorgement with Serrapeptase (Danzen): a randomised double-blind controlled trial. Singapore Med J 1989 Feb;30(1):48-54.

(20) Roberts KL, Reiter M, Schuster D. Effects of cabbage leaf extract on breast engorgement. J Hum Lact 1998 Sep;14(3):231-6.

(21) Khosravan S, Mohammadzadeh-Moghadam H, Mohammadzadeh F, Fadafen SA, Gholami M. The Effect of Hollyhock (Althaea officinalis $L$ ) Leaf Compresses Combined With Warm and Cold Compress on Breast Engorgement in Lactating Women: A Randomized Clinical Trial. J Evid Based Complementary Altern Med 2015 Nov 23.

(22) Lim A-R, Song J-A, Hur M-H, Lee M-K, Lee MS. Cabbage compression early breast care on breast engorgement in primiparous women after cesarean birth: A controlled clinical trial. International Journal of Clinical and Experimental Medicine 2015 Nov 30;8(11):21335-42. 


\section{PREGUNTA CLÍNICA № 27}

\section{¿Qué hacer si hay dificultades en el agarre por las características anatómicas del pezón?}

\section{1- Pregunta clínica en formato PICO}

Pregunta 27.1: ¿Qué hacer si hay dificultades en el agarre por pezones invertidos retráctiles (pseudoinvertidos)?

Tabla 1- Componentes de la pregunta clínica en formato PICO

\begin{tabular}{|l|l|}
\hline Pacientes & $\begin{array}{l}\text { Madre sana con pezones invertidos retráctiles } \\
\text { (pseudoinvertidos) que amamanta y recién nacido sano }\end{array}$ \\
\hline Intervención & $\begin{array}{l}\text { Ejercicios de Hoffman durante el embarazo, formadores de } \\
\text { pezón (niplettes, jeringuilla, "conchas"), técnica del sandwich, } \\
\text { y realización de "biological nurturing" y contacto piel con piel } \\
\text { inmediato }\end{array}$ \\
\hline Comparación & Utilización de pezonera durante el amamantamiento \\
\hline Resultados & $\begin{array}{l}\text { Tasa de lactancia materna exclusiva al alta } \\
\text { Tasa de lactancia materna exclusiva al mes } \\
\text { Tasa de lactancia materna a los 4 meses } \\
\text { Tasa de lactancia materna exclusiva a los 4 meses } \\
\text { Duración de la lactancia materna (exclusiva y no exclusiva) } \\
\text { Satisfacción materna } \\
\text { Complicaciones de las mamas (grietas, ingurgitaciones) } \\
\text { Pérdida ponderal del bebé (48-72h.) }\end{array}$ \\
\hline Tipo de estudio & $\begin{array}{l}\text { RS de ECA, ECA, RS de estudios observacionales o } \\
\text { estudios observacionales }\end{array}$ \\
\hline
\end{tabular}

Pregunta 27.2: ¿Qué hacer si hay dificultades en el agarre por pezones planos?

Tabla 1- Componentes de la pregunta clínica en formato PICO

\begin{tabular}{|l|l|}
\hline Pacientes & $\begin{array}{l}\text { Madre sana con pezones planos que amamanta y recién } \\
\text { nacido sano }\end{array}$ \\
\hline Intervención & $\begin{array}{l}\text { Ejercicios de Hoffman durante el embarazo, formadores de } \\
\text { pezón (niplettes, jeringuilla, "conchas"), técnica del sándwich, } \\
\text { y realización de "biological nurturing" y contacto piel con piel } \\
\text { inmediato. }\end{array}$ \\
\hline Comparación & Utilización de pezonera durante el amamantamiento \\
\hline Resultados & $\begin{array}{l}\text { Tasa de lactancia materna exclusiva al alta } \\
\text { Tasa de lactancia materna exclusiva al mes } \\
\text { Tasa de lactancia materna a los 4 meses } \\
\text { Tasa de lactancia materna exclusiva a los 4 meses } \\
\text { Duración de la lactancia materna (exclusiva y no exclusiva) } \\
\text { Satisfacción materna } \\
\text { Complicaciones de las mamas (grietas, ingurgitaciones) }\end{array}$ \\
\hline
\end{tabular}




\begin{tabular}{|l|l|}
\hline & Pérdida ponderal del bebé (48-72h.) \\
\hline Tipo de estudio & $\begin{array}{l}\text { RS de ECA, ECA, RS de estudios observacionales o } \\
\text { estudios observacionales }\end{array}$ \\
\hline
\end{tabular}

Pregunta 27.3: ¿Qué hacer si hay dificultades en el agarre por pezones grandes?

Tabla 1- Componentes de la pregunta clínica en formato PICO

\begin{tabular}{|l|l|}
\hline Pacientes & $\begin{array}{l}\text { Madre sana con pezones grandes que amamanta y recién } \\
\text { nacido sano }\end{array}$ \\
\hline Intervención & $\begin{array}{l}\text { Utilización de pezonera (para facilitar el agarre), extracción } \\
\text { de leche y administración al niño mientras se espera a que } \\
\text { su crecimiento le permita un mejor agarre }\end{array}$ \\
\hline Comparación & Atención habitual (ayuda y apoyo para colocar al bebé) \\
\hline Resultados & $\begin{array}{l}\text { Tasa de lactancia materna exclusiva al alta } \\
\text { Tasa de lactancia materna exclusiva al mes } \\
\text { Tasa de lactancia materna a los 4 meses } \\
\text { Tasa de lactancia materna exclusiva a los 4 meses } \\
\text { Duración de la lactancia materna (exclusiva y no exclusiva) } \\
\text { Satisfacción materna } \\
\text { Complicaciones de las mamas (grietas, ingurgitaciones) } \\
\text { Pérdida ponderal del bebé (48-72h.) }\end{array}$ \\
\hline Tipo de estudio & $\begin{array}{l}\text { RS de ECA, ECA, RS de estudios observacionales o } \\
\text { estudios observacionales }\end{array}$ \\
\hline
\end{tabular}

\section{2- Introducción}




\section{ESTRATEGIA DE ELABORACIÓN DE LA PREGUNTA}

\subsection{GPC Base}

Tabla 2- Resumen de GPC Base

\begin{tabular}{|c|c|c|c|c|}
\hline $\begin{array}{c}\text { Guía } \\
\text { (Enfoque) }\end{array}$ & $\begin{array}{l}\text { Resumen sobre la evidencia } \\
\text { (Calidad de la evidencia) }\end{array}$ & $\begin{array}{l}\text { Recomendaciones } \\
\text { (Grado) }\end{array}$ & $\begin{array}{c}\text { Referencias } \\
\text { bibliográficas } \\
\text { (Tipo de } \\
\text { publicación) }\end{array}$ & Comentarios \\
\hline $\begin{array}{l}\text { NICE, } \\
2006\end{array}$ & $\begin{array}{l}\text { Other factors associated with suboptimal feeding } \\
\text { behaviour included use of non breast milk feeds } \\
\text { during the first } 48 \text { hours, and maternal flat or } \\
\text { inverted nipples. Dewey et al ( 2003) } \\
\text { Treatment } \\
\text { No literature was found in the search strategy for } \\
\text { treatment of inverted or non protractile nipples in } \\
\text { postpartum women. }\end{array}$ & $\begin{array}{l}\text { Women with inverted nipples should receive extra support and } \\
\text { care to ensure successful breastfeeding. [D(GPP)] } \\
\text { Women with flat or inverted nipples should be advised that these } \\
\text { are not contraindications to breastfeeding and support offered as } \\
\text { needed. }\end{array}$ & & \\
\hline $\begin{array}{l}\text { Perinatal } \\
\text { Services } \\
\text { BC } 2013\end{array}$ & $\begin{array}{l}\text { Inverted or Flat Nipples } \\
\text { Breastfeeding over time can elongate the nipple and } \\
\text { lessen an inversion } \\
\text { Types38 } \\
\text { - Retractile: the nipple can evert with suckling and/or } \\
\text { when the areola is gently pressed between thumb } \\
\text { and forefinger. Is the most common } \\
\text { - Invaginated or true inversion: nipple retracts when } \\
\text { areola is compressed; rare }\end{array}$ & $\begin{array}{l}\text { Care } 38,39 \\
\text { - Initiate breastfeeding as soon as possible; the mother's } \\
\text { nipple/breast should be the first object introduced into the } \\
\text { infant's mouth } \\
\text { - A cold compress to a flat nipple before breastfeeding may help } \\
\text { evert the nipple } \\
\text { - Mother may stimulate and shape the nipple before } \\
\text { breastfeeding by using hand expression technique or a breast } \\
\text { pump } \\
\text { - Position the infant to achieve a deep latch } \\
\text { - Use an ultrathin silicone nipple shield for breastfeeding (see } \\
\text { Appendix G) } \\
\text { - If inability to latch persists express breastmilk and feed to infant } \\
\text { until latch is possible } \\
\text { - Avoid use of artificial nipples and pacifiers }\end{array}$ & & \\
\hline $\begin{array}{l}\text { GPC } \\
\text { embaraz } \\
\text { o, } 2014\end{array}$ & $\begin{array}{l}\text { Exploración mamaria } \\
\text { Una RS Cochrane (Lee, 2008) y la GPC sobre } \\
\text { atención al embarazo del NICE (P. Brocklehurst et } \\
\text { al, 2008) valoran la necesidad de realizar una } \\
\text { exploración mamaria durante la exploración física. }\end{array}$ & & & \\
\hline
\end{tabular}




\begin{tabular}{|l|l|l|c|}
\hline $\begin{array}{c}\text { Guía } \\
\text { (Enfoque) }\end{array}$ & \multicolumn{1}{|c|}{$\begin{array}{c}\text { Resumen sobre la evidencia } \\
\text { (Calidad de la evidencia) }\end{array}$} & $\begin{array}{c}\text { Referencias } \\
\text { bibliográficas } \\
\text { (Tipo de } \\
\text { publicación) }\end{array}$ & $\begin{array}{c}\text { Recomendaciones } \\
\text { (Grado) }\end{array}$ \\
\hline $\begin{array}{l}\text { Comentarios } \\
\text { posible estrategia para ha pricipar problemas durante } \\
\text { la lactancia mediante la determinación de pezones } \\
\text { planos o invertidos (Calidad baja). }\end{array}$ & $\begin{array}{l}\text { La RS Cochrane que trató de identificar ECA en los } \\
\text { que se comparara la exploración mamaria en alguna } \\
\text { de las visitas prenatales frente a no hacerlo (Lee, } \\
\text { 2008), no identificó ningún estudio sobre el tema. } \\
\text { Sin embargo, un ECA ha mostrado que un } \\
\text { tratamiento propuesto para los pezones planos } \\
\text { (ejercicios de Hoffman) no mostró un aumento de la } \\
\text { lactancia materna, e incluso en algunos casos } \\
\text { provocó una reticencia para iniciarla (Alexander, } \\
\text { 1992). Los resultados de esta RS y los del ECA que } \\
\text { evaluó los ejercicios de Hoffman no permiten } \\
\text { confirmar que la exploración mamaria aporte ningún } \\
\text { beneficio para promover la lactancia materna. }\end{array}$ \\
\hline
\end{tabular}




\subsection{Revisiones sistemáticas}

En la búsqueda realizada, no se han encontrado revisiones sistemáticas que presenten evidencia sobre qué hacer frente a lactantes con dificultades en el agarre a pezones invertidos retráctiles (pseudoinvertidos), planos o grandes. Por lo tanto se ha realizado una búsqueda sin límite temporal hasta agosto 2015 de todo tipo de estudios con diseños comparativos (ensayos controlados aleatorios (ECA), ensayos no aleatorios, estudios de cohorte prospectivos o retrospectivos), series de casos y reporte de casos.

Para el caso de pezones invertidos, se han identificado dos ECA (1;2), un estudio de cohorte prospectivo (3) y tres series de casos (4-6) que valoran diferentes métodos correctores de pezones invertidos. En el caso de pezones planos, se ha identificado un ECA (6), una serie de casos (7) y una encuesta (8) que valora los métodos correctores de pezones planos o cortos. Y por último, para el caso de pezones grandes, se ha identificado el reporte de un caso sobre una madre con pezones grandes y dificultad con la lactancia materna. 


\subsection{Resumen de GPC base y RS disponibles}

La guía NICE (9) señala que las mujeres con pezones invertidos deberían recibir apoyo y cuidados adicionales para asegurar el éxito de la lactancia materna ( $D$, GPP) y que a las mujeres con pezones planos o invertidos se les debería informar de que la lactancia materna no está contraindicada en esos casos y ofrecer apoyo en función de sus necesidades.

En la PSBC (10) se recomienda iniciar la lactancia materna tan pronto como sea posible. También se señala que una compresa fría antes de comenzar la toma puede ayudar a evertir el pezón plano y que la madre puede estimular el pezón antes de la toma mediante la extracción manual o la utilización de extractores de leche.

Se debe posicionar al lactante para que alcance un agarre profundo. También indica que se puede utilizar una pezonera de silicona ultradelgada para la lactancia, y que si todavía no se consigue un buen agarre, se puede extraer la leche materna y alimentar al lactante hasta que el agarre sea posible.

\subsection{Conclusión (marcar con una $\mathrm{X}$ ):}

\begin{tabular}{|l|l|}
\hline & Adopción GPC/Revisión sistemática \\
\hline & Elaboración parcial \\
\hline $\mathrm{X}$ & Elaboración de novo \\
\hline
\end{tabular}

\subsection{Diseño de la estrategia de búsqueda de estudios individuales}

\begin{tabular}{|l|l|}
\hline Criterios de selección de estudios & $\begin{array}{l}\text { ECA, estudios de cohortes, series de casos, reporte } \\
\text { de casos }\end{array}$ \\
\hline Período de búsqueda & Sin limites \\
\hline Bases de datos & Cochrane, PUMBED y EMBASE y CINHAL \\
\hline
\end{tabular}

Ver estrategias de búsqueda de estudios originales en el ANEXO I. 


\section{2- Resumen de la evidencia}

\section{1-GRADE Evidence Profile}

\section{Pregunta 27.1. ¿Qué hacer si hay dificultades en el agarre por pezones invertidos retráctiles (pseudoinvertidos)?}

Comparación 1: Utilización de escudos de pezón vs no utilización de escudos de pezón Bibliografía: Alexander 1992; MAIN 1994

\begin{tabular}{|c|c|c|c|c|c|c|c|c|c|c|c|c|}
\hline \multirow{2}{*}{\multicolumn{7}{|c|}{ Evaluación de la calidad }} & \multicolumn{4}{|c|}{ Resumen de los Resultados } & \multirow{3}{*}{ Calidad } & \multirow{3}{*}{ Importancia } \\
\hline & & & & & & & \multicolumn{2}{|c|}{ № de pacientes } & \multicolumn{2}{|c|}{ Magnitud del efecto } & & \\
\hline \begin{tabular}{|c|} 
№ de \\
estudios
\end{tabular} & Diseño & \begin{tabular}{|c|}
$\begin{array}{c}\text { Riesgo de } \\
\text { sesgo }\end{array}$ \\
\end{tabular} & Inconsistencia & \begin{tabular}{|l|}
$\begin{array}{l}\text { Evidencia } \\
\text { indirecta }\end{array}$ \\
\end{tabular} & Imprecisión & \begin{tabular}{|c|} 
Otras \\
consideraciones \\
\end{tabular} & $\begin{array}{c}\text { Grupo } \\
\text { escudos sí }\end{array}$ & \begin{tabular}{|c|} 
Grupo \\
escudos no
\end{tabular} & $\begin{array}{l}\text { Relativa } \\
(95 \% \mathrm{CI}) \\
\end{array}$ & \begin{tabular}{|l|} 
Absoluta \\
por 1000 \\
\end{tabular} & & \\
\hline \multicolumn{13}{|c|}{ Mejora en anatomía de pezón } \\
\hline $1^{1}$ & ECA & Seria $^{3}$ & No seria & No seria & Seria ${ }^{4}$ & Ninguna & $\begin{array}{l}25 / 48 \\
(52 \%) \\
\end{array}$ & $\begin{array}{l}29 / 48 \\
(60 \%) \\
\end{array}$ & $\begin{array}{c}\text { DM }-8 \% \text { (de }-28 \mathrm{a} \\
11)\end{array}$ & & BAJA & CRITICO \\
\hline \multicolumn{13}{|c|}{ Éxito en la lactancia a las seis semanas } \\
\hline $2^{1, .2}$ & ECA & Seria $^{3}$ & No seria & No seria & No seria & Ninguna & $\begin{array}{c}117 / 278 \\
(42 \%) \\
\end{array}$ & $\begin{array}{c}129 / 281 \\
(46 \%) \\
\end{array}$ & & & MODERADA & CRITICO \\
\hline \multicolumn{13}{|c|}{ Fracaso en la lactancia a las seis semanas } \\
\hline $2^{1,2}$ & ECA & Seria $^{3}$ & No seria & No seria & No seria & Ninguna & $\begin{array}{c}150 / 278 \\
(54 \%) \\
\end{array}$ & $\begin{array}{c}142 / 281 \\
(51 \%) \\
\end{array}$ & DM 3\% (de -5 a 12) & & MODERADA & CRITICO \\
\hline \multicolumn{13}{|c|}{ Edad gestacional al momento del parto } \\
\hline $1^{2}$ & ECA & Seria $^{3}$ & No seria & No seria & Seria $^{4}$ & Ninguna & $\begin{array}{c}11 / 230 \\
(5 \%) \\
\end{array}$ & $\begin{array}{r}6 / 233 \\
(3 \%) \\
\end{array}$ & DM 2\% (de -1 a 6 ) & & BAJA & IMPORTANTE \\
\hline \multicolumn{13}{|c|}{ Sangrado en el pezón } \\
\hline $2^{1,2}$ & ECA & Seria $^{3}$ & No seria & No seria & Seria $^{4}$ & Ninguna & $\begin{array}{c}81 / 278 \\
(29 \%) \\
\end{array}$ & $\begin{array}{l}76 / 281 \\
(27 \%) \\
\end{array}$ & $\begin{array}{c}\text { DM de } 2 \% \text { (de }-5 \text { a } \\
10)\end{array}$ & & BAJA & CRITICO \\
\hline \multicolumn{13}{|c|}{ Infección del seno con tratamiento antibiótico } \\
\hline $2 .{ }^{1.2}$ & ECA & Seria $^{3}$ & No seria & No seria & Seria ${ }^{4}$ & Ninguna & $\begin{array}{c}27 / 278 \\
(10 \%)\end{array}$ & $\begin{array}{c}27 / 281 \\
(10 \%) \\
\end{array}$ & \begin{tabular}{|c|} 
DM de $0 \%$ (de $-5 \mathrm{a}$ \\
$5)$
\end{tabular} & & BAJA & CRITICO \\
\hline
\end{tabular}

${ }^{3}$ Incumplimiento ( $\left.37 \%{ }^{1}-39 \%{ }^{2}\right) ;{ }^{4}$ Pocos eventos 
Comparación 2: Utilización de ejercicios de Hoffman vs no utilización de ejercicios de Hoffman

Bibliografía: Alexander 1992; MAIN 1994;

\begin{tabular}{|c|c|c|c|c|c|c|c|c|c|c|c|c|}
\hline \multirow{2}{*}{\multicolumn{7}{|c|}{ Evaluación de la calidad }} & \multicolumn{4}{|c|}{ Resumen de los Resultados } & \multirow[b]{3}{*}{ Calidad } & \multirow[b]{3}{*}{ Importancia } \\
\hline & & & & & & & \multicolumn{2}{|c|}{ № de pacientes } & \multicolumn{2}{|c|}{ Magnitud del efecto } & & \\
\hline $\begin{array}{c}\text { № de } \\
\text { estudios }\end{array}$ & Diseño & $\begin{array}{c}\text { Riesgo de } \\
\text { sesgo }\end{array}$ & Inconsistencia & $\begin{array}{l}\text { Evidencia } \\
\text { indirecta }\end{array}$ & Imprecisión & $\begin{array}{c}\text { Otras } \\
\text { consideraciones }\end{array}$ & $\begin{array}{c}\text { Grupo } \\
\text { ejercicios } \\
\text { Hoffman }\end{array}$ & $\begin{array}{l}\text { Grupo sin } \\
\text { ejercicios } \\
\text { Hoffman }\end{array}$ & $\begin{array}{l}\text { Relativa } \\
(95 \% \mathrm{Cl})\end{array}$ & $\begin{array}{l}\text { Absoluta } \\
\text { por } 1000\end{array}$ & & \\
\hline \multicolumn{13}{|c|}{ Mejora en anatomía del pezón } \\
\hline \begin{tabular}{|l|l}
11 &
\end{tabular} & ECA & Seria $^{3}$ & No seria & No seria & Seria ${ }^{4}$ & Ninguna & $\begin{array}{l}26 / 48 \\
(54 \%)\end{array}$ & $\begin{array}{l}28 / 48 \\
(58 \%) \\
\end{array}$ & \begin{tabular}{|c|} 
DM $-4 \%($ de $-24 a$ \\
$16)$
\end{tabular} & - & BAJA & CRITICO \\
\hline \multicolumn{13}{|c|}{ Éxito en la lactancia a los seis meses } \\
\hline $2^{1,2}$ & ECA & Seria $^{3}$ & No seria & No seria & No seria & Ninguna & $\begin{array}{c}126 / 282 \\
(45 \%) \\
\end{array}$ & $\begin{array}{c}120 / 277 \\
(43 \%) \\
\end{array}$ & \multicolumn{2}{|l|}{-} & MODERADA & CRITICO \\
\hline \multicolumn{13}{|c|}{ Fracaso en la lactancia a los seis meses } \\
\hline $2^{1,2}$ & ECA & Seria $^{3}$ & No seria & No seria & No seria & Ninguna & $\begin{array}{c}145 / 282 \\
(51 \%) \\
\end{array}$ & $\begin{array}{c}147 / 277 \\
(53 \%) \\
\end{array}$ & \begin{tabular}{|c|} 
DM $-2 \%($ de $-10 a$ \\
7 )
\end{tabular} & - & MODERADA & CRITICO \\
\hline \multicolumn{13}{|c|}{ Edad gestacional al momento del parto } \\
\hline $1^{2}$ & ECA & Seria $^{3}$ & No seria & No seria & Seria ${ }^{4}$ & Ninguna & $\begin{array}{c}10 / 234 \\
(4 \%) \\
\end{array}$ & $\begin{array}{r}7 / 229 \\
(3 \%) \\
\end{array}$ & DM 1\% (de -2 a 5) & - & BAJA & IMPORTANTE \\
\hline \multicolumn{13}{|c|}{ Sangrado en el pezón } \\
\hline \begin{tabular}{|l|}
$2^{1,2}$ \\
\end{tabular} & & Seria $^{3}$ & No seria & No seria & Seria $^{4}$ & Ninguna & $\begin{array}{r}56 / 282 \\
(20 \%) \\
\end{array}$ & $\begin{array}{c}101 / 277 \\
(36 \%) \\
\end{array}$ & $\begin{array}{c}\mathrm{DM}-16 \% \text { (de }-13 \mathrm{a} \\
-2)\end{array}$ & - & BAJA & CRITICO \\
\hline \multicolumn{13}{|c|}{ Infección del seno con tratamiento antibiótico } \\
\hline \begin{tabular}{|l|}
$2^{1,2}$ \\
\end{tabular} & & Seria $^{3}$ & No seria & No seria & Seria $^{4}$ & Ninguna & $\begin{array}{c}20 / 282 \\
(7 \%)\end{array}$ & $\begin{array}{r}34 / 277 \\
(12 \%) \\
\end{array}$ & \begin{tabular}{|c|} 
DM $-5 \%$ (de $--10 a$ \\
2 )
\end{tabular} & - & BAJA & CRITICO \\
\hline
\end{tabular}


Comparación 3: Eficacia del método de Jeringa vs. bandas de goma en la corrección de pezones invertidos Bibliografía: Jain 2013

\begin{tabular}{|c|c|c|c|c|c|c|c|c|c|c|c|c|}
\hline \multirow{2}{*}{\multicolumn{7}{|c|}{ Evaluación de la calidad }} & \multicolumn{4}{|c|}{ Resumen de los Resultados } & \multirow{3}{*}{ Calidad } & \multirow{3}{*}{ Importancia } \\
\hline & & & & & & & \multicolumn{2}{|c|}{ № de pacientes } & \multicolumn{2}{|c|}{\begin{tabular}{|l|} 
Magnitud del efecto \\
\end{tabular}} & & \\
\hline \begin{tabular}{|c|} 
№ de \\
estudios
\end{tabular} & Diseño & \begin{tabular}{|c|}
$\begin{array}{c}\text { Riesgo de } \\
\text { sesgo }\end{array}$ \\
\end{tabular} & Inconsistencia & \begin{tabular}{|l|}
$\begin{array}{l}\text { Evidencia } \\
\text { indirecta }\end{array}$ \\
\end{tabular} & Imprecisión & \begin{tabular}{|c|} 
Otras \\
consideraciones \\
\end{tabular} & $\begin{array}{l}\text { Grupo } \\
\text { jeringa }\end{array}$ & $\begin{array}{r}\text { Grupo } \\
\text { bandas }\end{array}$ & $\begin{array}{l}\text { Relativa } \\
(95 \% \mathrm{Cl})\end{array}$ & \begin{tabular}{|l|} 
Absoluta \\
por 1000
\end{tabular} & & \\
\hline \multicolumn{13}{|c|}{ Buen agarre al pezón (a los 3,7 y 14 días } \\
\hline \multirow[t]{3}{*}{11} & \multirow[t]{3}{*}{ EO } & \multirow[t]{3}{*}{ No seria } & \multirow[t]{3}{*}{ No seria } & \multirow[t]{3}{*}{ No seria } & \multirow[t]{3}{*}{ Seria ${ }^{2}$} & \multirow[t]{3}{*}{ Ninguna } & \multirow[t]{3}{*}{64} & \multirow[t]{3}{*}{65} & $\begin{array}{c}3 \text { días: OR } 0,64 \text { (IC95\% de } 0.36 \\
\text { a 1.15); } p=0,23\end{array}$ & \multirow{3}{*}{ t } & \multirow[t]{3}{*}{ MUY BAJA } & \multirow[t]{3}{*}{ CRITICO } \\
\hline & & & & & & & & & \begin{tabular}{|c|}
7 días: OR 0,45 (IC95\% de 0.26 \\
a 0.80$) ; p=0,027$ \\
\end{tabular} & & & \\
\hline & & & & & & & & & \begin{tabular}{|c|}
14 días: OR 0,63 (IC95\% de \\
0.35 a 1.16); $\mathrm{p}=0,23$ \\
\end{tabular} & & & \\
\hline
\end{tabular}

${ }^{2}$ Pocos pacientes.

Comparación 4: Eficacia del método de Jeringa vs. Succión marital en la corrección de pezones invertidos Bibliografía: Jain 2013

\begin{tabular}{|c|c|c|c|c|c|c|c|c|c|c|c|c|}
\hline \multirow{2}{*}{\multicolumn{7}{|c|}{ Evaluación de la calidad }} & \multicolumn{4}{|c|}{ Resumen de los Resultados } & \multirow[t]{3}{*}{ Calidad } & \multirow[t]{3}{*}{ Importancia } \\
\hline & & & & & & & \multicolumn{2}{|c|}{ № de pacientes } & \multicolumn{2}{|l|}{\begin{tabular}{|l|} 
Magnitud del efecto \\
\end{tabular}} & & \\
\hline \begin{tabular}{|c|} 
№ de \\
estudios \\
\end{tabular} & Diseño & \begin{tabular}{|c|}
$\begin{array}{c}\text { Riesgo de } \\
\text { sesgo }\end{array}$ \\
\end{tabular} & Inconsistencia & $\begin{array}{l}\text { Evidencia } \\
\text { indirecta }\end{array}$ & Imprecisión & \begin{tabular}{|c|} 
Otras \\
consideraciones
\end{tabular} & $\begin{array}{c}\text { Grupo } \\
\text { jeringa }\end{array}$ & $\begin{array}{l}\text { Grupo } \\
\text { succión }\end{array}$ & $\begin{array}{l}\text { Relativa } \\
(95 \% \mathrm{Cl}) \\
\end{array}$ & $\begin{array}{l}\text { Absoluta } \\
\text { por 1000 }\end{array}$ & & \\
\hline \multicolumn{13}{|c|}{ Buen agarre al pezón jeringa vs succión marital 3-7-14 días } \\
\hline 11 & EO & No seria & No seria & No seria & Seria $^{2}$ & Ninguna & 64 & 69 & $\begin{array}{c}3 \text { días: OR: } 0.45 \text { (IC95\% de } 0.25 \\
\text { a } 0.79) ; p=0.024\end{array}$ & & \multirow[t]{3}{*}{ MUY BAJA } & \multirow[t]{3}{*}{ CRITICO } \\
\hline & & & & & & & & & \begin{tabular}{|c|}
7 días: OR 0,12 (de 0.06 a 0.24$) ;$ \\
$p<0,001$
\end{tabular} & & & \\
\hline & & & & & & & & & $\begin{array}{c}14 \text { días: OR } 0,11 \text { (IC95\% de } 0.04 \\
\text { a.0.28); } p<0,001\end{array}$ & & & \\
\hline
\end{tabular}

${ }^{2}$ Pocos pacientes. 
GPC Lactancia Materna- Pregunta 27. Anatomía del pezón.

Comparación 5: Eficacia del método Bandas de goma vs. succión marital en la corrección de pezones invertidos Bibliografía: Jain 2013

\begin{tabular}{|c|c|c|c|c|c|c|c|c|c|c|c|c|}
\hline \multirow{2}{*}{\multicolumn{7}{|c|}{ Evaluación de la calidad }} & \multicolumn{4}{|c|}{$\begin{array}{c}\text { Resumen de los Resultados } \\
\end{array}$} & \multirow{3}{*}{ Calidad } & \multirow{3}{*}{ Importancia } \\
\hline & & & & & & & \multicolumn{2}{|c|}{ № de pacientes } & \multicolumn{2}{|l|}{ Magnitud del efecto } & & \\
\hline \begin{tabular}{|c|}
$\begin{array}{c}\text { № de } \\
\text { estudios }\end{array}$ \\
esta
\end{tabular} & Diseño & \begin{tabular}{|c|} 
Riesgo de \\
sesgo
\end{tabular} & Inconsistencia & \begin{tabular}{|c|} 
Evidencia \\
indirecta
\end{tabular} & Imprecisión & \begin{tabular}{|c|} 
Otras \\
consideraciones
\end{tabular} & $\begin{array}{l}\text { Grupo } \\
\text { bandas }\end{array}$ & $\begin{array}{l}\text { Grupo } \\
\text { succión }\end{array}$ & $\begin{array}{l}\text { Relativa } \\
(95 \% \mathrm{Cl})\end{array}$ & \begin{tabular}{|l|} 
Absoluta \\
por 1000
\end{tabular} & & \\
\hline \multicolumn{13}{|c|}{ Buen agarre al pezón (a los 3,7 y 14 días) } \\
\hline \multirow[t]{3}{*}{\begin{tabular}{|l|}
1, \\
\end{tabular}} & \multirow[t]{3}{*}{ EO } & \multirow[t]{3}{*}{ No seria } & \multirow[t]{3}{*}{ No seria } & \multirow[t]{3}{*}{ No seria } & \multirow[t]{3}{*}{ Seria $^{2}$} & \multirow[t]{3}{*}{ Ninguna } & \multirow{3}{*}{65} & \multirow{3}{*}{69} & $\begin{array}{c}3 \text { días: OR } 0,69 \text { (IC95\% de } 0.40 \\
\text { a 1.12); } p=0,29\end{array}$ & & \multirow[t]{3}{*}{ MUY BAJA } & \multirow[t]{3}{*}{ CRITICO } \\
\hline & & & & & & & & & $\begin{array}{c}7 \text { días: OR } 0,26 \text { (IC95\% de } 0.12 \\
\text { a } 0.54) ; p=0,002\end{array}$ & 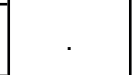 & & \\
\hline & & & & & & & & & $\begin{array}{c}14 \text { días: OR 0,17 (IC95\% de } \\
0.067 \text { a 0.45); p 0,001 }\end{array}$ & & & \\
\hline
\end{tabular}

${ }^{2}$ Pocos pacientes. 


\section{Pregunta 27.2. ¿Qué hacer si hay dificultades en el agarre por pezones planos?}

Comparación 1: conchas vs. control

Bibliografía: Chanprapaph 2013

\begin{tabular}{|c|c|c|c|c|c|c|c|c|c|c|c|c|}
\hline \multirow{2}{*}{\multicolumn{7}{|c|}{ Evaluación de la calidad }} & \multicolumn{4}{|c|}{ Resumen de los Resultados } & \multirow[t]{3}{*}{ Calidad } & \multirow[t]{3}{*}{ Importancia } \\
\hline & & & & & & & \multicolumn{2}{|c|}{ № de pacientes } & \multicolumn{2}{|c|}{ Magnitud del efecto } & & \\
\hline \begin{tabular}{|c|}
$\begin{array}{c}\text { № de } \\
\text { estudios }\end{array}$ \\
\end{tabular} & Diseño & $\begin{array}{c}\text { Riesgo de } \\
\text { sesgo }\end{array}$ & Inconsistencia & \begin{tabular}{|l|} 
Evidencia \\
indirecta
\end{tabular} & Imprecisión & \begin{tabular}{|c|} 
Otras \\
consideraciones
\end{tabular} & $\begin{array}{c}\text { Grupo con } \\
\text { conchas }\end{array}$ & $\begin{array}{c}\text { Grupo sin } \\
\text { conchas }\end{array}$ & $\begin{array}{l}\text { Relativa } \\
(95 \% \mathrm{Cl})\end{array}$ & $\begin{array}{l}\text { Absoluta } \\
\text { por } 1000\end{array}$ & & \\
\hline \multicolumn{13}{|c|}{ Alargamiento del pezón } \\
\hline \begin{tabular}{|l|}
$1^{1}$ \\
\end{tabular} & ECA & No seria & No seria & No seria & Seria $^{2}$ & Ninguna & 43 & 47 & $\begin{array}{c}\text { DM de } 0.53 \text { (de } \\
0.05 \text { a } 1.01)\end{array}$ & & MODERADA & CRITICO \\
\hline \multicolumn{13}{|c|}{ Éxito en la lactancia a los 3 días } \\
\hline \begin{tabular}{|l|}
11 \\
\end{tabular} & ECA & No seria & No seria & No seria & Seria $^{2}$ & Ninguna & $\begin{array}{l}37,5 \% \\
(16 / 43)\end{array}$ & $\begin{array}{c}23 \% \\
(11 / 47)\end{array}$ & \multicolumn{2}{|c|}{$p=0.082$} & MODERADA & CRITICO \\
\hline \multicolumn{13}{|c|}{ Lactancia exclusiva a las 6 y 12 semanas } \\
\hline \multirow[t]{2}{*}{ 11CRITICO } & \multirow[t]{2}{*}{ ECA } & \multirow[t]{2}{*}{ Seria $^{3}$} & \multirow[t]{2}{*}{ No seria } & \multirow[t]{2}{*}{ No seria } & \multirow[t]{2}{*}{ Seria $^{2}$} & \multirow[t]{2}{*}{ Ninguna } & $\begin{array}{c}68 \% \\
(19 / 28)\end{array}$ & $\begin{array}{c}67 \% \\
(20 / 30)\end{array}$ & \multicolumn{2}{|c|}{$\mathrm{p}=0.62$} & \multirow[t]{2}{*}{ BAJA } & CRITICO \\
\hline & & & & & & & $\begin{array}{l}65.4 \% \\
(17 / 26)\end{array}$ & $\begin{array}{c}50 \% \\
(15 / 30)\end{array}$ & $\mathrm{p}=0,35$ & & & CRITICO \\
\hline \multicolumn{13}{|c|}{ Lactancia no exclusiva a las 6 y 12 semanas } \\
\hline \multirow[t]{2}{*}{$1^{1}$} & \multirow[t]{2}{*}{ ECA } & \multirow[t]{2}{*}{ Seria $^{3}$} & \multirow[t]{2}{*}{ No seria } & \multirow[t]{2}{*}{ No seria } & \multirow[t]{2}{*}{ Seria $^{2}$} & \multirow[t]{2}{*}{ Ninguna } & $\begin{array}{l}32.1 \% \\
(9 / 28) \\
\end{array}$ & $\begin{array}{c}30 \% \\
(9 / 30) \\
\end{array}$ & NR & & \multirow[t]{2}{*}{ BAJA } & \multirow[t]{2}{*}{ CRITICO } \\
\hline & & & & & & & $\begin{array}{l}31 \% \\
(8 / 26)\end{array}$ & $\begin{array}{c}37 \% \\
(11 / 30) .\end{array}$ & NR & & & \\
\hline
\end{tabular}

${ }_{2}$ Pocos eventos; ${ }^{3}$ Elevadas pérdidas de seguimiento 


\section{2- Resumen de la Evidencia}

\section{Prequnta 27.1. Pezones invertidos}

Los 2 ECA $(1 ; 2)$, de diseño factorial en dos niveles, utilizan el mismo protocolo para valorar la eficacia de los ejercicios de Hoffman, escudos de pezón o de ambos métodos en mujeres con pezones invertidos o no protráctiles. El estudio prospectivo (3) compara 3 métodos formadores de pezón: la jeringa, las bandas de goma y la succión marital en mujeres con pezones invertidos tipo I y II, una serie de casos evalúa la técnica de la jeringa (4), otra el niplete (6) y la tercera las bandas de goma (6), esta última en mujeres con diferentes anomalías de pezón (incluidos los invertidos).

\section{Ejercicios de Hoffman y uso de escudos de pezón}

Dos ECA $(1 ; 2)$ evalúan ambas intervenciones.

El primer ECA (1) realizado en clínicas prenatales del Reino Unido incluyó mujeres de 25 a 35 semanas de gestación, nulíparas, con al menos un pezón invertido o no-protráctil, con intención de amamantar, sin antecedentes de cirugía del pezón o la areola, y que no hubieran utilizado escudos de pezón ni realizado ejercicios de Hoffman. Las 96 mujeres seleccionadas fueron aleatorizadas en cuatro grupos (24 en cada grupo): G1: ejercicios de Hoffman, G2: escudos de pezón, G3: ejercicios de Hoffman y escudos de pezón y G4: sin ninguna intervención. Se valoró la mejora sostenida o cambio anatómico de los pezones (registrado a ciegas por la matrona antes del primer periodo de lactancia) y el éxito de la lactancia materna a las seis semanas después del parto (mediante un cuestionario enviado por correo). De las 96 mujeres, 27 al menos tenían un pezón invertido $(\mathrm{G} 1=8, \mathrm{G} 2=8, \mathrm{G} 3=7, \mathrm{G} 4=4)$ y 80 al menos un pezón no protráctil $(\mathrm{G} 1=21, \mathrm{G} 2=19, \mathrm{G} 3=19, \mathrm{G} 4=21)$. No hubo diferencias entre los grupos en la edad gestacional y peso al nacer. La tasa de respuesta al cuestionario fue del $100 \%$.

El $62,5 \%(30 / 48)$ de las mujeres con escudos los utilizó todas o la mayoría de las veces, siendo las razones más comunes para no usarlos el dolor o malestar, ser visibles debajo de la ropa, vergüenza, sudoración, erupción cutánea y/o fuga de leche. El 75\% (36/48) de las mujeres asignadas a los ejercicios los hicieron siempre o en la mayoría de las ocasiones, siendo la razón más común de incumplimiento el olvido. Ninguna mujer en el grupo de control utilizo escudos ni realizó ejercicios.

El análisis principal del estudio fue comparar los grupos a los que se les había asignado escudos de pezón $(\mathrm{G} 1+\mathrm{G} 3)$ con los que no los utilizaron $(\mathrm{G} 2+\mathrm{G} 4)$ y los grupos que hacían ejercicios (G2+G3) con aquellos que no lo practicaban $(\mathrm{G} 1+\mathrm{G} 4)$. Se comprobó si había interacción entre los dos tratamientos escudos de pezón y ejercicios. En el cuestionario también se les pregunto si habían experimentado sangrado del pezón, o infección de las mamas que hubiera necesitado tratamiento antibiótico.

El segundo ECA (2) (MAIN) se basa en el protocolo de Alexander (1) anteriormente descrito. Fue realizado en 3 etapas, las dos primeras en 
clínicas prenatales del Reino Unido (de noviembre 1989 a abril 1992) y la tercera en centros hospitalarios canadienses (de agosto 1991 a diciembre 1992). A diferencia del anterior, este estudio también incluye mujeres multíparas y solo valora el éxito de la lactancia materna mediante cuestionario seis semanas después del parto. Las 463 mujeres seleccionadas fueron distribuidas de forma aleatoria en los mismos cuatro grupos del ECA anterior (G1, G2, G3 y G4), haciéndose las mismas comparaciones: mujeres que usan escudos de pezón $(\mathrm{G} 1+\mathrm{G} 3, \mathrm{n}=230)$ con las que no los utilizaban ( $\mathrm{G} 2+\mathrm{G} 4, \mathrm{n}=233$ ), y las que practicaban ejercicios de Hoffman $(G 2+G 3, n=234)$ versus las que no los hacían $(G 1+G 4, n=229)$. Finalmente fueron 442 las mujeres que entraron en el estudio (95\%) (21 no entregaron el cuestionario postnatal: dos porque sus hijos nacieron muertos; cuatro por olvido y 15 se perdieron en el seguimiento).

En este caso, el 51\% de las mujeres (119/234) asignadas a realizar ejercicios los hicieron al menos una o dos veces al día, siendo las razones más comunes para no hacerlos la incomodidad y el tiempo que requerían. $\mathrm{El}$ $61 \%(141 / 230)$ del grupo con escudos los usaron todos los días, o por lo menos dos veces a la semana, siendo las razones más comunes para no utilizarlas la incomodidad, dolor, vergüenza, y/o cambio de la forma o textura de las mamas. El 10\% (11/115) de las mujeres del grupo control habían utilizado escudos de pezón o realizado ejercicios. También se registraron los datos de sangrado en el pezón e infección en las mamas con necesidad de tratamiento antibiótico.

\section{Comparación 1: Utilización de escudos de pezón versus no utilización de escudos de pezón}

\section{Cambio anatómico del pezón}

Solo el ECA (1) de Alexander evalúa este desenlace, sin encontrar diferencias significativas entre los grupos. El 52\% (25/48) de las mujeres de los grupos que utilizaron escudos $(\mathrm{G} 1+\mathrm{G} 3))$ obtuvieron un cambio sostenido de mejora en el pezón frente al $60 \%$ de las que no los utilizaban (G2+G4 [Diferencia del -8\%; IC 95\% de -28 a 11).

\section{Éxito en la lactancia materna a las seis semanas del parto}

Calidad

moderada

Los dos ECA $(1 ; 2)$ evalúan este desenlace, aunque solo uno (1) encontró diferencias significativas a favor de no utilizar escudos En el primer ECA (1), 38 mujeres continuaban amamantando con éxito a las seis semanas después del nacimiento, $14(29 \%, \mathrm{G} 1+\mathrm{G} 3)$ de los grupos con escudos y 24 (50\%, G2+G4) sin escudos, (diferencia del $-21 \%$; IC $95 \%$ de -40 a 2); $p=0,05)$. En el grupo que usaba solo escudos (G1) la tasa de lactancia materna era más baja que en grupo que usaban escudos y realizaban ejercicios ((17\% vs. $42 \%$, respectivamente).

En el segundo ECA (2), a las seis semanas después del nacimiento, el $45 \%$ de las mujeres asignadas a utilizar escudos $(\mathrm{G} 1+\mathrm{G} 3)$ estaban dando el pecho frente al $45 \%$ de las que no los utilizaban (G2+G4) (Diferencia de $0 \%$; IC $95 \%$ de $-9 \%$ a $9 \%$; $p>0,9$ ). 
La combinación de los datos del estudio MAIN2 y del otro ECA (1), señala que en cuanto al fracaso en la lactancia materna a las 6 semanas, la diferencia es del $3 \%$ ( IC 95\% de $-5 \%$ a $12 \%$ ).

\section{Efectos adversos}

No se encuentran diferencias significativas entre grupos en referencia al sangrado del pezón o la presencia de infección de mama que requiera antibióticos.

En cuanto al sangrado del pezón, la combinación de los datos de ambos estudios $(1 ; 2)$ sugiere que la diferencia entre grupos es del $2 \%$ (IC $95 \%$ de $5 \%$ a $10 \%)$.

En cuanto a la infección mamaria, la combinación de los datos de ambos estudios sugieren que no hay diferencias entre grupos (Diferencia del $0 \%$; IC95\% de $-5 \%$ al $5 \%$ ).

\section{Edad gestacional al momento del parto}

Un solo ECA(2) aborda este desenlace, encontrando que los escudos de pezón no afectaban a la edad gestacional de parto.

Comparación 2: Realización de ejercicios de Hoffman vs. no realización de ejercicios de Hoffman

\section{Cambio anatómico del pezón}

Calidad

baja

Solo el ECA (1) de Alexander evalúa este desenlace, sin encontrar diferencias significativas entre los grupos. El 54\% (26/48) de las mujeres que hacían ejercicios (G2+G3) obtuvieron un buen agarre al pezón frente al 58\% $(28 / 48)$ de las que no los hacían (G1+G4) (Diferencia de $-4 \%$; IC 95\% de $24 \%$ a $16 \%)$.

\section{Éxito en la lactancia materna a las seis semanas del parto}

Ninguno de los dos ECA $(1 ; 2)$ evalúan este desenlace. En el primer ECA el mismo porcentaje $(40 \%)$ de mujeres continuaba la lactancia a las seis semanas en ambos grupos (Diferencia de 0\%; IC95\% de-20 a 20).

En el segundo ECA(2), el $46 \%$ de las madres del grupo que hacía los ejercicios estaban dando el pecho a las 6 semanas versus el $44 \%$ de las que no los hacían (Diferencia del 2\%; IC95\% de -7\% a 11\%; $p=0,7$ ).

\section{Fracaso en la lactancia a las seis semanas}

Los datos combinados de ambos ECA $(1 ; 2)$ de las mujeres que no amamantaban a las seis semanas (por abandono o porque nunca lo habían hecho) reportan que realizar ejercicios de Hoffman no mejora la posibilidad de que una mujer continúe amamantando a las seis semanas después del parto, siendo la diferencia de un -2\% (IC95\% de -10\% a 7\%).
Calidad moderada

\section{Calidad} moderada 


\section{Efectos adversos}

El estudio MAIN (2) combina sus datos y los de Alexander (1),y sugiere que las mujeres que hacían ejercicios de Hoffman reportaron menos sangrado baja del pezón postnatal e infección de las mamas en comparación con las que no practicaban dichos ejercicios. Los propios autores aducen un posible hallazgo casual debido al pequeño número de eventos y a los resultados no significativos del ECA de Alexander en la infección de senos.

En cuanto al sangrado postnatal del pezón, la diferencia entre grupos era de $-16 \%$ (IC95\% de $-13 \%$ a $-2 \%)$.

En cuanto a la infección de las mamas, la diferencia combinada entre grupos fue de-5\% (IC95\% de -10\% a 2\%).

\section{Edad gestacional al momento del parto}

Un solo ECA (2) aborda este desenlace, encontrando que los ejercicios de Hoffman no afectaban la edad gestacional en el momento del parto (dar a luz antes de la semana 37 , diferencia del $1 \%$ entre grupos (IC95\% de $-2 \%$ a $5 \%)$.

\section{Uso de jeringas, bandas de goma y succión marital}

Un estudio observacional (3) compara las tres intervenciones para corregir pezones invertidos. Una serie de casos evalúa la técnica de la jeringa (4), y otra las bandas de goma (6), esta ultima en mujeres con diferentes anomalías de pezón (incluidos los invertidos).

El estudio prospectivo (3) incluye 213 mujeres que dieron a luz en un hospital de la India de marzo a agosto de 2011 (204 primerizas y 9 en su segundo embarazo), con pezones invertidos de grado I y II. Las pacientes fueron divididas en tres grupos de forma aleatoria (71 en cada grupo): GA, que utiliza una jeringa como aparato de succión; GB con bandas de goma; y GC, con frecuentes y vigorosas succiones por parte del marido (succión del pezón hasta que sobresale, al menos por un momento). La distribución de los grados I y II de retracción del pezón en los 3 grupos fue: del $60.5 \%$ y $39.5 \%$ en el grupo GA; $53,5 \%$ y $46,5 \%$ en el grupo GB y del $56 \%$ y $44 \%$ en el grupo GC, respectivamente.

Las pacientes fueron evaluadas a los 3, 7 y 14 días por profesionales cegados al grupo de tratamiento que observaban el buen agarre al pezón. Hubo quince $(7 \%)$ pérdidas durante el seguimiento (siete en el GA, seis en el GB y dos en el GC). Quedando un total de 198 mujeres para el análisis final También se registraron el dolor en el pezón, la privacidad y la dificultad con la técnica. Como segunda parte del estudio, las 69 participantes del GC fueron interrogados por sus sentimientos acerca de la aceptabilidad y la vulgaridad del método de succión marital.

La serie de casos más reciente (6) realizada en la India incluyó a 19 madres que asisten después del parto a atención ambulatoria pediátrica con problemas en la lactancia y en la anatomía de sus pezones. A ninguna madre se le aconsejó durante el embarazo o después del parto el uso de escudos de pezón o ejercicios prenatales. Las madres fueron divididos en 
tres grupos según la anatomía del pezón: G1 con pezones invertidos $(n=8)$, G2 con pezones planos, $(n=7)$ y G3 otras anormalidades anatómicas $(n=4)$ (pezones grandes, ubicación atípica, forma de coliflor o deformidad de la mama posterior a quemadura). Las madres fueron instruidas a utilizar bandas de goma durante cada toma hasta que los recién nacidos lograran un buen agarre al pezón. El proceso consiste en poner una banda de goma alrededor de la base del pezón, para que sea prominente, de modo que el recién nacido pueda mamar. La banda se puede aplicar con la mano, pero es más conveniente usar una jeringa como aplicador). A cada madre se le proporcionó una jeringa y una banda elástica de látex. Dieciocho de los recién nacidos eran alimentados de forma exclusiva con biberón en el momento del estudio (95\%), a excepción de uno que era alimentado con leche materna extraída (5\%). La edad de los lactantes oscilo entre los ocho y más de 29 días de vida. Se realizaron seguimientos a los tres, siete, y 28 días y se recogió información sobre la práctica de alimentación, cualquier complicación (dolor, deslizamiento de banda, etc.), y si la madre utilizaba el método de la banda de goma o ya lo había abandonado.

Kesaree (4) evalúa por primera vez un simple método con una jeringa de 10 $\mathrm{ml}$ para revertir pezones invertidos, en ocho madres que fueron visitadas en el departamento de pediatría. El método consiste en sacar el émbolo de la jeringa y cortar el extremo de la misma tratando de que quede suave al tacto. Luego se coloca el émbolo y la madre coloca su pezón en el otro extremo de la jeringa y mantiene la presión del embolo hacia afuera durante 20 segundos a un minuto sin tener que sentir dolor ni molestia. Las ocho madres habían sido incapaces de amamantar antes del estudio y alimentaban a sus hijos con biberón, todos los lactantes habían estado ingresados por septicemia bronconeumonia o deshidratación.

\section{Comparación 3: Jeringa vs banda de goma}

EI EO (3) compara la jeringa y las bandas de goma y encuentra diferencias significativas a los siete días a favor de las bandas de goma.

\section{Buen agarre al pezón}

Al los tres días, el $32,8 \%$ de las madres del grupo con jeringa obtuvo un buen agarre al pezón frente al $(43,1 \%)$ del grupo con bandas, siendo a los siete días, del $46.9 \%$ y $66.1 \%$, respectivamente, y a los catorce del $64.1 \%$ y $73,8 \%$, respectivamente. Al comparar ambas técnicas hubo diferencias significativas al séptimo día (OR: 0,45; IC 95\% de 0.26 a $0.80 ; p=0,027$ )y no significativas a los 3 [OR: 0,64 ; IC $95 \%$ de 0.36 a $1.15 ; p=0,23$ ] y a los 14 días (OR: 0,63; IC 95\% de 0.35 a 1.16 ; $p=0,23$ ) a favor de las bandas.

\section{Problemas encontrados.}

El $38 \%$ de las madres del grupo con bandas de goma y el $22 \%$ del grupo con jeringa encontraron dificultad en la aplicación de la técnica. El 30\% del grupo con bandas y el $48 \%$ con jeringa presentaron dolor en el pezón.

En cuanto a problemas de privacidad, estos fueron reportados por el $31 \%$ del grupo con bandas frente al $0 \%$ del grupo con jeringa. 


\section{Comparación 4: Jeringa vs succión marital}

El estudio prospectivo (3) presenta datos favorables a la succión marital comparada con la jeringa en los tres seguimientos.

\section{Buen agarre al pezón}

Al tercer día, 21 de las mujeres del grupo con jeringa $(32,8 \%)$ lograron un buen agarre frente a 36 (52,2\%) del grupo con succión marital (OR 0,45; IC95\% de 0,25 a 0,79). Al séptimo día fueron 30 (46.9\%) frente a 61 (88.4 $\%$ ) (OR 0,12; IC95\% de 0,06 a 0,24), y al día catorce 41 (64.1\%) frente a 65 $(94.2 \%)($ OR 0,$11 ;$ IC95\% de 0,04 a 0,28$)$, respectivamente

\section{Problemas encontrados.}

El $22 \%$ de las madres en el grupo con jeringa encontró dificultad en la aplicación de la técnica y el $48 \%$ dolor en el pezón, mientras que ninguna de las mujeres del grupo de succión marital presentó estos problemas. El 100\% de las madres del grupo con succión marital tenía un problema de intimidad (requiere una habitación separada) y ninguna del grupo con jeringa. En el cuestionario realizado al grupo de succión marital, la aceptabilidad sociocultural era una preocupación para todos los participantes, siendo 55 $(79,7 \%)$ los que sentían que era culturalmente aceptable y no vulgar. De los 14 restantes, nueve $(13,1 \%)$ opinaron que era vulgar pero sin emitir opinión sobre la aceptabilidad social, y cinco $(7,2 \%)$ que era socialmente inaceptable.

\section{Jeringa}

Siete de las ocho madres del estudio (4) revirtieron sus pezones con la utilización de la jeringa, logrando amamantar a sus recién nacidos con éxito (dos a los dos días, dos a los tres días, y las otras tres a los cuatro, cinco, y siete días). Las madres y sus recién nacidos fueron seguidas durante seis meses y a medida que pasaba el tiempo disminuía la cantidad de suplemento administrado (50\% menos a las dos o tres semanas en seis de los recién nacidos). Una madre fue incapaz de revertir sus pezones con este procedimiento, puesto que presentaba una reversión severa. La lactancia exclusiva se logro en seis lactantes entre las cuatro y seis semanas. No se reportaron efectos adversos.

\section{Calidad muy baja}




\section{Problemas encontrados.}

El $38 \%$ de las madres del grupo con bandas de goma encontraron dificultades con la aplicación de la técnica, siendo un $30 \%$ el que presentó dolor en el pezón, frente a ninguna de las madres del grupo de succión marital. El 100\% de madres del grupo con succión marital tenían problemas de privacidad, siendo la aceptabilidad sociocultural una gran preocupación para ellas.

\section{Bandas de goma}

Una serie de casos (6) evalúa esta intervención en mujeres con diferentes anomalías de pezón (incluidos los pezones invertidos) valorando el buen agarre al pezón y la lactancia exclusiva.

A los 3 días de utilizar las bandas, el $40 \%$ de las madres con pezones invertidos lograron un buen agarre sin ellas, a los 7 días el $75 \%$ y a los 28 días las ocho madres lograron amamantar sin bandas de goma. Los datos de lactancia exclusiva no discriminan por tipo de pezón. No se produjo ningún caso de dolor, irritación local, o deslizamiento de la banda de goma.

\section{Buen agarre en el pezón}

A los 3 días, doce bebes (63\%) lograron un buen agarre (ocho sin el uso de bandas de goma (tres con pezones invertidos $\mathrm{G} 1$, cinco con pezones planos G2)) y cuatro con ellas (uno G1, dos G2 y uno en el grupo con otras malformaciones G3). Los siete restantes no lograron un buen agarre, ni siquiera utilizando las bandas de goma. A los 7 días las siete madres del G2 y seis del G1 lograron un buen agarre, suspendiendo el uso de bandas de goma. En el G3, una lo logró sin banda y dos con banda. En total, el $74 \%$ de las madres lograron con éxito un buen agarre sin utilizar las bandas. A los 28 días, todas las madres lograron amamantar sin bandas de goma.

\section{Lactancia exclusiva y no exclusiva}

A los 3 días, 18 recién nacidos (95\%) se alimentan al pecho y con fórmula y uno con leche materna extraída. A los 7 días, 14 (74\%) se alimentaba al pecho y con formula, cuatro $(21 \%)$ con sólo al pecho y uno con leche materna extraída (5\%). A los 28 días, seis (32\%) se alimentaban al pecho y con fórmula y $13(68 \%)$ sólo al pecho. No se presentan datos por tipo de pezón para este desenlace.

\section{Calidad muy baja}

\section{Uso de Niplete}

En una serie de 22 casos (5) (14 embarazadas) se evaluó la eficacia del Niplette como dispositivo de corrección no quirúrgica para pezones invertidos. El Niplette consiste en un dedal de plástico que se coloca en el pezón, se conecta a una jeringa de $2 \mathrm{~cm}$ y se hace el vacío, el pezón queda succionado dentro del dedal y se retira la jeringa.

Dieciséis mujeres fueron consideradas para el tratamiento quirúrgico (divisiones de conducto) de pezones invertidos. Dos de ellas ya habían

\section{Calidad muy baja}


fracasado en cirugías anteriores, y otras seis fueron remitidas de clínicas prenatales por inversión del pezón y deseo de amamantar. Se les realizaron controles mensuales y llamadas telefónicas para confirmar el mantenimiento de sus correcciones.

Todas las pacientes lo encontraron fácil de usar, siendo $18(81,8 \%)$ las que fueron capaces de utilizarlo correctamente en la primera cita de seguimiento. El tiempo en lograr un buen agarre y dejar el niplete dependió del grado de deformidad del pezón y de la frecuencia de uso. Finalmente 20 pacientes lo lograron (una se perdió en el seguimiento); dos al primer mes, cuatro a los 2 meses, trece a los 3 meses y la última lo continuo utilizando de forma intermitente. Dos pacientes tuvieron un ligero sangrado de sus pezones, lo que fue considerado una simple molestia.

\section{Prequnta 27.2. Pezones planos}

El ECA (6) identificado compara la utilización de conchas vs. no intervención para la corrección de pezones cortos. La serie de casos (7) evalúa el método de bandas de goma en mujeres con diferentes anomalías de pezón (incluidos los pezones planos) y la encuesta (8) trata sobre el uso de pezoneras.

EI ECA (6) fue realizado en un hospital en Tailandia donde se reclutaron 96 mujeres embarazadas nulíparas con pezones cortos $(<7,0 \mathrm{~mm})$, unilateral 0 bilateral, que asistieron a la atención prenatal entre julio de 2009 y julio de 2010, de 16 a 20 semanas de gestación y sin historia previa de lactancia materna ni de utilización de correctores de pezón. Fueron excluidas las pacientes con fecha incierta de embarazo, con pezones invertidos, cirugía anterior de mama o pezón y/o parto prematuro. Finalmente se incluyeron 90 mujeres (seis pérdidas: tres abortos y tres seguimientos incompletos), asignadas al azar al grupo intervención ( $\mathrm{Gl}: \mathrm{n}=43$ ) con conchas durante al menos 8 horas diarias o 56 horas por semana y al grupo control sin ninguna intervención (GC: $n=47$ ). Un evaluador cegado al grupo de tratamiento, registró la longitud y ancho de los pezones antes y después de la intervención. Para demostrar la mejoría clínica, la longitud del pezón se clasificó en tres grupos: muy corto $(<4,0 \mathrm{~mm})$, corto $(4,0$ a $6,9 \mathrm{~mm})$, y normal $(>/=7 \mathrm{~mm})$. Se midió la tasa de éxito de lactancia temprana mediante la puntuación LATCH al tercer día después del parto. Mediante un cuestionario telefónico a las 6 y 12 semanas se registro el tipo de alimentación infantil (lactancia materna exclusiva, alimentación mixta, o con fórmula), así como los efectos secundarios y la satisfacción del tratamiento por medio de un formulario de auto-evaluación.

La serie de casos realizada en la India incluyó a 19 madres que asisten después del parto a atención ambulatoria pediátrica con problemas en la lactancia y anatomías en sus pezones. A ninguna madre se le aconsejó durante el embarazo o después del parto el uso de escudos de pezón o ejercicios prenatales. Las madres fueron divididas en tres grupos: $\mathrm{G} 1$ con pezones invertidos $(n=8), G 2$ con pezones planos $(n=7)$ y $G 3$ con otras anormalidades anatómicas $(n=4)$ (mamas grandes con ubicación atípica del pezón, pezones en forma de coliflor, o deformidad de la mama posterior a quemadura). Las madres fueron instruidas a utilizar bandas de goma durante cada alimentación hasta que los lactantes obtuvieran un buen agarre. El 
proceso consiste en poner una banda de goma alrededor de la base del pezón, para que sea prominente y el recién nacido pueda amamantar. La banda se puede aplicar con la mano, aunque es más conveniente usar una jeringa como aplicador.

A cada madre se le proporcionó una jeringa y una banda elástica de látex. En el momento de enrolamiento en el estudio, dieciocho de los niños estaban siendo alimentados de forma exclusiva mediante biberón (95\%), con excepción, de uno que era alimentado con leche materna extraída (5\%). La edad de los recién nacidos oscilo entre 8 y más de 29 días. A los 3, 7 y 28 días se recogió información sobre la práctica de alimentación, cualquier complicación (dolor, deslizamiento de banda, etc.) y si la madre utilizaba el método de la banda de goma o ya lo había abandonado

Por último, en EEUU se realizó una encuesta (8) telefónica informal en 202 madres para determinar si las mujeres con pezones planos o invertidos utilizaban los escudos como ayuda al problema anatómico o simplemente como protectores de pezón.

\section{Comparación 1: Conchas vs no intervención}

En el ECA identificado que evalúa dicha comparación, el 95,3\% de las usuarias de la Conchas toleraron muy bien su uso, a pesar de la aparición de erupciones en la piel $(22,2 \%)$ y contracción uterina leve $(48,1 \%)$ en algunos casos.

\section{Alargamiento del pezón}

En el grupo de la intervención, el alargamiento fue 0,53 mm mayor (Diferencia de GI vs GC de $0.53 \mathrm{~mm}$ (SD \pm 0.24 ); IC 95\% de 0.05 a 1.01; $p=0,032$ ). También se observó un ensanchamiento del pezón en ambos grupos, siendo la diferencia no significativa en este caso. El Gl obtuvo mejores resultados en convertir pezones muy cortos y cortos en pezones normales en comparación con el grupo control (Gl vs. GC: $49 \%$ vs. $32 \%$ ), aunque la diferencia no es significativa (datos de $p$ no presentados).

\section{Éxito de la lactancia temprana}

El número de pacientes con una puntuación $\mathrm{LATCH} \geq 7$ al tercer día fue mayor en el Gl que en el GC (37,5\% vs. $23 \%$; $p=0,182)$.

\section{Lactancia exclusiva y no exclusiva a las 6 y 12 semanas}

\section{Calidad \\ Baja}

El porcentaje de lactancia materna exclusiva en el grupo intervención a las seis semanas fue del $68 \%$ vs el $67 \%$ en el GC ( $p=0.62)$. A las 12 semanas este era del $65.4 \%$ y $50 \%$, respectivamente $(p=0,35)$. La lactancia materna no exclusiva a sexta semana fue del $32.1 \%$ vs. $30 \%$ y a las 12 semanas del $31 \%$ y $37 \%$, respectivamente (datos de p no reportados).

Cabe destacar que el estudio tuvo una elevada pérdida de seguimiento tanto en el grupo de intervención como en el grupo control (a las seis semanas, pérdidas del $35 \%$ y el $40 \%$, respectivamente; a las 12 semanas, pérdidas de del $36 \%$ en ambos grupos). 


\section{Comparación 2: Bandas de goma}

Una serie de casos (7) evalúa esta intervención en mujeres con diferentes anomalías de pezón (incluidos los planos) valorando el buen agarre al pezón y la lactancia exclusiva.

En la serie de casos identificada, a los 3 días de seguimiento, el 71\% (5/7) de las madres con pezones planos lograron un buen agarre sin el uso de bandas de goma (el $100 \%$ a los 7 días). Los datos de lactancia exclusiva no discriminan por tipo de pezón. No se produjo ningún caso de dolor, irritación local, o deslizamiento de la banda de goma.

\section{Buen agarre en el pezón}

\section{Calidad}

A los tres días, doce recién nacidos (63\%) lograron un buen agarre (ocho sin el uso de bandas de goma (tres con pezones invertidos y cinco con pezones planos) y cuatro con ellas (uno con pezones invertidos, dos con pezones planos uno con otras anomalías). Los siete restantes no lograron un buen agarre, ni siquiera utilizando las bandas de goma. A los 7 días las siete madres con pezones planos y seis con pezones invertidos lograron un buen agarre al pecho y suspendieron el uso de bandas de goma, siendo en total un $74 \%$ (14/19) las madres las que lograban un buen agarre con éxito sin utilizar las bandas. A los $\mathbf{2 8}$ días las 19 madres lograban amamantar sin bandas de goma.

\section{Lactancia exclusiva y no exclusiva}

A los 3 días el 95\% de los niños se alimentan al al pecho y con fórmula, y uno muy baja con leche materna extraída. A los 7 días el $74 \%$ se alimenta al pecho y con fórmula, el $21 \%$ únicamente al pecho y el $5 \%$ con leche materna extraída. A las 28 días el $32 \%$ se alimentan al pecho y con formula y dl $68 \%$ sólo al pecho. No se presentan datos por tipo de pezón de este desenlace.

\section{Comparación 3: Nipple shields (8)}

La principal razón por la que las mujeres utilizaban las pezoneras fue la presencia de pezones cortos o planos (62\%). Otras razones fueron chupar desorganizado (43\%), dolor en los pezones (23\%), regurgitación (15\%), prematuridad (12\%), frenillo corto (1\%) y otras razones (1\%). El $46 \%$ de las mujeres señalaron más de una razón para usarlas.

El $67 \%$ de las mujeres que recibieron información sobre escudos de pezón optaron por usarlos. Al $51 \%$ los escudos les ayudaron a tener éxito con la lactancia, y para el $49 \%$ restante su uso era incómodo, especialmente a los 3 o 4 días cuando presentaban fugas de leche. 


\section{Pregunta 27.3. Pezones grandes}

El caso (11) reporta la dificultad con la lactancia de una madre con pezones grandes y su experiencia con la ayuda recibida por parte de las matronas.

El niño nació sano, por parto normal y a pesar de la buena predisposición de su madre, los tres primeros días se alimentó de manera intermitente. Se utilizaron diferentes técnicas para solucionar el problema de lactancia. En primer lugar se animó al niño a abrir la boca lo suficiente como para permitir entrar al pezón, para lo cual la madre debía de tirar con firmeza hacia abajo la barbilla del bebé para activar el reflejo y ofrecerle la mama rápidamente. Esta maniobra debe de ser delicada, de lo contrario el bebé puede resistirse provocando más daño y angustia, que fue lo que sucedió en este caso. También se tentó al lactante colocando sobre el pezón leche materna, lo que puede provocar decepción en el niño, puesto que si logra agarrarse espera una recompensa inmediata. Otras intervenciones fueron el contacto piel con piel, ofrecer el pecho cuando el lactante tenía sueño o en medio de un baño suave, pero ninguna funcionó. Se le ofrecieron sin éxito opciones de alimentación alternativa con pezoneras, cuchara y taza. Finalmente la madre decidió recurrir al biberón, utilizando el mayor tamaño disponible de tetina, y un extractor de leche eléctrico.

Una evaluación de los senos y los pezones debe identificar fácilmente las mujeres con factores de riesgo anatómicos, dando así una mejor oportunidad de éxito con la lactancia materna. El pezón grande presenta problemas de lactancia materna en pocas ocasiones, generalmente cuando el recién nacido es inmaduro o de pequeño tamaño. En estos casos es esencial una intervención inmediata con el apoyo de la matrona.

\section{ACTUALIZADO A FECHA DE: 31 de Octubre de 2016}




\section{5- De la evidencia a la recomendación (Tabla de EtR)}

\section{Pregunta 27.1. ¿Qué hacer si hay dificultades en el agarre por pezones invertidos retráctiles (pseudoinvertidos)?}

\section{Población:}

Intervención:

Comparación:

Perspectiva:

C1: Utilización de escudos de pezón versus no utilización de escudos de pezón; C2: Realización de ejercicios de Hoffman vs. no realización de ejercicios de Hoffman; C3: Jeringa vs banda de goma; C4: Jeringa vs succión marital; C5: banda de goma vs succión marital: C6: Uso de Niplette

\begin{tabular}{|c|c|c|c|c|}
\hline & CRITERIO & JUICIO & EVIDENCIA & $\begin{array}{l}\text { CONSIDERACIONES } \\
\text { ADICIONALES }\end{array}$ \\
\hline 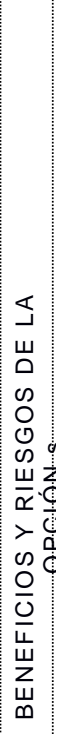 & $\begin{array}{l}\frac{\text { ¿Cuál es la }}{\text { confianza }} \\
\frac{\text { global en la }}{\text { evidencia }} \\
\frac{\text { disponible }}{\text { sobre los }} \\
\frac{\text { efectos? }}{}\end{array}$ & $\begin{array}{ll}\text { C1 } & \text { Baja } \\
\text { C2 } & \text { Baja } \\
\text { C3 } & \text { Muy baja } \\
\text { C4 } & \text { Muy baja } \\
\text { C5 } & \text { Muy baja } \\
\text { C6 } & \text { Muy baja }\end{array}$ & $\begin{array}{l}\text { Comparaciones } 1 \text { y 2: Tanto la utilización de escudos de pezón } \\
\text { como la realización de ejercicios de Hoffman no mejoran la } \\
\text { lactancia materna a las } 6 \text { semanas. } \\
\text { Comparación } 3 \text { : El uso de bandas de goma mejora el agarre a } \\
\text { los } 7 \text { y } 14 \text { días frente al uso de jeringa, pero no se sabe si } \\
\text { mejora o no el éxito de la lactancia materna. } \\
\text { Comparación } 4 \text { y } 5 \text { : la succión marital es mejor que el uso de } \\
\text { jeringas o bandas de goma para mejorar el agarre al pezón, } \\
\text { sobre todo a los } 7 \text { y } 14 \text { días, pero no se sabe su efecto sobre el } \\
\text { éxito de la lactancia materna. } \\
\text { Comparación } 6 \text { : no se trata de una comparación en sí, sino de } \\
\text { los datos de una serie de casos, en la que el tiempo en lograr } \\
\text { un buen agarre con el uso del niplette y dejar de utilizarlo } \\
\text { dependió del grado de deformidad del pezón y de la frecuencia } \\
\text { de uso. De } 22 \text { pacientes, } 20 \text { lo lograron: dos al primer mes, } \\
\text { cuatro a los } 2 \text { meses, trece a los } 3 \text { meses y la última lo continuo } \\
\text { utilizando de forma intermitente. }\end{array}$ & \\
\hline
\end{tabular}


GPC Lactancia Materna- Pregunta 27. Anatomía del pezón.

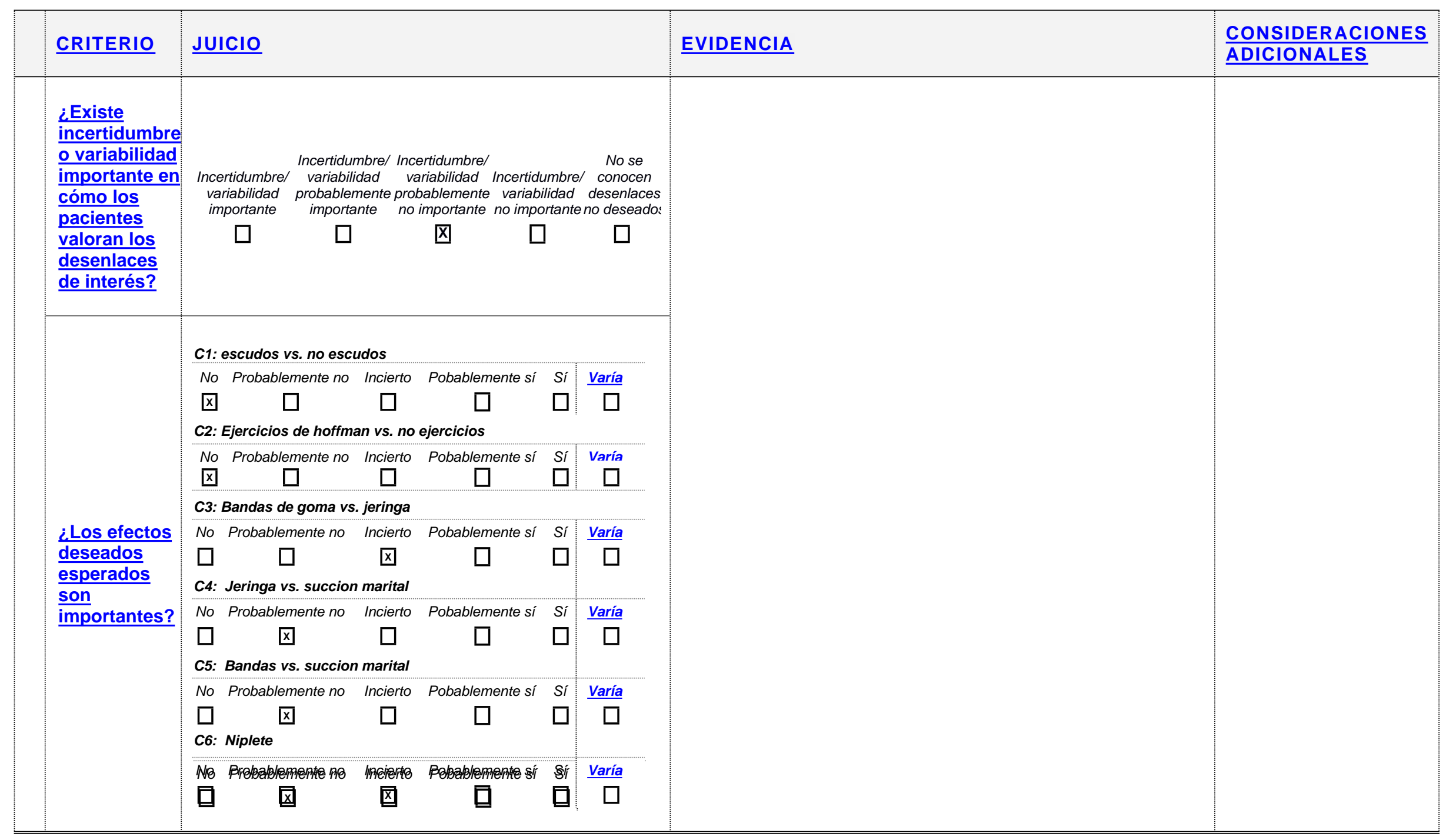


GPC Lactancia Materna- Pregunta 27. Anatomía del pezón.

\begin{tabular}{|c|c|c|c|c|c|c|}
\hline CRITERIO & $\underline{\text { JUICIO }}$ & & & & EVIDENCIA & $\begin{array}{l}\text { CONSIDERACIONES } \\
\text { ADICIONALES }\end{array}$ \\
\hline \multirow{8}{*}{$\begin{array}{l}\frac{\text { ¿Los }}{\text { efectos no }} \\
\frac{\text { deseados }}{\text { esperados }} \\
\text { son } \\
\text { pequeños? }\end{array}$} & \multicolumn{4}{|c|}{ C1: escudos vs. no escudos } & & \\
\hline & $\begin{array}{c}\text { No Probablemente no } \\
\square \quad \square \\
\text { C2: Eiercicios de hoffm }\end{array}$ & $\begin{array}{l}\text { Incierto } \\
\square \\
\text { an vs. no }\end{array}$ & $\begin{array}{cc}\text { Pobablemente sí } & \text { Sí } \\
\text { 邓 } & \square \\
\text { ejercicios } & \end{array}$ & $\frac{\text { Varía }}{\square}$ & & \\
\hline & $\begin{array}{l}\text { No } \text { Probablemente no } \\
\square \quad \square\end{array}$ & $\begin{array}{c}\text { Incierto } \\
\square\end{array}$ & $\begin{array}{cc}\text { Pobablemente sí } & \text { Sí } \\
\bigotimes & \square\end{array}$ & $\begin{array}{c}\text { Varía } \\
\square\end{array}$ & & \\
\hline & \multicolumn{4}{|c|}{ C3: Bandas de goma vs. jeringa } & & \\
\hline & $\begin{array}{l}\text { No Probablemente no } \\
\square \square \\
\text { c4: Jeringa vs. succion }\end{array}$ & $\begin{array}{l}\text { Incierto } \\
\square \\
\text { marital }\end{array}$ & $\begin{array}{cc}\text { Pobablemente sí } & \text { Sí } \\
\square & \square\end{array}$ & $\frac{\text { Varía }}{\square}$ & & \\
\hline & $\begin{array}{l}\text { No Probablemente no } \\
\square \quad \square \\
\text { C5: Bandas vs. succion }\end{array}$ & $\begin{array}{l}\text { Incierto } \\
\square \\
\text { marital }\end{array}$ & $\begin{array}{cc}\text { Pobablemente si } & \text { Sí } \\
\square & \square\end{array}$ & $\frac{\text { Varia }}{\square}$ & & \\
\hline & $\begin{array}{l}\text { No Probablemente no } \\
\square \square \square \\
\text { C6: Niplete }\end{array}$ & $\begin{array}{c}\text { Incierto } \\
\square\end{array}$ & $\begin{array}{cc}\text { Pobablemente si } & \text { Sí } \\
\square & \square\end{array}$ & $\frac{\text { Varía }}{\square}$ & & \\
\hline & 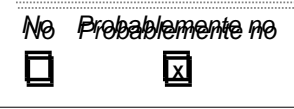 & $\begin{array}{l}\text { Mnacientre } \\
\text { 区 }\end{array}$ & 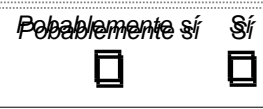 & $\frac{\text { Varía }}{\square}$ & & \\
\hline \multirow{5}{*}{$\begin{array}{l}\text { ¿El balance } \\
\text { entre los } \\
\text { efectos } \\
\frac{\text { deseados y }}{\text { no }} \\
\text { deseados } \\
\text { favorece la } \\
\text { opción? }\end{array}$} & \multicolumn{4}{|c|}{ C1: escudos vs. no escudos } & & \\
\hline & \begin{tabular}{l} 
No Probablemente no \\
$\square \quad$ \} $\\
{\text { C2: Ejercicios de hoffm }}$ & $\begin{array}{l}\text { Incierto } \\
\square \\
\text { an vs. no }\end{array}$ & $\begin{array}{cc}\text { Pobablemente si } & \text { Si } \\
\square & \square \\
\text { ejercicios } & \end{array}$ & $\frac{\text { Varía }}{\square}$ & & \\
\hline & $\begin{array}{l}\text { No } \\
\square \text { Probablemente no } \\
\square \quad \text { ख }\end{array}$ & $\begin{array}{c}\text { Incierto } \\
\square\end{array}$ & $\begin{array}{cc}\text { Pobablemente sí } & \text { Sí } \\
\square & \square\end{array}$ & $\begin{array}{c}\text { Varía } \\
\square\end{array}$ & & \\
\hline & \multicolumn{4}{|c|}{ C3: Bandas de goma vs. jeringa } & & \\
\hline & $\begin{array}{l}\text { No Probablemente no } \\
\square \quad \square\end{array}$ & $\begin{array}{l}\text { Incierto } \\
\square\end{array}$ & $\begin{array}{cc}\text { Pobablemente sí } & \text { Sí } \\
\square & \square\end{array}$ & $\frac{\text { Varía }}{\square}$ & & \\
\hline
\end{tabular}
\end{tabular}


GPC Lactancia Materna- Pregunta 27. Anatomía del pezón.

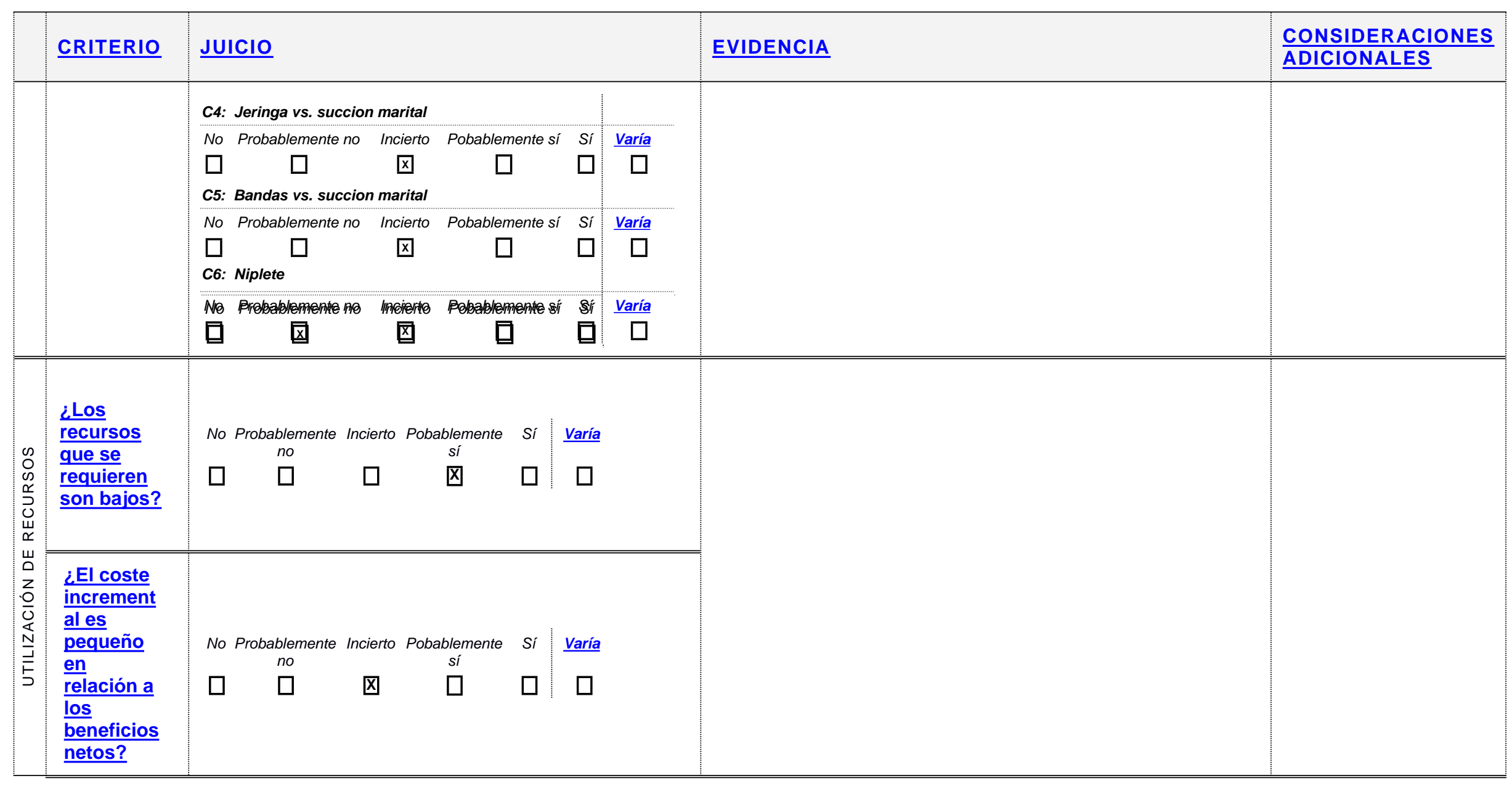




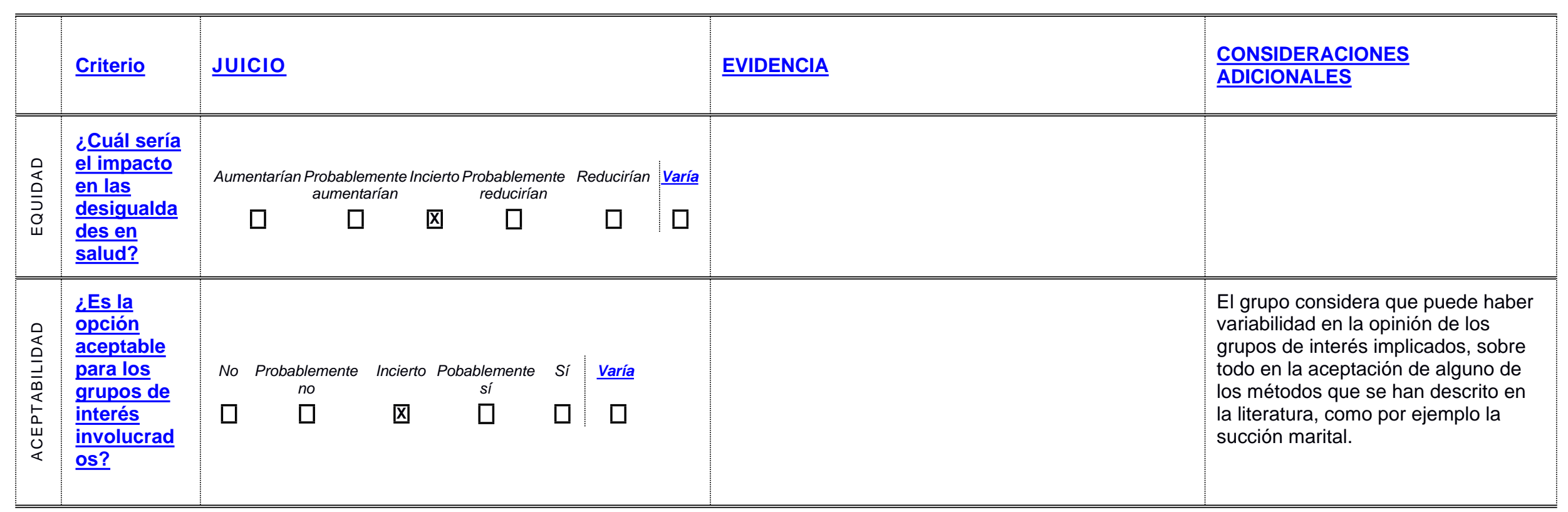




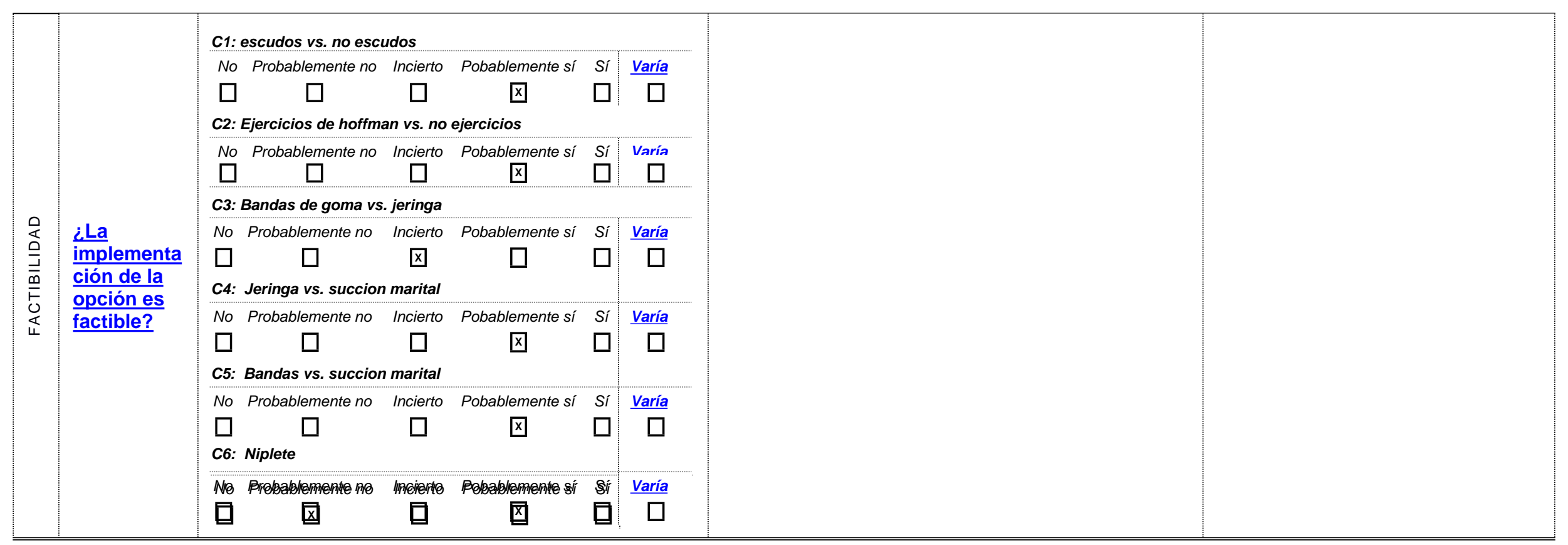




\begin{tabular}{|c|c|c|c|c|c|}
\hline $\begin{array}{l}\text { Balance de las } \\
\underline{\text { consecuencias }}\end{array}$ & $\begin{array}{l}\text { Las consecuencias no } \\
\text { deseadas superan } \\
\text { claramente las } \\
\text { consecuencias deseadas } \\
\text { en la mayoría de los } \\
\text { escenarios }\end{array}$ & $\begin{array}{l}\text { Las consecuencias no } \\
\text { deseadas probablemente } \\
\text { superan las } \\
\text { consecuencias deseadas } \\
\text { en la mayoría de los } \\
\text { escenarios }\end{array}$ & $\begin{array}{c}\text { El balance entre las } \\
\text { consecuencias deseadas y } \\
\text { no deseadas está muy } \\
\text { equilibrado o es incierto }\end{array}$ & $\begin{array}{c}\text { Las consecuencias } \\
\text { deseadas } \\
\text { probablemente superan } \\
\text { las consecuencias no } \\
\text { deseadas en la mayoría } \\
\text { de los escenarios }\end{array}$ & $\begin{array}{l}\text { Las consecuencias } \\
\text { deseadas claramente } \\
\text { superan las } \\
\text { consecuencias no } \\
\text { deseadas en la mayoría } \\
\text { de los escenarios }\end{array}$ \\
\hline C1 & $\square$ & 囚 & $\square$ & $\square$ & $\square$ \\
\hline C2 & $\square$ & 凶 & $\square$ & $\square$ & $\square$ \\
\hline C3 & $\square$ & $\square$ & 凶 & $\square$ & $\square$ \\
\hline C4 & $\square$ & $\square$ & 凶 & $\square$ & $\square$ \\
\hline C5 & $\square$ & $\square$ & 凶 & $\square$ & $\square$ \\
\hline C6 & $\square$ & $\square$ & 凶 & $\square$ & $\square$ \\
\hline $\begin{array}{l}\text { Tipo de } \\
\text { recomendación }\end{array}$ & \multicolumn{2}{|c|}{ Se recomienda no ofrecer la opción } & o ofrecer la opción & Se sugiere ofrecer la opción & $\begin{array}{l}\text { Se recomienda ofrecer } \\
\text { la opción }\end{array}$ \\
\hline C1 & \multicolumn{2}{|l|}{ 囚 } & $\square$ & $\square$ & $\square$ \\
\hline C2 & \multicolumn{2}{|l|}{ 冈 } & $\square$ & $\square$ & $\square$ \\
\hline C3 & \multicolumn{2}{|l|}{$\square$} & $\square$ & $\square$ & $\square$ \\
\hline C4 & \multicolumn{2}{|l|}{$\square$} & $\square$ & $\square$ & $\square$ \\
\hline C5 & \multicolumn{2}{|l|}{$\square$} & $\square$ & $\square$ & $\square$ \\
\hline C6 & \multicolumn{2}{|l|}{$\square$} & $\square$ & $\square$ & $\square$ \\
\hline
\end{tabular}




\section{Recomendación}

$\underline{\text { (Texto) }}$

\section{Recomendación fuerte en contra}

No se recomienda la realización de ejercicios de Hoffman ni el uso de escudos de pezón prenatales para favorecer el éxito de la lactancia materna en mujeres que presentan pezones invertidos.

\section{Recomendación débil a favor}

Se sugiere extraer el pezón invertido mediante el uso de una jeringa. El método consiste en cortar el extremo donde está el conector a la aguja, sacar el émbolo de la jeringa e introducirlo por el extremo cortado. Posteriormente la madre coloca su pezón en el extremo libre de la jeringa y traccionando del embolo, mantiene la presión hacia afuera durante 20 segundos a un minuto evitando provocar dolor intenso.

\section{Recomendación de buena práctica}

Tanto en el caso de pezones invertidos como planos, se puede prestar apoyo para favorecer el agarre al pecho, el contacto piel con piel y la utilización de la postura de afianzamiento espontáneo.

Asimismo, también se puede estimular el pezón rotándolo un poco, mojándolo con agua fría justo antes de mamar o aspirando con un extractor de leche o una jeringa.

Si tras estas medidas no se consigue un buen agarre, se puede probar con la utilización de pezoneras.

$\underline{\text { Justificación }}$

De todos los métodos que se han evaluado, en nuestro contexto las bandas de goma y la succión por parte de la pareja no son métodos conocidos. Por ello, no se mencionan en la recomendación. Lo que sí se utiliza en la práctica clínica son las pezoneras, porque aunque no se han identificado estudios que comparen su uso frente a no utilizarlas o frente al uso de la jeringa o el niplette, los expertos comunican buenos resultados. Por ello, se ha añadido una recomendación de buena práctica al respecto.

Por otro lado, sabiendo que los pezones invertidos protruyen como reflejo al contacto o al frío, se puede tratar de estimular el pezón rotándolo un poco o mojándolo con un poco de agua fría justo antes de mamar el recién nacido o también se puede probar con un extractor de leche.

En cuanto al dispositivo comercializado como Niplette (un dedal de plástico que se coloca en el pezón y se conecta a una jeringa de 2 $\mathrm{cm}$ con la que se hace el vacío, hasta que el pezón queda succionado dentro del dedal, momento en el que se retira la jeringa), los fabricantes sugieren su uso en mujeres embarazadas. 
Consideraciones de

subgrupos

Consideraciones para Creación de consultas de lactancia atendidas por profesionales especializados en lactancia materna.

la implementación

\section{Monitorización y}

evaluación

Prioridades para la

investigación

- Se necesitan más estudios de calidad que comparen la eficacia de la utilización de jeringas, niplettes y pezoneras de silicona y para facilitar el éxito de la lactancia materna. 


\section{Pregunta 27.2. ¿Qué hacer si hay dificultades en el agarre por pezones planos?}

Población:

Intervención:

Comparación

Perspectiva:

C1: Cup breast vs. no hacer nada; C2: Bandas de goma; C3: Nipple shields;

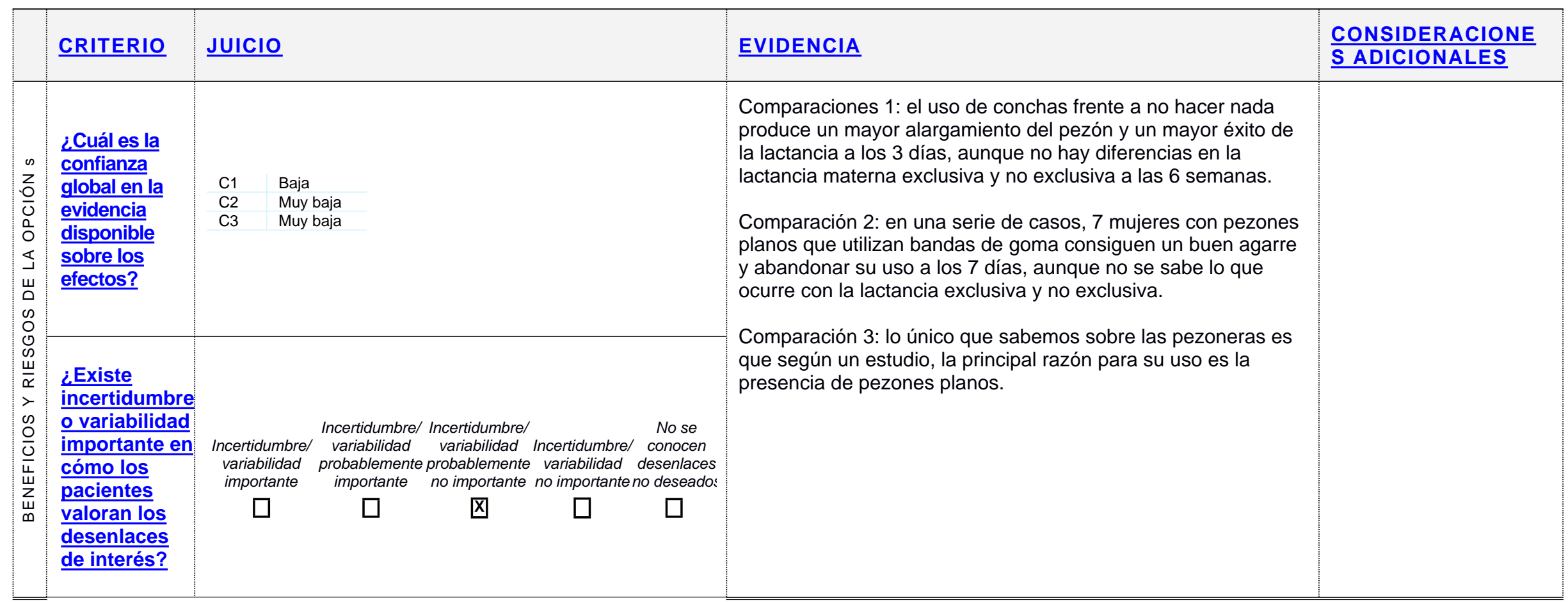


GPC Lactancia Materna- Pregunta 27. Anatomía del pezón.

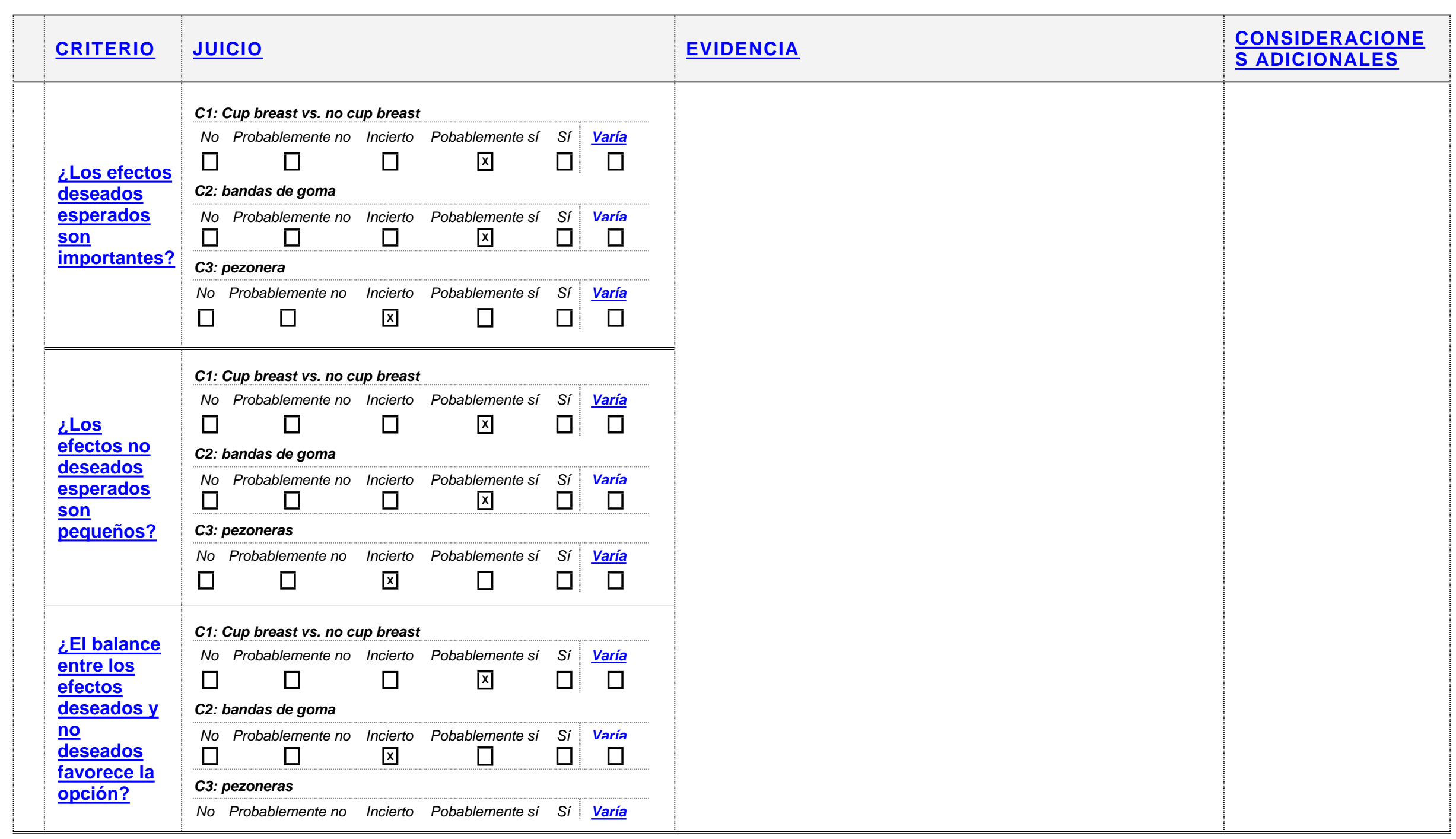


GPC Lactancia Materna- Pregunta 27. Anatomía del pezón.

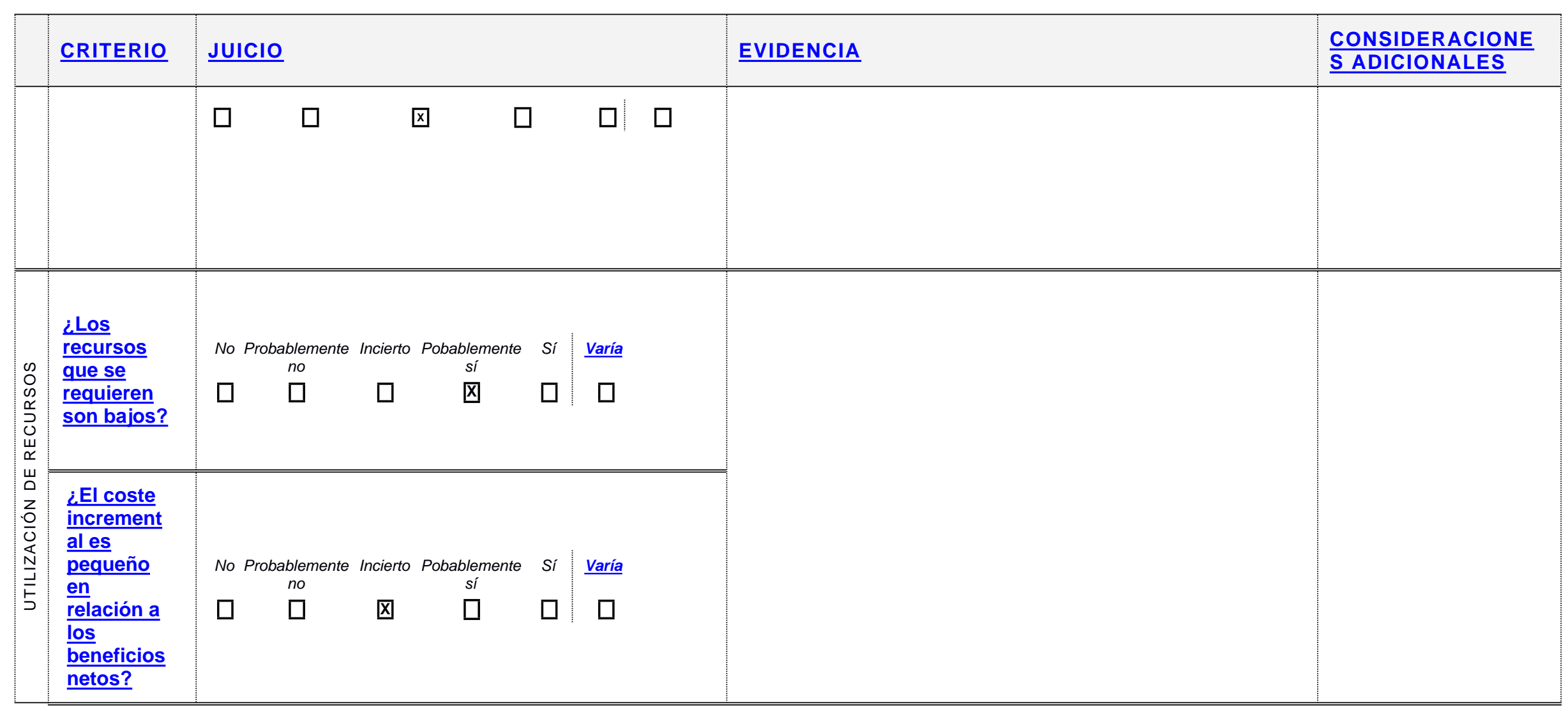




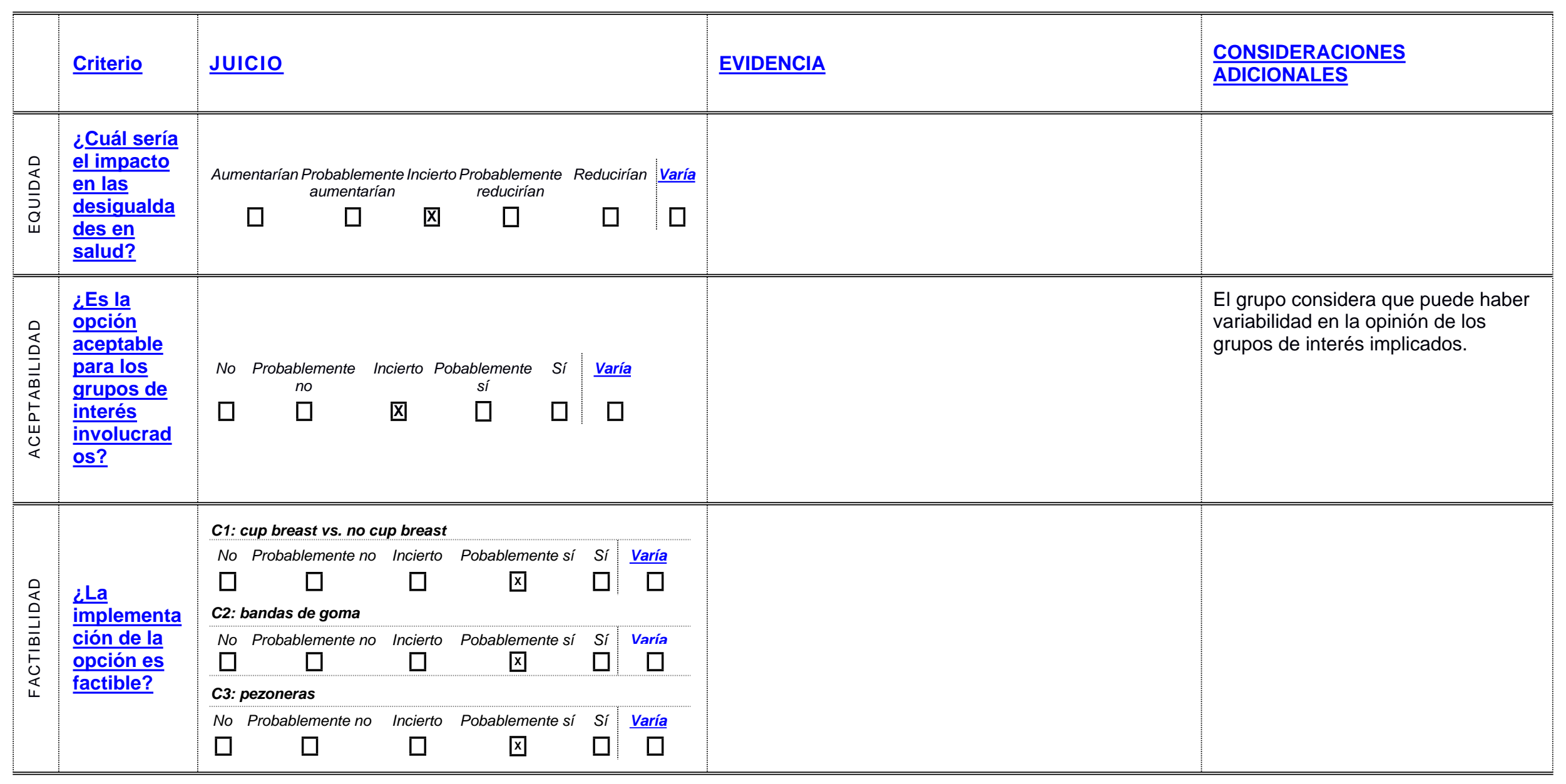




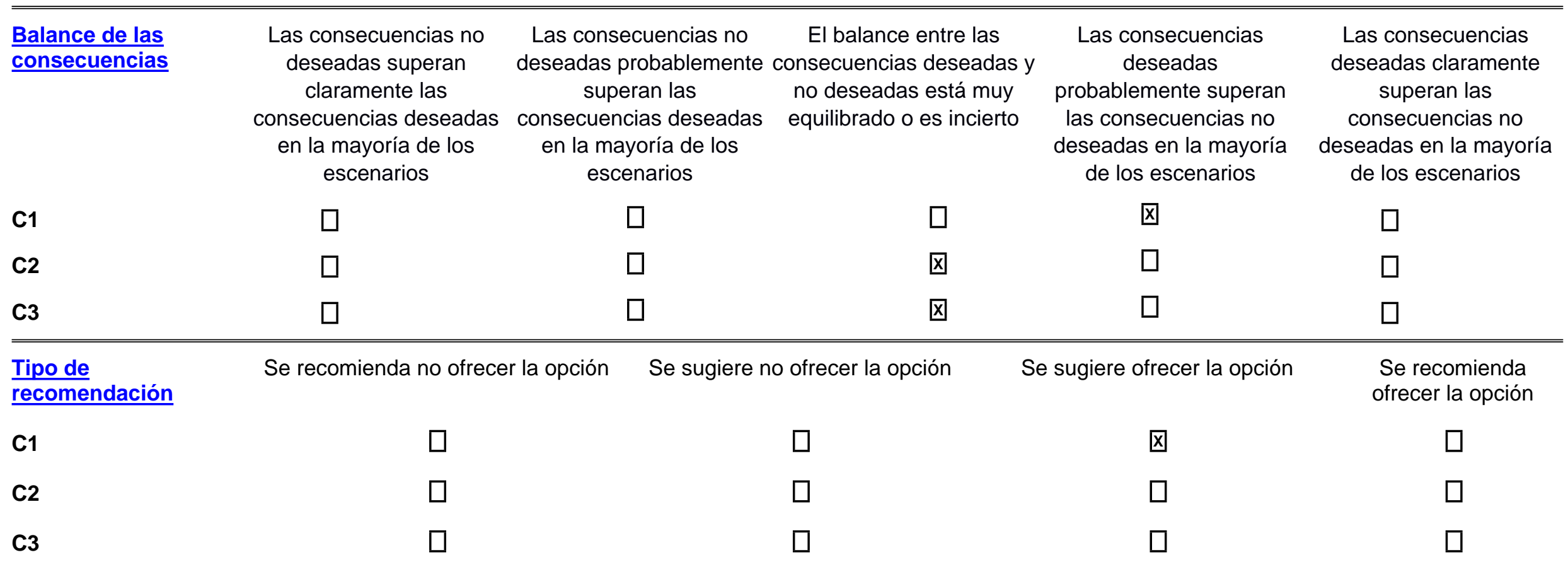




\section{Recomendación}

$\underline{\text { Recomento }}$

\section{Recomendación débil a favor}

Se sugiere la utilización de conchas de lactancia como intervención prenatal que podría aumentar la longitud de los pezones cortos en aquellas mujeres embarazadas que los presenten, aunque son necesarios estudios adicionales para demostrar su impacto en el éxito de la lactancia materna.

\section{Recomendación de buena práctica}

Tanto en el caso de pezones invertidos como planos, se puede prestar apoyo para favorecer el agarre al pecho, el contacto piel con piel y la utilización de la postura de afianzamiento espontáneo.

Asimismo, también se puede estimular el pezón rotándolo un poco, mojándolo con agua fría justo antes de mamar o aspirando con un extractor de leche o una jeringa.

Si tras estas medidas no se consigue un buen agarre, se puede probar con la utilización de pezoneras.

\section{Justificación}

El único estudio que evalúa el uso de conchas de lactancia como intervención en pezones planos o cortos, aunque comunica un efecto al aumentar la longitud de los pezones, no encuentra efecto sobre la lactancia materna exclusiva a las 6 o 12 semanas. Sin embargo, no parece tener efectos adversos y las mujeres del estudio indicaron que fueron fáciles de utilizar, por lo que se realiza una recomendación débil a favor aunque se necesitan estudios que demuestren su impacto en el éxito de la lactancia materna.

Aunque es cierto que el recién nacido necesita tiempo para aprender a engancharse bien al pezón de sus madres, en la práctica clínica hay posturas que facilitan ese aprendizaje, por lo que se hace una recomendación de buena práctica al respecto.

\section{Consideraciones de subgrupos}

Consideraciones para Creación de consultas de lactancia atendidas por profesionales especializados en lactancia materna. la implementación

\section{Monitorización y}

\section{evaluación}


Prioridades para la

investigación
- Se necesitan más estudios de calidad que comparen la eficacia de la utilización de las conchas de lactancia y del uso de ciertas posturas de amamantamiento en el éxito de la lactancia materna en casos de madres con pezones planos. 


\section{Pregunta 27.3. ¿Qué hacer si hay dificultades en el agarre por pezones grandes?}

\section{Recomendación \\ (Texto)}

\section{Recomendación de buena práctica}

En madres con pezones grandes, los profesionales expertos en lactancia materna pueden ayudar a intentar encontrar alguna postura que facilite el agarre. Si no puede conseguirse el amamantamiento, pueden utilizarse pezoneras del tamaño adecuado. En último caso se recomienda la extracción de la leche manualmente o con extractor de leche hasta que la cavidad oral del recién nacido adquiera el tamaño suficiente para poder mamar. La leche extraída se administrará mediante el método de suplementación más apropiado. Se asegurará a la madre que en unos días el crecimiento del bebé resolverá la situación.

\section{Justificación}

En la práctica clínica, ante la falta de estudios al respecto, se realiza sólo una recomendación de buena práctica, basada en la experiencia clínica.

\section{Consideraciones de}

subgrupos

Consideraciones para Creación de consultas de lactancia atendidas por profesionales especializados en lactancia materna.

la implementación

\section{Monitorización y}

evaluación

\section{Prioridades para la} investigación
- Se necesitan estudios de calidad que comparen la eficacia de la utilización de distintas estrategias sobre el éxito de la lactancia materna en casos de madres con pezones grandes. 


\section{ANEXO I, ESTRATEGIAS DE BÚSQUEDA}

\section{Cochrane Library}

Searched 10/07/2015

Updated search 10/07/2015 a xx/xx/xxxx

\#1 inverted or retracted or retractile or non-protractile or nonprotractile or invaginated or flat or large or oversized:ti,ab,kw and nipple or nipples:ti,ab,kw (Word variations have been searched) 39

\#2 lactation or lactational or lactating:ti,ab,kw or breastfeeding or "breast feeding":ti,ab,kw (Word variations have been searched) 9646

\#3

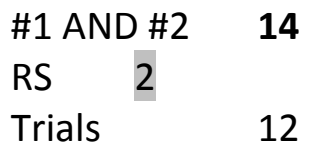

MEDLINE, via Pubmed

Searched 10/07/2015

Updated search 10/07/2015 a xx/xx/xxxx

\#1 Search ((inverted[Title/Abstract] OR retracted[Title/Abstract] OR retractile[Title/Abstract] OR non-protractile[Title/Abstract] OR nonprotractile[Title/Abstract] OR invaginated[Title/Abstract] OR flat[Title/Abstract] OR large[Title/Abstract] OR oversized[Title/Abstract])) AND (nipple[Title/Abstract] OR nipples[Title/Abstract]) 845

\#2 ((lactation[Title/Abstract] OR lactational[Title/Abstract] OR lactating[Title/Abstract])) OR (breastfeeding[Title/Abstract] OR "breast feeding"[Title/Abstract]) 63448

\#3 \#1 AND \#2 92

\#4 Search ((review[Title/Abstract] OR reviews[Title/Abstract])) OR (metaanalysis[Title/Abstract] OR meta-analysis[Title/Abstract] OR "meta analysis"[Title/Abstract]) 1153912

\#5 \#3 AND \#4 7

\#6 \#3 Filters: Systematic Reviews; Meta-Analysis 3

\#7 \#5 OR \#6 7

\section{EMBASE, via Ovid}

Searched 10/07/2015

Updated search 10/07/2015 a xx/xx/xxxx

\#1 (inverted or retracted or retractile or non-protractile or nonprotractile or invaginated or flat or large or oversized).ti,ab,kw. 1388687

\#2 (nipple or nipples).ti,ab,kw. 10911

\#3 \#1 AND \#2 1199

\#4 (lactation or lactational or lactating or breastfeeding or "breast

feeding").ti,ab,kw. 75633

\#5 \#3 AND \#4 112 


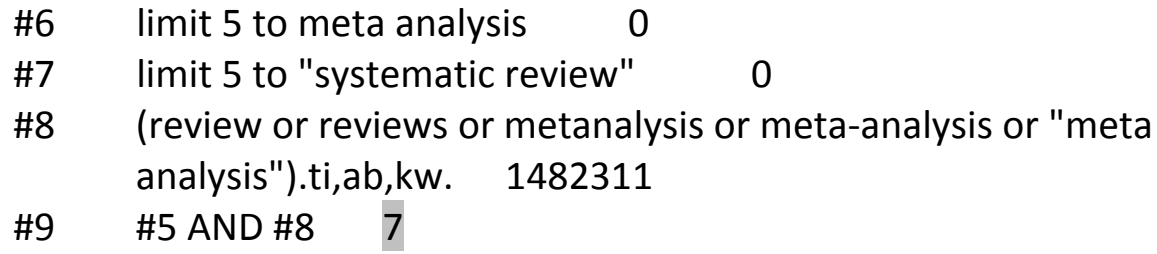

\section{CINAHL, via EBSCOhost databases}

\section{Searched 10/07/2015}

\section{Updated search 10/07/2015 a xx/xx/xxxx}

S1 (inverted or retracted or retractile or non-protractile or nonprotractile or invaginated or flat or large or oversized ) AND ( nipple OR nipples ) 55

S2 (lactation OR lactational OR lactating ) OR ( breastfeeding OR "breast feeding" ) 16417

S3 S1 AND S2 33

S4 S3 Limitadores - Tipo de publicación: Meta Analysis, Systematic Review

2

S5 ( review OR reviews ) OR ( metaanalysis OR meta-analysis OR "meta analysis" ) 36911

S6 S3 AND S5 2

S7 S4 OR S6 $\quad 2$ 


\section{ANEXO II, Tabla de estudios individuales para la pregunta}

\section{Pregunta sobre pezones invertidos}

\begin{tabular}{|c|c|c|c|c|c|c|}
\hline $\begin{array}{l}\text { Referencia } \\
\text { (Cita } \\
\text { Abreviada) }\end{array}$ & $\begin{array}{l}\text { Estudio (Diseño y } \\
\text { objetivo) }\end{array}$ & $\begin{array}{l}\text { Población } \\
\text { (no y características) }\end{array}$ & $\begin{array}{l}\text { Descripción de las intervenciones } \\
\text { comparaciones, exposiciones o pruebas } \\
\text { a estudio }\end{array}$ & $\begin{array}{l}\text { Resultados } \\
\text { (Estimadores de resultados-Magnitud } \\
\text { del efecto) }\end{array}$ & \begin{tabular}{|l} 
Conclusiones \\
(conclusiones)
\end{tabular} & $\begin{array}{l}\text { Comentarios } \\
\text { Calidad de la } \\
\text { evidencia } \\
\text { Financiación } \\
\text { comentarios) }\end{array}$ \\
\hline $\begin{array}{l}\text { Alexander } \\
1992\end{array}$ & $\begin{array}{l}\text { ECA diseño factorial } \\
\text { Objetivo: } \\
\text { determinar el valor } \\
\text { de recomendar } \\
\text { escudos de pezón o } \\
\text { ejercicios de } \\
\text { Hoffman, o ambas } \\
\text { cosas, a las mujeres } \\
\text { embarazadas con } \\
\text { pezones invertidos o } \\
\text { no protráctiles con } \\
\text { intenciones es .de } \\
\text { amamantar. }\end{array}$ & $\begin{array}{l}\text { País: UK } \\
\text { Periodo de reclutamiento: } \\
\text { clínicas prenatales durante } \\
23 \text { meses (1987 a 1989), } \\
\\
\text { Criterios de inclusión: } \\
\text { Al menos un pezón invertida } \\
\text { o no-protractil, } \\
\text { Nulíparas, } \\
\text { Embarazo único, } \\
\text { Con la intención de dar el } \\
\text { pecho, } \\
\text { Que no vaya a ofrecer el } \\
\text { bebé para su adopción, } \\
\text { Sin antecedentes de cirugía } \\
\text { que afecte al pezón o la } \\
\text { areola, } \\
\text { No estar utilizando escudos } \\
\text { de pezón o ejercicios, } \\
\text { Entre } 25 \text { y } 35 \text { semanas } \\
\text { completas de embarazo. }\end{array}$ & $\begin{array}{l}\text { Intervención: } \\
\text { Escudos de pezón son discos planos con } \\
\text { una cúpula semiesférica que se colocan } \\
\text { sobre el pezón bajo un sostén firme, de } \\
\text { manera que se presiona el pezón en la } \\
\text { cúpula de "estirar y aflojar gradualmente su } \\
\text { apego a las estructuras profundas de la } \\
\text { mama } \\
\text { Ejercicios de Hoffman colocar os dedos } \\
\text { pulgar e índices cerca del pezón invertido, a } \\
\text { continuación, pulsar en el tejido mamario } \\
\text { con bastante firmeza y empujando poco a } \\
\text { poco los dedos lejos de la areola" 'en el } \\
\text { plano horizontal y después cinco veces en el } \\
\text { plano vertical. } \\
\text { Grupos aleatorizados ( } n=96 ; 24 \text { c/u) } \\
\text { G1: Ejercicios de Hoffman } \\
\text { G2: Escudos de pezón } \\
\text { G3: Ejercicios de Hoffman + Escudos de } \\
\text { pezón } \\
\text { G4: Control sin ninguna intervención. } \\
\text { Grupos comparados: } \\
\text { Grupos con escudos (G1+G3) vs. Grupos } \\
\text { sin escudos (G2+G4) } \\
\text { Grupos que hacían ejercicios (G2+G3) vs, } \\
\text { grupos que no lo practicaban (G1+G4). } \\
\text { Variables de resultado: } \\
\text { Cambio anatómico del pezón (registrado a } \\
\text { ciegas por la matrona antes del primer }\end{array}$ & 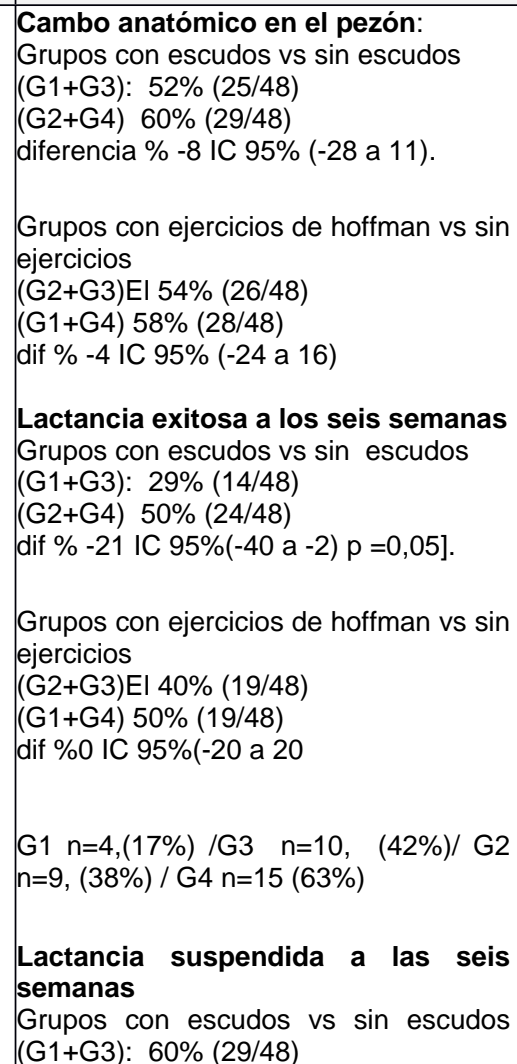 & $\begin{array}{l}\text { La principal limitación de } \\
\text { este estudio es el tamaño } \\
\text { de la muestra En espera } \\
\text { de un estudio multicentrico } \\
\text { no podemos recomendar el } \\
\text { uso de escudos el balance } \\
\text { de la evidencia actual es } \\
\text { que hacen más daño que } \\
\text { bien. El valor de los } \\
\text { ejercicios de Hoffman es } \\
\text { una pregunta que queda } \\
\text { bierta, y aunque nuestro } \\
\text { ensayo no mostró } \\
\text { diferencia entre los grupos } \\
\text { con ejercicios y sin } \\
\text { ejercicios, no podemos } \\
\text { descartar un efecto } \\
\text { cínicamente útil. }\end{array}$ & $\begin{array}{l}\text { Financiación: } \\
\text { Royal College of } \\
\text { Midwives } \\
\text { Department of } \\
\text { Health and } \\
\text { Birthright. } \\
\text { Conflicto de } \\
\text { intereses NR }\end{array}$ \\
\hline
\end{tabular}




\begin{tabular}{|c|c|c|c|c|c|c|}
\hline $\begin{array}{l}\text { Referencia } \\
\text { (Cita } \\
\text { Abreviada) }\end{array}$ & $\begin{array}{l}\text { Estudio (Diseño y } \\
\text { objetivo) }\end{array}$ & $\begin{array}{l}\text { Población } \\
\text { (no y características) }\end{array}$ & $\begin{array}{l}\text { Descripción de las intervenciones } \\
\text { comparaciones, exposiciones o pruebas } \\
\text { a estudio }\end{array}$ & $\begin{array}{l}\text { Resultados } \\
\text { (Estimadores de resultados-Magnitud } \\
\text { del efecto) }\end{array}$ & $\begin{array}{l}\text { Conclusiones } \\
\text { (conclusiones) }\end{array}$ & $\begin{array}{l}\text { Comentarios } \\
\text { Calidad de la } \\
\text { evidencia } \\
\text { Financiación } \\
\text { comentarios) }\end{array}$ \\
\hline & & & $\begin{array}{l}\text { periodo de lactancia), } \\
\text { Éxito en la lactancia materna a los seis } \\
\text { semanas (por medio de un cuestionario } \\
\text { enviado por correo a las madres) } \\
\text { De las } 96 \text { mujeres } 27 \text { mujeres al menos un } \\
\text { pezón invertido (G1=8, G2=8, G3=7, G4=4) } \\
\text { y } 80 \text { al menos un pezón no protráctiles } \\
\text { (G1=21, G2=19, G3=19, G4=21). } \\
\text { No hubo diferencias entre los grupos en } \\
\text { edad gestacional y peso al nacer. Se obtuvo } \\
\text { una tasa de respuesta del } 100 \% \text { del } \\
\text { cuestionario enviado por código postal para } \\
\text { ser completado seis semanas después del } \\
\text { parto. } \\
62,5 \% \text { (30/48) mujeres asignadas con } \\
\text { escudos informó utilizarlas todos o la } \\
\text { mayoría de las veces. Los razones más } \\
\text { comunes para no usarlas eran dolor o } \\
\text { malestar; conchas visibles debajo de la ropa; } \\
\text { la vergüenza; sudoración, erupción cutánea, } \\
\text { eczema, o dolor; y las fugas de leche. } \\
\text { 75\% (36/48) mujeres asignadas a ejercicios } \\
\text { informaron que los hicieron en todos o la } \\
\text { mayoría de las ocasiones; la más razón } \\
\text { común por incumplimiento fue el olvido. } \\
\text { Ninguna mujeres en el grupo de control } \\
\text { utilizo escudos o ejercicios. } \\
\end{array}$ & $\begin{array}{l}\text { (G2+G4) } 48 \% \text { (23/48) } \\
\text { Grupos con ejercicios de hoffman vs } \\
\text { sin ejercicios } \\
\text { (G2+G3)El } 56 \%(27 / 48) \\
\text { (G1+G4) } 52 \%(25 / 48) \\
\text { Nunca amamantaron } \\
\text { Grupos con escudos vs sin escudos } \\
\text { (G1+G3): } 10 \%(5 / 48) \\
\text { (G2+G4) } 2 \%(1 / 48) \\
\text { Grupos con ejercicios de hoffman vs sin } \\
\text { ejercicio } \\
\text { (G2+G3)El } 4 \%(2 / 48) \\
\text { (G1+G4) } 8 \%(4 / 48) \\
\text { Efectos adversos (sangrado del } \\
\text { pezón) } \\
\text { Grupos con escudos vs sin escudos } \\
\text { (G1+G3): } 29 \%(14 / 48) \\
\text { (G2+G4) } 25 \%(12 / 48) \\
\text { dif4\%,IC95\% (-14\% a } 2 \%) \\
\text { Grupos con ejercicios de hoffman vs sin } \\
\text { ejercicio } \\
\text { (G2+G3) } 23 \%(11 / 48) \\
\text { (G1+G4) } 31 \%(15 / 48) \\
\text { dif -8\%, IC } 95 \%(-26 \% \text { a -9\%) } \\
\text { Efectos adversos (infección de seno } \\
\text { con antibióticos) } \\
\text { Grupos con escudos vs sin escudos } \\
\text { (G1+G3): } 12 \%(6 / 48) \\
\text { (G2+G4) } 6 \%(3 / 48) \\
\text { dif } 6 \%, \text { IC } 95 \%(-5 \% \text { a } 18 \%) \\
\text { Grupos con ejercicios de hoffman vs sin } \\
\text { ejercicio } \\
\text { (G2+G3) } 12 \%(6 / 48) \\
\text { (G1+G4) } 6 \%(3 / 48)\end{array}$ & & \\
\hline
\end{tabular}




\begin{tabular}{|c|c|c|c|c|c|c|}
\hline $\begin{array}{l}\text { Referencia } \\
\text { (Cita } \\
\text { Abreviada) }\end{array}$ & $\begin{array}{l}\text { Estudio (Diseño y } \\
\text { objetivo) }\end{array}$ & $\begin{array}{l}\text { Población } \\
\text { (no y características) }\end{array}$ & $\begin{array}{l}\text { Descripción de las intervenciones } \\
\text { comparaciones, exposiciones o pruebas } \\
\text { a estudio }\end{array}$ & $\begin{array}{l}\text { Resultados } \\
\text { (Estimadores de resultados-Magnitud } \\
\text { del efecto) }\end{array}$ & \begin{tabular}{|l} 
Conclusiones \\
(conclusiones)
\end{tabular} & $\begin{array}{l}\text { Comentarios } \\
\text { Calidad de la } \\
\text { evidencia } \\
\text { Financiación } \\
\text { comentarios) } \\
\end{array}$ \\
\hline & & & & $\begin{array}{l}\text { dif } 6 \%, \text { IC } 95 \% \text { (-5\% a } 18 \% \\
\text { No se encontró ninguna evidencia de } \\
\text { que los ejercicios de Hoffman influyan } \\
\text { sobre la edad gestacional al momento } \\
\text { del parto promedio en semanas (G1 } \\
\text { 40; G2 40; G3 39,5; G4 40) }\end{array}$ & & \\
\hline MAIN 1994 & $\begin{array}{l}\text { ECA diseño factorial } \\
\text { Objetivo: } \\
\text { determinar el valor } \\
\text { de recomendar } \\
\text { escudos de pezón o } \\
\text { ejercicios de } \\
\text { Hoffman, o ambas } \\
\text { cosas, a las mujeres } \\
\text { embarazadas con } \\
\text { pezones invertidos o } \\
\text { no protráctiles con } \\
\text { intenciones es .de } \\
\text { amamantar }\end{array}$ & $\begin{array}{l}\text { País: UK y Canadá } \\
\text { Periodo de reclutamiento: } \\
\text { Basado en el protocolo del } \\
\text { ECA de Alexander. } \\
\text { Realizado en } 3 \text { etapas las } \\
\text { dos primeras en clínicas } \\
\text { prenatales de Inglaterra } \\
\text { (noviembre } 1989 \text { a abril } \\
\text { 1992) y la tercera parte } \\
\text { (agosto } 1991 \text { a diciembre } \\
\text { 1992), en centros } \\
\text { hospitalarios canadienses } \\
\text { Criterios de inclusión: } \\
\text { Al menos un pezón invertida } \\
\text { o no-protractil, } \\
\text { Nulíparas y multiparas } \\
\text { Embarazo único, } \\
\text { Con la intención de dar el } \\
\text { pecho, } \\
\text { Que no vaya a ofrecer el } \\
\text { bebé para su adopción, } \\
\text { Sin antecedentes de cirugía } \\
\text { que afecte al pezón o la } \\
\text { areola, } \\
\text { No estar utilizando escudos } \\
\text { de pezón o ejercicios, } \\
\text { Entre } 25 \text { y } 35 \text { semanas } \\
\text { completas de embarazo. }\end{array}$ & $\begin{array}{l}\text { Intervención: } \\
\text { Escudos de pezón } \\
\text { Ejercicios de Hoffman } \\
\text { Grupos aleatorizados ( } \mathrm{n}=463 \text { ) } \\
\text { G1: Ejercicios de Hoffman } \\
\text { G2: Escudos de pezón } \\
\text { G3: Ejercicios de Hoffman + Escudos de } \\
\text { pezón G4: Control sin ninguna intervención. } \\
\text { Grupos comparados: } \\
\text { Grupos con escudos (G1+G3, } \mathrm{n}=230 \text { ) vs. } \\
\text { Grupos sin escudos (G2+G4, } \mathrm{n}=233) \\
\text { Grupos que hacían ejercicios (G2+G3, } \mathrm{n}= \\
234) \text { vs, grupos que no lo practicaban } \\
\text { (G1+G4, n=229). } \\
\text { Variables de resultado: } \\
\text { Éxito en la lactancia materna a las seis } \\
\text { semanas (por medio de un cuestionario } \\
\text { enviado por correo a las madres) } \\
\text { Tambien se reportaron datos del efecto } \\
\text { sobre la edad gestacional al momento del } \\
\text { parto y efectos adversos (sangrado del } \\
\text { pezón, infección de seno mamario con } \\
\text { necesidad de tratamiento antibiótico) } \\
51 \% \text { mujeres (119/234) asignadas a }\end{array}$ & $\begin{array}{l}\text { Lactancia exitosa a los seis semanas } \\
\text { Grupos con escudos vs sin escudos } \\
\text { (G1+G3): } 45 \%(103 /) \\
\text { (G2+G4) } 45 \%(105 /) \\
\text { dif } 0 \% \text {, IC } 95 \%(-9 \% \text { a } 9 \%) \text { p }>0,9 \text {. } \\
\text { Grupos con ejercicios de hoffman vs sin } \\
\text { ejercicios } \\
\text { (G2+G3) } 46 \%(107 /) \\
\text { (G1+G4) } 44 \%(101 /) \\
\text { dif } 2 \%, \text { IC } 95 \%(-7 \% \text { a } 11 \%) \quad p=0,7 \\
\text { Lactancia suspendida a las seis } \\
\text { semanas } \\
\text { Grupos con escudos vs sin escudos } \\
\text { (G1+G3): } 45 \%(104 /) \\
\text { (G2+G4) } 42 \%(98 /) \\
\text { dif } 3 \% \text {, IC } 95 \%(-6 \% \text { a } 12) \\
\text { Grupos con ejercicios de hoffman vs sin } \\
\text { ejercicios } \\
\text { (G2+G3)El } 42 \%(99 /) \\
\text { (G1+G4) } 45 \%(103 /) \\
\text { dif -3\%, IC } 95 \%-12 \% \text { al } 6 \% \\
\text { Nunca amamantaron } \\
\text { Grupos con escudos vs sin escudos } \\
\text { (G1+G3): } 5 \%(12)\end{array}$ & $\begin{array}{l}\text { A las mujeres con pezones } \\
\text { invertidos y no protractiles } \\
\text { se les debe asegurar que la } \\
\text { lactancia materna es } \\
\text { posible. y se les debe } \\
\text { ofrecer una asistencia } \\
\text { especializada y establecer } \\
\text { un apoyo postnatal de la } \\
\text { lactancia. Esto debe incluir } \\
\text { ayuda con el } \\
\text { posicionamiento del bebé al } \\
\text { pecho, sin limitación de } \\
\text { tiempo sin biberones } \\
\text { suplementarios y el apoyo } \\
\text { permanente de una } \\
\text { persona especializada } \\
\text { Los estudios MAIN y } \\
\text { Southampton indican que } \\
\text { recomendar el uso de } \\
\text { ejercicios de Hoffman o } \\
\text { escudos de pezón durante } \\
\text { el embarazo no da lugar a } \\
\text { un beneficio clínico en } \\
\text { términos de aumento de la } \\
\text { tasa de lactancia materna } \\
\text { a las seis semanas } \\
\text { después del nacimiento. } \\
\text { Estos tratamientos no } \\
\text { deben ser recomendados }\end{array}$ & $\begin{array}{l}\text { Financiación: } \\
\text { UK by the } \\
\text { Department of } \\
\text { Health. and in } \\
\text { Ontario bv The } \\
\text { Hosnital for Sick } \\
\text { Children } \\
\text { Found\&ion, } \\
\text { Conflicto de } \\
\text { interés NR } \\
\end{array}$ \\
\hline
\end{tabular}




\begin{tabular}{|c|c|c|c|c|c|c|}
\hline $\begin{array}{l}\text { Referencia } \\
\text { (Cita } \\
\text { Abreviada) }\end{array}$ & $\begin{array}{l}\text { Estudio (Diseño y } \\
\text { objetivo) }\end{array}$ & $\begin{array}{l}\text { Población } \\
\text { (no y características) }\end{array}$ & $\begin{array}{l}\text { Descripción de las intervenciones } \\
\text { comparaciones, exposiciones o pruebas } \\
\text { a estudio }\end{array}$ & $\begin{array}{l}\text { Resultados } \\
\text { (Estimadores de resultados-Magnitud } \\
\text { del efecto) }\end{array}$ & $\begin{array}{l}\text { Conclusiones } \\
\text { (conclusiones) }\end{array}$ & $\begin{array}{l}\text { Comentarios } \\
\text { Calidad de la } \\
\text { evidencia } \\
\text { Financiación } \\
\text { comentarios) }\end{array}$ \\
\hline & & & $\begin{array}{l}\text { realizar ejercicios los hicieron al menos una } \\
\text { vez o dos veces al día; las razones comunes } \\
\text { para no hacerlos incomodidad, el tiempo o } \\
\text { que era embarazoso. } \\
61 \% \text { (141/230) de las mujeres del grupo con } \\
\text { escudos las usaron todos los días, o por lo } \\
\text { menos dos veces a la semana. Las razones } \\
\text { más comunes para no utilizarlas } \\
\text { incomodidad, dolor, vergüenza, y / o cambio } \\
\text { de la forma o textura de las mamas. } \\
10 \% \text { (11/115) de las mujeres asignadas a } \\
\text { ningún tratamiento habían utilizado } \\
\text { escudos o ejercicios } \\
\text { Razones mas comunes para detener la } \\
\text { lactancia materna en los primeros seis } \\
\text { semanas fueron: problemas en conseguir } \\
\text { que el bebé mamara; pensar que el bebé no } \\
\text { estaba recibiendo suficiente leche; y los } \\
\text { pezones o los pechos doloridos. No hubo } \\
\text { datos recopilados acerca de las razones de } \\
\text { las participantes que no comenzaron a } \\
\text { amamantar. }\end{array}$ & 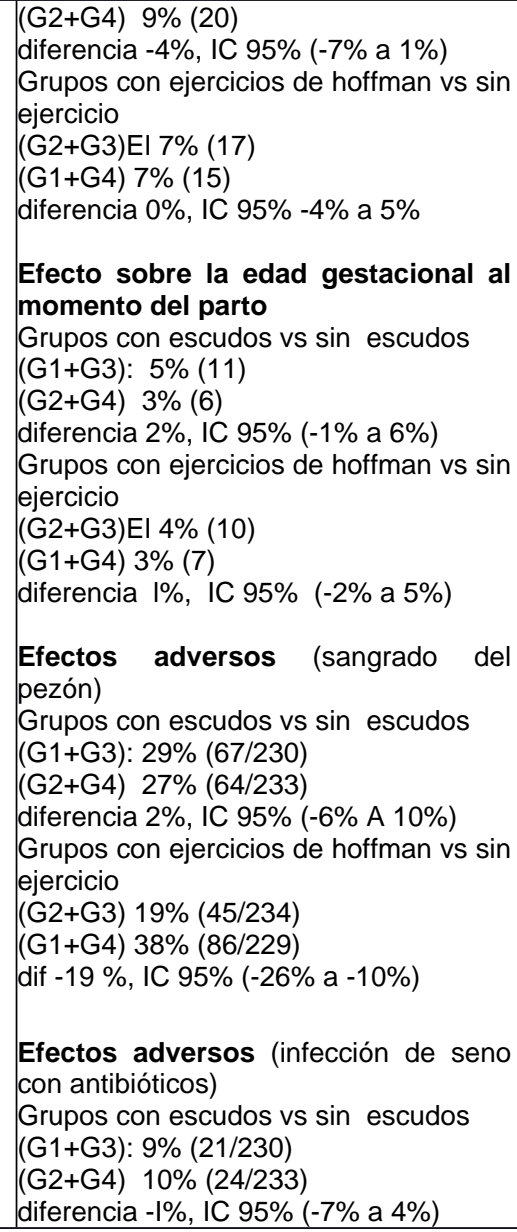 & $\begin{array}{l}\text { para las mujeres } \\
\text { embarazadas. }\end{array}$ & \\
\hline
\end{tabular}




\begin{tabular}{|c|c|c|c|c|c|c|}
\hline $\begin{array}{l}\text { Referencia } \\
\text { (Cita } \\
\text { Abreviada) }\end{array}$ & $\begin{array}{l}\text { Estudio (Diseño y } \\
\text { objetivo) }\end{array}$ & $\begin{array}{l}\text { Población } \\
\text { (no y características) }\end{array}$ & $\begin{array}{l}\text { Descripción de las intervenciones } \\
\text { comparaciones, exposiciones o pruebas } \\
\text { a estudio }\end{array}$ & $\begin{array}{l}\text { Resultados } \\
\text { (Estimadores de resultados-Magnitud } \\
\text { del efecto) }\end{array}$ & $\begin{array}{l}\text { Conclusiones } \\
\text { (conclusiones) }\end{array}$ & $\begin{array}{l}\text { Comentarios } \\
\text { Calidad de la } \\
\text { evidencia } \\
\text { Financiación } \\
\text { comentarios) } \\
\end{array}$ \\
\hline & & & & $\begin{array}{l}\text { Grupos con ejercicios de hoffman vs sin } \\
\text { ejercicio } \\
\text { (G2+G3) } 6 \%(14 / 234) \\
\text { (G1+G4) } 14 \%(31 / 229) \\
\text { dif - }-8 \% \text {, IC } 95 \% \text { (-13\% a -2\% } \\
\text { Combinación efectos adversos } \\
\text { ambos ECA: } \\
\text { Sangrado del pezón } \\
\text { Grupos con escudos vs sin escudos } \\
\text { dif } 2 \% \text {, IC } 95 \%(-5 \% \text { a } 10 \%) \text {. } \\
\text { Grupos con ejercicios de hoffman vs sin } \\
\text { ejercicio } \\
\text { dif -16\%, IC } 95 \% \text { (-13\% a -2\%). } \\
\text { infección del seno con antibióticos } \\
\text { Grupos con escudos vs sin escudos } \\
\text { dif } 0 \% \text {, IC95\% (-5\% a } 5 \%) \text {. } \\
\text { Grupos con ejercicios de hoffman vs sin } \\
\text { ejercicio } \\
\text { dif - } 5 \% \text { (IC } 95 \%-10 \% \text { a } 2 \%) \text {. }\end{array}$ & & \\
\hline Jain 2013 & \begin{tabular}{|l} 
Estudio \\
observacional \\
prospectivo \\
Objetivo: \\
determinar la \\
eficacia, los méritos \\
y deméritos de la \\
'método en uso de \\
la jeringa "y" dos \\
nuevos métodos \\
innovadores.
\end{tabular} & $\begin{array}{l}\text { País: India } \\
\text { Periodo de reclutamiento: } \\
\text { marzo a agosto } 2011 \\
\text { Criterios de inclusión: } \\
\text { mujeres que dieron a luz } \\
\text { (204 primerizas y } 9 \text { en su } \\
\text { segundo embarazo), con } \\
\text { pezones invertidos de grado I } \\
\text { y II. } \\
\text { criterios de exclusión: } \\
\text { aquellas con un grado III de }\end{array}$ & $\begin{array}{l}\text { Intervenciones } \\
\text { método de jeringa, banda de goma y succión } \\
\text { de los padres para la corrección de pezones } \\
\text { invertidos } \\
\text { Aleatorización: } 71 \text { en c/u } \\
15(7 \%) \text { perdidas durante el seguimiento. } \\
(G A 7, G B 6 \text { y GC } 2) \\
\text { Grupos comparados }(n=198) \text { : } \\
\text { GA } n=64) \text { que utiliza una jeringa como } \\
\text { aparato de succión } \\
\text { GB; }(n=65) \text { con bandas de goma }\end{array}$ & $\begin{array}{l}\text { Buen agarre al pezón } \\
\text { Día } 3 \text { 85 (42,8\%) } \\
21 \text { GA }(32,8 \%) \\
28 \text { GB }(43,1 \%) \\
\text { 36 GC }(52,2 \%) \\
\\
\text { Día } 7134(67.7 \%) \\
\text { GA } 30(46.9 \%) . \\
\text { GB } 43(66.1 \%) \\
\text { GC } 61(88.4 \%) \\
\\
\text { Dia } 14154(77.7 \%) \\
\text { GA } 41(64.1 \%) \\
\text { GB } 48(73.8 \%)\end{array}$ & $\begin{array}{l}\text { Aunque el método de la } \\
\text { jeringa está bien } \\
\text { establecida para el } \\
\text { tratamiento de pezones } \\
\text { invertidos, la succión } \\
\text { marital es sin duda un } \\
\text { método superior aun en los } \\
\text { casos difíciles, con la } \\
\text { ventaja de estimular la } \\
\text { lactancia. El método de las } \\
\text { bandas de goma es un } \\
\text { poco inferior debido a su } \\
\text { técnica complicada, dolor } \\
\text { local y no estimulación de } \\
\text { la lactancia. }\end{array}$ & $\begin{array}{l}\text { Financiamiento: NR } \\
\text { Conflicto de } \\
\text { intereses: NR }\end{array}$ \\
\hline
\end{tabular}


GPC Lactancia Materna- Pregunta 27. Anatomía del pezón.

\begin{tabular}{|c|c|c|c|c|c|c|}
\hline $\begin{array}{l}\text { Referencia } \\
\text { (Cita } \\
\text { Abreviada) }\end{array}$ & $\begin{array}{l}\text { Estudio (Diseño y } \\
\text { objetivo) }\end{array}$ & $\begin{array}{l}\text { Población } \\
\text { (no y características) }\end{array}$ & $\begin{array}{l}\text { Descripción de las intervenciones } \\
\text { comparaciones, exposiciones o pruebas } \\
\text { a estudio }\end{array}$ & $\begin{array}{l}\text { Resultados } \\
\text { (Estimadores de resultados-Magnitud } \\
\text { del efecto) }\end{array}$ & $\begin{array}{l}\text { Conclusiones } \\
\text { (conclusiones) }\end{array}$ & $\begin{array}{l}\text { Comentarios } \\
\text { Calidad de la } \\
\text { evidencia } \\
\text { Financiación } \\
\text { comentarios) }\end{array}$ \\
\hline & & $\begin{array}{l}\text { fibrosis severa quienes } \\
\text { tuvieron que ser intervenidas } \\
\text { quirúrgicamente } \\
\text { Edad: } 19 \text { a } 27 \text { años, } \\
\text { Grados de retracción del } \\
\text { pezón } \\
\text { GA } 60.5 \% \text { grado,39.5 \% } \\
\text { grado II; } \\
\text { GB } 53,5 \% \text { grado I. } 46,5 \% \\
\text { grado II } \\
\text { GC } 56 \% \text { grado I, } 44 \% \text { grado } \\
\text { II. }\end{array}$ & $\begin{array}{l}\text { GC: ( } n=69 \text { ) con frecuentes y vigorosas } \\
\text { succiones por parte del marido (una succión } \\
\text { de los pezones, hasta que sobresalen al } \\
\text { menos por un momento). } \\
\text { Variables de resultados } \\
\text { el buen agarre al pezón } \\
\text { a los } 3,7 \text { y } 14 \text { días (profesionales cegados } \\
\text { al grupo de tratamiento). } \\
\text { Se recogieron datos de, problemas en las } 3 \\
\text { técnicas: dolor en el pezón privacidad, } \\
\text { dificultad y malestar por leche en la boca } \\
\text { Como segunda parte del estudio, } 69 \\
\text { participantes (de seguimiento) fueron } \\
\text { interrogados por sus sentimientos acerca de } \\
\text { la aceptabilidad y la vulgaridad del método } \\
\text { de succión por el marido, (diciembre } 2011 \\
\text { a Marzo de 2012) }\end{array}$ & 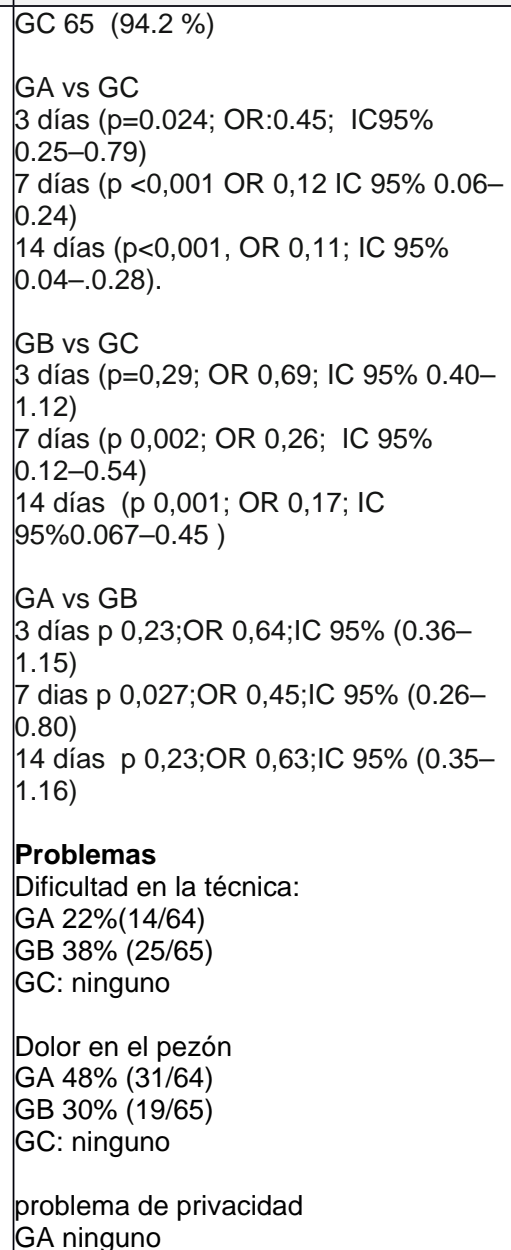 & & \\
\hline
\end{tabular}




\begin{tabular}{|c|c|c|c|c|c|c|}
\hline $\begin{array}{l}\text { Referencia } \\
\text { (Cita } \\
\text { Abreviada) }\end{array}$ & $\begin{array}{l}\text { Estudio (Diseño y } \\
\text { objetivo) }\end{array}$ & $\begin{array}{l}\text { Población } \\
\text { (no y características) }\end{array}$ & $\begin{array}{l}\text { Descripción de las intervenciones } \\
\text { comparaciones, exposiciones o pruebas } \\
\text { a estudio }\end{array}$ & $\begin{array}{l}\text { Resultados } \\
\text { (Estimadores de resultados-Magnitud } \\
\text { del efecto) }\end{array}$ & $\begin{array}{l}\text { Conclusiones } \\
\text { (conclusiones) }\end{array}$ & $\begin{array}{l}\text { Comentarios } \\
\text { Calidad de la } \\
\text { evidencia } \\
\text { Financiación } \\
\text { comentarios) }\end{array}$ \\
\hline & & & & $\begin{array}{l}\text { GB } 31 \%(20 / 65) \\
\text { GC100\% (69/69) } \\
\text { GC } 19(28 \%) \text { esposos se quejaron de } \\
\text { no gustarles la presencia de leche } \\
\text { materna en su boca } \\
\text { Cuestionario GC } \\
\text { Aceptabilidad sociocultural gran } \\
\text { preocupación } 69(100 \%) \\
\text { Culturalmente aceptable y no vulgar . } \\
55(79,7 \%) \\
14 \text { casos, } 9 \text { (13,1\%) opinó que era algo } \\
\text { vulgar, pero sin emitir opinión sobre la } \\
\text { aceptabilidad social y } 5(7,2 \%) \text { opinaron } \\
\text { que era socialmente inaceptable. }\end{array}$ & & \\
\hline $\begin{array}{l}\text { Chakravarti } \\
2011\end{array}$ & $\begin{array}{l}\text { Serie de casos } \\
\text { Un nuevo método } \\
\text { ideado por los } \\
\text { autores utilizando } \\
\text { bandas de goma } \\
\text { elásticas para } \\
\text { aplicar } \\
\text { sistemáticamente en } \\
\text { madres con } \\
\text { pezones planos, } \\
\text { invertidos, u otro } \\
\text { problema de pezón } \\
\text { y documentar los } \\
\text { resultados }\end{array}$ & $\begin{array}{l}\text { País India } \\
\text { Periodo de reclutamiento: } \\
\text { atención ambulatoria } \\
\text { pediátrica en un hospital } \\
\text { durante un período de } 6 \\
\text { meses } \\
\text { Población: } 19 \text { Madres con } \\
\text { dificultades en la lactancia y } \\
\text { anormalidades de pezón } \\
\text { G1 con pezones invertidos } \\
(n=8), \\
\text { G2 con pezones planos, } \\
(n=7) \text { y } \\
\text { G3 otras anormalidades } \\
\text { anatómicas }(n=4) \text { (incluye } \\
\text { pezones grandes, con }\end{array}$ & $\begin{array}{l}\text { Intervención: Bandas de goma } \\
\text { El proceso consiste en poner una banda de } \\
\text { goma alrededor de la base del pezón, para } \\
\text { que sea prominente de modo que el recién } \\
\text { nacido sea capaz de mamar. La banda se } \\
\text { puede aplicar con la mano, pero se } \\
\text { encontró que era más conveniente usar una } \\
\text { jeringa como aplicador. } \\
\text { Grupos comparados: } \\
\text { G1 vs. G2 vs. G3 } \\
\text { Variables de resultado: } \\
\text { buen agarre al pezón } \\
\text { lactancia exclusiva } \\
\text { Seguimiento a los } 37 \text { y } 28 \text { días }\end{array}$ & $\begin{array}{l}\text { Buen agarre al pezón } \\
\text { A los } 3 \text { días: } 12 \text { bebes }(63 \%) \text { lograron } \\
\text { un buen agarre: } \\
8 \text { sin bandas ( } 3 \mathrm{G} 1,5 \mathrm{G} 2) \\
4 \text { con bandas ( } 1 \mathrm{G} 1,2 \mathrm{G} 2,1 \mathrm{G} 3) \\
\text { A las } 7 \text { días } 16 \text { bebes }(84 \%) \text { lograron } \\
\text { un buen agarre. } \\
14 \text { sin bandas ( } 6 \mathrm{G} 1,7 \mathrm{G} 2, \mathrm{G} 31) \\
2 \text { con bandas (G3) } \\
\text { A las } 28 \text { días } 19 \text { bebes } 100 \% \text { sin } \\
\text { bandas } \\
\text { Lactancia exclusiva y no exclusiva } \\
\text { No se presentan datos por tipo de } \\
\text { pezón de este desenlace. } \\
\text { A los } 3 \text { días: } 18 \text { bebés (95\%) pecho + }\end{array}$ & $\begin{array}{l}\text { Este estudio demostró con } \\
\text { éxito la eficacia del simple } \\
\text { procedimiento de una } \\
\text { banda de goma para tratar } \\
\text { problemas de pezones } \\
\text { planos o invertidos y } \\
\text { algunas otras deformidades } \\
\text { Puede ayudar en el inicio } \\
\text { temprano de la lactancia } \\
\text { materna al ser aplicado } \\
\text { inmediatamente después } \\
\text { del parto cuando sea } \\
\text { necesario para aumentar la } \\
\text { confianza de la madre para } \\
\text { amamantar, } \\
\end{array}$ & $\begin{array}{l}\text { Financiación: NR } \\
\text { (Los autores no } \\
\text { tienen competencia } \\
\text { en intereses } \\
\text { financieros) } \\
\text { Conflicto de } \\
\text { intereses: NR }\end{array}$ \\
\hline
\end{tabular}




\begin{tabular}{|c|c|c|c|c|c|c|}
\hline $\begin{array}{l}\text { Referencia } \\
\text { (Cita } \\
\text { Abreviada) }\end{array}$ & $\begin{array}{l}\text { Estudio (Diseño y } \\
\text { objetivo) }\end{array}$ & $\begin{array}{l}\text { Población } \\
\text { (no y características) }\end{array}$ & $\begin{array}{l}\text { Descripción de las intervenciones } \\
\text { comparaciones, exposiciones o pruebas } \\
\text { a estudio }\end{array}$ & $\begin{array}{l}\text { Resultados } \\
\text { (Estimadores de resultados-Magnitud } \\
\text { del efecto) }\end{array}$ & \begin{tabular}{|l} 
Conclusiones \\
(conclusiones)
\end{tabular} & $\begin{array}{l}\text { Comentarios } \\
\text { Calidad de la } \\
\text { evidencia } \\
\text { Financiación } \\
\text { comentarios) }\end{array}$ \\
\hline & & $\begin{array}{l}\text { ubicación atípica, en forma } \\
\text { de coliflor, o deformidad de } \\
\text { la mama posterior a } \\
\text { quemadura). } \\
\text { Edad:.21 a } 32 \text { años } \\
18 \text { bebés estaban siendo } \\
\text { exclusivamente alimentados } \\
\text { con biberón (18/19; } 95 \%) \text {, } \\
\text { con excepción, de uno que } \\
\text { era alimentado con leche } \\
\text { materna extraída ( } 1 / 19 ; 5 \%) \text {. }\end{array}$ & & $\begin{array}{l}\text { fórmula en copas / } 1 \text { (5\%). con pecho y } \\
\text { con leche extraída de la madre } \\
\text { A las } 7 \text { días: } 14(74 \%) \text { pecho + formula } \\
\text { en copa / } 4(21 \%) \text { pecho solo / } 1(5 \%) \text {. } \\
\text { con pecho y con leche extraída de la } \\
\text { madre } \\
\text { A las } 28 \text { días: } 6(32 \%) \text { pecho + } \\
\text { formula en copa / } 13(68 \%) \text { con pecho } \\
\text { solo. } \\
\text { No se presentaron efectos adversos }\end{array}$ & & \\
\hline $\begin{array}{l}\text { Mc George } \\
1994\end{array}$ & $\begin{array}{l}\text { Serie de casos } \\
\text { Objetivo. evaluar la } \\
\text { eficacia de un nuevo } \\
\text { instrumento, el } \\
\text { 'Niplette', como } \\
\text { dispositivo de } \\
\text { corrección no } \\
\text { quirúrgica para } \\
\text { pezones invertidos. }\end{array}$ & $\begin{array}{l}22 \text { mujeres (14 } \\
\text { embarazadas) con pezones } \\
\text { invertidos. } 16 \text { mujeres fueron } \\
\text { consideradas para el } \\
\text { tratamiento quirúrgico dos de } \\
\text { ellas habían fracasado en } \\
\text { corregir sus pezones } \\
\text { invertidos en cirugías } \\
\text { anteriores. } \\
\text { Edad media } 30 \text { años ( } 19 \text { a } \\
44 \text { años), }\end{array}$ & $\begin{array}{l}\text { Intervención : Niplete } \\
\text { Se realizaron controles mensuales y } \\
\text { llamadas por teléfono para confirmar el } \\
\text { mantenimiento de su correcciones. }\end{array}$ & $\begin{array}{l}\text { Buen agarre, y abandono del niplete } \\
21 \text { pacientes, (Una se perdió en el } \\
\text { seguimiento) } \\
2 \text { al primer seguimiento } \\
4 \text { a los } 2 \text { meses, } \\
3 \text { a los } 3 \text { meses } \\
1 \text { lo continuo utilizando de forma } \\
\text { intermitente. } \\
2 \text { pacientes tuvieron un ligero sangrado } \\
\text { de sus pezones que ambas } \\
\text { consideraron una simple molestia }\end{array}$ & \begin{tabular}{|l} 
el Niplette' corrige \\
efectivamente los pezones \\
invertidas en todos los \\
casos (incluso en aquellos \\
pacientes con pezones \\
invertidos severos) sin la \\
necesidad de cirugía \\
invasiva. Como resultado, \\
la musculatura del pecho \\
no se vio afectada y las \\
madres podría seguir \\
amamantando sin ningún \\
problema.
\end{tabular} & $\begin{array}{l}\text { Financiación: NR } \\
\text { Conflicto de } \\
\text { intereses: NR }\end{array}$ \\
\hline $\begin{array}{l}\text { Kesaree } \\
1993\end{array}$ & $\begin{array}{l}\text { Serie de casos } \\
\text { Objetivo. evaluar la } \\
\text { eficacia de un } \\
\text { simple método para } \\
\text { la corrección de } \\
\text { pezones invertidos }\end{array}$ & $\begin{array}{l}8 \text { madres con pezones } \\
\text { invertidos que fueron } \\
\text { visitadas en el departamento } \\
\text { de pediatría, } \\
\text { Las } 8 \text { madres habían sido } \\
\text { incapaces de dar de mamar } \\
\text { antes del estudio y } \\
\text { alimentaban a sus bebes con } \\
\text { biberón, todos los bebes } \\
\text { habían estado ingresados } \\
\text { por septicemia }\end{array}$ & $\begin{array}{l}\text { Intervención: método de la jeringa (Se saca } \\
\text { el embolo, se corta el extremo de la jeringa } \\
\text { tratando de que quede suave al tacto, se } \\
\text { coloca el embolo en el extremo cortado y la } \\
\text { madre coloca su pezón en el otro extremo la } \\
\text { la jeringa y mantiene la presión del embolo } \\
\text { hacia afuera durante } 20 \text { segundos a un } \\
\text { minuto sin tener que sentir dolor ni molestia } \\
\text { y debe repetirlo varias veces al día) }\end{array}$ & $\begin{array}{l}7 \text { de las } 8 \text { mamas revirtieron sus } \\
\text { pezones con el método de la jeringa } \\
\text { utilizándola varias veces al día y } \\
\text { lograron amamantar a sus bebes con } \\
\text { éxito. } \\
\text { Las madres y sus bebes fueron } \\
\text { seguidas hasta los seis meses de vida } \\
\text { de los bebes } \\
\text { Cantidad de suplemento de comida } \\
50 \% \text { menos a las dos o } 3 \text { semanas. }\end{array}$ & $\begin{array}{l}\text { La técnica de la jeringuilla } \\
\text { es un método simple, } \\
\text { barato seguro y fácil de } \\
\text { aprender por las madres } \\
\text { para la corrección de sus } \\
\text { pezones invertidos. y se } \\
\text { puede utilizar tan a menudo } \\
\text { como sea necesario. }\end{array}$ & $\begin{array}{l}\text { Financiación: NR } \\
\text { Conflicto de } \\
\text { intereses: NR }\end{array}$ \\
\hline
\end{tabular}


GPC Lactancia Materna- Pregunta 27. Anatomía del pezón.

\begin{tabular}{|c|c|c|c|c|c|c|}
\hline $\begin{array}{l}\text { Referencia } \\
\text { (Cita } \\
\text { Abreviada) }\end{array}$ & $\begin{array}{l}\text { Estudio (Diseño y } \\
\text { objetivo) }\end{array}$ & $\begin{array}{l}\text { Población } \\
\text { (no y características) }\end{array}$ & $\begin{array}{l}\text { Descripción de las intervenciones } \\
\text { comparaciones, exposiciones o pruebas } \\
\text { a estudio }\end{array}$ & $\begin{array}{l}\text { Resultados } \\
\text { (Estimadores de resultados-Magnitud } \\
\text { del efecto) }\end{array}$ & $\begin{array}{l}\text { Conclusiones } \\
\text { (conclusiones) }\end{array}$ & $\begin{array}{l}\text { Comentarios } \\
\text { Calidad de la } \\
\text { evidencia } \\
\text { Financiación } \\
\text { comentarios) } \\
\end{array}$ \\
\hline & & $\begin{array}{l}\text { bronconeumonia o } \\
\text { deshidratación. }\end{array}$ & & $\begin{array}{l}\text { Una madre fue incapaz de revertir sus } \\
\text { pezones debido a severa reversión. } \\
\text { La lactancia exclusiva } \\
\text { seis bebes entre las } 4 \text { y } 6 \text { semanas, } \\
\text { No se reportaron efectos adversos, }\end{array}$ & & \\
\hline
\end{tabular}




\section{Pregunta sobre pezones planos}

\begin{tabular}{|c|c|c|c|}
\hline $\begin{array}{l}\text { Referencia } \\
\text { (Cita Abreviada) }\end{array}$ & Estudio (Diseño y objetivo) & $\begin{array}{l}\text { Población } \\
\text { (no y características) }\end{array}$ & $\begin{array}{l}\text { Descripción de las intervenciones } \\
\text { comparaciones, exposiciones o pruebas a estudio }\end{array}$ \\
\hline Chanprapaph 2013 & $\begin{array}{l}\text { ECA simple ciego } \\
\text { El objetivo de este estudio es } \\
\text { demostrar el valor de las conchas en } \\
\text { mejorar la longitud del pezón en } \\
\text { mujeres embarazadas. de pezón corto } \\
\text { El objetivo secundario es determinar la } \\
\text { tasa de éxito de la lactancia entre el } \\
\text { grupo tratado y el grupo control }\end{array}$ & $\begin{array}{l}\text { País: Tailandia } \\
\text { Periodo de reclutamiento: julio } 2009 \text { - julio de } 2010 \\
\text { Criterios de inclusión: } \\
\text { Mujeres embarazadas nuliparas con pezones cortos } \\
\text { unilateral o bilaterales (<7,0 mm) que asistieron a la } \\
\text { atención clínica prenatal. } \\
\text { Edad de } 18 \text { a } 40 \text { años de edad } \\
\text { Edad gestacional (GA) } 16-20 \text { semanas, } \\
\text { Sin historia anterior de lactancia materna } \\
\text { Criterios de exclusión: Pacientes con fecha incierta } \\
\text { de embarazo } \\
\text { Con pezón invertido, } \\
\text { Cirugía anterior de mama o pezón } \\
\text { Casos de mala adherencia al protocolo. }\end{array}$ & $\begin{array}{l}\text { Intervención: conchas } \\
\text { Grupos aleatorizados (N=96): } \\
\text { Seis se retiraron del estudio (tres abortos y tres de seguimiento incompleto) } \\
\text { Grupos comparados ( } N=90 \text { ) } \\
\text { Grupo intervención } \mathrm{Gl} \text { con las dos conchas por al menos } 8 \text { horas diarias o } 56 \\
\text { horas por semana; }(\mathrm{n}=43 \text { ) } \\
\text { Grupo control GC (no llevaban conchas ( } \mathrm{n}=47) \\
\text { Variables de resultado: } \\
\text { Alargamiento del pezón (longitud en mm) } \\
\text { Eficacia de la lactancia temprana (puntuación LATCH) } \\
\text { Tasa de lactancia exclusiva y no exclusiva } \\
\text { Pérdida de seguimiento del estudio, } \\
\text { Seis semanas Gl } 35 \%(15 / 43), G C 36 \%(17 / 47) \\
\text { Doce semanas Gl } 40 \%(17 / 43), G C 36 \%(17 / 47)\end{array}$ \\
\hline Chakravarti 2011 & $\begin{array}{l}\text { Serie de casos } \\
\text { Un nuevo método ideado por los } \\
\text { autores utilizando bandas de goma } \\
\text { elásticas para aplicar sistemáticamente } \\
\text { en madres con pezones planos, } \\
\text { invertidos, u otro problema de pezón y } \\
\text { documentar los resultados }\end{array}$ & $\begin{array}{l}\text { País India } \\
\text { Periodo de reclutamiento: atención ambulatoria } \\
\text { pediátrica en un hospital durante un período de } 6 \\
\text { meses } \\
\text { Población: } 19 \text { Madres con dificultades en la lactancia y } \\
\text { anormalidades de pezón } \\
\text { G1 con pezones invertidos }(n=8), \\
\text { G2 con pezones planos, }(n=7) \text { y } \\
\text { G3 otras anormalidades anatómicas ( } n=4) \text { (incluye } \\
\text { mamas grandes, con ubicación atípica, en forma de } \\
\text { coliflor, o deformidad de la mama posterior a } \\
\text { quemadura). } \\
\text { Edad: } 21 \text { a } 32 \text { años } \\
18 \text { bebés estaban siendo exclusivamente alimentados } \\
\text { con biberón }(18 / 19 ; 95 \%) \text {, con excepción, de uno que }\end{array}$ & $\begin{array}{l}\text { Intervención: Bandas de goma } \\
\text { El proceso consiste en poner una banda de goma alrededor de la base del } \\
\text { pezón, para que sea prominente de modo que el recién nacido sea capaz de } \\
\text { mamar. La banda se puede aplicar con la mano, pero se encontró que era más } \\
\text { conveniente usar una jeringa como aplicador. } \\
\text { Grupos comparados: } \\
\text { G1vs. G2 vs. G3 } \\
\text { Variables de resultado: } \\
\text { buen agarre al pezón } \\
\text { lactancia exclusiva } \\
\text { Seguimiento a los } 37 \text { y } 28 \text { días }\end{array}$ \\
\hline
\end{tabular}


GPC Lactancia Materna- Pregunta 27. Anatomía del pezón.

\begin{tabular}{|c|c|c|c|}
\hline $\begin{array}{l}\text { Referencia } \\
\text { (Cita Abreviada) }\end{array}$ & Estudio (Diseño y objetivo) & $\begin{array}{l}\text { Población } \\
\text { (nํy características) }\end{array}$ & $\begin{array}{l}\text { Descripción de las intervenciones } \\
\text { comparaciones, exposiciones o pruebas a estudio }\end{array}$ \\
\hline & & era alimentado con leche materna extraída ( $1 / 1$ & \\
\hline
\end{tabular}

\section{ANEXO III, Forest-Plot}

No procede. 
GPC Lactancia Materna- Pregunta 27. Anatomía del pezón.

9. ANEXO IV. Evaluación de la calidad

No procede 


\section{0- BIBLIOGRAFÍA}

(1) Alexander JM, Grant AM, Campbell MJ. Randomised controlled trial of breast shells and Hoffman's exercises for inverted and non-protractile nipples. BMJ 1992 Apr 18;304(6833):1030-2.

(2) Preparing for breast feeding: treatment of inverted and non-protractile nipples in pregnancy. The MAIN Trial Collaborative Group. Midwifery 1994 Dec;10(4):20014.

(3) Jain S, Jain A, Singh AK, Goswami D, Upadhyay AN, Negi N. Newer innovations in treatment of retracted nipple. Indian J Pediatr 2013 Jun;80(6):483-7.

(4) Kesaree N, Banapurmath CR, Banapurmath S, Shamanur K. Treatment of inverted nipples using a disposable syringe. J Hum Lact 1993 Mar;9(1):27-9.

(5) McGeorge DD. Ideas and innovations - The 'Niplette ': An instrument for the non-surgical correction of inverted nipples. British Journal of Plastic Surgery 1994;47(1):46-9.

(6) Chakrabarti K, Basu S. Management of flat or inverted nipples with simple rubber bands. Breastfeed Med 2011 Aug;6(4):215-9.

(7) Chanprapaph P, Luttarapakul J, Siribariruck S, Boonyawanichkul S. Outcome of non-protractile nipple correction with breast cups in pregnant women: a randomized controlled trial. Breastfeed Med 2013 Aug;8(4):408-12.

(8) Powers D, Tapia VB. Women's experiences using a nipple shield. J Hum Lact 2004 Aug;20(3):327-34.

(9) NICE. Postnatal care up to 8 weeks after birth. Julio 2006 (actualizado en Febrero de 2015). Disponible en: http://guidance.nice.org.uk/CG37.

(10) Perinatal Services BC Health Promotion Guideline. Breastfeeding Healthy Term Infants. March 2015. Disponible en: http://www.perinatalservicesbc.ca/Documents/GuidelinesStandards/HealthPromotion/BreastfeedingHealthyTermInfantGuideline.pdf.

(11) Hagan A. Breastfeeding attachment difficulties related to large nipple size: a case report and review of practice. New Zealand College of Midwives Journal 2003 Oct;29:10-4. 
PREGUNTA CLÍNICA № 29

¿Cuál sería el tratamiento más adecuado para tratar el dolor y las grietas en el pezón que pueden aparecer durante la lactancia materna?

\section{1- Pregunta clínica en formato PICO}

Tabla 1- Componentes de la pregunta clínica en formato PICO

\begin{tabular}{|l|l|}
\hline Pacientes & $\begin{array}{l}\text { Madre sana con dolor o grietas en los pezones y recién } \\
\text { nacido sano }\end{array}$ \\
\hline Intervención & $\begin{array}{l}\text { Uso de pezonera (para ayudar con el dolor), mupirocina } \\
\text { (antibiótico), corticoides tópicos con betametasona, lanolina, } \\
\text { parches de hidrogel entre tomas, bolsas de té, clorhexidina, } \\
\text { pezonera de plata, pezonera de cera (riesgo de clostridium) }\end{array}$ \\
\hline Comparación & $\begin{array}{l}\text { Aplicación de la propia leche y asegurar una buena } \\
\text { postura/enganche }\end{array}$ \\
\hline Resultados & $\begin{array}{l}\text { Tasa de lactancia materna exclusiva al alta } \\
\text { Tasa de lactancia materna exclusiva al mes } \\
\text { Tasa de lactancia materna a los 4 meses } \\
\text { Tasa de lactancia materna exclusiva a los 4 meses } \\
\text { Satisfacción materna } \\
\text { Complicaciones de las mamas (grietas, ingurgitaciones) } \\
\text { Pérdida ponderal del bebé (48-72h.) } \\
\text { Seguridad de los métodos (riesgo de clostridium etc). }\end{array}$ \\
\hline Tipo de estudio & $\begin{array}{l}\text { RS de ECA, ECA, RS de estudios observacionales o } \\
\text { estudios observacionales }\end{array}$ \\
\hline
\end{tabular}

\section{2- Introducción}


3. ESTRATEGIA DE ELABORACIÓN DE LA PREGUNTA

\subsection{GPC Base}

Tabla 2- Resumen de GPC Base

\begin{tabular}{|c|c|c|c|c|}
\hline $\begin{array}{c}\text { Guía } \\
\text { (Enfoque) }\end{array}$ & $\begin{array}{l}\text { Resumen sobre la evidencia } \\
\text { (Calidad de la evidencia) }\end{array}$ & $\begin{array}{l}\text { Recomendaciones } \\
\text { (Grado) }\end{array}$ & $\begin{array}{c}\text { Referencias } \\
\text { bibliográficas } \\
\text { (Tipo de } \\
\text { publicación) }\end{array}$ & Comentarios \\
\hline NICE & $\begin{array}{l}\text { DOLOR DEL PEZON, PEZONES AGRIETADOS O } \\
\text { TRAUMA DEL PEZON NIPPLE PAIN, SORE } \\
\text { NIPPLES OR NIPPLE TRAUMA } \\
\text { Prevención y tratamiento } \\
\text { Las grietas y/o dolor de los pezones son problemas } \\
\text { comunes asociados a una escasa información y } \\
\text { apoyo. Frecuentemente es debido a una succión } \\
\text { traumática secundaria a una posición incorrecta. Por } \\
\text { lo tanto es de suma importancia el agarre correcto } \\
\text { del bebe para alimentarse. } \\
\text { Una revisión sistemática sobre el manejo del dolor } \\
\text { del pezón y/o del trauma asociado a la lactancia } \\
\text { (Page, Lockwood, \& Guest } 2003 \text { ) identificó ocho } \\
\text { estudios de intervención centrados en la prevención } \\
\text { del dolor/trauma del pezón (otros cinco estudios } \\
\text { incluidos examinaron las intervenciones para el } \\
\text { manejo del dolor). Los meta-análisis podrían no } \\
\text { haberse llevado a cabo debido a la heterogeneidad } \\
\text { del estudio, sin embargo, se llevaron a cabo } \\
\text { resúmenes de cada estudio y la comparación de las } \\
\text { intervenciones entre los estudios. Seis estudios de } \\
\text { prevención solo incluyeron mujeres primíparas. } \\
\text { Los estudios se detallan a continuación. } \\
\text { La educación prenatal estándar para mujeres } \\
\text { primíparas ( } n=79 \text { ) se comparó con una sesión } \\
\text { adicional de media hora de educación individual } \\
\text { dentro de las primeras } 24 \text { horas postparto ( } n= \\
79 \text { ) (Henderson et al, 2001). Estadísticamente hubo } \\
\text { menos dolor en el pezón en el grupo de intervención }\end{array}$ & & $\begin{array}{l}\text { Page, Lockwod } \\
2003 \\
\\
\text { Buchko et al, } \\
1994\end{array}$ & \\
\hline
\end{tabular}




\begin{tabular}{|c|c|c|c|c|}
\hline $\begin{array}{c}\text { Guía } \\
\text { (Enfoque) }\end{array}$ & $\begin{array}{l}\text { Resumen sobre la evidencia } \\
\text { (Calidad de la evidencia) }\end{array}$ & $\begin{array}{l}\text { Recomendaciones } \\
\text { (Grado) }\end{array}$ & $\begin{array}{c}\text { Referencias } \\
\text { bibliográficas } \\
\text { (Tipo de } \\
\text { publicación) }\end{array}$ & Comentarios \\
\hline & 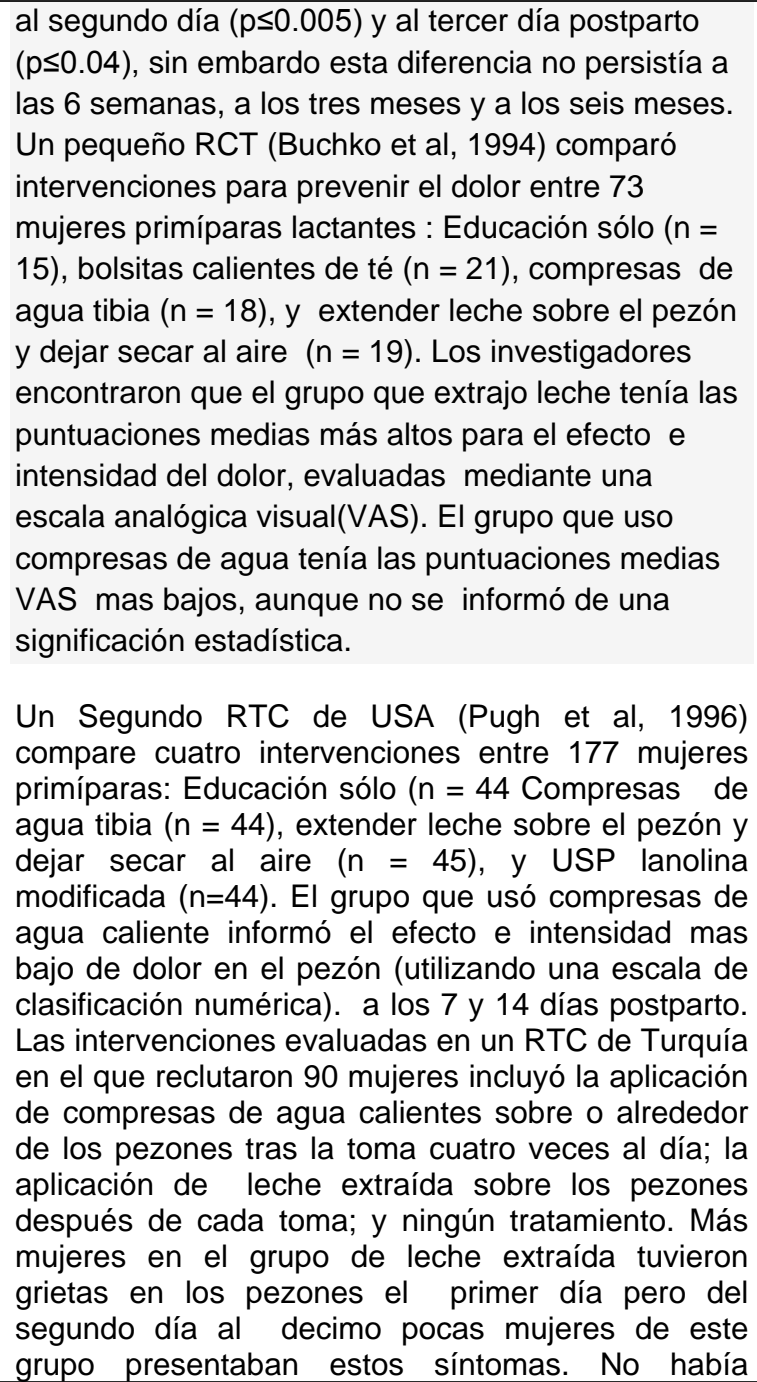 & & $\begin{array}{l}\text { Pugh et al, } \\
1996\end{array}$ & \\
\hline
\end{tabular}




\begin{tabular}{|c|c|c|c|c|}
\hline $\begin{array}{c}\text { Guía } \\
\text { (Enfoque) }\end{array}$ & $\begin{array}{l}\text { Resumen sobre la evidencia } \\
\text { (Calidad de la evidencia) }\end{array}$ & $\begin{array}{l}\text { Recomendaciones } \\
\text { (Grado) }\end{array}$ & $\begin{array}{c}\text { Referencias } \\
\text { bibliográficas } \\
\text { (Tipo de } \\
\text { publicación) }\end{array}$ & Comentarios \\
\hline & $\begin{array}{l}\text { diferencia estadística en los valores del dolor del } \\
\text { pezón aunque no estaba claro cómo se evaluaron } \\
\text { esos valores. Un estudio piloto de } 23 \text { mujeres que } \\
\text { comparaba el uso de lanolina versus leche sobre el } \\
\text { pecho no encontró diferencia entre el dolor o el } \\
\text { traume en el pezón. Las mujeres actuaron como sus } \\
\text { propios controles. Aśí mismo el dolor fue evaluado } \\
\text { mediante una escala de } 4 \text { puntos completada } \\
\text { después de cada toma durante los diez días } \\
\text { postparto, y el trauma evaluado evaluado por un } \\
\text { investigador ciego para estudiar la distribución } \\
\text { durante los día } 0,1,2,3,5,7,7 \text { y } 10 \text {. Cabe señalar que el } \\
\text { uso de lanolina hidratada ha sido interrumpido } \\
\text { debido a la preocupación por la existencia de } \\
\text { residuos de pesticidas. Solo es adecuado el uso de } \\
\text { lanolina anhidro altamente purificada. } \\
\text { Un estudio de UK evaluó los resultados en } 200 \\
\text { mujeres randomizadas que usaron uno de dos } \\
\text { aerosoles: placebo de agua destilada versus } \\
\text { clorhexidina (0.2\%)/alcohol (Herd \& Feeney, } 1986 \text { ). } \\
\text { Los resultados en relación a la situación de los } \\
\text { pezones se evaluó usando la escala de Likert. } \\
\text { Ambos grupos mostraron una reducción } \\
\text { significativa en el dolor y trauma del pecho de la } \\
\text { primera a la cuarta semana. El grupo de la } \\
\text { clorhexidina experimentó menos dolor y } \\
\text { significativamente más madres del grupo de } \\
\text { clorhexidina estaban amamantando a las } 4 \\
\text { semanas. } \\
\text { Un segundo RTC de Italia incluyó } 219 \text { mujeres } \\
\text { primíparas y comparaba el aerosol y/o las cremas } \\
\text { evitando el tratamiento. Los resultados del estudio } \\
\text { sugerían que el uso de los sprays de aerosol } \\
\text { podrían no ser mejores que no hacer nada. } \\
\text { Un RCT incluyó a } 50 \text { mujeres primíparas y } \\
\text { multíiparas para evaluar la efectividad de un apósito } \\
\text { frente a ningún tratamiento (Ziemer et al, } 1995 \text {. Las } \\
\text { mujeres actuaron como sus propios controles con }\end{array}$ & & $\begin{array}{l}\text { Ziemer et al, } \\
1995\end{array}$ & \\
\hline
\end{tabular}




\begin{tabular}{|c|c|c|c|c|}
\hline $\begin{array}{c}\text { Guía } \\
\text { (Enfoque) }\end{array}$ & $\begin{array}{l}\text { Resumen sobre la evidencia } \\
\text { (Calidad de la evidencia) }\end{array}$ & $\begin{array}{l}\text { Recomendaciones } \\
\text { (Grado) }\end{array}$ & $\begin{array}{c}\text { Referencias } \\
\text { bibliográficas } \\
\text { (Tipo de } \\
\text { publicación) }\end{array}$ & Comentarios \\
\hline & $\begin{array}{l}\text { los pechos asignados al azar en cada grupo. El } \\
\text { apósito era de polietileno y estaba especialmente } \\
\text { diseñado para el estudio. Aunque hubo una } \\
\text { disminución estadísticamente significativa en los } \\
\text { valores totales de dolor, evaluados usando una } \\
\text { escala de descripción verbal de seis puntos, para } \\
\text { el grupo del apósito, hubo una tasa de deserción } \\
\text { (16\%), debido, probablemente, a la eliminación } \\
\text { dolorosa del apósito que podía contrarrestar el } \\
\text { resultado de la reducción en la escala de dolor. Los } \\
\text { revisores concluyeron que debido al pequeño } \\
\text { tamaño muestral, al inadecuado informe de los } \\
\text { datos y a la inclusión solo de mujeres primíparas } \\
\text { en bastantes estudios los resultados no pueden } \\
\text { generalizarse. La evidencia limitada disponible } \\
\text { muestra que ninguna intervención única ofreció } \\
\text { beneficios concluyentes en cuanto a la prevención } \\
\text { de dolor en los pezones. } \\
\text { Dyson et al (2006) revisaron } 3 \text { estudios sobre el uso } \\
\text { de agentes tópicos para tratar los pezones doloridos } \\
\text { y concluyeron que ningún tratamiento es mas eficaz } \\
\text { que otro. Su revisión también identificó un estudio } \\
\text { que evaluaba el beneficio de las conchas } \\
\text { protectoras, evidencia que no apoyaba su uso como } \\
\text { una intervención efectiva para el manejo de los } \\
\text { pezones doloridos. } \\
\text { Una revisión anterior de Renfrew y cols. (2002) } \\
\text { incluyó evidencia de tres estudios de pezoneras, en } \\
\text { los que no se encontró ningún efecto beneficioso de } \\
\text { su uso sobre al duración de la lactancia, la } \\
\text { transferencia de leche o el volumen de la misma. } \\
\text { Si se sospecha problema con el agarre la madre } \\
\text { debería separar al bebé introduciendo un dedo por } \\
\text { la comisura de la boca del bebé para romper el } \\
\text { vacío y soltar el pezón/areola. La posición y el } \\
\text { agarre correcto son cruciales, y no hay evidencia } \\
\text { que sugiera que limitar la duración de la lactancia o }\end{array}$ & & $\begin{array}{l}2006 \\
\text { Renfrew et al, } \\
2000\end{array}$ & \\
\hline
\end{tabular}




\begin{tabular}{|c|c|c|c|c|}
\hline $\begin{array}{c}\text { Guía } \\
\text { (Enfoque) }\end{array}$ & $\begin{array}{l}\text { Resumen sobre la evidencia } \\
\text { (Calidad de la evidencia) }\end{array}$ & $\begin{array}{l}\text { Recomendaciones } \\
\text { (Grado) }\end{array}$ & $\begin{array}{c}\text { Referencias } \\
\text { bibliográficas } \\
\text { (Tipo de } \\
\text { publicación) } \\
\end{array}$ & Comentarios \\
\hline & $\begin{array}{l}\text { la aplicación de agentes tópicos, tal como leche } \\
\text { materna o lanolina tengan un efecto sobre los } \\
\text { pezones doloridos. El uso de pezoneras no resuelve } \\
\text { el agarre y la colocación incorrecta. } \\
\text { El dolor de los pezones puede estar relacionado con } \\
\text { hongos, sobre esto se incluye información y } \\
\text { consejos en el capitulo del manejo del infante. }\end{array}$ & & & \\
\hline $\begin{array}{l}\text { NICE } \\
\text { update } \\
2011\end{array}$ & $\begin{array}{l}\text { Un RTC } 100 \text { evaluó la efectividad del agua de menta } \\
\text { en la prevención de las grietas del pezón durante la } \\
\text { lactancia en comparación con la leche maternal } \\
\text { extraída. }\end{array}$ & & $\begin{array}{l}\text { 100. Sayyah } \\
\text { MM, 2007 }\end{array}$ & \\
\hline $\begin{array}{l}\text { Perinatal } \\
\text { Services } \\
\text { BC, } 2013\end{array}$ & $\begin{array}{l}\text { DOLOR DE PEZON } \\
\text { Dolor de pezón inicial o transitorio } \\
\text { El malestar aparece en la primera semana } \\
\text { postparto, alcanza el pico entre los días } 3 \text { y } 6 \text { y } \\
\text { generalmente disminuye después del séptimo día. } \\
\text { La causa más común es la posición y el agarre del } \\
\text { bebé durante la toma } 38 \\
\text { Cuidado } \\
\text { Evaluar y facilitar la colocación y el agarre del bebé } \\
\text { durante la toma. } \\
\text { Aplicar calostro/ leche maternal o agua templada en } \\
\text { los pezones después de la toma y luego dejarlos } \\
\text { secar al aire } 39 \\
\text { Limitar la duración de la toma no alivia o previene el } \\
\text { dolor de los pezones y es perjudicial para el } \\
\text { establecimiento de la lactancia. } 38,39 \\
\text { Dolor prolongado o persistente: causas variadas } \\
\text { y el diagnóstico específico es difícil } \\
{ }^{*} \text { Causas físicas/mecánicas } \\
\text { Caracterizado por irritación del pezón y } \\
\text { enrojecimiento, aplastamiento del pezón tras la } \\
\text { toma, abrasión, fisuras y/o morado o sangrante. } \\
\text { *Causas posibles e irritantes } \\
\text {-- Agarre inadecuado o superficial; fricción del pezón }\end{array}$ & & $\begin{array}{l}\text { 38. Riordan J, } \\
2010 \text { (libro). } \\
\text { 39. Lawerence } \\
\text { RA, } 2005 \text { (libro). } \\
\text { 107. Morland- } \\
\text { Schultz } 2005 \\
\text { (RS). }\end{array}$ & \\
\hline
\end{tabular}




\begin{tabular}{|c|c|c|c|c|}
\hline $\begin{array}{c}\text { Guía } \\
\text { (Enfoque) }\end{array}$ & $\begin{array}{l}\text { Resumen sobre la evidencia } \\
\text { (Calidad de la evidencia) }\end{array}$ & $\begin{array}{l}\text { Recomendaciones } \\
\text { (Grado) }\end{array}$ & $\begin{array}{c}\text { Referencias } \\
\text { bibliográficas } \\
\text { (Tipo de } \\
\text { publicación) }\end{array}$ & Comentarios \\
\hline & $\begin{array}{l}\text { dentro de la boca del bebé; la mandíbula del bebé } \\
\text { aprieta con fuerza el pecho. } \\
\text {-- Bebé con paladar alto o hendido: anquiloglosia o } \\
\text { succión desorganizada debido a prematuridad o } \\
\text { compromiso neurológico. } \\
\text {--Excesiva presión durante la extracción o el uso } \\
\text { incorrecto de la copa } \\
\text {--Sensibilidad de los pezones a cremas o geles } \\
\text {---Irritación por al ropa o el uso de productos tales } \\
\text { como jabones y detergentes } \\
\text { Cuidado: evaluar y tratar la posible causa } \\
\text { - Facilitar una posición y agarre efectiva del bebe } \\
\text { durante la toma. } \\
\text { - Tratar los pezones agrietados, fisurados o con } \\
\text { sangre; aplicar leche maternal extraída y/o } \\
\text { enjuagar con agua después de la toma y dejar al } \\
\text { aire ;38 } \\
\text { - Empezar la toma por el pezón menos afectado; } \\
\text { - Dejar de amamantar con el pecho afectado solo } \\
\text { cuando la lactancia sea intolerable y extraerse } \\
\text { leche manualmente durante este periodo para } \\
\text { mantener la producción. } \\
\text { - Corregir el uso inadecuado de los extractores y } \\
\text { del equipo } \\
\text { - Dejar de usar cremas, geles u otras posibles } \\
\text { sustancias irritantes } \\
\text { Remitir a los bebes con anquiloglosia o disfunción } \\
\text { en la succión a la clínica de lactancia o a un } \\
\text { profesional de la salud experto en lactancia materna. } \\
\text { Uso de cremas, geles y agentes tópicos } \\
\text { - "Ningún agente tópico muestra mejores resultados } \\
\text { en el alivio de las molestias del pezón”107 } \\
\text { - Consenso general: si una madre esta usando un } \\
\text { producto que ella cree que la esta ayudando y no es }\end{array}$ & & & \\
\hline
\end{tabular}




\begin{tabular}{|c|c|c|c|c|}
\hline $\begin{array}{c}\text { Guía } \\
\text { (Enfoque) }\end{array}$ & $\begin{array}{l}\text { Resumen sobre la evidencia } \\
\text { (Calidad de la evidencia) }\end{array}$ & $\begin{array}{l}\text { Recomendaciones } \\
\text { (Grado) }\end{array}$ & $\begin{array}{l}\text { Referencias } \\
\text { bibliográficas } \\
\text { (Tipo de } \\
\text { publicación) }\end{array}$ & Comentarios \\
\hline & $\begin{array}{l}\text { prejudicial para su salud o la de su bebé, no } \\
\text { oponerse a su uso38. }\end{array}$ & & & \\
\hline $\begin{array}{l}\text { GPC } \\
\text { embarazo } \\
, 2014\end{array}$ & $\begin{array}{l}\text { La RS de Page (2009) tuvo como objetivo } \\
\text { determinar la eficacia de las intervenciones } \\
\text { disponibles para prevenir o reducir el dolor o las } \\
\text { lesiones en el pezón asociado a la lactancia } \\
\text { materna. La revisión evaluó información de } 12 \\
\text { estudios, que examinaban una gran variedad de } \\
\text { intervenciones no comparables entre sí, por lo que } \\
\text { no se realizó metanálisis. La especificidad del } \\
\text { diseño de algunos de estos estudios, normalmente } \\
\text { con muestras de estudio pequeña, limita la } \\
\text { aplicabilidad de alguno de sus resultados. } \\
\text { Varios ECAs han comparado la aplicación de } \\
\text { compresas de agua tibia, bolsitas de té o leche } \\
\text { materna extraída manualmente para controlar el } \\
\text { dolor y las lesiones del pezón. La colocación de } \\
\text { compresas de agua tibia ha mostrado los mejores } \\
\text { resultados. } \\
\text { Un ECA en } 73 \text { mujeres comparó estos tres sistemas } \\
\text { para controlar el dolor como complemento a la } \\
\text { formación sobre lactancia materna a partir de } \\
\text { información verbal y escrita. Se animó a las mujeres } \\
\text { a que usaran el sistema al que habían sido } \\
\text { asignadas cuatro veces al día tras amamantar a sus } \\
\text { bebés. El grupo que obtuvo una mayor disminución } \\
\text { del dolor medido con una escala visual, fue el que } \\
\text { usó compresas de agua tibia. Los resultados fueron } \\
\text { similares en otro ensayo clínico en } 65 \text { madres en las } \\
\text { que las compresas o el uso de bolsas de té } \\
\text { mostraron una mayor disminución del dolor que la } \\
\text { leche materna extraída manualmente (Calidad } \\
\text { moderada) (Buchko et al, } 1994) \text {. } \\
\text { Un ECA que comparó la aplicación de clorhexidina } \\
\text { (0,2\%) frente a un placebo de agua destilada en }\end{array}$ & $\begin{array}{l}\text { Se sugiere el uso de compresas de agua tibia tras el } \\
\text { amamantamiento en aquellas madres que amamanten con dolor } \\
\text { o lesiones en los pezones (Recomendación débil). }\end{array}$ & & $\begin{array}{l}\text { La revisión } \\
\text { cochrane excluye el } \\
\text { ECA de clorexidina } \\
\text { por tratarse de } \\
\text { prevención y no de } \\
\text { manejo del dolor en } \\
\text { el pezón (Herd } \\
\text { 1986), así como el } \\
\text { estudio de } \\
\text { Lavergne1997sobre } \\
\text { bolsas de té y } \\
\text { compresas } \\
\text { calientes por su } \\
\text { calidad } \\
\text { metodológica. } \\
\text { No incluyen el } \\
\text { estudio de Clark } \\
1985 \text { sobre el uso } \\
\text { de calor, entre otras } \\
\text { intervenciones... } \\
\text { El estudio de } \\
\text { Buchko et al, } 1994 \text {, } \\
\text { sobre agua vs. } \\
\text { bolsas de té } \\
\text { también fue } \\
\text { excluido de la } \\
\text { revisión Cochrane } \\
\text { por ser preventivo. }\end{array}$ \\
\hline
\end{tabular}




\begin{tabular}{|l|l|l|l|}
\hline $\begin{array}{c}\text { Guía } \\
\text { (Enfoque) }\end{array}$ & \multicolumn{1}{|c|}{$\begin{array}{c}\text { Resumen sobre la evidencia } \\
\text { (Calidad de la evidencia) }\end{array}$} & $\begin{array}{c}\text { Referencias } \\
\text { bibliográficas } \\
\text { (Tipo de } \\
\text { publicación) }\end{array}$ & $\begin{array}{c}\text { Recomendaciones } \\
\text { (Grado) }\end{array}$ \\
\hline $\begin{array}{l}\text { Comentarios } \\
\text { las madres, mostró una reducción significativa de generales en el grupo que había usado } \\
\text { clorhexidina aunque no se observaron diferencias } \\
\text { significativas en el número o la gravedad de las } \\
\text { lesiones que se redujeron significativamente en } \\
\text { ambos grupos (Calidad moderada) (Herd et al, } \\
\text { 1986). } \\
\text { La RS de Page (2009) no aportó pruebas suficientes } \\
\text { para sustentar el uso de apósitos de polietileno o de } \\
\text { hidrogel, ungüentos o discos protectores de lanolina, } \\
\text { colagenasa o dexpantenol. }\end{array}$ & & \\
\hline
\end{tabular}




\subsection{Revisiones sistemáticas}

Tabla 3- Resumen de RS actuales

\begin{tabular}{|c|c|c|c|c|c|c|}
\hline $\begin{array}{l}\text { Referencia } \\
\text { (Cita } \\
\text { Abreviada) }\end{array}$ & $\begin{array}{l}\text { Estudio (Diseño } \\
\text { y objetivo) }\end{array}$ & $\begin{array}{l}\text { Población } \\
\text { (no y características) }\end{array}$ & $\begin{array}{l}\text { Descripción de las intervenciones } \\
\text { comparaciones, exposiciones o } \\
\text { pruebas a estudio }\end{array}$ & $\begin{array}{l}\text { Resultados } \\
\text { (Estimadores de resultados-Magnitud } \\
\text { del efecto) }\end{array}$ & $\begin{array}{l}\text { Conclusiones } \\
\text { (conclusiones) }\end{array}$ & $\begin{array}{l}\text { Comentarios } \\
\text { Calidad de la } \\
\text { evidencia } \\
\text { Financiación } \\
\text { comentarios) }\end{array}$ \\
\hline Dennis CL, 2014 & $\begin{array}{l}\text { Diseño } \\
\text { Revisión } \\
\text { sistemática } \\
\text { Objetivo } \\
\text { Evaluaron los } \\
\text { efectos de } \\
\text { diferentes } \\
\text { intervenciones en } \\
\text { la resolución o la } \\
\text { reducción del } \\
\text { dolor en los } \\
\text { pezones y el } \\
\text { impacto de estas } \\
\text { intervenciones en } \\
\text { otros desenlaces } \\
\text { como la curación } \\
\text { de las lesiones } \\
\text { del pezón, las } \\
\text { infecciones del } \\
\text { pezón, la } \\
\text { aparición de } \\
\text { mastitis, la } \\
\text { duración de la } \\
\text { lactancia } \\
\text { (exclusiva y no } \\
\text { exclusiva) y la } \\
\text { satisfacción } \\
\text { materna }\end{array}$ & $\begin{array}{l}4 \text { ensayos, que } \\
\text { incluyeron un total } \\
\text { de } 656 \text { mujeres en } \\
\text { lactancia materna: } \\
-2 \text { ensayos cuasi } \\
\text { aletorizado } \\
-1 \text { ensayo clínico } \\
\text { aleatorizado } \\
-1 \text { ensayo clínico } \\
\text { aleatorizado doble } \\
\text { ciego }\end{array}$ & $\begin{array}{l}\text { Se incluyeron intervenciones } \\
\text { diseñadas para reducir el dolor en el } \\
\text { pezón en la lactancia materna. } \\
\text { Esto incluyó tratamientos } \\
\text { farmacológicos, y tratamientos no } \\
\text { farmacológicos. } \\
\text { Se compararon los siguientes } \\
\text { intervenciones entre sí } \\
\text { o con educación sobre la correcta } \\
\text { lactancia. } \\
\text { 1.Apósitos en gel de glicerina } \\
\text { 2. Pezoneras con lanolina } \\
\text { 3. Lanolina sola } \\
\text { 4. Aplicación de leche materna } \\
\text { extraída } \\
5 \text { Ungüentos multiusos para el pezón } \\
\text { (mupirocina } 2 \%+\text { miconazol polvo } \\
2 \% \text { betametasona } 0,1 \% \text { ) } \\
\text { Todas las mujeres incluidas en los } \\
\text { diferentes grupos de los estudios de } \\
\text { Cadwell } 2014 \text {, Mohammadzadeh } \\
\text { 2005, y Jackson } 2013 \text { recibieron } \\
\text { educación para corregir su técnica de } \\
\text { lactancia materna. En Dennis } 2012 \text {, } \\
\text { todas las participantes recibieron } \\
\text { atención posparto habitual que } \\
\text { incluyó la remisión a un especialista } \\
\text { en lactancia para las mujeres que } \\
\text { experimentaran pezones agrietados. }\end{array}$ & $\begin{array}{l}\text { Sólo se pudo realizar el análisis } \\
\text { agrupado para la comparación de la } \\
\text { lanolina frente a no recibir ninguna } \\
\text { intervención. En la revisión sistemática } \\
\text { no se pudo agrupar los datos para otros } \\
\text { desenlaces, debido a la heterogeneidad } \\
\text { en las medidas de los resultados o a la } \\
\text { variabilidad de las intervenciones. } \\
\text { En general, no hubo pruebas suficientes } \\
\text { para recomendar ninguna de las } \\
\text { intervenciones evaluadas para el } \\
\text { tratamiento del dolor en los pezones. Sin } \\
\text { embargo, un hallazgo importante fue } \\
\text { que independientemente del tratamiento } \\
\text { utilizado, para la mayoría de las mujeres } \\
\text { con dolor en el pezón, este se reduce a } \\
\text { niveles leves después de } \\
\text { aproximadamente } 7 \text { a } 10 \text { días post- } \\
\text { parto. La provisión de orientación } \\
\text { anticipada sobre el tiempo habitual para } \\
\text { la reducción del dolor puede ser una } \\
\text { estrategia útil para ayudar las mujeres } \\
\text { seguir con la lactancia materna } \\
\text { exclusiva. }\end{array}$ & $\begin{array}{l}\text { No hubo pruebas } \\
\text { suficientes para } \\
\text { demostrar que los } \\
\text { apósitos de gel de } \\
\text { glicerina, las pezoneras } \\
\text { con lanolina, la lanolina } \\
\text { sola, o los ungüentos } \\
\text { multiusos para el pezón } \\
\text { mejoraran } \\
\text { significativamente las } \\
\text { percepciones maternas } \\
\text { de dolor en los pezones. } \\
\text { Los resultados de estos } \\
\text { cuatro ensayos de } \\
\text { buena calidad } \\
\text { metodológica sugirieron } \\
\text { que no aplicarse nada o } \\
\text { leche materna extraída } \\
\text { puede ser igual o más } \\
\text { beneficioso en la } \\
\text { experiencia a corto plazo } \\
\text { de mejora del dolor del } \\
\text { pezón que la aplicación } \\
\text { de la lanolina. }\end{array}$ & $\begin{array}{l}\text { La calidad } \\
\text { metodológica de } \\
\text { los estudios } \\
\text { incluidos fue } \\
\text { buena pero la } \\
\text { calidad general } \\
\text { de las pruebas } \\
\text { para el } \\
\text { desenlace } \\
\text { primario de } \\
\text { dolor en el } \\
\text { pezón era de } \\
\text { baja calidad, } \\
\text { sobre todo } \\
\text { porque los } \\
\text { estudios que } \\
\text { aportaron datos } \\
\text { para el análisis } \\
\text { tuvieron pocos } \\
\text { participantes. }\end{array}$ \\
\hline Vieiria F, 2013 & Diseño & 6 ensayos, que las & Tres estudios evaluaron el uso de la & Los mejores resultados para el & Teniendo en cuenta los & \\
\hline
\end{tabular}




\begin{tabular}{|c|c|c|c|c|c|c|}
\hline $\begin{array}{l}\text { Referencia } \\
\text { (Cita } \\
\text { Abreviada) }\end{array}$ & $\begin{array}{l}\text { Estudio (Diseño } \\
\text { y objetivo) }\end{array}$ & $\begin{array}{l}\text { Población } \\
\text { (no y características) }\end{array}$ & $\begin{array}{l}\text { Descripción de las intervenciones } \\
\text { comparaciones, exposiciones o } \\
\text { pruebas a estudio }\end{array}$ & $\begin{array}{l}\text { Resultados } \\
\text { (Estimadores de resultados-Magnitud } \\
\text { del efecto) }\end{array}$ & $\begin{array}{l}\text { Conclusiones } \\
\text { (conclusiones) }\end{array}$ & $\begin{array}{l}\text { Comentarios } \\
\text { Calidad de la } \\
\text { evidencia } \\
\text { Financiación } \\
\text { comentarios) }\end{array}$ \\
\hline & $\begin{array}{l}\text { Revisión } \\
\text { sistemática } \\
\text { Objetivo } \\
\text { Identificar las } \\
\text { intervenciones } \\
\text { más eficaces para } \\
\text { tratar las lesiones } \\
\text { del pezón } \\
\text { en las madres } \\
\text { que dan lactancia } \\
\text { materna. }\end{array}$ & $\begin{array}{l}\text { muestras variaron } \\
\text { entre } 42 \text { y } 225 \\
\text { mujeres en lactancia } \\
\text { materna: } \\
-1 \text { ensayos clínico } \\
\text { controlado } \\
-4 \text { ensayo clínico } \\
\text { aleatorizado } \\
-1 \text { ensayo clínico } \\
\text { doble ciego }\end{array}$ & $\begin{array}{l}\text { lanolina en comparación con la leche } \\
\text { materna. Un estudio comparó el uso } \\
\text { de lanolina en asociación con las } \\
\text { pezoneras de protección frente al } \\
\text { hidrogel. } \\
\text { Otro tratamiento investigado para el } \\
\text { manejo del trauma pezón consistió en } \\
\text { una comparación entre el uso de } \\
\text { película de polietileno frente a ningún } \\
\text { tratamiento. } \\
\text { Finalmente, un estudio analizó } \\
\text { tratamiento usando un spray con } \\
\text { alcohol y clorhexidina } 0,2 \% \text { en } \\
\text { comparación con un spray placebo } \\
\text { (agua destilada). } \\
\text { Todos los grupos en cada estudio } \\
\text { recibieron educación sobre lactancia } \\
\text { materna }\end{array}$ & $\begin{array}{l}\text { tratamiento de las lesiones del pezón } \\
\text { fueron utilizando lanolina y la leche } \\
\text { materna. Aunque un estudio clínico } \\
\text { encontró que resultados positivos } \\
\text { resultantes del tratamiento usando un } \\
\text { aerosol que contiene alcohol y } \\
\text { clorhexidina } 0,2 \% \text {, en esta RS sugieren } \\
\text { que este tratamiento debería } \\
\text { investigarse ya que el uso de } \\
\text { sustancias antisépticas no se } \\
\text { recomiendan como tratamiento de } \\
\text { heridas de la piel. }\end{array}$ & $\begin{array}{l}\text { tratamientos } \\
\text { investigados, la } \\
\text { evidencia más favorable } \\
\text { indica el uso de lanolina } \\
\text { sola o en asociación con } \\
\text { pezoneras y la leche } \\
\text { materna frotada en el } \\
\text { pezón y la areola } \\
\text { después de cada sesión } \\
\text { de alimentación. Sin } \\
\text { embargo, los resultados } \\
\text { obtenidos en esta } \\
\text { revisión no son } \\
\text { concluyentes, lo que } \\
\text { indica la necesidad de } \\
\text { realizar más estudios } \\
\text { para aclarar la acción de } \\
\text { la leche materna y la } \\
\text { lanolina en los tejidos } \\
\text { dañados, así como } \\
\text { estudios con muestras } \\
\text { representativas del } \\
\text { número necesario a } \\
\text { tratar. }\end{array}$ & \\
\hline
\end{tabular}

En la búsqueda realizada se identificaron tres revisiones sistemáticas. Una revisión sistemática Cochrane publicada en el año 2014 (1), otra revisión publicada en el año 2013 (2) que fue excluida (Ver anexo I), y una tercera revisión, Araujo et al, 2013, también excluida porque tuvo como objetivo principal valorar la eficacia de una serie de intervenciones sobre la prevención primaria de las lesiones del pezón en mujeres en lactancia materna. Se incluyó sólo a Dennis 2014, por estar más actualizada, tener mayor calidad metodológica y responder a nuestra pregunta de interés. 
En la revisión sistemática Cochrane (1), los autores incluyeron estudios que evaluaron los efectos de diferentes intervenciones (apósitos en gel de glicerina, pezoneras con lanolina, lanolina sola, aplicación de leche materna extraída, y ungüentos multiusos para el pezón) en la resolución o la reducción del dolor de los pezones y el impacto de estas intervenciones en otros desenlaces, como la curación de las lesiones o de infecciones del pezón, el desarrollo de mastitis, la duración de la lactancia (exclusiva y no exclusiva), y la satisfacción materna con la lactancia y el tratamiento instaurado. Cabe señalar que en esta revisión fueron excluidas las mujeres que presentaron dolor en el pezón como consecuencia de la extracción manual de leche materna, debido a que el tratamiento en esta población difiere del de la población incluida en la revisión.

Debido a la variabilidad en las intervenciones y en la medición de los resultados, los autores de la revisión sólo pudieron meta-analizar los datos de los estudios para la comparación del uso de lanolina frente a no recibir ninguna intervención. 


\subsection{Resumen de GPC base y RS disponibles}

La guía NICE señala que se debe advertir a las mujeres que si tienen dolor en el pezón o estos están agrietados, es probable que se deba a un mal agarre (Recomendación de buena práctica). En cuanto a los tratamientos tópicos para el dolor en el pezón (como la propia leche materna o lanolina), los escudos y las pezoneras, señalan que no se ha demostrado que sean eficaces (3).

En la Perinatal Services $B C$, se distingue entre el dolor inicial o transitorio del pezón y el dolor prolongado y persistente. En el primer caso se recomienda valorar y facilitar la posición y el agarre y aplicar leche materna extraída o agua caliente sobre el pezón tras el amamantamiento y dejar secar. En el segundo caso, se aconseja además empezar a amamantar del pecho con el pezón menos afectado y discontinuar la lactancia del pecho afectado sólo cuando la lactancia es insoportable, realizando extracción manual durante este tiempo para mantener la producción de leche, rectificar el uso inapropiado de los extractores de leche y discontinuar el uso de cremas, geles u otros posibles irritantes. También se recomienda referir los niños con anquiloglosia o succión disfuncional a clínicas de lactancia o expertos en lactancia materna.

En cuanto al uso de cremas o pomadas para los pezones, aunque ninguno ha demostrado aliviar el disconfort en el pezón, el consenso general es que si la mujer está utilizando un producto que cree que le ayuda y no es dañino para ella o el niño, no oponerse a que lo use (4).

En la guía del embarazo del Ministerio de Salud (5), se sugiere el uso de compresas de agua tibia tras el amamantamiento en aquellas madres que amamantan con dolor o lesiones en los pezones (recomendación débil). Se basan en una revisión sistemática de 2005 incluida en la NICE y en la revisión de Cochrane identificada, pero que se basa en estudios que los autores excluyen por mala calidad o por tener carácter preventivo.

La conclusión a la que llegan los autores de la revisión sistemática incluida (1) es que no hay pruebas suficientes para demostrar que los apósitos de gel de glicerina, las pezoneras con lanolina, la lanolina sola o las pomadas multiusos para el pezón mejoren significativamente la percepción materna de dolor en los pezones. Los resultados de los cuatro ensayos clínicos de buena calidad incluidos sugieren que no aplicarse nada o aplicarse la leche materna extraída podría ser igual o más beneficioso que la aplicación de la lanolina en la mejoría del dolor en el pezón a corto plazo.

\subsection{Conclusión (marcar con una X):}

\begin{tabular}{|l|l|}
\hline & Adopción GPC/Revisión sistemática \\
\hline $\mathrm{X}$ & $\begin{array}{l}\text { Elaboración parcial (desde la fecha final de la revisión de...) } \\
\text { Elaboración de novo }\end{array}$ \\
\hline
\end{tabular}




\subsection{Diseño de la estrategia de búsqueda de estudios individuales}

\begin{tabular}{|l|l|}
\hline Criterios de selección de estudios & ECA, estudios de cohortes \\
\hline Período de búsqueda & Desde 2014 en adelante \\
\hline Bases de datos & Cochrane, PUMBED y EMBASE y CINHAL \\
\hline
\end{tabular}

Ver estrategias de búsqueda de estudios originales en el ANEXO I.

Primero se incluye la búsqueda de revisiones sistemáticas y luego se elimina el filtro de revisiones y se limita la búsqueda desde 2014 para localizar nuevos estudios publicados a partir de la fecha de la revisión sistemática incluida. 


\section{2- Resumen de la evidencia}

\section{1-GRADE Evidence Profile}

Comparación 1: Apósito en gel de glicerina versus educación sobre la lactancia materna (las mujeres de todos los grupos del estudio recibieron educación para corregir su técnica de lactancia)

Bibliografía (RS): Dennis CL, Jackson K,Watson J. Interventions for treating painful nipples among breastfeeding women. Cochrane Database of Systematic Reviews 2014, Issue 12. Art. No.: CD007366. DOI: 10.1002/14651858.CD007366.pub2.

\begin{tabular}{|c|c|c|c|c|c|c|c|c|c|c|c|c|}
\hline \multicolumn{7}{|c|}{ Evaluación de la calidad } & \multicolumn{2}{|c|}{ № de pacientes } & \multicolumn{2}{|r|}{ Efecto } & \multirow[b]{2}{*}{ Calidad } & \multirow[b]{2}{*}{ Importancia } \\
\hline $\begin{array}{c}\text { № de } \\
\text { estudios }\end{array}$ & $\begin{array}{l}\text { Diseño de } \\
\text { estudio }\end{array}$ & $\begin{array}{l}\text { Riesgo } \\
\text { de sesgo }\end{array}$ & Inconsistencia & $\begin{array}{l}\text { Evidencia } \\
\text { indirecta }\end{array}$ & Imprecisión & $\begin{array}{c}\text { Otras } \\
\text { consideraciones }\end{array}$ & $\begin{array}{l}\text { Apósito } \\
\text { en gel de } \\
\text { glicerina }\end{array}$ & $\begin{array}{l}\text { Educación } \\
\text { sobre la } \\
\text { lactancia } \\
\text { materna }\end{array}$ & $\begin{array}{l}\text { Relativo } \\
(95 \% \mathrm{Cl})\end{array}$ & $\begin{array}{l}\text { Absoluto } \\
(95 \% \mathrm{Cl})\end{array}$ & & \\
\hline \multicolumn{13}{|c|}{ Reducción del dolor en el pezón - Medido con escala descriptora verbal de 5 puntos al final de la evaluación (tras 10 días) } \\
\hline 1 & ECA & serio 1 & no serio $\underline{2}$ & no serio & serio $^{3}$ & ninguno & 33 & 30 & - & $\begin{array}{c}\text { MD } 0.22 \text { más } \\
(0.32 \text { menos a } 0.76 \text { más })\end{array}$ & BAJA & CRÍTICO \\
\hline \multicolumn{13}{|c|}{ Lesiones en el pezón (curación)- al final de la evaluación (tras10 días)ํㅗㄴ } \\
\hline 1 & ECA & serio 1 & no serio $\stackrel{2}{2}$ & no serio & serio4 & ninguno & $\begin{array}{l}27 / 33 \\
(81.8 \%)\end{array}$ & $\begin{array}{l}25 / 30 \\
(83.3 \%)\end{array}$ & $\begin{array}{c}\text { RR } 0.98 \\
(0.78 \text { a } 1.23)\end{array}$ & $\begin{array}{l}17 \text { menos por } 1000 \text { (de } \\
183 \text { menos a } 192 \text { más ) }\end{array}$ & BAJA & CRÍTICO \\
\hline \multicolumn{13}{|c|}{ Satisfacción materna con el tratamiento $\underline{\underline{ }}$} \\
\hline 1 & ECA & serio 1 & no serio $\underline{2}$ & no serio & serio4 & ninguno & $\begin{array}{c}33 / 33 \\
(100.0 \%)\end{array}$ & $\begin{array}{l}27 / 30 \\
(90.0 \%)\end{array}$ & $\begin{array}{c}\text { RR } 1.11 \\
(0.97 \text { a } 1.27)\end{array}$ & $\begin{array}{l}99 \text { más por } 1000 \text { (de } 27 \\
\text { menos a } 243 \text { más ) }\end{array}$ & BAJA & CRÍTICO \\
\hline
\end{tabular}

MD-Diferencia de medias, RR-riesgo relativo

1. Riesgo de sesgo, el estudio de Cadwell 2004 mostró un alto riesgo de sesgo de selección)

1. Ŕ́ngo de sesgo

3. Bajo número de participantes.

3. Bajo número de participantes.

4. Medido a través de una evaluación de la partera basado en una escala ( 1 a 3 puntos) donde $1=$ mejor $/$ resuelto, $2=\sin$ cambio, y $3=$ peor

6. Medico mediante autoinforme materno que van desde muy o algo satisfechas a muy o bastante insatisfechas 
Comparación 2: Pezoneras con lanolina versus educación sobre la lactancia materna (las mujeres de todos los grupos del estudio recibieron educación para corregir su técnica de lactancia)

Bibliografía (revisiones sistemáticas): Dennis CL, Jackson K,Watson J. Interventions for treating painful nipples among breastfeeding women. Cochrane Database of Systematic Reviews 2014, Issue 12. Art. No.: CD007366. DOI: 10.1002/14651858.CD007366.pub2.

\begin{tabular}{|c|c|c|c|c|c|c|c|c|c|c|c|c|}
\hline \multicolumn{7}{|c|}{ Evaluación de la calidad } & \multicolumn{2}{|c|}{ № de pacientes } & \multicolumn{2}{|r|}{ Efecto } & \multirow[b]{2}{*}{ Calidad } & \multirow[b]{2}{*}{ Importancia } \\
\hline $\begin{array}{c}\text { № de } \\
\text { estudios }\end{array}$ & $\begin{array}{l}\text { Diseño de } \\
\text { estudio }\end{array}$ & $\begin{array}{l}\text { Riesgo de } \\
\text { sesgo }\end{array}$ & Inconsistencia & $\begin{array}{l}\text { Evidencia } \\
\text { indirecta }\end{array}$ & Imprecisión & $\begin{array}{c}\text { Otras } \\
\text { consideraciones }\end{array}$ & $\begin{array}{c}\text { Pezoneras } \\
\text { con } \\
\text { lanolina }\end{array}$ & $\begin{array}{c}\text { Educación } \\
\text { sobre la } \\
\text { lactancia } \\
\text { materna }\end{array}$ & $\begin{array}{l}\text { Relativo } \\
(95 \% \mathrm{Cl})\end{array}$ & $\begin{array}{l}\text { Absoluto } \\
(95 \% \mathrm{Cl})\end{array}$ & & \\
\hline \multicolumn{13}{|c|}{ Reducción del dolor en el pezón - Medido con escala descriptora verbal de 5 puntos al final de la evaluación (tras10 días) } \\
\hline 1 & ECA & serio 1 & no serio $\stackrel{2}{2}$ & no serio & serio $\underline{3}$ & ninguno & 31 & 30 & - & $\begin{array}{c}\text { MD } 0.2 \text { menos } \\
(0.6 \text { menos a } 0.2 \text { más })\end{array}$ & BAJA & CRÍTICO \\
\hline \multicolumn{13}{|c|}{ Lesiones en el pezón (curación) - al final de la evaluación (tras 10 días) $\frac{5}{5}$} \\
\hline 1 & ECA & serio 1 & no serio $\underline{2}$ & no serio & serio 4 & ninguno & $3 / 31(9.7 \%)$ & $5 / 30(16.7 \%)$ & $\begin{array}{c}\text { RR } 0.58 \\
(0.15 \text { a } 2.22)\end{array}$ & $\begin{array}{l}70 \text { menos por } 1000 \text { (de } \\
142 \text { menos a } 203 \text { más ) }\end{array}$ & BAJA & CRÍTICO \\
\hline \multicolumn{13}{|c|}{ Satisfacción materna con el tratamiento $\underline{6}$} \\
\hline 1 & ECA & serio 1 & no serio $\underline{2}$ & no serio & serio 4 & ninguno & $\begin{array}{l}28 / 31 \\
(90.3 \%)\end{array}$ & $27 / 30(90.0 \%)$ & $\begin{array}{c}\text { RR } 1.00 \\
(0.85 \text { a } 1.18)\end{array}$ & $\begin{array}{l}0 \text { menos por } 1000 \text { (de } \\
135 \text { menos a } 162 \text { más ) }\end{array}$ & BAJA & CRÍTICO \\
\hline
\end{tabular}

MD-Diferencia de medias, RR-riesgo relativo

1. Riesgo de sesgo, el estudio de Cadwell 2004 mostró un alto riesgo de sesgo de selección)

2. Único estudio

3. Bajo número de participantes.

EI IC 95\% no excluye apreciable beneficio ni apreciable daño

5. Medido a través de una evaluación de la partera basado en una escala ( 1 a 3 puntos) donde $1=$ mejor $/$ resuelto, $2=\sin$ cambio, y $3=$ peor

6. Medido mediante autoinforme materno que van desde muy o algo satisfechas a muy o bastante insatisfechas 
Comparación 3: Apósito en gel de glicerina versus pezoneras con lanolina (las mujeres de todos los grupos del estudio recibieron educación para corregir su técnica de lactancia)

Bibliografía (revisiones sistemáticas): Dennis $\mathrm{CL}$, Jackson $\mathrm{K}$,Watson J. Interventions for treating painful nipples among breastfeeding women. Cochrane Database of Systematic Reviews 2014, Issue 12. Art. No.: CD007366. DOI: 10.1002/14651858.CD007366.pub2.

\begin{tabular}{|c|c|c|c|c|c|c|c|c|c|c|c|c|}
\hline \multicolumn{7}{|c|}{ Evaluación de la calidad } & \multicolumn{2}{|c|}{ № de pacientes } & \multicolumn{2}{|r|}{ Efecto } & \multirow[b]{2}{*}{ Calidad } & \multirow[b]{2}{*}{ Importancia } \\
\hline $\begin{array}{c}\text { № de } \\
\text { estudios }\end{array}$ & $\begin{array}{c}\text { Diseño } \\
\text { de } \\
\text { estudio }\end{array}$ & $\begin{array}{c}\text { Riesgo } \\
\text { de } \\
\text { sesgo }\end{array}$ & Inconsistencia & $\begin{array}{l}\text { Evidencia } \\
\text { indirecta }\end{array}$ & Imprecisión & $\begin{array}{c}\text { Otras } \\
\text { consideraciones }\end{array}$ & $\begin{array}{l}\text { Apósito en } \\
\text { gel de } \\
\text { glicerina }\end{array}$ & $\begin{array}{l}\text { Pezoneras } \\
\text { con lanolina }\end{array}$ & $\begin{array}{l}\text { Relativo } \\
(95 \% \mathrm{Cl})\end{array}$ & $\begin{array}{l}\text { Absoluto } \\
(95 \% \mathrm{Cl})\end{array}$ & & \\
\hline \multicolumn{13}{|c|}{ Reducción del dolor en el pezón - Medido con escala descriptora verbal de 5 puntos al final de la evaluación (tras 10 días) } \\
\hline 1 & ECA & serio-1 & no serio? & no serio & serio $\underline{3}$ & ninguno & 33 & 31 & - & $\begin{array}{c}\text { MD } 0.42 \text { más } \\
(0.09 \text { menos a } 0.93 \text { más })\end{array}$ & BAJA & CRÍTICO \\
\hline \multicolumn{13}{|c|}{ Lesiones en el pezón (curación) - al final de la evaluación (tras10 días) } \\
\hline 1 & ECA & serio1 & no serio? & no serio & serio4 & ninguno & $\begin{array}{c}6 / 33 \\
(18.2 \%)\end{array}$ & $3 / 31(9.7 \%)$ & $\begin{array}{c}\text { RR } 1.88 \\
(0.51 \text { a } 6.87)\end{array}$ & $\begin{array}{l}85 \text { más por } 1000 \text { (de } 47 \\
\text { menos a } 568 \text { más ) }\end{array}$ & BAJA & CRÍTICO \\
\hline \multicolumn{13}{|c|}{ Satisfacción materna con el tratamiento $\underline{6}$} \\
\hline 1 & ECA & serio1 & no serio 2 & no serio & serio 4 & ninguno & $\begin{array}{c}33 / 33 \\
(100.0 \%)\end{array}$ & $\begin{array}{c}28 / 31 \\
(90.3 \%)\end{array}$ & $\begin{array}{c}\text { RR } 1.11 \\
(0.97 \text { a } 1.26)\end{array}$ & $\begin{array}{l}99 \text { más por } 1000 \text { (de } 27 \\
\text { menos a } 235 \text { más ) }\end{array}$ & BAJA & CRÍTICO \\
\hline
\end{tabular}

MD-Diferencia de medias, RR-riesgo relativo

1. Riesgo de sesgo, el estudio de Cadwell 2004 mostró un alto riesgo de sesgo de selección)

2. Único estudio

3. Bajo número de participantes.

4. Bajo número de eventos. El IC $95 \%$ no excluye apreciable beneficio ni apreciable daño

5. Medido a través de una evaluación de la partera basado en una escala ( 1 a 3 puntos) donde $1=$ mejor $/$ resuelto, $2=\sin$ cambio, y $3=$ peor

6. Medido mediante autoinforme materno que van desde muy o algo satisfechas a muy o bastante insatisfechas 
Comparación 4: Lanolina versus ninguna intervención (las mujeres de todos los grupos del estudio recibieron educación para corregir su técnica de lactancia) Bibliografía (revisiones sistemáticas): Dennis CL, Jackson K, Watson J. Interventions for treating painful nipples among breastfeeding women. Cochrane Database of Systematic Reviews 2014, Issue 12. Art. No.: CD007366. DOI: 10.1002/14651858.CD007366.pub2.

\begin{tabular}{|c|c|c|c|c|c|c|c|c|c|c|c|c|}
\hline \multicolumn{7}{|c|}{ Evaluación de la calidad } & \multicolumn{2}{|c|}{ № de pacientes } & \multicolumn{2}{|r|}{ Efecto } & \multirow[b]{2}{*}{ Calidad } & \multirow[b]{2}{*}{ Importancia } \\
\hline $\begin{array}{c}\text { № de } \\
\text { estudios }\end{array}$ & $\begin{array}{l}\text { Diseño de } \\
\text { estudio }\end{array}$ & $\begin{array}{c}\text { Riesgo } \\
\text { de } \\
\text { sesgo }\end{array}$ & Inconsistencia & $\begin{array}{l}\text { Evidencia } \\
\text { indirecta }\end{array}$ & Imprecisión & $\begin{array}{c}\text { Otras } \\
\text { consideraciones }\end{array}$ & Lanolina & $\begin{array}{c}\text { Ninguna } \\
\text { intervención }\end{array}$ & $\begin{array}{l}\text { Relativo } \\
(95 \% \mathrm{Cl})\end{array}$ & $\begin{array}{l}\text { Absoluto } \\
(95 \% \mathrm{Cl})\end{array}$ & & \\
\hline \multicolumn{13}{|c|}{ Reducción del dolor en el pezón - al 1er-3er dia post tratamiento [Medido por autoinforme materno (ausencia o presencia de irritación)] } \\
\hline 1 & ECA & serio 1 & no serio? & no serio & serio $\underline{3}$ & ninguno & $\begin{array}{c}70 / 74 \\
(94.6 \%)\end{array}$ & $\begin{array}{l}71 / 73 \\
(97.3 \%)\end{array}$ & $\begin{array}{c}\text { RR } 0.97 \\
(0.91 \text { a } 1.04)\end{array}$ & $\begin{array}{l}29 \text { menos por } 1000 \text { (de } \\
39 \text { más a } 88 \text { menos ) }\end{array}$ & BAJA & CRÍTICO \\
\hline \multicolumn{13}{|c|}{ Reducción del dolor en el pezón ${ }^{4}$ - al 4to-5to dia post tratamiento } \\
\hline 2 & ECA & serio $\underline{5}$ & serio $\underline{6}$ & no serio & serio $\underline{3}$ & ninguno & $\begin{array}{l}100 / 154 \\
(64.9 \%)\end{array}$ & $\begin{array}{l}89 / 158 \\
(56.3 \%)\end{array}$ & $\begin{array}{c}\text { RR } 1.30 \\
(0.63 \text { a } 2.66)\end{array}$ & $\begin{array}{l}169 \text { más por } 1000 \text { (de } \\
208 \text { menos a } 935 \text { más ) }\end{array}$ & $\begin{array}{l}\text { MUY } \\
\text { BAJA }\end{array}$ & CRÍTICO \\
\hline \multicolumn{13}{|c|}{ Reducción del dolor en el pezón ${ }^{4}$-al 6 to-7mo dia post tratamiento } \\
\hline 2 & ECA & serio1 & no serio? & no serio & serio ${ }^{3}$ & ninguno & $\begin{array}{l}39 / 148 \\
(26.4 \%)\end{array}$ & $\begin{array}{l}47 / 149 \\
(31.5 \%)\end{array}$ & $\begin{array}{c}\text { RR } 0.85 \\
(0.63 \text { a } 1.14)\end{array}$ & $\begin{array}{l}47 \text { menos por } 1000 \text { (de } \\
44 \text { más a } 117 \text { menos ) }\end{array}$ & BAJA & CRÍTICO \\
\hline \multicolumn{13}{|c|}{ Lesiones en el pezón (curación) - al 1er-3er dia post tratamiento [medición subjetiva de la cicatrización a cargo de un evaluador] } \\
\hline 1 & ECA & serio 1 & no serio $\stackrel{2}{2}$ & no serio & serio ${ }^{3}$ & ninguno & $\begin{array}{c}74 / 74 \\
(100.0 \%)\end{array}$ & $\begin{array}{c}73 / 73 \\
(100.0 \%)\end{array}$ & $\begin{array}{c}\text { RR } 1.00 \\
(0.97 \text { a } 1.03)\end{array}$ & $\begin{array}{l}0 \text { menos por } 1000 \text { (de } \\
30 \text { menos a } 30 \text { más ) }\end{array}$ & BAJA & CRÍTICO \\
\hline \multicolumn{13}{|c|}{ Lesiones en el pezón (curación) - al 4to-5to dia post tratamiento [medición subjetiva de la cicatrización a cargo de un evaluador] } \\
\hline 1 & ECA & serio 1 & no serio? & no serio & serio ${ }^{3}$ & ninguno & $\begin{array}{c}61 / 74 \\
(82.4 \%)\end{array}$ & $\begin{array}{l}56 / 73 \\
(76.7 \%)\end{array}$ & $\begin{array}{c}\text { RR } 1.07 \\
(0.91 \mathrm{a} 1.27)\end{array}$ & $\begin{array}{c}54 \text { más por } 1000 \text { (de } 69 \\
\text { menos a } 207 \text { más ) }\end{array}$ & BAJA & CRÍTICO \\
\hline \multicolumn{13}{|c|}{ Lesiones en el pezón (curación) - al 6to-7mo dia post tratamiento [medición subjetiva de la cicatrización a cargo de un evaluador] } \\
\hline 1 & ECA & serio 1 & no serio $\stackrel{2}{2}$ & no serio & serio $\underline{8}$ & ninguno & $\begin{array}{c}33 / 74 \\
(44.6 \%)\end{array}$ & $\begin{array}{c}18 / 73 \\
(24.7 \%)\end{array}$ & $\begin{array}{c}\text { RR } 1.81 \\
(1.13 \mathrm{a} 2.91)\end{array}$ & $\begin{array}{l}200 \text { más por } 1000 \text { (de } \\
32 \text { más a } 471 \text { más ) }\end{array}$ & BAJA & CRÍTICO \\
\hline \multicolumn{13}{|c|}{ Duración de la lactancia materna - 4 semanas post parto } \\
\hline 1 & ECA & serio 9 & no serio? & no serio & serio $\underline{3}$ & ninguno & $66 / 78$ & $64 / 84$ & RR 1.11 & 84 más por 1000 (de 38 & BAJA & CRÍTICO \\
\hline
\end{tabular}




\begin{tabular}{|c|c|c|c|c|c|c|c|c|c|c|c|c|}
\hline \multicolumn{7}{|c|}{ Evaluación de la calidad } & \multicolumn{2}{|c|}{ № de pacientes } & \multicolumn{2}{|r|}{ Efecto } & \multirow[b]{2}{*}{ Calidad } & \multirow[b]{2}{*}{ Importancia } \\
\hline $\begin{array}{c}\text { № de } \\
\text { estudios }\end{array}$ & $\begin{array}{l}\text { Diseño de } \\
\text { estudio }\end{array}$ & $\begin{array}{c}\text { Riesgo } \\
\text { de } \\
\text { sesgo }\end{array}$ & Inconsistencia & $\begin{array}{l}\text { Evidencia } \\
\text { indirecta }\end{array}$ & Imprecisión & $\begin{array}{c}\text { Otras } \\
\text { consideraciones }\end{array}$ & Lanolina & $\begin{array}{c}\text { Ninguna } \\
\text { intervención }\end{array}$ & $\begin{array}{l}\text { Relativo } \\
(95 \% \mathrm{Cl})\end{array}$ & $\begin{array}{l}\text { Absoluto } \\
(95 \% \mathrm{Cl})\end{array}$ & & \\
\hline & & & & & & & $(84.6 \%)$ & $(76.2 \%)$ & (0.95 a 1.29) & menos a 221 más ) & & \\
\hline \multicolumn{13}{|c|}{ Duración de la lactancia materna - 12 semanas post parto } \\
\hline 1 & ECA & serio 9 & no serio? & no serio & serio $\underline{3}$ & ninguno & $\begin{array}{c}59 / 81 \\
(72.8 \%)\end{array}$ & $\begin{array}{c}53 / 84 \\
(63.1 \%)\end{array}$ & $\begin{array}{c}\text { RR } 1.15 \\
(0.94 \text { a } 1.43)\end{array}$ & $\begin{array}{l}95 \text { más por } 1000 \text { (de } 38 \\
\text { menos a } 271 \text { más) }\end{array}$ & BAJA & CRÍTICO \\
\hline \multicolumn{13}{|c|}{ Lactancia materna exclusiva- 4 semanas post parto } \\
\hline 1 & ECA & serio 9 & no serio $\stackrel{2}{2}$ & no serio & serio $\underline{3}$ & ninguno & $\begin{array}{l}51 / 78 \\
(65.4 \%)\end{array}$ & $\begin{array}{c}52 / 84 \\
(61.9 \%)\end{array}$ & $\begin{array}{c}\text { RR } 1.06 \\
(0.84 \text { a } 1.33)\end{array}$ & $\begin{array}{l}37 \text { más por } 1000 \text { (de } 99 \\
\text { menos a } 204 \text { más) }\end{array}$ & BAJA & CRÍTICO \\
\hline \multicolumn{13}{|c|}{ Lactancia materna exclusiva - 12 semanas post parto } \\
\hline 1 & ECA & serio 9 & no serio? & no serio & serio $\underline{3}$ & ninguno & $\begin{array}{c}43 / 81 \\
(53.1 \%)\end{array}$ & $\begin{array}{l}42 / 84 \\
(50.0 \%)\end{array}$ & $\begin{array}{c}\text { RR } 1.06 \\
(0.79 \text { a } 1.43)\end{array}$ & $\begin{array}{l}30 \text { más por } 1000 \text { (de } \\
105 \text { menos a } 215 \text { más) }\end{array}$ & BAJA & CRÍTICO \\
\hline \multicolumn{13}{|c|}{ Satisfacción maternal con el tratamiento 10} \\
\hline 1 & ECA & serio 9 & no serio? & no serio & serio 7 & ninguno & $\begin{array}{l}78 / 79 \\
(98.7 \%)\end{array}$ & $\begin{array}{l}70 / 81 \\
(86.4 \%)\end{array}$ & $\begin{array}{c}\text { RR } 1.14 \\
(1.04 \text { a } 1.25)\end{array}$ & $\begin{array}{l}121 \text { más por } 1000 \text { (de } \\
35 \text { más a } 216 \text { más) }\end{array}$ & BAJA & CRÍTICO \\
\hline
\end{tabular}

MD-Diferencia de medias, RR-riesgo relativo

1. Limitaciones en el diseño en el estudio de Mohammadzadeh 2005 (alto riesgo de sesgo para el cegamiento y riesgo incierto para el sesgo de selección.

2. Unico estudio

Estos dos estudios midieron de manera diferente el dolor en el pezón, Jackson (2013) lo valoró mediante un autoinforme materno usando la Escala "Numeric Rating”(0-10 puntos) y Mohammadzadeh 2005 lo valoró

5. Limitaciones en el diseño de estudio en ambos estudios: Mohammadzadeh 2005 y Jackson 2013, mostraron limitaciones por el alto riesgo de sesgo para el cegamiento y Mohammadzadeh 2005 adicionalmente presentó riesgo incierto para el sesgo de selección.

6. Heterogeneidad considerable: I cuadrado: $90 \%, \mathrm{p}=0,002$

8. Bajo número de eventos

9. Limitaciones en el diseño de estudio en Jackson 2013, mostró limitaciones por un alto riesgo de sesgo para el cegamiento.

10. Medido mediante cuestionario de satisfacción (Escala de Likert 1:definitivamente satisfecha al 5 :definitivamente insatisfecha) 
Comparación 5: Leche materna extraída versus ninguna intervención (las mujeres de todos los grupos del estudio recibieron educación para corregir su técnica de lactancia)

Bibliografía (revisiones sistemáticas): Dennis $\mathrm{CL}$, Jackson K,Watson J. Interventions for treating painful nipples among breastfeeding women. Cochrane Database of Systematic Reviews 2014, Issue 12. Art. No.: CD007366. DOI: 10.1002/14651858.CD007366.pub2

\begin{tabular}{|c|c|c|c|c|c|c|c|c|c|c|c|c|}
\hline \multicolumn{7}{|c|}{ Evaluación de la calidad } & \multicolumn{2}{|c|}{ № de pacientes } & \multicolumn{2}{|r|}{ Efecto } & \multirow[b]{2}{*}{ Calidad } & \multirow[b]{2}{*}{$\begin{array}{l}\text { Importanci } \\
\quad \mathrm{a}\end{array}$} \\
\hline $\begin{array}{l}\text { № de } \\
\text { estudio } \\
\text { s }\end{array}$ & $\begin{array}{l}\text { Diseño de } \\
\text { estudio }\end{array}$ & $\begin{array}{l}\text { Riesgo de } \\
\text { sesgo }\end{array}$ & $\begin{array}{c}\text { Inconsistenci } \\
a\end{array}$ & $\begin{array}{c}\text { Evidenci } \\
a \\
\text { indirecta }\end{array}$ & $\underset{\mathbf{n}}{\text { Imprecisió }}$ & $\begin{array}{c}\text { Otras } \\
\text { consideraciones }\end{array}$ & $\begin{array}{l}\text { Leche } \\
\text { materna } \\
\text { extraída }\end{array}$ & $\begin{array}{c}\text { Ninguna } \\
\text { intervención }\end{array}$ & $\begin{array}{l}\text { Relativo } \\
(95 \% \mathrm{Cl})\end{array}$ & $\begin{array}{l}\text { Absoluto } \\
(95 \% \mathrm{Cl})\end{array}$ & & \\
\hline \multicolumn{13}{|c|}{ Reducción del dolor en el pezón - al 1er-3er día post tratamiento [Medido por autoinforme materno (ausencia o presencia de irritación)] } \\
\hline 1 & ECA & serio 1 & no serio $\stackrel{2}{2}$ & no serio & serio $\underline{3}$ & ninguno & $\begin{array}{c}73 / 78 \\
(93.6 \%)\end{array}$ & $71 / 73(97.3 \%)$ & $\begin{array}{c}\text { RR } 0.96 \\
(0.90 \text { a } 1.03)\end{array}$ & $\begin{array}{l}39 \text { menos por } 1000 \text { (de } \\
29 \text { más a } 97 \text { menos ) }\end{array}$ & BAJA & CRÍTICO \\
\hline \multicolumn{13}{|c|}{ Reducción del dolor en el pezón - al 4to-5to día post tratamiento [Medido por autoinforme materno (ausencia o presencia de irritación)] } \\
\hline 1 & ECA & serio 1 & no serio $\underline{2}$ & no serio & serio $\underline{3}$ & ninguno & $\begin{array}{c}25 / 78 \\
(32.1 \%)\end{array}$ & $20 / 73(27.4 \%)$ & $\begin{array}{c}\text { RR } 1.17 \\
(0.71 \text { a } 1.92)\end{array}$ & $\begin{array}{l}47 \text { más por } 1000 \text { (de } 79 \\
\text { menos a } 252 \text { más ) }\end{array}$ & BAJA & CRÍTICO \\
\hline \multicolumn{13}{|c|}{ Reducción del dolor en el pezón - al 6to-7mo día post tratamiento [Medido por autoinforme materno (ausencia o presencia de irritación)] } \\
\hline 1 & ECA & serio 1 & no serio $\underline{2}$ & no serio & serio $\underline{3}$ & ninguno & $\begin{array}{c}2 / 78 \\
(2.6 \%)\end{array}$ & $3 / 73(4.1 \%)$ & $\begin{array}{c}\text { RR } 0.62 \\
(0.11 \text { a } 3.63)\end{array}$ & $\begin{array}{l}16 \text { menos por } 1000 \text { (de } \\
37 \text { menos a } 108 \text { más ) }\end{array}$ & BAJA & CRÍTICO \\
\hline \multicolumn{13}{|c|}{ Lesiones del pezón (curación)- al 1er-3er día post tratamiento [medición subjetiva de la cicatrización a cargo de un evaluador] } \\
\hline 1 & ECA & serio 1 & no serio $\stackrel{2}{2}$ & no serio & serio $\underline{3}$ & ninguno & $\begin{array}{c}77 / 78 \\
(98.7 \%)\end{array}$ & $\begin{array}{c}73 / 73 \\
(100.0 \%)\end{array}$ & $\begin{array}{c}\text { RR } 0.99 \\
(0.95 \text { a } 1.02)\end{array}$ & $\begin{array}{l}10 \text { menos por } 1000 \text { (de } \\
20 \text { más a } 50 \text { menos ) }\end{array}$ & BAJA & CRÍTICO \\
\hline \multicolumn{13}{|c|}{ Lesiones del pezón (curación)- al 4to-5to día post tratamiento [medición subjetiva de la cicatrización a cargo de un evaluador] } \\
\hline 1 & ECA & serio 1 & no serio $\underline{2}$ & no serio & serio $\underline{3}$ & ninguno & $\begin{array}{c}52 / 78 \\
(66.7 \%)\end{array}$ & $56 / 73(76.7 \%)$ & $\begin{array}{c}\text { RR } 0.87 \\
(0.71 \text { a } 1.06)\end{array}$ & $\begin{array}{l}100 \text { menos por } 1000 \text { (de } \\
46 \text { más a } 222 \text { menos ) }\end{array}$ & BAJA & CRÍTICO \\
\hline \multicolumn{13}{|c|}{ Lesiones del pezón (curación)- al 6to-7mo día post tratamiento [medición subjetiva de la cicatrización a cargo de un evaluador] } \\
\hline 1 & ECA & serio 1 & no serio $\underline{2}$ & no serio & serio $\underline{3}$ & ninguno & $\begin{array}{l}25 / 78 \\
(32.1 \%)\end{array}$ & $18 / 73(24.7 \%)$ & $\begin{array}{c}\text { RR } 1.30 \\
(0.78 \text { a } 2.18)\end{array}$ & $\begin{array}{c}74 \text { más por } 1000 \text { (de } 54 \\
\text { menos a } 291 \text { más ) }\end{array}$ & BAJA & CRÍTICO \\
\hline
\end{tabular}

1. Limitaciones en el diseño en el estudio de Mohammadzadeh 2005 (alto riesgo de sesgo para el cegamiento y riesgo incierto para el sesgo de selección. 
2. Único estudio

3. Bajo número de eventos. El IC $95 \%$ no excluye apreciable beneficio ni apreciable daño

Comparación 6: Lanolina versus leche materna extraída (las mujeres de todos los grupos del estudio recibieron educación para corregir su técnica de lactancia)

Bibliografía (revisiones sistemáticas): Dennis CL, Jackson K,Watson J. Interventions for treating painful nipples among breastfeeding women. Cochrane

Database of Systematic Reviews 2014, Issue 12. Art. No.: CD007366. DOI: 10.1002/14651858.CD007366.pub2

\begin{tabular}{|c|c|c|c|c|c|c|c|c|c|c|c|c|}
\hline \multicolumn{7}{|c|}{ Evaluación de la calidad } & \multicolumn{2}{|c|}{ № de pacientes } & \multicolumn{2}{|r|}{ Efecto } & \multirow[b]{2}{*}{ Calidad } & \multirow[b]{2}{*}{ Importancia } \\
\hline $\begin{array}{l}\text { № de } \\
\text { estudio } \\
\text { s }\end{array}$ & $\begin{array}{l}\text { Diseño de } \\
\text { estudio }\end{array}$ & $\begin{array}{c}\text { Riesgo } \\
\text { de sesgo }\end{array}$ & $\begin{array}{c}\text { Inconsistenci } \\
\text { a }\end{array}$ & $\begin{array}{l}\text { Evidencia } \\
\text { indirecta }\end{array}$ & Imprecisión & $\begin{array}{c}\text { Otras } \\
\text { consideraciones }\end{array}$ & Lanolina & $\begin{array}{l}\text { Leche } \\
\text { materna } \\
\text { extraída }\end{array}$ & $\begin{array}{l}\text { Relativo } \\
(95 \% \mathrm{Cl})\end{array}$ & $\begin{array}{l}\text { Absoluto } \\
(95 \% \mathrm{Cl})\end{array}$ & & \\
\hline \multicolumn{13}{|c|}{ Reducción del dolor en el pezón - al 1er-3er día post tratamiento [Medido por autoinforme materno (ausencia o presencia de irritación)] } \\
\hline 1 & ECA & serio 1 & no serio $\stackrel{2}{2}$ & no serio & serio $\underline{3}$ & ninguno & $\begin{array}{c}70 / 74 \\
(94.6 \%)\end{array}$ & $\begin{array}{l}73 / 78 \\
(93.6 \%)\end{array}$ & $\begin{array}{c}\text { RR 1.01 } \\
(0.93 \text { a } 1.09)\end{array}$ & $\begin{array}{l}9 \text { más por } 1000 \text { (de } 66 \\
\text { menos a } 84 \text { más ) }\end{array}$ & BAJA & CRÍTICO \\
\hline \multicolumn{13}{|c|}{ Reducción del dolor en el pezón - al 4to-5to día post tratamiento [Medido por autoinforme materno (ausencia o presencia de irritación)] } \\
\hline 1 & ECA & serio 1 & no serio $\stackrel{2}{2}$ & no serio & serio 4 & ninguno & $\begin{array}{c}37 / 74 \\
(50.0 \%)\end{array}$ & $\begin{array}{c}25 / 78 \\
(32.1 \%)\end{array}$ & $\begin{array}{c}\mathbf{R R} \mathbf{1 . 5 6} \\
(1.05 \mathrm{a} 2.32)\end{array}$ & $\begin{array}{l}179 \text { más por } 1000 \text { (de } \\
16 \text { más a } 423 \text { más ) }\end{array}$ & BAJA & CRÍTICO \\
\hline \multicolumn{13}{|c|}{ Reducción del dolor en el pezón - al 6to-7mo día post tratamiento [Medido por autoinforme materno (ausencia o presencia de irritación)] } \\
\hline 1 & ECA & serio 1 & no serio $\underline{2}$ & no serio & serio $\underline{3}$ & ninguno & $\begin{array}{c}3 / 74 \\
(4.1 \%)\end{array}$ & $\begin{array}{c}2 / 78 \\
(2.6 \%)\end{array}$ & $\begin{array}{c}\text { RR } \mathbf{1 . 5 8} \\
(0.27 \text { a } 9.20)\end{array}$ & $\begin{array}{l}15 \text { más por } 1000 \text { (de } 19 \\
\text { menos a } 210 \text { más ) }\end{array}$ & BAJA & CRÍTICO \\
\hline \multicolumn{13}{|c|}{ Lesiones del pezón (curación)- al 1er-3er día post tratamiento [medición subjetiva de la cicatrización a cargo de un evaluador] } \\
\hline 1 & ECA & serio 1 & no serio $\underline{2}$ & no serio & serio $\underline{3}$ & ninguno & $\begin{array}{c}74 / 74 \\
(100.0 \%)\end{array}$ & $\begin{array}{l}77 / 78 \\
(98.7 \%)\end{array}$ & $\begin{array}{c}\text { RR 1.01 } \\
(0.98 \text { a } 1.05)\end{array}$ & $\begin{array}{c}10 \text { más por } 1000 \text { (de } 20 \\
\text { menos a } 49 \text { más ) }\end{array}$ & BAJA & CRÍTICO \\
\hline \multicolumn{13}{|c|}{ Lesiones del pezón (curación)- al 4to-5to día post tratamiento [medición subjetiva de la cicatrización a cargo de un evaluador] } \\
\hline 1 & ECA & serio 1 & no serio $\underline{2}$ & no serio & serio 4 & ninguno & $\begin{array}{c}61 / 74 \\
(82.4 \%)\end{array}$ & $\begin{array}{l}52 / 78 \\
(66.7 \%)\end{array}$ & $\begin{array}{c}\mathbf{R R} \mathbf{1 . 2 4} \\
(1.02 \mathrm{a} 1.49)\end{array}$ & $\begin{array}{l}160 \text { más por } 1000 \text { (de } \\
13 \text { más a } 327 \text { más ) }\end{array}$ & BAJA & CRÍTICO \\
\hline \multicolumn{13}{|c|}{ Lesiones del pezón (curación)- al 6to-7mo día post tratamiento [medición subjetiva de la cicatrización a cargo de un evaluador] } \\
\hline 1 & ECA & serio 1 & no serio $\stackrel{2}{3}$ & no serio & serio $\underline{3}$ & ninguno & $\begin{array}{c}33 / 74 \\
(44.6 \%)\end{array}$ & $\begin{array}{l}25 / 78 \\
(32.1 \%)\end{array}$ & $\begin{array}{c}\text { RR } 1.39 \\
(0.92 \text { a } 2.10)\end{array}$ & $\begin{array}{l}125 \text { más por } 1000 \text { (de } \\
26 \text { menos a } 353 \text { más ) }\end{array}$ & BAJA & CRÍTICO \\
\hline
\end{tabular}

MD-Diferencia de medias, RR-riesgo relativo 
1. Limitaciones en el diseño en el estudio de Mohammadzadeh 2005 (alto riesgo de sesgo para el cegamiento y riesgo incierto para el sesgo de selección.

2. Único estudio

3. Bajo número de eventos. El IC $95 \%$ no excluye apreciable beneficio ni apreciable daño

4. Bajo número de eventos

Comparación 7: Lanolina versus ungüento multiusos para pezones (las mujeres de todos los grupos del estudio recibieron atención posparto habitual)

Bibliografía (revisiones sistemáticas): Dennis CL, Jackson K,Watson J. Interventions for treating painful nipples among breastfeeding women. Cochrane Database of Systematic Reviews 2014, Issue 12. Art. No.: CD007366. DOI: 10.1002/14651858.CD007366.pub2

\begin{tabular}{|c|c|c|c|c|c|c|c|c|c|c|c|c|}
\hline \multicolumn{7}{|c|}{ Evaluación de la calidad } & \multicolumn{2}{|c|}{ № de pacientes } & \multicolumn{2}{|r|}{ Efecto } & \multirow[b]{2}{*}{ Calidad } & \multirow[b]{2}{*}{ Importancia } \\
\hline $\begin{array}{l}\text { № de } \\
\text { estudios }\end{array}$ & $\begin{array}{l}\text { Diseño de } \\
\text { estudio }\end{array}$ & $\begin{array}{l}\text { Riesgo } \\
\text { de } \\
\text { sesgo }\end{array}$ & Inconsistencia & $\begin{array}{l}\text { Evidencia } \\
\text { indirecta }\end{array}$ & Imprecisión & $\begin{array}{c}\text { Otras } \\
\text { consideraciones }\end{array}$ & Lanolina & $\begin{array}{l}\text { Ungüento } \\
\text { multiusos }\end{array}$ & $\begin{array}{l}\text { Relativo } \\
(95 \% \mathrm{Cl})\end{array}$ & $\begin{array}{l}\text { Absoluto } \\
(95 \% \mathrm{Cl})\end{array}$ & & \\
\hline \multicolumn{13}{|c|}{ Reducción del dolor en el pezón -1 semana post aleatorización [Medido por el formulario abreviado "McGill Pain"] } \\
\hline 1 & ECA & $\begin{array}{l}\text { no } \\
\text { serio } 1\end{array}$ & no serio $\stackrel{2}{2}$ & no serio & serio $\underline{3}$ & ninguno & 75 & 75 & - & $\begin{array}{c}\text { MD } 2.51 \text { más } \\
\text { (0.61 más a } 4.41 \text { más })\end{array}$ & MODERADO & CRÍTICO \\
\hline \multicolumn{13}{|c|}{ Reducción del dolor en el pezón - 1 semana post aleatorización [Medido por el índice "Present Pain Index"] } \\
\hline 1 & ECA & $\begin{array}{l}\text { no } \\
\text { serio } 1\end{array}$ & no serio 2 & no serio & serio $\underline{3}$ & ninguno & 75 & 75 & - & $\begin{array}{c}\text { MD } 0.12 \text { más } \\
(0.24 \text { menos a } 0.48 \text { más })\end{array}$ & MODERADO & CRÍTICO \\
\hline \multicolumn{13}{|c|}{ Reducción del dolor en el pezón - 1 semana post aleatorización [Medido por la escala "Pain Scale"] } \\
\hline 1 & ECA & $\begin{array}{l}\text { no } \\
\text { serio } 1\end{array}$ & no serio $\stackrel{2}{2}$ & no serio & serio $\underline{3}$ & ninguno & 75 & 75 & - & $\begin{array}{c}\text { MD } 0.14 \text { más } \\
(0.67 \text { menos a } 0.95 \text { más })\end{array}$ & MODERADO & CRÍTICO \\
\hline \multicolumn{13}{|c|}{ Mastitis - a las 12 semanas post parto [Medido por el autoreporte de los criterios de Fetherston] } \\
\hline 1 & ECA & $\begin{array}{l}\text { no } \\
\text { serio } 1\end{array}$ & no serio $\underline{2}$ & no serio & serio 4 & ninguno & $\begin{array}{c}2 / 73 \\
(2.7 \%)\end{array}$ & $\begin{array}{l}3 / 72 \\
(4.2 \%)\end{array}$ & $\begin{array}{c}\text { RR } 0.66 \\
(0.11 \text { a } 3.82)\end{array}$ & $\begin{array}{c}14 \text { menos por } 1000 \text { (de } 37 \\
\text { menos a } 118 \text { más) }\end{array}$ & MODERADO & CRÍTICO \\
\hline \multicolumn{13}{|c|}{ Duración de la lactancia - 1 semana post aleatorización } \\
\hline 1 & ECA & $\begin{array}{l}\text { no } \\
\text { serio } 1\end{array}$ & no serio $\underline{2}$ & no serio & serio 4 & ninguno & $\begin{array}{c}72 / 75 \\
(96.0 \%)\end{array}$ & $\begin{array}{c}73 / 75 \\
(97.3 \%)\end{array}$ & $\begin{array}{c}\text { RR } 0.99 \\
(0.93 \text { a } 1.05)\end{array}$ & $\begin{array}{c}10 \text { menos por } 1000 \text { (de } 49 \\
\text { más a } 68 \text { menos ) }\end{array}$ & MODERADO & CRÍTICO \\
\hline
\end{tabular}




\begin{tabular}{|c|c|c|c|c|c|c|c|c|c|c|c|c|}
\hline \multicolumn{7}{|c|}{ Evaluación de la calidad } & \multicolumn{2}{|c|}{ № de pacientes } & \multicolumn{2}{|r|}{ Efecto } & \multirow[b]{2}{*}{ Calidad } & \multirow[b]{2}{*}{ Importancia } \\
\hline $\begin{array}{c}\text { № de } \\
\text { estudios }\end{array}$ & $\begin{array}{l}\text { Diseño de } \\
\text { estudio }\end{array}$ & $\begin{array}{c}\text { Riesgo } \\
\text { de } \\
\text { sesgo }\end{array}$ & Inconsistencia & $\begin{array}{l}\text { Evidencia } \\
\text { indirecta }\end{array}$ & Imprecisión & $\begin{array}{c}\text { Otras } \\
\text { consideraciones }\end{array}$ & Lanolina & $\begin{array}{l}\text { Ungüento } \\
\text { multiusos }\end{array}$ & $\begin{array}{l}\text { Relativo } \\
\text { (95\% Cl) }\end{array}$ & $\begin{array}{l}\text { Absoluto } \\
(95 \% \mathrm{Cl})\end{array}$ & & \\
\hline 1 & ECA & $\begin{array}{l}\text { no } \\
\text { serio } 1\end{array}$ & no serio $\stackrel{2}{2}$ & no serio & serio 4 & ninguno & $\begin{array}{c}62 / 73 \\
(84.9 \%)\end{array}$ & $\begin{array}{c}52 / 72 \\
(72.2 \%)\end{array}$ & $\begin{array}{c}\text { RR 1.18 } \\
(0.99 \text { a } 1.40)\end{array}$ & $\begin{array}{c}130 \text { más por } 1000 \text { (de } 7 \\
\text { menos a } 289 \text { más ) }\end{array}$ & MODERADO & CRÍTICO \\
\hline \multicolumn{13}{|c|}{ Lactancia exclusiva - 1 semana post aleatorización } \\
\hline 1 & ECA & $\begin{array}{l}\text { No } \\
\text { serio } 1\end{array}$ & no serio $\stackrel{2}{3}$ & no serio & serio 4 & ninguno & $\begin{array}{c}48 / 75 \\
(64.0 \%)\end{array}$ & $\begin{array}{c}54 / 75 \\
(72.0 \%)\end{array}$ & $\begin{array}{c}\text { RR } \mathbf{0 . 8 9} \\
(0.71 \text { a } 1.11)\end{array}$ & $\begin{array}{c}79 \text { menos por } 1000 \text { (de } 79 \\
\text { más a } 209 \text { menos ) }\end{array}$ & MODERADO & CRÍTICO \\
\hline \multicolumn{13}{|c|}{ Lactancia exclusiva - 12 semanas post parto } \\
\hline 1 & ECA & $\begin{array}{l}\text { no } \\
\text { serio } 1\end{array}$ & no serio & no serio & serio 4 & ninguno & $\begin{array}{c}44 / 73 \\
(60.3 \%)\end{array}$ & $\begin{array}{c}33 / 72 \\
(45.8 \%)\end{array}$ & $\begin{array}{c}\text { RR 1.32 } \\
(0.96 \text { a } 1.80)\end{array}$ & $\begin{array}{l}147 \text { más por } 1000 \text { (de } 18 \\
\text { menos a } 367 \text { más ) }\end{array}$ & MODERADO & CRÍTICO \\
\hline \multicolumn{13}{|c|}{ Satisfacción materna con la lactancia - 12 semanas post parto } \\
\hline 1 & ECA & $\begin{array}{l}\text { no } \\
\text { serio } 1\end{array}$ & no serio $\underline{2}$ & no serio & serio $\underline{3}$ & ninguno & 72 & 70 & - & $\begin{array}{c}\text { MD } 3.12 \text { más } \\
(0.85 \text { más a } 5.39 \text { más })\end{array}$ & MODERADO & CRÍTICO \\
\hline \multicolumn{13}{|c|}{ Satisfacción materna con el tratamiento $\underline{5}$} \\
\hline 1 & ECA & $\begin{array}{l}\text { no } \\
\text { serio } 1\end{array}$ & no serio $\underline{2}$ & no serio & serio 4 & ninguno & $\begin{array}{c}68 / 73 \\
(93.2 \%)\end{array}$ & $\begin{array}{c}65 / 72 \\
(90.3 \%)\end{array}$ & $\begin{array}{c}\text { RR 1.03 } \\
(0.94 \text { a } 1.14)\end{array}$ & $\begin{array}{l}27 \text { más por } 1000 \text { (de } 54 \\
\text { menos a } 126 \text { más ) }\end{array}$ & MODERADO & CRÍTICO \\
\hline
\end{tabular}

MD-Diferencia de medias, RR-riesgo relativo

1. Dennis 2012, no presenta limitaciones en el diseño del estudio.

2. Único estudio

3. Bajo número de participantes en el estudio

4. Bajo número de eventos. El IC $95 \%$ no excluye apreciable beneficio ni apreciable daño

5. Medido mediante cuestionario de satisfacción (Escala de Likert 1:definitivamente satisfecha al 5:definitivamente insatisfecha)

Comparación 8: Gel de aloe vera versus lanolina (las mujeres de todos los grupos del estudio recibieron educación para corregir su técnica de lactancia) Bibliografía: Saedi R, Tafazoli M, Gholami M, Mazloom R. New treatment for nipple soreness in breastfeeding mothers: A clinical trial study. Iranian Journal of Neonatology 2015; 6(2): 48-51

\begin{tabular}{|l|l|l|l|l|}
\hline Evaluación de la calidad & № de pacientes & Efecto & Importancia \\
\hline
\end{tabular}


GPC Lactancia Materna- Pregunta 29. Dolor y grietas en el pezón.

\begin{tabular}{|c|c|c|c|c|c|c|c|c|c|c|c|c|}
\hline $\begin{array}{c}\text { № de } \\
\text { estudios }\end{array}$ & $\begin{array}{l}\text { Diseño } \\
\text { de } \\
\text { estudio }\end{array}$ & $\begin{array}{c}\text { Riesgo } \\
\text { de } \\
\text { sesgo }\end{array}$ & Inconsistencia & $\begin{array}{l}\text { Evidencia } \\
\text { indirecta }\end{array}$ & Imprecisión & $\begin{array}{c}\text { Otras } \\
\text { consideraciones }\end{array}$ & Aloe vera & Lanolina & p-valor & $\begin{array}{l}\text { Absoluto } \\
(95 \% \mathrm{Cl})\end{array}$ & & \\
\hline \multicolumn{13}{|c|}{ Reducción del dolor en el pezón - 3er dia post tratamiento (evaluado con : Escala Storr) } \\
\hline 1 & ECA & $\begin{array}{l}\text { no } \\
\text { serio }\end{array}$ & no serio 1 & serio $\stackrel{2}{2}$ & serio $\underline{3}$ & ninguno & $\begin{array}{l}\quad 50 \\
\text { Score dolor pre- } \\
\text { tratamiento: } 3,04 \\
\text { Score dolor post- } \\
\text { tratamiento: } 1,26\end{array}$ & $\begin{array}{l}50 \\
\\
\text { Score dolor pre- } \\
\text { tratamiento: } 3,1 \\
\text { Score dolor post- } \\
\text { tratamiento: } 1,7\end{array}$ & $\mathrm{p}: 0,048$ & -- & BAJA & CRÍTICO \\
\hline \multicolumn{13}{|c|}{ Reducción del dolor en el pezón - 7mo día post tratamiento (evaluado con : Escala Storr) } \\
\hline 1 & ECA & $\begin{array}{l}\text { no } \\
\text { serio }\end{array}$ & no serio 1 & serio $\stackrel{2}{2}$ & serio $\underline{3}$ & ninguno & $\begin{array}{l}\qquad 50 \\
\text { Score dolor post- } \\
\text { tratamiento:0,26 }\end{array}$ & $\begin{array}{l}\quad 50 \\
\text { Score dolor post- } \\
\text { tratamiento: } 1,02\end{array}$ & $\mathrm{p}: 0,003$ & -- & BAJA & CRÍTICO \\
\hline
\end{tabular}

MD-Diferencia de medias, RR-riesgo relativo

1. Único estudio

2. Saedi 2015 , incluyó mujeres sanas en lactancia materna que informaron de dolor en el pezón, previamente tratadas con la aplicación de su propia leche materna, sin mejoría tras el tratamiento y

que mostraron un empeoramiento del dolor (aumento como mínimo dos puntos, medido a través escala de Storr).

3. Bajo número de participantes 
Comparación 9: Esencia de menta versus aplicación de leche materna extraída

Bibliografía: Akbari SA, Alamolhoda SH, Baghban AA, Mirabi P. Effects of menthol essence and breast milk on the improvement of nipple fissures in breastfeeding women. J Res Med Sci. 2014 Jul;19(7):629-33.

\begin{tabular}{|c|c|c|c|c|c|c|c|c|c|c|c|c|}
\hline \multicolumn{7}{|c|}{ Evaluación de la calidad } & \multicolumn{2}{|c|}{ № de pacientes } & \multicolumn{2}{|r|}{ Efecto } & \multirow[b]{2}{*}{ Calidad } & \multirow[b]{2}{*}{ Importancia } \\
\hline $\begin{array}{l}\text { № de } \\
\text { estudios }\end{array}$ & $\begin{array}{l}\text { Diseño de } \\
\text { estudio }\end{array}$ & $\begin{array}{l}\text { Riesgo } \\
\text { de sesgo }\end{array}$ & Inconsistencia & $\begin{array}{l}\text { Evidencia } \\
\text { indirecta }\end{array}$ & Imprecisión & $\begin{array}{c}\text { Otras } \\
\text { consideraciones }\end{array}$ & $\begin{array}{c}\text { esencia } \\
\text { de } \\
\text { menta }\end{array}$ & $\begin{array}{l}\text { leche } \\
\text { materna } \\
\text { extraída }\end{array}$ & $\begin{array}{l}\text { Relativo } \\
\text { (95\% Cl) }\end{array}$ & $\begin{array}{l}\text { Absoluto } \\
(95 \% \mathrm{Cl})\end{array}$ & & \\
\hline \multicolumn{13}{|c|}{ Reducción del dolor - 3er día post parto (evaluado con : Escala analógica visual) } \\
\hline 1 & ECA & serio 1 & no serio $\stackrel{2}{2}$ & no serio & serio $\underline{3}$ & ninguno & 55 & 55 & - & $\begin{array}{c}\text { MD } 0.14 \text { más } \\
(0.59 \text { menos a } 0.87 \text { más })\end{array}$ & BAJA & CRÍTICO \\
\hline \multicolumn{13}{|c|}{ Reducción del dolor - 10mo día post parto (evaluado con : Escala analógica visual) } \\
\hline 1 & ECA & serio 1 & no serio $\stackrel{2}{2}$ & no serio & serio $\underline{3}$ & ninguno & 55 & 55 & - & $\begin{array}{c}\text { MD } 2.41 \text { menos } \\
\text { (4.93 menos a } 0.11 \text { más ) }\end{array}$ & BAJA & CRÍTICO \\
\hline \multicolumn{13}{|c|}{ Reducción del dolor - Día 14 post parto (evaluado con : Escala analógica visual ) } \\
\hline 1 & ECA & serio 1 & no serio $\stackrel{2}{2}$ & no serio & serio $\underline{3}$ & ninguno & 55 & 55 & - & $\begin{array}{c}\text { MD } 3 \text { menos } \\
\text { (3.87 menos a } 2.13 \text { menos ) }\end{array}$ & BAJA & CRÍTICO \\
\hline \multicolumn{13}{|c|}{ Lesiones del pezón (curación)- al 3er día post parto (evaluado con : Escala de Amir) } \\
\hline 1 & ECA & serio 1 & no serio $\stackrel{2}{2}$ & no serio & serio $\underline{3}$ & ninguno & 55 & 55 & - & $\begin{array}{c}\text { MD } 0.29 \text { más } \\
(1.14 \text { menos a } 1.72 \text { más })\end{array}$ & BAJA & CRÍTICO \\
\hline \multicolumn{13}{|c|}{ Lesiones del pezón (curación)- 10mo día post parto (evaluado con : Escala de Amir) } \\
\hline 1 & ECA & serio 1 & no serio $\stackrel{2}{2}$ & no serio & serio $\underline{3}$ & ninguno & 55 & 55 & - & $\begin{array}{c}\text { MD } 0.88 \text { menos } \\
(2.05 \text { menos a } 0.29 \text { más })\end{array}$ & BAJA & CRÍTICO \\
\hline \multicolumn{13}{|c|}{ Lesiones del pezón (curación)- al día 14 post parto (evaluado con : Escala de Amir) } \\
\hline 1 & ECA & serio 1 & no serio $\stackrel{2}{2}$ & no serio & serio $\underline{3}$ & ninguno & 55 & 55 & - & $\begin{array}{c}\text { MD } 3.52 \text { menos } \\
(4.43 \text { menos a } 2.61 \text { menos })\end{array}$ & BAJA & CRÍTICO \\
\hline \multicolumn{13}{|c|}{ Secreciones a través de las grietas del pezón - 3er día post parto } \\
\hline 1 & ECA & serio 1 & no serio $\stackrel{2}{2}$ & no serio & serio 4 & ninguno & $41 / 55$ & $40 / 55$ & RR 1.02 & 15 más por 1000 (de 131 & BAJA & CRÍTICO \\
\hline
\end{tabular}


GPC Lactancia Materna- Pregunta 29. Dolor y grietas en el pezón.

\begin{tabular}{|c|c|c|c|c|c|c|c|c|c|c|c|c|}
\hline \multicolumn{7}{|c|}{ Evaluación de la calidad } & \multicolumn{2}{|c|}{ № de pacientes } & \multicolumn{2}{|r|}{ Efecto } & \multirow[b]{2}{*}{ Calidad } & \multirow[b]{2}{*}{ Importancia } \\
\hline $\begin{array}{l}\text { № de } \\
\text { estudios }\end{array}$ & $\begin{array}{l}\text { Diseño de } \\
\text { estudio }\end{array}$ & $\begin{array}{c}\text { Riesgo } \\
\text { de sesgo }\end{array}$ & Inconsistencia & $\begin{array}{l}\text { Evidencia } \\
\text { indirecta }\end{array}$ & Imprecisión & $\begin{array}{c}\text { Otras } \\
\text { consideraciones }\end{array}$ & $\begin{array}{c}\text { esencia } \\
\text { de } \\
\text { menta }\end{array}$ & $\begin{array}{l}\text { leche } \\
\text { materna } \\
\text { extraída }\end{array}$ & $\begin{array}{l}\text { Relativo } \\
(95 \% \mathrm{Cl})\end{array}$ & $\begin{array}{l}\text { Absoluto } \\
(95 \% \mathrm{Cl})\end{array}$ & & \\
\hline & & & & & & & $(74.5 \%)$ & $(72.7 \%)$ & $(0.82$ a 1.28$)$ & menos a 204 más ) & & \\
\hline \multicolumn{13}{|c|}{ Secreciones a través de las grietas del pezón - 10mo día post parto } \\
\hline 1 & ECA & serio 1 & no serio $\stackrel{2}{2}$ & no serio & serio $\underline{5}$ & ninguno & $\begin{array}{c}17 / 55 \\
(30.9 \%)\end{array}$ & $\begin{array}{c}29 / 55 \\
(52.7 \%)\end{array}$ & $\begin{array}{c}\text { RR } 0.59 \\
(0.37 \text { a } 0.94)\end{array}$ & $\begin{array}{l}216 \text { menos por } 1000 \text { (de } 32 \\
\text { menos a } 332 \text { menos ) }\end{array}$ & BAJA & CRÍTICO \\
\hline \multicolumn{13}{|c|}{ Secreciones a través de las grietas del pezón - día 14 post parto } \\
\hline 1 & ECA & serio 1 & no serio $\stackrel{2}{2}$ & no serio & serio $\underline{5}$ & ninguno & $\begin{array}{c}8 / 55 \\
(14.5 \%)\end{array}$ & $\begin{array}{c}16 / 55 \\
(29.1 \%)\end{array}$ & $\begin{array}{c}\text { RR } \mathbf{0 . 2 8} \\
(0.14 \text { a } 0.55)\end{array}$ & $\begin{array}{l}209 \text { menos por } 1000 \text { (de } 131 \\
\text { menos a } 250 \text { menos ) }\end{array}$ & BAJA & CRÍTICO \\
\hline
\end{tabular}

MD-Diferencia de medias, RR-riesgo relativo

El estudio Akbari 2014, no especifica si realizaron cegamiento de la medida de resultados, motivo por el cual podrían haber incurrido en un riesgo de sesgo de detección.

Bajo número de participantes

Bajo número de eventos. El IC $95 \%$ no excluye apreciable beneficio ni apreciable daño

5. Bajo número de eventos. 


\section{2- Resumen de la Evidencia}

En la RS que se ha incluido finalmente para responder a la pregunta (1) el desenlace principal considerado ha sido la disminución del dolor en el pezón.

Otros desenlaces que consideraron como secundarios han sido la curación de las lesiones del pezón, la aparición de mastitis, así como la duración de la lactancia (exclusiva y no exclusiva) y la satisfacción materna con el tratamiento y con la propia lactancia.

Los autores realizaron una búsqueda de estudios publicados hasta el 30 de septiembre del 2014, incluyendo finalmente en su revisión 4 estudios: 2 ensayos cuasi aleatorizados y 2 ECA, uno de ellos doble ciego.

El primero de los ensayos cuasialeatorizado (6) evaluó mediante un ensayo de tres brazos las siguientes intervenciones durante un período de 10 días: Grupo 1. La aplicación del apósito de gel de glicerina entre tomas (grupo de gel de glicerina); Grupo 2. Aplicación de lanolina asociada al uso de pezoneras hasta la próxima toma; y Grupo 3. Provisión de evaluación sobre la lactancia materna y la educación individualizada correctiva (grupo de control).Todas las mujeres recibieron evaluación de la lactancia materna y la intervención educativa correctora por matronas capacitadas. Vídeos, modelos en vivo, fotografías y pruebas post sesiones se utilizaron para garantizar que las matronas completaron correcta y consistentemente la herramienta de evaluación y documentación. Este estudio fue desarrollado en 12 diferentes hospitales, e incluyó una muestra de 94 mujeres letonas caucásicas que daban lactancia materna y que presentaron dolor en los pezones o lesiones en el pezón, y que hayan dado a luz en los 10 últimos días.

El segundo ensayo cuasialeatorizado (7) evaluó mediante un ensayo de tres brazos las siguientes intervenciones en el transcurso de 7 días: Grupo 1: Aplicación de lanolina tres veces al día; Grupo 2: Aplicación de la leche materna después de cada toma; y Grupo 3: Aplicación de ninguna intervención (grupo de control). Todas las mujeres recibieron educación para corregir su técnica de lactancia. Este estudio fue desarrollado en Irán, e incluyó una muestra de 225 mujeres que presentaron fisura en la superficie del pezón o alrededor de los pezones.

El tercer ensayo (8) evaluó mediante un ECA de dos brazos las siguientes intervenciones durante 7 días: Grupo 1: La aplicación de la lanolina después de cada toma y Grupo 2: La aplicación de ninguna intervención (grupo control). Todas las mujeres recibieron educación para corregir su técnica de lactancia. Este estudio fue desarrollado en un hospital universitario en Canadá, e incluyó una muestra de 186 mujeres, todas las mujeres presentaron quejas de dolor en el pezón con signos de lesión en el pezón. Todas se encontraban dando lactancia materna y habían dado a luz a un recién nacido a término, y se encontraban en el día 4 post parto.

El cuarto ensayo (9), evaluó mediante un ensayo clínico aleatorizado doble ciego, de dos brazos las siguientes intervenciones en el transcurso de 14 
días: Grupo 1. Un grupo recibió lanolina, Grupo 2: El otro grupo recibió ungüento multiusos para pezones, este ungüento estaba compuesto por $15 \mathrm{~g}$ de pomada de mupirocina $2 \%$, miconazol en polvo al $2 \%$ y $15 \mathrm{~g}$ de pomada betametasona al $0,1 \%$; El tratamiento lo recibieron de forma continuada durante 10 días luego de cada toma, y después se aplicó cada dos tomas por 4 días más. Este estudio incluyó 151 mujeres canadienses que estaban amamantando, con pezones dolorosos y que tuvieran áreas abiertas visualmente de la piel en uno o ambos pezones y/o areolas dentro de las 2 primeras semanas post parto. Fue realizado en un hospital universitario en Canadá.

Los estudios incluidos evaluaron la eficacia de todas las intervenciones anteriormente descritas para reducir el dolor en el pezón en la lactancia materna.

Todas las mujeres incluidas en los diferentes grupos de los estudios de Cadwell 2014, Mohammadzadeh 2005, y Jackson 2013 recibieron educación para corregir su técnica de lactancia materna. En Dennis 2012, todas las participantes recibieron atención posparto habitual que incluyó la remisión a un especialista en lactancia para las mujeres que experimentaran pezones agrietados.

La conclusión final a la que llegan los autores de la revisión es que no hubo pruebas suficientes para demostrar que los apósitos de gel de glicerina, las pezoneras con lanolina, la lanolina sola, o los ungüentos multiusos para el pezón mejorara significativamente la percepción materna de dolor en los pezones. Los resultados de estos cuatro ensayos de buena calidad metodológica sugirieron que no aplicarse nada o aplicarse leche materna extraída podría ser igual o más beneficioso que la aplicación de la lanolina en la mejoría del dolor en el pezón a corto plazo.

En relación a los dos ensayos clínicos que se localizaron para actualizar la RS de Denis 2014, se encontró un primer estudio (10), que incluyó una muestra de 110 mujeres en lactancia materna con fisuras en los pezones. Este ensayo constó de dos brazos, para evaluar las siguientes intervenciones: Grupo 1: Aplicación de 4 gotas de esencia de menta sobre el pezón y la areola luego de cada toma (cada dos horas). Grupo 2: Aplicación de 4 gotas de su propia leche materna sobre el pezón y la areola luego de cada toma. La escala Amir fue utilizada para valorar la gravedad de las lesiones en el pezón (1-2 mm refleja menor severidad, 3$9 \mathrm{~mm}$ mediana severidad, $\geq 10 \mathrm{~mm}$ daño severo) y la escala analógica visual se utilizó para medir la intensidad del dolor (sobre la cinta $10 \mathrm{~cm}$ ). En esta escala, los números 1-3 refleja el dolor leve, dolor moderado 4-7 y 8-10 representa el dolor severo. Llegó a la conclusión que la esencia de menta puede mejorar las fisuras en los pezones en las mujeres primíparas que amamantan.

El otro (11) fue un ensayo clínico doble ciego que evaluó mediante dos brazos las siguientes intervenciones: Grupo 1: Aloe vera, Grupo 2: Lanolina. El tratamiento lo recibieron de forma continuada, 3 veces al día (luego de las tomas) durante 7 días en total. Todas las mujeres incluidas recibieron educación sobre las correctas posiciones de la lactancia materna. La muestra incluyó 100 mujeres sanas en lactancia materna que 
informaron de sólo dolor en el pezón y sin mejoría tras el tratamiento previo con la aplicación de la leche materna, y a quienes empeoró el dolor (aumento de al menos dos puntos en la escala de Storr). La conclusión final a la que llegó este estudio fue que el aloe vera es más eficaz que la lanolina en la curación de dolor en los pezones.

Ambos estudios fueron desarrollados en hospitales universitarios en Irán, y ninguno de sus resultados pudo ser meta-analizado a los resultados aportados en la RS de Dennis 2014, por tratarse de comparaciones diferentes a las evaluadas.

Para responder a esta pregunta, los desenlaces de interés que se han tenido en cuenta han sido la duración de la lactancia materna (exclusiva y no exclusiva), y la resolución de los problemas en los pezones (dolor, y curación de lesiones). No se encontró evidencia sobre desenlaces de seguridad de las intervenciones evaluadas.

Comparación 1. Apósito en gel de glicerina frente a la educación individualizada sobre la lactancia materna (las mujeres de todos los grupos del estudio recibieron educación para corregir su técnica de lactancia materna)

En cuanto a la mejoría del dolor en el pezón, un estudio incluido en la RS Dennis 2014 (6) midió esta mejoría, a través de una escala descriptora verbal de 5 puntos (puntaje $0=\sin$ dolor y puntaje 5 : dolor inimaginable) que comparaba el dolor entre la primera visita y la última visita. Este estudio no encontró diferencias significativas en la mejoría subjetiva del dolor al final del tratamiento (tras 10 días) entre las mujeres que aplicaron apósitos en gel de glicerina y quienes recibieron educación individualizada sobre la lactancia e instrucciones correctivas (1 ECA; 63 pacientes; DM: 0,22; IC 95\% de -0,32 a 0,76).

En cuanto a la a la curación de las lesiones del pezón, el mismo estudio (6) no encontró diferencias significativas en la curación de las lesiones del pezón al final del tratamiento (1 ECA; 52 eventos; RR 0,98, IC $95 \%$ de 0,78 a 1,23$)$.

$\mathrm{Ni}$ tampoco encontró diferencias significativas en relación a la satisfacción materna con el tratamiento instaurado (6) (1 ECA; 60 eventos; RR 1,11, IC 95\% de 0,97 a 1,27).

Calidad

baja

Calidad

baja

Calidad

baja

Comparación 2. Pezoneras con lanolina frente a la educación individualizada sobre la lactancia materna (las mujeres de todos los grupos del estudio recibieron educación para corregir su técnica de lactancia materna)

En relación al dolor en el pezón, un estudio incluido en la RS Dennis 2014 (6) no encontró diferencias significativas en la mejoría subjetiva del dolor entre ambas intervenciones al final del tratamiento (1 ECA; 61 pacientes; DM: -0,20; IC 95\% de -0,60 a 0,20)

En cuanto a la a la curación de las lesiones del pezón, este mismo

Calidad

baja

Calidad 
estudio (6) tampoco encontró diferencias significativas en la curación de las lesiones del pezón al final del tratamiento. (1 ECA; 8 eventos; RR $0,58, I C$ 95\% de 0,15 a 2,22).

$Y$ finalmente este mismo estudio (6) no halló diferencias significativas en a la satisfacción materna con el tratamiento. (1 ECA; 65 eventos; RR 1,00, IC $95 \%$ de 0,85 a 1,18).

Comparación 3. Apósito en gel de glicerina en relación a las pezoneras con lanolina (las mujeres de todos los grupos del estudio recibieron educación para corregir su técnica de lactancia materna)

En cuanto al dolor en el pezón, el mismo estudio (6) no localizó diferencias significativas en la mejoría subjetiva del dolor entre ambas intervenciones al final del tratamiento. (1 ECA; 64 pacientes; DM: 0,42; IC $95 \%$ de $-0,09$ a 0,93 ).

En relación a la curación de las lesiones del pezón, no se encontraron diferencias significativas al final del tratamiento (1 ECA; 9 eventos; RR 1,88 , IC $95 \%$ de 0,51 a 6,87 ) (6).

Así mismo, tampoco se encontraron diferencias entre ambas intervenciones y su impacto sobre la satisfacción materna con el tratamiento (1 ECA; 61 eventos; RR 1,11, IC 95\% de 0,97 a 1,26).

Comparación 4. Lanolina frente a ninguna intervención (las mujeres de todos los grupos del estudio recibieron educación para corregir su técnica de lactancia materna)

En cuanto al dolor en el pezón entre el 1er-3er día post tratamiento, en 1 ensayo cuasi aleatorizado (7) no encontró diferencias significativas en la mejoría del dolor entre ambas intervenciones, medido mediante un autoinforme materno que definía la mejoría como la ausencia de irritación (1 ECA; 141 eventos; RR: 0,97; IC 95\% de 0,91 a 1,04)

En relación al dolor en el pezón entre el 4to-5to día y entre el 6to-7mo día post tratamiento, del meta-análisis realizado por los autores de la revisión sistemática de los dos estudios primarios que incluían $(7 ; 8)$, no encontraron diferencias significativas en la mejoría subjetiva del dolor entre ambas intervenciones ni entre el 4to-5to día (2 ECA, 189 eventos, RR: $1,30,95 \%$ IC 0,63 a 2,66) ni entre el 6 to-7mo día post tratamiento (2 ECA, 86 eventos, RR: 0,85; IC 95\% de 0,63 a 1,14).

En cuanto a la curación de las lesiones del pezón, un estudio (7) incluido en la RS de Dennis 2014, no encontró diferencias significativas en la curación de las lesiones del pezón ni entre el 1er-3er día post tratamiento (1 ECA; 147 eventos; RR: 1,00, 95\% IC 0,97 a 1,03), ni entre 4to-5to día post tratamiento (1 ECA, 117 eventos, RR: 1,07, 95\% IC 0,91 a 1,27$)$, entre las intervenciones evaluadas.

Sin embargo, en la curación de las lesiones del pezón entre el 6to-7mo día post tratamiento, la lanolina mostró mayor eficacia en relación a no recibir ninguna intervención. (1 ECA, 51 eventos, RR: 1,81, 95\% IC 1,13 a 2,91). 
En relación a la duración de la lactancia, 1 ensayo incluido (8) en la RS de Dennis 2014, evaluó la duración de la lactancia. Este estudio no encontró diferencias significativas entre el número de mujeres que amamantaran durante las 4 primeras semanas post parto (1 ECA, 130 eventos, RR: 1,11, 95\% IC 0,95 a 1,29), ni las 12 semanas post parto (1 ECA, 112 eventos, RR: 1,15, 95\% IC 0,94 a 1,43), entre la aplicación de lanolina frente a no recibir ninguna intervención.

Este mismo estudio (8) tampoco encontró diferencias significativas en relación las tasas de mujeres que dieron lactancia materna exclusiva entre ambas intervenciones evaluadas durante las 4 primeras semanas post parto (1 ECA, 103 eventos, RR: 1,06, 95\% IC 0,84 a 1,33) y las 12 semanas post parto ( $1 \mathrm{ECA}, 85$ eventos, RR: 1,06, 95\% IC 0,79 a 1,43) entre la aplicación de lanolina frente a no recibir ninguna intervención.

En relación a la satisfacción materna con el tratamiento, el mismo estudio (8) mencionado anteriormente, encontró mayor satisfacción de las mujeres tratadas con el tratamiento con lanolina que aquellas que no recibieron ninguna intervención. (1 ECA, 148 eventos, RR: 1,14, 95\% IC 1,04 a 1,25).

Comparación 5. Aplicación de leche materna extraída frente a ninguna intervención (las mujeres de todos los grupos del estudio recibieron educación para corregir su técnica de lactancia materna)

En referencia a la mejoría del dolor en el pezón, 1 estudio (7) incluido en la RS de Dennis 2014, no encontró diferencias significativas en la mejoría subjetiva del dolor entre ambas intervenciones entre el 1er-3er día post tratamiento (1 ECA; 144 eventos; RR: 0,96; IC 95\% de 0,90 a 1,03), ni entre el 4to-5to día post tratamiento (1 ECA; 45 eventos; RR: 1,17; IC $95 \%$ de 0,71 a 1,92), ni entre el 6 to-7mo día post tratamiento (1 ECA; 5 eventos; RR: 0,62; IC 95\% de 0,11 a 3,63).

En cuanto a la curación de las lesiones del pezón el mismo estudio (7) tampoco encontró diferencias significativas en la mejoría en la curación de las lesiones entre ambas intervenciones ni entre el 1er-3er día post tratamiento (1 ECA; 150 eventos; RR: 0,99; IC 95\% de 0,95 a 1,02), ni entre el 4to-5to día post tratamiento (1 ECA; 108 eventos; RR: 0,87; IC $95 \%$ de 0,71 a 1,06 ), ni entre el 6 to-7mo día post tratamiento (1 ECA; 43 eventos; RR: 1,30; IC 95\% de 0,78 a 2,18), entre la aplicación de leche materna extraída frente a no recibir ninguna intervención.

Comparación 6. Lanolina versus aplicación de leche materna extraída (las mujeres de todos los grupos del estudio recibieron educación para corregir su técnica de lactancia materna)

En relación a la mejoría del dolor en el pezón, 1 ensayo (7) incluido en la RS de Dennis 2014, no encontró diferencias en las mejoras del dolor en el pezón entre 1er -3er día post tratamiento entre el grupo de lanolina y el

Calidad baja

Calidad baja Calidad
baja

Calidad baja

Calidad baja

Calidad baja 
grupo de aplicación de leche materna (1 ECA; 143 eventos; RR: 1,01; IC $95 \%$ de 0,93 a 1,09). Sin embargo hubo una disminución del dolor en las mujeres en el grupo que se aplicó leche materna entre el 4to-5to día post tratamiento (1 ECA; 62 eventos; RR 1,56; IC 95\% de 1,05 a 2,32), que no fue evidente entre el 6to-7mo día después del tratamiento (1 ECA; 5 eventos; RR 1,58; IC 95\% de 0,27 a 9,20).

Del mismo modo, este estudio (7) no mostró diferencias en la curación de las lesiones del pezón entre el 1er-3er día después del tratamiento entre las mujeres que recibió lanolina y las que recibieron leche materna extraída (1 ECA; 151 eventos; RR 1,01; IC 95\% de 0,98 a 1,05), mientras que si evidencio una mejora significativa en la curación de las lesiones del pezón entre las mujeres del grupo que recibió leche materna extraída entre el 4to-5to post tratamiento (1 ECA; 113 eventos; RR 1,24; IC 95\% de 1,02 a 1,49). Sin embargo, esta diferencia en la curación del pezón no fue evidente entre el 6to-7mo después del tratamiento (1 ECA; 58 eventos; RR 1,39; IC 95\% de 0,92)

Comparación 7. Lanolina versus ungüento multiusos para pezones (las mujeres de todos los grupos del estudio recibieron atención postparto habitual)

En cuanto a la mejoría del dolor en el pezón, 1 ensayo (9) incluido en la RS de Dennis 2014, no encontró diferencias en la disminución del dolor entre la lanolina y el ungüento multiusos tras una semana postaleatorización. Empleó diferentes escalas para la medición de dolor: Escala Intensidad del dolor presenta (PPI 'Present Pain Intensity) (1 ECA; 150 pacientes; DM: 0,12; IC95\%: de $-0,24$ a 0,48$)$ ni con la Escala de Dolor (1 ECA; 150 pacientes; DM: 0,14, IC95\% de $-0,67$ a 0,95). Sin embargo hubo una diferencia en la disminución del dolor a favor del grupo que recibió el ungüento multiusos para el pezón en relación a la lanolina, tras 1 semana de la aleatorización utilizando el formulario abreviado para medición del dolor de McGill (1 ECA; 150 pacientes; DM: 2,51; IC $95 \%$ de 0,61 a 4,41$)$.

Este mismo estudio, tampoco encontró diferencias en la incidencia de mastitis, entre aquellas mujeres que recibieron la lanolina y las que recibieron el ungüento multiusos tras 12 semanas post parto. (1 ECA, 5 eventos, RR: 0,66; IC 95\% de 0,11 a 3,82)

En relación a la duración de la lactancia, este mismo estudio (9) no encontró diferencias significativas entre el número de mujeres que amamantaran durante la primera semana post aleatorización (1 ECA, 145 eventos, RR: 0,99; IC 95\% de 0,93 a 1,05), ni a las 12 semanas post parto (1 ECA, 114 eventos, RR: 1,18; IC 95\% de 0,99 a 1,40), entre la aplicación de lanolina frente el ungüento multiusos para el pezón.

Tampoco encontró diferencias significativas entre la lanolina y el ungüento multiusos para el pezón en relación a la práctica de la lactancia materna exclusiva ni a la primera semana post aleatorización (1 ECA, 102 eventos, RR: 0,89; IC95\% de 0,71 a 1,11) ni a las 12 semanas post

\section{Calidad baja}

Calidad moderada

Calidad moderada

Calidad moderada

Calidad moderada 
parto (1 ECA, 77 eventos, RR: 1,32; IC 95\% de 0,96 a 1,80) (9).

En cuanto a la satisfacción materna con la lactancia a las 12 semanas post parto, las mujeres que recibieron lanolina, estuvieron más satisfechas con la lactancia materna que aquellas que recibieron el ungüento multiusos. (1 ECA; 142 pacientes; DM: 3,12; IC95\%: de 0,85 a $5,39)(9)$.

$Y$ finalmente en relación a la satisfacción materna con el tratamiento no hubieron diferencias significativas entre ambas intervenciones (1 ECA; 133 eventos; RR: 1,03; IC95\%: de 0,94 a 1,14) (9).

Comparación 8: Gel de aloe vera versus lanolina (las mujeres de todos los grupos del estudio recibieron educación para corregir su técnica de lactancia materna)

En cuanto a la reducción del dolor en el pezón, 1 ensayo (11) encontró una mejoría del dolor a favor del grupo que recibió aloe vera en relación a la lanolina, al 3er día del tratamiento $(p=0,048)$ y al $7 \mathrm{mo}(\mathrm{p}=0,003)$ día de tratamiento.

\section{Comparación 9: Esencia de menta versus leche materna}

En cuanto a la reducción del dolor en el pezón, 1 estudio (10) no mostró diferencias en la reducción del dolor ni al 3er día post parto (1 ECA; 110 pacientes; DM: 0,14; IC95\%: de $-0,59$ a 0,87) ni al 10mo día post parto (1 ECA; 110 pacientes; DM: $-2,41$; IC95\%: de $-4,93$ a 0,11).

Sin embargo en el día 14 post parto este mismo estudio (10) si mostró una reducción significativa del dolor a favor de la esencia de menta en relación a la obtenida con la leche materna. (1 ECA; 110 pacientes; DM: 3,00; IC95\%: de $-3,87$ a $-2,13$ ). Para obtener estos resultados fue necesario calcular las diferencias de medias obtenidas de ambos grupos.

El mismo patrón se observó para la curación de las grietas del pezón, este mismo estudio (10), no mostró diferencias en la curación de las grietas del pezón ni al 3er (1 ECA; 110 pacientes; DM: 0,29; IC95\%: de $1,14$ a 1,72$)$ ni al 10mo día post parto (1 ECA; 110 pacientes; DM: -0,88; IC95\%: de $-2,05$ a 0,29).

Pero en el día 14 post parto (10) si encontró una mejoría significativa de las grietas en el pezón con la esencia de menta en relación a la leche materna. (1 ECA; 110 pacientes; DM: -3,52; IC95\%: de -4,43 a -2,61). Para obtener estos resultados fue necesario calcular las diferencias de medias obtenidas de ambos grupos de intervención.

Finalmente, este estudio (10), también valoró el porcentaje de mujeres que presentó secreciones a través de las grietas del pezón. Se realizó el cálculo de los riesgos relativos y no encontramos diferencias en el riesgo de presentar secreciones al 3er día post parto entre ambas intervenciones (1 ECA; 81 eventos; RR: 1,02; IC95\%: de 0,82 a 1,28) sin embargo si hubo un menor número de mujeres que presentaron

Calidad moderada

Calidad moderada

Calidad baja

\section{Calidad} baja

\section{Calidad baja}

Calidad baja 
secreciones, a favor del grupo que recibió la esencia de menta en el día 10 post parto (1 ECA; 46 eventos; RR: 0,59; IC95\%: de 0,37 a 0,94) y día 14 post parto (1 ECA; 24 eventos; RR: 0,28; IC95\%: de 0,14 a 0,55).

Resultados de la actualización de la búsqueda a octubre de 2016

En la actualización de la búsqueda realizada se han identificado dos ensayos clínicos $(12 ; 13)$, uno de los cuales ya se había identificado previamente como otra publicación (8). Así, en el único nuevo ECA doble ciego identificado se incluyen 126 madres que son tratadas durante 14 días con lanolina, menta o dexpantenol, encontrando resultados similares en cuanto a la resolución del dolor y las grietas en los tres grupos (12), por lo que las recomendaciones no se ven afectadas por los resultados de este estudio.

ACTUALIZADO A FECHA DE: 31 de Octubre de 2016 


\section{5- De la evidencia a la recomendación (Tabla de EtR)}

\section{¿Cuál sería el tratamiento más adecuado para tratar el dolor y las grietas en el pezón mientras se resuelven las dificultades con la lactancia} materna?

Población: Madre sana con dolor o grietas en los pezones y recién nacido sano

Intervención: Uso de pezonera (para ayudar con el dolor), mupirocina (antibiótico), corticoides tópicos con betametasona, lanolina, parches de hidrogel entre tomas, bolsas de té, clorhexidina, pezonera de plata, pezonera de cera (riesgo de clostridium)

Comparación: Aplicación de la propia leche y asegurar una buena postura/enganche

Perspectiva: Clínica

C1: Apósito en gel de glicerina vs. educación individual sobre LM; C2: Pezoneras con lanolina vs. educación individual sobre LM; C3: Apósito en gel de glicerina vs. Pezoneras con lanoina; C4: Lanolina vs. ninguna intervención; C5: Leche materna vs. ninguna intervención; C6: Lanolina vs. leche materna extraída; C7: Lanolina vs. pomada multiusos; C8: Gel aloe vera vs. lanolina; C9: Esencia de menta vs. leche materna.

\begin{tabular}{|c|c|c|c|c|c|}
\hline & CRITERIO & \multicolumn{2}{|l|}{ JUICIO } & EVIDENCIA & $\begin{array}{l}\text { CONSIDERACIONE } \\
\underline{\text { ADICIONALES }}\end{array}$ \\
\hline $\begin{array}{l}0 \\
z \\
0 \\
0 \\
0 \\
0 \\
0 \\
\leq\end{array}$, & $\begin{array}{l}\frac{\text { ¿Existe }}{\text { incertidumbre }} \\
\text { o variabilidad } \\
\text { importante en } \\
\text { cómo los } \\
\text { pacientes } \\
\text { valoran los } \\
\text { desenlaces } \\
\text { de interés? }\end{array}$ & $\begin{array}{ll}\text { C1 } & \text { Baja } \\
\text { C2 } & \text { Baja } \\
\text { C3 } & \text { Baja } \\
\text { C4 } & \text { Baja } \\
\text { C5 } & \text { Baja } \\
\text { C6 } & \text { Baja } \\
\text { C7 } & \text { Moder } \\
\text { C8 } & \text { Baja } \\
\text { C9 } & \text { Baja }\end{array}$ & 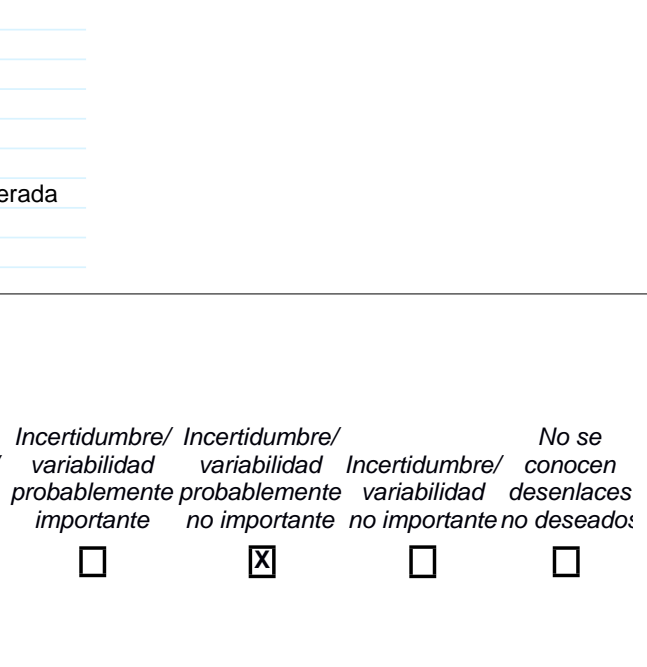 & $\begin{array}{l}\text { Comparación 1: } \\
\text { Añadir apósitos en gel de glicerina no mejora el dolor, la } \\
\text { curación de las lesiones ni la satisfacción materna frente a la } \\
\text { educación individual. } \\
\text { Comparación 2: } \\
\text { Las pezoneras con lanolina tampoco mejoran el dolor, la } \\
\text { curación de las lesiones ni la satisfacción materna } \\
\text { Comparación 3: } \\
\text { Los apósitos en gel de glicerina podrían curar más que las } \\
\text { pezoneras con lanolina, pero el intervalo no es significativo. } \\
\text { Comparación 4: } \\
\text { Añadir lanolina no reduce el dolor, las lesiones ni aumenta la } \\
\text { duración de la lactancia materna, aunque la satisfacción } \\
\text { materna es ligeramente superior con lanolina versus nada. }\end{array}$ & $\begin{array}{l}\text { En todas las } \\
\text { comparaciones } \\
\text { descritas, la evidencia } \\
\text { es de baja calidad. De la } \\
\text { revisión Cochrane se } \\
\text { extrae que la aplicación } \\
\text { de leche materna versus } \\
\text { lanolina es más efectiva } \\
\text { que la lanolina en } \\
\text { reducir el dolor y curar } \\
\text { las lesiones del pezón } \\
\text { (calidad baja), aunque } \\
\text { parece que el aloe vera } \\
\text { y la esencia de menta } \\
\text { también funcionan mejor } \\
\text { que la lanolina en } \\
\text { reducir el dolor (aloe } \\
\text { vera y la esencia de }\end{array}$ \\
\hline
\end{tabular}


GPC Lactancia Materna- Pregunta 29. Dolor y grietas en el pezón.

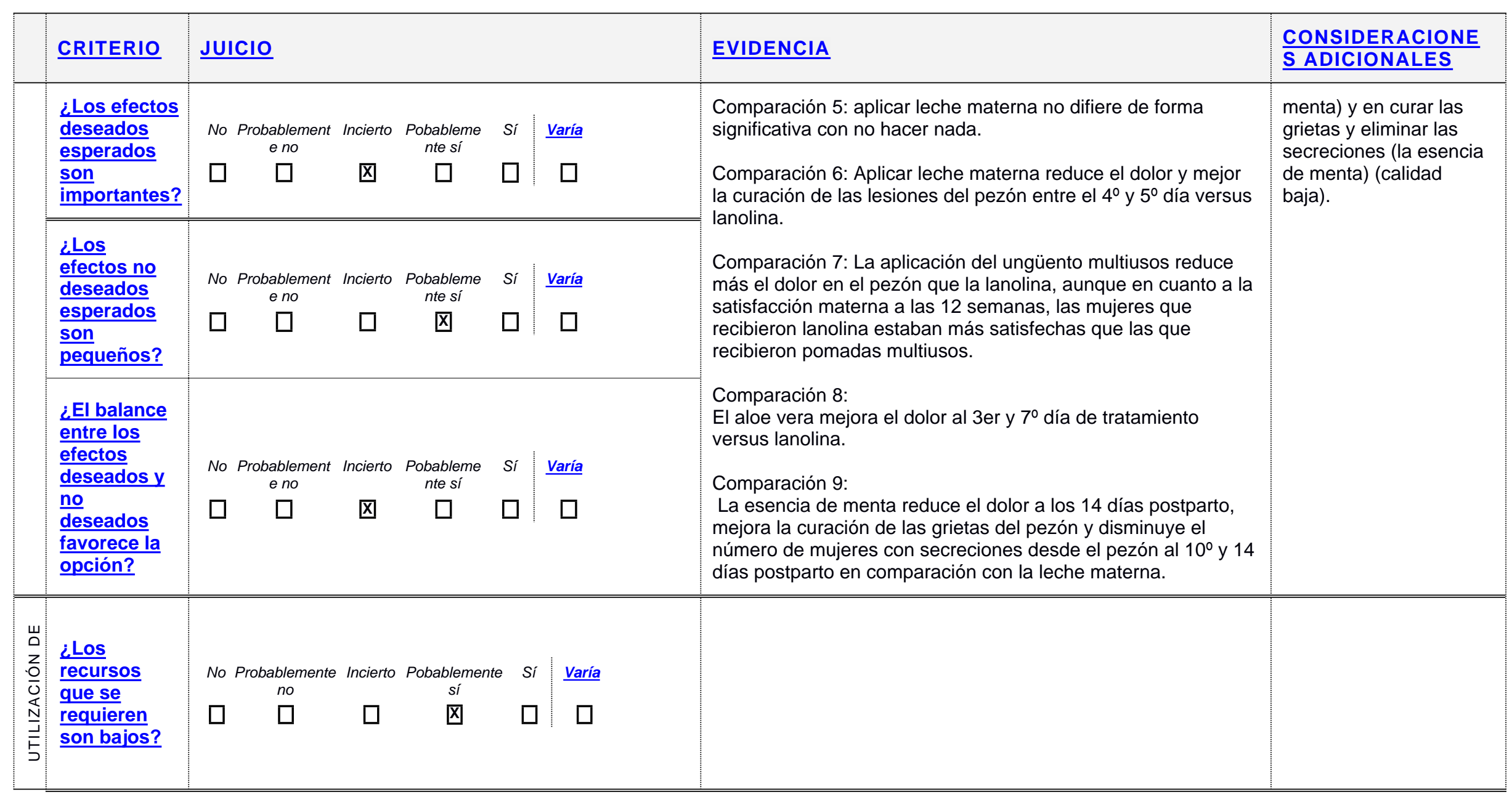


GPC Lactancia Materna- Pregunta 29. Dolor y grietas en el pezón.

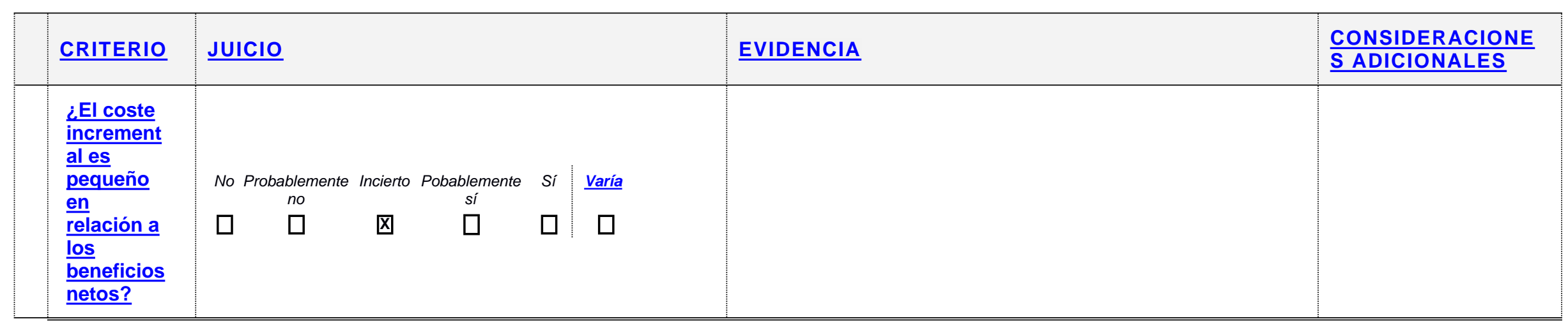


GPC Lactancia Materna- Pregunta 29. Dolor y grietas en el pezón.

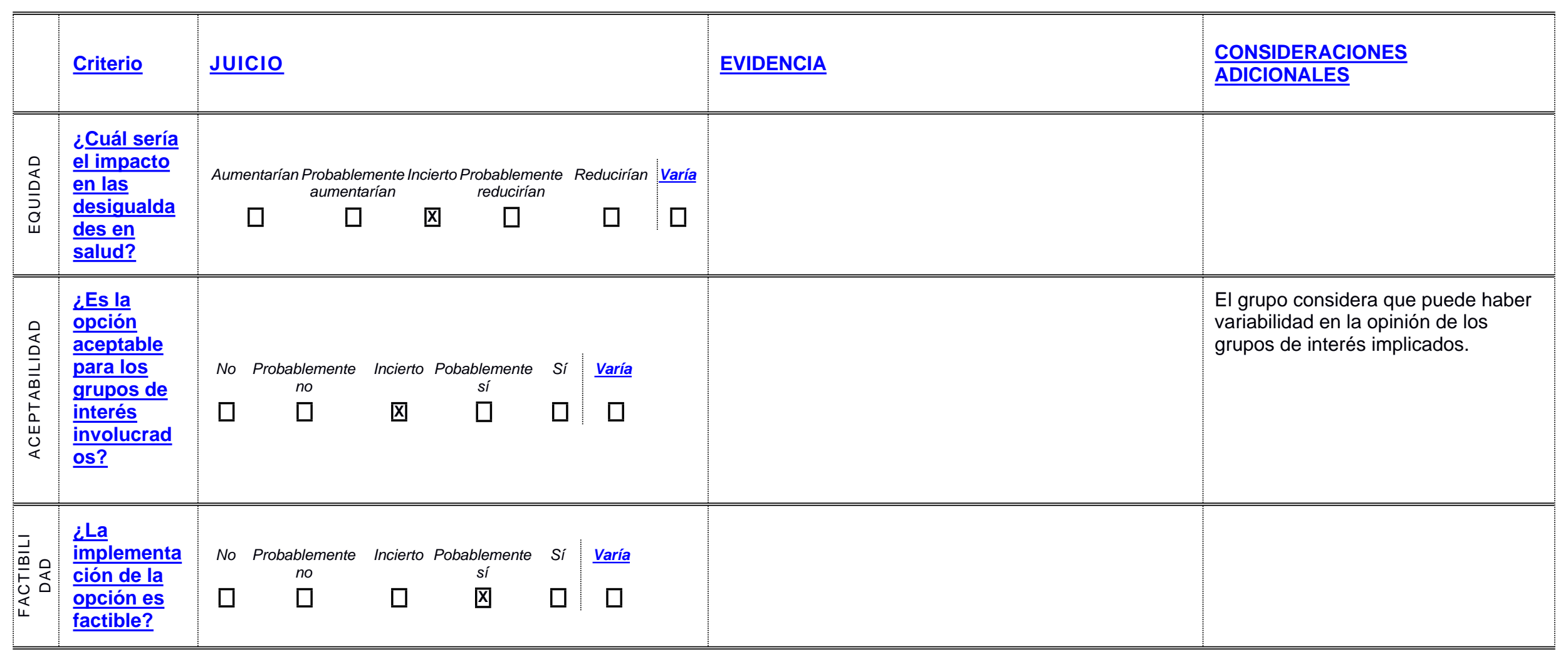




\begin{tabular}{|c|c|c|c|c|c|}
\hline \multirow[t]{2}{*}{$\begin{array}{l}\text { Balance de las } \\
\underline{\text { consecuencias }}\end{array}$} & $\begin{array}{l}\text { Las consecuencias no } \\
\text { deseadas superan } \\
\text { claramente las } \\
\text { consecuencias deseadas } \\
\text { en la mayoría de los } \\
\text { escenarios }\end{array}$ & $\begin{array}{l}\text { Las consecuencias no } \\
\text { deseadas probablemente } \\
\text { superan las } \\
\text { consecuencias deseadas } \\
\text { en la mayoría de los } \\
\text { escenarios }\end{array}$ & $\begin{array}{l}\text { El balance entre las } \\
\text { consecuencias deseadas y } \\
\text { no deseadas está muy } \\
\text { equilibrado o es incierto }\end{array}$ & $\begin{array}{c}\text { Las consecuencias } \\
\text { deseadas } \\
\text { probablemente superan } \\
\text { las consecuencias no } \\
\text { deseadas en la mayoría } \\
\text { de los escenarios }\end{array}$ & $\begin{array}{l}\text { Las consecuencias } \\
\text { deseadas claramente } \\
\text { superan las } \\
\text { consecuencias no } \\
\text { deseadas en la mayoría } \\
\text { de los escenarios }\end{array}$ \\
\hline & $\square$ & $\square$ & 凶 & $\square$ & $\square$ \\
\hline $\begin{array}{l}\text { Tipo de } \\
\text { recomendación }\end{array}$ & \multicolumn{2}{|l|}{$\square$} & $\square$ & $\square$ & $\square$ \\
\hline$\frac{\text { Recomendación }}{\text { (Texto) }}$ & \multicolumn{5}{|c|}{$\begin{array}{l}\text { Recomendación de buena práctica } \\
\text { Identificar la causa y prestar el apoyo necesario hasta conseguir una posición y agarre adecuados. }\end{array}$} \\
\hline
\end{tabular}

\section{Consideraciones de}

\section{subgrupos}


GPC Lactancia Materna- Pregunta 29. Dolor y grietas en el pezón.

Consideraciones para Creación de consultas de lactancia atendidas por profesionales especializados en lactancia materna.

la implementación

\section{Monitorización y}

evaluación

Prioridades para la investigación
Se necesitan más estudios de calidad que comparen la eficacia de las intervenciones existentes a la hora de reducir el dolor y curar las grietas de los pezones en madres que amamantan a sus hijos para saber si estos pueden ser recomendados. 


\section{ANEXO I, ESTRATEGIAS DE BÚSQUEDA}

\section{Cochrane Library}

\section{Searched 02/07/2015}

\section{Updated search 02/07/2015 a xx/xx/xxxx}

\#1 nipple or nipples:ti,ab,kw or breast:ti,ab,kw (Word variations have been searched) 24677

\#2 pain or trauma or cracked or sore or bleeding or oedematous or erythemic or blistered:ti,ab,kw (Word variations have been searched) 103695

\#3 \#1 and \#2 2296

\#4 lactation:ti,ab,kw or breastfeeding or "breast feeding":ti,ab,kw (Word variations have been searched) 3601

\#5 \#3 and \#4 Publication Year from 2009 to 201593

RS 20

\section{MEDLINE, via Pubmed}

\section{Searched 02/07/2015}

\section{Updated search 02/07/2015 a xx/xx/xxxx}

\#1 Search ((nipple[Title/Abstract] OR nipples[Title/Abstract])) OR breast[Title/Abstract] 315981

\#2 Search (pain[Title/Abstract] OR trauma[Title/Abstract] OR cracked[Title/Abstract] OR sore[Title/Abstract] OR bleeding[Title/Abstract] OR oedematous[Title/Abstract] OR erythemic[Title/Abstract] OR blistered[Title/Abstract]) 731088

\#3 \#1 AND \#2 9055

\#4 Search (lactation[Title/Abstract]) OR (breastfeeding[Title/Abstract] OR "breast feeding"[Title/Abstract]) 51138

\#5 \#3 AND \#4 740

\#6 \#5 Filters: Publication date from 2009/01/01 to 2015/12/31 247

\#7 Search ((review[Title/Abstract] OR reviews[Title/Abstract])) OR (metaanalysis[Title/Abstract] OR meta-analysis[Title/Abstract] OR "meta analysis"[Title/Abstract]) 1152262

\#8 \#6 AND \#7 38

\#9 \#6 Filters: Systematic Reviews; Meta-Analysis 27

\#10 \#8 OR \#9 43

EMBASE, via Ovid

Searched 02/07/2015

Updated search 02/07/2015 a xx/xx/xxxx

\#1 (nipple or nipples or breast).ti,ab,kw. 429654

\#2 (pain or trauma or cracked or sore or bleeding or oedematous or erythemic or blistered).ti,ab,kw. 1081334

\#3 \#1 AND \#2 14679

\#4 (lactation or breastfeeding or "breast feeding").ti,ab,kw.

62202

\#5 \#3 AND \#4 1002

\#6 limit 5 to $y r=" 2009$-Current" $\mathbf{4 7 2}$

\#7 limit 6 to meta analysis 11

\#8 limit 6 to "systematic review" 12

\#9

\#7 OR \#8

19 
\#10 (review or reviews or metaanalysis or meta-analysis or "meta analysis").ti,ab,kw. 1479312

\#11 \#6 AND \#10 66

\#12 \#9 OR \#11 69

\section{CINAHL, via EBSCOhost databases}

Searched 02/07/2015

\section{Updated search 02/07/2015 a xx/xx/xxxx}

S1 (nipple OR nipples ) OR breast 59,791

S2 pain or trauma or cracked or sore or bleeding or oedematous or erythemic or blistered 177,393

S3 S1 AND S2 2744

S4 lactation OR ( breastfeeding or "breast feeding" ) 16289

S5 S3 AND S4 588

S6 S5 Limitadores - Fecha de publicación: 20090101-20151231 210

S7 S6 Limitadores - Tipo de publicación: Meta Analysis 1

S8 S6 Limitadores - Tipo de publicación: Systematic Review 20

S9 $\quad$ S7 OR S8 20

S10 review or reviews or metaanalysis or meta-analysis or "meta analysis 253130

S11 S6 AND S10 37

S12 S9 OR S11 38

JBI, via Ovid

\section{Searched 02/07/2015}

Updated search 02/07/2015 a xx/xx/xxxx

1 (nipple or nipples or breast).ti,ab,kw. 46

2 (pain or trauma or cracked or sore or bleeding or oedematous or erythemic or blistered).ti,ab,kw. $\quad 279$

$3 \quad 1$ and 2

$4 \quad$ (lactation or breastfeeding or "breast feeding").ti,ab,kw. 79

$5 \quad 3$ and $4 \quad 7$

$6 \quad$ limit 5 to $y r=" 2009$-Current" $\mathbf{5}$ 


\section{ANEXO II, Tabla de estudios individuales para la pregunta}

\begin{tabular}{|c|c|c|c|c|c|c|}
\hline $\begin{array}{l}\text { Referencia } \\
\text { (Cita Abreviada) }\end{array}$ & $\begin{array}{l}\text { Estudio (Diseño y } \\
\text { objetivo) }\end{array}$ & $\begin{array}{l}\text { Población } \\
\text { (nº y características) }\end{array}$ & $\begin{array}{l}\text { Descripción de las intervenciones } \\
\text { comparaciones, exposiciones o } \\
\text { pruebas a estudio }\end{array}$ & $\begin{array}{l}\text { Resultados } \\
\text { (Estimadores de resultados-Magnitud del } \\
\text { efecto) }\end{array}$ & $\begin{array}{l}\text { Conclusiones } \\
\text { (conclusiones) }\end{array}$ & $\begin{array}{l}\text { Comentarios } \\
\text { Calidad de la } \\
\text { evidencia } \\
\text { Financiación } \\
\text { comentarios) }\end{array}$ \\
\hline Cadwell, 2004 & $\begin{array}{l}\text { Diseño: Ensayo cuasi } \\
\text { aleatorizado } \\
\text { Objetivo: } \\
\text { El objetivo fue usar tres } \\
\text { diferentes tratamientos } \\
\text { para compararlos en la } \\
\text { curación del pezón, } \\
\text { cambios en el dolor del } \\
\text { pezón, y la satisfacción de } \\
\text { las madres en relación al } \\
\text { tratamiento. }\end{array}$ & $\begin{array}{l}94 \text { mujeres letonas y } \\
\text { caucásicas en } \\
\text { lactancia materna con } \\
\text { dolor en los pezones } \\
\text { o traumas del pezón } \\
\text { que dieron a luz en } \\
\text { los últimos } 10 \text { días. } \\
\text { Mujeres excluidas con } \\
\text { mastitis, abscesos, } \\
\text { infecciones por } \\
\text { hongos, u otras } \\
\text { condiciones } \\
\text { relacionadas con el } \\
\text { dolor. }\end{array}$ & $\begin{array}{l}\text { Grupo de intervención 1: lanolina + } \\
\text { pezoneras ( } n=31 \text { ): Las mujeres } \\
\text { secaban el pezón al aire después de la } \\
\text { lactancia materna, se aplicaba la } \\
\text { lanolina con las manos lavadas y } \\
\text { usaban las pezoneras hasta la próxima } \\
\text { toma. El tratamiento continuó durante } 10 \\
\text { días o hasta la resolución de síntomas. } \\
\text { Grupo de intervención 2: gel de } \\
\text { glicerina ( } n=33 \text { ): con las manos } \\
\text { limpias, las mujeres aplicaban glicerina } \\
\text { en gel en el pecho y durante } 10 \text { días o } \\
\text { hasta la resolución de los síntomas. } \\
\text { Grupo control: ( } n=30 \text { ) evaluación } \\
\text { individualizada de la lactancia materna, } \\
\text { educación, e intervenciones correctivas. } \\
\text { Continuó medición durante } 10 \text { días o } \\
\text { hasta la resolución de los síntomas. } \\
\text { Todos los grupos de intervención } \\
\text { recibieron la misma evaluación de la } \\
\text { lactancia materna, la educación, y las } \\
\text { intervenciones correctivas que se } \\
\text { proporciona a las mujeres en el grupo } \\
\text { control. }\end{array}$ & $\begin{array}{l}\text { Los resultados no encontraron diferencias } \\
\text { significativas entre los dos grupos. Casi } \\
\text { todas las mujeres experimentaron } \\
\text { curación de las lesiones del pezón, según } \\
\text { la evaluación de la partera. Las madres } \\
\text { que usaron glicerina en gel estuvieron } \\
\text { más satisfechas con el método de } \\
\text { tratamiento, pero este hallazgo no fue } \\
\text { significativo estadísticamente. Los } \\
\text { resultados muestran que el cuidado } \\
\text { efectivo y la educación perinatal de } \\
\text { enfermería incluye la posición correcta de } \\
\text { la lactancia, y el engache correcto del } \\
\text { bebe al pezón. }\end{array}$ & $\begin{array}{l}\text { No encontraron } \\
\text { diferencias en las } \\
\text { intervenciones } \\
\text { evaluadas, el } \\
\text { cuidado efectivo y } \\
\text { la educación } \\
\text { perinatal de } \\
\text { enfermería incluye } \\
\text { la posición } \\
\text { correcta de la } \\
\text { lactancia, y el } \\
\text { engache correcto } \\
\text { del bebe al pezón }\end{array}$ & \\
\hline Dennis, 2012 & $\begin{array}{l}\text { Diseño: ensayo controlado } \\
\text { aleatorizado doble ciego } \\
\text { Objetivo: } \\
\text { El objetivo de este estudio } \\
\text { fue evaluar el efecto del }\end{array}$ & $\begin{array}{l}151 \text { mujeres } \\
\text { canadienses que } \\
\text { estaban amamantando, } \\
\text { con pezones dolorosos } \\
\text { y que tuvieran áreas } \\
\text { abiertas visualmente de }\end{array}$ & $\begin{array}{l}\text { Grupo de intervención: uso de } \\
\text { pomada múltiple para el pezón }(n=75) \text { : } \\
\text { las mujeres aplicaron el ungüento con } \\
\text { moderación después de cada toma y no } \\
\text { lavaron la pomada hasta antes de la } \\
\text { siguiente toma. }\end{array}$ & $\begin{array}{l}\text { No hubo diferencias significativas entre los } \\
\text { grupos en las puntuaciones medias de } \\
\text { dolor } 1 \text { semana después de la } \\
\text { aleatorización. Las mujeres del grupo de } \\
\text { lanolina informaron significativamente } \\
\text { mayor satisfacción con el tratamiento y no }\end{array}$ & $\begin{array}{l}\text { Los resultados } \\
\text { sugieren que el } \\
\text { ungüento múltiples } \\
\text { usos para el pezón } \\
\text { no es superior a la } \\
\text { lanolina en } \\
\text { relación a la }\end{array}$ & \\
\hline
\end{tabular}




\begin{tabular}{|c|c|c|c|c|c|c|}
\hline $\begin{array}{l}\text { Referencia } \\
\text { (Cita Abreviada) }\end{array}$ & $\begin{array}{l}\text { Estudio (Diseño y } \\
\text { objetivo) }\end{array}$ & $\begin{array}{l}\text { Población } \\
\text { (no y características) }\end{array}$ & $\begin{array}{l}\text { Descripción de las intervenciones } \\
\text { comparaciones, exposiciones o } \\
\text { pruebas a estudio }\end{array}$ & $\begin{array}{l}\text { Resultados } \\
\text { (Estimadores de resultados-Magnitud del } \\
\text { efecto) }\end{array}$ & $\begin{array}{l}\text { Conclusiones } \\
\text { (conclusiones) }\end{array}$ & $\begin{array}{l}\text { Comentarios } \\
\text { Calidad de la } \\
\text { evidencia } \\
\text { Financiación } \\
\text { comentarios) } \\
\end{array}$ \\
\hline & $\begin{array}{l}\text { ungüento multiusos para } \\
\text { el pezón frente a la } \\
\text { lanolina sobre el dolor del } \\
\text { pezón en madres que } \\
\text { amamantan con lesiones } \\
\text { en el pezón. }\end{array}$ & $\begin{array}{l}\text { la piel en uno o ambos } \\
\text { pezones y/o areolas } \\
\text { dentro de las } 2 \\
\text { primeras semanas post } \\
\text { parto. Las mujeres } \\
\text { excluidas fueron } \\
\text { aquellas que utilizaban } \\
\text { dispositivos de } \\
\text { alimentación para dar } \\
\text { leche artificial, que } \\
\text { usaran pezoneras, y } \\
\text { antecedentes de } \\
\text { cirugía de reducción de } \\
\text { senos o con } \\
\text { anormalidades en el } \\
\text { seno que impidieran la } \\
\text { lactancia materna } \\
\text { exclusiva. } \\
\text { Las participantes } \\
\text { potenciales fueron } \\
\text { identificadas por los } \\
\text { consultores de } \\
\text { lactancia del hospital o } \\
\text { por el personal de } \\
\text { enfermería y fueron } \\
\text { reclutados de un gran } \\
\text { hospital universitario en } \\
\text { Canadá. }\end{array}$ & $\begin{array}{l}\text { El tratamiento continuó hasta después } \\
\text { de cada comida en los primeros } 10 \text { días } \\
\text { del ensayo, tras este periodo, la pomada } \\
\text { se aplicó cada dos tomas para los } \\
\text { restantes } 4 \text { días del ensayo. Este } \\
\text { ungüento estuvo compuesto por } 15 \mathrm{~g} \text { de } \\
\text { pomada de mupirocina al } 2 \%+ \\
\text { miconazol polvo al } 2 \% \text { y } 15 \mathrm{~g} \text { de } \\
\text { pomada de betametasona al } 0,1 \% \text {. } \\
\text { Grupo control: lanolina ( } \mathrm{n}=76) \text { : las } \\
\text { mujeres se aplicaron lanolina con } \\
\text { moderación después de cada toma } \\
\text { y no la lavaban hasta la siguiente toma. } \\
\text { El tratamiento continuó hasta después } \\
\text { de cada comida en los primeros } 10 \text { días } \\
\text { del ensayo, tras este periodo, la pomada } \\
\text { se aplicó cada dos tomas para los } \\
\text { restantes } 4 \text { días del ensayo. } \\
\text { Todas las participantes recibieron } \\
\text { atención posparto habitual que incluyó } \\
\text { la remisión a un especialista en } \\
\text { lactancia para las mujeres que } \\
\text { experimentaran pezones agrietados. } \\
\text { a }\end{array}$ & $\begin{array}{l}\text { se encontraron diferencias significativas } \\
\text { en la duración de la lactancia y en la tasa } \\
\text { de la lactancia exclusiva a las } 12 \text { semanas } \\
\text { después del parto. }\end{array}$ & $\begin{array}{l}\text { efectividad del } \\
\text { tratamiento de las } \\
\text { lesiones del pezón. }\end{array}$ & \\
\hline Jackson, 2013 & $\begin{array}{l}\text { Diseño: Ensayo controlado } \\
\text { aleatorizado } \\
\text { Objetivo: El propósito de } \\
\text { este estudio es evaluar la } \\
\text { eficacia de la lanolina para } \\
\text { el tratamiento de pezones } \\
\text { dolorosos / dañados entre } \\
\text { las mujeres que }\end{array}$ & $\begin{array}{l}\text { Se reclutó } 186 \text { mujeres } \\
\text { en lactancia en el } \\
\text { hospital que habían } \\
\text { dado a luz a un recién } \\
\text { nacido a término y } \\
\text { estaban dentro de } 4 \\
\text { días después del parto. } \\
\text { Todas las mujeres que } \\
\text { presentaron quejas de }\end{array}$ & $\begin{array}{l}\text { Grupo de intervención: la lanolina }(\mathrm{n}= \\
\text { 93). A las mujeres se les proporcionó } \\
\text { un tubo de lanolina y un folleto con } \\
\text { instrucciones para su uso. Los } \\
\text { participantes fueron instruidos para } \\
\text { lavarse las manos, y luego aplicarse una } \\
\text { cantidad pequeña de lanolina para el } \\
\text { pezón y la areola después de cada toma } \\
\text { hasta la resolución de los síntomas o el }\end{array}$ & & & $\begin{array}{l}\text { La RS no } \\
\text { proporciona los } \\
\text { resultados } \\
\text { individuales del } \\
\text { estudio de } \\
\text { Jackson } 2013 \text {. }\end{array}$ \\
\hline
\end{tabular}




\begin{tabular}{|c|c|c|c|c|c|c|}
\hline $\begin{array}{l}\text { Referencia } \\
\text { (Cita Abreviada) }\end{array}$ & $\begin{array}{l}\text { Estudio (Diseño y } \\
\text { objetivo) }\end{array}$ & $\begin{array}{l}\text { Población } \\
\text { (no y características) }\end{array}$ & $\begin{array}{l}\text { Descripción de las intervenciones } \\
\text { comparaciones, exposiciones o } \\
\text { pruebas a estudio }\end{array}$ & $\begin{array}{l}\text { Resultados } \\
\text { (Estimadores de resultados-Magnitud del } \\
\text { efecto) }\end{array}$ & $\begin{array}{l}\text { Conclusiones } \\
\text { (conclusiones) }\end{array}$ & $\begin{array}{l}\text { Comentarios } \\
\text { Calidad de la } \\
\text { evidencia } \\
\text { Financiación } \\
\text { comentarios) }\end{array}$ \\
\hline & $\begin{array}{l}\text { amamantan, y para } \\
\text { evaluar si el uso de } \\
\text { lanolina tiene un efecto } \\
\text { sobre los resultados de la } \\
\text { lactancia materna como la } \\
\text { duración y exclusividad. }\end{array}$ & \begin{tabular}{l|} 
dolor en el pezón con \\
signos de lesiones \\
fueron incluidas. Las \\
mujeres excluidas \\
tuvieron: 1 . Recién \\
nacidos que no fueron \\
dados de alta con la \\
madre; 2 . Recién \\
nacidos con anomalías \\
congénitas que puedan \\
menoscabar la \\
lactancia materna, y 3. \\
la alergia materna a la \\
lanolina \\
Los participantes \\
potenciales fueron \\
identificados por el \\
personal de enfermería \\
del hospital y fueron \\
reclutados de un gran \\
hospital universitario en \\
Canadá.
\end{tabular} & $\begin{array}{l}\text { final del período de intervención. } \\
\text { Grupo control: atención habitual }(n= \\
\text { 93). Las mujeres fueron instruidas para } \\
\text { no aplicarse nada en sus pezones } \\
\text { durante el tiempo que duró el estudio. } \\
\text { Todas las mujeres del estudio fueron en } \\
\text { la técnica de la lactancia. }\end{array}$ & & & \\
\hline $\begin{array}{l}\text { Mohammadzadeh, } \\
2005\end{array}$ & $\begin{array}{l}\text { Diseño: Ensayo cuasi } \\
\text { aleatorizado } \\
\text { Objetivo: Fue comparar el } \\
\text { efecto de frotar la leche } \\
\text { materna extraída frente a } \\
\text { la lanolina en el } \\
\text { tratamiento de los } \\
\text { síntomas de dolor en los } \\
\text { pezones. }\end{array}$ & $\begin{array}{l}\text { Se incluyeron } 225 \\
\text { mujeres que daban } \\
\text { lactancia materna, en } \\
\text { un único hospital en } \\
\text { lrán que presentaron } \\
\text { fisuras en la superficie } \\
\text { del pezón o alrededor } \\
\text { de los pezones. }\end{array}$ & $\begin{array}{l}\text { Grupo } 1 \text { Intervención: Recibió la } \\
\text { aplicación de leche materna }(n=78) \text { : las } \\
\text { mujeres frotaron leche en sus pezones } \\
\text { al final de cada toma por un período de } \\
7 \text { días. } \\
\text { Grupo de intervención 2: lanolina ( } n= \\
74 \text { ): las mujeres aplicaron lanolina en } \\
\text { los pezones } 3 \text { veces al día y era retirada } \\
\text { con un paño húmedo antes de la } \\
\text { siguiente toma por un periodo } 7 \text { días. } \\
\text { Grupo control: atención habitual ( } n= \\
\text { 73): las mujeres fueron instruidas para } \\
\text { no aplicar nada en sus pezones para el } \\
\text { período del ensayo. } \\
\text { Todas las mujeres del estudio fueron en } \\
\text { la técnica de la lactancia y, si era }\end{array}$ & $\begin{array}{l}\text { El tiempo de curación fue diferente en } \\
\text { estos } 3 \text { grupos }(p=0,038) \text { de acuerdo con } \\
\text { el ranking de las medias de tres los } \\
\text { grupos. El tiempo de curación en el grupo } \\
\text { de lanolina fue más largo que en el grupo } \\
\text { de la leche de materna }(p=0,029) \text { y el } \\
\text { grupo control }(p=0,028) \text {. No se } \\
\text { observaron efectos secundarios durante el } \\
\text { estudio. }\end{array}$ & $\begin{array}{l}\text { Este estudio } \\
\text { sugiere que, } \\
\text { debido a la mejoría } \\
\text { del dolor de pezón } \\
\text { con leche materna, } \\
\text { su disponibilidad, } \\
\text { su coste cero y } \\
\text { ausencia de } \\
\text { efectos adversos, } \\
\text { se recomienda la } \\
\text { aplicación de leche } \\
\text { materna para el } \\
\text { tratamiento de } \\
\text { dolor en los } \\
\text { pezones. }\end{array}$ & \\
\hline
\end{tabular}




\begin{tabular}{|c|c|c|c|c|c|c|}
\hline $\begin{array}{l}\text { Referencia } \\
\text { (Cita Abreviada) }\end{array}$ & $\begin{array}{l}\text { Estudio (Diseño y } \\
\text { objetivo) }\end{array}$ & $\begin{array}{l}\text { Población } \\
\text { (nº y características) }\end{array}$ & $\begin{array}{l}\text { Descripción de las intervenciones } \\
\text { comparaciones, exposiciones o } \\
\text { pruebas a estudio }\end{array}$ & $\begin{array}{l}\text { Resultados } \\
\text { (Estimadores de resultados-Magnitud del } \\
\text { efecto) }\end{array}$ & $\begin{array}{l}\text { Conclusiones } \\
\text { (conclusiones) }\end{array}$ & $\begin{array}{l}\text { Comentarios } \\
\text { Calidad de la } \\
\text { evidencia } \\
\text { Financiación } \\
\text { comentarios) }\end{array}$ \\
\hline & & & $\begin{array}{l}\text { necesario, corregidas. Los recién } \\
\text { nacidos se alimentaron a demanda de } \\
\text { lactancia materna exclusiva. }\end{array}$ & & & \\
\hline Saeidi, 2015 & $\begin{array}{l}\text { Diseño: Ensayo clínico } \\
\text { doble ciego } \\
\text { Objetivo: Fue comparar el } \\
\text { efecto de frotar la leche } \\
\text { materna extraída frente a } \\
\text { la lanolina en el } \\
\text { tratamiento de los } \\
\text { síntomas de dolor en los } \\
\text { pezones. }\end{array}$ & $\begin{array}{l}\text { La muestra incluyó } \\
100 \text { mujeres sanas en } \\
\text { lactancia materna que } \\
\text { informaron de dolor } \\
\text { en el pezón y sin } \\
\text { mejoría tras el } \\
\text { tratamiento previo con } \\
\text { la aplicación de la } \\
\text { leche materna, y a } \\
\text { quienes empeoró el } \\
\text { dolor (aumento de al } \\
\text { menos dos puntos en } \\
\text { la escala de Storr). } \\
\text { Fue desarrollado en } \\
\text { hospital an un } \\
\text { universitario en Irán. }\end{array}$ & $\begin{array}{l}\text { Evaluó mediante dos brazos las } \\
\text { siguientes intervenciones: Grupo 1: Aloe } \\
\text { vera, Grupo 2: Lanolina. El tratamiento } \\
\text { lo recibieron de forma continuada, } 3 \\
\text { veces al día (luego de las tomas) } \\
\text { durante } 7 \text { días en total. Todas las } \\
\text { mujeres incluidas recibieron educación } \\
\text { sobre las correctas posiciones de la } \\
\text { lactancia materna }\end{array}$ & $\begin{array}{l}\text { Un total de } 100 \text { mujeres fueron incluidas, } \\
\text { con } 50 \text { para el grupo de la lanolina y } 50 \\
\text { para el grupo de aloe vera. En el grupo } \\
\text { del aloe Vera, la puntuación de dolor } \\
\text { disminuyó significativamente en el tercer } \\
\text { día versus al que presentaron previo al } \\
\text { tratamiento }(p=0,00 \text { y y también en el } \\
\text { séptimo día versus al que presentaron } \\
\text { previo al tratamiento y al tercer día ( } p= \\
0,000 \text { ). El dolor en ambos grupos fue } \\
\text { homogéneo en el día previo al } \\
\text { tratamiento ( } p=0,711) \text {, y presentaron } \\
\text { diferencias significativas en la disminución } \\
\text { del dolor a favor del grupo aloe vera } \\
\text { grupos en el tercero y el séptimo día de } \\
\text { tratamiento }(p=0,048, p=0,003 \text {, } \\
\text { respectivamente). }\end{array}$ & $\begin{array}{l}\text { El aloe vera es } \\
\text { más eficaz que la } \\
\text { lanolina en la } \\
\text { curación de dolor } \\
\text { en los pezones. }\end{array}$ & \\
\hline Akbari, 2014 & $\begin{array}{l}\text { Diseño: Ensayo clínico } \\
\text { Objetivo: Fue determinar la } \\
\text { efectividad de la esencia } \\
\text { de la menta en relación a } \\
\text { la aplicación de leche } \\
\text { extraída en la mejora de } \\
\text { las grietas en los pezones } \\
\text { en mujeres primíparas que } \\
\text { amamantan }\end{array}$ & $\begin{array}{l}\text { Incluyó una muestra } \\
\text { de } 110 \text { mujeres en } \\
\text { lactancia materna con } \\
\text { fisuras en los } \\
\text { pezones. } \\
\text { Los criterios de } \\
\text { inclusión haber tenido } \\
\text { un embarazo a } \\
\text { término, neonato } \\
\text { único, y ausencia de } \\
\text { anormalidades en los } \\
\text { senos y ser } \\
\text { primíparas. } \\
\text { Las mujeres que } \\
\text { tuvieron fiebre } \\
\text { puerperal o infección }\end{array}$ & $\begin{array}{l}\text { Este ensayo constó de dos brazos, para } \\
\text { evaluar las siguientes intervenciones: } \\
\text { Grupo 1: Aplicación de } 4 \text { gotas de } \\
\text { esencia de menta sobre el pezón y la } \\
\text { areola luego de cada toma (cada dos } \\
\text { horas). Grupo } 2 \text { : Aplicación de } 4 \text { gotas } \\
\text { de su propia leche materna sobre el } \\
\text { pezón y la areola luego de cada toma. } \\
\text { La escala Amir fue utilizada para valorar } \\
\text { la gravedad de las lesiones en el pezón } \\
\text { (1-2 mm refleja menor severidad, } 3-9 \\
\text { mm mediana severidad, } \geq 10 \mathrm{~mm} \text { daño } \\
\text { severo) y la escala analógica visual se } \\
\text { utilizó para medir la intensidad del dolor } \\
\text { (sobre la cinta } 10 \mathrm{~cm} \text { ). En esta escala, } \\
\text { los números } 1-3 \text { refleja el dolor leve, }\end{array}$ & $\begin{array}{l}\text { La intensidad media de dolor y las grietas } \\
\text { del pezón antes del tratamiento }(8,55 \pm \\
1,74) \text { y el día } 10 \text { después post parto }(4,26 \\
\pm 1,57) \text { y antes del tratamiento y día } 14 \\
\text { post parto en el grupo de que recibió } \\
\text { menta }(1,32 \pm 1,02) \text { tuvieron una } \\
\text { diferencia significativa }(p<0,001) \text {. La } \\
\text { presencia de secreción del pezón en el } \\
\text { grupo que recibió menta: antes del } \\
\text { tratamiento }(75,2 \%) \text { y el día } 10 \text { post parto } \\
(31,6 \%) \text { y antes del tratamiento y el día } \\
14 \text { post parto }(15,7 \%) \text {, tuvo una } \\
\text { diferencia significativa ( } p<0,001) \\
\text { Hubieron diferencias significativas entre } \\
\text { ambos grupos (menta versus leche } \\
\text { materna) en para los tres desenlaces }\end{array}$ & $\begin{array}{l}\text { La esencia de } \\
\text { menta puede } \\
\text { mejorar las fisuras } \\
\text { en los pezones en } \\
\text { las mujeres } \\
\text { primíparas que } \\
\text { amamantan. }\end{array}$ & $\begin{array}{l}\text { Este estudio fue } \\
\text { financiado por la } \\
\text { Universidad } \\
\text { Shahid Beheshti } \\
\text { de Ciencias } \\
\text { Médicas } \\
\text { (Número de } \\
\text { proyecto de } \\
\text { Investigación } \\
\text { 25/12/566) } \\
\text { Número IRCT: } \\
\text { IRCT201206166 } \\
\text { 807N5 }\end{array}$ \\
\hline
\end{tabular}


GPC Lactancia Materna- Pregunta 29. Dolor y grietas en el pezón.

\begin{tabular}{|c|c|c|c|c|c|c|}
\hline $\begin{array}{l}\text { Referencia } \\
\text { (Cita Abreviada) }\end{array}$ & $\begin{array}{l}\text { Estudio (Diseño y } \\
\text { objetivo) }\end{array}$ & $\begin{array}{l}\text { Población } \\
\text { (nº y características) }\end{array}$ & $\begin{array}{l}\text { Descripción de las intervenciones } \\
\text { comparaciones, exposiciones o } \\
\text { pruebas a estudio }\end{array}$ & $\begin{array}{l}\text { Resultados } \\
\text { (Estimadores de resultados-Magnitud del } \\
\text { efecto) }\end{array}$ & $\begin{array}{l}\text { Conclusiones } \\
\text { (conclusiones) }\end{array}$ & $\begin{array}{l}\text { Comentarios } \\
\text { Calidad de la } \\
\text { evidencia } \\
\text { Financiación } \\
\text { comentarios) }\end{array}$ \\
\hline & & $\begin{array}{l}\text { de mama (mastitis) o } \\
\text { sus recién nacidos } \\
\text { tenido infecciones } \\
\text { orales y bebés con } \\
\text { frenillo corto fueron } \\
\text { excluidos. } \\
\text { Fue desarrollado en } \\
\text { hospital un } \\
\text { universitario en Irán. }\end{array}$ & $\begin{array}{l}\text { dolor moderado } 4-7 \text { y } 8-10 \text { representa el } \\
\text { dolor severo. }\end{array}$ & $\begin{array}{l}\text { evaluados (dolor, severidad de la lesión y } \\
\text { presencia de secreciones en el pezón) en } \\
\text { el día } 10 \text { y día } 14 \text { post parto a favor del } \\
\text { grupo de la menta. }\end{array}$ & & \\
\hline
\end{tabular}

\section{ANEXO III, Forest-Plot}

No procede. 


\section{ANEXO IV. Evaluación de la calidad}

\section{Valoración AMSTAR de las revisiones sistemáticas identificadas}

1. Dennis $C L$, Jackson $K$, Watson J. Interventions for treating painful nipples among breastfeeding women. Cochrane Database of Systematic Reviews 2014, Issue 12. Art. No.: CD007366. DOI: 10.1002/14651858.CD007366.pub2.

\section{AMSTAR - a measurement tool to assess the methodological quality of systematic reviews.}

\section{Was an 'a priori' design provided?}

The research question and inclusion criteria should be established before the conduct of the review.

Note: Need to refer to a protocol, ethics approval, or pre-determined/a priori published research objectives to score a "yes."

$\checkmark$ Yes

$\square$ No

$\square$ Can't answer

$\square$ Not applicable

2. Was there duplicate study selection and data extraction?

There should be at least two independent data extractors and a consensus procedure for disagreements should be in place.

Note: 2 people do study selection, 2 people do data extraction, consensus process or one person checks the other's work.
$\checkmark$ Yes
$\square$ No
$\square$ Can't answer
$\square$ Not applicable

\section{Was a comprehensive literature search performed?}

At least two electronic sources should be searched. The report must include years and databases used (e.g., Central, EMBASE, and MEDLINE). Key words and/or MESH terms must be stated and where feasible the search strategy should be provided. All searches should be supplemented by consulting current contents, reviews, textbooks, specialized registers, or experts in the particular field of study, and by reviewing the references in the studies found.

Note: If at least 2 sources + one supplementary strategy used, select "yes" (Cochrane register/Central counts as 2 sources; a grey literature search counts as supplementary).
( Yes
$\square$ No
$\square$ Can't answer
$\square$ Not applicable

4. Was the status of publication (i.e. grey literature) used as an inclusion criterion?

The authors should state that they searched for reports regardless of their publication type. The authors should state whether or not they excluded any reports (from the systematic review), based on their publication status, language etc. 
Note: If review indicates that there was a search for "grey literature" or "unpublished literature," indicate "yes." SIGLE database, dissertations, conference proceedings, and trial registries are all considered grey for this purpose. If searching a source that contains both grey and non-grey, must specify that they were searching for grey/unpublished lit.

$\checkmark$ Yes

$\square$ No

$\square$ Can't answer

$\square$ Not applicable

\section{Was a list of studies (included and excluded) provided?}

A list of included and excluded studies should be provided.

Note: Acceptable if the excluded studies are referenced. If there is an electronic link to the list but the link is dead, select "no."

$\checkmark$ Yes

$\square$ No

$\square$ Can't answer

$\square$ Not applicable

\section{Were the characteristics of the included studies provided?}

In an aggregated form such as a table, data from the original studies should be provided on the participants, interventions and outcomes. The ranges of characteristics in all the studies analyzed e.g., age, race, sex, relevant socioeconomic data, disease status, duration, severity, or other diseases should be reported.

Note: Acceptable if not in table format as long as they are described as above.

$\checkmark$ Yes

$\square$ No

$\square$ Can't answer

$\square$ Not applicable

7. Was the scientific quality of the included studies assessed and documented? 'A priori' methods of assessment should be provided (e.g., for effectiveness studies if the author(s) chose to include only randomized, double-blind, placebo controlled studies, or allocation concealment as inclusion criteria); for other types of studies alternative items will be relevant.

Note: Can include use of a quality scoring tool or checklist, e.g., Jadad scale, risk of bias, sensitivity analysis, etc., or a description of quality items, with some kind of result for EACH study ("Iow" or "high" is fine, as long as it is clear which studies scored "low" and which scored "high"; a summary score/range for all studies is not acceptable).

$\checkmark$ Yes

$\square$ No

$\square$ Can't answer

$\square$ Not applicable

8. Was the scientific quality of the included studies used appropriately in formulating conclusions?

The results of the methodological rigor and scientific quality should be considered in the analysis and the conclusions of the review, and explicitly stated in formulating recommendations.

Note: Might say something such as "the results should be interpreted with caution due to poor quality of included studies." Cannot score "yes" for this question if scored "no" for question 7. 
$\checkmark$ Yes
$\square$ No
$\square$ Can't answer
$\square$ Not applicable

9. Were the methods used to combine the findings of studies appropriate?

For the pooled results, a test should be done to ensure the studies were combinable, to assess their homogeneity (i.e., Chi-squared test for homogeneity, I2). If heterogeneity exists a random effects model should be used and/or the clinical appropriateness of combining should be taken into consideration (i.e., is it sensible to combine?).

Note: Indicate "yes" if they mention or describe heterogeneity, i.e., if they explain that they cannot pool because of heterogeneity/variability between interventions.

$\checkmark$ Yes

$\square$ No

$\square$ Can't answer

$\square$ Not applicable

10. Was the likelihood of publication bias assessed?

An assessment of publication bias should include a combination of graphical aids (e.g., funnel plot, other available tests) and/or statistical tests (e.g., Egger regression test, Hedges-Olken).

Note: If no test values or funnel plot included, score "no". Score "yes" if mentions that publication bias could not be assessed because there were fewer than 10 included studies.

$\square$ Yes

$\checkmark$ No

$\square$ Can't answer

$\square$ Not applicable

\section{Was the conflict of interest included?}

Potential sources of support should be clearly acknowledged in both the systematic review and the included studies.

Note: To get a "yes," must indicate source of funding or support for the systematic review AND for each of the included studies.
$\checkmark$ Yes
$\square$ No
$\square$ Can't answer
$\square$ Not applicable

Shea et al. BMC Medical Research Methodology 2007 7:10 doi:10.1186/1471-2288-710

Additional notes (in italics) made by Michelle Weir, Julia Worswick, and Carolyn Wayne based on conversations with

Bev Shea and/or Jeremy Grimshaw in June and October 2008 and July and September 2010. 
2. Vieira F, Bachion MM, Mota DD, Munari DB. A systematic review of the interventions for nipple trauma in breastfeeding mothers. $J$ Nurs Scholarsh. 2013 Jun;45(2):116-25.

En la revisión sistemática de Vieira 2012, los autores incluyeron estudios que valoraron la efectividad de diferentes intervenciones (lanolina, lanolina en asociación con pezoneras, la leche materna, hidrogel, apósitos adhesivos de película de polietileno, clorhexidina con alcohol en aerosol y agua destilada) para el tratamiento del trauma del pezón en madres que daban lactancia materna, a su vez todos los grupos de cada estudio recibieron educación sobre la correcta lactancia materna. Esta revisión sistemática fue excluida debido a que presentó los datos de estilo narrativo, y porque cinco de los seis estudios que incluyó fueron excluidos por la RS Cochrane de Dennis 2014: tres (Abou-Dakn 2011, Coca 2008, y Brent 1998) debido a falta de datos disponibles para la evaluación de los desenlaces primarios y secundarios pese al intento del contacto vía electrónica con los autores y dos (Ziemer 1995, Herd 1986), porque eran ensayos cuyo objetivo de investigación fue la prevención primaria de las lesiones del pezón.

\section{AMSTAR - a measurement tool to assess the methodological quality of systematic reviews.}

\section{Was an 'a priori' design provided?}

The research question and inclusion criteria should be established before the conduct of the review.

Note: Need to refer to a protocol, ethics approval, or pre-determined/a priori published research objectives to score a "yes."

$\square$ Yes

$\checkmark$ No

$\square$ Can't answer

$\square$ Not applicable

\section{Was there duplicate study selection and data extraction?}

There should be at least two independent data extractors and a consensus procedure for disagreements should be in place.

Note: 2 people do study selection, 2 people do data extraction, consensus process or one person checks the other's work.

$\checkmark$ Yes

$\square$ No

$\square$ Can't answer

$\square$ Not applicable

\section{Was a comprehensive literature search performed?}

At least two electronic sources should be searched. The report must include years and databases used (e.g., Central, EMBASE, and MEDLINE). Key words and/or MESH terms must be stated and where feasible the search strategy should be provided. All searches should be supplemented by consulting current contents, reviews, textbooks, specialized registers, or experts in the particular field of study, and by reviewing the references in the studies found.

Note: If at least 2 sources + one supplementary strategy used, select "yes" (Cochrane 
GPC Lactancia Materna- Pregunta 29. Dolor y grietas en el pezón.

register/Central counts as 2 sources; a grey literature search counts as supplementary).

$\checkmark$ Yes

$\square$ No

$\square$ Can't answer

$\square$ Not applicable

\section{Was the status of publication (i.e. grey literature) used as an inclusion criterion?}

The authors should state that they searched for reports regardless of their publication type. The authors should state whether or not they excluded any reports (from the systematic review), based on their publication status, language etc.

Note: If review indicates that there was a search for "grey literature" or "unpublished literature," indicate "yes." SIGLE database, dissertations, conference proceedings, and trial registries are all considered grey for this purpose. If searching a source that contains both grey and non-grey, must specify that they were searching for grey/unpublished lit.

$\square$ Yes

$\checkmark$ No

$\square$ Can't answer

$\square$ Not applicable

\section{Was a list of studies (included and excluded) provided?}

A list of included and excluded studies should be provided.

Note: Acceptable if the excluded studies are referenced. If there is an electronic link to the list but the link is dead, select "no."

$\square$ Yes

$\checkmark$ No

$\square$ Can't answer

$\square$ Not applicable

6. Were the characteristics of the included studies provided?

In an aggregated form such as a table, data from the original studies should be provided on the participants, interventions and outcomes. The ranges of characteristics in all the studies analyzed e.g., age, race, sex, relevant socioeconomic data, disease status, duration, severity, or other diseases should be reported.

Note: Acceptable if not in table format as long as they are described as above.

$\checkmark$ Yes

$\square$ No

$\square$ Can't answer

$\square$ Not applicable

7. Was the scientific quality of the included studies assessed and documented? 'A priori' methods of assessment should be provided (e.g., for effectiveness studies if the author(s) chose to include only randomized, double-blind, placebo controlled studies, or allocation concealment as inclusion criteria); for other types of studies alternative items will be relevant.

Note: Can include use of a quality scoring tool or checklist, e.g., Jadad scale, risk of bias, sensitivity analysis, etc., or a description of quality items, with some kind of result for EACH study ("low" or "high" is fine, as long as it is clear which studies scored "low" and which scored "high"; a summary score/range for all studies is not acceptable).

$\square$ Yes 
$\checkmark$ No

$\square$ Can't answer

$\square$ Not applicable

8. Was the scientific quality of the included studies used appropriately in formulating conclusions?

The results of the methodological rigor and scientific quality should be considered in the analysis and the conclusions of the review, and explicitly stated in formulating recommendations.

Note: Might say something such as "the results should be interpreted with caution due to poor quality of included studies." Cannot score "yes" for this question if scored "no" for question 7.

$\square$ Yes

$\checkmark$ No

$\square$ Can't answer

$\square$ Not applicable

9. Were the methods used to combine the findings of studies appropriate?

For the pooled results, a test should be done to ensure the studies were combinable, to assess their homogeneity (i.e., Chi-squared test for homogeneity, I2). If heterogeneity exists a random effects model should be used and/or the clinical appropriateness of combining should be taken into consideration (i.e., is it sensible to combine?).

Note: Indicate "yes" if they mention or describe heterogeneity, i.e., if they explain that they cannot pool because of heterogeneity/variability between interventions.

$\square$ Yes

$\checkmark$ No

$\square$ Can't answer

$\square$ Not applicable

10. Was the likelihood of publication bias assessed?

An assessment of publication bias should include a combination of graphical aids (e.g., funnel plot, other available tests) and/or statistical tests (e.g., Egger regression test, Hedges-Olken).

Note: If no test values or funnel plot included, score "no". Score "yes" if mentions that publication bias could not be assessed because there were fewer than 10 included studies.

$\square$ Yes

$\checkmark$ No

$\square$ Can't answer

$\square$ Not applicable

\section{Was the conflict of interest included?}

Potential sources of support should be clearly acknowledged in both the systematic review and the included studies.

Note: To get a "yes," must indicate source of funding or support for the systematic review AND for each of the included studies.

$\square$ Yes

$\checkmark$ No

$\square$ Can't answer

$\square$ Not applicable 
GPC Lactancia Materna- Pregunta 29. Dolor y grietas en el pezón.

Shea et al. BMC Medical Research Methodology 2007 7:10 doi:10.1186/1471-2288-710

Additional notes (in italics) made by Michelle Weir, Julia Worswick, and Carolyn Wayne based on conversations with

Bev Shea and/or Jeremy Grimshaw in June and October 2008 and July and September 2010. 


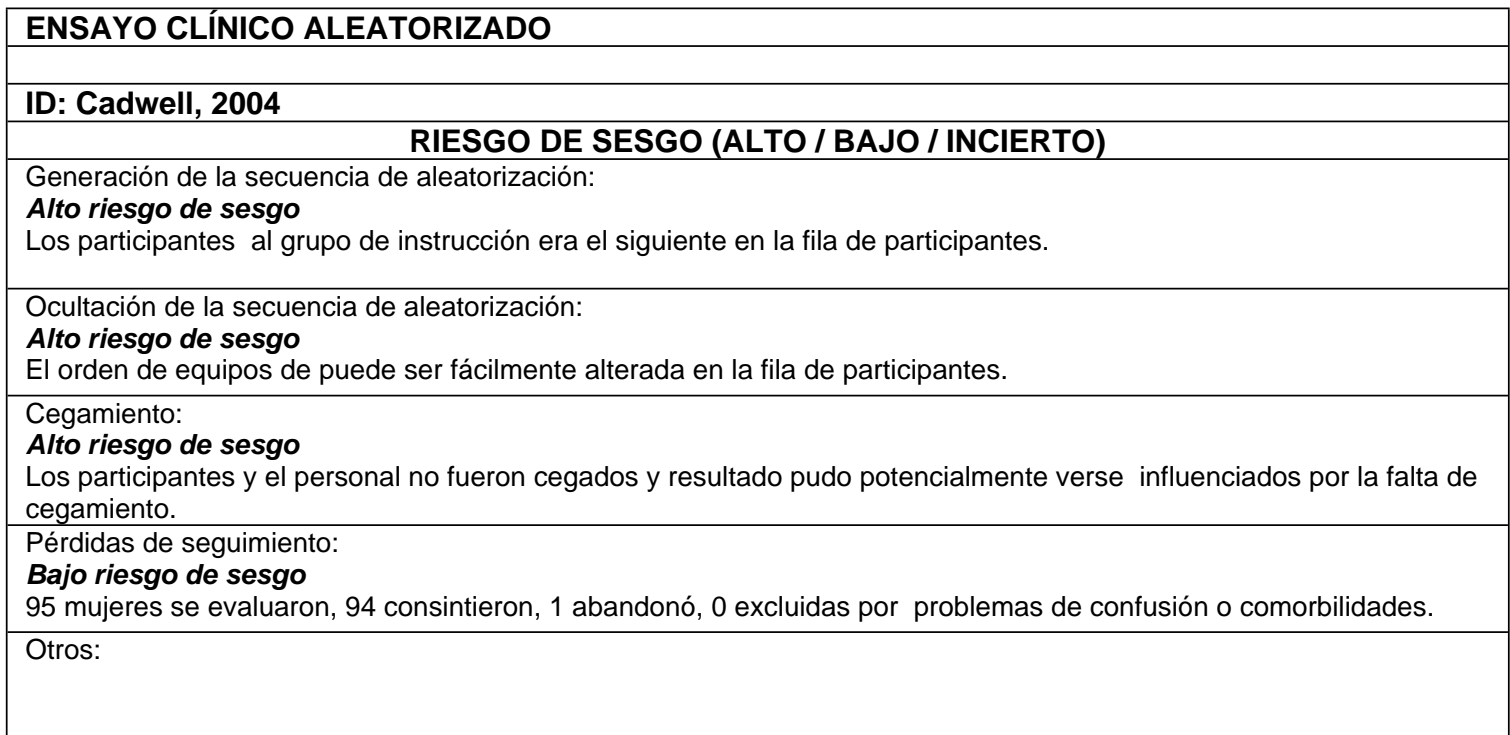

\section{ANEXO V, Evaluación del riesgo de los estudios individuales ENSAYO CLÍNICO ALEATORIZADO}

\section{ID: Dennis, 2012 \\ RIESGO DE SESGO (ALTO / BAJO / INCIERTO)}

Generación de la secuencia de aleatorización:

Bajo riesgo de sesgo

Ocultación de la secuencia de aleatorización:

Bajo riesgo de sesgo

\section{Cegamiento:}

Bajo riesgo de sesgo

Pérdidas de seguimiento:

Bajo riesgo de sesgo

Otros:

\begin{tabular}{|c|}
\hline ENSAYO CLÍNICO ALEATORIZADO \\
\hline ID: Jackson, 2013 \\
\hline RIESGO DE SESGO (ALTO / BAJO / INCIERTO) \\
\hline $\begin{array}{l}\text { Generación de la secuencia de aleatorización: } \\
\text { Bajo riesgo de sesgo }\end{array}$ \\
\hline $\begin{array}{l}\text { Ocultación de la secuencia de aleatorización: } \\
\text { Bajo riesgo de sesgo }\end{array}$ \\
\hline $\begin{array}{l}\text { Cegamiento: } \\
\text { Alto riesgo de sesgo } \\
\text { Los participantes no pudieron ser cegados a la asignación de grupos }\end{array}$ \\
\hline $\begin{array}{l}\text { Pérdidas de seguimiento: } \\
\text { Bajo riesgo de sesgo }\end{array}$ \\
\hline
\end{tabular}




\section{ENSAYO CLÍNICO ALEATORIZADO}

ID: Mohammadzadeh, 2005

RIESGO DE SESGO (ALTO / BAJO / INCIERTO)

Generación de la secuencia de aleatorización:

Riesgo incierto de sesgo

La falta de información disponible con respecto a la generación de secuencias

Ocultación de la secuencia de aleatorización:

Riesgo incierto de sesgo

Falta de información disponible sobre el método de generación de la asignación y el ocultamiento de la asignación

Cegamiento:

Alto riesgo de sesgo

Los participantes no pudieron ser cegados a la asignación de grupos.

Se desconoce si el evaluador de resultados fue cegado a la asignación de grupos.

Pérdidas de seguimiento:

Bajo riesgo de sesgo

Otros:

\section{ENSAYO CLÍNICO ALEATORIZADO}

\section{ID: Saedi, 2014}

Generación de la secuencia de aleatorización:

Riesgo de sesgo incierto

Falta de información disponible sobre el método de generación de la asignación

Ocultación de la secuencia de aleatorización:

Riesgo incierto de sesgo

Falta de información disponible sobre el el ocultamiento de la asignación

Cegamiento:

Bajo riesgo de sesgo

Pérdidas de seguimiento:

Bajo riesgo de sesgo

Otros:

\section{ENSAYO CLÍNICO ALEATORIZADO}

\section{ID: Akbari, 2014}

RIESGO DE SESGO (ALTO / BAJO / INCIERTO)

Generación de la secuencia de aleatorización:

Bajo riesgo de sesgo

Ocultación de la secuencia de aleatorización:

Riesgo incierto de sesgo

Falta de información disponible sobre el el ocultamiento de la asignación

Cegamiento:

Riesgo de sesgo incierto

Falta de información disponible sobre el proceso de cegamiento

Pérdidas de seguimiento:

Bajo riesgo de sesgo 


\section{1- BIBLIOGRAFÍA}

(1) Dennis CL, Jackson K, Watson J. Interventions for treating painful nipples among breastfeeding women. Cochrane Database Syst Rev 2014;12:CD007366.

(2) Vieira F, Bachion MM, Mota DD, Munari DB. A systematic review of the interventions for nipple trauma in breastfeeding mothers. J Nurs Scholarsh 2013 Jun;45(2):116-25.

(3) NICE. Postnatal care up to 8 weeks after birth. Julio 2006 (actualizado en Febrero de 2015). Disponible en: http://guidance.nice.org.uk/CG37.

(4) Perinatal Services BC Health Promotion Guideline. Breastfeeding Healthy Term Infants. March 2015. Disponible en: http://www.perinatalservicesbc.ca/Documents/GuidelinesStandards/HealthPromotion/BreastfeedingHealthyTermInfantGuideline.pdf.

(5) Grupo de trabajo de la Guía de práctica clínica de atención en el embarazo y puerperio. Guía de práctica clínica de atención en el embarazo y puerperio. Ministerio de Sanidad, Servicios Sociales e Igualdad. Agencia de Evaluación de Tecnologías Sanitarias de Andalucía: 2014. Guías de Práctica Clínica en el SNS: AETSA 2011/10.

(6) Cadwell K, Turner-Maffei C, Blair A, Brimdyr K, Maja MZ. Pain reduction and treatment of sore nipples in nursing mothers. J Perinat Educ 2004;13(1):29-35.

(7) Mohammadzadeh A, Farhat A, Esmaeily $\mathrm{H}$. The effect of breast milk and lanolin on sore nipples. Saudi Med J 2005 Aug;26(8):1231-4.

(8) Jackson K, Dennis CL, Hodnett E, McGillion M. A randomized controlled trial evaluating lanolin for the treatment of nipple pain among breastfeeding (Doctoral dissertation). Toronto:University of Toronto, 2013.

(9) Dennis CL, Schottle N, Hodnett E, McQueen K. An all-purpose nipple ointment versus lanolin in treating painful damaged nipples in breastfeeding women: a randomized controlled trial. Breastfeed Med 2012 Dec;7(6):473-9.

(10) Akbari SAA, Alamolhoda SH, Baghban AA, Mirabi P. Effects of menthol essence and breast milk on the improvement of nipple fissures in breastfeeding women. Journal of Research in Medical Sciences 2014;19(7):629-33.

(11) Saeidi R, Tafazoli M, Gholami M, Mazloom R. New treatment for nipple soreness in breastfeeding mothers: A clinical trial study. Iranian Journal of Neonatology 2015 Mar 1;6(2):48-51.

(12) Shanazi M, Farshbaf KA, Kamalifard M, Asghari JM, Masoudin K, Esmaeli F. Comparison of the Effects of Lanolin, Peppermint, and Dexpanthenol Creams on Treatment of Traumatic Nipples in Breastfeeding Mothers. J Caring Sci 2015 Dec;4(4):297-307.

(13) Jackson KT, Dennis CL. Lanolin for the treatment of nipple pain in breastfeeding women: a randomized controlled trial. Matern Child Nutr 2016 Aug 1. 
PREGUNTA CLÍNICA № 30

¿Qué síntomas y signos deben hacer sospechar una infección en la mama?

\section{1- Pregunta clínica en formato PICO}

Analizar los síntomas y signos que presentan las mujeres que tienen cultivos de leche materna positivos a determinadas especies bacterianas y ver de las mujeres de los estudios que incluyen pacientes con dolor en el pecho, síntomas de mastitis aguda etc cuáles son las que tienen cultivos positivos y a qué bacterias.

\section{2- Introducción}




\section{3- ESTRATEGIA DE ELABORACION DE LA PREGUNTA}

\subsection{GPC}

Tabla 2- Resumen de GPC Base

\begin{tabular}{|c|c|c|c|c|}
\hline $\begin{array}{c}\text { Guía } \\
\text { (Enfoque) }\end{array}$ & $\begin{array}{l}\text { Resumen sobre la evidencia } \\
\text { (Calidad de la evidencia) }\end{array}$ & $\begin{array}{l}\text { Recomendaciones } \\
\text { (Grado) }\end{array}$ & $\begin{array}{c}\text { Referencias } \\
\text { bibliográficas } \\
\text { (Tipo de } \\
\text { publicación) } \\
\end{array}$ & Comentarios \\
\hline $\begin{array}{l}\text { NICE, } \\
2006\end{array}$ & $\begin{array}{l}\text { Se define mastitis lactacional como "la celulitis del tejido conectivo } \\
\text { interlobular de la glándula mamaria que ocurre generalmente en las } \\
\text { primeras } 6 \text { semanas postparto. El espectro clínico va desde la inflamación } \\
\text { local con síntomas sistémicos mínimos al absceso y la sepsis (Foxman et } \\
\text { al, 2002). } \\
\text { Algunos clínicos hacen la distinción entre mastitis infecciosa y no infecciosa } \\
\text { (Osterman y Rahm, 2000). Sin embargo, tanto la identificación de } \\
\text { organismos causales como el tratamiento apropiado no han sido bien } \\
\text { estudiados. } \\
\text { Thomsen et al (Thomsen, Espersen y Maigaard 1984) sugirieron que los } \\
\text { síntomas inflamatorios del pecho podrían ser clasificados de acuerdo con el } \\
\text { recuento de leucocitos y de colonias bacterianas. Se consideró que había } \\
\text { una mastitis infecciosa cuando había un número de colonias bacterianas } \\
\text { mayor a } 103 \text { cfu/ml de leche. } \\
\text { En un estudio observacional de Dinamarca de } 339 \text { casos de mastitis en } 213 \\
\text { mujeres, Thomsen et al (Thomsen, Espersen y Maigaard 1984) también } \\
\text { demostraron que el vaciado del pecho resultó en una disminución } \\
\text { significativa de la duración de los síntomas y un resultado mejorado de } \\
\text { forma significativa (p<0,001). La duración y los resultados de los casos } \\
\text { fueron comparados entre las mujeres que no recibieron tratamiento frente a } \\
\text { las que sí lo recibieron. Si los síntomas se resolvían, seguidos de } \\
\text { continuación de la lactancia normal durante los siguientes dos semanas, el } \\
\text { resultado fue definido por el autor como "bueno". Un resultado definido } \\
\text { como "malo" incluia síntomas que persistían más de dos semanas, } \\
\text { disminución de la secreción de leche, recurrencia de la infección o } \\
\text { desarrollo de sepsis o de absceso mamario. La mastitis infecciosa sin } \\
\text { tratamiento fue seguido por un buen resultado en sólo } 15 \% \text { y el } 11 \% \text { de las } \\
\text { mujeres desarrollaron abscesos. El vaciamiento del pecho aumentó la tasa } \\
\text { de buenos resultados al } 50 \% \text { y disminuyó significativamente la duración de } \\
\text { los síntomas. }\end{array}$ & & $\begin{array}{l}\text { Foxman } 2002 \\
\text { Thomsen et al, } \\
1984 \\
\text { Osterman et al, } \\
2000\end{array}$ & $\begin{array}{l}\text { En esta guía, } \\
\text { cuando se habla } \\
\text { del abordaje de los } \\
\text { problemas con la } \\
\text { lactancia se } \\
\text { señalan los } \\
\text { pezones irritados, } \\
\text { doloridos y trauma } \\
\text { en el pezón, la } \\
\text { ingurgitación } \\
\text { mamaria y la } \\
\text { mastitis. También } \\
\text { se señala el dolor } \\
\text { en el pecho, } \\
\text { aunque los } \\
\text { autores de la guía } \\
\text { indican que no se } \\
\text { encontró literatura } \\
\text { relacionada de } \\
\text { forma específica } \\
\text { con el manejo del } \\
\text { dolor en el pecho } \\
\text { que no estuviera } \\
\text { relacionado con el } \\
\text { pezón y con la } \\
\text { ingurgitación } \\
\text { mamaria. }\end{array}$ \\
\hline
\end{tabular}




\begin{tabular}{|c|c|c|c|c|}
\hline $\begin{array}{l}\text { Guía } \\
\text { (Enfoque) }\end{array}$ & $\begin{array}{l}\text { Resumen sobre la evidencia } \\
\text { (Calidad de la evidencia) }\end{array}$ & $\begin{array}{l}\text { Recomendaciones } \\
\text { (Grado) }\end{array}$ & $\begin{array}{c}\text { Referencias } \\
\text { bibliográficas } \\
\text { (Tipo de } \\
\text { publicación) }\end{array}$ & Comentarios \\
\hline $\begin{array}{l}\text { CKS Safe } \\
\text { practical } \\
\text { clinical } \\
\text { answers } \\
\text { Mastitis } \\
\text { and } \\
\text { breast } \\
\text { abscess- } \\
\text { Managem } \\
\text { ent }\end{array}$ & $\begin{array}{l}\text { ¿Cómo sé que mi paciente tiene una mastitis? } \\
\text { Estas características clínicas se basan en la opinión de expertos de una } \\
\text { revisión de causas y manejo de la mastitis de la OMS 2000, y artículos de } \\
\text { revisión Barbosa-Cesnik et al, 2003; Betzold 2007). Como es imposible } \\
\text { distinguir de forma fiable entre una mastitis infecciosa y no infecciosa, CKS } \\
\text { sugiere que si estas características están presentes, la infección es más } \\
\text { probable y que el tratamiento antibiótico es apropiado. } \\
\text { La opinión de expertos de la guía GAIN sobre el tratamiento, manejo y } \\
\text { prevención de la mastitis de Irlanda del Norte indica que es más probable } \\
\text { que los síntomas parecidos a la gripe y la pirexia duren más de } 24 \text { horas en } \\
\text { mujeres con mastitis infecciosa en comparación con la mastitis no } \\
\text { infecciosa, y que es más probable que en las mastitis infecciosas las } \\
\text { mujeres experimenten un disconfort considerable en el pecho (GAIN 2009). } \\
\text { En el sub-apartado ¿Qué más puede ser? } \\
\text { Infección de los conductos mamarios (algunos expertos consideran la } \\
\text { infección ductal como una de las causas de dolor de mama localizado } \\
\text { profundamente, aunque otros expertos cuestionan su existencia). } \\
\text { - Hay un dolor profundo con sensación de quemazón, constante o } \\
\text { intenso en la mama que empeora durante o justo después de la } \\
\text { toma- puede ser insoportable. Se puede acompañar de dolor hacia } \\
\text { el brazo o la espalda. } \\
\text { La mujer no presenta fiebre o malestar. } \\
\text { Los síntomas clínicos son variables y puede no haber rojez, } \\
\text { induración o sensibilidad (es decir, sin signos clínicos en la areola } \\
\text { o en el pezón); rojez escamas, brillo o fisuras en el pezón; } \\
\text { exudado purulento o costras de color miel que sugieren infección } \\
\text { bacteriana. }\end{array}$ & $\begin{array}{l}\text { ¿Cómo sé que mi paciente tiene una } \\
\text { mastitis? } \\
\text { No es posible distinguir clínicamente entre } \\
\text { una mastitis no infecciosa y una mastitis } \\
\text { infecciosa. Se debería sospechar de } \\
\text { infección si: } \\
\text { - Los síntomas no mejoran o empeoran } \\
\text { tras 12-24 horas después de haber } \\
\text { intentado la eliminación efectiva de la } \\
\text { leche. } \\
\text { - La mujer presenta fisuras infectadas en } \\
\text { el pezón } \\
\text { - El resultado del cultivo de la leche } \\
\text { materna es positivo. }\end{array}$ & $\begin{array}{l}\text { OMS, } 2000 \\
\text { Barbosa-Cesnik, } \\
2003 \\
\text { Betzold } 2007\end{array}$ & \\
\hline $\begin{array}{l}\text { Protocolo } \\
\text { ABM \#4, } \\
2014\end{array}$ & $\begin{array}{l}\text { Definición de mastitis: Inflamación del pecho, en la que puede o no estar } \\
\text { implicada una infección bacteriana. }\end{array}$ & & & \\
\hline
\end{tabular}




\begin{tabular}{|c|c|c|c|c|}
\hline $\begin{array}{c}\text { Guía } \\
\text { (Enfoque) }\end{array}$ & $\begin{array}{l}\text { Resumen sobre la evidencia } \\
\text { (Calidad de la evidencia) }\end{array}$ & $\begin{array}{l}\text { Recomendaciones } \\
\text { (Grado) }\end{array}$ & $\begin{array}{c}\text { Referencias } \\
\text { bibliográficas } \\
\text { (Tipo de } \\
\text { publicación) }\end{array}$ & Comentarios \\
\hline $\begin{array}{l}\text { Perinatal } \\
\text { Services } \\
\text { BC, } 2013\end{array}$ & $\begin{array}{l}\text { Mastitis } \\
\text { Inflammation of the breast, in which milk stasis is the primary cause that } \\
\text { may or may not be accompanied by or progress to infection. } 101,104 \text { Occurs } \\
\text { at any time during lactation but is most common in the first } 2-6 \text { weeks } \\
\text { postpartum } 104 \\
\text { Breast is hot, swollen, and tender; skin may be reddened; and mothers may } \\
\text { complain of malaise, fever of } 38.5^{\circ} \mathrm{C} \text { or higher, chills, headache, and flu like } \\
\text { aching. } 38,39,104 \text { Usually only one breast is affected } \\
\text { En cuanto al síntoma de dolor en forma de pinchazos de la mama o la } \\
\text { sensación de quemazón durante o después de la toma que puede irradiar a } \\
\text { la espalda o al brazo, lo atribuyen a la infección por cándida. }\end{array}$ & & $\begin{array}{l}\text { 38. Riordan J \& } \\
\text { Wambach, K. } \\
\text { (2010). } \\
\text { 39. Lawrence RA } \\
\text { \& Lawrence RM. } \\
\text { (2005). } \\
\text { 100. Humenick } \\
\text { SS, Hill PD, } \\
\text { Anderson MA } \\
\text { (1994). } \\
\text { 101. OMS (2000) } \\
\text { 102. Snowden } \\
\text { HM, Renfrew MJ, } \\
\text { \& Woolridge MW. } \\
\text { (2002). } \\
\text { 103. Hale WT. } \\
\text { (2006). } \\
\text { 104.ABM } 2008\end{array}$ & \\
\hline $\begin{array}{l}\text { Guía del } \\
\text { embarazo } \\
2014\end{array}$ & $\begin{array}{l}\text { Uso de antibióticos para las mastitis en mujeres que amamantan } \\
\text { La revisión de Jahanfar (2010) incluyó } 2 \text { estudios con aproximadamente } \\
125 \text { mujeres que amamantaban con síntomas de mastitis tales como } \\
\text { sensibilidad aumentada, enrojecimiento de los pechos, una disminución de } \\
\text { la secreción de leche o fiebre. } \\
\text { Ambos estudios evaluaron la resolución de los síntomas (fiebre, eritema, } \\
\text { sensibilidad) como su desenlace principal. Por otro lado, uno de los ECA } \\
\text { evaluó el mantenimiento de la lactancia materna a las dos semanas de } \\
\text { haber finalizado el tratamiento, y ambos estudios evaluaron otros } \\
\text { desenlaces como la persistencia de los síntomas, los problemas con la } \\
\text { secreción de leche o la recurrencia de la infección. }\end{array}$ & & Jahanfar 2010 & \\
\hline
\end{tabular}




\subsection{Revisiones sistemáticas}

Se ha identificado una revisión que habla sobre la clarificación del concepto de mastitis que se utiliza en los estudios empíricos que tratan sobre la inflamación de las mamas durante la lactancia (1).

En esta revisión se analizan 18 artículos publicados entre 1998 y 2008, entre los cuales 4 sugerían que la mastitis era una infección, 4 no mencionaban la etiología de los síntomas y 10 describían la mastitis como una infección o una inflamación. 8 estudios no diferenciaban entre la estasis de leche, la mastitis no infecciosa y la mastitis infecciosa. Los cultivos bacterianos fueron utilizados en 5 artículos, y 1 midió además el recuento de leucocitos y la proteína $\mathrm{C}$ reactiva. Por otro lado, los autores indican que en cuatro de los artículos se señalaba como tratamiento adecuado el uso de antibióticos en el tratamiento de la mastitis. Por todo ello, la revisión concluye que el uso del concepto de mastitis en los estudios empíricos es inconsistente, y que se necesita comprender la etiología de los síntomas así como por qué algunas mujeres con síntomas que sugieren una reacción séptica se recuperan sin tratamiento antibiótico.

También se ha identificado otra revisión que incluye estudios no aleatorizados y que explora la etiología del dolor profundo en la mama durante la lactancia (2). En esta revisión los autores concluyen que en mujeres lactantes que reportan dolor profundo en la mama, hay evidencia consistente de presencia de infección. Aunque es más probable que estas mujeres den resultados positivos al cultivo de Candida, el riesgo de que el cultivo sea positivo a $S$. aureus también está presente, por lo que se señala que en estas mujeres deberían realizarse cultivos de la leche materna. De los 7 estudios incluidos, todos menos 1 realizaron cultivos. El problema de esta revisión es que incluyen estudios con mujeres que presentan únicamente dolor profundo en la mama, así como estudios que incluyen mujeres con dolor en los pezones asociado o no con dolor en el pecho, por lo que puede haberse dado una infraestimación del riesgo de presentar cultivos positivos. 


\subsection{Resumen de GPC base y RS disponibles}

En general las guías se centran en abordar la mastitis, que se define como inflamación del pecho en la que puede o no estar implicada una infección bacteriana y cuyo espectro clínico puede ir desde la presencia de inflamación local con síntomas sistémicos mínimos al absceso y la sepsis (3-6).

También se señala que no es posible distinguir clínicamente entre una mastitis no infecciosa y una mastitis infecciosa, y que ante un cuadro de este tipo lo que debería llevar a sospechar una infección sería lo siguiente:

- Los síntomas no mejoran o empeoran tras estar 12-24 horas realizando un vaciamiento efectivo de las mamas afectadas

- La mujer presenta fisuras infectadas en el pezón

- El resultado del cultivo de la leche materna es positivo.

En los Safe Practical Clinical Answers de NICE (7) se habla de la infección de los conductos mamarios, sospechando su presencia si:

- Hay un dolor profundo con sensación de quemazón, constante o intenso en la mama que empeora durante o justo después de la toma (que puede ser insoportable y que puede acompañarse de dolor hacia el brazo o la espalda.

- La mujer no presenta fiebre o malestar.

Los síntomas clínicos son variables y puede no haber enrojecimiento o eritema, induración o aumento de la sensibilidad o dolor (es decir, sin signos clínicos en la areola o en el pezón); color salmón o enrojecido, escamas, brillo o fisuras en el pezón; exudado purulento o costras de color miel que sugieren infección bacteriana.

Se han identificado dos RS relacionadas. La primera revisión (1) trata la inconsistencia de los estudios a la hora de definir lo que se entiende por mastitis, y en la segunda (2) se estudia el dolor profundo en la mama en madres que amamantan y su relación con la presencia de infección en la mama.

\subsection{Conclusión}

\begin{tabular}{|l|l|}
\hline & Adopción GPC/Revisión sistemática \\
\hline $\mathrm{X}$ & Elaboración parcial \\
\hline & Elaboración de novo \\
\hline
\end{tabular}

ACTUALIZADO A FECHA DE: 23 DE SEPTIEMBRE DE 2015 


\section{Resumen de la evidencia}

En referencia al dolor profundo en la mama como síntoma de infección, se ha identificado un estudio prospectivo (8) que incluía 86 mujeres lactantes con dolor en el pecho que duraba más de una semana y excluía aquellas con evidencia clínica de inflamación aguda (eritema, calor, induración, mastitis, absceso), conductos obstruidos o si los síntomas se resolvían en consulta tras corregir las posibles causas mecánicas.

En la visita inicial se recogieron muestras del pezón y de la leche materna para realizar un cultivo, recibiendo todas un tratamiento inicial conservador. Cuando los resultados del cultivo estaban disponibles a los cinco días y el tratamiento conservador fracasaba se ofrecía tratamiento antibiótico.

Desde la visita inicial a la llamada telefónica, el dolor mejoró en 1,8 puntos para las madres que luego continuaron con el tratamiento conservador, pero sólo 0,77 puntos para las que recibieron tratamiento antibiótico a partir de la llamada telefónica (diferencia no estadísticamente significativa). Tras el inicio del tratamiento con antibióticos, el nivel del dolor mamario disminuyó de forma significativa entre la llamada telefónica y el cuestionario de la segunda semana, no habiendo diferencias significativas en la cuarta semana entre grupos $(1,8$ vs. 1,$4 ; p=0,088)$. Al final del seguimiento (12 semanas) las madres de ambos grupos tenían un nivel de dolor menor a 1 punto, aunque en el grupo control era un nivel estadísticamente menor $(0,18 / 10$ vs. $0,98 / 10)$.

La evolución del dolor a lo largo del tiempo de las madres tratadas con antibióticos con y sin crecimiento de Staphylococcus aureus no reveló diferencias significativas, lo que sugiere que la mejora con el antibiótico no se asociaba sólo al cultivo positivo de $S$ aureus. Los autores señalan que en las pacientes que no responden al tratamiento conservador crecían otras bacterias potencialmente patógenas, aunque los números son tan pequeños que limitan el análisis.

No se observaron diferencias en la frecuencia de estafilococos coagulasa negativos (SCN), aunque tampoco se evaluaron los subtipos o los factores de virulencia, propuesta que ha sido utilizada para explicar su patogénesis (9) al encontrarse que el número de cepas que contienen el gen icaD relacionado con la producción de biofilm y resistencia a meticilina o cloxaciclina, eritromicina, clindamicina y mupirocina, era significativamente mayor entre las cepas aisladas de la leche de madres con mastitis.

La conclusión final a la que llegan los autores es que en mujeres en las que falla el tratamiento conservador, el tratamiento con antibiótico asociado al cultivo de la leche puede disminuir de forma significativa el dolor y no se asocia con el aumento de complicaciones.

En cuanto a las especies bacterianas implicadas en el dolor crónico en la mama, los mismos autores realizaron un estudio (10) en el que incluyeron 61 casos de mujeres lactantes con dolor en el pecho de más de una semana de duración y sin síntomas de infección aguda y 53 controles por semanas postparto y paridad. Un mayor número de casos presentaba en su historia mastitis (14\% vs. $2 \%)$, pezones agrietados (64\% vs. $17 \%)$ y mayor crecimiento de S. aureus $(19,7 \%$ VS. $1,9 \%)$, siendo la frecuencia de SCN similar entre grupos, aunque el recuento de la mediana de colonias era significativamente menor en los casos (900 UFC/ml vs. $5000 \mathrm{UFC} / \mathrm{ml}$ ) (correlación negativa entre el crecimiento de SCN y $S$. aureus; $r=0,265 ; p=0,004)$ ). Lo que concluyen los autores es que un mayor crecimiento de $S$. aureus apoya su rol patogénico y refuerza la necesidad de estudios sobre tratamiento antibiótico en 
madres lactantes con dolor crónico, aunque asimismo, los resultados del estudio sugieren que ni los SCN ni su sobrecrecimiento causan dolor crónico en la mama.

ACTUALIZADO A FECHA DE: 31 de Octubre de 2016 


\section{4- De la evidencia a la recomendación (Tabla de EtR)}

Por lo tanto, en el caso de mastitis agudas no se puede saber si existe o no infección en base a la clínica presentada. Hay que esperar a ver si hay respuesta con tratamiento conservador o ver si el cultivo de la leche es positivo.

Por otro lado, parece que la presencia de un dolor profundo en el pecho puede ser indicativo de la presencia de infección en la mama, aunque existe controversia sobre su etiopatogenia.

\section{Recomendación de buena práctica}

Sospechar la existencia de infección mamaria si:

- se presentan síntomas agudos en la mama como inflamación o edema, calor y aumento de la sensibilidad o dolor, síntomas generales como malestar, fiebre de más de $38,5^{\circ} \mathrm{C}$, escalofríos y dolor de cabeza.

- se presenta un dolor profundo en la mama durante la toma o después de la misma que no se resuelve tras la evaluación e intervención por profesionales expertos en lactancia materna que descarten y traten otras posibles causas de la mastalgia.

\section{Necesidades de investigación:}

Se necesitan más estudios para confirmar qué bacterias son las patogénicas en madres lactantes que presentan síntomas como dolor profundo en las mamas 0 síntomas agudos de inflamación y estudiar si puede haber una asociación entre la aparición de determinados síntomas y la presencia de una u otra especie o cepa bacteriana. 


\section{ESTRATEGIA DE BÚSQUEDA}

\section{Cochrane Library}

Searched 28/07/2015

\section{Updated search 28/07/2015 a xx/xx/xxxx}

\#1 mastitis:ti,ab,kw or "breast pain":ti,ab,kw (Word variations have been searched) 282

\#2 lactation or lactating:ti,ab,kw or breastfeeding or "breastfeeding":ti,ab,kw or nursing or puerperal:ti,ab,kw (Word variations have been searched) 25614

\#3 \#1 and \#2 64

\#4 culture:ti,ab,kw (Word variations have been searched) 11553

\#5 \#3 and \#4 5

\section{Medline, via Pubmed}

Searched 28/07/2015

\section{Updated search 28/07/2015 a xx/xx/xxxx}

\#1 Search (mastitis[Title/Abstract]) OR "breast pain"[Title/Abstract] 10516

\#2 Search (((lactation[Title/Abstract] OR lactating[Title/Abstract])) OR (breastfeeding[Title/Abstract] OR "breast feeding"[Title/Abstract])) OR (nursing[Title/Abstract] OR puerperal[Title/Abstract]) 279153

\#3 Search \#1 AND \#2 2542

\#4 Search culture[Title/Abstract] 483479

\#5 Search \#3 AND \#4 173

\#6 Search \#5 Filters: Humans

\section{Embase, vía OvidWeb}

\section{Searched 28/07/2015}

\section{Updated search 28/07/2015 a xx/xx/xxxx}

1 (mastitis or "breast pain").ti,ab,kw.

2 (lactation or lactating or breastfeeding or "breast feeding" or nursing or puerperal).ti,ab,kw. 313114

$3 \quad 1$ and $2 \quad 2758$

4 culture.ti,ab,kw. 600630

$5 \quad 3$ and $4 \quad 182$

$6 \quad$ limit 5 to human $\quad 30$

\section{Cinahl, vía EbscoHost}

\section{Searched 28/07/2015}

Updated search 28/07/2015 a xx/xx/xxxx

S1 TI mastitis OR AB mastitis 230

S2 TI "breast pain" OR AB "breast pain" 153

S3 S1 OR S2 377

S4 TI ( lactation OR lactating ) OR AB ( lactation OR lactating ) 2103

S5 TI ( breastfeeding OR "breast feeding") OR AB (breastfeeding OR "breast feeding" ) 9254

S6 TI ( nursing OR puerperal ) OR AB ( nursing OR puerperal ) 190593 
S7 $\quad$ S4 OR S5 OR S6 200380

S8 S3 AND S7 117

S9 TI culture OR AB culture 24954

S10 S8 AND S9 0 


\section{5- Bibliografía}

(1) Kvist LJ. Toward a clarification of the concept of mastitis as used in empirical studies of breast inflammation during lactation. J Hum Lact 2010 Feb;26(1):539.

(2) Betzold CM. Results of microbial testing exploring the etiology of deep breast pain during lactation: a systematic review and meta-analysis of nonrandomized trials. J Midwifery Womens Health 2012 Jul;57(4):353-64.

(3) NICE. Postnatal Care: Routine postnatal care of women and their babies. Julio 2006. Disponible en: http://guidance.nice.org.uk/CG37.

(4) ABM Clinical Protocol \#4: Mastitis, Revised March 2014. Breastfeeding Medicine, Volume 9, Number 5, 2014.

(5) Perinatal Services BC Health Promotion Guideline. Breastfeeding Healthy Term Infants. March 2015. Disponible en: http://www.perinatalservicesbc.ca/Documents/GuidelinesStandards/HealthPromotion/BreastfeedingHealthyTermInfantGuideline.pdf.

(6) Grupo de trabajo de la Guía de práctica clínica de atención en el embarazo y puerperio. Guía de práctica clínica de atención en el embarazo y puerperio. Ministerio de Sanidad, Servicios Sociales e Igualdad. Agencia de Evaluación de Tecnologías Sanitarias de Andalucía: 2014. Guías de Práctica Clínica en el SNS: AETSA 2011/10.

(7) Mastitis and breast abscess. Clinical Knowledge Summaries-CSK. 2015. Disponible en:

http://ykmu.tbzmed.ac.ir/uploads/125/CMS/user/file/813/sexual/Mastitis\%20and \%20breast\%20abscess.pdf.

(8) Witt AM, Burgess K, Hawn TR, Zyzanski S. Role of oral antibiotics in treatment of breastfeeding women with chronic breast pain who fail conservative therapy. Breastfeed Med 2014 Mar;9(2):63-72.

(9) Delgado S, Arroyo R, Jimenez E, Marin ML, del CR, Fernandez L, et al. Staphylococcus epidermidis strains isolated from breast milk of women suffering infectious mastitis: potential virulence traits and resistance to antibiotics. BMC Microbiol 2009;9:82.

(10) Witt A, Mason MJ, Burgess K, Flocke S, Zyzanski S. A case control study of bacterial species and colony count in milk of breastfeeding women with chronic pain. Breastfeed Med 2014 Jan;9(1):29-34. 
PREGUNTA CLÍNICA: № 31

Ante sospecha de infección, ¿cuándo está indicada la realización del cultivo de la leche?

\section{1- Pregunta clínica en formato PICO}

Tabla 1. Componentes de la pregunta clínica en formato PICO

\begin{tabular}{|l|l|}
\hline Pacientes & Madre lactante con sospecha clínica de infección \\
\hline Intervención & Cultivo de leche y tratamiento antibiótico dirigido \\
\hline Comparación & Tratamiento empírico \\
\hline Resultados & $\begin{array}{l}\text { Tasa de curación, necesidad de cambio de antibiótico... } \\
\text { Duración lactancia materna (exclusiva y no exclusiva), lactancia } \\
\text { materna exclusiva al mes, a los } 4 \text { meses, a los } 6 \text { meses, problemas en } \\
\text { las mamas (dolor, grietas etc) }\end{array}$ \\
\hline Tipo de estudio & $\begin{array}{l}\text { RS de ECA, ECA, RS de Estudios observacionales, estudios } \\
\text { observacionales }\end{array}$ \\
\hline
\end{tabular}

\section{2- Introducción}




\section{3- ESTRATEGIA DE ELABORACIÓN DE LA PREGUNTA}

\subsection{GPC}

La guía NICE no menciona cuándo se debe realizar el cultivo de la leche (1). Sin embargo, en el Clinical Knowdlege Summaries (CKS) de NICE (2) sobre el manejo de las mastitis y abscesos mamarios, se recomienda realizar un cultivo de la leche cuando:

- Se han prescrito antibióticos y no hay respuesta tras $48 \mathrm{~h}$ de tratamiento

- Se trata de una mastitis severa antes de cualquier prescripción antibiótica

- Se trata de una mastitis recurrente

- Es probable que haya una infección hospitalaria adquirida

- La mujer no puede tomar los antibióticos habituales (como flucoxacilina y eritromicina)

- Hay un dolor profundo severo con sensación de quemazón en la mama (indicativo de infección ductal)

Estas recomendaciones se basan en la opinión de expertos de la OMS (3), el protocolo sobre mastitis de la ABM (4) y la revisión narrativa de Betzold et al, 2007 (5).

En cuanto a la actualización del protocolo de la ABM (2014), en este se señala que se debería realizar el cultivo si la mastitis no mejora después de $48 \mathrm{~h}$ de tratamiento de primera línea. Además también se sugiere que se realice cultivo cuando la mastitis ha recurrido, la adquisición es nosocomial, cuando la paciente es alérgica a los antibióticos habituales y en casos graves o raros (4).

Ni la Perinatal Services BC (6) ni la Guía del Embarazo del Ministerio mencionan cuándo es necesario el cultivo de la leche en una mastitis (7).

\subsection{Revisiones sistemáticas}

No existen revisiones sistemáticas que aborden esta cuestión. Sí se ha identificado una revisión sistemática (8) en la que se demuestra que en las mujeres que presentan dolor mamario localizado profundamente o síntomas similares presentan tasas mayores de microbios en la leche materna que las mujeres sanas que amamantan. En esta revisión se concluye que la realización de cultivos en mujeres con esos síntomas, seguido del tratamiento correspondiente, es un método de manejo razonable. 
Tabla 2. Resumen de RS

\begin{tabular}{|c|c|c|c|c|c|c|}
\hline $\begin{array}{l}\text { Referencia } \\
\text { (Cita } \\
\text { Abreviada) }\end{array}$ & $\begin{array}{l}\text { Estudio } \\
\text { (Diseño y } \\
\text { objetivo) }\end{array}$ & $\begin{array}{l}\text { Población } \\
\text { (no y } \\
\text { características) }\end{array}$ & $\begin{array}{l}\text { Intervención/ } \\
\text { Comparación. } \\
\text { exposiciones o } \\
\text { pruebas a estudio }\end{array}$ & $\begin{array}{l}\text { Resultados } \\
\text { (Estimadores de resultados-Magnitud } \\
\text { del efecto) }\end{array}$ & $\begin{array}{l}\text { Conclusiones } \\
\text { (Conclusiones) }\end{array}$ & $\begin{array}{l}\text { Comentarios } \\
\text { (Calidad de la evidencia, } \\
\text { financiación comentarios) }\end{array}$ \\
\hline $\begin{array}{l}\text { Betzold CM, } \\
2012\end{array}$ & $\begin{array}{l}\text { Diseño: RS y } \\
\text { Metaanálisis de } \\
\text { ensayos no } \\
\text { aleatorizados } \\
\text { Objetivo: } \\
\text { Explorar la } \\
\text { etiología del } \\
\text { dolor mamario } \\
\text { localizado } \\
\text { profundamente, } \\
\text { resumir los } \\
\text { resultados e } \\
\text { identificar } \\
\text { posibles } \\
\text { explicaciones de } \\
\text { las controversias } \\
\text { alrededor de } \\
\text { este trastorno. }\end{array}$ & $\begin{array}{l}\text { N: } 1 \text { estudio de } \\
\text { casos control sin } \\
\text { emparejar y } 6 \\
\text { estudios de } \\
\text { cohortes }\end{array}$ & $\begin{array}{l}\text { Descripción de los } \\
\text { microorganismos } \\
\text { detectados en la } \\
\text { leche materna de } \\
\text { madres que } \\
\text { presentan dolor } \\
\text { mamario } \\
\text { localizado } \\
\text { profundamente } \\
\text { frente a las que no } \\
\text { lo presentan. }\end{array}$ & $\begin{array}{l}\text { Los estudios detectaban mayores } \\
\text { niveles de microorganismos en la leche, } \\
\text { en los pezones o en ambos en mujeres } \\
\text { sintomáticas, independientemente del } \\
\text { método de detección o del tipo y rango } \\
\text { de microorganismos (bacterias, } \\
\text { levaduras u hongos). } \\
\text { En los casos, la leche materna se } \\
\text { asociaba con un mayor riesgo de } \\
\text { presencia de Staphylococcus aureus } \\
\text { (RR 7,29 (IC 95\% de 3,25 a 16,36) o } \\
\text { Candida (RR } 8,45 \text { (IC95\% de 3,96 a } \\
\text { 18,06). }\end{array}$ & $\begin{array}{l}\text { En mujeres lactantes que } \\
\text { reportan dolor mamario } \\
\text { localizado, se encuentra } \\
\text { evidencia consistente de } \\
\text { presencia de infección, } \\
\text { existiendo explicaciones } \\
\text { sobre las características } \\
\text { atípicas de este trastorno. } \\
\text { Aunque es más probable } \\
\text { que las mujeres lactantes } \\
\text { con dolor mamario } \\
\text { localizado profundamente } \\
\text { den resultados positivos } \\
\text { para Candida, el riesgo de } \\
\text { presentar resultados } \\
\text { positivos para } \\
\text { Staphylococcus aureus } \\
\text { también existe. Por ello, } \\
\text { se deberían realizar } \\
\text { cultivos a estas mujeres. } \\
\text { Las opciones de manejo } \\
\text { incluyen tratar de forma } \\
\text { inmediata mientras } \\
\text { esperan los resultados o } \\
\text { esperar hasta tener los } \\
\text { resultados para guiar el } \\
\text { tratamiento. }\end{array}$ & $\begin{array}{l}\text { Incluir cultivos del pezón } \\
\text { sesga los resultados, ya } \\
\text { que puede haber dolor } \\
\text { por grietas que estén } \\
\text { infectadas o colonizadas } \\
\text { por S. aureus y } \\
\text { colonizadas por levaduras } \\
\text { sin que haya mastitis o sin } \\
\text { que éstas sean las } \\
\text { causas. De hecho, las } \\
\text { levaduras son causa muy } \\
\text { infrecuente de mastitis } \\
\text { (Arroyo R, Acta Pediatr } \\
\text { Esp. 2011; 69(6): 235- } \\
240 ; \text { Delgado S. Acta } \\
\text { Pediatr Esp. 2009; 67(2): } \\
77-84)\end{array}$ \\
\hline
\end{tabular}




\subsection{Resumen de GPC base y RS disponibles}

En resumen, ante la sospecha de infección, se recomienda realizar un cultivo en las siguientes situaciones:

- No hay respuesta tras $48 \mathrm{~h}$ de tratamiento antibiótico empírico apropiado

- Siempre antes de cualquier prescripción antibiótica en caso de mastitis grave (sepsis o shock séptico, absceso mamario, necesidad de ingreso hospitalario)

- Mastitis recurrente

- Mastitis de adquisición nosocomial o con factores de riesgo de Staphylococcus aureus resistente a meticilina (SARM).

- Alergia a penicilina con intolerancia a cefalosporinas

- Hay un dolor profundo severo con sensación de quemazón "en la mama (indicativo de infección ductal)

\subsection{Conclusión}

\begin{tabular}{|l|l|}
\hline$X$ & Adopción GPC/Revisión sistemática \\
\hline & Elaboración parcial \\
\hline & Elaboración de novo \\
\hline
\end{tabular}

\subsection{Diseño de la estrategia de búsqueda de estudios individuales}

\section{Criterios de selección de estudios}

Período de búsqueda

Bases de datos 


\section{4- Evidencia}

\subsection{GRADE Evidence Profile}

No aplicable.

4.2. Resumen de la evidencia

No aplicable.

ACTUALIZADO A FECHA DE: 31 de Octubre de 2016 


\section{5- De la evidencia a la recomendación (Tabla de EtR)}

\begin{tabular}{|c|c|}
\hline \multicolumn{2}{|c|}{ Ante sospecha de infección, ¿cuándo está indicada la realización del cultivo de la leche? } \\
\hline$\frac{\text { Recomendación }}{\text { (Texto) }}$ & 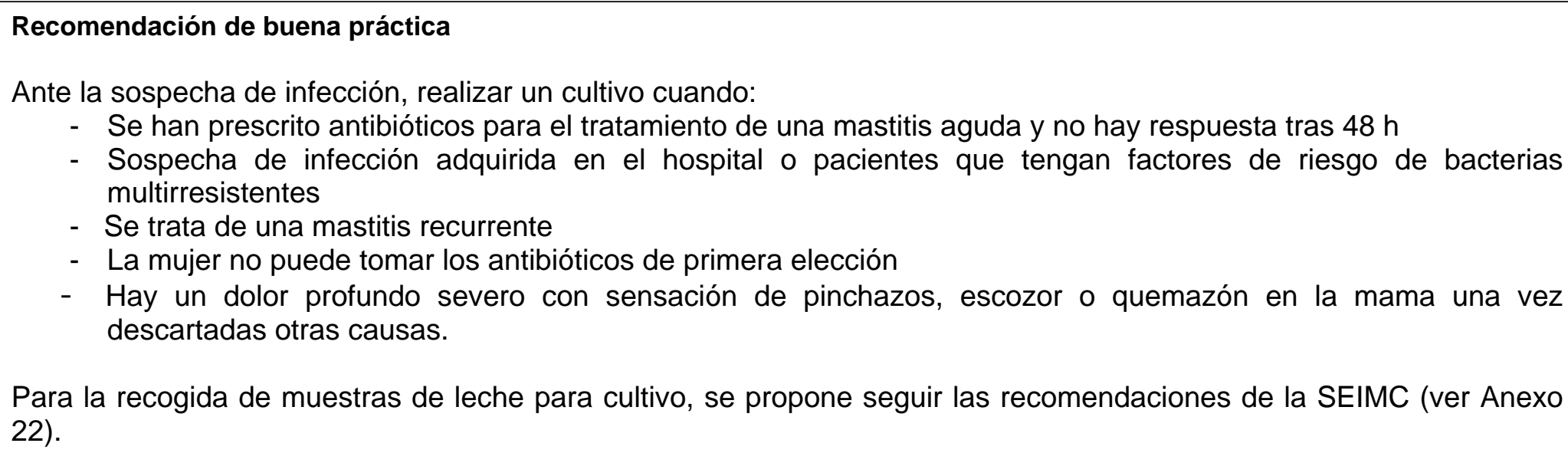 \\
\hline Justificación & $\begin{array}{l}\text { Las recomendaciones de buena práctica son las que se hacen en las diferentes guías de práctica clínica identificadas, } \\
\text { y que el grupo elaborador considera adecuadas. }\end{array}$ \\
\hline $\begin{array}{l}\text { Consideraciones de } \\
\text { subgrupos }\end{array}$ & - \\
\hline $\begin{array}{l}\text { Consideraciones para } \\
\text { la implementación }\end{array}$ & Creación de consultas de lactancia atendidas por profesionales especializados en lactancia materna. \\
\hline $\begin{array}{l}\text { Monitorización y } \\
\text { evaluación }\end{array}$ & $\begin{array}{l}\text { Sería de interés que hubiera un registro que recogiera cuáles han sido los resultados de los cultivos realizados en los } \\
\text { casos señalados para saber si en realidad han servido para facilitar el manejo de la situación, es decir, si ha } \\
\text { modificado el tratamiento y la evolución de la infección. }\end{array}$ \\
\hline
\end{tabular}




\begin{tabular}{|l|l|l|l|l|l|l}
\hline Prioridades para la & $\begin{array}{l}\text { Son necesarios estudios que demuestren que la realización de cultivos en estos casos mejora el manejo de las } \\
\text { pacientes y los resultados sobre la lactancia materna. } \\
\text { - Son necesarios estudios que conduzcan a la estandarización de la realización e interpretación de los resultados de } \\
\text { los cultivos. }\end{array}$ \\
\hline
\end{tabular}


GPC Lactancia Materna - pregunta 31. Cultivo leche

\section{ANEXOS}




\section{ANEXO I. ESTRATEGIAS DE BÚSQUEDA}

\section{Cochrane Library}

Searched 28/07/2015

\section{Updated search 28/07/2015 a xx/xx/xxxx}

\#1 mastitis:ti,ab,kw or "breast pain":ti,ab,kw or mastodynia or mastodynias or mammalgia or mammalgias or mastalgia or mastalgias:ti,ab,kw (Word variations have been searched) 531

\#2 lactation or lactating:ti,ab,kw or breastfeeding or "breastfeeding":ti,ab,kw or nursing or puerperal:ti,ab,kw (Word variations have been searched) 25614

\#3 \#1 and \#2 78

\#4 culture:ti,ab,kw (Word variations have been searched) 11553

\#5 \#3 and \#4 5

Medline, via Pubmed

Searched 28/07/2015

Updated search 28/07/2015 a xx/xx/xxxx

\#1 Search ((mastitis[Title/Abstract]) OR "breast pain"[Title/Abstract]) OR (mastodynia[Title/Abstract] OR mastodynias[Title/Abstract] OR mammalgia[Title/Abstract] OR mammalgias[Title/Abstract] OR mastalgias[Title/Abstract] OR mastalgia[Title/Abstract]) 10947

Search (((lactation[Title/Abstract] OR lactating[Title/Abstract])) OR (breastfeeding[Title/Abstract] OR "breast feeding"[Title/Abstract])) OR (nursing[Title/Abstract] OR puerperal[Title/Abstract]) 279153

\#3 Search \#1 AND \#2 2555

\#4 Search culture[Title/Abstract] 483479

\#5 Search \#3 AND \#4 173

\#6 Search \#5 Filters: Humans 13

\section{Embase, vía OvidWeb}

\section{Searched 28/07/2015}

\section{Updated search 28/07/2015 a xx/xx/xxxx}

$1 \quad$ (mastitis or "breast pain").ti,ab,kw. 11764

2 (mastodynia or mastodynias or mammalgia or mammalgias or matalgia or mastalgias).ti,ab,kw. 328

31 or 212062

4 (lactation or lactating or breastfeeding or "breast feeding" or nursing or puerperal).ti,ab,kw. 313199

$5 \quad 3$ and $4 \quad 2764$

$6 \quad$ culture.ti,ab,kw. 600630

$7 \quad 5$ and $6 \quad 182$

$8 \quad$ limit 7 to human $\quad \mathbf{3 0}$

Cinahl, vía EbscoHost

Searched 28/07/2015

Updated search 28/07/2015 a xx/xx/xxxx

S1 TI mastitis OR AB mastitis 230

S2 TI "breast pain" OR AB "breast pain" 153 
S3 TI ( mastodynia or mastodynias or mammalgia or mammalgias or mastalgia or mastalgias ) OR AB ( mastodynia or mastodynias or mammalgia or mammalgias or mastalgia or mastalgias ) 60

S4 S1 OR S2 OR S3 412

S5 TI ( lactation OR lactating ) OR AB ( lactation OR lactating ) 2104

S6 TI ( breastfeeding OR "breast feeding") OR AB (breastfeeding OR "breast feeding" ) 9256

S7 TI ( nursing OR puerperal ) OR AB ( nursing OR puerperal ) 190618

S8 S5 OR S6 OR S7 200408

S9 S3 AND S7 118

S10 TI culture OR AB culture 24957

S11 S8 AND S9 0 


\section{BIBLIOGRAFÍA}

(1) NICE. Postnatal care up to 8 weeks after birth. Julio 2006 (actualizado en Febrero de 2015). Disponible en: http://guidance.nice.org.uk/CG37.

(2) Mastitis and breast abscess. Clinical Knowledge Summaries-CSK. 2015. Disponible en:

http://ykmu.tbzmed.ac.ir/uploads/125/CMS/user/file/813/sexual/Mastitis\%20and\%20bre ast\%20abscess.pdf.

(3) Mastitis. Causas y manejo. Departamento de Salud y Desarrollo del niño y del adolescente. Organización Mundial de la Salud. 2000. Disponible en: apps.who.int/iris/bitstream/10665/66925/1/WHO_FCH_CAH_00.13_spa.pdf.

(4) ABM Clinical Protocol \#4: Mastitis, Revised March 2014. Breastfeeding Medicine, Volume 9, Number 5, 2014.

(5) Betzold CM. An update on the recognition and management of lactational breast inflammation. J Midwifery Womens Health 2007 Nov;52(6):595-605.

(6) Perinatal Services BC Health Promotion Guideline. Breastfeeding Healthy Term Infants. $\quad 2015 . \quad$ Darch 2 Disponible http://www.perinatalservicesbc.ca/Documents/Guidelines-

Standards/HealthPromotion/BreastfeedingHealthyTermInfantGuideline.pdf.

(7) Grupo de trabajo de la Guía de práctica clínica de atención en el embarazo y puerperio. Guía de práctica clínica de atención en el embarazo y puerperio. Ministerio de Sanidad, Servicios Sociales e Igualdad. Agencia de Evaluación de Tecnologías Sanitarias de Andalucía: 2014. Guías de Práctica Clínica en el SNS: AETSA 2011/10.

(8) Betzold CM. Results of microbial testing exploring the etiology of deep breast pain during lactation: a systematic review and meta-analysis of nonrandomized trials. J Midwifery Womens Health 2012 Jul;57(4):353-64. 
PREGUNTAS CLÍNICAS: № 32 Y 33

¿Qué intervención es más eficaz en el tratamiento de la mastitis aguda?

\section{1- Pregunta clínica en formato PICO}

Pregunta 32. En madres que amamantan y presentan mastitis aguda, ¿se debería empezar de forma inmediata con tratamiento antibiótico o con vaciamiento efectivo de la mama, tratamiento antiinflamatorio y reposo?

Tabla 1. Componentes de la pregunta clínica en formato PICO

\begin{tabular}{|l|l|}
\hline Pacientes & Madre que amamanta y presenta mastitis aguda \\
\hline Intervención & $\begin{array}{l}\text { Tratamiento con antibióticos de forma inmediata, junto con vaciamiento } \\
\text { efectivo de la mama, tratamiento antiinflamatorio y reposo }\end{array}$ \\
\hline Comparación & $\begin{array}{l}\text { Adición de antibióticos tras fallo de respuesta al tratamiento con sólo } \\
\text { vaciamiento, antiinflamatorios y reposo }\end{array}$ \\
\hline Resultados & $\begin{array}{l}\text { Duración lactancia materna (exclusiva y no exclusiva), lactancia } \\
\text { materna exclusiva al mes, a los } 4 \text { meses, a los } 6 \text { meses, problemas en } \\
\text { las mamas (dolor, grietas etc) }\end{array}$ \\
\hline Tipo de estudio & RS, ECAs y estudios observacionales \\
\hline
\end{tabular}

Pregunta 33. En madres que amamantan y presentan mastitis aguda, ¿es más eficaz el tratamiento con probióticos que el tratamiento con antibióticos?

Tabla 2. Componentes de la pregunta clínica en formato PICO

\begin{tabular}{|l|l|}
\hline Pacientes & Madre que amamanta y presenta mastitis aguda \\
\hline Intervención & Tratamiento con probióticos \\
\hline Comparación & Tratamiento con antibióticos \\
\hline Resultados & $\begin{array}{l}\text { Duración lactancia materna (exclusiva y no exclusiva), lactancia } \\
\text { materna exclusiva al mes, a los } 4 \text { meses, a los } 6 \text { meses, problemas en } \\
\text { las mamas (dolor, grietas etc) }\end{array}$ \\
\hline Tipo de estudio & RS, ECAs y estudios observacionales \\
\hline
\end{tabular}

\section{2- Introducción}




\section{3- ESTRATEGIA DE ELABORACION DE LA PREGUNTA}

\subsection{GPC}

Tabla 2- Resumen de GPC Base

\begin{tabular}{|c|c|c|c|c|}
\hline $\begin{array}{l}\text { Guía } \\
\text { (Enfoque) }\end{array}$ & $\begin{array}{l}\text { Resumen sobre la evidencia } \\
\text { (Calidad de la evidencia) }\end{array}$ & $\begin{array}{l}\text { Recomendaciones } \\
\text { (Grado) }\end{array}$ & $\begin{array}{c}\text { Referencias } \\
\text { bibliográficas } \\
\text { (Tipo de publicación) }\end{array}$ & Comentarios \\
\hline $\begin{array}{l}\text { NICE, } \\
2006\end{array}$ & $\begin{array}{l}\text { 83. Las mastitis no infecciosas deberían ser tratadas de forma } \\
\text { conservadora con calor húmedo y continuación de la lactancia materna } \\
\text { para asegurar un drenaje efectivo (Nivel } 1++ \text { ). } \\
\text { 84. El tratamiento de mastitis infecciosas incluye el uso de un antibiótico } \\
\text { beta lactamasa resistente junto con calor húmedo y lactancia materna } \\
\text { continuada (Nivel } 2 \text { ). } \\
\text { La opinión de expertos del BIRTH TO FIVE (Departamento de Salud, 2005) } \\
\text { recomienda que toda mujer que presente un área rojiza, caliente, dolorosa } \\
\text { en el pecho debería continuar alimentando al bebé, asegurándose de que } \\
\text { el agarre es correcto. Se anima a que la lactancia sea a demanda. } \\
\text { También se recomienda a las mujeres descansar y no llevar sujetador, } \\
\text { sobre todo por la noche. Si los síntomas no se resuelven, puede ser } \\
\text { necesario el tratamiento antibiótico. } \\
\text { Thomsen et al (Thomsen, Espersen y Maigaard 1984) sugirieron que los } \\
\text { síntomas inflamatorios del pecho podrían ser clasificados de acuerdo con el } \\
\text { recuento de leucocitos y de colonias bacterianas. Se consideró que había } \\
\text { una mastitis infecciosa cuando había un número de colonias bacterianas } \\
\text { mayor a } 103 \text { cfu/ml de leche. Sin embargo, existe una serie de bacterias } \\
\text { presentes en la leche que representan la flora normal de la piel y Osterman } \\
\text { y Rahm (2000) se refieren a estudios en los que se indica que la bacteria } \\
\text { potencialmente patógena que se aisla en la leche de mujeres con mastitis } \\
\text { lactacional es el S. aureus y raramente el Streptococo B hemoliticos. En } \\
\text { este estudio se cultivo la leche de } 40 \text { mujeres con mastitis. Las mujeres con } \\
\text { cultivos positivos a la flora cutánea normal (61\%) fueron tratados de forma } \\
\text { conservativa con descanso y vaciamiento frecuente del pecho y no } \\
\text { presentaron complicaciones ni tuvieron que recibir tratamiento con } \\
\text { antibióticos. } 9 \text { de las } 16 \text { mujeres que presentaban cultivos que indicaban } \\
\text { una bacteria potencialmente patógena recibieron antibióticos. El } 81 \% \text { de } \\
\text { esas mujeres tuvieron síntomas durante más de una semana y el } 31 \%\end{array}$ & $\begin{array}{l}\text { 37. Se debería aconsejar a las mujeres que en } \\
\text { caso de presentar cualquier signo y síntoma de } \\
\text { mastitis, incluyendo síntomas similares a la gripe, } \\
\text { mamas doloridas, sensibles y enrojecidas, lo } \\
\text { reportaran de forma urgente al profesional sanitario } \\
\text { (C). } \\
\text { 38. Se debería ofrecer asistencia con el } \\
\text { posicionamiento y el agarre a las mujeres que } \\
\text { reportan signos y síntomas de mastitis, junto con el } \\
\text { consejo de: } \\
\text { - Continuar con la lactancia y/o con al } \\
\quad \text { expresión manual para asegurar la } \\
\quad \text { eliminación efectiva de leche y si es } \\
\text { necesario, se debería realizar además un } \\
\text { masaje suave del pecho para vencer } \\
\text { cualquier bloqueo. } \\
\text { tomar analgesia compatible con la } \\
\quad \text { lactancia materna (por ejemplo } \\
\text { paracetamol) (D (GPP)) } \\
\text { Aumentar la ingesta de fluidos (D (GDP)). } \\
\text { 39. Si los signos y síntomas continuan por más de } \\
\text { unas horas de automanejo, se debería aconsejar a } \\
\text { la mujer volver a contactar con el profesional } \\
\text { sanitario (acción urgente). (D (GDP)). } \\
\text { 40. Si los signos y síntomas de mastitis no han } \\
\text { cesado, se debería evaluar a la mujer puesto que } \\
\text { podría necesitar tratamiento antibiótico (Acción } \\
\text { urgente) (B). }\end{array}$ & $\begin{array}{l}\text { Departamento de } \\
\text { Salud, } 2005\end{array}$ & \\
\hline
\end{tabular}




\begin{tabular}{|c|c|c|c|c|}
\hline $\begin{array}{l}\text { Guía } \\
\text { (Enfoque) }\end{array}$ & $\begin{array}{l}\text { Resumen sobre la evidencia } \\
\text { (Calidad de la evidencia) }\end{array}$ & $\begin{array}{l}\text { Recomendaciones } \\
\text { (Grado) }\end{array}$ & $\begin{array}{c}\text { Referencias } \\
\text { bibliográficas } \\
\text { (Tipo de publicación) }\end{array}$ & Comentarios \\
\hline & 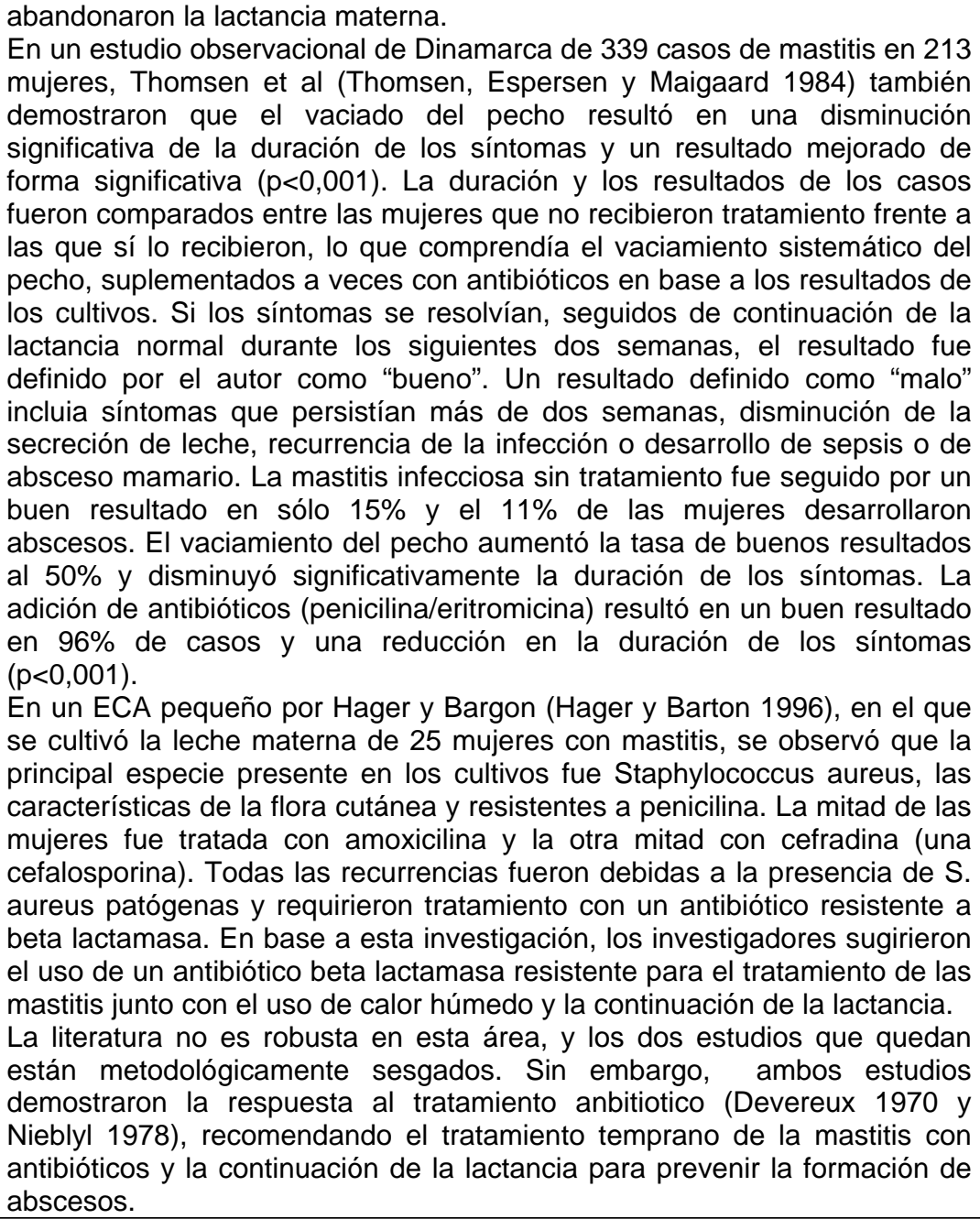 & & $\begin{array}{l}\text { Thomsen et al, } \\
1984 \\
\text { Hager et al, } 1996 \\
\text { Nieblyl et al, } 1978\end{array}$ & \\
\hline
\end{tabular}




\begin{tabular}{|c|c|c|c|c|}
\hline $\begin{array}{c}\text { Guía } \\
\text { (Enfoque) }\end{array}$ & $\begin{array}{l}\text { Resumen sobre la evidencia } \\
\text { (Calidad de la evidencia) }\end{array}$ & $\begin{array}{l}\text { Recomendaciones } \\
\text { (Grado) }\end{array}$ & $\begin{array}{c}\text { Referencias } \\
\text { bibliográficas } \\
\text { (Tipo de publicación) }\end{array}$ & Comentarios \\
\hline $\begin{array}{l}\text { CKS Safe } \\
\text { practical } \\
\text { clinical } \\
\text { answers } \\
\text { Mastitis } \\
\text { and } \\
\text { breast } \\
\text { abscess- } \\
\text { Managem } \\
\text { ent }\end{array}$ & $\begin{array}{l}\text { ¿Cuál es el tratamiento de primera línea de la mastitis? } \\
\text { 1. Asegurar a la mujer que aunque la mastitis es una condición } \\
\text { dolorosa, el pecho volverá a su estado normal } \\
\text { * La opinión de expertos de la guía de la OMS dice que si se trata de forma } \\
\text { adecuada, el resultado es el retorno a la función completamente normal y a } \\
\text { la lactancia (OMS 2000). } \\
\text { 3. Para reducir el dolor y el disconfort: } \\
\text { * NICE recomienda un analgésico compatible con la lactancia, como el } \\
\text { paracetamol (NICE, 2006). Para mayor información sobre el uso de } \\
\text { NSAIDs en mujeres que amamantan ver la sección de Lactancia en los } \\
\text { CKS Topics en el apartado NSAIDS-prescribing issues. } \\
\text { * Tanto la recomendación de usar compresas calientes, o darse un baño o } \\
\text { ducha con agua caliente, así como la del descanso se basa en la opinión } \\
\text { de expertos de la OMS (OMS 2000). } \\
\text { 4. Aconsejar a la mujer que continúe amamantando } \\
\text { * La OMS revisa la evidencia disponible y concluye que el cese de la } \\
\text { lactancia no ayuda, pudiendo hacer además que la mujer empeore (WHO } \\
\text { 2000). } \\
\text { * El cese repentino de la lactancia se asocia con mayor riesgo de } \\
\text { desarrollar absceso mamario en comparación con continuar la lactancia } \\
\text { (ABM 2008). } \\
\text { * La única excepción son las madres con HIV positivo. } \\
\text { 5. Si el amamantamiento no es posible... } \\
\text { * Esta recomendación se basa en la opinión de expertos del NICE (la mujer } \\
\text { debería continuar la lactancia y/o realizar la extracción manual para } \\
\text { asegurar la eliminación efectiva de la leche (NICE 2006). El vaciado del } \\
\text { pecho tras una toma también se recomienda por la ABM } 2008 \text { y la revisión } \\
\text { de Betzold, 2007. El Breastfeeding Network también señala que la mujer } \\
\text { puede necesitar extraerse la leche tras las tomas (The Breastfeeding } \\
\text { Network, 2006). } \\
\text { * Hay buena evidencia de que el vaciado regular del pecho es importante } \\
\text { tanto para el tratamiento de las mastitis infecciosas como no infecciosas. } \\
\text { También hay evidencia limitada de que el vaciado del pecho y el descanso } \\
\text { es curativo en mujeres que no tienen bacterias patógenas en la leche. }\end{array}$ & $\begin{array}{l}\text { ¿Cuál es el tratamiento de primera línea de la } \\
\text { mastitis? } \\
\text { 1. Asegurar a la mujer que aunque la mastitis } \\
\text { es una condición dolorosa, el pecho volverá } \\
\text { a su estado normal } \\
\text { 2. Prescribir un antibiótico si: } \\
\text { - Los síntomas no mejoran o empeoran tras 12-24 } \\
\text { horas a pesar de la eliminación efectiva de la } \\
\text { leche } \\
\text { - La mujer tiene una fisura en el pezón que está } \\
\text { infectada } \\
\text { 3. Para reducir el dolor y el disconfort: } \\
\text { - Ofrecer paracetamol como primera opción } \\
\text { - El ibuprofeno es una alternativa. Utilizar la dosis } \\
\text { efectiva más baja por el menor tiempo posible. } \\
\text { - Aconsejar a la mujer: } \\
\text { - Colocar una compresa templada sobre la } \\
\text { mama, o tomar un baño o ducha caliente } \\
\text { (reducirá el dolor y ayudará al flujo de la leche). } \\
\text { - Descansar, si es posible } \\
\text { - No llevar un sujetador (especialmente por la } \\
\text { noche). } \\
\text { 4. Aconsejar a la mujer que continúe } \\
\text { amamantando } \\
\text { Si la mama afectada no está completamente vacía } \\
\text { tras la toma, aconsejar a la mujer extraerse la leche } \\
\text { restante de forma manual o mediante un } \\
\text { sacaleches. } \\
\text { 5. Si el amamantamiento no es posible, } \\
\text { aconsejar la extracción manual o mediante } \\
\text { extractores hasta que pueda continuar con la } \\
\text { lactancia }\end{array}$ & $\begin{array}{l}\text { OMS, } 2000 \\
\text { Barbosa-Cesnik, } \\
2003 \\
\text { Betzold } 2007\end{array}$ & \\
\hline
\end{tabular}




\begin{tabular}{|c|c|c|c|c|}
\hline $\begin{array}{l}\text { Guía } \\
\text { (Enfoque) }\end{array}$ & $\begin{array}{l}\text { Resumen sobre la evidencia } \\
\text { (Calidad de la evidencia) }\end{array}$ & $\begin{array}{l}\text { Recomendaciones } \\
\text { (Grado) }\end{array}$ & $\begin{array}{c}\text { Referencias } \\
\text { bibliográficas } \\
\text { (Tipo de publicación) }\end{array}$ & Comentarios \\
\hline & & $\begin{array}{l}\text { 6. Tratar el daño en el pezón (el dolor por el daño } \\
\text { en el pezón puede inhibir la eliminación efectiva de } \\
\text { la leche }\end{array}$ & & \\
\hline $\begin{array}{l}\text { Protocolo } \\
\text { ABM \#4, } \\
2014\end{array}$ & $\begin{array}{l}\text { Para el manejo: } \\
\text { 1. Extracción efectiva de la leche } \\
\text { Las madres deberían ser animadas a amamantar más frecuentemente, } \\
\text { empezando por el lado afectado } \\
\text { - Si el dolor interfiere con el abandono, la alimentación puede } \\
\text { empezar por el lado no afectado, pasando al lado afectado en } \\
\text { cuanto se pueda } \\
\text { El posicionamiento del niño al pecho con la barbilla o la nariz } \\
\text { apuntando al bloqueo podría ayudar en el drenaje del área } \\
\text { afectada } \\
\quad \text { Masajear la mama durante la alimentación con un aceite } \\
\quad \text { comestible o lubricante no tóxico en los dedos puede facilitar la } \\
\quad \text { extracción de la leche. El masaje, ya sea la misma madre u otra } \\
\quad \text { persona que lo haga, debería ser dirigido desde el área bloqueada } \\
\text { hacia el pezón. } \\
\quad \text { Tras el amamantamiento, la extracción de la leche, ya sea de } \\
\text { acelerar la resolución del problema } 11 \text { (III). } \\
\text { Otra aproximación alternativa sería la movilización de fluidos de la mama } \\
\text { hinchada, que consistiría en promover el drenaje de fluidos hacia los } \\
\text { nódulos linfáticos axilares. La madre se reclina, y realiza movimientos } \\
\text { suaves con las manos golpeando la superficie de la piel desde la areola } \\
\text { hasta la axila 12. (III). } \\
\text { No hay evidencia sobre el riesgo para el niño sano a término de continuar } \\
\text { con la lactancia cuando la madre tiene mastitis7. Las mujeres que no } \\
\text { pueden continuar con la lactancia deberían extraerse la leche de la mama } \\
\text { manualmente o con el uso de un extractor, puesto que el cese repentino } \\
\text { lleva a un aumento del riesgo de absceso mamario } 11 \text { (III). } \\
\text { 2. Medidas de apoyo } \\
\text { Descanso, nutrición e ingesta adecuada de fluidos }\end{array}$ & $\begin{array}{l}\text { 7. OMS } 2000 \\
\text { 11. Thomsen } 1984 \\
\text { 12. Bolman } 2013 \\
\text { 13. Sachs } 2013 \\
\text { 14. Amir LH, } 2006 \\
\text { 15. Kvist LJ, } 2008 \\
\text { 16. Antibiotic Expert Group, } 2010 \\
\text { 17. Olsson R, } 1992 \\
\text { 20. Perez A, } 2013 \\
\text { 21. Branch-Ellliman W, } 2012 \\
\text { 22. Stafford I, } 2008 \\
\text { 26. Johnson MD, } 2008 \\
\text { 27. Rodvold KA, } 2014\end{array}$ & & \\
\hline
\end{tabular}




\begin{tabular}{|c|c|c|c|c|}
\hline $\begin{array}{l}\text { Guía } \\
\text { (Enfoque) }\end{array}$ & $\begin{array}{l}\text { Resumen sobre la evidencia } \\
\text { (Calidad de la evidencia) }\end{array}$ & $\begin{array}{l}\text { Recomendaciones } \\
\text { (Grado) }\end{array}$ & $\begin{array}{c}\text { Referencias } \\
\text { bibliográficas } \\
\text { (Tipo de publicación) }\end{array}$ & Comentarios \\
\hline & $\begin{array}{l}\text { Aplicación de calor antes de la toma puede ayudar con el flujo de la leche. } \\
\text { Tras las tomas o la extracción de la leche, se puede aplicar frío para reducir } \\
\text { el dolor y el edema. } \\
\text { 3. Tratamiento farmacológico } \\
\text { Analgesia: } \\
\text { Puede ayudar al reflejo de bajada. Un agente antiinflamatorio, como el } \\
\text { ibuprofeno, puede ser más efectivo en reducir los síntomas inflamatorios } \\
\text { que un simple analgésico, como el paracetamol. El ibuprofeno no se } \\
\text { detecta en la leche al utilizar dosis hasta } 1,6 \text { gramos /día, y se muestra } \\
\text { compatible con la lactancia materna. } 13 \text { (III). } \\
\text { Antibióticos } \\
\text { Si los síntomas no mejoran tras } 12-24 \text { horas o si la mujer está muy } \\
\text { enferma, el tratamiento con antibióticos debería comenzar. } \\
\text { El patógeno más común involucrado en la mastitis infecciosa es S. aureus } \\
14,15, \text { siendo menos común el Streptococo o E. coli. } 11 \text {. }\end{array}$ & & & \\
\hline $\begin{array}{l}\text { Perinatal } \\
\text { Services } \\
\text { BC, } 2012\end{array}$ & $\begin{array}{l}\text { Mastitis } \\
\text { Inflammation of the breast, in which milk stasis is the primary cause that } \\
\text { may or may not be accompanied by or progress to infection. } 101,104 \text { Occurs } \\
\text { at any time during lactation but is most common in the first } 2 \text { - } 6 \text { weeks } \\
\text { postpartum } 104 \\
\text { Breast is hot, swollen, and tender; skin may be reddened; and mothers may } \\
\text { complain of malaise, fever of } 38.5^{\circ} \mathrm{C} \text { or higher, chills, headache, and flu like } \\
\text { aching.38,39,104 Usually only one breast is affected } \\
\text { Contributing factors are numerous and can be due to: breast engorgement; } \\
\text { delayed breastfeeding initiation; infrequent and/or time restricted } \\
\text { breastfeedings; supplementation; breast surgery; any situation where milk } \\
\text { stasis occurs; a break in the integrity of the nipple skin (cracked or damaged } \\
\text { nipple); inadequate milk removal from the breast; poor latch/attachment; } \\
\text { oversupply of milk; pressure on the breast (tight bra or car seatbelt); } \\
\text { blocked nipple pore; stress; fatigue; poor maternal nutrition; use of a } \\
\text { pacifier; rapid weaning; and ankyloglossia in the infant100,104 }\end{array}$ & $\begin{array}{l}\text { Care } \\
\text { - Reassure mother that continued breastfeeding is } \\
\text { advised and that milk from the affected breast is } \\
\text { safe for her infant } 39,101,102,104,105 \text {. } \\
\text { - First } 12 \text { to } 24 \text { hours } \\
\text { Shower or warm compresses to breast before } \\
\text { feeding may facilitate milk flow } \\
\text { Breastfeed frequently ensuring effectual milk } \\
\text { removal. Start on the affected breast. If discomfort } \\
\text { inhibits let-down then start on the unaffected breast } \\
\text { and switch to the affected breast when letdown } \\
\text { occurs } 104 \text {. } \\
\text { Position the infant on the breast with chin or nose } \\
\text { pointing towards the affected area. During } \\
\text { breastfeeding massage the breast starting at the } \\
\text { blocked area, moving toward the nipple } 104 \\
\text { After breastfeeding any additional milk may be }\end{array}$ & $\begin{array}{l}\text { 38. Riordan J \& } \\
\text { Wambach, K. } \\
\text { (2010). } \\
\text { 39. Lawrence RA \& } \\
\text { Lawrence RM. } \\
\text { (2005). } \\
\text { 100. Humenick SS, } \\
\text { Hill PD, Anderson } \\
\text { MA (1994). } \\
\text { 101. OMS (2000) } \\
\text { 102. Snowden HM, } \\
\text { Renfrew MJ, \& } \\
\text { Woolridge MW. } \\
\text { (2002). } \\
\text { 103. Hale WT. } \\
\text { (2006). } \\
\text { 104.ABM 2008 } \\
\text { 105. Spencer JP. } \\
\text { (2008) }\end{array}$ & \\
\hline
\end{tabular}




\begin{tabular}{|c|c|c|c|c|}
\hline $\begin{array}{l}\text { Guía } \\
\text { (Enfoque) }\end{array}$ & $\begin{array}{l}\text { Resumen sobre la evidencia } \\
\text { (Calidad de la evidencia) }\end{array}$ & $\begin{array}{l}\text { Recomendaciones } \\
\text { (Grado) }\end{array}$ & $\begin{array}{c}\text { Referencias } \\
\text { bibliográficas } \\
\text { (Tipo de publicación) }\end{array}$ & Comentarios \\
\hline & & $\begin{array}{l}\text { expressed by hand or pump and cold compresses } \\
\text { may reduce pain and edema39,104 } \\
\text { Advise bed rest, adequate fluids and nutrition, and } \\
\text { support at home } \\
\text { Use an analgesic, e.g., ibuprofen ( } 400 \text { mg. every } 4 \\
-6 \text { hours) to decrease inflammation and } \\
\text { pain } 101,103,104 \\
\text { - Subsequent treatment after } 24 \text { hours } \\
\text { Use antibiotics judiciously and only recommended if } \\
\text { symptoms have not improved after } 12-24 \\
\text { hours of rest and applying the above } \\
\text { recommendations; } 101 \text { maternal fever has not } \\
\text { subsided and illness remains acute; or if the nipple } \\
\text { is cracked/fissured indicating possible infectious } \\
\text { mastitis. }\end{array}$ & & \\
\hline $\begin{array}{l}\text { Guía del } \\
\text { embarazo } \\
2014\end{array}$ & $\begin{array}{l}\text { Uso de antibióticos para las mastitis en mujeres que amamantan } \\
\text { La revisión de Jahanfar (2010) incluyó } 2 \text { estudios con aproximadamente } \\
125 \text { mujeres que amamantaban con síntomas de mastitis tales como } \\
\text { sensibilidad aumentada, enrojecimiento de los pechos, una disminución de } \\
\text { la secreción de leche o fiebre. Un estudio comparó la ausencia de } \\
\text { tratamiento, el vaciamiento de la mama y vaciamiento de la mama con } \\
\text { algunos de los siguientes antibióticos en un tratamiento de seis días: } \\
\text { penicilina } 500.000 \text { Ul tres veces al día, ampicilina oral } 500 \text { mg cuatro veces } \\
\text { al día, o eritromicina } 500 \text { mg dos veces al día. El otro ECA comparó dos } \\
\text { antibióticos (amoxicilina frente a cefradina) en una dosis de } 500 \text { mg por vía } \\
\text { oral cada ocho horas durante siete días. Se realizaron análisis de } \\
\text { sensibilidad y análisis de subgrupos. Aunque se planearon análisis de } \\
\text { sensibilidad para comparar los resultados dependiendo de las dosis } \\
\text { evaluadas en los estudios, o las reacciones provocadas por el tratamiento } \\
\text { en la madre o el bebé, las diferencias entre los estudios no permitieron la } \\
\text { realización de un metanálisis. } \\
\text { Ambos estudios evaluaron la resolución de los síntomas (fiebre, } \\
\text { eritema,sensibilidad) como su desenlace principal. Por otro lado, uno de los } \\
\text { ECA evaluó el mantenimiento de la lactancia materna a las dos semanas } \\
\text { de haber finalizado el tratamiento, y ambos estudios evaluaron otros } \\
\text { desenlaces como la persistencia de los síntomas, los problemas con la }\end{array}$ & $\begin{array}{l}\text { Débil } \\
\text { Se sugiere utilizar un tratamiento antibiótico, } \\
\text { además del mantenimiento de la lactancia materna } \\
\text { con un vaciado frecuente para resolver la mastitis } \\
\text { infecciosa. } \\
\text { Débil } \\
\text { Se sugiere el uso de compresas de agua tibia tras } \\
\text { el amamantamiento en aquellas madres que } \\
\text { amamanten con dolor o lesiones en los pezones. }\end{array}$ & Jahanfar 2010 & \\
\hline
\end{tabular}




\begin{tabular}{|c|c|c|c|c|}
\hline $\begin{array}{c}\text { Guía } \\
\text { (Enfoque) }\end{array}$ & $\begin{array}{l}\text { Resumen sobre la evidencia } \\
\text { (Calidad de la evidencia) }\end{array}$ & $\begin{array}{l}\text { Recomendaciones } \\
\text { (Grado) }\end{array}$ & $\begin{array}{c}\text { Referencias } \\
\text { bibliográficas } \\
\text { (Tipo de publicación) }\end{array}$ & Comentarios \\
\hline & $\begin{array}{l}\text { secreción de leche o la recurrencia de la infección. } \\
\text { Un ECA mostró que el tratamiento con antibiótico y vaciamiento de la } \\
\text { mama contribuyó a la mejoría de los síntomas de la mastitis infecciosa en } \\
\text { una proporción significativamente mayor ( } 96 \% \text { ) que el hecho de no } \\
\text { tratar ( } 15 \% \text { ) (1 ECA, } 110 \text { mujeres; RR } 6,63 ; \text { OR } 95 \% 3,48 \text { a } 12,60) \text {. Los } \\
\text { resultados también fueron significativos al comparar el tratamiento con } \\
\text { antibiótico y vaciamiento de la mama frente a vaciar la mama solamente } \\
\text { (RR } 1,89 ; \text { OR } 95 \% 1,45 \text { a } 2,47) \text {. } \\
\text { La resolución de la sintomatología fue más rápida en el grupo de } \\
\text { mujeres que recibió antibióticos y vaciamiento de la mama (media de } \\
2,1 \text { días) que en los otros dos grupos (vaciamiento de la mama: medida de } \\
4,2 \text { días; no tratamiento: media de } 6,7 \text { días). } \\
\text { El ECA que comparó amoxicilina frente a cefradina no mostró diferencias } \\
\text { entre los grupos relacionadas con el número de mujeres con una mejoría } \\
\text { de los síntomas a juicio del clínico (1 ECA, } 25 \text { mujeres; RR } 0,85 ; \text { IC } 95 \% \\
0,65 \text { a } 1,12 \text { ), aunque prácticamente todas las mujeres habían mostrado una } \\
\text { mejoría después de siete días de tratamiento. } \\
\text { Ninguno de los dos ECA describió que el uso de antibióticos provocara } \\
\text { efectos adversos. }\end{array}$ & & & \\
\hline
\end{tabular}

\subsection{Revisiones sistemáticas}

En cuanto al tratamiento de las mastitis agudas, se ha identificado una revisión Cochrane (1) sobre el uso de antibióticos en mujeres que amamantan con mastitis, que ya se incluye en la Guía sobre el embarazo del Ministerio (2) y que incluye dos artículos que están incluidos tanto en la guía de NICE (3) o en el protocolo de la ABM sobre mastitis de 2014 (4).

Esta revisión lo que pretende es valorar la efectividad de los antibióticos en resolver los síntomas de las mujeres que amamantan y presentan mastitis con o sin realización de cultivo de la leche. La conclusión a la que llegan los autores es que la evidencia que existe no es suficiente para confirmar o refutar la efectividad de la terapia con antibióticos en el tratamiento de las mastitis puerperales, y que existe una necesidad urgente de realizar ECA doble ciego de alta calidad para determinar si los antibióticos deberían ser utilizados en esta condición común postparto. 
Tabla 2. Resumen de RS

\begin{tabular}{|c|c|c|c|c|c|c|}
\hline $\begin{array}{l}\text { Referencia } \\
\text { (Cita } \\
\text { Abreviada) }\end{array}$ & $\begin{array}{l}\text { Estudio } \\
\text { (Diseño y } \\
\text { objetivo) }\end{array}$ & $\begin{array}{l}\text { Población } \\
\left(n^{0} y\right. \\
\text { características) }\end{array}$ & $\begin{array}{l}\text { Intervención/ } \\
\text { Comparación. } \\
\text { exposiciones o } \\
\text { pruebas a estudio }\end{array}$ & $\begin{array}{l}\text { Resultados } \\
\text { (Estimadores de resultados-Magnitud } \\
\text { del efecto) }\end{array}$ & $\begin{array}{l}\text { Conclusiones } \\
\text { (Conclusiones) }\end{array}$ & $\begin{array}{l}\text { Comentarios } \\
\text { (Calidad de la evidencia, } \\
\text { financiación comentarios) }\end{array}$ \\
\hline $\begin{array}{l}\text { Jahanfar S, } \\
2013\end{array}$ & $\begin{array}{l}\text { Diseño: } \\
\text { RS } \\
\text { Objetivo: } \\
\text { Examinar la } \\
\text { efectividad del } \\
\text { tratamiento } \\
\text { antibiótico en } \\
\text { aliviar los } \\
\text { síntomas de las } \\
\text { madres que } \\
\text { amamantan y } \\
\text { tienen mastitis } \\
\text { con o sin } \\
\text { pruebas de } \\
\text { laboratorio. }\end{array}$ & $\begin{array}{l}\text { N: } 2 \text { ECA } \\
\text { Características: } \\
\text { Un ECA } \\
\text { pequeño(n=25) } \\
\text { que compara } \\
\text { amoxicilna con } \\
\text { cefralina y otro } \\
\text { que compara el } \\
\text { vaciamiento de } \\
\text { las mamas como } \\
\text { tratamiento de } \\
\text { apoyo frente al } \\
\text { tratamiento } \\
\text { antibiótico y } \\
\text { tratamiento de } \\
\text { apoyo. }\end{array}$ & $\begin{array}{l}\text { Comparación 1: } \\
\text { Amoxicilina vs. } \\
\text { cefradina (1 } \\
\text { estudio, n=25) } \\
\text { Comparación 2: } \\
\text { Tratamiento } \\
\text { antibiótico junto a } \\
\text { vaciamiento versus } \\
\text { vaciamiento sólo } \\
\text { (1 estudio, } 165 \\
\text { casos) }\end{array}$ & $\begin{array}{l}\text { Comparación 1: } \\
\text { Mejora de los síntomas valorado de } \\
\text { forma clínica } \\
\text { Comparación 2: } \\
\text { Mejora de los síntomas valorados por el } \\
\text { clínico y la continuación de la lactancia }\end{array}$ & $\begin{array}{l}\text { La evidencia es } \\
\text { insuficiente para confirmar } \\
\text { o refutar la efectividad del } \\
\text { tratamiento con } \\
\text { antibióticos en el manejo } \\
\text { de la mastitis puerperal. } \\
\text { Existe una necesidad } \\
\text { urgente de que se } \\
\text { realicen ECAs de alta } \\
\text { calidad, doble ciego para } \\
\text { determinar si los } \\
\text { antibióticos deberían ser } \\
\text { utilizados en esta } \\
\text { condición postparto } \\
\text { común. } \\
\text { Los resultados del estudio } \\
\text { más grande sugieren } \\
\text { mayor alivio de los } \\
\text { síntomas al utilizar } \\
\text { antibióticos, aunque el } \\
\text { diseño del estudio es } \\
\text { problemático. }\end{array}$ & $\begin{array}{l}\text { Ver valoración AMSTAR } \\
\text { en ANEXOS. }\end{array}$ \\
\hline
\end{tabular}




\subsection{Resumen de GPC base y RS disponibles}

Las recomendaciones que hace la guía NICE (3) son las siguientes:

1. Ofrecer asistencia con el posicionamiento y el agarre a las mujeres que reportan signos y síntomas de mastitis, junto con el consejo de:

- Continuar con la lactancia y/o con al expresión manual para asegurar la eliminación efectiva de leche y si es necesario, se debería realizar además un masaje suave del pecho para vencer cualquier bloqueo.

- tomar analgesia compatible con la lactancia materna (por ejemplo paracetamol) (D (GPP))

- Aumentar la ingesta de fluidos (D (GDP)).

2. Si los signos y síntomas continuan por más de unas horas de automanejo, se debería aconsejar a la mujer volver a contactar con el profesional sanitario (acción urgente). (D (GDP)).

3. Si los signos y síntomas de mastitis no han cesado, se debería evaluar a la mujer puesto que podría necesitar tratamiento antibiótico (Acción urgente) (B).

El protocolo de la ABM (4) recomienda una extracción efectiva de la leche, medidas de apoyo como el descanso, ingesta adecuada de fluidos y ducha o aplicación de compresas con agua tibia antes de la toma y de frío después de las tomas o la extracción de la leche, tratamiento analgésico (sobre todo ibuprofeno) que puede ayudar al reflejo de bajada, y tratamiento con antibióticos si los síntomas no mejoran tras 12-24 horas.

La guía de la Perinatal Services BC (5) recomienda la lactancia continuada y asegurar a las madres que es seguro para el niño amamantar por el pecho afectado. Durante las primeras 12-24 horas, se recomienda el amamantamiento continuado, el uso de compresas calientes antes de amamantar para facilitar el flujo de la leche, extraerse la leche restante y aplicar compresas frías tras las tomas. Una vez transcurridas 24 horas sin mejoría de los síntomas tras la aplicación de las medidas anteriores, se recomienda el uso de antibióticos que empíricamente cubren al germen más frecuentemente implicado, que es el $S$. aureus.

Por último, la guía del embarazo sugiere utilizar un tratamiento antibiótico, además del mantenimiento de la lactancia materna con un vaciado frecuente para resolver la mastitis infecciosa y el uso de compresas de agua tibia tras el amamantamiento en aquellas madres que amamanten con dolor o lesiones en los pezones (2).

La única revisión que se ha encontrado, sobre la efectividad de los antibióticos en el tratamiento de las mastitis de madres que amamantan, concluye que la evidencia sobre su efectividad en esta condición es insuficiente.

\subsection{Conclusión}

\begin{tabular}{|l|l|}
\hline & Adopción GPC/Revisión sistemática \\
\hline $\mathrm{X}$ & Elaboración parcial \\
\hline & Elaboración de novo \\
\hline
\end{tabular}

\subsection{Diseño de la estrategia de búsqueda de estudios individuales}


GPC Lactancia Materna - Preguntas 32 y 33. Tratamiento mastitis aguda

\begin{tabular}{|l|l|}
\hline $\begin{array}{l}\text { Criterios de selección de } \\
\text { estudios }\end{array}$ & ECA, Estudios observacionales \\
\hline Período de búsqueda & Sin limite \\
\hline Bases de datos & $\begin{array}{l}\text { Cochrane Library } \\
\text { Medline via Pubmed } \\
\text { Embase via OVID } \\
\text { Cinahl via EBSCO } \\
\text { PsylNFO via OVID }\end{array}$ \\
\hline
\end{tabular}

Ver estrategias de búsqueda de estudios originales en el anexo I. 


\section{4- Resumen de la evidencia (Tablas de estudios individuales y valoración de calidad en el ANEXO II)}

\section{1- GRADE Evidence Profile}

Pregunta 32. En madres que amamantan y presentan mastitis aguda, ¿se debería empezar de forma inmediata con tratamiento antibiótico o con vaciamiento efectivo de la mama, tratamiento antiinflamatorio y reposo?

La comparación que se muestra no responde expresamente a la pregunta, sino a la eficacia de añadir tratamiento antibiótico al tratamiento conservador tras conocer el resultado del cultivo de leche materna (no de forma empírica ni precoz).

Comparación: Antibióticos + vaciamiento vs. Vaciamiento

Bibliografía: Thomsen AC, 1984

\begin{tabular}{|c|c|c|c|c|c|c|c|c|c|c|c|c|}
\hline \multirow{2}{*}{\multicolumn{7}{|c|}{ Evaluación de la calidad }} & \multicolumn{4}{|c|}{ Resumen de los Resultados } & \multirow{3}{*}{ Calidad } & \multirow{3}{*}{ Importancie } \\
\hline & & & & & & & \multicolumn{2}{|c|}{ № de pacientes } & \multicolumn{2}{|c|}{ Magnitud del efecto } & & \\
\hline \begin{tabular}{|c|}
$\begin{array}{c}\text { № de } \\
\text { estudios }\end{array}$ \\
\end{tabular} & Diseño & \begin{tabular}{|c|}
$\begin{array}{c}\text { Riesgo de } \\
\text { sesgo }\end{array}$ \\
\end{tabular} & Inconsistencia & \begin{tabular}{|l}
$\begin{array}{l}\text { Evidencia } \\
\text { indirecta }\end{array}$ \\
\end{tabular} & Imprecisión & $\begin{array}{c}\text { Otras } \\
\text { consideraciones }\end{array}$ & $\begin{array}{c}\text { Grupo } \\
\text { vaciado + Ab }\end{array}$ & $\begin{array}{c}\text { Grupo } \\
\text { vaciado }\end{array}$ & $\begin{array}{l}\text { Relativa } \\
(95 \% \text { Cl) }\end{array}$ & Absoluta por 1000 & & \\
\hline \multicolumn{13}{|c|}{ Lactancia materna normal dos semanas después del inicio del episodio } \\
\hline 1 & ECA & Serio $^{1}$ & \begin{tabular}{|l|} 
No seria \\
\end{tabular} & No seria & Seria $^{2}$ & Ninguna & $\begin{array}{c}53 / 55 \\
(96,4 \%)\end{array}$ & $\begin{array}{c}28 / 55 \\
(50,9 \%)\end{array}$ & $\begin{array}{l}\text { RR } 1,89 \text { (de } \\
1,45 \text { a } 2,47 \text { ) }\end{array}$ & $\begin{array}{l}453 \text { más por } 1000 \\
\text { (de } 229 \text { más a } 748 \\
\text { más) }\end{array}$ & BAJA & CRITICO \\
\hline \multicolumn{13}{|c|}{ Duración de los síntomas de mastitis } \\
\hline 1 & ECA & Serio ${ }^{1}$ & No seria & No seria & Seria 2,3 & Ninguna & 2,1 días & 4,2 días & $p<0,001$ & - & BAJA & CRITICO \\
\hline
\end{tabular}

1 No se menciona el método de aleatorización, no está claro el cegamiento, no se describe el seguimiento con claridad y no hay tabla de características basales. ${ }^{2}$ Pocos eventos; 3 no se dan las desviaciones estándar para cada grupo 
Pregunta 33. En madres que amamantan y presentan mastitis aguda, ¿es más eficaz el tratamiento con probióticos que el tratamiento con antibióticos?

Comparación: Probióticos vs. Antibióticos

Bibliografía: Arroyo R et al, 2010

\begin{tabular}{|c|c|c|c|c|c|c|c|c|c|c|c|c|c|}
\hline \multirow{2}{*}{\multicolumn{7}{|c|}{ Evaluación de la calidad }} & \multicolumn{5}{|c|}{ Resumen de los Resultados } & \multirow[b]{3}{*}{ Calidad } & \multirow[b]{3}{*}{ Importancia } \\
\hline & & & & & & & \multicolumn{3}{|c|}{ № de pacientes } & \multicolumn{2}{|c|}{ Magnitud del efecto } & & \\
\hline \begin{tabular}{|c|} 
No de \\
estudio \\
S
\end{tabular} & Diseño & $\begin{array}{c}\text { Riesgo } \\
\text { de sesgo }\end{array}$ & $\begin{array}{c}\text { Inconsistenci } \\
\text { a }\end{array}$ & $\begin{array}{l}\text { Evidencia } \\
\text { indirecta }\end{array}$ & $\begin{array}{c}\text { Imprecisió } \\
\mathrm{n}\end{array}$ & $\begin{array}{c}\text { Otras } \\
\text { consideraciones }\end{array}$ & $\begin{array}{c}\text { Grupo A } \\
\text { (Probiótico) }\end{array}$ & $\begin{array}{c}\text { Grupo B } \\
\text { (Probiótico) }\end{array}$ & $\begin{array}{c}\text { Grupo C } \\
\text { (Antibiótico) }\end{array}$ & $\left|\begin{array}{l}\text { Relativa } \\
(95 \% \mathrm{Cl})\end{array}\right|$ & $\begin{array}{l}\text { Absoluta } \\
\text { por } 1000\end{array}$ & & \\
\hline \multicolumn{14}{|c|}{ Número de unidades formadoras de colonias a los 21 días } \\
\hline 1 & ECA & $\begin{array}{l}\text { Muy } \\
\text { serio }^{1}\end{array}$ & No seria & No seria & Seria ${ }^{2}$ & Ninguna & \begin{tabular}{|c|} 
Media $=2,61$ \\
$S D= \pm 0,64$ \\
$n=124$
\end{tabular} & \begin{tabular}{|c|} 
Media $=2,33$ \\
$S D= \pm 0,90$ \\
$n=127$
\end{tabular} & \begin{tabular}{|c|} 
Media $=3,28$ \\
$S D= \pm 1,10$ \\
$n=101$
\end{tabular} & $\begin{array}{c}p^{*}<0,00 \\
1\end{array}$ & - & MUY BAJA & CRITICO \\
\hline \multicolumn{14}{|c|}{ Puntuación del dolor a los 21 días del inicio del tratamiento (extremadamente doloroso: 0 ; sin dolor: 10) } \\
\hline 1 & ECA & $\begin{array}{l}\text { Muy } \\
\text { serio }^{1}\end{array}$ & No seria & No seria & Seria ${ }^{2}$ & Ninguna & \begin{tabular}{|c|} 
Media $=8,68$ \\
$S D= \pm 1,25$ \\
$n=124$
\end{tabular} & \begin{tabular}{|c|} 
Media $=8,61$ \\
$\mathrm{SD}= \pm 1,26$ \\
$\mathrm{n}=124$
\end{tabular} & \begin{tabular}{|c|} 
Media $=5,81$ \\
$\mathrm{SD}= \pm 2,5$ \\
$\mathrm{n}=101$
\end{tabular} & $\begin{array}{c}\mathrm{p}^{*}<0,00 \\
1\end{array}$ & - & MUY BAJA & CRITICO \\
\hline \multicolumn{14}{|c|}{ Recurrencia síntomas tres meses después de que los parámetros hubieran alcanzado valores fisiológicos (no síntomas clínicos y concentración bacterias $<3$ log ${ }_{10}$ UFC/ml } \\
\hline 1 & ECA & $\begin{array}{l}\text { Muy } \\
\text { serio }^{1}\end{array}$ & No seria & No seria & Seria $^{3}$ & Ninguna & $\begin{array}{c}13 / 124 \\
(10,5 \%)\end{array}$ & \begin{tabular}{|c|}
$9 / 127$ \\
$(7,1 \%)$
\end{tabular} & $\begin{array}{c}31 / 101 \\
(30,7 \%)\end{array}$ & $\begin{array}{c}\mathrm{X}^{2}=27,0 \\
8 \\
\mathrm{p}^{*}<0,00 \\
1\end{array}$ & - & MUY BAJA & CRITICO \\
\hline \multicolumn{14}{|c|}{ Candidiasis vaginal } \\
\hline 1 & ECA & $\begin{array}{l}\text { Muy } \\
\text { serio }^{1}\end{array}$ & No seria & No seria & Seria $^{3}$ & Ninguna & 0 & 0 & $\begin{array}{l}9 / 101 \\
(8,9 \%) \\
\end{array}$ & ns & - & MUY BAJA & CRITICO \\
\hline \multicolumn{14}{|c|}{ Flatulencia } \\
\hline 1 & ECA & \begin{tabular}{|l} 
Muy \\
serio
\end{tabular} & No seria & No seria & Seria $^{3}$ & Ninguna & $\begin{array}{l}9 / 124 \\
(5,6 \%) \\
\end{array}$ & 0 & 0 & ns & - & MUY BAJA & CRITICO \\
\hline \multicolumn{14}{|c|}{ Abandono lactancia materna } \\
\hline 1 & ECA & $\begin{array}{l}\text { Muy } \\
\text { serio }^{1}\end{array}$ & No seria & No seria & Seria $^{3}$ & Ninguna & 0 & 0 & $\begin{array}{c}9 / 101 \\
(8,9 \%)\end{array}$ & ns & - & MUY BAJA & CRITICO \\
\hline
\end{tabular}

${ }_{1}^{1}$ Aleatorizado, aunque no se describe el método y doble ciego; el grupo con antibiótico, cada paciente recibe uno, dependiendo del centro de salud y no se describe el tiempo de tratamiento con antibiótico; ${ }^{2}$ Las variables número de unidades formadoras de colonias y la puntuación del dolor a los 21 no siguieron una distribución normal; ${ }^{3}$ Pocos eventos.

* Diferencias significativas entre el grupo de antibiótico con los grupos probióticos 


\subsection{Resumen de la evidencia}

\section{Pregunta 32. En madres que amamantan y presentan mastitis aguda, ¿se debería empezar de forma inmediata con tratamiento antibiótico o con vaciamiento efectivo de la mama, tratamiento antiinflamatorio y reposo?}

No hay estudios que comparen la adición temprana de tratamiento antibiótico al tratamiento conservador (tratamiento con antiinflamatorios y vaciamiento de la mama) frente a la adición tardía del mismo.

El estudio que más se acerca a esta comparación es el de Thomsen et al, 1984 (6). Y aunque en él no se utilizan (o no se reporta al menos) los antiinflamatorios, se compara el vaciamiento versus el vaciamiento junto con el tratamiento antibiótico dirigido por cultivo.

El estudio demuestra que cuando en madres que amamantan se da una inflamación no infecciosa de la mama, el vaciamiento es suficiente para tratar la condición. Sin embargo, cuando se trata de una mastitis infecciosa, la eficacia del tratamiento es mayor si se combina el vaciamiento con el tratamiento antibiótico dirigido por cultivo. Lo que no se compara es si la adición precoz de antibiótico al tratamiento conservador es más eficaz que su adición tardía en caso de fracaso del tratamiento conservador.

Los autores incluyeron 213 mujeres que presentaban síntomas inflamatorios (aumento de sensibilidad 0 dolor, inflamación y enrojecimiento o eritema, calor y disminución de secreción de leche), aunque consideran como caso a cada pecho afectado, por lo que finalmente incluyeron 339 casos. La definición de las tres entidades (estasis de leche, inflamación no infecciosa y mastitis infecciosa) se realizó teniendo en cuenta el recuento de leucocitos y el número de unidades formadoras de colonias por $\mathrm{ml}$ de la leche materna, por lo que finalmente se contabilizaron 126 casos de estasis de leche, 48 casos de inflamación no infecciosa y 165 casos de mastitis infecciosas.

En los casos de estasis e inflamación no infecciosa, las intervenciones que se compararon fueron no hacer nada frente al vaciado del pecho mediante el amamantamiento seguido de la extracción manual o mecánica para la eliminación de la leche sobrante. En el caso de las mastitis infecciosas, se comparó no hacer nada frente al vaciado del pecho mediante el amamantamiento seguido de la extracción manual o mecánica y adición de tratamiento antibiótico dirigido por estudios de sensibilidad microbiana de las bacterias aisladas en el cultivo de la leche. La eficacia de las intervenciones se midió según si la lactancia materna era o no normal y la duración de los síntomas.

En cuanto a la estasis de leche se observó que el vaciado de la mama tuvo un resultado similar a no hacer nada $(93,7 \%$ vs. $90,5 \%$; duración de 2,1 días vs. 2,3 días), mientras que en la inflamación no infecciosa la eficacia del vaciamiento fue superior a no hacer nada (Lactancia normal: 95,8\% vs. 20,8\%; Duración síntomas: 3,2 días vs. 7,9 días).

En las mastitis infecciosas, la combinación del vaciado de la mama y el tratamiento antibiótico fue lo más eficaz, encontrándose una lactancia 
normal en el $96,4 \%$ de los casos frente al $50,9 \%$ y $14,5 \%$ de los casos en los que sólo se realizó el vaciado y en los que no se hizo nada, respectivamente. La duración de los síntomas fue de 2,1 días cuando además del vaciado se añadía tratamiento antibiótico, siendo de 4,2 y 6,7 días en los otros dos grupos, respectivamente.

Los autores señalan que en las mastitis infecciosas no tratadas, se desarrollaron abscesos en el $11 \%$ de los casos, frente a ningún caso en los otros dos grupos.

En el estudio de Hager de 1996 (7), en el que se compara la eficacia del tratamiento empírico de los dos antibióticos más frecuentemente prescritos en el tratamiento de las mastitis agudas puerperales por la Sociedad de Enfermedades Infecciosas de Ginecología y Obstetricia (amoxicilina y cefradina, este último no disponible en España), a todas las pacientes se les recomendaba continuar con la lactancia y aplicar compresas húmedas calientes en la o las mamas afectadas cada cuatroseis horas. Sin embargo, no se puede saber cuál es el efecto de estas medidas, puesto que son aplicadas a todas las madres de ambos grupos.

\section{Pregunta 33. En madres que amamantan y presentan mastitis aguda, ¿es más eficaz el tratamiento con probióticos que el tratamiento con antibióticos?}

El único estudio que compara el uso de probióticos frente a antibióticos es el estudio de Arroyo et al, 2010 (8), que incluye mujeres con síntomas de mastitis aguda (presencia de inflamación de la mama, una lactancia dolorosa, un nivel de unidades formadoras de colonias (UFC) por $\mathrm{ml}$ mayor a $4 \log _{10}$ en la leche materna y de leucocitos mayor a $6 \log _{10}$ ).

El objetivo de este estudio es analizar la eficacia de la administración oral de lactobacillus (Lactobacillus fermentum y Lactobacillus salivarius) frente al tratamiento antibiótico en las mastitis infecciosas asociadas a la lactancia materna.

352 mujeres con mastitis infecciosa fueron aleatorizadas en tres grupos. Las mujeres de los grupos $A(n=124)$ y $B(n=127)$ recibieron una dosis oral diaria de $9 \log _{10}$ UFC, bien de $L$. fermentum CECT5716 o de $L$. salivarius CECT5713 durante tres semanas, mientras que las del grupo $C(n=101)$ reciben el tratamiento antibiótico de forma empírica y prescrito por su centro de salud correspondiente (no se especifica durante cuánto tiempo).

En el artículo no se señala si hubo otra intervención concomitante, como el vaciamiento adecuado del pecho. Los autores también señalan que la efectividad de los antibióticos prescritos variaba de forma significativa, tanto en la reducción del número de colonias bacterianas como en la mejora de la puntuación del dolor, y que era probable que un cambio en el antibiótico prescrito llevara a mejores resultados cuando el tratamiento era inefectivo tras los primeros días.

Se observaron diferencias estadísticamente significativas en el número de unidades formadoras de colonias (Grupo A: 2,61 $\pm 0,64$; Grupo B: $2,33 \pm 0,90$; Grupo C: $3,28 \pm 1,10$ ); $p<0,001$ ), así como en la puntuación

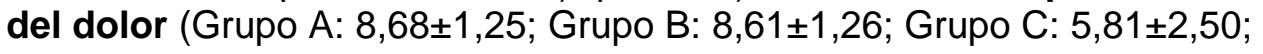

\section{Calidad baja \\ Calidad baja}

Calidad
muy baja
para todas
las


$p<0,001)$ entre las madres tratadas con probióticos y las tratadas con variables antibióticos.

Entre las madres tratadas con probióticos o antibióticos se observa que la recurrencia de los síntomas se da en un $8,8 \%$ vs. $30,7 \%$ de los casos, la candidiasis vaginal en el $0 \%$ vs. $8,9 \%$ y el abandono de la lactancia en el $0 \%$ vs, el $8,9 \%$ de los casos, aunque no se señala que las diferencias sean significativas, salvo para la recurrencia de los síntomas. En el caso de las flatulencias estas ocurren en el $3,6 \%$ vs. el $0 \%$ de los casos, respectivamente.

\section{Resultados de la actualización de la búsqueda a octubre de 2016}

En la actualización de la búsqueda realizada se han identificado dos ensayos clínicos $(9 ; 10)$, uno de los cuales ya se había identificado previamente como otra publicación (11). Así, en el único nuevo ECA doble ciego identificado se incluyen 126 madres que son tratadas durante 14 días con lanolina, menta o dexpantenol, encontrando resultados similares en cuanto a la resolución del dolor y las grietas en los tres grupos (9), por lo que las recomendaciones no se ven afectadas por los resultados de este estudio.

ACTUALIZADO A FECHA DE: 31 de Octubre de 2016 


\section{5- De la evidencia a la recomendación (Tabla de EtR)}

\section{¿Qué intervención es más eficaz en el tratamiento de la mastitis aguda?}

\section{Población:}

Intervención:

Comparación:

Perspectiva:

Pregunta 32 (C1): Antibióticos + Vaciamiento vs. Vaciamiento; Pregunta 33 (C2): Probióticos vs. Antibióticos

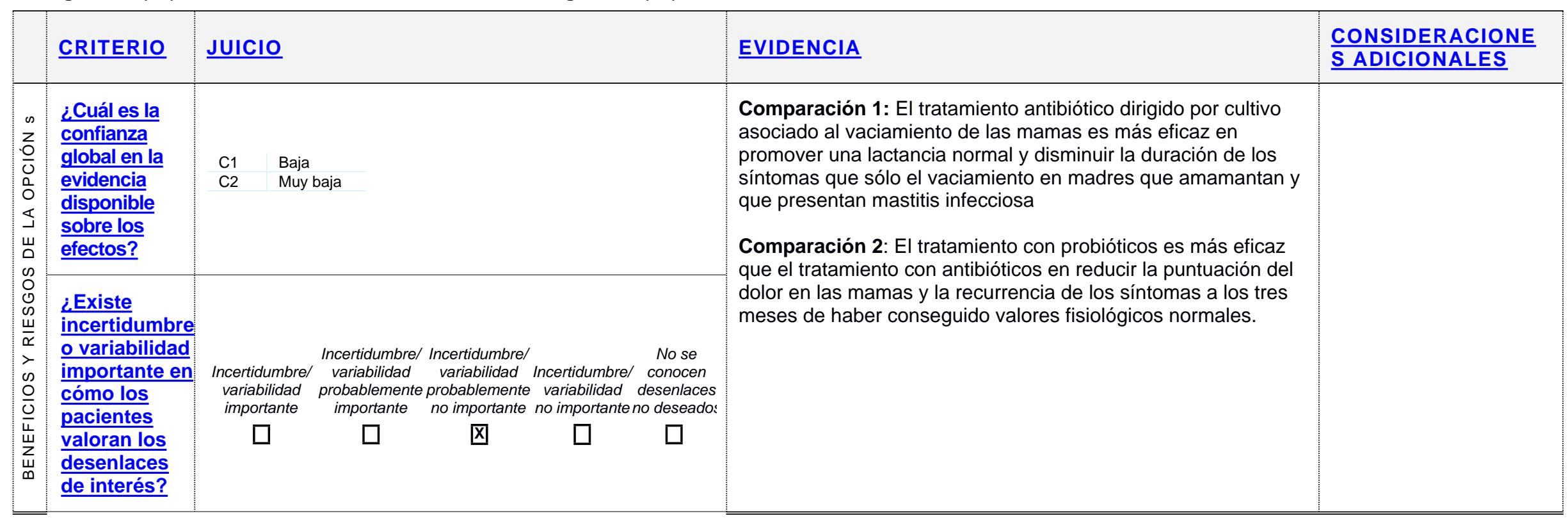




\begin{tabular}{|c|c|c|c|c|c|c|}
\hline & CRITERIO & $\underline{\text { JUICIO }}$ & & & EVIDENCIA & $\begin{array}{l}\text { CONSIDERACIONE } \\
\underline{\text { SADICIONALES }}\end{array}$ \\
\hline & \multirow{3}{*}{$\begin{array}{l}\frac{\text { ¿Los efectos }}{\text { deseados }} \\
\text { esperados } \\
\text { importantes? }\end{array}$} & \multicolumn{3}{|c|}{ C1: Antibiótico y vaciamiento vs. Antibiótico } & & \\
\hline & & $\begin{array}{l}\text { No Probablemente no Incierto } \\
\square \quad \square \quad \square\end{array}$ & $\left.\begin{array}{cc}\text { Pobablemente si } & \text { Si } \\
\square & \square\end{array}\right]$ & $\frac{\text { Varía }}{\square}$ & & \\
\hline & & $\begin{array}{l}\text { No Probablemente no Incierto } \\
\square\end{array} \square \quad \square$ & $\begin{array}{cc}\text { Pobablemente si } & \text { Si } \\
\square & \square\end{array}$ & $\begin{array}{r}\text { Varía } \\
\square\end{array}$ & & \\
\hline \multirow{3}{*}{\multicolumn{2}{|c|}{$\begin{array}{l}\frac{\text { ¿Los }}{\text { efectos no }} \\
\frac{\text { deseados }}{\text { esperados }} \\
\text { son } \\
\text { pequeños? }\end{array}$}} & \multicolumn{3}{|c|}{ C1: Antibiótico y vaciamiento vs. Antibiótico } & & \\
\hline & & 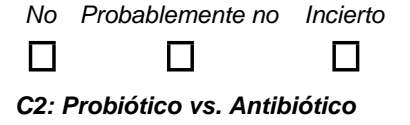 & $\begin{array}{cc}\text { Pobablemente sí } & \text { Sí } \\
\text { 冈 } & \square\end{array}$ & $\frac{\frac{\text { Varia }}{\square}}{\square}$ & & \\
\hline & & $\begin{array}{ll}\text { No } & \text { Probablemente no Incierto } \\
\square & \square\end{array} \square$ & $\begin{array}{cc}\text { Pobablementesi } & \text { Si } \\
\text { ख } & \square\end{array}$ & $\begin{array}{r}\text { Varía } \\
\square\end{array}$ & & \\
\hline & \multirow{3}{*}{$\begin{array}{l}\text { ¿El balance } \\
\text { entre los } \\
\text { efectos } \\
\text { deseados y } \\
\text { no } \\
\text { deseados } \\
\text { favorece la } \\
\text { opción? }\end{array}$} & \multicolumn{3}{|c|}{ C1: Antibiótico y vaciamiento vs. Antibiótico } & & \\
\hline & & $\begin{array}{l}\text { No Probablemente no Incierto } \\
\square \square \square \\
\text { C2: Probiótico vs. Antibiótico }\end{array}$ & $\begin{array}{cc}\text { Pobablemente si } & \text { Sí } \\
\text { 冈 } & \square\end{array}$ & $\frac{\text { Varía }}{\square}$ & & \\
\hline & & $\begin{array}{l}\text { No } \\
\square \text { Probablemente no Incierto }\end{array}$ & $\begin{array}{cc}\text { Pobablemente sí } & \text { Sí } \\
\square & \square\end{array}$ & $\begin{array}{c}\text { Varía } \\
\square\end{array}$ & & \\
\hline \multirow{5}{*}{ 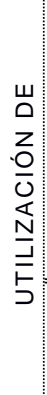 } & \multirow{3}{*}{$\begin{array}{l}\frac{\text { ¿Los }}{\text { recursos }} \\
\text { que se } \\
\text { requieren } \\
\text { son bajos? }\end{array}$} & \multicolumn{3}{|c|}{ C1: Antibiótico y vaciamiento vs. Antibiótico } & & \\
\hline & & $\begin{array}{l}\text { No Probablemente no Incierto } \\
\square \quad \square \quad \square \\
\text { C2: Probiótico vs. Antibiótico }\end{array}$ & $\begin{array}{cc}\text { Pobablemente sí } & \text { Sí } \\
\text { 冈 } & \square\end{array}$ & $\frac{\text { Varía }}{\square}$ & & \\
\hline & & $\begin{array}{lcc}\text { No } & \text { Probablemente no } & \text { Incierto } \\
\square & \square & \square\end{array}$ & \begin{tabular}{cc} 
Pobablemente si & Si \\
\} $&{\square}$ & $\begin{array}{c}\text { Varía } \\
\square\end{array}$ & & \\
\hline & \multirow{2}{*}{$\frac{\text { ¿El coste }}{\text { increment }}$} & \multicolumn{3}{|c|}{ C1: Antibiótico y vaciamiento vs. Antibiótico } & & \\
\hline & & No Probablemente no Incierto & Pobablemente si Sí & Varía & & \\
\hline
\end{tabular}
\end{tabular}




\begin{tabular}{|c|c|c|c|c|c|}
\hline CRITERIO & $\underline{\text { JUICIO }}$ & & & EVIDENCIA & $\begin{array}{l}\text { CONSIDERACIONE } \\
\underline{\text { SADICIONALES }}\end{array}$ \\
\hline \multirow{2}{*}{$\begin{array}{l}\frac{\text { al es }}{\text { pequeño }} \\
\frac{\text { en }}{\text { relación a }} \\
\frac{\text { los }}{\text { beneficios }} \\
\text { netos? }\end{array}$} & $\begin{array}{lll}\square & \square & \square \\
\text { C2: Probiótico vs. Antibiótico }\end{array}$ & ఐ $\square$ & $\square$ & & \\
\hline & No Probablemente no Incierto & $\begin{array}{cc}\text { Pobablemente sí sí } \\
\square & \square\end{array}$ & $\begin{array}{r}\text { Varía } \\
\square\end{array}$ & & \\
\hline
\end{tabular}

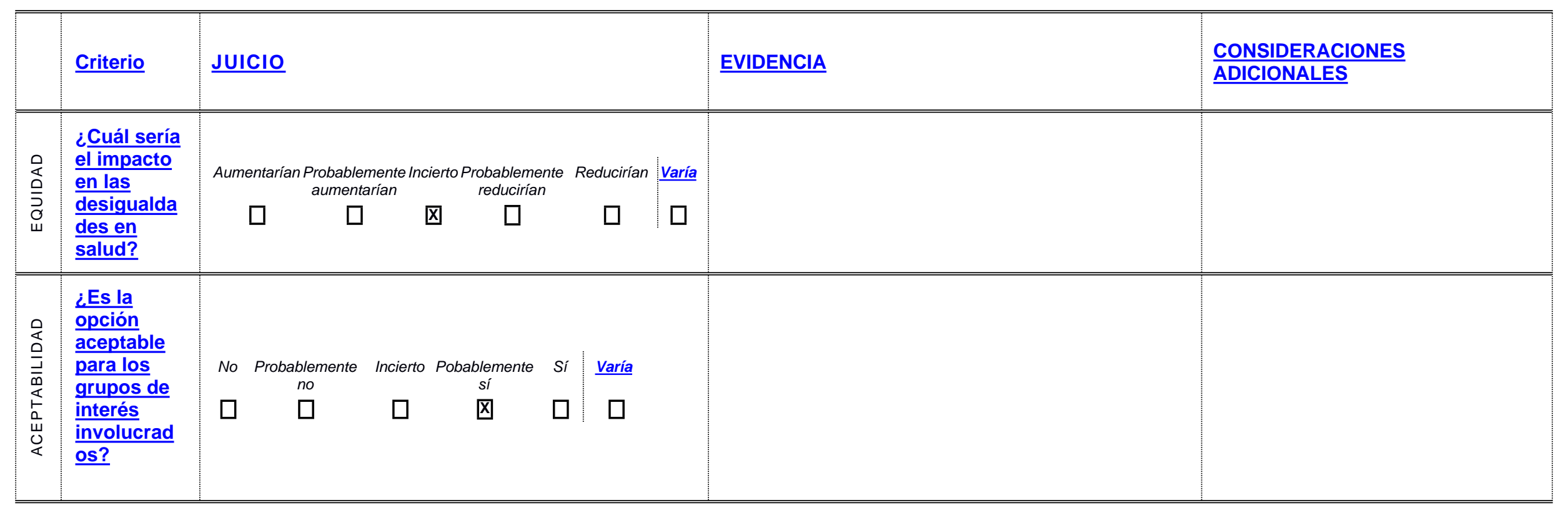




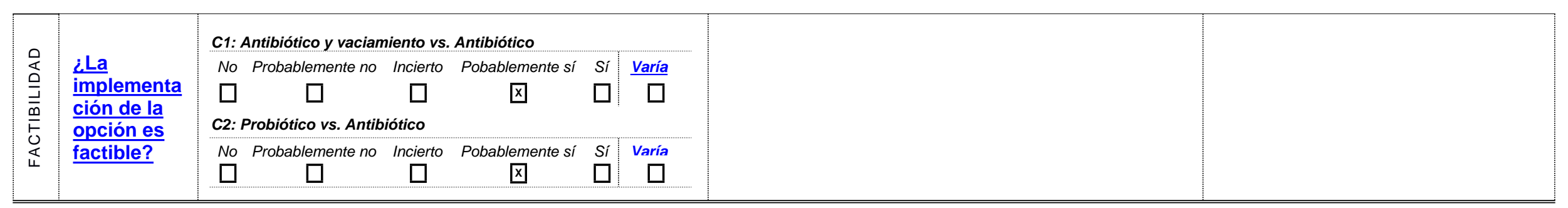

\begin{tabular}{|c|c|c|c|c|c|}
\hline $\begin{array}{l}\text { Balance de las } \\
\text { consecuencias }\end{array}$ & $\begin{array}{l}\text { Las consecuencias no } \\
\text { deseadas superan } \\
\text { claramente las } \\
\text { consecuencias deseadas } \\
\text { en la mayoría de los } \\
\text { escenarios }\end{array}$ & $\begin{array}{l}\text { Las consecuencias no } \\
\text { deseadas probablemente } \\
\text { superan las } \\
\text { consecuencias deseadas } \\
\text { en la mayoría de los } \\
\text { escenarios }\end{array}$ & $\begin{array}{c}\text { El balance entre las } \\
\text { consecuencias deseadas y } \\
\text { no deseadas está muy } \\
\text { equilibrado o es incierto }\end{array}$ & $\begin{array}{l}\text { Las consecuencias } \\
\text { deseadas } \\
\text { probablemente superan } \\
\text { las consecuencias no } \\
\text { deseadas en la mayoría } \\
\text { de los escenarios }\end{array}$ & $\begin{array}{c}\text { Las consecuencias } \\
\text { deseadas claramente } \\
\text { superan las } \\
\text { consecuencias no } \\
\text { deseadas en la mayoría } \\
\text { de los escenarios }\end{array}$ \\
\hline C1 & $\square$ & $\square$ & $\square$ & 凶 & $\square$ \\
\hline C2 & $\square$ & $\square$ & 凶 & $\square$ & $\square$ \\
\hline C1 & \multicolumn{2}{|l|}{$\square$} & $\square$ & 囚 & $\square$ \\
\hline C2 & \multicolumn{2}{|l|}{$\square$} & $\square$ & $\square$ & $\square$ \\
\hline
\end{tabular}




\section{Recomendación}

\section{(Texto)}

\begin{abstract}
Recomendación débil a favor
Se sugiere mantener la lactancia materna y el vaciado adecuado del pecho mediante extracción de la leche restante como tratamiento inicial (durante las primeras 24 horas) para el manejo de las mastitis agudas con síntomas leves. Transcurridas esas
\end{abstract} horas se debe valorar la evolución del cuadro

\section{Recomendación débil a favor}

Se sugiere la adición de tratamiento antibiótico si no ha habido respuesta al tratamiento inicial durante las primeras 24 horas y mantener el amamantamiento y el vaciado adecuado del pecho.

\section{Recomendación de buena práctica}

En caso de sospecha de mastitis aguda infecciosa (presencia de síntomas como edema, inflamación, calor, aumento de sensibilidad o dolor, malestar general, fiebre mayor a $38,5^{\circ} \mathrm{C}$ y síntomas generales como escalofríos, dolor de cabeza, náuseas o vómitos) se debería valorar el inicio precoz del tratamiento antibiótico, manteniendo la lactancia y el vaciado adecuado del pecho.

La aplicación de calor local con agua tibia antes de realizar una toma puede facilitar el flujo de la leche, y la aplicación de frío entre tomas puede ser útil por su efecto antiinflamatorio.

Se aconseja tomar analgésicos compatibles con la lactancia materna, como paracetamol e ibuprofeno, hacer reposo y aumentar la ingesta de fluidos.

Se debe realizar una reevaluación a las 48-72 horas para comprobar la respuesta al tratamiento, puesto que la adición empírica de un antibiótico no garantiza la resolución del cuadro. 
$\underline{\text { Justificación }}$

El estudio de Thomsen et al, 1984, define como mastitis infecciosa la presencia y persistencia de sensibilidad, inflamación, enrojecimiento, calor y disminución en la producción de leche, así como un nivel de leucocitos superior a $10^{6}$ leucocitos y $10^{3}$ bacterias por $\mathrm{ml}$ de leche materna. En este estudio se señala que la adición de tratamiento antibiótico al vaciado de las mamas mejora la resolución de los síntomas, aunque para ello esperan a tener el resultado del cultivo realizado a los 5 días de inicio del estudio. En nuestro caso, se considera que la sospecha de infección es mayor cuanto peor es el estado general de la mujer o más graves son los síntomas que presenta (síntomas más graves que los que presentan las madres del estudio de Thomsen), por lo que se considera que en estos casos puede ser más conveniente valorar el inicio de tratamiento antibiótico sin esperar a ver si sólo con el vaciamiento del pecho se consigue mejorar el cuadro.

La evidencia que apoya el uso de probióticos para el tratamiento de mastitis aguda es de muy baja calidad, por lo que no se hacen recomendaciones en relación al uso de probióticos en el tratamiento de las mastitis agudas.

\section{Consideraciones de}

subgrupos

Consideraciones para Creación de consultas de lactancia atendidas por profesionales especializados en lactancia materna.

la implementación

\section{Monitorización y}

\section{evaluación}

Prioridades para la investigación
- Se necesitan estudios de mayor calidad metodológica que estudien la eficacia del tratamiento antibiótico en el manejo de las mastitis agudas (tanto de forma empírica como dirigido por los resultados de los cultivos).

- Se necesitan estudios que describan el efecto de los analgésicos sobre la resolución de los síntomas de las mastitis agudas.

- Se necesitan estudios de calidad que comparen el uso de probióticos frente al tratamiento con antibióticos según los resultados de los cultivos para ver si realmente las diferencias observadas por el estudio de Arroyo et al, 2010 se deben a la mayor eficacia de los probióticos o al tratamiento empírico con los antibióticos. 
GPC Lactancia Materna - Preguntas 32 y 33. Tratamiento mastitis aguda

\section{ANEXOS}

Anexo I. Estrategias de búsqueda

Anexo II. Valoración de la calidad de los estudios

Anexo III. Tablas de estudios individuales 


\section{ANEXO I. ESTRATEGIAS DE BÚSQUEDA}

\section{Cochrane Library}

Searched 29/07/2015

\section{Updated search 29/07/2015 a xx/xx/xxxx}

\#1 mastodynia or mastodynias or mammalgia or mammalgias or mastalgia or mastalgias:ti,ab,kw or mastitis or "breast pain":ti,ab,kw (Word variations have been searched) 531

\#2 lactation or lactating:ti,ab,kw or breastfeeding or "breast feeding":ti,ab,kw or nursing or puerperal:ti,ab,kw (Word variations have been searched) 26807

\#3 \#1 and \#2 78

\#4 anti-bacterial or antibacterial or antibiotic or antibiotics or bacteriocidal or bacteriocides or anti-mycobacterial or antimycobacterial:ti,ab,kw (Word variations have been searched) 22232

\#5 probiotic or probiotics:ti,ab,kw (Word variations have been searched) 2328

\#6 anti-inflammatory or antiinflammatory or anti-inflammatories or antiinflammatories or paracetamol or acetaminophen or acetaminophenol or acetominophen or acetominophenol or acephen or acetaco or tylenol or anacin or datril or panadol or acamol or algotropyl or hydroxyacetanilide or acetamidophenol or ibuprofen or ibumetin:ti,ab,kw (Word variations have been searched) 23318

\#7 \#4 or \#5 or \#6 46653

\#8 \#3 and \#7 18

RS 2

Medline, via Pubmed

Searched 29/07/2015

Updated search 29/07/2015 a xx/xx/xxxx

\#1 Search ((mastitis[Title/Abstract]) OR "breast pain"[Title/Abstract]) OR (mastodynia[Title/Abstract] OR mastodynias[Title/Abstract] OR mammalgia[Title/Abstract] OR mammalgias[Title/Abstract] OR mastalgias[Title/Abstract] OR mastalgia[Title/Abstract]) 10950

\#2 Search (((lactation[Title/Abstract] OR lactating[Title/Abstract])) OR (breastfeeding[Title/Abstract] OR "breast feeding"[Title/Abstract])) OR (nursing[Title/Abstract] OR puerperal[Title/Abstract]) 279193

\#3 Search \#1 AND \#2 2555

\#4 Search (anti-bacterial[Title/Abstract] OR antibacterial[Title/Abstract] OR antibiotic[Title/Abstract] OR antibiotics[Title/Abstract] OR bacteriocidal[Title/Abstract] OR bacteriocides[Title/Abstract] OR antimycobacterial[Title/Abstract] OR antimycobacterial[Title/Abstract]) 298588

\#5 Search (probiotic[Title/Abstract] OR probiotics[Title/Abstract]) 12557

\#6 Search (anti-inflammatory[Title/Abstract] OR antiinflammatory[Title/Abstract] OR anti-inflammatories[Title/Abstract] OR antiinflammatories[Title/Abstract] OR paracetamol[Title/Abstract] OR acetaminophen[Title/Abstract] OR acetaminophenol[Title/Abstract] OR acetominophen[Title/Abstract] OR acetominophenol[Title/Abstract] OR acephen[Title/Abstract] OR acetaco[Title/Abstract] OR 
tylenol[Title/Abstract] OR anacin[Title/Abstract] OR datril[Title/Abstract] OR panadol[Title/Abstract] OR acamol[Title/Abstract] OR algotropyl[Title/Abstract] OR hydroxyacetanilide[Title/Abstract] OR acetamidophenol[Title/Abstract] OR ibuprofen[Title/Abstract] OR ibumetin[Title/Abstract]) 138070

\#7 $\quad$ Search \#4 OR \#5 OR \#6 441071

\#8 Search \#3 AND \#7 404

\#9 Search \#8 Filters: Humans 115

\section{Embase, vía OvidWeb}

Searched 29/07/2015

Updated search 29/07/2015 a xx/xx/xxxx

$1 \quad$ (mastitis or "breast pain").ti,ab,kw. 11765

2 (mastodynia or mastodynias or mammalgia or mammalgias or matalgia or mastalgias).ti,ab,kw. 328

31 or 212062

4 (lactation or lactating or breastfeeding or "breast feeding" or nursing or puerperal).ti,ab,kw. 313199

$5 \quad 3$ and $4 \quad 2764$

6 (anti-bacterial or antibacterial or antibiotic or antibiotics or bacteriocidal or bacteriocides or anti-mycobacterial or antimycobacterial).ti,ab,kw. 412023

7 (probiotic or probiotics).ti,ab,kw. 17219

8 (anti-inflammatory or antiinflammatory or anti-inflammatories or antiinflammatories or paracetamol or acetaminophen or acetaminophenol or acetominophen or acetominophenol or acephen or acetaco or tylenol or anacin or datril or panadol or acamol or algotropyl or hydroxyacetanilide or acetamidophenol or ibuprofen or ibumetin).ti,ab,kw. 196460

96 or 7 or 8613233

$10 \quad 5$ and $9 \quad 459$

11 limit 10 to human $\mathbf{1 5 1}$

Cinahl, vía EbscoHost

Searched 29/07/2015

Updated search 29/07/2015 a xx/xx/xxxx

S1 TI mastitis OR AB mastitis 230

S2 TI "breast pain" OR AB "breast pain" 153

S3 TI ( mastodynia or mastodynias or mammalgia or mammalgias or mastalgia or mastalgias ) OR AB ( mastodynia or mastodynias or mammalgia or mammalgias or mastalgia or mastalgias ) $\quad 60$

S4 S1 OR S2 OR S3 412

S5 TI ( lactation OR lactating ) OR AB ( lactation OR lactating ) 2104

S6 TI ( breastfeeding OR "breast feeding") OR AB (breastfeeding OR "breast feeding" ) 9256

S7 TI ( nursing OR puerperal ) OR AB ( nursing OR puerperal ) 190618

S8 S5 OR S6 OR S7 200408

S9 S3 AND S7 118 
S10 TI ( anti-bacterial OR antibacterial OR antibiotic OR antibiotics OR bacteriocidal $O R$ bacteriocides $O R$ anti-mycobacterial OR antimycobacterial ) OR AB ( anti-bacterial OR antibacterial OR antibiotic OR antibiotics OR bacteriocidal OR bacteriocides OR anti-mycobacterial OR antimycobacterial ) 18147

S11 TI ( probiotic OR probiotics ) OR AB ( probiotic OR probiotics ) 1544

S12 TI ( anti-inflammatory OR antiinflammatory OR anti-inflammatories OR antiinflammatories $\mathrm{OR}$ paracetamol $\mathrm{OR}$ acetaminophen $\mathrm{OR}$ acetaminophenol OR acetominophen OR acetominophenol OR acephen OR acetaco OR tylenol OR anacin OR datril OR panadol OR acamol OR algotropyl OR hydroxyacetanilide OR acetamidophenol OR ibuprofen OR ibumetin ) OR AB ( anti-inflammatory OR antiinflammatory $O R$ antiinflammatories OR antiinflammatories $O R$ paracetamol $O R$ acetaminophen OR acetaminophenol OR acetominophen OR acetominophenol OR acephen OR acetaco OR tylenol OR anacin OR datril OR panadol OR acamol OR algotropyl OR hydroxyacetanilide OR acetamidophenol OR ibuprofen OR ibumetin ) 10098

S13 S10 OR S11 OR S12 29130

S14 S9 AND S13 20 


\section{ANEXO II. EVALUACIÓN DE LA CALIDAD DE LOS ESTUDIOS}

\section{Revisiones sistemáticas - AMSTAR}

\begin{tabular}{|c|c|}
\hline AMSTAR & $\begin{array}{l}\text { Jahanfar } \\
2013\end{array}$ \\
\hline $\begin{array}{l}\text { 1. ¿Se brindó un diseño “a priori”? } \\
\text { La pregunta de la investigación y los criterios de inclusión deberían establecerse } \\
\text { antes de llevar a cabo la revisión }\end{array}$ & $\mathrm{Si}$ \\
\hline $\begin{array}{l}\text { 2. ¿Hubo duplicación en la selección de estudios y extracción de datos? } \\
\text { Debería haber al menos dos personas independientes a cargo de la extracción de } \\
\text { datos, y debería existir un procedimiento consensuado para los desacuerdos }\end{array}$ & $\mathrm{Si}$ \\
\hline $\begin{array}{l}\text { 3. ¿Se realizó una búsqueda exhaustiva de literatura? } \\
\text { Deberían consultarse al menos dos fuentes electrónicas. El informe debe incluir los } \\
\text { años y las bases de datos utilizadas (por ej. Central, EMBASE y MEDLINE). Deben } \\
\text { especificarse las palabras clave y/o los términos MESH y, de ser posible, debe } \\
\text { proveerse la estrategia de búsqueda. Todas las búsquedas deberían ser } \\
\text { complementadas con consultas a contenidos actuales, revisiones, libros de textos, } \\
\text { registros especializados, o expertos en el campo particular de estudio, y mediante la } \\
\text { revisión de las referencias en los estudios encontrados }\end{array}$ & $\mathrm{Si}$ \\
\hline $\begin{array}{l}\text { 4. ¿Se utilizó el estado de publicación (es decir, literatura gris) como criterio de } \\
\text { inclusión? } \\
\text { Los autores deberían especificar que buscaron informes sin tener en cuenta el tipo de } \\
\text { publicación. Los autores deberían especificar si excluyeron o no algún informe (de la } \\
\text { revisión sistemática), en función del estado de publicación, idioma, etc. }\end{array}$ & $\mathrm{Si}$ \\
\hline $\begin{array}{l}\text { 5. ¿Se brindó una lista de estudios (incluidos y excluidos)? } \\
\text { Debería proveerse una lista de estudios incluidos y excluidos }\end{array}$ & $\mathrm{Si}$ \\
\hline $\begin{array}{l}\text { 6. ¿Se brindaron las características de los estudios incluidos? } \\
\text { De manera adjunta tal como una tabla, deberían proveerse los datos de los estudios } \\
\text { originales sobre los participantes, las intervenciones y los resultados. Deberían } \\
\text { informarse los rangos de las características en todos los estudios analizados, por ej, } \\
\text { la edad, la raza, el sexo, los datos socioeconómicos relevantes, el estado de } \\
\text { enfermedad, la duración, la severidad, o cualquier otra enfermedad }\end{array}$ & $\mathrm{Si}$ \\
\hline $\begin{array}{l}\text { 7. ¿Se evaluó y documentó la calidad científica de los estudios incluidos? } \\
\text { Deberían proveerse métodos "a priori" (por ej, para estudios de efectividad si el autor } \\
\text { o los autores eligen incluir sólo estudios aleatorizados, de doble ciego, controlados } \\
\text { con placebo, u ocultamiento de las asignaciones como criterios de inclusión). Para } \\
\text { otros tipos de estudios, serán relevantes los ítems alternativos }\end{array}$ & $\mathrm{Si}$ \\
\hline $\begin{array}{l}\text { 8. ¿Se utilizó de manera adecuada la calidad científica de los estudios incluidos } \\
\text { al formular las conclusiones? } \\
\text { El rigor metodológico y la calidad científica de los estudios deberían considerarse en } \\
\text { el análisis y las conclusiones de la revisión, y plantearse explícitamente al formular } \\
\text { las recomendaciones }\end{array}$ & $\mathrm{Si}$ \\
\hline $\begin{array}{l}\text { 9. ¿Fueron adecuados los métodos utilizados para combinar los hallazgos de } \\
\text { los estudios? } \\
\text { Para los resultados conjuntos, debería hacerse una prueba para garantizar que los } \\
\text { estudios pudieron combinarse y para evaluar sus homogeneidad (es decir, la prueba } \\
\text { chi-cuadrado para la homogeneidad, }\left.\right|^{2} \text { ). Si existe heterogeneidad debería utilizarse } \\
\text { un modelo de efectos aleatorios y/o debería considerarse lo adecuado de la } \\
\text { combinación (es decir, ¿fue adecuado combinar los resultados?) }\end{array}$ & $\mathrm{Si}$ \\
\hline $\begin{array}{l}\text { 10. ¿Se valoró la probabilidad de sesgo de publicación? } \\
\text { Una evaluación de sesgo de publicación debería incluir una combinación de ayudas } \\
\text { gráficas (por ej. un gráfico en embudo - funnel plot - , otras pruebas disponibles) y/o } \\
\text { pruebas estadísticas (por ej. prueba de regresión de Egger) }\end{array}$ & Sí \\
\hline $\begin{array}{l}\text { 11. ¿Se planteó el conflicto de intereses? } \\
\text { Deberían reconocerse claramente las fuentes posibles de apoyo tanto en la revisión } \\
\text { sistemática como en los estudios incluidos }\end{array}$ & $\mathrm{Si}$ \\
\hline
\end{tabular}




\section{ECAs - Risk of bias - Cochrane}

\section{Riesgo de sesgo de los estudios incluidos en la Comparación 1 (de la Revisión Cochrane de Jahanfar 2013}

Risk of bias summary: review authors' judgements about each risk of bias item for each included study. (Jahanfar 2013)

\section{Thomsen et al, 1984}

\begin{tabular}{|c|c|c|}
\hline \multicolumn{3}{|l|}{ Risk of bias } \\
\hline Bias & Authors' judgement & Support for judgement \\
\hline $\begin{array}{l}\text { Random sequence generation (selection } \\
\text { bias) }\end{array}$ & Unclear risk & Method is not mentioned. \\
\hline Allocation concealment (selection bias) & Unclear risk & $\begin{array}{l}\text { Antibiotic therapy was rather directed by } \\
\text { susceptibility tests of the isolated bacteria }\end{array}$ \\
\hline $\begin{array}{l}\text { Blinding (performance bias and detection } \\
\text { bias) } \\
\text { All outcomes }\end{array}$ & High risk & $\begin{array}{l}\text { It is unclear whether women or outcome } \\
\text { assessors were blinded }\end{array}$ \\
\hline $\begin{array}{l}\text { Incomplete outcome data (attrition bias) } \\
\text { All outcomes }\end{array}$ & Unclear risk & $\begin{array}{l}\text { Follow-up is not described clearly. From the } \\
\text { definition of bad outcome it can be implied } \\
\text { that patients were visited } 2 \text { weeks after the } \\
\text { attack. There is no report of drop-outs or } \\
\text { for any of the subgroups }\end{array}$ \\
\hline Selective reporting (reporting bias) & Unclear risk & $\begin{array}{l}\text { Unclear from study report. No study pro- } \\
\text { tocol. }\end{array}$ \\
\hline Other bias & Unclear risk & No baseline characteristics table. \\
\hline
\end{tabular}

\section{Hager et al, 1996}

\begin{tabular}{lll}
\hline Risk of bias & & \\
\hline Bias & Authors' judgement & Support for judgement \\
\hline $\begin{array}{l}\text { Random sequence generation (selection } \\
\text { bias) }\end{array}$ & Unclear risk & Method is not mentioned. \\
\hline $\begin{array}{l}\text { Allocation concealment (selection bias) } \\
\text { Alinding (performance bias and detection }\end{array}$ & Low risk & $\begin{array}{l}\text { Adequate concealment of allocation is } \\
\text { mentioned inclusive of using pre-sealed, } \\
\text { opaque envelopes }\end{array}$ \\
\hline $\begin{array}{l}\text { All outcomes } \\
\text { Ancomplete outcome data (attrition bias) } \\
\text { All outcomes }\end{array}$ & Low risk & $\begin{array}{l}\text { It was mentioned that investigators were } \\
\text { blinded. }\end{array}$ \\
\hline Selective reporting (reporting bias) & Low risk & $\begin{array}{l}\text { Follow-up is described. Patients were seen } \\
\text { for follow-up visits in 7 days. } \\
25 \text { recruited and no drop-outs. }\end{array}$ \\
\hline Other bias & Low risk & $\begin{array}{l}\text { All expected outcomes appear to have been } \\
\text { reported. }\end{array}$ \\
\hline & & $\begin{array}{l}\text { Groups appear balanced for baseline char- } \\
\text { acteristics (apart from duration of symp- } \\
\text { toms - see Table 1, page 99) }\end{array}$ \\
\hline
\end{tabular}


Riesgo de sesgo estudios Comparación 2 (low unclear high

\begin{tabular}{|c|c|c|c|c|c|c|}
\hline $\begin{array}{l}\text { Referencia } \\
\text { (Cita Abreviada) }\end{array}$ & $\begin{array}{l}\text { Random sequence } \\
\text { generation (selection } \\
\text { bias) }\end{array}$ & $\begin{array}{l}\text { Allocation conceallement } \\
\text { (selection bias) }\end{array}$ & $\begin{array}{l}\text { Blinding (performance } \\
\text { bias and detection } \\
\text { bias) } \\
\text { All outcomes }\end{array}$ & $\begin{array}{l}\text { Incomplete outcome data } \\
\text { (attrition bias) } \\
\text { All outcomes }\end{array}$ & $\begin{array}{l}\text { Selective reporting } \\
\text { (reporting bias) }\end{array}$ & Other bias \\
\hline Arroyo et al, 2010 & $\begin{array}{l}\text { Poco claro } \\
\text { "Volunteers were randomly } \\
\text { assigned to three } \\
\text { groups..." }\end{array}$ & Poco claro & $\begin{array}{l}\text { Bajo riesgo } \\
\text { "neither the volunteers } \\
\text { nor the investigators } \\
\text { knew the assignments } \\
\text { during the study period" }\end{array}$ & Poco claro/ Riesgo bajo & $\begin{array}{l}\text { Riesgo poco } \\
\text { claro/Bajo riesgo }\end{array}$ & $\begin{array}{l}\text { Riesgo alto } \\
\text { No se sabe cuál es la pauta } \\
\text { de antibióticos con la que } \\
\text { se trata al grupo que los } \\
\text { recibe. }\end{array}$ \\
\hline
\end{tabular}




\section{ANEXO III. Tabla de estudios individuales}

Tabla de estudios para la pregunta 1

\begin{tabular}{|c|c|c|c|c|c|c|}
\hline Referencia & Estudio & Población & $\begin{array}{l}\text { Descripción de las } \\
\text { intervenciones } \\
\text { comparaciones, exposiciones o } \\
\text { pruebas a estudio }\end{array}$ & Resultados & Conclusiones & Comentarios \\
\hline $\begin{array}{l}\text { Thomsen } \\
\text { et al, } 1984\end{array}$ & $\begin{array}{l}\text { ECA } \\
\text { Objetivo: } \\
\text { estimar la } \\
\text { duración y el } \\
\text { resultado de la } \\
\text { estasis de leche, } \\
\text { inflamación no } \\
\text { infecciosa y } \\
\text { mastitis } \\
\text { infecciosa en } \\
\text { mujeres } \\
\text { lactantes. } \\
\text { Además se } \\
\text { estudiaron la } \\
\text { necesidad de } \\
\text { intervenir y los } \\
\text { resultados de los } \\
\text { tratamientos } \\
\text { comúnmente } \\
\text { utilizados. }\end{array}$ & $\begin{array}{l}213 \text { mujeres que } \\
\text { amamantan con } \\
\text { diagnóstico de mastitis } \\
\text { infecciosa (el caso se } \\
\text { define como cada } \\
\text { pecho afectado, no } \\
\text { cada mujer). } \\
\text { Diagnóstico realizado } \\
\text { por síntomas clínicos, } \\
\text { niveles de leucocitos y } \\
\text { cultivos de bacterias. } \\
\text { Había } 3 \text { grupos. Un } \\
\text { grupo incluía las estasis } \\
\text { de leche, el grupo } 2 \text { la } \\
\text { mastitis no infecciosa y } \\
\text { el tercero } 165 \text { mamas } \\
\text { con mastitis infecciosa } \\
\text { probada (>106 } \\
\text { leucocitos y } 103 \\
\text { bacterias). } \\
\text { No se dan las } \\
\text { características basales } \\
\text { de las participantes. }\end{array}$ & $\begin{array}{l}\text { El grupo final de mastitis infecciosa } \\
\text { (165 casos) se divide en tres } \\
\text { grupos de } 55 \text { casos de forma } \\
\text { aleatoria: } \\
\text {-Grupo sin tratamiento } \\
\text {-Tratamiento estándar } \\
\text {-Tratamiento estándar + antibiótico } \\
\text { El tratamiento estándar consiste en } \\
\text { el vaciamiento de la mama: cada } 6 \\
\text { horas se recomienda vaciar el } \\
\text { pecho mediante el } \\
\text { amamantamiento seguido de la } \\
\text { extracción de la leche de forma } \\
\text { manual o mediante succión } \\
\text { mecánica. } \\
\text { El tratamiento con antibiótico podía } \\
\text { ser: penicilina } 500.000 \text { IU } 3 \text { por día } \\
\text { durante } 6 \text { días, ampicilina oral } 500 \\
\text { mg, } 4 \text { veces al día por } 6 \text { días o } \\
\text { eritromicina } 500 \text { mg dos veces al } \\
\text { día durante } 6 \text { días. En el grupo } \\
\text { control, se realiza el vaciamiento } \\
\text { del pecho cada } 6 \text { horas } \\
\text { amamantando al bebé y seguido } \\
\text { de la extracción manual o por } \\
\text { succión mecánica de la leche } \\
\text { restante. }\end{array}$ & $\begin{array}{l}\text { Se considera como bueno si los } \\
\text { síntomas de mastitis desaparecen } \\
\text { seguidos de una lactancia normal } \\
\text { durante las } 2 \text { semanas tras el inicio del } \\
\text { episodio. }\end{array}$ & $\begin{array}{l}\text { En consecuencia, se } \\
\text { sugiere que se deberían } \\
\text { obtener muestras de } \\
\text { leche de mujeres que } \\
\text { amamantan y que } \\
\text { presentan síntomas } \\
\text { inflamatorios en las } \\
\text { mamas. Se deberían } \\
\text { realizar recuentos de } \\
\text { bacterias en la leche y } \\
\text { test de susceptibilidad a } \\
\text { antibióticos. En el único } \\
\text { caso que se recomienda } \\
\text { el tratamiento antibiótico } \\
\text { (junto con el vaciamiento } \\
\text { del pecho) es en la } \\
\text { mastitis infecciosa. }\end{array}$ & $\begin{array}{l}\text { No se menciona el } \\
\text { método de } \\
\text { aleatorización, el } \\
\text { tratamiento } \\
\text { antibiótico fue dirigido } \\
\text { por test de } \\
\text { susceptibilidad a las } \\
\text { bacterias aisladas. } \\
\text { No está claro el } \\
\text { cegamiento y el } \\
\text { seguimiento no está } \\
\text { claramente descrito. } \\
\text { No se reportan las } \\
\text { pérdidas para } \\
\text { ninguno de los } \\
\text { subgrupos. }\end{array}$ \\
\hline
\end{tabular}




\begin{tabular}{|c|c|c|c|c|c|}
\hline & $\begin{array}{l}\text { ECA } \\
\text { Objetivo: } \\
\text { comparar la } \\
\text { eficacia de la } \\
\text { amoxicilina y la } \\
\text { cefradina para el } \\
\text { tratamiento de } \\
\text { mastitis puerperal } \\
\text { aguda y } \\
\text { esporádica y } \\
\text { evaluar los } \\
\text { parámetros } \\
\text { clínicos y } \\
\text { microbiológicos } \\
\text { de esta infección. }\end{array}$ & $\begin{array}{l}25 \text { mujeres que } \\
\text { amamantan con } \\
\text { mastitis aguda } \\
\text { puerperal esporádica. } \\
\text { Criterios de inclusión: } \\
\text { tempreratura oral de } \\
37,56^{\circ} \mathrm{C} \text {, sensibilidad al } \\
\text { palpar la mama y } \\
\text { "segmental erythema". } \\
\text { Criterios basales de los } \\
\text { grupos similares. }\end{array}$ & $\begin{array}{l}\text { Tratamiento: amoxicilina oral } \\
500 \mathrm{mg} \text {, cada } 8 \text { horas, durante } 7 \\
\text { días o cefradina oral, } 500 \mathrm{mg} \text { cada } \\
8 \text { horas durante } 7 \text { días. Se } \\
\text { recomienda a todas las pacientes } \\
\text { continuar con la lactancia materna } \\
\text { y utilizar compresas húmedas } \\
\text { templadas en el pecho afectado } \\
\text { cada } 4-6 \text { horas. }\end{array}$ & $\begin{array}{l}\text { Resolución de la mastitis (fiebre, eritema } \\
\text { y sensibilidad): no encuentran } \\
\text { diferencias entre los antibióticos en tasa } \\
\text { de curación, duración media de } \\
\text { síntomas y recurrencia en } 30 \text { días. } \\
\\
\text { Los dos fallos de tratamiento, así como } \\
1 \text { de las tres recurrencias en } 30 \text { días se } \\
\text { dieron en pacientes tratados con } \\
\text { amoxicilina en cuyos cultivos crecía S. } \\
\text { aureus. } \\
\text { Presencia de cepas bacterianas: } \\
\text { Staphylococcus aureus los más } \\
\text { frecuentes, seguidos de S. coagulasa } \\
\text { negativos y streptococos a hemolíticos. }\end{array}$ & $\begin{array}{l}\text { La amoxicilina oral y la } \\
\text { cefradina parecen ser } \\
\text { igualmente eficaces en el } \\
\text { tratamiento de las } \\
\text { mastitis puerperales } \\
\text { agudas esporádicas. Los } \\
\text { Staphylococcus son la } \\
\text { cepa más } \\
\text { frecuentemente aislada } \\
\text { de la leche de madres } \\
\text { con mastitis. }\end{array}$ \\
\hline
\end{tabular}

Tabla de estudios para la pregunta 2

\begin{tabular}{|l|l|l|l|l|l|}
\hline Referencia & Estudio & Población & $\begin{array}{l}\text { Descripción de las } \\
\text { intervenciones } \\
\text { comparaciones, exposiciones o } \\
\text { pruebas a estudio }\end{array}$ & Resultados & Comentarios \\
\hline $\begin{array}{l}\text { Arroyo et } \\
\text { al, 2010 }\end{array}$ & ECA & $\begin{array}{l}352 \text { mujeres con } \\
\text { mastitis infecciosa } \\
\text { Objetivo: } \\
\text { de dos cepas de } \\
\text { lactobacillus } \\
\text { aislados de la } \\
\text { leche materna } \\
\text { para tratar la } \\
\text { mastitis puerperal } \\
\text { en comparación } \\
\text { con el tratamiento } \\
\text { con antibióticos }\end{array}$ & $\begin{array}{l}\text { Tres grupos aleatorios: } \\
\text { Grupo A: 124, 9log10 UFC de L. } \\
\text { fermentum durante 3 semanas } \\
\text { Grupo B: 127, 9log10 UFC de L. } \\
\text { salivarius durante 3 semanas } \\
\text { Grupo C: 101 (tratamiento con } \\
\text { antibiótico) (no se sabe en qué } \\
\text { pauta). }\end{array}$ & $\begin{array}{l}\text { Día 0: recuento bacteriano similar en los } \\
\text { tres grupos; a los 21 días, menores } \\
\text { recuentos en grupos con probióticos. } \\
\text { Las mujeres de los grupos probióticos } \\
\text { mejoraron más y tuvieron menores } \\
\text { tasas de recurrencia de mastitis que } \\
\text { aquellas asignadas al grupo con } \\
\text { antibiótico. }\end{array}$ & $\begin{array}{l}\text { Latilización de L. } \\
\text { fermentum o L. salivarius } \\
\text { parecen ser una } \\
\text { alternativa eficiente } \\
\text { frente a la prescripción } \\
\text { antibiótica en el } \\
\text { tratamiento de mastitis } \\
\text { infecciosas durante la } \\
\text { lactancia. }\end{array}$ \\
\hline
\end{tabular}




\section{BIBLIOGRAFÍA}

(1) Jahanfar S, Ng CJ, Teng CL. Antibiotics for mastitis in breastfeeding women. Cochrane Database Syst Rev 2013;2:CD005458.

(2) Grupo de trabajo de la Guía de práctica clínica de atención en el embarazo y puerperio. Guía de práctica clínica de atención en el embarazo y puerperio. Ministerio de Sanidad, Servicios Sociales e Igualdad. Agencia de Evaluación de Tecnologías Sanitarias de Andalucía: 2014. Guías de Práctica Clínica en el SNS: AETSA 2011/10.

(3) NICE. Postnatal care up to 8 weeks after birth. Julio 2006 (actualizado en Febrero de 2015). Disponible en: http://guidance.nice.org.uk/CG37.

(4) ABM Clinical Protocol \#4: Mastitis, Revised March 2014. Breastfeeding Medicine, Volume 9, Number 5, 2014.

(5) Perinatal Services BC Health Promotion Guideline. Breastfeeding Healthy Term Infants. March 2015. Disponible en: http://www.perinatalservicesbc.ca/Documents/GuidelinesStandards/HealthPromotion/BreastfeedingHealthyTermInfantGuideline.pdf.

(6) Thomsen AC, Espersen T, Maigaard S. Course and treatment of milk stasis, noninfectious inflammation of the breast, and infectious mastitis in nursing women. Am J Obstet Gynecol 1984 Jul 1;149(5):492-5.

(7) Hager WD, Barton JR. Treatment of sporadic acute puerperal mastitis. Infect Dis Obstet Gynecol 1996;4(2):97-101.

(8) Arroyo R, Martin V, Maldonado A, Jimenez E, Fernandez L, Rodriguez JM. Treatment of infectious mastitis during lactation: antibiotics versus oral administration of Lactobacilli isolated from breast milk. Clin Infect Dis 2010 Jun 15;50(12):1551-8.

(9) Shanazi M, Farshbaf KA, Kamalifard M, Asghari JM, Masoudin K, Esmaeli F. Comparison of the Effects of Lanolin, Peppermint, and Dexpanthenol Creams on Treatment of Traumatic Nipples in Breastfeeding Mothers. J Caring Sci 2015 Dec;4(4):297-307.

(10) Jackson KT, Dennis CL. Lanolin for the treatment of nipple pain in breastfeeding women: a randomized controlled trial. Matern Child Nutr 2016 Aug 1.

(11) Jackson K, Dennis CL, Hodnett E, McGillion M. A randomized controlled trial evaluating lanolin for the treatment of nipple pain among breastfeeding (Doctoral dissertation). Toronto:University of Toronto, 2013. 
PREGUNTA CLÍNICA: № 34

Ante un proceso doloroso de la mama, ¿es más útil el paracetamol o el ibuprofeno?

\section{1- Pregunta clínica en formato PICO}

Tabla 1. Componentes de la pregunta clínica en formato PICO

\begin{tabular}{|l|l|}
\hline Pacientes & Madre que amamanta y presenta un proceso doloroso de la mama \\
\hline Intervención & Paracetamol \\
\hline Comparación & lbuprofeno \\
\hline Resultados & $\begin{array}{l}\text { Duración lactancia materna (exclusiva y no exclusiva), lactancia } \\
\text { materna exclusiva al mes, a los } 4 \text { meses, a los } 6 \text { meses, problemas en } \\
\text { las mamas (dolor, grietas etc) }\end{array}$ \\
\hline Tipo de estudio & RS, ECA y estudios observacionales \\
\hline
\end{tabular}

\section{2- Introducción}




\section{3- ESTRATEGIA DE ELABORACION DE LA PREGUNTA}

\subsection{GPC}

Tabla 2- Resumen de GPC Base

\begin{tabular}{|c|c|c|c|c|}
\hline $\begin{array}{l}\text { Guía } \\
\text { (Enfoque) }\end{array}$ & $\begin{array}{l}\text { Resumen sobre la evidencia } \\
\text { (Calidad de la evidencia) }\end{array}$ & $\begin{array}{l}\text { Recomendaciones } \\
\text { (Grado) }\end{array}$ & $\begin{array}{c}\text { Referencias } \\
\text { bibliográficas } \\
\text { (Tipo de } \\
\text { publicación) }\end{array}$ & Comentarios \\
\hline $\begin{array}{l}\text { NICE, } \\
2006\end{array}$ & - & $\begin{array}{l}\text { 38. Se debería ofrecer asistencia con el } \\
\text { posicionamiento y el agarre a las mujeres que } \\
\text { reportan signos y síntomas de mastitis, junto } \\
\text { con el consejo de: } \\
\text { - Continuar con la lactancia y/o con al } \\
\text { expresión manual para asegurar la } \\
\text { eliminación efectiva de leche y si es } \\
\text { necesario, se debería realizar además } \\
\text { un masaje suave del pecho para } \\
\text { vencer cualquier bloqueo. } \\
\text { tomar analgesia compatible con la } \\
\text { lactancia materna (por ejemplo } \\
\text { paracetamol) (D (GPP)) } \\
\text { Aumentar la ingesta de fluidos (D } \\
\text { (GDP)). }\end{array}$ & 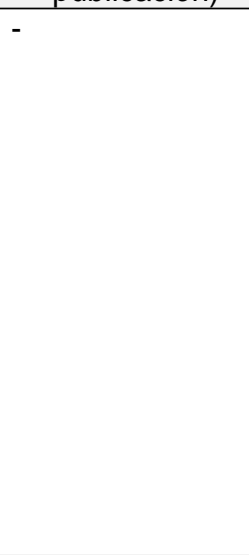 & $\begin{array}{l}\text { En el caso de } \\
\text { mastitis, se aconseja } \\
\text { tomar analgesia } \\
\text { compatible con la } \\
\text { lactancia materna, y } \\
\text { se pone como } \\
\text { ejemplo paracetamol. }\end{array}$ \\
\hline $\begin{array}{l}\text { CKS Safe } \\
\text { practical } \\
\text { clinical } \\
\text { answers } \\
\text { Mastitis } \\
\text { and } \\
\text { breast } \\
\text { abscess- } \\
\text { Managem } \\
\text { ent }\end{array}$ & $\begin{array}{l}\text { ¿Cuál es el tratamiento de primera línea de la mastitis? } \\
\text { 1. Asegurar a la mujer que aunque la mastitis es una } \\
\text { condición dolorosa, el pecho volverá a su estado normal } \\
\text { * La opinión de expertos de la guía de la OMS dice que si se trata } \\
\text { de forma adecuada, el resultado es el retorno a la función } \\
\text { completamente normal y a la lactancia (OMS 2000). } \\
\text { 3. Para reducir el dolor y el disconfort: } \\
\text { * NICE recomienda un analgésico compatible con la lactancia, } \\
\text { como el paracetamol (NICE, 2006). Para mayor información sobre } \\
\text { el uso de NSAIDs en mujeres que amamantan ver la sección de } \\
\text { Lactancia en los CKS Topics en el apartado NSAIDS-prescribing } \\
\text { issues. }\end{array}$ & $\begin{array}{l}\text { ¿Cuál es el tratamiento de primera línea de la } \\
\text { mastitis? } \\
\text { 1. Asegurar a la mujer que aunque la } \\
\text { mastitis es una condición dolorosa, el } \\
\text { pecho volverá a su estado normal } \\
\text { 3. Para reducir el dolor y el disconfort: } \\
\text { - Ofrecer paracetamol como primera opción } \\
\text { - El ibuprofeno es una alternativa. Utilizar la } \\
\text { dosis efectiva más baja por el menor tiempo } \\
\text { posible. } \\
\text { - Aconsejar a la mujer: } \\
\text { - Colocar una compresa templada sobre la } \\
\text { mama, o tomar un baño o ducha caliente }\end{array}$ & $\begin{array}{l}\text { OMS, } 2000 \\
\text { GAIN, } 2009 \\
\text { ABM } 2008\end{array}$ & $\begin{array}{l}\text { En el CSK Topics } \\
\text { sobre NSAIDS, se } \\
\text { señala que el } \\
\text { paracetamol es el } \\
\text { fármaco de elección } \\
\text { durante la lactancia } \\
\text { materna, pero que si } \\
\text { está indicado el uso } \\
\text { de NSAID, se } \\
\text { aconseja el uso de } \\
\text { ibuprofeno a la dosis } \\
\text { efectiva más baja y } \\
\text { durante el menor } \\
\text { tiempo posible. }\end{array}$ \\
\hline
\end{tabular}




\begin{tabular}{|c|c|c|c|c|}
\hline $\begin{array}{c}\text { Guía } \\
\text { (Enfoque) }\end{array}$ & $\begin{array}{l}\text { Resumen sobre la evidencia } \\
\text { (Calidad de la evidencia) }\end{array}$ & $\begin{array}{l}\text { Recomendaciones } \\
\text { (Grado) }\end{array}$ & $\begin{array}{c}\text { Referencias } \\
\text { bibliográficas } \\
\text { (Tipo de } \\
\text { publicación) }\end{array}$ & Comentarios \\
\hline & & $\begin{array}{l}\text { (reducirá el dolor y ayudará al flujo de la } \\
\text { leche). } \\
\text { - Descansar, si es posible } \\
\text { - No llevar un sujetador (especialmente por la } \\
\text { noche) }\end{array}$ & & \\
\hline $\begin{array}{l}\text { Protocolo } \\
\text { ABM \#4, } \\
2014\end{array}$ & $\begin{array}{l}\text { 3. Tratamiento farmacológico } \\
\text { Analgesia: } \\
\text { Puede ayudar al reflejo de bajada. Un agente antiinflamatorio, } \\
\text { como el ibuprofeno, puede ser más efectivo en reducir los } \\
\text { síntomas inflamatorios que un simple analgésico, como el } \\
\text { paracetamol. El ibuprofeno no se detecta en la leche al utilizar } \\
\text { dosis hasta } 1,6 \text { gramos /día, y se muestra compatible con la } \\
\text { lactancia materna. } 13 \text { (III). }\end{array}$ & & $\begin{array}{l}\text { 13. Sachs } 2013 \\
\text { (Clinical Report } \\
\text { or Guideline). }\end{array}$ & $\begin{array}{l}\text { Lo que dice la } \\
\text { revisión de Sachs: } \\
\text { Cuando no se } \\
\text { requiere analgesia } \\
\text { opioide para aliviar el } \\
\text { dolor leve o } \\
\text { moderado, se pueden } \\
\text { utilizar otros agentes } \\
\text { analgésicos. } \\
\text { Asumiendo que el } \\
\text { alivio de dolor es } \\
\text { adecuado, se pueden } \\
\text { utilizar agentes de } \\
\text { acción corta, como } \\
\text { ibuprofeno y } \\
\text { acetaminofen (78). } \\
\text { Aunque la vida media } \\
\text { del ibuprofeno puede } \\
\text { ser prolongada en } \\
\text { neonatos, sobre todo } \\
\text { en pretérminos } \\
\text { (según el prospecto), } \\
\text { la cantidad de } \\
\text { ibuprofeno que se } \\
\text { excreta a la leche } \\
\text { materna es mínima } \\
\text { (72). A pesar del } \\
\text { aclaramiento reducido } \\
\text { del paracetamol (79), } \\
\text { la hepatotoxicidad en } \\
\text { neonatos es menos }\end{array}$ \\
\hline
\end{tabular}




\begin{tabular}{|c|c|c|c|c|}
\hline $\begin{array}{c}\text { Guía } \\
\text { (Enfoque) }\end{array}$ & $\begin{array}{l}\text { Resumen sobre la evidencia } \\
\text { (Calidad de la evidencia) }\end{array}$ & $\begin{array}{l}\text { Recomendaciones } \\
\text { (Grado) }\end{array}$ & $\begin{array}{l}\text { Referencias } \\
\text { bibliográficas } \\
\text { (Tipo de } \\
\text { publicación) } \\
\end{array}$ & Comentarios \\
\hline & & & & $\begin{array}{l}\text { común que en niños } \\
\text { mayores, en parte por } \\
\text { los bajos niveles del } \\
\text { citocromo p-450 que } \\
\text { convierten el } \\
\text { acetaminofeno en } \\
\text { metabolitos tóxicos. } \\
\text { Acetaminofeno está } \\
\text { disponible tanto de } \\
\text { forma oral como } \\
\text { intravenosa. }\end{array}$ \\
\hline $\begin{array}{l}\text { Perinatal } \\
\text { Services } \\
\text { BC, } 2015\end{array}$ & & $\begin{array}{l}\text { Care } \\
\text { Use an analgesic, e.g., ibuprofen ( } 400 \mathrm{mg} \text {. every } \\
4-6 \text { hours) to decrease inflammation and } \\
\text { pain } 101,103,104\end{array}$ & $\begin{array}{l}\text { 101. OMS } \\
\text { (2000) } \\
\text { 103. Hale WT. } \\
\text { (2006). } \\
\text { 104.ABM } 2008\end{array}$ & \\
\hline $\begin{array}{l}\text { Guía del } \\
\text { embarazo } \\
2014\end{array}$ & e & - & - & \\
\hline
\end{tabular}




\begin{tabular}{|l|l|l|l|}
\hline $\begin{array}{c}\text { Guía } \\
\text { (Enfoque) }\end{array}$ & \multicolumn{1}{|c|}{$\begin{array}{c}\text { Resumen sobre la evidencia } \\
\text { (Calidad de la evidencia) }\end{array}$} & $\begin{array}{c}\text { Referencias } \\
\text { bibliográficas } \\
\text { (Tipo de } \\
\text { publicación) }\end{array}$ & $\begin{array}{c}\text { Recomendaciones } \\
\text { (Grado) }\end{array}$ \\
\hline & $\begin{array}{l}\text { Comentarios } \\
\text { (31,32). } \\
\text { Analgésicos: Antiinflamatorios no esteroideos: }\end{array}$ & $\begin{array}{l}\text { El uso de AlNEs tras parto normal o en combinación con opioides } \\
\text { tras parto por cesárea pueden mejorar el control del dolor } \\
\text { ayudando con el dolor debido a los entuertos. Los AlNEs son } \\
\text { seguros en general para la lactancia materna y pueden ayudar a } \\
\text { minimizar la dosis total de opioides necesaria para controlar el } \\
\text { dolor 32 (III). } \\
\text { Dentro de todos los AlNEs se considera al ibuprofeno como el } \\
\text { analgésico ideal, así como moderadamente efectivo. Su } \\
\text { transferencia a la leche es de baja a nula (56). }\end{array}$ & \\
\hline
\end{tabular}

\subsection{Revisiones sistemáticas}

No hay revisiones concretas sobre el uso de paracetamol o ibuprofeno ante un proceso doloroso de la mama. 


\subsection{Resumen de GPC base y RS disponibles}

El Clinical Knowdledge Summaries (CKS) de NICE recomienda ofrecer paracetamol como primera opción, y plantea el ibuprofeno como alternativa (1).

En el protocolo sobre mastitis de la ABM (2) se indica que un agente antiinflamatorio, como el ibuprofeno, puede ser más efectivo que un analgésico como el paracetamol para ayudar al reflejo de bajada de la leche. En el protocolo específico sobre la analgesia y la anestesia en la madre lactante (3) se señala que dentro de todos los AINE se considera al ibuprofeno como moderadamente efectivo y el analgésico ideal, ya que su transferencia a la leche es de baja a nula.

Y en la PSBC (4) se recomienda utilizar un analgésico, poniendo como ejemplo al ibuprofeno (400mg cada cuatro-seis horas), para disminuir la inflamación y el dolor.

No se han encontrado revisiones sistemáticas al respecto.

\subsection{Conclusión}

Adopción GPC/Revisión sistemática

X Elaboración parcial

Elaboración de novo

Ver en el ANEXO I la estrategia de búsqueda.

ACTUALIZADO A FECHA DE: 31 de Octubre de 2016 


\section{4- De la evidencia a la recomendación (Tabla de EtR)}

\begin{tabular}{|c|c|}
\hline \multicolumn{2}{|c|}{ Ante un proceso doloroso de la mama, ¿es más útil el paracetamol o el ibuprofeno? } \\
\hline Recomendación & $\begin{array}{l}\text { Recomendación de buena práctica. } \\
\text { Cuando el dolor va asociado a un proceso inflamatorio, puede ser de mayor utilidad el ibuprofeno. }\end{array}$ \\
\hline Justificación & $\begin{array}{l}\text { No existen estudios que demuestren que el paracetamol sea más útil que el ibuprofeno ante un proceso doloroso en la mama de } \\
\text { madres lactantes. En las guías consultadas, se aconseja el uso de paracetamol o ibuprofeno, alegando en una de ellas que el } \\
\text { ibuprofeno, cuyo uso es seguro durante la lactancia, puede ser mejor antiinflamatorio y puede tener un efecto de bajada de la } \\
\text { leche. De ahí que se haga la siguiente recomendación de buena práctica clínica. }\end{array}$ \\
\hline $\begin{array}{l}\text { Consideraciones de } \\
\underline{\text { subgrupos }}\end{array}$ & - \\
\hline $\begin{array}{l}\text { Consideraciones para } \\
\text { la implementación }\end{array}$ & - \\
\hline $\begin{array}{l}\text { Monitorización y } \\
\text { evaluación }\end{array}$ & - \\
\hline $\begin{array}{l}\text { Prioridades para la } \\
\text { investigación }\end{array}$ & $\begin{array}{l}\text { Estudios que comparen la eficacia del paracetamol versus AINE (como ibuprofeno) en mejorar los síntomas en los p } \\
\text { dolorosos de la mama en madres lactantes y su efecto sobre el éxito de la lactancia materna. }\end{array}$ \\
\hline
\end{tabular}




\title{
ANEXO I. ESTRATEGIAS DE BÚSQUEDA
}

\author{
Cochrane Library \\ Searched 17/09/2015/2015 \\ Updated search 17/09/2015 a xx/xx/xxxx \\ \#1 MeSH descriptor: [Anti-Inflammatory Agents, Non-Steroidal] explode all \\ trees 6594 \\ \#2 "non-steroidal anti-inflammatory agents" or nsaid or nsaids:ti,ab,kw \\ (Word variations have been searched) 2997 \\ \#3 MeSH descriptor: [lbuprofen] explode all trees 1193 \\ \#4 ibuprofen:ti,ab,kw (Word variations have been searched) 2668 \\ \#5 \#1 or \#2 or \#3 or \#4 10166 \\ \#6 MeSH descriptor: [Acetaminophen] explode all trees 1866 \\ \#7 acetaminophen or paracetamol:ti,ab,kw (Word variations have been \\ searched) $\quad 5413$ \\ \#8 \#6 or \#7 5413 \\ \#9 \#5 and \#8 1358 \\ \#10 MeSH descriptor: [Breast Feeding] explode all trees 1364 \\ \#11 breastfeeding or "breast feeding":ti,ab,kw (Word variations have been \\ searched) 2948 \\ \#12 MeSH descriptor: [Lactation] explode all trees 469 \\ \#13 lactation or lactating:ti,ab,kw (Word variations have been searched) \\ 7296 \\ \#14 \#10 or \#11 or \#12 or \#13 9762 \\ \#15 \#9 and \#14 9
}

\section{MEDLINE, via Pubmed}

\section{Searched 17/09/2015/2015}

\section{Updated search 17/09/2015 a xx/xx/xxxx}

\#1 Search "Anti-Inflammatory Agents, Non-Steroidal"[Mesh] 69531

\#2 Search ("non-steroidal anti-inflammatory agents"[Title/Abstract] OR nsaid[Title/Abstract] OR nsaids[Title/Abstract]) 20319

\#3 $\quad$ Search "Ibuprofen"[Mesh] 6989

\#4 Search ibuprofen[Title/Abstract] 10078

\#5 Search \#1 OR \#2 OR \#3 OR \#4 83242

\#6 Search "Acetaminophen"[Mesh] 14584

\#7 Search (acetaminophen[Title/Abstract] OR paracetamol[Title/Abstract]) 18713

\#8 Search \#6 OR \#7 21812

\#9 Search \#5 AND \#8 4203

\#10 Search "Breast Feeding"[Mesh] 27173

\#11 Search (breastfeeding[Title/Abstract] OR "breast feeding"[Title/Abstract]) 26853

\#12 Search "Lactation"[Mesh] 34134

\#13 Search (lactation[Title/Abstract] OR lactating[Title/Abstract]) 41510

\#14 Search \#10 OR \#11 OR \#12 OR \#13 83967

\#15 Search \#9 AND \#14 28 


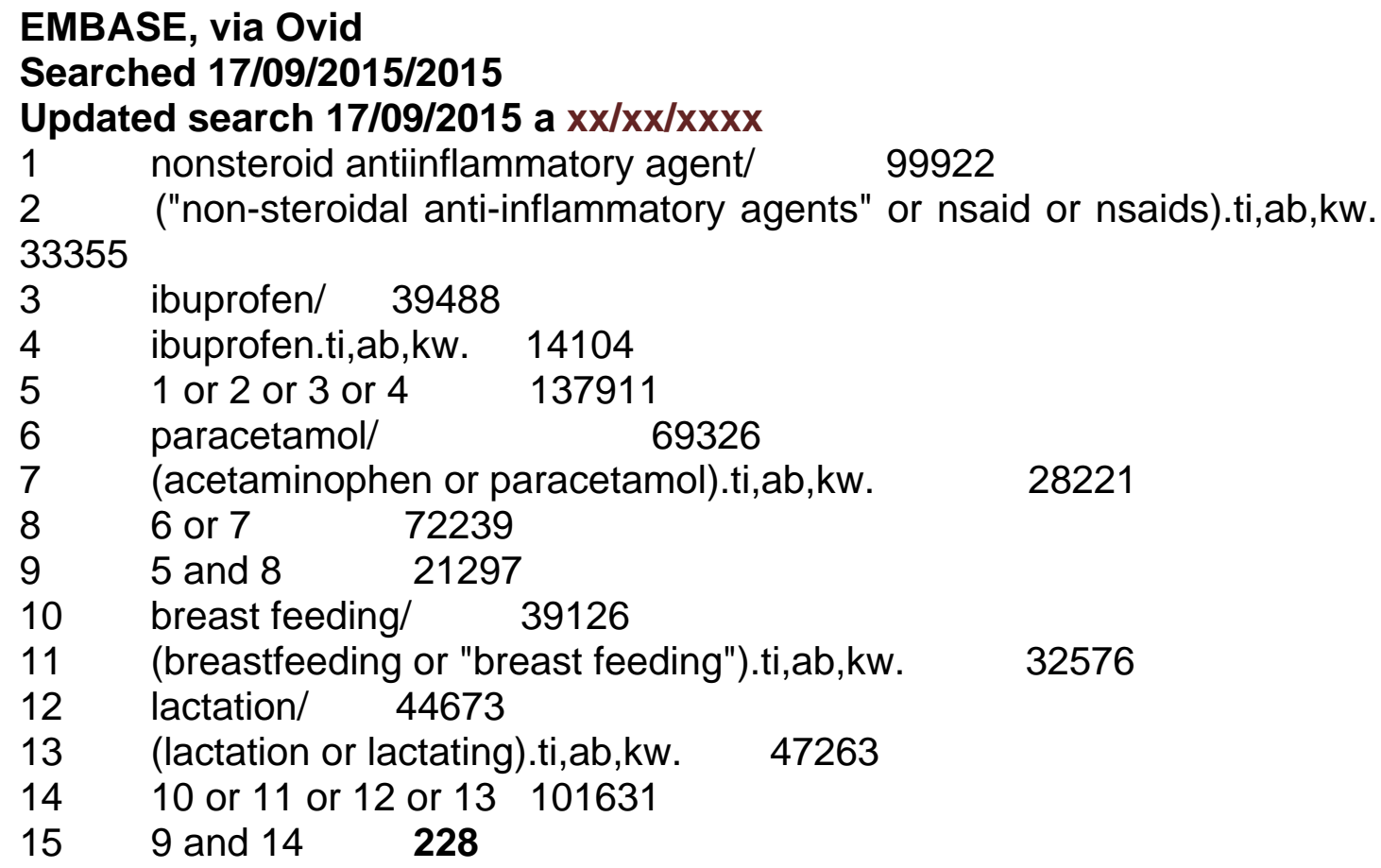

CINAHL, via EBSCOhost databases

Searched 17/09/2015/2015

Updated search 17/09/2015 a xx/xx/xxxx

S1 (MH "Antiinflammatory Agents, Non-Steroidal") 7288

S2 "non-steroidal anti-inflammatory agents" or nsaid or nsaids 2628

S3 nonsteroidal anti-inflammatory drugs 1277

S4 (MH "lbuprofen") 1077

S5 ibuprofen 1402

S6 S1 OR S2 OR S3 OR S4 OR S5 9605

S7 (MH "Acetaminophen") 2742

S8 acetaminophen or paracetamol 3556

S9 S7 OR S8 3556

S10 S6 AND S9 1216

S11 (MH "Breast Feeding") 12379

S12 breastfeeding OR "breast feeding" 15119

S13 (MH "Lactation") 1683

S14 lactation OR lactating 3347

S15 S11 OR S12 OR S13 OR S14 16616

S16 S10 AND S15 8 


\section{Bibliografía}

(1) Mastitis and breast abscess. Clinical Knowledge Summaries-CSK. 2015. Disponible en:

http://ykmu.tbzmed.ac.ir/uploads/125/CMS/user/file/813/sexual/Mastitis\%20and\% 20breast\%20abscess.pdf.

(2) ABM Clinical Protocol \#4: Mastitis, Revised March 2014. Breastfeeding Medicine, Volume 9, Number 5, 2014.

(3) Montgomery A, HaleTW and The Academy of Breastfeeding Medicine. ABM Clinical Protocol \#15: Analgesia and Anesthesia for the Breastfeeding Mother, Revised 2012. Breastfeeding Medicine. Volume 7, Number 6, 2012.

(4) Perinatal Services BC Health Promotion Guideline. Breastfeeding Healthy Term Infants. March 2015. Disponible en: http://www.perinatalservicesbc.ca/Documents/Guidelines-

Standards/HealthPromotion/BreastfeedingHealthyTermInfantGuideline.pdf. 
PREGUNTA CLÍNICA: № 35

¿Cuál sería el antibiótico de elección en el tratamiento empírico de las mastitis agudas?

\section{1- Pregunta clínica en formato PICO}

Tabla 1. Componentes de la pregunta clínica en formato PICO

\begin{tabular}{|l|l|}
\hline Pacientes & $\begin{array}{l}\text { Madre que amamanta y que presenta mastitis aguda y no responde a } \\
\text { las medidas iniciales conservadoras (vaciamiento, reposo e } \\
\text { antiinflamatorios). }\end{array}$ \\
\hline Intervención & $\begin{array}{l}\text { Amoxicilina clavulánico o cloxacilina con clindamicina (se da por efecto } \\
\text { antitoxina en pacientes con síntomas inflamatorios muy importantes) }\end{array}$ \\
\hline Comparación & Cloxacilina \\
\hline Resultados & $\begin{array}{l}\text { Duración lactancia materna (exclusiva y no exclusiva), lactancia } \\
\text { materna exclusiva al mes, a los } 4 \text { meses, a los } 6 \text { meses, problemas en } \\
\text { las mamas (dolor, grietas etc) }\end{array}$ \\
\hline Tipo de estudio & $\begin{array}{l}\text { RS de ECA, ECA, RS de Estudios observacionales, estudios } \\
\text { observacionales }\end{array}$ \\
\hline
\end{tabular}

\section{2- Introducción}




\section{3- ESTRATEGIA DE ELABORACION DE LA PREGUNTA}

\subsection{GPC}

Tabla 2- Resumen de GPC Base

\begin{tabular}{|c|c|c|c|c|}
\hline $\begin{array}{l}\text { Guía } \\
\text { (Enfoque) }\end{array}$ & $\begin{array}{l}\text { Resumen sobre la evidencia } \\
\text { (Calidad de la evidencia) }\end{array}$ & $\begin{array}{l}\text { Recomendaciones } \\
\text { (Grado) }\end{array}$ & $\begin{array}{l}\text { Referencias } \\
\text { bibliográficas } \\
\text { (Tipo de } \\
\text { publicación) } \\
\end{array}$ & Comentarios \\
\hline $\begin{array}{l}\text { NICE, } \\
2006\end{array}$ & $\begin{array}{l}\text { 84. El tratamiento de mastitis infecciosas incluye el uso de un antibiótico } \\
\text { beta lactamasa resistente junto con calor húmedo y lactancia materna } \\
\text { continuada (Nivel } 2 \text { ). } \\
\text { Osterman y Rahm (2000) se refieren a estudios en los que se indica que la } \\
\text { bacteria potencialmente patógena que se aisla en la leche de mujeres con } \\
\text { mastitis lactacional es el S. aureus y raramente Streptococo B hemoliticos. } \\
\text { En este estudio se cultivo la leche de } 40 \text { mujeres con mastitis (fiebre >38ㅜ, } \\
\text { y al menos dos de los siguientes: eritema, sensibilidad e hinchazó). Las } \\
\text { mujeres con cultivos positivos a la flora cutánea normal (61\%) fueron } \\
\text { tratados con descanso y vaciamiento frecuente del pecho y no presentaron } \\
\text { complicaciones ni tuvieron que recibir tratamiento con antibióticos. } 9 \text { de las } \\
16 \text { mujeres que presentaban cultivos con bacterias potencialmente } \\
\text { patógenas recibieron antibióticos. El } 81 \% \text { de esas mujeres tuvieron } \\
\text { síntomas durante más de una semana y el } 31 \% \text { abandonaron la lactancia } \\
\text { materna. } \\
\text { En un estudio observacional de Dinamarca de } 339 \text { casos de mastitis en } 213 \\
\text { mujeres, Thomsen et al (Thomsen, Espersen y Maigaard } 1984 \text { ) } \\
\text { demostraron que tanto en la inflamación de la mama como en la mastitis } \\
\text { infecciosa, el vaciado del pecho resultó en una disminución significativa de } \\
\text { la duración de los síntomas y un resultado mejorado de forma significativa } \\
\text { (p<0,001). En el caso de las mastitis infecciosas, la adición de antibióticos } \\
\text { (penicilina/eritromicina) resultó en un buen resultado en } 96 \% \text { de casos y } \\
\text { una reducción en la duración de los síntomas (p<0,001). } \\
\text { En un ECA pequeño (Hager y Barton } 1996 \text { ), cultivaron la leche materna de } \\
25 \text { mujeres con mastitis, observando que la principal especie presente en } \\
\text { los cultivos era Staphylococcus aureus, las características de la flora } \\
\text { cutánea y resistentes a penicilina. La mitad de las mujeres fue tratada con } \\
\text { amoxicilina y la otra mitad con cefradina (una cefalosporina). Todas las }\end{array}$ & $\begin{array}{l}\text { 40. Si los signos y síntomas de mastitis no han } \\
\text { cesado, se debería evaluar a la mujer puesto } \\
\text { que podría necesitar tratamiento antibiótico } \\
\text { (Acción urgente) (B). }\end{array}$ & $\begin{array}{l}\text { Osterman et al, } \\
2000 \\
\\
\text { Thomsen et al, } \\
1984 \\
\text { Hager et al, } \\
1996\end{array}$ & $\begin{array}{l}\text { No se señala } \\
\text { qué antibiótico. }\end{array}$ \\
\hline
\end{tabular}




\begin{tabular}{|c|c|c|c|c|}
\hline $\begin{array}{c}\text { Guía } \\
\text { (Enfoque) }\end{array}$ & $\begin{array}{l}\text { Resumen sobre la evidencia } \\
\text { (Calidad de la evidencia) }\end{array}$ & $\begin{array}{l}\text { Recomendaciones } \\
\text { (Grado) }\end{array}$ & $\begin{array}{c}\text { Referencias } \\
\text { bibliográficas } \\
\text { (Tipo de } \\
\text { publicación) }\end{array}$ & Comentarios \\
\hline & $\begin{array}{l}\text { recurrencias fueron debidas a la presencia de S. aureus patógenas y y } \\
\text { requirieron tratamiento con un antibiótico resistente a beta lactamasa. En } \\
\text { base a esta investigación, los investigadores sugirieron el uso de un } \\
\text { antibiótico beta lactamasa resistente para el tratamiento de las mastitis } \\
\text { junto con el uso de calor húmedo y la continuación de la lactancia. } \\
\text { La literatura no es robusta en esta área, y los dos estudios restantes están } \\
\text { metodológicamente sesgados. Sin embargo, ambos estudios demostraron } \\
\text { la respuesta al tratamiento anbitiotico (Devereux } 1970 \text { y Nieblyl 1967), } \\
\text { recomendando el tratamiento temprano de la mastitis con antibióticos y la } \\
\text { continuación de la lactancia para prevenir la formación de abscesos. }\end{array}$ & & $\begin{array}{l}\text { Devereux et al, } \\
1970 \\
\text { Nieblyl et al, } \\
1978\end{array}$ & \\
\hline $\begin{array}{l}\text { CKS Safe } \\
\text { practical } \\
\text { clinical } \\
\text { answers } \\
\text { Mastitis } \\
\text { and } \\
\text { breast } \\
\text { abscess- } \\
\text { Managem } \\
\text { ent }\end{array}$ & $\begin{array}{l}\text { ¿Qué antibiótico se debería prescribir? } \\
\text { * Una RS Cocrhane no encuentra evidencia suficiente para evaluar la } \\
\text { efectividad de los antibióticos en la mastitis lactacional. } \\
\text { * La Guía del NICE y la ABM recomiendan, en base a la opinión de } \\
\text { expertos, un antibiótico b-lactamasa resistente para el tratamiento de la } \\
\text { mastitis infecciosa. } \\
\text { * La Agencia de protección de la salud recomienda evitar el uso de } \\
\text { antibióticos de amplio espectro (como co-amoxiclav) cuando los antibióticos } \\
\text { de espectro reducido son efectivos. Los antibióticos de amplio espectro } \\
\text { aumentan el riesgo de Clostridium difficile y S.aureus resistentes a } \\
\text { meticilina (HPA, 2009). } \\
\text { Por lo tanto CKS recomienda flucoxacilina como primera opción, con } \\
\text { eritromicina (macrólido) como alternativa para mujeres que no pueden } \\
\text { tomar penicilinas. Son considerados efectivos contra organismos } \\
\text { productores de b-lactamasas, pueden ser tomados de forma oral y son } \\
\text { considerados adecuados para mujeres que amamantan. } \\
\text { * Una revisión de la OMS encuentra que: } \\
\text { - } 6 \text { estudios pequeños realizados entre los años } 1948 \text { y } 1988 \text { no } \\
\text { encuentran efectos perjudiciales del amamantamiento continuado } \\
\text { - Existen reportes de casos esporádicos de Síndrome de piel } \\
\text { escaldada por estafilococo en niños de madres con mastitis o } \\
\text { absceso mamario. Sin embargo, no está claro si la transmisión se } \\
\text { da por el contacto estrecho o por la leche materna. } \\
\text { - Se han reportado alqunos casos de transmisión al niño de }\end{array}$ & $\begin{array}{l}\text { ¿Qué antibiótico se debería prescribir? } \\
\text { 1. Si se trata de un tratamiento empírico: } \\
\text { Flucloxacilina } 500 \mathrm{mg}, 4 \text { veces al día, por } 14 \\
\text { días. } \\
\text { Alternativa: eritromicina, } 250 \mathrm{mg} \text { a } 500 \mathrm{mg}, 4 \\
\text { veces al día, } 14 \text { días } \\
\text { 2. Si se conocen los resultados del cultivo: } \\
\text { prescribir un Antibiótico de acuerdo a las } \\
\text { sensibilidades del organismo identificado } \\
\text { 3. Es improbable que el niño se encuentre } \\
\text { mal, pero si se confirma infección estafilocócica } \\
\text { o estreptocócica, observar al niño para } \\
\text { identificar síntomas de infección y pedir consejo } \\
\text { al pediatra si el niño no se encuentra bien. } \\
\text { 4. Duración del tratamiento } \\
\text { Las guías de la OMS (OMS } 2000 \text { ) y de la ABM } \\
\text { (2008), apoyándose en la opinión de expertos, } \\
\text { recomiendan que el tratamiento debería } \\
\text { prescribirse durante } 10-14 \text { días. Según la } \\
\text { opinión de los expertos, la recaída es más } \\
\text { frecuente en mujeres con tratamientos de menor } \\
\text { duración (OMS } 2000 \text { ). CKS recomienda un } \\
\text { curso de } 14 \text { días, porque permite la }\end{array}$ & $\begin{array}{l}\text { OMS, } 2000 \\
\text { Barbosa-Cesnik, } \\
2003 \\
\text { Betzold } 2007 \\
\text { GAIN, } 2009\end{array}$ & \\
\hline
\end{tabular}




\begin{tabular}{|c|c|c|c|c|}
\hline $\begin{array}{c}\text { Guía } \\
\text { (Enfoque) }\end{array}$ & $\begin{array}{l}\text { Resumen sobre la evidencia } \\
\text { (Calidad de la evidencia) }\end{array}$ & $\begin{array}{l}\text { Recomendaciones } \\
\text { (Grado) }\end{array}$ & $\begin{array}{c}\text { Referencias } \\
\text { bibliográficas } \\
\text { (Tipo de } \\
\text { publicación) }\end{array}$ & Comentarios \\
\hline & $\begin{array}{l}\text { Streptococo del grupo B de una mujer con absceso mamario. } \\
\text { La conclusión de la OMS es que la transmisión de infección es rara y } \\
\text { normalmente el resultado es benigno. La recomendación se basa en la } \\
\text { opinión de experto de la OMS. } \\
\text { ¿Cómo se debería tratar a una mujer que no ha respondido al tratamiento } \\
\text { de primera línea? } \\
\text { *Un tratamiento demasiado corto de Antibióticos y el no haber completado } \\
\text { el curso de tratamiento, se han asociado con una mayor incidencia de } \\
\text { relapso (OMS 2000; Deshpande 2007). } \\
\text { * Una revisión sistemática encontró evidencia insuficiente para evaluar la } \\
\text { efectividad de los antibióticos en mastitis lactacional. } \\
\text { Las guías de NICE y la ABM recomiendan un antibiótico b-lactamasa } \\
\text { resistente, en base a la opinión de expertos como primera opción. } \\
\text { Si los resultados del cultivo están disponibles, ajustar el antibiótico } \\
\text { Si no, tratar empíricamente con Co-amoxiclav } 500 / 125 m g \text { tres veces por } \\
\text { día. Revisar cuando los resultados del cultivo estén disponibles. } \\
\text { *CKS recomienda prescribir co-amoxiclav por ser un antibiótico b- } \\
\text { lactamasa resistente que tiene un espectro mayor que la flucoxacilina. } \\
\text { Puede ser tomado de forma oral y es apropiado para su uso en atención } \\
\text { primaria. } \\
\text { * Las penicilinas son los antibióticos de elección durante la lactancia } \\
\text { materna, porque sólo se encuentran trazas en la leche materna (Schaefer } \\
\text { et al, 2007). }\end{array}$ & $\begin{array}{l}\text { dispensación única de un pack. } \\
\text { ¿Cómo se debería tratar a una mujer que no ha } \\
\text { respondido al tratamiento de primera línea? } \\
\text { 1. Asegurarse de que la mujer ha tomado el } \\
\text { antibiótico de forma correcta } \\
\text { 2. Realizar un cultivo } \\
\text { 3. Prescribir un antibiótico diferente por } 14 \text { días. } \\
\text { 4. Considerar un diagnóstico alternativo } \\
\text { - Investigación urgente para descartar cáncer } \\
\text { - Sospecha de absceso } \\
\text { - Derivación a frenulotomía }\end{array}$ & & \\
\hline $\begin{array}{l}\text { Protocolo } \\
\text { ABM \#4, } \\
2014\end{array}$ & $\begin{array}{l}\text { 3. Tratamiento farmacológico } \\
\text { Antibióticos } \\
\text { Si los síntomas no mejoran tras } 12-24 \text { horas o si la mujer está muy } \\
\text { enferma, el tratamiento con antibióticos debería comenzar. } \\
\text { El patógeno más común involucrado en la mastitis infecciosa es } \mathrm{S} \text {. aureus } \\
14,15 \text {, siendo menos común el Streptococo o E. coli. } 11 \text {. } \\
\text { Los antibióticos de preferencia son las penicilinas resistentes a b- } \\
\text { lactamasas, como dicloxacilina o flucloxacilina } 500 \text { mg vía oral cuatro veces }\end{array}$ & $\begin{array}{l}\text { 11. Thomsen } 1984 \\
\text { 12. Bolman } 2013 \\
\text { 13. Sachs } 2013 \\
\text { 14. Amir LH, } 2006\end{array}$ & & $\begin{array}{l}\text { Mientras que en } \\
\text { USA hasta el } \\
50 \% \text { o más de } \\
\text { las infecciones } \\
\text { de piel y partes } \\
\text { blandas por } S \text {. } \\
\text { aureus son } \\
\text { causadas por } \\
\text { cepas } \\
\text { resistentes a }\end{array}$ \\
\hline
\end{tabular}




\begin{tabular}{|c|c|c|c|c|}
\hline $\begin{array}{c}\text { Guía } \\
\text { (Enfoque) }\end{array}$ & $\begin{array}{l}\text { Resumen sobre la evidencia } \\
\text { (Calidad de la evidencia) }\end{array}$ & $\begin{array}{l}\text { Recomendaciones } \\
\text { (Grado) }\end{array}$ & $\begin{array}{c}\text { Referencias } \\
\text { bibliográficas } \\
\text { (Tipo de } \\
\text { publicación) }\end{array}$ & Comentarios \\
\hline & $\begin{array}{l}\text { al día. 16, o lo recomendado a nivel local según las sensibilidades (III). Las } \\
\text { cefalosporinas de primera generación también se aceptan como primera } \\
\text { línea de tratamiento, aunque son menos aceptadas por su mayor espectro } \\
\text { de cobertura (III). } \\
\text { La cefalexina es normalmente segura para mujeres con alergia a penicilina, } \\
\text { pero en casos de hipersensibilidad severa se sugiere el uso de la } \\
\text { clindamicina } 16 \text { (III). } \\
\text { La dicoxacilina parece tener menor ratio de efectos adversos hepáticos que } \\
\text { la flucoxacilina 17. Muchas autoridades recomiendan 10-14 días de } \\
\text { tratamiento), aunque no se sustentan en ensayos controlados (III). } \\
\text { La presencia de S.aureus resistente a penicilinas resistentes a penicilasas } \\
\text { (MRSA o resistentes a oxacilina) en mastistis y abscesos ha ido en } \\
\text { aumento (20-22). (II-2). Si la mastitis no mejora tras } 48 \text { h de tratamiento de } \\
\text { primera línea, se debería realizar un cultivo. } \\
\text { La mayoría de las cepas son sensibles a vancomicina o } \\
\text { trimetoprim/sulfamethoxazole pero pueden no ser susceptibles a } \\
\text { rifampicina 26. Se debería asumir que las MRSA son resistentes al } \\
\text { tratamiento con macrólidos y quinolonas, aun sin tener los resultados de } \\
\text { susceptibilidad } 27 \text { (III). }\end{array}$ & $\begin{array}{l}\text { 15. Kvist LJ, } 2008 \\
\text { 16. Antibiotic Expert Group, } 2010 \\
\text { 17. Olsson R, } 1992 \\
\text { 20. Perez A, } 2013 \\
\text { 21. Branch-Ellliman W, } 2012 \\
\text { 22. Stafford I, } 2008 \\
\text { 26. Johnson MD, } 2008 \\
\text { 27. Rodvold KA, } 2014\end{array}$ & & $\begin{array}{l}\text { meticilina, en } \\
\text { Europa y en } \\
\text { particular en } \\
\text { España esta } \\
\text { etiología es } \\
\text { excepcional en } \\
\text { infección } \\
\text { comunitaria } \\
\text { (Pérez A,et al, , } \\
\text { 2013) }\end{array}$ \\
\hline $\begin{array}{l}\text { Perinatal } \\
\text { Services } \\
\text { BC, } 2012\end{array}$ & & $\begin{array}{l}\text { Subsequent treatment after } 24 \text { hours } \\
\text { Use antibiotics judiciously and only } \\
\text { recommended if symptoms have not improved } \\
\text { after } 12-24 \text { hours of rest and applying the } \\
\text { above recommendations; } 101 \text { maternal fever has } \\
\text { not subsided and illness remains acute; or if the } \\
\text { nipple is cracked/fissured indicating possible } \\
\text { infectious mastitis.107 Most common pathogen } \\
\text { is penicillin-resistant Staphylococcus aureus; } \\
\text { less common are streptococcus or Escherichia } \\
\text { coli104. Suggested antibiotics are penicillinase } \\
\text { resistant penicillins, e.g., dicloxacillin or } \\
\text { flucloxacillin } 500 \mathrm{mg} \text { qid or cephalexin when } \\
\text { penicillin allergy is suspected. } 104 \text { Although not }\end{array}$ & $\begin{array}{l}\text { 101. OMS } \\
\text { (2000) } \\
\text { 104.ABM } 2008 \\
\text { 105. Spencer } \\
\text { JP. (2008) } \\
\text { 107. Morland- } \\
\text { Schultz K, Hill } \\
\text { PD (2005). }\end{array}$ & \\
\hline
\end{tabular}




\begin{tabular}{|c|c|c|c|c|}
\hline $\begin{array}{c}\text { Guía } \\
\text { (Enfoque) }\end{array}$ & $\begin{array}{l}\text { Resumen sobre la evidencia } \\
\text { (Calidad de la evidencia) }\end{array}$ & $\begin{array}{l}\text { Recomendaciones } \\
\text { (Grado) }\end{array}$ & $\begin{array}{l}\text { Referencias } \\
\text { bibliográficas } \\
\text { (Tipo de } \\
\text { publicación) }\end{array}$ & Comentarios \\
\hline & & $\begin{array}{l}\text { clinically studied, it is recommended that } \\
\text { antibiotic therapy should continue for } 10 \text { to } 14 \\
\text { days } 104,105 .\end{array}$ & & \\
\hline $\begin{array}{l}\text { Guía del } \\
\text { embarazo } \\
2014\end{array}$ & $\begin{array}{l}\text { Uso de antibióticos para las mastitis en mujeres que amamantan } \\
\text { La revisión de Jahanfar (2010) incluyó } 2 \text { estudios con aproximadamente } \\
125 \text { mujeres que amamantaban con síntomas de mastitis tales como } \\
\text { sensibilidad aumentada, enrojecimiento de los pechos, una disminución de } \\
\text { la secreción de leche o fiebre. Un estudio comparó la ausencia de } \\
\text { tratamiento, el vaciamiento de la mama y vaciamiento de la mama con } \\
\text { algunos de los siguientes antibióticos en un tratamiento de seis días: } \\
\text { penicilina } 500.000 \text { Ul tres veces al día, ampicilina oral } 500 \text { mg cuatro veces } \\
\text { al día, o eritromicina } 500 \text { mg dos veces al día. El otro ECA comparó dos } \\
\text { antibióticos (amoxicilina frente a cefradina) en una dosis de } 500 \text { mg por vía } \\
\text { oral cada ocho horas durante siete días. Se realizaron análisis de } \\
\text { sensibilidad y análisis de subgrupos. Aunque se planearon análisis de } \\
\text { sensibilidad para comparar los resultados dependiendo de las dosis } \\
\text { evaluadas en los estudios, o las reacciones provocadas por el tratamiento } \\
\text { en la madre o el bebé, las diferencias entre los estudios no permitieron la } \\
\text { realización de un metanálisis. } \\
\text { Ambos estudios evaluaron la resolución de los síntomas (fiebre, } \\
\text { eritema,sensibilidad) como su desenlace principal. Por otro lado, uno de los } \\
\text { ECA evaluó el mantenimiento de la lactancia materna a las dos semanas } \\
\text { de haber finalizado el tratamiento, y ambos estudios evaluaron otros } \\
\text { desenlaces como la persistencia de los síntomas, los problemas con la } \\
\text { secreción de leche o la recurrencia de la infección. } \\
\text { Un ECA mostró que el tratamiento con antibiótico y vaciamiento de la } \\
\text { mama contribuyó a la mejoría de los síntomas de la mastitis infecciosa en } \\
\text { una proporción significativamente mayor (96\%) que el hecho de no } \\
\text { tratar (15\%) ( } 1 \text { ECA, } 110 \text { mujeres; RR } 6,63 ; \text { OR } 95 \% 3,48 \text { a } 12,60) \text {. Los } \\
\text { resultados también fueron significativos al comparar el tratamiento con } \\
\text { antibiótico y vaciamiento de la mama frente a vaciar la mama solamente } \\
\text { (RR } 1,89 ; \text { OR } 95 \% 1,45 \text { a } 2,47) \text {. } \\
\text { La resolución de la sintomatología fue más rápida en el grupo de } \\
\text { mujeres que recibió antibióticos y vaciamiento de la mama (media de }\end{array}$ & $\begin{array}{l}\text { Débil } \\
\text { Se sugiere utilizar un tratamiento antibiótico, } \\
\text { además del mantenimiento de } \\
\text { la lactancia materna con un vaciado frecuente } \\
\text { para resolver la mastitis } \\
\text { infecciosa. } \\
\text { Débil } \\
\text { Se sugiere el uso de compresas de agua tibia } \\
\text { tras el amamantamiento en aquellas madres } \\
\text { que amamanten con dolor o lesiones en los } \\
\text { pezones. }\end{array}$ & Jahanfar 2010 & $\begin{array}{l}\text { No se } \\
\text { recomienda un } \\
\text { antibiótico sobre } \\
\text { otro. } \\
\text { Ni la penicilina ni } \\
\text { la ampicilina son } \\
\text { activos frente a } \\
\text { la mayoría } \\
\text { (>90\%) de } \\
\text { cepas de S. } \\
\text { aureus sensible } \\
\text { a } \\
\text { meticilina...que } \\
\text { es la causa más } \\
\text { frecuente de } \\
\text { mastitis aguda. } \\
\text { (Mensa J et al, } \\
\text { Guía de } \\
\text { tratamiento } \\
\text { antimicrobiano } \\
\text { de la infección } \\
\text { por } \\
\text { Staphylococcus } \\
\text { aureus. } \\
\text { Rev Esp } \\
\text { Quimioter 2013; } \\
26 \text { (Suppl. 1):1- } \\
84\end{array}$ \\
\hline
\end{tabular}




\begin{tabular}{|c|c|c|c|c|}
\hline $\begin{array}{c}\text { Guía } \\
\text { (Enfoque) }\end{array}$ & $\begin{array}{l}\text { Resumen sobre la evidencia } \\
\text { (Calidad de la evidencia) }\end{array}$ & $\begin{array}{l}\text { Recomendaciones } \\
\text { (Grado) }\end{array}$ & $\begin{array}{c}\text { Referencias } \\
\text { bibliográficas } \\
\text { (Tipo de } \\
\text { publicación) }\end{array}$ & Comentarios \\
\hline & $\begin{array}{l}\text { 2,1 días) que en los otros dos grupos (vaciamiento de la mama: medida de } \\
4,2 \text { días; no tratamiento: media de } 6,7 \text { días). } \\
\text { El ECA que comparó amoxicilina frente a cefradina no mostró diferencias } \\
\text { entre los grupos relacionadas con el número de mujeres con una mejoría } \\
\text { de los síntomas a juicio del clínico ( } 1 \text { ECA, } 25 \text { mujeres; RR } 0,85 ; \text { IC } 95 \% \\
0,65 \text { a } 1,12 \text { ), aunque prácticamente todas las mujeres habían mostrado una } \\
\text { mejoría después de siete días de tratamiento. } \\
\text { Ninguno de los dos ECA describió que el uso de antibióticos provocara } \\
\text { efectos adversos. }\end{array}$ & & & \\
\hline
\end{tabular}

\subsection{Revisiones sistemáticas}

La única revisión que se ha identificado que aborda parcialmente esta pregunta es la ya mencionada revisión Cochrane de Jahanfar et al, 2013, que incluye el artículo de Hager et al, 1996 en el que se compara el uso de la amoxicilina frente a la cefradina para el tratamiento de las mastitis agudas puerperales.

\section{Tabla 2. Resumen de RS}

\begin{tabular}{|c|c|c|c|c|c|c|}
\hline $\begin{array}{l}\text { Referencia } \\
\text { (Cita } \\
\text { Abreviada) }\end{array}$ & $\begin{array}{l}\text { Estudio } \\
\text { (Diseño y } \\
\text { objetivo) }\end{array}$ & $\begin{array}{l}\text { Población } \\
\text { (noy } \\
\text { características) }\end{array}$ & $\begin{array}{l}\text { Intervención/ } \\
\text { Comparación. } \\
\text { exposiciones o } \\
\text { pruebas a estudio }\end{array}$ & $\begin{array}{l}\text { Resultados } \\
\text { (Estimadores de resultados-Magnitud } \\
\text { del efecto) }\end{array}$ & $\begin{array}{l}\text { Conclusiones } \\
\text { (Conclusiones) }\end{array}$ & $\begin{array}{l}\text { Comentarios } \\
\text { (Calidad de la evidencia, } \\
\text { financiación comentarios) }\end{array}$ \\
\hline $\begin{array}{l}\text { Jahanfar S, } \\
2013\end{array}$ & $\begin{array}{l}\text { Diseño: } \\
\text { RS } \\
\text { Objetivo: } \\
\text { Examinar la } \\
\text { efectividad del } \\
\text { tratamiento } \\
\text { antibiótico en }\end{array}$ & $\begin{array}{l}\text { N: } 2 \text { ECA } \\
\text { Características: } \\
\text { Un ECA } \\
\text { pequeño(n=25) } \\
\text { que compara } \\
\text { amoxicilna con } \\
\text { cefralina y otro }\end{array}$ & $\begin{array}{l}\text { Comparación 1: } \\
\text { Amoxicilina vs. } \\
\text { cefradina (1 } \\
\text { estudio, } n=25) \\
\text { Comparación 2: } \\
\text { Tratamiento } \\
\text { antibiótico junto a }\end{array}$ & $\begin{array}{l}\text { Comparación 1: } \\
\text { Mejora de los síntomas valorado de } \\
\text { forma clínica } \\
\text { Comparación 2: } \\
\text { Mejora de los síntomas valorados por el } \\
\text { clínico y la continuación de la lactancia }\end{array}$ & $\begin{array}{l}\text { La evidencia es } \\
\text { insuficiente para confirmar } \\
\text { o refutar la efectividad del } \\
\text { tratamiento con } \\
\text { antibióticos en el manejo } \\
\text { de la mastitis puerperal. } \\
\text { Existe una necesidad }\end{array}$ & $\begin{array}{l}\text { Ver valoración AMSTAR } \\
\text { en ANEXOS. }\end{array}$ \\
\hline
\end{tabular}




\begin{tabular}{|c|c|c|c|c|c|c|}
\hline $\begin{array}{l}\text { Referencia } \\
\text { (Cita } \\
\text { Abreviada) }\end{array}$ & $\begin{array}{l}\text { Estudio } \\
\text { (Diseño y } \\
\text { objetivo) }\end{array}$ & $\begin{array}{l}\text { Población } \\
\text { (noy } y \\
\text { características) }\end{array}$ & $\begin{array}{l}\text { Intervención/ } \\
\text { Comparación. } \\
\text { exposiciones o } \\
\text { pruebas a estudio }\end{array}$ & $\begin{array}{l}\text { Resultados } \\
\text { (Estimadores de resultados-Magnitud } \\
\text { del efecto) }\end{array}$ & $\begin{array}{l}\text { Conclusiones } \\
\text { (Conclusiones) }\end{array}$ & $\begin{array}{l}\text { Comentarios } \\
\text { (Calidad de la evidencia, } \\
\text { financiación comentarios) }\end{array}$ \\
\hline & $\begin{array}{l}\text { aliviar los } \\
\text { síntomas de las } \\
\text { madres que } \\
\text { amamantan y } \\
\text { tienen mastitis } \\
\text { con o sin } \\
\text { pruebas de } \\
\text { laboratorio. }\end{array}$ & $\begin{array}{l}\text { que compara el } \\
\text { vaciamiento de } \\
\text { las mamas como } \\
\text { tratamiento de } \\
\text { apoyo frente al } \\
\text { tratamiento } \\
\text { antibiótico y } \\
\text { tratamiento de } \\
\text { apoyo. }\end{array}$ & $\begin{array}{l}\text { vaciamiento versus } \\
\text { vaciamiento sólo } \\
\text { (1 estudio, } 165 \\
\text { casos) }\end{array}$ & & $\begin{array}{l}\text { urgente de que se } \\
\text { realicen ECAs de alta } \\
\text { calidad, doble ciego para } \\
\text { determinar si los } \\
\text { antibióticos deberían ser } \\
\text { utilizados en esta } \\
\text { condición postparto } \\
\text { común. } \\
\text { Los resultados del estudio } \\
\text { más grande sugieren } \\
\text { mayor alivio de los } \\
\text { síntomasal utilizar } \\
\text { antibióticos, aunque el } \\
\text { diseño del estudio es } \\
\text { problemático. }\end{array}$ & \\
\hline
\end{tabular}




\subsection{Resumen de GPC base y RS disponibles}

En el CKS de NICE sobre mastitis (1), cuando se trata de un tratamiento empírico, se recomienda el uso de flucloxacilina $500 \mathrm{mg}$, cuatro veces al día durante 14 días y como alternativa eritromicina, $250-500 \mathrm{mg}$ cuatro veces al día durante 14 días.

También recomiendan que si se confirma infección estafilocócica o estreptocócica, se observe al niño para identificar síntomas de infección y pedir consejo al pediatra si el niño no se encuentra bien (aunque señalan que es improbable que ocurra esto).

En el protocolo de la ABM de 2014 (2), se señala que los antibióticos de preferencia son las penicilinas resistentes a betalactamasas, como dicloxacilina o flucloxacilina $500 \mathrm{mg}$ vía oral cuatro veces al día o lo recomendado a nivel local según los microorganismos aislados y su sensibilidad (mapa microbiológico) las sensibilidades (III), aunque la dicoxacilina parece tener menor ratio de efectos adversos hepáticos que la flucoxacilina. También se consideran las cefalosporinas de primera generación como primera línea de tratamiento, aunque son menos aceptadas por su mayor espectro de cobertura, con la consiguiente posibilidad de seleccionar cepas con resistencia antibacteriana. Cefalexina es normalmente segura para mujeres con alergia a penicilina, pero en casos de hipersensibilidad severa se sugiere el uso de clindamicina. En cuanto a la duración, se señala que muchas autoridades recomiendan 10-14 días de tratamiento, aunque se trata de una recomendación que no se apoya en ECA.

En este protocolo se señala que la presencia de $S$. aureus resistentes a meticilina (SARM) en mastistis y abscesos ha ido en aumento (sobre todo en EEUU) por lo que, si la mastitis no mejora tras $48 \mathrm{~h}$ de tratamiento de primera línea, se debería realizar un cultivo. La mayoría de las cepas son sensibles a vancomicina o trimetoprim/sulfamethoxazole pero pueden no ser susceptibles a rifampicina. Se debería asumir que las SARM son resistentes al tratamiento con macrólidos y quinolonas, aun sin tener los resultados de susceptibilidad.

En la PSBC (3) tras las 12-24 horas iniciales se recomienda el uso de antibióticos si no ha habido mejoría, o si se presentan fisuras en el pezón o están agrietados, lo que indicaría una posible mastitis infecciosa. Señalan que el patógeno más común es $S$. aureus resistente a penicilina, siendo el estreptococo o Escherichia coli menos comunes. Se sugiere el uso de penicilinas resistentes a meticiclina (dicloxaciclina 0 flucloxacilina $500 \mathrm{mg} /$ día o cefalexina cuando se sospecha de alergia a penicilina). Se basa en el protocolo de ABM de 2008. Y aunque no está clínicamente estudiado, recomiendan una duración de 10-14 días de tratamiento antibiótico.

En la guía del embarazo de 2014 (4) no se señala qué antibiótico utilizar.

\subsection{Conclusión}

\begin{tabular}{|l|l|}
\hline & Adopción GPC/Revisión sistemática \\
\hline $\mathrm{X}$ & Elaboración parcial \\
\hline & Elaboración de novo \\
\hline
\end{tabular}

\subsection{Diseño de la estrategia de búsqueda de estudios individuales}




\begin{tabular}{|l|l|}
\hline $\begin{array}{l}\text { Criterios de selección de } \\
\text { estudios }\end{array}$ & $\begin{array}{l}\bullet \text { ECAs } \\
\bullet \text { Estudios observacionales }\end{array}$ \\
\hline Período de búsqueda & \\
\hline Bases de datos & $\begin{array}{l}\text { Cochrane Library } \\
\text { Medline via Pubmed } \\
\text { Embase via OVID } \\
\text { Cinahl via EBSCO } \\
\text { PsylNFO via OVID }\end{array}$ \\
\hline
\end{tabular}

Ver estrategias de búsqueda de estudios originales en el anexo I. 


\section{4- Resumen de la evidencia (Tablas de estudios individuales y valoración de calidad en el ANEXO II)}

\section{1- GRADE Evidence Profile}

Comparación 1: Amoxicilina vs. Cefradina

Bibliografía: Hager et al, 1996

\begin{tabular}{|c|c|c|c|c|c|c|c|c|c|c|c|c|}
\hline \multirow{2}{*}{\multicolumn{7}{|c|}{ Evaluación de la calidad }} & \multicolumn{4}{|c|}{ Resumen de los Resultados } & \multirow{3}{*}{ Calidad } & \multirow{3}{*}{ Importancia } \\
\hline & & & & & & & \multicolumn{2}{|c|}{ № de pacientes } & \multicolumn{2}{|c|}{ Magnitud del efecto } & & \\
\hline \begin{tabular}{|c|} 
№ de \\
estudios
\end{tabular} & Diseño & \begin{tabular}{|c|} 
Riesgo de \\
sesgo
\end{tabular} & Inconsistencia & \begin{tabular}{|l|}
$\begin{array}{c}\text { Evidencia } \\
\text { indirecta }\end{array}$ \\
\end{tabular} & Imprecisión & \begin{tabular}{|c|} 
Otras \\
consideraciones
\end{tabular} & Amoxicilina & Cefradina & $\begin{array}{l}\text { Relativa } \\
(95 \% \mathrm{Cl}) \\
\end{array}$ & Absoluta por 1000 & & \\
\hline \multicolumn{13}{|c|}{ Resolución de los síntomas valorado por el clínico a los 7 días } \\
\hline 1 & ECA & Serio ${ }^{1}$ & No seria & Seria ${ }^{2}$ & Seria $^{3}$ & Ninguna & $\begin{array}{c}11 / 13 \\
(84,6 \%) \\
\end{array}$ & $\begin{array}{c}12 / 12 \\
(100 \%) \\
\end{array}$ & $\begin{array}{l}\text { RR } 0,89 \text { (de } \\
0,65 \text { a } 1,12 \text { ) } \\
\end{array}$ & $\begin{array}{l}110 \text { menos por } 1000 \text { (de } \\
350 \text { menos a } 120 \text { más) }\end{array}$ & MUY BAJA & CRITICA \\
\hline \multicolumn{13}{|c|}{ Recurrencia de los síntomas a los 30 días de haber respondido al tratamiento } \\
\hline 1 & ECA & Serio $^{1}$ & No seria & Seria ${ }^{2}$ & \begin{tabular}{|l|l|} 
Seria $^{3}$ & $\wedge$
\end{tabular} & Ninguna & $1 / 13^{*}(7,7 \%)$ & $\begin{array}{l}2 / 12^{\star *} \\
(16,7 \%)\end{array}$ & $\begin{array}{l}\text { RR } 0,91 \text { (de } \\
0,69 \text { a } 1,1 \text { ) }\end{array}$ & $\begin{array}{l}18 \text { menos por } 1000 \text { (de } \\
58 \text { menos a } 20 \text { más) }\end{array}$ & MUY BAJA & CRITICA \\
\hline
\end{tabular}

${ }_{1}^{1}$ No se menciona el método de aleatorización y el tamaño muestral es pequeño; ${ }^{2}>90 \%$ de resistencia de SAMS a penicilina y por tanto a amoxicilina; quizá la frecuencia de resistencia no era tan alta en el año del estudio, pero era ya significativa como muestra el propio estudio (recurrencias en pacientes tratadas con amoxicilina, por cepas resistentes); ${ }^{3}$ Pocos eventos

* La recurrencia se da en un caso con $\mathrm{S}$. aureus, y cuando se da la recurrencia crece el mismo organismo.

** Las dos recurrencias se dan en pacientes que eran positivos a cultivo de estafilococo coagulasa negativo en la admisión al estudio. Cuando se da la recurrencia, los cultivos de estos pacientes fueron negativos. 


\subsection{Resumen de la evidencia}

El único ECA identificado que compara la eficacia de dos antibióticos diferentes (amoxicilina frente a cefradina) en el tratamiento empírico de las mastisis agudas es el de

ya comentado

Hager et al, 1996 (5),

Aunque cabe

anteriormente

de un estudio

señalar que se trata

que incluye

de más de 20 años y

muy pocos casos.

Además del

han

estudio de Hager, se identificado otros dos objetivo no es

ECA (6) cuyo

eficacia de diferentes

antibióticos en el tratamiento empírico de las mastitis agudas, aunque proporcionan datos secundarios sobre la eficacia de los diferentes antibióticos utilizados en el grupo de comparación que sí era tratado con antibióticos.

En el estudio de Hager et al, 1996, se incluyeron 25 mujeres con fiebre $>37,56^{\circ} \mathrm{C}$, que presentaban dolor a la palpación de la mama y "segmental erythema". 13 de ellas fueron tratadas con amoxicilina oral 500mg cada ocho horas y 12 con cefradina oral $500 \mathrm{mg}$ cada seis horas.,En ambos grupos el tratamiento duró siete días. A todas las pacientes se les recomendaba continuar con la lactancia materna y aplicar compresas húmedas calientes en la o las mamas afectadas cada cuatro-seis horas.

La visita de seguimiento se hizo a los siete días de iniciar el tratamiento, no encontrándose diferencias significativas entre los dos grupos en la resolución de los síntomas (RR de 0,85; IC95\% de 0,65 a 1,12).

El número de días en el que se resolvieron los síntomas fue de 4,2 (rango de 1 a 5) frente a 3,8 días (rango de 1 a 4) y sólo se registró un absceso mamario en el grupo tratado con amoxicilina. La recurrencia de los síntomas a los $\mathbf{3 0}$ días se dio en una madre tratada con amoxicilina y dos madres tratadas con cefradina (diferencias no significativas).

Los autores recomendaron la utilización empírica de antibióticos resistentes a blactamasas como cefalosporinas, a la vez de aplicar calor húmedo y continuar con la lactancia materna.

S.aureus (71/165) y SCN (48/165).. De las 71 cepas aisladas de Staphylococcus aureus, $48(67,6 \%)$ eran resistentes a penicilina, siendo la mayoría sensibles a meticilina, eritromicina y sulfonamidas. De las 41 cepas aisladas de SCN, 23 $(56,1 \%)$ eran resistentes a penicilina, aunque casi todas eran sensibles a eritromicina y sulfonamidas. Sin embargo, se trata de un estudio muy antiguo, puesto que en la actualidad más del $90 \%$ de las cepas de $S$. aureus meticilino sensible ('SAMS) y de SCN son resistentes a penicilina

Cabe destacar que en este estudio se incluyeron madres que presentaban síntomas inflamatorios en las mamas (sensibilidad o dolor, inflamación y rojez, calor y disminución de secreción de leche) y que se trata de un estudio antiguo, por lo que probablemente sus resultados no son aplicables en la actualidad.

En el estudio de Arroyo de 2010 (7), que incluye mujeres con dolor e inflamación uni o bilateral,, las especies más frecuentemente aisladas fueron $S$. epidermidis y S. aureus (ver tabla 1) en los tres grupos en estudio. 
TABLE 2. Bacteriology (principal isolates) of SAPM

\begin{tabular}{|c|}
\hline 5 aaress (FCNR, Caph-ST) \\
\hline Amoxiciln-trested \\
\hline Cophridhe-reated \\
\hline Staphpiseoceal species (RCN-R, Ceph-S) \\
\hline Amoxiciln-evatad \\
\hline Cephradineureawed \\
\hline a Serepocococaus \\
\hline Group 3 streptockopean. \\
\hline Prepistoscserim acse \\
\hline
\end{tabular}

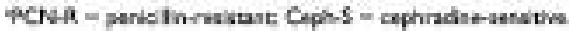

\begin{tabular}{|l|l|l|l|}
\hline Tipo bacteria & Grupo A & Grupo B & $\begin{array}{l}\text { Grupo } \\
\text { C }\end{array}$ \\
\hline S. epidermidis & $92 / 124(74,2 \%)$ & $\begin{array}{l}88 / 127 \\
(69,3 \%)\end{array}$ & $\begin{array}{l}76 / 101 \\
(75,2 \%)\end{array}$ \\
\hline S. aureus & $67 / 124(54 \%)$ & $55 / 127(43,3 \%)$ & $30 / 101$ \\
& & & $(29,7 \%)$ \\
\hline S. mitis & $36 / 124(29 \%)$ & $36 / 127$ & $35 / 101$ \\
& & $(28,3 \%)$ & $(34,7 \%)$ \\
\hline
\end{tabular}

En este caso, se incluyeron madres que presentaban dolor al amamantar e inflamación en las mamas, así como un recuento de bacterias superior a $4 \log _{10}$ de $\mathrm{UFC} / \mathrm{ml}$ y un recuento de leucocitos de $>6 \log _{10}$ células $/ \mathrm{ml}$.

Delgado S et al, 2009 (8) publicaron un estudio en el que aislaron los estafilococos en la leche de mujeres con mastitis lactacional para caracterizar las cepas aisladas de SCN y comparar sus propiedades con las de las cepas aisladas de mujeres sanas que amamantan.

Se incluyeron 30 mujeres en el estudio, aunque los cultivos fueron positivos en 27 de ellas, siendo las especies más frecuentemente aisladas $S$. epidermidis y $S$. aureus. Se consiguieron aislar 76 perfiles diferentes de $S$. epidermidis, observando que el número de cepas que contiene el gen relacionado con la producción de biofilms y la resistencia a oxaciclina, eritromicina, clindamicina y mupirocina era significativamente mayor en las cepas aisladas de la leche de madres con mastitis que de la leche de las madres control. 


\section{4- De la evidencia a la recomendación (Tabla de EtR)}

No hay evidencia sobre las comparaciones que se quieren estudiar. Los estudios que hay no aportan pruebas de cuál es el mejor antibiótico a utilizar en caso de mastitis agudas, por lo que finalmente se realizan recomendaciones de buena práctica, siguiendo las recomendaciones que realizan otras guías y la opinión del grupo de trabajo de la guía.

\begin{tabular}{|c|c|}
\hline$\frac{\text { Recomendación }}{\text { (Texto) }}$ & $\begin{array}{l}\text { Recomendación de buena práctica } \\
\text { Para el tratamiento empírico de las mastitis agudas que no responden a las medidas conservadoras, utilizar cefalosporinas de } \\
\text { primera generación (cefalexinao cefadroxilo) o en su caso cloxaciclina durante } 10 \text { a } 14 \text { días. } \\
\text { Si la madre es alérgica a los betalactámicos, se puede utilizar clindamicina. Cuando el lactante tenga más de 4-6 semanas de vida } \\
\text { puede utilizarse también trimetroprim sulfametoxazol. }\end{array}$ \\
\hline Justificación & $\begin{array}{l}\text { En ausencia de evidencia o de ensayos clínicos que comparen los antibióticos en el tratamiento de la mastitis aguda, se deberían } \\
\text { recomendar aquellos que son más eficaces en el tratamiento de las infecciones por } S \text {. aureus, que es el agente etiológico más } \\
\text { frecuente en las mastitis agudas. } \\
\text { No se recomienda el uso de amoxicilina clavulánico por ser un antibiótico de amplio espectro con efectos adversos en la microbiota } \\
\text { intestinal, y existir otras alternativas también eficaces, como las cefalosporinas de primera generación. Cloxaciclina es activa frente } \\
\text { a S.aureus pero hay que tener en cuenta que su biodisponibilidad oral es del } 50-75 \% \text { y que en infecciones moderadas o graves } \\
\text { debería administrarse por vía intravenosa, por lo que no se recomendaría su uso en general en mastitis aguda por vía oral. } \\
\text { En cuanto a los macrólidos, no se suelen utilizar para el tratamiento de } S \text {. aureus. Y en referencia a clindamicina y cotrimoxazol, } \\
\text { además de ser activos frente a S. aureus sensible a meticilina (SAMS), también lo son frente a SARM comunitaria y frente a } \\
\text { Streptococcus sp, y pueden utilizarse en caso de alergia a penicilina. } \\
\text { En general no se recomienda el tratamiento con una quinolona, como ciprofloxacino en monoterapia por riesgo de desarrollo de } \\
\text { resistencias, sobre todo en infecciones de inóculo alto y en tratamiento prolongado. Ciprofloxacino podría ser una alternativa en } \\
\text { casos de mastitis aguda en pacientes que no toleran cefalosporinas ni clindamicina (9). }\end{array}$ \\
\hline \multicolumn{2}{|l|}{$\begin{array}{l}\text { Consideraciones de } \\
\text { subgrupos }\end{array}$} \\
\hline \multicolumn{2}{|l|}{$\begin{array}{l}\text { Consideraciones para } \\
\text { la implementación }\end{array}$} \\
\hline $\begin{array}{l}\text { Monitorización y } \\
\text { evaluación }\end{array}$ & - \\
\hline
\end{tabular}




\begin{tabular}{|c|c|}
\hline $\begin{array}{l}\text { Prioridades para la } \\
\text { investigación }\end{array}$ & $\begin{array}{l}\text { - Se necesitan estudios que comparen la eficacia de los diferentes antibióticos en el tratamiento empírico de las mastitis agudas } \\
\text { puerperales y de la duración que éstos deberían temer. } \\
\text { - Se necesitan estudios epidemiológicos recientes sobre la etiología de la mastitis aguda lactacional en nuestro medio. }\end{array}$ \\
\hline
\end{tabular}


GPC Lactancia Materna - Pregunta 35. Antibiótico de elección en mastitis

\section{ANEXOS}

Son los mismos que los de la pregunta sobre tratamiento de las mastitis agudas 


\section{BIBLIOGRAFÍA}

(1) Mastitis and breast abscess. Clinical Knowledge Summaries-CSK. 2015. Disponible en:

http://ykmu.tbzmed.ac.ir/uploads/125/CMS/user/file/813/sexual/Mastitis\%20and\% 20breast\%20abscess.pdf.

(2) ABM Clinical Protocol \#4: Mastitis, Revised March 2014. Breastfeeding Medicine, Volume 9, Number 5, 2014.

(3) Perinatal Services BC Health Promotion Guideline. Breastfeeding Healthy Term Infants. March 2015. Disponible en: http://www.perinatalservicesbc.ca/Documents/GuidelinesStandards/HealthPromotion/BreastfeedingHealthyTermInfantGuideline.pdf.

(4) Grupo de trabajo de la Guía de práctica clínica de atención en el embarazo y puerperio. Guía de práctica clínica de atención en el embarazo y puerperio. Ministerio de Sanidad, Servicios Sociales e Igualdad. Agencia de Evaluación de Tecnologías Sanitarias de Andalucía: 2014. Guías de Práctica Clínica en el SNS: AETSA 2011/10.

(5) Hager WD, Barton JR. Treatment of sporadic acute puerperal mastitis. Infect Dis Obstet Gynecol 1996;4(2):97-101.

(6) Thomsen AC, Espersen T, Maigaard S. Course and treatment of milk stasis, noninfectious inflammation of the breast, and infectious mastitis in nursing women. Am J Obstet Gynecol 1984 Jul 1;149(5):492-5.

(7) Arroyo R, Martin V, Maldonado A, Jimenez E, Fernandez L, Rodriguez JM. Treatment of infectious mastitis during lactation: antibiotics versus oral administration of Lactobacilli isolated from breast milk. Clin Infect Dis 2010 Jun 15;50(12):1551-8.

(8) Delgado S, Arroyo R, Jimenez E, Marin ML, del CR, Fernandez L, et al. Staphylococcus epidermidis strains isolated from breast milk of women suffering infectious mastitis: potential virulence traits and resistance to antibiotics. BMC Microbiol 2009;9:82.

(9) Mensa J. Guía de tratamiento antimicrobiano de la infección por Staphylococcus aureus. Rev Esp Quimioter 2013;26 (Suppl 1:1-84). 
PREGUNTA CLÍNICA № 36

¿Se puede utilizar el drenaje por aspiración con aguja bajo control ecográfico como alternativa al drenaje quirúrgico tradicional en el tratamiento del absceso mamario?

\section{1- Pregunta clínica en formato PICO}

Tabla 1- Componentes de la pregunta clínica en formato PICO

\begin{tabular}{|l|l|}
\hline Pacientes & Madre que amamanta y presenta un absceso mamario \\
\hline Intervención & Drenaje por aguja bajo control ecográfico \\
\hline Comparación & Drenaje quirúrgico \\
\hline Resultados & $\begin{array}{l}\text { Tasa de curación del absceso } \\
\text { Recidiva del absceso } \\
\text { Tiempo de curación } \\
\text { Tasa de abandono de la lactancia materna } \\
\text { Complicaciones de las intervenciones }\end{array}$ \\
\hline Tipo de estudio & ECA, Estudios observacionales \\
\hline
\end{tabular}

\section{2- Introducción}




\section{ESTRATEGIA DE ELABORACIÓN DE LA PREGUNTA}

\subsection{GPC Base}

Tabla 2- Resumen de GPC Base

\begin{tabular}{|c|c|c|c|c|}
\hline $\begin{array}{c}\text { Guía } \\
\text { (Enfoque) }\end{array}$ & $\begin{array}{l}\text { Resumen sobre la evidencia } \\
\text { (Calidad de la evidencia) }\end{array}$ & $\begin{array}{l}\text { Recomendaciones } \\
\text { (Grado) }\end{array}$ & $\begin{array}{c}\text { Referencias } \\
\text { bibliográficas } \\
\text { (Tipo de } \\
\text { publicación) }\end{array}$ & Comentarios \\
\hline $\begin{array}{l}\text { NICE, } \\
2006 \\
\text { (Actualiz } \\
\text { 2011) }\end{array}$ & - & - & & \\
\hline $\begin{array}{l}\text { Protocolo } \\
\text { ABM \#4, } \\
2014\end{array}$ & $\begin{array}{l}\text { The collection can often be drained by needle } \\
\text { aspiration, which itself can be diagnostic as } \\
\text { well as therapeutic. Serial needle aspirations may be } \\
\text { required. } 31-33 \text { (III) Ultrasound guidance for needle } \\
\text { aspiration may be necessary in some cases. Fluid or } \\
\text { pus aspirated should be sent for culture. } \\
\text { Consideration of resistant organisms should also be } \\
\text { given depending on the incidence of resistant } \\
\text { organisms in that particular environment. Surgical } \\
\text { drainage may be necessary if the abscess is very } \\
\text { large or if there are multiple abscesses. After } \\
\text { surgical drainage, breastfeeding on the affected } \\
\text { breast should continue, even if a drain is } \\
\text { present, with the proviso that the infant's mouth does } \\
\text { not come into direct contact with purulent drainage } \\
\text { or infected tissue. A course of antibiotics should } \\
\text { follow drainage of the abscess. (III). }\end{array}$ & & & \\
\hline
\end{tabular}




\begin{tabular}{|c|l|c|c|}
\hline $\begin{array}{c}\text { Guía } \\
\text { (Enfoque) }\end{array}$ & \multicolumn{1}{|c|}{$\begin{array}{c}\text { Resumen sobre la evidencia } \\
\text { (Calidad de la evidencia) }\end{array}$} & $\begin{array}{c}\text { Referencias } \\
\text { bibliográficas } \\
\text { (Tipo de } \\
\text { publicación) }\end{array}$ & $\begin{array}{c}\text { Recomendaciones } \\
\text { (Grado) }\end{array}$ \\
\hline & $\begin{array}{l}\text { Comentarios } \\
\text { initiation of antibiotic treatment if the mother is } \\
\text { comfortable and the infant's mouth has no contact } \\
\text { - Otherwise or infected tissue101,104 } \\
\text { during this period to mains milk from affected breast }\end{array}$ & & \\
\hline
\end{tabular}

\subsection{Revisiones sistemáticas}

En la búsqueda realizada se identificó una revisión sobre el manejo de la mastitis y los abscesos puerperales(1), que fue excluida por tratarse de una revisión narrativa. 


\subsection{Resumen de GPC base y RS disponibles}

El Protocolo 4 de la ABM señala que la colección de pus puede ser drenada a menudo por aspiración por aguja, y que pueden requerirse aspiraciones seriadas, siendo a veces necesaria la aspiración guiada por ultrasonidos. El drenaje quirúrgico puede ser necesario si el absceso es muy grande o si hay abscesos múltiples. Tras el drenaje quirúrgico se recomienda seguir amamantando del pecho afectado, incluso si hay un sistema de drenaje, siempre y cuando la boca del lactante no entre en contacto directo con el drenaje purulento o tejido infectado. Tras el drenaje se debería administrar un curso de tratamiento antibiótico (2).

En la PSBC (3) se indica que se aconseja el uso de ultrasonidos para diagnosticar y guiar la aspiración o el drenaje quirúrgico, si es necesario. La lactancia materna puede continuar por el pecho no afectado y puede continuar del pecho afectado tras el drenaje del absceso y el inicio de tratamiento antibiótico, si la madre está cómoda y si la boca del niño no entra en contacto con el drenaje o tejido infectado. Si no, se puede extraer la leche de forma manual del pecho afectado durante este período para mantener la producción de la misma.

En cuanto a la búsqueda de RS, no se han encontrado $\mathrm{RS}$ al respecto.

\subsection{Conclusión (marcar con una X):}

\begin{tabular}{|l|l|}
\hline & Adopción GPC/Revisión sistemática \\
\hline & Elaboración parcial \\
\hline$X$ & Elaboración de novo \\
\hline
\end{tabular}

\subsection{Diseño de la estrategia de búsqueda de estudios individuales}

Criterios de selección de estudios
Período de búsqueda
Bases de datos

Bases de datos

Ver estrategias de búsqueda de estudios originales en el ANEXO I.
ECA, estudios de cohortes

Sin limites

Cochrane, PUMBED y EMBASE y CINHAL

*También se realizó una búsqueda de términos libres en google 


\section{4- Resumen de la evidencia (Tablas de estudios individuales y valoración de calidad en el ANEXO II)}

\section{1- GRADE Evidence Profile}

Comparación: Drenaje por aguja bajo control ecográfico versus al drenaje quirúrgico tradicional en el tratamiento del absceso mamario Bibliografía:

1. Chandika AB1, Gakwaya AM, Kiguli-Malwadde E, Chalya PL. Ultrasound Guided Needle Aspiration versus Surgical Drainage in the management of breast abscesses: a Ugandan experience. BMC Res Notes. 2012 Jan 6;5:12.

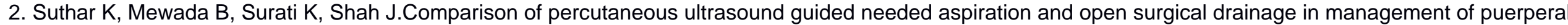
breast abscess Int J Med Sci Public Health. 2013; 2(1): 69-72.

\begin{tabular}{|c|c|c|c|c|c|c|c|c|c|c|c|c|}
\hline \multicolumn{7}{|c|}{ Evaluación de la calidad } & \multicolumn{2}{|c|}{ № de pacientes } & \multicolumn{2}{|r|}{ Efecto } & \multirow[b]{2}{*}{ Calidad } & \multirow[b]{2}{*}{ Importancia } \\
\hline $\begin{array}{c}\text { № de } \\
\text { estudios }\end{array}$ & $\begin{array}{l}\text { Diseño de } \\
\text { estudio }\end{array}$ & $\begin{array}{l}\text { Riesgo de } \\
\text { sesgo }\end{array}$ & Inconsistencia & $\begin{array}{l}\text { Evidencia } \\
\text { indirecta }\end{array}$ & Imprecisión & $\begin{array}{c}\text { Otras } \\
\text { consideraciones }\end{array}$ & $\begin{array}{l}\text { Drenaje con } \\
\text { aguja bajo } \\
\text { control } \\
\text { ecográfico }\end{array}$ & $\begin{array}{l}\text { Drenaje } \\
\text { quirúrgico } \\
\text { tradicional }\end{array}$ & $\begin{array}{l}\text { Relativo } \\
(95 \% \mathrm{Cl})\end{array}$ & $\begin{array}{l}\text { Absoluto } \\
(95 \% \mathrm{Cl})\end{array}$ & & \\
\hline \multicolumn{13}{|c|}{ Tasa de curación (abscesos $\leq 5 \mathrm{~mm}$ de diámetro) a los $30-35$ días } \\
\hline 2 & ECA & serio $^{1}$ & no serio ${ }^{2}$ & no serio $^{3}$ & serio $^{4}$ & ninguno & $\begin{array}{c}48 / 53 \\
(90.6 \%)\end{array}$ & $48 / 52(92.3 \%)$ & $\begin{array}{c}\text { RR } 0.97 \\
(0.87 \text { a } 1.08)\end{array}$ & $\begin{array}{l}28 \text { menos por } 1000 \text { (de } \\
74 \text { menos a } 120 \text { más) }\end{array}$ & $\begin{array}{c}\oplus \oplus \bigcirc \bigcirc \\
\text { BAJA }\end{array}$ & CRÍTICA \\
\hline \multicolumn{13}{|c|}{ Tasa de curación (abscesos $>5 \mathrm{~cm}$ de diámetro) a los 35 días } \\
\hline 1 & ECA & serio $^{5}$ & no serio 6 & no serio & serio $^{7}$ & ninguno & $\begin{array}{c}10 / 15 \\
(66.7 \%)\end{array}$ & $15 / 15(100.0 \%)$ & $\begin{array}{c}\text { RR } 0.68 \\
(0.47 \text { a } 0.98)\end{array}$ & $\begin{array}{l}320 \text { menos por } 1000 \text { (de } \\
20 \text { menos a } 530 \text { menos ) }\end{array}$ & $\begin{array}{c}\oplus \oplus \bigcirc \bigcirc \\
\text { BAJA }\end{array}$ & CRÍTICA \\
\hline \multicolumn{13}{|c|}{ Recidiva del absceso a los 30-35 días de seguimiento } \\
\hline 2 & ECA & serio $^{8}$ & serio $^{9}$ & no serio ${ }^{3}$ & serio $^{10}$ & ninguno & - & - & - & $\begin{array}{l}\text { Ver resumen de la } \\
\text { evidencia }\end{array}$ & $\begin{array}{l}\oplus \bigcirc \bigcirc \bigcirc \\
\text { MUY BAJA }\end{array}$ & CRÍTICO \\
\hline \multicolumn{13}{|c|}{ Tiempo de curación } \\
\hline 2 & ECA & serio $^{1}$ & no serio ${ }^{10}$ & no serio ${ }^{3}$ & serio $^{11}$ & ninguno & - & - & - & $\begin{array}{l}\text { Ver resumen de la } \\
\text { evidencia }\end{array}$ & $\begin{array}{c}\oplus \oplus \bigcirc \bigcirc \\
\text { BAJA }\end{array}$ & CRÍTICA \\
\hline
\end{tabular}


GPC Lactancia Materna-Pregunta 36. Drenaje absceso mamario.

\begin{tabular}{|c|c|c|c|c|c|c|c|c|c|c|c|c|}
\hline \multicolumn{7}{|c|}{ Evaluación de la calidad } & \multicolumn{2}{|c|}{ № de pacientes } & \multicolumn{2}{|r|}{ Efecto } & \multirow[b]{2}{*}{ Calidad } & \multirow[b]{2}{*}{ Importancia } \\
\hline $\begin{array}{c}\text { № de } \\
\text { estudios }\end{array}$ & $\begin{array}{l}\text { Diseño de } \\
\text { estudio }\end{array}$ & $\begin{array}{l}\text { Riesgo de } \\
\text { sesgo }\end{array}$ & Inconsistencia & $\begin{array}{l}\text { Evidencia } \\
\text { indirecta }\end{array}$ & Imprecisión & $\begin{array}{c}\text { Otras } \\
\text { consideraciones }\end{array}$ & $\begin{array}{c}\text { Drenaje con } \\
\text { aguja bajo } \\
\text { control } \\
\text { ecográfico }\end{array}$ & $\begin{array}{l}\text { Drenaje } \\
\text { quirúrgico } \\
\text { tradicional }\end{array}$ & $\begin{array}{l}\text { Relativo } \\
(95 \% \mathrm{Cl})\end{array}$ & $\begin{array}{l}\text { Absoluto } \\
(95 \% \mathrm{Cl})\end{array}$ & & \\
\hline 1 & ECA & serio $^{5}$ & no serio 6 & no serio & serio $^{4}$ & ninguno & $0 / 35(0.0 \%)$ & $3 / 35(8.6 \%)$ & $\begin{array}{c}\text { RR } 0.14 \\
(0.01 \text { a } 2.67)\end{array}$ & $\begin{array}{l}74 \text { menos por } 1000 \text { (de } \\
85 \text { menos a } 143 \text { más ) }\end{array}$ & $\begin{array}{c}\oplus \oplus \bigcirc \bigcirc \\
\text { BAJA }\end{array}$ & CRÍTICA \\
\hline
\end{tabular}

MD-Diferencia de medias, RR-riesgo relativo

1. Chandika 2012, y Suthar 2012, no especifican si realizaron ocultación de la secuencia de aleatorización en ambos estudio, así como tampoco clarifican si se realizó cegamiento.

2. 12: $0 \%(p=0,60)^{2}$

3. El estudio de Chandika 2012, incluye abscesos mamarios puerperales y no puerperales

4. Bajo número de eventos. El IC $95 \%$ no excluye apreciable beneficio ni apreciable daño

5. Suthar 2012, no especifica si realizaron ocultación de la secuencia de aleatorización en el estudio, así como tampoco clarifica si realizó cegamiento.

6. Estudio único

7. Bajo número de eventos

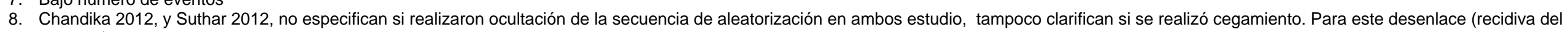
absceso) creemos que el tiempo de seguimiento ha sido muy corto en ambos estudios, lo que podria indicarnos un sesgo de reporte selectivo de datos.

9. Datos inconsistentes entre los dos estudios

10. Datos no agrupados

11. Bajo número de participantes 


\section{2- Resumen de la evidencia}

En la búsqueda de estudios individuales se localizaron cinco estudios. Uno de ellos fue un ECA (4), cuyo objetivo era establecer si el drenaje con aguja bajo control ecográfico es una opción de tratamiento factible de los abscesos mamarios, puerperales y no puerperales.

El segundo estudio (5) fue un ECA que tuvo por objetivo comparar el manejo del absceso mamario puerperal por aspiración percutánea con ecografía guiada frente al drenaje quirúrgico abierto con especial atención a la resolución y las complicaciones.

El tercero, fue un ECA (6) que buscó comparar la eficacia del drenaje con aguja sin control ecográfico en relación al drenaje quirúrgico habitual en el tratamiento de abscesos mamarios puerperales. Fue excluido porque la intervención no se realizó con control ecográfico.

El cuarto estudio (7) tuvo por objetivo comparar las siguientes técnicas: la aspiración percutánea de los abscesos con guía ecográfica versus el drenaje estándar de los abscesos mamarios puerperales y no puerperales. Fue excluido por ser cuasiexperimental y de baja calidad metodológica.

Finalmente, el quinto estudio (8) también fue excluido por ser una serie de casos de mujeres con abscesos mamarios puerperales que fueron tratadas a través de la aspiración percutánea con guía ecográfica de los abscesos.

El primer ECA (4) fue desarrollado en un hospital de alta complejidad en Uganda. Tuvo por objetivo evaluar durante un periodo de 30 días el drenaje con aguja bajo control ecográfico del absceso mamario frente al. drenaje quirúrgico tradicional del absceso mamario

Todas las mujeres recibieron tras las intervenciones, tratamiento analgésico (Diclofenaco $75 \mathrm{mg}$ I.M. y $50 \mathrm{mg}$ cada 8 horas V.O. por tres días), además de tratamiento antibiótico (Cloxacilina $500 \mathrm{mg}$ cada ocho horas V.O. por 10 días.)

El estudio incluyó una muestra de 65 mujeres con absceso mamario (puerperal y no puerperal) de un tamaño máximo cinco $\mathrm{cm}$ de diámetro (medido por ecografía).

El diagnóstico clínico se basó en la presencia de dolor mamario, tumefacción, fiebre, fluctuación de una masa en la mama y fue confirmado por diagnóstico ecográfico. Se excluyeron mujeres con características clínicas de inmunosupresión (estadio clínico según la OMS III y IV) y con alergia a la penicilina.

Los desenlaces evaluados fueron el tiempo de resolución (curación), la tasa de recurrencia, la tasa de aceptabilidad del tratamiento y los costes que implicaban ambas intervenciones.

La conclusión final a la que llegaron los autores es que el drenaje con aguja bajo control ecográfico es una opción de tratamiento factible y coste efectiva de los abscesos mamarios por debajo de cinco centímetros por ecografía y con un sistema inmunitario competente (en mujeres con y sin lactancia materna).

El segundo estudio (5), fue desarrollado en la India e incluyó un total de 70 pacientes con características clínicas sugerentes de absceso mamario puerperal (fiebre, dolor, hinchazón, enrojecimiento de mama asociado con sensibilidad localizada). El diagnóstico fue confirmado por ecografía y por aspiración de pus que se envió para cultivo y pruebas de sensibilidad. Las pacientes con condiciones comórbidas fueron excluidas del estudio. Las pacientes fueron divididas de manera aleatoria en dos grupos (35 
pacientes en cada grupo), con un tiempo total de seguimiento de 35 días: Grupo A. Drenaje con aguja con control ecográfico del absceso mamario; Grupo B. Drenaje quirúrgico tradicional del absceso mamario.

Los desenlaces recogidos fueron la tasa de fracaso del tratamiento, el tiempo de resolución, número de aspiraciones practicadas, y las complicaciones principales.

Se aconsejó a todas las mujeres tratadas con drenaje quirúrgico tradicional continuar con la lactancia materna por el pecho no afectado además de extraerse la leche del pecho afectado, mientras que aquellas tratadas con drenaje con aspiración por aguja se les aconsejo continuar con la lactancia con higiene.

Las conclusiones a las que llega el estudio es que la aspiración percutánea con aguja guiada por ecografia tiene una tasa de fracaso aceptable y es una alternativa efectiva al drenaje quirúrgico del absceso mamario puerperal especialmente para los abscesos mamarios que están comenzando y son de pequeño tamaño.

Los desenlaces de interés que se han tenido en cuenta han sido la tasa de resolución de abscesos, las complicaciones en las mamas, la tasa de continuación de la lactancia, la duración de la lactancia materna (exclusiva y no exclusiva), la lactancia materna exclusiva al mes, a los cuatro meses, a los seis meses y la seguridad en el lactante (infección que pasa al niño).

\section{Comparación 1. Drenaje con aguja bajo control ecográfico versus drenaje quirúrgico tradicional del absceso mamario}

\section{Tasa de curación de los abscesos}

Se realizó un metaanálisis de los dos estudios encontrados $(4 ; 5)$ teniendo en consideración un análisis de subgrupo en función del tamaño del absceso.

En relación a la tasa de resolución de abscesos $\leq 5 \mathrm{~cm}$ de diámetro, no se encontraron diferencias entre ambas técnicas (2 ECA; 96 eventos; RR 0,97; IC 95\% de 0,87 a 1,08).

Calidad

baja

Considerando sólo los datos del estudio de Suthar, que incluyó pacientes con abscesos mamarios $>5 \mathbf{c m}$ de diámetro, se encontró una mayor tasa de resolución de este tipo de abscesos con el drenaje quirúrgico tradicional frente al drenaje con aguja bajo control ecográfico. (1 ECA; 25 eventos; RR 0,68, IC 95\% de 0,47 a 0,98) (5).

\section{Recidiva del absceso}

Dos estudios reportaron los casos de recidiva del absceso; uno de ellos reportó un caso a los 30 días de seguimiento en el grupo tratado con drenaje quirúrgico, y ningún caso en el tratado con aspiración con aguja bajo control ecográfico, no encontrando diferencias entre ambas intervenciones (1 ECA; 1 evento; RR 0,32, IC 95\% de 0,01 a 7,66) (4).

El otro estudio reportó tres casos de recidiva en el grupo tratado con aspiración con aguja bajo control ecográfico a los 35 días de seguimiento. muy baja (5). Nuestra confianza en estos reportes es de muy baja calidad, debido al corto tiempo de seguimiento en ambos estudios que podrían condicionar el reporte de este desenlace. 


\section{Tiempo de curación}

Se calculó la diferencia de medias de los tiempos de curación aportados por un estudio, y no se encontraron diferencias significativas en el tiempo de curación de los abscesos $\leq 5 \mathrm{~cm}$ de diámetro entre el drenaje con aguja bajo control ecográfico y el drenaje quirúrgico tradicional. (1 ECA; 65 pacientes; DM: 0,08; IC 95\% de $-1,40$ a 1,56) (4).

\section{Calidad}

baja

Otro estudio, que incluyó abscesos $\leq 5 \mathrm{~cm}$ y $>5 \mathrm{~cm}$ de diámetro, reportó que todas las pacientes sometidos al drenaje con aguja bajo control ecográfico se curaron antes de los 20 días (el 44,8\% entre el día 1 y el día $5)$, mientras que todos los abscesos mamarios sometidos al drenaje quirúrgico tradicional, todos se curaron antes de los 35 días (ninguno se curó antes del día 10 y sólo el 5,71\% entre el día 16 y el día 20) (5).

\section{Tasa de abandono de la lactancia materna}

Un estudio reportó que $3 / 35$ (8\%) pacientes sometidas al drenaje quirúrgico tradicional abandonaron la lactancia materna como consecuencia de la aparición de una fístula mamaria frente a 0/35 (0\%) de las madres tratadas por aspiración con aguja con control ecográfico, aunque el riesgo relativo no fue estadísticamente significativo (1 ECA; 3 eventos; RR 0,14, IC 95\% de 0,01 a 2,67) (5).

Es importante recalcar que a las mujeres tratadas con drenaje quirúrgico tradicional se les aconsejó continuar con la lactancia materna por el pecho no afectado además de extraerse la leche del pecho afectado, mientras que a aquellas tratadas con drenaje con aspiración por aguja se les aconsejo continuar con la lactancia con higiene, situación que podría haber influido en los resultados reportados por este estudio.

\section{Complicaciones}

Un estudio describió que la principal complicación para el grupo sometido al drenaje percutáneo con aguja con guía ecográfica fue el dolor en un $80 \%$ de las pacientes, siendo la fístula mamaria en tres de las pacientes del grupo sometido al drenaje quirúrgico tradicional la mayor complicación presentada (5).

\section{Calidad baja}

Calidad muy baja

ACTUALIZADO A FECHA DE: 31 de Octubre de 2016 


\section{5- De la evidencia a la recomendación (Tabla de EtR)}

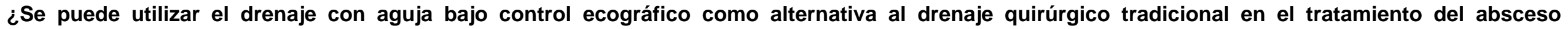
mamario?

Población: Madre sana que amamanta y presenta un absceso mamario

Intervención: Drenaje por aguja bajo control ecográfico

Comparación: Drenaje quirúrgico

Perspectiva: Clínica

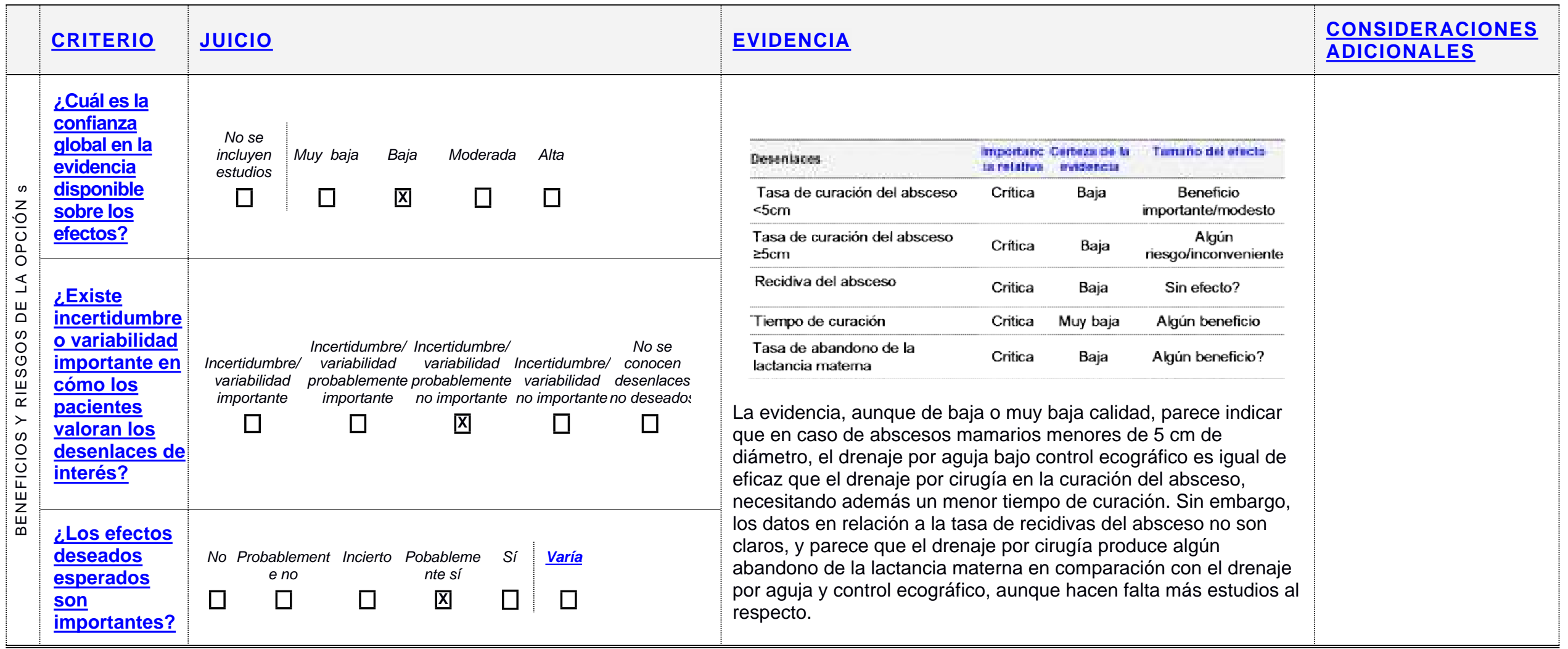




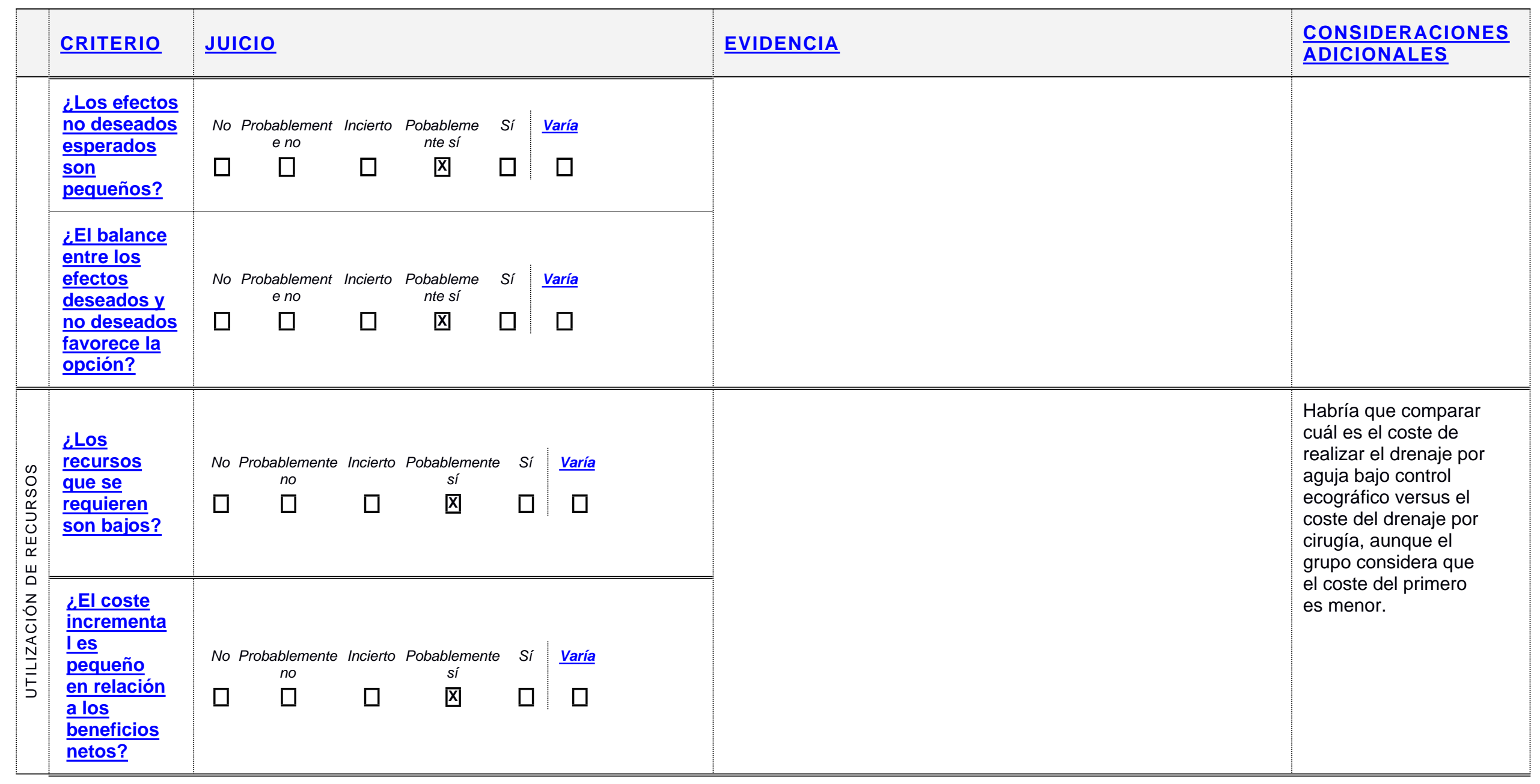




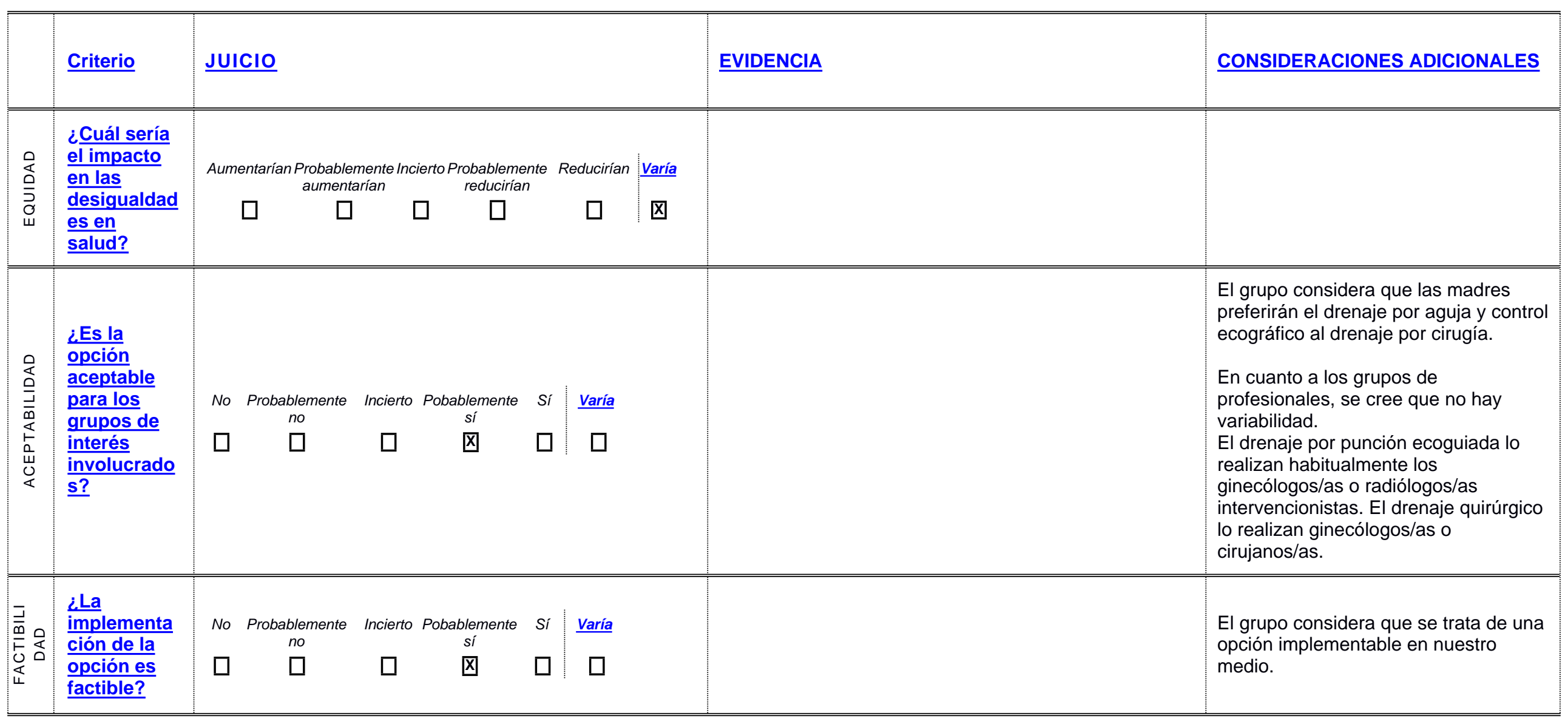




\begin{tabular}{|c|c|c|c|c|c|}
\hline \multirow[t]{2}{*}{$\begin{array}{l}\text { Balance de las } \\
\text { consecuencias }\end{array}$} & $\begin{array}{l}\text { Las consecuencias no } \\
\text { deseadas superan } \\
\text { claramente las } \\
\text { consecuencias deseadas } \\
\text { en la mayoría de los } \\
\text { escenarios }\end{array}$ & $\begin{array}{c}\text { Las consecuencias no } \\
\text { deseadas probablemente } \\
\text { superan las } \\
\text { consecuencias deseadas } \\
\text { en la mayoría de los } \\
\text { escenarios }\end{array}$ & $\begin{array}{c}\text { El balance entre las } \\
\text { consecuencias deseadas y } \\
\text { no deseadas está muy } \\
\text { equilibrado o es incierto }\end{array}$ & $\begin{array}{l}\text { Las consecuencias } \\
\text { deseadas } \\
\text { probablemente superan } \\
\text { las consecuencias no } \\
\text { deseadas en la mayoría } \\
\text { de los escenarios }\end{array}$ & $\begin{array}{l}\text { Las consecuencias } \\
\text { deseadas claramente } \\
\text { superan las } \\
\text { consecuencias no } \\
\text { deseadas en la mayoría } \\
\text { de los escenarios }\end{array}$ \\
\hline & $\square$ & $\square$ & $\square$ & 凶 & $\square$ \\
\hline \multirow[t]{2}{*}{$\frac{\text { Tipo de }}{\text { recomendación }}$} & \multicolumn{2}{|c|}{ Se recomienda no ofrecer la opción } & ofrecer la opción & Se sugiere ofrecer la opción & $\begin{array}{l}\text { Se recomienda } \\
\text { ofrecer la opción }\end{array}$ \\
\hline & \multicolumn{2}{|l|}{$\square$} & $\square$ & 凶 & $\square$ \\
\hline$\frac{\text { Recomendación }}{\text { (Texto) }}$ & \multicolumn{5}{|c|}{$\begin{array}{l}\text { Recomendación débil a favor } \\
\text { Se sugiere el drenaje por aspiración con aguja bajo control ecográfico como alternativa eficaz al drenaje quirúrgico en el tratamiento } \\
\text { de abscesos mamarios de madres lactantes, sobre todo si el diámetro es inferior a cinco centímetros. } \\
\text { En caso de abscesos mamarios mayores de cinco centímetros de diámetro, a la hora de elegir la técnica se sugiere tener en cuenta } \\
\text { las preferencias de la madre, sabiendo que la tasa de fracasos del drenaje por aspiración con aguja bajo control ecográfico puede ser } \\
\text { mayor que la presentada en los casos de drenaje quirúrgico. } \\
\text { Buena práctica } \\
\text { A la hora de realizar un drenaje quirúrgico, siempre que sea posible realizar la incisión en la zona más distal con respecto al pezón } \\
\text { para disminuir la probabilidad de dañar conductos y proporcionar una mayor comodidad para amamantar. }\end{array}$} \\
\hline
\end{tabular}

\section{Justificación}

La evidencia sugiere que el drenaje por aguja bajo control ecográfico es igualmente eficaz que el drenaje por cirugía, sobre todo en abscesos de menos de cinco centímetros de diámetro, además de suponer un menor tiempo para la curación. Sin embargo, la evidencia es menos clara con respecto a las diferencias en su efecto sobre la lactancia materna y las recidivas del absceso.

\section{Consideraciones de Según la evidencia, parece haber diferencias en el éxito de la intervención dependiendo del tamaño inicial del absceso mamario.} subgrupos 
Consideraciones para Hay que tener en cuenta que el drenaje por punción ecoguiada lo realizan habitualmente los ginecólogos/as o radiólogos/as la implementación intervencionistas. El drenaje quirúrgico lo realizan ginecólogos/as o cirujanos/as.

\section{Monitorización y}

evaluación

Prioridades para la investigación

- Se necesitan más estudios sobre la eficacia del drenaje por aguja bajo control ecográfico y sus efectos sobre la lactancia materna. 


\section{ANEXO I, ESTRATEGIAS DE BÚSQUEDA}

\section{Cochrane Library}

Searched 10/07/2015

Updated search 10/07/2015 a xx/xx/xxxx

\#1 breast or puerperal:ti,ab,kw and abscess or abscesses:ti,ab,kw (Word variations have been searched) 52

\#2 drainage:ti,ab,kw or incision:ti,ab,kw (Word variations have been searched) 9294

\#3 \#1 and \#2 8

\#4 lactation or lactational or lactating:ti,ab,kw or breastfeeding or "breast feeding":ti,ab,kw

(Word variations have been searched) 9646

\#5 \#3 and \#4 2

\section{MEDLINE, via Pubmed}

Searched 10/07/2015

Updated search 10/07/2015 a xx/xx/xxxx

\#1 Search ((breast[Title/Abstract] OR puerperal[Title/Abstract])) AND

(abscess[Title/Abstract] OR abscesses[Title/Abstract]) 1007

\#2 Search drainage[Title/Abstract] 69475

\#3 \#1 AND \#2 172

\#4 Search ((lactation[Title/Abstract] OR lactational[Title/Abstract] OR

lactating[Title/Abstract])) OR (breastfeeding[Title/Abstract] OR "breast feeding"[Title/Abstract]) 63448

\#5 \#3 AND \#4 43

\#6 \#5 Filters: Meta-Analysis; Systematic Reviews 0

\#7 Search ((review[Title/Abstract] OR reviews[Title/Abstract])) OR

(metaanalysis[Title/Abstract] OR meta-analysis[Title/Abstract] OR "meta analysis"[Title/Abstract]) 1153912

\#8 $\quad$ \#5 AND \#7 10

\section{EMBASE, via Ovid}

\section{Searched 10/07/2015}

\section{Updated search 10/07/2015 a xx/xx/xxxx}

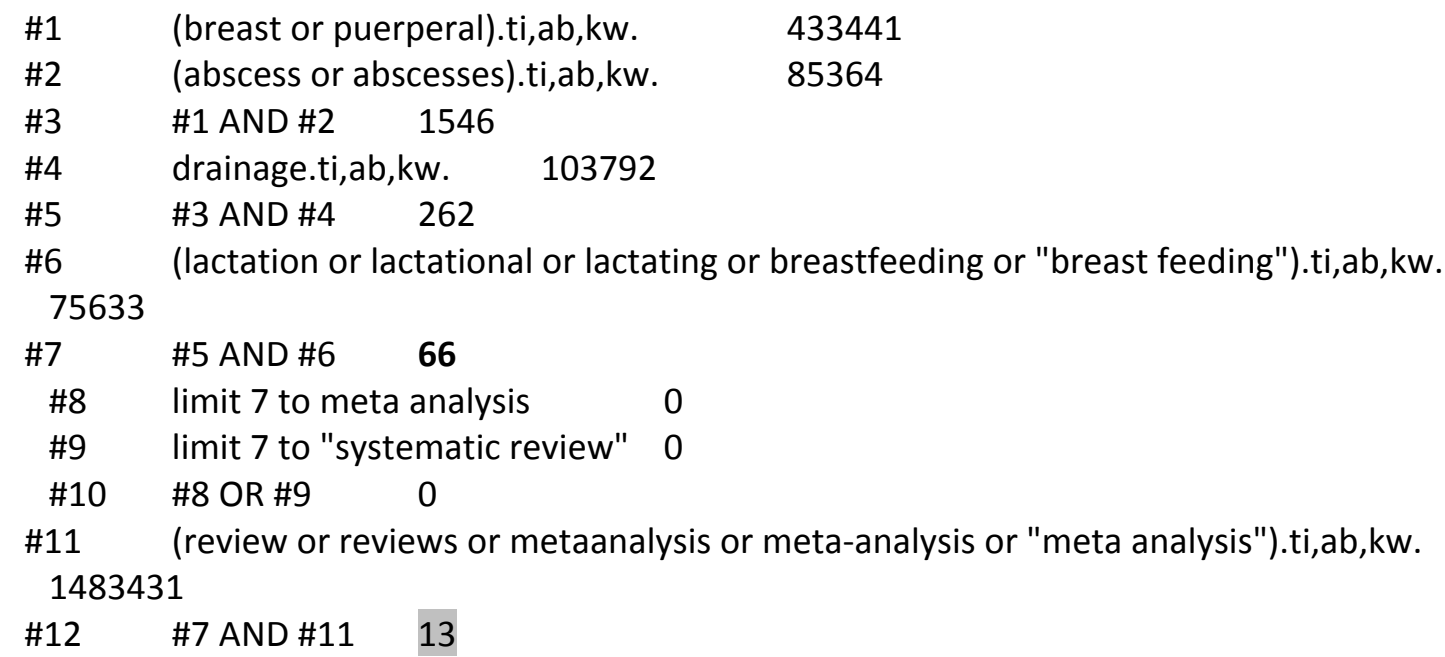

\section{CINAHL, via EBSCOhost databases}


Searched 10/07/2015

Updated search 10/07/2015 a xx/xx/xxxx

S1 (breast OR puerperal) AND ( abscess OR abscesses ) 128

S2 drainage 4721

S3 S1 AND S2 21

S4 (lactation OR lactational OR lactating ) OR ( breastfeeding OR "breast feeding" ) 16,417

S5 $\quad$ S3 AND S4 6 


\section{ANEXO II, TABLAS DE ESTUDIOS INDIVIDUALES}

\begin{tabular}{|c|c|c|c|c|c|c|}
\hline $\begin{array}{l}\text { Referencia } \\
\text { (Cita Abreviada) }\end{array}$ & $\begin{array}{l}\text { Estudio (Diseño y } \\
\text { objetivo) }\end{array}$ & $\begin{array}{l}\text { Población } \\
\text { (nº y características) }\end{array}$ & $\begin{array}{l}\text { Descripción de las intervenciones } \\
\text { comparaciones, exposiciones o } \\
\text { pruebas a estudio }\end{array}$ & $\begin{array}{l}\text { Resultados } \\
\text { (Estimadores de resultados-Magnitud del } \\
\text { efecto) }\end{array}$ & $\begin{array}{l}\text { Conclusiones } \\
\text { (conclusiones) }\end{array}$ & $\begin{array}{l}\text { Comentarios } \\
\text { Calidad de la } \\
\text { evidencia } \\
\text { Financiación } \\
\text { comentarios) }\end{array}$ \\
\hline Chandika, 2012 & $\begin{array}{l}\text { Diseño: Ensayo clínico } \\
\text { aleatorizado } \\
\text { Objetivo: } \\
\text { Evaluar si el drenaje con } \\
\text { aguja bajo control } \\
\text { ecográfico es una opción } \\
\text { de tratamiento factible al } \\
\text { tratamiento de los } \\
\text { abscesos mamarios, } \\
\text { puerperales y no } \\
\text { puerperales. }\end{array}$ & $\begin{array}{l}\text { Incluyó una muestra } \\
\text { de } 65 \text { mujeres con } \\
\text { absceso mamario } \\
\text { (puerperal y no } \\
\text { puerperal) de un } \\
\text { tamaño máximo } 5 \mathrm{~cm} \\
\text { de diámetro (medido } \\
\text { por ecografía). } \\
\text { El diagnóstico clínico } \\
\text { se basó en la } \\
\text { presencia de dolor } \\
\text { mamario, } \\
\text { tumefacción, } \pm \text { fiebre, } \\
\text { fluctuación de una } \\
\text { masa en la mama, y } \\
\text { fue confirmado por } \\
\text { diagnóstico } \\
\text { ecográfico. Se } \\
\text { excluyeron mujeres } \\
\text { con características } \\
\text { clínicas de } \\
\text { inmunosupresión } \\
\text { (estadio clínico según } \\
\text { la OMS III y IV) y con } \\
\text { alergia a la penicilina. }\end{array}$ & $\begin{array}{l}\text { Las intervenciones fueron evaluadas en } \\
\text { un periodo de } 30 \text { días } \\
\text { Grupo de intervención 1: Drenaje con } \\
\text { aguja bajo control ecográfico del } \\
\text { absceso mamario } \\
\begin{array}{l}\text { Grupo de intervención 2: Drenaje } \\
\text { quirúrgico tradicional del absceso } \\
\text { mamario }\end{array}\end{array}$ & $\begin{array}{l}\text { Se analizaron un total de } 65 \text { mujeres con } \\
\text { absceso mamario, de estas } 33 \text { pacientes } \\
\text { fueron asignadas al azar a la aspiración } \\
\text { con aguja con ecografía guiada y } 32 \\
\text { pacientes al brazo de la incisión y el } \\
\text { drenaje. } \\
\text { La edad media fue de } 23,12 \text {, la mayoría } \\
\text { de ellas fueron mujeres dando lactancia } \\
\text { materna }(66.2 \%) \text { primíparas }(44,6 \%) \text { con } \\
\text { abscesos periféricos ( } 73,8 \% \text { ), y situados } \\
\text { en el cuadrante lateral superior }(56 \%) \text {. } \\
\text { El tamaño mamario medio fue } 3,49 \mathrm{~cm} \text {. } \\
\text { Los dos grupos fueron comparables en } \\
\text { sus características demográficas y del } \\
\text { tamaño del absceso mamario. } \\
\text { El análisis de supervivencia no mostró } \\
\text { diferencias en la tasa de curación del } \\
\text { absceso mamario entre los dos grupos } \\
\text { (log rank } 0,24 \text { df } 1 \text { y } \mathrm{P}=0,63 \text { ). La Incisión } \\
\text { y drenaje (método de aspiración } \\
\text { tradicional) se encontró que era más } \\
\text { costoso que el drenaje con aguja bajo } \\
\text { control ecográfico (relación costo efectivo } \\
\text { de } 2,85 \text { ). }\end{array}$ & $\begin{array}{l}\text { El drenaje con aguja } \\
\text { bajo control } \\
\text { ecográfico es una } \\
\text { opción viable y } \\
\text { rentable como } \\
\text { tratamiento para } \\
\text { abscesos mamarios } \\
\text { puerperales y no } \\
\text { puerperales que } \\
\text { tengan un diámetro } \\
\text { de hasta } 5 \mathrm{~cm} \\
\text { (medido por } \\
\text { ecografía) en un } \\
\text { pacientes } \\
\text { inmunocompetentes }\end{array}$ & \\
\hline Suthar, 2012 & $\begin{array}{l}\text { Diseño: ensayo clínico } \\
\text { aleatorizado } \\
\text { Objetivo: } \\
\text { Comparar el manejo de } \\
\text { absceso mamario } \\
\text { puerperal por ecografía } \\
\text { percutánea guiada por } \\
\text { aspiración con aguja } \\
\text { versus drenaje quirúrgico }\end{array}$ & $\begin{array}{l}\text { La muestra estuvo } \\
\text { compuesta por } 70 \\
\text { pacientes puérperas } \\
\text { con características } \\
\text { clínicas sugerentes } \\
\text { de absceso mamario } \\
\text { puerperal (fiebre, } \\
\text { dolor, hinchazón, } \\
\text { enrojecimiento de } \\
\text { mama asociado una }\end{array}$ & $\begin{array}{l}\text { Grupo de intervención A: } \\
\text { Fueron sometieron a la aspiración } \\
\text { percutánea guiada ecográficamente, se } \\
\text { utilizó una aguja Nro } 18 \text { con una jeringa } \\
\text { de } 10 \mathrm{cc} \text { bajo anestesia local por } \\
\text { infiltración de } 2 \mathrm{ml} \text { de lidocaína } 2 \% \text {. } \\
\text { Ecografías post procedimiento fueron } \\
\text { realizadas para evaluar cualquier } \\
\text { acumulación de líquido residual. Se } \\
\text { realizaron otras aspiraciones en caso }\end{array}$ & $\begin{array}{l}\text { La tasa de fracaso de la terapia con } \\
\text { aspiración fue del } 17.14 \% \text { con } 06 \\
\text { pacientes que requierieron la conversión a } \\
\text { drenaje quirúrgico después de la } \\
\text { aspiración y fueron excluidos del estudio. } \\
\text { El tiempo de resolución fue menor en el } \\
\text { grupo de aspiración. Tres pacientes } \\
\text { presentaron como complicación una fistula } \\
\text { mamaria, asociada a una gran cicatriz en } \\
\text { el grupo de drenaje quirúrgico abierto. Sin }\end{array}$ & $\begin{array}{l}\text { La aspiración } \\
\text { percutánea con } \\
\text { aguja guiada por } \\
\text { ecografía aspiración } \\
\text { tiene una tasa de } \\
\text { fracaso aceptable y } \\
\text { es una alternativa } \\
\text { efectiva para el } \\
\text { drenaje quirúrgico } \\
\text { del absceso }\end{array}$ & \\
\hline
\end{tabular}




\begin{tabular}{|c|c|c|c|c|c|c|}
\hline $\begin{array}{l}\text { Referencia } \\
\text { (Cita Abreviada) }\end{array}$ & $\begin{array}{l}\text { Estudio (Diseño y } \\
\text { objetivo) }\end{array}$ & $\begin{array}{l}\text { Población } \\
\text { (noy características) }\end{array}$ & $\begin{array}{l}\text { Descripción de las intervenciones } \\
\text { comparaciones, exposiciones o } \\
\text { pruebas a estudio }\end{array}$ & $\begin{array}{l}\text { Resultados } \\
\text { (Estimadores de resultados-Magnitud del } \\
\text { efecto) }\end{array}$ & $\begin{array}{l}\text { Conclusiones } \\
\text { (conclusiones) }\end{array}$ & $\begin{array}{l}\text { Comentarios } \\
\text { Calidad de la } \\
\text { evidencia } \\
\text { Financiación } \\
\text { comentarios) }\end{array}$ \\
\hline & $\begin{array}{l}\text { abierto con especial } \\
\text { atención a la resolución y } \\
\text { las complicaciones. }\end{array}$ & $\begin{array}{l}\text { sensibilidad } \\
\text { localizada). El } \\
\text { diagnóstico fue } \\
\text { confirmado por } \\
\text { ecografia. Los } \\
\text { pacientes se } \\
\text { dividieron en dos } \\
\text { grupos de tratamiento } \\
\text { A y B con } 35 \\
\text { pacientes en cada } \\
\text { grupo por la técnica } \\
\text { de muestreo } \\
\text { aleatorio. Los } \\
\text { pacientes con } \\
\text { condiciones } \\
\text { comórbidas (diabetes } \\
\text { mellitus, insuficiencia } \\
\text { renal, los en } \\
\text { tratamiento con } \\
\text { esteroides, con } \\
\text { sospecha de } \\
\text { malignidad } \\
\text { (antecedentes } \\
\text { familiares de } \\
\text { neoplasia maligna de } \\
\text { mama / presencia de } \\
\text { masas de muchos } \\
\text { años con o sin } \\
\text { axilares palpables los } \\
\text { ganglios linfáticos), } \\
\text { los pacientes con } \\
\text { abscesos recurrentes, } \\
\text { los pacientes con } \\
\text { pulmonar activa } \\
\text { tuberculosis o } \\
\text { Escrófula, absceso } \\
\text { mamario sub-areolar, } \\
\text { con necrosis de la piel } \\
\text { que recubre del } \\
\text { pecho) fueron } \\
\text { excluidas del estudio. }\end{array}$ & $\begin{array}{l}\text { de ser necesarias a intervalos de } 4-5 \\
\text { días hasta que la resolución de los } \\
\text { signos y síntomas con pruebas de } \\
\text { ecografía para la confirmación de la } \\
\text { resolución. El fracaso del tratamiento en } \\
\text { el grupo fue declarado en base a la } \\
\text { persistencia de los síntomas y signos } \\
\text { después de } 04 \text { aspiraciones (por } \\
\text { ecografía). } \\
\text { Grupo de intervención B: Fueron } \\
\text { sometidos a drenaje quirúrgico abierto } \\
\text { bajo anestesia general. Se realizó } \\
\text { cambio de gasas de manera diaria con } \\
\text { pruebas de ultrasonido hasta la curación } \\
\text { completa } \\
\text { Todos los pacientes en ambos grupos } \\
\text { recibieron por vía oral amoxicilina-ácido } \\
\text { clavulánico } 1 \text { g, dos veces al día por un } \\
\text { máximo de } 5 \text { días y luego fue cambiado } \\
\text { el antibiótico en función al cultivo y } \\
\text { sensibilidad del mismo. } \\
\text { Todas las mujeres tratadas con drenaje } \\
\text { quirúrgico tradicional, } \text { fueron } \\
\text { aconsejadas continuar la lactancia por el } \\
\text { pecho no afectado además de extraerse } \\
\text { la leche del pecho afectado, mientras } \\
\text { que aquellas tratadas con drenaje con } \\
\text { aspiración por aguja se les aconsejo } \\
\text { continuar con la lactancia con higiene. }\end{array}$ & $\begin{array}{l}\text { embargo, hubo una alta tasa de fracaso } \\
\text { del tratamiento con la aspiración de } \\
\text { abscesos que presenten a más tardar } 5 \\
\text { días }(45,83 \%) \text { y aquellos con> } 5 \mathrm{~cm} \text { de } \\
\text { tamaño }(55,55 \%) \text { en la ecografía. }\end{array}$ & $\begin{array}{l}\text { mamario puerperal } \\
\text { especialmente para } \\
\text { los iniciales y de } \\
\text { pequeño tamaño. }\end{array}$ & \\
\hline
\end{tabular}




\begin{tabular}{|c|c|c|c|c|c|c|}
\hline $\begin{array}{l}\text { Referencia } \\
\text { (Cita Abreviada) }\end{array}$ & $\begin{array}{l}\text { Estudio (Diseño y } \\
\text { objetivo) }\end{array}$ & $\begin{array}{l}\text { Población } \\
\text { (no y características) }\end{array}$ & $\begin{array}{l}\text { Descripción de las intervenciones } \\
\text { comparaciones, exposiciones o } \\
\text { pruebas a estudio }\end{array}$ & $\begin{array}{l}\text { Resultados } \\
\text { (Estimadores de resultados-Magnitud del } \\
\text { efecto) }\end{array}$ & $\begin{array}{l}\text { Conclusiones } \\
\text { (conclusiones) }\end{array}$ & $\begin{array}{l}\text { Comentarios } \\
\text { Calidad de la } \\
\text { evidencia } \\
\text { Financiación } \\
\text { comentarios) }\end{array}$ \\
\hline Eryilmaz, 2005 & $\begin{array}{l}\text { Diseño: Ensayo clínico } \\
\text { aleatorizado } \\
\text { Objetivo: } \\
\text { Comparar la eficacia del } \\
\text { drenaje con aguja sin } \\
\text { control ecográfico en } \\
\text { relación al drenaje } \\
\text { quirúrgico habitual en el } \\
\text { tratamiento de abscesos } \\
\text { mamarios puerperales. }\end{array}$ & $\begin{array}{l}\text { Incluyó una muestra } \\
\text { de } 45 \text { mujeres que } \\
\text { daban lactancia } \\
\text { materna y que } \\
\text { presentaron absceso } \\
\text { mamario. } \\
\text { El diagnóstico fue } \\
\text { clínico y se basó en la } \\
\text { presencia de } \\
\text { enrojecimiento, calor, } \\
\text { dolor, induración y } \\
\text { presencia de una } \\
\text { masa fluctuante en la } \\
\text { mama. No se usó } \\
\text { guía ecográfica. }\end{array}$ & $\begin{array}{l}\text { Las intervenciones fueron evaluadas en } \\
\text { un periodo de } 14 \text { días } \\
\text { Grupo de intervención 1: Drenaje con } \\
\text { aguja sin control ecográfico del absceso } \\
\text { mamario. } \\
\text { Grupo de intervención 2: Drenaje } \\
\text { quirúrgico tradicional del absceso } \\
\text { mamario. Todas las mujeres recibieron } \\
\text { por vía oral ampicilina-sulbactam } 375 \\
\mathrm{mg} 2 \text { veces al día por } 10 \text { días, en el } \\
\text { caso que el absceso fuera más grande } \\
\text { (> } 10 \mathrm{~cm} \text { de diámetro) recibieron } \\
\text { ampicilina-sulbactam } 1 \mathrm{gr} \text { (E.V.) } 2 \text { veces } \\
\text { al día por } 3 \text { días, y luego } 7 \text { días más de } \\
\text { la medicación por vía oral anteriormente } \\
\text { descrita. }\end{array}$ & $\begin{array}{l}\text { En el grupo de incisión y drenaje todos los } \\
\text { pacientes fueron tratados con éxito, sólo } 1 \\
\text { paciente (4\%) presentó una recurrencia } \\
\text { tras } 2 \text { meses después de la curación } \\
\text { completa. } 16 \text { pacientes ( } 70 \% \text { ) de este } \\
\text { grupo no estuvieron satisfechos con el } \\
\text { resultado estético. } \\
\text { En el grupo de aspiración con aguja, en } \\
\text { general } 3 \text { pacientes fueron tratados con } \\
\text { una sola aspiración y } 10 \text { pacientes ( } 45 \% \text { ) } \\
\text { con múltiples aspiraciones, pero } 9 \\
\text { pacientes ( } 41 \% \text { ) no alcanzaron la curación } \\
\text { con la aspiración con aguja y } \\
\text { posteriormente requirieron el método } \\
\text { tradicional (incisión y drenaje). Los } \\
\text { factores de riesgo para el fracaso de la } \\
\text { aspiración con aguja de los abscesos } \\
\text { mamarios fue el tamaño mayor a de } 5 \mathrm{~cm} \\
\text { de diámetro de los abscesos, } \\
\text { inusualmente gran cantidad de pus } \\
\text { aspirado, y la demora en el tratamiento. }\end{array}$ & $\begin{array}{l}\text { En conclusión, } \\
\text { abscesos mamarios } \\
\text { por debajo de } 5 \mathrm{~cm} \\
\text { de diámetro en el } \\
\text { examen físico se } \\
\text { pueden tratar con } \\
\text { aspiraciones } \\
\text { repetidas con aguja } \\
\text { con buenos } \\
\text { resultados } \\
\text { cosméticos. } \\
\text { La incisión y el } \\
\text { drenaje deben } \\
\text { reservarse para su } \\
\text { uso en pacientes } \\
\text { con abscesos más } \\
\text { grandes }\end{array}$ & \\
\hline Strauss, 2003 & $\begin{array}{l}\text { Diseño: Ensayo } \\
\text { quasiexperimental } \\
\text { Objetivo: } \\
\text { Comparar las siguientes } \\
\text { técnicas: la aspiración } \\
\text { percutánea de los } \\
\text { abscesos con guía } \\
\text { ecográfica versus el } \\
\text { drenaje estándar de los } \\
\text { abscesos mamarios } \\
\text { puerperales y no } \\
\text { puerperales }\end{array}$ & $\begin{array}{l}\text { Comprendió un total } \\
\text { de } 24 \text { pacientes con } \\
28 \quad \text { abscesos } \\
\text { mamarios, de las } \\
\text { cuales el } 25 \% \text { de } \\
\text { estas pacientes }(6 / 24) \\
\text { sufrió de un absceso } \\
\text { puerperal y el } 75 \% \\
\text { (18/24) de un } \\
\text { absceso mamario no } \\
\text { puerperal. }\end{array}$ & $\begin{array}{l}\text { Grupo de intervención 1: Drenaje con } \\
\text { aguja con control ecográfico del } \\
\text { absceso mamario. } \\
\begin{array}{l}\text { Grupo de intervención 2: Drenaje } \\
\text { quirúrgico tradicional del absceso } \\
\text { mamario }\end{array}\end{array}$ & $\begin{array}{l}\text { El abordaje mínimamente invasivo no } \\
\text { extendió la duración del tratamiento } \\
\text { antibiótico intravenoso o de la estancia } \\
\text { hospitalaria ni dio lugar a un aumento en } \\
\text { la necesidad de fármacos analgésicos. } \\
\text { Nos encontramos con abscesos } \\
\text { recurrentes en el } 31 \% \text { (5/16) del grupo de } \\
\text { tratamiento quirúrgico, pero ninguno en el } \\
\text { grupo sometido a tratamiento } \\
\text { mínimamente invasivo. El desenlace } \\
\text { cosmético estético así como el resultado } \\
\text { funcional en pacientes lactantes fue } \\
\text { satisfactorio en todos los casos. }\end{array}$ & $\begin{array}{l}\text { La aspiración } \\
\text { percutánea guiada } \\
\text { ecográficamente de } \\
\text { los abscesos de } \\
\text { mama representa } \\
\text { una alternativa } \\
\text { menos invasiva y } \\
\text { muy prometedora a } \\
\text { la incisión } \\
\text { quirúrgica, y } \\
\text { muestra las } \\
\text { siguientes ventajas: } \\
\text { no requiere } \\
\text { anestesia general, el } \\
\text { resultado cosmético } \\
\text { es superior y } \\
\text { requiere }\end{array}$ & \\
\hline
\end{tabular}




\begin{tabular}{|c|c|c|c|c|c|c|}
\hline $\begin{array}{l}\text { Referencia } \\
\text { (Cita Abreviada) }\end{array}$ & $\begin{array}{l}\text { Estudio (Diseño y } \\
\text { objetivo) }\end{array}$ & $\begin{array}{l}\text { Población } \\
\text { (nํy características) }\end{array}$ & $\begin{array}{l}\text { Descripción de las intervenciones } \\
\text { comparaciones, exposiciones o } \\
\text { pruebas a estudio }\end{array}$ & $\begin{array}{l}\text { Resultados } \\
\text { (Estimadores de resultados-Magnitud del } \\
\text { efecto) }\end{array}$ & $\begin{array}{l}\text { Conclusiones } \\
\text { (conclusiones) }\end{array}$ & $\begin{array}{l}\text { Comentarios } \\
\text { Calidad de la } \\
\text { evidencia } \\
\text { Financiación } \\
\text { comentarios) }\end{array}$ \\
\hline & & & & & $\begin{array}{l}\text { hospitalizaciones } \\
\text { más cortas. El } \\
\text { método fue } \\
\text { altamente aceptado } \\
\text { por todos los } \\
\text { pacientes tratados. }\end{array}$ & \\
\hline
\end{tabular}




\section{ANEXO III. Forest-Plot.}

Como medida del efecto, para las variables dicotómicas se utilizó el riesgo relativo (RR) con intervalo de confianza del $95 \%$. Como método estadístico se utilizó el método de Mantel-Haenszel. Para el metanálisis se utilizó el Modelo de efectos fijos, excepto cuando se encontró heterogeneidad significativa; en ese caso se utilizó el modelo de efectos aleatorios.

\section{Tasa de curación}

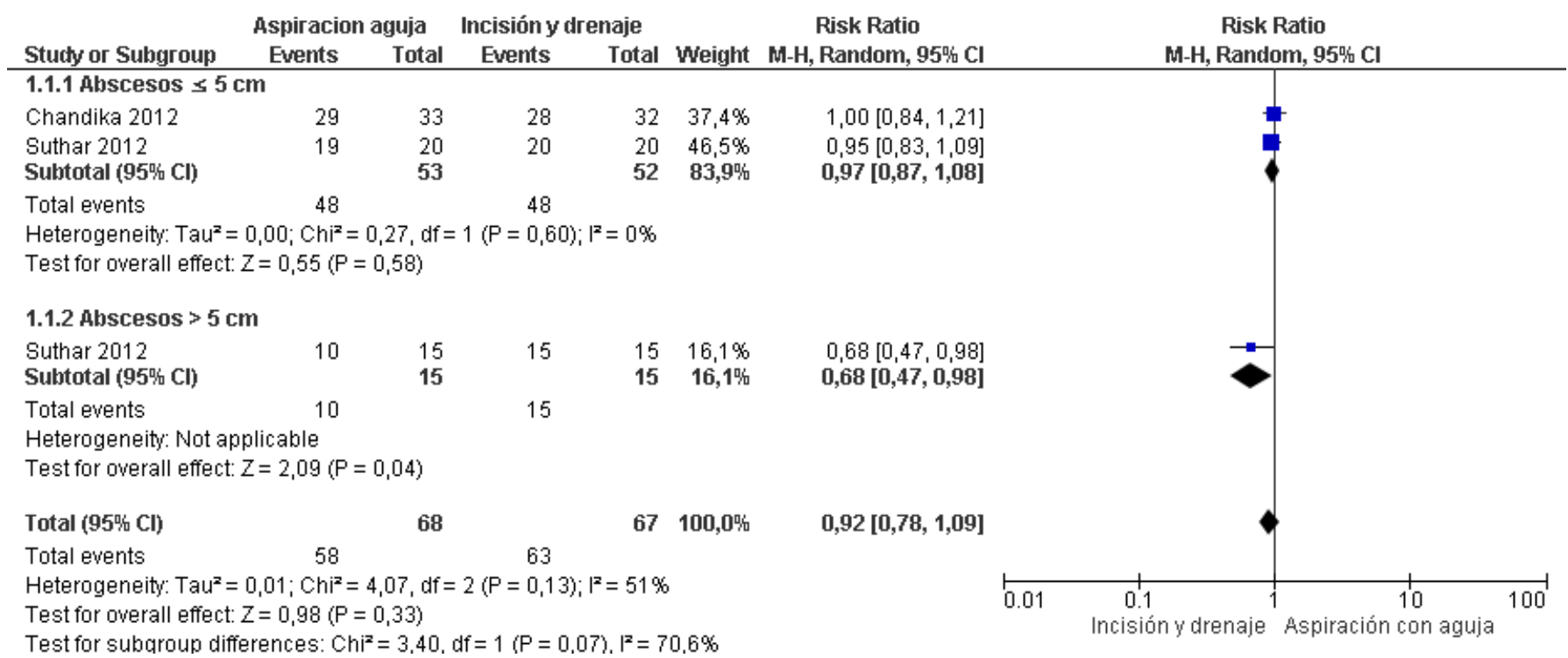




\section{ANEXO IV. Valoración del riesgo de sesgo de los estudios individuales}

\begin{tabular}{|c|}
\hline ENSAYO CLÍNICO ALEATORIZADO \\
\hline ID: Chandika 2012 \\
\hline RIESGO DE SESGO (ALTO / BAJO / INCIERTO) \\
\hline $\begin{array}{l}\text { Generación de la secuencia de aleatorización: } \\
\text { Bajo riesgo de sesgo }\end{array}$ \\
\hline $\begin{array}{l}\text { Ocultación de la secuencia de aleatorización: } \\
\text { Incierto riesgo de sesgo } \\
\text { No se especifica si se realizó ocultación de la secuencia de aleatorización }\end{array}$ \\
\hline $\begin{array}{l}\text { Cegamiento: } \\
\text { Incierto riesgo de sesgo } \\
\text { No es especificado }\end{array}$ \\
\hline $\begin{array}{l}\text { Pérdidas de seguimiento: } \\
\text { Bajo riesgo de sesgo }\end{array}$ \\
\hline $\begin{array}{l}\text { Otros: } \\
\text { Podría haber incurrido en el reporte selectivo de datos, al considerar bajos tiempos de seguimiento para el desenlace } \\
\text { de recidiva del absceso. }\end{array}$ \\
\hline
\end{tabular}

\begin{tabular}{|l|}
\hline ENSAYO CLÍNICO ALEATORIZADO \\
\hline \multicolumn{1}{|c|}{ RIESGO DE SESGO (ALTO / BAJO / INCIERTO) } \\
\hline ID: Suthar, 2012 \\
\hline $\begin{array}{l}\text { Generación de la secuencia de aleatorización: } \\
\text { Bajo riesgo de sesgo }\end{array}$ \\
\hline $\begin{array}{l}\text { Ocultación de la secuencia de aleatorización: } \\
\text { Incierto riesgo de sesgo } \\
\text { No se especifica si se realizó ocultación de la secuencia de aleatorización }\end{array}$ \\
\hline $\begin{array}{l}\text { Incierto riesgo de sesgo } \\
\text { No es especificado }\end{array}$ \\
\hline $\begin{array}{l}\text { Pérdidas de seguimiento: } \\
\text { Bajo riesgo de sesgo }\end{array}$ \\
\hline $\begin{array}{l}\text { Otros: } \\
\text { Podría haber incurrido en el reporte selectivo de datos, al considerar bajos tiempos de seguimiento para el desenlace } \\
\text { de recidiva del absceso. }\end{array}$ \\
\hline
\end{tabular}




\section{1- BIBLIOGRAFÍA}

(1) Kataria K, Srivastava A, Dhar A. Management of lactational mastitis and breast abscesses: review of current knowledge and practice. Indian J Surg 2013 Dec;75(6):430-5.

(2) ABM Clinical Protocol \#4: Mastitis, Revised March 2014. Breastfeeding Medicine, Volume 9, Number 5, 2014.

(3) Perinatal Services BC. Health Promotion Guideline. Breastfeeding Healthy Term Infants. 2013 Feb.

(4) Chandika AB, Gakwaya AM, Kiguli-Malwadde E, Chalya PL. Ultrasound Guided Needle Aspiration versus Surgical Drainage in the management of breast abscesses: a Ugandan experience. BMC Res Notes 2012;5:12.

(5) Suthar K, Mewada BN, Surati K, Shah J. Comparison of percutaneous ultrasound guided needed aspiration and open surgical drainage in management of puerperal breast abscess. Int J Med Sci Public Health 2013;2(1):69-72.

(6) Eryilmaz R, Sahin M, Hakan TM, Daldal E. Management of lactational breast abscesses. Breast 2005 Oct;14(5):375-9.

(7) Strauss A, Middendorf K, Muller-Egloff S, Heer IM, Untch M, Bauerfeind I. [Sonographically guided percutaneous needle aspiration of breast abscesses - a minimal-invasive alternative to surgical incision]. Ultraschall Med 2003 Dec;24(6):393-8.

(8) Harish SK. The catheter drainage of breast abscesses: Is it going to be the future treatment of choice for puerperal breast abscess disease? Breast Journal 1997;3(6):357-9. 
ANEXO V.

RECOGIDA Y RESPUESTA A LOS COMENTARIOS RECIBIDOS SOBRE LA ESTRUCTURA Y LAS PREGUNTAS CLÍNICAS A ABORDAR EN LA GPC SOBRE LACTANCIA MATERNA. 


\section{PROPUESTA ESTRUCTURA GPC LACTANCIA MATERNA-}

\section{PROMOCIÓN DE LA LACTANCIA MATERNA DURANTE EL EMBARAZO}

- ¿Cuál es la intervención más adecuada durante el embarazo para favorecer el inicio de la lactancia materna?

- $\mid .$.

\section{PARTO NORMAL Y ANESTESIA EPIDURAL}

- ¿Hay factores relacionados con el parto y el nacimiento que pueden influir en el establecimiento de la lactancia materna (inducción del parto, anestesia epidural, operatoria obstétrica, tipo de atención, satisfacción con la atención recibida?

\section{ATENCIÓN POSTNATAL INMEDIATA}

- ¿Es eficaz y seguro el contacto piel con piel durante la estancia en el hospital para el buen inicio de la lactancia materna? ¿Es beneficioso permitir que el bebé realice agarre espontáneo en la primera toma?

- ¿Cuándo debe de comenzar la primera toma?¿Cuánto tiempo se puede esperar a que el lactante realice la primera toma efectiva sin que suponga un riesgo para su salud? (importancia de hacer la primera toma en la primera hora)

- $|\ldots|$

\section{PRÁCTICAS QUE FAVORECEN LA LACTANCIA MATERNA}

- ¿Cómo deberían colocarse la madre y el bebé para facilitar el agarre?

- ¿Es eficaz y seguro el colecho en las madres que amamantan para facilitar el buen inicio y el mantenimiento de la lactancia materna?

- ¿Qué efectos tienen las tomas nocturnas en el éxito de la lactancia materna?

- ¿Influye el uso del chupete durante las primeras semanas en la lactancia materna? .....

\section{EVALUACIÓN DE LA LACTANCIA MATERNA}

- ¿Qué criterios indican un buen inicio y una adecuada instauración de la lactancia materna?

- ¿Se debe recoger la historia clínica de lactancia materna a todas las madres que amamantan durante la estancia en la maternidad?

- ¿Se debe realizar la observación y valoración de la toma con una herramienta estandarizada durante la estancia en la maternidad a las madres que amamantan?

- $|\ldots|$

\section{PROBLEMAS CON LA LACTANCIA MATERNA}

Problemas en los primeros días

- ¿Qué se debe hacer ante un niño adormilado que no realiza tomas efectivas?

- ¿Qué se debe hacer cuando se produce un retraso en la lactogénesis?

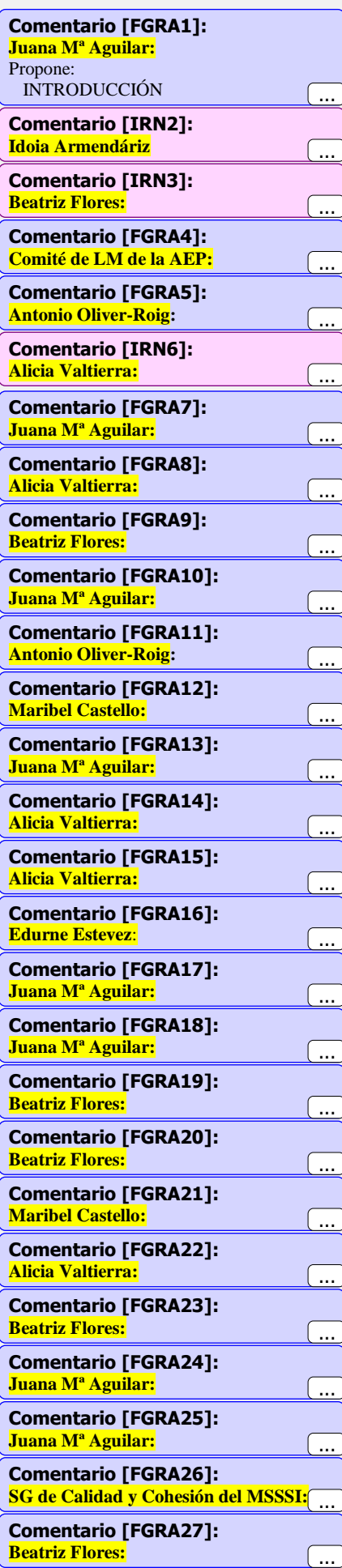


- ¿Cómo se debe abordar el dolor en las mamas o pezones durante el amamantamiento?

- ¿Qué se debe hacer ante la ingurgitación mamaria?

- ¿Qué debe recomendarse si hay dificultades en el agarre por pezones planos o invertidos?

- ¿Cómo se deben tratar las grietas del pezón?

- ¿Cuándo puede ser necesaria la utilización de pezoneras para resolver problemas con la lactancia materna?

- ¿Qué se debe hacer ante un bebé amamantado que presenta una pérdida excesiva de peso?

- ¿Cómo se debe tratar la ictericia por falta de ingesta de leche materna en el recién nacido amamantado?

- ¿Cómo influye la anquiloglosia en el éxito de la lactancia materna y qué debemos hacer cuando un lactante la presenta?

- $\mid . .$.

\section{Problemas tardíos con la lactancia materna}

- ¿Qué se debe hacer cuando se da una hipogalactia (cómo diagnosticarla, cuáles son las principales causas de hipogalactia y cómo abordarla (analítica a pedir a la madre etc)?

- ¿Cuáles son las indicaciones de los galactogogos? ¿Cuál es su eficacia y seguridad?

- ¿Cuáles son los signos o síntomas que permiten diagnosticar una mastitis?

- ¿Cómo se debe tratar la mastitis aguda, subaguda y la mastitis abcesificada?

- ¿Se pueden establecer criterios diagnósticos diferenciales para cada una de estas causas: eczema, síndrome de Raynaud y psoriasis?

- ¿Cómo se debe tratar el ezcema, el síndrome de Raynaud y la psoriasis?

\section{EXTRACCIÓN DE LA LECHE MATERNA}

- ¿Cuándo está indicada la extracción del calostro y de la leche materna?

- ¿Cuáles son los mejores métodos para extraer el calostro y la leche materna?

\section{SUPLEMENTOS Y LACTANCIA MATERNA}

- ¿Qué efectos tienen los suplementos en el éxito de la lactancia materna?

- $|\ldots|$

- ¿En qué circunstancias debe de proporcionarse alimentación suplementaria a un recién nacido amamantado?

- ¿Cuál es el suplemento más adecuado para los recién nacidos a término cuando no disponemos de leche materna extraída (suero glucosado, fórmula de inicio, hidrolizado de proteínas, leche pasteurizada procedente de bancos de leche)?

- ¿Cómo deben administrarse los suplementos? (en el hospital y fuera del hospital)

- ¿Cuál es el efecto del cumplimiento del código de comercialización de sucedáneos y de la independencia de las instituciones y los profesionales sanitarios de la industria sobre las tasas de lactancia materna?

\section{INFORMACIÓN Y APOYO A LA LACTANCIA MATERNA}

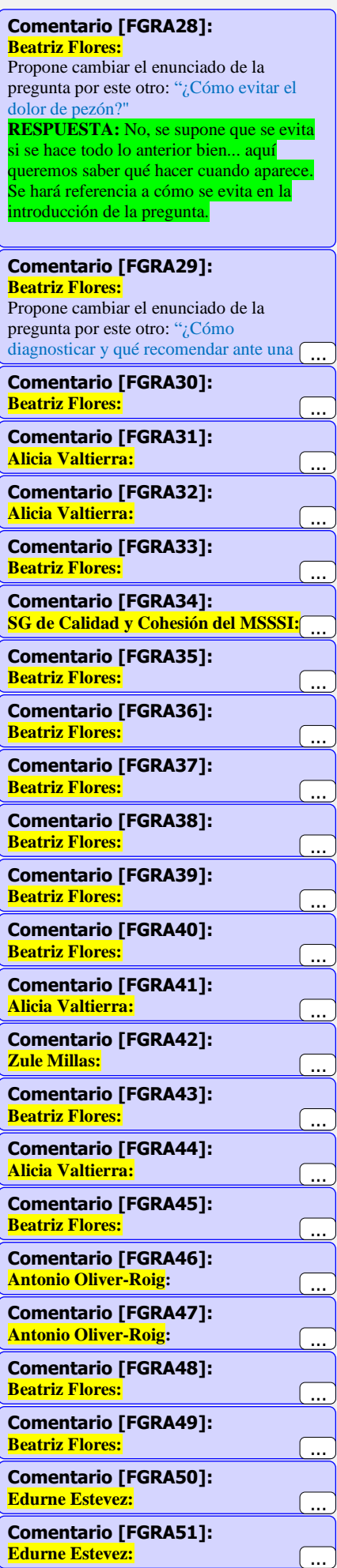


- ¿Qué información y apoyo se debe dar a la mujer, a su pareja y familia para facilitar el inicio y el mantenimiento de la lactancia materna?

- ¿Cuál es la mejor forma de proporcionar esa información y apoyo?

- ¿QQué estrategias contribuyen al mantenimiento de la lactancia materna cuando la madre se incorpora al trabajo?

\section{PROMOCIÓN INSTITUCIONAL DE LA LACTANCIA MATERNA}

- ¿Son eficaces las estrategias estructuradas en los hospitales para el apoyo y protección de la lactancia materna?

- ¿Son eficaces las estrategias estructuradas en los centros de salud para el apoyo y protección de la lactancia materna?

- $\quad \ldots$

\section{SEGUIMIENTO DEL CRECIMIENTO DEL LACTANTE AMAMANTADO}

- ¿Qué parámetros y tablas de crecimiento deben utilizarse para evaluar si el bebé se está alimentando correctamente? ....

\section{DESTETE Y ALIMENTACIÓN COMPLEMENTARIA}

- ¿Cuáles son las indicaciones médicas para el destete?

- ¿Cuáles son los mejores métodos de destete?

- ¿Cómo se debe incorporar la alimentación complementaria en el lactante?

- Indicaciones y riesgos del destete farmacológico

(ANEXO CÓMO HACER UN DESTETE DE FORMA NATURAL)

....

12.
Comentario [FGRA52]

Cómite de LM de la AEP:

Propone incluir las siguiente pregunta:

- Qué información hay que dar al alta

del hospital? Qué estrategias de

continuidad de los cuidados en atención primaria son útiles?

RESPUESTA: Se hace una pregunta

general sobre qué información hay que dar,

luego ya se verá si hay estudios que digan

qué tipo de información se debe dar en cada

"etapa".

Beatriz Flores:

Su comentario a esta pregunta es: "¿Cómo dar una ayuda eficaz a las madres? ¿Cuales son y para que sirven las habilidades de

comunicación?", supongo que serán

preguntas a añadir

RESPUESTA: Las habilidades en

comunicación se pueden dar como

\section{Comentario [FGRA53]}

Juana $\mathbf{M}^{\mathrm{a}}$ Aguilar:

Comenta: " Este punto también iría en otro

apartado de atención al puerperio"

Comentario [FGRA54]:

Beatriz Flores:

Añadiría también:

Comentario [FGRA55]:

Alicia Valtierra:

Comentario [FGRA56]:

Alicia Valtierra:

Propone cambiar el enunciado de

pregunta por este otro: " ¿Son eficaces la ...

\section{Comentario [IRN57]:}

Nora Ibargoyen:

Posibilidad de unificar los apartados 8 y 9

en un único apartado denominado:

Comentario [FGRA58]:

Alicia Valtierra:

Propone cambiar el enunciado de la

pregunta por este otro: "¿Son eficaces la

Comentario [FGRA59]:

Beatriz Flores:

Propone añadir las siguientes preguntas:

Comentario [FGRA60]:

Maribel Castello:

Propone cambiar el enunciado de la

pregunta por este otro: "¿Qué parámetro

Comentario [FGRA61]: Alicia

Valtierra:

Añade otra pregunta:

Comentario [FGRA62]:

Beatriz Flores:

Comentario [FGRA63]

Juana Ma Aguilar:

Comenta: "No entiendo este punto ya que el

destete pocas veces se realiza por

Comentario [FGRA64]:

Alicia Valtierra:

Añade otra pregunta:

Comentario [FGRA65]:

Maribel Castello:

Propone un último capítulo:

12. NORMATIVA IHAN 
ANEXO VI.

RECOGIDA Y RESPUESTA A LOS COMENTARIOS DE LOS REVISORES EXTERNOS POR PARTE DE LOS AUTORES DE LA GPC 



\begin{tabular}{|c|c|c|c|}
\hline Revisor & Sección & Comentario & Respuesta del grupo elaborador \\
\hline \multirow[t]{4}{*}{ Revisor 1} & $\begin{array}{l}\text { Comentarios } \\
\text { generales }\end{array}$ & $\begin{array}{l}\text { En algún capítulo, como por ejemplo el número } 11 \text { “Manejo de los problemas con la } \\
\text { lactancia materna", la estructura resulta redundante y puede llevar a confusión a la hora de } \\
\text { realizar la lectura de la guía. Personalmente considero que una versión más simplificada } \\
\text { sería más fácil de asimilar sin suponer una pérdida en la calidad metodológica. }\end{array}$ & $\begin{array}{l}\text { Es la estructura general que hemos seguido en toda la GPC. La } \\
\text { versión que se ha enviado a los revisores es la versión completa, } \\
\text { pero se va a hacer una versión resumida que únicamente llevará } \\
\text { el resumen de la evidencia de cada pregunta, con lo que se } \\
\text { acortará el contenido de cada pregunta abordada. }\end{array}$ \\
\hline & $\begin{array}{l}\text { Atención postparto } \\
\text { inmediata }\end{array}$ & $\begin{array}{l}\text { ¿Cuánto tiempo se puede esperar a que el recién nacido haga la primera toma? Se señala } \\
\text { que no hay diferencias entre el nivel de glucosa en la primera, tercera o sexta hora de vida } \\
\text { entre los recién nacidos que realizan la primera toma en la primera media hora de vida y los } \\
\text { que no, y que dado el mecanismo autorregulador de la glucemia de los recién nacidos, se } \\
\text { podría esperar sin intervenir durante las primeras } 6 \text { horas post-parto. Sin embargo, aunque } \\
\text { es cierto que la hipoglucemia inicial es fisiológica, ésta tiene su nadir a las } 2 \text { horas de vida } \\
\text { (40mg/dL), para ir aumentando y estabilizarse a las } 4-6 \text { horas de vida entorno a 60-80mg/dL } \\
\text { (Cowett, Selected Principles Of Perinatal-Neonatal Glucose Metabolism. Seminars in } \\
\text { Neonatology, 9:37, 2004). Por otro lado, un estudio longitudinal prospectivo llevado a cabo } \\
\text { en RN a término, sanos y sin factores de riesgo (Samayam, Study of asymptomatic } \\
\text { hypoglycemia in full term exclusively breastfed neonates in first } 48 \text { hours of life, Journal of } \\
\text { Clinical and Diagnostic Research, 9:SC07, 2015), con buen reflejo de succión y sin colecho } \\
\text { materno, encuentra un aumento no significativo de hipoglucemia en aquellos niños en los } \\
\text { que la lactancia materna se inicia más tarde de la primera hora de vida, pudiendo encontrar } \\
\text { resultados parecidos en estudios similares (De AK, Study of blood glucose levels in normal } \\
\text { and low birth weight neonates and impact of early breast feeding in a tertiary care centre, } \\
\text { Ann Nigerian Med } 51: 53,2011 \text { ). Si bien dichos estudios no tienen la potencia suficiente } \\
\text { como para considerarlos como una recomendación de tipo fuerte, quizás sería } \\
\text { recomendable que la intervención en caso de no producirse el agarre espontáneo no se } \\
\text { retrasase más allá del tiempo durante el cual se produce el nadir fisiológico, esto es, a las } \\
\text { dos horas de vida. }\end{array}$ & $\begin{array}{l}\text { Se ha discutido en el grupo. Al final, se ha decidido modificar la } \\
\text { recomendación y poner que se espere una hora sin intervenir. Si } \\
\text { tras la hora no ha habido una primera hora se sugiere ayudar, no } \\
\text { dar suplementos. }\end{array}$ \\
\hline & $\begin{array}{l}\text { Valoración de la } \\
\text { lactancia materna }\end{array}$ & $\begin{array}{l}\text { En base a la bibliografía ya reportada en la Guía, se podría considerar la LATCH como la } \\
\text { mejor herramienta de evaluación de las tomas, y posiblemente la mejor opción sería } \\
\text { utilizarla al menos dentro de las primeras } 24 \text { horas de vida y al alta hospitalaria. }\end{array}$ & $\begin{array}{l}\text { El grupo piensa que no, porque sigue sin estar validada... Aunque } \\
\text { sí traducida al castellano... Se prefiere mantener varias opciones, } \\
\text { queriendo además facilitar herramientas que ayuden a tener en } \\
\text { cuenta todos los aspectos que hay que valorar cuando se observa } \\
\text { una toma }\end{array}$ \\
\hline & $\begin{array}{l}\text { Suplementos y } \\
\text { lactancia materna }\end{array}$ & $\begin{array}{l}\text { ¿Cuándo está indicada la administración de suplementos en recién nacidos sanos? en las } \\
\text { indicaciones que hacen referencia al niño se incluye la hipoglucemia, y se señala que debe } \\
\text { determinarse por medio de una analítica de laboratorio y no por medio de un glucómetro. } \\
\text { Sin embargo, si bien es cierto que la medición de la glucemia mediante tiras reactivas ha } \\
\text { demostrado importantes discrepancias con respecto al análisis de laboratorio, sobre todo en }\end{array}$ & $\begin{array}{l}\text { El grupo admite la tira reactiva como prueba de screening... Lo } \\
\text { que dice es que no se suplemente hasta que no se haya } \\
\text { confirmado la hipoglucemia por medio de la medición en } \\
\text { laboratorio. } \\
\text { Por otro lado, aquí sólo se contempla niños sanos a término con }\end{array}$ \\
\hline
\end{tabular}




\begin{tabular}{|c|c|c|c|}
\hline Revisor & Sección & Comentario & Respuesta del grupo elaborador \\
\hline & & $\begin{array}{l}\text { situaciones de hipoglucemia, se trata de un procedimiento aceptado como screening, y no } \\
\text { debe retrasarse la instauración del tratamiento oportuno a la espera de recibir el resultado } \\
\text { de laboratorioEstos controles no se van a realizar de rutina en todos los recién nacidos, sino } \\
\text { sólo en aquellos que presenten algún factor de riesgo para el desarrollo de hipoglucemia, } \\
\text { quizás sería conveniente destacar qué factores obligan a dicho screening, que según las } \\
\text { mismas guías que he citado previamente son: RN pretérminos (edad gestacional <37 } \\
\text { semanas), macrosómicos, CIR, hijos de madre diabética, con sufrimiento perinatal, post- } \\
\text { maduros, que requieran de cuidados intensivos, hijos de madres a tratamiento con agentes } \\
\text { beta-adrenérgicos o hipoglucemiantes, con historia familiar de hipoglucemia genética o con } \\
\text { síndromes asociados con hipoglucemia. En estos pacientes la alimentación debe instaurarse } \\
\text { en la primera hora de vida, realizando controles de glucemia pre-toma cada 3-6h durante las } \\
\text { primeras } 24-48 \text { horas de vida. Las tomas deben ofrecerse cada } 2-3 \text { horas monitorizándose de } \\
\text { forma estrecha los síntomas de hipoglucemia.Los criterios establecidos por dichas guías para } \\
\text { suplementar la lactancia materna, ya sea mediante leche materna (si está disponible), suero } \\
\text { glucosado por vía oral (sólo en este caso de hipoglucemia) o leche de fórmula son:- RN }<4 \\
\text { horas de vida con cifras de glucosa }<25 \mathrm{mg} / \mathrm{dL} \text {. Si no hay respuesta, administrar glucosa iv. Si } \\
\text { la hay, mantener la alimentación oral cada } 2 \text {-3h con medidas de glucemia pre-toma.- RN } 4- \\
24 \text { horas de vida con cifras de glucosa <35 mg/dL. Si no hay respuesta, administrar glucosa iv. } \\
\text { Si la hay pero el paciente desarrolla síntomas o no eleva la glucemia por encima de } 45 \mathrm{mg} / \mathrm{dL} \\
\text { tras tres tomas orales, debe iniciarse glucosa iv.(Rozance, Management and outcome of } \\
\text { neonatal hypoglycemia, UpToDate, Jun } 2016 \text { ).Con respecto al tipo de suplemento más } \\
\text { adecuado, simplemente sugerir que dada la evidencia científica disponible, a la que ya se } \\
\text { hace referencia en la guía, quizás el mejor suplemento para los niños con historia familiar de } \\
\text { atopia en primer grado serían las fórmulas de caseína extensamente hidrolizadas. }\end{array}$ & $\begin{array}{l}\text { posible hipoglucemia. } \\
\text { En cuanto al tipo de suplemento, solo había un estudio y con } \\
\text { pocos pacientes. Además está el problema de la aceptabilidad } \\
\text { por parte de los niños de este tipo de fórmulas. Por ello no se ha } \\
\text { realizado una recomendación a favor de una en concreto y se ha } \\
\text { dejado la recomendación más abierta. }\end{array}$ \\
\hline & $\begin{array}{l}\text { Seguimiento del } \\
\text { lactante amamantado }\end{array}$ & $\begin{array}{l}\text { En el apartado 11.1, en la última recomendación, se sugiere, cuando no se utilicen gráficas } \\
\text { de pérdida de peso neonatal, intensificar el apoyo a la lactancia materna en aquellos casos } \\
\text { en los que se identifique una pérdida de peso igual o superior al } 7 \% \text {, y habría que añadir "en } \\
\text { los tres primeros días". }\end{array}$ & $\begin{array}{l}\text { El grupo ha estado discutiendo esto. En principio es así, pero qué } \\
\text { ocurre si tras una semana se recibe a un niño que ha perdido más } \\
\text { del } 7 \% \text { del peso a la semana? Por ello no se ha definido } \\
\text { finalmente que sea una perdida en los tres primeros días. }\end{array}$ \\
\hline & $\begin{array}{l}\text { Manejo de los } \\
\text { problemas con la } \\
\text { lactancia materna }\end{array}$ & $\begin{array}{l}\text { En el apartado 7.2, ¿Qué métodos son más eficaces para aumentar la producción de leche?, } \\
\text { en base a la evidencia ya expuesta en la propia guía, aunque es cierto que debe dejarse a la } \\
\text { madre escoger el método de extracción que más se adecue a sus necesidades y preferencias, } \\
\text { quizás en los primeros } 2-3 \text { días, para la extracción de calostro, sería más adecuado } \\
\text { aconsejarle la extracción manual. } \\
\text { En el caso de las mastitis agudas, personalmente considero que es más aconsejable recoger } \\
\text { un cultivo de leche materna antes de instaurar un tratamiento antibiótico, sobre todo de } \\
\text { cara al control evolutivo }\end{array}$ & $\begin{array}{l}\text { Sí, de hecho así se indica en algún lugar. Lo que ocurre es que si la } \\
\text { madre no se encuentra cómoda, puede querer utilizar un } \\
\text { sacaleches, por eso se decidió dejar más abierta la } \\
\text { recomendación (aunque en el texto así se indica). } \\
\text { En cuanto al cultivo en mastitis agudas, el grupo entiende que } \\
\text { cuanto se trata de mastitis aguda se puede empezar el } \\
\text { tratamiento empírico porque generalmente es S. aureus el } \\
\text { causante de tal infección... Y que el cultivo se realizará en esos } \\
\text { casos cuando no haya respuesta al tt antibiótico prescrito. }\end{array}$ \\
\hline
\end{tabular}




\begin{tabular}{|c|c|c|c|}
\hline Revisor & Sección & Comentario & Respuesta del grupo elaborador \\
\hline & Anexos & $\begin{array}{l}\text { En el Anexo 8, junto con cada escala figurar una pequeña nota sobre la valoración de las } \\
\text { puntuaciones obtenidas. Por ejemplo, en la escala LATCH, explicar que cada ítem se puntúa } \\
\text { de } 0 \text { a } 2 \text { de menos a más favorable, siendo la puntuación más alta de 10, que se corresponde } \\
\text { con una situación muy favorable que no requiere intervención, y la puntuación más baja } 0 \text {, } \\
\text { que es la que más atención va a necesitar por nuestra parte. }\end{array}$ & $\begin{array}{l}\text { Ya se ha incluido en el ANEXO en el que aparece la escala LATHC. } \\
\text { Las otras dos herramientas no incluyen puntuaciones, solo se } \\
\text { tiene que marcar en cada item la opción correspondiente. }\end{array}$ \\
\hline \multirow[t]{8}{*}{ Revisor 2} & General & Estructurada de manera poco práctica para la consulta y la búsqueda. & $\begin{array}{l}\text { Se ha tratado de estructurar mejor los capítulos, siguiendo las } \\
\text { recomendaciones de la revisora. }\end{array}$ \\
\hline & Metodología & $\begin{array}{l}\text { Se utilizan trabajos que tienen más de } 10 \text { años que no aportan nada. Parecen que muchos } \\
\text { trabajos se referencias por "rellenar espacios" pero lo que se consigue es que se dificulte la } \\
\text { lectura y búsqueda de solución de problemas. Inaceptable poner tan excesivamente número } \\
\text { de veces el término "bebé". }\end{array}$ & $\begin{array}{l}\text { Las búsquedas de los estudios se han realizado sin límite } \\
\text { temporal. En algunas áreas existen pocos estudios y viejos. Esto } \\
\text { se ha reflejado de forma explícita en el texto, y se han puesto } \\
\text { porque es lo único que hay... } \\
\text { Esta versión es la versión extensa de la guía. Se va a elaborar una } \\
\text { versión resumida para un uso más práctico de la misma. }\end{array}$ \\
\hline & $\begin{array}{l}\text { Atención postparto } \\
\text { inmediata }\end{array}$ & $\begin{array}{l}\text { Excesivo uso del término bebé, no bien señalizados los apartados de respuesta, parece todo } \\
\text { uno. No se diferencian los diferentes tipos de analgesia/anestesia y su influencia en la LM. }\end{array}$ & $\begin{array}{l}\text { Se han tratado de diferenciar mejor los apartados. Se ha } \\
\text { eliminado el uso del término bebé, sustituyéndolo por lactante o } \\
\text { recién nacido, según el caso. En cuanto a los tipos de } \\
\text { analgesia/anestesia, esto se barajó en un principio, pero debido a } \\
\text { las limitaciones en tiempo y recursos, se decidió no abordar en } \\
\text { este momento preguntas relacionadas con el embarazo o el parto } \\
\text { y la lactancia materna. Se indica en el documento metodológico } \\
\text { qué preguntas quedarían por contestar por la guía. }\end{array}$ \\
\hline & Extracción de calostro & $\begin{array}{l}\text { En general, bien. Excesivo uso de "bebé". Señalizar bien los subapartados o preguntas que se } \\
\text { responden. }\end{array}$ & $\begin{array}{l}\text { Se ha sustituido el término bebé por lactante o recién nacido, } \\
\text { según el caso. En cuanto a los subapartados, se ha tratado de } \\
\text { señalizarlos mejor. }\end{array}$ \\
\hline & $\begin{array}{l}\text { Promoción } \\
\text { institucional de la } \\
\text { lactancia materna }\end{array}$ & $\begin{array}{l}\text { En general, bien. Señalizar bien los subapartados o preguntas que se responden. Poner la } \\
\text { legislación vigente que protege la LM y que se debe cumplir (Derechos de la madre lactante } \\
\text { y del RN, Lactarios en puestos de trabajo, etc.) }\end{array}$ & \\
\hline & $\begin{array}{l}\text { Seguimiento del } \\
\text { lactante amamantado }\end{array}$ & $\begin{array}{l}\text { Los subapartados no tienen el mismo código numérico que corresponde al tema. Ya no se } \\
\text { utiliza el término "raza" sino el de "etnia". No se ajusta el texto ni viene la calidad de los } \\
\text { estudios descritos. }\end{array}$ & $\begin{array}{l}\text { Corregidos los subapartados. } \\
\text { Sustitiuido el término de raza (puesto mujeres caucásicas). }\end{array}$ \\
\hline & $\begin{array}{l}\text { Difusión e } \\
\text { implementación }\end{array}$ & $\begin{array}{l}\text { Promoción desde los direcciones de los diferentes Departamentos de Salud y de las } \\
\text { Consejerías de las diferentes CCAA. Formación obligatoria y con compensación en los } \\
\text { indicadores de productividad. }\end{array}$ & \\
\hline & Anexos & En general bien aunque algunos, pero intolerable y excesivo el uso del término "bebé" & $\begin{array}{l}\text { Corregido, solo se ha mantenido en los ANEXOS dirigidos a las } \\
\text { mujeres. }\end{array}$ \\
\hline
\end{tabular}




\begin{tabular}{|c|c|c|c|}
\hline Revisor & Sección & Comentario & Respuesta del grupo elaborador \\
\hline & Otros & $\begin{array}{l}\text { Haría uno de la repercusión de los analgésicos/ anestésicos en la LM, es decir, uno completo } \\
\text { sobre métodos farmacológicos y no farmacológicos en embarazo y parto y su repercusión } \\
\text { sobre LM. }\end{array}$ & $\begin{array}{l}\text { No se han podido abordar más preguntas en la guía, pero sí se } \\
\text { identificaron como preguntas de interés al inicio. Se propondrá su } \\
\text { abordaje en una futura actualización de la guía. }\end{array}$ \\
\hline \multirow[t]{2}{*}{ Revisor 3} & $\begin{array}{l}\text { Comentarios } \\
\text { generales }\end{array}$ & $\begin{array}{l}\text { Preguntas que echo en falta que se hayan hecho:1. Conveniencia de iniciar en cesáreas el } \\
\text { contacto piel con piel e iniciar la primera toma intracesárea, dentro de quirófano. } 2 \text {. } \\
\text { Porcentaje de madres que no necesitan ayuda para iniciar el amamantamiento3. Incidencia } \\
\text { de anquiloglosia en la población de lactantes4. Causa más frecuente en las mastitis } \\
\text { infecciosas5. Existencia de los diagnósticos mastitis subaguda o mastitis subclínica en los } \\
\text { humanos, es decir en las mujeres madres lactantes. }\end{array}$ & $\begin{array}{l}\text { El contacto piel con piel en cesáreas se ha incluido como } \\
\text { subpregunta o subgrupo en la pregunta sobre el contacto piel con } \\
\text { piel. Se han realizado modificaciones (ver en el borrador). } \\
\text { El \% de madres que no necesitan ayuda para iniciar lactancia es } \\
\text { un dato de interés pero no lo tenemos. } \\
\text { Lo mismo con la incidencia de anquiloglosia, no se ha mirado. } \\
\text { En la causa más frecuente de mastitis infecciosa, ya se comenta } \\
\text { en la pregunta sobre cuáles son los síntomas y signos de } \\
\text { infección. } \\
\text { cuanto a la existencia de mastitis subaguda o subclinica, es un } \\
\text { tema controvertido y no se ha querido indagar más en } \\
\text { profundidad. Se ha preferido abordar de forma indirecta cuáles } \\
\text { pueden ser los síntomas de infección (estudios en los que con } \\
\text { determinados síntomas se demuestra la existencia de bacterias } \\
\text { en cantidad suficiente como para pensar en infección). En la } \\
\text { literatura internacional no se habla de mastitis subagudas, sino } \\
\text { de dolor profundo en la mama o mastitis con síntomas de } \\
\text { inflamación en la mama y dolor etc. }\end{array}$ \\
\hline & Introducción & $\begin{array}{l}\text { Echo de menos una gráfica conocida tipo esta sobre al situación mundial y si hay datos más } \\
\text { actualizados, mejor. Estos están sacados de anteriores ediciones de UNICEF, El estado } \\
\text { mundial de la infancia } \\
\text { falta imagen } \\
\text { (Fuente más actualizada: UNICEF: El estado mundial de la infancia 2016, página 125) } \\
\text { En la introducción quizás o sino en el punto 13: Compromiso social y político.... hacer una } \\
\text { serie de consideraciones de porqué están las cifras de la lactancia tan estancadas. } \\
\text { Bibliografía la hay abundante, baste lo que pone en IBFAN: Breaking the Rules } 2014 \text { en } \\
\text { donde tenemos el honor de que nombren al congreso de nuestra AEP en } 2013 \text { y eso que no } \\
\text { saben aún que será ampliamente superado en el de } 2016 \text {. }\end{array}$ & $\begin{array}{l}\text { No se ha podido realizar dicha gráfica a partir de esos datos } \\
\text { aunque hubiera sido de interés. } \\
\text { Finalmente no va a haber un capítulo sobre Compromiso social y } \\
\text { político con la lactancia, sino que se va a comentar esto en la } \\
\text { introducción. }\end{array}$ \\
\hline
\end{tabular}




\begin{tabular}{|c|c|c|c|}
\hline \multirow[t]{2}{*}{ Revisor } & Sección & Comentario & Respuesta del grupo elaborador \\
\hline & $\begin{array}{l}\text { Atención postparto } \\
\text { inmediata }\end{array}$ & $\begin{array}{l}\text { Echo a faltar la pregunta y el haber estudiado la conveniencia de iniciar en cesáreas el } \\
\text { contacto piel con piel y hasta la primera toma intra-cesárea, dentro de quirófano. Es un tema } \\
\text { que está de actualidad e intentándose con mejor o peor éxito en muchas de las } \\
\text { maternidades del país. Habéis manejado bibliografía en que se habla de ello y hay más. Pero } \\
\text { ni en al discusión ni en la recomendación se habla de ello o no se entiende; pág } 39: \text { "[...] se } \\
\text { recomienda realizar el contacto piel con piel inmediato tras el parto [...]" no se dice nada de } \\
\text { cuando es el momento inmediato y convendría poner cesárea y no parto. Creo que es } \\
\text { necesario decir algo sobre la evidencia que hay de esta intervención ya que es motivo de } \\
\text { discusión de pediatras, matronas, enfermeras, ginecólogos y anestesistas. En las } \\
\text { consideraciones para la implementación de la página } 40 \text { se podría retomar el tema con las } \\
\text { implicaciones que hay de iniciarlo intra-quirófano, los problemas que ponen enfermería y los } \\
\text { anestesistas para permanecer juntos madre y bebé en las salas de reanimación } \\
\text { postanestésica y la práctica del contacto sustituto piel con piel con el padre. Todo un } \\
\text { temazo. }\end{array}$ & $\begin{array}{l}\text { El CPP con cesárea se incluye en la pregunta general sobre CPP, } \\
\text { aunque se han hecho modificaciones al texto para dejar claro que } \\
\text { la recomendación se da para cesáreas es en quirófano. Se han } \\
\text { añadido también consideraciones a tener en cuenta para que } \\
\text { esto se pueda dar etc... Se han mirado los estudios que incluimos } \\
\text { sobre cesáreas y se ha visto que no se trataba de CPP } \\
\text { intraquirófano... Y se ha añadido esto en el texto también. }\end{array}$ \\
\hline & $\begin{array}{l}\text { Prácticas que } \\
\text { favorecen la lactancia } \\
\text { materna }\end{array}$ & $\begin{array}{l}\text { 5.1. Echo en falta el que se exprese que las madres y bebés que no tengan problemas, no se } \\
\text { interfiera para nada y no se les intente ayudar. Quizá debía haber sido una pregunta a } \\
\text { explorar: ¿Qué porcentaje hay de madres que no necesitan ayuda para iniciar el } \\
\text { amamantamiento? } \\
\text { Ojo, en la página } 56 \text { pone "en un estudio publicado recientemente" y hace mención a la } \\
\text { referencia } 16 \text { que es de } 2011 \text {. Quizás no se debe poner "recientemente" } \\
\text { 5.2. No estoy de acuerdo con las recomendaciones sobre el colecho en la maternidad. Creo } \\
\text { que hay muy pocos trabajos y muy pocas pruebas para hacer recomendaciones ni de fuerza } \\
\text { Débil ni mucho menos Fuerte sobre ello. Además me parece impráctico lo que se propone. } \\
\text { No creo que se lleguen a comprar de modo masivo cunas sidecar en las maternidades con el } \\
\text { déficit presupuestario que tenemos, aparte de que el fabricante no ha solucionado los } \\
\text { problemas de la cama articulada y no podemos ofrecer muchas pruebas de que es mejor que } \\
\text { el que duerman juntos o en una cuna normal según desee la madre. No todas las camas de } \\
\text { maternidades son tan estrechas, la tendencia es a hacerlas más anchas y confortables. No se } \\
\text { define qué es una cama de maternidad no preparada para hacer un colecho seguro } \\
\text { ¿depende del ancho? La misma consideración que se hace para el colecho en el hogar se } \\
\text { debería hacer aquí: pese a lo que pese, muchas madres en la maternidad se van a quedar } \\
\text { dormidas con su bebé en la cama de maternidad. Habrá que explicarles medidas de } \\
\text { seguridad para evitar accidentes. } \\
\text { Todavía quedan los nidos adosados en algunas maternidades públicas: habría que insistir } \\
\text { sobre su falta de conveniencia. } \\
\text { En definitiva a mi me parece que no hay motivo para recomendar con fuerza Fuerte lo de no } \\
\text { compartir cama si no se cumplen... No sé, yo lo expresaría de otra manera, como consenso } \\
\text { de expertos como mucho y siendo muy prudentes en recomendar unas cunas poco probadas }\end{array}$ & $\begin{array}{l}\text { 5.1. No sabemos cuál es ese porcentaje, aunque sería de interés } \\
\text { conocerlo. En cuanto a la recomendación que se hace, el grupo } \\
\text { no está de acuerdo porque entiende que siempre hay que } \\
\text { observar una toma y que decir lo que señala el revisor puede } \\
\text { llevar a que no siempre se realice la observación de la toma. Lo } \\
\text { del estudio ya está solucionado. } 5.2 \text {. Se han realizado cambios } \\
\text { importantes en las recomendaciones de colecho. Ahora las } \\
\text { recomendaciones son coherentes con las del colecho en el hogar } \\
\text { (ver en el borrador de la guía). Se ha quitado lo de las cunas } \\
\text { sidecar en el hospital (el revisor tiene razón). Y se han añadido } \\
\text { recomendaciones sobre las camas en las maternidades (que } \\
\text { permitan realizar un colecho seguro). }\end{array}$ \\
\hline
\end{tabular}




\begin{tabular}{|c|c|c|c|}
\hline \multirow[t]{2}{*}{ Revisor } & \multirow[t]{2}{*}{ Sección } & \multirow{2}{*}{$\begin{array}{l}\text { Comentario } \\
\text { y aún no adaptadas sin pruebas claras. }\end{array}$} & \multirow[t]{2}{*}{ Respuesta del grupo elaborador } \\
\hline & & & \\
\hline & $\begin{array}{l}\text { Valoración de la } \\
\text { lactancia materna }\end{array}$ & $\begin{array}{l}\text { Me parece todo correcto. Quizás en la página } 80 \text {, en Factibilidad haya que hacer alguna } \\
\text { consideración de la situación de los profesionales de Enfermería para poder desempeñar } \\
\text { bien sus funciones, dados los recortes generalizados de personal y que las maternidades se } \\
\text { utilizan con facilidad para ingresar otros enfermos que no caben en sus salas. De hecho } \\
\text { ¿conocemos la proporción de maternidades del país o de una comunidad autónoma en las } \\
\text { que se hace la observación sistemática de una toma? }\end{array}$ & No se conoce la proporcion. \\
\hline & Extracción de calostro & $\begin{array}{l}\text { Yo insistiría en la necesidad de formación de los profesionales en ambas técnicas: sacaleches } \\
\text { y sobre todo manual. }\end{array}$ & \\
\hline & $\begin{array}{l}\text { Promoción } \\
\text { institucional de la } \\
\text { lactancia materna }\end{array}$ & $\begin{array}{l}\text { El título de este punto induce a error. Parece que vaya a hablar de las campañas, } \\
\text { promociones, planes, guías, leyes, etc. de la Administración sanitaria incluidas consejerías y } \\
\text { ministerio } \\
\text { Yo creo que debería llamarse “Programas hospitalarios y de Atención Primaria eficaces en la } \\
\text { promoción de la lactancia materna", pero dado que de lo único que se habla es de la IHAN, } \\
\text { se podría titular simplemente } 9 \text {. La IHAN. } \\
\text { En la página } 103 \text { hay una frase que no se entiende por un posible error de redacción: [...] y el } \\
\text { dar un apoyo adecuado y de calidad una las madres que no amamantan[...]. } \\
\text { Y otro: [...] y dirigido por un profesionales [...]. }\end{array}$ & $\begin{array}{l}\text { Se ha modificado el título siguiendo las recomendaciones del } \\
\text { revisor, aunque no se ha puesto un título tan largo. La frase de la } \\
\text { página } 103 \text { ya se ha modfificado. }\end{array}$ \\
\hline & $\begin{array}{l}\text { Seguimiento del } \\
\text { lactante amamantado }\end{array}$ & $\begin{array}{l}10.1 \text { (está equivocado, pone 11.1)- Lo del peso lo veo muy largo y farrragoso, quizás no hay } \\
\text { otra manera, pero habría que intentarlo. En el resumen de la evidencia en la página } 111 \text { y de } \\
\text { la } 118 \text { falta poner la calidad de la misma. Veo poco práctico introducir tablas ni de Bertini ni } \\
\text { otras para evaluar la pérdida de peso en los primeros días. Creo que el porcentaje de pérdida } \\
\text { que manejamos habitualmente junto a la evaluación clínica es suficiente. Yo me quedaría } \\
\text { con la } 3 \text { a recomendación de la página } 112 \text {. } \\
\text { Las recomendaciones de la página } 119 \text { me parecen muy bien. }\end{array}$ & $\begin{array}{l}\text { Se han corregido los números y se ha abreviado la pregunta sobre } \\
\text { pérdida de peso, incluyendo las gráficas al final en un ANEXO. La } \\
\text { calidad de la evidencia es que no hay, es decir, no hay estudios } \\
\text { que comparen la utilidad de una u otra gráfica en detectar } \\
\text { problemas en el niño. Por eso no se ha puesto calidad de la } \\
\text { evidencia para la pregunta, solo se describen los estudios que } \\
\text { han elaborado dichas gráficas (en su caso, la calidad sería muy } \\
\text { baja). En cuanto a las recomendaciones, nos hemos quedado } \\
\text { finalmente solo con la tercera, como indica el revisor. }\end{array}$ \\
\hline & $\begin{array}{l}\text { Manejo de los } \\
\text { problemas con la } \\
\text { lactancia materna }\end{array}$ & $\begin{array}{l}\text { ¿Por qué en la pregunta ¿Qué hacer ante un lactante amamantado que presenta una } \\
\text { pérdida excesiva de peso en los tres primeros días? no se ha seguido la misma metodología } \\
\text { que en el resto de preguntas de la guía, es decir, buscar las pruebas, hacer un resumen de las } \\
\text { mismas, y hacer unas recomendaciones, etc.?Creo que para hablar de la anquiloglosía } \\
\text { primero se debería hacer un esfuerzo en determinar qué dice la literatura científica sobre su } \\
\text { incidencia en la población de lactantes ya que tenemos una falsa epidemia de anquiloglosia } \\
\text { en España, dependiendo del profesional que examina y del grupo de apoyo al que ha } \\
\text { consultado la madre. Me parecen bien, no obstante las recomendaciones al respecto, pero }\end{array}$ & $\begin{array}{l}\text { Porque se trataba de una pregunta introductoria que lleva a otras } \\
\text { preguntas. Se quería hacer referencia al ANEXO que se ha } \\
\text { elaborado para tal fin. De ahí que la estructura no es igual. De } \\
\text { todas formas, lo que se ha hecho ha sido dejar un párrafo } \\
\text { introductorio y se hace referencia al ANEXO en cuestión. Así } \\
\text { queda más sencillo. } \\
\text { En cuanto a la anquiloglosia, ya se ha señalado la dificultad que } \\
\text { existe en el diagnóstico. Aunque sabemos su importancia, en esta }\end{array}$ \\
\hline
\end{tabular}




\begin{tabular}{|c|c|c|c|}
\hline Revisor & Sección & Comentario & Respuesta del grupo elaborador \\
\hline & & 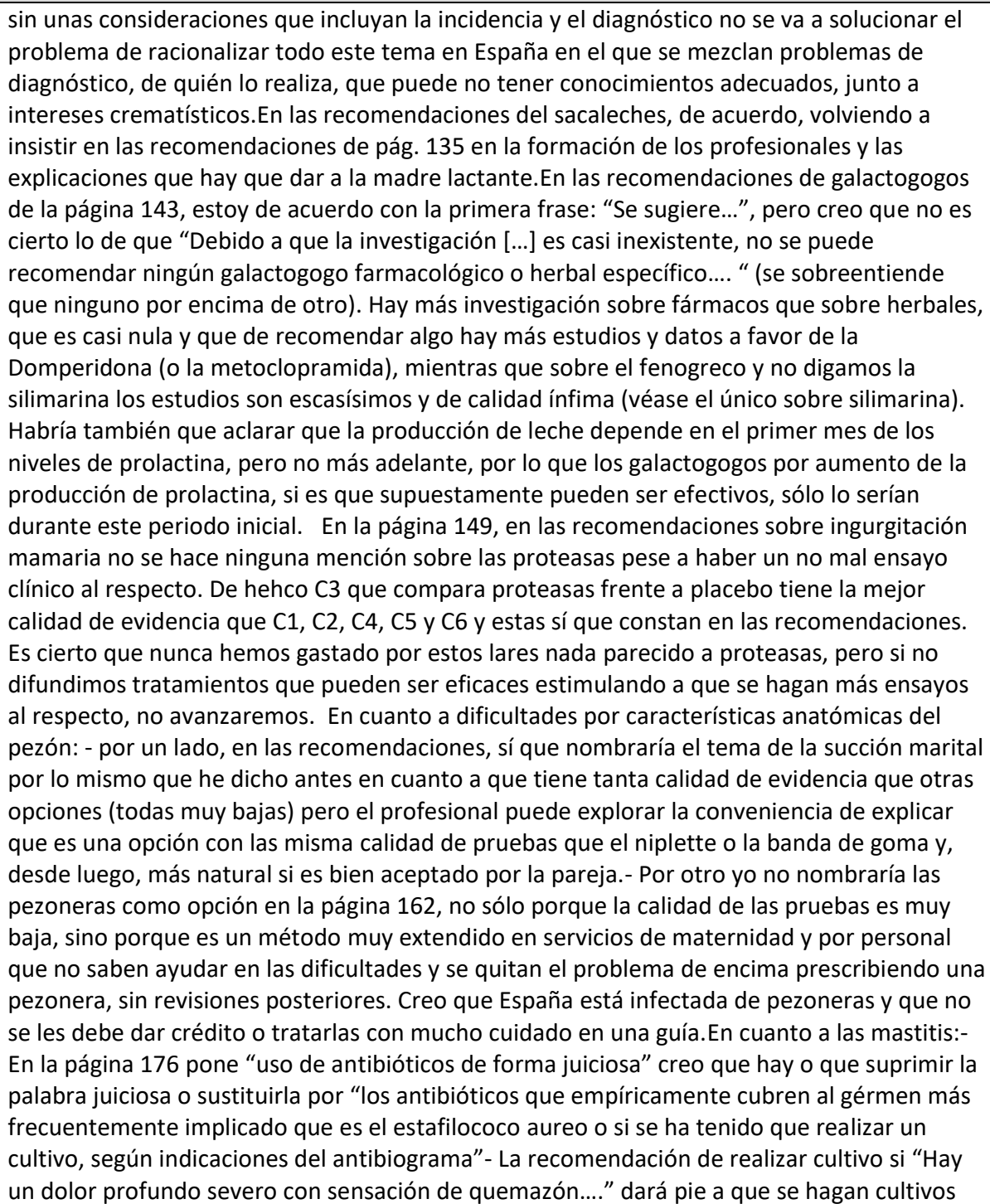 & $\begin{array}{l}\text { guia no hemos podido abordar cómo realizar el diagnóstico de la } \\
\text { misma... } \\
\text { En las recomendaciones de sacaleches deacuerdo. }\end{array}$ \\
\hline
\end{tabular}




\begin{tabular}{|c|c|c|c|}
\hline Revisor & Sección & Comentario & Respuesta del grupo elaborador \\
\hline & & $\begin{array}{l}\text { siempre, que es lo que preconizan algunos en España sin datos científicos. Yo no la pondría. } \\
\text { Ya está bastante medicalizada la lactancia y extendidas las pseudomastitis en nuestro país } \\
\text { como para darles el más mínimo apoyo. De hecho el protocolo de la ABM de } 2014 \text { no recoge } \\
\text { esa indicación sino que pone la de "in severe or unusual cases." (y con calidad de evidencia } \\
\text { II-2)- Me parece muy bien no haber hecho recomendaciones sobre probióticos para el } \\
\text { tratamiento de la mastitis, pero no se si no convendría advertir claramente que no hay } \\
\text { pruebas para el uso de probióticos y que no está justificado su utilización, ya que en estos } \\
\text { momentos muchas mujeres en España están tomándolos, y a precio nada barato, colectivos } \\
\text { enteros de matronas creen a pies juntillas en los probióticos como cura milagro... - Aunque } \\
\text { en la página } 184 \text { consta que el estafilococo aúreo es la causa más frecuente en las mastitis } \\
\text { agudas, echo en falta que no se haya hecho la pregunta justamente: ¿Cuál es al causa más } \\
\text { frecuente en las mastitis infecciosas?-Y la última pregunta, que quizá se debería haber } \\
\text { investigado al estar aquí en España es: ¿Qué pruebas hay de que la mastitis subaguda o la } \\
\text { subclínica sean entidades a diagnosticar en mujeres y en qué condiciones? Esta pregunta es } \\
\text { fácil de contestar tras una breve consulta en Pubmed: no existen en humanos, es un término } \\
\text { de veterinaria y como mucho se ha hablado de ellas en algunos casos de madres lactantes } \\
\text { VIH positivas. }\end{array}$ & \\
\hline & $\begin{array}{l}\text { Difusión e } \\
\text { implementación }\end{array}$ & $\begin{array}{l}\text { Prácticamente ya se ha pensado en todo. Muy de acuerdo.En el punto de la promoción } \\
\text { institucional (IHAN) creo que deberían introducirse en la negociación IHAN con las diversas } \\
\text { administraciones de salud el compromiso de las mismas de "premiar" de alguna manera al } \\
\text { centro sanitario que lo consiga permitiendo alguna mejora (se me ocurre que permitir } \\
\text { utilizar un mínimo de personal para instaurar una consulta de lactancia o una persona } \\
\text { referente en lactancia). En el último punto, manejo de los problemas yo pondría una } \\
\text { advertencia sobre varios temas que carecen de pruebas científicas: las pezoneras, el exceso } \\
\text { de diagnósticos de anquiloglosia, el diagnóstico de mastitis subaguda, la toma incontrolada } \\
\text { de ciprofloxacino y de probióticos, terapias sin pruebas como la llamada terapia sacral y } \\
\text { otras..., son temas que circulan fuera de los cauces científicos, están muy arraigados en } \\
\text { muchos colectivos, muchas veces de manera muy emocional y hacen un flaco favor a la } \\
\text { lactancia. }\end{array}$ & \\
\hline & Anexos & $\begin{array}{l}\text { Anexo } 5 \text {. El apartado de meconio y caca hay que martizarlo. Si las aguas fueron meconiales } \\
\text { es fácil que no haga meconio el primer día. Algunos bebés pueden empezar a tener el falso } \\
\text { estreñimiento del lactante antes del mes. } \\
\text { Anexo 13. ¿Vale la pena decir que todos estos métodos son útiles en las primeras semanas, } \\
\text { mientras el lactante (y la madre) aprende a mamar, pero que a lo mejor no vale la pena en } \\
\text { lactantes ya expertos y mayorcitos? }\end{array}$ & $\begin{array}{l}\text { El Anexo } 5 \text { ya se ha matizado (se ha incluido en la tabla un } \\
\text { asterisco que dice " ". } \\
\text { En el Anexo } 13 \text {, ya se ha hecho la modificación. }\end{array}$ \\
\hline
\end{tabular}




\begin{tabular}{|c|c|c|c|}
\hline Revisor & Sección & Comentario & Respuesta del grupo elaborador \\
\hline \multirow[t]{5}{*}{ Revisor 4} & Introducción & $\begin{array}{l}\text { Define el problema y los objetivos, queda clara la trascendencia del tema que aborda y } \\
\text { plantea un análisis de la situación. } \\
\text { En la figura 2, (página } 27 \text {, Datos de lactancia materna a las } 6 \text { semanas, } 3 \text { y } 6 \text { meses por CCAA } \\
\text { I sería interesante indicar de donde proceden los datos, puesto que se supone que derivan } \\
\text { de la encuesta nacional de salud, pero de la de } 2006 \text { o de la de } 2012 \text { ? }\end{array}$ & $\begin{array}{l}\text { Las gráficas las elaboró una de las autoras de la guía. Los datos } \\
\text { son comparaciones de } 2006 \text { y } 2013 \text {. Se ha tratado de señalar esto } \\
\text { mejor en el borrador, para no crear confusión. }\end{array}$ \\
\hline & Metodología & $\begin{array}{l}\text { Poner el link directo a la guía y a los documentos relacionados con la guía de tal forma que } \\
\text { desde la versión electrónica se pueda acceder directamente. }\end{array}$ & Está previsto hacerlo cuando se finalice el documento. \\
\hline & $\begin{array}{l}\text { Prácticas que } \\
\text { favorecen la lactancia } \\
\text { materna }\end{array}$ & $\begin{array}{l}\text { En cuanto a la "recomendación del colecho en la maternidad", no hay evidencia de que el } \\
\text { colecho en la cama de la maternidad aumente el riesgo de SMSL, sólo describen que es más } \\
\text { frecuente que el lactante se exponga a situaciones "potencialmente peligrosas" que por otro } \\
\text { lado no se especifican. Sin embargo, sí describe que el colecho en la cama y en la cuna } \\
\text { sidecar aumentan el número de tomas. Además la lactancia se asocia con menor riesgo de } \\
\text { muerte súbita y el colecho con mayor duración de la lactancia. Creo que la recomendación } \\
\text { siendo acertada, debe ser redactada en otro sentido y en lugar de expresar que la madre } \\
\text { que amamanta en la maternidad no comparta la cama con el RN si no se cumplen las } \\
\text { condiciones de colecho seguro, la recomendación debería hacerse reforzando que se deben } \\
\text { cumplir las normas de colecho seguro en la maternidad si la madre que amamanta hace } \\
\text { colecho con el recién nacido, es esencialmente lo mismo pero dicho de otra forma. Se } \\
\text { refuerza la idea de que el colecho favorece la lactancia y de que los profesionales deben } \\
\text { informar y favorecer que se cumplan los criterios de colecho seguro, puesto que no hay } \\
\text { evidencia de que aumente el riesgo de SMSL. Estoy totalmente de acuerdo con que lo ideal } \\
\text { sería disponer de cunas sidecar, pero me parece una opción poco factible y sin embargo no } \\
\text { se menciona que las camas en la maternidad deberían disponer siempre de barreras. }\end{array}$ & $\begin{array}{l}\text { Ya se han modificado las recomendaciones de colecho. Ver en el } \\
\text { borrador cómo han quedado finalmente. }\end{array}$ \\
\hline & $\begin{array}{l}\text { Seguimiento del } \\
\text { lactante amamantado }\end{array}$ & Los apartados del capítulo están mal numerados, son el 10.1 y el 10.2 y pone 11.1 y 11.2 & Modificado. \\
\hline & $\begin{array}{l}\text { Manejo de los } \\
\text { problemas con la } \\
\text { lactancia materna }\end{array}$ & $\begin{array}{l}\text { - ¿Qué hacer ante un lactante amamantado que presenta pérdida excesiva de peso en los } \\
\text { tres primeros días?. En esta pregunta no se ha evaluado evidencia, simplemente se hace un } \\
\text { resumen del algoritmo que es muy útil y me parece muy bien estructurado, pero se ha } \\
\text { evaluado la evidencia?, el algoritmo se entiende como recomendación?, En el tratamiento } \\
\text { de ingurgitación mamaria, no se menciona la maniobra de presión inversa suavizante que sí } \\
\text { está recogida en la revisión Cochrane } 2010 \text { y en el protocolo revisado de la ABM. } 2016 \\
\text { BREASTFEEDING MEDICINE Volume } 11 \text {, Number } 4,2016 \text { (actualización del de } 2009 \text { que sí } \\
\text { aparece en la guía como referencia } 364 \text { ). creo que se debería incluir en las recomendaciones } \\
\text { así como en un anexo que lo explique. Los trabajos que recoge la guía ABM son: - Cotterman } \\
\text { KJ. Reverse pressure softening: A simple tool to prepare areola for easier latching during } \\
\text { engorgement. J Hum Lact 2004;20:227-237.- Miller V, Riordan J. Treating postpartum breast } \\
\text { edema with areolar compression. J Hum Lact 2004;20:223-226.• ¿Qué hacer si hay }\end{array}$ & $\begin{array}{l}\text { Ya se ha mencionado esto en el comentario de un revisor } \\
\text { anterior. Ver respuesta. } \\
\text { Se ha incluido la presión inversa. También en un anexo nuevo. } \\
\text { Se recomienda también en el pezón plano el uso de jeringa. En } \\
\text { cuanto a la pregunta cómo abordar el dolor en los pezones, se } \\
\text { trata de una pregunta similar a la de la pérdida de peso en el } \\
\text { recién nacido. Lo único que se quería hacer era introducir el } \\
\text { algoritmo de posibles diagnósticos, para ordenar las preguntas de } \\
\text { tratamiento corrrespondiente a cada una de las posibles causas } \\
\text { del dolor. }\end{array}$ \\
\hline
\end{tabular}




\begin{tabular}{|c|c|c|c|}
\hline Revisor & Sección & Comentario & Respuesta del grupo elaborador \\
\hline & & $\begin{array}{l}\text { dificultades en el agarre por las características anatómicas del pezón?No sé si se ha evaluado } \\
\text { la utilización de la jeringa para favorecer la salida del pezón en el pezón plano o sólo en el } \\
\text { invertido, pero creo que en el pezón plano también se puede recomendar su uso al igual que } \\
\text { el del sacaleches para favorecer la salida el pezón. Sería útil un anexo explicativo sobre cómo } \\
\text { se aplica la jeringa cortada sobre el pezón plano o invertido• ¿Cómo abordar el dolor en los } \\
\text { pezones y en las mamas durante el amamantamiento?Para esta pregunta tampoco se evalúa } \\
\text { evidencia, es a modo de introducción, explicativo? Dejar constancia de que no se ha hecho } \\
\text { búsqueda o no se ha encontrado. • ¿Cuál sería el tratamiento más adecuado para tratar el } \\
\text { dolor y las grietas en el pezón que pueden aparecer durante la lactancia materna?Sugiero } \\
\text { añadir en las recomendaciones (página } 71 \text { ) que mejor cremas que no haya que retirar. Las } \\
\text { preguntas que responden a cómo se manifiestan las mastitis, a cuándo está indicada la } \\
\text { realización de cultivo, a la intervención más eficaz y la utilización de antibióticos me parecen } \\
\text { muy clarificadoras, las recomendaciones se derivan de la evidencia disponible y de forma } \\
\text { adecuada responden a un tema que actualmente es muy controvertido. }\end{array}$ & \\
\hline & $\begin{array}{l}\text { Difusión e } \\
\text { implementación }\end{array}$ & $\begin{array}{l}\text { En el último apartado las implicaciones del manejo de los problemas del pecho. Añadiría: } \\
\text { "Impulsar la creación de unidades de lactancia, la derivación de patología a profesionales } \\
\text { especializados". }\end{array}$ & De acuerdo (no está ya en la guía???) \\
\hline & Anexos & $\begin{array}{l}\text { Anexo 3: Posturas para amamantar, el dibujo de la postura de dancer no ilustra bien lo } \\
\text { importante de la postura que además de que el niño esté vertical consiste en colocar los } \\
\text { dedos a los lados de la barbilla en forma de U para darle soporte. Con la imagen que aparece } \\
\text { es difícil apreciar este aspecto. Anexo 13: la imagen del dedo con el finger-feeder, no es muy } \\
\text { ilustrativa, En el dibujo no se aprecia lo importante de esta técnica, aparece con el dedo } \\
\text { poco metido como si el bebé sólo chupara la punta y muy horizontal. Sería interesante que a } \\
\text { golpe de vista se apreciara que la yema del dedo debe estar metida hasta el paladar, con el } \\
\text { labio inferior evertido (se ve regular) y la mano hacia abajo para forzar la apertura de la boca } \\
\text { del niño. Anexo 14: incluiría las curvas de peso para la longitud que están en la } \\
\text { recomendación. Y también las de pérdida de peso de los primeros días. Como se ha } \\
\text { comentado anteriormente creo que serían útiles un anexo sobre la utilización de la jeringa } \\
\text { en el pezón plano e invertido y otro sobre la técnica de presión inversa suavizante. }\end{array}$ & $\begin{array}{l}\text { De acuerdo. Se han modificado los dibujos de los Anexos } 3 \text { y } 13 \text {. } \\
\text { Se ha modificado el Anexo } 14 \text { y se ha creado otro anexo nuevo } \\
\text { con las curvas de pérdida de peso en los primeros días. } \\
\text { También se ha incluido un anexo sobre la utilización de la jeringa } \\
\text { en el pezón plano e invertido y otro sobre la técnica de presión } \\
\text { inversa suavizante. }\end{array}$ \\
\hline & Otros & $\begin{array}{l}\text { Como sugerencia, las referencias bibliográficas en las que se especifica una dirección web } \\
\text { podrían estar disponibles en forma de hipervínculos para poder acceder directamente desde } \\
\text { el link de la versión electrónica de la guía. Son las referencias:1,3,5, 23,94, 95, 100, 113, } \\
114,117,118,131,269,279,283,301,396 \text { y } 402 \text {. } \\
\text { Al probar a acceder, en algunas de las direcciones electrónicas da error o no localiza la } \\
\text { referencia especificada: } 23,131,94,95,269 \text {. }\end{array}$ & Se han realizado las correcciones. \\
\hline
\end{tabular}




\begin{tabular}{|c|c|c|c|}
\hline Revisor & Sección & Comentario & Respuesta del grupo elaborador \\
\hline Revisor 5 & $\begin{array}{l}\text { Atención postparto } \\
\text { inmediata }\end{array}$ & 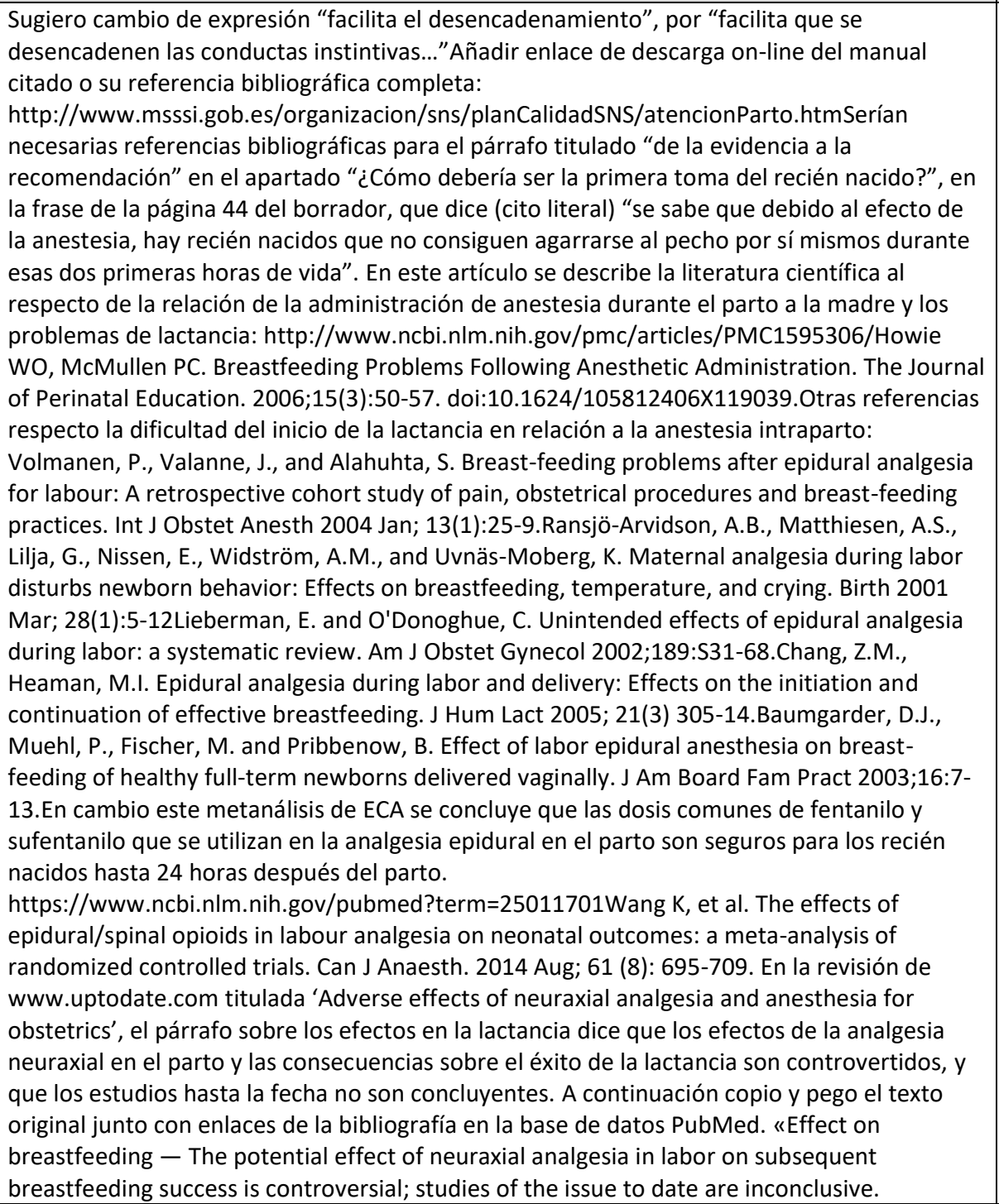 & $\begin{array}{l}\text { Se ha eliminado la frase sobre el efecto de la antestesia, porque } \\
\text { en realidad no se ha revisado este tema (aunque se propuso } \\
\text { como pregunta a incluir en una actualización futura de la guía). }\end{array}$ \\
\hline
\end{tabular}




\begin{tabular}{|c|c|c|c|}
\hline Revisor & Sección & Comentario & Respuesta del grupo elaborador \\
\hline & & 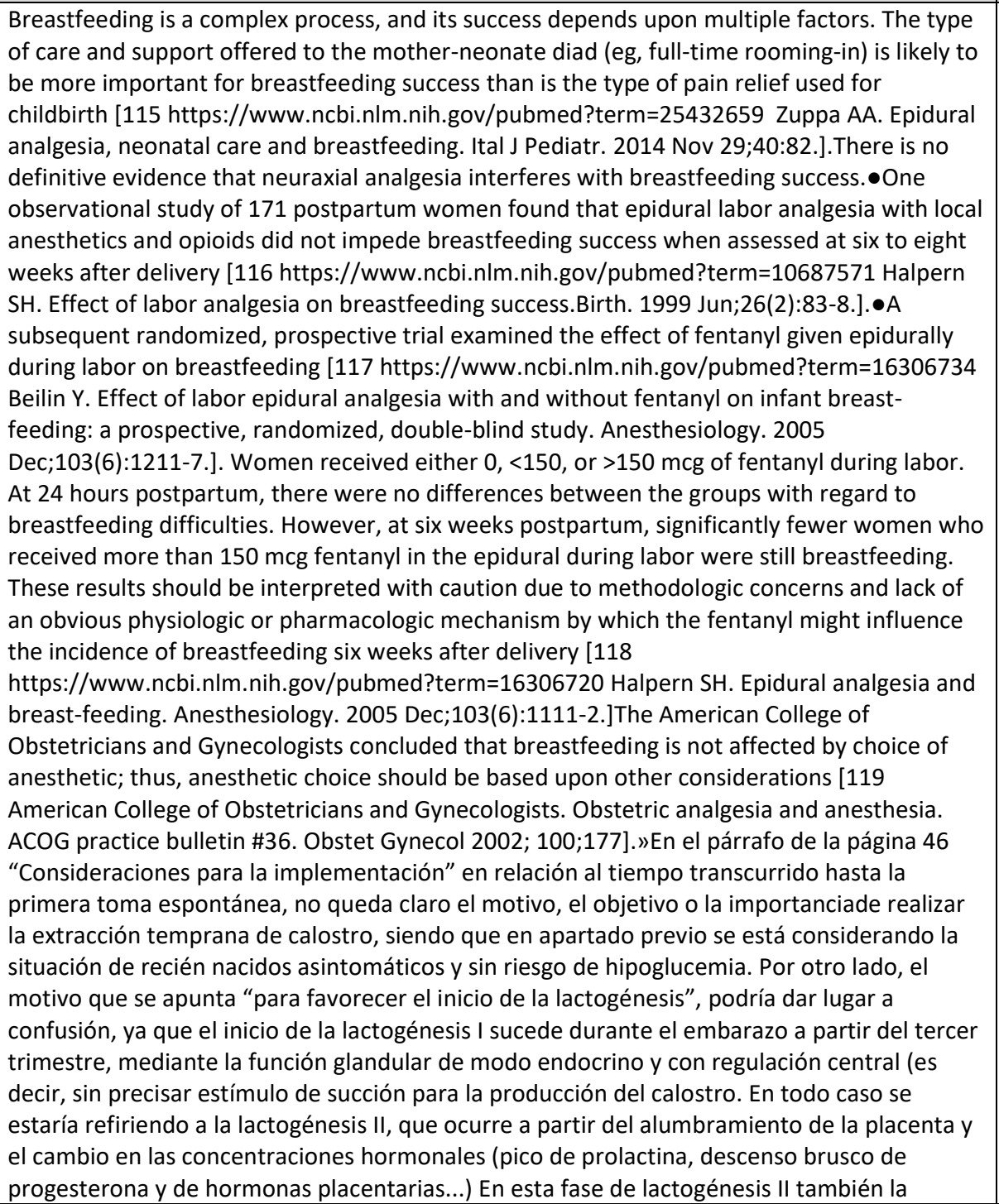 & \\
\hline
\end{tabular}




\begin{tabular}{|c|c|c|c|}
\hline Revisor & Sección & Comentario & Respuesta del grupo elaborador \\
\hline & & $\begin{array}{l}\text { función glandular es en modo endocrino con regulación central todavía poco dependiente de } \\
\text { la succión.Neville MC, Morton J. Physiology and endocrine changes underlying human } \\
\text { lactogenesis II. J Nutr. } 2001 \text { Nov;131(11):3005S-8S. } \\
\text { http://jn.nutrition.org/content/131/11/3005S.long }\end{array}$ & \\
\hline & Extracción de calostro & 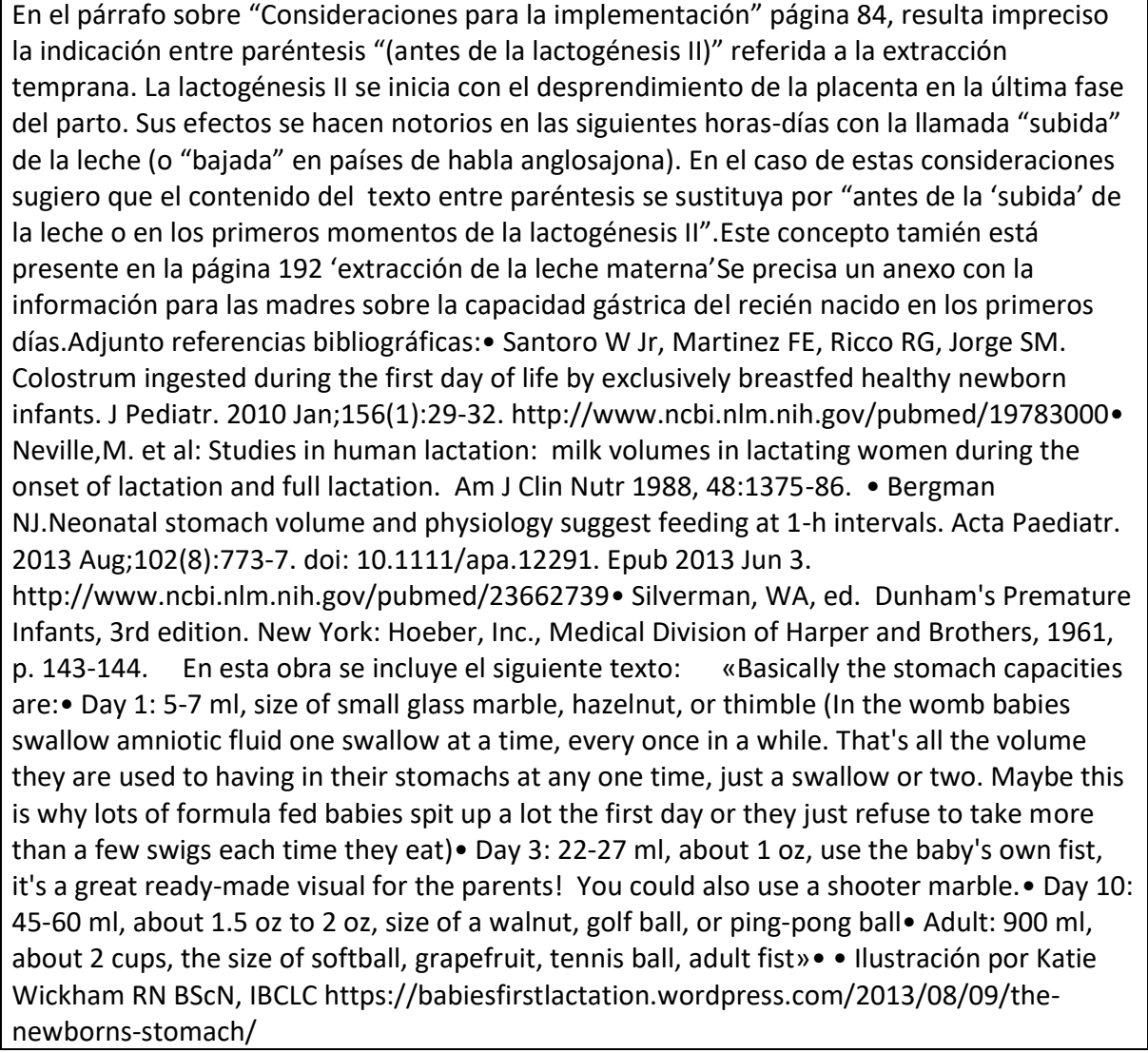 & $\begin{array}{l}\text { se ha modificado esa frase. } \\
\text { Se ha valorado la elaboración de este anexo, pero se querían } \\
\text { verificar los volúmenes que se presentan en la imagen propuesta, } \\
\text { que en principio vienen de un libro sobre prematuros (no } \\
\text { tenemos acceso al mismo). De hecho, en el artículo de Bergman } \\
2013 \text { se habla de un volumen de } 20 \text { ml. Debido a las dudas y al } \\
\text { poco tiempo disponible, se ha considerado no hacer el anexo en } \\
\text { esta ocasión. }\end{array}$ \\
\hline
\end{tabular}




\begin{tabular}{|c|c|c|c|}
\hline Revisor & Sección & Comentario & Respuesta del grupo elaborador \\
\hline & $\begin{array}{l}\text { Manejo de los } \\
\text { problemas con la } \\
\text { lactancia materna }\end{array}$ & 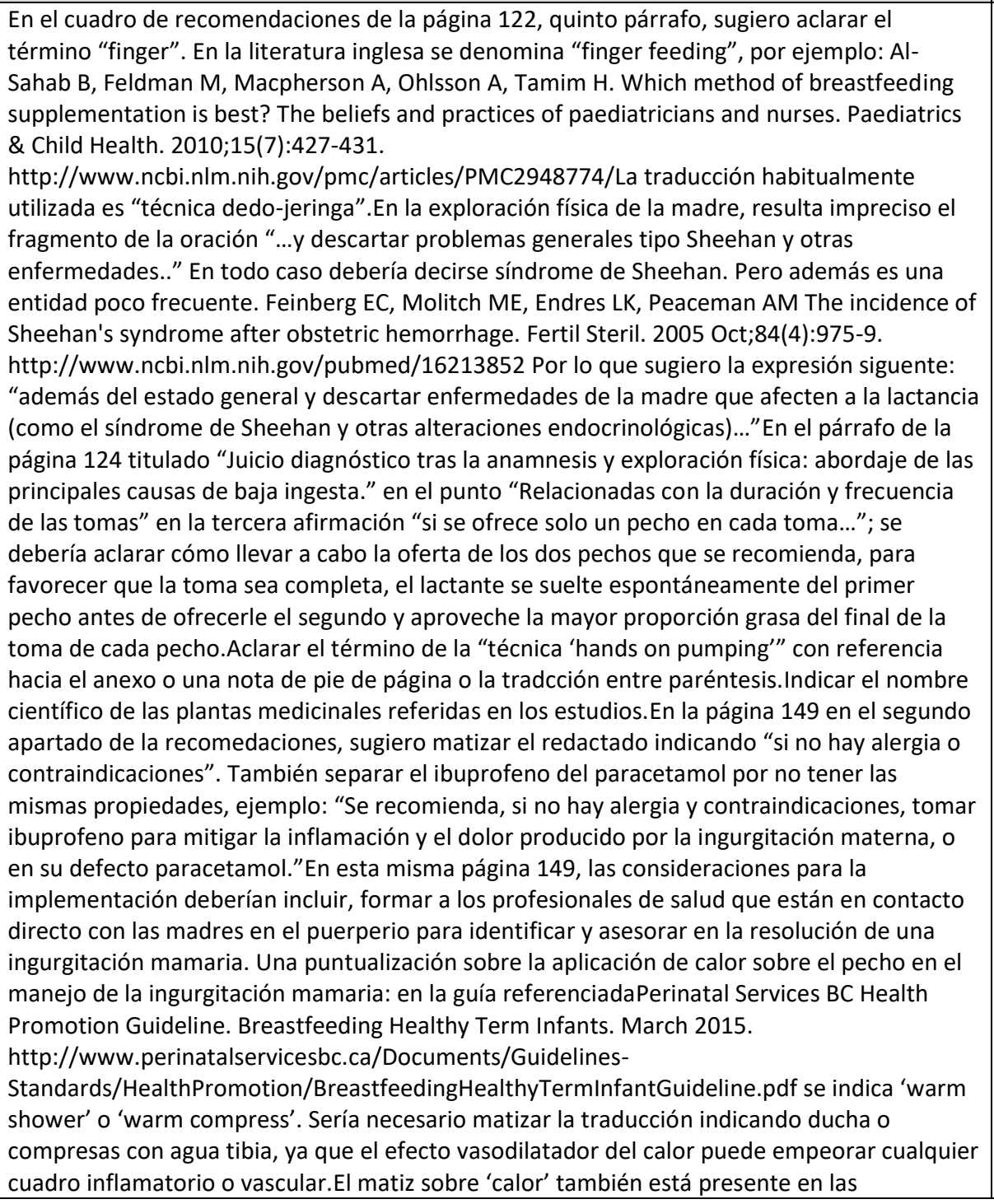 & Se han hecho las modificaciones señaladas. \\
\hline
\end{tabular}




\begin{tabular}{|c|c|c|c|}
\hline Revisor & Sección & Comentario & Respuesta del grupo elaborador \\
\hline & & recomendaciones del tratamiento de las mastitis agudas, página 180. & \\
\hline & $\begin{array}{l}\text { Difusión e } \\
\text { implementación }\end{array}$ & $\begin{array}{l}\text { Registro en el documento de alta hospitalaria. Registro informatizado en la primera visita } \\
\text { ambulatoria de la madre y/o el lactante en su centro de salud, bien sea en consulta de } \\
\text { pediatra, matrona/matrón, o médico de familia.Número de consultas por dificultades de } \\
\text { lactanciaTasas de lactancia materna al mes, } 3 \text { meses, } 6 \text { meses. Evaluación de la satisfacción } \\
\text { de las madresNúmero de consultas/descargas de la guía a través de medios } \\
\text { telemáticosNúmero de centros adheridos al programa IHAN. }\end{array}$ & \\
\hline & Anexos & $\begin{array}{l}\text { La postura denominada de “Crianza Biológica" es un término registrado }{ }^{\circledR} \text { por "The nurturing } \\
\text { project" de Suzane Colson http://www.biologicalnurturing.com/pages/contactus.html } \\
\text { La posición Dancer es original de Sarah Coulter Danner, RN, CPNP, CNM, IBCLC y Ed Cerutti, } \\
\text { MD. El nombre "dancer" corresponde a las tres primeras letras de los apellidos de los } \\
\text { respectivos profesionales que acuñaron el nombre de esta posición (Dan + Cer) } \\
\text { http://www.lalecheleague.org/faq/down.html } \\
\text { Judith Lauwers, Anna Swisher. Counseling the Nursing Mother. Ed. Jones \& Bartlett Learning, } \\
\text { 2016, pag 753. } \\
\text { https://books.google.es/books?id=6r8nCgAAQBAJ\&printsec=frontcover\&dq=Judith+Lauwers } \\
\text {,+Anna+Swisher.+Counseling+the+Nursing+Mother\&hl=ca\&sa=X\&ved=0ahUKEwio- } \\
\text { LOY6pnPAhWBthQKHcpODvQQ6AEIGzAA } \\
\text { McBride MC, Danner SC. Sucking disorders in neurologically impaired infants: assessment } \\
\text { and facilitation of breastfeeding. Clin Perinatol 1987;14:109-130. } \\
\text { Danner, SC. Breastfeeding the neurologically impaired infant. Perin Womens Health Nurs } \\
\text { 1992;3:640-646 } \\
\text { Añadir técnica de "presión inversa suavizante" (en inglés 'Reverse pressure softening') de la } \\
\text { autora K Jean Cotterman: } \\
\text { Cotterman KJ. Reverse pressure softening: a simple tool to prepare areola for easier latching } \\
\text { during engorgement. J Hum Lact. 2004 May;20(2):227-37. } \\
\text { http://www.ncbi.nlm.nih.gov/pubmed/15117523 } \\
\text { https://www.Illi.org/docs/spanish/RPS 2005 spanish1.pdf }\end{array}$ & $\begin{array}{l}\text { Se menciona esta información en el ANEXO. En cuanto a la } \\
\text { técnica de presión inversa suavizante, se ha elaborado un anexo } \\
\text { nuevo. }\end{array}$ \\
\hline
\end{tabular}




\begin{tabular}{|c|c|c|c|}
\hline Revisor & Sección & Comentario & Respuesta del grupo elaborador \\
\hline \multirow[t]{5}{*}{ Revisor 6} & $\begin{array}{l}\text { Atención postparto } \\
\text { inmediata }\end{array}$ & $\begin{array}{l}\text { En consideraciones para la implementación de la primera pregunta (CPP), en el último } \\
\text { punto: o “Ayudar a la madre a adoptar, tras el parto, una posición semi-incorporada (15-65) } \\
\text { que facilite la adaptación fisiológica del recién nacido". Lo cambiaría por permeabilidad de la } \\
\text { vía aéreaEn la siguiente pregunta: “¿Cómo debería ser la primera toma del recién nacido?”, } \\
\text { primer párrafo, "los profesionales coloquen al recién nacido directamente sobre el pezón y } \\
\text { fuercen un agarre espontáneo.", si fuerzan el agarre, ya no es espontáneo..., mejor: fuercen } \\
\text { un agarre que debería ser espontáneo }\end{array}$ & De acuerdo con los cambios. \\
\hline & Extracción de calostro & $\begin{array}{l}\text { Becker GE, Smith HA, Cooney F. Methods of milk expression for lactating women. Cochrane } \\
\text { Database of Systematic Reviews 2015, Issue 2. Art. No.: CD006170. DOI: } \\
\text { 10.1002/14651858.CD006170.pub4. } \\
\text { Higher Fat Content in Breastmilk Expressed Manually: A Randomized Trial. } \\
\text { Mangel L, Ovental A, Batscha N, Arnon M, Yarkoni I, Dollberg S. } \\
\text { Breastfeed Med. } 2015 \text { Sep;10(7):352-4 } \\
\text { En esta revisión de la Cochrane, y en este artículo, también hablan de la diferencias en la } \\
\text { composición de la leche según la forma de extracción (manual o eléctrica) }\end{array}$ & $\begin{array}{l}\text { Esta revisión ya está incluida. En cuanto al contenido en grasa de } \\
\text { la leche, no se consideró como desenlace de interés, por lo que } \\
\text { en principio no se incluiría este estudio ni los resultados sobre } \\
\text { ello presentados en la revisión. }\end{array}$ \\
\hline & $\begin{array}{l}\text { Suplementos y } \\
\text { lactancia materna }\end{array}$ & $\begin{array}{l}\text { De acuerdo. } \\
\text { - En las últimas recomendaciones, donde pone: "La aceptación del método por el recién } \\
\text { nacido (la alimentación con sonda puede ser agotadora para un recién nacido con pocas } \\
\text { fuerzas)", especificaría dedo+sonda. }\end{array}$ & De acuerdo con los cambios. \\
\hline & $\begin{array}{l}\text { Seguimiento del } \\
\text { lactante amamantado }\end{array}$ & $\begin{array}{l}\text { En recomendaciones de la primera pregunta: 11.1. Seguimiento de la pérdida de peso } \\
\text { durante los primeros días, valorar añadir hasta dónde se considera normal la pérdida de } \\
\text { peso si la exploración del RN es normal. Lo especificáis al principio del apartado como } \\
\text { recomendación de la IHAN: "La iniciativa IHAN señala que una pérdida ponderal superior al } \\
\text { 7\% puede indicar una transferencia inadecuada de leche o una producción baja de la misma. } \\
\text { Si no existen problemas y el examen físico es normal, las pérdidas de peso entre el } 8 \text { y } 10 \% \\
\text { pueden considerarse dentro de los límites normales, aunque es indicación de evaluación } \\
\text { cuidadosa y de posible asistencia técnica" } \\
\text { Resto del apartado, de acuerdo. }\end{array}$ & $\begin{array}{l}\text { Creemos que con la recomendación que se presenta ya se cubre } \\
\text { este aspecto. Finalmente se ha decidido eliminar las } \\
\text { recomendaciones } 1 \text { y } 2 \text {, y dejar sólo la tercera. }\end{array}$ \\
\hline & $\begin{array}{l}\text { Manejo de los } \\
\text { problemas con la } \\
\text { lactancia materna }\end{array}$ & $\begin{array}{l}\text { En la pregunta de "pérdida excesiva de peso los tres primeros día". En punto 3: Abordaje de } \\
\text { principales causas de baja ingesta: "Si se ofrece solo un pecho en cada toma: Informar sobre } \\
\text { la importancia de ofrecer los dos pechos en cada toma"... ¿qué importancia tienen ofrecer } \\
\text { los dos pechos en cada toma?. Es importante que se vacíe bien un pecho en cada toma y } \\
\text { luego ofrecer el otro pecho, como dicen en el punto inmediatamente anteriorü Considero } \\
\text { que se ha revisado poco sobre las mastitis subclínicas, prevención y probióticos, tan de moda } \\
\text { últimamente. Últimamente hay estudios sobre administración de probióticos al final del } \\
\text { embarazo para prevenir mastitis. Ej. Fernández L, Cárdenas N, et al. Prevention of Infectious } \\
\text { Mastitis by oral administration of lactobacillus salivarius PS2 during late pregnancy. Cin }\end{array}$ & $\begin{array}{l}\text { Se ha modificado la frase que habla del ofrecimiento de los } \\
\text { pechos en cada toma. En cuanto a mastitis subclinicas y } \\
\text { probióticos, no se ha considerado la prevención de las mastitis, } \\
\text { sino su tratamiento. Puede ser una pregunta de interés a incluir } \\
\text { en futuras actualizaciones de la guía. }\end{array}$ \\
\hline
\end{tabular}




\begin{tabular}{|c|c|c|c|}
\hline Revisor & Sección & Comentario & Respuesta del grupo elaborador \\
\hline & & $\begin{array}{l}\text { Infect Dis. } 2016 \text { Mar 1;62(5):568-73. ü Esto último, probióticos y prevención de mastitis, se } \\
\text { podría poner como línea de investigación futura en apartado } 14 \text {. }\end{array}$ & \\
\hline & $\begin{array}{l}\text { Difusión e } \\
\text { implementación }\end{array}$ & $\begin{array}{l}\text { ü (№ de madres que inician la lactancia en la primera hora tras el parto / No de partos } \\
\text { realizados) x } 100 \\
\text { ü (№ niños alojados con su madre, a los que se realizó la observación de una toma en las } \\
\text { primeras seis horas de vida en la planta de maternidad /no niños alojados con su madre en } \\
\text { la planta de la maternidad) x } 100 \\
\text { ü (№ niños a los que se le ha dado al menos una toma de sucedáneo de leche materna antes } \\
\text { del alta hospitalaria / No de altas de niños Recién Nacidos) x } 100 \\
\text { ü (№ de niños que al alta hospitalaria, han recibido exclusivamente lactancia materna / No } \\
\text { de altas de niños Recién Nacidos) x 100. }\end{array}$ & \\
\hline & $\begin{array}{l}\text { Líneas de } \\
\text { investigación futura }\end{array}$ & Probióticos y prevención de mastitis. & \\
\hline \multirow[t]{2}{*}{ Revisor 7} & $\begin{array}{l}\text { Atención postparto } \\
\text { inmediata }\end{array}$ & $\begin{array}{l}\text { La recomendación (fuerte) de contacto piel con piel tras cesárea ¿conllevaría el NO ingreso } \\
\text { materno en URPA, si la madre dispone de un acompañante competente? O por el contrario, } \\
\text { se realizaría el ingreso separadamente (madre/recién nacido) tras el período de } 120 \text { minutos } \\
\text { de contacto precoz? Quizás podría ser interesante especificar este punto. }\end{array}$ & $\begin{array}{l}\text { En principio no conllevaría a cambios en el ingreso materno en } \\
\text { URPA... }\end{array}$ \\
\hline & $\begin{array}{l}\text { Manejo de los } \\
\text { problemas con la } \\
\text { lactancia materna }\end{array}$ & $\begin{array}{l}\text { Entiendo que no hay evidencia disponible acerca de la presión inversa suavizante para aliviar } \\
\text { la ingurgitación mamaria y por esa razón no se ha valorado como recomendación.En las } \\
\text { consideraciones acerca de la técnica para resolver un absceso mamario, en referencia al } \\
\text { drenaje quirúrgico, tal vez sería de utilidad indicar que siempre que sea posible sería } \\
\text { interesante realizar la incisión en la zona más distal con respecto al pezón (menos posibilidad } \\
\text { de dañar conductos, mayor comodidad para amamantar) }\end{array}$ & $\begin{array}{l}\text { Se ha incluido finalmente como buena práctica, con anexo y todo. } \\
\text { De acuerdo con la inclusión de la modificación en el absceso } \\
\text { mamario. }\end{array}$ \\
\hline Revisor 8 & $\begin{array}{l}\text { Suplementos y } \\
\text { lactancia materna }\end{array}$ & $\begin{array}{l}\text { Las recomendaciones son claras y están vinculadas a la evidencia científica. El lenguaje } \\
\text { empleado, en general es adecuado. El apartado de Evidencia científica correspondiente a la } \\
\text { primera pregunta (páginas } 85 \text { y 86) y el correspondiente a la tercera pregunta (páginas 91- } \\
\text { 93) requieren corrección de estilo, para mejorar la claridad y la comprensión del texto. } \\
\text { En el sexto párrafo de la página } 96 \text { hay una frase que no se entiende y que convendría } \\
\text { explicar brevemente lo que es el paladai para que se entienda mejor, añadiendo por } \\
\text { ejemplo, lo señalado en negrita:" ....un segundo estudio piloto, no aleatorizado, que evalúa } \\
\text { el uso del paladai (pequeña taza con un pico en forma de "lámpara de Aladino", utilizada } \\
\text { como dispositivo de alimentación tradicionalmente en la India) en comparación al } \\
\text { biberón...". }\end{array}$ & De acuerdo con los cambios. \\
\hline
\end{tabular}




\begin{tabular}{|c|c|c|c|}
\hline Revisor & Sección & Comentario & Respuesta del grupo elaborador \\
\hline & $\begin{array}{l}\text { Manejo de los } \\
\text { problemas con la } \\
\text { lactancia materna }\end{array}$ & $\begin{array}{l}\text { Las recomendaciones respecto a la pregunta: ¿Qué hacer ante un lactante amamantado que } \\
\text { presenta pérdida excesiva de peso en los tres primeros días?, y la pregunta ¿Cómo abordar } \\
\text { el dolor en los pezones y en las mamas durante el amamantamiento?, si bien son adecuadas, } \\
\text { no están vinculadas a la evidencia científica. }\end{array}$ & $\begin{array}{l}\text { Ya se ha explicado en comentarios de otros revisores, se trata de } \\
\text { dos preguntas que lo que pretenden es introducir los algoritmos } \\
\text { que engloban las preguntas que luego sí se abordan mediante la } \\
\text { evaluaicón de la evidencia científica. Se ha decido abreviar su } \\
\text { contenido, haciendo referencia a los algoritmos que se han } \\
\text { elaborado en respuesta a estas preguntas. }\end{array}$ \\
\hline & Anexos & $\begin{array}{l}\text { Algunos dibujos no ilustran bien lo que se indica en el texto, como el de la posición de } \\
\text { Dancer en el anexo } 3 \text { y el de alimentación con dedo-jeringa en el anexo } 13 \\
\text { En el anexo } 12 \text { En el apartado "Preocupación sobre ictericia" no se entiende la respuesta "El } \\
\text { calostro actúa como un laxante natural que ayuda a eliminar el fondo común de bilirrubina } \\
\text { retenida que se haya contenida", por lo que se debería redactar de una forma más clara. } \\
\text { En el anexo } 14 \text { se podrían incluir las curvas de Bertini y las de Flaherman, que se recomienda } \\
\text { utilizar y además de las curvas de peso para la edad y longitud para la edad de la OMS, } \\
\text { incluir también las de peso para la longitud. }\end{array}$ & $\begin{array}{l}\text { Modificados los dibujos de los Anexos } 3 \text { y } 13 \text {. En cuanto al anexo } \\
\text { 12, se modifica por: "...ayuda a eliminar el exceso de bilirrubina } \\
\text { (que se excreta en el meconio) ayudando a prevenir la ctericia". } \\
\text { Las curvas de bertini etc se han incluido en otro anexo nuevo. En } \\
\text { el anexo de las curvas de la OMS se han incluido las curvas de } \\
\text { peso para longitud. }\end{array}$ \\
\hline \multirow[t]{2}{*}{ Revisor 9} & $\begin{array}{l}\text { Prácticas que } \\
\text { favorecen la lactancia } \\
\text { materna }\end{array}$ & $\begin{array}{l}\text { En general, las recomendaciones son claras y el resumen de la evidencia . El apartado sobre } \\
\text { colecho resulta algo confuso por incluir dos apartados (colecho en la maternidad y en el } \\
\text { domicilio) y las recomendaciones sobre todo en el segundo caso (colecho en domicilio) son } \\
\text { un poco ambiguas: se recomienda con evidencia débil (se sugiere) el colecho como una } \\
\text { opción para ayudar a mantener la LM; pero se aconseja informar de la existencia de cunas } \\
\text { sidecar que favorecen el colecho seguro, a pesar de que dentro de las consideraciones del } \\
\text { colecho seguro NO se incluye como característica de seguridad que utilice cuna sidecar. Es } \\
\text { decir, se sugiere que el colecho (en el domicilio) en cuna sidecar es más seguro que en la } \\
\text { cama familiar, aunque realmente no hay evidencia al respecto. Según se deduce del resto } \\
\text { del texto el colecho es seguro si se cumplen las consideraciones del listado (sea en cuna } \\
\text { sidecar o en cama). }\end{array}$ & $\begin{array}{l}\text { Se han realizado cambios en las recomendaciones sobre el } \\
\text { colecho. Ver los cambios en el borrador. }\end{array}$ \\
\hline & $\begin{array}{l}\text { Manejo de los } \\
\text { problemas con la } \\
\text { lactancia materna }\end{array}$ & $\begin{array}{l}\text { Pregunta } 27 \text { “¿Qué hacer si hay dificultades en el agarre por las características anatómicas } \\
\text { del pezón?". hacer hincapié en que la mayoría de las veces la anatomía del pezón (en } \\
\text { particular el pezón plano, que es mucho más frecuente que el invertido retráctil) no presenta } \\
\text { problemas para la lactancia y que es importante reforzar la confianza en las madres con } \\
\text { pezón plano desde antes del parto; y subrayar que estas medidas están disponibles cuando } \\
\text { hay problemas de agarre atribuibles a la anatomía del pezón, pero que no serían medidas } \\
\text { rutinarias o de uso frecuente.-Pregunta } 28 \text { “¿Cómo abordar el dolor en los pezones y en las } \\
\text { mamas durante el amamantamiento?”En la página } 163 \text {, se habla de explorar si hay signos } \\
\text { sugestivos de candidiasis del pezón en la madre. Sin embargo, esta entidad es muy } \\
\text { controvertida, y el diagnóstico mediante la exploración externa del pezón lo está aún más } \\
\text { (Betzold CM. Results of microbial testing exploring the etiology of deep breast pain during } \\
\text { lactation: a systematic review and meta-analysis of nonrandomized trials. J Midwifery } \\
\text { Womens Health. } 2012 \text { Jul-Aug;57(4):353-64; Hale TW, Bateman TL, Finkelman MA, Berens }\end{array}$ & $\begin{array}{l}\text { De acuerdo con los cambios de la pregunta } 27 \text {. En cuanto a la } \\
\text { pregunta } 28 \text {, aunque resulte controvertida, el grupo considera } \\
\text { que se debe mantener, puesto que sí pueden aparecer casos de } \\
\text { candidiasis en pezón, aunque no sean los más. }\end{array}$ \\
\hline
\end{tabular}




\begin{tabular}{|c|c|c|c|}
\hline Revisor & Sección & Comentario & Respuesta del grupo elaborador \\
\hline & & 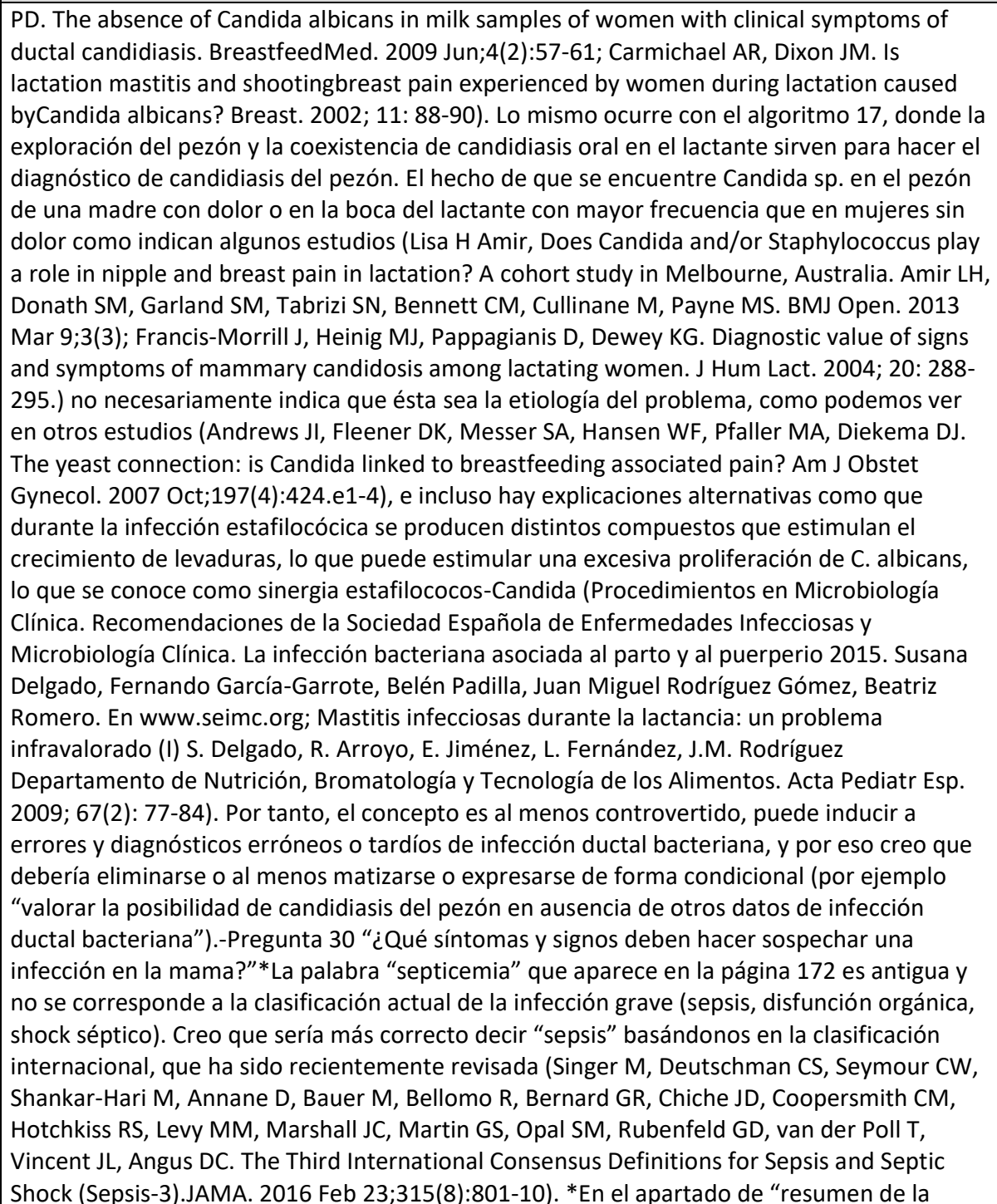 & \\
\hline
\end{tabular}




\begin{tabular}{|c|c|c|c|}
\hline Revisor & Sección & Comentario & Respuesta del grupo elaborador \\
\hline & & 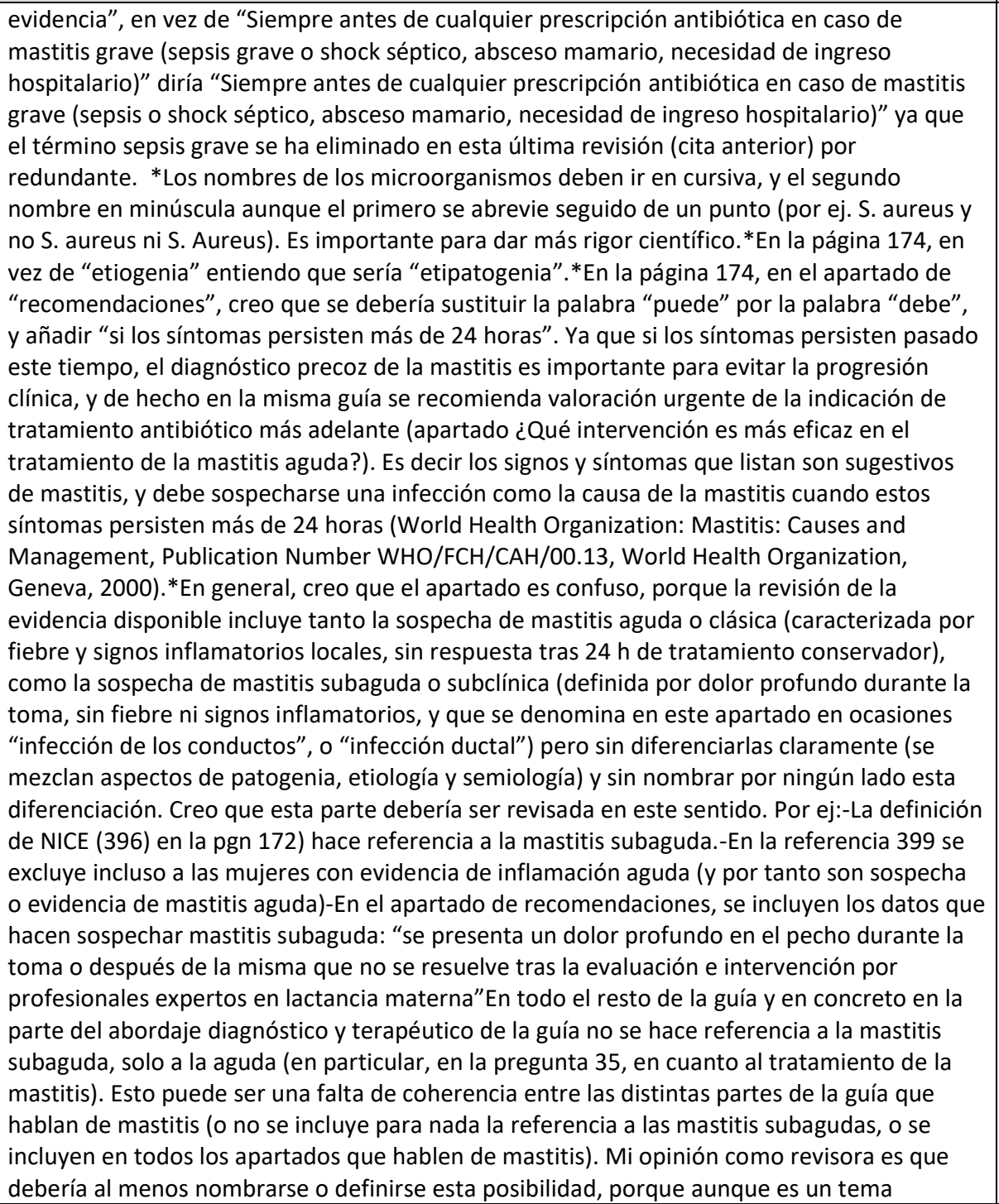 & \\
\hline
\end{tabular}




\begin{tabular}{|c|c|c|c|}
\hline Revisor & Sección & Comentario & Respuesta del grupo elaborador \\
\hline & & 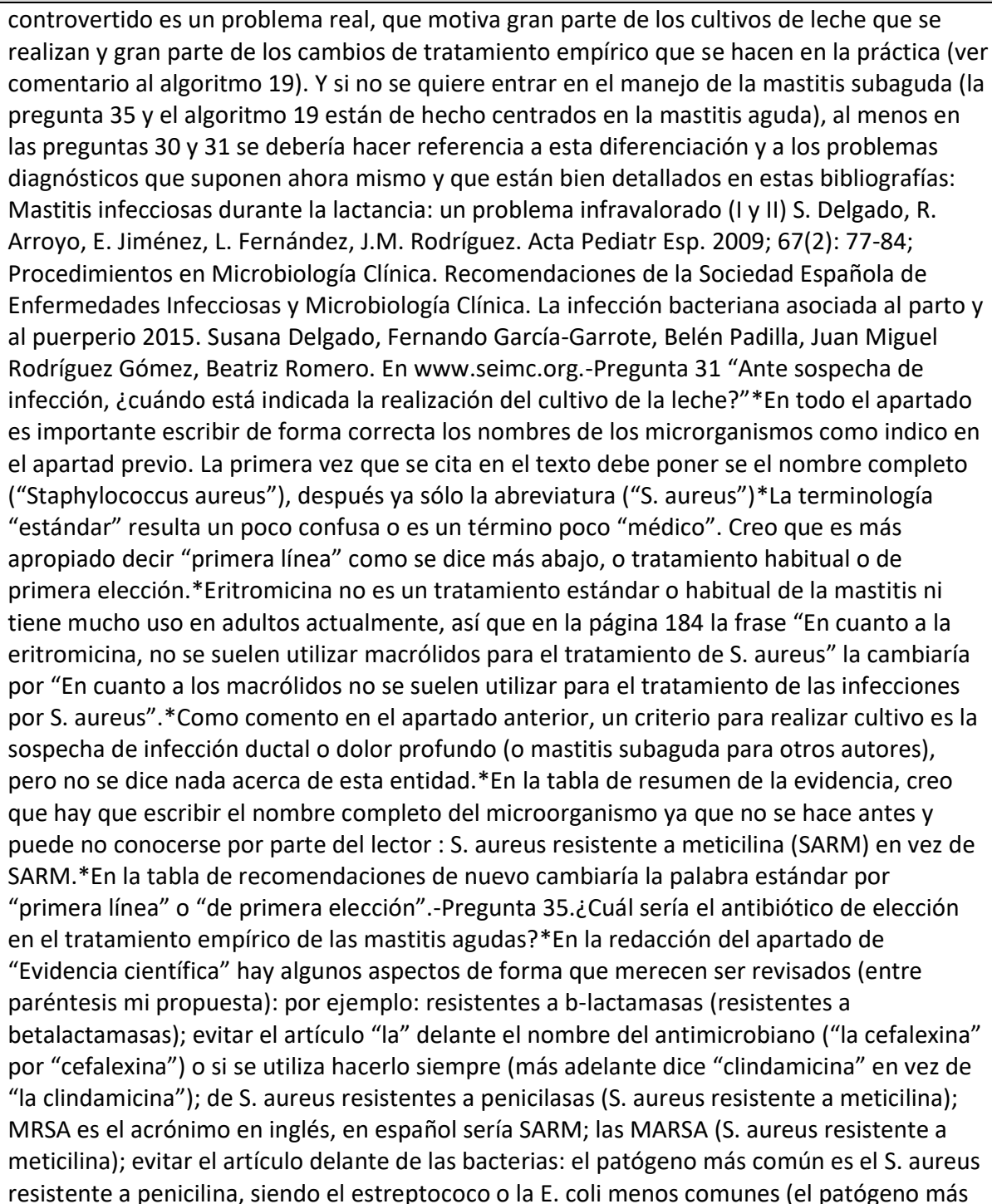 & \\
\hline
\end{tabular}




\begin{tabular}{|c|c|c|c|}
\hline Revisor & Sección & Comentario & Respuesta del grupo elaborador \\
\hline & & 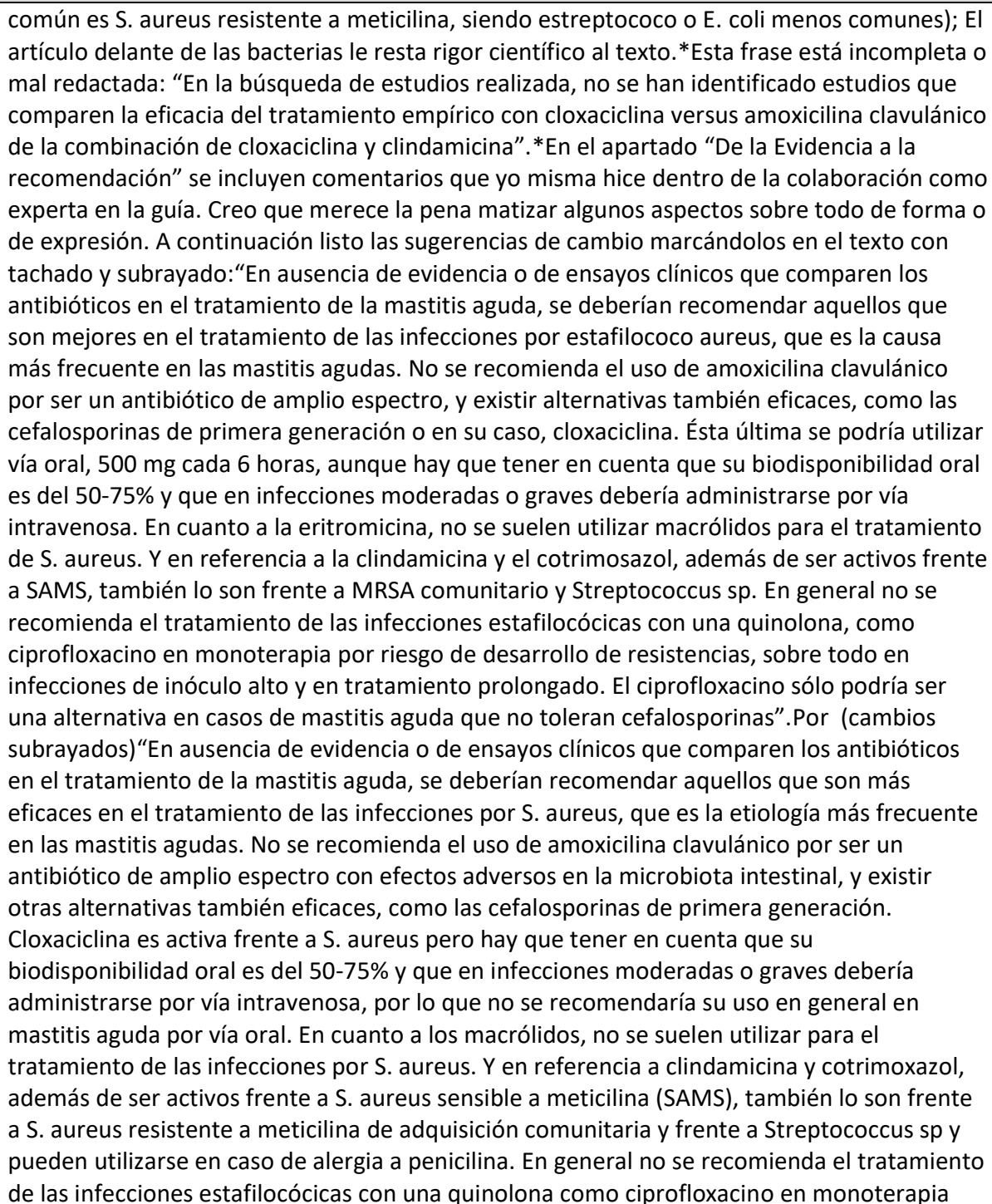 & \\
\hline
\end{tabular}




\begin{tabular}{|c|c|c|c|}
\hline Revisor & Sección & Comentario & Respuesta del grupo elaborador \\
\hline & & $\begin{array}{l}\text { por riesgo de desarrollo de resistencias, sobre todo en infecciones de inóculo alto y en } \\
\text { tratamiento prolongado. Ciprofloxacino podría ser una alternativa en casos de mastitis } \\
\text { aguda en pacientes que no toleran cefalosporinas ni clindamicina." (José Mensa. Guía de } \\
\text { tratamiento antimicrobiano de la infección por Staphylococcus aureus. Rev Esp Quimioter } \\
2013 ; 26 \text { (Suppl. 1):1-84)*En el apartado de recomendaciones, NO incluiría cloxacilina por los } \\
\text { problemas de biodisponibilidad antes descritos, habiendo alternativas tan o más eficaces } \\
\text { como clindamicina. La cloxacilina tiene su papel en el uso por vía endovenosa. La } \\
\text { concentración sérica de cloxacilina que se alcanza con la administración por vía oral no } \\
\text { garantiza el tratamiento óptimo de las infecciones de gravedad moderada. En la infección } \\
\text { leve puede emplearse cloxaci-lina por vía oral a dosis de } 0,5-1 \text { g/6h o, preferiblemente, } \\
\text { cefadroxilo a la misma dosis (José Mensa. Guía de tratamiento antimicrobiano de la } \\
\text { infección por Staphylococcus aureus. Rev Esp Quimioter } 2013 ; 26 \text { (Suppl. 1):1-84).Mi } \\
\text { propuesta es que si se aún así se incluye cloxacilina en las recomendaciones, se especifique } \\
\text { que la recomendación de utilizar cloxacilina por vía oral debe restringirse a los casos leves, y } \\
\text { siempre a dosis altas de } 0,5 \text { a } 1 \text { gr/6 horas por vía oral. }\end{array}$ & \\
\hline & Anexos & $\begin{array}{l}\text { Anexo 17: Abordaje del dolor en el pezón y las mamasLa existencia de la candidiasis del } \\
\text { pezón está en controversia, como comenté y documenté en el apartado anterior (ver } \\
\text { Comentarios por capítulos, apartado 11, pregunta 28). No parece que se pueda diagnosticar } \\
\text { solo por la exploración externa del pezón (eritema, piel brillante y fisuras), ya que estos } \\
\text { signos son inespecíficos, pueden aparecer en muchas patologías. Tampoco hay relación clara } \\
\text { entre la dermatitis del pañal y el muguet del RN (que es fisiológico) y la supuesta candidiasis } \\
\text { del pezón. Yo personalmente quitaría este apartado, porque puede inducir a error y a tratar } \\
\text { infecciones ductales, o mastitis subagudas e incluso eccemas como supuestas candidiasis del } \\
\text { pezón, sin serlo.-Anexo 18: recogida de muestra de leche para cultivo-No parece que sea } \\
\text { necesario limpiar los pezones con alcohol antes de tomar la muestra. Desconozco la } \\
\text { referencia bibliográfica por la que se ha incluido (porque en la referencia que consta en el } \\
\text { algoritmo no encuentro dónde se recomienda la limpieza con alcohol del pezón), pero } \\
\text { aporto estas dos donde no indica que sea necesario (Procedimientos en Microbiología } \\
\text { Clínica. Recomendaciones de la Sociedad Española de Enfermedades Infecciosas y } \\
\text { Microbiología Clínica. La infección bacteriana asociada al parto y al puerperio } 2015 \text {. Susana } \\
\text { Delgado, Fernando García-Garrote, Belén Padilla, Juan Miguel Rodríguez Gómez, Beatriz } \\
\text { Romero. En www.seimc.org; Propuesta de protocolo para el cultivo de muestras de leche } \\
\text { humana. R. Arroyo, P. Mediano, V. Martín, E. Jiménez, S. Delgado, L. Fernández, M. Marín, } \\
\text { J.M. Rodríguez. Acta Pediatr Esp. 2011; 69(6): 235-240). Además, hay un problema adicional } \\
\text { y es que en mujeres con indicación de cultivo, que muchas veces pueden tener grietas o } \\
\text { fisuras, puede ser doloroso y producir irritación. Como en las bilbliografías que aporto, creo } \\
\text { que es más importante indicar que se evite el uso de pomadas o conchas o pezoneras, y si se } \\
\text { han usado se limpie con agua y jabón suave. Tampoco veo otras indicaciones importantes }\end{array}$ & $\begin{array}{l}\text { En cuanto al Anexo 17, el grupo ha considerado que a pesar de la } \\
\text { controversia, ese apartado debe quedarse porque sí pueden } \\
\text { darse casos (aunque pocos) de candida. En cuanto al Anexo 18, } \\
\text { se ha adaptado la informacion de la SEIM en cuanto a recogida y } \\
\text { cultivo de la muestra). En cuanto al Anexo 19, se han realizado } \\
\text { los cambios propuestos, aunque con algunas modificaciones (ver } \\
\text { en el borrador cómo queda finalmente el algoritmo). Se ha } \\
\text { consutado la guía de Mensa para incluir las dosis. }\end{array}$ \\
\hline
\end{tabular}




\begin{tabular}{|c|c|c|c|}
\hline Revisor & Sección & Comentario & Respuesta del grupo elaborador \\
\hline & & 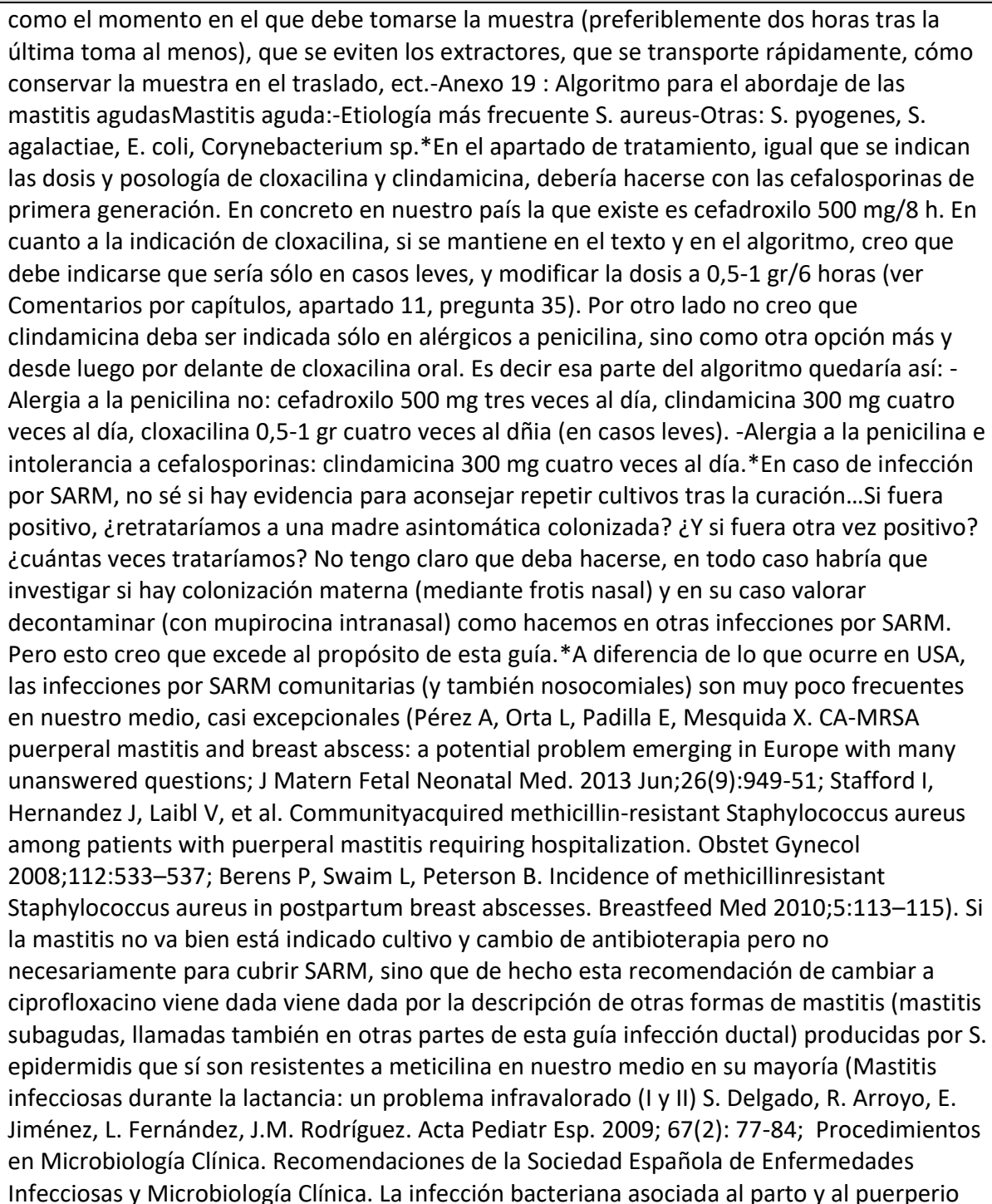 & \\
\hline
\end{tabular}




\begin{tabular}{|c|c|c|c|}
\hline Revisor & Sección & Comentario & Respuesta del grupo elaborador \\
\hline & & $\begin{array}{l}\text { 2015. Susana Delgado, Fernando García-Garrote, Belén Padilla, Juan Miguel Rodríguez } \\
\text { Gómez, Beatriz Romero. En www.seimc.org). La definición y el reconocimiento de las } \\
\text { mastitis subagudas y del papel patogénico de los estafilococos coagulasa negativa es } \\
\text { controvertido y probablemente está fuera de los objetivos de esta guía, y de este tema que } \\
\text { versa sobre mastitis aguda, pero entonces no deberíamos indicar ciprofloxacino aquí, porque } \\
\text { éste sería el motivo de la indicación de ciprofloxacino en nuestro medio, en el que NO hay } \\
\text { SARM comunitario salvo de forma excepcional y es poco frecuente el SARM nosocomial en } \\
\text { mastitis. Otro motivo para no incluir quinolonas como segunda línea en el tratamiento de la } \\
\text { mastitis es el impacto que sabemos que las quinolonas tienen en la microbiota intestinal no } \\
\text { sólo a nivel personal sino también poblacional (Aldeyab MA, Harbarth S, Vernaz } \mathrm{N} \text { et al. The } \\
\text { impact of antibiotic use on the incidence and resistance pattern of extended-spectrum beta- } \\
\text { lactamase-producing bacteria in primary and secondary healthcare settings. Br J Clin } \\
\text { Pharmacol. 2012;74:171-9). En tercer lugar, como se describe en el texto de la pregunta 35, } \\
\text { ciprofloxacino no es apropiado para el tratamiento de las infecciones estafilocócicas en } \\
\text { monoterapia. Como TMP-SMX es activo frente a las cepas de SARM comunitarias, y también } \\
\text { frente a S. epidermidis, creo que podríamos incluir sólo esta alternativa, o bien especificar } \\
\text { que podemos utilizar ciprofloxacino como tratamiento dirigido en caso de otras etiologías } \\
\text { (por ej. E. coli).En función de todo lo anteriormente expuesto, mi propuesta de algoritmo } \\
\text { sería: ver formulario }\end{array}$ & \\
\hline Revisor 10 & No hay comentarios. & & \\
\hline \multirow[t]{3}{*}{ Revisor 11} & $\begin{array}{l}\text { Suplementos y } \\
\text { lactancia materna }\end{array}$ & $\begin{array}{l}\text { Se recomienda no usar suero glucosado, pero a la vez, en 11. Manejo de los problemas con } \\
\text { la lactancia materna, "se sugiere instilar gotas de leche materna, o en su defecto suero } \\
\text { glucosado..." }\end{array}$ & De acuerdo. Se modifica. \\
\hline & $\begin{array}{l}\text { Manejo de los } \\
\text { problemas con la } \\
\text { lactancia materna }\end{array}$ & $\begin{array}{l}\text { En ingurgitación mamaria; además de la extracción manual, se puede incluir la presión } \\
\text { inversa suavizante. }\end{array}$ & De acuerdo. Se modifica. \\
\hline & $\begin{array}{l}\text { Difusión e } \\
\text { implementación }\end{array}$ & $\begin{array}{l}\text { Un indicador podría ser la afluencia de madres lactanctes con problemas en la lactancia a los } \\
\text { grupos de apoyo. }\end{array}$ & \\
\hline \multirow[t]{2}{*}{ Revisor 12} & $\begin{array}{l}\text { Atención postparto } \\
\text { inmediata }\end{array}$ & $\begin{array}{l}\text { Merece la pena incluir y comentar el trabajo publicado por la academia americana ped sobre } \\
\text { seguridad en el periodo neonatal. He anotado la cita en el texto borrador Safe Sleep and } \\
\text { Skin-to-Skin Care in the Neonatal Period for Healthy Term Newborns Lori Feldman-Winter, } \\
\text { MD, MPH, FAAP, Jay P. Goldsmith, MD, FAAP, COMMITTEE ON FETUS AND NEWBORN, TASK } \\
\text { FORCE ON SUDDEN INFANT DEATH SYNDROME Pdiatrics 138(3) sep } 2016\end{array}$ & $\begin{array}{l}\text { Se ha incluido, pero en realidad ya se habían incluido el colapso } \\
\text { postnatal en la pregunta... De ahí las recomendaciones de } \\
\text { vigilancia en el CPP que se hacen, incluidos también en el Anexo } \\
\text { para los padres. }\end{array}$ \\
\hline & $\begin{array}{l}\text { Difusión e } \\
\text { implementación }\end{array}$ & $\begin{array}{l}\text { Encuestas de satisfacción materna y de los profesionales } \\
\text { Tasa de lactancia al alta y en seguimiento }\end{array}$ & \\
\hline
\end{tabular}




\begin{tabular}{|c|c|c|c|}
\hline Revisor & Sección & Comentario & Respuesta del grupo elaborador \\
\hline Revisor 13 & Ningún comentario & & \\
\hline \multirow[t]{2}{*}{ Revisor 14} & $\begin{array}{l}\text { Promoción } \\
\text { institucional de la } \\
\text { lactancia materna }\end{array}$ & $\begin{array}{l}\text { Aunque se alude explícitamente a documentos e iniciativas de apoyo a la lactancia materna } \\
\text { de valides reconocida internacionalmente, los contenidos de las mismas no tienen por qué } \\
\text { ser conocidOs por todo el mundo. Recomendaría un poco más de detalle y sobretodo } \\
\text { destacar de forma explícita y específica las } 10 \text { pasos hacia una feliz lactancia natural que es } \\
\text { la base de la IHAN y asimismo los } 7 \text { pasos de los CS- IHAN }\end{array}$ & $\begin{array}{l}\text { Se han incluido los } 10 \text { pasos en hospitales y los } 7 \text { pasos en centros } \\
\text { de salud en un anexo nuevo. }\end{array}$ \\
\hline & Otros & $\begin{array}{l}\text { El capítulo } 13 \text { de esta GPC referido al Compromiso Social y Político con la lactancia materna } \\
\text { está pendiente y sin contenidos. } \\
\text { Como representante precisamente de una Federación de Grupos de Apoyo a la Lactancia } \\
\text { Materna (FEDALMA) claramente perteneciente al sector social, creo que es en este capítulo } \\
\text { donde mi experiencia de voluntariado y organización asociativa más puede aportar, sin } \\
\text { embargo me encuentro que no puedo opinar ni revisar nada sobre lo que no se ha escrito } \\
\text { nada. } \\
\text { Con todo quisiera señalar que considero importante que esta GPC incluya información de los } \\
\text { recursos de apoyo a madres lactantes dentro del sector social, sobre la evidencia científica } \\
\text { sobre su validez y eficacia como recurso comunitario de apoyo a la lactancia materna, y su } \\
\text { importancia en la implementación de iniciativas validadas y recogidas en esta GPC como la } \\
\text { IHAN y los CS-IHAN. Asimismo sobre la importancia de la colaboración entre el sector social y } \\
\text { el sanitario. }\end{array}$ & $\begin{array}{l}\text { Finalmente, no va a haber capítulo 13, puesto que se sale de la } \\
\text { estructura propuesta por Guiasalud para las GPC. Sin embargo, la } \\
\text { información que estaba pensada para incluir aquí va a ser incluida } \\
\text { en parte en la introducción de la GPC. En cuantoa la información } \\
\text { de los recursos de apoyo a madres lactantes dentro del sector } \\
\text { social, no se han podido elaborar las preguntas relacionadas. En } \\
\text { la versión para mujeres que se está elaborando en paralelo con el } \\
\text { contenido de esta GPC se ha incluido un punto en el que se } \\
\text { referencian los recursos que las madres pueden consultar... En } \\
\text { futuras actualizaciones se considerará la inclusión de estas } \\
\text { preguntas para completar el abordaje de la lactancia materna. }\end{array}$ \\
\hline \multirow[t]{2}{*}{ Revisor 15} & $\begin{array}{l}\text { Comentarios } \\
\text { generales }\end{array}$ & $\begin{array}{l}\text { La estructura de los temas de la guía es adecuada (desde el parto al posparto, de la } \\
\text { normalidad a los problemas de lactancia). No obstante, la agrupación de "PREGUNTAS PARA } \\
\text { RESPONDER" no es excluyente y puede dar lugar a confusión. Por ejemplo, el contacto piel } \\
\text { con piel (apartado 2, se podría incluir en el } 1 \text { (atención posparto inmediata).Por otra parte, } \\
\text { en el apartado } 2 \text { (PRÁCTICAS QUE FAVORECEN LA LACTANCIA MATERNA), hay preguntas que } \\
\text { están referidas a prácticas que NO favorecen la lactancia materna (por ejemplo, las dos } \\
\text { últimas: 6.¿Cómo afecta la restricción de las tomas de pecho nocturnas en la instauración y } \\
\text { duración de la lactancia materna?; 7.¿Se debería evitar el uso del chupete en las primeras } \\
\text { semanas para favorecer la instauración de la lactancia materna?). }\end{array}$ & $\begin{array}{l}\text { No se puede cambiar la estructura, pero sí se ha matizado en el } \\
\text { apartado } 2 \text {, modificando el título por "Prácticas que influyen en la } \\
\text { lactancia materna". }\end{array}$ \\
\hline & Introducción & $\begin{array}{l}\text { Al final de la introducción, en el párrafo sobre la necesidad de una guía se dice que “...se } \\
\text { considera necesario elaborar una guía de práctica clínica que: } 1 \text { ) identifique cuáles son las } \\
\text { condiciones que favorecen el inicio, la instauración y el mantenimiento de la lactancia } \\
\text { materna y que } 2 \text { ) incluya recomendaciones basadas en la evidencia científica que ayuden a } \\
\text { los profesionales sanitarios a dar respuesta a los problemas que se encuentran las madres } \\
\text { que quieren amamantar a sus hijos". Sin embargo, en mi opinión, ninguna de las preguntas } \\
\text { propuestas en la guía trata directamente sobre intervenciones para favorecer el inicio (salvo }\end{array}$ & $\begin{array}{l}\text { Entendemos el comentario, pero en este caso no se trata de una } \\
\text { guía que pretenda aumentar el número de madres que inician la } \\
\text { lactancia materna, sino que las que lo hacen (ver que en el } \\
\text { alcance se han incluido madres que desean amamantar) inicien la } \\
\text { lactancia de la mejor manera posible y sin problemas. }\end{array}$ \\
\hline
\end{tabular}




\begin{tabular}{|c|c|c|c|}
\hline Revisor & Sección & Comentario & Respuesta del grupo elaborador \\
\hline & & $\begin{array}{l}\text { alguna referencia en las intervenciones estructurales, que indirectamente influyen sobre las } \\
\text { tasas de inicio de la lactancia). Más bien es una guía enfocada al apoyo a la madre una vez se } \\
\text { inicia la lactancia. Aunque las intervenciones de apoyo a la lactancia favorecen también el } \\
\text { inicio (debido al cambio cultural que puede suponer la mejora de las tasas y la } \\
\text { "normalización" de la lactancia...), las intervenciones que favorecen el inicio no son tratadas } \\
\text { específicamente en esta guía (ver por ejemplo lbanez G, de Reynal de Saint Michel C, } \\
\text { Denantes M, Saurel-Cubizolles MJ, Ringa V, Magnier AM. Systematic review and meta- } \\
\text { analysis of randomized controlled trials evaluating primary care-based interventions to } \\
\text { promote breastfeeding in low-income women. Fam Pract. } 2012 \text { Jun;29(3):245-54. doi: } \\
\text { 10.1093/fampra/cmr085; Dyson L, McCormick F, Renfrew MJ. Interventions for promoting } \\
\text { the initiation of breastfeeding. Cochrane Database Syst Rev. } 2005 \text { Apr 18;(2):CD001688...). }\end{array}$ & \\
\hline & $\begin{array}{l}\text { Atención postparto } \\
\text { inmediata }\end{array}$ & $\begin{array}{l}\text { En la pregunta “¿Cómo deben de colocarse la madre y el recién nacido para facilitar el } \\
\text { amamantamiento?”, cuando se expone que la evidencia de la GPC NICE, se dice que: “...La } \\
\text { toma debe de ser cómoda y ha de sentirse una deglución audible. Ambos deben de estar } \\
\text { relajados...”. Habría que añadir que existen estudios que han referido la dificultad para } \\
\text { escuchar una deglución audible durante los primeros } 2-3 \text { días y que podría no ser un } \\
\text { indicador válido para evaluar la toma. Ver: Côté-Arsenault, D., \& McCoy, T. P. (2012). } \\
\text { Reliability and validity of swallows as a measure of breast milk intake in the first days of life. } \\
\text { Journal of Human Lactation, 28(4), 483-489. } \\
\text { Cuando se haba sobre la evidencia del “Colecho en el hogar" (punto 5.2), hay una frase que } \\
\text { parece incompleta: “...Para el efecto del colecho sobre la lactancia materna, no se ha } \\
\text { utilizado el metanálisis de Daas (119) pero sí los resultados de un estudio longitudinal que } \\
\text { incluye (126) y otro estudio...” }\end{array}$ & Atención postparto inmediata \\
\hline & $\begin{array}{l}\text { Valoración de la } \\
\text { lactancia materna }\end{array}$ & $\begin{array}{l}\text { Este punto parece que se ha desarrollado de forma incompleta. No se han incluido algunas } \\
\text { revisiones existentes sobre las herramientas de valoración de la toma y existen algunos } \\
\text { errores conceptuales (quizá por eso no se han incluido las revisiones). En este punto, podría } \\
\text { incluirse la información que he expuesto arriba, sobre la "deglución audible" como indicador } \\
\text { poco válido para evaluar una toma los primeros días de vida: existen estudios que han } \\
\text { referido la dificultad para escuchar una deglución audible durante los primeros } 2-3 \text { días y } \\
\text { que podría no ser un indicador válido para evaluar la toma. Ver: Côté-Arsenault, D., \& } \\
\text { McCoy, T. P. (2012). Reliability and validity of swallows as a measure of breast milk intake in } \\
\text { the first days of life. Journal of Human Lactation, 28(4), 483-489.En el punto } 6.3 \text { sobre } \\
\text { "Observación y valoración de una toma", se dice que "Se ha identificado una RS publicada en } \\
2010 \text { (195) sobre las herramientas de evaluación de la autoeficacia de la lactancia materna } \\
\text { con el objetivo de contrastar su utilidad clínica y propiedades psicométricas. Sin embargo, } \\
\text { esta revisión no incluye las herramientas como el LATCH, The infant breastfeeding } \\
\text { assessment tool (IBFAT), o el Mother Baby Assessment Tool (MBA), que sirven para evaluar } \\
\text { la eficacia de una toma". Sin embargo, la revisión citada (Ho YJ, 2010) no solo explora la }\end{array}$ & $\begin{array}{l}\text { Se han incluido las revisiones que con acierto comenta el revisor. } \\
\text { Sin embargo, en general todas las revisiones concluyen que no } \\
\text { hay herramientas suficientemente validadas, por lo que } \\
\text { consideramos que no altera el discurso de la pregunta. Además la } \\
\text { única que ha sido traducida y validada al español es la } \\
\text { herramienta LATCH, lo que no quita que sea mejor que otras } \\
\text { herramientas. De todas formas, ver los cambios que se han hecho } \\
\text { en la pregunta. }\end{array}$ \\
\hline
\end{tabular}




\begin{tabular}{|c|c|c|c|}
\hline Revisor & Sección & Comentario & Respuesta del grupo elaborador \\
\hline & & 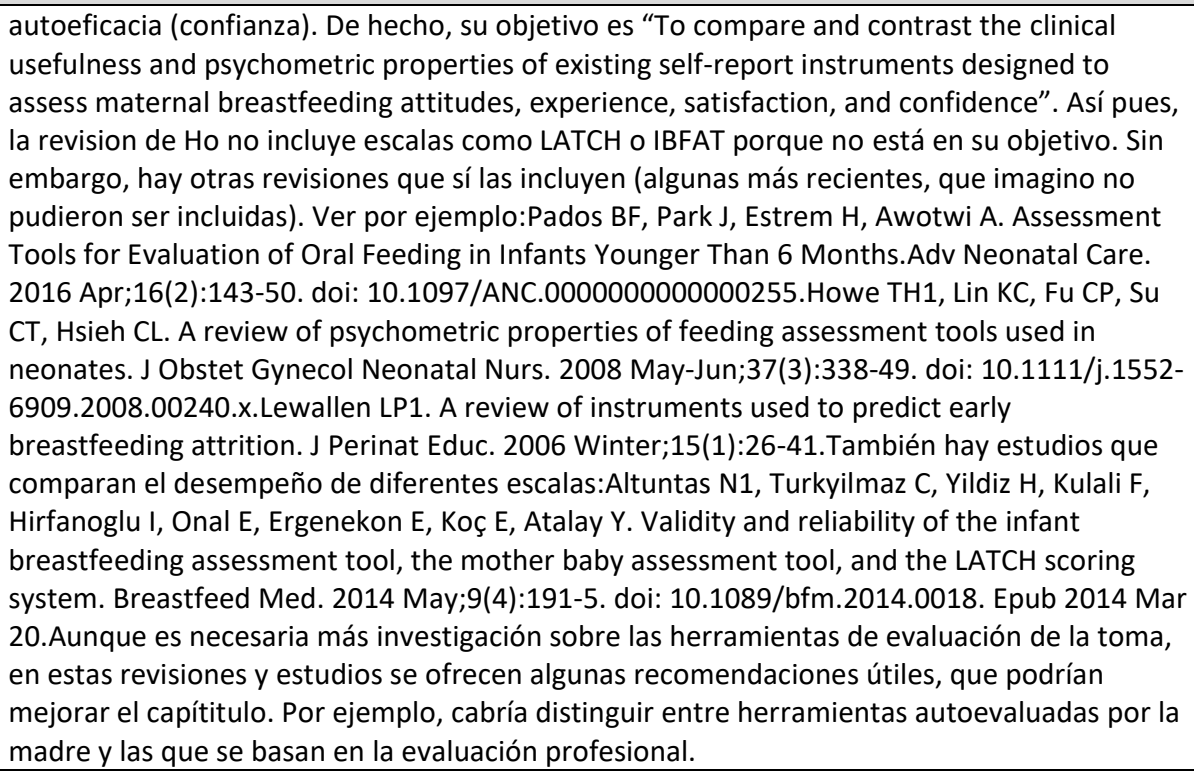 & \\
\hline & Extracción de calostro & $\begin{array}{l}\text { En la página } 83 \text {, en el punto sobre “¿Cuál es la forma más eficaz de extraer el calostro?”, } \\
\text { parece haber un error tipográfico en los IC del RR: “...Finalmente, los datos de dos ensayos } \\
(213 ; 214)(n=90) \text { no mostraron diferencias significativas en cuanto a las molestias en las } \\
\text { mamas entre ambos métodos de extracción (RR 2,56; IC95\% de } 1,08 \text { a } 1,66) . . . " .\end{array}$ & De acuerdo. Se modifica. \\
\hline & $\begin{array}{l}\text { Suplementos y } \\
\text { lactancia materna }\end{array}$ & $\begin{array}{l}\text { En la recomendación se sugiere "...monitorizar la glucemia antes de las tomas". Sin embargo, } \\
\text { esto puede ser confuso si se realiza lactancia materna a demanda (las tomas podrían ser } \\
\text { muy seguidas o en forma de "salvas").En la recomendación sobre el método para } \\
\text { suplementar se sugiere que un criterio es la "Duración prevista: breve o prolongada (en el } \\
\text { caso de utilizar tetinas, elegir aquellas que interfieran lo menos posible con la succión al } \\
\text { pecho)". Sería interesante especificar cuáles son estas tetinas que interfieren menos en la } \\
\text { succión al pecho }\end{array}$ & Se ha modificado ligeramente el texto \\
\hline & $\begin{array}{l}\text { Difusión e } \\
\text { implementación }\end{array}$ & Tasa de madres con, al menos, una toma evaluada al alta por el profesional. & \\
\hline & $\begin{array}{l}\text { Líneas de } \\
\text { investigación futura }\end{array}$ & $\begin{array}{l}\text { Las líneas de investigación propuestas se adecúan a lo descrito en cada uno de los apartados } \\
\text { específicos. Sin embargo, hay una de las recomendaciones: "Valoración de la lactancia } \\
\text { materna...Se identifica la necesidad de estudios para valorar la fiabilidad y validez de las } \\
\text { herramientas que existen y si su utilización sirve para aumentar las tasas de lactancia } \\
\text { materna". }\end{array}$ & De acuerdo. Se modifica. \\
\hline
\end{tabular}




\begin{tabular}{|c|c|c|c|}
\hline Revisor & Sección & Comentario & Respuesta del grupo elaborador \\
\hline & & $\begin{array}{l}\text { Es importante considerar, que la valoración de la lactancia materna, especialmente desde la } \\
\text { perspectiva materna, no sólo incluye la duración de la lactancia, sino la satisfacción de la } \\
\text { madre (que está relacionada con su confort y la satisfacción del bebé). Así pues, la influencia } \\
\text { del uso de las escalas de evaluación de la toma no sólo debe estudiarse respecto a la } \\
\text { duración de la lactancia, también deberían incluirse aspectos como los problemas precoces } \\
\text { de lactancia o la satisfacción materna. Se podría redactar así: } \\
\text { "...Se identifica la necesidad de estudios para valorar la fiabilidad y validez de las } \\
\text { herramientas que existen y si su utilización sirve para identificar grupos de riesgo y reducir } \\
\text { los problemas de lactancia tras el alta y para aumentar las tasas de lactancia materna y la } \\
\text { satisfacción materna con la lactancia". }\end{array}$ & \\
\hline \multirow[t]{6}{*}{ Revisor 16} & $\begin{array}{l}\text { Comentarios } \\
\text { generales }\end{array}$ & $\begin{array}{l}\text { La guía es completa, exhaustiva y abarca los aspectos fundamentales de la lactancia materna } \\
\text { para recién nacidos sanos. Algunos apartados son excesivamente extensos. El tema de la } \\
\text { conservación de la leche sólo es tratado en un anexo, no consta la bibliografía ni la evidencia } \\
\text { de las recomendaciones de tiempo y temperatura que se dan. }\end{array}$ & \\
\hline & $\begin{array}{l}\text { Atención postparto } \\
\text { inmediata }\end{array}$ & $\begin{array}{l}\text { Respecto a la vigilancia por parte del acompañante, sería interesante saber si este aspecto } \\
\text { ha sido estudiado: qué información deben recibir, si son capaces de detectar una cianosis o } \\
\text { dificultad respiratoria. }\end{array}$ & No se ha estudiado. \\
\hline & $\begin{array}{l}\text { Prácticas que } \\
\text { favorecen la lactancia } \\
\text { materna }\end{array}$ & $\begin{array}{l}\text { En el apartado "postura más eficaz" en "resumen de evidencia" en la página } 51 \text { se incluye } \\
\text { información extensa de opinión de experto ( González). }\end{array}$ & \\
\hline & $\begin{array}{l}\text { Suplementos y } \\
\text { lactancia materna }\end{array}$ & $\begin{array}{l}\text { En la pagina } 20 \text { y en la } 98 \text { consta que la "alimentación con sonda puede ser agotadora para } \\
\text { recién nacidos con pocas fuerzas". ¿ Se refiere a la alimentación por succión o método } \\
\text { alternativo? La sonda es la que menos esfuerzo requiere. }\end{array}$ & De acuerdo. Modificado. \\
\hline & $\begin{array}{l}\text { Seguimiento del } \\
\text { lactante amamantado }\end{array}$ & $\begin{array}{l}\text { El apartado de patrones de referencia para monitorizar el crecimiento del niño es muy } \\
\text { extenso, contiene información prescindible como el recordatorio histórico inicial del primer } \\
\text { párrafo. Sería interesante mencionar las gráficas del proyecto Intergrowth } 21\end{array}$ & $\begin{array}{l}\text { Se han realizado modificaciones para abreviarlo. Se han } \\
\text { mencionado las gráficas del proyecto Intergrowth } 21 .\end{array}$ \\
\hline & $\begin{array}{l}\text { Manejo de los } \\
\text { problemas con la } \\
\text { lactancia materna }\end{array}$ & $\begin{array}{l}\text { En el apartado de extracción en la página } 132 \text { se describe un estudio en el que se comparan } \\
2 \text { sacaleches ( UNO vs Swing) y se utiliza en el texto indistintamente el nombre del } \\
\text { sacaleches y el de la casa comercial ( Playtex / Medela), siendo confuso para quien no los } \\
\text { conozca. }\end{array}$ & $\begin{array}{l}\text { Puede ser, pero es que se resumen lo que dicen los estudios, y } \\
\text { estos hablan de estos sacaleches. }\end{array}$ \\
\hline
\end{tabular}




\begin{tabular}{|c|c|c|c|}
\hline Revisor & Sección & Comentario & Respuesta del grupo elaborador \\
\hline & Anexos & $\begin{array}{l}\text { El anexo sobre la conservación de la leche no contiene referencias, y no está descrito en } \\
\text { ningún sitio la evidencia en la que se basan dichas recomendaciones. La recomendación de } \\
\text { tiempo de conservación del calostro a temperatura ambiente entre } 12-24 \text { horas no coincide } \\
\text { con las recomendaciones de conservación de otros alimentos. }\end{array}$ & Tiene razón. \\
\hline & Otros & $\begin{array}{l}\text { La guía no contiene ningún tipo de información sobre fármacos y lactancia materna, ni sobre } \\
\text { contraindicaciones. }\end{array}$ & $\begin{array}{l}\text { Se ha incluido dentro del primer anexo, sobre todo en referencia } \\
\text { a los recursos que se pueden consultar sobre los fármacos y las } \\
\text { contraindicaciones de lactancia materna. }\end{array}$ \\
\hline \multirow[t]{3}{*}{ Revisor 17} & $\begin{array}{l}\text { Prácticas que } \\
\text { favorecen la lactancia } \\
\text { materna }\end{array}$ & $\begin{array}{l}\text { La recomendación que da la GPC del colecho en la maternidad creo que no se ajusta a la } \\
\text { realidad asistencial ya que la camas de los hospitales son articuladas y recomienda la cuna } \\
\text { sidecar reconociendo que no existe en el mercado una cuna sidecar para éstas camas. } \\
\text { Por otro lado se recomienda que la madre que amamanta al recién nacido en la maternidad } \\
\text { no comparta su cama si no se cumplen las condiciones de colecho seguro. En la GPC se } \\
\text { incluye las condiciones de colecho seguro en el hogar (pag 59) pero no especifica cuáles son } \\
\text { para la maternidad. Resumiendo, si no se dispone de cuna sidecar y las camas son } \\
\text { articuladas no queda clara,a mi modo de ver, la recomendación que da la guía sobre el } \\
\text { colecho en la maternidad. }\end{array}$ & $\begin{array}{l}\text { Ya se ha explicado anteriormente, se han modificado las } \\
\text { recomendaciones sobre el colecho (ver en el texto las } \\
\text { modificaciones). }\end{array}$ \\
\hline & $\begin{array}{l}\text { Manejo de los } \\
\text { problemas con la } \\
\text { lactancia materna }\end{array}$ & $\begin{array}{l}\text { En relación a la ingurgitación mamaria, no se cita en ningún momento la presión inversa } \\
\text { suavizante. Adjunto un documento que habla sobre ella, por si consideráis adecuado } \\
\text { valorarla.En cuanto al manejo de la mastitis, la Sociedad Española de Microbiología elabora } \\
\text { en } 2015 \text { un documento con la bibliografía correspondiente que difiere totalmente de las } \\
\text { recomendaciones dadas por esta GPC ( el antibiótico de elección en mastitis aguda, la } \\
\text { recomendación de dar calor en la mastitis, el protocolo de recogida de la leche para } \\
\text { cultivo...). Os adjunto en el mail dicho documento por si considerarais oportuno valorarlo. En } \\
\text { muchos hospitales habíamos adoptado dicho documento de la SEIMC como guía para el } \\
\text { manejo de la mastitis y me ha llamado mucho la atención que la evidencia encontrada por la } \\
\text { GPC es totalmente distinta. }\end{array}$ & $\begin{array}{l}\text { Añadida la presión inversa suavizante, así como un anexo } \\
\text { explicativo. }\end{array}$ \\
\hline & Anexos & $\begin{array}{l}\text { Estaría bien que se pusiera la referencia desde donde se ha extraído el anexo } 2 \text {. Ya que me } \\
\text { ha parecido un material muy aconsejado para tener en las unidades de post parto inmediato }\end{array}$ & $\begin{array}{l}\text { No se ha extraído de ningún sitio. Ha sido un miembro del equipo } \\
\text { quien ha trabajado el anexo. }\end{array}$ \\
\hline Revisor 18 & $\begin{array}{l}\text { Suplementos y } \\
\text { lactancia materna }\end{array}$ & $\begin{array}{l}\text { Habría de hacerse una recomendación más específica y normativa acerca de la } \\
\text { suplementación con leche materna donada, como prioridad en todos los casos en los que } \\
\text { fuera necesaria la suplementación recogerse en un protocolo de actuación la } \\
\text { suplementación con leche materna donada en todos los casos como primera opción. si } \\
\text { desde las administraciones e instituciones se instaurara la donación de leche materna dando } \\
\text { prioridad a la creación de bancos de leche humana. por otra parte y tenemos ejemplos } \\
\text { claros que han mostrado su funcionalidad y eficacia con poca inversión de que la creación de } \\
\text { un banco de leche materna donada es viable, posible y económico } \\
\text { (. en el hospital materno infantil de málaga tenemos un centro receptor de donantes de }\end{array}$ & \\
\hline
\end{tabular}




\begin{tabular}{|c|c|c|c|}
\hline Revisor & Sección & Comentario & Respuesta del grupo elaborador \\
\hline & & $\begin{array}{l}\text { leche materna, un protocolo de selección de las mismas, la leche donada se almacena en } \\
\text { una nevera ex profeso para ello, se envía a procesar a un hospital de granada, desde que se } \\
\text { instauró este sistema, no hay casos de enterocolitis necrotizante en la unidad de gestión } \\
\text { clínica de neonatología de este hospital, con lo que el argumento esgrimido generalmente } \\
\text { por todos los hospitales del gasto y despliegue de medios imposibles puede demostrarse } \\
\text { que no tiene solidéz, por otra parte el gasto que genera al hospital las leches de fórmula } \\
\text { especiales suponen un gasto que supera con creces a corto y medio plazo tanto al módico } \\
\text { gasto inicial de esta alternativa y de los problemas de salud de los derivados de la } \\
\text { suplementación con leche de fórmula). }\end{array}$ & \\
\hline & $\begin{array}{l}\text { Líneas de } \\
\text { investigación futura }\end{array}$ & $\begin{array}{l}\text { Anquiloglosia, frenotomía, valoración, diagnóstico y tratamiento de la misma habría de ser } \\
\text { motivo de estudio, en la actualidad y carecemos de datos en nuestro país, hay una tendencia } \\
\text { al tratamiento invasivo cuando no quirúrgico de estas situaciones que se diagnostican sin } \\
\text { herramientas validadas, sin protocolos consensuados ni actuaciones basadas en la mejor } \\
\text { evidencia científica disponible }\end{array}$ & \\
\hline Revisor 19 & No hay comentarios & & \\
\hline \multirow[t]{2}{*}{ Revisor 20} & $\begin{array}{l}\varnothing \text { Pag } 99 \text { y sucesivas } \\
\text { Apartado "9. } \\
\text { Promoción } \\
\text { institucional de la } \\
\text { lactancia materna". }\end{array}$ & $\begin{array}{l}\text { La protección y el apoyo a la lactancia materna debería comenzar en el embarazo, aspecto } \\
\text { importante que no se recoge en este apartado "actividades de promoción de la lactancia } \\
\text { materna en embarazadas". Es difícil la promoción la lactancia materna una vez se sale del } \\
\text { hospital, si no se ha informado y trabajado previamente con la mujer/pareja desde el } \\
\text { embarazo. Importante el papel de la pareja desde antes del parto, el apoyo del padre es } \\
\text { importante antes del parto. }\end{array}$ & $\begin{array}{l}\text { No se recoge porque ya se explica que no ha sido posible abarcar } \\
\text { todas las preguntas que en un principio se plantearon incluir en la } \\
\text { guía, por falta de recursos y de personal. Sin embargo, este hecho } \\
\text { se señalará en el informe metodológico que acompañará a la } \\
\text { guía, y se hará una puntualización en el apartado de actualización } \\
\text { en el que se planteará la inclusión de otras preguntas que no han } \\
\text { podido ser abordadas en esta versión de la guía. }\end{array}$ \\
\hline & $\begin{array}{l}\varnothing \text { Pag } 141 \\
\text { "Comparación } 6 . \\
\text { Tratamiento con } \\
\text { hierbas" }\end{array}$ & $\begin{array}{l}\text { Según el artículo } 8 \text {.a de la Ley } 29 / 2006 \text {, de } 26 \text { de julio, de garantías y uso racional de los } \\
\text { medicamentos y productos sanitarios, medicamento de uso humano es «toda sustancia o } \\
\text { combinación de sustancias que se presente como poseedora de propiedades para el } \\
\text { tratamiento o prevención de enfermedades en seres humanos o que pueda usarse en seres } \\
\text { humanos o administrarse a seres humanos con el fin de restaurar, corregir o modificar las } \\
\text { funciones fisiológicas ejerciendo una acción farmacológica, inmunológica o metabólica, o de } \\
\text { establecer un diagnóstico médico». } \\
\text { Por lo tanto, no es correcto hablar de "tratamiento con hierbas" sino de tratamiento con } \\
\text { medicamentos a base de plantas medicinales y en este sentido, cuando la Agencia Española } \\
\text { de Medicamentos y Productos Sanitarios (AEMPS) autoriza un medicamento establece sus } \\
\text { indicaciones autorizadas, sus dosis, su seguridad, etcétera, y garantiza su uso en las } \\
\text { condiciones establecidas. Un producto que no esté registrado como medicamento no puede, } \\
\text { por tanto, presentarse como poseedor de propiedades para el tratamiento o prevención de } \\
\text { enfermedades y en esto se diferencia de otros productos de consumo. }\end{array}$ & $\begin{array}{l}\text { Ninguno de los medicamentos (domperidona, metocropramida } \\
\text { etc) denominados "galactogogos" no recogen en su ficha técnica } \\
\text { como indicación de uso en lactancia en situaciones en las que se } \\
\text { necesita aumentar la producción de leche. Sí se ha descrito como } \\
\text { reacción adversa la galactorrea en alguno de ellos. Sin embargo, } \\
\text { se trata de medicamentos que sí han sido utilizados para el } \\
\text { aumento de la producción de leche en mujeres que quieren } \\
\text { amamantar y presentan problemas con la producción de la } \\
\text { misma. La oxitocina sólo está autorizada por la AEMPS para el } \\
\text { uso intrahospitalario (por vía intravenosa), y lo mismo para la } \\
\text { hormona del crecimiento. La hormona liberadora de tirotropina } \\
\text { no está comercializada en la actualidad. En cuanto a los } \\
\text { medicamentos a base de plantas medicinales, solo fenogreco y } \\
\text { cardo de leche aparecen como autorizado por la AEMPS, aunque } \\
\text { en ningún caso para la lactancia materna. }\end{array}$ \\
\hline
\end{tabular}




\begin{tabular}{|c|c|c|c|}
\hline Revisor & Sección & Comentario & Respuesta del grupo elaborador \\
\hline & & $\begin{array}{l}\text { Los estudios que se describen pueden llevar a errores y malas interpretaciones. Solo se } \\
\text { deberían reflejar la información referente a los estudios de los medicamentos referenciados } \\
\text { en el anexo } 16 \text { teniendo siempre en cuenta que cada uno de ellos recoja esta indicación en } \\
\text { su ficha técnica ya que de lo contrario no se puede prescribir para dicha indicación. } \\
\text { En el caso de domperidona y metoclopramida la galactorrea es una reacción adversa } \\
\text { descrita para ambos fármacos y no una indicación autorizada. } \\
\text { En definitiva sugerimos que se pueda valorar el contenido de esta pregunta dado que los } \\
\text { medicamentos evaluados no han sido aprobados para su uso como inductores de la } \\
\text { lactancia. O clarificar la justificación de su inclusión. }\end{array}$ & \\
\hline & $\begin{array}{l}\varnothing \text { Pág } 25 \\
\text { "amamantar ayuda la } \\
\text { madre a mejorar su } \\
\text { salud presente y } \\
\text { futura, reduciendo las } \\
\text { hemorragias } \\
\text { posparto, } \\
\text { proporcionando } \\
\text { anticoncepción } \\
\text { durante los seis } \\
\text { primeros meses...." }\end{array}$ & $\begin{array}{l}\text { anticoncepción durante los seis primeros meses...dicho así, puede dar lugar a confusión, la } \\
\text { lactancia en sí funciona como método natural de control de la natalidad durante algún } \\
\text { tiempo y mientras se den determinadas circunstancias, que se deberían especificar: El bebé } \\
\text { debe tener menos de } 6 \text { meses, La madre debe seguir en amenorrea..etc... }\end{array}$ & Modificado. \\
\hline & $\begin{array}{l}\varnothing \text { Pág. } 149 . \\
\text { Consideraciones para } \\
\text { la implementación: } \\
\text { Creación de Consultas } \\
\text { de lactancia atendidas } \\
\text { por profesionales } \\
\text { especializados en } \\
\text { lactancia materna. }\end{array}$ & $\begin{array}{l}\text { En este sentido desde el punto de vista institucional más que la creación de consultas, se } \\
\text { podría poner el foco en promover una adecuada capacitación en lactancia materna de los } \\
\text { profesionales que participan en la atención de la mujer embarazada, parto y postparto, con } \\
\text { la redacción de la recomendación que considere el grupo elaborador. }\end{array}$ & $\begin{array}{l}\text { El grupo considera que se trata de ambas cosas, tanto crear } \\
\text { consultas especializadas a las que derivar mujeres que tengan } \\
\text { problemas con la lactancia como promover una adecuada } \\
\text { capacitación en lactancia materna de los profesionales que } \\
\text { participan en la atención de la mujer embarazada, parto y } \\
\text { postparto. }\end{array}$ \\
\hline & $\begin{array}{l}\text { Pág. 134. Con el } \\
\text { extractor eléctrico de } \\
\text { Medela se obtiene } \\
\text { mayor cambio en la } \\
\text { producción de leche } \\
\text { en } 24 \text { horas que con } \\
\text { el extractor eléctrico } \\
\text { de Playtex. Con el } \\
\text { extractor eléctrico }\end{array}$ & Se sugiere evitar en la medida de lo posible la utilización de marcas comerciales. & $\begin{array}{l}\text { Se trata del resumen de los estudios que se han realizado con } \\
\text { esos extractores de leche en concreto, no se pueden no } \\
\text { mencionar los nombres de los mismos. }\end{array}$ \\
\hline
\end{tabular}




\begin{tabular}{|c|c|c|c|}
\hline Revisor & Sección & Comentario & Respuesta del grupo elaborador \\
\hline & $\begin{array}{l}\text { UNO se necesita más } \\
\text { tiempo para realizar } \\
\text { una extracción que } \\
\text { con el Swing, así como } \\
\text { un mayor tiempo para } \\
\text { la eyección de la leche } \\
(316 ; 319) .\end{array}$ & & \\
\hline & Otros & $\begin{array}{l}\text { Ø Por último solo una reflexión. Se echa en falta apartados importantes que una guía de } \\
\text { lactancia materna debería contemplar para el apoyo de los profesionales: alcohol, drogas y } \\
\text { lactancia materna. Medicamentos, vacunas y lactancia materna. ¿Qué hacer cuando el niño } \\
\text { no quiere amamantar o "huelga de lactancia”? .Crisis o brotes de crecimiento o escalones de } \\
\text { crecimiento. } \\
\text { Se sugiere que se tengan en cuenta de cara a posibles actualizaciones. }\end{array}$ & $\begin{array}{l}\text { En un principio se consideró la posibilidad de incluir más } \\
\text { preguntas en la guia, pero la falta de personal y recursos hizo que } \\
\text { se tuvieran que priorizar las preguntas. En el informe } \\
\text { metodológico que acompañará a la guía se incluirán las posibles } \\
\text { preguntas que se podrían incluir en futuras actualizaciones de la } \\
\text { guía. }\end{array}$ \\
\hline
\end{tabular}

